\title{
Wilson-Leonard An 11,000-year Archeological Record of Hunter- Gatherers in Central Texas Volume I: Introduction, Background, and Syntheses
}

Michael B. Collins

Texas Archeological Research Laboratory

Gail L. Bailey

Texas Archeological Research Laboratory

C. Britt Bousman

Department of Anthropology, Texas State University

Susan W. Dial

Texas Archeological Research Laboratory

Paul Goldberg

Texas Archeological Research Laboratory

See next page for additional authors

Follow this and additional works at: https://scholarworks.sfasu.edu/ita

Part of the American Material Culture Commons, Archaeological Anthropology Commons, Environmental Studies Commons, Other American Studies Commons, Other Arts and Humanities Commons, Other History of Art, Architecture, and Archaeology Commons, and the United States History Commons

Tell us how this article helped you.

This Article is brought to you for free and open access by the Center for Regional Heritage Research at SFA ScholarWorks. It has been accepted for inclusion in Index of Texas Archaeology: Open Access Gray Literature from the Lone Star State by an authorized editor of SFA ScholarWorks. For more information, please contact cdsscholarworks@sfasu.edu. 


\section{Wilson-Leonard An 11,000-year Archeological Record of Hunter-Gatherers in Central Texas Volume I: Introduction, Background, and Syntheses}

Authors

Michael B. Collins, Gail L. Bailey, C. Britt Bousman, Susan W. Dial, Paul Goldberg, Jan Guy, Vance T.

Holliday, C. E. Mear, and Paul R. Takac

Creative Commons License

(c) (i) $(\Theta$

This work is licensed under a Creative Commons Attribution-NonCommercial-No Derivative Works 4.0 International License. 


\title{
WILSON-LEONARD
}

\section{An 11,000-year Archeological Record of Hunter-Gatherers in Central Texas}

\section{Volume I: Introduction, Background, and Syntheses}

\author{
Assembled and Edited by Michael B. Collins
}

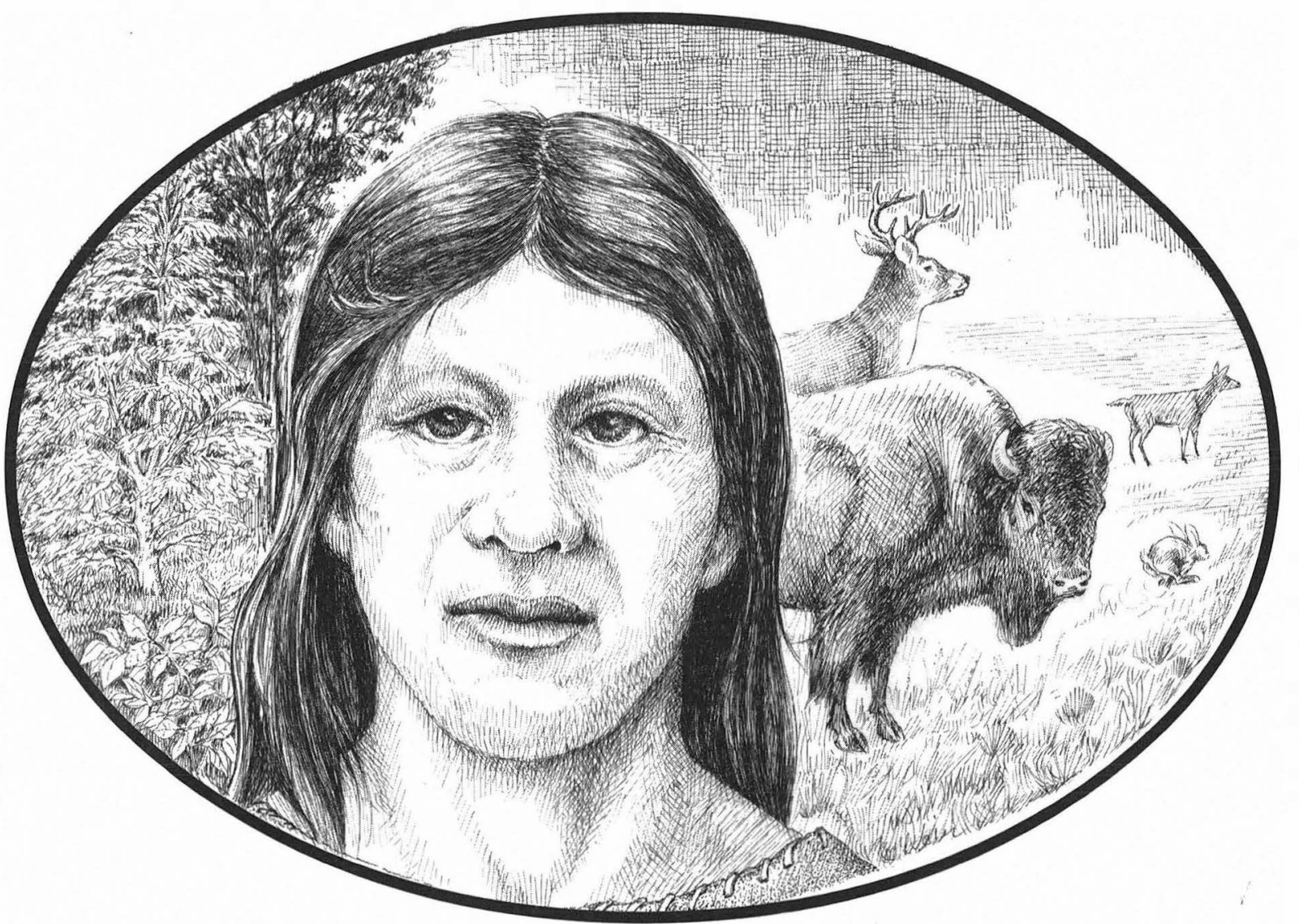

Studies in Archeology 31

Texas Archeological Research Laboratory The University of Texas at Austin
Archeology Studies Program, Report 10

Texas Department of Transportation Environmental Affairs Division 


\title{
WILSON-LEONARD
}

\section{An 11,000-year Archeological Record of Hunter-Gatherers in Central Texas}

\author{
ASSEMBLED AND EDITED BY MICHAEL B. COLLINS
}

WITH CONTRIBUTIONS BY

Gail L Bailey

Barry W. Baker

Robin Balinsky

CurtW. Beck

Joy Becker

Jonathan Bingham

C. Britt Bousman

MichaelB. Collins

Susan Decker

J. Philip Dering

Susan W. Dial

Boyce N. Driskell

Glen Fredlund

Paul Goldberg

WulfA.Gose

Jan Guy

Pamela Headrick

Marion J. Henry

Thomas R. Hester

Vance T. Holliday

Dale B. Hudler
W. Jeffrey Hurst

MarvinKay

AnneC.Kerr

Mervin Kontrovitz

Marilyn A. Masson

C. E. Mear

Sean Nash

Raymond W. Neck

KeithPrilliman

Leslie C. Shaw

Jerry Marie Slack

Thomas W. Stafford, Jr.

D. Gentry Steele

Edith C. Stout

Lauren A. Sullivan

Paul R. Takac

James L. Theler

Larry L. Tiezen

Diane Wilson

Barbara Winsborough 
This monograph is dedicated to Glen L. Evans whose knowledge and insights into Quaternary Geology greatly assisted in the investigation and interpretation of the Wilson-Leonard site. 


\title{
WILSON-LEONARD
}

\author{
An 11,000-year Archeological Record \\ ofHunter-Gatherers in Central Texas
}

\section{Volume I: Introduction, Background, and Syntheses}

\author{
assembled and edited by \\ Michael B. Collins \\ with contributions by \\ Gail L Bailey \\ C. Britt Bousman \\ Michael B. Collins \\ Susan W. Dial \\ Paul Goldberg \\ Jan Guy \\ Vance T. Holliday \\ C.E.Mear \\ Paul R. Takac
}

Principal Investigator: Nancy Kenmotsu

Frank Weir (1982-1998)

Texas Antiquities Committee Permit No. 300

Stmlies in Archeology 31

Tt:xas Archcological Research Laboratory

The Unh crsity of Texas at Austin

Archeology Studies Program, Report 10

Texas Department of Transportation

Environmental Affairs Division 
Cover drawing by Frank Weir

The University of Texas at Austin Texas Archeological Research Laboratory J. J. Pickle Research Campus 5

Austin, Texas 78712-1100

Printed 1998, on acid-free, 60-pound paper

ISBN 1-887072-25-X(VolumeI)

ISBN 1-887072-24-1 (5-Volume Set) 


\section{TABLE OF CONTENTS \\ Volume I}

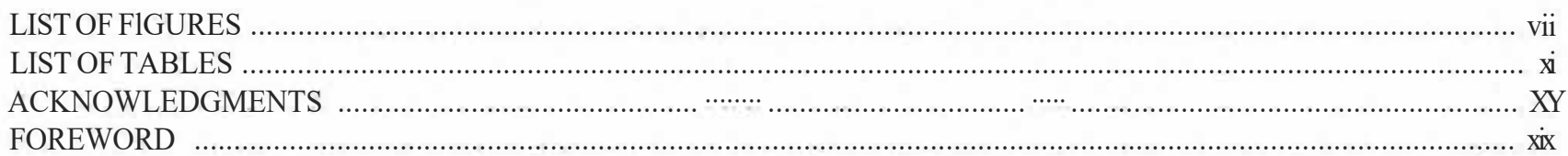

\section{CHAPTER I: INTRODUCTION}

by Michael B. Collins

CHAPTER2: THESITEANDITSSETTING

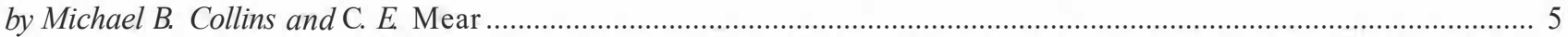

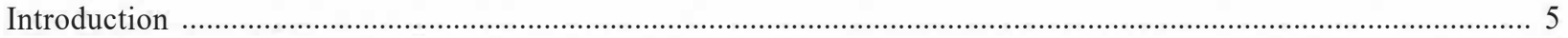

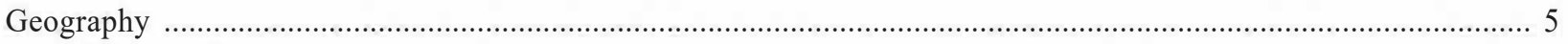

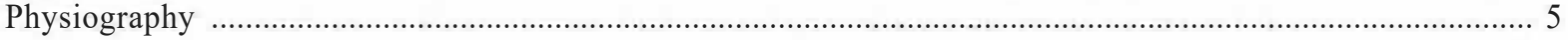

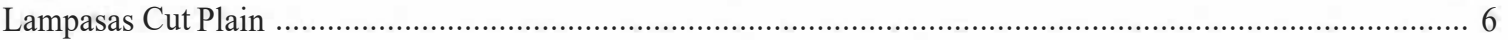

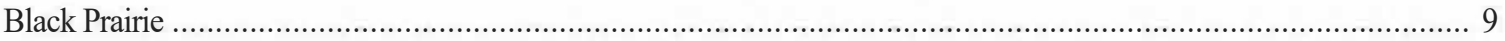

Edwards Plateau

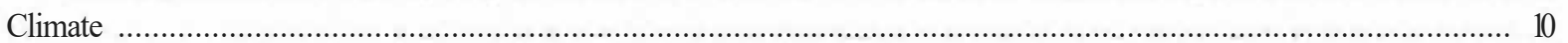

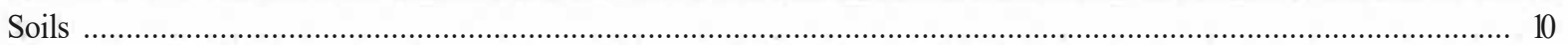

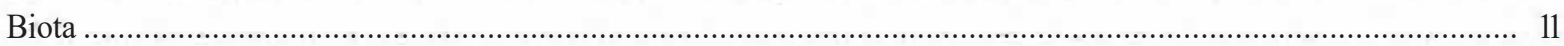

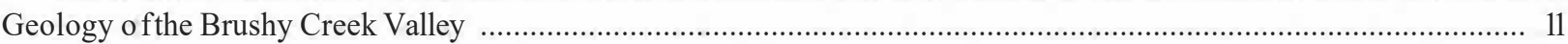

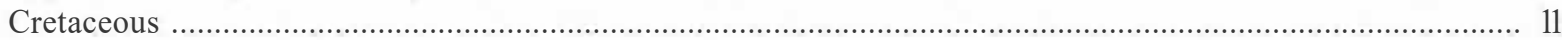

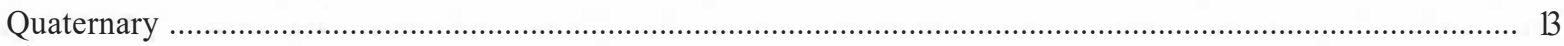

Pleistocene Terrace-deposit Remnants ................................................................................................. B

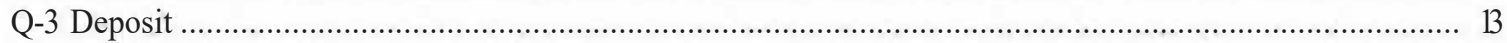

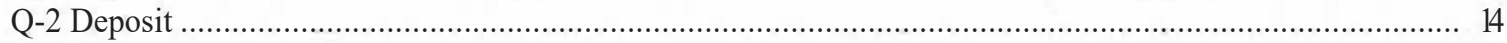

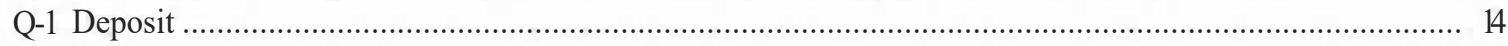

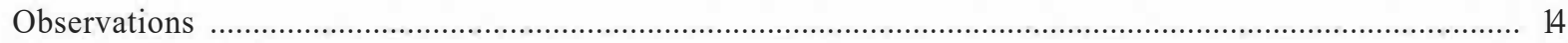

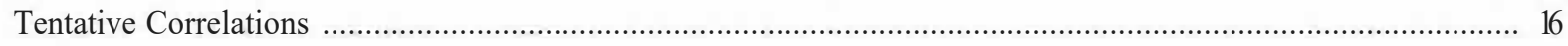

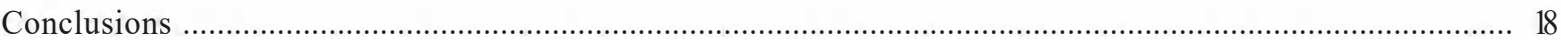

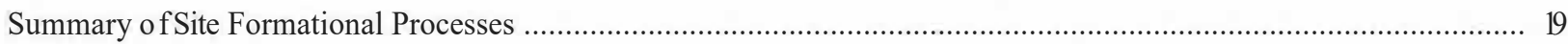

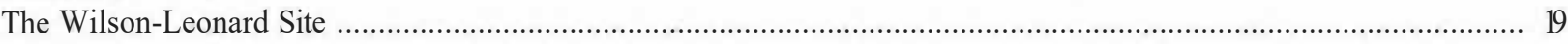

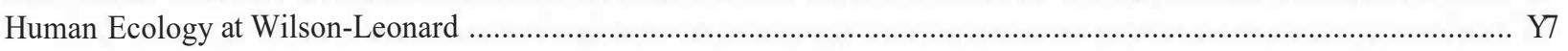

CHAPTER3: HISTORYOFINVESTIGATIONS

by C. Britt Bousman, Michael B. Collins, Jan Guy, Paul R. Takac, and Gail L Bailey ................................................. 33

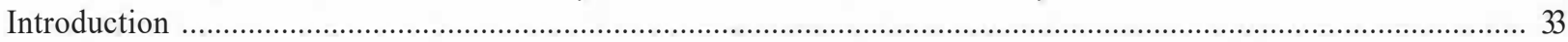

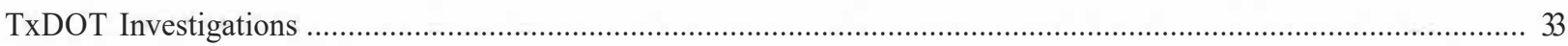

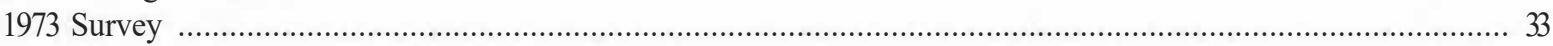

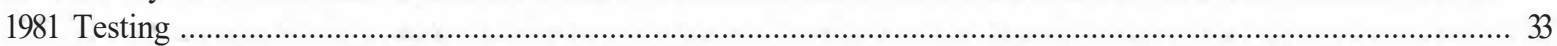

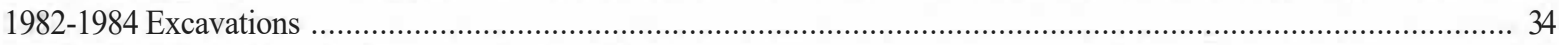

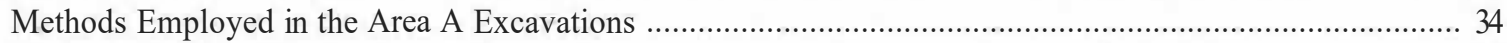

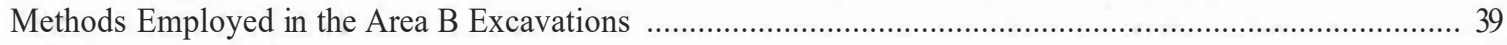

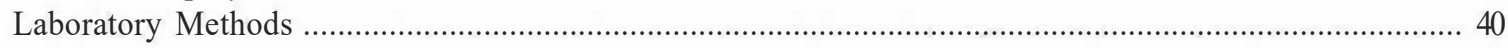

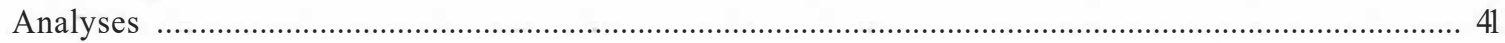

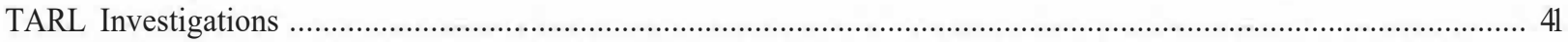

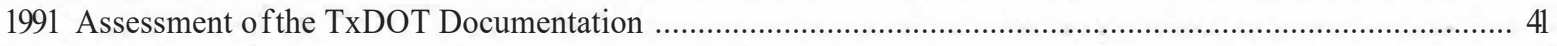

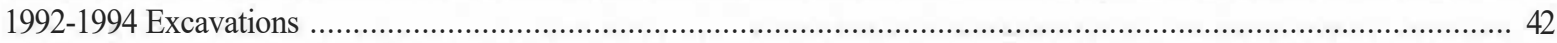

Relocating the TxDOT Excavations ................................................................................................... 42

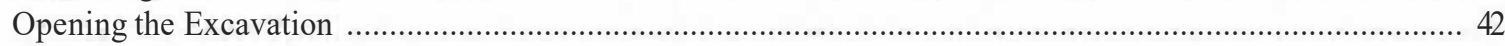

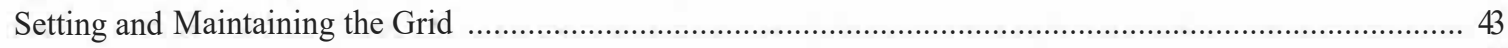

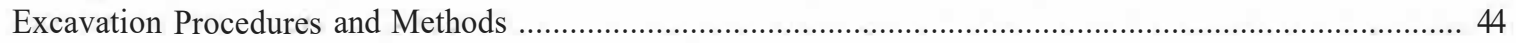




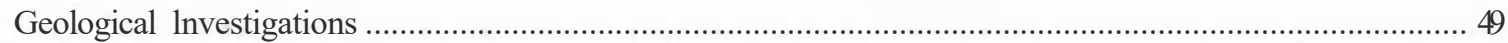

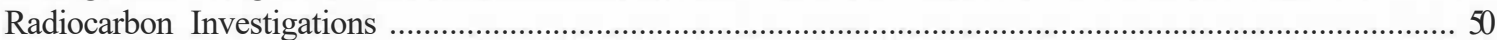

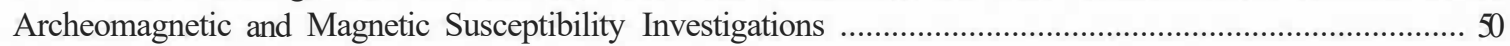

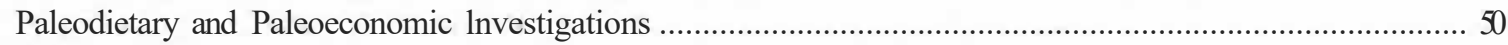

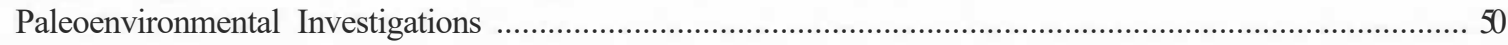

Vertebrate Paleontology Water Screening and Sorting ………................................................................. 51

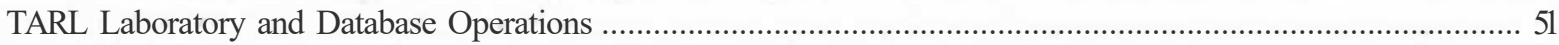

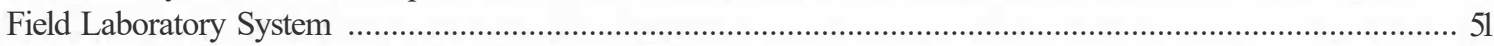

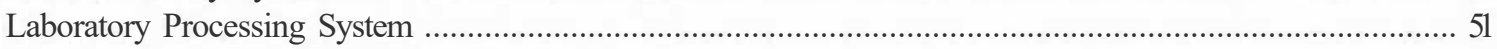

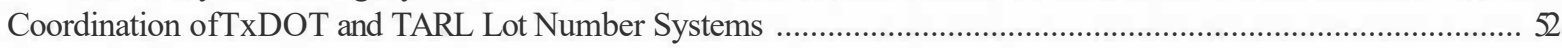

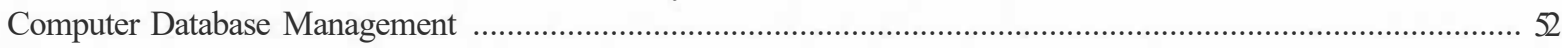

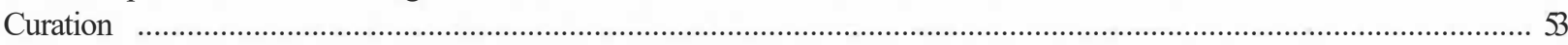

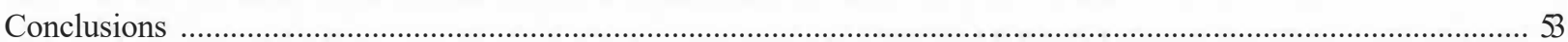

\section{CHAPTER 4: BACKGROUND TO THEARCHEOLOGICAL INVESTIGATIONS}

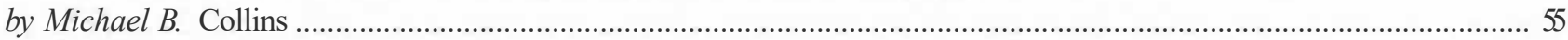

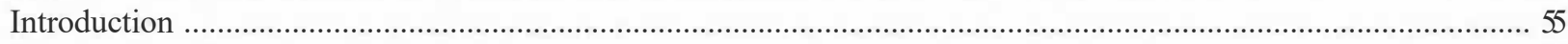

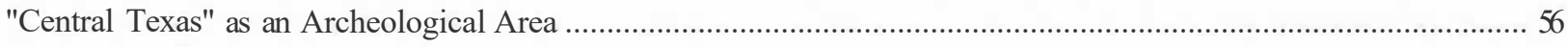

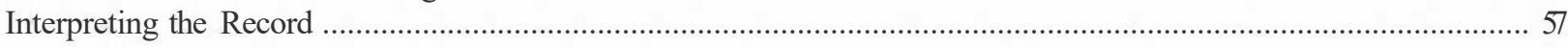

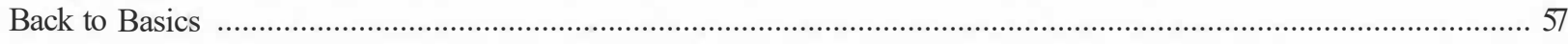

An Archeological Chronology and Paleoenvironmental Sequence for Central Texas .............................................. 58

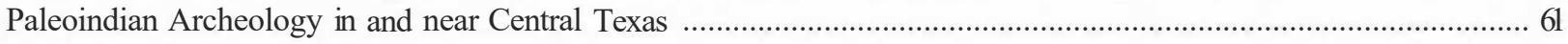

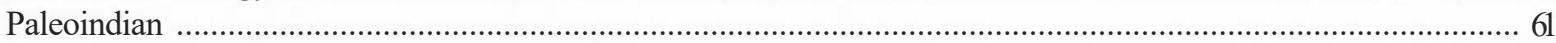

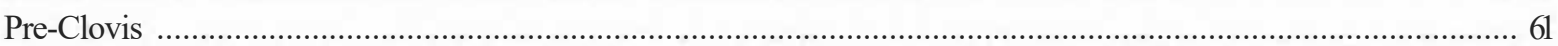

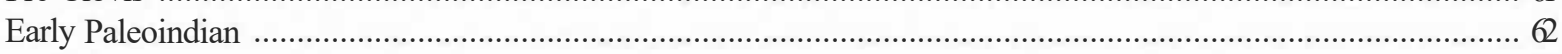

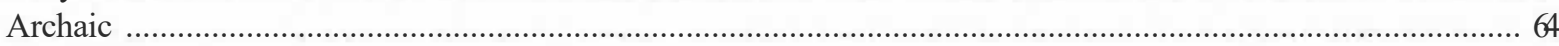

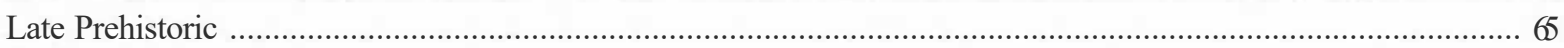

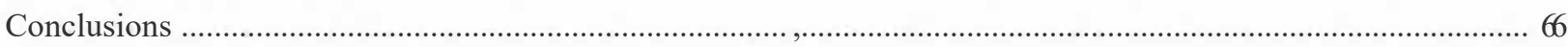

CHAPTER 5: RESEARCH OBJECTNES: HUMAN ECOLOGY AT THE WJLSON-LEONARD SITE

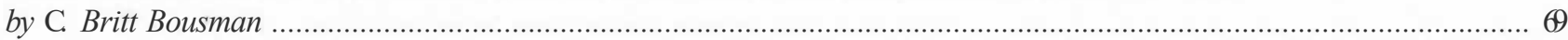

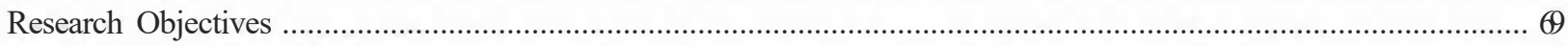

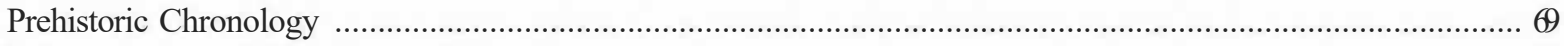

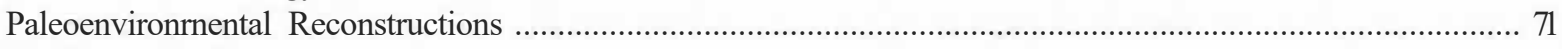

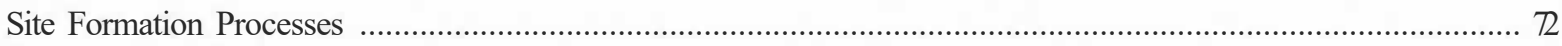

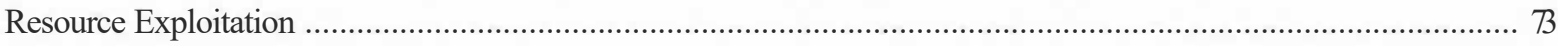

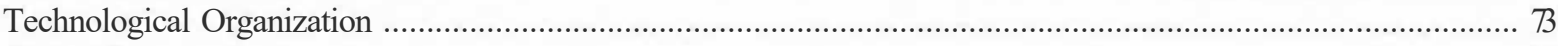

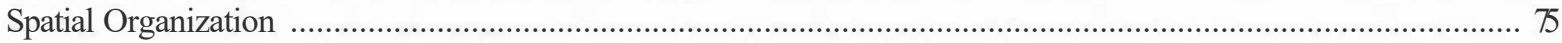

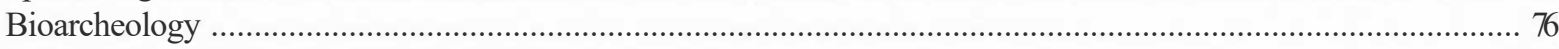

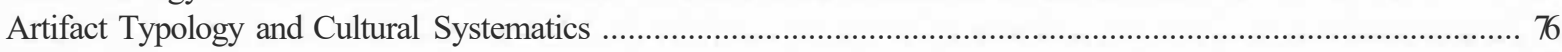

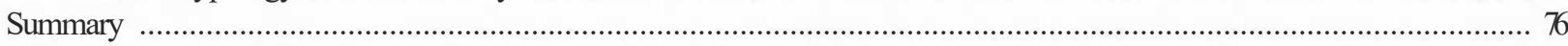

CHAPTER 6: GEOLOGY AND STRATIGRAPHY

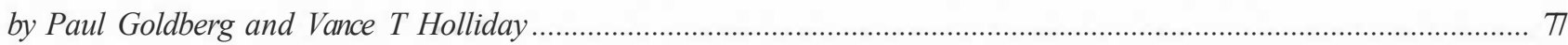

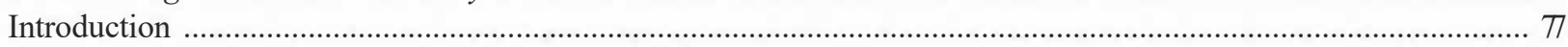

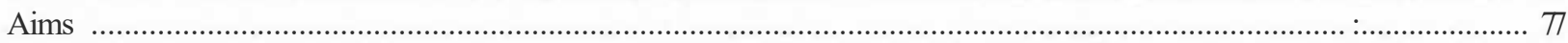

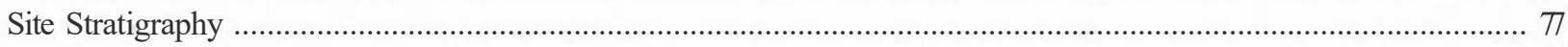

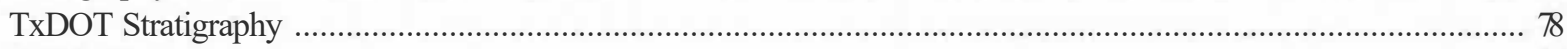

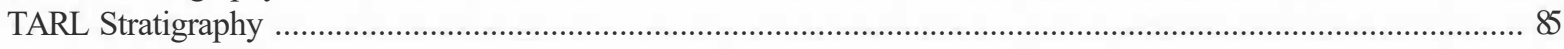

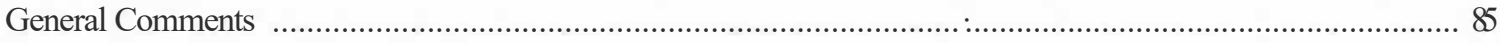

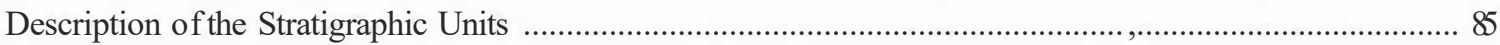

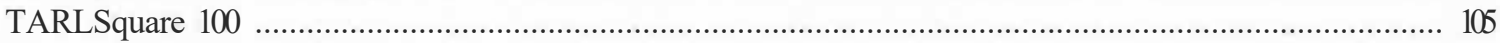

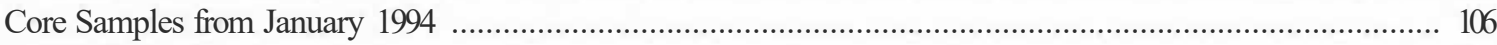

Sediment and Soil Analyses ............................................................................................................ 106

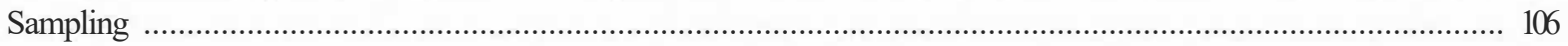




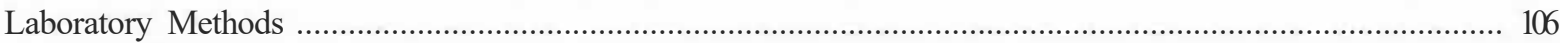

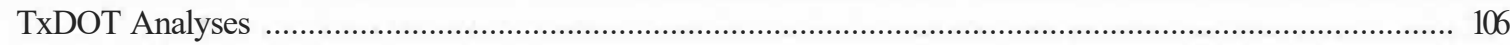

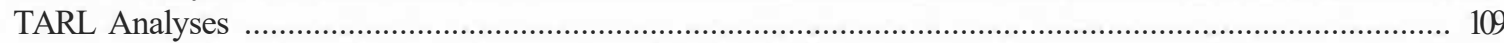

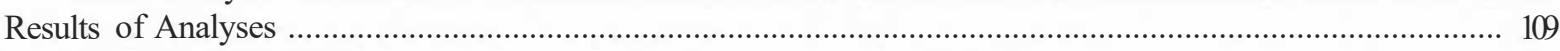

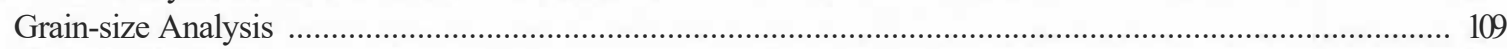

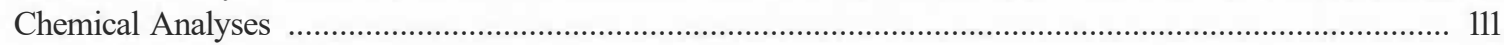

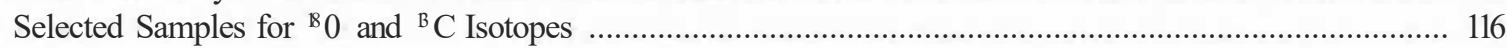

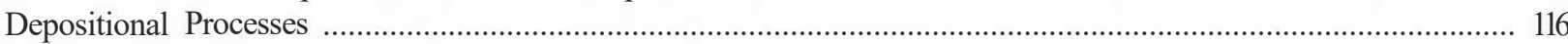

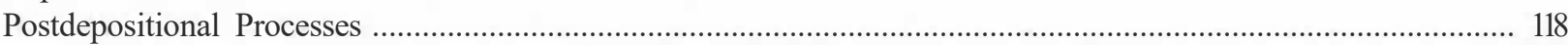

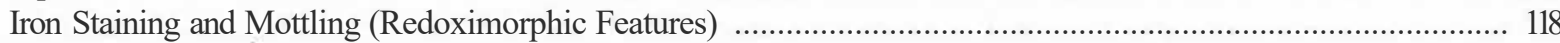

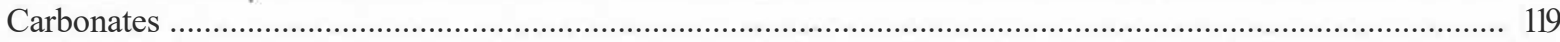

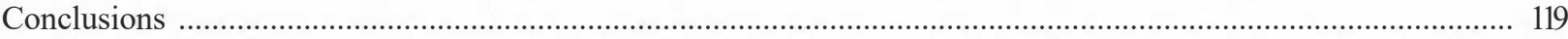

\section{CHAPTER 7: EARLYPALEOINDIAN COMPONENTS}

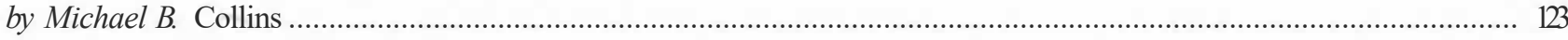

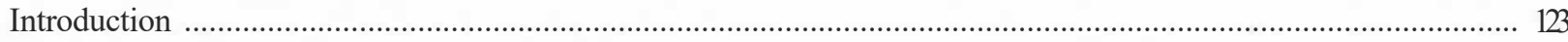

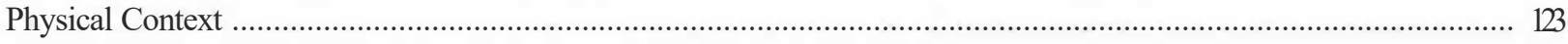

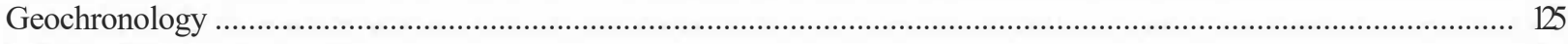

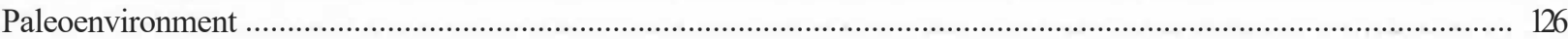

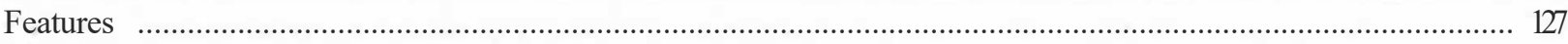

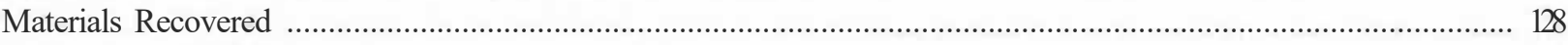

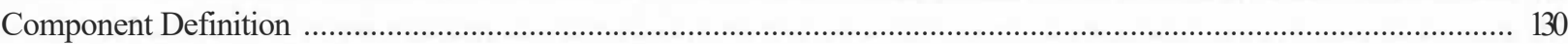

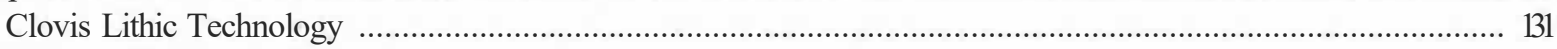

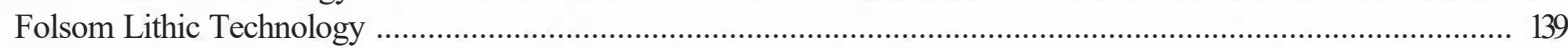

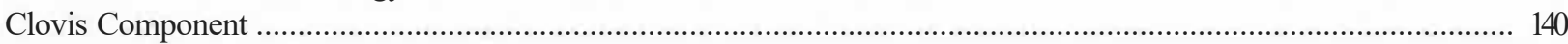

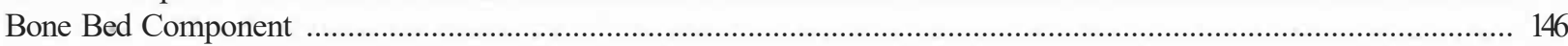

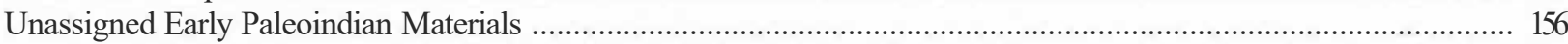

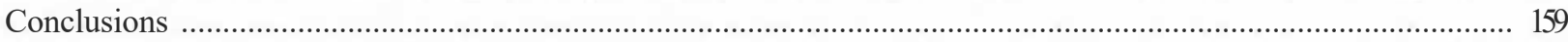

\section{CHAPTER8:LATEPALEOINDIANARCHEOLOGY}

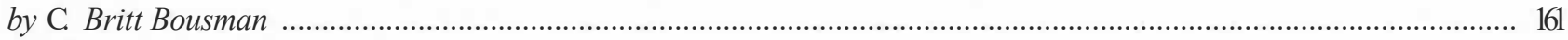

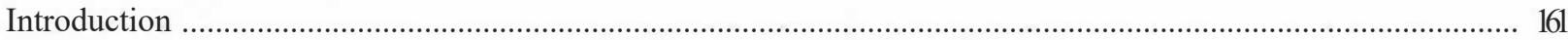

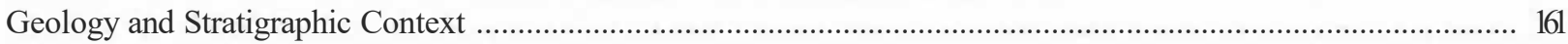

Radiocarbon Chronology ...................................................................................................................... 162

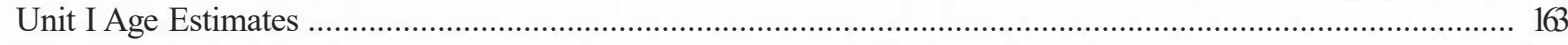

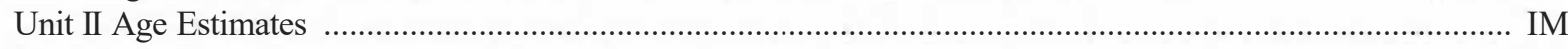

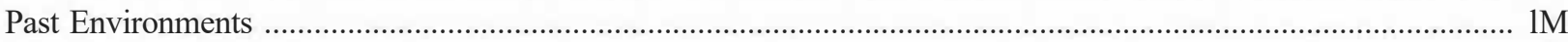

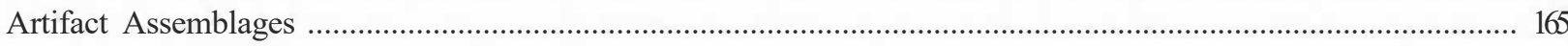

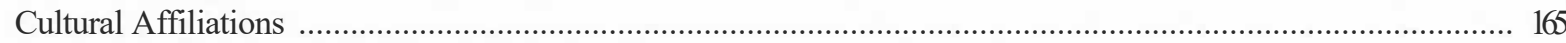

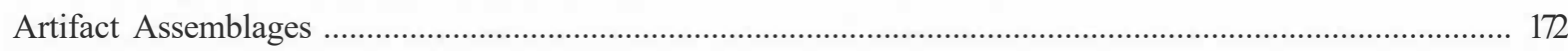

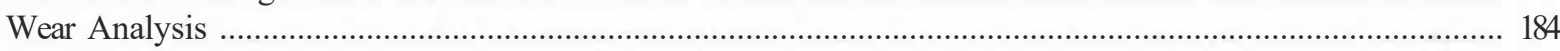

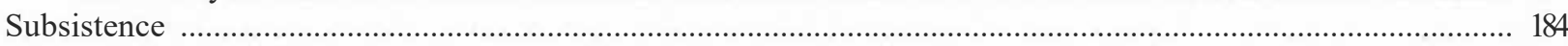

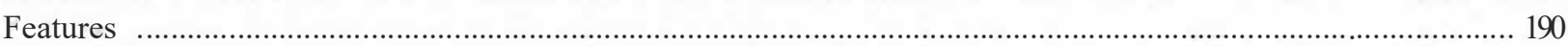

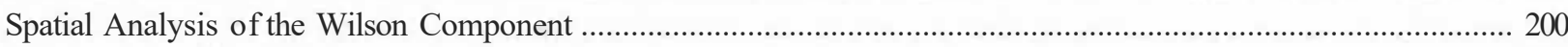

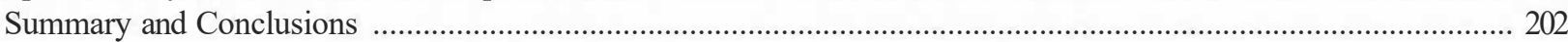

CHAPTER 9: THE ARCHAIC PERIOD, 8800 TO 1300 s.r.

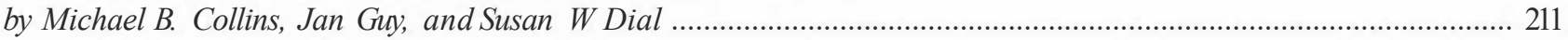

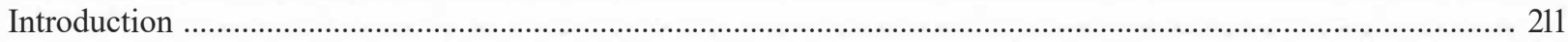

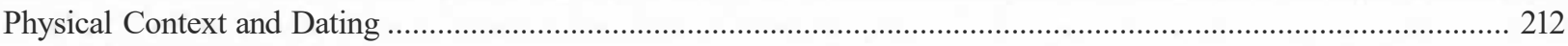

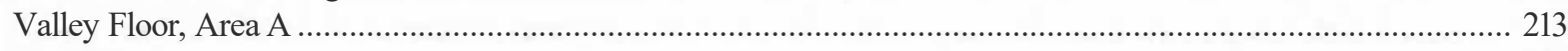

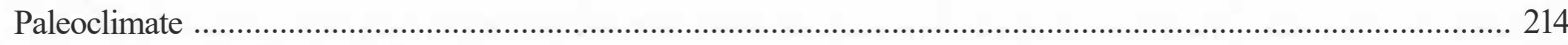

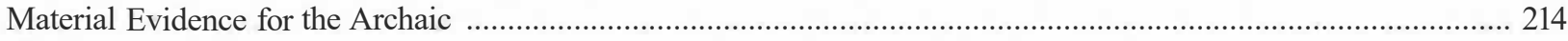

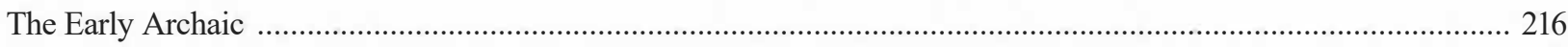

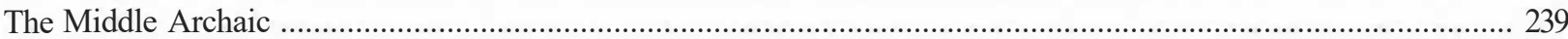




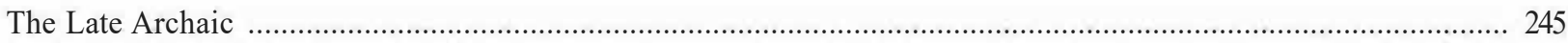

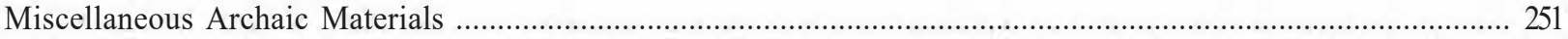

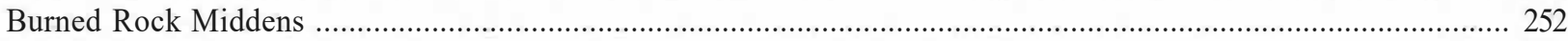

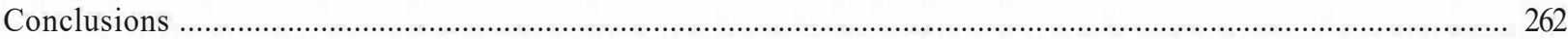

CHAPTER I0: LATE PREHISTORIC COMPONENTS

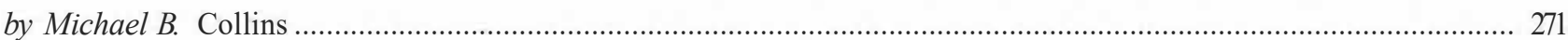

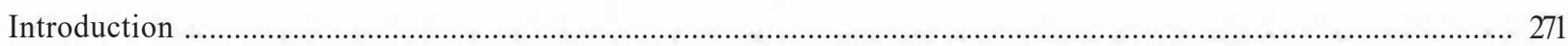

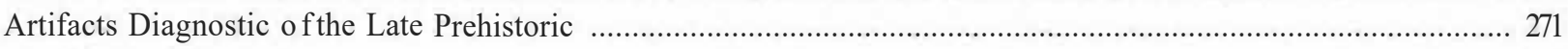

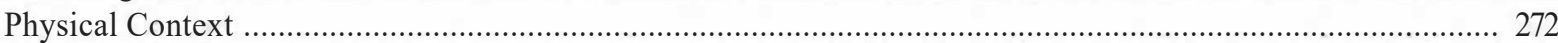

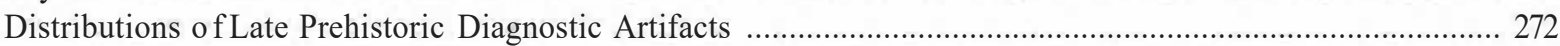

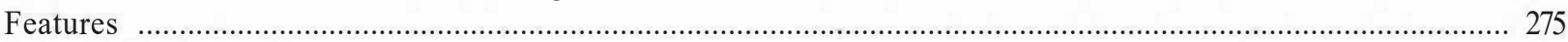

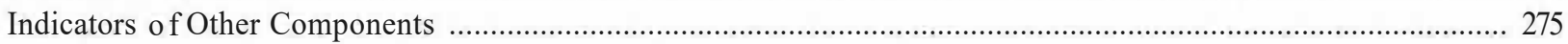

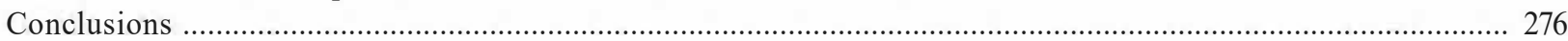

CHAPTER I 1: THE PLACE OF WILSON-LEONARD IN SOUTHERN PLAINS PREHISTORY

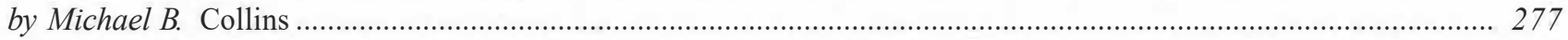

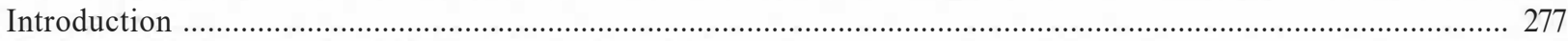

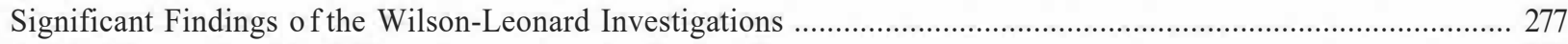

A Brief Synopsis of the Wilson-Leonard Archeological Sequence ……................................................................. 280

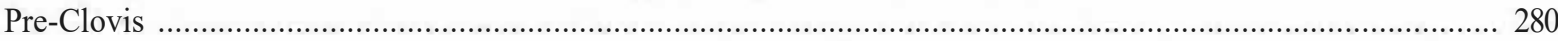

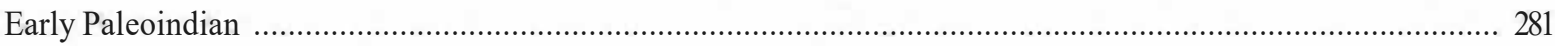

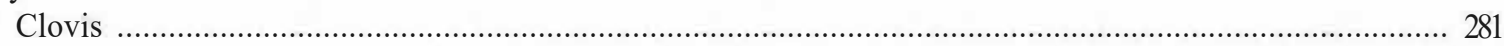

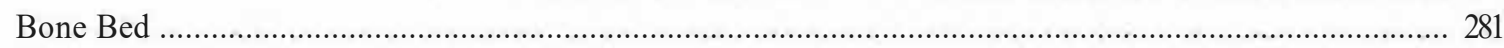

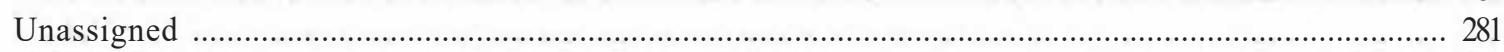

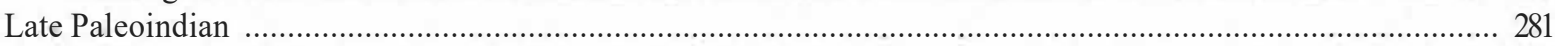

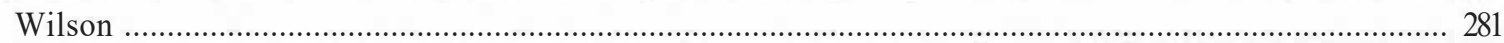

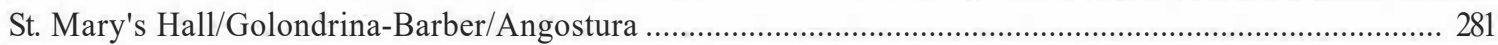

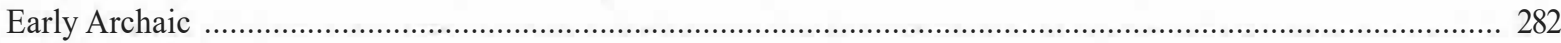

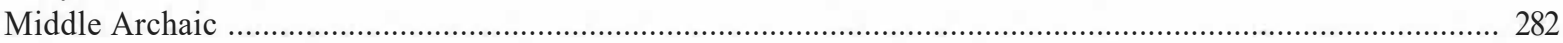

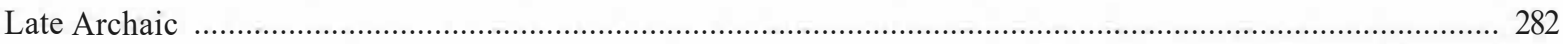

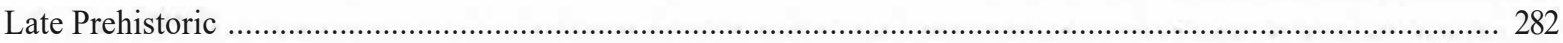

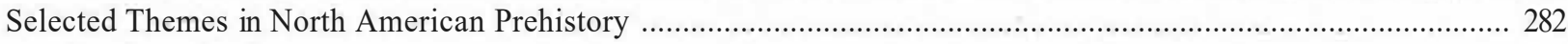

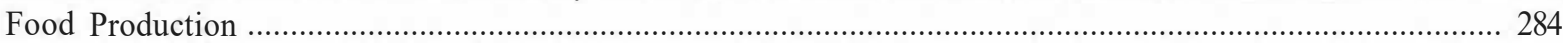

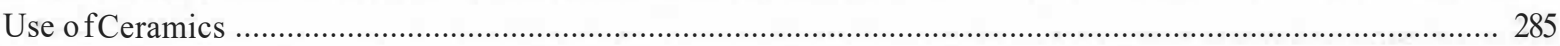

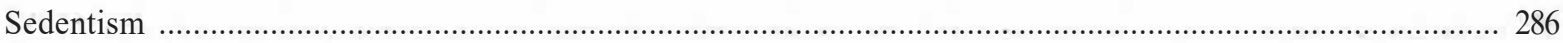

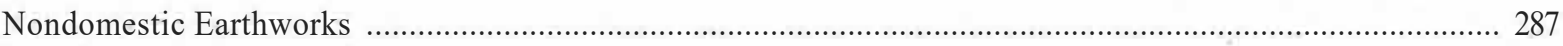

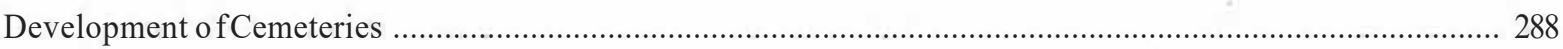

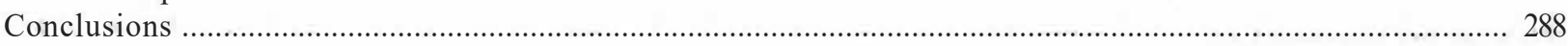

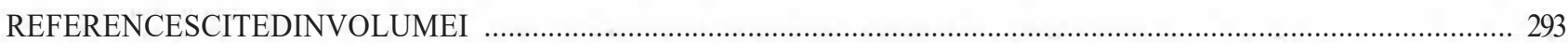




\title{
LIST OF FIGURES \\ Volumel
}

1-1. Location of the Wilson-Leonard site in Texas and in relation to the Brazos and

Colorado stream systems.

Schematic representations of the formational history of the Wilson-Leonard site ...

2-1. The Wilson-Leonard location in relation to prominent geographic and cultural features ............................... 6

2-2. Wilson-Leonard in relation to regional landforms and selected archeological localities .................................. 7

2-3. Oblique aerial view taken 21 March 1984 over the Wilson-Leonard site showing

the landscape northeast of the site

24. Oblique aerial view taken 21 March 1984 over the Wilson-Leonard site showing

the landscape southwest of the site

2-5. Geologic map of Brushy Creek valley in the vicinity of Wilson-Leonard

12

2-6. Diagrammatic section across Brushy Creek valley showing relationship

of Quaternary deposits

2-7. Isopach map ofQ-2 deposit at the Wilson-Leonard site .................................................................... 15

2-8. Northeast-southwest section of Q-2 deposit in the southern part of the site ............................................. 16

2-9. Isopach map of basal gravels at the Wilson-Leonard site from core hole and excavation data

2-10. Vertical aerial view taken 21 March 1984 showing the Wilson-Leonard site in relation

to Brushy and Spanish Oak creeks

2-11. Low altitude vertical aerial view taken 19 March 1984 showing the Wilson-Leonard site

during excavation

2-12. Contour map of the western portion of the Wilson-Leonard site showing burned rock

middens and areas of excavation

2-13. Vertical aerial view of the Wilson-Leonard locality taken in 1990 after completion of

RR1431

2-14. Vertical aerial view ofBrushy Creek valley taken in January of 1953 showing extent of

cultivation, including the field where the Wilson-Leonard site is located

2-15. Vertical aerial view of the Wilson-Leonard locality taken in February of 1962 showing

the site area as under cultivation

2-16. Oblique aerial view of the Wilson-Leonard site excavations in early 1984 showing the form of the natural terrace, the creek confluence, and main excavation area ............................................ 27

2-17. North wall of Blocks 4 and 6 in the final days of the TxDOT excavations ...................................................... 28

2-18. East wall ofBlock 6 in the final days of the TxDOT excavations with the inferred boundaries ofTARL stratigraphic Units I, II, Illa, Illb, and Ilic superimposed ............................................. 29

2-19. East wall of Block 6 with TARL's stepped "witness column" excavation near completion .............................. 30

2-20. Synoptic, simplified section along the west wall ofTxDOT Blocks 1, 2, 3, and 4 showing major TARL stratigraphic units, burned rock midden, and Burial 2 .............................................. 31

2-21. Diagrammatic depiction of all TARL stratigraphic designations with radiocarbon ages for the major valley floor stratigraphic unit boundaries

\author{
2
}

3-1. Plan map of the Wilson-Leonard site showing excavations for TxDOT and TARL phases ofwork

3-2. Photograph ofTxDOT excavations in progress in Block 3 ........................................................................ 37

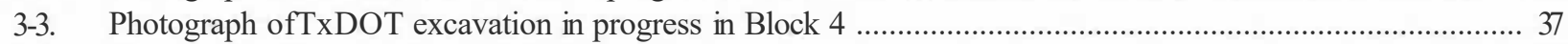

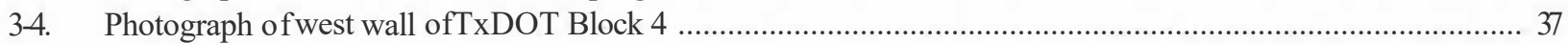

3-5. $\quad$ Photograph of the "deep unit" (E20/S72) in the north end ofTxDOT Block 4 .............................................. 38

3-6. Photograph of hand excavations in progress in TxDOT Block 6 ............................................................ 38

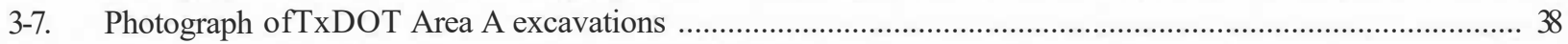

3-8. Photograph of the "Fine Screen Unit" (E28/S78) in the early stages of excavation ...................................... 39

3-9. Photograph ofTxDOT crew water screening matrix from the "Fine Screen Unit" .......................................... 39

3-10. Photograph ofTxDOT excavation Area A at the termination of fieldwork .................................................. 39

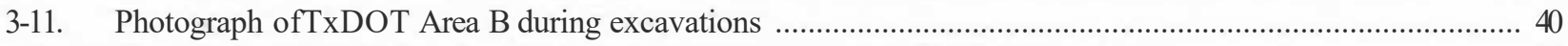

3-12. Photograph of the Wilson-Leonard site as it apeared prior to TARL excavations ......................................... 42 
3-13. Photograph of the installation of steel I-beams along east side of RR 1431 prior to TARL excavations

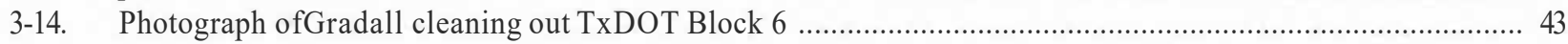

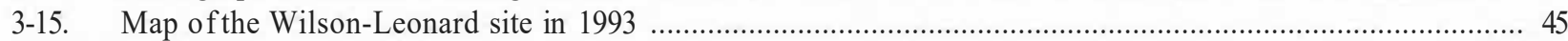

3-16. Photograph ofTARL excavations in progress ................................................................................. 46

3-17. Photograph ofTARL excavations in progress in Test Units A and B ................................................... 46

3-18. Photograph of the initial stage ofTARL excavations in Squares 18-22 ..................................................... 46

3-19. North-south section through TARL excavation Squares 14, 33, 48, and 56 ................................................ 47

3-20. Photograph of scaffolding in place during TARL excavations ................................................................... 48

3-21. Photograph of water screens in use during TARL excavations ................................................................ 48

3-22. Photograph of core drilling at Wilson-Leonard prior to TARL excavations ................................................. 49

4-1. Synoptic archeological and environmental sequence for Central Texas ...................................................... 59

5-1. Capacity planning model for prehistoric features ...................................................................................... 75

6-1. $\quad$ Map of the site area showing location ofTxDOT and TARL excavated areas .............................................. 79

6-2. Semischematic profile drawing of East Profile showing stratigraphic relationships among the different units exposed during the TARL excavations ............................................................. 84

6-3. Stratigraphic section in Square 12, showing the abundance of

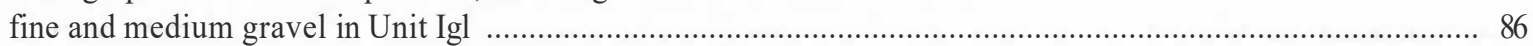

6-4. Stratigraphic section in Square 20, showing the abundance of gravel in Unit Igl ....................................... 87

6-5. Inferred semischematic, roughly north-south stratigraphic profile of Wilson-Leonard ................................... 89

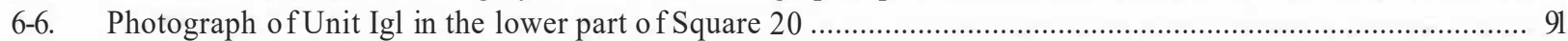

6-7. Profile drawing of Squares 27 and 28 showing the major excavated stratigraphic units ............................... 92

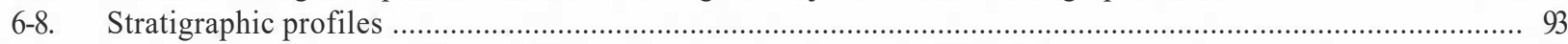

6-9. East and south faces of Square 35 showing the pinching out of Unit lei .................................................... 94

6-10. Profile drawing of Squares 35, 55, 56, and 57 showing secondary features .............................................. 94

6-11. Profile drawing of the east wall of Square 35 and lower part of Square 59 .................................................. 101

6-12. Profile drawing of the east wall of Squares 37, 38, and 39 .................................................................... 103

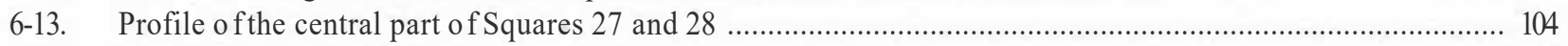

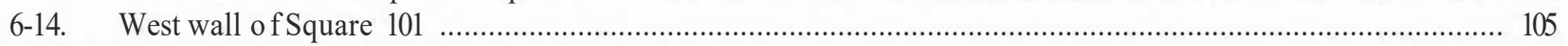

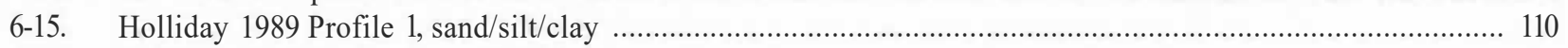

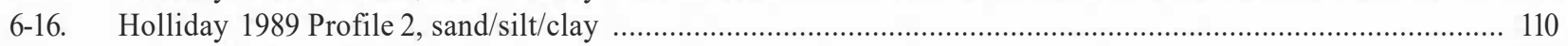

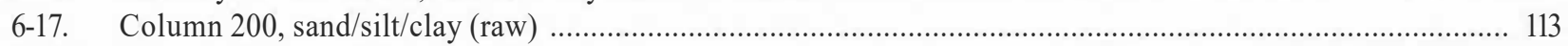

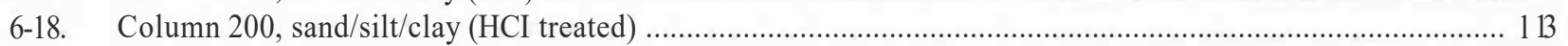

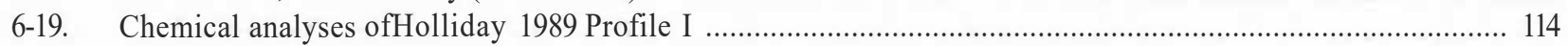

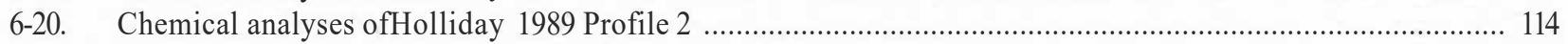

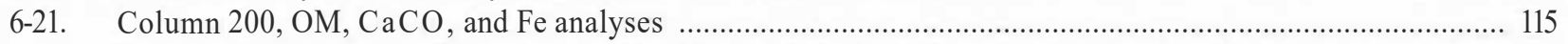

7-1. Plan of excavations showing the units in which Early Paleoindian-age deposits were encountered ............... 124

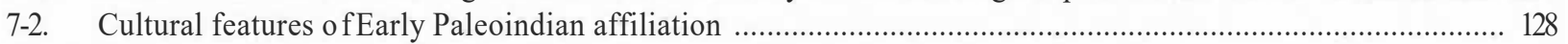

7-3. Early Paleoindian debitage frequencies by square, level, stratigraphic unit, and component ........................ 132

7-4. Early Paleoindian artifact frequencies by square, level, stratigraphic unit, and component .......................... 135

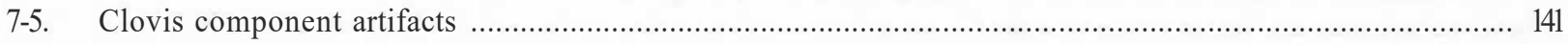

7-6. Chert core and limestone hammerstone from Feature 188 ........................................................................ 143

7-7. Early Paleoindian diagnostic artifacts from later contexts ....................................................................... 144

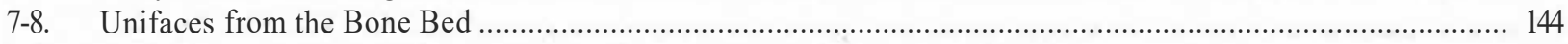

7-9. Artifacts with Clovis technological attributes recovered from Bone Bed ………........................................ 145

7-10. General view of the Bone Bed in TxDOT Squares E26/S76 and E26/S78 …….......................................... 146

7-11. Eroded bone and nearby core fragment in Bone Bed, TxDOT Square E26/S76 ............................................. 146

7-12. Characteristic cracking and breakage of bones in the Bone Bed showing the mandible

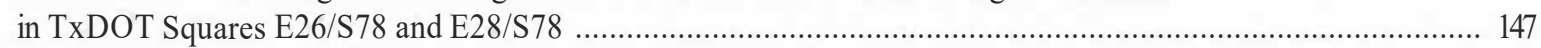

7-13. Projectile point and thin bifaces (preforms) from the Bone Bed …............................................................ 148

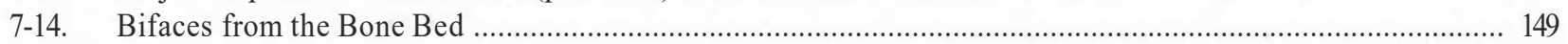

7-15. Bifacial tools and cores with evidence of heavy use as chopping or hammering tools ................................. 150

7-16. Thin bifaces and engraved stone from the Bone Bed .......................................................................... 151

7-17. Bone Bed core and flake pieces with evidence of battering ……........................................................... 152

7-18. Bone Bed core tools with evidence of use as chopping or hammering tools ................................................ 153 
7-19. Mano/hammerstone from the Bone Bed component (34NN1-D-I)

7-20. Map of the Bone Bed component showing the location of all piece-plotted bone and artifacts ........ map packet

7-21. Map of the Bone Bed component showing distributions of debitage, tools, and refitted objects

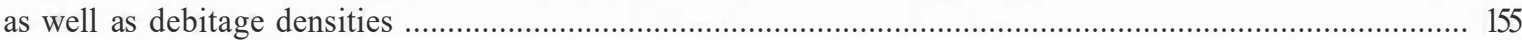

7-22. Limestone slab and large bone splinters in TxDOT Square E26/S72, bone bed ......................................... 155

7-23. Representative artifacts of Early Paleoindian age but unassigned to any cultural affiliation ....................... 157

7-24. Representative altifacts of Early Paleoindian age unassigned to any cultural complex ................................ 158

7-25. Unassigned Early Paleoindian core tools .......................................................................................... 158

8-1. Percent of extracted weight as measured in phytolith samples in Units I and II ............................................. 165

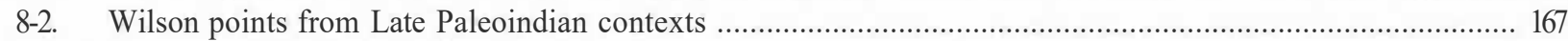

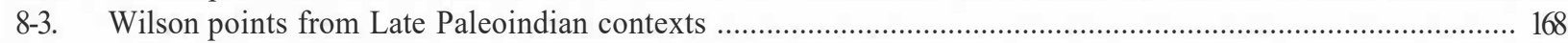

8-4. Wilson point 17AA2-2 recycled as a possible hafted scraper ................................................................. 168

8-5. Representative Golondrina-Barber and other Late Paleoindian projectile points ........................................... 169

8-6. Representative Saint Mary's Hall projectile points ................................................................................... 170

8-7. Stratigraphic distribution of projectile points in Blocks 4 and 6, and the FSU …........................................ 173

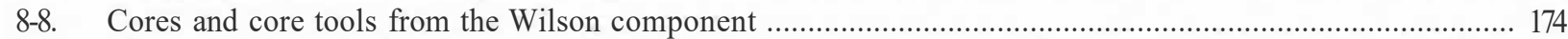

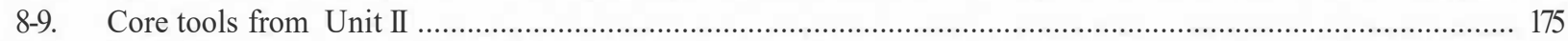

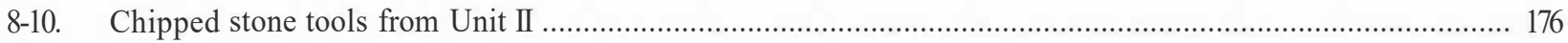

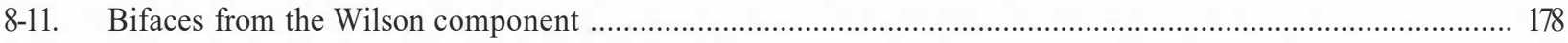

8-12. Bifaces and piece esquillee from Unit II deposits ................................................................................. 179

8-13. Bifacial tools from the Wilson component ……............................................................................... 180

8-14. Brushy Creek and Clear Fork bifaces from Unit II .................................................................................... 181

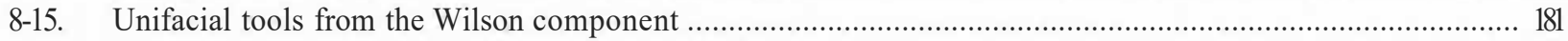

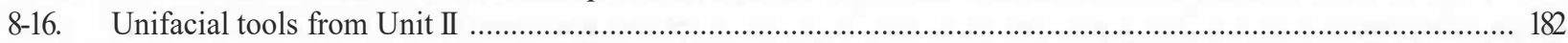

8-17. Limonite sandstone mano from the Wilson component ……….............................................................. 184

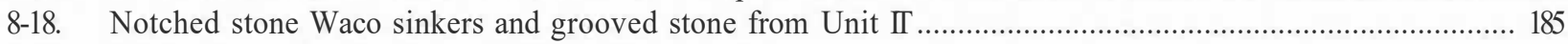

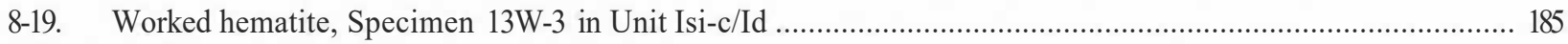

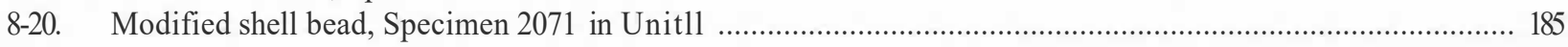

8-21. Relative abundance of small animals in fine-screen sample .................................................................... 194

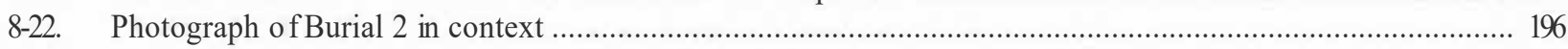

8-23. Ground stone tool (two faces and edge-on) from Wilson component Burial 2 .......................................... 196

8-24. Fossil shark tooth from Wilson component Burial 2 _................................................................................ 197

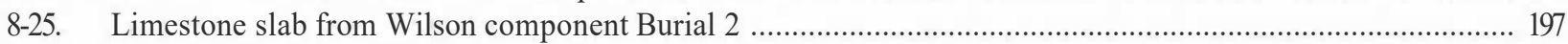

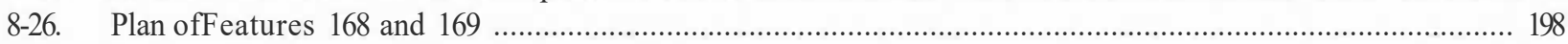

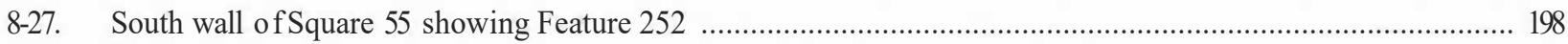

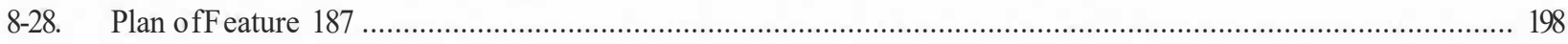

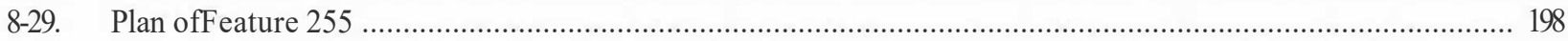

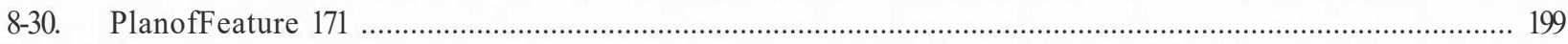

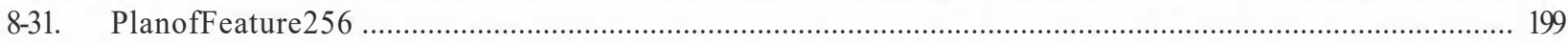

8-32. Bone density distributions in the Wilson component in Blocks 4 and 6, and the FSU ............................... 203

8-33. Debitage density distributions in the Wilson component in Blocks 4 and 6, and the FSU ........................... 203

8-34. Core density distributions in the Wilson component in Blocks 4 and 6, and the FSU ................................. 204

8-35. Uniface density distributions in the Wilson component in Blocks 4 and 6, and the FSU ............................. 204

8-36. Biface density distributions in the Wilson component in Blocks 4 and 6, and the FSU ................................ 205

8-37. Projectile point density distributions in the Wilson component in Blocks 4 and 6, and the FSU ...................205

8-38. Core tool density distributions in the Wilson component in Blocks 4 and 6, and the FSU ........................... 206

8-39. Hammerstone density distributions in the Wilson component in Blocks 4 and 6 and the FSU .......................206

840. Mano density distributions in the Wilson component in Blocks 4 and 6, and the FSU ................................ 207

841. Worked hematite density distributions in the Wilson component in Blocks 4 and 6, and the FSU ................ 207

8-42. Plan of the distribution of burned rock features, possible pits, and human burial in Upper Unit I,

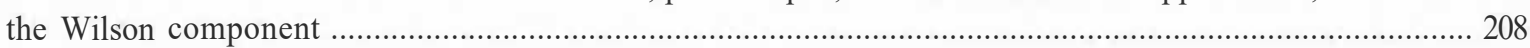

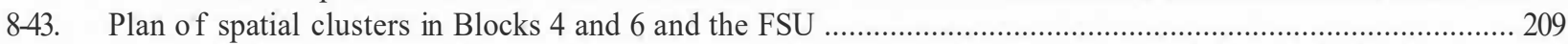

8-44. Distribution of sites with Wilson projectile points or similar early stemmed projectile points .........................2210

9-1. Diagrammatic depiction of the stratigraphic units and their relationships .................................................... 213

9-2. North-south section showing the major stratigraphic units and major burned rock features ........................ 214 
9-3. Stratigraphic profile of the Valley Margin/Valley Floor showing Late Paleoindian/Early Archaic units ........... 218

9-4. Stratigraphic profile of the Valley Margin/Valley Floor showing Early Archaic units ...................................... 219

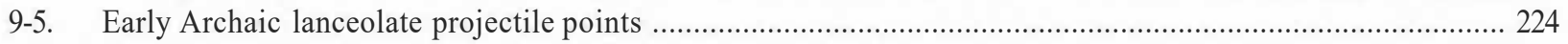

9-6. Representative early split stern points from lower Early Archaic deposits ................................................... 225

9-7. Early corner-notched projectile points from later Early Archaic contexts ...................................................... 226

9-8. Expanding stem points from Unit II, Late Paleoindian contexts .............................................................. 226

9-9. Representative Clear Fork tools from Early Archaic contexts ................................................................... 227

9-10. Representative bifacial preforms from Early Archaic and mixed contexts ..................................................... 228

9-11. Representative bifacial and unifacial tools from Early Archaic contexts ....................................................... 229

9-12. Representative flake tools from Early Archaic contexts ........................................................................... 230

9-13. Representative ground stone manos from Early Archaic contexts ......................................................... 231

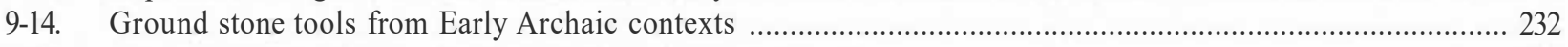

9-15. Ground stone tools from Early Archaic and mixed deposits ..................................................................... 233

9-16. Representative battered stone, cores, and core tools from Early Archaic contexts ....................................... 234

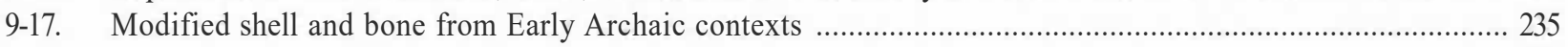

9-18. Examples of small fish bones from Early Archaic contexts ........................................................................ 235

9-19. Sample of charred bulbs recovered from Early Archaic Feature 181 ............................................................. 235

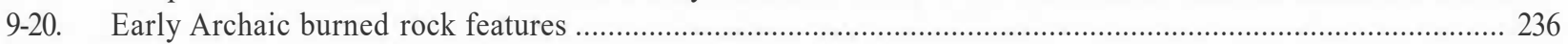

9-21. Discrete large burned rock basins comprising Early Archaic proto midden B ............................................ 237

9-22. CompositeplandrawingofFeatures 130,131,146,150, 181, and245 ................................................... 238

9-23. Stratigraphic profile of the Valley Margin/Valley Floor showing Middle/Early Archaic units ........................ 243

9-24. Stratigraphic profile of the Valley Margin/Valley Floor showing Middle Archaic units .................................. 244

9-25. Projectile points from Middle Archaic and mixed Early/Middle Archaic contexts ......................................... 245

9-26. Representative bifaces and bifacial tools from Middle Archaic and mixed contexts ..................................... 246

9-27. Representative tools from Middle and mixed Middle Archaic contexts ......................................................... 247

9-28. Notched "practice" flake Specimen 556-4 from Middle Archaic deposits (Unit IIlb) ..................................... 247

9-29. Representative mano (Specimen 51 KB-3) from Middle Archaic context ........................................................ 247

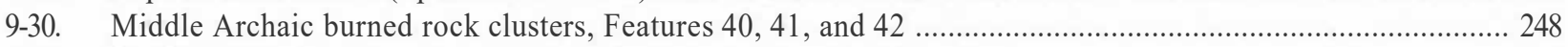

9-31. Section through Burned Rock Midden 2 and proto midden C ................................................................. 248

9-32. Stratigraphic profile of the Valley Margin/Valley Floor showing Late/Middle Archaic units ......................... 249

9-33. Stratigraphic profile of the Valley Margin/Valley Floor showing Late Archaic units ..................................... 250

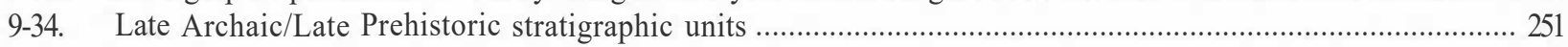

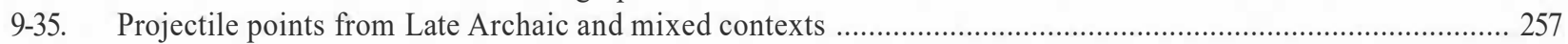

9-36. Representative projectile points from the later part of the Late Archaic ..................................................... 258

9-37. Representative bifaces and preforms from Late Archaic contexts ........................................................... 258

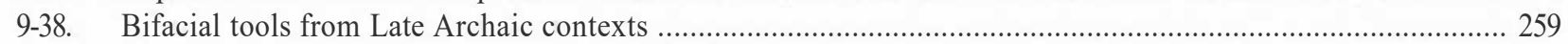

9-39. Representative unifacial tools from Late Archaic contexts ......................................................................... 260

9-40. Representative cores and core tools from Late Archaic contexts ................................................................ 261

9-41. Ground stone cylindrical pipe fragment (Specimen 16C-2) from Late Archaic context.................................. 262

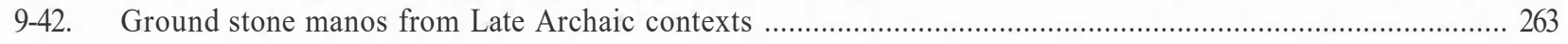

9-43. Metate fragment 17C-5 from Late Archaic context ......................................................................................... 264

9-44. Incised tubular bone and pointed bone tool fragments from possible Late Archaic contexts ......................... 264

9-45. Stratigraphic profile of the Valley Margin/Valley Floor showing Archaic units ........................................... 265

9-46. Stratigraphic profile of the Valley Margin/Valley Floor showing Archaic/Late Prehistoric units ..................... 266

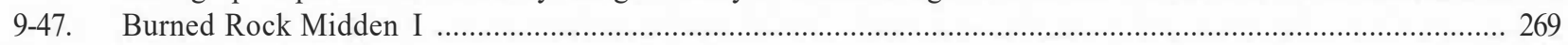

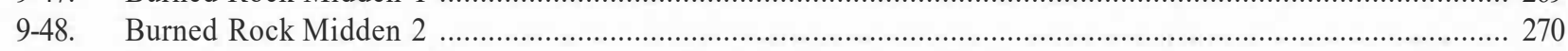

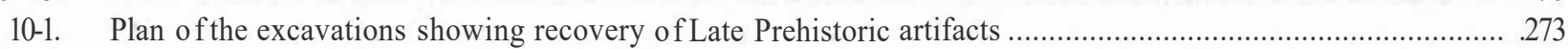

11-1. Approximate time depthofselected formative cultural traits and cemeteries in Central Texas compared with the Southwest, Southeast, Plains, and Huastecan/Tamaulipan culture areas 


\section{LISTOFTABLES \\ Volumel}

41. Alphabetical listing of sites discussed in text and listed in Figure 4-1, with bibliographic references ................. (f)

6-1. Soil/sediment analytical data from TxDOT excavations ............................................................................ 80

6-2. Stratigraphic breakdown ofTxDOT excavations as recognized by Holliday (I 989b) with

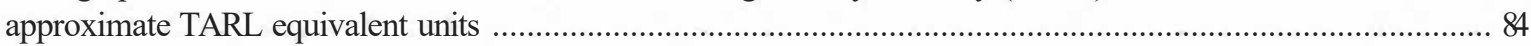

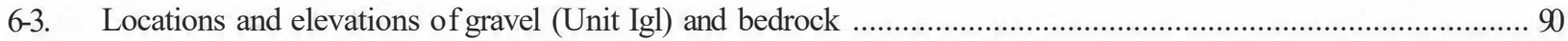

6-4. Uppermost occurrences of iron mottling/staining at Wilson-Leonard ......................................................95

6-5. Elevation of contacts and thicknesses of stratigraphic units ................................................................96

6-6. Elevations of contacts and thicknesses of stratigraphic units ................................................................9.

6-7. $\quad$ Logs of cores from area around Wilson-Leonard site and Archaeological Conservancy ............................... 107

6-8. Wilson-Leonard grain-size and chemical analyses for Column 200 series ................................................ I 12

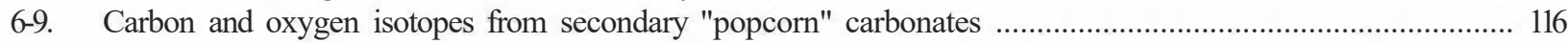

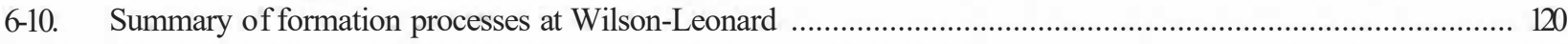

7-1. Early Paleoindian cultural materials by natural stratigraphic provenience ................................................ 129

7-2. Early Paleoindian cultural materials by cultural component ............................................................ 130

7-3. Summary offaunal data from Early Paleoindian stratigraphic units ........................................................ 130

8-1. Reliable radiocarbon determinations from nonburial contexts in Unit Isi-c ................................................ 163

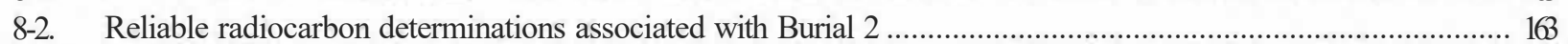

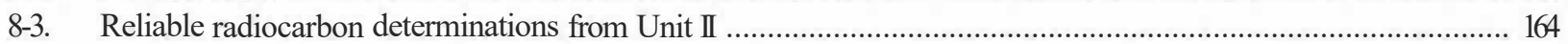

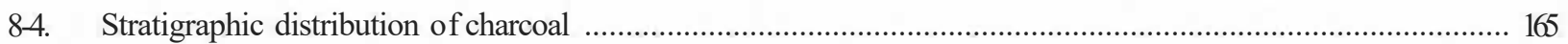

8-5. Distribution of projectile points in stratigraphic units ...................................................................... 172

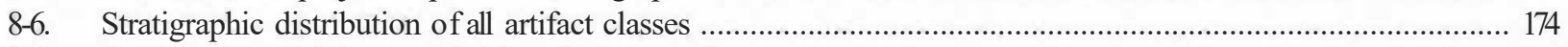

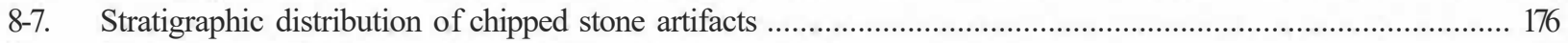

8-8. Stratigraphic distribution of complete and broken projectile points ...................................................... 177

8-9. Stratigraphic distribution of bifaces assignable to reduction stage ................................................. 177

8-10. Stratigraphic distribution of formal bifacial tools ............................................................................... 180

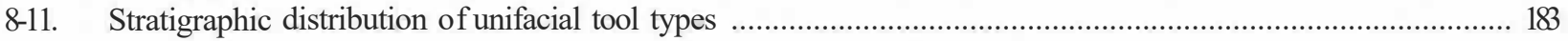

8-12. Stratigraphic distribution of ground and battered stone tools ............................................................. 184

8-13. Stratigraphic distribution of artifact use history as determined by microwear analysis .................................. 186

8-14. Artifact use history as determined by microwear analysis by artifact type ............................................... 187

8-15. Fauna! remains from TxDOT and TARL excavations diagnostic only to vertebrata categories ........................ 188

8-16. Fauna! remains from TxDOT and TARL excavations diagnostic only to class categories .............................. 189

8-17. Fauna! remains from TxDOT and TARL excavations diagnostic only to mammal-size categories ..................... 190

8-18. Fauna! remains from TxDOTand TARL excavations diagnostic only to mammal order categories ................... 191

8-19. Fauna! remains from TxDOTand TARL excavations diagnostic to family, genera, or species categories ........... 192

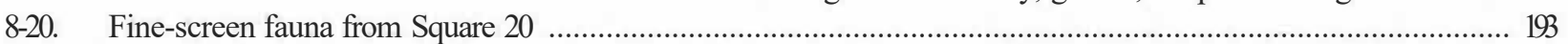

8-21. Frequency of eggshell by feature and thickness of eggshell .................................................................... 194

8-22. Attributes of features recorded in the Late Paleoindian deposits at Wilson-Leonard ..................................... 195

8-23. Distribution of burned rock feature types in the Late Paleoindian strata .................................................... 200

8-24. Average number of rocks per feature and average size of features in stratigraphic units ................................ 200

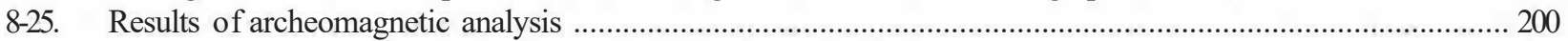

8-26. Fauna) remains associated with Late Paleoindian burned rock features ....................................................... 201

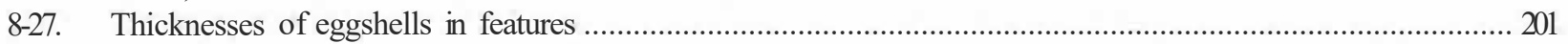

8-28. Total identified specimens and percents offaunal remains from features in upper Unit I ................................ 202

8-29. Artifact and fauna! counts for each square along with volume of excavation by square ............................... 209

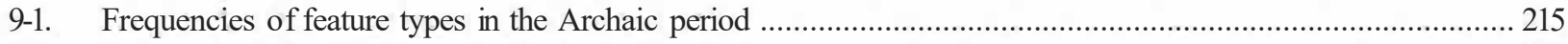

9-2. Frequencies of artifact types in the Archaic period .......................................................................... 217

9-3. Ratios of selected artifact types by Archaic subperiods ........................................................................... 218

9-4. Frequencies of projectile points by types from Early Archaic/Late Paleoindian contexts ............................... 219

9-5. Frequencies of projectile points by types from Early Archaic contexts .................................................... 220

9-6. Frequencies ofbifaces, Clear Fork tools, core tools, and cores from Early Archaic/Late Prehistoric

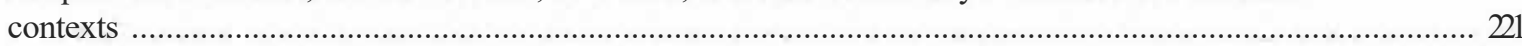

9-7. Frequencies ofbifaces, Clear Fork tools, cores, and core tools from Early Archaic contexts ........................... 221 
9-8. Frequencies ofperforators and burins from Early Archaic/Late Paleoindian contexts ..................................... 222

9-9. Frequencies ofperforators and burins from Early Archaic contexts ........................................................... 222

9-10. Frequencies ofunifaces and edge-modified flake tools from Early Archaic/Late Paleoindian contexts ............. 222

9-11. Frequencies ofunifaces and edge-modified flake tools from Early Archaic contexts ...................................... 223

9-12. Frequencies of ground stone tools from Early Archaic/Late Paleoindian contexts .......................................... 223

9-13. Frequencies of ground stone tools from Early Archaic contexts .................................................................. 223

9-14. Frequencies of projectile points by types from Middle/Early Archaic contexts ............................................. 240

9-15. Frequencies of projectile points by types from Middle Archaic contexts ..................................................... 241

9-16. Frequencies ofbifaces, Clear Fork tools, cores, and core tools from Middle/Early Archaic contexts ................. 241

9-17. Frequencies ofbifaces, Clear Fork tools, cores, and core tools from Middle Archaic contexts ......................... 241

9-18. Frequencies ofperforators and burins from Middle/Early Archaic contexts .................................................. 242

9-19. Frequencies ofperforators and burins from Middle Archaic contexts ......................................................... 242

9-20. Frequencies ofunifaces and edge-modified flake tools from Middle/Early Archaic contexts .......................... 242

9-21. Frequencies ofunifaces and edge-modified flake tools from Middle Archaic contexts ................................... 242

9-22. Frequencies of ground stone tools from Middle/Early Archaic contexts ....................................................... 243

9-23. Frequencies of ground stone tools from Middle Archaic contexts ............................................................. 243

9-24. Frequencies of projectile points by type from Late/Middle Archaic contexts ................................................ 252

9-25. Frequencies of projectile points by type from Late Archaic contexts ............................................................. 253

9-26. Frequencies of projectile points by type from Late Prehistoric/Late Archaic contexts ........................................ 253

9-27. Frequencies ofbifaces, Clear Fork tools, cores, and core tools from Late/Middle Archaic contexts .................. 254

9-28. Frequencies ofbifaces, Clear Fork tools, cores, and core tools from Late Archaic contexts ............................ 254

9-29. Frequencies of bifaces, core tools, and cores from Late Prehistoric/Late Archaic contexts .............................. 255

9-30. Frequencies ofperforators and burins from Late/Middle Archaic contexts .................................................... 255

9-31. Frequencies of perforators and burins from Late Archaic contexts ................................................................ 255

9-32. Frequencies of perforators, burins, and burin spalls from Late Prehistoric/Late Archaic contexts .................... 255

9-33. Frequencies ofunifaces and edge-modified flake tools from Late/Middle Archaic contexts ............................. 256

9-34. Frequencies ofunifaces and edge-modified flake tools from Late Archaic contexts ....................................... 256

9-35. Frequencies ofunifaces and edge-modified flake tools from Late Prehistoric/Late Archaic contexts ................. 256

9-36. Frequencies of ground stone tools from Late/Middle Archaic contexts ....................................................... 256

9-37. Frequencies of ground stone tools from Late Archaic contexts ................................................................... 257

9-38. Frequencies of ground stone tools from Late Prehistoric/Late Archaic contexts ............................................ 257

9-39. Frequencies of projectile points by type from Archaic contexts ................................................................... 267

9-40. Frequencies of projectile points by type from Late Prehistoric/Archaic contexts .............................................. 267

941. Frequencies ofbifaces, Clear Fork tools, and cores from Archaic contexts ...................................................... 268

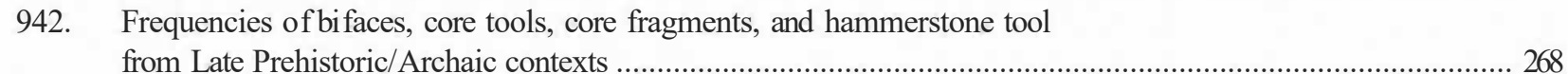

943. Frequencies of perforators and burins from Archaic contexts ...................................................................... 268

944. Frequencies ofperforators and burins from Late Prehistoric/Archaic contexts .............................................. 268

945. Frequencies ofunifaces and edge-modified flake tools from Archaic contexts ............................................... 268

9-46. Frequencies ofunifaces and edge-modified flake tools from Late Prehistoric/Archaic contexts ....................... 268

947. Frequencies of ground stone tools from Archaic contexts ................................................................... 268

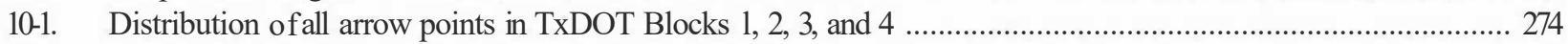

10-2. Distribution ofall Scallorn arrow points in TxDOT Blocks 1, 2, 3, and 4 .................................................... 274

10-3. Distribution of all Ensor and Dari dart points, not including three specimens from pothole contexts ................ 274

104. Distribution of Bulverde, Castroville, Edgewood, Fairland, Frio, Marcos, Marshall, Nolan, and other dart points 


\section{ACKNOWLEDGMENTS}

\section{Introduction}

In the quarter century since the site of Wilson-Leonard was discovered, many scores of people have contributed in diverse ways to bringing the project to its present status. My involvement began in 1991, so I write these acknowledgments from the perspective of a relative late-comer. The project saw little activity in the years between discovery (1973) and testing (1981), and there were also protracted lulls between the first major excavation (1982-1984) and the final phase of evaluation, excavation, analysis, and reporting (1991-1998). Besides the long span of time, this project was conducted under the auspices of two different organizations, the Texas Department of Transportation from 1973 to 1991 and The University ofTexas at Austin from 1991 to the present. It is inevitable that under these circumstances, the contributions of numerous individuals have slipped into obscurity. To those whose efforts go unacknowledged here, it does not mean that they go unappreciated, so I thank each of these individuals, and I also sincerely apologize for their omission on these pages.

All ofthe investigation and reporting ofthe Wilson-Leonard site was sponsored by the Texas Department of Transportation (formerly State Department of Highways and Public Transportation). This agency has earned the lasting appreciation of everyone involved for its recognition of and commitment to the importance of the Wilson-Leonard site.

\section{Acknowledgments for 1973-1990}

These acknowledgments are reconstructed from records generated during the investigations of 19731990. In many of these records, names are incomplete or appear with more than one spelling; also, some names that appear are not ascribed any affiliation or status, nor is any particular activity attributed to the individual. Every effort has been made to properly recognize the efforts of the many people who contributed to the early investigation of the Wilson-Leonard site, but after the passage of so many years, undoubtedly there are many omissions and the potential exists for numerous errors.

Frank Weir was the principal investigator and Wayne Young was the project archeologist. Among crew members at various times over the more than two years of fieldwork were Erwin Bonilla, Mike Davis, Pat Garrett, Brian Gay, Molly Godwin, Tom Gorman, Wayne Klement, Maxine Miller, J. Morrison, Lonnie Paenitz, Jody Pevey-Perroni, Douglas Powell, M. Stevenson, Bob Stiba, and Jeff Turpin.

Joe Denton and Woody Woolridge extracted at least one soil monolith as a record of the site's stratigraphy. Mark Denton and Bill Blakeley conducted supplemental excavations at the site. Mark also served as an advocate of the site from his position in the Texas Historical Commission and participated in many of the activities and decisions regarding the site, its investigations, and permit-related matters.

A number ofpeople, especially Al Wesolowsky and Elton Prewitt, assisted in the excavation and removal of Burial 2. Gill King conducted an early study of the human remains from the site.

Vance T. Holliday occasionally assisted by B. L. Allen conducted a comprehensive study of the geology and pedology of the site during excavation. Glen L. Evans, too, spent many hours evaluating the geologic context of the site, informing the crew about the site stratigraphy, and encouraging ever deeper excavations. It was this latter encouragement that led to discovery of the Paleoindian-age Burial 2, one of the more significant finds at the site.

Sam Valastro, Jr. of the Radiocarbon Dating Laboratory of the University of Texas at Austin assayed a number of soil samples for radiocarbon age-estimates and established the basic dating for Burial 2.

Chuy Gonzales presided over the enormous task of processing the collections from Wilson-Leonard through the TxDOT laboratory. 


\section{Acknowledgments for 1991-1998}

Texas Department ofTransportation personnel, Ann Irwin, Kenneth Bohuslav, Frank Weir, Wayne Young, and Glenn Goode each worked diligently on behalfofthe project in the early years of the University's work. Their roles eventually shifted primarily to Nancy Kenmotsu, Dianna Noble. The efforts of all of these individuals were essential, and are all sincerely appreciated.

Tim Perttula, James Bruseth, Bill Martin, and others at the Texas Historical Commission as well as Robert Mallouf and Pat Mercado-Allinger in the Office of the State Archeologist were very helpful at various times in the statutory as well as the research aspects of the University's investigations at Wilson-Leonard.

Certainly one of the most lasting contributions was the gift of 2.5 acres of the site to the Archaeological Conservancy by Will R. Wilson, establishing the Marjorie Ashcroft Wilson Archaeological Preserve. Evelyone who supports site preservation owes Judge Wilson a debt of gratitude. Jim Walker of the Archaeological Conservancy was very helpful, cooperative, and forthcoming when we sought to establish permanent site datum points and conduct subsurface coring on the Conservancy tract. Members of the Travis County Archeological Society have also promoted preservation on the conservancy tract by backfilling potholes and by clearing the brush that had been used as cover by looters.

Jan Guy, Marilyn Masson, and Susan Dial were the sustaining force in the long, arduous analytical phase of this study. Jan served as project manager for most of two years while also conducting the analysis of fall of the site's archeological features. Marilyn, as co-principal investigator and project director for two years, also studied and reported the debitage as well as conducted significant analysis of the fauna! material. Susan Dial kept tabs on the flow ofmaterials back and forth between the main analytical laboratory, the photographic studio, the technical illustrator, and all of the outside consultants and analysts while also completing in-depth study and reporting of much of the lithic assemblage. Without the talent, commitment, and yeoman effort of these three, this project could never have been concluded, and I can never adequately thank Jan, Marilyn, and Susan.

Britt Bousman as contract co-principal investigator formulated much of the research design, excavation methodology, and analytical strategy employed in this project. Britt also supervised the field and laboratory work while handling most of the managerial tasks from 1991 until 1994. After leaving the University for another job, Britt continued with writing and analytical tasks as well as contributing to larger research issues and directions. I thank Britt for his many contributions to all aspects of this project.

The 41 authors who contributed to this volume are the ones who conducted most of the analytical research of this project with assistance from Palma Buttles-Valdez, Robin Benson, Lori Douglass, Mark Holderby, Jose Luis Lanata, Valentina Martinez, Elizabeth Pintar, and especially Paige Hake Shehan.

An early and fundamental aspect of this project was an assessment of the extant records and collections generated during the early investigations of Wilson-Leonard. This was ably conducted by Jan Guy and Steve Carpenter whose efforts set the stage for all of the subsequent investigations.

Fieldwork was accomplished under the supervision ofBritt Bousman assisted by crew chiefs Paul Maslyk, Paul Takac (who also carried out the archeomagnetic field sampling), Matt Tomaso, and Chris Ward. The crew consisted of Ed Barnhart, Mat Bobo, Scott Brosowske, Mary Buell, Diane Cargill, Maria Davis, Aina Dodge, Doug Drake, Terry Ernsberger, Ellen Garrett, Jan Guy, Courtney Kearse, Dorothy Lippert, Valentina Martinez, Greg Mele, Sarah Meyer, Barry Nowlin, Camille Quinn, Chris Ringstaff, Steve Ross, Karen Rumpf, Frederick Sellet, Kaylee Stallings, T. Thompson, Tammy Walter, Pam Weiss, and Diane Wilson.

Archeological laboratory work was supervised by Gail Bailey who also managed the computerization of the data. The archeological laboratory crew included Elizabeth Andrews, Kathy Collins, Jennifer Hodgkins, Anne Jung, Dorothy Lippe11, Carole Medlar, Barry Nowlin, and Karen Rumpf. Ernie Lundelius supervised the finescreen sediment washing and picking in the Vertebrate Paleontology facility at the University of Texas at Austin. Susan Decker took a leading role in the washing as well as the picking phases of this work; other crew members 
were Ed Baker, Robert Barnett, Joy Becker, Leslie Cox, Sam Coyner, Billy Davidson, R. C. Harmon, Mark Howell, Jennifer Logan, Mike Powers, Julie Roska, and Vicki Yarborough.

Geological investigations at the site were conducted by Paul Goldberg and in the vicinity of the site by Gene Mear. Considerable assistance was provided by Vance Holliday who had studied the geology and soils of the site during the earlier phase of study. Also, valuable observations in the field as well as help with rock and mineral identifications were contributed by Ed Gamer and Tom Gustavson.

Site photographer Jose Luis Lanata took the majority of the photographs during the 1992-1993 investigations. Elisabeth Andrews and especially Milton Bell did most of the photographic work in the laboratory. Rosario Casarez labeled and cataloged for curation all of the photographs for the entire project. The extensive graphic work seen in this report as well as that needed during analyses was done or aided by Robin Benson, Gillian Dietz, Pamela Headrick, Kerza Prewitt, Drew Patterson, Sarah Meyer, and Matt Williams. Pamela Headrick did the artifact drawings. Charles Locke, with the help of Karen Rumpf and Anne Jung, video-taped aspects of the field as well as the interpretive effort.

The immense task of technical report production was under the direction of editor JeJTilyn McLerran assisted especially by Robin Benson and Kelly Scott Garcia. Jennifer Ramsey, Pat Ramsey, Matt Williams, Mary Jo Galindo, Abe Kinney, Mitch Wilson, and Scott Speal also contributed to this effort.

Mickey Burleson generously guided Glen Fredlund and Britt Bousman to the several remnant prairies in Central Texas where Glen collected phytoliths as background spectra for his study.

Many professional colleagues aided in the analyses and report preparation by sharing their experience and insights. I especially thank Steve Black, Bruce Bradley, Kenneth M. Brown, Darrell Creel, John Cross, Mott Davis, Boyce Driskell, Reid FeJTing, Dave Froehlich, Glenn Goode, Tom Hester, Pegi Jodry, LeRoy Johnson, Ernie Lundelius, Bob Mallouf, David Meltzer, Dan Morse, Tim Perttula, Elton Prewitt, Dan Prikryl, Dennis Stanford, Dee Ann Story, Alston Thoms, Steve Tomka, and Rickard Toomey, III.

Several participants in the earlier excavations contributed information used in the evaluation and analysis stages of this project. These include Bill Blakeley, Mike Davis, Molly Godwin, Wayne Klement, Bob Stiba, Frank Weir, and Wayne Young.

Computer support and data management staff were essential in the course of this project and included Dale Hudler, Matt Williams, Mark Shipley, Tim Decker, Jason Lucas, Gail Bailey, Elizabeth Andrews, Robin Benson, Susan Decker, Ed Baker, and Kevin Jolly.

A cadre of volunteers worked in the laboratory or assisted with the analyses conducted at the University, many of them as part of a program of volunteerism promoted by Fred Valdez and Tom Hester in their archeology classes. Two volunteers, Monica Trejo and Moody Miller, worked especially long and well. Others include Margaret Brown, Bill Childers, Sandra Fernandez, Trisha Grey, Wendy Kirby, David McDow, Joe Pena, Mike Powers, Darren Schubert, Eva Shipp, Leah Skillen, and Stella Stevenson.

R. C. Harmon coordinated the field and laboratory handling of records and collections, worked on the picking crew in the vertebrate paleontology laboratory, volunteered in several field and laboratory activities, and participated in the Travis County Archeological Society's stabilization efforts on the Conservancy Tract.

Tom Hester as Director of the Texas Archeological Research Laborite deserves special recognition for his tireless support, encouragement, professional input, and administrative efforts throughout this project.

To all of these many people, I extend my heartfelt appreciation-this project could not have been done without their help. As always, of course, no burden of responsibility for errors or omissions belongs to anyone but myself.

Michael B. Collins Austin, Texas

20 August 1998 


\title{
FOREWORD
}

\author{
An awareness of the gaps in our knowledge of the prehistory of \\ central Texas is as important as a good understanding of the \\ reconstructions and interpretations presented to date.
}

Dee Ann Suhm

1958

Study of the archeology of the Wilson-Leonard site has opened broad new vistas for the reexamination and improved interpretation of regional prehistory. Beyond that, it is of national importance in terms of both data and interpretation (for example, on the Paleoindian era) and the concepts used in its excavation and analysis. It is unique in other ways. In most cases, deep, stratified, multicomponent sites of this integrity are rarely excavated (in Texas, at least) more than once and the potential for long-term research is not fully met. As the reader will learn, Wilson-Leonard was first excavated on a large scale by archeologists of the Texas Department of Trans-portation (TxDOT) from 1982-1984 but was not formally published. Much attention went, deservedly, to the discovery of a Paleoindian burial at the site. Beginning in 1991, the Texas Archeological Research Laboratory was contracted by TxDOT to evaluate the records from the excavations and to make recommendations on the preparation of a comprehensive report. Given the many changes that had occurred in the technology of archeological excavation and the rise of new theoretical and analytical approaches, the TxDOT data appeared to be insufficient for more than a descriptive study. Yet, it was clear that the rich body of information from Wilson-Leonard warranted more than that. Thus, Michael B. Collins and his staff recommended that a second major excavation be undertaken in order to provide a better context for the TxDOT materials. Further, the findings from both excavations would then be fully integrated into a final report. Thanks to the foresight of Kenneth Bohuslav and Ann Irwin at TxDOT, this proposal was accepted and excavations directed by Collins were carried out in 1992-1993.

The excavations were extremely successful as evidenced in these five volumes. Here again, we are grateful to TxDOT, both to the two persons noted above, and to Dianna Noble and Nancy Kenmotsu, in more recent years, for their support of, and patience during, the intensive period of analysis and report preparation.

While no one site contains all the "answers," and while a number of impoltant monographs on Central Texas prehistory have appeared in recent years, it is clear that the information gained from the research at Wilson-Leonard will prove invaluable. For instance, many of the traditional archeological problems that plague this and surrounding regions, in terms of culture history, typology, material culture, and interpretation of site features have been addressed and materially reduced through these investigations. As reflected in the quote above from Dee Ann Suhm Story, the answers may not be, in some cases, what we had hoped, but archeology makes progress through acquisition and interpretation of new data and not through intractable adherence to old concepts. Human ecology and facets of ancient behavior are given special emphasis in these volumes, providing new ideas for future work in sites of this sort, as well as in broader topical studies. In this regard, the renewed examination of hearth and burned rock midden fonnation ("hot rock cooking") will be furthered by the WilsonLeonard data. The site was painstakingly analyzed in terms of its formation processes, through traditional geomorphology and more-recently developed micromorphological techniques. Stratified sites or components in Central Texas have often been misinterpreted without having such data available. Multiple approaches toward a better understanding of ancient diet is reflected in special studies of carbon isotopes, residues on stone tools, phytolith and botanical analyses, and even the study of eggshells recovered in the excavations. And, the number and quality of radiocarbon assays (92) provide critical anchors to the overall interpretations. Indeed, WilsonLeonard is currently one of the best-dated sites in Texas.

As a gauge in measuring change in the nature of archeological inquiry reflected by Wilson-Leonard, one need only look back to the study of other major stratified sites, such as those at Stillhouse Hollow Reservoir (Sorrow et al. 1967). That is an excellent report; it reflects the research strategies of the mid-1 960s and certainly results from a much lower level of funding. Yet the report is only 148 pages long, deals mainly with stratigraphy, lithics, and a projectile point sequence. The fauna! remains are reported as a "laundry list." On the other hand, the 
reader may wish for a "portable" volume like Stillhouse Hollow and not risk the muscle strains inherent in carrying around these five volumes. Yet, I think this comparison is a valid one in that it happily shows the vast difference (clearly an understatement) in how much more we are learning about prehistory today than we were 30 years ago. To be sure, Stillhouse Hollow still holds great value in the continuing, and important, studies of cultural chronology, and indeed, the Wilson-Leonard volumes build on this important research question, while having the opportunity to address many others.

Continuing in the spirit of Dee Ann Suhm's observations set forth in the opening quote, the WilsonLeonard report concludes with a challenge for scholars to devote more attention to the persistence of the hunting and gathering tradition in this region, and to seek to better understand why it never gave way to horticulture, mound-building, or other "formative" traits. As seen in the culture history ofCentral California, the Central Texas peoples clearly had knowledge of, and trade connections with, agriculturally based societies, yet never adopted any of their characteristics beyond limited pottery making and even more imited maize horticulture in the Late Prehistoric.

There are many people to acknowledge at TARL and TxDOT, as well as others associated with the project. This is done at length in Volume 1. From my personal perspective as Director, I want to take this opportunity to highly commend Dr. Collins and the hardworking staff of the Wilson-Leonard Project for their incredible effort, the likes of which I have never before seen. In the same vein, I would also like to especially recognize Jerrilyn McLerran, TARL editor, for her thorough work on these volumes, both in terms of content and in preparation for report production.

Thomas R. Hester 24 August 1998 


\section{CHAPTER 1}

\section{INTRODUCTION}

by Michael B. Collins

Wilson-Leonard is a deeply stratified, prehistoric archeological site in Central Texas (Figure 1-1). Deposits at the site are part of the Quaternary fill ofBrushy Creek valley, are more than $6 \mathrm{~m}$ in total thickness, and contain the most complete temporal sequence of prehistoric archeological assemblages known at a single site in Central Texas. Cultural and noncultural evidence relating to much of the last 12,000 years and covering the Paleoindian, Archaic, and Late Prehistoric archeological periods has been recovered from excavations at the Wilson-Leonard site. This evidence has been analyzed, interpreted, and here reported from the perspective of human ecology.

Wilson-Leonard is in the ecotonal zone between the savanna habitats of the Edwards Plateau and the tall grass prairie habitats of the Black Prairie on the interior coastal plain. This setting (discussed in more detail in Chapter 2) is near the headwaters ofBrushy Creek, a tributary in the Brazos River system, but the site is separated from the Colorado River drainage only by a low, narrow divide, and its cultural history is intimately linked to both of these two great river basins of Texas.

Archeological investigation of the Wilson-Leonard locality began in advance of construction of Ranch-to-Market Road (RR) 1431, which crosses the western end of the site, and the work has been conducted to mitigate damage to the site by that road project. These investigations have been in four phases. The site was found during archeological reconnaissance of the right of way in April, 1973, and minor testing was conducted in July, 1981. Conspicuous mounds of burned rocks, "burned rock middens," were the most visible aspects of the site at the time it was found and tested.

Large-scale excavation commenced in January, 1982, and, prolonged by a series of unexpected findings, lasted for 28 months, ending in April, 1984. During this time, the site generated considerable interest among archeologists who were aware of it, and widely publicized accounts of the discovery of an early human burial focused considerable public attention on the project in 1983. The site and its sizable yield of data remained unanalyzed and umeported for almost 10 years during which time the field of archeology advanced significantly both in methods and in substantive findings. As part of the effort to analyze and report the Wilson-Leonard findings of 1982-1984, a fourth phase of fieldwork was conducted on a "witness column" in 19921993 for the purpose of bringing more-current methods and perspectives to the interpretation of this important site, particularly its geological aspects. Ancillary to these direct investigations have been two episodes of core-drilling at the site (in 1992-1993). Also, geological reconnaissance was conducted some distance up and down the valley (in 1994) and a series of shallow auger holes was drilled in a part of the site by staff of the Office of the State Archeologist, Texas Historical Commission, in 1983. No report is available for the latter auguring effort.

The 1973 reconnaissance, 1981 test excavation, 19821984 excavation, and preliminary processing of the data generated by those activities were conducted by personnel of the Texas Department of Transportation (TxDOT [formerly State Department of Highways and Public Transportation, SDHPT]). The 1992-1993 field investigation, 1994 geological reconnaissance, and all subsequent analyses have been conducted under auspices of the Texas Archeological Research Laboratory (TARL) of The University of Texas at Austin under contract with TxDOT. All work was performed under Texas Antiquities Committee Permit Number 300. This report and the curation of the artifacts and records will complete TxDOT's responsibilities under that permit.

This five-volume monograph presents an analysis and interpretation based on attempts to unify data from all of these sources, integrate them with regional findings, and offer a comprehensive report in human ecological terms. The report has two distinctive aspects. One is a descriptive report of the site, the investigations conducted there, and archeological, physical anthropological, geological, and 


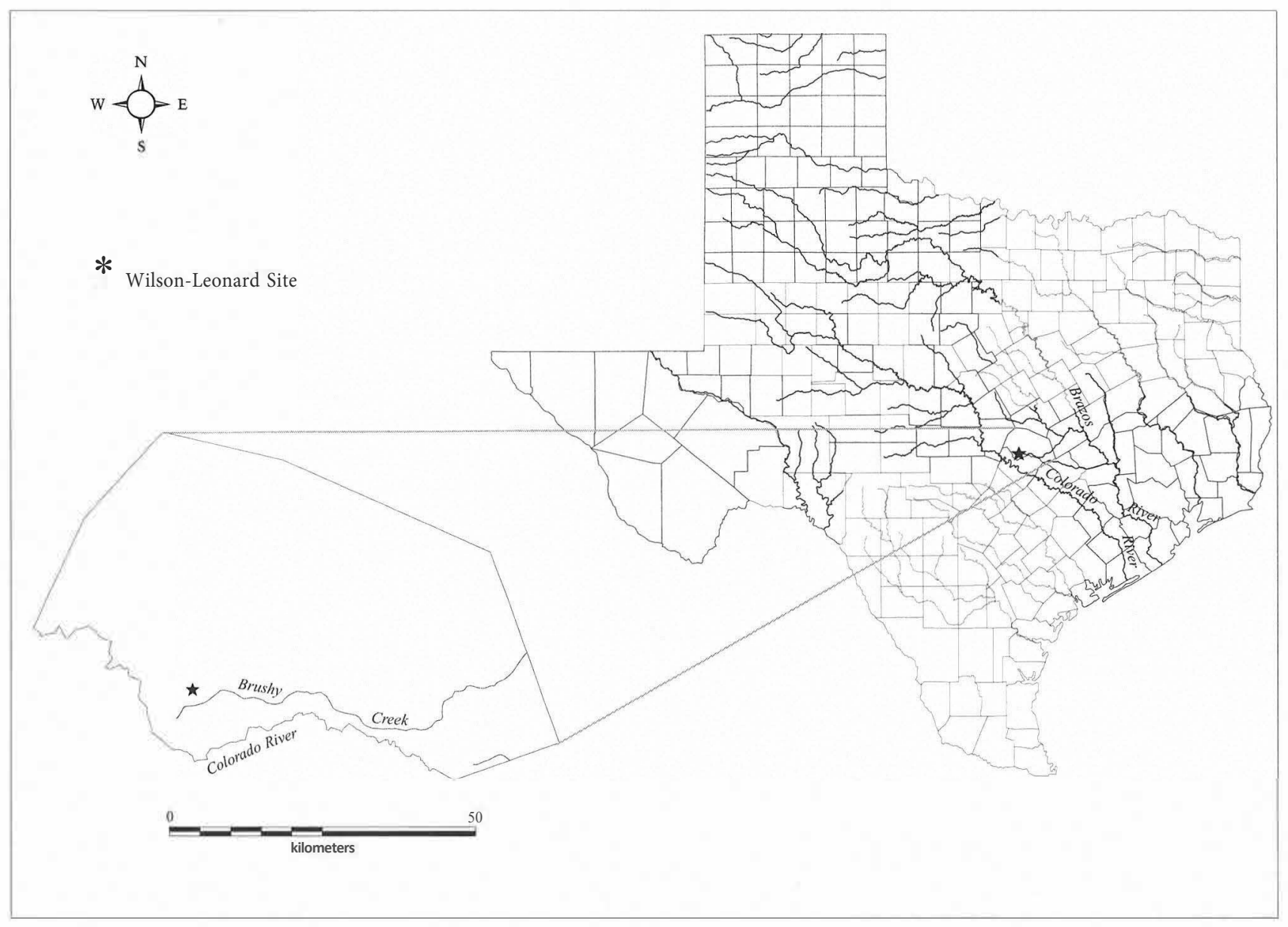

FlaRE 1-1. Location of the Wilson-Leonard site in Texas and in relation to the Brazos and Colorado stream systems.

ecological data recovered. This material and a discussion of the archeological background to this study appear in Chapters 1-6 and 12-42. The other aspect covers the interpretive findings for each of the major archeological periods (Early Paleoindian, Late Paleoindian, Archaic, and Late Prehistoric) at the site and concludes with a diachronic summary of the site and a consideration of its place in the cultural history of the Southern Plains of North America (Chapters 7-1 1).

Wilson-Leonard is a complex and extensive site. In aggregate, the various investigations, too, have been complex and extensive. Over the years that intermittent fieldwork transpired, perceptions of the site and the paradigm guiding the investigations changed substantially. Initially, during the 1981 testing and early months of the 1982-1984 excavations ofTXDOT, the site was thought to be fairly superficial and to consist primarily of burned rock middens with shallow archeological deposits around them. The objective of excavation under that initial perception was to investigate two burned rock middens and the "activity areas" between them in terms of similarities and differences among the archeological manifestations of Weir's (1976) "phases" of the Archaic. As the deep, stratified nature of the site gradually became evident, the objective became one of recovering data on as many of Weir's "phases" as were discovered in the site.

During the interval 1984 to 1990, some analysis and preliminary interpretation were attempted, but the copious data from the site remained mostly unanalyzed and uninterpreted; no report was produced (Collins et al. 1991). Meanwhile, there were significant changes in the regional archeological paradigm with a move from refining archeological "phases" and chronologies to better understanding human adaptations (Collins 1988; Hester 1991; Johnson 1987). For these reasons, a second excavation was mounted in 1992-1993 for the purpose of meeting the more rigorous data requirements to address more-substantive research issues. Issues guiding this field effort fell into seven general topics: (1) cultural chronology, (2) site formation processes, (3) site structure, (4) lithic technology, (5) human ecology and subsistence, (6) systematics and typology, and (7) biological anthropology of the early human remains (Collins et al. 1991 :iv). These were Later expanded and refined into eight objectives during analysis (see Chapter 5).

As reported here, establishing chronological control for this site required extraordinary measures, because, like so many sites in the region, material suitable for standard 
dating techniques is sparse. Given the site's long occupational sequence and the importance of that sequence to the regional archeological chronology, these measures were warranted, largely successful, and bring almost a hundred new radiocarbon assays (mostly AMS) to bear on the problem of dating the prehistory of Central Texas. Beyond the specific results, this study demonstrates an approach that holds considerable promise for sites with similar dating problems.

Archeological data quality is dependent upon its context, and for Central Texas, sites formed in fluvial settings are generally the ones with the greatest potential value (Collins 1995). Wilson-Leonard afforded the opportunity to gain detailed knowledge about some of the significant factors in the formation of such sites and several avenues of research were followed in investigating this process. Wilson-Leonard sediments and soils reveal fluvial and colluvial deposition, minor episodes of erosion, and intervals of surface stability during which natural and cultural processes formed complex soils. In spite of the general integrity of the depositional sequence, disturbances caused by plants, animals (especially earthworms), and humans have been commonplace throughout the site's history. Typically for the region, the fluvial sequence is one of more-rapid rates of deposition early in the sequence followed by less-rapid accumulation late in the sequence. Atypically, natural deposition at this site experienced very little interruption, and there was only minor loss of deposits to erosion during the Middle Holocene. Into this actively aggrading geologic context were introduced cultural materials at frequent intervals for more than 11,000 years with no long-term hiatuses (Figure 1-2).

At an undetermined time not long before 12,000 B.P., Brushy Creek was flowing against the south wall of its bedrock valley. It abandoned that channel, leaving a swale that filled with stream and pond deposits between about 12,000 and 10,500 B.P., during which time the earliest human use of the site is evidenced. Subsequently, the locality aggraded until valley fill lapped over the bedrock valley wall by about 8000 B.P. Aggradation after that time was comparatively minor. As depicted in the schematic sections (see Figure 12), archeological deposits become denser from bottom to top in this stratigraphic sequence.

Because of the slowing rates of deposition, the archeological and paleoecological record is better stratified in Early and Late Paleoindian times. By the advent of Early Archaic lifeways around 8,700 years ago, rates of deposition had slowed, and although significant cultural evidence pertaining to the Archaic (especially the Early Archaic) and the early part of the Late Prehistoric was recovered from the site, these did not occur as fully isolable components.

Wilson-Leonard is rich in archeological features containing heat-altered limestone rocks. Such features afford important data on past human behavior, especially related to subsistence, and intensive analysis of burned rock features and their changes through time at this site supports significant new interpretations of subsistence patterns in the prehistory of Central Texas.

Lithic artifacts, since they survive where less-durable kinds of artifacts do not, are necessarily one of the primary sources of information about prehistoric people, and cultural materials recovered from Wilson-Leonard are predominantly of chipped stone. These have been analyzed in an attempt to elucidate more about the adaptive behaviors of the people who made and used them, especially how stone tools were designed, made, maintained, recycled, and used during the various time periods represented at the site. Artifact typology is integral to the comparative method of archeology, and the present study applies traditional and notso-traditional techniques of typology to the more formal artifact classes. Significant revisions are proposed for the typological status of certain projectile points of Paleoindian and Early Archaic ages.

Floral, fauna!, microfloral, and microfaunal evidence was not recovered in abundance, but careful analysis of these data contributes to understanding both the cultural and natural history of the site. The human biology of the Paleoindian found buried at Wilson-Leonard and dated to 10,000 years ago contributes to the meager but growing evidence on the nature of the earliest peoples on this continent.

Data recovered from Wilson-Leonard and integrated with those from other sources in the region provide the basis for proposing a long sequence of environmental changes and the human adaptive responses to those changes. Largescale shifts from mesic to xeric and back to mesic conditions characterize the prevailing climatic conditions for the last 11,000 years. Through most of that time, local peoples subsisted through gathering and hunting diverse plants and animals. Intensive bulk processing of plant foods is documented at Wilson-Leonard as beginning roughly 8,700 years ago, the debut of a lifeway that prevailed in Central Texas for the next 8,000 years.

In recognition of the importance of Wilson-Leonard, the portion of the site that remains on adjoining private land has been donated to the Archeological Conservancy. Remaining intact deposits within TxDOT's ownership have been designated a State Archeological Landmark. 


\section{i.}
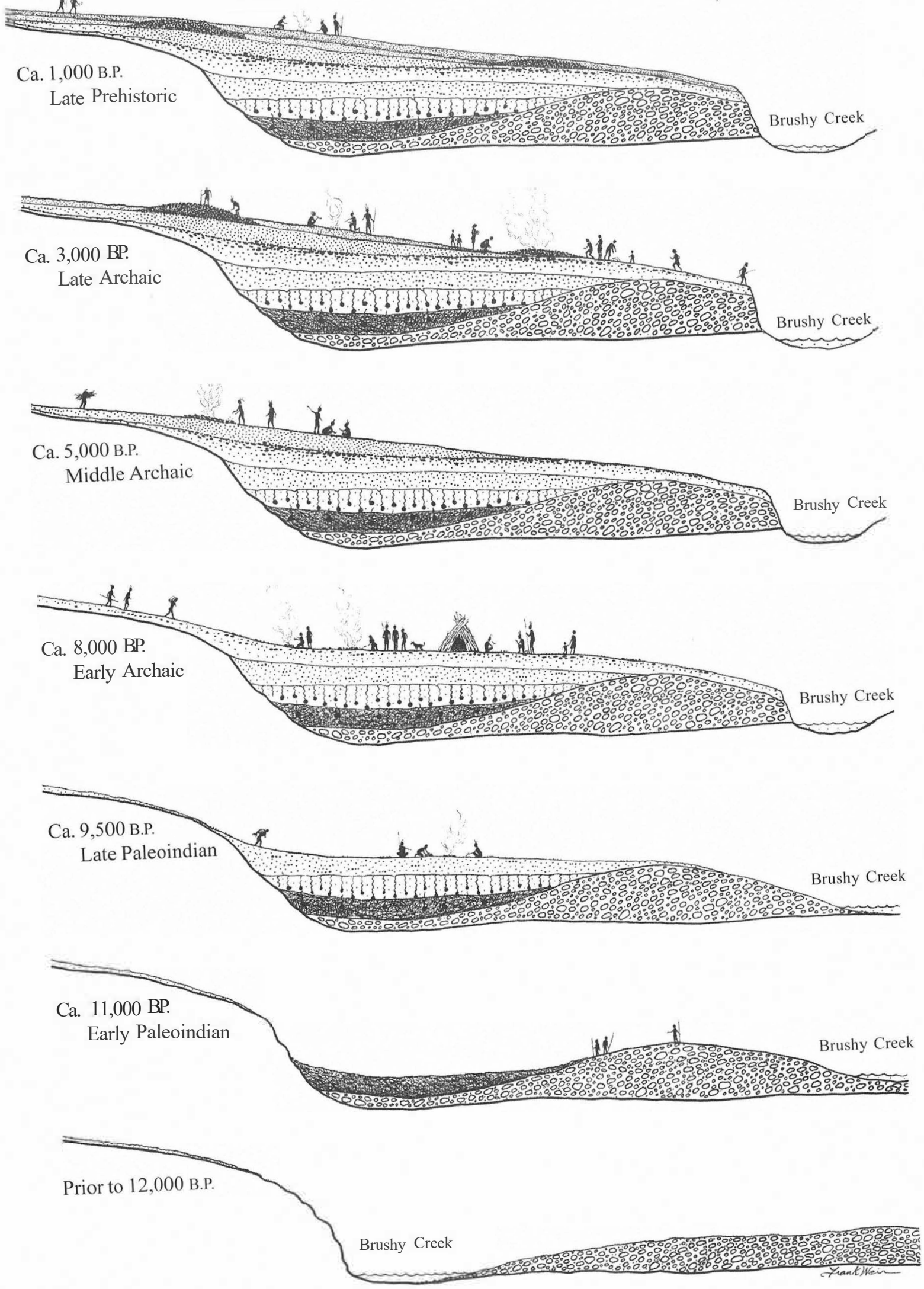

FIGURE 1-2. Schematic representations of the formational history of the Wilson-Leonard site. 


\section{THE SITE AND ITS SETTING}

$\mathrm{b}_{\mathrm{y}}$ Michael B. Collins and C. E. Mear

\section{INTRODUCTION}

This chapter moves from the general to the specific in presenting the geographic and geologic setting of the Wilson-Leonard site (41 WM235), a partial description of the site's surface characteristics, and an introduction to the more salient aspect of the site-its subsurface characteristics in the areas excavated. Physiographic data along with a geological field study of the Brushy Creek valley emphasizing the Quaternary landforms constitute the geologic sections of this chapter. An integral part of this fieldwork was describing 11 geologic sections where Quaternary deposits, soils, and in some cases, archeological materials were exposed. These descriptions are on file at TARL (Mear 1995). Geology is emphasized here because archeological geology was the fundamental concept upon which the 19921993 field investigations of the Wilson-Leonard site were structured.

The surface indications of Wilson-Leonard as an archeological site were never thoroughly documented, and no comprehensive site description can be written from the partial record that exists. To the extent possible, a description of the site prior to its partial destruction by highway construction is presented in this chapter. Although it is unfortunate that more is not known about the nature of the unexcavated parts of the site, its prime importance lies in the stratigraphic sequence that was revealed by excavation. This was documented and is introduced in this chapter.

The Wilson-Leonard site is in southwestern Williamson County, Texas, about $33 \mathrm{~km}$ north-northwest of Austin and $5 \mathrm{~km}$ northeast of Cedar Park (Figure 2-1) It is also about $6 \mathrm{~km}$ southeast of Leander, the community which loaned its name in 1983 to the site's widely publicized "Leanderthal Lady" burial (Burial 2). Cultural remains are exposed at the surface, but the importance of the site derives from a stratified cultural sequence within deep valley fill on the right bank of Brushy Creek, a major tributary to the San Gabriel River in the Brazos River drainage basin. This location is at $30^{\circ} 32^{\prime} 06^{\prime \prime}$ North Latitude, $97^{\circ} 46^{\prime} 42^{\prime \prime}$ West Longitude or Zone $14617250 \mathrm{E} / 3358625 \mathrm{~N}$ of the Universal Transverse Mercator grid. The primary datum of the site is at an elevation of just over $250 \mathrm{~m}$ (812 feet) above sea level.

Numerous questions regarding the natural and hurrian histories of this site have been engaged by the authors of this monograph. These diverse questions range from the particular to the general in scope, but in a sense, they would almost all be resolved if we could confidently establish the answer to just one, "why for nearly 11,000 years did people keep returning to this rather nondescript place?" Were this an imposing rockshelter, an inviting terrace near a large spring, a major outcrop of the best Edwards Chert, a rich riparian forest, or some combination of these, it would seem apparent why people were repeatedly drawn there. The location is none of these-just a nar-row bit of valley floor alongside a small stream in rolling limestone hill country with thin soils and ordinary vegeta-tion. Good chert is nearby, but no more abundant nor of better quality than can be found at hundreds of outcrops in the region. The question persists. Perhaps its answer lies in the diversity of resources that characterize the area.

\section{GEOGRAPHY}

\section{Physiography}

The Wilson-Leonard site is at the southern end of the Lampasas Cut Plain (Hill 1901; Hill and Vaughn 1900;Johnson 1931: 125), near the center of Texas and close to the common junction of three significant physiographic provinces-the Lampasas Cut Plain, the Black Prairie, and the Edwards Plateau (Figures 2-2, 2-3, and 2-4). A great fault system (the Balcones) arcing across Texas forms a distinct boundary 


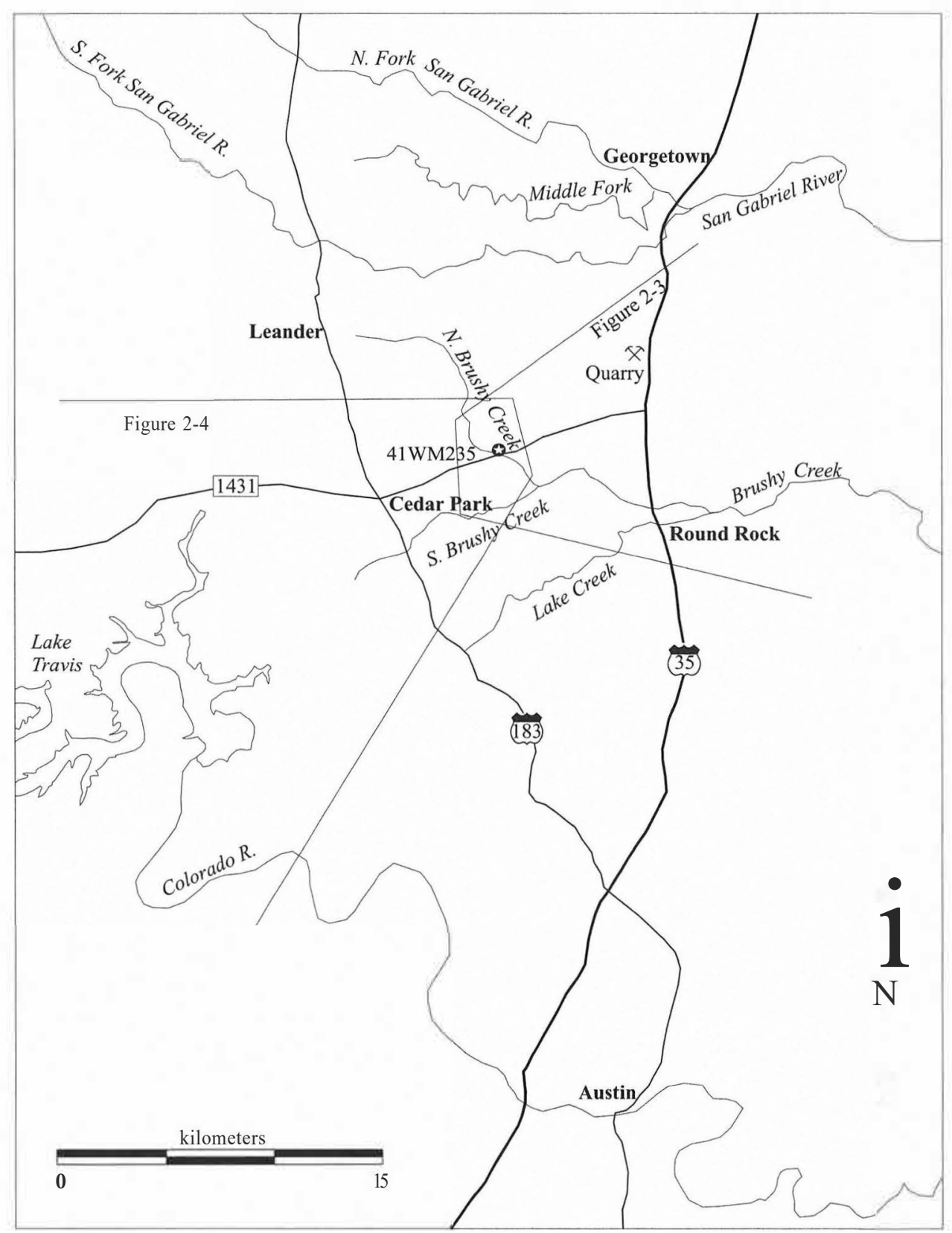

FGURE 2-1. The Wilson-Leonard location in relation to prominent geographic and cultural features. The coverages of aerial photographs in Figures 2-3 and 2-4 are indicated.

between uplands of mostly limestone bedrock (the Edwards Plateau, Lampasas Cut Plain, and Grand Prairie) and lower plains of mostly softer rocks (the South Texas Plains and Black Prairie). In places, this boundary is marked by an abrupt scarp (the Balcones Escarpment) and in others by a more gradational ramp (see Figures 2-3 and 2-4), but for its entire length, it is a major ecotone in terms of topography, bedrock, hydrology, soils, vegetation, and animal life. From WilsonLeonard, the biomes of three physiographic provinces are within easy reach, and the site is situated squarely in the enriched mix of resources that characterize this ecotone.

\section{Lampasas Cut Plain}

The Lampasas Cut Plain is a roughly triangular area of rolling hill country in central and north-central Texas between the Brazos and Colorado rivers. Ranging in elevation from about 230 to $400 \mathrm{~m}$ above sea level, it forms a limestone upland that has been dissected by the Brazos River and its tributaries. The Wilson-Leonard site is near the southern tip of the Lampasas Cut Plain, in the upper reaches of a Brazos tributary system, only $16 \mathrm{~km}$ from the Colorado River (see Figure 2-4). 


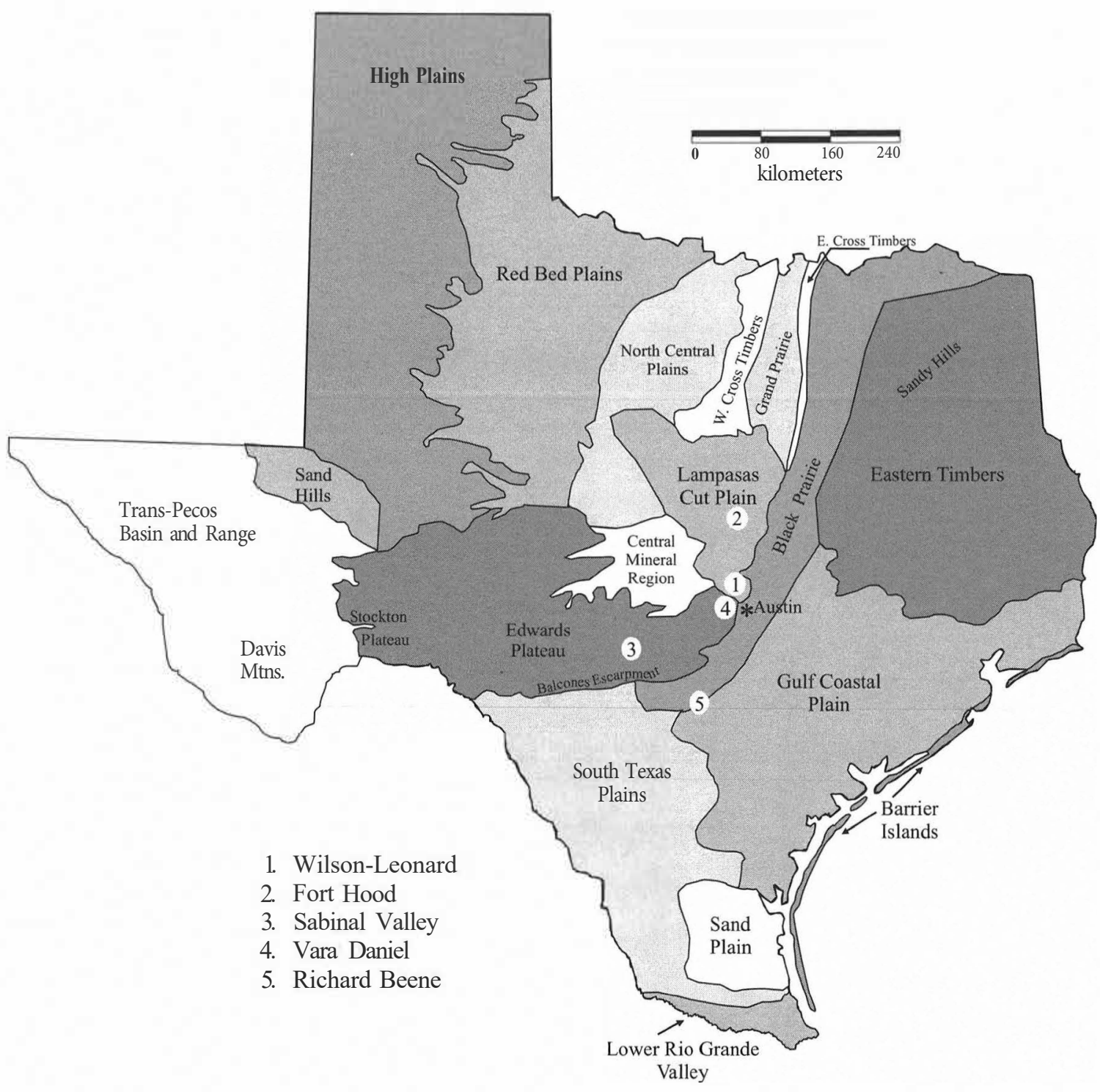

FlauRE 2-2. Wilson-Leonard in relation to regional landforms and selected archeological localities.

Characteristic landforms are generally rounded uplands cut by moderately broad, shallow valleys. Soils are thin to absent on the bedrock and support a mixed savanna flora; they are moderately deep in valley floors where mixed riparian woodlands and forests are found. Karst features include sinks, caves, and rockshelters, but these are neither common nor extensive. Edwards chert occurs in areas of the Cut Plain where it is not widespread but locally abundant and, in some places, of high quality.

In the vicinity of Wilson-Leonard, the Lampasas Cut Plain is characterized by low rolling hills having about $30 \mathrm{~m}$ of relief and by narrow alluviated valleys along the larger creeks and rivers. The Lampasas Cut Plain merges with the Black Prairie to the southeast along a southeasterly sloping ramp (see Figure 2-3). To the northwest, the plain grades into the North Central Plains (see Figure 2-2), thus affording easy pedestrian access from the Texas coastal plain to the North Central Plains, and thence to the Northern Great Plains of North America. It is nowhere recorded that this muted stretch of the scarp was an important game corridor, but for those herbivores preferring open terrain, notably bison and antelope, this may have been a preferred route. If so, movement of game through the area may have attracted human groups.

Brushy Creek and its tributaries have a catchment area above the Wilson-Leonard site of about $100 \mathrm{~km}^{2}$ (see Figure 2-1), and the site is about $12 \mathrm{~km}$ south of the head of Brushy Creek. The creeks are known to have been intermittent during much of the past 100 years, but infusion of Leander's municipal waste water now makes Brushy Creek perennial. All of Brushy Creek's major tributaries are in the western part of the drainage basin, are less than $8 \mathrm{~km}$ Jong 


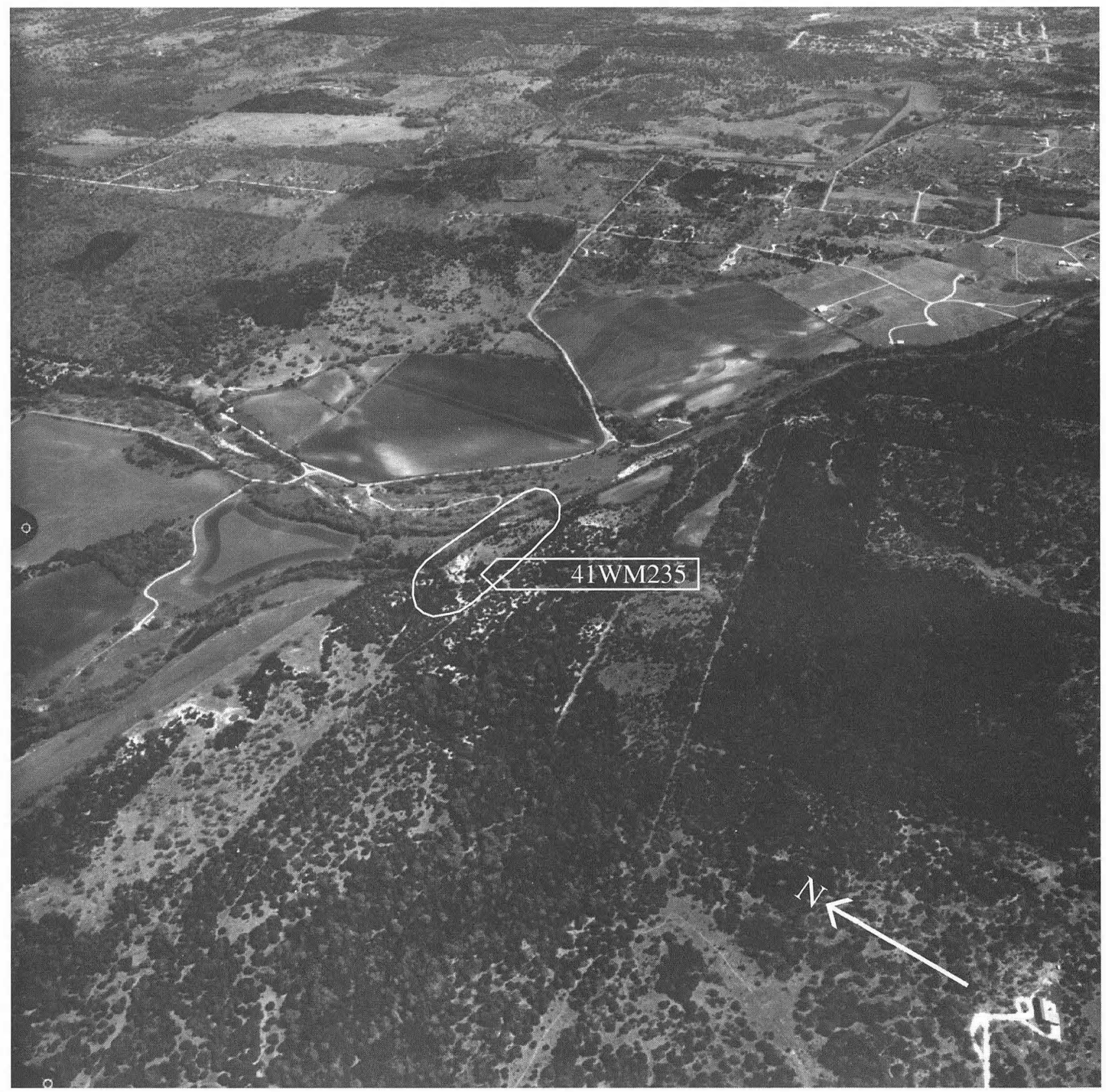

FIGURE 2-3. Oblique aerial view taken 21 March 1984 over the Wilson-Leonard site showing the landscape northeast of the site. This is the gradational zone between the Lampasas Cut Plain (fore and middle ground) and the Black Prairie (distant ground).

(see Figure 2-1), and contain flood-control dams. No flowing tributaries are present along the northern edge of the drainage basin, which is separated from the South Fork of the San Gabriel River by a nan-ow divide, about 2-5 km wide. Numerous dry gullies on both sides of the valley provide runoff into Brushy Creek and its tributaries during and following rains. During times of moderate to heavy rainfall, the creeks develop high-energy, short-lived floods along their floodplains. In general, the creeks are bedload dominated and contain gravel along their channels.

In the vicinity of the Wilson-Leonard site, the valley of Brushy Creek is about $1 \mathrm{~km}$ wide and has about $40 \mathrm{~m}$ of relief. Roughly one-third of the valley floor along its eastern side is a thin colluvium and soil-covered rock-cut bench that slopes gently southwestward toward Brushy Creek. The remainder of the valley is underlain by flu vial Quaternary deposits (see Figure 2-5). About $1.2 \mathrm{~km}$ north of the site at the junction of Block House Creek with Brushy Creek, the alluviated part of the valley is about $0.65 \mathrm{~km}$ wide. Downstream from the site about $2.8 \mathrm{~km}$, the valley becomes a canyon about $0.2 \mathrm{~km}$ wide and $20 \mathrm{~m}$ high that has been eroded by Brushy Creek through hard Cretaceous lime- 


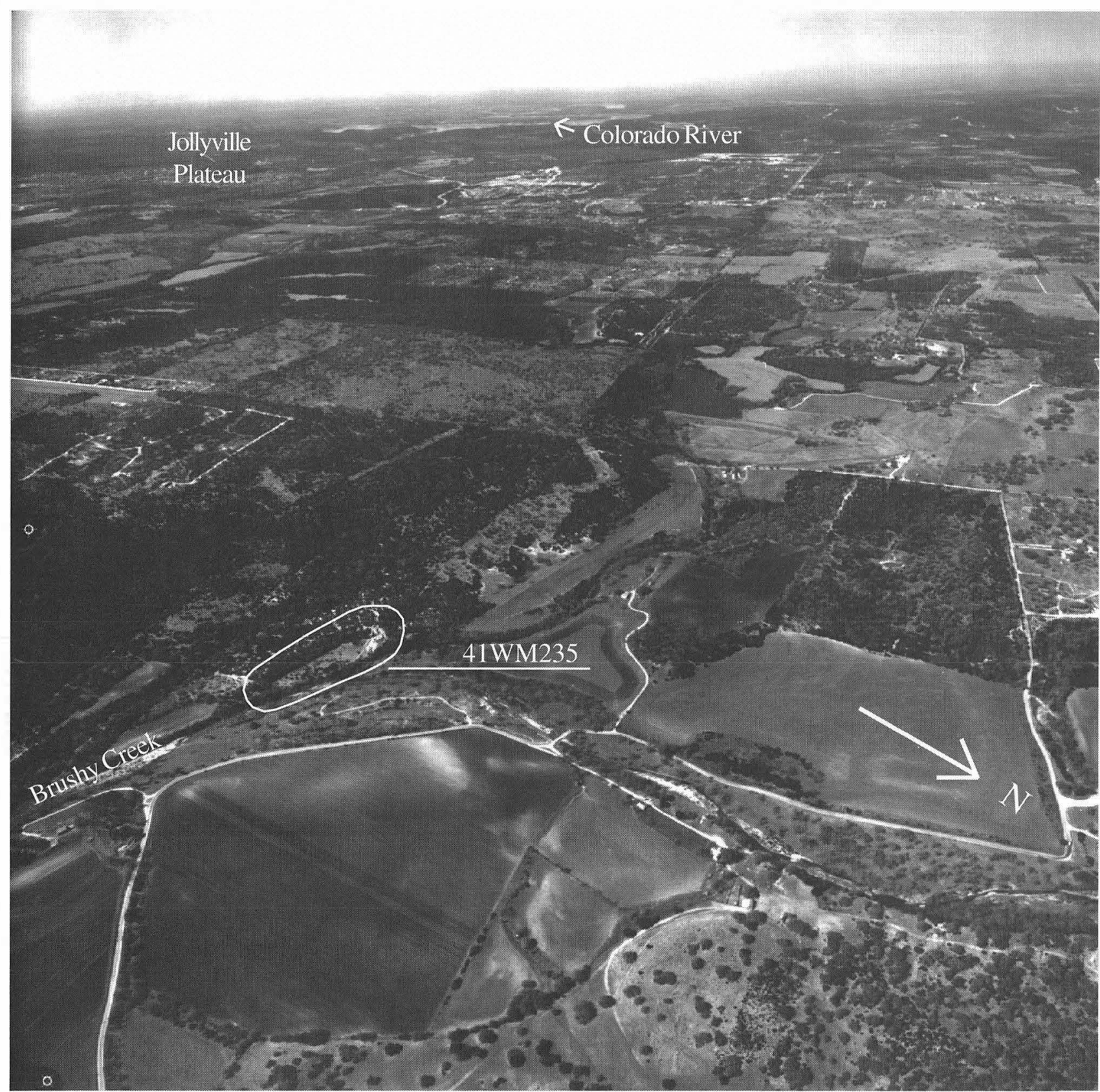

FIGURE 2-4. Oblique aerial view taken 21 March 1984 over the Wilson-Leonard site showing the landscape southwest of the site. The present character of Brushy Creek and the Lampasas Cut Plain are shown. In the distance are seen the Jollyville Plateau and Lake Travis on the Colorado River.

stone of the Edwards Formation. South Brushy Creek, a major eastward-flowing tributary, joins Brushy Creek within this narrow gorge. Southeast of the area of interest, Brushy Creekjoins the San Gabriel River, which in turn, flows into the Little River, a tributary of the Brazos River.

\section{Black Prairie}

The Black Prairie is low rolling land that extends in a narrow band just east and southeast of the Balcones fault zone from the Red River valley in northeastern Texas south and southwest to the southern edge of the Edwards Plateau (see Figure 2-2). This is an area of low relief and poor drainage where water often ponds after rain. Streams flow at very gentle gradients. Elevations on the Black Prairie are mainly in the range of 120 to $215 \mathrm{~m}$ above sea level. Deep, calcareous clayey soils formed in soft bedrock support predominately prairie vegetation broken by small woods and forests (Weniger 1984). Rock of any kind is scarce on the Black Prairie, and the only chert sources are gravels in the beds of streams that drain exposures of Edwards limestone to the west. 


\section{Edwards Plateau}

As an extensive dissected limestone upland, the Edwards Plateau is one of the major geographic features of central and west-central Texas (see Figure 2-2). Along its eastern margin, it is particularly deeply dissected with local relief of more than $100 \mathrm{~m}$ in places (the "Balcones Canyonlands"). The plateau is supported by nearly flat-lying limestone with common and extensive karstic sinks, caves, and rockshelters and many springs, both flowing and seeping. Chert ranging in quality from poor to excellent is abundant and widespread on the Plateau and can be found far downstream in the rivers that drain from the Plateau and flow across the Gulf Coastal Plain. Soils are thin on upland surfaces and on slopes and support xeric vegetation. Larger streams occupy cuts that range from canyons with little or no floor to moderately broad valleys with alluvial bottomlands and riparian forests. In some deeper valleys, particularly the narrower ones, are found cool, moist microhabitats where mesic vegetation thrives. The northeastern limit of the Plateau, a localized feature called the Jollyville Plateau, reaches to within about $10 \mathrm{~km}$ of Wilson-Leonard (see Figure 2-4). The Jollyville Plateau is a nearly flat-lying upland that is deeply incised by streams in the upper Bull Creek drainage to form a mosaic of xeric uplands and mesic canyons and valleys (Cofman et al. 1986). Elevation on the Jollyville Plateau generally ranges from about 230 to $335 \mathrm{~m}$ above sea level.

\section{Climate}

Across this mosaic of landforms and soil types is found a climatic regime with its own characteristic variability. On average during this century, precipitation and temperature manifest regional clines with mean annual precipitation totals declining fairly evenly from east to west and mean annual temperature declining as evenly from northwest to southeast (Larkin and Bomar 1983:18, 50). Climate has fluctuated from subtropical humid to subtropical subhumid in the vicinity of the Wilson-Leonard site. Average annual precipitation has totaled 32 inches $(81.3 \mathrm{~cm})$ and temperature has averaged $67^{\circ} \mathrm{F}$ annually, $96^{\circ} \mathrm{F}$ in August, and $59^{\circ} \mathrm{F}$ in January (Larkin and Bomar 1983). But during this time, drier periods lasting from three to seven years when total annual rainfall ranged from 12 to 25 inches were followed by three to six abnormally wet years with 45 to 50 inches of rainfall per year. In fact, annual rainfall amounts tend to deviate by more than $25 \%$ from the long-term average in almost half of the years (Blum and Valastro 1989:438). Furthermore, WilsonLeonard is located in one of the highest flood-risk areas of the United States (Baker 1975; Caran and Baker 1986; Slade 1986).

Normally there are two precipitation peaks per year, in May and September. These are associated with frontal storms that occur when cool air masses moving southward collide with warm, moist air masses moving inland from the Gulf of Mexico (Bomar 1983; Carr 1967). The topographic break along the Balcones Escarpment lies directly across the path of the Gulf storm trace and increases the lift in convective storms to produce extreme rainfall amounts (Baker 1975). Two examples are the more than 36 inches of rain that fell in 18 hours in the vicinity of Thrall (45 km east of Wilson-Leonard) in September, 1921, and the 22 inches that fell in less than 3 hours near O'Harris (190 km southwest of Wilson-Leonard) in May, 1935 (Baker 1975:3).

Lower rainfall amounts are characteristic of winter and late summer. In winter, frontal storms pass so frequently that there is little time for moisture to increase, and prevailing upper-level winds from west to east often dominate over meridional flow, meaning that much of the available moisture is derived from the Pacific rather than from the Gulf of Mexico. In summer, cool fronts rarely penetrate into the region and rainfall is primarily in the form of localized, thermal convective storms. An inferred climatic history for the region, based on floral and fauna! evidence, is presented in Chapter 4.

\section{Soils}

The limestone uplands of the Lampasas Cut Plain and Edwards Plateau are distinguished from the Black Prairie as much by soils as by any other characteristic. On the Cut Plain and the Plateau are moderately deep to shallow clayey to loamy soils, locally stoney or gravelly. These are primarily mollisols and range from dark to light in color. In contrast, the Black Prairie is characterized by very deep, dark calcareous vertisolic clayey soils (Godfrey et al. 1973; Werchan and Coker 1983). Black Prairie soils have some of the most extreme shrink-swell properties of any soils in the world and locally develop gilgai (Boule et al. 1989:262; Newman 1982; Werchan and Coker 1983). Although erosion has resulted from clearing in historic times, it has not been excessive in most of the Black Prairie soils (Werchan and Coker 1983); the earlier edaphic history of the Black Prairie is poorly known.

Because a record of soil erosion has been captured in the karsts of the Lampasas Cut Plain and especially of the Edwards Plateau, it is possible to reconstruct a partial history of soils in the late Quaternary of these limestone uplands (Collins et al. 1991; Young 1986). At least four phases of soil history can be surmised for the Edwards Plateau. The first phase began at a remote and presently unknown time in the past and lasted until late in the Pleistocene. During this initial period, which had to be of long duration (though not necessarily as long as postulated by Young [1986]), a soil covered the top of the Plateau and remained in place long enough to become deeply rubified. Much of this soil cover was lost late in the Pleistocene and early in the Holocene and today is found redeposited as fill in numerous caves (cf. Dalquest et al. 1969; Evans 1961; Graham 1976; Lundelius 1974; Semken 1961; Toomey 1989) as well as in situ in a few favored localities on the Plateau surface (Young 1986:86, 
Figure 1). Radiocarbon dating places the stripping of this soil and its redeposition in Hall's Cave in Kerr County from ca. 20,000 to 10,000 years ago (Toomey 1989; Rickard Toomey and Thomas Stafford, personal communication 1995).

The second edaphic phase is less well represented in Edwards Plateau caves or has gone less noticed. Its clearest expression is at Bering Sinkhole in Kerr County where its redeposition is dated at about 5,000 to 3,000 years ago (Bement 1991). The fill is a dark brown clay loam with moderate organic content. It appears to represent erosion of a moderately well-developed soil with A- and B-horizons becoming mixed in the cave. No in-place soils on the Plateau surface are yet correlated with this deposit.

The third phase is represented by dark-colored, loamy soils that prevail on the Plateau surface today as they have through much of the Holocene. These same soils are found in caves as very dark deposits, such as the upper stratigraphic unit at Bering Sinkhole where radiocarbon evidence dates their erosion as occurring over the last 2,600 years (Bement 1991). Archeological remains of Archaic and Late Prehistoric ages are commonly buried in these dark deposits, confirming their age (Bement 1991; Toomey 1989).

The most recent edaphic phase is that of extensive soil loss resulting from abusive agrarian practices in Historic times (cf. Semken 1961). Widespread loss of soil depth has brought about the disappearance of gophers since overgrazing and farming disrupted the native vegetative cover and prompted erosion in the past 100 years or so. It can be assumed that a similar edaphic history transpired on the Lampasas Cut Plain, although evidence is much more limited. Fill in caves in Coryell, Bell, and Williamson counties (Elliot and Veni 1994) contain minor amounts of sediment derived from erosion of upland soils that may represent periods of erosion similar to those postulated for the Edwards Plateau.

\section{Biota}

Conditions of climate, soil, topography, and biotic community dynamics influence vegetation, as is clearly shown by the contrasts between plant communities of the Black Prairie, Lampasas Cut Plain, and Edwards Plateau as well as more-localized variations within each of these areas (Anonymous 1978; Diamond et al. 1987; Gehlbach 1988; Van Auken 1988). Equally diverse and heterogeneous are the fauna of these areas (Blair 1950; Davis 1974; Gehlbach 1991).

Fauna in that part of Central Texas that would be within a reasonable range of accessibility from the Wilson-Leonard site-say $25 \mathrm{~km}$-would occupy ranges in the Black Prairie, Jollyville Plateau (part of the Balcones Canyonlands), and Lampasas Cut Plain. Important stream valleys-those of the Colorado and main forks of the San Gabriel rivers as well as the two branches of Brushy Creek-with reliable water and bottom-land habitats punctuate these physiographic provinces. The boundary, characterized as "approximate," be- tween Blair's (1950:Figure 1) Texan and Balconian biotic provinces passes through western Williamson County in the vicinity of the Wilson-Leonard site. The full complement of terrestrial as well as aquatic fauna! species noted in the Texan and Balconian biota of Blair (1950) and the demarcation between the ranges of several species along the Balcones Escarpment noted by Neck (1986) are the characteristics of the modern fauna that are of interest from the perspective of the Wilson-Leonard locality. An indication of the richness of these faunas is the observation that there are in excess of 400 vertebrate species in the Balconian Biotic Province alone (Toomey 1989). Many of these, particularly the smaller forms, are distributed unevenly across the area's diverse microenvironments (Gehlbach 1991). Perhaps the single most important aspect of the zoogeographic setting of Wilson-Leonard is its position on the boundary between two large biotic provinces (Texan and Balconian [Blair 1950]) and the increased diversity of fauna to be found along this ecotone (Gehlbach 1991).

\section{GEOLOGYOFTHEBRUSHYCREEKVALLEY}

\section{Cretaceous}

Bedrock at the Wilson-Leonard site is nodular limestone of the Comanche Peak Formation (Kc) (Figure 2-5). Northeast and southwest of $41 \mathrm{WM} 235$, the interfluvial divides are capped by younger Edwards Limestone (Ked) that overlies the Comanche Peak. Most of the uppermost drainage basin of Brushy Creek is in Keys Valley Marl (Kkv) that underlies the Comanche Peak. All of the formations are in the Fredericksburg Group of Early Cretaceous age (Barnes 1981).

Keys Valley Marl is soft, white, marine marl that contains Exogyra texana, $G_{r}$ phae mucronata, ammonites, and other marine fossils. It ranges to $17 \mathrm{~m}$ thick at the outcrop. The Comanche Peak Formation is composed of up to $26 \mathrm{~m}$ of fine-grained, fossiliferous, medium hard, nodular limestone that weathers into subrounded nodules up to $12 \mathrm{~cm}$ long. It contains some thin interbeds of dark gray shale and fossils similar to the Keys Valley Marl. Youngest Cretaceous rock in the mapped area is the Edwards Limestone, which ranges to $17 \mathrm{~m}$ thick in the vicinity of Wilson-Leonard site. The Edwards is composed of hard micritic limestone beds, some of which are chert-bearing. Other beds are extensively burrowed and weathered into "honeycombed" porous rock. Caverns and sinkholes are known to occur in the Edwards in the Central Texas area.

Structurally, the area appears to have only one mappable fault that strikes northeasterly across Brushy Creek about $1 \mathrm{~km}$ northwest of the Wilson-Leonard site (Barnes 1981) (see Figure 2-5). According to Barnes, this fault is downthrown to the southeast and has little displacement in the Cretaceous rocks and none in Quaternary rocks. The fault seems to control the direction of flow of Brushy Creek for a short distance above the confluence of the Block House 


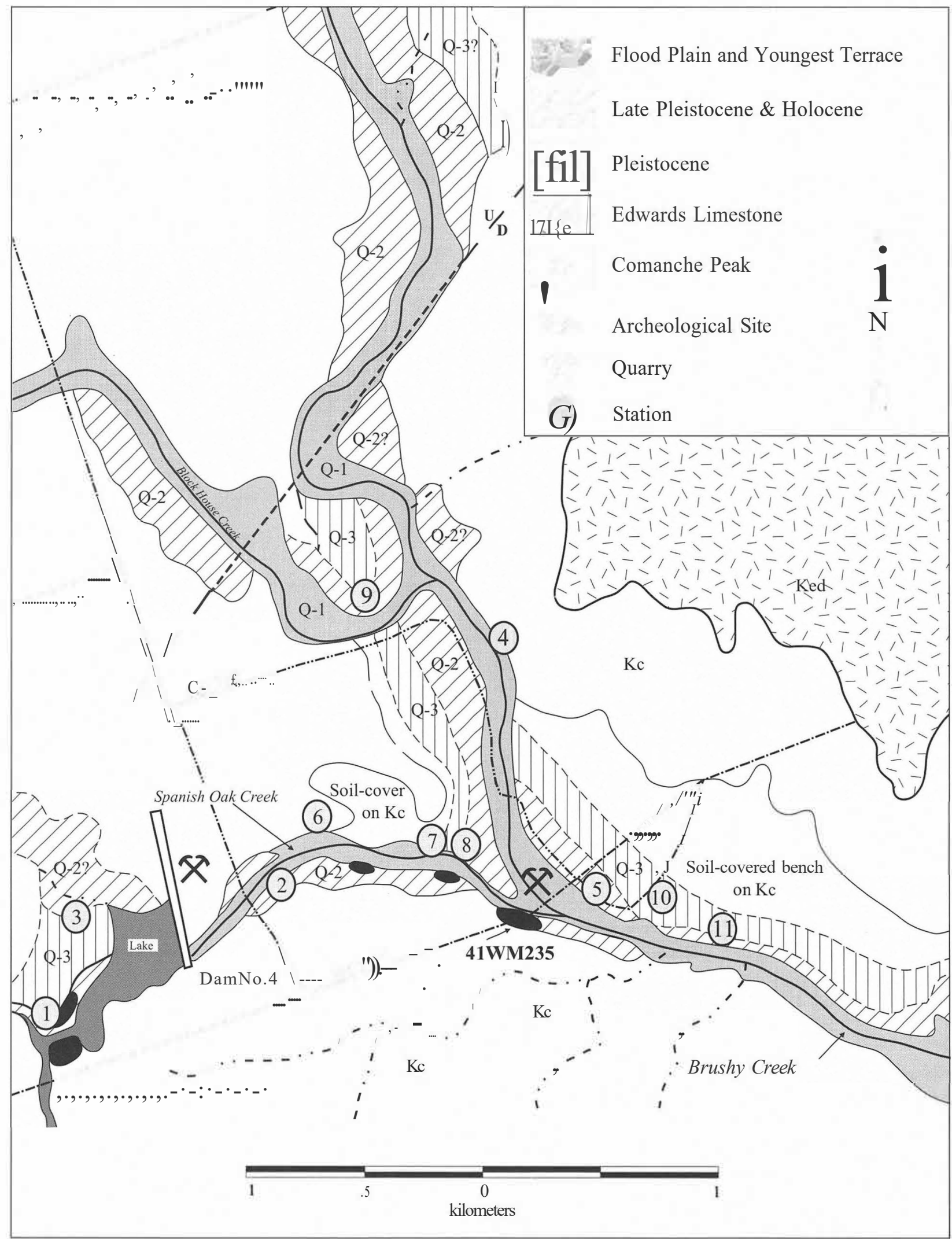

FGURE 2-5. Geologic map of Brushy Creek valley in the vicinity of Wilson-Leonard. 
Creek (see Figure 2-5). Dip on the Cretaceous rocks in the area of interest appears to be south-southeasterly at less than one-half degree. According to mapping by Atchison (1954), the Edwards limestone beds immediately southeast of the area of this report dip south-southeast at the rate of about 51 feet per mile (slightly more than one-half degree).

\section{Quaternary}

Three thin and nan-ow flu vial terrace deposits are present in the Brushy Creek valley the Wilson-Leonard site. In this report, these were informally designated Q-3, Q-2, and Q-1 in order of decreasing age. Q-1 includes a narrow floodplain about $\mathrm{O} \mathrm{m}$ wide that parallels the channel of Brushy Creek (Figure 2-6). In addition, remnants of older alluvial deposits are present in the valley.

Dates $\left({ }^{14} \mathrm{C}\right)$ and artifacts from the Q-2 deposit at WilsonLeonard indicate that here it ranges in age from late Pleistocene to late Holocene. Based on the degree of soil development and height above Q-2, it is concluded that Q-3 is Pleistocene in age. Age of the Q-1 deposit has not been determined, but based on its position and lesser soil development, it is younger than Q-2.

\section{Pleistocene Terrace-deposit Remnants}

AtStation4 (see Figure 2-5), $0.9 \mathrm{~km}$ north of the WilsonLeonard site, two high terrace-deposit remnants are exposed in the west-facing bluff along the east side of Brushy Creek (Mear 1995). The surface of each deposit is about $11 \mathrm{~m}$ above the water level of the creek. The base of the northernmost deposit is on Comanche Peak limestone, about $8 \mathrm{~m}$ above creek level. The deposit is composed of about $3 \mathrm{~m}$ of indurated buff gravel and silt (Bk-horizon) that is capped by a thick crust of secondary calcium carbonate.

The southern deposit is composed of about $5 \mathrm{~m}$ of buff to pale orange angular limestone gravel and silt (Bk-horizon) capped by the same calcium carbonate crust present on the northern deposit. The base of the deposit is on Comanche Peak limestone, about $6 \mathrm{~m}$ above water level. The exposure clearly reveals that the southernmost deposit is channel fill that cut through the older, northern deposit.
No A-horizon material is present on the deposits, which are not extensive enough to map. The age of the deposits cannot be determined, but they probably are Pleistocene in age and older than Q-3 deposit.

\section{Q-3 Deposit}

Q-3 is located mostly along the other edge of the Brushy Creek valley, downslope $\mathrm{f}^{\mathrm{r}} \mathrm{om}$ colluvium and soilcovered rock-cut benches (or pediments) that contain angular fragments of Edwards chert up to $10 \mathrm{~cm}$ long; but remnants of Q-3 are present within the younger Q-2 deposit (e.g., Station 5 [see Figure 2-5]). The surface of Q-3 ranges from 6 to $7 \mathrm{~m}$ above the water level of Brushy Creek, and it slopes gently toward the creek (see Figure 2-6). The base of the deposit is 3 to $4 \mathrm{~m}$ above the water level of Spanish Oak Creek at Stations 6 and 7. At Station 9, Q-3 is about $2 \mathrm{~m}$ thick, and the contact with Q-2 is exposed in a gravel pit. At Station 10, it is $2.14 \mathrm{~m}$ thick, and its base is about $4 \mathrm{~m}$ above Brushy Creek.

Q-3 exceeds $20 \mathrm{~cm}$ in thickness along the roadside drainage ditch on the northern side of RR 1431, 160 m east of the intersection with County Road 178. At this locality the deposit has well-developed A- and B-horizons. The Ahorizon is about $50 \mathrm{~cm}$ thick and is dark gray to black vertic clayey loam. About $60 \mathrm{~cm}$ of B-horizon is exposed in the ditch, and it is grayish white silt and gravel that contains secondary calcium carbonate cement and nodules ranging from 5 to $7 \mathrm{~mm}$ in diameter. The Bk-horizon has an abrupt boundary and is capped by a moderately hard calcium carbonate crust ranging $\mathrm{f}^{\mathrm{r}} \mathrm{Om} 2$ to $4 \mathrm{~cm}$ in thickness. Remnants of similar crusts are present about $30 \mathrm{~cm}$ below the top of the Bk-horizon.

At some occurrences where the Q-3 is coarse gravel and well-drained, the B-horizon is not strongly indurated with secondary calcium carbonate (Station 6). Werchan and Coker (1983) mapped the soil on Q-3 as the Fairlie clay and Denton clay loam in some occurrences and the Sunev silty clay in others. Probably colluviation and slopewash from one deposit to another has commingled A-horizon materials from different deposits, making the soils difficult to differentiate.

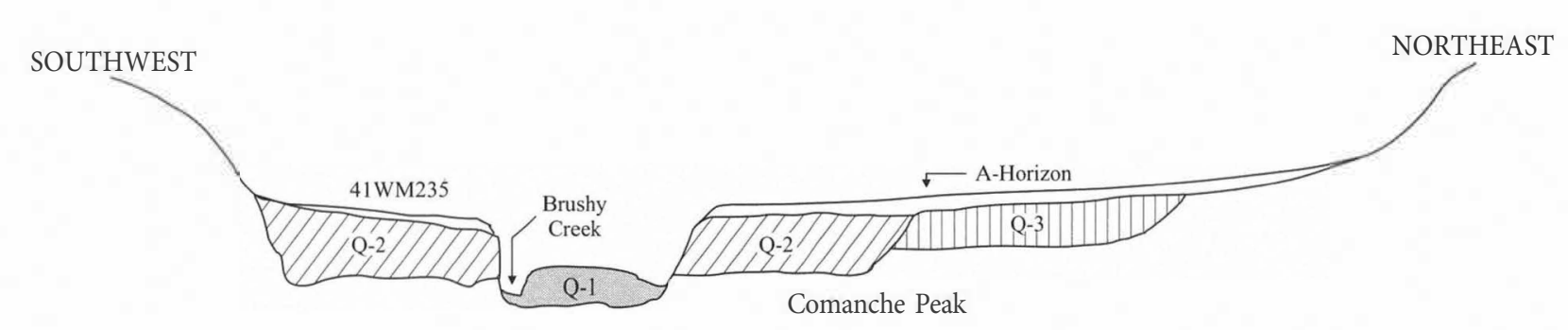

FlGURE 2-6. Diagrammatic section across Brushy Creek valley showing relationship of Quaternary deposits. Section is subparallel to RR $143 \mathrm{I}$; not to scale. 
Cultivated fields are present on most of the Q-3 deposits. Some live oak (Quercus virginiana) and juniper (Juniperus ashei), however, are still present on uncultivated parts of the deposit.

\section{Q-2 Deposit}

Q-2 is composed of 4 to $5 \mathrm{~m}$ of fining-upward elastics consisting of silt and limestone gravel and sand. It has a well-developed A-horizon and moderately well-developed B-horizon in the upper $15 \mathrm{~m}$. The basal 1 to $3 \mathrm{~m}$ of the deposit is predominately gravel, originally derived $\mathrm{f}^{\mathrm{r}} \mathrm{om}$ Comanche Peak nodular limestone beds. Limestone sand and clay lenses are present in the basal gravel. The upper 2 to 4 mofQ-2 is dominantly buff to pale yellow silt in which a moderately well-developed soil is present. At the WilsonLeonard site, two paleosols occur in Q-2 (Holliday 1992). The base of the Q-2 rests on Comanche Peak limestone and shale, 15 to $2 \mathrm{~m}$ above the water level of Brushy Creek. The surface of Q-2 ranges from 5 to $7 \mathrm{~m}$ above the water level.

The soil developed in the upper part of Q-2 deposit was called the Wilson-Leonard soil by Holliday (1992). It has an A-horizon about $45 \mathrm{~cm}$ thick that is dark grayish brown, silty, vertic clay loam. The underlying Bk- or Et-horizon ranges to $106 \mathrm{~cm}$ in thickness and is composed of light yellowish brown silty clay loam that in some areas has large amounts of calcium carbonate in the lower part. The Bk-horizon exposed in the roadside ditch along the north side of RR 1431, just east of the junction with County Road 178, contains abundant nodules of calcium carbonate disseminated throughout a buff to pale yellow silt. The boundary between the A- and B-horizons is gradual. The Bk-horizon in Q-2 is considerably less indurated than that in Q-3 and has no calcium carbonate crust at the top of the horizon, as does Q3 in most occurrences. Werchan and Coker (1983) mapped the soil on Q-2 as the Sunev silty clay in much of the area. At the Wilson-Leonard site, they mapped the soil as being in the Oakalla series, which probably was a drafting error. Much of Q-2 deposit is under cultivation, but some areas support cedar elm, juniper, walnut, and live oak trees.

At the Wilson-Leonard excavation, Q-2 is 15 to $2.0 \mathrm{~m}$ thicker than at the outcrop along Brushy Creek, some $60 \mathrm{~m}$ northeast (Figure 2-7). Most of this increased thickness appears to be the result of anthropogenic deposition (Figure 28), although slopewash from the adjacent bedrock also contributes to the thickness.

\section{Q-1 Deposit}

Q-1 closely parallels the present course of Brushy Creek and its tributaries. It includes the modem floodplain deposit and ranges to 3 min thickness. Q-1 consists of basal gravel, overlain by irregular deposits of gray to grayish brown silty clay loam (Oakalla series of Werchan and Coker [1983:88, 89]). The surface of $\mathrm{Q}-1$ ranges from 1 to $3 \mathrm{~m}$ above the present water level of the creeks and is I 5 to $2.5 \mathrm{~m}$ below the surface ofQ-2. Its surface in most occurrences is in the form of a ridge and swale topography that is elongated parallel to the streams, but in a few areas it has a flat terrace surface. The higher parts of Q-1 are flooded occasionally. At many localities, Q-1 is separated from Q-2 by a swale. A dense growth of sycamore,juniper, cedar elm, and live oak is present on the deposit.

\section{Observations}

Brushy Creek and its tributaries have occupied a shallow valley in the Lampasas Cut Plain since at least late Pleistocene times. Thin and narrow fluvial deposits record a history of down-cutting and deposition of terrace deposits during this period. Only a few very small point bars are present in the sediments, and most of the fluvial deposits are nan-ow strips of alluvium that parallel the course of the streams. The creeks are not graded (Brushy Creek slopes about $4 \mathrm{~m}$ per $\mathrm{km}$ above the Wilson-Leonard site). During the Holocene, the creeks have cut and filled successively narrower floodplains so that now they occupy the narrowest part of the valley. In general, during the late Holocene the floodplain has consisted of flood chutes that shifted laterally to form ridge and swale topography on Q-1.

So far as is known, no geological reports have been published on the Quaternary deposits of the upper Brushy Creek area. Although Atchison (1954) mapped the geology of the Brushy Creek Quadrangle, which is southeast of the area of interest of this report, his study focused on the Cretaceous rocks. Few detailed studies have been published that deal with the fluvial deposits along small streams in the uplands of Central Texas. Collins et al. (I 990) determined that an Early Archaic site was present at Camp Pearl Wheat (41 KR243) in the upper part of a 4-6-m terrace of Town Creek, a small upland tributary of the Guadalupe River in the Edwards Plateau (see Figure 2-2). Nordt(1992) reported on a comprehensive geoarcheological investigation of the upland tributaries of the Leon River at Fort Hood, located in the northern Lampasas Cut Plain, north of Wilson-Leonard (see Figure 22).

Holliday (1992: 104-107) discussed the archeological significance of paleosols at Wilson-Leonard and provided a concise geoarcheological evaluation of the site. He recognized three terrace deposits along Spanish Oak Creek and noted that the Wilson-Leonard site is in the second terrace deposit. He described two paleosols that were exposed during the 1982-1984 excavations of the site by TxDOT personnel and a surficial soil that he called the Wilson-Leonard (Holliday 1992: 105-106). The subsequent TARL archeological investigation of the site during 1992-1993 has shown that alluviation at the site probably began about 1,000 years earlier than originally indicated by the excavation reported on by Holliday. Collins et al. (1993: 10-12) further refined the site stratigraphy using data furnished by their excavation. 


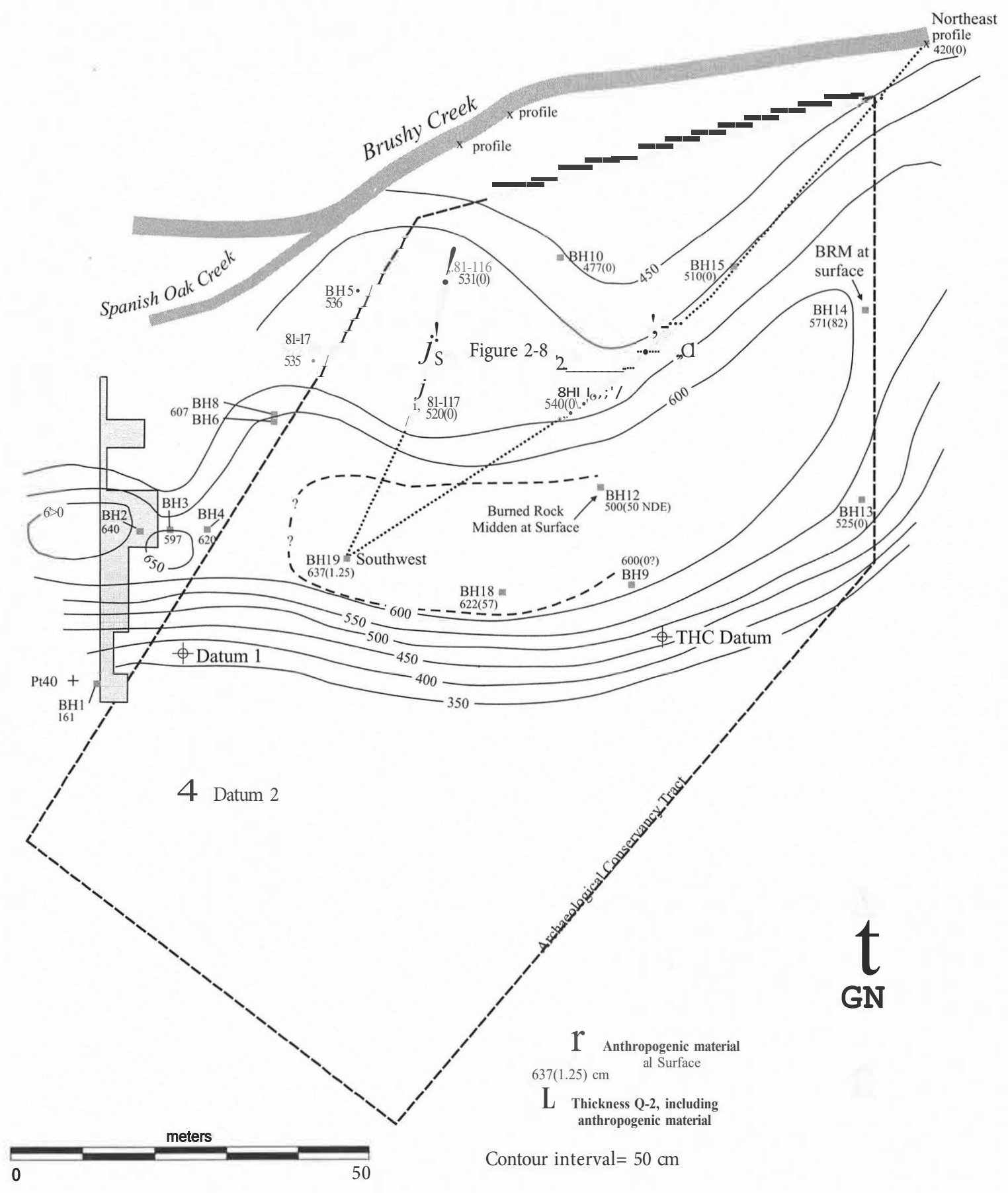

FlouRE 2-7. Isopach map of Q-2 deposit at the Wilson Leonard site. Based on core hole data (see Figure 2-8 for profiles BH 19-Northeast and $\mathrm{BH} 19-\mathrm{BH} 16)$.

Additional radiocarbon dates were obtained, and a Clovis dart point fragment was found near the base of the deposit during their excavation.

In early 1994, 13 additional core holes were drilled by TARL south of the excavated part of the site. These cores provide subsurface data that were utilized in the present evaluation of the site and the Q-2 deposit.
It is difficult to determine the absolute age limits ofterrace deposits with the precision desired. Each deposit is unique in some ways and highly variable stratigraphically. In a gross sense, terrace deposits grade upward from coarser to finer sediments (fining upward), but when studied in detail they are seen to vary from this relationship (see Figure 28). In addition, terrace deposits are time-transgressive and 

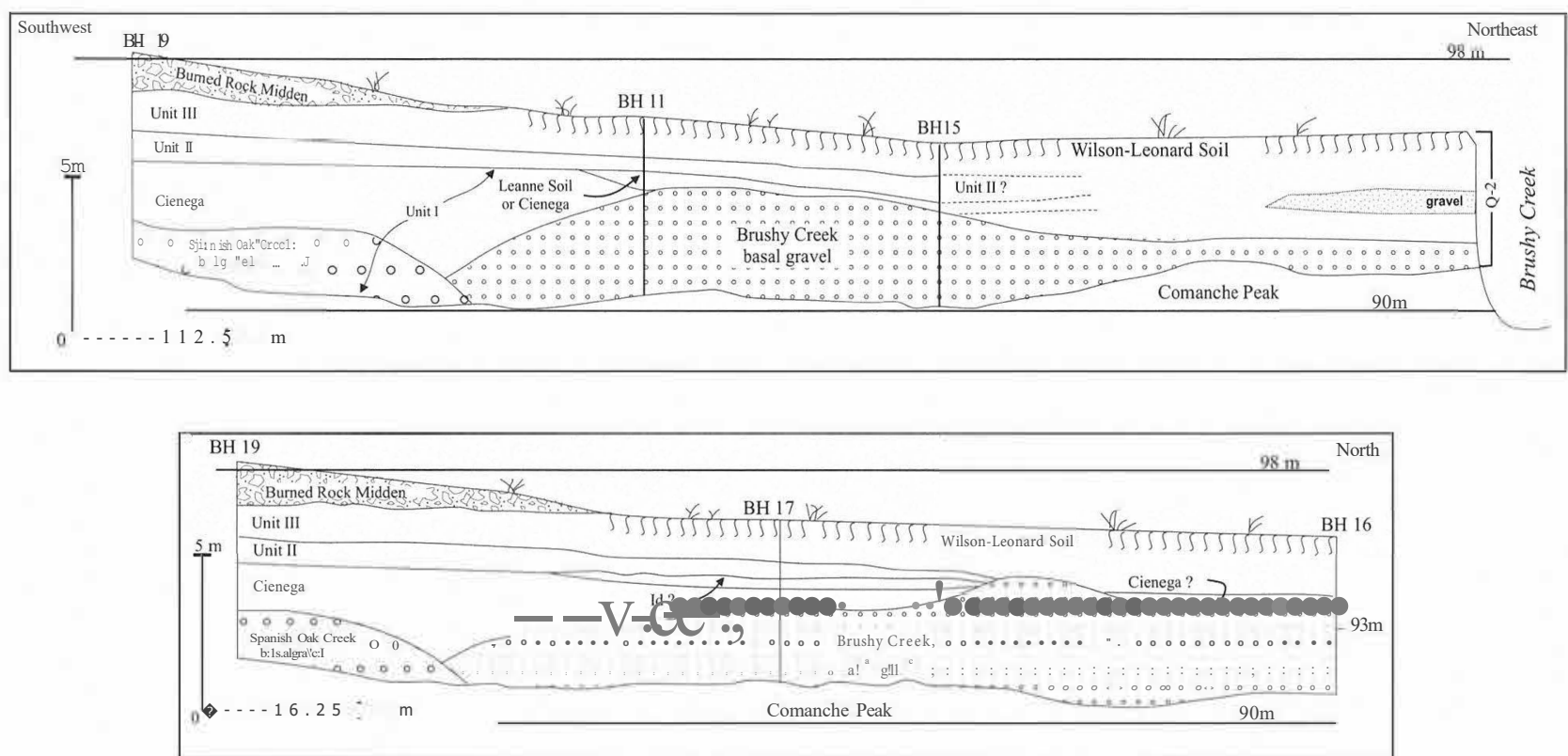

FIGURE 2-8. Northeast-southwest section of Q-2 deposit in the southern part of the Wilson-Leonard site (based on core descriptions by Goldberg).

range in age laterally as well as vertically. Terrace deposits contain minor diastems that do not occur throughout their areal extent. Localized and widespread unconformities are present in most terrace deposits of Central Texas. The extent and severity of the erosion recorded by the unconformities are highly variable and depend on the geological history of each deposit. These factors ensure that geological correlations of terrace deposits can be made only in a general way. Furthermore, even when ages are obtained within a terrace deposit by ${ }^{14} \mathrm{C}$ or artifact analyses, care should be taken not to extrapolate these precise data very far from the archeological site. After a terrace deposit is formed, wind erosion and deposition, pedogenesis, and colluviation take place on the terrace. In addition, human occupation may deposit sediments on the surface, and in some cases, minor amounts of overbank sedimentation may occur on isolated parts ofterraces long after the terrace has been formed. From a geological standpoint, all these minor deposits are postdepositional and not part of the terrace deposit.

Data furnished from the archeological investigations of the Wilson-Leonard site date the Q-2 deposit from probably 12,000 в.P. to probably 4440 в.P. Q-2 deposition at the site began as a limestone gravel bar (see Figure 2-8; Figure 2-9) shortly before Clovis occupation, possibly about 500 B.P. About 11,000 B.P., the channel of Brushy Creek shifted from its position southwest of the basal gravel bar to an area northeast of the site, and a cienega formed in the abandoned channel. Overbank deposition of silt and thin lenses of small limestone gravel occurred on the Q-2 deposit northeast of the basal gravel bar. In the abandoned channel, organic debris mixed with slopewash and overbank silt accumulated in the wet meadow (cienega). Paleoindian occupation of the site continued, as indicated by the presence of diagnostic dart points.

By about 9900 B.P., the abandoned channel was filled to the level of the rest of the terrace deposit, and the cienega dried up. Deposition was sparse or lacking long enough for the Leanne soil (Holliday 1992: 106, Figure 3-2) to develop at the site. Following formation of the Leanne soil, overbank deposition mixed with slopewash and anthropogenic sediments at the site began again and continued until about 8090 в.P. During this time Paleoindian cultures utilized the site.

The archeological investigations at Wilson-Leonard also revealed that a younger soil called the Stiba (Holliday 1992: 105) developed or was deposited about 8090 в.P. After formation of the Stiba, thin windblown (?), anthropogenic, and overbank deposits accumulated on Q-2 until about 4000 B.P., during which time about $1.25 \mathrm{~m}$ of sediment mixed with slopewash accumulated on the Stiba soil. Subsequently, about $1 \mathrm{~m}$ of anthropogenic sediment, including burned rock middens (Archaic) accumulated on the terrace (see Figure 28).

After deposition of the Q-2 deposit, Brushy Creek and its tributaries have downcut their channels 1.5 to $2 \mathrm{~m}$ below the base of Q-2 and have formed the Q-1 deposit. At most exposures, the creeks have lowered their channels only a few centimeters below the base of Q-1.

\section{Tentative Correlations}

Q-2 probably is partly equivalent to Unit $\mathrm{E}$ of the Pedemales River (Blum and Valastro 1989), which ranges in age from about 11,000 to 6500 B.P. Unit Eis up to $7 \mathrm{~m}$ thick 


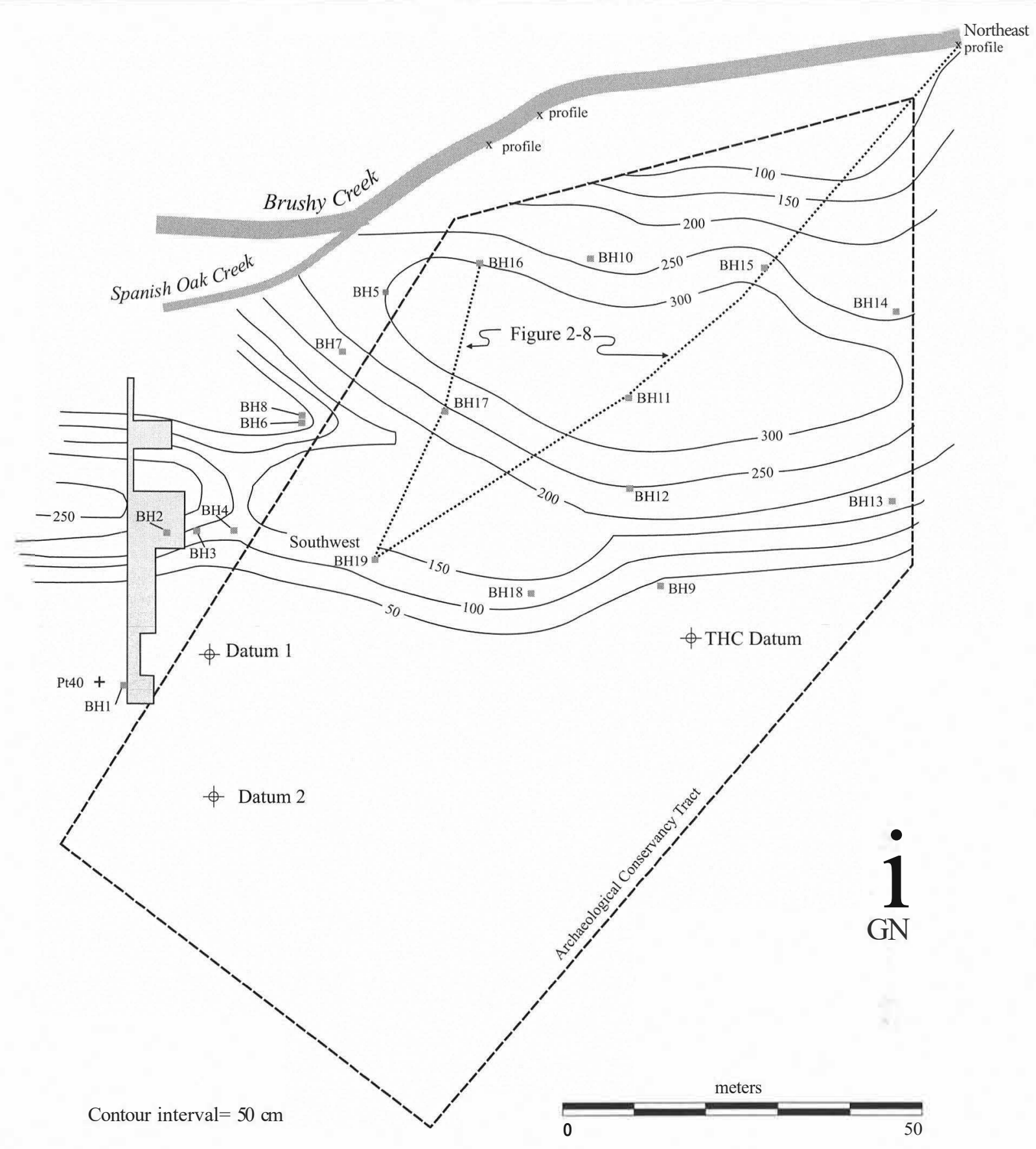

FIGURE 2-9. Isopach map of basal gravels at the Wilson-Leonard site from core hole and excavation data.

and is composed of fine-grained sand, mud, and gravel deposited in a laterally confined channel (Blum and Valastro 1989:440). Q-1 may be equivalent to Units F and $\mathrm{G}$ along the Pedernales River, where Fis an undissected terrace $9 \mathrm{~m}$ above water level, and Unit $\mathrm{G}$ is the modern floodplain deposit. Q2 correlates with the 4-6-m terrace of Town Creek discussed by Collins et al. (1990), but they found no archeological or other data to securely date the lower part of the deposit as Pleistocene in age.

Q-2 is equivalent to the Georgetown and Fort Hood deposits which underlie the T-1 terrace at Cowhouse Creek (Nordt 1992; Nordtet al. 1994: 111, Figure 2). Two soils in this section, the Royalty at the top of the Georgetown at about 8,000 years old and an unnamed soil at the top of T-1 appar- 
ently developed during the past 5,000 years. It is likely that the latter is equivalent to the Wilson-Leonard soil, and the Royalty may be equivalent to the Stiba soil at the WilsonLeonard site.

Ricklis et al. (1991) conducted an archeological investigation at the Yara Daniel site (41 TV 1364) located $35 \mathrm{~km}$ southwest of Wilson-Leonard in Austin at Zilker Park near the confluence of Barton Creek with the Colorado River (see Figure 2-2). Here they mapped a modern floodplain, a Holocene Terrace (lower surface), a Holocene Terrace (upper surface), and an older (and topographically highest) Pleistocene Terrace. Ricklis et al. (1991) concluded that the Holocene Terrace (upper surface) has $1.8 \mathrm{~m}$ of late Holocene alluvium at the top, unconformably overlying latest Pleistocene to early-middle Holocene alluvium. Carbon-14 dates of humates collected $6 \mathrm{~m}$ below the unconformity indicate its age is $11,050 \pm 270$ B.P. at that level. A humate date of 3340 \pm 90 B.P. was obtained from the lower part of the upper $1.8 \mathrm{~m}$ of the terrace deposit. It is postulated that Q-2 at WilsonLeonard is roughly equivalent to the $6 \mathrm{~m}$ of the Holocene Terrace (upper surface) deposit that lies between 1.8 and 7.8 $m$ in depth at the Vara Daniel site.

It is likely that the Q-2 deposit at Wilson-Leonard is largely equivalent to the middle part of the Applewhite terrace deposit (Beene site, 41BX83 1) in southern Bexar County, Texas (see Figure 2-2). Located on the Medina River in the Inner GulfCoastal Plain, the Applewhite is about $16 \mathrm{~m}$ thick, and its surface is $19 \mathrm{~m}$ above the Medina (Thoms 1992). According to Thoms, the Applewhite contains stratified artifacts that range from Pleistocene to Late Prehistoric.

\section{Conclusions}

The Q-1 deposit contains some reworked archeological material, and Q-3 could contain early Paleoindian material in its upper part; but Q-2 is the deposit most likely to contain buried, stratified archeological deposits ranging from Paleoindian to Late Archaic. Deposition of the 2 to $3 \mathrm{~m}$ of basal gravel in Q-2 at Wilson-Leonard took place before the dry period that occurred about 11,000 B.P. in the southwestern United States (Haynes 1991). An additional $2 \mathrm{~m}$ of Q-2 was deposited during a 2,500-year span of time when the climate was in transition from the wet and cool latest Pleistocene $(10,500$ B.P.) to the drier and warmer early Holocene (8000 B.P.). The Early and Middle Archaic sediment in Q-2, consisting of anthropogenic material, overbank silt, slopewash, and windblown sediment, is about $0.75 \mathrm{~m}$ thick and was deposited in about 3,700 years (8150 to 4440 B.P.) indicating that little overbank deposition occurred on Q-2 during the Altithermal (7000 B.P. to 5000 B.P.). During the Altithermal, Brushy Creek and its tributaries may have responded to the possibly warmer and drier climate by downcutting into the Comanche Peak bedrock, while transporting gravel, silt, and soil out of the upper reaches of the creeks. This may indicate that during the Altithermal, the climate was characterized by short-lived but extreme rainfall periods and floods that were able to transport most of the elastics out of the upland valley. On the other hand, it is possible that the basal gravels and some of the higher silt deposits of Q-1 may have been deposited during the Altithermal, at the same time that some overbank silt was laid down in the upper $0.75 \mathrm{~m}$ ofQ-2 at the Wilson-Leonard site. Until such time as reliable dating of the older part of QI is available, we cannot be sure of the effects of the Altithermal on the erosion-deposition cycle in the area of interest.

The thick Bk-horizon in the Q-3 deposit resulted from the downward leaching and redeposition of calcium carbonate during pedogenesis, and it is probable that Q-3 was considerably thicker when it was deposited during the Pleistocene. Some leaching of Q-2 has occurred, but little or no reduction in original thickness is likely. Thus it appears only fortuitous that the surfaces of Q-2 and Q-3 have such little topographic relief. The gently dipping surface of the soilcovered bedrock and Q-3 indicate that a pediment developed along the east side of Brushy Creek prior to the deposition ofQ-2.

In the upper Brushy Creek area, soil creep, slopewash, and probably colluviation of A-horizon material has occurred on Q-2 and Q-3 deposits and on the higher rock-cut benches. Their A-horizons are very similar except for the presence of chert gravel in the higher rock-cut bench east of the WilsonLeonard site. The surfaces of Q-2 and Q-3 and the soil-covered rock-cut bench have merged to form one terrace (see Figure 2-6), due to the leaching of Q-3 and downslope movement of the A-horizon material. Differentiation of the soils and the deposits in which they formed largely depends on a comparison of their B-horizons and on measuring the elevation above creek level of the base of each deposit.

The Leanne and Stiba soils are not areally mappable units and do not fit the geological definition of members or formations. They probably resulted from soil formation during periods of nondeposition in Q-2 deposits, but by themselves, they do not prove the existence of significant unconformities. The paleosols are significant for the interpretation of paleoclimates and depositional history of the Quaternary deposits, but they do not provide sufficient evidence to warrant postulating an upper and lower terrace deposit in Q-2.

The Quaternary paleoclimate in the Wilson-Leonard vicinity should have been similar to that of the upper Lampasas River valley (Nordt et al. 1994). As a result of their studies, Nordt et al. (1994) concluded from ratios of $\mathrm{C}_{3}$ to $\mathrm{C}_{4}$ plant production that the late Pleistocene was cooler and wetter than at any time in the last 15,000 years. They found the climate to be transitional to warmer and drier conditions of the Holocene between 11,000 and 8000 B.P. During the middle Holocene, 6500 to 5000 B.P., the climate was similar to the Early Holocene, and a renewal of cooler and wetter conditions occurred at Fort Hood and "has persisted to the 
present, except for a possible brief drying episode about 2000 B.P." (Nordtet al. 1994: 119). Data unavailable at the time Nordt et al. concluded their study indicate a significantly different sequence (Collins 1995; see also Chapter 4 of this volume).

\section{SUMMARY OF SITE FORMATIONAL PROCESSES}

Any specific point along a stream such as Brushy Creek is subject at various times to deposition, stability, and erosion. At Wilson-Leonard, the net outcome of these processes over the last 12,000 years or so has been the accumulation of more than $6 \mathrm{~m}$ of mostly fluvial valley fill with some colluvial deposition, comparatively minor erosion, significant but not protracted periods of stability, and frequent additions of cultural detritus (see Figure 1-2). Superficially, the location would seem to be one where erosion would have been the prevailing process since it is on the outside of a moderately large bend in Brushy Creek. And, in fact, at ca. 12,000 B.P., the stream was cutting into the right bedrock wall of its valley at this point and was flowing on solid bedrock. Shortly thereafter, probably due to a drop in its peak energy flow, Brushy Creek at this point shifted to a channel somewhere nearer the center of its valley. From that time on, conditions generally favored deposition over erosion.

Three aspects of valley geometry seem best to account for this (Figure 2-10). Just upstream, the creek today flows against the bedrock of its right wall, and its course is deflected sufficiently to cause a very slight bend in the opposite direction (toward the left bank) at the site; presumably this condition has existed for some time. Spanish Oak Creek enters the Brushy Creek valley at this point and, due to an abrupt drop in gradient, contributes sizable amounts of coarse sediment to the locality. Also, the constriction of Brushy Creek valley $2.8 \mathrm{~km}$ downstream undoubtedly retards flow during floods, which in times of very high flow could cause some backwater effect as far upstream as the mouth of Spanish Oak Creek. The extraordinary rainfall events that occur along the Balcones Escarpment would be expected to occasionally bring about very high runoff rates along Brushy Creek. It is surmised that had it not been for the bedrock constriction of the valley downstream, large floods likely would have partially or completely destroyed the site.

\section{THE WJLSON-LEONARD 1IT E}

Once Brushy Creek valley at Wilson-Leonard had filled to its present elevation, the locality consisted of a slightly sloping terrace $\mathrm{sm}^{\mathrm{f}} \mathrm{a}$ ce bounded on the north by Spanish Oak and Brushy creeks and on the south by a sloping valley wall oflimestone bedrock covered with thin, rocky soil (Figure 2-11). A cluster of burned rock middens protruding through the terrace surface constituted the most visible aspect of the site at the time of its discovery. Also, it was apparent that both plowing and uncontrolled digging for artifacts had disturbed some of the near-surface deposits. The extent of the site was never fully determined, and even the exact number of burned rock middens at the site is not known (see Figure 2-11; Figure 2-12), in part because initial investigation was confined to the right of way and later investigations only extended southeastward onto that portion of the site that was to be donated to the Archeological Conservancy (see below). The creeks mark the northern boundary of the site as well as the terrace, and cultural evidence extends only a few meters up the sloping valley wall behind the terrace on the south. As a best approximation, the western boundary of the site, now destroyed by road construction (Figure 2-13), is vaguely established as the extent of visible cultural materials just west of a gully that cuts the terrace and enters Spanish Oak Creek from the south. No precise eastern boundary has been identified, but cultural evidence becomes less noticeable toward the downstream (east) end of the terrace. Basically, it is presumed that the site occupies most of the terrace remnant, an area estimated to be roughly $160 \mathrm{~m}$ long east-west by $60 \mathrm{~m}$ wide, north-south (see Figure 2-11).

The remainder of this description of the site is in two parts. That part of the site in the highway right of way can only be described from documents produced prior to road construction whereas that outside of the right of way can be described as it was at the time of the 1992-1993 investigations; each of these has its limitations.

Sketch maps, field notes, and photographs produced in 1973, 1981, and 1982-1984 were reviewed in an effort to reconstruct a description of that part of the site lost to construction (Collins et al. 1991). These documents are inconsistent and incomplete. For example, one undated map shows the areas excavated in 1982-1984 in relation to only one burned rock midden, another undated map shows four burned rock middens in and near the right of way, and another dated January 20, 1982, indicates these same four middens plus a fifth upslope to the south. This fifth midden is outside of the area of the site as depicted on all other maps, is on private land that was not accessible in 1992-1993, and is not considered further in this discussion.

The greatest concentration of cultural evidence at the surface seems to have been at the western edge of the site on both sides of a small gully that entered Spanish Oak creek from the south at a point about $90 \mathrm{~m}$ up from the confluence of Spanish Oak and Brushy creeks. Digging by relic collectors was most rampant in this part of the site, and either two or three burned rock middens seem to have been discernible. One small midden west of the gully appears on some (but not alJ) versions of the site map along with indications of considerable looting; nothing further can be said about the area west of the gully, which is underneath the roadway at present. Along the eastern margin of the gully are two large, more-intact areas of burned rocks. These were the focus of archeological testing and the excavations of 1982-1984. One of these middens was close to the edge of 


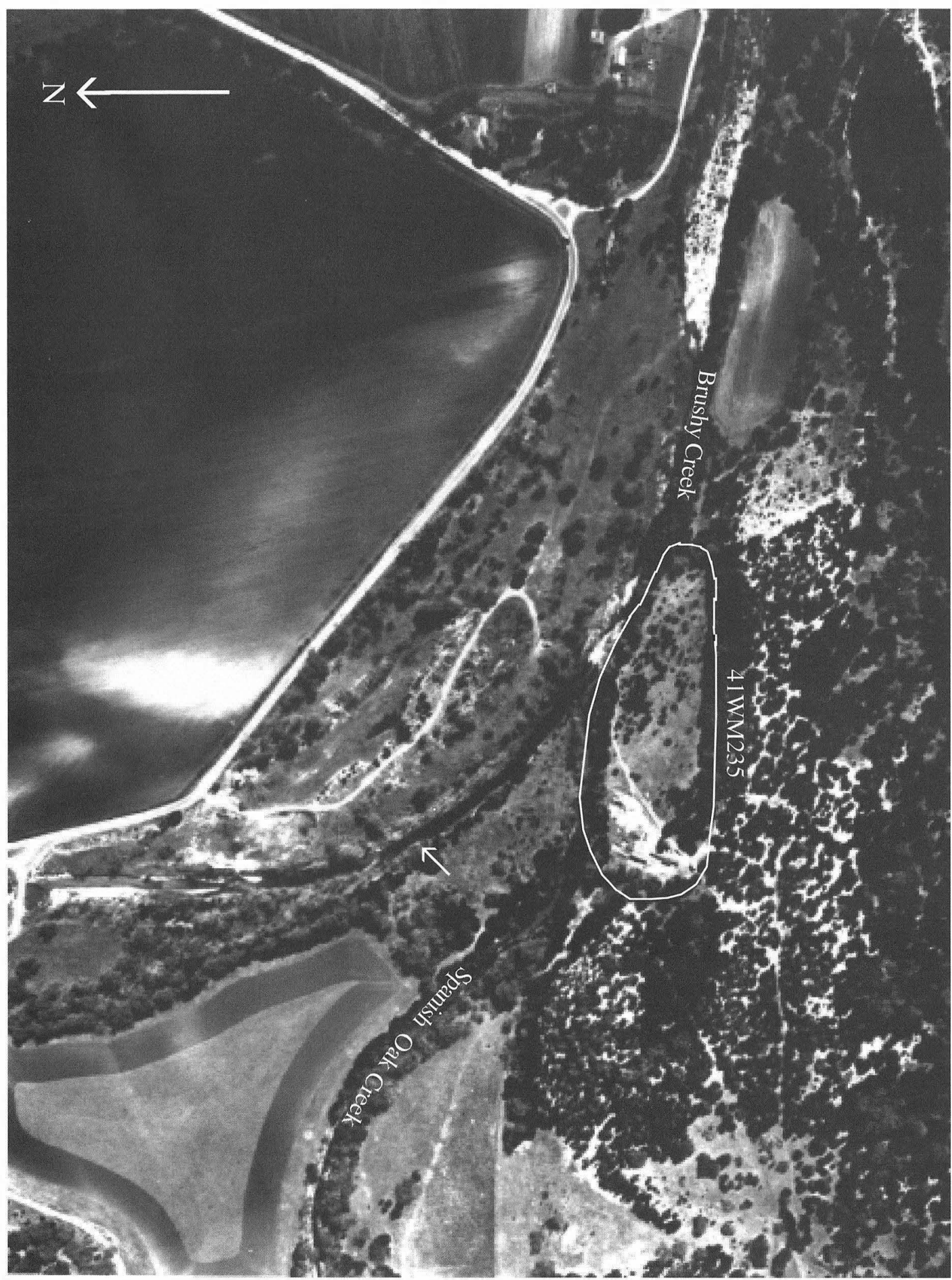

FIGURE 2-10. Vertical aerial view taken 21 March 1984 showing the Wilson-Leonard.site in relation to Brushy and Spanish Oak creeks. Note the point at which Brushy Creek is deflected away from the site area bu bedrock (arrow). 


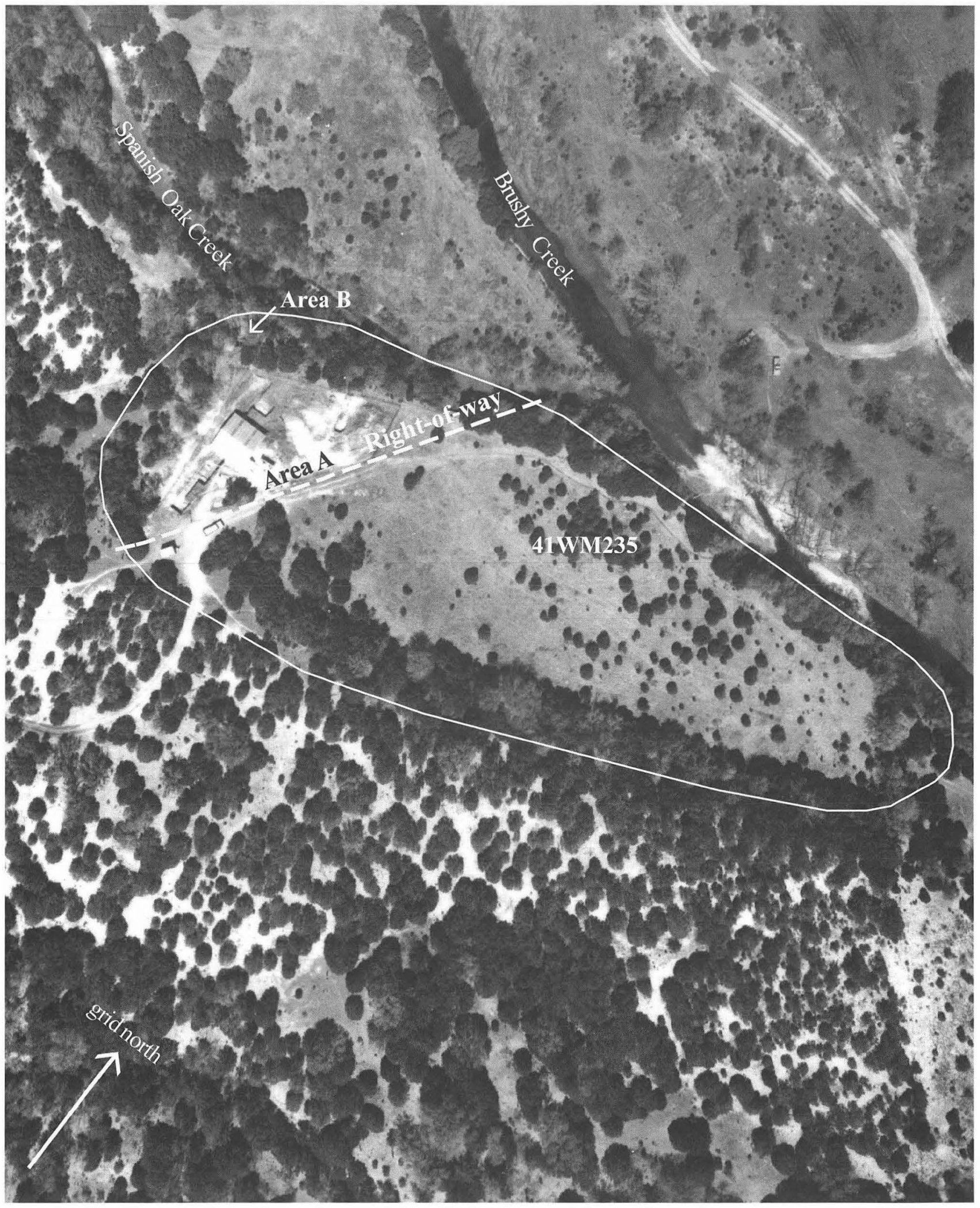

FlouRE 2-11. Low altitude vertical aerial view taken 19 March 1984 showing the Wilson-Leonard site during excavation. The fallow field in which the site occurs is bounded by large hardwood trees. 


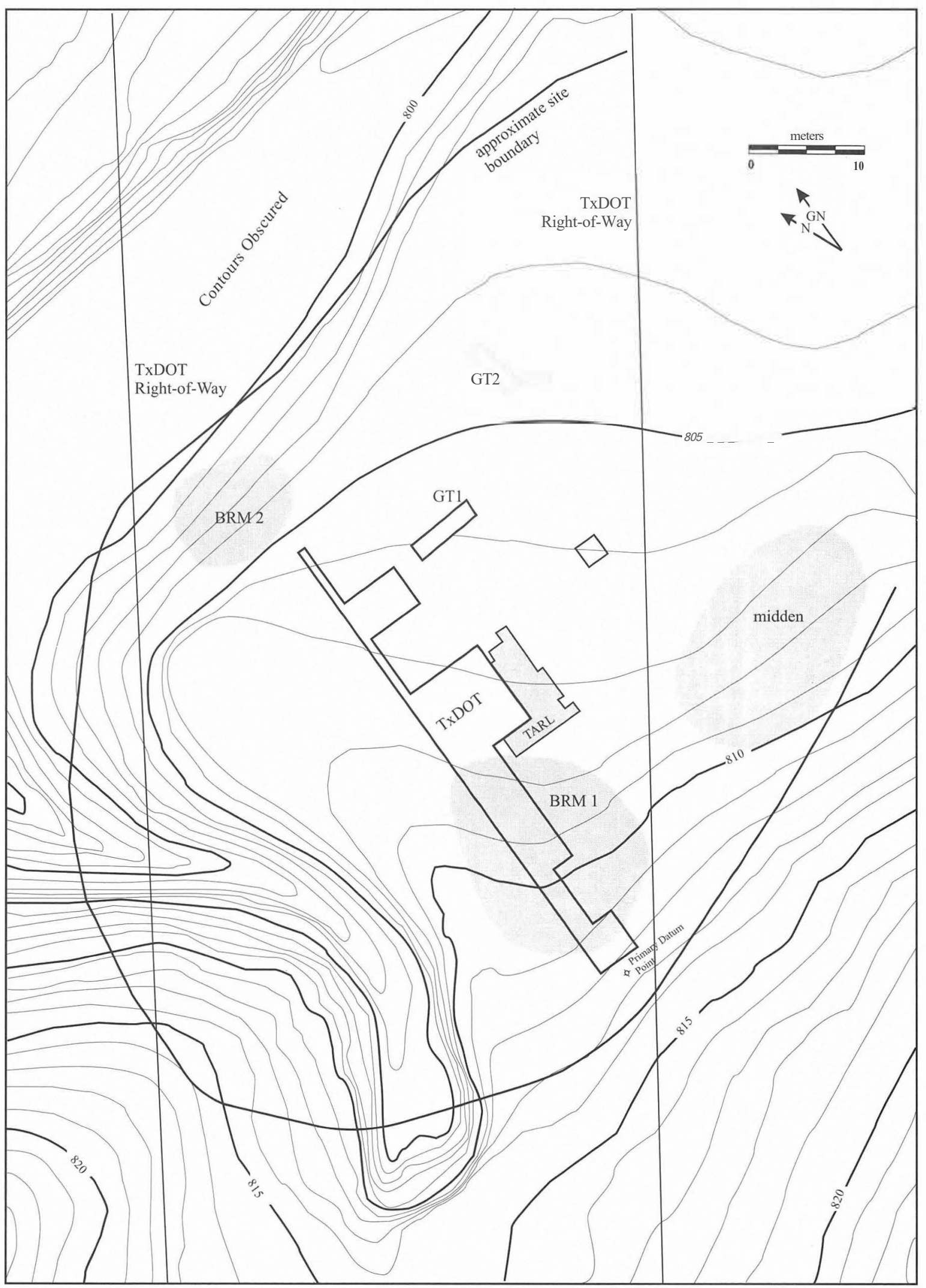

HGURE 2-12. Contour map of the western portion of the Wilson-Leonard site showing burned rock middens and areas of excavation. 


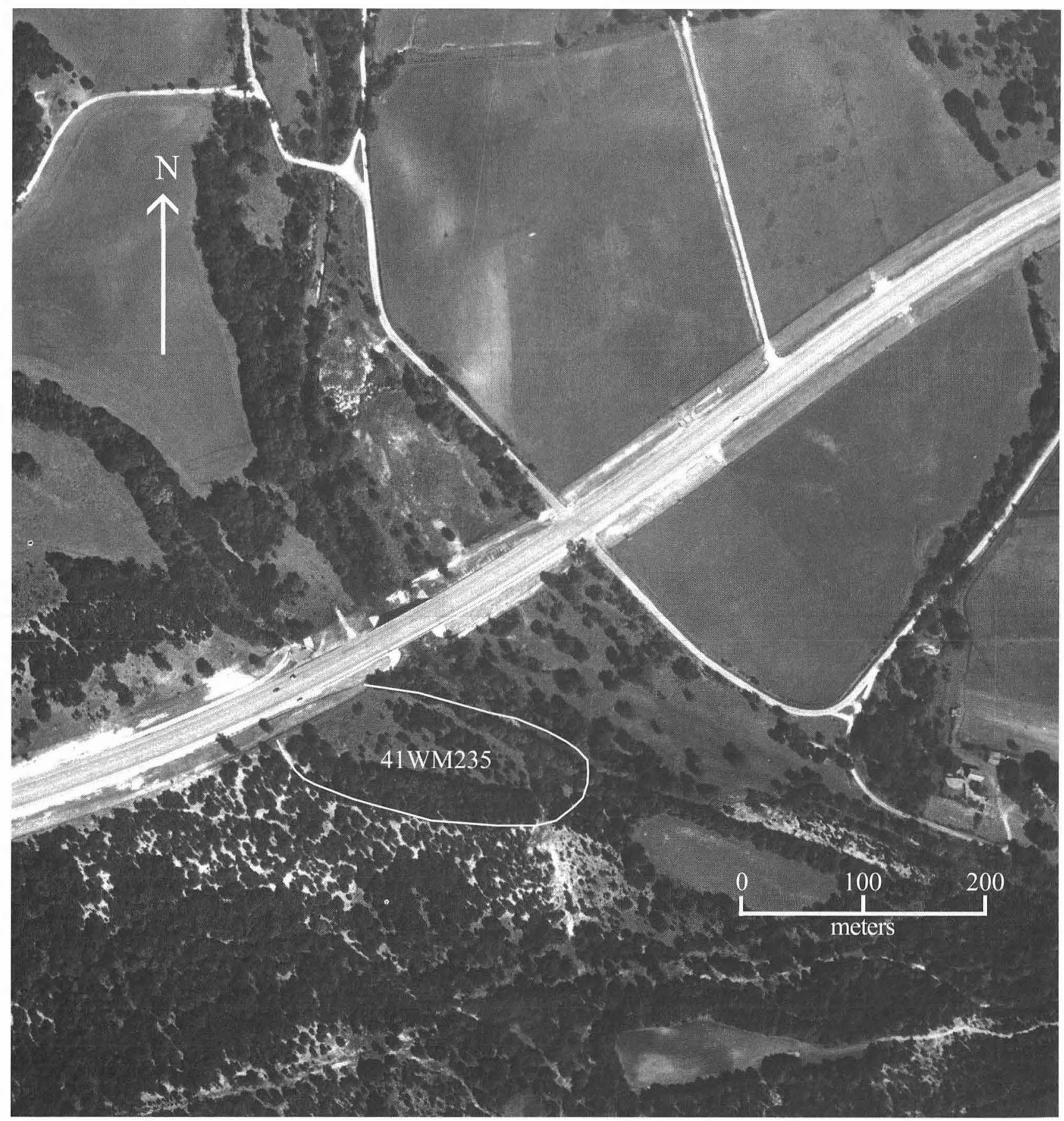

F,auRE 2-13. Vertical aerial view of the Wilson-Leonard locality taken in 1990 after completion of RR 1431.

the terrace next to Spanish Oak Creek, but its location is not precisely known, and there is relatively little description of the midden's appearance. Tx.DOT excavation Area B was placed in this midden (see Figures 2-11 and 2-12).

Another large burned rock midden at the southern edge of the terrace extended a short distance up the slope of the valley wall and was cut by Area A of the TxDOT excavation (Blocks I, 2, 3, and 5; see Figure 2-12). This midden was barely exposed at the surface but was found during excavation to be a little more than $16 \mathrm{~m}$ across, north-south and about $0.75 \mathrm{~m}$ thick. Burned rocks and other cultural debris were visible in moderately abundant amounts on the surface in the western edge of the site, undoubtedly in part because of plowing and clandestine digging.

The field in which most of the Wilson-Leonard site occurs was no longer in cultivation at the time of the 1982-1984 excavations, but it had not been fallow for very many years to judge by the moderate sizes of the juniper trees in photographs (e.g., see Figure 2-11 ). Plow disturbance is an important factor in interpreting the upper deposits at the site. 
Aerial photographs show that cultivation in western Williamson County was widespread in the early 1950s (Figure 2-14). In later decades, previously cultivated fields became fa! low and began to be covered with juniper and other brush and trees (see, for example, Figure 2-13). It is appar- ent from aerial photography (Figure 2-15) that only a small part of the Wilson-Leonard site along its northwestern and southwestern edges escaped being plowed (that is in TxDOT excavation Area Band possibly in Block 1 of Area A).

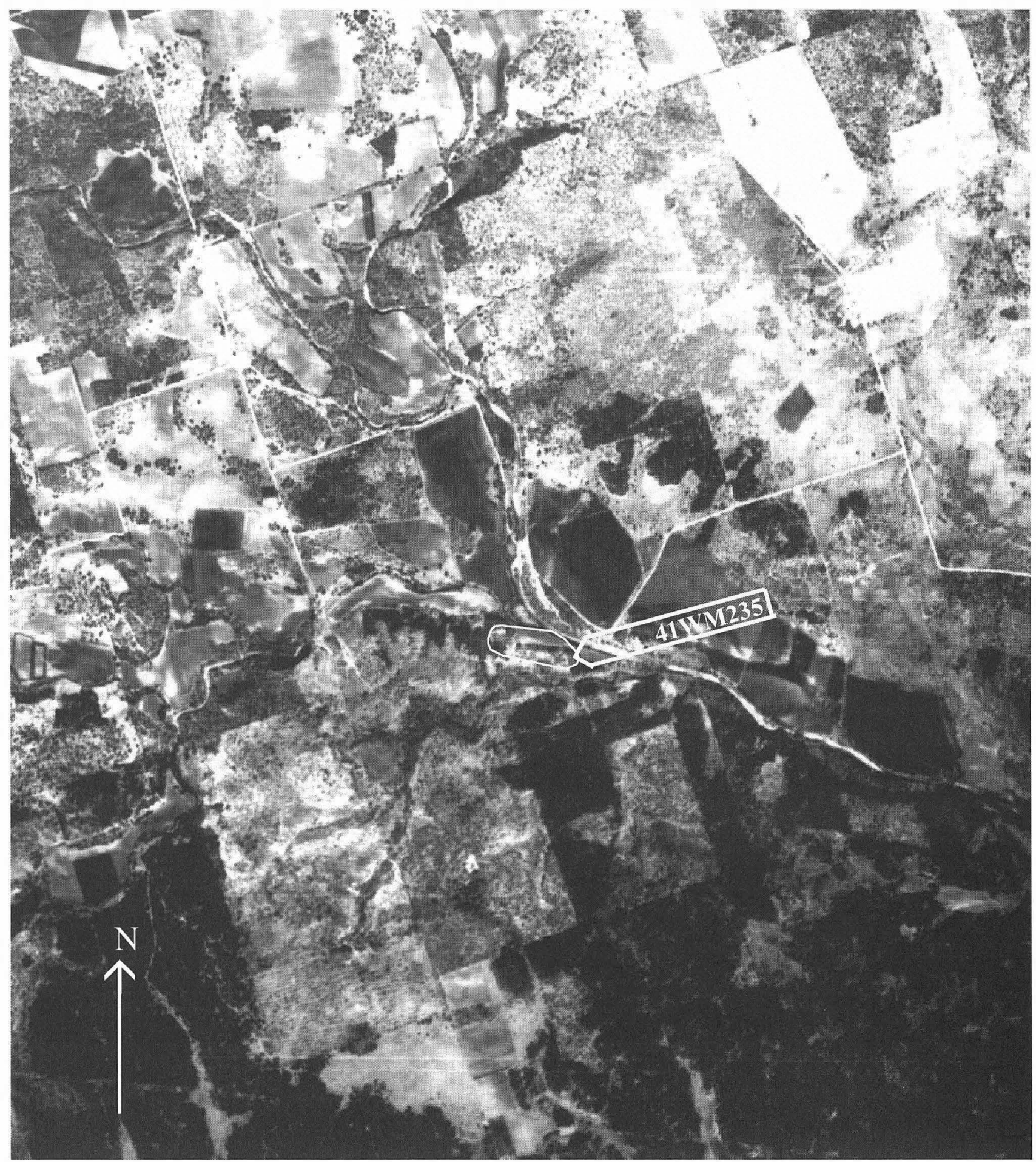

FtouRE 2-14. Vertical aerial view of Brushy Creek valley taken in January of 1953 showing extent of cultivation, including the field where the Wilson-Leonard site is located. 


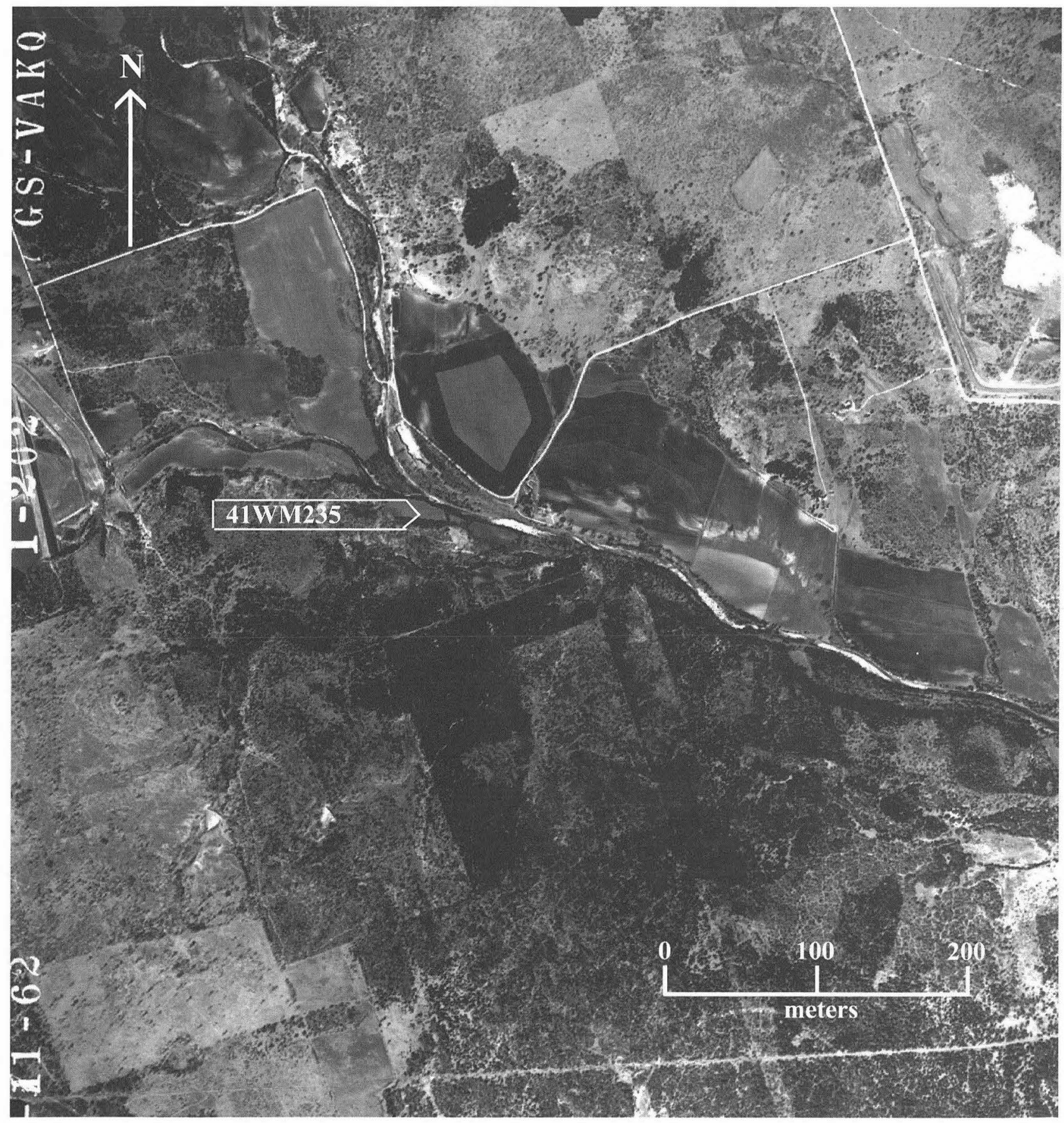

FGURE 2-15. Vertical aerial view of the Wilson-Leonard locality taken in February of 1962 showing the site area as under cultivation.

The Archaeological Conservancy tract extends from Brushy Creek southward up the valley wall and includes parts of the valley floor, valley margin, and bedrock valley wall. A large burned rock midden is situated in the valley margin setting (see Figures 2-7, 2-8, and 2-12). The valley floor has deep fuvial deposits and an almost flat surface. This surface is covered with second growth grass, sedges, and juniper brush that have become established since cessation of cultivation. There is almost no archeological material visible on this surface. In contrast, the valley wall con- sists almost entirely of exposed bedrock and extremely thin stony soil covered primarily with large juniper brush and a few live oaks and other trees; there is almost no ground cover. Very sparse chert and small burned rocks are visible on this slope. Most of the chert consists of patinated flakes with edge damage, both being attributes presumed to have resulted from long exposure on this rocky surface.

Of particular interest is the valley margin area where fluvial and colluvial deposits have accumulated. These deposits have a noticeable surface slope and can be inferred to 
thin out steeply along the lower contact with bedrock; in the area of the burned rock midden, there is a mounded aspect to the surface. Larger trees and fairly dense brush grow along this toeslope, and there is a thick deposit (up to $50 \mathrm{~cm}$ in places) of leaf litter, rotting timber, and other humus built up in this vegetation. This area is probably less affected than the valley floor by modern land use in that it has not been plowed, but if disruption of vegetative cover has accelerated slope erosion, these deposits may have been artificially thickened in this century. Nonetheless, the buildup of thick humus and the denser growth of brush here may be somewhat analogous to conditions that existed along the valley margin in the past and could support inferences concerning deposits and localized biota (such as land snails) in the area excavated.

Although it was never precisely mapped, Tx.DOT records show that the burned rock middens and an extensive area of the site adjacent to the cutbank of Spanish Oak Creek were heavily damaged by pothunters. Much of this seems to have been relatively shallow, but disturbance to depths of a meter or more were encountered at places in the excavations. The fuller account of the history and nature of excavations at the site appear in Chapter 3, but aspects need to be mentioned here in order to describe the stratigraphy of the site.

The 1982-1984 excavations by Tx.DOT (Figure 2-16) consisted of forty 2-x-2-m squares organized into 6 excavation blocks and 3 gradall trenches; the 1992-1993 excavations by TARL consisted of 46 squares, mostly $1-\mathrm{x}-1-\mathrm{m}$ in size in an Lshaped block around the east and south sides of TxDOT Block 6 as well as 2 squares adjacent to Tx.DOT Block 2 (see Figure 2-12). Extensive as these excavations were, they cover only an estimated $1 \%$ of the area of the site. Although a thorough and valuable study of the stratigraphy and soils ofWilson-Leonard was conducted by Vance Holliday in 1983, it was done after most of the excavations had been completed, and the geologic context of much of the cultural evidence was notclear. Therefore, a primary thrust of the 19921993 excavations was to conduct an integrated geological and archeological program of data recovery. The results of this effort included definition of physical depositional and pedogenic units that provided the contextual structure for data recovery and data analysis. As defined, this system consists of three basic units (designated I, II, and III, from the base upward) with several subunits and transitional zones. Details on all of these stratigraphic units are presented in Chapter 6, but because the system is complex and it constitutes the organizational framework for all of the analyses reported in this monograph, it is introduced at this time.

The main excavation areas of 1982-1984 were dug mostly to depths of about $4 \mathrm{~m}$ or less (Figures 2-17 and 2-18), exposing deposits and archeological materials dating from about 11,000 to 1,000 years ago. As noted briefly above in the discussions of the Quaternary geology of Brushy Creek valley and presented in more detail in Chapter 6, these deposits resulted from a series of different valley-filling and soil-forming events first described by Holliday in 1983 and later by Goldberg in 1992-1993. The accompanying photographs of the north wall of Blocks 4 and 6 (see Figure 2-17) and the east wall of Block 6 (see Figure 2-18) show the profiles late in the TxDOT excavations superimposed with the principal stratigraphic designations employed by Goldberg. TxDOT excavators reached bedrock in only one limited area, so most of the definition of the lower part of Unit 1 (mostly gravels) is based on data recovered in the TARL excavations. For the remainder of the geologic section, all of the TxDOT excavation records-notes, profiles, photographswere closely scrutinized in order to interpret the stratigraphy in the TARL stratigraphic system. This effort was largely successful and is the principal basis for integrating the two sets of data.

Stratigraphically, the Wilson-Leonard section can be briefly described from the base upward as resulting initially and predominantly from fluvial deposition (Unit l) followed by a marked increase in the contribution of slope-derived materials (Units II and III). The latter, in addition to contributions of slope material, received considerable amounts of anthropogenic detritus in the fonn of burned rocks, bone, ash, chert, and so forth, both in Unit II but mostly in Unit III.

Subsequent excavations by TARL exposed Unit 1 to bedrock in four 1-x-1-m squares and also explored Unitrin several square meters to -depths slightly greater than those reached by TxDOT excavators (Figure 2-19). The general stratigraphic picture that emerges from all of the work at Wilson-Leonard is presented in Figure 2-20, a schematic profile representing the west face of TxDOT Blocks I, 2, 3, and 4.

Depositionally, Wilson-Leonard is divisible into valley floor and valley margin areas that are almost as different as two sites. Initially, the valley floor aggraded primarily through fluvial deposition that gave way to primarily colluvial and anthropogenic deposition some 9,500 years ago. The valley margin lacks any fluvial deposition (see Figure 2-20), and the total thickness of deposits is about half that of deposits in the valley floor. With its compressed archeological sequence and large burned rock midden, the valley margin area ofthe site is similar to many that have been excavated in this patt ofTexas (Collins 1995).

Unit $\mathrm{I}$ is subdivided into subunits based on texture. These are Igl (fluvial gravels), lsi (predominantly silt), lei (predominantly clay), and lsi-c (a soil). Unit Id is a mix of alluvium and remarked valley floor deposits. Unit II is primarily a colluvial deposit that is not subdivided. Units I and II occur only in the valley floor part of the site. Paleoindian cultural remains were found in Units I and II.

Unit III is divided into three subunits, IIla, Illb, and Ilic. Unit Ilic is continuous across the investigated part of the site, whereas the lower Units Illa and IIIb are mostly found in the valley floor. The large burned rock midden of Area A is found in the valley margin portion of Unit Ilic. Archaic materials were recovered from Unit III along with a minor 


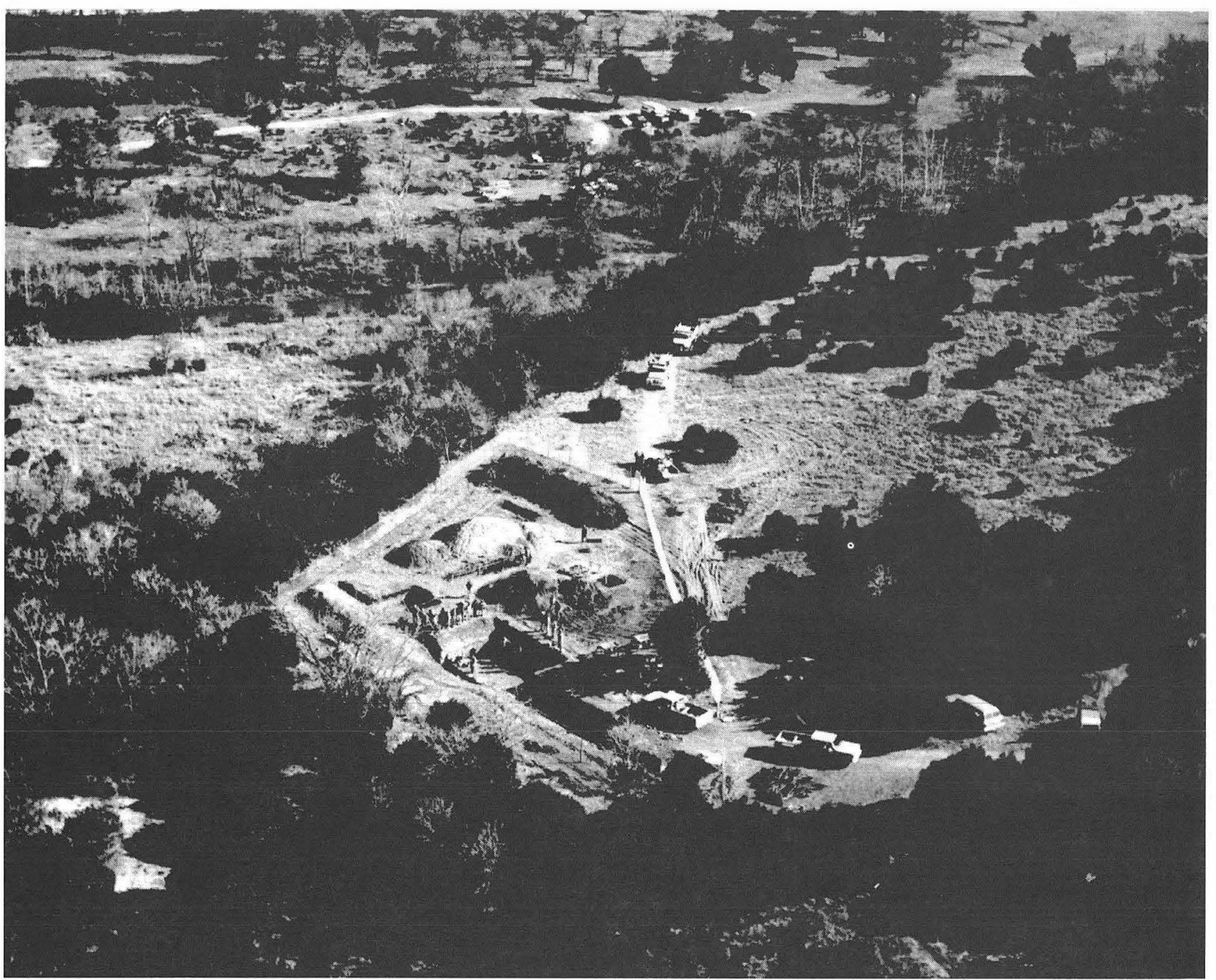

FGURE 2- I6. Oblique aerial view of the Wilson-Leonard site excavations in early 1984 showing the form of the natural terrace, the creek confluence, and main excavation area. Visitors to the site are standing on the east and north sides of excavation Block 6 . The diagonal section of fence between the two pickup trucks is along the southeastern edge of RR 1431 right-of-way.

amount of Late Prehistoric evidence in upper Unit Ille. Two units on the valley margin, $\mathrm{X}$ and $\mathrm{Y}$, consist of silty colluvium containing sparse amounts of archeological material. Time-diagnostic specimens among these artifacts permit a rough temporal correspondence to be established between valley floor and valley margin units, but the physical stratigraphic correlations are uncertain. Although these major stratigraphic units are reasonably distinctive, boundaries between them are generally indistinct. Because of this lack of sharp boundaries, both TxDOT and TARL excavators relied on arbitrary vertical excavation controls. Almost all of the arbitrary excavation levels could be assigned to a natural stratigraphic unit after being excavated.

Because stratigraphic boundaries were not always clear and because natural boundaries do not correlate perfectly with arbitrary level boundaries, the assignments of arbitrary provenience units to the natural stratigraphic units include a plethora of gradational designations, as between $\mathrm{lgl}$ and
Isi, denoted with slashes (Igl/Isi). The full array of these is depicted in Figure 2-21 along with the approximate ages of the primary contacts. The early human interment (Burial 2) is also depicted in Figure 2-21 along with its inferred age of ca. 10,000 years. Figures $2-20$ and $2-21$ are the stratigraphic "roadmaps" to the remainder of this report, and Figure 1-2 provides a graphic summary of the development of the site overtime.

What follows in Chapters 3 and 4 are the objectives guiding the work at Wilson-Leonard and the archeological background to that work. In Chapters 5 and 6 are to be found details on the methods of investigation and the site stratigraphy.

\section{HUMAN ECOLOGY ATWILSON-LEONARD}

Biotic data relevant to the interpretation of paleoecology are neither copious nor pristine for this site, but concerted 


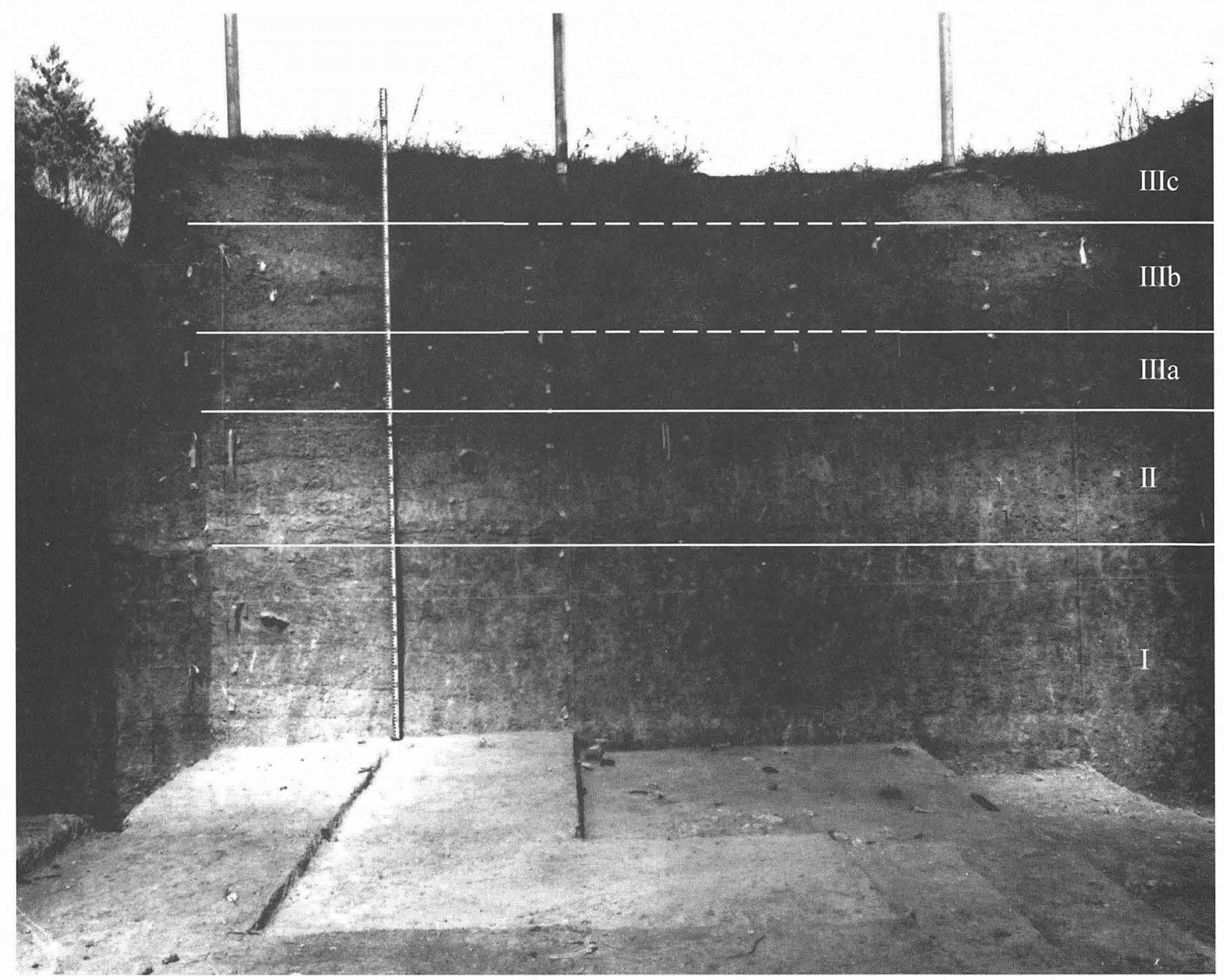

FIGURE 2-17. North wall of Blocks 4 and 6 in the final days of the TxDOT excavation. The inferred boundaries ofTARL stratigraphic Units 1, II Illa, IIlb, and Hie have been superimposed. (Photo courtesy Texas Historical Commission).

effort and, in a few cases, fortunate circumstances, resulted in the recovery and analysis of floral and fauna! indicators of past environments. When these data are arrayed and interpreted in the context of the more abundant geologic and pedogenic paleoenvironmental indicators as well as other regional evidence, a consistent and intriguing history of human ecology at the locality emerges. This cannot be considered the final word on the matter, but it should be the point of departure for future studies.

Remains oflarge and small terrestrial, aquatic, and avian vertebrates (and bird eggshells) were recovered from virtually all stratigraphic contexts, but neither their condition nor quantities made analysis and interpretation easy. Nonetheless, a broad range of cultural and environmental inferences was possible from these data. Terrestrial and aquatic mollusks were recovered in much higher numbers and in generally better conditions than the vertebrates, and these provided evidence which supported interpretations of natural environmental as well as human behavioral history at the site. A small number of ostracodes augmented the paleoenvironmental evidence from the earliest levels of the site.

Macrofloral remains were particularly scarce and pollen was essentially absent. Phytoliths were sufficiently abundant and well preserved from the upper levels of the site to provide important paleoenvironmental indicators. Wood charcoal and a small number of charred plant macrofossils were recovered, identified, and interpreted as primarily cultural products from much of the stratigraphic colunm, but a number of thoroughly charred bulbs recovered from very Early Archaic ovens are the most significant find in terms of direct evidence for an aspect of Early Archaic subsistence.

Stratigraphic evidence for rates and environments of deposition along with pedogenic indicators of times of land surface stability provide the framework for identifying cycles of valley filling and cutting. Such cycles are interpreted as stream responses to broad paleoenvironmental (mostly climatic) conditions. These large-scale data are augmented with 


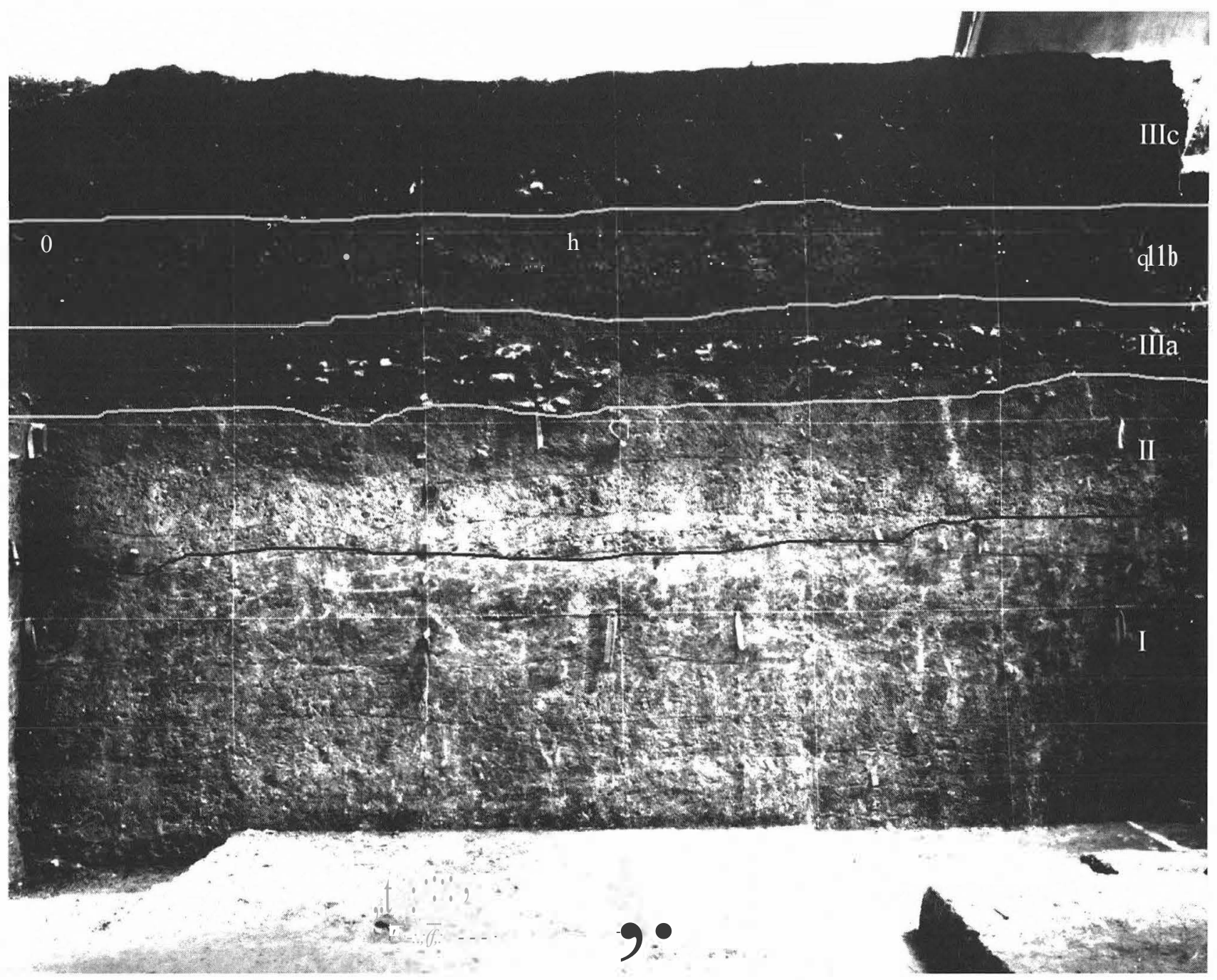

FIGURE 2-18. East wall of Block 6 in the final days of the TxDOT excavation with the inferred boundaries ofTARL stratigraphic Units I, II, TIla, 1llb, and 11lc superimposed. (Photo courtesy Texas Historical Commission).

a limited array of chemical (including isotopic) and physical evidence for depositional, pedogenic, and groundwater conditions throughout the history of the site.

In aggregate this physical and biotic evidence matches closely with previously reported pollen and fauna! sequences from the region and encourage the synthetic interpretation of environmental history presented in Chapter 4. In its simplest form, the inferred sequence begins with a drought and stream entrenchment from near 12,000 to ca. 11,500 years ago followed by generally more mesic conditions that deteriorated by ca. 8,500 years ago into an early phase of the now widely recognized middle Holocene drought. That long interval of deficient effective moisture lasted until ca. 2,500 years ago with a brief reversal ca. 6000 to $5500 \mathrm{BP}$. Mesic conditions returned between about 2,500 and 1,000 years ago, followed by a brief xeric interval and then establishment of conditions not greatly different from those of today.

The tools with their traces of wear and chemical residues along with the cultural features of the site round out the human ecological picture for Wilson-Leonard. In the pages that follow, these data are described, synthesized, and interpreted. Even with its limitations of imperfect preservation and somewhat blurred stratigraphy, the importance of this site lies in the near completeness of its record from ca. 12,000 to 1,000 years ago. 


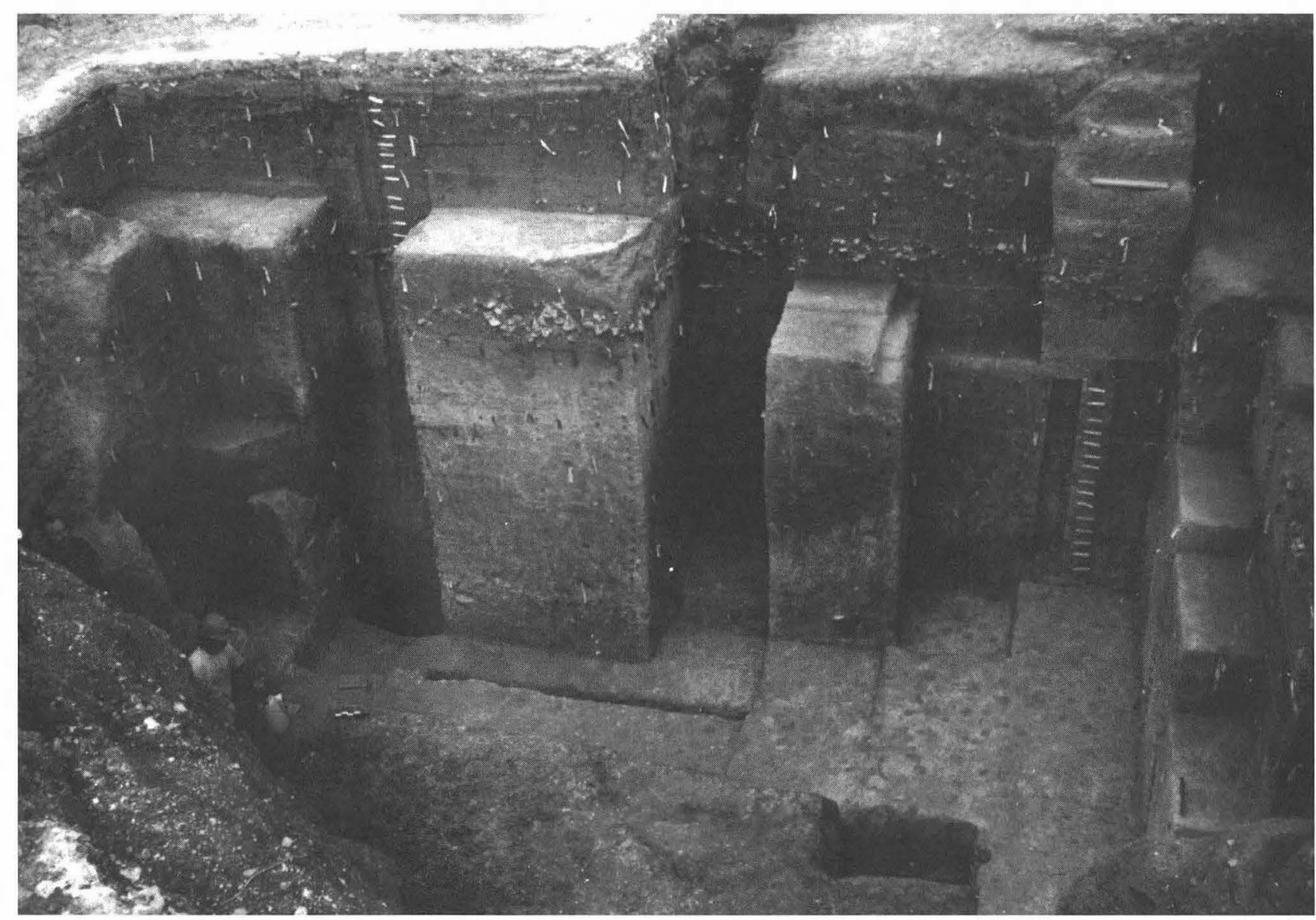

FlauRE 2-19. East wall of Block 6 with TARL's stepped "witness-column" excavation nearing completion. More of Unit I is exposed in the floor ofBlock 6. (The original plan was for the witness column to be a 1-m-wide block dug along the south and east walls ofTxDOT Block 6 , but when Block 6 was reopened in I992, it was found that its walls sloped as a result of erosion and pothunting, a circumstance that caused the witness column to be dug in a stepped fashion). 


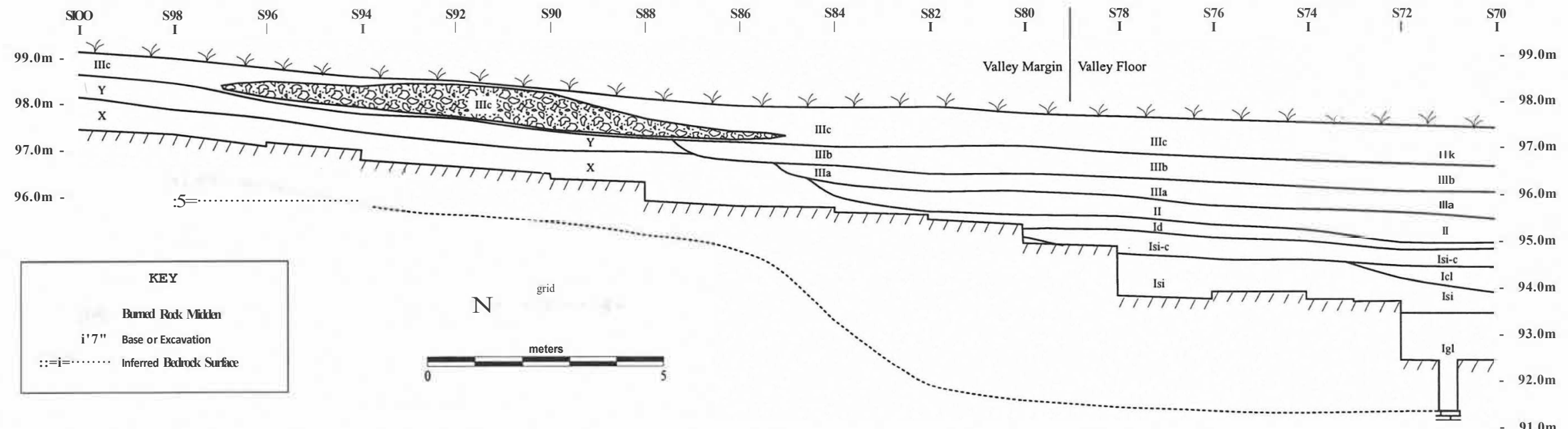

FIGURE 2-20. Synoptic, simplified section along the west wall ofTxDOT Blocks 1, 2, 3, and 4 showing major TARL stratigraphic units, burned rock midden, and Burial 2. Note division of the section into two areas of contrasting depositional regimes; these are the valley floor and the valley margin. 


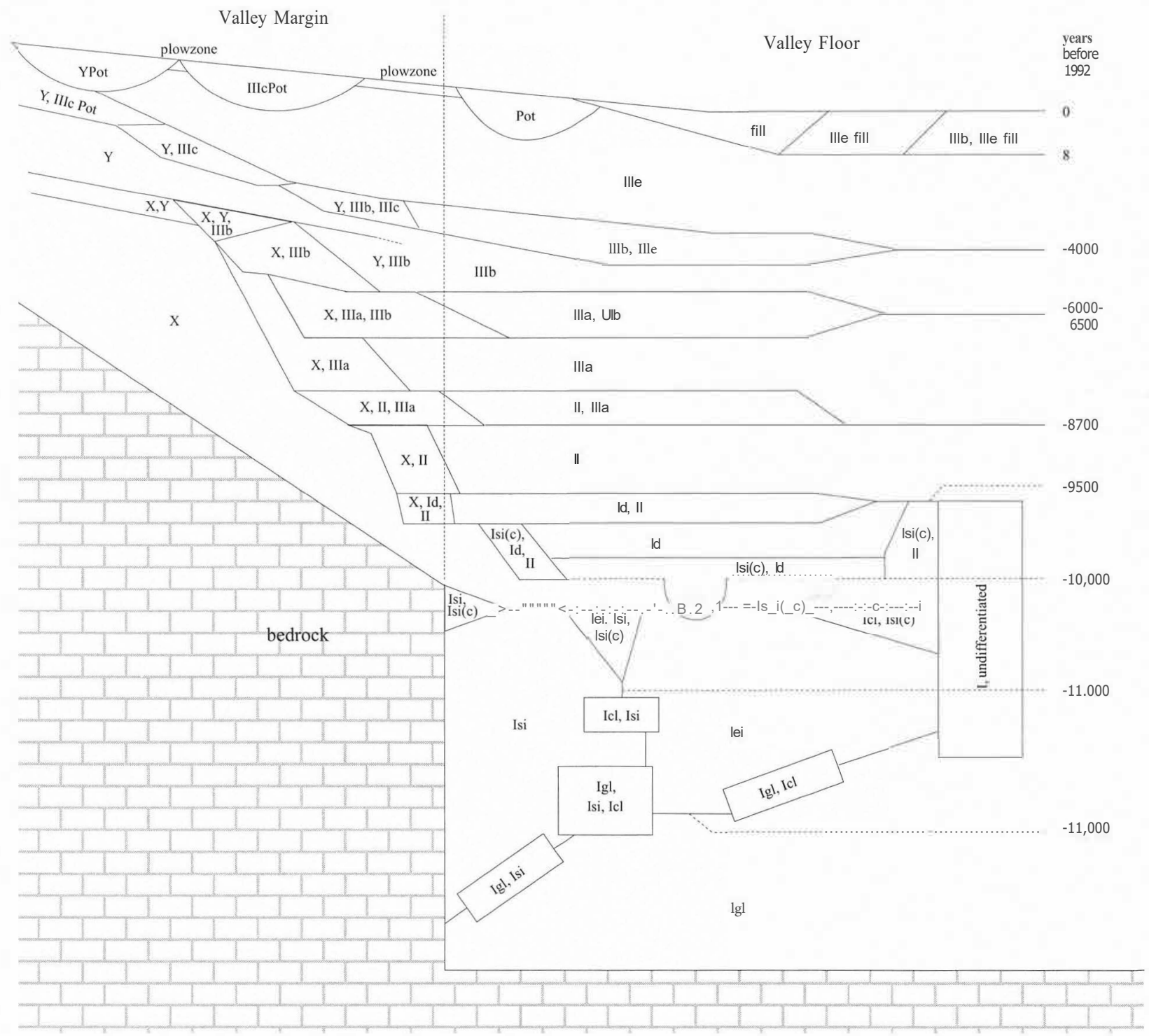

HGURE 2-21. Diagrammatic depiction of all TARL stratigraphic designations with radiocarbon ages for the major valley floor stratigraphic unit boundaries. 


\section{CHAPTER3}

\section{HISTORY OF INVESTIGATIONS}

by C. Britt Bousman, Michael 8. Collins, Jan Guy, Paul R. Takac, and Gail L Bailey

\section{INTRODUCTION}

Archeological investigations at the Wilson-Leonard site have spanned more than two decades. The site was first recorded during a 1973 TxDOT reconnaissance of the proposed construction corridor forthe extension of RR 1431. After 1981 test excavations demonstrated the site's importance, TxDOT archeologists spent 28 consecutive months in 1982-1984 conducting extensive excavations within the highway right-ofway at the west end of the site. Further excavations were carried out in this area by TARL archeologists for eight months in 1992-1993. Approximately $477 \mathrm{~m}^{3}$ were excavated by hand in the combined TxDOT and TARL investigations and this represents one of the larger excavated samples from a Texas site.

Although the TxDOT and TARL excavations were confined to the highway right-of-way, limited exploratory testing has also been conducted to the east of RR 1431 in the portion of the site now owned by the Archaeological Conservancy (Marjorie Ashcroft Wilson Archaeological Preserve). Archeologists from the Office of State Archeologist of Texas (OSAT) carried out survey and limited shallow augertesting in this area in 1983, primarily in an effort to delineate the horizontal extent of the site. Additional subsurface probing was conducted on the Conservancy property in 1994 when a series of geological cores was drilled to bedrock as part of the TARL investigations.

In the sections that follow, additional information is presented on the various TxDOT and TARL investigations at the Wilson-Leonard site. Documentation of the OSAT investigations is on file at that office and their work is not discussed further in this chapter.

\section{TXOOTINVF5TIGATIONS}

\section{Survey}

The Wilson-Leonard site (41 WM235) and three other prehistoric sites (41 WM233, 41 WM234, and 41 WM236) were recorded by TxDOT archeologist Daymond Crawford during a 1973 survey of the proposed extension of RR 1431 between Cedar Park and Round Rock. A brief letter report apparently was prepared on this survey, and the site records are on file at TARL. Crawford's 1973 description of Wilson-Leonard is quite brief, and it focuses primarily on the portion of the site lying within the cleared field (apparently still in cultivation at that time; see Figures 2-14 and 2-15 and discussion of this field in Chapter 2). He observed scattered burned rocks and lithic artifacts within an area measuring ca. 300-x-100 feet, with the greatest concentration occurring at the northwest end of the field (probably near Burned Rock Midden 2). He collected a few artifacts from the surface but excavated no shovel tests or made any other subsurface probes. Burned Rock Middens 1 and 2 may have been obscured by vegetation at that time because Crawford states "no midden noted" on the site record. He does not mention any damage to the site from relic collectors, although his site record for 41 WM234 (immediately west of Wilson-Leonard) notes that both of the burned rock middens at this nearby site were "slightly potted."

\section{Testing}

Limited exploratory testing was conducted at the Wilson-Leonard site in July 1981 by TxDOT archeologist Wayne Young. Young's field notes include a useful description of the site's appearance and general condition at that time. He reports that the cleared field was no longer being cultivated or grazed and the surface was now obscured with a good cover of native grasses. Small "cedar" (or juniper) and "cedar elm" trees were scattered throughout the field with thicker stands of trees and brush growing along the base of the ridge, along the gully near the west edge of the site, and along the terrace edge above Spanish Oak and Brushy creeks. $\mathrm{He}$ also notes that "several" burned rock middens were in 
evidence, but they were somewhat obscured by dense grass cover. There are two undated sketch maps of the site that Young probably drew during the testing phase, and both of these maps depict four middens within the site boundaries (designated Burned Rock Middens 1-4 in the subsequent mitigation phase). Burned Rock Middens 1 and 2 were clearly located within the highway right-of-way (see Figure 2-12 in Chapter 2). Burned Rock Midden 3 was located east of the right-of-way (on what later became the Conservancy property) and Burned Rock Midden 4 was located west of the gully near the western edge of the site (possibly outside the right-of-way; see discussion in Chapter 2). One of these maps depicts extensive "pothunting" in and around Burned Rock Middens 2 and 4 at the west end of the site. Young briefly discusses the pothunting in his description and notes that one of the landowners was "currently encouraging pothunting." He also mentions meeting one of the pothunters who reported finding "Nolan, Travis, and Calf Creek" points in this area.

No report was written on the testing phase investigations and unfortunately the field documentation is rather limited. We know that Young and at least one assistant spent several days excavating three $1-x-1-m$ test pits within the highway right-of-way. Though the exact locations of these pits were not documented, Test Pit 1 was apparently located within Burned Rock Midden 1, and the other squares lay to the north of this midden (but probably east of Burned Rock Midden 2). They were excavated by hand in IO-cm-thick levels with Test Pit 1 excavated to a depth of $1 \mathrm{~m}$ below surface, Test Pit 2 to a depth of $60 \mathrm{~cm}$, and Test Pit 3 to a depth of $1 \mathrm{~m}$ (total volume of approximately $2.6 \mathrm{~m}^{3}$ ). A small probe excavated at the base of Test Pit 1 demonstrated that the cultural deposits extended to a depth of at least $1.5 \mathrm{~m}$ below surface. Although these excavations were limited, they were sufficient to demonstrate that the site contained at least $1.5 \mathrm{~m}$ of stratified cultural deposits dating to the Early through Late Archaic periods (and possibly earlier).

On the basis of these results, Young recommended that more extensive excavations be undertaken before highway construction began. He prepared a very simple research design for further work that primarily focused on two points: (1) the testing data suggested that "most, if not all of the Central Texas Archaic phases (Weir 1976)" were represented at the site (implying that additional data could be collected on each of these phases), and (2) additional excavations should focus on the areas between the burned rock middens in an effort to locate Archaic habitation/activity areas associated with the middens.

\section{2-1984 Excavations}

In January 1982, TxDOT archeologists began an intensive excavation under the terms of Texas Antiquities Permit No. 300. Young directed the field investigations with Frank Weir serving as the Principal Investigator. Initially the excavation was scheduled to be finished within six months, however a number of significant findings led to several extensions, and the excavation did not end until April 1984.

The excavations (Figure 3-1) consisted of forty 2-x-2-m hand-excavated squares and three machine-excavated trenches (with an area of ca. $25.6 \mathrm{~m}^{2}$ ). Maximum depths of the 2-x-2-m squares ranged from 1 to $5 \mathrm{~m}$ below the surface, and the trenches were excavated to depths ranging from 2 to $4 \mathrm{~m}$ The hand-excavated volume totaled approximately 390.04 $\mathrm{m}^{3}$ with an estimated $179.77 \mathrm{~m}^{3}$ removed in machine excavations. The latter total includes the three trenches mentioned above as well as some machine stripping of overburden that preceded hand-excavations in several areas (discussed further below).

The TxDOT field documentation makes a clear distinction between a main excavation area, designated Area A, and a secondary area, designated Area B (see Figure 2-12 in Chapter 2). Area A extended about $40 \mathrm{~m}$ northward from

Burned Rock Midden I. All of the machine excavations and most of the hand excavations occurred in this area (see Figure 3-1). Area B consisted of only two 2-x-2-m squares excavated in Burned Rock Midden 2 fairly late in the investigations. The two areas were separated by a chainlink fence that was constructed around Area A in early 1983 (after the discovery of Burial 2 had heightened public awareness of the site and increased security risks).

\section{Methods Employed in the Area A Excavations}

The work in Area A included three machine-excavated trenches and thirty-eight 2-x-2 m squares excavated primarily by hand (see Figure 3-1). The three machine trenches in Area A included a long, narrow backhoe trench, designated the "slit trench," and two shorter, wider gradall trenches, designated Gradall Trenches 1 and 2. Other than locational information, there is relatively little documentation of these three trenches. The hand-excavations were documented more thoroughly with sundry field data recorded in the daily journal, level records, plan and profile drawings, photographic records, feature notes, elevation records, and stratigraphy notes.

Thirty-five of the hand-excavated squares in Area A were clustered in six contiguous "blocks" of squares designated Blocks 1-6 (see Figure 3-1). Late in the investigations, a thirty-sixth square (E78/S78) was excavated immediately east of the southeast corner of Block 6. This square was excavated primarily for fine-screen recovery, and it was referred to in the field records as the "Fine Screen Unit" (FSU). Two additional, isolated 2-x-2-m squares in Area A are referred to by grid coordinate designations only: E40/S70 and E24/S64. The latter square was part of an area initially staked out as a 4-x-4-m block, machine stripped to a depth of $13 \mathrm{~m}$, and then, because of time constraints, reduced to a single 2$\mathrm{x}-2-\mathrm{m}$ square for hand excavations.

The grid system used in the Area A excavations is briefly described in the field notes. A grid north baseline 


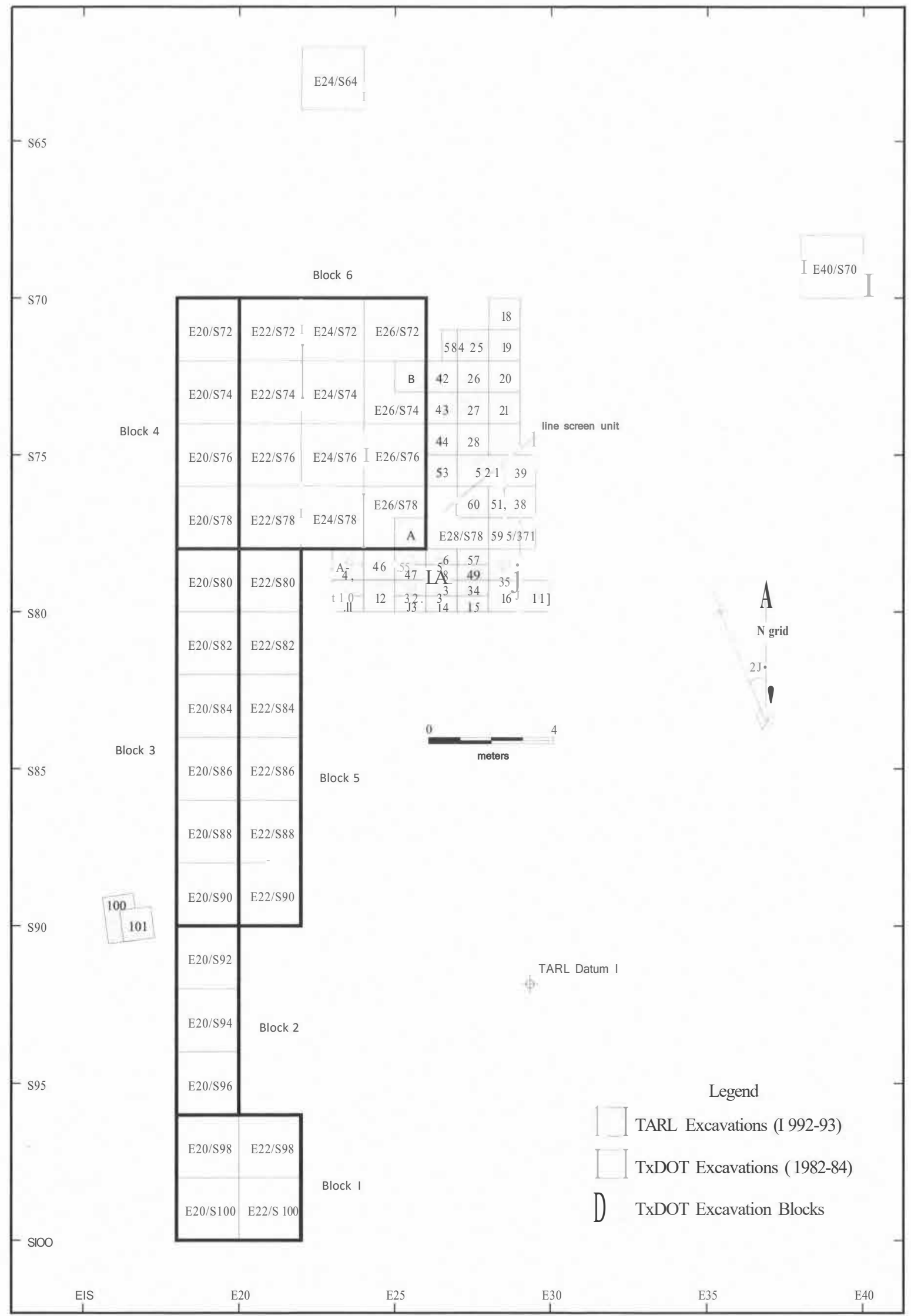

FIGURE 3-1. Plan map of the Wilson-Leonard site showing excavations for TxDOT and TARL phases of work (excluding machine excavations). 
was established with a transit on January 20, 1982. It was oriented on an axis that ran northward from Burned Rock Midden 1 toward Burned Rock Midden 2. The line was intended to intersect both middens on a magnetic north bearing, however, the line was inadvertently established on a bearing of ca. $\mathrm{N} 23^{\circ} \mathrm{E}$.

This grid north baseline was designated the E20 line with the south end of the line starting at the intersection with thE S100 line. This intersection, designated E20/S100, lay near the eastern margin of the right-of-way,just south of Burned Rock Midden 1. From this point, grid south coordinates decreased northward and grid east coordinates increased eastward. Stakes were apparently set with the transit every $10 \mathrm{~m}$ along the E20 baseline, and then a series of 2$\mathrm{x}-2-\mathrm{m}$ squares was laid out to the east and west of this line, with the squares labeled according to the coordinates of their southeast corners.

A primary vertical datum was established "just south" of the E20/S100 grid point "on an elevation higher than any projected excavation area." It was assigned an arbitrary elevation of $100 \mathrm{~m}$ and was "later shot into" a benchmark. The location of this datum is depicted on one of the site maps with both its arbitrary and actual elevation (813.86 ftAMSL) noted. Field records indicate that the primary datum was used to set several secondary datum points, but their locations and elevations were not consistently documented.

Each of the 2-x-2-m squares in Area A was excavated in sequentially numbered, arbitrary (rather than stratigraphic) levels. The levels were initially excavated in 10-cm- (and later $5-\mathrm{cm}$ ) thick increments, but instead of excavating level floors, the floors were sloped to follow the gentle slope of the present ground surface (downward to the north; see Figure 2-12 in Chapter 2). For example, at the base ofLevel 1 in Square E20/S 100 the southwest comer of the floor was at an elevation of ca. $99.69 \mathrm{~m} \mathrm{(10} \mathrm{cm} \mathrm{below} \mathrm{the} \mathrm{surface} \mathrm{eleva-}$ tion of 99.79 mat that comer), and the northwest corner was ca. $99.55 \mathrm{~m}(10 \mathrm{~cm}$ below the surface elevation of $99.65 \mathrm{~m})$. Since the surface slope was greatest at the southern end of Area A (Blocks 1-3, 5), the levels slope more dramatically in these squares than in the Block 4 and 6 squares. Young described the rationale for this approach in his field notes, noting that since the modern terrace surface sloped gently downward to the north he decided to follow this slope to avoid cross-cutting any cultural stratigraphy. This sloping level approach was used in all of the Area A excavations (though not in Area B as discussed below). Unfortunately, this strategy was not very effective, and it ultimately made it far more difficult to correlate arbitrary excavation levels to natural strata during the TARL analysis.

Beginning in May 1982, excavation in 5-cm-thick sublevels in some squares (beginning with Level 9 in Block 4, Level 15 in the FSU, and all levels in Block 6) were initiated. The sublevels were numbered just like $10-\mathrm{cm}$ levels with the suffix "A" designating the upper 5-cm half and "B" denoting the lower half(e.g., Levels 18A, 18B). In December 1982, horizontal controls were tightened by dividing the 2-x-2-m levels in most squares into $1-x-1-m$ quads (designated NE, NW, SE, and SW quads). This began with Level 29B or 32A in three of the Block 4 squares, Level 19 in one Block 5 square, Level 19B in all Block 6 squares, Level 27 in E40/S70, and all levels in E24/S64 and the FSU.

Although all hand-excavated levels in Area A were dug in relation to ground surface, evidently surface elevations were not consistently recorded for the corners of squares before excavation commenced. No surface elevations were recorded for Blocks 1, 2, 3, and 5, or for Square E24/S64 before they were excavated, however some surface elevations were later recorded in profile drawings. There are surface elevations for most corners of the Block 4 squares, but these data are missing for two grid points in this block. The Block 6 situation is not documented clearly, but it appears that levels were excavated in relation to a set of partly reconstructed surface elevations. The FSU and E40/S70 are the only Area A squares for which adequate surface elevations were recorded before excavation began.

There is very little documentation of the methods used to measure the depth below surface at the base of each level. Field records indicate elevations were not consistently recorded at the base of each level until late May 1982. Blocks $1,2,3$, and the upper five or six levels of Block 4 were completed by this time. A few brief notes on level records suggest that, at least in the early months, floor depths were determined by measuring the walls with a metric hand tape.

In the course of the Area A investigations, a number of significant changes occurred in the general excavation strategy and techniques. Young initially planned to excavate every fifth square along the baseline to test Burned Rock Middens 1 and 2 and locate an activity area between them for large-scale excavation. After three squares were excavated (one each in what later became Blocks 1-3), the strategy shifted to a "block system" of peeling several squares, a level at a time to "expose larger areas and learn more about living floors in the site." This basic strategy was maintained during the first four months as Blocks I through 3 and the upper portion of Block 4 were excavated by hand (in that sequence) using shovels, picks, hoes, and spading forks (Figure 3-2). Young notes that in that period "troweling to be troweling was ruled out as soils are too hard for any progress." All excavated soil was dry-screened through 1/4inch mesh.

As excavations moved northward with Blocks 1 through 4, deposits of increasing depth were encountered; thus, the maximum depths of the excavations deepened accordingly (Figure 3-3). Blocks 1 through 3 were completed by spring 1982, with various squares excavated to maximum depths of ca. 15 to 1.7 min Block 1; 1.7 to 1.8 min Block 2; and 1.9 to 2.7 min Block 3. When Block 4 reached a depth of ca. $3 \mathrm{~m}$ later in the summer, work stopped there for awhile because of the belief (at that time) that little if any deeper cultural material would be found. 


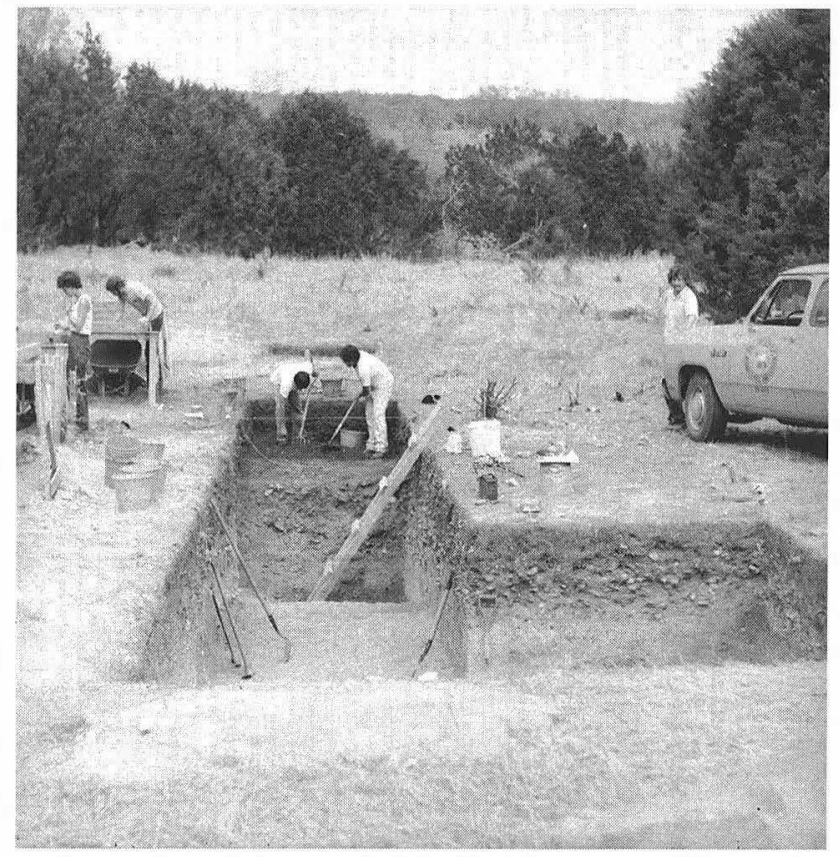

FIGURE 3-2. TxDOT excavations in progress in Block 3, March 1982. Block I is in the foreground; the ladder is in Block 2. View is downslope, grid north toward Spanish Oak Creek and shows the stubble and stumps left after the site was cleared.

After work had ceased in Block 4 for five months, excavation resumed in the square at the north end of the block (E20/S72; see Figure 3-1) in late December of 1982. At the suggestion of geologist Glen Evans, one of the crew members was instructed to excavate this square to bedrock to provide a complete stratigraphic exposure. Since the current thinking was that the excavation was in culturally sterile deposits, about $25 \mathrm{~cm}$ (ca. two to three levels) were tossed without screening before it became apparent that there was still some cultural material present. Controlled excavations were resumed, and shortly thereafter the northern edge of the late Paleoindian burial (designated Burial 2) was exposed in the south wall. After the burial was removed in January 1983, work continued intermittently in various Block 4 squares through early 1984 when excavations terminated at depths ranging from 3.5 to $5 \mathrm{~m}$. Square E20/S72 was the deepest excavated by the TxDOT crew (ca. $5 \mathrm{~m}$ completed in May 1983 ), and thus it is sometimes referred to as "the deep unit" in field notes (Figure 3-4). An auger boring in the bottom of this unit reached bedrock (Figure 3-5).

After work ceased in Block 4 in the summer of 1982, Block 5 (adjacent to Block 3) was opened with the principal objective of further exposing an Early Archaic "living floor or surface" identified in Block 3. Since, at this point in the investigations, the primary objective was increasing the sample of significant Early Archaic and Paleoindian components, the upper $50 \mathrm{~cm}$ of Block 5 deposits were stripped with a backhoe. This was the first time machine excavations were employed at the site, and it was at this time that the slit trench northward from Block 4 was excavated, both

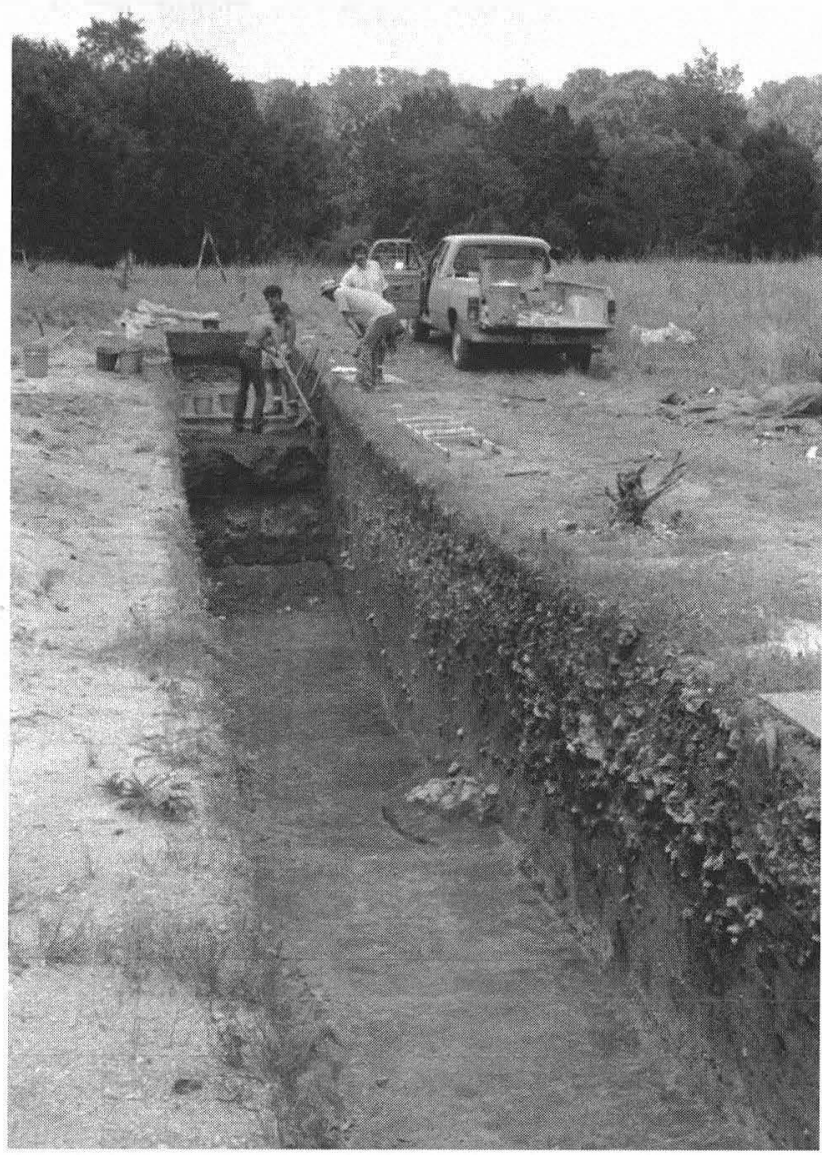

FIGURE 3-3. TxDOT excavation in progress in Block 4 (background), May 1982. Burned Rock Midden 1 is prominent in the east (right) wall ofBlocks 2 and 3 (foreground, middle ground). View is toward grid north-northeast.

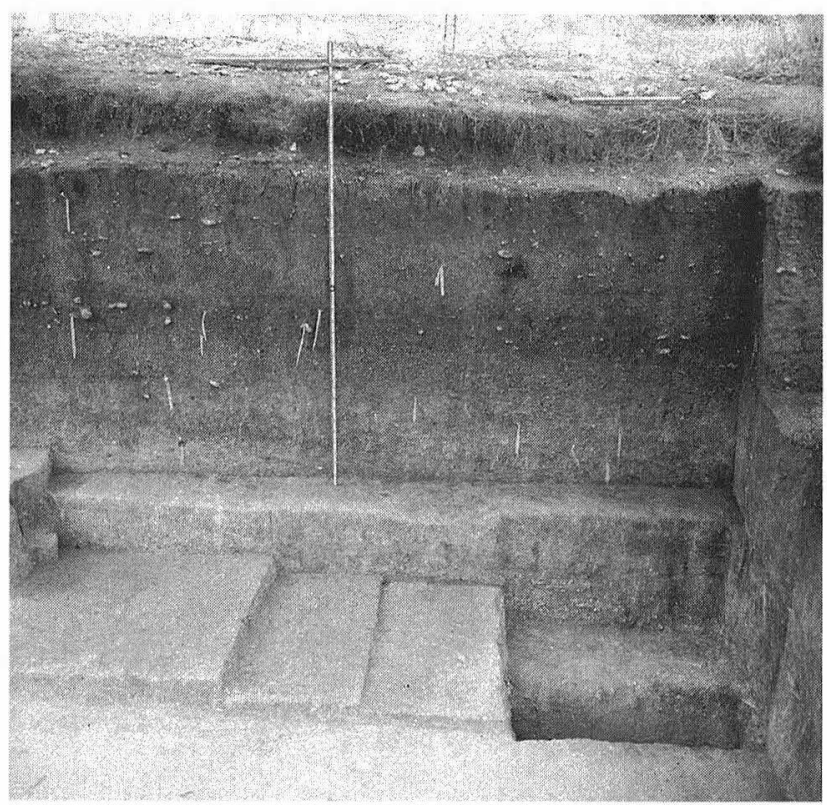

FIGURE 3-4. West wall of TxDOT Block 4 in January 1984. The "deep unit" (E20/S72) is at right, and the steps in front of the stadia rod are beneath the location of Burial 2. 


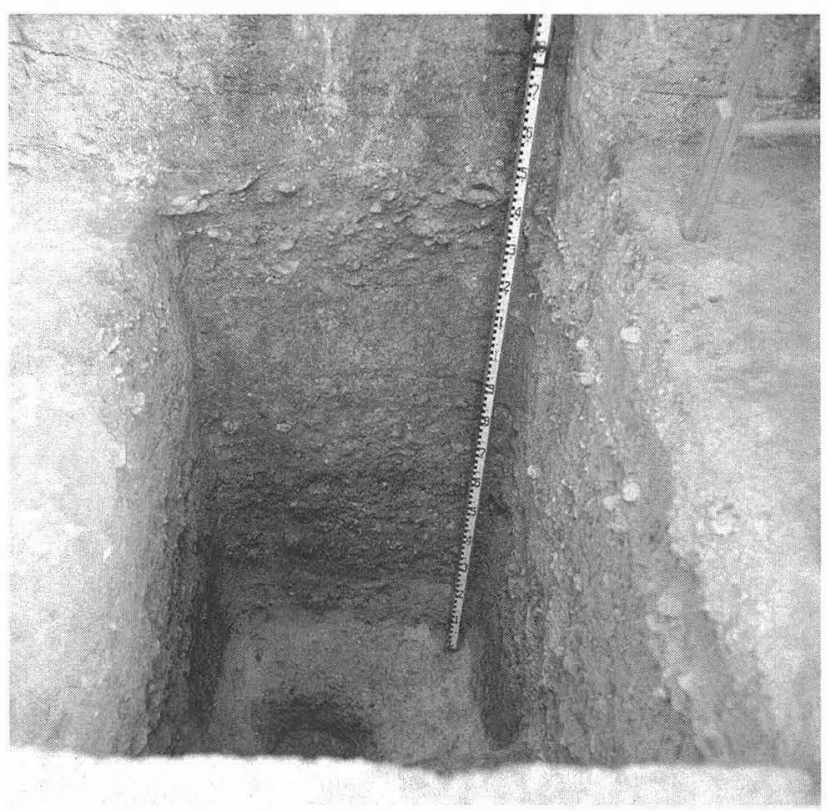

FGURE3-5. The "deep unit" (E20/S72) in the north end ofTxDOT Block 4 as it appeared in February 1984 with auger hole dug from the $5 \mathrm{~m}$ depth to bedrock. View is toward grid north.

to extend the Block 1-4 trench to the right-of-way centerline and to obtain a stratigraphic exposure through the southern edge of Burned Rock Midden 2. The machine excavations were not screened, but beginning with Level 6, Block 5 was dug and screened in the same manner as the earlier blocks.

Work ceased in Block 5 in early fall 1982 when the squares had reached depths of 2.4 to $2.7 \mathrm{~m}$. Shortly thereafter, isolated Square E40/S70 was opened near the southeast edge of the right-of-way primarily to learn if the "early components" extended this far east. Work continued in this square intermittently until it was terminated at $4 \mathrm{~m}$ below surface in spring 1984.

Additional machine excavations were undertaken in October 1982 when a Gradall was used to strip the upper 1.5 mofBJock 6. At the same time, the upper 13 m ofthe E24/S64 block were stripped and Gradall Trenches 1 and 2 were excavated. As in the earlier work, none of the machine-excavated material was screened but 1/4-inch screening commenced with hand excavations. The hand work began in Block 6 (with Level 15) immediately after the machine stripping, but no work occurred in E24/S64 until April 1983 when the southeast quad was excavated to a depth of $1.6 \mathrm{~m}$ and then abandoned.

Although the Block 6 investigations initially employed the same general excavation techniques used in Blocks 1 through 5, after the first couple oflevels, techniques changed considerably. Picks and spading forks were abandoned and levels were excavated primarily with trowels and other small hand tools (Figure 3-6). Work slowed considerably at this point, but more artifacts were found in situ, features were exposed more carefully, and more and better information was recorded in level records, floor plans, and feature notes. A

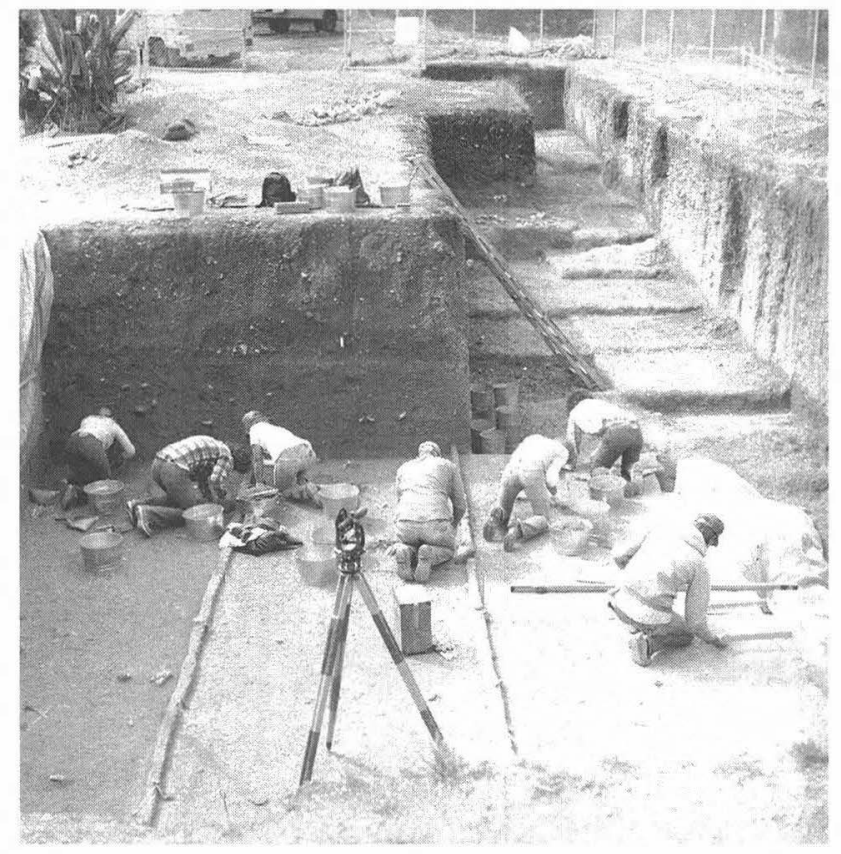

FGURE 3-6. Hand excavation in progress in TxDOT Block 6 in February 1983. View is toward grid south with Blocks 1, 2, 3, and 5 shown in right background.

roof constructed over the Block 4 - Block 6 area in May of 1983 improved the working conditions and afforded some protection from rain (Figure 3-7), and the trend ofmore careful excavation and better documentation continued throughout the Block 6 excavations which ended in spring 1984 at depths of 3.7 to $4.2 \mathrm{~m}$

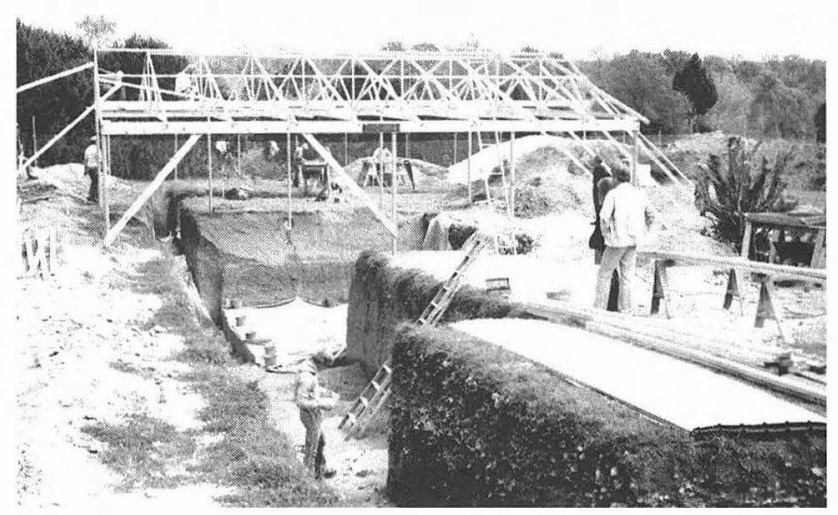

HGURE3-7. TxDOT Area A excavations in May 1983 as roof was being constructed over Blocks 4 and 6 View is toward grid northeast. Crew member is standing in Block 3 and Bumed Rock Midden 1 is visible in the east wall of Block 2

The Fine Screen Unit was the last new square of the project (Figure 3-8). It was started in summer 1983 and terminated at a depth of 4.5111 in early 1984. The FSU was excavated entirely by hand (beginning at the surface) in much the same manner as the Block 6 squares. However, in this 


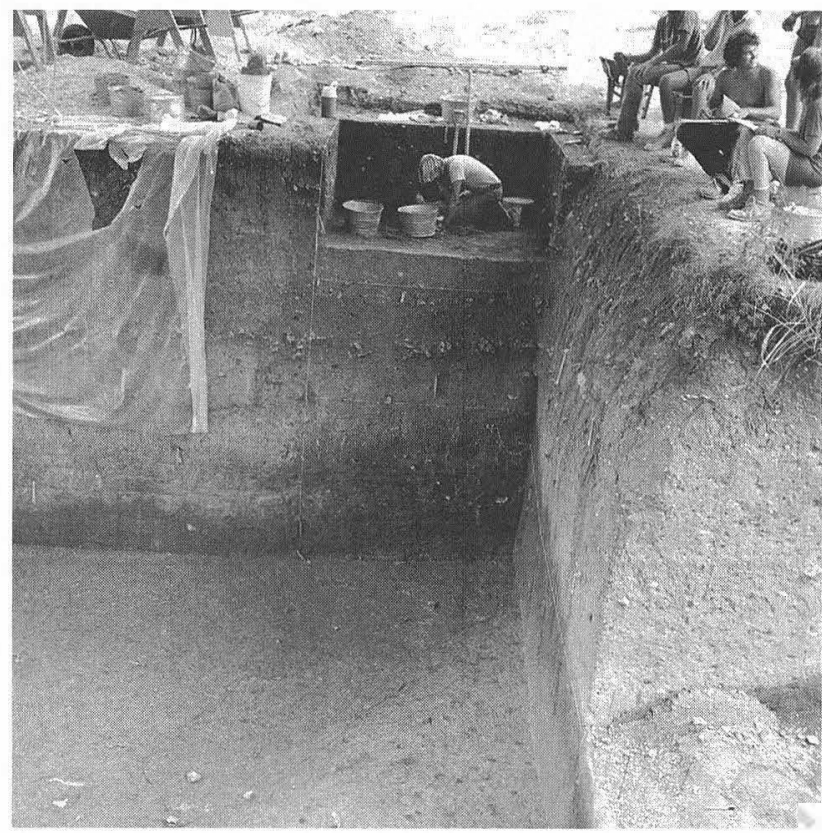

FGURE 3-8. The "Fine Screen Unit" (E28/S78) in early stages of excavation (August 1983). The unit is east of the southeast corner of Block 6. View is toward grid east.

square, all soil from all levels was water-screened (Figure 39) through nested 1/4-inch- and 1/16-inch-mesh screens. This was the only square screened in this manner, although soil samples were occasionally collected from other squares (usually from feature contexts) for later processing as fine-screen or flotation samples. The final stage of the Area A excavations is shown in Figure 3-10.

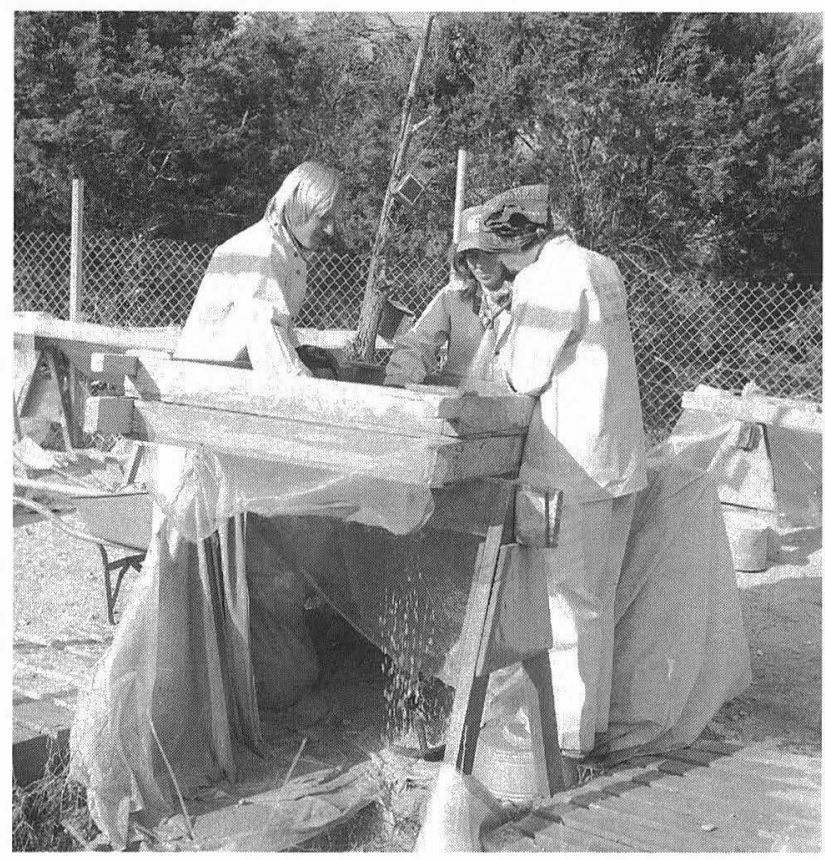

HGURE 3-9. TxDOT crew water screening matrix from the "Fine Screen Unit" (E28/S78) in December 1983; note the stack of two screens (1/4-inch mesh and 1/16-inch mesh).

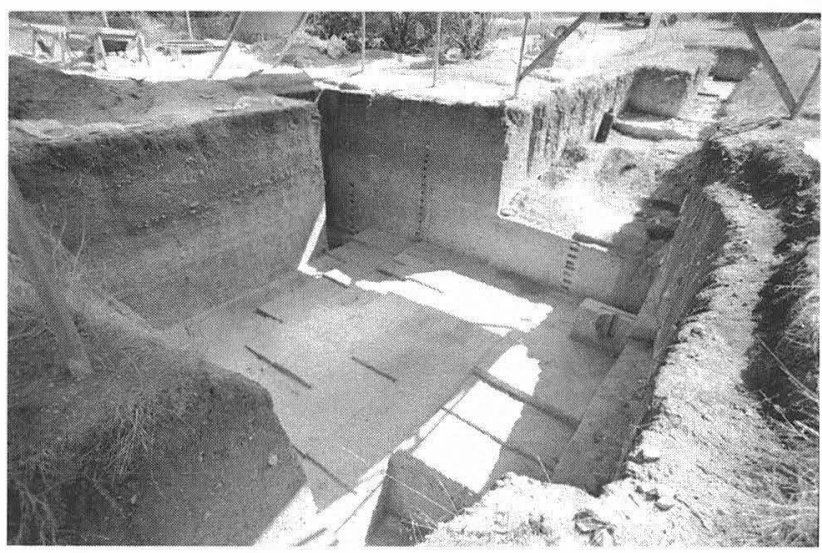

FGURE 3-10. TxDOT excavation Area $A$ at the termination of fieldwork in April 1984.

As a final comment on the variations in Area A methods, it is important to note that some significant changes also occurred in the crew composition during these investigations. For the first six weeks of the project, Young's crew was composed entirely ofTxDOT road construction workers with no formal archeological training. These workers excavated and screened while Young handled all documentation. Most ofBlock I and several squares in Blocks 2 and 3 were excavated during this period.

The road workers were replaced in March 1982 by a crew that included only two trained and experienced archeologists. The experienced crew members assisted Young in training the others and soon almost all crew members participated in most of the necessary recording tasks (level ree:ords, plan drawings, feature notes, etc.). Over the next several months additional experienced archeologists were added to the team and the inexperienced crew members continued to develop their newly acquired skills. These changes in the general experience level of the crew is strongly reflected in the variable quality of the field documentation.

\section{Methods Employed in the Area B Excavations}

The work in Area B was initiated in April 1983 during a ca. 2-week period in which Young was absent from the site. Most of Young's regular crew continued work in Area A during this period while TxDOT staff archeologist Glenn Goode and various assistants investigated Burned Rock Midden 2 (Figure 3-11). The Area B investigations are documented in a separate set of field notes by Goode, and these records essentially constitute combined daily journal, level records, and feature notes.

The locations of the two Area B squares are not well documented. The most useful location references are a sketch map included in Goode's field notes (see Figure 26-130 in Chapter 26) and aerial photographs (see Figure 2-11 in Chapter 2). The sketch map depicts only Area B but it includes the first square excavated (N8/WO), grid reference points, the secondary vertical datum, the northwest corner of the 


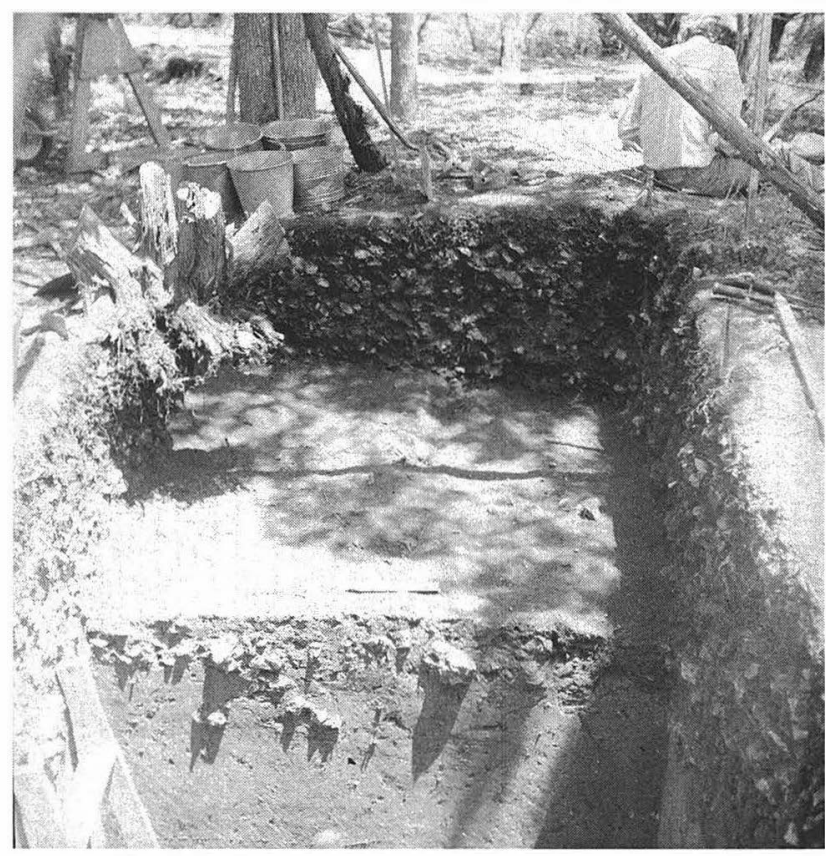

F1ouRE 3-11. TxDOT Area B during excavations in May 1983. Bumed Rodk Midden 2 is evident in the profiles. View is toward grid east with Square WON8 in foreground and E2/N8 in middle ground.

chainlink fence, and several barbed wire fence lines. It also depicts the approximate surface extent of Burned Rock Midden 2, several "potholes" in the midden, and nearby topographic features (gully, creekbank).

For a variety oflogistical reasons, a different grid system was used in the Area B excavations. A grid north baseline, designated "WO," was established on a bearing of $\mathrm{N} 15^{\circ} \mathrm{W}$. The south end of this line (near the south edge of the midden) was designated "NO/WO." The two squares were excavated $8 \mathrm{~m}$ north of this point on the N8 line (adjacent to one another) and were designated according to their southeast comer coordinates as WON8 and E2/N8.

Although a different grid system was used, the vertical datum for the Area B work was established using the Area A primary datum. The Area B datum was the top ofa "rebar" rod driven in the ground just north of the northwest comer of the chainlink fence around the Area A excavations.

The excavation methods employed in Area B were generally comparable to Area A methods with a few notable differences. As in many of the Area A squares, both Area B squares were excavated in I0-cm arbitrary levels divided into $1-\mathrm{x}-1-\mathrm{m}$ quads. A few of the deeper levels were also divided into 5-cm sublevels. Levels were excavated with picks, shovels, and trowels and dry-screened through 1/4-inch mesh. Elevations were recorded with a transit at the surface and at the base of almost every level. The most important difference is that the sloping level approach was not used in Area B; rather than following surface slope, floors were leveled horizontally.
The six features identified in Area B were not assigned feature numbers in the same sequence used for Area A features. The Area B sequence started over with Feature I, thus duplicating the first part of the Area A sequence. Only one Area B feature (Feature 5) was cross-referenced with a number in the Area A sequence (Feature 166). In the TARL analysis, however, numbers from the Area A sequence were assigned to Area B Features 1-4 and 6, designating them Features 194-198.

Goode concluded his work in Area Bin summer 1983 with WON8 at a depth of 4 mand E2/N8 at a depth of $2.65 \mathrm{~m}$ The following spring, two additional 5-cm levels were excavated in only the SW quad of E2/N8 (to cross-section a feature) bringing this square to a final depth of $2.75 \mathrm{~m}$ No further work occurred in Area B.

\section{Laboratory Methods}

The initial washing, labeling, and cataloging of the materials recovered in the $41 \mathrm{WM} 235$ excavations were carried out in the TxDOT archeology lab, both during and after the field investigations. Standardized TxDOT lab procedures were evidently followed in this work, however, no descriptions ofthese procedures are included in the 41 WM235 documentation.

The materials processed in the TxDOT lab were listed in a catalog consisting of a series of standardized "specimen inventory" forms upon which handwritten lists of materials found in each "lot" were recorded. Lot numbers were assigned to materials from different proveniences according to the system described below. For some lot numbers, there is only one "specimen inventory" form or "lot sheet" while for others, there are multiple sheets. All lot numbers were assigned in the lab (no field numbers were used) according to provenience information found on field bags. Lot numbers were usually written on the front of field tags and information found on field bags was transcribed onto corresponding lot sheets. Usually, the entire field bag label was transcribed exactly onto the back of the lot sheet, and then some or all of those data were also listed under the appropriate blanks on the front of the form. Individual lot sheets were generally completed for each field bag, but sometimes more than one bag from related proveniences were listed as separate entries on the same sheet.

The lot number system used to catalog the WilsonLeonard materials in the TxDOT lab generally follows a standardized approach used in many TxDOT projects. In the 41 WM235 system, lot numbers usually consist of a two- to four-part sequence of numbers and letters. The first two parts of the sequence generally refer to square and level proveniences. These two parts seem to have been used in almost all of the lot numbers assigned for the 41 WM235 material and were the only parts used for materials found early in the excavations (testing phase, Blocks 1-3 of mitigation phase). The last two parts of the sequence refer to 
subdivisions of levels and squares that were used later in the investigations (primarily in Blocks 4 and 6).

Typically, the first part of the sequence is a number that represents the 2-x-2-m square provenience. For example, numbers 1 through 4 were assigned to the four $2-x-2-m$ squares in Block 1. Numbers were assigned in this fashion to each of Area A and B hand-excavated squares. There are a few exceptions to this pattern and these include cases where the first part of the sequence is a number assigned to something other than a 2-x-2-m square (e.g., numbers 38, 39, 40 , and 43 were assigned to specimens found while cleaning profiles) and cases where the first part of the sequence is something other than a number (e.g., TP 1 for Test Pit I).

The second part of the sequence is a letter representing the level provenience: letters "A" to "Z" correspond to Levels I through 26 respectively and letters "AA" to "ZZ" represent Levels 27 through 52 (e.g., Level I in Square E22/S98 was assigned lot number 4A, Level 2 was 48 , Level 41 in Square E26/S76 was 3300 , and so on).

These letter designations correspond to $10-\mathrm{cm}$ levels only. When the excavation strategy changed to $5-\mathrm{cm}$ sublevels the third part of the lot sequence was used: the number 1 was assigned to the first $5-\mathrm{cm}$ half of a level, and the number 2 was assigned to the second half(e.g., Level $18 \mathrm{~A}$ in Square E20/S78 was assigned lot number 14R1 and Level 18B was assigned 14R2).

The last part of the sequence was used when the 2-x$2-\mathrm{m}$ squares began to be excavated in $1-\mathrm{x}-1-\mathrm{m}$ quads. The letters A, B, C, and D were assigned to the NE, NW, SE, and SW quads, respectively. Thus, in Level 20A of Square E26/ S72, material found in the NE quad was assigned lot number $35 \mathrm{TlA}$ and material from the NW quad was assigned number 35T1B.

There are certainly advantages to this sort of lot-numbering system, with the most obvious being that square and level provenience are readily retrieved without consulting a lengthy index. Nonetheless, it is important to note some of the more serious disadvantages.

Most importantly, since it was structured to reflect square, quad, and level provenience, this system does not easily accommodate more-specific proveniences such as features or point-plotted specimens. The feature or specimen number provenience can only be maintained by recording this information below the lot number on the specimen or by keeping the material with more-specific provenience bagged separately from the rest of the material with the same lot number. Inevitably this type of situation leads to loss of important provenience data.

When this system is applied to some of the more-complicated proveniences, it can also produce lot numbers of an unwieldy length, especially for labeling small specimens. Some provenience information is inevitably relegated to tags thus increasing the potential loss of provenience.

The compound nature of the lot numbers assigned to any one provenience also increases the likelihood of an error being made in at least one part of the sequence. Although these sorts of errors can usually be resolved by cross-checking various sources of provenience information, this process is very time consuming and therefore costly.

Finally, mixed alphabetic and numeric codes are not suited for most computerized data analytic or management applications. They necessitate either use of awkward protocols with the alphanumeric codes or creation of a converted numeric code system with risk of conversion errors. A converted code does nothing to lessen the afore-mentioned problems and poses the choice of relabeling specimens, working with a conversion table when manipulating specimens with alphanumeric labels in relationship to computerized numeric provenierice records, or carrying the alphanumeric code along with the converted numeric code as a passive variable in all data manipulations and printouts.

\section{Analyses}

Preliminary analyses and initial drafting of a report of investigations were begun by TXDOT archeologists after completing the fieldwork. In conjunction with traditional studies ofthe artifacts underway by TxDOT staff, five categories of biological material were submitted to outside specialists for study. Sediment samples were evaluated for the presence of pollen by Vaughn M. Bryant, Jr. (Texas A\&M University); macrofaunal bone and the human skeletal material were analyzed by D. Gentry Steele and his students atTexasA\&M University; microfaunal samples were analyzed by Alissa Winkler of the University of Texas Vertebrate Paleontology Laboratory; and molluscan fauna were analyzed by Raymond Neck, then with the Texas Parks and Wildlife Department.

Holloway and Bryant (n.d.) reported pollen to be insufficient in quantity and quality for worthwhile analysis. Steele and Powell (1992, 1993, 1994, n.d.) studied and reported the Burial 2 remains and Steele continued with the project and contributed to the present report (see Chapter 31). Baker (1994) concluded an initial study of the macrofaunal bone under Steele's supervision; this team, too, has continued with the project and conducted a more-comprehensive analysis and interpretation (see Chapter 33). Winkler (1990) published a report of findings on the microfaunal sample. Neck, too, concluded an analysis ofTxDOT materials (Neck n.d.) and continued with the TARL phase of analysis, contributing to Chapter 37.

\section{TARLINVESTIGATIONS}

\section{Assessment of the TxDOT Documentation}

In January 1991, TARL began a review and evaluation of documentation and collections associated with the TXDOT archeological investigations at the Wilson-Leonard site (41 WM235). The three purposes of this effort were to inventory and assess all existing documents from the 
TxDOT excavations, to write a statement of the site's significance at regional, state, and national levels, and provide recommendations to TxDOT concerning subsequent phases of analysis.

This study presented $1 \mathrm{O}$ recommendations: (I) continue the comprehensive treatment of the primary documentation in order to prepare it for analysis and curation; (2) scale the analytical/interpretive effort in each part of the site to data quality; (3) conduct background research to further establish research issues and questions; (4) determine the status of on-going special studies in order to continue those worthy of pursuit and initiate other special studies that could provide new and important types of data comensurate with the unique potential of the site; (5) conduct a limited excavation ("witness column") of the full sediment column adjacent to Block 6 and the FSU to collect special samples for new special studies; (6) conduct a standard and systematic description and analysis of the large volume of materials collected by the TxDOT excavations; (7) conduct detailed analyses of certain data sets in order to better interpret the site; (8) conduct an intensive effort to establish a reliable absolute chronology for Burial 2 and the remainder of the site; (9) evaluate, interpret, and report the entire body of data in reference to specific research themes such as culture chronology, site formation processes, horizontal structure of isolable components, lithic technology, human ecology/subsistence, archeological systematics, and human biology (see Chapter 5); (10) prepare all materials for curation and transfer to a curation facility.

\section{2-1994 Excavations}

Additional fieldwork was proposed in order to collect a series of samples and information from the surface to bedrock immediately adjacent to the large TxDOT block excavation. Additional excavations would serve three purposes, the first to obtain specific samples for special analyses $\left({ }^{14} \mathrm{C}\right.$, micromorphology, phytoliths, microfauna, archeomagnetic analysis of burned rocks, and others) from a set of excavated squares adjoining the TXDOT excavations, especially Block 6. A number of new techniques were developed or significantly refined during the 10 or so years since the excavation, and application of these new techniques would provide important new insights on the Wilson-Leonard site. The strategy of excavating new squares adjacent to the 19821984 excavation would link the new information directly to the older excavated material. The second objective for the new excavations was to give the TARL team direct experience with the site and the sediments from the site. Multiple stratigraphic schemes were used in the original excavations. Without viewing and analyzing the full sediment column, it was unlikely that the stratigraphic sequence could be understood with anything approaching a reasonable level of accuracy. Finally, a number of inconsistencies and inadequa- cies in the 1982-1984 records could not be resolved without further field investigations.

\section{Relocating the TxDOT Excavations}

As stated above, the TARL excavations were planned to be adjacent to the TxDOT excavations, but no surface datum or other landmark survived highway construction (Figure 3-12). However, at the end of the 1982-1984 excavation, TxDOT surveyors mapped the corners of the excavation perimeter in relation to the centerline of RR 1431. In December 1991, TxDOT surveyors replotted the perimeter of the 1982-1984 excavation, and a map was prepared using one of their mapping points ( $\mathrm{Pt} 40)$ as a temporary datum. A nail was placed in a tree in the right-of-way. This nail served as an arbitrary elevation point. The 1991 mapping used magnetic north as azimuth. Thenorthwestern portion of Block 6 was under the RR 1431 roadbed, while the southeastern portion of Block 6 and the FSU were immediately adjacent to the existing roadway. The orientation of the trench placed the extreme southeast corner of Block 1(E22/S 100) adjacent to the right-of-way boundary fence and the "slit trench" and the "Gradall Excavation" extended into the existing RR 1431 roadway. In general, the Block 1-Block 4 trench was oriented diagonally across the existing right-of-way. The location of the TxDOT excavation in relation to the existing roadway presented some logistical and safety concerns. These were addressed by a plan developed and implemented by the TxDOT District Office. TARL also developed its own safety plan for the excavations.

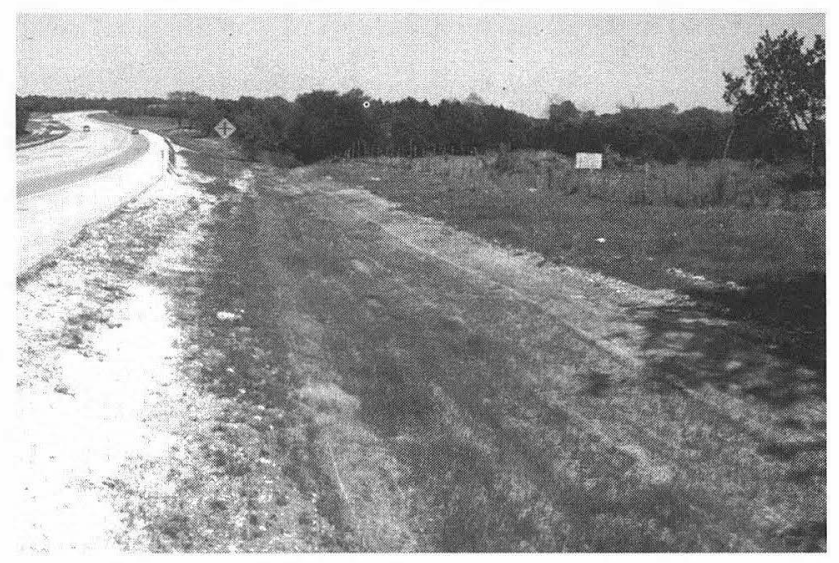

FlouRE 3-12. The Wilson-Leonard site as it appeared in the spring of 1992 prior to TARL excavations. View is toward the northeast, and RR 1431 is at left with the bridge across Brushy Creek in the distance. TxDOT excavation Block 6 was located in the middle ground of this scene.

\section{Opening the Excavation}

During the first week of fieldwork in June 1992, TxDOT set thirteen 30-foot steel I-beams vertically in bedrock and cement along the edge of the roadbed as shoring to 
keep RR 1431 from collapsing into the open excavation pit and provide a protective wall between the excavation and highway traffic (Figure 3-13). TxDOT also built a coffer dam upslope of the excavation block and placed a drainpipe between the highway and I-beams in order to direct slopewash around the open excavation block. Finally, the entire operation was enclosed with a fence and a guard was hired to protect the site from looters and protect interested individuals from falling into the deep excavations during nonexcavation hours. These efforts set the stage for beginning the TARL excavations.

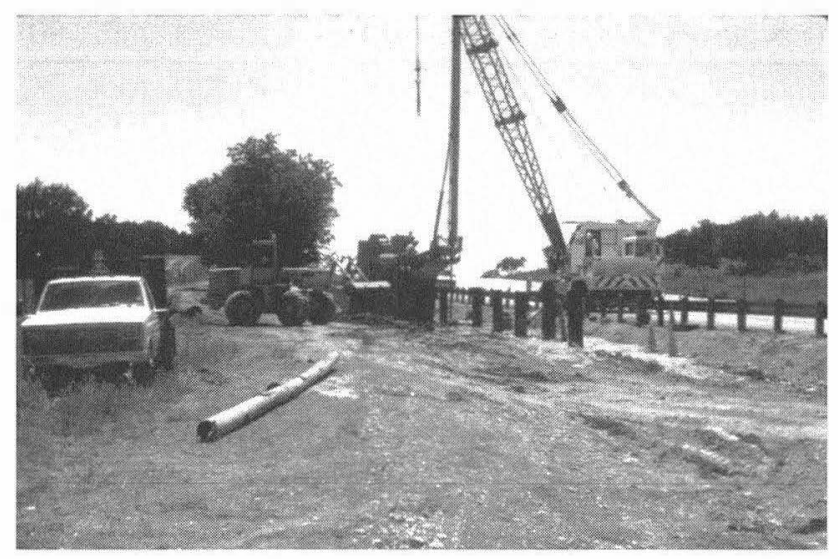

FIGURE 3-13. Installation of steel I-beams along east side of RR 1431 prior to TARL excavations, June 1992.

The fust step of the TARL excavations removed backfill from the southeastern portion of Block 6 and the FSU using a Gradall in an attempt to re-expose the original walls of the 1982-1984 blocks (Figure 3-14). A triangular pit was opened exposing the east and south walls of Block 6. The hypotenuse of this triangular pit extended from the northeast corner (E26/S72) to the southwest comer (E22/S78) of Block 6. An earthen stairway was cut in the southern portion of the open pit and it extended up through the backdirt that filled Blocks 3 and 5.

After the excavation in the main block had begun, two squares were opened along the Block I-Block 4 trench. These squares were labeled Squares I00 and IOI and their primary purpose was to obtain new samples from the burned rock midden known as BRM 1 (see Figure 31). The TxDOT trench was first identified by cutting a perpendicular trench with a backhoe. A geological profile was made from the trench wall, and then Square I00 was laid out, followed by Square 10I.

At the beginning of excavations, TARL also provided site tours two afternoons each week to interested individuals and groups. During the course of the excavation approximately 900 people visited the site during these tours.

\section{Setting and Maintaining the Grid}

Remarkably, all but the uppermost part of the walls of the original excavation survived along the south side of

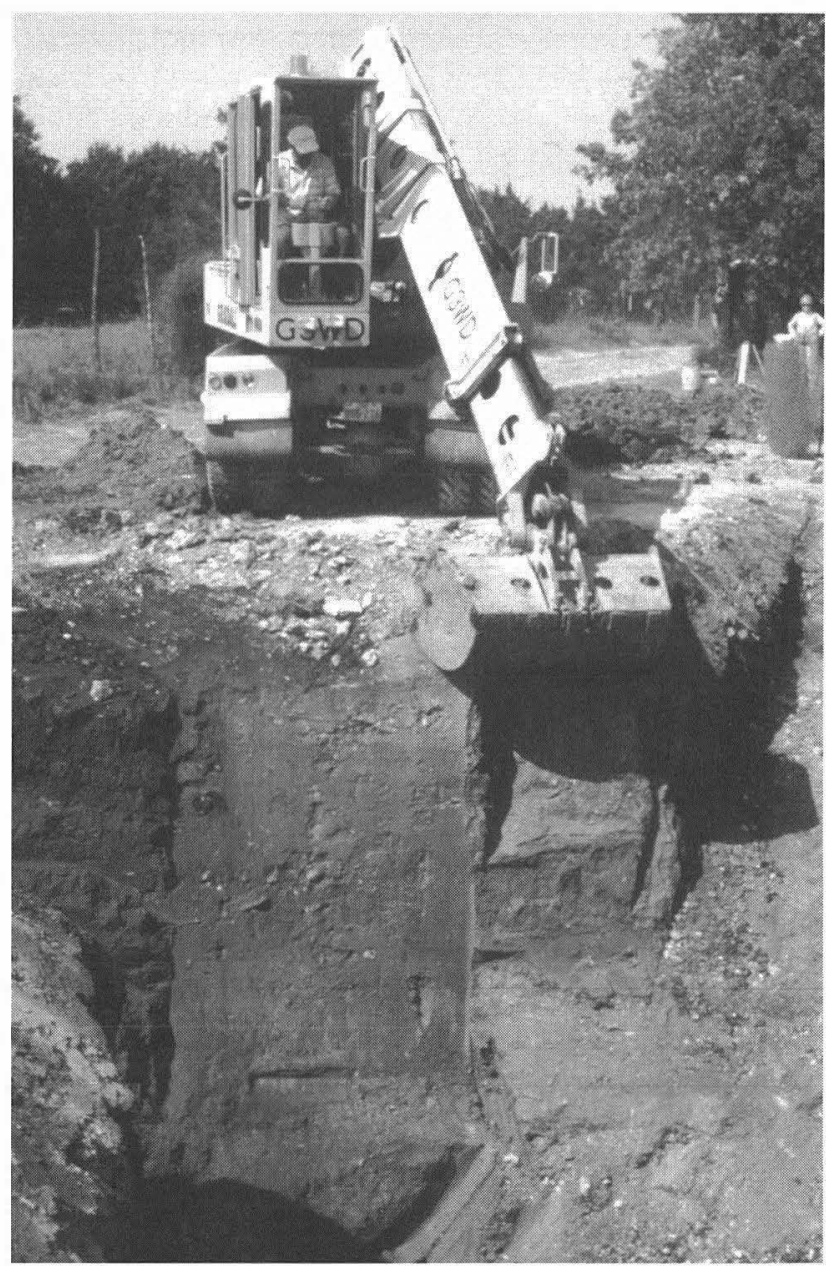

FIGURE 3-14. Gradall cleaning out TxDOT Block 6 in June 1992. View is toward grid south and the intact south face of Block 6 is visible to the left of the Gradall bucket.

Block 6 and the south, east, and north walls of the FSU. The lower portion of the Block 6 east wall was also found intact. Once the walls were cleaned by hand, some original TxDOT elevation nails, flagging tape, and even stratigraphic score marks were found on the TxDOT excavation walls. Since no permanent datum was placed on the site during the 1982-1984 field season, the 1992-1993 excavation was aligned with the previous excavation by sighting along the original excavation walls with plumb-bob and transit. Not surprisingly, the 4-5-m-high walls were not perfectly flat vertical planes. The placement of the north and east grid points was averaged between all possible alignments. In retrospect, it appears that the north-south TARL excavation grid point is very close $( \pm 2 \mathrm{~cm})$, but the east-west TARL grid point is approximately $9 \mathrm{~cm}( \pm 2 \mathrm{~cm})$ too far to the east. Since it was obvious that the alignment parallel with the south wall was the most accurate, grid north was established by aligning the transit along the south wall and turning exactly $90^{\circ}$ clockwise to the direction of grid north. The remaining grid was laid out with a transit and metric tape. 
The TARL excavations, like the TxDOT excavations, had difficulty in maintaining the grid. Initially a transit was used to periodically reestablish the grid. But the easiest and most effective method, especially after the excavation began to gain depth, was to place sets of two cotter pins on opposite profiles on perpendicular gridlines and stretch the strings tautly. The intersection of the two strings directly overlaid a grid point that could be placed on an excavation floor with a plumb-bob. The strings could be stretched at anytime by a single crew member and the grid reestablished with a fafr degree of accuracy.

Although an effort was made to relocate the vertical datum from the 1982-1984 excavations, it was necessary to conduct the 1992-1993 excavations using a new elevation datum. It proved to be $63 \mathrm{~cm}$ lower than that of the TxDOT datum, so throughout the analysis and in this report, TxDOT elevations have been corrected by subtracting $63 \mathrm{~cm}$ from TxDOT elevations as originally recorded in order to have all of the excavations tied to a single elevational system.

At the conclusion of the excavation, two permanent datum points consisting ofrebars set in concrete were placed along the north-south axis of the excavation and the site mapped as it existed in 1993 (Figure 3-15). These were placed on the Archaeological Conservancy's Marjorie Ashcroft Wilson Archaeological Preserve, where they should remain in place for future investigations.

\section{Excavation Procedures and Methods}

The concept behind the excavation strategy was to remove sixteen $1-\mathrm{x}-1-\mathrm{m}$ squares along the east and south faces of the old excavation block.(Block 6 and the FSU; Figure 316). In this manner, the various forms of data collected by the TARL excavations would be immediately adjacent to the best-documented and most-complete stratigraphic section from the TxDOT excavations. The initial TARL excavation crew was large ( 27 people) and members had varying levels of education, ability, and experience. In order to facilitate standardizing excavation procedures and recording information, a I-day orientation meeting was held where the excavation procedures and methods and the various excavation forms were reviewed.

Crew members were asked to complete level records for each excavated level in each square, feature records when appropriate, and draw plan maps when necessary. Level record forms required systematic information on the sediments, elevations, features, artifacts, and excavation and screening methods. Elevations of the middle and each corner were recorded for each level of each square. At the beginning of the excavation these elevations were taken with a transit, but work progressed too rapidly to continue this strategy, and later elevations were usually determined with a hand tape and a line-level on a string strung from a known elevation nail set with a transit. Elevations were also collected for most point-plotted data such as special samples, features, and the like. Also recorded on the level forms were sample lists and sample numbers for any type of collected sample, lists for associated documents such as plans, and lists of photographs. Plan maps show features, any associated artifacts or materials, and provenience and elevations.

Separate forms were used for features. These provide a record for each recognized feature and include provenience information as well as special sample lists, geological information, and discussions of archeological materials. Plan maps showing artifact distributions and features as well as cross-section profiles were also drawn when possible. If archeomagnetic or other special samples were collected, the location and number of the sample was plotted on the feature maps.

Initially the crew consisted of excavators, screeners, a site materials manager, a photographer, block supervisors, and the directors. Personnel were rotated between excavating and screening. A single photographer took all photographs and was responsible for keeping detailed records of the photographs. To help organize the flood of paperwork and materials flowing into TARL, a portable combination storage shed and office was moved on-site. This provided work space for people to write field notes, check field records, store all excavation equipment and materials, and escape a few heavy downpours.

The excavation period was originally planned to extend from June 29 until October 16, 1992 with a crew of approximately 27 people in the field. A concurrent lab was also operated with approximately 5 people, as was a sediment washing and matrix sorting operation at the Laboratory for Vertebrate Paleontology with 3 to 5 people. However, by mid-October the excavation had not reached bedrock, and work was continued but with a smaller crew. After October, the crew varied but hovered at approximately 15 field crew members. The excavation ceased after eight months in February of 1993.

The first excavation task was to excavate two 1-x-1-m squares to bedrock, starting from existing TxDOT squares on the bottom of the old excavation floor. Recovery from these two squares would quickly demonstrate whether or not archeological materials were present below the bottom of the TxDOT excavations and, if so, to what depths and in what quantities. These were labeled Test Squares A and B, and they continued existing TxDOT squares (NE quad of E26/S74 and SE quad ofE26/S78, respectively; Figure 3-17). TxDOT records and discussions with TxDOT crew members indicated that excavation of sediment in these squares would be tough and thus work proceeded with trowels, small hand picks, steel bars, and shovels.

When the backdirt was removed from the TxDOT excavations it was revealed that the top of the old profiles had collapsed or had been cut back. This created a sloping profile rather than a straight vertical wall. This forced a revision in the TARL excavation strategy. The 1992-1993 excavations would be required to step back a full meter along the south 


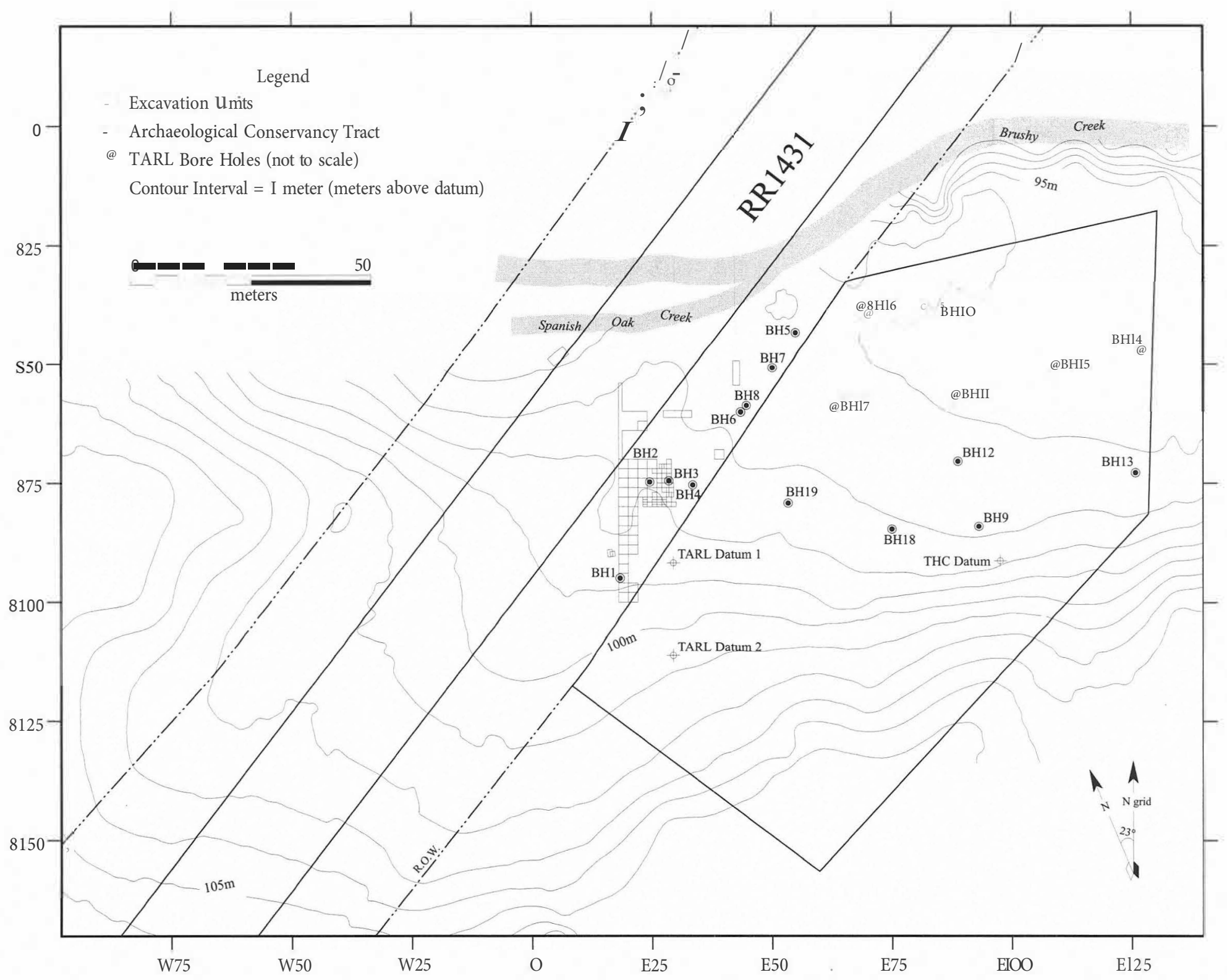




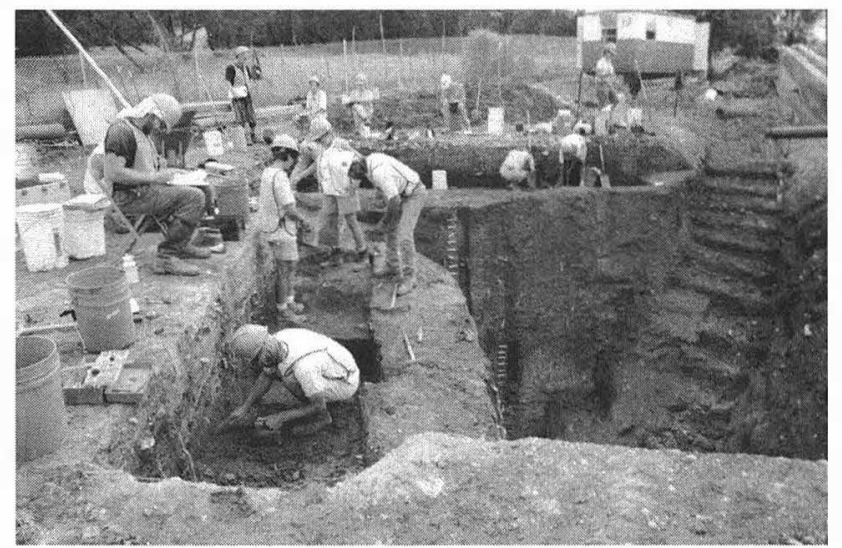

F1GURE 3-16. TARL excavations in progress. View is toward grid south and shows the eastern block at left and the southern block in the distance. The south wall ofTxDOT Block 6 and the steps cut into the backfill ofTxDOT Blocks 3 and 5 are also shown.

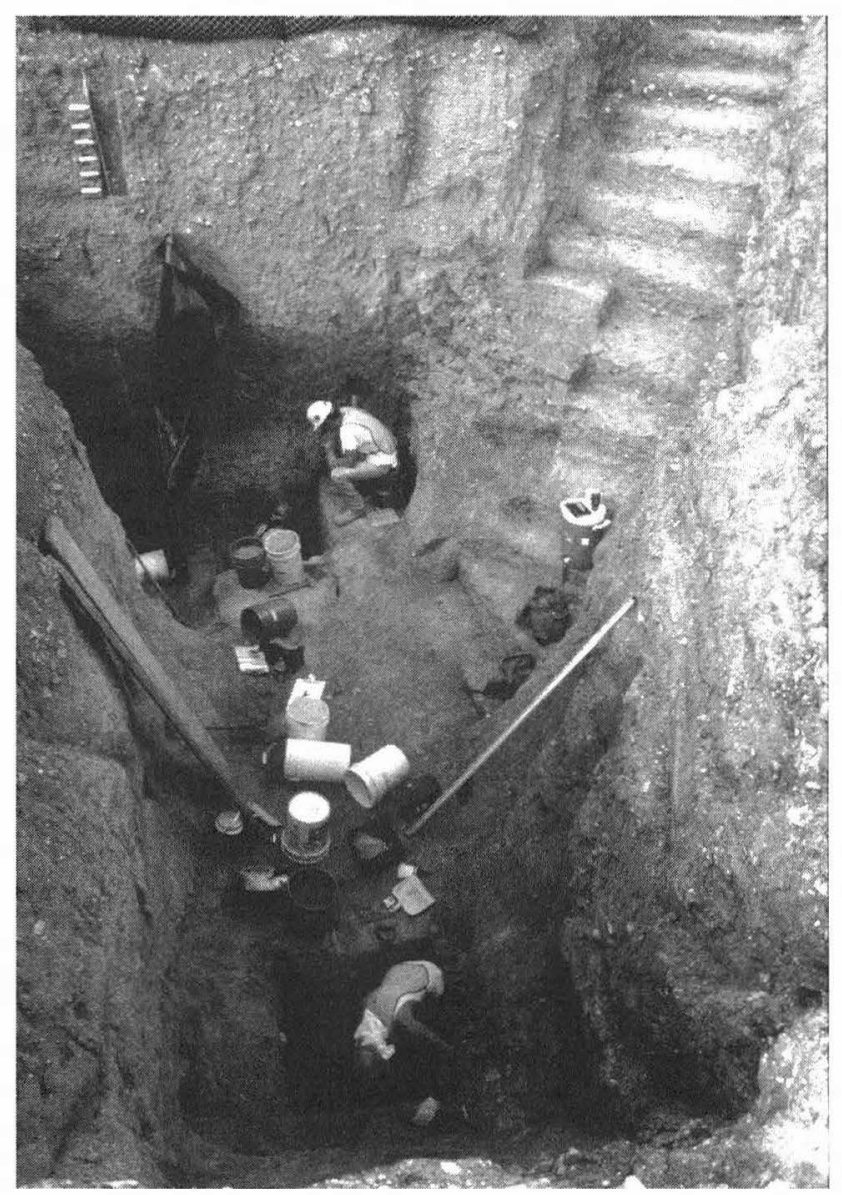

FIGURE 3-17. TARL excavation in progress in Test Unit A (middle ground) and Test Unit B (foreground); view it toward grid south.

and east walls. Initially two blocks were laid out. The first was on the south wall of Block 6 and consisted of seven squares numbered 11 through 17 (the "South Block"). The second was along the east wall of Block 6 and consisted of five squares numbered 18 through 22 (the "East Block"). As the contour of the open pit allowed, the TARL squares would step-out as far as permitted in I00- or 50-cm increments (Figures 3-18 and 3-19). Squares were numbered consecutively. Initially, new squares adjacent to the FSU were not opened, but as work progressed in the south and east blocks, additional squares were opened around the FSU. Two squares (Square 12 on the South Block and Square 20 on the East Block) were excavated in a single vertical column from surface to bedrock. These squares would provide vertical samples from top to bottom from single squares where superposition could not be questioned. Thus these squares were designated for collecting a variety of specialized samples (microfauna, snails, phytoliths, micromorphology, radiocarbon, and others). Ultimately, 21 full and partial units were dug in the South Block; and, 23 in the East Block.

These 44 squares plus the 2 test units (A and B) dug in the floor of Block 6 and the 2 squares $(100, \mathrm{OI})$ dug in Burned Rock Midden 1 would seem to represent a much greater excavation effort than the planned 16 squares, however, the total volume actually excavated from these 48 $\left(86.9 \mathrm{~m}^{3}\right)$ is close to that projected for the originally planned 16 units that were expected to average between 5.5 and $6.0 \mathrm{~m}$ in depth (giving total volume estimates of 88-96 $\mathrm{m}^{3}$ ). Also, because of the stepped nature of many of the units (see Figure 3-19), the actual total area excavated in the 48 units is only about $37 \mathrm{~m}^{2}$ (see Figure 3-1 ).

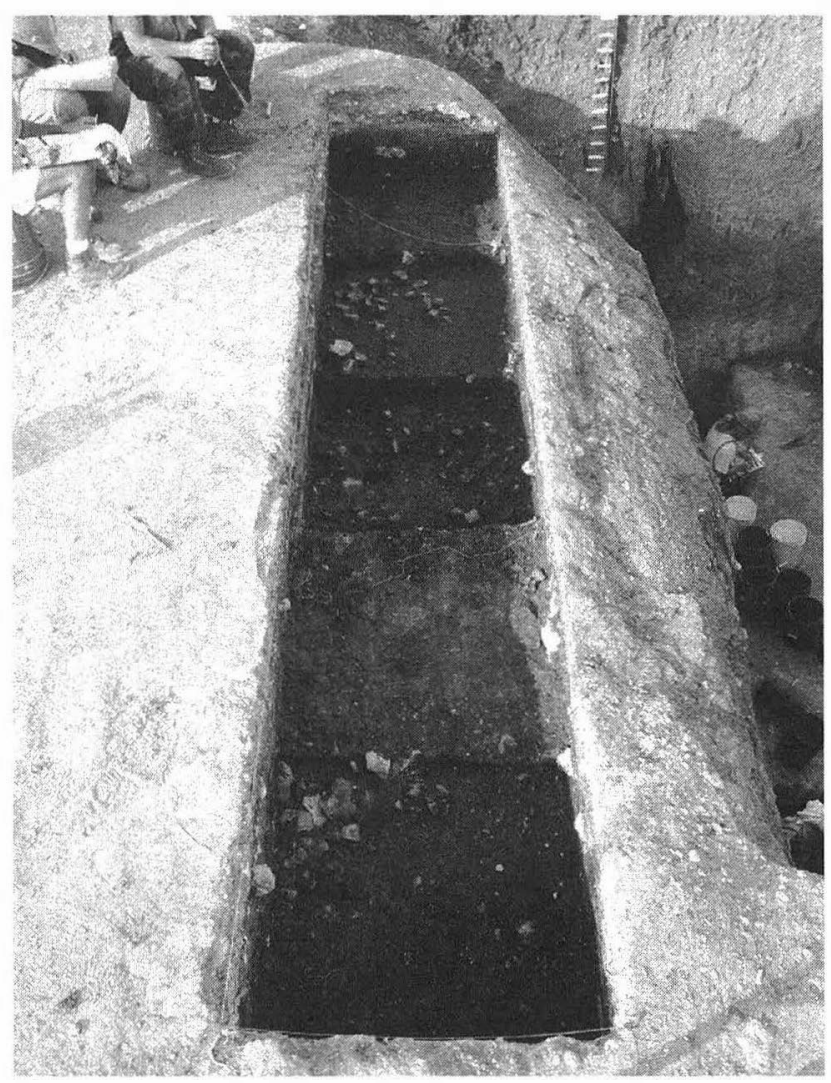

F1GURE 3-18. Initial stage ofTARL excavations in Squares 18-22 (the East Block) along the east side of TxDOT Block 6. View is toward grid south. Note sloping south wall of Block 6 that necessitated a $1 \mathrm{~m}$ setback for the TARL excavation squares. 


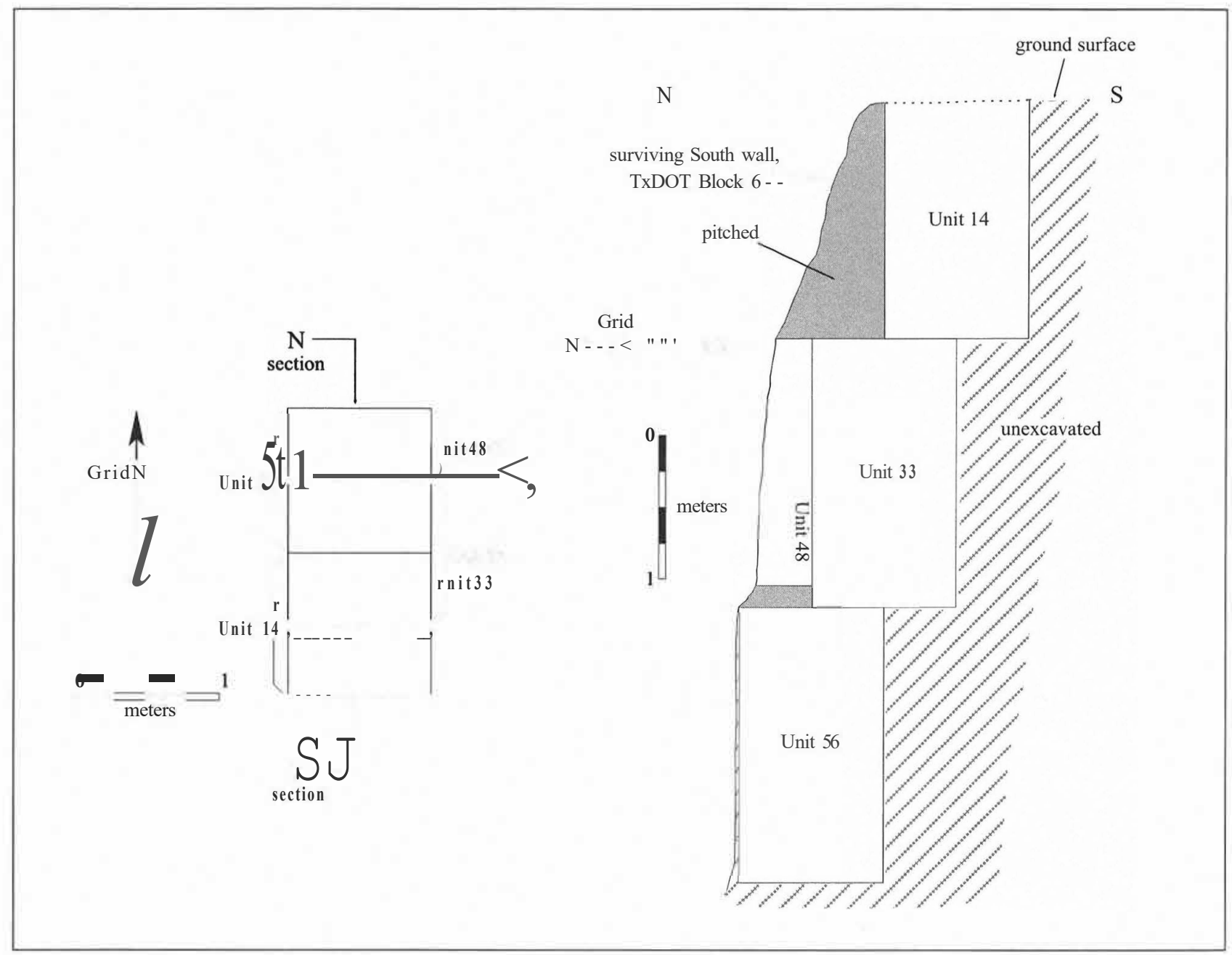

FlaiRE 3-19. North-south section through TARL excavation Squares 14, 33, 48, and 56 illustrating the nature of the stepped excavations; analogous steps were employed in columns beginning in TARL Squares 11, 13, 15, 25, and 37.

In order to maintain provenience information and separation of individual lot assignments, the TARL excavation employed a system whereby each excavator could subdivide individual excavation levels and discriminate between feature and nonfeature contexts as well as between stratigraphic zones occurring within an arbitrary excavation level. This was done by assigning level subdesignations (-a, -b, c, etc.) to subunits and the resultant subsamples. For example, the beginning of every level, with or without a letter subdesignation, was assumed to be "-a." Ifa feature or other stratigraphic boundary was encountered, the matrix and artifacts from it were kept separate by assigning them to level "-b." In this sense, a feature was treated as a stratigraphic break.

From the beginning, the open pit presented logistical and safety problems, and consequently, scaffolding was erected in the bottom of the TxDOT excavations (Figure 320). One line of scaffolding flanked the southern block and a second flanked the eastern block. When excavations began around the FSU, the southern set of scaffolds was extended into the FSU opening. As the excavations proCf $<$ led down, the work surface of the scaffolds could be lowered to match the excavation level. Besides simplifying excavation logistics, the scaffolds proved to be a safety feature as well. A hand-cranked winch was also installed on the north end of the TxDOT excavation pit, allowing buckets to be lifted to the surface without transporting them by hand up the earthen stairway.

The 1992-1993 excavation consisted of digging by arbitrary levels and stratigraphic breaks, when recognized. The arbitrary levels shifted between 5 or $10 \mathrm{~cm}$, but variations did occur. In order to better relate arbitrary levels to stratigraphy, nails with flagging tape were placed into the back wall at the corners of each excavated level in each square. Level nails were plotted on stratigraphic profiles that directly linked arbitrary levels to stratigraphy and also accurately recorded the actual depth of each arbitrary level. Color and black and white photographs were taken at the beginning and end of each day, and the bottom of each finished level; photographs were also taken of each feature. 


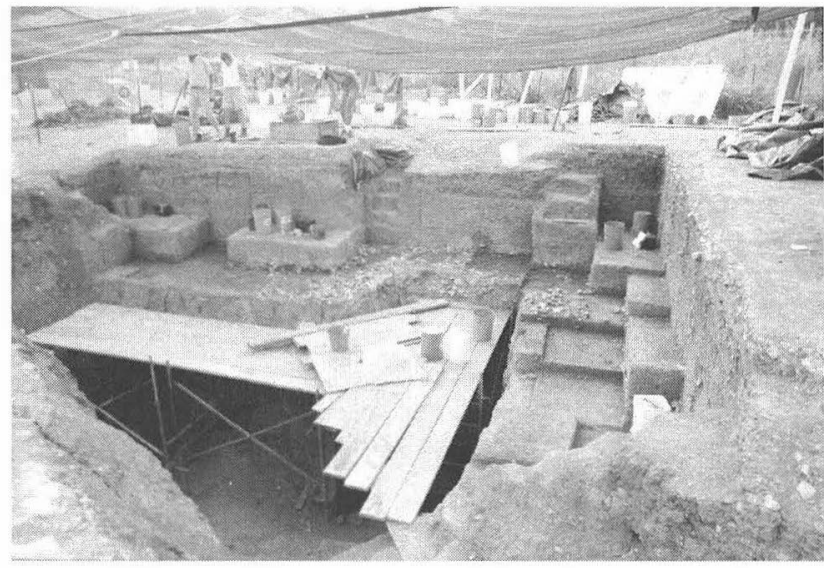

FIGURE 3-20. Scaffolding in place during TARL excavations. View is toward grid east. Note stepped nature of the excavation blocks east and south of the scaffolding.

The squares were excavated at different rates mainly due to the speed of various crew members, delays caused by feature recording, and, especially in the upper levels, the logistical need to stagger excavators in adjacent squares. The crew used a variety of hand tools for excavation, but primarily shovels and trowels as well as hand picks were used. One of the effects of the staggered excavation method was that square plans were drawn at different times and by different individuals. This presented a problem that was especially serious for the Early Archaic levels in stratigraphic Unit IIIa. Here a complex set of interlocking burned rock features, partially exposed by TxDOT, was expected, and it was imperative to obtain a good consistent floor plan of the entire complex. Thus a single crew member was assigned the task ofpreparing a floor plan of this feature in all the squares were it was exposed and as it was exposed. This was drawn at a different scale than the normal floor plans, and it was called the composite plan map.

Stratigraphic profiles were drawn at various times. However, at the beginning of the excavations, profiles were drawn of the existing walls and included the stratigraphic scoring marks extant on the old TxDOT walls and the position of the remaining elevation nails. At the conclusion of the TARL excavations, detailed profiles were drawn of each existing wall. Besides including the boundaries of all recognized stratigraphic units, these "finish" profiles also record the locations of all level nails. In this way, a clear correlation can be readily made between the TARL excavation levels and the recorded stratigraphy. Detailed photographs were also taken of each wall so that the drawn profile could be compared to a color and black and white photographs.

Six water screen stations were set in a row against the back (east) side ofthe right-of-way (Figure 3-21 ). Two pumps were placed in Brushy Creek with feeder hoses leading to the screens. A "pump crew" responsible for the daily setup and maintenance of the pumps and a screen supervisor were assigned. Sediment runoff from the water screens was channeled

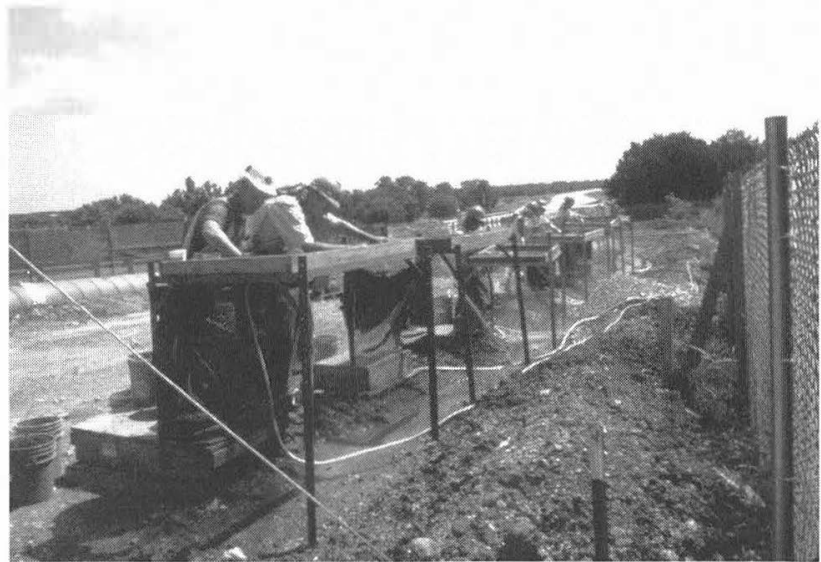

FIGURE 3-21. Water screens in use during TARL excavations.

into a earthen holding tank. The runoff never exceeded the capacity of the holding tank. Natural water infiltration rates through the structure and soil surface usually dispersed the daily water ration. A silt trap was installed downslope of the holding tank by TxDOT, but the earthen holding tank was such an effective filter that the silt trap was seldom used except after heavy rains when extraneous surface slopewash from adjacent slopes washed into the filter. Accumulated sediment was removed from the holding tank on a few occasions. Toward the end of the excavation season when the push to finish fieldwork was critical, water screening on-site was stopped and sediment stockpiled. A large amount of sediment was transported to TARL and the water screening was finished on the grounds of the University ofTexas Pickle Research Campus after the excavations at the site had ended.

All sediment from all squares (excluding Squares 12 and 20) was passed through $1 / 8$-inch hardware cloth using pressurized water sprayed through garden hoses. Material that did not pass through the $1 / 8$-inch screens was sorted on the screen. All bone, artifacts, charred materials, a grab sample of snail shells, and anything unusual were collected. All other material was discarded. The overwhelming majority of the discarded material consisted of calcium carbonate nodules, modern flora primarily consisting of root fragments, and unburned limestone. Burned limestone recovered directly from the excavations and from the water screens was weighed and discarded on-site.

A system of bag numbers was used in the field to insure that all collected materials reached the laboratory. A single individual assigned bag numbers for all materials (artifacts from single levels, unique artifacts, special samples such as Vertebrate Paleontology sediment samples), maintained a list of bag numbers, and tracked the movement of bags to the TARL laboratory. Missing numbers could be readily identified and searches for missing bags could begin the same afternoon or next day.

All sediment from Squares 12 and 20 was transported to the Vertebrate Paleontology Laboratory at The University ofTexas J. J. Pickle Research Campus. There the sediment 
was washed through fine-screen mesh by a procedure described in Chapter 34. These samples were collected in large cloth bags, marked with sharpies, and further marked with unique combinations of colored flagging tape for each level of each square. Materials could then be stored and retrieved by flagging tape color.

At the conclusion of excavations, the site was immediately backfilled. TxDOT District personnel assisted with the use of a front-end loader. Since all sediment was water screened, very little was available on-site for backfilling. The local TxDOT district hauled archeologically sterile dirt to the site and filled the TARL excavations with the foreign sediment.

\section{Geological Investigations}

The geological investigations were designed to provide new data on the geological context of the site and its archeological components, especially in tenns of site formation processes. Prior to the TARL excavation, data on samples from the TxDOT excavations and from cores drilled by TARL were used to frame the TARL field strategy. Paul Goldberg, then ofTARL, was scheduled to conduct a detailed geological investigation, including a micromorphological analysis of sediments. Vance T. Holliday had conducted a preliminary geological study of the site in 1983 (Holliday 1992, n.d.), but his system was not used by nor integrated into the TxDOT orTARL excavations (see Chapter 6 for discussion).

The first step of the TARL geological studies was to extract and process micromorphological samples from a sediment monolith previously collected by the TxDOT excavation team. The intended purpose was to identify Holliday's soil/stratigraphic units, however, the most important result of this limited effort indicated that the sediment column had suffered from extensive small-scale bioturbation by earthwom1s. This indicated that the sampling strategy for radiocarbon samples especially needed to consider the stratigraphic context of each sample.

Additionally, the depth and thickness of the alluvial deposits in the site area needed to be established in order to develop a realistic excavation plan. In early 1992, three days were spent extracting six cores from the right-of-way between Pt 40 and Brushy Creek. A coring rig with a hammerdriven core barrel was used and six cores were obtained (Figure 3-22). These cores indicated that the sediment column was approximately $6.5 \mathrm{~m}$ deep and bedrock sloped down, but only slightly, toward the creek. Review ofTxDOT records showed that their excavations stopped at approximately $5 \mathrm{~m}$ below the surface and artifacts were still being recovered. This suggested that additional archeological materials might still be present below the TxDOT excavations. If so, these materials could be highly significant because of their age.

Inspection of the eastern and southern profiles at the beginning of the 1992-1993 field season failed to identify Holliday's stratigraphic units. Holliday was unfortunately

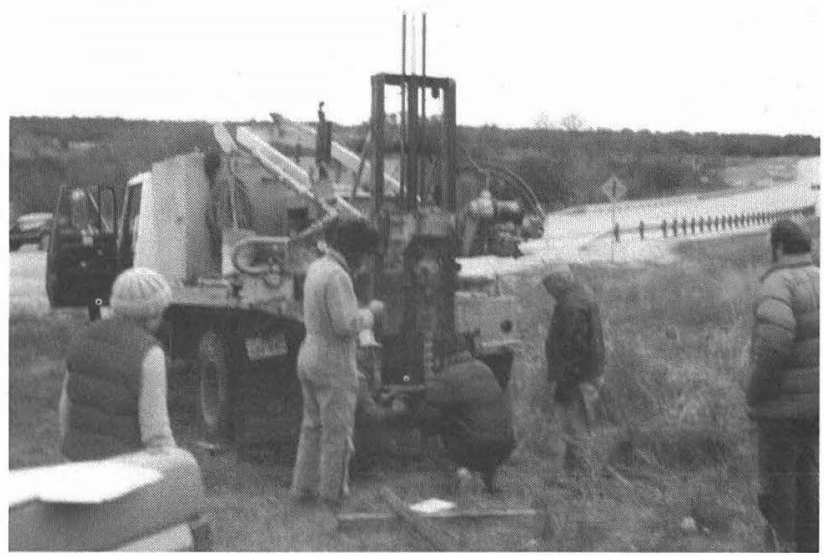

FIGURE 3-22. Core drilling at Wilson-Leonard in January 1992 prior to the TARL excavations. View is toward northwest with RR 1431 and the bridge over Brushy Creek in the background.

unavailable for a field visit immediately, and Goldberg formalized a new system consisting of three major stratigraphic units (see Chapter 6). The majority of geological data collected in the field consisted of profile descriptions and a series ofmicromorphological samples from four vertical columns and isolated samples. Additional micromorphological samples were processed using TxDOT sediment samples even though these were not collected for micromorphological analysis. Specially collected TARL samples, usually from feature contexts, were also obtained. Other collected geological samples included sediments for textural analysis, sediments for chemical analysis, and portions of Feature 231 in Square 51 and in Square 100 that were set in large plaster blocks.

At the conclusion of fieldwork and throughout the next few months ofanalysis, it became clear that the window into the site was limited, and several alternative interpretations concerning the accumulation of alluvial deposits were possible. In January 1994, 13 additional cores were drilled on the Archaeological Conservancy's Marjorie Ashcroft Wilson Archaeological Preserve with The University of Texas Bureau of Economic Geology's core drilling rig. These cores were not compacted, and familiar stratigraphic units could be clearly identified. A few months later, additional geological data were collected by C. E Mear on the local Quaternary geomorphology within the Brushy Creek drainage. Along with the on-site geological data, these additional observations resulted in a geomorphic map of the general area that provides a picture of late Pleistocene and Holocene alluviation in Brushy Creek. Also a detailed sequence of sediment accumulation was documented at the excavation locale.

Stratigraphic descriptions for the 1982-1984 excavations depended heavily on the west profile of the main excavation block that was inaccessible during 1992-1993. It was, therefore, necessary to develop a separate system for denoting the stratigraphy exposed in 1992-1993. In order to correlate these, the TARL designations were applied to the materials 
excavated by TxDOT to the maximum extent possible. This was accomplished by evaluating all written descriptions of matrix encountered by the excavators, TxDOT profiles, and especially TxDOT photographs. Color, texture, structure, content, position, slope, and all other aspects of any depositional unit were considered in making assignments of TxDOT-excavated matrix to the TARL stratigraphic system. This was a laborious process in which several members of the TARL analytical team participated.

\section{Radiocarbon Investigations}

From the outset, it was clear that a major effort was necessary to establish a reliable absolute chronology for the site and especially for Burial 2. Thomas Stafford (INSTAAR-University of Colorado) had already been involved in the AMS radiocarbon dating of Burial 2. Stafford agreed to take on the larger problem of developing a radiocarbon chronology for the site. The details of the radiocarbon methodology are presented in Chapter 25, but in summary, they include a number of important strategies. First, it was imperative that Stafford collect as many of the radiocarbon samples as possible. The general strategy employed for the radiocarbon investigations was to sample multiple sources of material from similar stratigraphic contexts and determine the most reliable radiocarbon chronology. Unfortunately, preservation of organic materials allowed for this degree of sampling in only a few cases. Specific sampling requirements called for secure stratigraphic placement of each sample along with recording the XYZ coordinates. As the radiocarbon analysis proceeded, each sample submitted to Stafford was reviewed and assessed by the TARL crew and by Stafford.

\section{Archeomagnetic and Magnetic Susceptibility Investigations}

The archeornagnetic analysis of burned limestone and magnetic susceptibility of sediments from the WilsonLeonard site was undertaken under the direction of Wulf Gose (Department of Geological Sciences, The University of Texas). Previous studies by Gose indicated that these analyses could provide detailed information regarding the formation of burned rock features, and the TxDOT excavations had uncovered an important series of burned rock features spanning all but the earliest part of the prehistoric record at the site. Thus, a large sample was collected for archeomagnetic analysis. Paul Takac coordinated collection of the archeomagnetic samples. About 1,300 samples were drilled using a portable gasoline-powered rock drill, labeled, and mapped; XYZ proveniences were recorded for each archeomagnetic sample as well. In addition to the archeomagnetic sample, certain parent rocks as well as a few nonburned rocks were collected from the excavations. As the excavation proceeded, a higher percentage of archeomagnetic parent rocks were collected.

Magnetic susceptibility measurement of sediments was undertaken to help identify stratigraphic breaks. Two columns were collected. One from the south wall of the TxDOT excavations and the other from the Square 20 east wall. Samples were collected initially with a square metal form and placed into small archeomagnetic cubes. Later a small hand pick was used to gather sediment into the cubes as small rocks and pebbles damaged the metal form.

\section{Paleodietary and Paleoeconomic Investigations}

Two primary sources of data were collected to provide information on the utilization ofanimal and plant resources. Fauna! remains collected from the 1/8-inch screens were sorted in the field and lab and sent to Gentry Steele and Barry Baker at Texas A\&M University for analysis. In addition, a number of sediment samples were collected for flotation processing. Usually these were from feature contexts, plotted on feature maps, and collected in plastic bags. Most of these were processed in the TARL laboratory and sent to Phil Dering (TexasA\&M University) for analysis of botanical remains. Large carbonized floral parts were also collected in the field and sent to Dering as individual samples. Susan Decker examined avian eggshell fragments. Leslie Shaw identified the freshwater mussels, and Diane Wilson assessed the stable isotopes of the Burial 2 skeleton as additional paleodietary evidence. These samples were plotted on feature maps and other appropriate forms and documents.

\section{Paleoenvironmental Investigations}

A number of lines of evidence were pursued in order to obtain independent sources of paleoenvironmental data. These data are essential to provide a background for interpreting environmental change. Both biased and unbiased sources of paleoenvironmental data were collected. Biased sources are those influenced by the behavior of the prehistoric human inhabitants of the site, while unbiased sources are those that are largely independent of any prehistoric behavioral influence. Both types of information were targeted.

The most voluminous special samples collected from the TARL excavations were the sediments for fine-screen washing (see below). However a number of other special samples were also collected by the excavation crew and a number of consultants. When possible it was deemed best to allow the various specialists to collect their own samples. This gave them a great deal more familiarity with the site and insured that samples were collected by correct procedures. Not surprisingly, this strategy was not always possible. Glen Fredlund collected all the samples from the stratigraphic column, but none of the feature samples for phytolith analysis. Barbara Winsborough collected samples for dia- 
tom analysis. Other specialists provided guidance for the collection of materials for their specific forms of data. Raymond Neck directed the collection of bulk sediment samples for the analysis of snails from Squares 12 and 20. These sediment samples were sent to Neck and he processed these for snail shell recovery through a series of nested screens. Additional samples were collected for other forms of analysis and for potential future analyses not yet identified. Samples were provided to Merv Kontrovitz for ostracode analysis and to Larry Tiezen for stable isotope analysis.

\section{Vertebrate Paleontology Water Screening and Sorting}

Two 1-x-1-m squares (12 and 20) were dug from surface to bedrock and sampled in bulk for fine-screen recovery. The details of this process are described in Chapter 34, but in essence, it consists of gently dissolving dried sediment and passing it through nested screens of $1 / 8$-inch and 1/16inch mesh in order to recover the small bones and teeth of environmentally sensitive fauna. Robin Balinsky, with guidance from E L. Lundelius, Jr., identified and interpreted the mircrofaunal remains recovered from one of the squares (20). A number of avian eggshell fragments were also recovered. Those have been analyzed by Susan Decker (see Chapter 36.

\section{Laboratory and Database Operations}

The materials recovered from the Wilson-Leonard site excavations were processed at the Texas Archeological Research Laboratory ofThe University of Texas at Austin. The laboratory methods were designed to maintain provenience controls and expedite the analysis phase by processing the materials simultaneously with the fieldwork. All procedures and methods employed were based on the Council of Texas Archeologists Standards of Data Analysis Guidelines Section 5.1 and the Texas Archeological Research Laboratory Stipulations and Procedures for Preparation of Archeological Records and Material Collections (Council of Texas Archeologists 1992; Texas Archeological Research Laboratory 1995).

\section{Field Laboratory System}

Prior to fieldwork, the Wilson-Leonard crew underwent an 8-hour orientation to the excavation procedures and methods of documentation. During the orientation, the field bag numbering system was explained and the category terms for material identification were defined. In addition to the orientation, each field crew member was given a field manual which presented the forms and explanation of the procedures for excavation and data control.

The item-to-provenience control system used for the 1992-1993 excavations utilized a field bag numbering approach to ensure that all excavated materials were accounted for and brought to the laboratory at the end of each workday. A field laboratory supervisor was designated to track the bag throughout the excavation process. Upon completion of an excavated level, a sample collection, or the point plotting of a specific item, the excavator requested a bag number and tag. The field laboratory supervisor provided the next bag number, labeled a water-resistent linoleum tag with the provenience data, and recorded the information onto the field bag inventory. Materials were then placed in plastic bags along with the labeled linoleum tag. Upon arrival at the lab, the bag numbers and provenience information were checked in and inspected for possible errors. When discrepancies were identified, the laboratory crew communicated with the field crew to resolve the problem the next day or at the end of each week. The data were then entered onto the laboratory computer.

\section{Laboratory Processing System}

The laboratory processing procedures were outlined in a manual specific for the Wilson-Leonard project's lot system. Forms were created on acid-free, lignin-free paper for the specimen inventories that were used to record provenience information, excavators, excavation date, lot number, and field bag number. Other forms were created for processing schedules, flotation, and transfer of materials to consultants. Once the materials were checked into the TARL laboratory, a lot numbering system based on unique provenience was employed. This system assigned sequential lot numbers to each new provenience containing unique information. All materials related to a specific provenience were grouped from the inventory database and assigned the same lot number. Each excavation level within a unit was assigned a lot number while point-plotted items or samples within these same levels were assigned their own lot numbers, since they had more-specific provenience data. Specimen numbers were assigned sequentially to all lithic tools within a given lot number. This system allows for all provenience information to be tied to a lot number and controls for itemspecific analysis. A drawback to this system is that it is dependent upon a key to correlate all provenience data related to the lot numbers. With today's database software, there are myriad benefits that include efficient data manipulation, rapid retrieval capabilities, and complete provenience control methods for all materials associated with the investigations.

Most categories of lithic materials were gently cleaned and placed on drying racks along with other materials from the same bag provenience. After drying, the materials were transferred to the inventory table to be counted or weighed, labeled with Pelikan 17 black ink and coated with a 10\% solution of Polyvinyl Acetate Resin AYAF (PVA) dissolved in Acetone. The items were then left to dry and later placed in polyethylene bags with acid-free, lignin-free tags. Each item was then placed in the appropriate category box for 
analysis. Special samples, such as organic residue specimens collected in aluminum foil pouches by excavators, were not opened in the lab. Charcoal and ${ }^{14} \mathrm{C}$ samples, however, collected in foil pouches were opened in the lab to air $d_{r y}$. Other samples such as humates, pollen, phytolith, or thermoluminescence samples were not opened but simply inventoried and tagged with the necessa ${ }_{\mathrm{ry}}$ information and set aside for later analysis. Soil samples were collected in large cl0th bags which allowed moisture to escape thereby negating the need to open them to air $\mathrm{d}_{\mathrm{ry}}$ in the lab. Bone was not washed upon request of the analysts but air dried.

Flotation samples were processed at the TARL laborato $_{\mathrm{ry}}$ using the bucket-to-bucket method. This method, taken from Texas A\&M procedures in use since the 1970s, consists of pouring a 2-liter float sample in one bucket and adding 6 liters of water, then gently stirring with a rubber spatula to break apart sediment thereby releasing any botanics into the water. The mixture is then allowed to settle for $45 \mathrm{sec}-$ onds, permitting the soil to settle to the bottom while the fine fraction remains suspended in the water. The water is then poured into a second bucket through a $.45-\mathrm{mm}$ screen capturing any botanical materials in the screen. The water from the second bucket is poured back into the first, and the process is repeated at least two more times. A poppy seed spike (50 count) is added to particular soil samples prior to floating for control and demonstrates the efficiency of the flotation process. The Wilson-Leonard flotations yielded a recovery rate of $80 \%$. This bucket-to-bucket method generally takes 12 minutes per sample. The soil residue from the floats was then processed through an 1/8-inch hardware mesh screen to recover any artifacts that were then sent through the inventory and cataloging process.

Special procedures were used in the field for extracting sediment peels and the removal and storage of large unexcavated blocks offeature matrix. The extraction of sediment peels was accomplished by Goldberg, TARL, and by Jessica Johnson of the Texas Memorial Museum Materials Conservation Laborato ${ }_{\mathrm{r}}$ of The University of Texas at Austin following procedures outlined in Goldberg (1974). The blocks offeature matrix were taken by cutting back the area around the block and applying plaster bandages to the outer edges and top. The block was then lifted out and let $d_{r y}$. The bottom was then plastered and provenience information and directional arrow marked on the outer surface. These samples were transported to the laborato $_{\mathrm{ry}}$ for eventual curation.

\section{Coordination of TxDOT and TARL Lot Number Systems}

As previously noted, the 1982-1984 TxDOT Jot numbering system allows the analyst to translate the lot number to its general provenience, but it does not provide for feature or point-plotted information to be transmitted to the lot number. Because all 1982-1984 documentation and materials relate to the TxDOT alphanumeric lot system, it was essential to continue their system throughout the analysis. Early in 1991, the TxDOT invento $_{\mathrm{r} y}$ data were entered onto a database using dBase III. The database was later exported into Boreland Paradox 3.5, printed out, and then each catego $\mathrm{r}_{\mathrm{r}}$ of materials was checked in by laborato ${ }_{\mathrm{ry}}$ technicians. This process allowed the lab to identify any missing materials as well as correct any data ent $\mathrm{r}_{\mathrm{y}}$ errors. Also at this time, specimen numbers were assigned and labeled onto each lithic tool artifact. In most cases, the TxDOT lot number did not have to be removed in order to add the specimen number and a coating of PVA applied over the entire lot number.

\section{Computer Database Management}

The project utilized two 386 and four 486 PC computers, three HP DeskJet printers, one HP Laser printer, and one HP scanner. After an investigation into commercial software database programs available, Boreland Paradox 3.5 was chosen for its versatility, speed, compatibility, and flexibility in programming. Other software utilized during the project included Microsoft Word 2.0 and 6.0 for Windows and Microsoft Excel 5.0 for Windows. Two primary Paradox databases were created for the TARL and the TxDOT excavated materials, respectively. The prima ${ }_{\mathrm{ry}}$ databases were checked for data ent $t_{\mathrm{ry}}$ errors and two back-ups created each work session. From these prima $\mathrm{r}_{\mathrm{y}}$ tables, all other seconda $\mathrm{r}_{\mathrm{y}}$ cat$\mathrm{ego}_{\mathrm{ry}}$ tables could quickly be created and interlinked to each other and the main database through the lot number field to ensure accuracy and provide data ent $t_{\mathrm{r} y}$ cross-checking. Hard copies oftables containing primary analytical data were made for additional back-up copies as well as for data ent $_{\mathrm{r}}$ checking.

During analysis of the materials, new database fields for "analyst's identification" and "analyst's count" were added in the TARL and TxDOT database tables to account for any changes from laboratory identification to the TARL analysis identification. This simple method tracks materials throughout the project as well as provides the means for future researchers to trace the steps taken from the fieldwork through final analysis.

The analysis phase relied heavily on Paradox database which also could be transferred to Microsoft Excel files for graphical and statistical manipulation. Each analyst was provided with basic Paradox tables containing provenience and cultural/stratigraphic data into which the analysts added observations specific to each category investigated. The provisioning of analysts with templated files made from the primary databases enabled alJ of the raw data files to be uniform and compatible with each other. Downloading provenience, stratigraphic, and artifact specimen numbers into tables for each analyst to enter their data also prevented ent $_{\mathrm{ry}}$ errors in all of these categories of information. Stratigraphic assignments were periodically up-dated on the pri$\mathrm{ma}_{\mathrm{r} y}$ databases and electronicalJy transferred to the analysts' raw data tables. AIJ materials and any items with speci- 
men numbers could be systematically tracked from field and laboratory identifications to the final analytical category. This process allowed for better data entry control, error checking, and cross-reference to provenience and stratigraphic data. Ultimately the primary database was migrated to Microsoft Access to be compatible with other TARL databases and for report production purposes.

\section{CURATION}

Most materials associated with the Wilson-Leonard site are curated at the Texas Archeological Research Laboratory and the Vertebrate Paleontology Laboratory of The University ofTexas at Austin. Exceptions are the snails, phytoliths, diatoms, and ostracodes extracted and identified by Neck, Theler, Fredlund, Winsborough, and Kontravitz, repectively; each of these specialists is currently housing their respective samples. All paper-based records are on acid-free, lignin-free paper except for profile and map drawings. The primary electronic databases are in ASCII format.

Beyond the artifactual materials, photographic records, field records, inventory records, and a great deal of documentary evidence from the analysis phase is also curated. These records were determined to be significant for curation by the project archivist on the basis of their potential research value for documenting the anthropological record as outlined in Silverman and Parezo (1992). The records prima- rily document the procedures used for analyzing each material category by the analysts including descriptions of categories and definitions of terms as they evolved, the laboratory procedures and methods used throughout the project, correspondence with consultants and staff, and administrative and management processes. The records also document the public and professional lectures and exhibits presented by staff regarding the Wilson-Leonard site, news articles and television spots, and video tape of the fieldwork.

\section{CONCLUSIONS}

Since its discovery in 1973 and testing in 1981, the Wilson-Leonard site has undergone two substantial excavations. The first, conducted by archeologists with TxDOT, was the larger of the two and generated the majority of the collection of cultural materials and exposed a significant portion of the site. The second, carried out by archeologists with the Texas Archeological Research Laboratory, was supplementary in nature, considerably less extensive, and generated fewer artifacts; however, because the intent of this effort was to recover geological, ecological, and specific kinds of archeological data, the yield of evidence upon which interpretations are based is about equal from the two excavations. Clearly, the whole exceeds the sum of the two parts. 


\section{CHAPTER4}

\section{BACKGROUND TO THE ARCHEOLOGICAL INVESTIGATIONS}

by Michael B. Collins

\section{INTRODUCTION}

Wilson-Leonard almost perfectly epitomizes the archeological record of Central Texas. The site possesses many of the salient characteristics of the local archeological manifestations; virtually all of the temporally diagnostic artifact types of Central Texas are present at the site, at least in small numbers, and their positions in the site are generally consistent with previously established chronologies. A variety of features and multiple burned rock middens also are present. Biotic and abiotic evidence for changing environmental conditions over time round out the site's content.

Investigation of this site touches upon a majority of the current research issues in the prehistory of the region and raises several new ones. The very long sequence of occupations represented at Wilson-Leonard is the basis for diachronic analyses with one important variable-placeheld constant. It is a distinct advantage to be able to conduct diachronic, especially processual, research at a single site where the relative chronology of the data is more secure than it is in a sequence built on seriation or cross-dating of data from multiple sites.

This discussion considers the relevance of previous, current, and future archeological inquiry in the region to that of Wilson-Leonard. A reflection of the long period of time between the beginning of investigations and this publication is the fact that some preliminary data from the Wilson-Leonard site have been incorporated into the regional literature (e.g., Collins 1995).

Generally the archeological record of central North America north of Mexico is conceptually organized into the major cultural-evolutionary periods, Paleoindian, Archaic, and a post-Archaic often labeled Woodland (Jennings I974:265; Willey 1966:311-319). These concepts are mirrored in the Central Texas archeological chronologies where the terms, Paleoindian and Archaic, are employed, but the postArchaic is variously referred to as Late Prehistoric, Neo-
Archaic, or Post-Archaic (Collins 1995). Although these terms continue to be used to denote principal subdivisions of the prehistoric time-line, they derive from largely obsolete views that Paleoindian peoples were specialized hunters of big game, Archaic cultures reflect a contrasting subsistence base of plant-gathering and small-game hunting, and Late Prehistoric (the term adopted in this study) adaptations were influenced by the technological innovations of pottery, the bow-and-arrow, and agriculture.

Central Texas is virtually ignored in most treatments of the great archeological cultural areas of North America (e.g., Fiedel 1987; Jennings 1974; Wedel 1961; Willey 1966). Wedel (1961) draws the southern boundary of the Great Plains archeological area just north of Central Texas. Fiedel (1987) mentions only one Paleoindian site in Central Texas (Levi Rockshelter) and skirts the region in all of his discussion of Archaic and later cultures. Jennings (1974: 154) includes much of Texas in his "Edwards Plateau Area" when he discusses the Western Archaic but covers it very superficially and relies primarily on out-of-date publications; he sees the region as intermediate between eastern and western Archaic traditions (Jennings 1974: 152). Willey (I 966:6, 329-337) carved out a minor new archeological culture area, "Northeast Mexico-Texas," noting that it" ... embraces that territory which lies surrounded by Mesoamerica, the Southwest, the Plains, and the Eastern Woodlands, so that its borders are drawn at the limits of spread of these neighboring areas" (Willey 1966:329). In his discussion, Willey (1966:329-337) covers the archeology of coastal and western Texas almost to the exclusion of Central Texas.

Certainly the provincialism of archeologists working in Texas contributes to this condition (cf. Johnson 1991), but perhaps there is also a significant issue of cultural history underscored here. Explicitly (Fiedel 1987 :ix) or implicitly (Willey 1966), the sweeping syntheses of continent- or hemispherewide scope are concerned with the development of those complex cultures based on agricultural subsistence, 
which clearly excludes Central Texas. The question of why this is so has been largely ignored by those working in the area as well as by those penning the grand compendia. But, in fact, it is an important question. There is nothing inherent in the soils, climate, or other natural conditions to preclude the growing of crops. So, why did people who were aware of food production continue to forage or gather and hunt (Fiedel 1987: 163), and why did others who had experimented with horticulture revert to hunting and gathering (Jelinek 1967; Smith 1972).

Willey's (1966) treatment of the area as nearly archeologically barren landscape holding the more significant culture areas together is both inaccurate and unfortunate. Central Texas is rich in archeological remains and quite possibly affords one of the better case studies for investigating why a shift from food-getting to food-producing never occurred. After all, as Willey's quote above makes quite clear, hunter-gatherers in Central Texas were for centuries within a few days walk of farmers in the Southeastern U.S., Southwestern U.S., and northern Mesoamerican culture areas, and undoubtedly they were well aware of that fact (Collins 1995).

In reviewing the archeological background to the study of the Wilson-Leonard site, it is suggested that Central Texas was sufficiently endowed with resources that generalized hunting and gathering began in Clovis times and continued until historic times with brief intervals of specialized bisonhunting adaptations in Folsom and in Late Prehistoric (Toyah) times. The issue central to this theme is discovering the patterns of successful human adaptation that prevailed for more than a hundred centuries in spite of significant changes in natural conditions. These adaptations evidently varied considerably but did not stray beyond the limits imposed by the interplay of ecology and food-getting technology.

These and other substantive lines of inqui ${ }_{r y}$ have languished in archeology as practiced in Central Texas while questions of archeological chronology received excessive amounts of attention. As a result, archeological effort and findings have been highly redundant. Preoccupation with chronology prevailed without development of a very effective methodology for its pursuit. Rigorously established typologies of diagnostic artifacts were seriated chronologically and the sondage technique was adopted to secure temporal sequences of artifacts, but the greatest effort has been expended on precisely the kinds of sites with the least potential for yielding good chronological information while sites with that potential attracted comparatively little attention. The vast archeological database generated for Central Texas has had $\mathrm{ve}_{\mathrm{ry}}$ little synthetic treatment beyond description and chronological ordering of assemblages (Collins 1995).

Syntheses of North American prehisto ${ }_{\mathrm{r}}$ all portray a trend of increasing cultural differentiation with nearly continentwide uniformity in early Paleoindian "cultures," broad regional patterns (e.g., "eastern Archaic") during the Archaic, and more-localized and distinctive manifestations (e.g., Hohokam, Adena) in the post-Archaic. In this depiction, which is probably overemphasized, Paleoindian sites in Texas are usually fairly prominent, but later sites are not. Central Texas, which has almost no well-known Paleoindian sites, is often overlooked completely in the broad syntheses. In this case, lack of reporting is the primary factor because sites such as Kincaid, Horn Shelter 2, and Pavo Real (see below) are certainly significant on the continental scale, as is Wilson-Leonard.

Wilson-Leonard findings make proportionally greater contributions to regional Paleoindian and Early Archaic studies, but the site adds important information to the record of the Middle and Late Archaic as well. The site's contribution to the early part of the Late Prehistoric record is minor, and to the late part, nil. This unevenness is reflected in the following review which emphasizes the regional record from ca, 12,000 to ca. 6000 BP. Accordingly, it begins with a wider geographic scope for the earlier periods and increasingly focuses more closely on Central Texas for the later ones. Issues relating to research at Wilson-Leonard are also selectively emphasized. More general treatments can be found in recently published reviews by Ellis (1994), Johnson and Goode (1994), and Collins (1995). Earlier reviews of the archeology of Central Texas are also useful sources of background information (Black 1989; Prewitt 1981, 1985; Suhm 1960; Weir 1976). As noted by Collins (1995), there is great need for more concerted effort toward the discovery and thorough investigation of gisements, sites with archeological components sealed in natural deposits.

\section{"CENTRAL TEXAS" AS AN ARCHEOLOGICALAREA}

Over the last four decades, several concepts of an archeological area referred to as "Central Texas" have been proposed. The more influential of these concepts are the ones suggested by Suhm et al. (1954), Suhm (1960), Weir (1976), and Prewitt (1981, 1985). Although the boundaries of this archeological area have differed according to each of these author's perceptions, they have in common a core area and a fairly distinctive cultural pattern. Ellis et al. (1995) have critically reviewed these constructs and correctly observed that none of them constitutes a coherent unit, environmentally or culturally, and, therefore, none of them serves well in any effort to understand processes of human adaptation. Collins (1995:363) summed up a similar view with the opinion that "in the past 11,000 years, there probably has never been any cultural group whose key resources, geographic range, or political sphere conformed even approximately to what archeologists designate as 'Central Texas."'

This circumstance of our regional research being conducted within an inappropriate framework reflects the fundamental shift from cultural-historical to cultural-processual orientation experienced by Americanist archeology during 
the late I960s and early 1970s. Culture areas (Kroeber 1939) and the daughter concept of archeological areas (e.g., Willey 1960) were intended primarily as descriptors, and it is a common acknowledgment that, even at the level of description, the concepts are far from pe1fect. In the case of Central Texas, archeologists often continue to employ some version of "Central Texas" as an archeological area in cultural-historical summations, but concerns with adaptation and culture process are more often addressed using research domains defined by more local geographic considerations, as for example, the continuing studies of prehistoric adaptation to the mosaic of microenvironments within the 880 square kilometers at Fort Hood (Abbott and Trierweiler 1995) or the tightly constrained environmental contexts of the investigations conducted at the Camp Pearl Wheat site (Collins et al. 1990) or in the Middle Onion Creek Valley (Ricklis and Collins 1994). Alternatively, there have been the occasional wide area studies bounded by specific research conditions, as in the case of live oak savanna and burned rock middens investigated by Creel (1991).

The daunting task of explicitly curing the defects articulated by Ellis et al. (1995) has not yet been undertaken on a broad areal scale. To do so would entail systematically reevaluating copious environmental and archeological data and taking into account not only the spatial dimensions of both but the persistent changes that have occurred in both environments and cultures throughout prehistory. There is, however, an interesting bias hidden in the earlier "Central Texas" archeological area constructs and the articulation of a concept explicitly recognizing that bias by some of the more recent studies.

In spite of its use in support of a widespread "Central Texas" area, the bulk of the archeological information considered by Suhm et al. (1954), Suhm (1960), Weir (1976), Prewitt (1981, 1985), and Collins (1995) derived from sites in the eastern part of the area, in fact, mostly from in and near the physiographic areas of the Balcones Canyonlands and the southern parts of the Lampasas Cut Plain (see Chapter 2). This same area has been explicitly identified by McKinney (1981), Johnson (1991), and Johnson and Goode (1994) as having archeological coherence worthy of close scrutiny. It is apparent that the trend in research is away from broad archeological area concepts and toward sets of environmental units of varying character considered relevant to the problems being addressed. It is equally apparent that the broader trends in cultural history are shared to some extent across multiple environments. In this study of the WilsonLeonard site, research is focused on the site's setting on the southern tip of the Lampasas Cut Plain near the northern tip of the Balcones Canyonlands and close to the center of the long north-south strip of the Black Prairie (see Chapter 2). As background to this more-focused study unit, the prehistoric cultural history of the broader region presented below is appropriate because it is more complete and because it maintains continuity with the substantial body of literature that exists for the region. This outline of regional prehistory largely follows that recently presented by Collins (1995).

\section{INTERPRETING THE RECORD}

Archeologists working in Central Texas have touched on fundamental issues concerning the meaning of the prehistoric record we have been studying, but these issues want for a more-thorough and systematic treatment. There are aspects of the regional prehistory that we know with some certainty, and, of course, others that we are unlikely to ever know. The most important set, however, are those that we probably could know with more productive inquiry.

Among those that we do know is that the area was occupied without any noticeable breaks for at least 11,000 years. The occupants were hunter-gatherers. Their durable material culture of chipped and ground stone is well known, including many details of the technology by which it was produced. There are changes over time in the artifact forms and assemblage compositions making up this durable material culture. Subsistence included exploitation of numerous terrestrial and aquatic animals, the remains of which have been found and identified in some detail. Change occurred in this aspect of subsistence over time. Different kinds of sites and variation in features within sites have been noted (Johnson and Goode 1994; Prewitt 1981). Evidence is sparse, but human physical traits (Steele and Powell 1994) as well as the manner in which the dead were treated (Taylor 1995) have also varied over the span of prehistoric time. It is unlikely that we will ever know specific languages, ethnic groups, social structures, or political alliances and antagonisms, but, with improved approaches, we have the potential to learn considerably more about plant foods, seasonality, perishable material culture, site types, cooking technology, housing and maybe the nature of - as opposed to the specifics of-the cultural groups, their ranges, and their adaptations.

To do this, we need to establish base line data. First is to systematically review the data at hand, second is to target sources of those additional data identified as lacking but probably obtainable. The nature of these basic data is outlined next.

\section{BACK TO BASICS}

We have a great array of semi-organized data on hand. What is lacking is a sound conceptual scheme for more completely organizing those data and for directing future data acquisition. Two vague conceptual schemes have been debated in recent decades to account for the variation we see in archeological assemblages through time and across space. The most conspicuous aspect of that variation is "stylistic" attributes in chipped stone artifacts, mostly projectile points. In various ways and to varying degrees, these are seen as 
reflecting ethnicity of groups in the past, or alternatively, as being of technological and functional significance crosscutting ethnic boundaries (as seen, for example, in the debate over the nature of the late Prehistoric Toyah manifestation between Johnson and Ricklis [see below]). In resolving this issue, we need to rigorously and systematically develop sound, alternative concepts and evaluate them thoroughly and objectively. To date, we have argued largely from casually selected theoretical propositions and used subjectively chosen data sets. Probably, the scope of the questions being researched needs to be reduced, at least initially.

The region almost entirely lacks the more-powerful ethnic identifiers such as art, basketry, or sophisticated ceramics. Thus, a first order of business is to objectively, systematically, and thoroughly evaluate the regional archeological record for its potential indicators of ethnicity at three levels: artifacts, artifact assemblages, and components. At the level of the individual artifacts, we should begin with asking what attributes of what artifacts? (Do projectile points really embody purely stylistic elements in their design? If so, what elements? Are they the same elements over time? What is the case for ethnicity of projectile point styles-is it maleonly with the potential of crossing exogamous social boundaries and comingling with others?) In the case of artifact assemblage, can the composition of assemblages be interpreted as reflecting ethnic or only technological causes of variation (and how readily shared is technology)? At the level of the component in a site, horizontal patterning of artifacts as well as features, associations among artifacts, and the spatial patterns of those activities related to artifact manufacture, breakage, discard, and reuse are added to assemblage composition; how much ethnic identity resides in these kinds of data and how much is situational? Thoughtful construction of research designs addressing questions of this kind should be pursued and the research conducted in sites with the best possible contexts (Collins 1995).

Because these basic issues have not been resolved, this review is written and the research was conducted at Wilson-Leonard at the prevailing level of inquiry where our data are organized informally as a mix of archeological technocomplexes and artifact style intervals.

\section{ANARCHEOLOGICALCHRONOLOGY ANDPALEOENVIRONMENTALSEQUENCE FOR CENTRAL TEXAS}

A reasonably comprehensive archeological chronology has grown out of the efforts of archeologists in Central Texas over the last half century or so. One version of this sequence has been offered by Collins (1995:Table 2), and a simplified version is here presented as Figure 4-1; bibliographic references to the sites shown in the figure as well as some of those discussed in the text are listed in Table 4-1. As already noted, some aspects of this chronology are based on preliminary findings from Wilson-Leonard (Collins,
Bousman, Goldberg et al. 1993; Masson and Collins 1995). Three main periods, Paleoindian, Archaic, and Late Prehistoric are used approximately in the conventional sense which, as mentioned above, is based on inferred fundamental changes in subsistence patterns. Subdivisions of these periods into subperiods are also based on adaptive shifts thought to reflect changes in subsistence strategies. Subdivisions of the Archaic follow the recent revisions proposed by Johnson and Goode (1994). Early and late subperiods of the Paleoindian are based on Quaternary fauna! associations; similar divisions in the Late Prehistoric period reflect distinctive archeological patterns.

The finer subdivisions, style intervals (Collins 1995), are dependent primarily on diagnostic projectile point styles ("types") which change for reasons not yet determined by our archeological efforts. These, too, follow approximately the scheme offered by Johnson and Goode (1994) and derive from the syntheses of Weir (1976) and Prewitt (1981, 1985).

Absolute dating is portrayed in Figure 41 as radiocarbon years before the present, the convention generally followed by geoarcheologists. This convention facilitates use of uncalibrated dates from the literature of the geological sciences and from that of earlier archeological reports. It also allows any calibration to be applied.

Geological, palynological, and paleontological records (Collins 1995) in and near the Central Texas archeological area reflect a consistent but generalized environmental sequence (see Figure 4-1). Alternating intervals of comparatively mesic or xeric conditions have been inferred by Bousman from the pollen sequences from bogs in east Central Texas (Bousman 1994; Collins, Bousman, and Perttula 1993:57-59) and by Toomey from the vertebrate fauna! record of Hall's Cave (Toomey 1993; Toomey et al. 1993). The bogpollen sequence is not well controlled chronologically, however, the available dates indicate relatively constant rates of sedimentation from which Bousman interpolated the depicted sequence. Bousman's interpretation of the reported pollen data from Weakly and Boriack bogs considered the relative frequency of grass to arboreal pollens. In doing this, a climatically sensitive aspect of the pollen record emerges from the complete spectrum which otherwise contains numerous taxa, the abundances of which more likely reflect localized conditions around the bogs.

Hall's Cave yielded a rich and well-stratified sequence of small, environmentally sensitive animal remains. Toomey excavated $3.7 \mathrm{~m}$ deep into the fill of the cave and recovered more than 12,000 fauna! specimens. Only the upper $2 \mathrm{~m}$ of the Hall's Cave sequence accumulated during the time when humans were present. The climatic history depicted in Figure 41 derives from these upper $2 \mathrm{~m}$ of fill and is based on the relative proportions of the least shrew $\left(C_{r}\right.$, ptotis [which requires a relatively moist habitat]) to the desert shrew (Notiosorex [found in more-arid habitats]) following Toomey (1993) and Toomey et al. (1993). This portion of the Hall's 

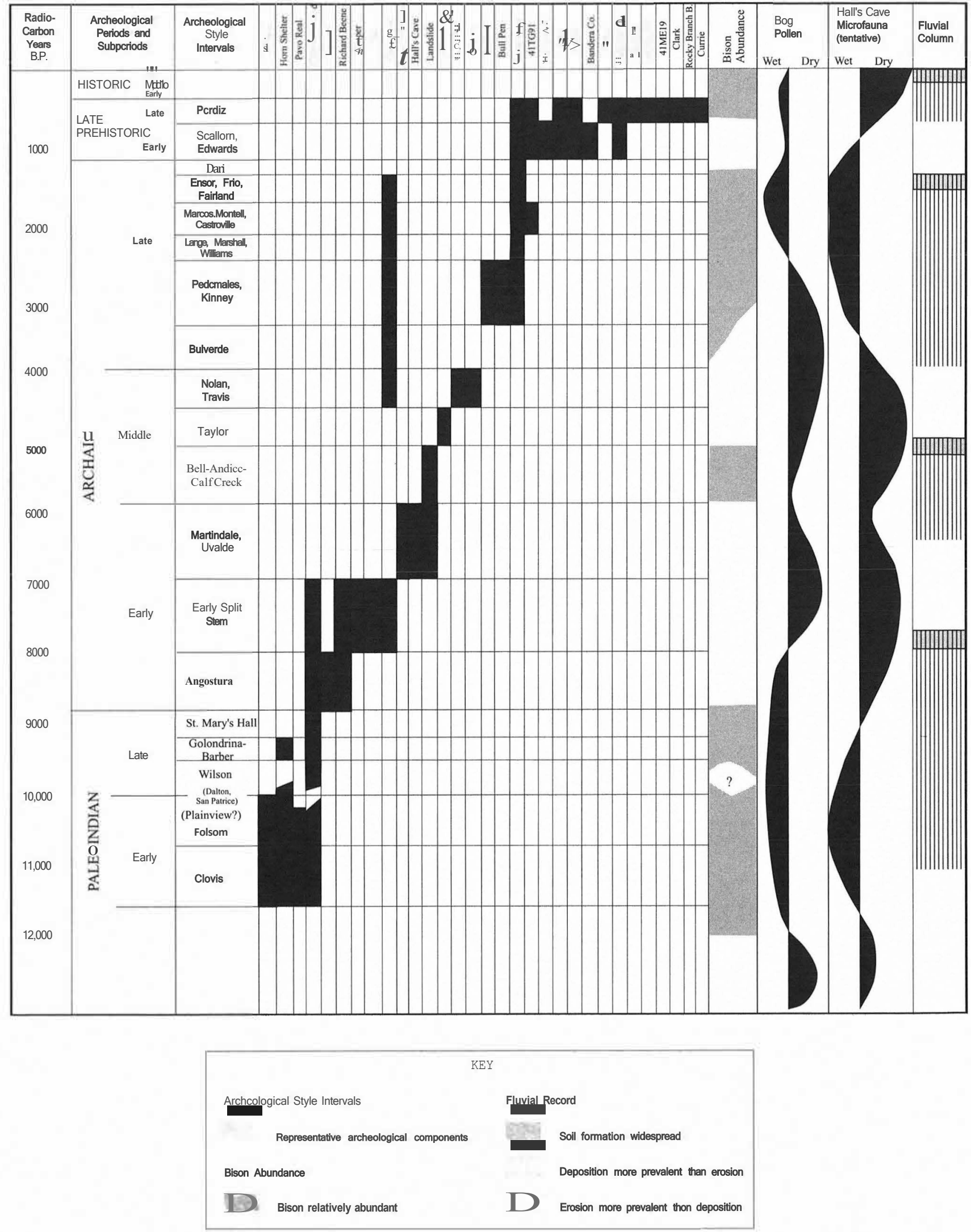

FIGURE 4-1. Synoptic archeological and environmental sequence for Central Texas (modified from Collins 1995). 
TABLE4-1

Alphabetical Listing of Sites Discussed in Text and Listed in Figure 4-1, with Bibliographie References

\begin{tabular}{|c|c|}
\hline Site & Bibliographie Reference \\
\hline Anthon & Goode n.d. \\
\hline Buckner Ranch & Sellards et al. 1940 \\
\hline Bull Pen & Ensor and Mueller-Willie 1988 \\
\hline Buzzard & Stephenson 1970 \\
\hline Camp Pearl Wheat & Collins et al. 1990 \\
\hline Clark & Watt 1965 \\
\hline Crockett Gardens & McCormick 1982 \\
\hline Currie & Treece, Quigg, Miller, and O'Neill 1993 \\
\hline Domebo & Leonhardy 1966 \\
\hline Finis Frost & Green and Hester 1973 \\
\hline Frish Auf! & Hester and Collins 1969 \\
\hline Gault & Collins et al. 1991; Collins et al. 1992 \\
\hline Gibson & Ray 1940 \\
\hline Hall's Cave & Toomey 1993; Toomey et al. J993 \\
\hline Horn Shelter 2 & Redder 1985 \\
\hline Jetta Court & Wesolowsky et al. 1976 \\
\hline Kincaid & Collins I990b; Collins et al. 1989 \\
\hline Kyle & Jelks 1962 \\
\hline Landslide & Sorrow et al. I967 \\
\hline Levi Rockshelter & Alexander 1963, 1983 \\
\hline Lindner & Brown 1985 \\
\hline Loeve & Prewitt 1982 \\
\hline Loeve Fox & Prewitt 1974 \\
\hline Mill Iron & Frison 1996 \\
\hline Mustang Branch & Ricklis and Collins 1994 \\
\hline Pavo Real & Henderson and Goode 1991 \\
\hline Plainview & Sellards et al. 1947 \\
\hline Rex Rodgers & Hughes and Willey 1978 \\
\hline Richard Beene & Thoms and Mandel 1992 \\
\hline Rocky Branch & Treece, Quigg, Lintz, and Miller 1993 \\
\hline Rush & Quigg and Peck 1995 \\
\hline Sleeper & Johnson 1991 \\
\hline Smith & Suhm 1957 \\
\hline Turkey Bend Ranch & Treece, Quigg, Miller, and Lintz 1993 \\
\hline Wilson-Leonard & Collins, Bousman, Goldberg et al. I993; Mear n.d.; Masson and Collins 1995 \\
\hline Wounded Eye & Luke 1980 \\
\hline Youngsport & Shafer 1963 \\
\hline Unnamed site in Bandera County & Beasley 1978 \\
\hline $41 \mathrm{GL} 160$ & Kelly 1987 \\
\hline 41ME19 & Hester and Kelly 1976 \\
\hline 41TG91 & Creel 1990 \\
\hline $41 \mathrm{TV} 29$ & TARL files \\
\hline
\end{tabular}

Cave sequence is controlled by 41 radiocarbon dates on bone provided by Stafford (personal communication 1995) and by 3 charcoal dates (Toomey 1993 ). This is a large number of dates, and they are in almost perfect stratigraphic order. There is also high internal agreement between radiocarbon ages determined on different chemical fractions of the same bone. These factors make this sequence one of the best-dated and most environmentally sensitive records in North America. Concern expressed by Johnson and Goode
(1994:22) in regard to dates on the earthen fill ofHall 's Cave are clearly dispelled by the bone-organic chronology. These pollen and fauna! records both indicate an early xeric interval ending near 12,000 B.P., correlative with the "Clovis Drought" discerned by Haynes (1991). This is followed by a significant time of relatively mesic conditions. The faunal and pollen records then indicate a long middle Holocene interval of relatively xeric conditions, which was slightly ameliorated at roughly its midpoint. That the two records are 
not synchronous probably results largely, if not entirely, from inaccuracy in the ages interpolated for the bog-pollen sequence. In general terms, the Middle Holocene xeric interval lasted approximately 5,000 years-close to half of the local prehistory. The effects of middle Holocene aridity are seen widely in Central Texas, often in the form of stream incision, but precise dating is often difficult (cf. Abbott 1994).

Late Holocene conditions returned to being more mesic. The pollen and fauna! indicators are inconsistent only in the latest Holocene where a final swing toward xeric conditions appears in the Hall's Cave fauna. Other than relatively small samples of the species (and, therefore, possible sampling error) on which Toomey based the depicted interpretations, the inconsistency is not readily understood. It is possible, of course, that the pollen record being from the easternmost and the fauna! record from more nearly the westernmost edges of the area could account for contrasting conditions.

The relative abundance of bison in and near Central Texas has been inferred from occurrences in archeological sites (Collins et al. 1990; Dillehay 1974; Prewitt 1981, 1985). There is a general correlation between bison occurrences and comparatively mesic portions of the bog-pollen and cavefaunal records.

The generalized geologic record in Figure 41 is based on fluvial sequences where episodes of valley filling alternate with periods of erosion and/or stability and soil formation. Consistently, the valleys of Central Texas (and much of North America [Haynes 1991, 1992, 1993]) were downcut and scoured of sediment in the Late Pleistocene, ca. 15,000 to 12,000 years ago. Valley filling followed during the ensuing mesic interval, and it is in these sediments that a number of the important early Paleoindian sites have been found.

Erosion and stability with soil formation are more characteristic of the middle Holocene, during the long xeric interval. This interval was first recognized in North America on the basis of extensive evidence for erosion and arroyo-cutting in the Southwest and has been called the Altithermal (Antevs 1955). Whether or not the interval was significantly warmer, it was drier, and the paleoenvironmental record of Central Texas was clearly affected by those conditions. It is not yet known exactly what the consequences of this xeric interval were in terms of human ecology. But it is clear that the archeological record has been significantly and adversely affected by erosion and curtailed deposition during the middle Holocene. Erosion undoubtedly destroyed many sites and many others formed on stable surfaces, resulting in the mixing of cultural materials over long periods of time. Comparatively few well-stratified sites in Central Texas are available for the approximately 5,000 years of the Middle Holocene xeric interval (Collins 1995 :379).

Downcutting of valleys occurred widely in the middle Holocene leaving former flood plains above the reach of most flooding and bringing deposition on these surfaces to a virtual halt. Major soils formed on these long stable sur- faces over wide areas in the valleys of Central Texas during the middle Holocene, and many sites, especially burned rock middens, formed on those surfaces. Much of the archeological data for the middle Holocene is from these numerous, highly visible, artifact-rich sites.

Valley filling prevailed through most of the late Holocene, but one widespread episode of downcutting occurred ca. 1000 BP. (Hall 1990). In part because the evidence is better preserved, the Late Holocene record includes several less significant interruptions to deposition (see Figure 41).

\section{PALEOINDIANARCHEOLOGYINANDNEAR CENTRAL TEXAS}

\section{Paleoindian}

Any cultural manifestation in Central Texas dating to earlier than ca. 8,800 years ago is arbitrarily assigned to the Paleoindian period (Collins 1995). Adaptations varied during this period, and no single, broadly defined Paleoindian lifeway applies. Three temporal subdivisions have been proposed within the Paleoindian period, Preclovis (which for Central Texas is currently theoretical rather than empirical), Early Paleoindian (for materials contemporary with now-extinct Pleistocene megafauna), and Late Paleoindian (contemporary with early Holocene fauna).

\section{Pre-Clovis}

A search continues for evidence of the earliest peoples in the New World, a quest energized by increasing acceptance of indications that authors of Clovis artifacts may not be the founding population (Fagan 1997). In the first place, the nearly continent-wide distribution of the Clovis manifestation in North America (Frison 1991; Stanford 1991) and the sophisticated knowledge Clovis people had of their natural surroundings (Collins 1996) are not what we should expect of a population just "coming into the country" (Kelly and Todd 1988). There are also discoveries that apparently place humans in North America well before the earliest dates (ca. 11,200 B.P.[Haynes 1992]) for Clovis. Meadowcroft Rock Shelter (Adovasio 1993), two sites near Calgary, Alberta (Chlachula 1994), and multiple mammoth localities investigated by S. Holen in the loess beds of Nebraska (Hall 1995) cannot be dismissed as Preclovis sites as readily as former contenders such as those on Krieger's (1964) list of "PreProjectile Point" localities. Furthermore, a date of 12,500 BP. for a cultural component at the site of Monte Verde in southern South America (Dillehay 1996) certainly implies that people were in North America at an earlier time (unless we are to abandon the Bering Straits or Landbridge as the probable point of entry). But these are issues that cannot be addressed directly with any of the findings from WilsonLeonard and are not discussed in this presentation. Instead, the lower part of the Wilson-Leonard cultural sequence is 
typical ofa majority ofPaleoindian sites in North America in that it is found near the base of deposits that began aggrading on bedrock in stream valleys at the waning of the "Clovis Drought" (Haynes 1991 ). A few artifacts deep in the gravels at the base of the Wilson-Leonard sequence may be either pre-Clovis or very early Clovis in age. The other two Paleoindian subperiods, early and late, are represented in Central Texas as well as at Wilson-Leonard. Within the early subperiod are recognized two well-established style intervals, Clovis and Folsom. There are also more problematic style intervals that fall within, or at least may begin within, the early subperiod. These are Plainview, inferred to belong to the early subperiod, and Dalton and San Patrice, for which there is evidence that they may begin during the early subperiod.

\section{Early Paleoindian}

Clovis is the earliest cultural horizon documented in Central Texas. It is assumed on the basis of dating at sites elsewhere in North America to have existed here between approximately 11,200 and 10,900 B.P. (Haynes 1992). Clovis components have been reported at Kincaid Rockshelter, Wilson-Leonard, Gault, Horn Shelter 2, Pavo Real, and Crockett Gardens, and surface finds of distinctive Clovis points are reported from a number of other localities (Meltzer and Bever 1995). Clovis manifestations are the most diverse in the Paleoindian period of North America and include kill sites, quarry and stone-working localities, caches, camps, and burial sites. The artifact inventory includes chipped stone artifacts on bifaces, flakes, and prismatic blades; these are generally made on high quality and often exotic stones (Collins 1990a). Engraved stones (Collins et al. 1992), bone and ivory points, a bone shaft straightener, stone bolas, and ochre have been reported from Clovis contexts in Texas and elsewhere (Frison 1991; Stanford 1991).

The once popular notion that Clovis was a culture based on nomadic pursuit of mammoths is no longer supported by the evidence (Meltzer 1993). Better fauna! data and indicators of a less nomadic lifeway are consistently emerging. Subsistence in Clovis times included large herbivores such as mammoth, bison, and horse but was probably based more consistently on smaller animals such as water turtles, land tortoises, alligator, mice, badger, and raccoon (Collins et al. 1989; Story 1990: 182-184) and presumably also included an array of plants. Nomadic hunters could not afford the investment of labor represented by the stone pavement in the floor of Kincaid Rockshelter if it were a fleeting habitation. Some 2 metric tons of cobbles and boulders were brought in from the nearby river bed to cover $10 \mathrm{~m}^{2}$ of the muddy shelter floor (Collins 1990b; Collins et al. 1989;). Caches ofClovis artifacts have been found in Texas and elsewhere in North America (Collins 1996). Caching is more useful to people with hunting and gathering rounds that predictably returned them to the same places than it is to wandering big-game hunters whose movements are less predictable.

Overall, the Clovis lifeway seems to have been that of well-adapted, generalized hunter-gatherers with the technology to hunt big game but not the need to rely exclusively on it. Either their travels or their contacts with other groups enabled them to acquire exotic stone from great distances. In Texas, the conditions under which Clovis peoples existed were during a mesic recovery from the long "Clovis drought" which ended near the beginning of Clovis times (Haynes 1991 ). Clovis material is widely distributed in Texas in a number ofdifferent environmental zones (Meltzer and Bever 1995).

In contrast, subsistence in Folsom times seems to have been focused on specialized bison hunting, as bison remains predominate at most Folsom sites (Hofman 1989:36). Sites with Folsom-age components in Central Texas include Kincaid, Pavo Real, and Hom Shelter 2. Isolated Folsom points are also found on the surface in Central Texas, mostly in areas that have been predominately grasslands (Largent et al. 1991 ). Paleoclimatic data indicate that conditions were mesic.

Horn Shelter 2 appears to have been a habitation site; Kincaid, a kill site; and Pavo Real, a stone-working locality. No other kinds of Folsom sites are known in Central Texas. Folsom sites as well as the isolated points in Texas are most often found in and near grassland habitats. This in conjunction with the fauna! evidence and a tool kit of projectile points, end scrapers, and knives bespeak the adaptations of specialized hunters. Diagnostic artifacts are large thin bifaces (some being "ultra-thin"), fluted Folsom points, small end scrapers, and thin unfluted (Midland) points.

The "Plainview" manifestation in and beyond Central Texas is problematic in that no consistent assemblage has been defined, the type name has been indiscriminately applied, and it is not certain where true Plainview points fit chronologically. The existing archeological and contextual evidence bearing on this problem needs to be reconsidered, and there is a great need for new and better data. Present evidence suggests that true Plainview points (as at the Plainview site) are at least 10,000 years old (Dibble 1970; Dibble and Lorrain 1968; Holliday 1987:23; Johnson and Holliday 1987; Johnson et al. 1982). Some consider typologically similar forms (the Goshen-Plainview suite) to be older than (i.e., greater than 10,200 B.P. [cf.Haynes 1993]), or partly contemporary with, Folsom points (Frison et al. 1996:205209; Haynes 1993).

The consensus that Plainview is at least $\mathrm{I} 0,000$ years old is helpful in approaching the first major problem with "Plainview" as it is currently viewed in Central Texas. This is the problem of sorting out the unfluted, lanceolate forms that have been called Plainview but lack the distinctive flaking details of the type assemblage. After fust addressing that issue, this discussion will return to the chronological issues.

Many of the Central Texas projectile points that have been called Plainview (various unfluted, lanceolate dart point 
forms) fail to match the type-site points in thinness and pressure-flaking technology and, in fact, true Plainview points are absent from, or are extremely rare in, Central Texas. Plainview points at Horn Shelter 2 are thicker and have moredeeply concave bases than those at the Plainview site and come from zones dated ca. 8400 B.P. (Redder 1985). At Wilson-Leonard, the unfluted lanceolate points previously identified as Plainview (Weir 1985) are morphologically distinct from points at the Plainview type site and date to the interval 9500-8000 s.r. If the makers of true Plainviews existed ca. 10,000 years ago, mesic conditions seem to have prevailed, and the evidence is that they were bison hunters with primarily a plains orientation.

Recent work on the northern Plains has brought the dormant issue of Goshen points back into the Plainview problem (Frison 1996). There is no question that what have been called Goshen and Plainview are either the same type (implying historical relatedness) or remarkably similar forms lacking historical relatedness (implying morphological and technological convergence). Were the chronological evidence similar on the northern and southern Plains, investigators would probably agree that they are a single type and that they should be called Plainviews based on precedence of that name. However, stratigraphic as well as chronometric data (Frison 1996; Frison et al. 1996) seem to place the northern ("Goshen") form in a pre-Folsom position with an age roughly a millennium earlier than the southern counterpart ("Plainview"). There is not a consensus on this view, and various opinions have been expressed for some time. Haynes (1991, 1993) notes the morphological similarities between Goshen and Plainview (as well as Midland) points and suggests an age for these at the Mill Iron site as being between 10,700 and 10,800 B.P., near the younger end of the Clovis and the older end of the Folsom ranges (Haynes 1993 :224-225). At the Domebo site in Oklahoma, two points were found near a single mammoth, one a typical Clovis, the other typologically more akin to Plainview; but, in part because they were associated with mammoth remains, Leonhardy (1966) concluded that both probably should be classified as Clovis points. Jennings (1974: 104) also questioned the interpretation that Plainview postdates Folsom, suggesting that Plainview may be earlier than, as well as contemporary with, Folsom. Irwin (1971) also proposed an early temporal placement for Plainview. The occurrences of true Plainview points have mostly been in kill sites or other contexts where the artifact assemblages are limited in scope, and there does not exist a very complete picture of what the range of artifacts associated with Plainview points may be. Until the typological, chronological, and assemblage variability issues relating to these unfluted lanceolate points are resolved, it is premature to speculate on the adaptive stance of the archeological culture or cultures represented.

Beginning near the end of the early Paleoindian subperiod and probably continuing into the late subperiod in Central Texas are found two more diagnostic projectile point types, Dalton and San Patrice. Neither of these is particularly common nor is their temporal position or cultural significance well understood. Of the two, San Patrice (variously called San Patrice, Brazos Fishtail, and Rodgers SideHollowed) is the more numerous. San Patrice occur at Wilson-Leonard and at Kincaid and both occur at Hom Shelter 2 in Central Texas. Daltons are dated in the Middle Mississippi valley to the interval, 9500 to 10,500 years B.P. (Morse and Morse 1983) and are close to that age at Hom Shelter 2 (ca. 9500-9980 s.r. [Redder 1985]). San Patrice-like Rex Rodgers points are associated with a Clovis point and an unfluted lanceolate point in what appears to be a single-event bison kill site in the Texas Panhandle (Willey et al. 1978). They occur in a deposit dated between 9500 and 9980 B.P. at Hom Shelter 2 (Redder 1985) but remain undated at Kincaid (Collins 1990b). Everything about the fauna, associated artifacts, and features (including a double burial) found with San Patrice (Brazos Fishtail) and Dalton points at Horn Shelter 2 suggests an Archaic-like, hunter-gatherer cultural manifestation (Redder 1985). Tentatively, I have placed this material as transitional between early and late Paleoindian in Figure 4-1; hopefully future work or new finds will clarify the picture.

Makers of San Patrice (including Rex Rodgers and Brazos Fishtail) points apparently practiced generalized hunting and gathering (seen at Horn Shelter 2) but were capable of successfully taking bison (Rex Rodgers). As yet, no large game kill sites have been found to contain Golondrina points, but these, too, may represent a generalized hunting and gathering lifeway in possession of a weapon system similar to those used in big-game hunting.

Three style intervals, Wilson, Golondrina-Barber, and St. Mary's Hall, are here proposed for the late subperiod of the Paleoindian period (see Figure 4-1). Climate was trending from mesic toward more moderate conditions during this time, and it is not known how abundant bison may have been. These point styles are moderately well defined at the site of Wilson-Leonard (Masson and Collins 1995). The Wilson component is the better represented and is characterized as having corner-notched, Archaic-like Wilson dart points (Masson and Collins 1995; Weir 1985) in association with features, a burial, artifacts, and fauna) remains more Archaic than Paleoindian in appearance. Dates for this component are ca. 10,000 to 9650 s.r. (Masson and Collins 1995).

Wilson points are found at campsites along with an array of chipped-stone bi faces and unifaces (including hafted endscrapers), burins, manos, and battered stones of unknown function. The fauna associated with Wilson points is mostly small animals and deer. Dart points similar to Wilson points were found with the bones of large animals (including proboscideans, horse, bison, and glyptodon) at the Buckner Ranch (Berclair Terrace, Bee County) locality (Sellards et al. 1940), but the depositional context is a stream bed, and it cannot be determined whether or not a kill site is represented. 
The Archaic-like character continues for the GolondrinaBarber and St. Mary's Hall components, dated between 9500 and 8000 B.P. All three of these components (Wilson, Golondrina-Barber, and St. Mary's Hall) have burned rock features, but the size of the features and the amounts of rock present is decidedly Jess than that in Archaic features of younger ages. The subperiod here called late Paleoindian is in many ways archeologically intermediate (or "transitional") between early Paleoindian and the Archaic; the question to be answered is how accurately this material-culture-based impression reflects their respective human adaptations.

\section{Archaic}

Two-thirds of the prehistory of Central Texas is Archaic in character. Archeologists have viewed the Archaic as a time when hunting and gathering oflocal resources was intensified over that in Paleoindian times and when material culture shows greater diversity-especially in the application of ground stone technology. Archaic sites in Central Texas are characterized by copious amounts----sometimes multiple to n s-of heat-altered rocks in various forms of hearths, ovens, middens, scatters, and other kinds of features. The full gamut of uses of these heated-rock appliances can only be guessed at from available evidence, but thoughtful inqui $_{\mathrm{r}}$ into this problem is increasingly common.

The basic Archaic mode of life prevailed for more than 7,500 years in Central Texas. There are distinctive changes to be seen within the Archaic archeological record, but their significance is not known. It is known, however, that, in the broadest sense, this Jong span represents a basic adaptation that was successful. A priority in the investigation of the Archaic record is to better understand the fundamentals of that adaptation and to determine the significance of the variations seen over time and across space. In briefly reviewing the Archaic of Central Texas, the cultural chronological framework recently proposed by Johnson and Goode (1994) is adopted with minor adjustments.

The Early Archaic, from ca. 8800 to 6000 s.r., is subdivided into the three projectile point style intervals, Angostura, Early Split Stem, and Martindale-Uvalde (see Figure 4 1). Open campsites (including Loeve, Wilson-Leonard, Richard Beene, Sleeper, Jetta Court, Youngsport, Camp Pearl Wheat, and Landslide) as well as Hall's Cave (occupied at the far reach ofdaylight), contain Early Archaic components. Numerous dart points and Guadalupe tools attributable to the Early Archaic also are present in Kincaid Rockshelter but in mixed context. Other rockshelters were probably occupied during the Early Archaic, but the sample may be small due to rockshelter degradation (Coll ins 1991 ).

A number of authors have noted a concentration of Early Archaic components near the eastern and southern margins of the Edwards Plateau (Black 1989; Ellis 1994; Johnson 1991; Johnson and Goode 1994; McKinney 1981 ).
Large and varied burned-rock features (Sleeper, Camp Pearl Wheat, Wilson-Leonard, Richard Beene), domestic structures (Turkey Bend Ranch), and caches (Lindner) are known from the Early Archaic. Clear Fork and Guadalupe bifaces (both inferred to be specialized tools, probably for woodworking), grinding and hammering stones, along with a variety of unifacial and bifacial chipped stone implements are reported from Early Archaic components. Subsistence data are sparse for the subperiod, but hunting of deer, exploitation of various small animals including fish, and the cooking of bulbs in earth ovens are indicated.

If the presently known site distributional data reflect land use in the Early Archaic, this was a time when people were living in the better-watered parts of the live oak savanna habitats on the Edwards Plateau, particularly in and near the Balcones Canyonlands. Acorns, deer, and turkey are conspicuous among live oak savanna resources, but geophytes (e.g., onions, prairie turnip), other nuts (e.g., pecan, walnut), berries (e.g., agarita, hawthorn), fruits (e.g., grapes, plums, persimmons), and grass seeds, along with a host of small terrestrial, amphibious, and aquatic animals round out a potentially diverse and reliable subsistence base.

Pollen, faunal, and geologic evidence portrays an oscillation from mesic through extremely xeric and back to mildly xeric conditions during the Early Archaic. Bison (and antelope?) were evidently scarce or absent. What mix of other foods constituted the staple diet(s) during the Early Archaic is unknown at this time. The distributions of Angostura and especially Gower, Martindale, and Uvalde dart points as determined by Prewitt (1995) show the tendency noted by others for the makers of these point styles to mainly occupy the better-watered eastern part of the Edwards Plateau.

Specialized cooking appliances that use quantities of stone as heating elements appear during the Early Split Stem interval and reflect a sophisticated technology for exploiting the oak-savanna resource base. These features almost certainly represent the technological antecedents of the larger burned rock middens that become typical of later intervals in the Archaic of Central Texas.

The Middle Archaic, from ca. 6000 to 4000 s.r., is subdivided into three style intervals (Bell-Andice-CalfCreek, Taylor, and Nolan-Travis; see Figure 4-1). The earlier two of these intervals reflect a shift in lithic technology from that which had prevailed previously. Bell-Andice-CalfCreek and Taylor are thin, basically triangular bifaces with long thinning flakes emanating bifacially from the base; Taylor bi faces remain unnotched whereas Bell, Andice, and Calf Creek bi faces are characterized by very deep, narrow basal notches. All of these thin-bladed forms would serve equally well as knives or as tips of lances, spears, or darts. Impact fractures common on the Bell-Andice-CalfCreek forms attest to their use as weapon tips.

Climate during the earliest interval (Bell-Andice-Calf Creek) was somewhat mesic. It was a time when bison were 
hunted, leading Johnson and Goode (1994) to surmise, correctly I think (Collins 1994a:94, 1995), that these thin bifaces were part ofa specialized bison-hunting weaponry, possibly brought to the region by peoples moving southwesterly from the prairie, prairie margins, and woodlands of eastern Oklahoma (Wyckoff 1995). The distributions of these points reported by Prewitt (1995) shows their greatest numbers to be in the prairie grasslands.

Bison seem to have disappeared from the record by the later Middle Archaic style intervals (Taylor and NolanTravis), and more xeric climate had returned-in fact, culminating toward the end of the Nolan-Travis interval in what appears from pollen and fauna! data to have been the onset of the most xeric conditions ever experienced by humans in Central Texas. Interestingly, Taylor and Nolan-Travis components have the appearance of either long-term or intensive use, or both. These point styles are distributed widely across the Edwards Plateau and into western Texas but also seem to be concentrated on the eastern margin of the Plateau (Prewitt 1995). Burned rock middens debut (best seen at the Wounded Eye site in Kerr County where Taylor bifaces dominate the assemblage recovered from a small burned rock midden). Another technological shift is seen in the production and morphology of Nolan and Travis projectile points which are comparatively thick and often have narrow blades (especially on Travis points) with stems and modest shoulders; distinctive beveling of the stems is characteristic of Nolan points.

Johnson and Goode (1994:26) speculate, as Prewitt (n.d.) had done earlier, that burned rock middens at this time were being used more frequently to cook xerophytes such as sotol that may have thrived in Central Texas as conditions became drier. This does not necessarily signal an end to extraction of the more typical oak-savanna floral and fauna! resources but perhaps a shift in emphasis with concomitant adjustments in subsistence technology, strategic planning, and scheduling (cf. Bousman 1993).

The Late Archaic, ca. 4000 to 1200 or 1300 B.P., began as effective moisture was at its lowest in Central Texas, but the climate slowly became substantially more mesic (see Figure 4-1 ). Six style intervals are recognized in Late Archaic (see Figure 4-1). Middle Archaic subsistence technology, including the activities that produced burned rock middens, continued well into the Late Archaic. In fact, during the second style interval (best known for its Pedernales points), the growth ofburned rock middens was at its greatest, especially in the easterly parts of the area. It appears, however, that xeric vegetation and whatever reliance people placed upon it, gradually disappeared from the easterly parts ofCentral Texas between 3500 and 2500 B.P. and burned rock midden growth slowed but did not cease. The xeric vegetation remained, and continues to remain, in the western reaches of the area where its exploitation continued to include use of communal earth ovens into Late Prehistoric times (Goode 1991 ). Bison again show up in the archeo- logical record and, except for Montell and Fairland, the point styles for the Late Archaic are among the most widely distributed among dart points (Prewitt 1995).

Johnson and Goode (1994) discuss cultural aspects of the Late Archaic on the eastern Edwards Plateau and point out diverse and comparatively complex archeological manifestations toward the end of the Late Archaic that reflect lifeways with little precedent in the area. Among factors that have been cited as contributing to these developments are increasing population size (Prewitt 1981; Weir 1976) and stimuli from ceremonial practices in the eastern part of the continent (Johnson and Goode 1994).

\section{Late Prehistoric}

Archeologists insert an arbitrary break in the archeological record between the Archaic and the Late Prehistoric periods based largely on the appearance of arrow points. Previously, the latter was referred to as the "NeoAmerican Stage" (Suhm et al. 1954:20) in the expectation that all three defining traits (pottery, bow and arrow, and agriculture) would eventually be recognized. It now appears that generally for Central Texas, only the bow and arrow appeared initially, pottery was added later, and horticulture came last and was of quite minor importance. Because basic hunting and gathering subsistence continued, what is here called the Late Prehistoric has also been labeled the "Neo-Archaic" (Prewitt 1981) or the "Post-Archaic" (Johnson and Goode 1994). Two subperiods, early and late (see Figure 4-1) are recognized in the Late Prehistoric; these correspond to the Austin and Toyah "phases" of long-standing in the systematics of the local prehistory (Jelks 1962; Prewitt 1981 ). More than projectile-point-style change distinguishes Austin from Toyah manifestations, and the subperiod level of designation reflects the importance of these differences. Johnson and Goode (1994:3940) make an appropriate point when they note that an equally satisfactory solution would be to place the break between the Archaic and the Late Prehistoric at ca. 800 B.P., when Toyah replaces Austin as the prevailing archeological configuration in Central Texas. However, in the surrounding areas, especially southeastern and northeastern Texas, important changes occurred earlier and traits are shared between these areas and Central Texas, making it prudent at this time to maintain the presently established break between Archaic and Late Prehistoric.

The most apparent change seen at the beginning of the early Late Prehistoric (or Austin interval) is from a prevalence of dart points to one of arrow points; presumably this reflects a change from use of the atlatl and dart to that of the bow and arrow. Widespread hostilities seem to have occurred based on what are inferred to be numerous incidents of arrow-wound fatalities (Prewitt 1974). Otherwise, comparatively little change is noted from terminal late Archaic patterns, particularly in subsistence behavior. Goode (1991) 
even finds evidence that in western Central Texas, burned rock middens continued to be produced in what he believes to be the cooking of sotol.

The late subperiod (Toyah) of the Late Prehistoric is expressed as a single-style interval, designated in Figure 41 by the Perdiz arrow point. However, the Toyah archeological manifestation consists of a constellation of traits, notably pottery (both local and imported from the Caddoan area), large thin bifaces, Perdiz arrow points, end scrapers, and prismatic blades all associated with the hunting of bison as well as deer and antelope. The occurrence of these distinctive traits on about the same time line across a wide area of the state distinguishes the Toyah as an archeological "horizon."

A question that arises is whether such a horizon is the spread of a people across the landscape or the spread of ideas and their adoption by different peoples. Johnson (1994) and Ricklis (1994) have recently articulated differing views on Toyah lifeways. In keeping with traditional interpretations, Johnson sees Toyah as the material leavings of a single ethnic group ("folk"). Ricklis, in contrast, observes that the cultural materials that define Toyah represent tools and technologies that can be spread among different groups rather easily-a technocomplex. The issue hinges on how similar do lithic and ceramic objects and their technologies of production have to be to represent the work of a single ethnic group? In the absence of linguistic evidence (which is precluded by a pre-contact truncation of Toyah culture) or more robust archeological data, the issue will not be resolved since the question as posed is too general.

There are many well-stratified Toyah components and the prospects for discovering more and better ones are good, making this the interval in the local prehistory where comparatively high resolution of the archeological data can be expected. The debate framed by Ricklis and Johnson is a kind of anthropological issue that has been rare in the history of Central Texas archeology. Because it is both intriguing and substantive, such a debate can be expected to continue, grow, and be refined-maybe even resolved to a degree with robust new data in the future. More importantly, perhaps, it has the potential of becoming a methodological testing ground for dealing with similar issues in earlier parts of the regional sequence. Such considerations are particularly important, because an almost complete discontinuity exists between the prehistoric and historic native American peoples of Central Texas.

For the most part, the first native groups encountered and documented by early Europeans were recent arrivals into Central Texas, and, furthermore, traditional lifeways had already been altered by demographic change and disease as well as the availability of horses, metal, and guns occasioned by the European intrusion. For these reasons, historical accounts do not offer directly applicable analogs for interpreting Central Texas prehistory.

\section{CONCLUSIONS}

Central Texas was occupied by native American huntergatherers more or less continuously for longer than 11,000 years. During that time, population increased, though certainly not uniformly. Such population growth undoubtedly increasingly constrained subsistence and mobility options and may have fostered political conflict, but it also led to a cosmopolitan condition where more knowledge, commodities, words, and mates could be exchanged within Central Texas and between its peoples and those in neighboring regions.

Exchange in the nonmaterial domains of culture is likely to have comparatively low archeological visibility in contrast to the movement of nonperishable commodities or the transmission of ideas that are reflected in durable items of material culture. The more exchange occurs, no matter its form, the more likely it is to have archeological visibility.

In the course ofCentral Texas prehistory, archeological evidence for the exchange of ideas and exotic commodities becomes more apparent in the latter part of the Late Archaic and reaches its greatest expression in the Toyah interval (assuming that exotic lithics in Paleoindian times more often represent high mobility). When Late Archaic sites in Central Texas contain exotic obsidian and marine shells and there are interments influenced by Hopewellian burial ceremonialism, the indigenous populations are not living in isolation. Unseen behind these tangibles are undoubtedly culture brokers, travelers, multilingual interpreters, and diplomats.

Horticulture or agriculture had come to be practiced in all directions (MesoAmerica, the Southwest, Southeast, and parts of the Plains) while Late Archaic people in Central Texas were still subsisting entirely by hunting and gathering. Early European settlers found Central Texas optimal for farming (Fehrenbach 1968), and much ofit is farmland today, so it is clear that a shift to horticulture or agriculture by natives of the region was not precluded by natural conditions of soil or climate. Nor is it reasonable to argue that it was precluded out of ignorance on the part of its inhabitants because there is evidence that at least a modicum of extraregional contacts has always existed.

These conclusions argue for the alternative interpretation that Central Texas was one of those places in the world where the labors and limitations of food production had no appeal. Instead, efficient technologies for hunting and gathering prevailed and the resource base was both rich and diverse. The geologist Robert T. Hill expressed the same opinion over a century ago: "No country can present such ideal conditions for aboriginal nomadic existence as the lower Cretaceous hills of Central Texas, and here the Comanches, Huecos, Lipan and Kiowas for many centuries lived what must have been a most perfect savage life" (Hill 1891 :367).

What then was that technology and the characteristics of that resource base? The axiom that specialization is the path to extinction seems to be born out by it corollary- 
11,000 years of successful, generalized exploitations of a diverse resource base in Central Texas. The adaptability of hunter-gatherer subsistence in Central Texas is underscored by the swings in climate depicted in Figure 4-1.

From the earliest arrival of peoples into the area, which present evidence places near the middle of the twelfth millennium B.P., until ca. 8800 B.P. conditions were relatively mesic and the archeological record reflects hunter-gatherers ofmoderately high mobility. Campsites ofthese Paleoindians usually have simple fireplaces with little or no use of rocks. During Folsom times, there seems to have been a substantial reliance on bison hunting, but otherwise Paleoindian subsistence seems to have been rather generalized. A small human population and reasonably abundant plant and animal resources would seem to best account for the evidence.

Beginning around 8,800 years ago, large fireplaces with quantities of burned rocks appear and signal important changes in adaptations, ushering in what we refer to as the Archaic. It is in the Archaic that we see the development and perseverance of archeological patterns distinctive to Central Texas; a conspicuous element in that distinctiveness is extensive use ofrocks in a variety of fireplaces. It is apparent that these rocks were used primarily for their heatstorage capacity in most cases and that this is central to the long histo $_{\mathrm{r} \text { y }}$ of successful Archaic adaptations.

There is a clear correlation between mesic climatic indicators and the archeological occurrence of bison remains. There is a less clear but suggestive appearance that burned rock features (middens and complexes of earth ovens) grew at faster rates in the more xeric intervals. In general, large hot-rock cooking appliances are needed for plant foods requiring long cooking times, whether baking or steaming. The labor and fuel required for efforts of this kind are efficient only ifa large volume offood is cooked. It follows that the existence of the large hot-rock cooking appliances is prima facie evidence of bulk processing of inulin-rich or starchy plants, be they sotol bulbs, prairie turnip roots, cattail roots, acorns, or wild onion bulbs. But it is important to consider that once the effort is made to construct and fuel a hot-rock cooking appliance, it can be used to cook almost any kind of food, plant or animal-wherein lies the adaptability of these facilities. Bulk processing can also imply food storage, a matter scarcely considered in the archeological inqui ${ }_{\mathrm{r} y}$ of the region.

As the abundance of various plant foods change seasonally or in response to longer-term climatic shifts, rock ovens can be used to bake or steam, as appropriate, the most available bulk staple augmented with anything from river mussels or turtle meat to hawthorn or persimmon fruits. It would appear, in this vein, that at those (mesic) times when bison were more abundant, somewhat less reliance was placed on the bulk processing of plant foods. One of those times was when CalfCreek, Bell, and And ice bi faces were in vogue, another when Marcos, Montell, and Castroville points prevailed. Johnson and Goode (J 994) offer the suggestion that makers of Calf Creek and related forms migrated into the region as bison ranges spread. Relatively less use of hot-rock appliances is seen during the Bell-Andice-Calf Creek style interval, and possibly even during the interval identified by Marcos, Montell, and Castroville forms, but this is far less evident.

Central Texas environments are, and have been, far from uniform, and the foregoing generalizations will not apply equally over the region and possibly not at all in some places. Certainly such potentially important resources as desert succulents, bison, acorns, and riverine plants and animals have varied greatly over time, and archeological understanding of their importance will emerge locally, not regionally.

During the late (Toyah) interval of the Late Prehistoric, when bison-hunting and mobility were evidently at their highest levels since Folsom times, the ancient practice of using large hot-rock appliances came to an end. Once again, as in the Bell-Andice-CalfCreek interval, there is good evidence that the Toyah interval is the archeological expression of bison hunters that migrated into the area and neither depended very much on other local resources nor adopted the technology for their exploitation.

A final issue that has not been pursued by archeologists working in the region is how often have breaks occurred in the ethnic or biological continuity of central peoples. The one that occurred just before the arrival of Europeans is known, but were there other, earlier disruptions? If breaks occurred, the consequences are not obvious in the record. 


\section{RESEARCH OBJECTIVES: HUMAN ECOLOGY AT THE WILSON-LEONARD SITE}

by C. Britt Bousman

Peoples whose leavings comprise the prehistoric archeological record ofCentral Texas were almost exclusively hunter-gatherers. The research design implemented for the investigations at the Wilson-Leonard site was created to take full advantage of the unique opportunity afforded by the site. The site offers a virtually complete 11,000 -year view of prehistoric adaptations from the vantage point of a single locale. The general theoretical approach considers the ecology of the prehistoric hunter-gatherers who lived at the Wilson-Leonard site during the late Pleistocene and Holocene epochs. Plus new analytical techniques, not known or poorly developed in 1982, were employed in the 19921993 excavations to more fully exploit the information potential of the site.

With this site and in this setting, the most profitable theoretical approach is one that considers the interaction between hunter-gatherers and their natural environments. This direction is within the realm of human ecology and paleoecology (Butzer 1982), and it is concerned with analyzing the spatial, procurement, technological, and social strategies by which prehistoric hunters and gatherers obtained raw materials and food resources. Studies ofhuman ecology integrate analysis of natural environments with social and cultural processes, emphasizing their interactions. Empirical- and theoretical-based models of huntergatherer exploitation by ethnologists and archeologists are providing new views of hunter-gatherer adaptations (Bettinger 1991; Binford 1980, 1981; Bousman 1993; Kelly 1983, 1995; O'Connell and Hawkes 1981; Smith 1991; Smith and Winterhalder 1992; Speth 1983; Winterhalder and Smith 1981 ). Archeologists usually rely on ethnographic analogs and on theoretical constructs based on a limited number of ethnographic cases (Freeman 1968; Wobst 1978), but little attention has been paid to those aspects of archeological patterns without ethnographic analogs (Hayden 1986). It has been suggested that aspects of the Central Texas Archaic may represent nonanalogous subsistence patterns
(Collins 1991 b, 1995), and care must be taken when using ethnographic-based constructs.

A series of general research issues was addressed by investigating hunter-gatherer paleoecology at the WilsonLeonard site. A flexible level of inquiry was used instead of a more-restrictive format of specific hypotheses, alternative hypotheses, and test implications that can act to restrict and hamper investigations. The general research topics included chronology, reconstruction of past environments, site formation processes, resource exploitation, technological organization, spacing strategies, bioarchaeology, artifact typology, and cultural systematics. There are numerous aspects in each of these topics that allow for their integration in the overall investigation.

\section{RESEARCH OBJECTIVES}

\section{Prehistoric Chronology}

Chronology is the framework on which ultimately all archeological investigations depend, Wilson-Leonard being especially so given its long sequence. Chronological efforts were focused on two objectives. The first was clarification of archeological dating which includes culture chronology, and the second was dating of depositional and pedogenic events on the site. The methods for addressing the geological and archeological chronological problems are similar and are discussed together here. Both require the careful application of absolute dating techniques, such as radiocarbon, and relative dating techniques, such as stratigraphic superpositioning.

An intensive and integrated AMS radiocarbon dating program was implemented in the TARL excavations at Wilson-Leonard (see Chapter 25). AMS methods have the ability to provide very accurate assays on small samples, and even a brief review of absolute age estimates for Paleoindian components in the southern Plains demonstrates that many 
existing age estimates have intolerably large error estimates. This inaccuracy renders many Paleoindian radiocarbon determinations useless for modem tree-ring calibration or high resolution chronological analysis. AMS techniques, when integrated with molecular chemistry, have the ability to sample large, immobile, and stratigraphically secure objects (Stafford et al. 1987). Sophisticated chemical pretreatments reduce these objects into materials, such as amino acids, that are chemically pure, very rare in natural settings, and thus less likely to be contaminated by postdepositional processes. Combined with AMS dating methods, these rare materials can produce very accurate age estimates that are securely linked with geological events. However, materials that are significantly altered chemically by weathering or pedogenic processes can never produce accurate age estimates.

In the course of the TxDOT excavations, three conceptual systems existed for organizing the stratigraphic evidence at the site. The TxDOT excavators developed one that was used for most of the site, another was used for the finescreen unit, and Vance Holliday developed a third system for the entire site (Holliday 1992). The two archeological stratigraphic systems were overly complex and did not distinguish clearly nor systematically between depositional and pedogenic processes. Holliday's system was less complex but interpretively more sophisticated. Unfortunately, Holliday's stratigraphic system was not used by the TxDOT excavators, and it was not firmly correlated to any archeological or chronological evidence. Also for logistical reasons, it was difficult to implement in the TARL excavations (principally because it was based on exposures that were not accessible at the time of the TARL investigations). The TARL excavations developed yet another stratigraphic system, but it was fully integrated with the I992-1993 excavations, and, so far as possible, all three TxDOT systems were correlated to it. At the start of the TARL excavations, eight radiocarbon assays provided only a crude absolute chronology. The beginning and ending ages of all stratigraphic units, however defined, were unknown, and the durations, even on a crude scale, of soil formation events were unavailable. Also significant ambiguities between radiocarbon determinations existed, and these had to be resolved.

For example, uncertainties existed concerning the absolute age of Burial 2 (Stafford et al. 1987). The burial pit was observed in the lower portion of a buried soil, the Leanne soil as defined by Holliday (1992). However, the top of the burial pit was not clearly discerned stratigraphically, and this left the stratigraphic position of the burial open toquestion. A broad spread of six radiocarbon age estimates on human bone from the burial (from $1270 \pm 280$ B.P. to $6700 \pm 460$ s.r.), a single AMS assay from loose charcoal in the burial pit fill $(13,000 \pm 3000$ B.P.), and sediment assays from the burial pit sediment $(9470 \pm 170$ B.P. and $9650 \pm 120$ B.P.) did not establish a limited age range for the burial. A single radiocarbon determination from a burned tree stump in the Leanne soil,
$9530 \pm 88$ s.r., was coeval with the sediment ages from the burial pit sediment. Assuming it was shallow, the top of the burial pit appeared to be temporally constrained below four determinations on two charcoal samples $(7470 \pm 230$ B.P. and $8820 \pm 120$ в.P., $8940 \pm 100$ B.P. and $8860 \pm 150$ в.P.), butthe stratigraphic position of these two samples was unclear and various interpretations were possible.

At least two scenarios could account for the situation as understood in 1992, and the implications influenced the chronological sampling strategies employed during the TARL excavations. First, the oldest, but nevertheless young, bone assays might be correct, and the small charcoal AMS and sediment-derived age estimates reflect the recycling of old carbon and bioturbation. This would suggest an Archaic age for the burial. The second possibility is that the bone has taken on younger carbon through translocation and, thus, the bone did not provide reliable radiocarbon estimates. In this alternative, the sediment, tree stump, and AMS assays would be more nearly correct, and, because of large standard deviations, not in disagreement. This set of radiocarbon dates available at the beginning of the TARL excavations in 1992 did not provide enough information to assess the relative merits of these two alternatives. Considering that Burial 2, with all of its uncertainties, had the most secure chronology for the entire site, it was obvious that a major effort on the chronology was warranted.

Additional chronological efforts focused on various issues concerning archeological chronology. Even a brief review of the Central Texas archeological chronology demonstrates that the Paleoindian and Early Archaic periods are poorly documented chronologically and thus behaviorally (Prewitt I981, 1985). The accurate identification and characterization of cultural entities distinguished by diagnostic projectile points such as Clovis, Midland, Wilson, Plainview, Golondrina, Barber, Angostura, and Gower during these early time periods were primary goals. Further, chronological issues included determining when the various types ofburned rock features began to be used, how long they were used, and by which groups.

Sample selection used a strategy ofresolving both geological and archeological chronological issues in an integrated fashion. Before the TARL excavations started, preliminary micromorphological analysis on existing sediment samples disclosed that much of the sediment column had been bioturbated by earthworms. Therefore, small isolated charcoal flecks would not provide a high resolution chronology. AMS dating of charcoal, bone, and soils recovered from secure stratigraphic contexts was implemented, and multiple fractions measured. In this way, the sources of older and younger carbon contamination could be more easily identified and inaccurate age estimates ignored and a reliable radiocarbon chronology constructed. The actual selection of samples for radiocarbon analysis emphasized the material for dating and the context of the sample. The process was a multistaged selection process between the 
radiocarbon specialists and the archeological team. After the completion of an initial radiocarbon run, the results were analyzed, reviewed, and new samples selected where chronological issues remained to be answered.

Large pieces of clearly in situ charcoal was the preferred material, and burned rock features were the preferred contexts. Other materials selected for radiocarbon dating were sediments and bone. These two materials usually provide less-reliable age estimates than charcoal. Burned rock features were the preferred contexts because charcoal was more likely to be preserved in these contexts. Also, the features could be further studied by other techniques such as archeomagnetic analysis and organic residue analysis, and the features could be more reliably anchored to geological and archeological events. A number of charred tree stumps with abundant charcoal, however, did provide an additional excellent sampling context. A few samples also were submitted to conventional radiocarbon laboratories, but the primary thrust was a suite of AMS samples.

\section{Paleoenvironmental Reconstructions}

The second research objective in this study centered on reconstructing the past environments and climates. Reconstruction of past environments provides information that is critical for understanding a variety of issues, especially those concerned with site formation processes and human resource exploitation. The documentation of the plant and animal remains discarded by humans or deposited by natural processes on the site is the most direct avenue for determining which resources the prehistoric inhabitants exploited (discussed more fully in the resource exploitation section below) and the potential of the general region for supplying food and material resources. Hunter-gatherer theory indicates that the nature of the environment and the structure of the resource base exploited by humans directly and significantly affects the economic and technological strategies employed by modem hunter-gatherers. The objective is to document the changes in the floral, fauna!, and physical environments, and develop an understanding of why these fluctuations occurred. Paleoenvironmental reconstructions are a function of local landscape factors (discussed in the following section on formational processes) and regional changes in past climates. A variety of data sources that provide indirect evidence are pursued by archeologists and earth scientists, and this research objective was pivotal in both the TxDOT and TARL investigative strategies.

In 1992, the only published paleoenvironmental results available from the TxDOT excavation was a brief paper on the microfauna from the fine-screen unit by Winkler (1990). However, this paper did not provide an indication of the temporal changes in the fauna! remains, and no effort had been marshaled for understanding any human biases imposed on the record. Thus, it represented only an initial step in a reconstruction of past environments. During the TxDOT excavations, Holloway and Bryant (n.d.) unsuccessfully attempted to recover fossil pollen from the deposits, but Neck (n.d.) sampled and successfully documented a sequence of changes in the snail remains from the site. Other samples for paleoenvironmental analysis were collected but never processed.

The TARL excavations systematically collected samples for complementary forms ofpaleoenvironmental data. These included phytoliths, diatoms, insects, snails, stable isotopes, ostracodes, and microfauna. The purpose of collecting these additional forms ofdata was to obtain new and independent sources ofpaleoenvironmental information that were directly associated with the TARL excavations and archeological materials. All the Wilson-Leonard paleoenvironmental data are suited for comparison with the regional record through correlation on the radiocarbon time scale.

Phytoliths are opal silicate bodies that form as inclusions in plant cells. Taxonomic distinctiveness varies, but the grasses are among the most diverse, distinctive, and easily recognized. Three diagnostic grass phytoliths occur: panicoid, festucoid, and chloridoid. Limited modem studies in east Central Texas show that panicoid forms occur in greater frequencies in open grassy communities, while both festucoid and chloridoid forms are common in forested communities (Scott-Cummings 1991). The geological profile was sampled for phytoliths, and modem control samples were collected from nearby and little-disturbed plant communities. Discerning major changes in relative frequencies of grass phytoliths through time is the objective of the phytolith analysis.

Diatoms are single-cell algae with ornate siliceous exoskeletons. Generally diatoms are found in wet or moist habitats and can be transported by water (Winsborough 1991). Diatoms are very habitat specific, and a bewildering number of taxa from different habitats are common. These include forms characteristic of euplanktonic (open water, but not necessarily deep), epipelic (mud), epiphytic (plant stalks), and aerophilious (moist soil) environments. Diatoms provide extremely diagnostic measures of water depth, flow, and alkalinity. Diatom samples from the pond deposits in stratigraphic Unit Iwere processed. Poor recovery hampered investigations, but, surprisingly, diatoms were found in Unit I calcium carbonate nodules.

A large number of macrofloral remains were recovered by the TxDOT excavations and additional samples were recovered from the TARL excavations. In this geological setting, macrofloral remains are limited to charred plant parts, but an analysis of charcoal remains allows for a moredetailed reconstruction of past floral changes including the identification ofrelic plant communities (Dering 1992; Holloway and Pendleton 1986). Macrofloral remains were identified from sediments and feature fill at WilsonLeonard.

Other sources of paleoenvironmental data include stable isotopes from sediment samples. These samples were ana- 
lyzed, as were ostracodes discovered in samples from the Unit I pond deposits.

Additional microfaunal samples were collected and processed. These samples were processed with a very gentle procedure utilized by the Vertebrate Paleontology Laboratory at The University of Texas at Austin. Recovery of vertebrate (including bird eggshell fragments) and invertebrate remains was good, even though bone was not well preserved.

Other recent research in Central Texas has produced detailed pollen and fauna! sequences spanning the last 16,000-15,000 years (Bryant 1977; Camper 1991; Toomey 1993). These sequences overlap with the Wilson-Leonard geological sequence, and provide high-resolution comparative records. Recent reinterpretations of the pollen sequences (Bousman 1998; Collins and Bousman 1993) suggest that major changes in past climates have significantly altered past environments (summarized in Collins 1995). These fluctuations must have had dramatic influences on the distribution of plants and animals used for food and raw materials by people from Paleoindian through Late Prehistoric periods.

\section{Site Formation Processes}

Schiffer (1987) divides archeological formation processes into cultural and natural sources. Natural formation includes all environmental processes that affect the structure of a site or an artifact assemblage. This objective is directly related to the one of paleoenvironmental reconstruction, but the emphasis between the two is very different. The primary approaches used to analyze formation processes include the study of landscape evolution and alluvial geology. Over the last 10 years or so in Texas, geological approaches have become common in archeological investigations and produced important results (e.g., Blum 1992; Bousmanetal.1988; Hall 1982, 1990; Holliday 1985; Meltzer 1991; Nordt et al. 1994). Two nontraditional techniques were used in the study offormation processes at Wilson-Leonard: micromorphological characterization of sediments and magnetic studies of burned rocks.

Micromorphology ofarcheological sediments provides a clear-cut methodology for umaveling the effects of sedimentation, pedogenesis, and human occupation (Courty et al. 1989). Traditional bulk sample techniques (i.e., textural and chemical analyses) cannot provide the same level ofinformation. Micromorphology is particularly well suited for investigating site formation processes since it recognizes and identifies many forms of coeval and. postoccupation processes such as sedimentary processes (water versus airborne deposition), various pedogenic processes (e.g., dissolution of phosphates, dissolution and reprecipitation of carbonates, or trans location of clay minerals), and bioturbation (e.g., root disturbances, insect and rodent burrows, trampling, and human disturbance). Plus, and this is a major point, micromorphological techniques often can determine the sequence of events which is criti- cal for understanding site formation processes.

Magnetic properties of burned rock features and sediments produce important insights into site formation processes. The constant magnetic pole wanderings known as secular variation are recorded in burned limestone. When limestone is heated, for example, when it is used in a prehistoric hearth or a cooking oven, the magnetic particles align on the current magnetic pole. As the rock cools, the particles "freeze" on that alignment. Archeomagnetic analysis ofburned rock can accurately measure this fossil alignment, and with an incremental measurement procedure, changes in the rock's position that may have occurred as it cooled can be documented. With multiple samples that presumably were heated at the same time from a single feature, the magnetic alignments should all have the same dip and strike, if the rocks in the feature remained in their original positions. If the feature was disturbed or if it is a dump and not an in situ heating, the fossil alignments will be in conflict. Recently, the analysis of secular variations recorded in burned rocks from hearths and burned rock middens has shown that individual rocks had been heated more than once. The implications of this reheating are that at least some middens are jumbled, probably through reuse, and as such are disturbed masses that no longer are in primary archeological context (Cheek et al. 1980; Collins et al. 1990; Ricklis and Collins 1994).

Magnetic susceptibility, an estimate of the magnetic potential of sediment, was measured from geological columns and various features. Soil horizons often have a much higher magnetic susceptibility signal than alluvium and magnetic susceptibility measurements provide a stratigraphic sequence of the variations. A comparison of the magnetic characteristics of the burial and feature fills to the geological profile characteristics can provide an independent relative chronological assessment of Burial 2 and other features and pedogenic events.

Alluviation in the upper San Gabriel drainage system has produced a geological record spanning the last 12,000 years or so. At the Wilson Leonard site on Brushy Creek, which is in the San Gabriel River basin, cultural materials are stratified within those natural deposits. From a perspective concerned with the formation of archeological sites, the integration of geological and cultural information is of key importance. Archeological interpretation is improved when the natural factors of site formation are understood. Data from Wilson Leonard indicate that natural conditions changed substantially at the locality over the last 12,000 years and that some of these changes profoundly and differentially affected the conditions, as well as the densities, of artifacts and features at different times. Analysis of the Wilson-Leonard data from this perspective has the potential of improving our understanding of the local prehistory.

For example, patterns oflandscape change and stability have an enormous affect on the formation of the archeological record and determining the depositional context of 
archeological materials. While the terminology sounds new, the approach is not. For example, Kelley and Campbell (1942) argued that changing deposition rates are the primary factor that caused the creation of burned rock middens in Central Texas. Since so many burned rock middens occur in alluvial settings and so many are Middle Archaic in age, it is tempting to propose that Middle Archaic burned rock middens are common, in part, because Middle Archaic human occupations on stable middle Holocene alluvial surfaces created palimpsest burned rock accumulations now known as burned rock middens. Obviously the geological and archeological contexts of these burned rock middens are important. Archeomagnetic analysis of burned stone features can provide an indication of whether the burned stones were left in place or moved after firing and reheated (Cheek et al. 1980; Collins et al. 1990). A related and broader issue is to what degree do bioturbation and pedoturbation influence stratification and artifact context? Other sources of information can be brought to bear on this issue. One question is whether organic matter, including phosphates, originates from depositional, anthropogenic, pedogenic, or other postdepositional processes.

An example exists at the Wilson-Leonard site where Gower and Angostura projectile points are found, apparently, associated together in the Stiba soil. Do these technologically and typologically distinct projectile points represent different cultural groups, as suggested by Prewitt's (1981, 1985) culture chronology and perhaps indirectly implied by Johnson's (1989) provocative analysis. Thus, is their association in the Stiba soil simply a function of a long stable surface or some form ofturbation? Or do these represent different types of tools perhaps with different functions, and Prewitt's Early Archaic Circleville (Angostura) and San Geronimo (Gower) phases should be collapsed into a single cultural entity? This problem was addressed with excavation aimed at clarifying the geological associations of the cultural components, carefully selecting samples for radiocarbon dating, and the micromorphological study of the sediments and soils. In addition, archeomagnetic investigations on the burned rocks in the large Gower-Angostura hearths would provide important clues regarding the context of these features. These and other issues can be resolved by a consideration of natural formation processes.

Other examples of critical micromorphological study of sediments compared burial pit fill to the buried soils and sediments that comprise the geological sediments surrounding Burial 2, because the exact stratigraphic position of the Burial 2 pit was not recorded on geological profiles. Samples from the fill of the Burial 2 pit and surrounding geological deposits were collected in bulk during the TxDOT excavations and thin-sections were prepared during the TARL excavations. Detailed characteristics of soil development were used to identify likely and unlikely sources of burial pit fill from the stratigraphic column at the site.

\section{Resource Exploitation}

Determining changes in the types of resources (mineral, animal, and plant) exploited by the prehistoric inhabitants is an essential part of these investigations. Exploitation patterns are conditioned by numerous environmental and cultural factors including density or availability of resources, seasonal availability of resources, hunter-gatherer group mobility, and size and distribution of exploited territory or range by hunter-gatherer groups.

Obviously, the occurrence of fauna! remains provides an indication of which animals were hunted, collected, and/ or trapped by the various prehistoric groups who occupied the Wilson-Leonard site and how intensively these animals were exploited. Research in the last 15 years or so has amply demonstrated that the fauna! record is complicated by human and nonhuman processes (Binford 1981; Blumenschine 1991; Brain 1981; Haynes 1991 ). The analysis of fauna! remains must identify the different agents responsible for fauna! remains at the site, and the events that have altered the bone after occupation and burial. Beyond taxonomic analysis, this study considers the human and natural taphonomic processes affecting the assemblage.

Microfaunal samples derived from TxDOT excavations were previously analyzed and contribute to paleoenvironmental and paleoeconomic reconstructions (Winkler 1990). Additional microfaunal samples collected by TARL were processed and analyzed. The standard technique of the Vertebrate Paleontology Laboratory at The University of Texas at Austin was used for extraction of fauna! materials from sediments in an attempt to obtain better representation of fauna! materials. This technique has been used on late Pleistocene and Holocene deposits at numerous paleontological sites in Central Texas with excellent results and involves gentle water screening of totally dry sediments which is more gentle on the fauna remains. Patterns in the occurrence of environmentally sensitive taxa through time are the basis for interpreting environmental conditions and change in the site's history.

Macrofloral remains were rare at Wilson-Leonard and only wood charcoal and other charred plant remains are considered reliable indicators of prehistoric plant use. Both flotation and large charred remains were sampled and identified to provide some of the more important subsistence data in this project.

Mineral resources recovered at the site are derived from local as well as nonlocal sources. In some cases, exotic stone can be identified as coming from a particular region and serve as an indicator of the geographic range from which occupants of the site derived materials, but it cannot be determined ifthis represents procurement directly or through one or more intermediary groups.

\section{Technological Organization}

Another dimension that reflects prehistoric human ecology is the study of how prehistoric hunters and gatherers 
constructed and maintained their technological devices. Artifacts recovered by archeologists are a reflection of the strategies used to exploit resources. However, artifact assemblage composition and other characteristics of discarded tools can be affected by a multitude of factors such as tool design, maintenance, use-life, and replacement strategies (Bleed 1986; Kuhn 1989; Nelson 1991; Shott 1989; Torrence 1989). These studies show that assemblage composition is strongly influenced by the above formation processes (Ammerman and Feldman 1974; Shott 1989) and variations in raw material availability (Bamforth 1986). Most archeological studies have focused on extractive tools-tools used to extract food from the environment, especially weapons (Bleed 1986), but recently more effort has been spent on all tools: extractive and maintenance (Bousman 1993). Maintenance tools are those tools used to manufacture other tools or devices. Furthermore, while cooking features have not been a primary source of data for developing models oftechnological organization, the Central Texas archeological record suggests that much can be learned from their systematic study and analysis. Prima $a_{\mathrm{r}}$ in an organization-of-technology approach is a concern with the costs and benefits of tools, equipment, and facilities. Theoretical models ofhuntergatherer adaptations demonstrate that the analysis of technological organization should be integrated with other aspects of hunter-gatherer adaptations such as food procurement, mobility patterns, and territorial organization (Binford 1977, 1979; Collins 1975; Gould 1980; Kelly 1988, 1995; Shott 1986, 1989; Torrence 1983, 1989).

A long sequence oftechnological evidence from a single locality such as the Wilson-Leonard site permits a thorough study of changes in technological behavior with one variable-location and thus access to resources-held constant. Most artifacts recovered from the Wilson-Leonard site are made of stone, and almost all of those are of chipped stone. The organization of technology in terms of lithic artifacts considers the following: raw materials used; techniques of manufacture; forms of stone objects produced; patterns of discard, use, breakage, use wear, refurbishing, and recycling; microscopic evidence of use wear; and chemical residues from use and hafting (Collins 1993). Spatial and temporal patterns in each of these variables within and among sites provide the basis for interpreting adaptive behaviors associated with stone tools.

Surprisingly, many artifacts still retain traces of chemical residues on their surfaces resulting from use or hafting. Extraction and identification of chemical residues from ceramics, chipped stones, ground stones, wooden, and burned rock artifacts recovered from a variety of archeological contexts has proven feasible, if still somewhat developmental (Briuer 1976; Collins et al. 1990; Marchbanks 1989; Marchbanks and Quigg 1989; Shafer and Holloway 1979). The materials identified as organic residues on tools include lipids (saturated and polyunsaturated) and sterols. Inorganic residues (Stein 1984) are another important indicator of the life history of stone artifacts. The interpretations derived from chemical residues on stone tools is potentially so informative that an effort was made to study these residues, and two independent chemical residue analyses were conducted on a small representative sample of artifacts from the long sequence at the Wilson-Leonard site.

Interpretations regarding the kinds of organic and inorganic materials processed with lithic tools are also possible through the integrated study of macro- and microscarring, scratches, abrasions, and polish on the surface of stone tools. By careful analysis of wear patterns on tools, distinctions can be made concerning tool action and material processed. Microscars and polishes provide an indication of which surfaces were selected as working surfaces and the direction of tool movement. Distinctions can be made between tool edges used to process plant and animal tissues and tools edges that have been modified by technological processes or altered through natural causes. Under ideal conditions, the type of animal product (muscle, hide, antler, or bone) or plant material (wood, soft plant) processed by the tool can be identified. Such interpretations might also include characterization of single and multiple functions of artifacts and working edges, reduction techniques, and composite tool construction (e.g., hafting damage). Finally, functional, behavioral, and technical diagnoses obtained in usewear analyses may be verified, illuminated, or questioned through a variety of additional studies, such as chemical residue analyses and archeological contexts. Three independent wear-pattern analyses were conducted on chipped stone artifacts from Wilson-Leonard.

The application of efficiency models to features and cooking technology is another ripe field of inqui $i_{r}$. Recent study of cooking technology indicates that heated rocks are not required for cooking foods over short periods of time. However, the thermal properties of rocks allow for cooking over long periods of time, 24-48 hours, since rock acts as a slow-release heat storage element (Thoms 1989). Collecting rocks for cooking features, such as the Central Texas burned rock middens, requires a great deal of work. Capacity planning models (Meredith 1980: 132) indicate that as larger and larger packets of food are cooked together, larger and larger cooking features will be constructed in order to reduce the per unit costs of food processing. In other words, small amounts of food can be cooked most efficiently in small cooking features, and large amounts of food, perhaps for larger groups of people, can be cooked most efficiently in large cooking features. Thus the size of a cooking feature is a rough measure of the amount of food cooked in that feature. This hypothetical relationship is illustrated in Figure $5-1$, where the cost of processing food in a medium-sized feature (e.g., large hearth) is projected by the middle curve. The most efficient use of this feature in terms of capacity is shown by point B. Unit costs rise as processing capacity increases or decreases above or below point B. For example, costs rise if food capacity increases because the amount of 


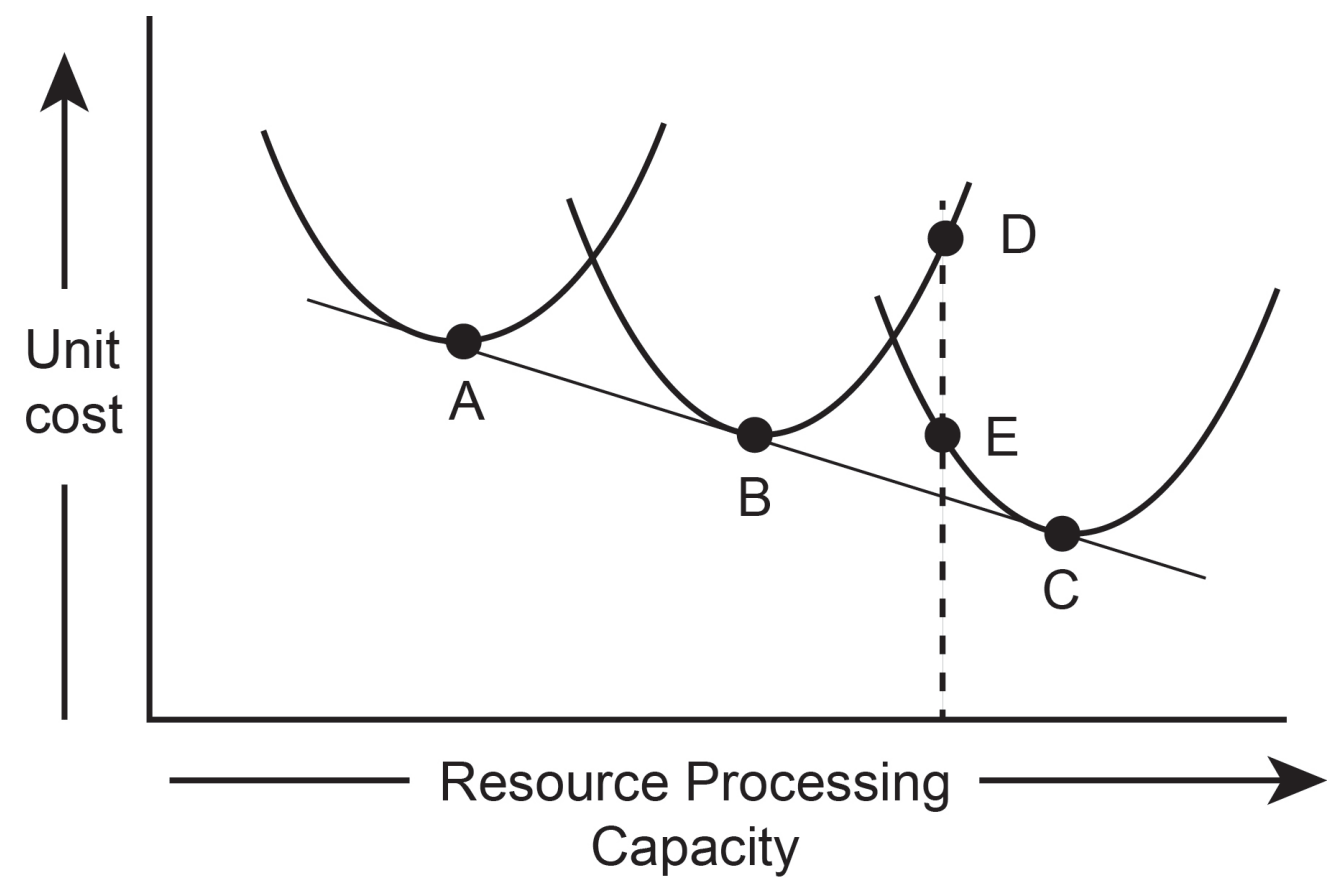

FlaRE 5-1. Capacity planning model for prehistoric features (adapted from Meredith 1980).

wood required for fuel is greater per unit of food than in a larger feature; also costs rise if food capacity decreases because the amount of rock collected for the feature is more than necessary for the amount of food processed. If the food capacity increases to point $\mathrm{D}$ on the medium feature curve, then at some stage it will be more efficient to shift to a larger cooking feature (point Eon the large feature curve). Points A, B, and C represent the most efficient use, in terms processing capacities, for the different-sized features.

The concept of capacity planning for cooking features is important because ifhunters and gatherers are exploiting foods in bulk and storing large quantities of food for lean seasons, then the capacity planning models strongly suggest that evidence should be present in the features. The size of burned rock features also provides proxy evidence on hunter-gatherer group size.

At the Wilson-Leonard site, the analysis of lithic artifacts, chipped stones, and ground stones utilized the concepts of tool design and capacity planning to analyze specific attributes that can provide information on the exploitation of resources by the prehistoric hunters and gatherers. Wear patterns and analysis of organic residues provide important additional sources of evidence on the function of tools. These data are integrated with intrasite spatial patterns and archeological and cultural systemics.

\section{Spatial Organization}

Ideally, distributions of artifacts and features on ancient living surfaces can be interpreted to provide insights into the activities that produced the patterns, however, as
Brown (1975) reminded us more than 20 years ago, deep excavations in a small area of a stratified site are blind to the unexposed extent of each component, and it is far from clear what each sample represents or whether the samples are comparable. In spite of these limitations, the stratigraphicaUy better defined components at Wilson-Leonard appear to preserve potentially informative patterns in the distributions of artifacts and features. These are the early Paleoindian bone bed and the Wilson component.

Models of modern hunter-gatherer use and organization of space and their spatial distribution of activities (discard, human/natural dispersion ofartifacts, e.g., through size sorting) provide crucial keys for understanding the patterning observed on archeological sites (Bartram et al. 1991; O'Connell et al. 1991). Also the integration ofmultiple lines of evidence from other forms of analysis can provide a view of hunter-gatherer intrasite spatial organization that was unobtainable until recently (Cahen et al. 1979; Keeley 1991; Leroi-Gourhan and Brezillon 1972).

The first step in this procedure is to find high resolution stratigraphic contexts in the proposed excavations that are appropriate for spatial analyses. Too often lengthy and costly spatial analyses are conducted on sites where the context does not justify the effort (e.g., Rigaud and Simek 1991). A number of procedures are now commonly used that help archeologist see spatial patterns (Hietala 1984; Whallon 1984), and the realization that human activities and postabandonment processes act to distort the artifact discard patterns through size sorting and other processes is critical (Stevenson 1991). On a larger scale, changing site function (e.g., campsite versus kill-butchering site) must be 
considered as well as the possibility of unrecognized structures when searching for intrasite spatial patterns.

It appears that groups (collectors) reliant on larger amounts of stored food will have a different camp layout than groups (foragers) that are not. For example, O'Connell (1987) argues that foragers and collectors have different internal site structure. Foragers (e.g., the !Kung Bushmen of the Kalahari and Alyawara Aborigines of Australia) have household clusters at residential camps with little internal complexity, while collectors (e.g., Nunamiut Eskimos of Alaska) have more-complex residential camps that are more highly structured. At forager residential sites, research demonstrates that the most important determinants of site structure and size is length of occupation, number of occupants, seasonal variation in weather, degree of food sharing between households, reliance on food storage, and perhaps risk from larger predators (O'Connell 1987; Yellen 1977). A critical aspect of this type of research is discriminating between archeological deposits that are the product of reoccupations and those that are the product of a single occupation.

Stevenson (1991) looked at the processes involved in determining artifact distributions around hunter-gatherers' hearths. A series of intentional (expedient cleaning, systematic refuse disposal) and unintentional (scuffage, trampling, and children's play) processes result in spatial size sorting of artifacts. Small artifacts are more likely to escape cleaning, secondary removal, or a variety of unintentional processes. Thus, smaller items are discarded and remain in the locations of original use (O'Connell 1987; Stevenson 1991). Stevenson (1991) effectively argues that the longer a site is occupied, the greater the degree of size sorting. Keeley (1991), using edge-wear analysis and refitting of lithic artifacts, demonstrates this process on a prehistoric site where some artifacts were moved while others remained in the original locus ofuse. This strategy is well suited to determine the work patterns of hunters and gatherers, although no archeologists have identified gearing-up or make-and-mend work patterns in a prehistoric setting.

\section{Bioarcheology}

Human burials reliably dated to greater than 8,000 years ago are extremely few in the Americas, making the early human burial (Burial 2) at the Wilson-Leonard site important to questions of early human ecology as well as to the issue of biological relatedness to Eurasian and other early American Indian remains. This burial is now reliably dated to greater than 9,500 years ago, and its significance to the early peopling of the Americas is continent-wide.

Priority objectives in this project have been to fully describe the individual represented by these early human remains and then to consider the individual in reference to the population of which she was a member. Both of these goals are constrained by the imperfect condition of the Wilson-
Leonard skeleton; the latter goal is also acheivable only to the extent permitted by the very limited sample of early remains in the Western Hemisphere.

\section{Artifact Typology and Cultural Systematics}

Archeologists have applied various terms to artifacts, artifact complexes, and sequences of artifact complexes found in Central Texas. Little consensus exists in the use of these terms, and the appropriateness of many are hotly debated. Although it should not be the case, the terms sometimes interfere with analysis and interpretation by predisposing the investigator toward one conclusion or another. This point has been made cogently by Johnson (1987) concerning use of the term "phase." Functional terms (e.g., "scraper," "projectile point"), and formal stylistic or type names ("Plainview," "Andice") applied to artifacts also strongly influence interpretations. The debate about these terms in Texas archeology mirrors debates that are occurring throughout the discipline of archeology in terms of the meaning of artifact style as used by archeologists (Sackett 1982, 1985, 1989; Wiessner 1983, 1984, 1985).

Careful, objective analysis of the Wilson-Leonard data was aimed at improving these terminological problems. The long sequence of cultural deposits at the site impinge on almost every aspect of Central Texas archeology and issues of systematics and typology are to be addressed repeatedly. For example, a number of unfluted Paleoindian lanceolate type names are used without strict adherence to the original definitions and type collections. Plainview is an extreme case. Other examples are the Early Archaic split-stem forms (Gower and Hoxie). These are not recognized with the same typological rigor as later Archaic forms. A systematic analysis of the unfluted Paleoindian lanceolate points and the Early Archaic split-stem projectile points was undertaken in an attempt to better understand the typological variability represented by these forms, to better define the chronostratigraphic patterns, and to refine the cultural systematics for these two major but poorly understood cultural intervals.

\section{SUMMARY}

The eight primary research objectives for the WilsonLeonard site are prehistoric chronology, paleoenvironmental reconstruction, site formation processes, resource exploitation, technological organization, spatial organization, bioarcheology, and artifact typology and cultural systematics. Each is addressed with varying success and effort. A great deal of data addressing these research objectives is presented in this and its companion volumes, and the resulting story provides one of the more comprehensive views of the prehistoric record in Texas. Beyond the analyses and interpretations reported here, considerable raw data have been assembled, organized, and preserved for future study. 


\section{GEOLOGY AND STRATIGRAPHY}

by Paul Goldberg and Vance T. Holliday

\section{INTRODUCTION}

Geoarcheological research has a long history in the Old World (e.g., Lavi lle et al. 1980) and in many parts of North America (e.g., Lasca and Donahue 1990). In Texas, however, the tradition of integrating geoscientific and archeological research at the time the Wilson-Leonard work began was regionally localized and almost nonexistent in cultural resource mitigation. The only area with a long and continuous record of geoarcheological investigations was on the High Plains, including immediately neighboring parts of New Mexico (Holliday 1997, in press; Sellards 1952). Other regions of Texas have a more limited history of geoarcheological research (e.g., Ferring in press).

The initial excavation strategy at Wilson-Leonard (19821984) was exclusively archeological in design and purpose, but in its later stages, was influenced by Glen L Evans who is one of the pioneers of integrated geological and archeological investigations (Holliday 1989a). Evans repeatedly urged the excavators to deepen their exposures to determine the fu II extent of the Quaternary fill at the site and one ofthe soundings dug as a result of that urging resulted in discovety ofBurial 2 in December 1982. That discovery further led to excavations that exposed the three earliest components at the site (Wilson, Folsom, and Clovis). It also led to a posthoc description and interpretation of the exposed geologic section by Vance T. Holliday. The geologic insights ofEvans and the detailed and thorough study of the exposures by Holliday constitute historically as well as empirically significant contributions to the archeology ofCentral Texas. Nonetheless, important geologic questions remained unaddressed and unanswered.

By the time of the later excavation (1992-1993), archeologists in Texas were more often with integrating their methods with those of geologists (e.g., Blum and Valastro 1992; Bousman and Fields 1988; Ferring 1990; Holliday 1985; Meltzer 1991; Ricki is 1993). This second phase of excava- tion was explicitly geoarcheological in its approach and included (I) an assessment of the geologic setting of the site (see Chapter 2); (2) an excavation strategy of exposing the full vertical extent of the section and core-drilling to determine the geometry ofbedrock and the Quaternary valley fill units; (3) an expanded stratigraphic/pedogenic documentation of the exposures; and (4) an examination of the microscopic properties of the Quaternary sediments and soils (see Chapter 29). This chapter integrates the findings of both phases of excavation and presents all of the descriptive material except that of the regional geologic setting and the micromorphological thin sections.

\section{AIMS}

As in the excavation of all archeological sites regardless of locality or time period, it is imperative to understand the geological context if we are to appreciate fully the significance ofthe archeological data. The aim ofthis chapter is to describe and characterize the stratigraphy at the WilsonLeonard site.

This effort follows the presentation of the regional geology and stratigraphic setting of the site (Chapter 2) and presents a consideration of the stratigraphy of the site itself, including a discussion of the lithostratigraphic units and the results of bulk sediment analyses. This chapter closes with a summary of the paleoenvironmental interpretations based on these geological data and an evaluation of paleoenvironmental change during the period of occupation, from the end of the Pleistocene through the Holocene.

\section{SITE STRATIGRAPHY}

The stratigraphy at the Wilson-Leonard site is complex, and comprehension of it has evolved from the time of the original TxDOT excavations through the course of the morerecent TARL excavations. This complexity has stemmed from 
a number of factors. These include the intrinsic difficulties in studying any natural pedostratigraphic exposures, the fact that much of what was exposed in 1982 by TxDOT was not observed by TARL researchers, and the differences in approach and experience of the personnel in each digging campaign. For the sake of clarity, the stratigraphic aspects of the site as exposed during the TxDOT phase of excavation are summarized, followed by detailed stratigraphic descriptions as revealed during the TARL phase.

\section{TxDOT Stratigraphy}

The initial work on the geoarcheology of the WilsonLeonard site was carried out by Vance T. Holliday during the TxDOT phase of excavation in the spring and summer of 1983. This work focused on the stratigraphy, sedimentology, and soil geomorphology of the site, with the ultimate goal ofreconstructing the late Quaternary history of the site (Holliday 1989b, 1992). Holliday summarized the regional setting, stratigraphy, sedimentology, pedology, and geological environment of the site based on field observations of both excavated and natural exposures and on laboratory analyses (particle-size analysis, organic carbon, calcium carbonate, and phosphorus content).

The bulk of the stratigraphic information came from exposures associated with the TxDOT Area A excavations and from individual test trenches in the area (Figure 6-1). Holliday studied 13 profiles in detail. Profiles $1,2,12$, and 13 are from the main block (Blocks 4 and 6), whereas Profiles 3 through 8 are from the west wall of the large main trench (Blocks 1-3) that extends south from the southwest corner of the main block(seeFigure 6-1). Profile 10 comes from a2$\mathrm{x}-2-\mathrm{m}$ square east of the of main block (E40/S70); Profile 9 is one of two 2-x-2-m squares in Area B (northwest of the main block). Profile 11 is situated along the cutbank at the confluence of Spanish Oak and Brushy creeks (Holliday 1989b:3).

Holliday's detailed descriptions of these profiles followed basically a soil-geographic approach using standard soil nomenclature (Soil Survey Staff 1951, 1975), in which stratigraphic units were characterized using a system that combines the recognition of depositional units and pedological ones. These descriptions are presented in Table 6-1 along with the approximate equivalents of the TARL stratigraphic units (Figure 6-2). Thus, for example, using this nomenclature in Holliday's Profile 1, he recognized "Stratum 4" as "2Bt2bl" (which corresponds to TARL Unit II [see below]), where $2 \mathrm{Bt} 2 \mathrm{bl}$ represents from the top down, the second sedimentary layer ("2") and the first buried soil ("bl") which in this case corresponds to a Bt2 (illuvial) horizon. As discussed below, the TARL stratigraphic units were formulated using essentially descriptive criteria with fewer genetic overtones (e.g., soil horizons).

Holliday (1989b) recognized six stratigraphic units on the basis oflithology, unconformities, and soils (Table 6-2).
Several units were composed of more than one deposit but were not subdivided because only limited exposures were available. Overall, however, he recognized that the sediments are composed of calcareous alluvium and colluvium, the latter derived from the calcareous valley walls; these sediments are inclined toward the north, in the direction of Brushy Creek.

Stratum 1, the oldest, rested on bedrock in the northern part of the TxDOT excavation and was exposed both in Block 6 and in Brushy and Spanish Oak creeks. It is composed of both alluvial sand and gravel and colluvially derived angular limestone fragments, reaching a thickness of approximately $3.5 \mathrm{~m} \mathrm{~A}$ few flakes of chert appeared to be redeposited.

Stratum 2 is the most complex unit, with evidence for several periods of occupation. It was examined in Profiles 1 , $2,9,11,12$, and 13 and is generally fine-grained loam with little sand. It is about $1 \mathrm{~m}$ thick and exhibits two depositional/pedologic facies.

Stratum 2A is yellow brown, better drained, and probably accumulated in a low-energy, overbank environment; a weakly developed A horizon caps the subunit and represents a significant, though brief hiatus in its deposition. Stratum $2 \mathrm{~A}$ constitutes part of a ridge-and-swale topography that was filled by the sediments in Stratum 2B. Stratum $2 \mathrm{~A}$ is apparently coeval with the so-called Bison bone bed. The Burial 2 pit, adjacent to the deep test at the north of the trench, seems to have intersected the top of the A horizon of Unit2A.

Stratum 2B covers and postdates Stratum 2A and is a dark brown, organic-rich facies representing poor drainage probably associated with marshy conditions. This swale gradually became filled with $2 \mathrm{~B}$, and the higher surfaces were subaerially weathered and subjected to pedogenesis, which formed a weak soil at the top of Stratum 2A, termed the "Leanne soil" (Holliday 1989b: 10). Yellow and gray mottling (oxidation and reduction of iron) exhibited in Strata 2A and $2 \mathrm{~B}$ point to a high and fluctuating water table.

Stratum 3, ca. $70 \mathrm{~cm}$ thick, is composed of two brown, fine-grained units, with some lenses of gravel that dip to the north and have been truncated upslope of the main block. These probably represent primarily overbank deposits. "The lower part (Unit 3A) rests unconformably on Stratum 2 and the upper part (3B) rests unconformably on 3A. Reddening and weak structural development in both $3 \mathrm{~A}$ and $\mathrm{B}$ indicate some soil formation in each unit" (Holliday 1989b: 13). This stratum also exhibited signs of mottling, which was probably produced at the same time as that in the underlying Stratum 2 "The radiocarbon ages and weakly developed nature of the soils in Stratum 3 indicate that deposition and erosion of and soil formation in the unit did not involve a significant amount of time" (Holliday 1989b: 14).

Stratum 4, a yellow-brown gravelly silt up to 80 am thick, is prominent in the main block. Its lithology points to a relatively active stream channel characterized by several events 


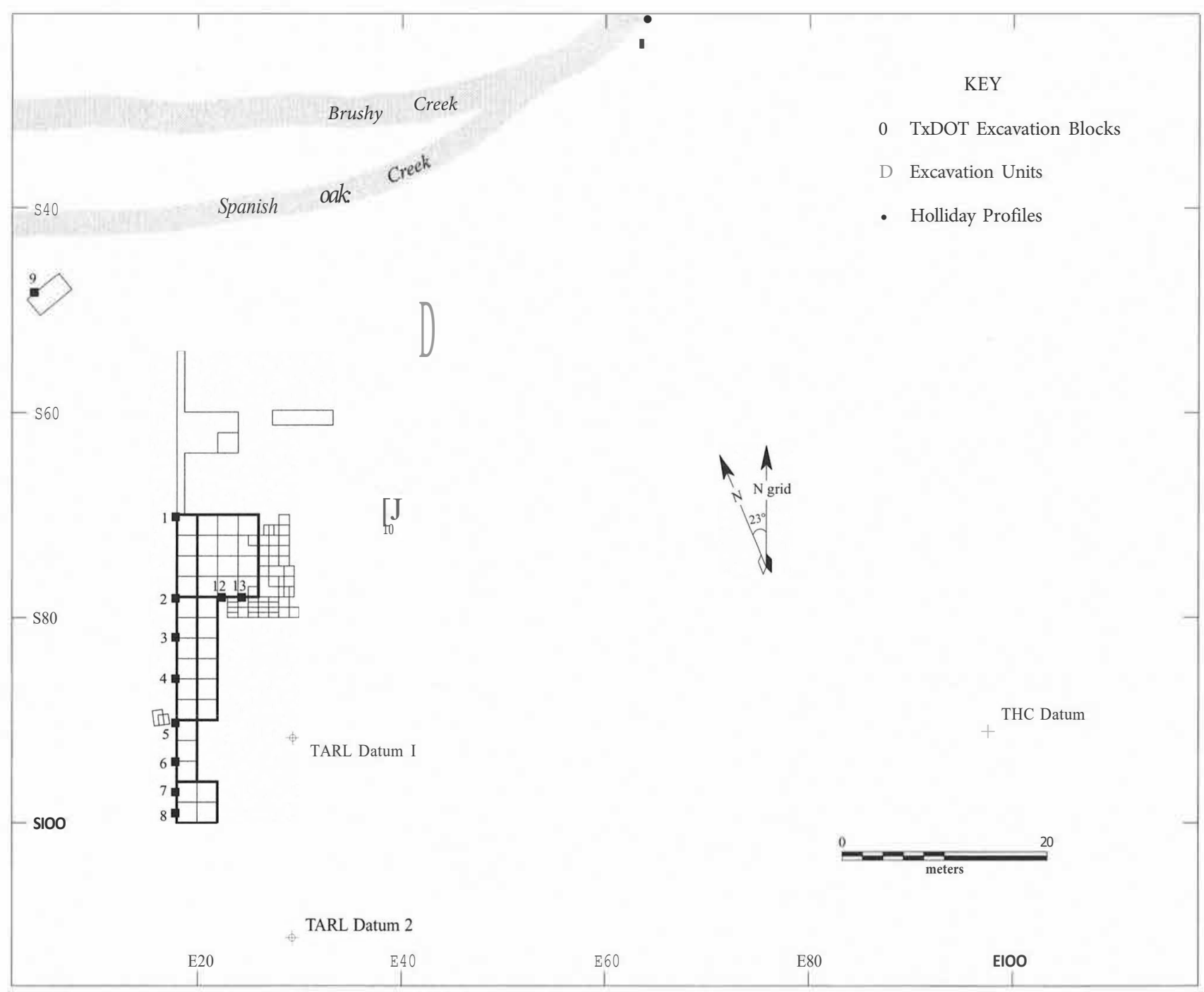

FIGURE 6-1. Map of the site area showing location of TxDOT and TARL excavated areas. Numbered points refer to location of sampling columns of Vance Holliday from TxDOT excavations.

of erosion and gravel deposition as well as some overbank sedimentation.

Stratum 5 is a brown, silty clay to silty clay loam to clay loam associated with common occurrences of pebbles, angular limestone fragments, and fire-cracked rocks; the latter increase in frequency in the direction of the valley walls to the south. This stratum is primarily the result of low-energy, overbank sedimentation with additions of slopewash. A moderately well-developed soil formed in Stratum 5 is termed the "Stiba soil," and it is characterized by a thick, dark A horizon that occurs throughout the main block, particularly in association with Early Archaic features and artifacts (these archeological horizons are discussed below in relation to the TARL stratigraphic system). The B horizon has moder- ate color and structural development and exhibits an accumulation of $\mathrm{CaC}_{3} \cdot 1$

Stratum 6, up to $160 \mathrm{~cm}$ thick, is lithologically and pedologically identical to Stratum 5 and likewise thins to the south. The main difference between the two strata is the presence of a dense, artificial accumulation of burned rocks (Burned Rock Midden 1) near the surface at the south end of the main trench. In addition, burned angular limestone fragments are also common throughout the unit. Subdivisions of Stratum 6 were not apparent, and it has aggraded slowly throughout the Holocene as a result of mostly slopewash and some occasional overbank sedimentation.

The soil formed in Stratum 6 is the present surface soil of the Wilson-Leonard terrace and therefore was named the

\footnotetext{
Ih thin section, this accumulation of $\mathrm{CaCO}_{3}$ is interpreted as having probably developed in the underlying sediment of Stratum 4 and is not apparently related to the formation of the Stiba soil. In fact, there appears to be a slight unconformity between these "A" and "B" horizons.
} 
TABLE 6-1

Soil/Sediment Analytical Data from TxDOT Excavations (Holliday 1989b)

\begin{tabular}{|c|c|c|c|c|c|c|c|c|c|c|}
\hline Profile & $\begin{array}{l}\text { Holliday } \\
\text { Stratum }\end{array}$ & Horizon & $\begin{array}{l}\text { Average } \\
\text { Depth }\end{array}$ & $\% 0 . C$. & $\% \mathrm{CaCO}_{3}$ & $\mathrm{p}(\mathrm{ppm})$ & $\%$ Sand & $\%$ Silt & \%Clay & $\begin{array}{l}\text { TARL-equivalent Unit } \\
\text { (Columns } 1 \text { and } 2 \text { ) }\end{array}$ \\
\hline \multicolumn{11}{|c|}{ A. Sorted by Profile } \\
\hline $\mathrm{I}$ & & Al & & 2.1 & 61.3 & 90 & 21.2 & 42.7 & 36.1 & Ilic \\
\hline 1 & & A2 & & 2 & 50.7 & 245 & 4.6 & 52.6 & 42.8 & Ille \\
\hline $\mathrm{I}$ & & Ap & & 2.2 & 64.6 & 165 & 29 & 39.7 & 31.3 & IIlc \\
\hline $\mathrm{I}$ & & Bit & & 13 & 53.9 & 263 & 6.5 & 53 & 40.5 & IIIb \\
\hline $\mathrm{I}$ & & $\mathrm{B} 2 \mathrm{t}$ & & $\mathrm{I}$ & 57.3 & 269 & 12.2 & 51.1 & 36.8 & $\mathrm{IIIb}$ \\
\hline $\mathrm{I}$ & & B3t & & 0.9 & 55.7 & 330 & 17.6 & 47.4 & 35 & IIIb \\
\hline 1 & & BA & & 1.6 & 59.6 & 263 & 5.2 & 53.5 & 41.3 & $\mathrm{IIIb}$ \\
\hline $\mathrm{I}$ & & $2 \mathrm{Bt} 2 \mathrm{bl}$ & & & & & 24 & 43.9 & 32.2 & IIIIa \\
\hline $\mathrm{I}$ & & $2 \mathrm{Bt} 2 \mathrm{~b} 1(210)$ & & 0.5 & 55.6 & 225 & & & & Illa \\
\hline 1 & & $\mathrm{Ab} !$ & & & & & 15.5 & 48.7 & 35.8 & $\mathrm{ma}$ \\
\hline 1 & & Abl (160) & & 0.8 & 54.2 & 315 & & & & Illa \\
\hline $\mathrm{I}$ & & Abl (172) & & 0.8 & 54.9 & 338 & & & & Illa \\
\hline $\mathrm{I}$ & & $\mathrm{Ab} 1(182)$ & & 0.7 & 53.1 & 275 & & & & IIIIa \\
\hline 1 & & Btlbl & & & & & 24.2 & 46.4 & 29.4 & Illa \\
\hline $\mathrm{I}$ & & Btlbl (194) & & 0.7 & 59.2 & 263 & & & & Illa \\
\hline 1 & & Btlbl (202) & & 0.6 & 58.5 & 230 & & & & $\mathrm{ma}$ \\
\hline $\mathrm{I}$ & & $2 \mathrm{Bt} 2 \mathrm{~b} 1(220)$ & & 0.7 & 59.3 & 216 & & & & II \\
\hline 1 & 4 & $3 \mathrm{CBbl}$ & & 0.2 & 61.4 & 152 & 28.2 & 42.6 & 29.2 & II \\
\hline 1 & $3 \mathrm{~B}$ & 3Bwb2 & & 0.1 & 57.3 & 180 & 29.1 & 38.9 & 32 & Id? \\
\hline 1 & $3 \mathrm{~B}$ & 3Bwgb2 & & 0.1 & 59.9 & 160 & 28.1 & 43.3 & 28.6 & $\mathrm{Id} ?$ \\
\hline $\mathrm{I}$ & $3 \mathrm{~A}$ & 3Bwlb3 & & 0.1 & 57.9 & 180 & 23.2 & 44.1 & 32.7 & lsi \\
\hline 1 & $3 \mathrm{~A}$ & $3 \mathrm{Bw} 2 \mathrm{~b} 3$ & & 0.1 & 60.2 & 230 & 27 & 42 & 31 & lsi \\
\hline $\mathrm{I}$ & $2 \mathrm{~B}$ & $3 \mathrm{Ab} 4$ & & 0.2 & 60.4 & 480 & 24.8 & 43.8 & 31.4 & lsi \\
\hline 1 & $2 \mathrm{~A}$ & $3 \mathrm{Ab} 5$ & & 0.1 & 61.4 & 180 & 21.3 & 47.2 & 31.5 & lsi \\
\hline $\mathrm{I}$ & $2 \mathrm{~A}$ & 3Bwb5 & & 0.1 & 60.9 & 170 & 19.4 & 48.4 & 32.2 & Isi \\
\hline $\mathrm{I}$ & $2 \mathrm{~A}$ & 3 Cglb5 & & 0.1 & 58.7 & 90 & 13.9 & 52.4 & 33.7 & $\lg 1$ \\
\hline 1 & & $4 \mathrm{Cg} 2 \mathrm{~b} 5$ & & 0.1 & 66.3 & 93 & 40.6 & 34.8 & 24.7 & $\lg !$ \\
\hline 1 & & $5 \mathrm{Cg} 3 \mathrm{~b} 5$ & & 0.1 & 58.7 & 95 & 21.2 & 47.1 & 31.8 & Igl \\
\hline 1 & & 6Cg4b5 & & 0.1 & 68.4 & 85 & 39.6 & 36.8 & 23.7 & $\lg !$ \\
\hline 2 & & Al & 19 & 0.8 & 48.6 & 500 & 4.8 & 51.3 & 43.9 & Ilic \\
\hline 2 & & A2 & 39 & 0.7 & 50.9 & 460 & 6.5 & 51.6 & 41.9 & IIlc \\
\hline 2 & & Ap & 5 & 0.9 & 47.9 & 500 & 11.5 & 49.2 & 39.3 & IIIIc \\
\hline 2 & & BA & 64 & 0.3 & 54.5 & 460 & 6.4 & 52.7 & 40.8 & IIIc/11lb? \\
\hline 2 & & Bwl & 91 & 0.2 & 55.8 & 330 & 10 & 51.2 & 38.8 & IIIb \\
\hline 2 & & Bw2 & 116 & 0.2 & 55 & 590 & 16.7 & 47.9 & 35.4 & $\mathrm{IIIb}$ \\
\hline 2 & & Bw3 & 134 & 0.2 & 55.5 & 630 & 18.7 & 47.6 & 33.7 & $\mathrm{IIIb}$ \\
\hline 2 & 5 & Abl & 168 & 0.2 & 53.3 & 580 & 16.2 & 47.2 & 36.6 & Illa \\
\hline 2 & 5 & Bwbl & 185 & 0.1 & 56.8 & 360 & 22.1 & 46.4 & 31.5 & Illa \\
\hline 2 & & 2Bwlbl & 202 & 0.1 & 56.6 & 380 & 28.7 & 42.4 & 28.9 & II \\
\hline 2 & & 2Bw2b1 & 221 & 0.2 & 55.5 & 330 & 23.7 & 46.7 & 29.6 & II \\
\hline 2 & 3 & 3Bwb2 & 245 & 0.1 & 59.4 & 500 & 27.9 & 45.8 & 26.3 & lsi \\
\hline 2 & 2 & $4 \mathrm{Ab} 3$ & 268 & 0.1 & 63.2 & 400 & 27.7 & 45.5 & 26.8 & lsi \\
\hline 2 & 2 & $4 \mathrm{Cgb} 3$ & 276 & 0.1 & 67.1 & 230 & 32.2 & 43.5 & 24.3 & lsi \\
\hline 5 & 6 & $2 \mathrm{~A} 2$ & 22 & 2.8 & 27.5 & 570 & & & & III \\
\hline 5 & 6 & $2 \mathrm{~A} 3$ & 58 & 2.4 & 39.4 & 205 & & & & III \\
\hline 5 & 6 & $2 \mathrm{Bw}$ & 88 & 12 & 43.6 & 450 & & & & III \\
\hline 5 & 6 & 3Bwk & 107 & & & & & & & III \\
\hline 5 & 6 & $\mathrm{Al}$ & 3 & 2.9 & 29.7 & 405 & & & & III \\
\hline 5 & 5 & $3 \mathrm{Akb}$ & 121 & 0.9 & 45.7 & 450 & & & & III \\
\hline 5 & 5 & 3Bwklb & 146 & 0.6 & 46.6 & 555 & & & & III \\
\hline
\end{tabular}


Table 6-1, continued

\begin{tabular}{|c|c|c|c|c|c|c|c|c|c|c|}
\hline Profile & $\begin{array}{l}\text { Holliday } \\
\text { Stratum }\end{array}$ & Horizon & $\begin{array}{l}\text { Average } \\
\text { Depth }\end{array}$ & $\%$ O.C. & $\% \mathrm{CaCO}_{3}$ & $\mathrm{p}(\mathrm{ppm})$ & $\%$ Sand & $\%$ Silt & $\%$ Clay & $\begin{array}{l}\text { TARL-equivalent Unit } \\
\text { (Columns } 1 \text { and } 2 \text { ) }\end{array}$ \\
\hline 5 & 5 & 3Bwk2b & 177 & 0.4 & 46.4 & 495 & & & & III \\
\hline 8 & 6 & Al & 18 & 2 & 34.7 & 160 & 24.5 & 47.4 & 28.1 & III \\
\hline 8 & 6 & BA & 50 & 1.3 & 37.6 & 170 & 17.5 & 49.2 & 33.3 & III \\
\hline 8 & 6 & Bwkl & 72 & 0.7 & 43 & 495 & 24 & 36 & 40 & III \\
\hline 8 & 6 & Bwk2 & 88 & 0.4 & 49 & 390 & 21.6 & 47.8 & 30.6 & III \\
\hline 8 & 6 & Bwk3 & 105 & 0.3 & 47 & 642 & 28.6 & 47.6 & 23.8 & III \\
\hline 8 & 6 & Bwk4 & 143 & 0.3 & 49.6 & 185 & 39.2 & 39.1 & 21.7 & III \\
\hline 9 & 6 & Al & 18 & 1.9 & 47.9 & 500 & 16.6 & 52.1 & 31.3 & III \\
\hline 9 & 6 & A2 & 50 & 1.3 & 51.7 & 630 & 14.8 & 48.8 & 36.4 & III \\
\hline 9 & 6 & Abl & 72 & 0.6 & 53.5 & 690 & 11.9 & 52.5 & 35.6 & III \\
\hline 9 & 6 & BAbl & 88 & 0.5 & 53.1 & 650 & 9.9 & 53.4 & 36.6 & III \\
\hline 9 & 6 & Bwlbl & 105 & 0.3 & 49.7 & 440 & 8.3 & 54.9 & 36.7 & III \\
\hline 9 & 6 & Bw2bl & 1.43 & 0.1 & 47.9 & $3 ! 0$ & 9.1 & 48.8 & 42.1 & III \\
\hline 9 & 5 & Bkbl & 212 & O.1 & 54 & 200 & {$[2.1$} & 49.3 & 38.6 & III \\
\hline 9 & 5 & Bw3bl & 185 & 0.1 & 48.1 & 200 & 9.1 & 49.9 & 41 & III \\
\hline 9 & 5 & Clbl & 231 & 0.1 & 56.1 & 220 & 14.3 & 50.1 & 35.6 & III \\
\hline 9 & 4 & $2 \mathrm{C} 2 \mathrm{~b} 1$ & 249 & 0.1 & 61.5 & 150 & 30.9 & 41.1 & 28 & II \\
\hline 9 & 4 & $3 \mathrm{C} 3 \mathrm{bl}$ & 278 & 0.2 & 53.4 & 185 & 9.9 & 53.6 & 36.5 & II \\
\hline 9 & 2 & 3Alb2 & 305 & 0.2 & 53.8 & 220 & 11.5 & 51.3 & 37.2 & I \\
\hline 9 & 2 & $3 \mathrm{~A} 2 \mathrm{~b} 2$ & 320 & 0.4 & 36.9 & 110 & & & & I \\
\hline 9 & 2 & $3 \mathrm{Cgb} 2$ & 334 & 0.2 & 35.6 & 70 & & & & I \\
\hline 10 & 6 & Al & 8 & 2.4 & 30.9 & 645 & 19.9 & 59.9 & 20.2 & III \\
\hline 10 & 6 & A2 & 30 & 1.7 & 28 & 360 & 17.2 & 50.5 & 32.3 & III \\
\hline 10 & 6 & Bw & 54 & 0.8 & 33.2 & 696 & 12.9 & 50 & 37.1 & III \\
\hline 10 & 6 & BwKl & 84 & 0.5 & 32.5 & 225 & {$[4.2$} & 50 & 35.8 & III \\
\hline 10 & 6 & BwK2 & 103 & 0.4 & 27.5 & 60 & 10.2 & 54 & 35.8 & III \\
\hline 10 & 5 & Bwklbl & 132 & 0.4 & 30. I & 107 & 9.9 & 44.9 & 45.2 & III \\
\hline 10 & 5 & Bwk2bl & 177 & 0.3 & 35.7 & 70 & I 1.6 & 47 & 41.4 & III \\
\hline 10 & 5 & Bwkgbl & 215 & 0.1 & 33.9 & 55 & 19 & 51 & 30 & III \\
\hline 10 & $3 ?$ & Bwkgb2 & 243 & 0.2 & 38.9 & 70 & 21.6 & 49.5 & 28.9 & I \\
\hline 11 & $5 / 6$ & Al & JO & 2.2 & 27.3 & 55 & 23.5 & 50 & 26.5 & III ? \\
\hline 11 & $5 / 6$ & A2 & 31 & 15 & 25.8 & 110 & 13.4 & 49.4 & 37.2 & III ? \\
\hline 11 & $5 / 6$ & BwKl & 77 & 0.5 & 34.9 & 40 & J & 47.6 & 42.4 & III ? \\
\hline 11 & $5 / 6$ & BwK2 & 112 & 0.5 & 37 & 33 & 12.3 & 51.4 & 36.3 & III ? \\
\hline 11 & $5 / 6$ & BwK3 & 133 & 0.3 & 42.4 & 25 & 9.9 & 51 & 39.1 & III ? \\
\hline 11 & 2 & Abk & 166 & 0.3 & 43.1 & 33 & 9.3 & 54 & 36.7 & lsi? \\
\hline 11 & 2 & Bwkb & 188 & 0.3 & 44.8 & 98 & 12.8 & 54.7 & 32.5 & Isi? \\
\hline 11 & 1 & $3 \mathrm{Cgb}$ & 252 & 0.2 & 45.5 & 43 & 19.6 & 53.6 & 26.8 & $\operatorname{lgl}$ \\
\hline 12 & 3 & Alb & 259 & 0.3 & 45.7 & 170 & & & & Isi \\
\hline 12 & 2 & $\mathrm{~A} 2 \mathrm{~b}$ & 286 & 0.3 & 47.7 & 135 & & & & Isi \\
\hline 12 & 2 & $\mathrm{Cglb}$ & 320 & 0.2 & 51.1 & 75 & & & & Isi \\
\hline 12 & 2 & $\mathrm{Cg} 2 \mathrm{~b}$ & 352 & 0.2 & 51.4 & 110 & & & & lsi \\
\hline \multicolumn{11}{|c|}{ B. Sorted by Stratum } \\
\hline I & 6 & Al & & 2.1 & 61.3 & 90 & 21.2 & 42.7 & 36.1 & \\
\hline I & 6 & A2 & & 2 & 50.7 & 245 & 4.6 & 52.6 & 42.8 & \\
\hline 1 & 6 & Ap & & 2.2 & 64.6 & 165 & 29 & 39.7 & 31.3 & \\
\hline 1 & 6 & Bit & & 1.3 & 53.9 & 263 & 6.5 & 53 & 40.5 & \\
\hline 1 & 6 & B2t & & l & 57.3 & 269 & 12.2 & 51.1 & 36.8 & \\
\hline 1 & 6 & B3t & & 0.9 & 55.7 & 330 & 17.6 & 47.4 & 35 & \\
\hline \multirow[t]{3}{*}{1} & 6 & BA & & 1.6 & 59.6 & 263 & 5.2 & 53.5 & 41.3 & \\
\hline & & & $\mathrm{X}$ & 1.59 & 57.59 & 232.1.4 & 13.76 & 48.57 & 37.69 & \\
\hline & & & $1-\mathrm{cr}$ & 0.53 & 4.68 & 79.29 & 9.26 & 5.49 & 4.05 & \\
\hline
\end{tabular}


Table 6-1, continued

\begin{tabular}{|c|c|c|c|c|c|c|c|c|c|c|}
\hline Profile & $\begin{array}{l}\text { Holliday } \\
\text { Stratum }\end{array}$ & Horizon & $\begin{array}{l}\text { Average } \\
\text { Depth }\end{array}$ & $\% 0 . C$. & $\% \mathrm{CaCO}_{3}$ & $\mathrm{p}(\mathrm{ppm})$ & $\%$ Sand & $\%$ Silt & $\%$ Clay & $\begin{array}{l}\text { TARL-equivalent Unit } \\
\text { (Columns } 1 \text { and 2) }\end{array}$ \\
\hline 2 & 6 & $\mathrm{Al}$ & 19 & 0.8 & 48.6 & 500 & 4.8 & 51.3 & 43.9 & \\
\hline 2 & 6 & A2 & 39 & 0.7 & 50.9 & 460 & 6.5 & 51.6 & 41.9 & \\
\hline 2 & 6 & Ap & 5 & 0.9 & 47.9 & 500 & 11.5 & 49.2 & 39.3 & \\
\hline 2 & 6 & BA & 64 & 0.3 & 54.5 & 460 & 6.4 & 52.7 & 40.8 & \\
\hline 2 & 6 & Bwl & 91 & 0.2 & 55.8 & 330 & 10 & 51.2 & 38.8 & \\
\hline 2 & 6 & Bw2 & 116 & 0.2 & 55 & 590 & 16.7 & 47.9 & 35.4 & \\
\hline 2 & 6 & Bw3 & 134 & 0.2 & 55.5 & 630 & 18.7 & 47.6 & 33.7 & \\
\hline & & & $\mathrm{X}$ & 0.47 & 52.60 & 495.71 & 10.66 & 50.21 & 39.11 & \\
\hline & & & 1-cr & 0.31 & 3.39 & 97.44 & 5.36 & 1.98 & 3.58 & \\
\hline 5 & 6 & $2 \mathrm{~A} 2$ & 22 & 2.8 & 27.5 & 570 & & & & \\
\hline 5 & 6 & $2 \mathrm{~A} 3$ & 58 & 2.4 & 39.4 & 205 & & & & \\
\hline 5 & 6 & $2 \mathrm{Bw}$ & 88 & 1.2 & 43.6 & 450 & & & & \\
\hline 5 & 6 & 3Bwk & 107 & & & & & & & \\
\hline 5 & 6 & $\mathrm{Al}$ & 3 & 2.9 & 29.7 & 405 & & & & \\
\hline & & & $\mathrm{X}$ & 2.33 & 35.05 & 407.50 & & & & \\
\hline & & & 1-cr & 0.78 & 7.70 & 151.90 & & & & \\
\hline 8 & 6 & $\mathrm{Al}$ & 18 & 2 & 34.7 & 160 & 24.5 & 47.4 & 28.1 & \\
\hline 8 & 6 & BA & 50 & 1.3 & 37.6 & 170 & 17.5 & 49.2 & 33.3 & \\
\hline 8 & 6 & Bwkl & 72 & 0.7 & 43 & 495 & 24 & 36 & 40 & \\
\hline 8 & 6 & Bwk2 & 88 & 0.4 & 49 & 390 & 21.6 & 47.8 & 30.6 & \\
\hline 8 & 6 & Bwk3 & 105 & 0.3 & 47 & 642 & 28.6 & 47.6 & 23.8 & \\
\hline 8 & 6 & Bwk4 & 143 & 0.3 & 49.6 & 185 & 39.2 & 39.1 & 21.7 & \\
\hline & & & $\mathrm{X}$ & 0.83 & 43.48 & 340.33 & 25.90 & 44.52 & 29.58 & \\
\hline & & & 1 -cr & 0.69 & 6.20 & 201.52 & 7.47 & 5.52 & 6.65 & \\
\hline 9 & 6 & Al & 18 & 1.9 & 47.9 & 500 & 16.6 & 52.1 & 31.3 & \\
\hline 9 & 6 & A2 & 50 & 1.3 & 51.7 & 630 & 14.8 & 48.8 & 36.4 & \\
\hline 9 & 6 & Abl & 72 & 0.6 & 53.5 & 690 & 11.9 & 52.5 & 35.6 & \\
\hline 9 & 6 & BAbl & 88 & 0.5 & 53.1 & 650 & 9.9 & 53.4 & 36.6 & \\
\hline 9 & 6 & Bwlbl & 105 & 0.3 & 49.7 & 440 & 8.3 & 54.9 & 36.7 & \\
\hline 9 & 6 & Bw2bl & 143 & 0.1 & 47.9 & 310 & 9.1 & 48.8 & 42.1 & \\
\hline & & & $\mathrm{x}$ & 0.78 & 50.63 & 536.67 & 11.77 & 51.75 & 36.45 & \\
\hline & & & 1 -cr & 0.68 & 2.50 & 146.38 & 3.32 & 2.48 & 3.44 & \\
\hline 10 & 6 & Al & 8 & 2.4 & 30.9 & 645 & 19.9 & 59.9 & 20.2 & \\
\hline 10 & 6 & A2 & 30 & 1.7 & 28 & 360 & 17.2 & 50.5 & 32.3 & \\
\hline 10 & 6 & Bw & 54 & 0.8 & 33.2 & 696 & 12.9 & 50 & 37.1 & \\
\hline 10 & 6 & BwKI & 84 & 0.5 & 32.5 & 225 & 14.2 & 50 & 35.8 & \\
\hline 10 & 6 & BwK2 & 103 & 0.4 & 27.5 & 60 & 10.2 & 54 & 35.8 & \\
\hline & & & $\mathrm{x}$ & I. 16 & 30.42 & 397.2 & 14.88 & 52.88 & 32.24 & \\
\hline & & & $1=\mathrm{cr}$ & 0.8619 & 2.582053 & 271.765 & 3.77054 & 4.2657 & 6.96297 & \\
\hline 11 & 516 & $\mathrm{Al}$ & 10 & 2.2 & 27.3 & 55 & 23.5 & 50 & 26.5 & \\
\hline 11 & $5 / 6$ & A2 & 31 & 1.5 & 25.8 & $1 \mathrm{I} 0$ & 13.4 & 49.4 & 37.2 & \\
\hline II & $5 / 6$ & BwKI & 77 & 0.5 & 34.9 & 40 & 10 & 47.6 & 42.4 & \\
\hline 11 & $5 / 6$ & BwK2 & 112 & 0.5 & 37 & 33 & 12.3 & 51.4 & 36.3 & \\
\hline I I & $5 / 6$ & BwK3 & 133 & 0.3 & 42.4 & 25 & 9.9 & 51 & 39.1 & \\
\hline & & & & I & 33.48 & 52.6 & 13.82 & 49.88 & 36.3 & \\
\hline & & & 1-cr & 0.82 & 6.91 & 33.93 & 5.62 & 1.50 & 5.96 & \\
\hline 1 & 5 & $2 \mathrm{Bt} 2 \mathrm{bl}$ & & & & & 24 & 43.9 & 32.2 & \\
\hline $\mathrm{I}$ & 5 & 2Bt2b I (210) & & 0.5 & 55.6 & 225 & & & & \\
\hline $\mathrm{I}$ & 5 & Abl & & & & & 15.5 & 48.7 & 35.8 & \\
\hline 1 & 5 & Ab! (160) & & 0.8 & 54.2 & 315 & & & & \\
\hline $\mathrm{J}$ & 5 & Abl (172) & & 0.8 & 54.9 & 338 & & & & \\
\hline 1 & 5 & Ab! (182) & & 0.7 & 53.1 & 275 & & & & \\
\hline
\end{tabular}


Table 6- I, continued

\begin{tabular}{|c|c|c|c|c|c|c|c|c|c|c|}
\hline Profile & $\begin{array}{l}\text { Holliday } \\
\text { Stratum }\end{array}$ & Horizon & $\begin{array}{l}\text { Average } \\
\text { Depth }\end{array}$ & $\% 0 . \mathrm{C}$. & $\% \mathrm{CaCO}_{3}$ & $\mathrm{p}(\mathrm{ppm})$ & $\%$ Sand & $\%$ Silt & $\%$ Clay & $\begin{array}{l}\text { TARL-equivalent Unit } \\
\text { (Columns } 1 \text { and 2) }\end{array}$ \\
\hline 1 & 5 & Btlbl & & & & & 24.2 & 46.4 & 29.4 & \\
\hline I & 5 & Btlbl (194) & & 0.7 & 59.2 & 263 & & & & \\
\hline I & 5 & Btlbl (202) & & 0.6 & 58.5 & 230 & & & & \\
\hline 2 & 5 & $\mathrm{Abl}$ & 168 & 0.2 & 53.3 & 580 & 16.2 & 47.2 & 36.6 & \\
\hline 2 & 5 & Bwbl & 185 & 0.1 & 56.8 & 360 & 22.1 & 46.4 & 31.5 & \\
\hline 5 & 5 & $3 \mathrm{Akb}$ & 121 & 0.9 & 45.7 & 450 & & & & \\
\hline 5 & 5 & 3Bwklb & 146 & 0.6 & 46.6 & 555 & & & & \\
\hline 5 & 5 & $3 \mathrm{Bwk} 2 \mathrm{~b}$ & 177 & 0.4 & 46.4 & 495 & & & & \\
\hline 9 & 5 & Bkbl & 212 & 0.1 & 54 & 200 & {$[2.1$} & 49.3 & 38.6 & \\
\hline 9 & 5 & Bw3bl & 185 & 0.1 & 48.1 & 200 & 9.1 & 49.9 & 41 & \\
\hline 9 & 5 & Clbl & 231 & 0.1 & 56.1 & 220 & 14.3 & 50.1 & 35.6 & \\
\hline 10 & 5 & Bwklbl & 132 & 0.4 & 30.1 & $! 07$ & 9.9 & 44.9 & 45.2 & \\
\hline LO & 5 & Bwk2bl & 177 & 0.3 & 35.7 & 70 & 11.6 & 47 & 41.4 & \\
\hline 10 & 5 & Bwkgbl & 215 & 0.1 & 33.9 & 55 & 19 & 51 & 30 & \\
\hline 1 & 4 & 2Bt2b $1(220)$ & & 0.7 & 59.3 & 216 & & & & \\
\hline I & 4 & $3 \mathrm{CBbl}$ & & 0.2 & 61.4 & 152 & 28.2 & 42.6 & 29.2 & \\
\hline 2 & 4 & 2Bwlbl & 202 & 0.1 & 56.6 & 380 & 28.7 & 42.4 & 28.9 & \\
\hline 2 & 4 & 2Bw2bl & 221 & 0.2 & 55.5 & 330 & 23.7 & 46.7 & 29.6 & \\
\hline 9 & 4 & $2 \mathrm{C} 2 \mathrm{bl}$ & 249 & 0.1 & 61.5 & 150 & 30.9 & 41.1 & 28 & \\
\hline 9 & 4 & $3 \mathrm{C} 3 \mathrm{bl}$ & 278 & 0.2 & 53.4 & 185 & 9.9 & 53.6 & 36.5 & \\
\hline 2 & 3 & 3Bwb2 & 245 & 0.1 & 59.4 & 500 & 27.9 & 45.8 & 26.3 & \\
\hline 12 & 3 & Alb & 259 & 0.3 & 45.7 & 170 & & & & \\
\hline l & $3 \mathrm{~B}$ & 3Bwb2 & & 0.1 & 57.3 & 180 & 29.1 & 38.9 & 32 & \\
\hline I & $3 \mathrm{~B}$ & 3Bwgb2 & & 0.1 & 59.9 & 160 & 28.1 & 43.3 & 28.6 & \\
\hline I & $3 \mathrm{~A}$ & 3Bwlb3 & & O.1 & 57.9 & 180 & 23.2 & 44.1 & 32.7 & . \\
\hline l & $3 \mathrm{~A}$ & $3 \mathrm{Bw} 2 \mathrm{~b} 3$ & & 0.1 & 60.2 & 230 & 27 & 42 & 31 & \\
\hline 10 & $3 ?$ & Bwkgb2 & 243 & 0.2 & 38.9 & 70 & 21.6 & 49.5 & 28.9 & \\
\hline 1 & $2 \mathrm{~B}$ & $3 \mathrm{Ab} 4$ & & 0.2 & 60.4 & 480 & 24.8 & 43.8 & 31.4 & \\
\hline 1 & $2 \mathrm{~A}$ & $3 \mathrm{Ab} 5$ & & 0.1 & 61.4 & 180 & 21.3 & 47.2 & 31.5 & \\
\hline 1 & $2 \mathrm{~A}$ & 3Bwb5 & & 0.1 & 60.9 & 170 & 19.4 & 48.4 & 32.2 & \\
\hline $\mathrm{J}$ & $2 \mathrm{~A}$ & $3 \mathrm{Cglb} 5$ & & 0.1 & 58.7 & 90 & 13.9 & 52.4 & 33.7 & \\
\hline 2 & 2 & $4 \mathrm{Ab} 3$ & 268 & 0.1 & 63.2 & 400 & 27.7 & 45.5 & 26.8 & \\
\hline 2 & 2 & $4 \mathrm{Cgb} 3$ & 276 & O.1 & 67.1 & 230 & 32.2 & 43.5 & 24.3 & \\
\hline 9 & 2 & $3 \mathrm{Alb} 2$ & 305 & 0.2 & 53.8 & 220 & 11.5 & 51.3 & . 37.2 & \\
\hline 9 & 2 & $3 \mathrm{~A} 2 \mathrm{~b} 2$ & 320 & 0.4 & 36.9 & $\mathrm{I} 1 \mathrm{O}$ & & & & \\
\hline 9 & 2 & $3 \mathrm{Cgb} 2$ & 334 & 0.2 & 35.6 & 70 & & & & \\
\hline 11 & 2 & Abk & 166 & 0.3 & 43.1 & 33 & 9.3 & 54 & 36.7 & \\
\hline 11 & 2 & Bwkb & 188 & (J.3 & 44.8 & 98 & 12.8 & 54.7 & 53.5 & \\
\hline 12 & 2 & $\mathrm{~A} 2 \mathrm{~b}$ & 286 & 0.3 & 47.7 & 135 & & & & \\
\hline 12 & 2 & $\mathrm{Cglb}$ & 320 & 0.2 & 51.1 & 75 & & & & \\
\hline 12 & 2 & $\mathrm{Cg} 2 \mathrm{~b}$ & 352 & 0.2 & 51.4 & 110 & & & & \\
\hline 1 & 1 & $4 \mathrm{Cg} 2 \mathrm{~b} 5$ & & 0.1 & 66.3 & 93 & 40.6 & 34.8 & 24.7 & \\
\hline I & 1 & $5 \mathrm{Cg} 3 \mathrm{~b} 5$ & & 0.1 & 58.7 & 95 & 21.2 & 47.1 & 31.8 & \\
\hline 1 & 1 & 6Cg4b5 & & 0.1 & 68.4 & 85 & 39.6 & 36.8 & 12.7 & \\
\hline 11 & 1 & $3 \mathrm{Cgb}$ & 252 & 0.2 & 45.5 & 43 & 19.6 & 53.6 & 26.8 & \\
\hline
\end{tabular}




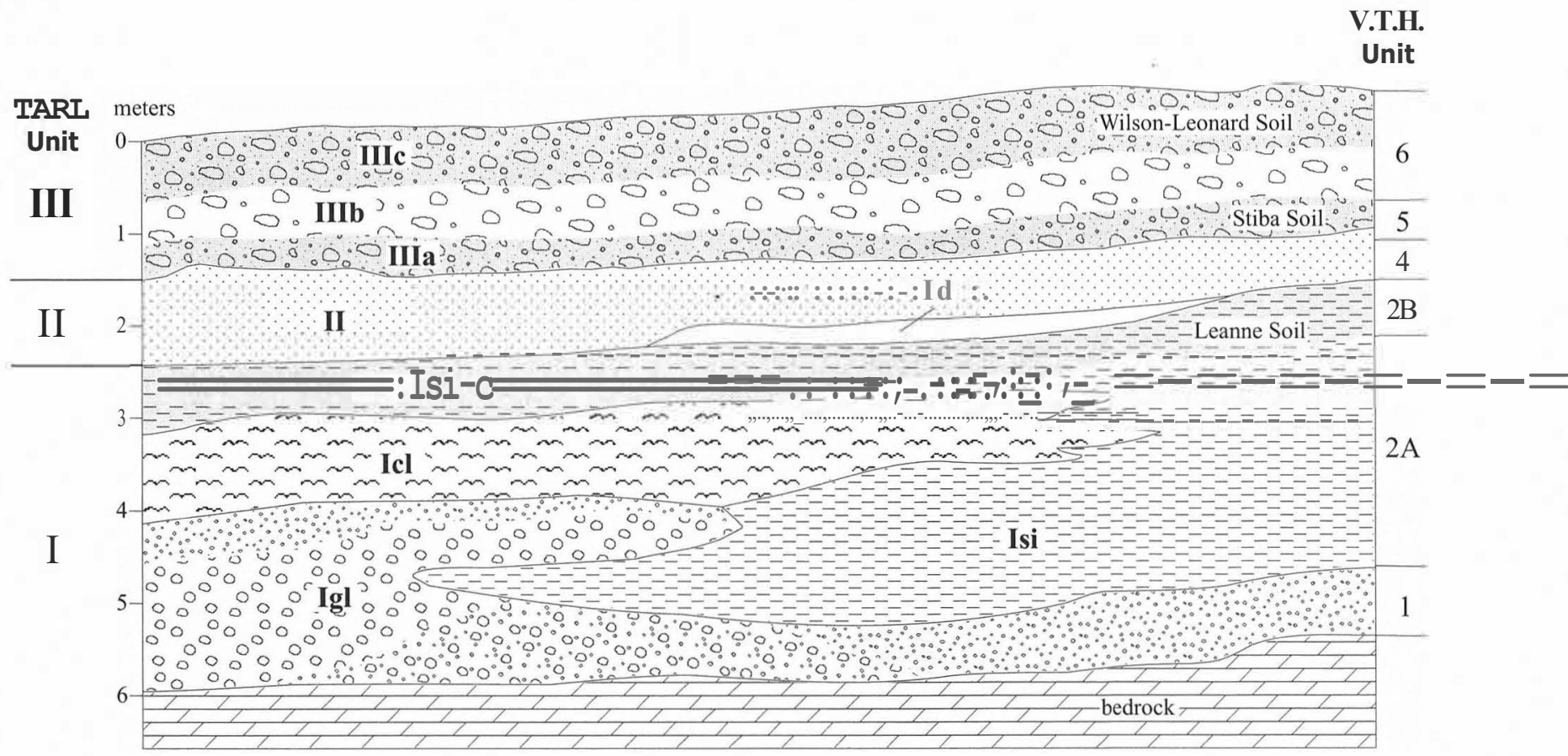

FGURE 6-2. Semi schematic profile drawing of East Profile showing stratigraphic relationships among the different units exposed during the TARL excavations. Note the approximate equivalents of the TARL units to those ofTxDOT as defined by Holliday.

TABLE 6-2

Stratlgraphic Breakdown of TxD0 T Excavations as Recognized by Hal 1 day (1989b) Wth Approximate TARLEqulvalent Units

\begin{tabular}{|c|c|c|c|c|c|}
\hline $\begin{array}{l}\text { Holliday } \\
\text { Stratum }\end{array}$ & Thickness & Composition & Depositional Environment & Soils & $\begin{array}{c}\text { Approximate TARL } \\
\text { Equivalent Units }\end{array}$ \\
\hline 6 & $\begin{array}{l}\text { up to } 160 \mathrm{~cm} \\
\text { but thins to } \mathrm{S}\end{array}$ & $\begin{array}{l}\text { similar lithology to } \\
\text { stratum } 5 \\
\text { burned rock midden }\end{array}$ & $\begin{array}{l}\text { overbank } \\
\text { slopewash (colluvium) }\end{array}$ & $\begin{array}{l}\text { Wilson- } \\
\text { Leonard }\end{array}$ & $\begin{array}{l}\text { Unit lIIc } \\
\text { Unit lIIb }\end{array}$ \\
\hline 5 & $-50 \mathrm{~cm}$ & $\begin{array}{l}\text { brown, silty clay to silty } \\
\text { clay loam to clay loam } \\
\text { pebbles and angular } \\
\text { limestone fragments } \\
\text { common } \\
\text { fire cracked rock }\end{array}$ & $\begin{array}{l}\text { overbank } \\
\text { some channel gravel }\end{array}$ & Stiba & Unit Illa \\
\hline 4 & $80 \mathrm{~cm}$ & $\begin{array}{l}\text { gravel } \\
\text { locally finer grained (e.g., } \\
\text { east test) }\end{array}$ & $\begin{array}{l}\text { channel and overbank } \\
\text { numerous cut and fills }\end{array}$ & & Unit II \\
\hline $3(3 \mathrm{~A}, 38)$ & up to $70 \mathrm{~cm}$ & $\begin{array}{l}\text { fine grained deposits with } \\
\text { lenses of gravel }\end{array}$ & $\begin{array}{l}\text { overbank but with some } \\
\text { localized channeling and } \\
\text { higher energy sediment } \\
\text { high water table---?gleying }\end{array}$ & $\begin{array}{l}\text { weakly } \\
\text { developed } \\
\text { soils in 3A } \\
\text { and 3B }\end{array}$ & Units Id and Isi \\
\hline $2(2 \mathrm{~A}, 28)$ & up to $1 \mathrm{~m}$ & $\begin{array}{l}\text { fine grained loam to clay } \\
\text { loam to silty clay loam }\end{array}$ & $\begin{array}{l}\text { low-energy overbank on } \\
\text { ridge-and-swale topography } \\
\text { high water table---?gleying }\end{array}$ & $\begin{array}{l}\text { Leanne } \\
\text { weak soil }\end{array}$ & Units Icl and Isi \\
\hline 1 & $\begin{array}{l}\text { test pit: } 2.5 \mathrm{~m} \\
\text { gully: } 3.5 \mathrm{~m}\end{array}$ & $\begin{array}{l}\text { interbedded gravel } \\
\text { sand and angular limestone } \\
\text { fragments }\end{array}$ & $\begin{array}{l}\text { high-energy channel } \\
\text { low-energy overbank } \\
\text { slopewash (colluvium) }\end{array}$ & & Unit lg! \\
\hline
\end{tabular}

"Wilson-Leonard soil." Its very dark and deep A horizon with high organic carbon and phosphorous content (see below) qualifies it as an anthropic epipedon, which is not surprising considering the substantial archeological material recovered from this zone.
The B horizon of the Wilson-Leonard soil is moderately well developed, with some color and structural development, and commonly shows an increase in $\mathrm{CaCO}_{3}$ content. It was originally thought to have pedogenic clay enrichment at the base of the A horizon, top of the B horizon, but this is not 
pronounced and could be depositional in origin. The stratigraphic evaluation discussed above is summarized in Table 6-2.

\section{TARLStratigraphy}

\section{General Comments}

The subdivision of the stratigraphic section at WilsonLeonard that evolved during the TARL excavations differs in a number of ways from that of the TxDOT excavation. These changes came about for a number of reasons. First, approximately 10 years elapsed between the time of the initial excavations by TxDOT and the later ones by TARL. The presence of RR 1431, which was constructed between the two excavation campaigns, dictated that the TARL efforts take place generally to the east of the previous ones, mostly east and somewhat south of the main TxDOT excavation block; the entire western half of the site was available only in the form of field notes, profile drawings, and photographs. Thus, the deposits exposed in 1992 and 1993 were not necessarily similar or directly comparable to those that Holliday viewed a decade earlier, since alluvial and colluvial environments such as those at the Wilson-Leonard site exhibit a great deal of lateral variation in the lithology and overall aspect of deposits.

Secondly, the TARL excavations have adopted a different approach to the stratigraphic classification and description of the deposits. Whereas the earlier TxDOT scheme was predominantly soil-geographic in nature, the present one takes a somewhat more-expansive tack. It became evident after exposure of new sections that the stratigraphic section at Wilson-Leonard was quite complex--more so than had been seen $1 \mathrm{O}$ years earlier-and that the section resulted from the combined effects of superimposed depositional and postdepositional processes that are geogenic (in its broadest sense, including pedological processes) or anthropogenic/biogenic in nature (see below for more detail).

Geogenic processes, as indicated by Holliday, are represented by alluvial and colluvial deposits. Alluvial deposition of silts and clays are particularly evident in the lower third to halfof the stratigraphic column and to a lesser extent in the upper part. Alluvial gravels occur at the base as massive accumulations, stringers, and lenses. Colluvial accretion is represented by silts and stone fragments that are derived from the bedrock hillslopes to the south/southwest. The present-day slopes of these hills are mantled by loose, angular clasts that are quite similar to those found in the profile both in terms of caliber and shape.

Anthropogenic/biogenic processes on the other hand are more varied. They include (1) the formation of burned rock middens and other cultural deposits; (2) centimetersized burrows (especially in the lower one-third of the profile) produced mainly by tree roots; (3) the formation of rhizocretions in many units; and (4) abundant earthworm activity (particularly in the upper 15 to $2.0 \mathrm{~m}$ of deposits) resulting in physical mixing of the deposits as well as secondary cementation by $\mathrm{CaCO}_{3}$.

Other manifestations ofpedogenic and other postdepositional processes are characterized by gleying of the lower strata (e.g., Strata 1-3), resulting in yellowish brown iron mottling and the precipitation of $\mathrm{CaC}_{3}$. The latter commonly takes the form of either filaments within the uppennost40-60 cm of the profile, soft rhizocretions (e.g., Stratum 4), or harder impregnations and concretions ("popcorn carbonates") that are typically well rounded and about $1 \mathrm{~cm}$ in diameter. These harder concretions occur typically in Strata 1 and 2. Finally, the probability of extensive calcium carbonate impregnations associated with earthworm activity is noted.

Consequently, in light of our inability to observe the entirety of the original TxDOT stratigraphic units in 1992/ 1993 and due to the fact that there are substantial lateral and local changes within the pedo-sedimentary units at WilsonLeonard, a more-generalized more-descriptive, and less-genetic stratigraphic scheme, in which the stratigraphic units encompass both depositional and postdepositional manifestations including humans as agents of deposition and modification, was adopted. Moreover, field observations revealed that the timing of these different processes commonly overlapped (e.g., locally, iron mottling commonly postdates the formation of popcorn carbonates). These overlapping spatio/temporal phenomena not only make field description and interpretation of the profile quite arduous but also encumber efforts to "define" consistent and meaningful units of excavation. As a result, descriptions and subdivisions of the stratigraphic profile are made on the basis of several generalized criteria that include a variety of descriptive characteristics: color and mottling, texture and stoniness, presence and absence of carbonate nodules and rhizoliths, and presence of biological and biogenic features, such as earthworm casts, root penetrations, and rodent burrows (krotovinas).

\section{Description of the Stratigraphic Units}

The TARL phase of excavation reached bedrock in several localities within the excavated area (e.g., Test Square A, Test Square B, Square I2, Square 20, Square 100) (Figures 6-3 and 6-4). As a result, entire sections of the deposits were observed, enabling more-complete documentation of the vertical and lateral facies changes. Overall, the stratigraphic sequence at Wilson-Leonard is characterized by yellow brown and brown silts in the lower half to twothirds (Strata 1, 2, 3, and 4 of Holliday) that are essentially of alluvial origin and occur primarily in the valley floor (see Chapter 2, Figures 2-20 and 2-21). These are overlain by darker brown, stony, clayey silts that are associated with anthropogenic burned rock middens and other cultural features (Strata 5 and 6 of Holliday). These upper sediments are also stonier and have a greater colluvial component 


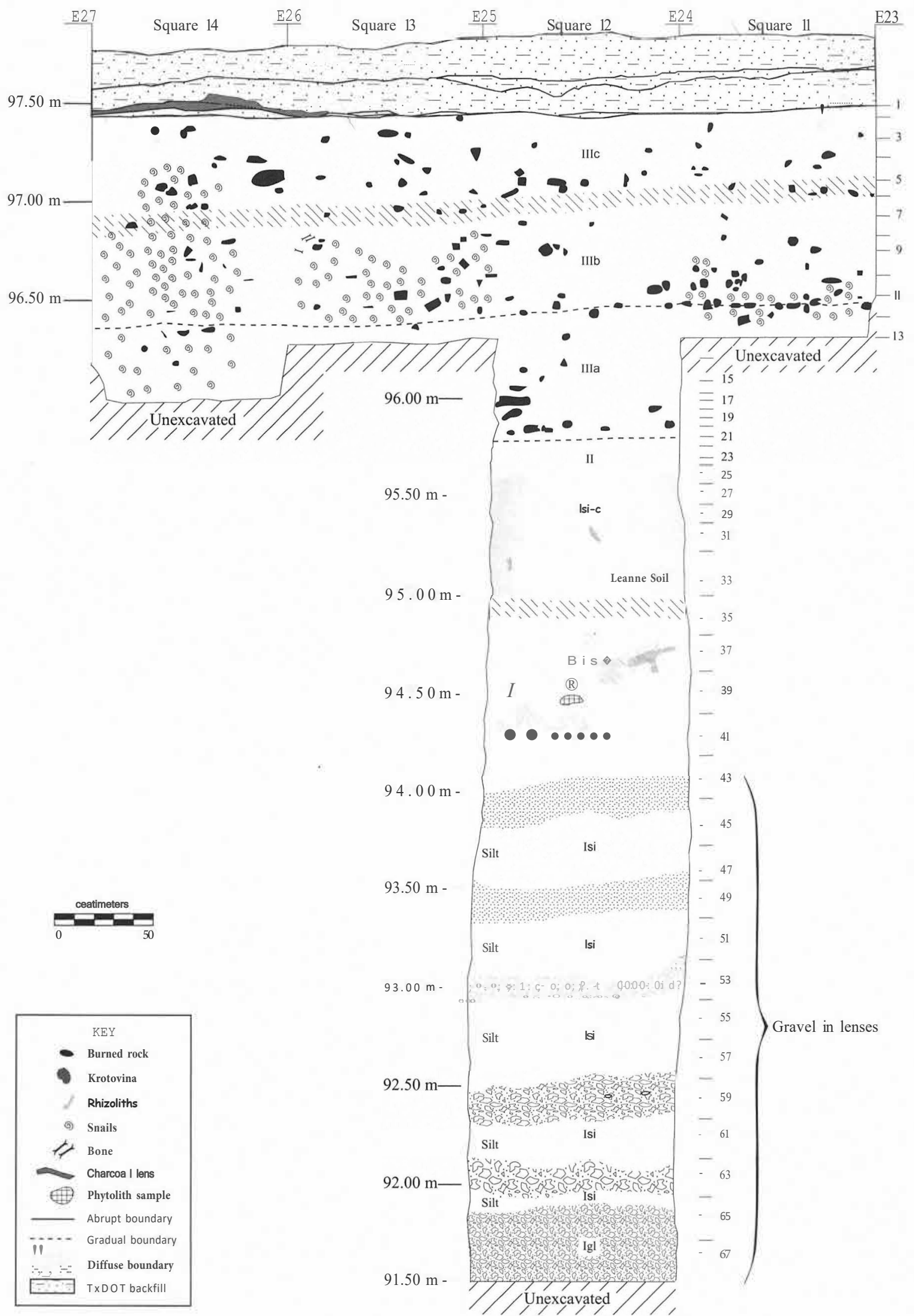

FlGURE 6-3. Stratigraphic section in Square 12, showing the abundance of fine and medium gravel in Unit Igl. 


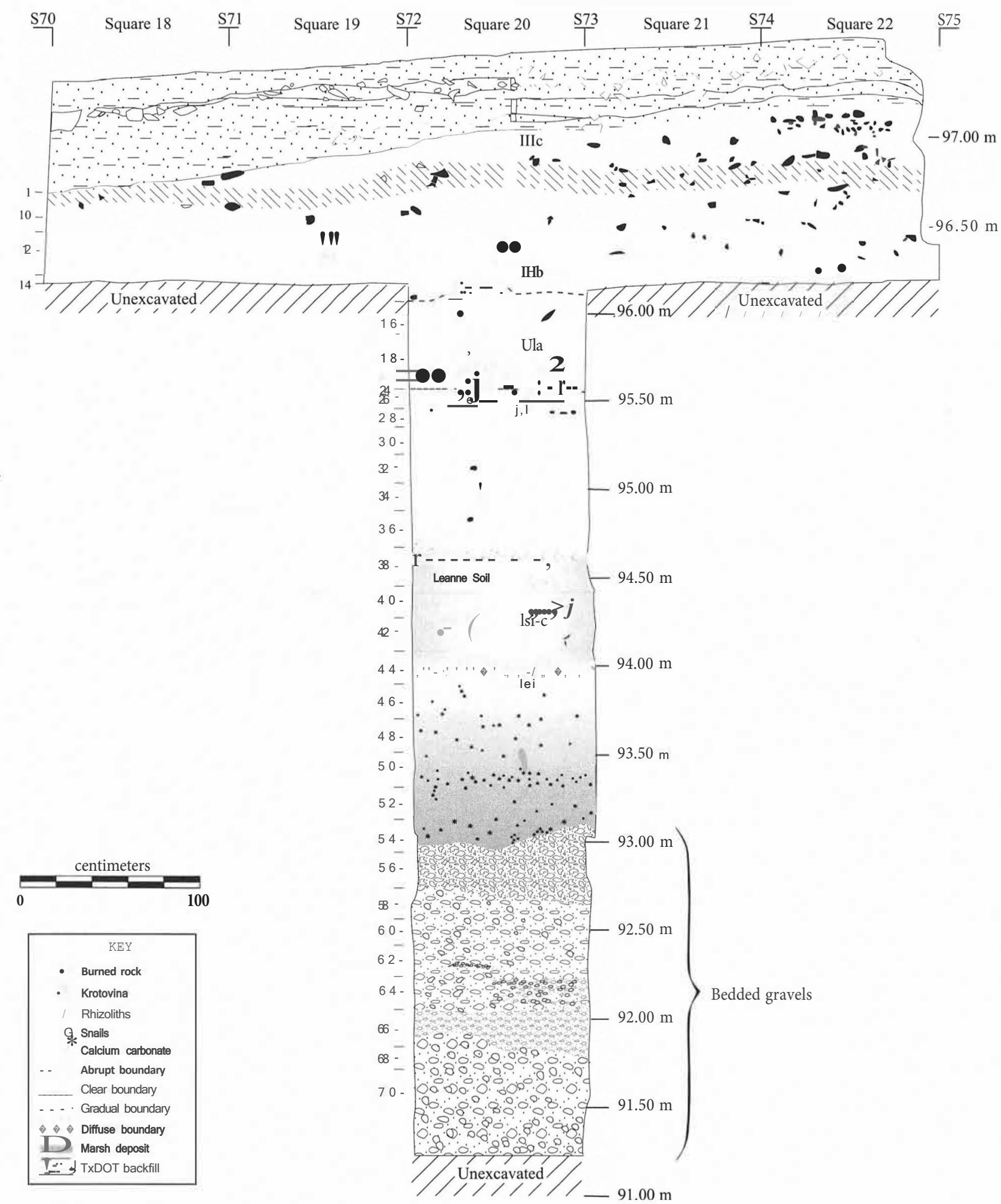

FIGURE 64. Stratigraphic section in Square 20, showing the abundance of gravel in Unit lgl.

than the sediments below. These occur on the valley floor and extend up the sloping valley wall (see Chapter 2, Figures 2-20 and 2-21).

Field observations reveal that the sequence can be subdivided into three major stratigraphic units, Unit I, Unit II, and Unit III (see Figure 6-2). These in tum can be further divided into a number of subunits. The emphasis in this study is on the sequence in the valley floor where better stratigraphic and archeological-component resolution ts possible. 


\section{UNITI}

Unit I, the lowest unit observed, rests upon bedrock and was observed in various locations, including Square I00, the main excavation block, pre-excavation boreholes, and in exposures at the confluence of Brushy and Spanish Oak creeks (Figure 6-5). As can be seen in this diagram and in Table 6-3, the elevation of the bedrock declines from south of the site, north to the area of the confluence of Brushy and Spanish Oak creeks.

The marked difference in elevation of ca. 4.5 moverjust 14 m horizontal distance between Square 100 (see Figure 65) and Square 12 indicates a stepped-like nature of the subsurface bedrock topography. This vertical relief, coupled with observations ofaerial photographs of the site area suggest that the basal sediments accumulated on, and abutted against, a canyon-like re-entrant that confined the channels of Brushy and Spanish Oak creeks to the south prior to the initial phases of deposition, about 12,000 or more years ago.

In the early phases of the TARL excavations, Unit I was examined on the basis of a number oflimited fresh exposures and sections that were excavated to bedrock in Test Squares A and B. As a result, Unit I was broken down into four roughly horizontal subunits (provisionally called Ia, lb, le, and Id) on the basis oftexture, color, mottling, and degree of cementation. Later, when the lower parts of the unit were revealed in other squares (e.g., Square 12 and Square 20), it was clear that this subdivision was not appropriate because the unit was indeed more complex, with both a marked degree of lateral and vertical variability. At the base of the section, a subunit of basal gravels interfingered with and was overlain by massive silty clays and clayey silts that were commonly intercalated with stringers and lenses of silty, angular fine gravel, particularly in the southern part of the excavation. The provisional subunits were replaced with subunits designated lgl, Isi, Isi-c, and Id.

\section{Unit lg!}

Unit lg!, stratigraphically the earliest subunit in Unit I, is composed of gravels that were well exposed in Squares 12, 20, 27, and 28 and Test Squares A and B (see Figures 6-3 and 6-4; Figures 6-6 and 6-7); similar gravels also appear along Brushy Creek. This unit varies in thickness from $80 \mathrm{~cm}$ in Test Square A in the south to $195 \mathrm{~cm}$ in Square 20 in the northern part of the excavation (see Figure 6-6). Part of this difference is due to the elevation of the bedrock (bedrock is ca. $50 \mathrm{~cm}$ higher at the south end of the site). Most of the difference, however, is due to a greater accumulation of gravels in the northeast halfofthe excavation block (see Table 63). This mass of gravels presumably reflects the proximity of the northern half of the site to the extant channels of Spanish Oak and Brushy creeks. Aithough these water courses are currently separated by a narrow silty flood plain (ca. $25 \mathrm{~m}$ to the north of the excavation; see Chapter 2, Figure 2-5), we do not know how this confluence appeared in the past or where it was situated; it could have been anywhere within the confines of the incised valley of the Brushy Creek drainage. The width of the roughly contemporary $\mathrm{T} 2$ deposit (see Chapter 2, Figures 2-5 and 2-6) is about $500 \mathrm{~m}$, and the confluence would have certainly been within those limits.

The gravels are not texturally uniform across the site. In the southern part (Test Square A, Square 12) they are generally finer-grained, finely bedded, silty and sandy angular gravels. The lithoclasts are bimodal in which the finer fraction $(<1-\mathrm{mm}$ diameter) is rounded, whereas the coarser fraction is more angular. Clasts tend to be more rounded in the basal $65-70 \mathrm{~cm}$ (ca. 2-4 $\mathrm{cm}$ in diameter), and become finer grained $(\mathrm{ca} .1-2 \mathrm{~cm}$ ) and more angular toward the top of the unit. The finer, silty fraction is also increasingly abundant upward, to the extent that near the top of the unit, clasts become matrix supported. In the northeast part of the site, the sediments are coarser, again reflecting proximity of the present and extant channels. In Square 20 where Unit lg! is thickest, the gravels are composed of poorly sorted, angular, flattish to subblocky and rounded clasts of limestone (see Figure 6-6). The lower $90 \mathrm{~cm}$ is more clearly bedded, is clast supported, and tends to be more rounded than the upper part. Many lenses exhibit slight depositional dips to the southeast, indicating bar migration in that direction. The upper part is generally finer, with matrix supported gravels and stringers of gravely sandy silts. Unit Igl is capped by a ca. 20-cm-thick bed of coarse, angular, platy to subequant clasts mixed with finer centimeter-sized pebbles that thin to the south. In north-south section, this bed is lens shaped, with a crest at an elevation of $93.10 \mathrm{~m}$ on the south wall of Square 27 (see Figure 6-7); in plan view, the gravels trend about $\mathrm{S} 30^{\circ} \mathrm{E}$, which is similar to the trend of overall gravel thickness as revealed in boreholes (see Chapter 2, Figures 28 and 2-9). The lens most likely represents a gravel bar of the proto-Brushy Creek/Spanish Oak Creek system.

The gravels are for the most part composed of local limestone, although clasts near the base are comprised of a relatively high proportion of caliche caprock gravels reworked from the uplands. As discussed below, the presence of these caliche gravels has implications related to landscape history of the area.

The gravels ofUnit lgl grade horizontally and vertically into finer-grained silts and silty clays, with a clear boundary (see Figures 6-2 and 6-7; Figure 6-8a). Overall, the gravels pinch out laterally to the south and southeast, in line with the distribution of gravels over the area of the terrace (see Chapter 2, Figure 2-9; see Table 6-3), and thus indicate a predominant Brushy Creek/Spanish Oak Creek source for this material. However, in the southern part of the excavation, the relative abundance of angular centimeter-sized gravel mixed with fresh fossil mollusk shells derived from the Comanche Peak Limestone indicate a localized source, presumably from the bedrock bench situated to the south of the excavation (see above). Limestone clasts and fossils of 


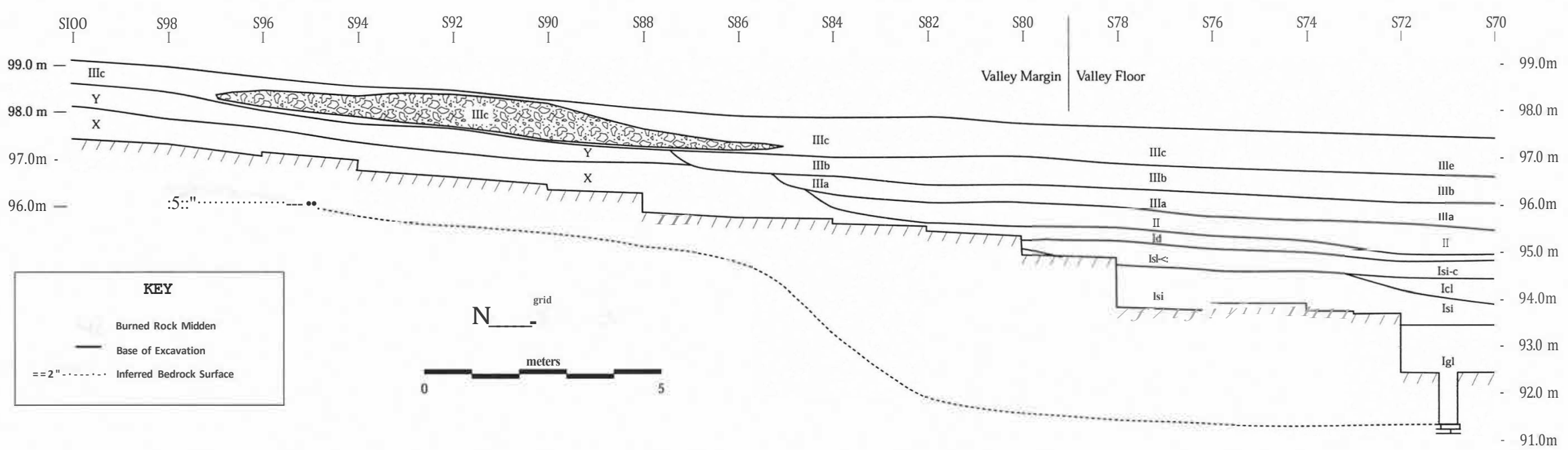

FIGURE 6-5. Inferred semischematic, roughly north-south stratigraphic profile of Wilson-Leonard. This profile was pieced together from observations made during the TARL phase of excavation and inferences from profiles and descriptions produced during the TxDOT phase. The location of bedrock at position S98 is determined from bore hole data. 
TABLE 6-3

Locations and Elevations of Gravel (Unit lg!) and Bedrock in Area of Wilson Leonard

\begin{tabular}{|c|c|c|c|c|c|c|}
\hline Location & $\begin{array}{c}\text { Wall of Square or Elevation } \\
\text { of Core Surface }\end{array}$ & $\begin{array}{l}\text { Easting } \\
(\mathrm{m})\end{array}$ & Southing (m) & $\begin{array}{l}\text { Elevation of Top } \\
\text { of Gravels (m) }\end{array}$ & $\begin{array}{l}\text { Thickness of } \\
\text { Unit lg! }\end{array}$ & $\begin{array}{l}\text { Elevation of } \\
\text { Bedrock (m) }\end{array}$ \\
\hline Borehole 01 & 98.88 & 18.08 & 96.95 & & & 96.42 \\
\hline Borehole 02 & 97.68 & 24.29 & 76.70 & & & 91.50 \\
\hline Borehole03 & 97.59 & 28.23 & 76.48 & & & 91.34 \\
\hline Borehole04 & 97.39 & 33.22 & 77.36 & & & 91.18 \\
\hline Borehole 07 & 96.65 & 50.70 & 52.10 & 93.63 & 2.33 & 91.30 \\
\hline Borehole08 & 97.03 & 44.40 & 60.90 & 93.33 & 2.47 & 90.93 \\
\hline Borehole 09 & 96.85 & 93.80 & 85.30 & 91.22 & 0.37 & 90.85 \\
\hline Borehole 10 & 96.00 & 84.30 & 39.90 & 93.57 & 2.34 & 91.23 \\
\hline Borehole 11 & 95.98 & 89.00 & 59.30 & 93.80 & 3.22 & 90.58 \\
\hline Borehole 12 & 96.15 & 89.30 & 71.60 & 93.20 & 2.40 & 90.80 \\
\hline Borehole 13 & 96.52 & 126.30 & 74.10 & 93.09 & 1.82 & 91.27 \\
\hline Borehole 14 & 95.74 & 127.70 & 48.20 & 92.49 & 2.46 & 90.03 \\
\hline Borehole 16 & 96.10 & 69.20 & 40.70 & 93.82 & 3.03 & 90.79 \\
\hline Borehole 17 & 96.35 & 63.60 & 60.50 & 93.52 & 2.37 & 91.15 \\
\hline Borehole 18 & 97.20 & 75.60 & 85.90 & 92.35 & 1.37 & 90.98 \\
\hline Borehole 19 & 98.40 & 54.00 & 80.40 & 93.66 & 1.63 & 92.03 \\
\hline Brushy Creek & & & & & & 91.51 \\
\hline $\begin{array}{l}\text { Square 12, } \\
\text { Column } 100\end{array}$ & South & 24.50 & 80.00 & 92.60 & 1.10 & 91.54 \\
\hline $\begin{array}{l}\text { Square } 20, \\
\text { Column } 200 \\
\end{array}$ & East & 29.00 & 72.50 & 93.00 & 1.84 & 91.16 \\
\hline Square 27 & East & 28.00 & 73.00 & 93.10 & & \\
\hline Square 28 & East & 28.00 & 75.00 & 93.04 & & \\
\hline $\begin{array}{l}\text { Square } 35, \\
\text { Column } 400 \\
\end{array}$ & East & 29.00 & 78.40 & 93.00 & & \\
\hline Square 39 & East & 29.50 & 75.50 & 93.00 & 0.20 & \\
\hline Square 57 & South & 27.50 & 79.00 & 93.36 & & \\
\hline $\begin{array}{l}\text { Test Unit I00, } \\
\text { Column } 300\end{array}$ & & & & & & 95.80 \\
\hline Test Unit A & & 24.50 & 78.50 & 92.30 & 0.80 & 91.50 \\
\hline Test Unit B & & 26.50 & 72.50 & 93.00 & 1.80 & 91.18 \\
\hline
\end{tabular}

similar freshness and caliber can be observed presently in Brushy Creek at the contact between the Q-2 fill and the bedrock.

Secondary features are widespread. As is the case for all of the deposits of Unit I, the gravels show extensive redoximorphic features (iron staining), which are particularly evident in the gravels in Square 20 (see Figure 6-8a). In addition, some light gray brown (1OYR 6/3) rhizoliths occur within the gravels. These secondary calcite accumulations are elongated and irregularly shaped, measuring about 25 $\mathrm{cm}$ long and $8 \mathrm{~cm}$ wide. Another secondary attribute, occurring not only in Unit Igl but also in overlying and adjacent units (e.g., Unit lei and Isi, see below) are elliptical to circular-shaped features, measuring ca. 4 to $8 \mathrm{~cm}$ across and filled with dark grayish brown ( 1OYR 4/2) silty clay similar to that found in the overlying Unit lei (see Figure 6-7). These objects appear to be traces of root burrows that are filled with silty clay originating from Unit lei (see below), suggesting that their formation is roughly contemporaneous with the accumulation of these dark clays (Figure 6-9).

Lateral variations in Unit $\operatorname{lgl}$ are also shown in Test Square B, where gravels are much siltier than in the East Block profiles and Square 20. In Test Square B, the gravels are generally matrix supported, but some strata are clast supported. Some cross bedding-inclined to the east southeast-was observed in the upper part. On the whole, the clasts are subspherical to slightly platy and mostly rounded to subrounded; ca. 20\% are angular. These shapes are dissimilar to the fresh angular gravels exposed in the South Block profiles or Test Square A, which are rich in fossils 


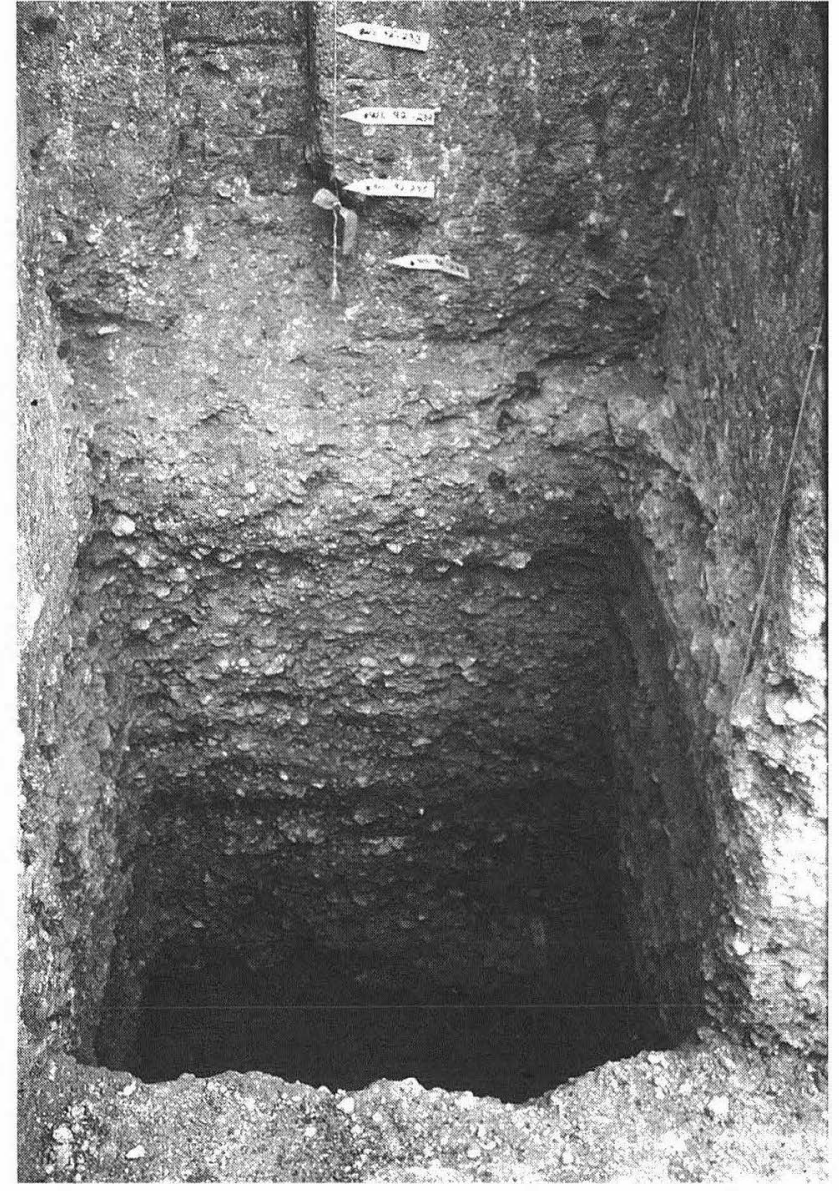

FIGURE 6-6. Unit lgl in the lower part of Square 20, showing the generally rounded nature of the gravels. Not particularly evident is the presence of marked iron staining of the gravels and other sediments in Unit lg! in general. Note that the cienega deposits of Unit lei occur roughly at the level of the lowermost tag.

locally derived from bedrock; some fossil shells, however, do occur in the Test Square B gravels. The upper part of the section in Test Square B also exhibits 12-x-12-cm circular root burrows, the lowest of which occur at an elevation of $92.05 \mathrm{~m}$ (Level 12). Some signs of iron staining on a gray (1 OYR 7/2) matrix can also be observed.

\section{Unitlsi}

The gravels of Unit lg! in the southern part of the site grade laterally into and interfinger with massive, calcareous iron-stained clayey silts containing centimeter-thick stringers of angular gravels. These Unit Isi silts distinctly thicken to the south and become less gravelly (see Figure 6-2).

Unit Isi as a whole consists of massive, mottled very pale brown (1 OYR 8/2) and brownish yellow (1OYR 6/8) silt and clayey silt. These silts contain stringers ( $\mathrm{ca} .40 \mathrm{~cm}$ wide and $10 \mathrm{~cm}$ thick) and lenses of generally angular to slightly subrounded limestone clasts derived from the bedrock. These clasts are commonly $1-3 \mathrm{~cm}$ in diameter, with some $4-6 \mathrm{~cm}$ in diameter and a few up to $8 \mathrm{~cm}$ across. The lenses predominate on the South Block profiles, between the elevation of $93.30 \mathrm{~m}$ and $94.25 \mathrm{~m}$ (Figure 6-10) and have a stepped appearance so that they are higher toward the southwest (e.g., Square 12 and Square 54; see Figure 6-3). In addition, the gravel lenses seem to be oriented approximately $\mathrm{N} 75^{\circ} \mathrm{E}$ and dip approximately $5^{\circ}$ northeast, suggesting a source to the southwest. The gravels disappear above about $94.25 \mathrm{~m}$.

The silts are generally dense and have a subangular to coarse crumbly structure; they are nonsticky and nonplastic. Locally in some levels (e.g., Square 12, Level 36, 94.75 m), they are quite spongy and porous in appearance, particularly in those sediments below the Leanne soil (see below for discussion of Leanne soil). Snail shells are rare in the lower part of the subunit and become increasingly abundant upward, although they never exceed about I\% by volume. Charcoal is rare, but remnants of several burned tree stumps were found in the upper portion ofUnitlsi (Features 167 and 253).

Burrowed root holes are similar in form and shape to those described above in Unit lg!, but here they are noticeably more abundant. There is some lateral variability, however, and in Square 12 and Square 54, they tend to be relatively rare but increase toward the east where they become very abundant in the laterally equivalent Unit lei (see below). In Unit lei, the holes are also more complex and commonly show signs of repeated perforation.

Lateral variation in the lithological aspects of the unit is also expressed by the occurrence of hard, 1-2-cm-diameter subspherical carbonate nodules, which are irregularly shaped and resemble popcorn (popcorn carbonates, see above). These nodules are sparse in Square 54 and increase noticeably eastward. They also appear to be confined to a subhorizontal band that dips to the northeast, with elevations of $94.30 \mathrm{~m}$ to $93.80 \mathrm{~min}$ Square 55 and $94.10 \mathrm{~m}$ to 93.35 min Square 57.

An additional form of secondary carbonate accumulation is represented by rhizoliths, which are centimeter-wide linear chalky concretions (see Figures 6-7, 6-8, 6-9, and 610). These extend on the South Block profile from $93.20 \mathrm{~m}$ up to the top of the unit. They are particularly prominent in a band between $93.50 \mathrm{~m}$ and $94.80 \mathrm{~m}$. A few of them display remains of modem roots, suggesting that some at least were formed relatively recently. Localized traces of carbonate filaments can be observed, but they are much less common than in Unit III (see below). More prominent are diffuse zones of carbonate cementation, as in the west wall of Square 12 between elevations of $93.50 \mathrm{~m}$ and $94.00 \mathrm{~m}$.

The most striking postdepositional feature observable in the field is extensive iron staining and depletion, an upward continuation of the same features in Unit lg!. On the South Block profiles, mottling extends up to an elevation of about $95.00 \mathrm{~m}$ (Table 6-4). The subunit is not uniformly mottled and some zones show more yellow coloration than others, such as between $92.75 \mathrm{~m}$ to $93.50 \mathrm{~m}$ and $94.20 \mathrm{~m}$ to 


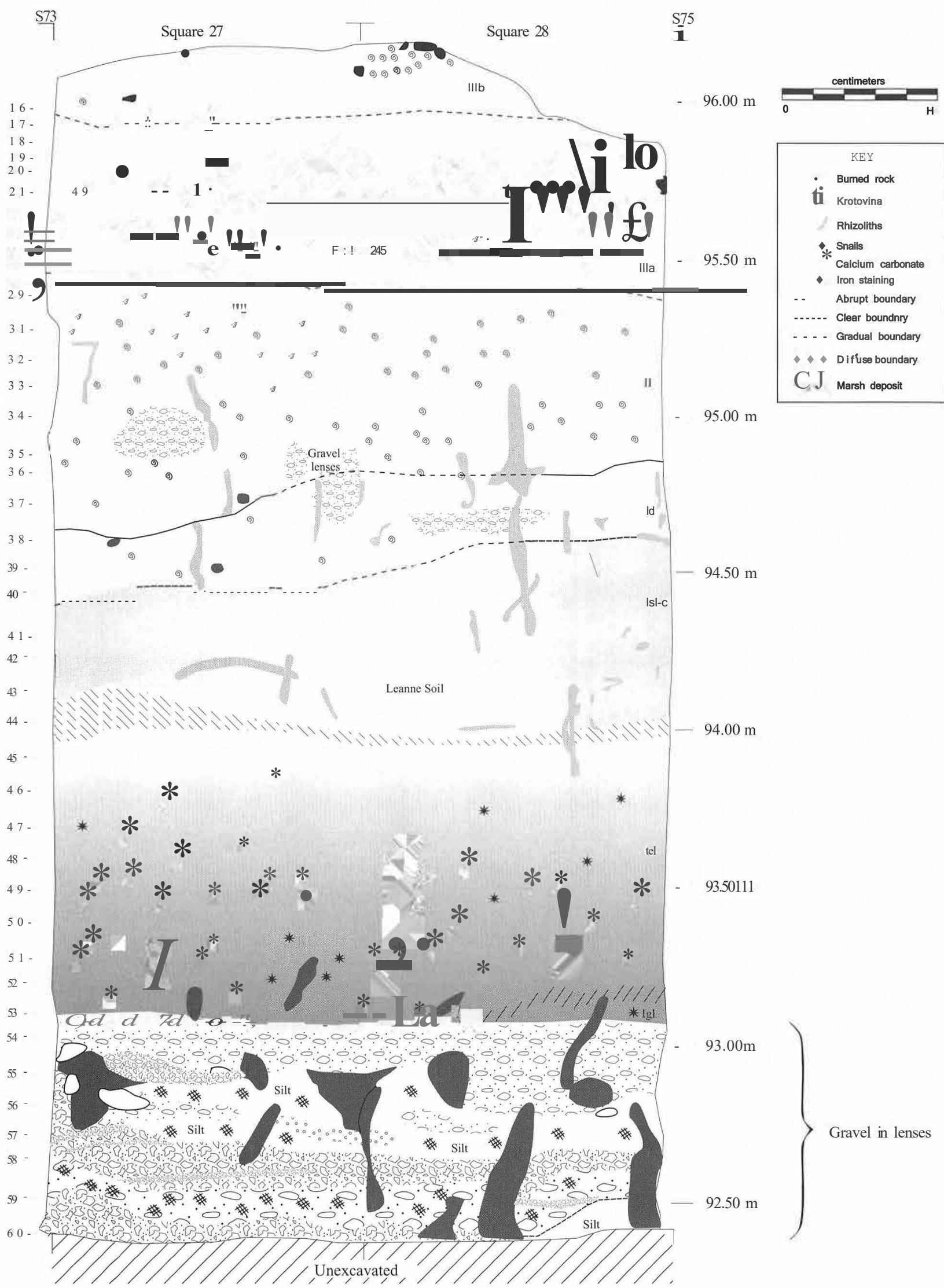

FGURE 6-7. Profile drawing of Squares 27 and 28 showing the major excavated stratigraphic units-the gravel units at the base (Unit Igl) overlain successively by cienega deposits (lei), silts ofisi, II, and III. Note both the organic-rich root holes at the base of the profile and the calcareous rhizoliths in the center of th profile. 


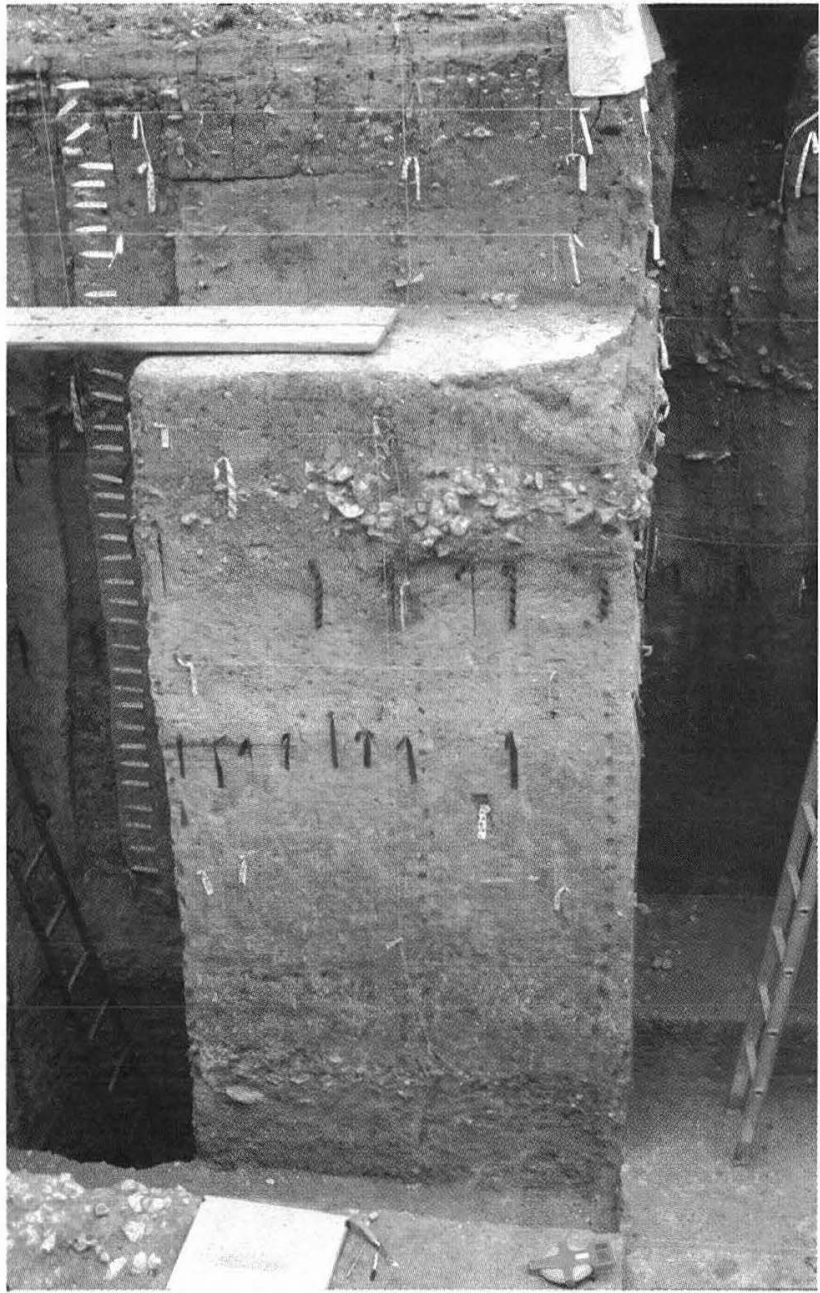

a

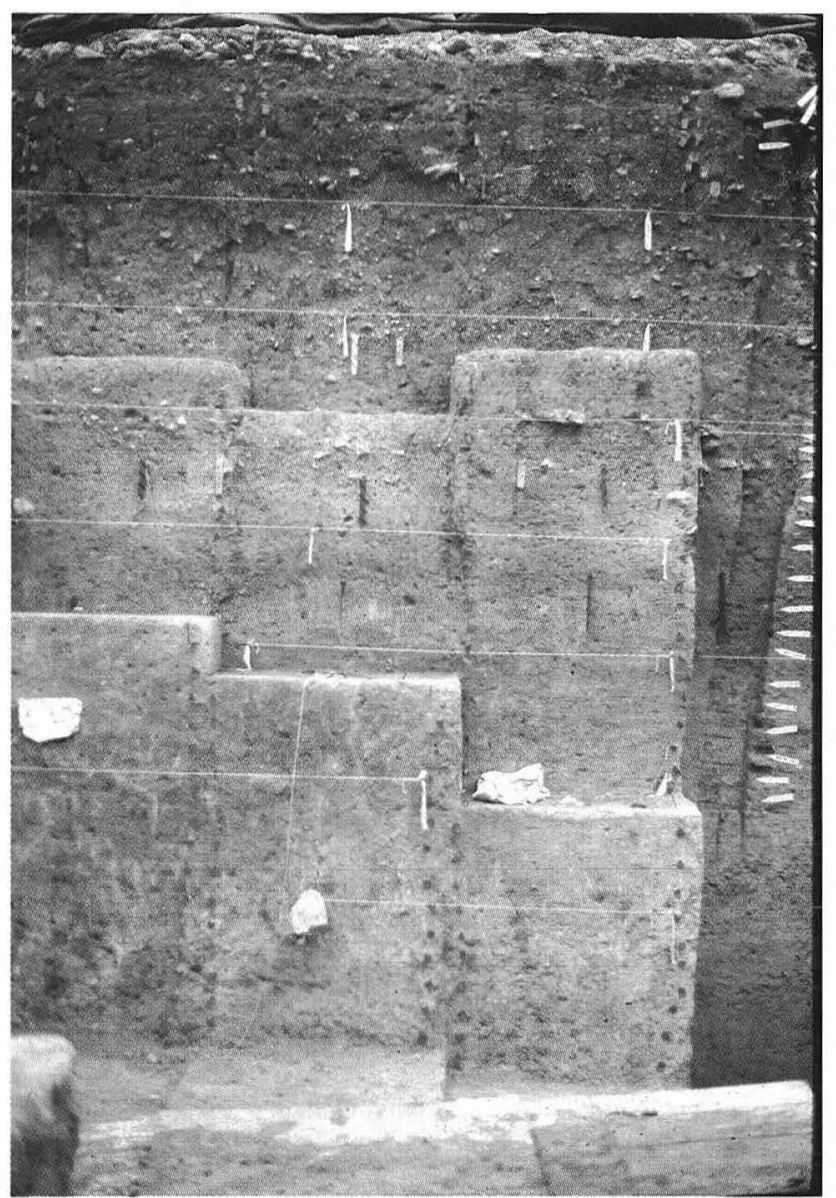

b

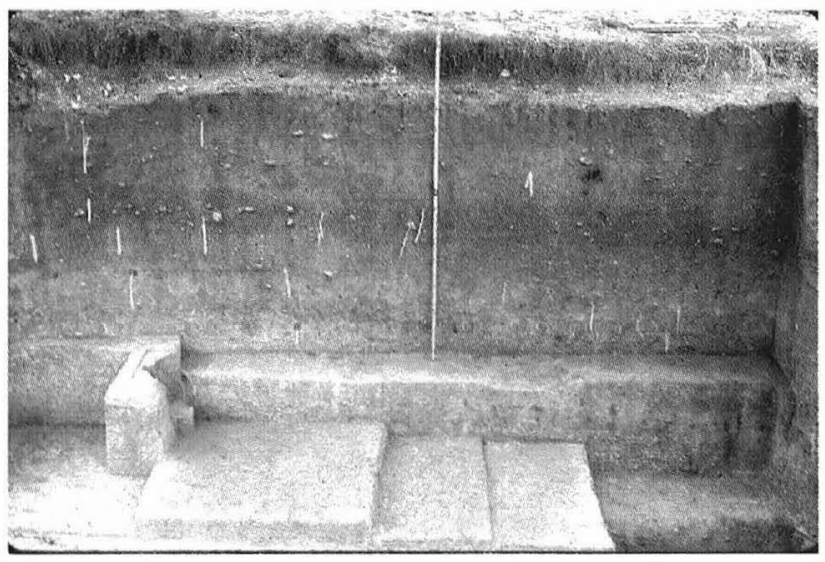

C

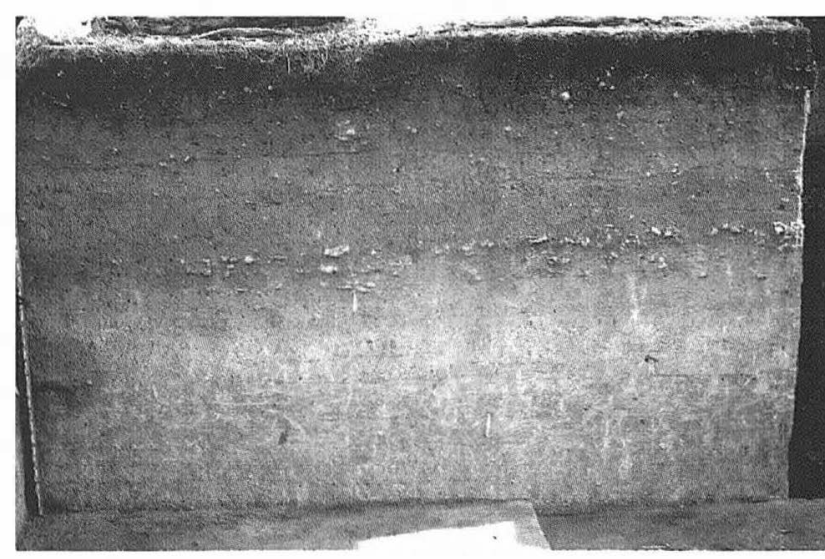

d

FlGiRE 6-8. Stratigraphic profiles. (a) Squares 27 and 28 in east profile ofTARL excavated area; (b) south profile showing Units Isi in lower third; (c) west profile ofTxDOT Block 4; (d) east profile ofTxDOT Block 6. 


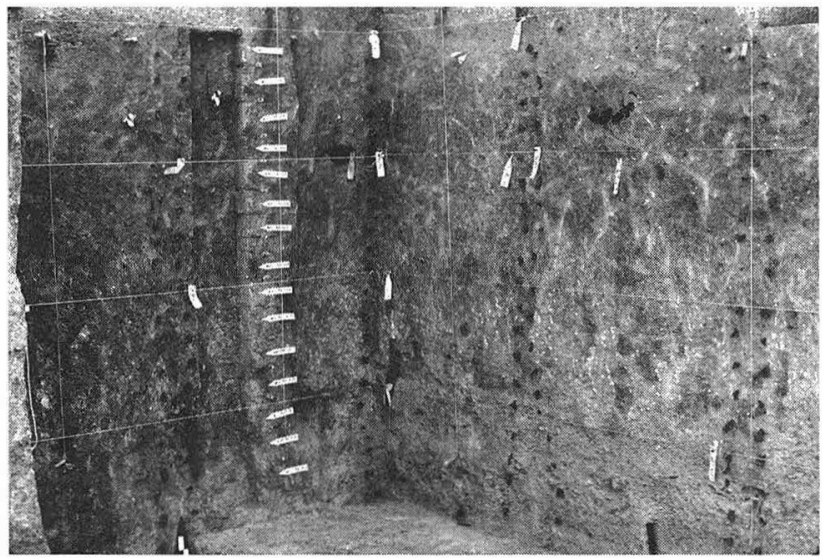

FlGURF6-9. East and south faces of Square 35 showing the pinching out of Unit !cl to the east (right). Note the root burrows that seem to postdate the popcorn carbonates (white spots) and numerous elongated rhizoliths within the Leanne soil. Remnants of a burned tree (Feature 253) are visible at right, and stringers ofangular gravel can be seen at the base of the south face.
$94.60 \mathrm{~m}$. Above about $94.60 \mathrm{~m}$, the mottling becomes finer and less distinct and blends in with the browner matrix of the Leanne soil, which partially masks the mottling effects. Iron staining is not readily apparent above $95.00 \mathrm{~m}$ on the south face. In areas without yellow mottling (e.g., Square 12 between elevations $92.20 \mathrm{~m}$ and $92.55 \mathrm{~m}$ ), the matrix is generally very pale brown (1 OYR 8/2). In the field, it was clear than many of the popcorn carbonates were stained with iron, although this is less evident in thin section (see Chapter 29).

The upper part of Unit Isi is represented by the Leanne soil. This soil, previously described by Holliday (I 989b), is widespread across the site and is characterized by an overall brown to yellowish brown (7.5YR to 1OYR 5/4) color and a stony clayey silt texture. It exhibits a moderate to coarse crumbly structure, most likely imparted by the presence of compacted ("aged") worm casts, visible in the field but more so in thin section (see Chapter 29). Visible with a hand lens and comparable to abundant rhizoliths noted in the field are numerous small $(<500 \mathrm{~mm}$ in diameter) tubes or pores that

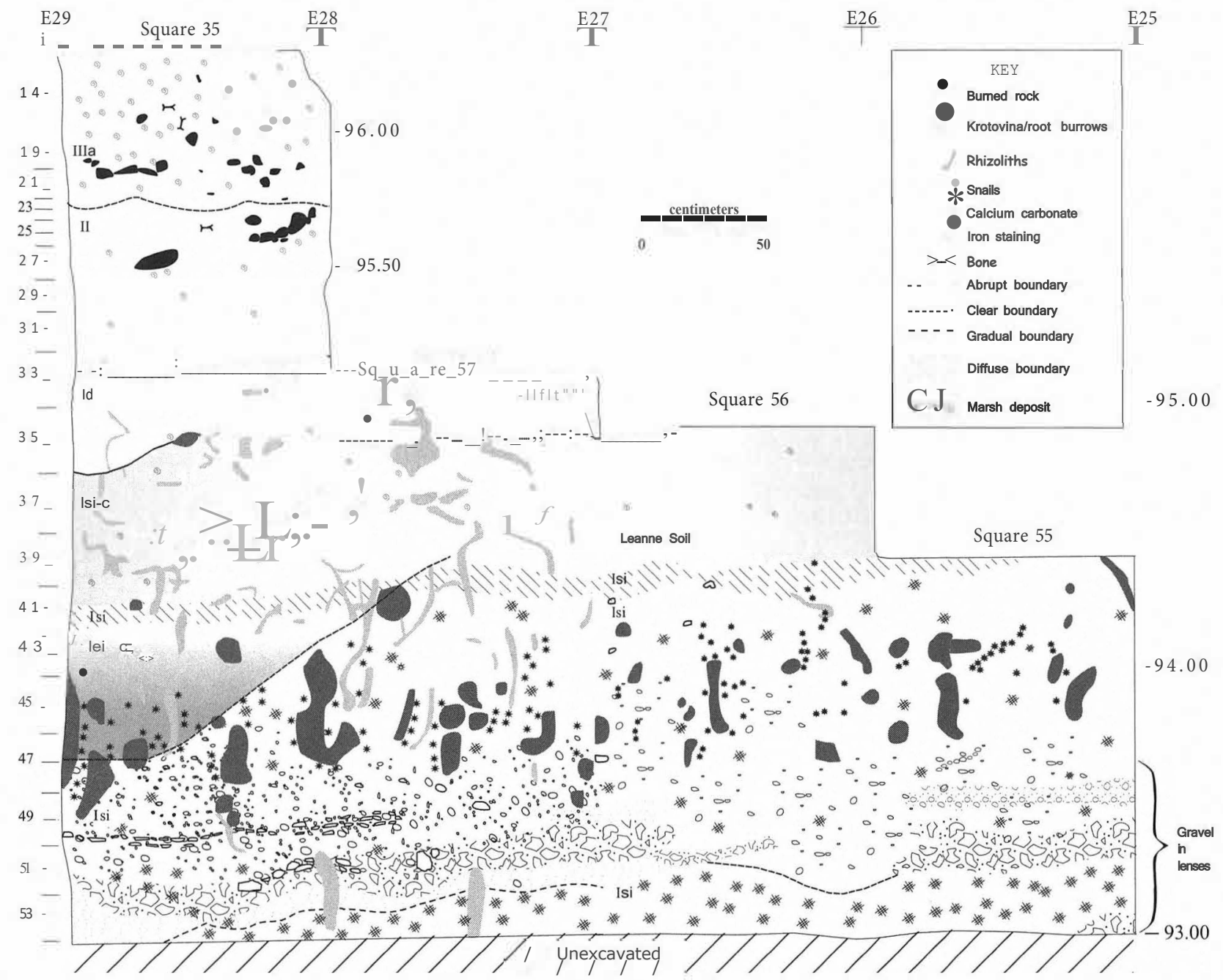

FGURE6-10. Profile drawing of Squares 35, 55, 56, and 57 showing secondary features that include numerous dark, clay-filled root holes and lighter-colored calcitic rhizoliths. Iron staining is particularly prominent at the base of the profile. 
TABLE6-4

Uppermost Occurrences of Iron Mottling/Staining at Wilson-Leonard

\begin{tabular}{c|c|c|c}
\hline Sauare & SamoleNo. & Elevation $(\mathrm{m})$ & Stratiinaphic Unit \\
\hline \multicolumn{2}{c|}{ Field Samples: } & & \\
33 & WL-92-032 & 94.41 & Isi \\
\hline 12 & WL-92-126 & 94.87 & Isi \\
\hline 20 & WL-92-219 & 95.09 & II \\
\hline 35 & WL-92-404 & 94.55 & Isi \\
\hline $\begin{array}{l}\text { Micromorphology Sample: } \\
12\end{array}$ WL-92-123 I & 95.10 & Isi \\
\hline \hline
\end{tabular}

exhibit carbonate coatings. These coatings contrast with the calcareous filaments that occur on ped faces more typically found above this in Unit UT. Stones are much less common in this upper part of Unit Isi and occur as isolated subangular to subround clasts that range in size from ca. I to $8 \mathrm{~cm}$ in diameter. Snail shells are much more common in the Leanne soil than below it and are possibly related to the slightly higher amounts of organic matter in the soil as seen in thin section.

The upper surface of the Leanne soil is inclined to the northeast (Tables 6-5 and 6-6) and is locally covered by Unit Id or Unit II, which has the same inclination. The contact between the Leanne soil and Unit Id on Unit II is quite distinct, particularly in the northeast comer of the excavation; overall it is clear and smooth, but locally it is abrupt (e.g., Square 20, [see Figure 6-4]) and wavy. The lower limits of the Leanne soi I are irregular and wavy and show a gradual transition from the brown clayey silt down to palercolored silt. Soil development is locally superimposed on Unit lei (see below) particularly toward the northeastern part of the site where the Leanne soil is found at lower elevations. Since both the Leanne soil and Unit lei have somewhat similar lithological characteristics in the field (e.g., dark color and texture) it is not easy to differentiate them, and it is not surprising that earlier excavators seemed to have confounded them as shown in their notes and drawings.

Unitlel

In the South Block profiles, the upper, essentially nongravelly part ofUnit I is represented by Unit Isi, with the Leanne soil developed in its upper part (see Figure 6-8b). In the East Block profiles, however, north of Square 35, the lower and middle parts ofUnit Isi grade laterally into a darker brown to dark brown (IOYR $4 / 3$ and 5/3) clayier sediment, Unit lei, which thickens to the northeast (see Figure 6-2, Table 6-6). Generally, Unit lei is made up ofmassive, coarse granular, brown to dark brown silty clay, with angular to subrounded limestone clasts 1 to $3 \mathrm{~cm}$ in diameter that are dispersed throughout.

Postdepositional effects are represented by iron staining and mottling, extensive root fillings or burrows, and abun- dant popcorn carbonates. Popcorn carbonates, along with the burrowing/root features described in Unit 1si, contribute to the granular structure of this material. Other secondary carbonates occur as coatings in fine $(<500 \mathrm{~m})$, tubular pores that in the field appear to postdate the phase of popcorn carbonate precipitation. Ped faces tend to be somewhat shiny as viewed in hand lens, representing the effects of oriented clay (stress cutans) produced by shrink-swell. Finally, we note that iron staining is quite pronounced at the base of the subunit and in the underlying Unit 1si; mottling decreases upward through Unit lei and the overlying lsi-c, where it becomes masked by the effects ofdevelopment of the Leanne soil. Clear signs of iron staining attain elevations of up to about $95.00 \mathrm{~m}$ (see Table 6-6).

Unit lei displays extensive signs of biological activity, as manifested in centimeter-sized elliptical to circular-shaped areas of dark silty clay measuring several centimeters in diameter (see Figure 6-7 and 6-1 O, Figure 6-11). These areas are particularly evident along the basal parts of the unit but also extend downward into the top of Unit lgl and laterally into Unit Isi as mentioned above. To the northeast, these features increase dramatically, tending to coalesce thus blurring the contacts between the underlying and adjacent units of Isi and $\lg$ !. As a consequence, the lower contact of Unit lei is quite jagged and irregular.

These circular areas are strikingly comparable to features forming today along the Pedemales River, where lightercolored fluvial silts are dotted with similar darker, circular ones. In the Pedernales context, it is clear that they are produced by the activity of tree roots growing along the banks of the river, since the diameter of the features matches those of the roots. In this light, the Pedernales River context serves as a reasonable analogy to the Wilson-Leonard setting where trees would have grown along the margins of the cienega represented by Unit lei, and roots would have thus burrowed into both the cienega deposits of lei as well as the interfingered silts ofUnit Isi.

The full lateral westward extent ofUnit Icl is not clear. It appears only in the northern part of the west profile of the TxDOT main block (Block 4; see Table 6-6). It is also visible on the north profile of Block 6. No traces of it show up in either Test Square A or Test Square B. This indicates that Unit lei pinches out to the west and northwest as observed in the South Block profiles (see Figures 6-9 and 6-10). The subunit corresponds broadly to Stratum 2 of Holliday (1989b) (see Table 6-2). Thus, on the basis of both present and past exposed sections, it seems that the westernmost limit of Unit lei is demarcated by a zone roughly trending $\mathrm{N} 10^{\circ} \mathrm{W}$. This trend matches the overall thickening of the unit to the northeast, as well as the orientation of the abandoned channel revealed by coring (see Chapter 2).

The contact of Unit lei with the interfingered silty Unit Isi is confounded by the development of the Leanne soil, and the distinction between these two units represents a phenomena that no doubt plagued the original excavators 
TABLE 6-5

Elevation of Contacts and Thicknesses of Stratigraphic Units

\begin{tabular}{|c|c|c|c|c|c|c|c|c|c|c|}
\hline & & Unit Ill & & & Unit Illa & & & UnitY & & Unit II/Ill Contact \\
\hline Coordinates & $\begin{array}{l}\text { Top (or } \\
\text { Surface) } \\
\end{array}$ & Bottom & Thickness & Too & Bottom & Thickness & Too & Bottom & Thickness & \\
\hline \multicolumn{11}{|c|}{ Block 6, North Profile: } \\
\hline $\mathrm{E} 18 / \mathrm{S} 70$ & 97.41 & 95.47 & 1.94 & 96.04 & 95.47 & 0.57 & & & & 95.47 \\
\hline $\mathrm{E} 26 / \mathrm{S} 70$ & 97.17 & 95.43 & 1.74 & 95.82 & 95.43 & 0.39 & & & & 95.43 \\
\hline $\mathrm{E} 24 / \mathrm{S} 70$ & 97.22 & 95.48 & 1.74 & 95.99 & 95.48 & 0.51 & & & & 95.48 \\
\hline $\mathrm{E} 22 / \mathrm{S} 70$ & 97.34 & 95.43 & 1.91 & 95.96 & 95.43 & 0.53 & & & & 95.43 \\
\hline $\mathrm{E} 20 / \mathrm{S} 70$ & 97.35 & 95.42 & 1.93 & 95.98 & 95.42 & 0.56 & & & & 95.42 \\
\hline El 8/S70 & 97.41 & 95.47 & 1.94 & 96.04 & 95.47 & 0.57 & & & & 95.47 \\
\hline E18/S72 & 97.54 & 95.61 & 1.93 & 96.07 & 95.61 & 0.46 & & & & 95.61 \\
\hline E1 8/S74 & 97.64 & 95.64 & 2.00 & 96.17 & 95.64 & 0.53 & & & & 95.64 \\
\hline El 8/S76 & 97.74 & 95.77 & 1.97 & 96.27 & 95.77 & 0.50 & & & & 95.77 \\
\hline E18/S78 & 97.67 & 95.92 & 1.75 & 96.30 & 95.92 & 0.38 & & & & 95.92 \\
\hline \multicolumn{11}{|c|}{ Block 6, East Profile: } \\
\hline $\mathrm{E} 26 / \mathrm{S} 70$ & 97.17 & 95.42 & 1.75 & 95.82 & 95.43 & 0.39 & & & & 95.43 \\
\hline $\mathrm{E} 26 / \mathrm{S} 72$ & 97.25 & 95.47 & 1.78 & 95.90 & 95.47 & 0.43 & & & & 95.47 \\
\hline E26/S74 & 97.33 & 95.51 & 1.82 & 95.97 & 95.51 & 0.46 & & & & 95.51 \\
\hline E26/S76 & 97.36 & 95.63 & 1.73 & 96.07 & 95.63 & 0.44 & & & & 95.63 \\
\hline \multicolumn{11}{|c|}{ Block 6, South Wall: } \\
\hline $\mathrm{E} 18 / \mathrm{S} 78$ & 97.67 & 95.92 & 1.75 & 96.30 & 95.92 & 0.38 & & & & 95.92 \\
\hline E20/S78 & NA & 95.84 & NA & 96.23 & 95.84 & 0.39 & & & & 95.84 \\
\hline $\mathrm{E} 22 / \mathrm{S} 78$ & 97.56 & 95.77 & 1.79 & 96.15 & 95.77 & 0.38 & & & & 95.77 \\
\hline E24/S78 & 97.55 & 95.75 & 1.80 & 96.11 & 95.75 & 0.36 & & & & 95.75 \\
\hline E26/S78 & 97.53 & 95.67 & 1.86 & 96.08 & 95.67 & 0.41 & & & & 95.67 \\
\hline \multicolumn{11}{|l|}{ Block 6: } \\
\hline E22/S74 & NA & 95.56 & NA & 96.03 & 95.56 & 0.47 & & & & 95.56 \\
\hline E24/S72 & NA & 95.50 & $\mathrm{NA}$ & 95.93 & 95.50 & 0.43 & & & & 95.50 \\
\hline E24/S76 & NA & 95.65 & $\mathrm{NA}$ & 96.12 & 95.65 & 0.47 & & & & 95.65 \\
\hline E24/S74 & NA & 95.53 & $\mathrm{NA}$ & 95.99 & 95.53 & 0.46 & & & & 95.53 \\
\hline $\mathrm{E} 22 / \mathrm{S} 72$ & NA & 95.52 & $\mathrm{NA}$ & 96.01 & 95.52 & 0.49 & & & & 95.52 \\
\hline E22/S76 & NA & 95.69 & $\mathrm{NA}$ & 96.12 & 95.69 & 0.43 & & & & 95.69 \\
\hline \multicolumn{11}{|c|}{ Blocks 4 and 6: } \\
\hline E20/S72 & $\mathrm{NA}$ & 95.57 & na & 96.06 & 95.57 & 0.49 & & & & 95.57 \\
\hline E20/S74 & $\mathrm{NA}$ & 95.60 & na & 96.10 & 95.60 & 0.50 & & & & 95.60 \\
\hline E20/S76 & $\mathrm{NA}$ & 95.71 & na & 96.25 & 95.71 & 0.54 & & & & 95.71 \\
\hline \multicolumn{11}{|l|}{ Block 3: } \\
\hline & & Unit III* & & & & & & & & \\
\hline $\mathrm{E} 18 / \mathrm{S} 80$ & 97.75 & 96.05 & 1.70 & 96.55 & 96.05 & 0.50 & & & & 96.05 \\
\hline El 8/S82 & 97.88 & 96.08 & 1.80 & 96.62 & 96.08 & 0.54 & & & & 96.08 \\
\hline $\mathrm{E} 18 / \mathrm{S} 84$ & 97.92 & 96.22 & 1.70 & 96.57 & 96.12 & 0.45 & & & & 96.22 \\
\hline E18/S86 & 97.96 & 96.42 & 1.54 & & & & 93.60 & 93.27 & 0.33 & 96.42 \\
\hline E18/S88 & 98.08 & 96.57 & 1.51 & & & & 93.77 & 93.42 & 0.35 & 96.57 \\
\hline E18/S90 & 98.26 & 96.92 & 1.34 & & & & 94.12 & 93.77 & 0.35 & 96.92 \\
\hline \multicolumn{11}{|l|}{ Block 2: } \\
\hline & & Unit Ill* & & & & & & & & \\
\hline E18/S91 & 98.37 & 96.92 & 1.45 & & & & 94.02 & 93.77 & 0.25 & 96.92 \\
\hline El 8/S92 & 98.42 & 97.12 & 1.30 & & & & 94.22 & 93.97 & 0.25 & 97.12 \\
\hline E1 8/S93 & 98.51 & 97.22 & 1.29 & & & & 94.37 & 94.07 & 0.30 & 97.22 \\
\hline E1 8/S94 & 98.57 & 97.27 & 1.30 & & & & 94.37 & 94.12 & 0.25 & 97.27 \\
\hline El 8/S95 & 98.62 & 97.47 & 1.15 & & & & 94.57 & 94.32 & 0.25 & 97.47 \\
\hline El 8/S96 & 98.77 & 97.62 & 1.15 & & & & 94.67 & 94.47 & 0.20 & 97.62 \\
\hline \multicolumn{11}{|l|}{ Block 1: } \\
\hline & & Unit Ill* & & & & & & & & \\
\hline El 8/S97 & 98.87 & 97.77 & 1.10 & & & & 94.97 & 94.62 & 0.35 & 97.77 \\
\hline El 8/S98 & 99.02 & 97.82 & 1.20 & & & & 95.02 & 94.67 & 0.35 & 97.82 \\
\hline El 8/S99 & 99.07 & 97.97 & 1.10 & & & & 95.07 & 94.82 & 0.25 & 97.97 \\
\hline E18/S100 & 99.17 & 98.30 & 0.87 & & & & NA & NA & NA & 98.30 \\
\hline \multicolumn{11}{|l|}{ Block 5: } \\
\hline $\mathrm{E} 22 / \mathrm{S} 78$ & NA & 95.94 & NA & 96.49 & 95.94 & 0.55 & & & & 95.94 \\
\hline
\end{tabular}


Table 6-5, continued

\begin{tabular}{|c|c|c|c|c|c|c|c|c|c|c|}
\hline & \multicolumn{3}{|c|}{ Unitill } & \multicolumn{3}{|c|}{ Unit Illa } & \multicolumn{3}{|c|}{ UnitY } & \multirow[t]{2}{*}{ Unit I1/111 Contact } \\
\hline Coordinates & $\begin{array}{l}\text { Top (or } \\
\text { Surface) }\end{array}$ & Bottom & Thickness & Top & Bottom & Thickness & Top & Bottom & Thickness & \\
\hline $\mathrm{E} 22 / \mathrm{S} 80$ & NA & 95.94 & NA & $\% .50$ & 95.94 & 0.56 & & & & 95.94 \\
\hline E22/S82 & NA & $\% .14$ & NA & $\% .53$ & $\% .14$ & 0.39 & & & & $\% .14$ \\
\hline E22/S84 & $\mathrm{NA}$ & $\% .32$ & NA & $\% .68$ & $\% .32$ & 0.36 & & & & $\% .32$ \\
\hline E22/S86 & $\mathrm{NA}$ & $\% .21$ & NA & & & & 93.50 & 93.06 & 0.44 & 96.21 \\
\hline E22/S88 & $\mathrm{NA}$ & $\% .33$ & NA & & & & 93.64 & 93.18 & 0.46 & $\% .33$ \\
\hline \multicolumn{11}{|c|}{ Fine-screen Unit: } \\
\hline E27/S76 & 97.36 & 95.54 & 1.82 & 95.95 & 95.54 & 0.41 & & & & \\
\hline E28/S77 & 97.36 & 95.38 & 1.98 & 95.95 & 95.38 & 0.57 & & & & \\
\hline E27/S78 & 97.42 & 95.68 & 1.74 & $\% .04$ & 95.68 & 0.36 & & & & \\
\hline \multicolumn{11}{|l|}{ TARL: } \\
\hline E24.S/S80 & 97.46 & 95.80 & 1.66 & 96.47 & 95.80 & 0.67 & & & & 95.80 \\
\hline E29.S/S80 & 97.46 & $\mathrm{NA}$ & NA & $\% .35$ & $\mathrm{NA}$ & NA & & & & 95.80 \\
\hline E29/S72.5 & 97.06 & 95.61 & 0.55 & $\% .20$ & 95.61 & 0.59 & & & & 95.61 \\
\hline E29.S/S75.5 & 97.12 & 95.56 & 0.56 & 96. IO & $\% .56$ & 0.54 & & & & 95.56 \\
\hline E23.S/S79 & 97.50 & 95.92 & 1.58 & 96.48 & 95.92 & 0.56 & & & & 95.92 \\
\hline E29/S78.S & $\% .32$ & 95.72 & 0.60 & 96.24 & 95.72 & 0.52 & & & & 95.72 \\
\hline E28.S/S79 & 97.44 & 95.70 & 1.74 & $\% .30$ & 95.70 & 0.60 & & & & 95.70 \\
\hline E25.S/S79 & 97.46 & 95.80 & 1.66 & $\% .39$ & 95.80 & 0.59 & & & & 95.80 \\
\hline E26.5/S79 & 97.46 & 95.68 & 1.78 & $\% .40$ & 95.68 & 0.72 & & & & 95.68 \\
\hline E27.5/S79 & 97.42 & 95.76 & 1.66 & $\% .34$ & 95.76 & 0.58 & & & & 95.76 \\
\hline E26.S/S72.S & NA & NA & NA & NA & NA & NA & & & & NA \\
\hline E24.S/S78.5 & $\mathrm{NA}$ & NA & NA & $\mathrm{NA}$ & NA & NA & & & & NA \\
\hline E27.S/S71.5 & 96.90 & 95.52 & 1.38 & 95.84 & 95.52 & 0.32 & & & & 95.52 \\
\hline E28/S73.5 & 97.10 & 95.48 & 1.62 & 95.94 & 95.48 & 0.46 & & & & 95.48 \\
\hline E28/S74.5 & 97.18 & 95.42 & 1.76 & $95 . \%$ & 95.42 & 0.54 & & & & 95.42 \\
\hline E29/S77.S & 97.34 & 95.64 & 1.70 & $\% .16$ & 95.64 & 0.52 & & & & 95.64 \\
\hline E27/S72.5 & & & & & & & & & & \\
\hline E27/S73.5 & & & & & & & & & & \\
\hline E27/S74.5 & & & & & & & & & & \\
\hline E27/S75.5 & & & & & & & & & & \\
\hline E28/S76 & NA & $\mathrm{NA}$ & NA & $\mathrm{NA}$ & $\mathrm{NA}$ & NA & & & & NA \\
\hline E27/S71 & NA & 95.51 & NA & 95.82 & 95.51 & 0.31 & & & & 95.51 \\
\hline
\end{tabular}

of the site. Their notes are unclear about the description of Unit lei and its differentiation from the darkened Leanne soil. These difficulties are understandable, considering the overall similarity ofaspect of these dark brown clayey units.

Unit Id

Unit Id is represented as a thin, irregular layer that overlies the Leanne soil and is in turn truncated by Unit II (see Figure 6-2). This truncation is particularly noticeable in the South Block of the TARL excavations where Unit Id occurs only as thin discontinuous patches and lenses. In the East Block, it is best visible on the north and east walls of Squares 59 and 35 (see Figure 6-11), where it is up to ca. $30 \mathrm{~cm}$ thick. To the north, it irregularly thickens and thins (see Figure 6-7) from about 15 to $25 \mathrm{~cm}$ thick.

Unit Id is composed of compact, very slightly sticky, very slightly plastic clayey silt with subangular blocky structure and spongy fabric with many fine pores. The color is gradational between that of the Leanne soil and Unit II, with lighter, pale brown (IOYR 6/3) and darker, dark yellowish brown (1OYR 4/4) millimeter-sized mottles; it is somewhat 
TABLE6-6

Elevations and Contacts and Thicknesses of Stratigraphic Units

\begin{tabular}{|c|c|c|c|c|c|c|c|c|c|c|c|c|c|c|c|c|c|c|c|c|c|c|c|c|c|}
\hline \multirow[b]{2}{*}{$\begin{array}{l}0 \\
0 \\
0 \\
\frac{1}{5} \\
\text { है } \\
\text { के }\end{array}$} & \multicolumn{3}{|c|}{ Unit II } & \multirow[t]{2}{*}{$\begin{array}{l}\text { Unit } 1 / 11 \\
\text { Contact }\end{array}$} & \multicolumn{3}{|c|}{ Unit Id } & \multirow[t]{2}{*}{$\begin{array}{c}\text { Top of } \\
\text { Leanne } \\
\text { Soil }\end{array}$} & \multicolumn{3}{|c|}{ Unit lei (Cienega) } & \multirow[t]{2}{*}{$\begin{array}{c}\text { Top of } \\
\text { Unit } \\
\text { 1si } \\
\end{array}$} & \multirow[t]{2}{*}{$\begin{array}{r}\text { Top of } \\
\text { Gravels }\end{array}$} & \multirow[t]{2}{*}{$\begin{array}{c}\text { Igl } \\
\text { Thick- } \\
\text { ness } \\
\end{array}$} & \multirow[t]{2}{*}{$\begin{array}{l}\text { Bed- } \\
\text { rock }\end{array}$} & \multicolumn{3}{|c|}{ Dark Roots } & \multicolumn{3}{|c|}{ Rhizoliths } & \multirow[t]{2}{*}{$\begin{array}{l}\text { Top of } \\
\text { Iron } \\
\text { Staining } \\
\end{array}$} & \multicolumn{3}{|c|}{$\begin{array}{c}\text { Popcorn } \\
\text { Carbonates }\end{array}$} \\
\hline & $\stackrel{\ddot{9} 9}{. \mathrm{cl}}$ & $\begin{array}{l}\mathrm{a} \\
\mathrm{g} \\
8 \\
3 \\
\end{array}$ & $\begin{array}{l}: \ddot{9} \\
\dddot{9} \\
9 \\
\prime \prime\end{array}$ & & il & $\begin{array}{l}\mathrm{Cl} \\
\mathrm{9} \\
8 \\
3 \\
\end{array}$ & 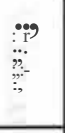 & & 99. & $\begin{array}{l}\mathrm{a} \\
\mathrm{9} \\
8 \\
3 \\
\end{array}$ & יa & & & & & $\begin{array}{ll}899 \\
. \mathrm{Cl}\end{array}$ & $\begin{array}{l}\mathrm{d} \\
\mathrm{o} \\
\mathrm{g} \\
\mathrm{g}\end{array}$ & $\ddot{\ddot{1}}$ & 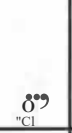 & $\begin{array}{l}\mathrm{d} \\
\mathrm{O} \\
\mathrm{g} \\
\mathrm{g} \\
\end{array}$ & 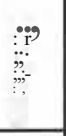 & & 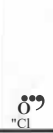 & $\begin{array}{l}\mathrm{d} \\
\mathrm{o} \\
\mathrm{g} \\
\mathrm{g}\end{array}$ & $\begin{array}{l}\stackrel{\ddot{\pi}}{\ddot{*}} \\
\text { 붑 }\end{array}$ \\
\hline TxDOT & & & & & & & & & & & & & & & & & & & & & & & & & \\
\hline Block 6: & & & & & & & & & & & & & & & & & & & & & & & & & \\
\hline El 8/S70 & 95.47 & 94.99 & 0.48 & 94.99 & 94.99 & 94.82 & 0.17 & 94.82 & 94.43 & 93.93 & 0.5( & 93.93 & 93.44 & & & & & & & & & & & & \\
\hline $\mathrm{E} 26 / \mathrm{S} 70$ & 95.43 & 94.62 & 0.81 & 94.62 & $\mathrm{NA}$ & NA & $\mathrm{NA}$ & 94.62 & 94.02 & 93.37 & 0.65 & 93.37 & 93.22 & & & & & & 94.57 & 93.82 & 0.75 & & & & \\
\hline $\mathrm{E} 24 / \mathrm{S} 70$ & 95.48 & 94.66 & 0.82 & $94.6 \mathrm{E}$ & $\mathrm{NA}$ & $\mathrm{NA}$ & NA & 94.66 & 94.07 & 93.65 & 0.42 & 93.65 & 93.31 & & & & & & 94.66 & 93.72 & 0.94 & & & & \\
\hline $\mathrm{E} 22 / \mathrm{S} 70$ & 95.43 & 94.68 & 0.75 & 94.68 & $\mathrm{NA}$ & NA & $\mathrm{NA}$ & 94.68 & 94.25 & 93.79 & $0.4 \mathrm{E}$ & 93.79 & 93.52 & & & & & & 94.72 & 93.67 & 1.05 & & & & \\
\hline $\mathrm{E} 20 / \mathrm{S} 70$ & 95.42 & 94.77 & 0.65 & 94.77 & 94.77 & 94.77 & 0.00 & 94.77 & 94.25 & 93.90 & 0.35 & 93.9( & 93.37 & & & 94.07 & 93.57 & & 94.82 & 93.77 & 1.05 & & & & \\
\hline $\mathrm{E} 18 / \mathrm{S} 70$ & 95.47 & 94.99 & 0.48 & 94.99 & 94.99 & 94.82 & 0.17 & 94.82 & 94.43 & 93.93 & $0.5 \mathrm{C}$ & 93.93 & 93.44 & & & 94.52 & 93.92 & & 94.99 & & & & & & \\
\hline $\mathrm{E} 18 / \mathrm{S} 72$ & 95.61 & 94.99 & 0.62 & 94.99 & 94.99 & 94.81 & 0.18 & 94.81 & 94.47 & 94.22 & 0.25 & 94.22 & & & & 94.47 & 94.22 & & 94.99 & 93.79 & $\mathrm{I} .2 \mathrm{C}$ & & & & \\
\hline $\mathrm{E} 18 / \mathrm{S} 74$ & 95.64 & 95.24 & 0.40 & 95.24 & 95.24 & $95.0 \mathrm{C}$ & 0.24 & 95.00 & NA & $\mathrm{NA}$ & NA & 94.60 & & & & & & & 95.24 & 93.92 & $l .3 L$ & & & & \\
\hline $\mathrm{E} 18 / \mathrm{S} 76$ & 95.77 & 95.34 & 0.43 & 95.34 & 95.34 & $95.0 \mathrm{~S}$ & 0.27 & 95.09 & $\mathrm{NA}$ & $\mathrm{NA}$ & NA & 94.61 & & & & & & & 95.34 & 94.02 & 1.32 & & & & \\
\hline $\mathrm{E} 18 / \mathrm{S} 78$ & 95.92 & 95.46 & 0.46 & 95.46 & 95.46 & $95.2 \mathrm{C}$ & 0.24 & 95.22 & NA & $\mathrm{NA}$ & NA & 94.75 & & & & & & & 95.46 & 94.32 & 1.14 & & & & \\
\hline $\mathrm{E} 26 / \mathrm{S} 70$ & 95.43 & 94.62 & 0.81 & 94.62 & NA & $\mathrm{NA}$ & NA & 94.62 & 94.02 & 93.37 & 0.65 & 93.37 & 93.22 & & & & & & & & & & & & \\
\hline $\mathrm{E} 26 / \mathrm{S} 72$ & 95.47 & 94.67 & 0.80 & 94.67 & $\mathrm{NA}$ & NA & NA & 94.67 & 94.11 & 93.42 & 0.69 & 93.42 & & & & & & & & & & & & & \\
\hline E26/S74 & 95.51 & 94.73 & 0.78 & 94.73 & $\mathrm{NA}$ & NA & NA & 94.73 & 94.13 & 93.44 & 0.69 & 93.44 & 93.24 & & & & & & & & & & & & \\
\hline $\mathrm{E} 26 / \mathrm{S} 76$ & 95.63 & 94.86 & 0.77 & 94.86 & 94.86 & 94.65 & 0.21 & 94.65 & 94.19 & 93.32 & 0.87 & 93.3, & & & & & & & & & & & & & \\
\hline E18/S78 & 95.92 & 95.46 & 0.46 & 95.46 & 95.46 & 95.22 & 0.24 & 95.22 & NA & $\mathrm{NA}$ & NA & 94.75 & & & & & & & & & & & & & \\
\hline $\mathrm{E} 20 / \mathrm{S} 78$ & 95.84 & 95.37 & 0.47 & 95.37 & 95.37 & 95.IL & 0.25 & 95.12 & $\mathrm{NA}$ & $\mathrm{NA}:$ & NA & 94.77 & & & & & & & & & & & & & \\
\hline $\mathrm{E} 22 / \mathrm{S} 78$ & 95.77 & 95.32 & 0.45 & 95.32 & $95.3 L$ & 95.05 & 0.27 & 95.05 & NA & $\mathrm{NA}$ & NA & 94.67 & & & & & & & & & & & & & \\
\hline E24/S78 & 95.75 & 95.12 & 0.63 & 95.12 & $95.1 \mathrm{C}$ & $95.0 \mathrm{C}$ & 0.12 & 95.00 & $\mathrm{NA}$ & $\mathrm{NA}$ & NA & 94.37 & & & & & & & & & & & & & \\
\hline E26/S78 & 95.67 & 95.IO & 0.57 & 95.10 & 95.10 & $94.8 \mathrm{D}$ & 0.28 & 94.82 & 94.24 & 93.78 & 0.46 & 93.78 & & & & & & & & & & & & & \\
\hline $\mathrm{E} 22 / \mathrm{S} 74$ & 95.56 & 94.88 & 0.68 & 94.88 & & & & 94.88 & 94.35 & 94.01 & 0.34 & 93.72 & & & & & & & & & & & & & \\
\hline $\mathrm{E} 24 / \mathrm{S} 72$ & 95.50 & 94.74 & 0.76 & 94.74 & NA & NA & NA & 94.74 & 94.19 & 93.65 & 0.54 & 93.34 & & & & & & & & & & & & & \\
\hline E24/S76 & 95.65 & 94.91 & 0.74 & 94.91 & 94.91 & 94.87 & 0.04 & 94.87 & 94.29 & 93.82 & 0.47 & 93.82 & & & & & & & & & & & & & \\
\hline $\mathrm{E} 24 / \mathrm{S} 74$ & 95.53 & 94.84 & 0.69 & 94.80 & $\mathrm{NA}$ & NA & NA & 94.84 & 94.22 & 93.70 & $0.5 L$ & 93.70 & & & & & & & & & & & & & \\
\hline $\mathrm{E} 22 / \mathrm{S} 72$ & 95.52 & 94.77 & 0.75 & 94.77 & $\mathrm{NA}$ & $N A$ & $\mathrm{NA}$ & 94.77 & 94.27 & 93.91 & $0.3 \mathrm{f}$ & 93.91 & 93.66 & & & & & & & & & & & & \\
\hline E22/S76 & 95.65 & 95.07 & 0.62 & 95.07 & 95.07 & 94.98 & 0.09 & 94.98 & 94.35 & 94.28 & 0.07 & 94.28 & & & & & & & & & & & & & \\
\hline
\end{tabular}




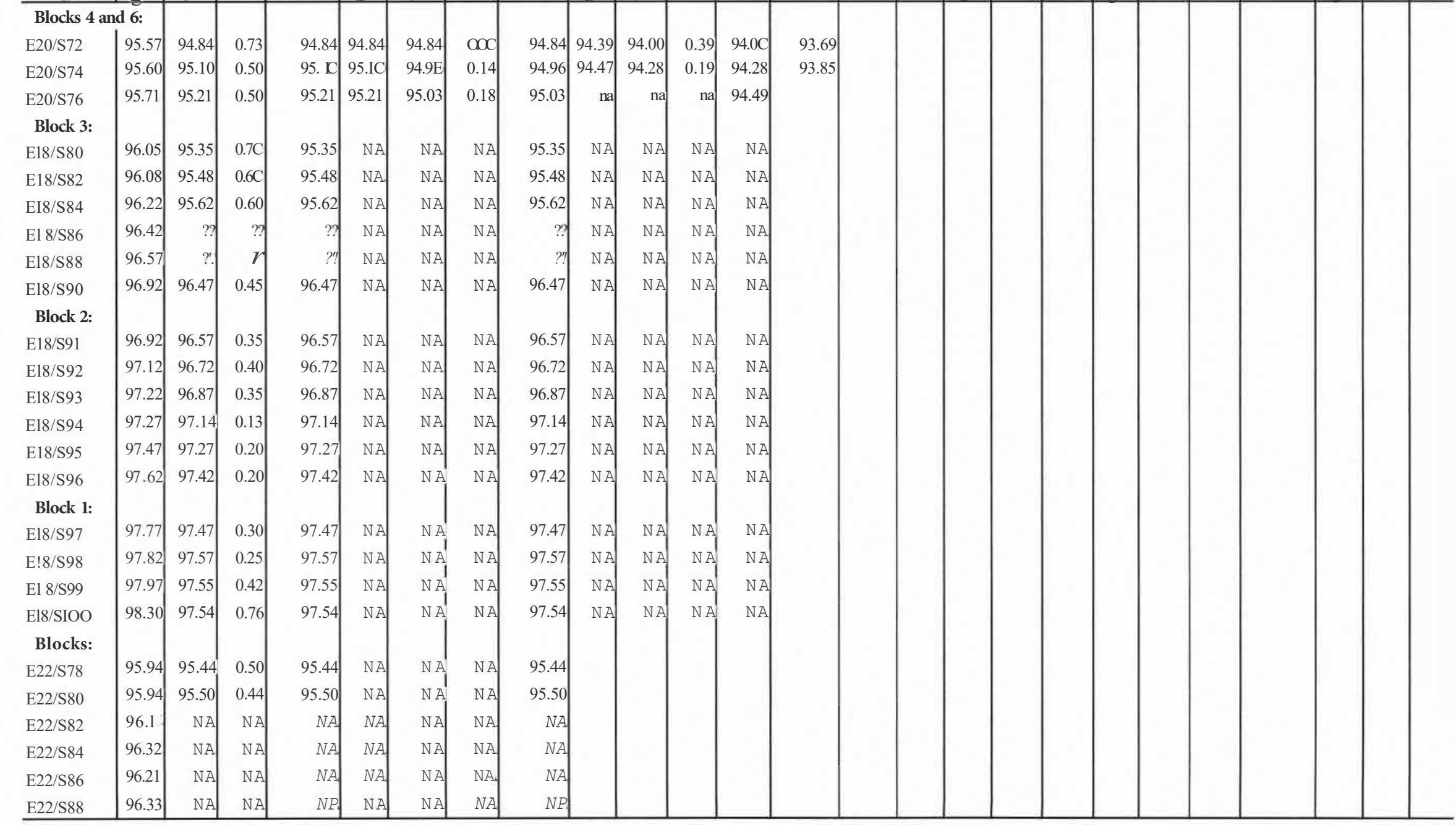




\begin{tabular}{|c|c|c|c|c|c|c|c|c|c|c|c|c|c|c|c|c|c|c|c|c|c|c|c|c|c|}
\hline \multirow[b]{2}{*}{ 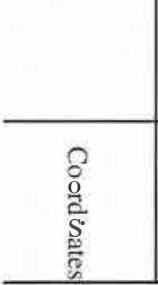 } & \multicolumn{3}{|c|}{ Unit II } & \multirow[t]{2}{*}{$\begin{array}{l}\text { Unit I/II } \\
\text { Contact }\end{array}$} & \multicolumn{3}{|c|}{ Unit Id } & \multirow[t]{2}{*}{$\begin{array}{c}\text { Top of } \\
\text { Leanne } \\
\text { Soil } \\
\end{array}$} & \multicolumn{3}{|c|}{ Unit lei (Cienega) } & \multirow[t]{2}{*}{$\begin{array}{c}\text { Top of } \\
\text { Unit } \\
\text { Isi } \\
\end{array}$} & \multirow[t]{2}{*}{$\begin{array}{r}\text { Top of } \\
\text { Gravels }\end{array}$} & \multirow[t]{2}{*}{$\begin{array}{c}\text { lgl } \\
\text { Thick- } \\
\text { ness }\end{array}$} & \multirow[t]{2}{*}{$\begin{array}{l}\text { Bed- } \\
\text { rock }\end{array}$} & \multicolumn{3}{|c|}{ Dark roots } & \multicolumn{3}{|c|}{ Rhizoliths } & \multirow[t]{2}{*}{$\begin{array}{c}\text { Top of } \\
\text { Iron } \\
\text { Staining } \\
\end{array}$} & \multicolumn{3}{|c|}{$\begin{array}{c}\text { Popcorn } \\
\text { Carbonates } \\
\end{array}$} \\
\hline & \begin{tabular}{c|c}
1 \\
8 \\
\end{tabular} & $\begin{array}{l}\text { कo } \\
0 \\
\S \\
3\end{array}$ & 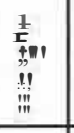 & & $\frac{1}{8}$ & $\begin{array}{l}\mathbf{0} \\
0 \\
\S \\
3 \\
\end{array}$ & 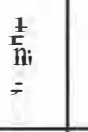 & & $\begin{array}{l}1 \\
0 \\
0\end{array}$ & $\begin{array}{l}\mathbf{0} \\
0 \\
\S \\
3\end{array}$ & 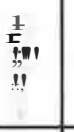 & & & & & d & $\begin{array}{l}\mathbf{0} \\
0 \\
\S \\
\$\end{array}$ & 売, & $0_{0}^{1}$ & $\begin{array}{l}\mathbf{O} \\
0 \\
\S \\
3\end{array}$ & 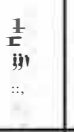 & & $\begin{array}{c}1 \\
0 \\
0\end{array}$ & $\begin{array}{l}\mathbf{0} \\
0 \\
\S \\
\xi\end{array}$ & $\frac{1}{2}$ \\
\hline \multicolumn{2}{|c|}{ Fine-screen Unit: } & & & & & & & & & & & & & & & & & & & & & & & & \\
\hline E27/S76 & | 95.54 & 94.87 & 0.67 & 94.87 & 94.87 & 94.4 & 0.43 & 94.44 & 94.27 & 93.07 & 1.2( & 91.81 & & & & & & & & & & & & & \\
\hline E28/S77 & 95.38 & 94.90 & 0.48 & 94.90 & 94.90 & $94.6 \mathrm{t}$ & 0.24 & 94.66 & 94.23 & 93.05 & J.18 & \begin{tabular}{|l|}
91.79 \\
\end{tabular} & & & & & & & & & & & & & \\
\hline $\mathrm{E} 27 / \mathrm{S} 78$ & 95.68 & 95.02 & 0.66 & 95.02 & 95.02 & 94.81 & 0.21 & 94.81 & 94.22 & 93.33 & $0.8 \mathrm{~S}$ & 92.07 & & & & & & & & & & & & & \\
\hline \multicolumn{26}{|l|}{ TARL } \\
\hline $\mathrm{E} 24.5 / \mathrm{S} 80$ & $95.8 \mathrm{C}$ & 95.60 & 0.20 & 95.60 & $\mathrm{NA}$ & $\mathrm{NA}$ & $\mathrm{NA}$ & 95.60 & $\mathrm{NA}$ & $\mathrm{NA}$ & $\mathrm{NA}$. & 94.94 & 92.00 & 0.46 & 91.54 & 94.76 & 94.30 & 0.46 & 95.38 & 94.62 & $0.7 t$ & 95.00 & $\mathrm{NA}$ & $\mathrm{NA}$ & $\mathrm{NA}$ \\
\hline $\mathrm{E} 29.5 / \mathrm{S} 80$ & $\mathrm{NA}$ & NA & $\mathrm{NA}$ & & & & & & & & & & & & & & & & & & & & & & \\
\hline $\mathrm{E} 29 / \mathrm{S} 72.5$ & 95.61 & 94.62 & 0.99 & 94.62 & $\mathrm{NA}$ & $\mathrm{NA}$ & $\mathrm{NA}$ & 94.62 & 94.00 & 92.94 & I.OE & $\mathrm{NA}$ & 92.94 & 1.78 & 91.1E & 94.60 & 93.38 & 1.22 & 94.60 & 94.00 & 0.60 & 93.96 & 94.00 & 92.9 & 1.06 \\
\hline $\mathrm{E} 29.5 / \mathrm{S} 75.5$ & 95.56 & 94.86 & 0.70 & 94.86 & 94.9 & 94.7 & 0.16 & 94.70 & 94.10 & 93.14 & $0.8 \mathrm{E}$ & 93.14 & 92.98 & $\mathrm{NA}$ & $\mathrm{NA}$ & 93.50 & 92.80 & 0.70 & 95.00 & 93.54 & $1.4 \mathrm{E}$ & 94.04 & 94.00 & 93.1 & 0.94 \\
\hline $\mathrm{E} 23.5 / \mathrm{S} 79$ & 95.92 & 95.40 & 0.52 & $95.4 \mathrm{C}$ & $\mathrm{NA}$ & $\mathrm{NA}$ & $\mathrm{NA}$ & 95.40 & $\mathrm{NA}$ & $\mathrm{NA}$ & $\mathrm{NA}$ & 94.88 & & & & & & & & & & & & & \\
\hline E29/S78.5 & 95.72 & 95.08 & 0.64 & 95.08 & 95.08 & 94.7 & 0.32 & 94.70 & 94.10 & 93.50 & 0.60 & 93.50 & $\mathrm{NA}$ & $\mathrm{NA}$ & $\mathrm{NA}$ & 93.52 & 93.18 & 0.34 & 95.02 & 94.06 & 0.96 & 94.10 & 94.JO & 93.6 & 0.54 \\
\hline $\mathrm{E} 28.5 / \mathrm{S} 79$ & 95.70 & 95.10 & 0.60 & $95.1 \mathrm{IC}$ & 95.10 & 94.88 & 0.22 & 94.88 & 94.10 & 93.80 & 0.30 & 93.80 & $\mathrm{NA}$ & $\mathrm{NA}$ & $\mathrm{NA}$ & 94.26 & 93.40 & 0.86 & 95.04 & 93.66 & 0.38 & 93.90 & 93.98 & 93.6 & 0.32 \\
\hline $\mathrm{E} 25.5 / \mathrm{S} 7$ & 95.80 & 95.30 & $0.5 \mathrm{C}$ & 95.30 & $\mathrm{NA}$ & $\mathrm{NA}$ & $\mathrm{NA}$ & 95.30 & $\mathrm{NA}$ & $\mathrm{NA}$ & $\mathrm{NA}$ & 94.70 & $\mathrm{NA}$ & $\mathrm{NA}$ & $\mathrm{NA}$ & 94.68 & 93.74 & 0.94 & 95.30 & 94.04 & 1.26 & 94.80 & \begin{tabular}{|l|}
94.12 \\
\end{tabular} & 93.9 & 0.26 \\
\hline $\mathrm{E} 26.5 / \mathrm{S} 79$ & 95.68 & 95.28 & 0.40 & 95.28 & 95.28 & 95.00 & 0.28 & 95.00 & $\mathrm{NA}$ & $\mathrm{NA}$ & $\mathrm{NA}$ & 94.30 & $\mathrm{NA}$ & $\mathrm{NA}$ & $\mathrm{NA}$ & 94.16 & 93.62 & 0.54 & 95.28 & 93.58 & 1.70 & 94.30 & 94.40 & 93.6 & 0.78 \\
\hline $\mathrm{E} 27.5 / \mathrm{S} 79$ & 95.76 & 95.18 & 0.58 & 95.18 & 95.18 & 94.84 & 0.34 & 94.84 & 94.40 & 94.39 & 0.01 & 94.39 & $\mathrm{NA}$ & $\mathrm{NA}$ & $\mathrm{NA}$ & 94.30 & 93.48 & 0.82 & 95.08 & 93.56 & 0.52 & 94.28 & 94.10 & 93.7 & 0.44 \\
\hline $\mathrm{E} 26.5 / \mathrm{S} 72.5$ & $\mathrm{NA}$ & $\mathrm{NA}$ & $\mathrm{NA}$ & $\mathrm{NA}$ & $\mathrm{NA}$ & $\mathrm{NA}$ & $\mathrm{NA}$ & $\mathrm{NA}$ & $\mathrm{NA}$ & $\mathrm{NA}$ & $\mathrm{NA}$ & $\mathrm{NA}$ & 93.14 & 2.08 & 91.0Е & $\mathrm{NA}$ & $\mathrm{NA}$ & $\mathrm{NA}$ & $\mathrm{NA}$ & $\mathrm{NA}$ & $\mathrm{NA}$ & $\mathrm{NA}$ & $\mathrm{NA}$ & $\mathrm{NA}$ & $\mathrm{NA}$ \\
\hline E24.5/S78.5 & $\mathrm{NA}$ & $\mathrm{NA}$ & $\mathrm{NA}$ & $\mathrm{NA}$ & $\mathrm{NA}$ & $\mathrm{NA}$ & $\mathrm{NA}$ & $\mathrm{NA}$ & $\mathrm{NA}$ & $\mathrm{NA}$ & $\mathrm{NA}$ & $\mathrm{NA}$ & 93.30 & 0.80 & 91.5( & $\mathrm{NA}$ & $\mathrm{NA}$ & $\mathrm{NA}$ & $\mathrm{NA}$ & $\mathrm{NA}$ & $\mathrm{NA}$ & $\mathrm{NA}$ & $\mathrm{NA}$ & $\mathrm{NA}$ & NA \\
\hline $\mathrm{E} 27.5 / \mathrm{S} 71.5$ & 95.52 & 94.70 & 0.82 & 94.82 & $\mathrm{NA}$ & $\mathrm{NA}$ & $\mathrm{NA}$ & 94.82 & 93.90 & 93.44 & 0.46 & $93.44^{\prime}$ & 93.00 & $\mathrm{NA}$ & .NA & $\mathrm{NA}$ & $\mathrm{NA}$ & $\mathrm{NA}$ & 94.70 & 94.18 & $0.5 L$ & 93.86 & 93.94 & 93.1 & 0.84 \\
\hline $\mathrm{E} 28 / \mathrm{S} 73.5$ & 95.48 & 94.68 & 0.80 & 94.68 & 94.68 & 94.44 & 0.24 & 94.44 & 94.06 & 93.08 & 0.98 & $\mathrm{NA}$ & 93.08 & $\mathrm{NA}$ & $\mathrm{NA}$ & 93.50 & 92.74 & 0.76 & 95.24 & 94.06 & 1.18 & 94.IO & 94.14 & 93.1 & 1.02 \\
\hline $\mathrm{E} 28 / \mathrm{S} 74.5$ & 95.42 & 94.82 & 0.60 & 94.82 & 94.82 & 94.65 & 0.20 & 94.62 & 93.94 & 93.18 & 0.76 & 93.18 & 93.06 & $\mathrm{NA}$ & $\mathrm{NA}$ & 93.66 & 92.80 & 0.86 & 95.10 & 93.86 & 1.24 & 93.90 & 93.92 & 93.1 & 0.84 \\
\hline E29/S77.5 & 95.64 & 94.90 & 0.74 & 94.90 & 94.90 & 94.64 & 0.26 & 94.64 & 94.14 & 93.40 & 0.74 & 93.40 & $\mathrm{NA}$ & $\mathrm{NA}$ & $\mathrm{NA}$ & 93.62 & 92.80 & 0.82 & 95.02 & 94.04 & 0.98 & 94.14 & 94.14 & 93.1 & 1.04 \\
\hline $\mathrm{E} 27 / \mathrm{S} 72.5$ & & & & & & & & & & & & & 93.22 & & & & & & & & & & & & \\
\hline E27/S73.5 & & & & & & & & & & & & & 93.08 & & & & & & & & & & & & \\
\hline $\mathrm{E} 27 / \mathrm{S} 74.5$ & & & & & & & & & & & & & 93.04 & & & & & & & & & & & & \\
\hline $\begin{array}{l}\text { E27/S75.5 } \\
\text { E28/S76 }\end{array}$ & $\mathrm{NA}$ & 94.90 & $\mathrm{NA}$ & 94.90 & 94.90 & 94.70 & 0.20 & 94.70 & 93.98 & 93.40 & 0.52 & 93.4E & $\begin{array}{l}92.74 \\
92.98\end{array}$ & $\mathrm{NA}$ & $\mathrm{NA}$ & 93.45 & 93.02 & 0.43 & 94.68 & 93.62 & I.OE & 93.96 & 93.90 & 93.1 & 0.76 \\
\hline $\mathrm{E} 27 / \mathrm{S} 71$ & 95.51 & 94.78 & 0.73 & 94.78 & $\mathrm{NA}$ & $\mathrm{NA}$ & $\mathrm{NA}_{4}$ & 94.78 & 93.94 & 93.54 & 0.40 & 93.54 & 93.JO & $\mathrm{NA}$. & $\mathrm{NA}$ & 93.50 & 92.8( & 0.70 & $94.2 t$ & 93.22 & 1.04 & 93.86 & 93.90 & 93.1 & 0.82 \\
\hline
\end{tabular}




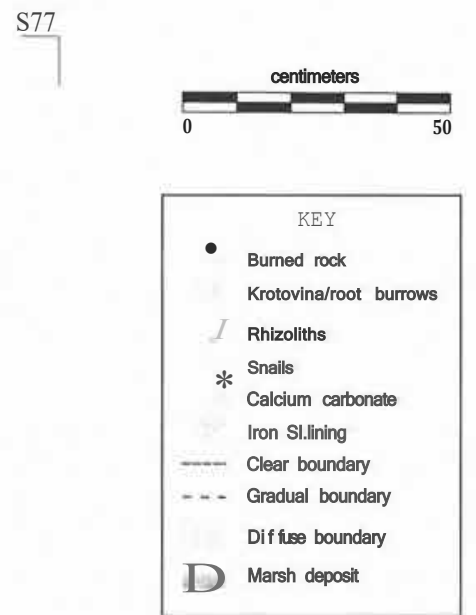

$\frac{S 78}{1}$

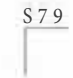

Square 35
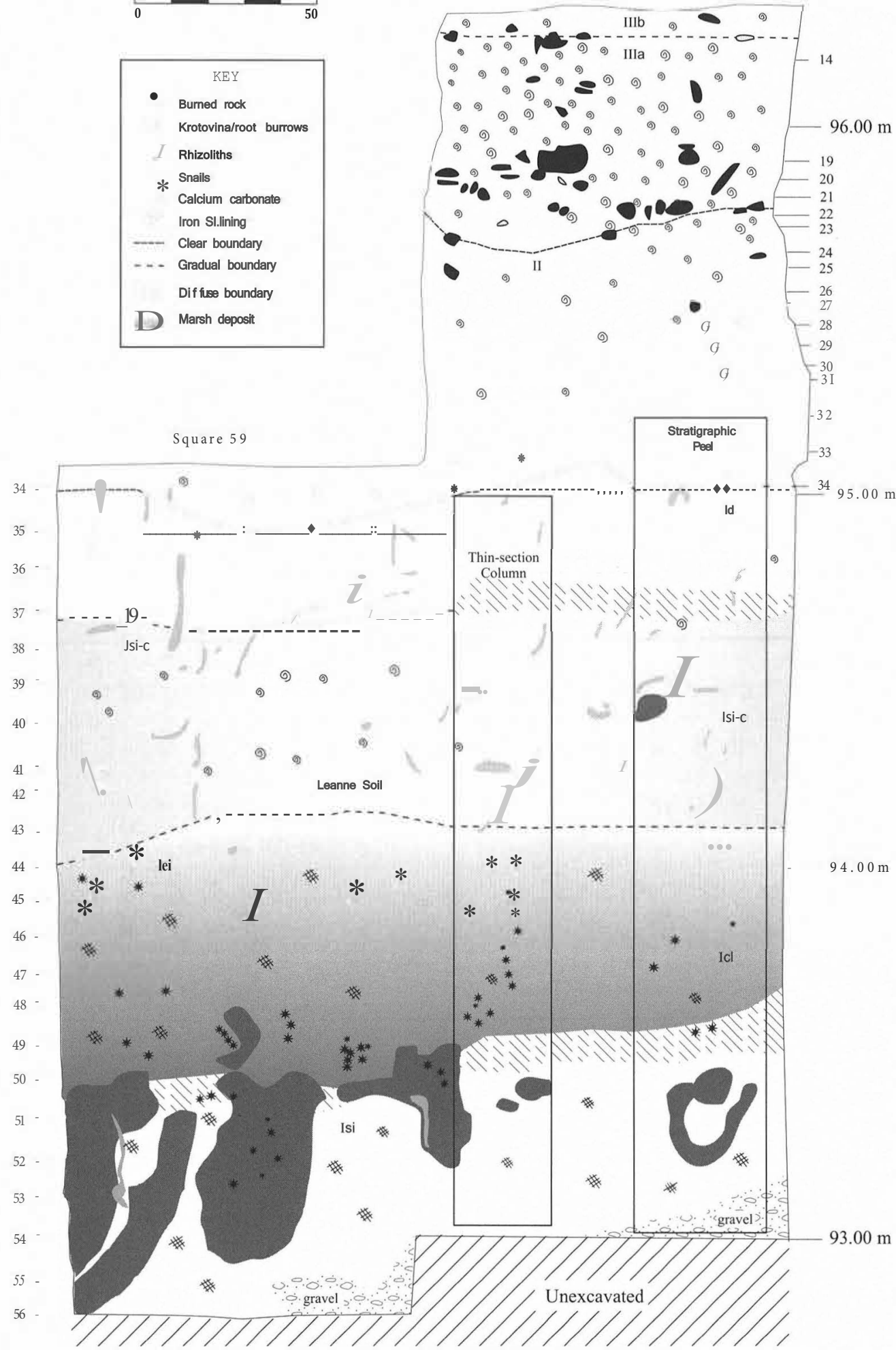

FlauRE 6-1 t. Profile drawing of the east wall of Square 35 and lower part of Square 59 showing iron staining and root borrows as well as numerous rhizoliths at the top of Unit lsi. Note the abundance of snail shells in the upper part of the profile. Unit lei thins to the south (right), indicating the edge of the cienega in this direction. 
stony, with some centimeter-sized portions of fossils. Charcoal is not common, but some was found in a burrowed pocket in the East Block profile.

Secondary effects are present but less abundant than in other subunits. Some rhizoliths occur as in the Leanne soil, but they are generally truncated by the overlying Unit II. Distinct rhizoliths are generally less clear above the contact between Unit Id and Unit II. Occurring locally, however, are diffuse impregnations of $\mathrm{CaCO}_{3}$ that exhibit an anastomosing pattern. Traces of iron staining and mottling occur, but they tend to be more abundant at the east end of the South Block and in the East Block.

The upper contact with Unit II is abrupt, smooth to wavy, and is marked by the occurrence of distinctly more gravelly silts above the contact. However, the upper part of Unit Id locally exhibits a number gravelly lenses, that appear to be either burrows or filled small gullies. The presence of these gravelly lenses makes identification of the contact more difficult. These lenses occur along the East Block (east face of Square 27; see Figures 6-7 and 6-8a) at elevations between $94.75 \mathrm{~m}$ and $94.85 \mathrm{~m}$. It would appear, therefore, that some gravel was deposited during the final stages of Unit Id, although it is possible that these lenses are actually associated with Unit II proper and cut into Unit Id.

Unit Id most likely represents post-Leanne alluvium deposited from the Brushy Creek/Spanish Oak Creek system with the addition of colluvial material derived from the drainage to the southwest of the site (see Chapter 2, Figure 2-1). Alternatively, Unit Id may represent reworked Leanne soil material that has been stripped from an unstable, actively eroding slope. In either case, the slightly unconformable relationship between the formation of the Leanne soil and the deposition of Unit Id indicates a small but distinct temporal hiatus, although the resolution of the radiocarbon dates is not sufficient to polish this suggestion.

\section{UNIT II}

Unit II is set off from Unit I by an abrupt increase in gravel and whole snail shells. Overall, Unit II is a massive, homogeneous deposit consisting of nonsticky and nonplastic brown (7.5YR 5/4), coarse crumbly, sandy, clayey silt with angular pebbles about $1-2 \mathrm{~cm}$ in diameter; the pebbles are abundant at the base and decrease upward. Small stones (ca. $5 \mathrm{~mm}$ in diameter) are found in association with burned rock features and are more abundant in the northeast half of the site where they tend to be concentrated in the lower part of the unit near the contact with Unit I Elsewhere in the unit, stones are dispersed throughout. Snail shells are present mostly as fragments, although whole pieces can be found in localized gravel pockets that are ca. $20 \mathrm{~cm}$ across.

The fine matrix in Unit II is calcareous and exhibits numerous worm casts. Fine pores are locally coated with $\mathrm{CaCO}_{3}$. In general, the material has more of an "aged" appearance than the sediments in Unit III (see below), where the worm casts are fresher and darker. This "aging" is evident in thin section as well and suggests somewhat greater soil development in Unit II than in the overlying Unit IIII.

Originally, the unit was subdivided into a lower, more gravelly part (Unit Ila) and a finer part with less gravel (Unit lib), but subsequent fieldwork showed this to be the case only in the northeast comer of the excavation, where the upper sediments tended to be slightly redder (especially true for the area north of Square 28). The reason for the increased redness is not clear and may be a result of burning or input ofredder sediment (see Chapter 29). The latter hypothesis is supported by the occurrence of dark reddish brown (5YR 3/4) clay found in karstic pockets that are developed within the Comanche Peak Limestone; one of these pockets was observed during highway construction. In thin section, the red color of sediments near Feature 169, for example, seems to be associated with finely divided iron oxide (see below) that is found on many pieces of bedrock within these sediments.

The thickness ofUnit II varies over the area of the excavation and clearly increases to the northeast (see Table 6-6). As can be seen here, the elevation of the contact with Unit I is also inclined to the northeast.

Evidence ofpostdepositional modification in Unit II is manifested in the lower halfof the unit, which exhibits broad, diffuse, chalky pink (7.5YR 7/4) lime concretions (ca. $4 \mathrm{~cm}$ wide by $35 \mathrm{~cm}$ long) and rhizoliths. The latter are typically better exposed in the northeast part of the excavation, but some are found in the South Block as well. In addition, worm casts are clearly evident and tend to be moderately abundant at the base of the unit. There, mixed domains of lighter and darker matrix are visible and presumably result from this biological reworking of the sediment.

\section{UNITIII}

The sediments from Unit Ill are overall quite distinct from those of the underlying units and consist of massive, nonsticky and nonplastic coarse crumbly to subangular blocky, poorly sorted stony clayey silts. Some localized concentrations of stones and snail shells occur and these are primarily of anthropogenic origin; the snails in particular appear to be associated with numerous burned rock features. Evidence of earthworm activity (casts) is abundant throughout the unit.

Pieces of stones are distributed both irregularly and locally in diffuse bands (e.g., as in Unit IIIa) that are up to several meters across and 10 to $20 \mathrm{~cm}$ thick. The fire-cracked nature of some of the stones in these bands show that they are clearly related to burned rock features, as, for example, in the East Block (Squares 37, 38, and 39; Figure 6-12). In the cultural layers, stones are quite angular and range in diameter from ca. 5 to $20 \mathrm{~cm}$. Elsewhere, where they are not in bands, they are quite angular and range in diameter from ca. I to $6 \mathrm{~cm}$, reaching up to 8 to $10 \mathrm{~cm}$. In the field, it was 


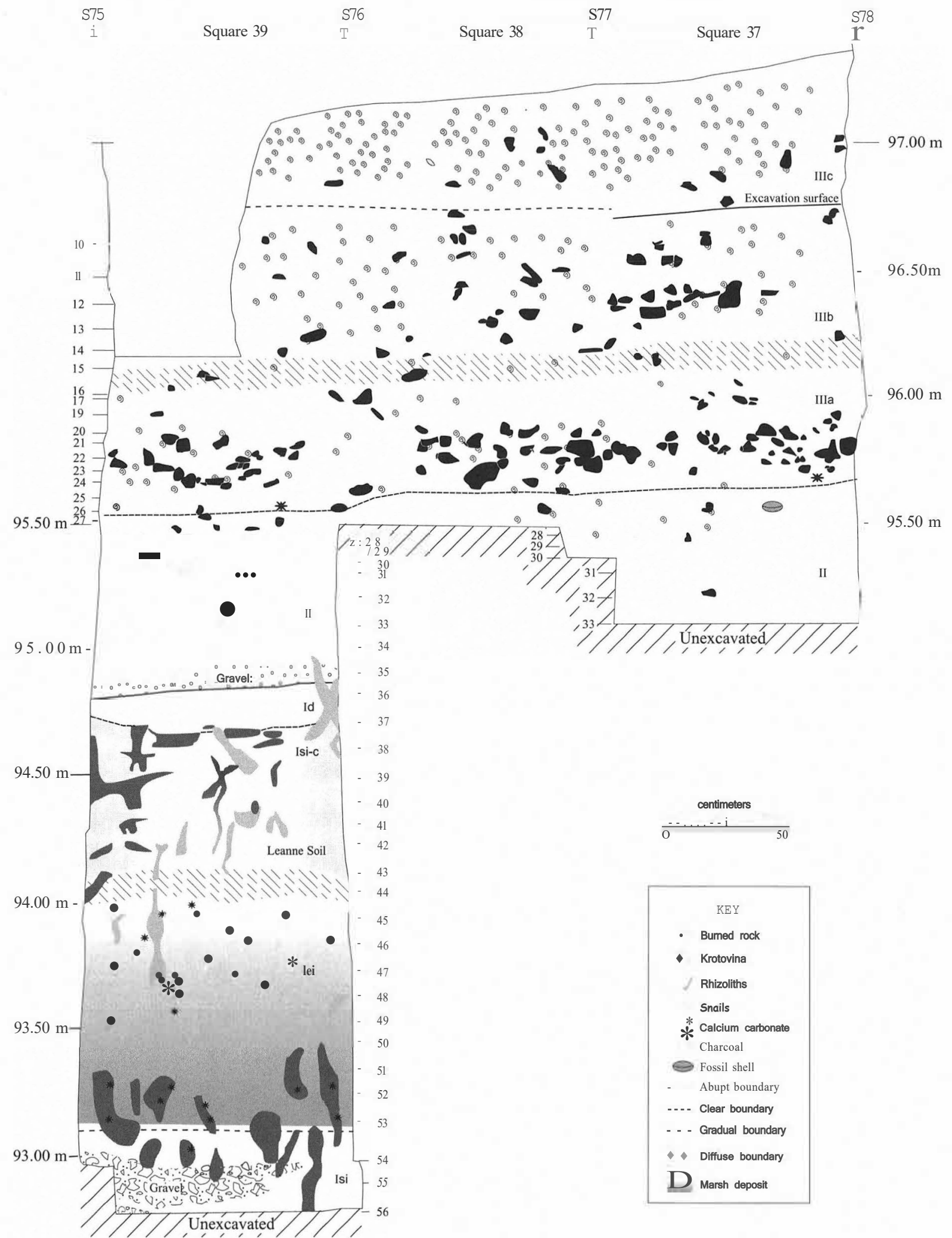

FGURE 6-12. Profile drawing of the east wall of Squares 37, 38, and 39. 
difficult to estimate the number of stones exposed in a given profile and more-realistic quantitative estimates can be made only from wet sieve data. Unfortunately, due to logistical problems, data from wet sieving were not systematically collected, and dependable estimates of stone abundance are therefore unavailable.

Pieces of charcoal are rare except in association with burned rock features in Unit IIII. In Units IIIlb and Ille, only one or two pieces of charcoal were noted in the South Block profiles. Snail shells-both whole and as fragments-occur throughout the unit and locally are distributed as diffuse bands or stringers ca. $60 \mathrm{~cm}$ wide and ca. $10 \mathrm{~cm}$ thick. Secondary effects are represented by localized occurrences of carbonate filaments and the presence of extensive worm casts that are visible both in hand lens and in thin section (see Chapter 29).

The thickness of Unit III varies from ca. $1.6 \mathrm{~m}$ in the South Block to ca. 1.1 min the East Block (see Table 6-5); it was truncated in the northeast comer of the main excavation block during the TxDOT excavations and subsequent road construction. Unit III was divided into three subunits, primarily on the basis of differences in color and stoniness (see Figure 6-2).

\section{Unit Illa}

Unit Illa is the lowest of the three subunits and is comprised of brown and dark yellowish brown (1 OYR 4/3 and 1OYR 4/4) stony clayey silt with numerous burned rock features. This is particularly true in the lower part of the subunit and in the middle of the East Block (Squares 27, 28, 39, and 52; see Figures 6-7, 6-8a, and 6-12), although Unit Illa is also well exposed in the South Block (see Figures 6-3, 6-8b, and 6-10). These burned rock features are often clearly situated above the contact with Unit II (Figure 6-13) and are separated from it in many places in the East Block by fine stony silts that locally are ca. $1 \mathrm{O} \mathrm{cm}$ thick.

This subunit corresponds in part to the Stiba soil (Holliday 1989b), which was best exposed on the west profile ofTxDOT Block 4 (Figure 6-8c). In the TARL excavations, the Stiba soil was clearest and best expressed only in the north and east walls of Square 25. It becomes much less distinct to the south, where on the South Block profiles it is visible but not striking (see Figure 6-8b).

The contact with Unit II is smooth to locally wavy and clear to gradual. It also slopes to the north and east but is less inclined than the lower contacts of subunits IIIb and IIIc (see Table 6-5).

\section{Unit IIIb}

This unit consists of dark gray brown to brown (7.5YR to IOYR $4 / 2$ and IOYR $4 / 3$ ) stony clayey silt. It is noticeably lighter in color and somewhat less stony than either Unit IIIIa or Unit Ilic, with fewer concentrations of angular stones.

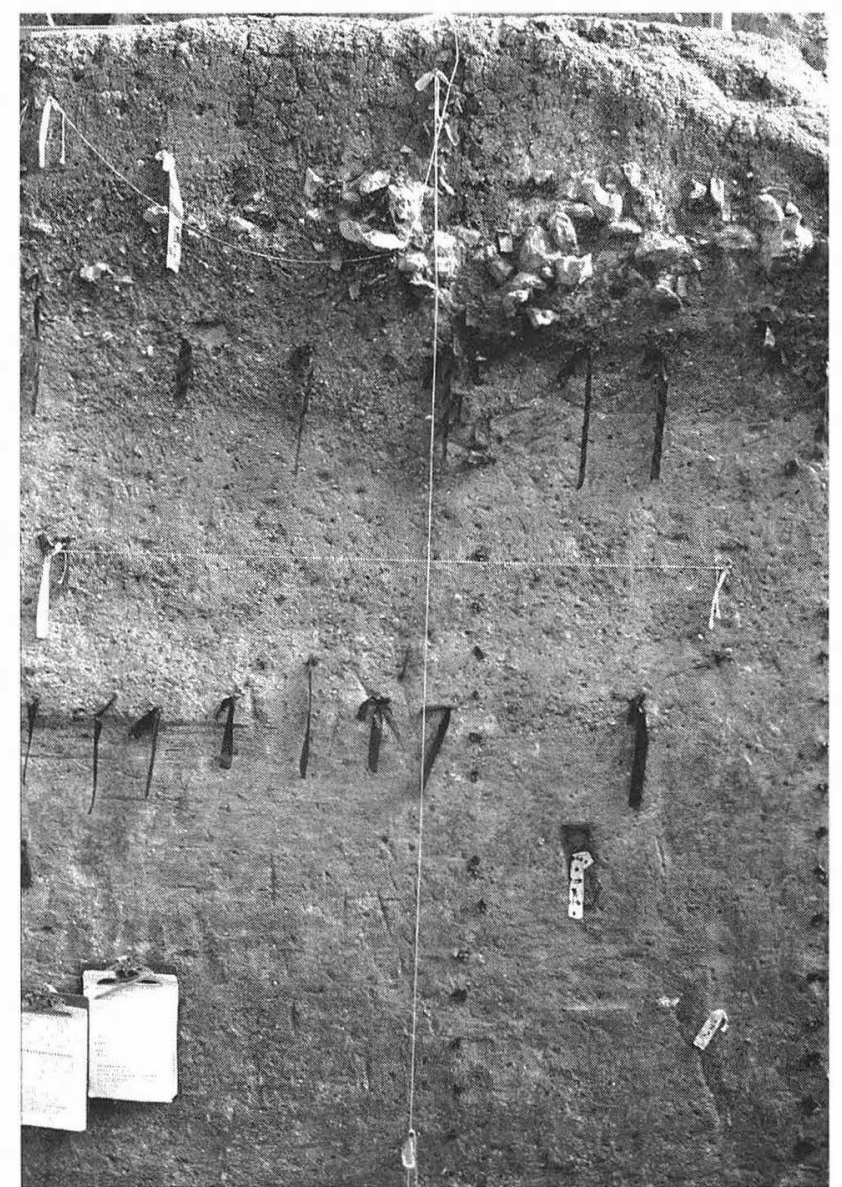

FlOURE 6-13. Profile of the central part of Squares 27 and 28, showing the upper part of Unit I, Unit II, and the burned rock feature (Feature 245) in Unit Illa. Note the ca. I0-15 am of darker, silty sediments between the Unit II/III contact and the burned rock feature.

This lighter color is visible throughout the site and is particularly prominent along the west and east profiles of the TxDOT main block (see Figures 6-8c, 6-8d). Unit IIIlb corresponds essentially to the lower portion ofHolliday's (1989b) Stratum 6. The contact with the underlying Unit Illa is gradual and smooth, and it is often difficult to isolate this boundary with certainty. As in other subunits Ille and Illa, the layer is inclined to the north and east (see Table 6-5), and evidence ofworm burrowing is prominent.

\section{Unitlllc}

This uppermost subdivision of Unit III consists of very dark gray (IOYR 3/1), very dark grayish brown (IOYR 3/2), and dark grayish brown (1OYR 4/2) stony clayey silt. Concentrations of angular stones and burned rock features occur locally over the entire subunit. Unit Ille aggraded slowly over the last 4,000 years (see Chapter 25), and as mentioned above, it exhibits a cumulic soil, the Wilson-Leonard soil, which is relatively rich in organic matter and phosphorous content. Its development and accumulation is likely tied to 
the combined effects of anthropogenic and geogenic sedimentation, however slow, and of pedogenesis. The latter is visible in the field by earthworm activity as shown by the abundance of casts; worms are also responsible for secondary calcite cementation of these upper deposits (see Chapter 29).

The upper part of Unit Ille was truncated and compacted during the TxDOT excavation and subsequent road construction. This disturbance is particularly true in the north and northeast portions of the main excavation block where the surviving portion ofIIIc is only a few centimeters thick. The contact with Unit Illb is gradual and somewhat wavy, becoming more smooth in the East Block; this contact also is inclined to the north and east (see Table 6-5).

\section{TARL Square JOO}

During the TARL excavation, a small 2-x-5-m Gradall trench and two hand-excavated squares were placed within Burned Rock Midden I at the Valley Margin. Stratigraphic observations were somewhat limited in these excavations, yet they were sufficient to reveal three major stratigraphic units-Burned Rock Midden 1 at the top (correlated to Unit Ille) grading into a brown stony silt (Unit Y), which rests upon a massive, pale brown, compact silt (Unit X) (see Figure 6-5; Figure 6-14). These stratigraphic units are described from bottom to top as follows.

Unit X, 160 to $260 \mathrm{~cm}$ below surface, is composed of massive very pale brown (IOYR 7/4), compact subangular blocky silts, with localized diffuse domains of angular, peasized gravels and diffuse gravel stringers about $5 \mathrm{~cm}$ thick; some coarse calcareous sand is present. The sediment is harder and more brittle than in overlying units and possibly more cemented toward the base. At a depth of about $220 \mathrm{~cm}$, fine veins of calcite were observed. There is much less porosity in this unit than in Unit $Y$ and very little evidence of biological activity. However, there is a relatively high proportion of fresh and angular fossiliferous rock fragments that are locally derived from the bedrock. On the north profile of the TARL Gradall trench, 1-3-mm-thick stringers of angular and rounded gravel appear and probably constitute fillings of former rills. Bedrock was reached at $270 \mathrm{~cm}$ below surface at an elevation of $95.80 \mathrm{~m}$.

Unit Y, 110 to $160 \mathrm{~cm}$ below surface, is a transitional zone characterized by compact, yellowish brown (1 OYR 5/ 4), subangular blocky fine stony silts with some centimeter-sized, angular burned rocks, small snail shells, and snail shell fragments. Mottling is present with centimeter-sized domains of darker bwwn, clayier, and more organic-rich silts; possibly some charcoal fragments were observed, but they were too small to be identified as such in the field. The sediment dries to a chalkier appearance than in Unit X, and numerous carbonate impregnations of the matrix could be observed. Sand-sized casts of mites are present, and their small size precludes earthworm activity; vesicular

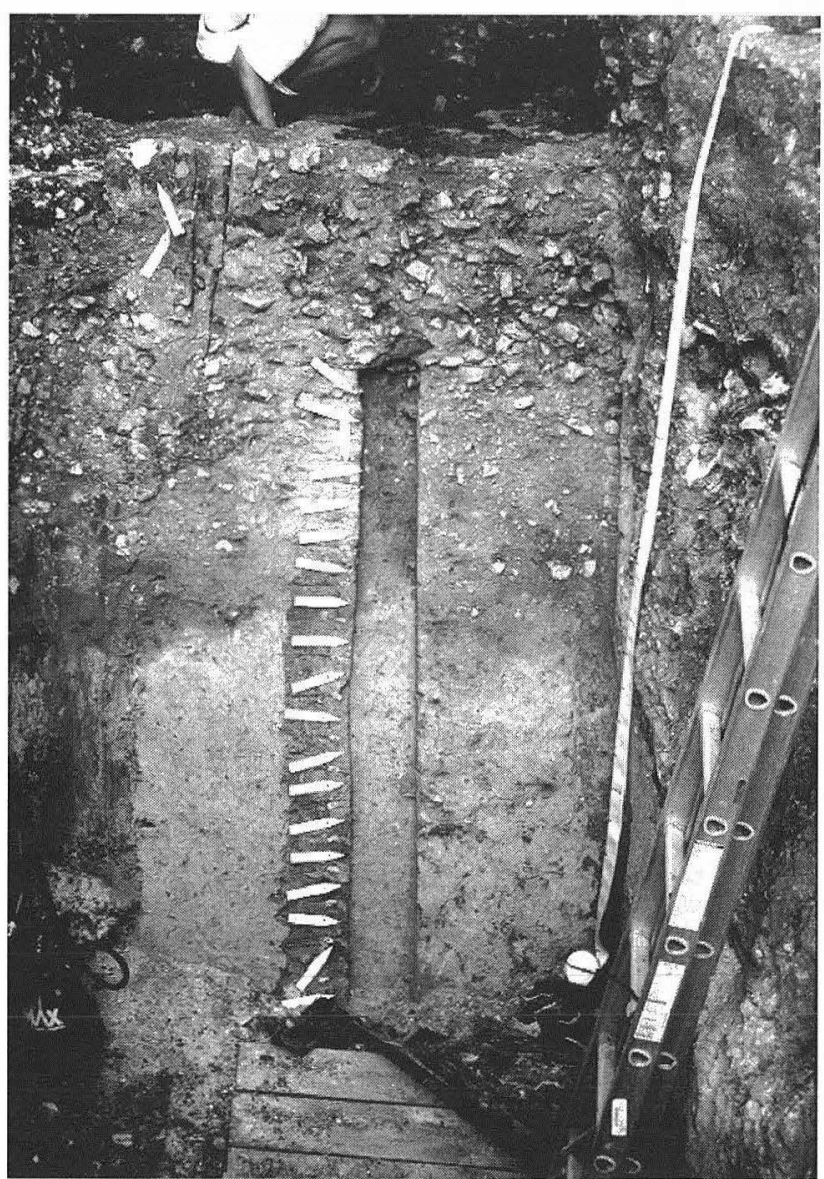

FIGURE 6-14. West wall of Square 101 (geological column 300) showing Burned Rock Midden 1 at the top (Unit Ille) grading to brown stoney silt (Unit $\mathrm{Y}$ ), which rests on hard, massive compact pale brown silt (Unit $\mathrm{X}$ ). The former is broadly correlated with Units II and IIIla in the Main Block (TxDOT Block 4), whereas Unit $\mathrm{X}$ is temporally roughly equivalent to Unit I

porosity was noted. The contact with Unit X below is clear and smooth.

Unit Ille, 0 to $110 \mathrm{~cm}$ below surface, consists of ashy, powdery burned rock midden. Rocks are generally angular and cracked and range from 3-15 cm in diameter (ca. 5-cm average). Although this unit represents numerous cultural occupations, it is overall geologically homogeneous. The matrix is quite uniform and consists of grayish brown (1 OYR $5 / 2$ ) powdery (ashy), clayey, organic-rich silts with abundant snail shells (Rabdotus) and coarse calcareous sand and granule-sized material. Some carbonate films are present. The lower contact with Unit Y is wavy clear to smooth.

The lithological and chronological correlation between these Valley Margin units and the sequence from the ValleyFloor described above is not readily apparent. However, Unit Ille, the uppermost unit, contains Middle Archaic and later material, which typologically would indicate that this unit is younger than ca. 5000-6000 BP. These data suggest that Unit Ille in the Valley Margin can roughly be correlated with Unit IIIb and Ille from the Valley Floor. Below this 
however, the correlation is less certain. Lithologically, the sediments should be broadly correlative with Unit Illa and/ or the upper part of Unit Isi. The occurrence of Late Paleoindian cultural material in Unit $\mathrm{X}$ and its absence in Unit $\mathrm{Y}$ suggests that the temporal boundary between these two units is roughly $8000-9000 \mathrm{BP}$. In the Valley Floor, this age would correspond stratigraphically to the Unit II/Illa boundary.

\section{Core Samplesfrom January 1994}

A number of cores were drilled in January 1994 in the area near the excavation and on the adjoining property of the Archaeological Conservancy (see Figure 6-1). The purpose of this drilling operation was to document the lateral continuity of strata in the Unit Q-2 deposits (see Chapter 2, Figure 2-7), as a means of establishing the sedimentary environments and paleogeography of the site during several intervals within the Holocene. Two holes were placed along the right-of-way and the rest within the Archaeological Conservancy Tract, where three transects were initially laid out roughly parallel to the strike of the terrace/bedrock contact (see Chapter 2, Figure 2-9). Three-inch cores were taken with a truck-mounted C.M.E. Model 75 H.T. 3.25-inch hollowstem auger supplied and operated by the Bureau of Economic Geology, The University of Texas at Austin.

The stratigraphic logs of these cores are presented in Table 6-7, and an attempt was made in the field to include the stratigraphic correlation with units in the Main Excavation Block. The most readily recognizable features are the depth to the top of the bedrock and the depth to the top of the gravels in what appears to be Unit lg!. Other stratigraphic markers, such as the "Stiba soil," the Unit II/III contact, the Leanne soil, and the cienega (Unit lei) were much more difficult to recognize unequivocally in the field, and their presentation in Appendix 2 should be considered as approximate.

These core data illustrate that the basal gravels of Unit $\mathrm{lg}$ ! thicken to the east-northeast of the excavated area. Moreover, the banana-like shape of the gravels (see Chapter 2, Figure 2-9) is suggestive of a gravel bar similar to modern ones along the confluence of Brushy Creek and Spanish Oak Creek. The data also show (see Figure 6-3) that the total sediment thickness is greatest in the area of the Main Excavation Block $(640 \mathrm{~cm})$ and eastward from it; thickness decreases rapidly to the south in the direction of the bedrock outcrops.

\section{SEDIMENT AND SOILANALYSES}

Several soil/sediment samples were collected for laboratory analysis during both field campaigns. This was done not only as a means to further characterize the sediments, but also to provide data to elucidate the depositional and postdepositional processes operating at the site.

\section{Sampling}

Numerous samples were taken during both the TxDOT and TARL phases of excavation. During the TxDOT phase, Holliday collected samples from soil and archeological profiles in the site area and along Brushy Creek (see Table 6-1) for grain-size and chemical analyses (organic carbon, $\mathrm{CaCO}_{3}$, and phosphate). At the same time, archeologists collected miscellaneous samples of sediments and features that were archived for future study. Many of these archived samples were used for micromorphological analyses during the later TARL phase. Such analyses were carried out in an attempt to correlate certain TxDOT stratigraphic units with those of TARL.

During the TARL phase, samples were taken mostly from excavated squares and profiles for grain-size and chemical analyses, as well as for micromorphological analysis. Two sampling strategies were employed in these analyses (Courty et al. 1989). The fust scheme utilized systematic, semicontinuous sampling columns from vertical exposures. Samples from the columns were numbered consecutively according to the location of each individual column. The location, stratigraphic position, and depths of the individual columns and samples are given in Chapter 29 (see Table 29-2).

The principal goal of this sampling was to monitor regular changes in sedimentary parameters through time. Examination of the data in Table 29-2 reveals some stratigraphic overlap in the column samples, with the same stratigraphic units being sampled in several localities. This duplication was performed in order to account for lateral variability of the units.

In addition to samples from the excavated areas, two additional sets of samples were collected from exposures close to the excavation. One set (WL-92-1 through WL-9210) was taken from the exposure of massive silts along Brushy Creek; these roughly correspond to Profile 11 in Holliday's original report (see Figure 6-1 ).

The other set of samples was collected from specific archeological features, mostly from hearths or burned rock features (see Chapter 29, Table 29-2). The purpose of these samples was to elucidate the nature and extent of depositional and postdepositional processes associated with anthropogenically related features. Was there, for example, evidence of in situ burning, or have the sediments and the sedimentary context been modified by postdepositional processes, such as pedogenesis. The field and laboratory procedures in sample collection and processing are described below.

\section{Laboratory Methods}

\section{TxDOTAnalyses}

Horizons from selected profiles were sampled and subjected to a variety of physical and chemical analyses in order to quantify the sedimentological and pedologic char- 
TABLE6-7

Logs of Cores from Area Around Wilson-Leonard Site and Archaeological Conservancy (see Figure 6-5 for map locations)

\begin{tabular}{|c|c|c|}
\hline Interval $(\mathrm{cm})$ & $\begin{array}{ll}\text { Field Description } \\
\end{array}$ & Comments \\
\hline \multicolumn{3}{|c|}{ Core WL-BH-7 (Elevation at surface= $96.65 \mathrm{~m})$ : } \\
\hline $0-45$ & Disturbed & \\
\hline $45-166$ & Dark brown silty clay with burned rocks & $\begin{array}{l}\text { Burned rocks at } 60 \mathrm{~cm} \text {; probably UI } \\
\text { III }\end{array}$ \\
\hline $166-230$ & Increase in gravel & Possibly Unit II \\
\hline 230-302 & Dark brown stony silty clay with some gleying and popcorn carbonates & $\begin{array}{l}\text { Increase in rhizoliths below }-230 \mathrm{cl} \\
\text { possibly cienega or Leanne soil }\end{array}$ \\
\hline $302-473$ & Gravel & \\
\hline $473-535$ & $\begin{array}{l}\text { Brown, calcareous stony clayey sand with pebbles and gray mottling, just } \\
\text { above bedrock }\end{array}$ & $\begin{array}{l}\text { Lower }-30 \mathrm{~cm} \text { are saturated, mudd) } \\
\text { gravel }\end{array}$ \\
\hline $535-538$ & Bedrock & \\
\hline \multicolumn{3}{|c|}{ Core WL-BH-8 (Elevation at surface $=97.03 \mathrm{~m})$ : } \\
\hline $0-60$ & Disturbed & \\
\hline $60-212$ & Dark brown silty clay & Unit III \\
\hline $212-243$ & Brown calcareous silty clay with some iron staining & Unit II(?) \\
\hline $243-259$ & Brownish silt & Unit Id \\
\hline $259-317$ & Brown calcareous silty clay with some iron staining & Unit lsi/Leanne \\
\hline $317-367$ & Dark brown silty clay with gradational base & cienega (?) \\
\hline $367-485$ & $\begin{array}{l}\text { Brownish clay with interbedded gravel lenses and masses of rounded gravel; } \\
\text { clay lens at } 478-485 \mathrm{~cm} .\end{array}$ & I \\
\hline $485-607$ & $\begin{array}{l}\text { Calcareous and bright yellow silts with relatively weathered limestone clasts } \\
\text { close to bedrock }\end{array}$ & I \\
\hline $607-611$ & Bedrock & \\
\hline \multicolumn{3}{|c|}{ Core WL-BH-9 (Elevation at surface $=96.85 \mathrm{~m})$ : } \\
\hline $0-210$ & $\begin{array}{l}\text { Dark brown, gravelly clay with dark zone between } 45 \text { and } 75 \mathrm{~cm} \text { and } \\
\text { increase in burned stones and flint below } 75 \mathrm{~cm}\end{array}$ & Midden? \\
\hline $210-254$ & $\begin{array}{l}\text { Gets lighter brown silty clay and more calcareous with some iron stains at } \\
-245 \mathrm{~cm}\end{array}$ & \\
\hline $300-390$ & Dark brown brittle clay with iron staining and carbonate veins (rhizoliths?) & \\
\hline $390-566$ & Fine, gritty, gray gleyed silt (diatomite?) & \\
\hline $566-600$ & $\begin{array}{l}\text { Saturated pebbly silt with chalky nodules and staining; water at contact with } \\
\text { bedrock }\end{array}$ & \\
\hline $600-614$ & Bedrock & \\
\hline \multicolumn{3}{|c|}{ Core WL-BH-10 (Elevation at $\operatorname{surface}=96.00 \mathrm{~m})$ : } \\
\hline $0-40$ & Dark brown organic rich clay & \\
\hline $40-115$ & $\begin{array}{l}\text { Calcareous lighter reddish brown clay with some rocks and calcareous } \\
\text { filaments and worm casts }\end{array}$ & \\
\hline $115-140$ & Darker brown clay & Stiba paleosol (?) \\
\hline $140-243$ & Sandier, lighter-colored silts and sands & \\
\hline $243-477$ & $\begin{array}{l}\text { Gravel with some iron staining; looser gravel at top with darker, more clayey } \\
\text { gravels at base }\end{array}$ & Partial recovery \\
\hline $477-506$ & Bedrock & $\begin{array}{l}\text { Sediments generally dry and withou } \\
\text { water at base as elsewhere }\end{array}$ \\
\hline \multicolumn{3}{|c|}{ Core WL-BH-11 (Elevation at surface $=95.98 \mathrm{~m})$ : } \\
\hline $0-45$ & Dark blackish brown clay & \\
\hline $45-134$ & $\begin{array}{l}\text { Homogeneous, lighter reddish brown silty clay with lime films and small, } \\
\text { mm-size calcareous pebbles or nodules; well turbated by earthworms }\end{array}$ & \\
\hline $134-164$ & Grayer brown sandy clay & \\
\hline $164-218$ & Browner and clayier than above; sharp contact with gravels below & Leanne soil or cienega (?) \\
\hline 218-519 & Gravel with abundant iron staining; locally silty and sandy gravel & Partial recovery \\
\hline $519-540$ & Wet, tan sticky muddy silty sand & Basal $\mathrm{O} \mathrm{cm}$ are wet \\
\hline $540-544$ & Bedrock & \\
\hline \multicolumn{3}{|c|}{ Core WL-BH-12 $($ Elevation at surface $=96.15 \mathrm{~m})$ : } \\
\hline $0-138$ & $\begin{array}{l}\text { Dark brownish clay with burned rock; upper }-50 \mathrm{~cm} \text { is darker and resembles } \\
\text { burned rock midden; carbonate films }\end{array}$ & Burned rock at $-25 \mathrm{~cm}$ \\
\hline $138-230$ & $\begin{array}{l}\text { Dark brownish clay that gets lighter below } 168 \mathrm{~cm} \text {; iron staining below } \\
-175 \mathrm{~cm}\end{array}$ & Unit II between 138-175 (?) \\
\hline $230-295$ & $\begin{array}{l}\text { Grayish brown clay, with extensive iron staining at base; sharp contact with } \\
\text { gravel below }\end{array}$ & cienega (?) \\
\hline
\end{tabular}


Table 6-7, continued

\begin{tabular}{|c|c|c|}
\hline Interval $(\mathrm{cm})$ & Field Description & Comments \\
\hline $295-535$ & Coarse gravel & Wetter at $-500 \mathrm{~cm}$ \\
\hline \multicolumn{3}{|c|}{ Core WL-BH-13 (Elevation at surface= $96.52 \mathrm{~m})$ : } \\
\hline $0-185$ & $\begin{array}{l}\text { Homogeneous brown silty clay with brunt rock at }-80 \mathrm{~cm} \text { and slightly } \\
\text { darker between } 70-80 \mathrm{~cm} \text {. }\end{array}$ & Unit III(?) \\
\hline $185-235$ & $\begin{array}{l}\text { Similar to above but slightly more gravelly, lighter color and more } \\
\text { carbonates. }\end{array}$ & $\begin{array}{l}\text { Possible contact between Units I an } \\
\text { II at } 235\end{array}$ \\
\hline $235-318$ & $\begin{array}{l}\text { Lighter brown clay with iron staining and distinct root fills of dark brown } \\
\text { clay, - to those on E profile at the site }\end{array}$ & \\
\hline $318-343$ & Gray, iron stained, silty clay, with sharp contact with gravels below & cienega (?) \\
\hline $343-525$ & $\begin{array}{l}\text { Yellow, iron stained gravels with some silts at the upper part; more gravelly } \\
\text { below } 421 \mathrm{~cm} \text {. Contact with gray bedrock quite sharp but not wet. }\end{array}$ & \\
\hline $525-540$ & Bedrock & \\
\hline \multicolumn{3}{|c|}{ Core WL-BH-14 (Elevation at surface $=95.74 \mathrm{~m})$ : } \\
\hline $0-82$ & Homogeneous, dark brown silty clay & Unit III \\
\hline $82-145$ & Lighter clayey silts with slight increase in stones & Unit II(?) \\
\hline $145-182$ & Brown clayey silt with iron staining and carbonate & Top of Leanne (?) \\
\hline $182-287$ & Grayer brown clayey silt with extensive iron staining & cienega \\
\hline $287-325$ & $\begin{array}{l}\text { Lighter and more yellow brown silt with gravel stringer between } 305-325 \text {; } \\
\text { sharp contact with gravels below }\end{array}$ & Unit Jsi \\
\hline $325-571$ & $\begin{array}{l}\text { Yellow and gray mottled gravels; wet at bottom with angular gravel at base } \\
\text { and little finer matrix; washed appearance }\end{array}$ & \\
\hline $571-599$ & Bedrock & \\
\hline \multicolumn{3}{|c|}{ Core WL-BH-15 (Elevation at surface $=95.23 \mathrm{~m})$ : } \\
\hline $0-91$ & Dark brown clay & Unit III \\
\hline $91-167$ & Lighter brown clay with limestone pebbles or calcareous nodules & Unit II(?) \\
\hline $167-217$ & Iron stained dark gray brown clay with root holes & cienega (?) \\
\hline $217-313$ & Gravel and sandy gravel, particularly at base & Igl \\
\hline $313-510$ & $\begin{array}{l}\text { Finer, siltier, angular, gray and yellow, iron stained gravel. Lower part is } \\
\text { quite wet and saturated and gravels without matrix }\end{array}$ & Igl \\
\hline $510-531$ & Bedrock & \\
\hline \multicolumn{3}{|c|}{ Core WL-BH-16 $($ Elevation at $\operatorname{surface}=96.10 \mathrm{~m})$ : } \\
\hline $0-33$ & Very dark brown clay & \\
\hline 33-195 & $\begin{array}{l}\text { Homogeneous, lighter brown clay with increase in calcareous filaments at } \\
90 \mathrm{~cm}\end{array}$ & \\
\hline $195-203$ & Lighter grayish brown clay with iron staining & Possibly cienega (?) \\
\hline $203-228$ & $\begin{array}{l}\text { Yellow brown silt with gravel stringers at contact with gray silt above; dark } \\
\text { brown clay root fill; sharp contact with gravel below }\end{array}$ & \\
\hline $228-291$ & Loose, rounded and angular gravel; iron stained & \\
\hline $291-531$ & Loose angular gravel in sandy and silty matrix; iron stained & Bedrock at $531 \mathrm{~cm}$; wet near base \\
\hline \multicolumn{3}{|c|}{ Core WL-BH-17 (Elevation at surface $=96.35 \mathrm{~m})$ : } \\
\hline $0-145$ & Massive, homogeneous dark brown clay & Increase in carbonate films at $-75 \mathrm{c}$ \\
\hline $145-190$ & Gravely brown clay & Top of Unit II at-145(?) \\
\hline $190-210$ & Brown clay with some stones & Unit $\operatorname{Id}(?)$ \\
\hline $210-283$ & Dark grayish brown clay with iron staining & cienega \\
\hline $283-500$ & Light brown massive gravel with some iron staining & \\
\hline $500-520$ & Wet, reddish yellow brown silt with some gravel & Bedrock at 520 \\
\hline \multicolumn{3}{|c|}{ Core WL-BH-18 (Elevation at surface $=97.20 \mathrm{~m})$ : } \\
\hline $0-57$ & Black, silty clay with many angular burned stones & Burned rock midden material? \\
\hline $57-211$ & Lighter brown, calcareous clayey silt to silty clay with many snails & \\
\hline $211-250$ & Similar to above but lighter and with increase in $1-2 \mathrm{~cm}$ carbonate nodules & \\
\hline $250-296$ & Pale grayish brown, powdery, alluvial(?) loessic (?) silts. & Possible aeolian input \\
\hline 296-381 & Chalky, gray brown, iron stained silty clay with rhizoliths & Possible top of Leanne soil \\
\hline $381-470$ & Darker, gray brown calcareous clay with carbonate nodules and iron staining & cienega (?) deposits \\
\hline $470-485$ & Less gray and more yellow than above & \\
\hline $485-622$ & Yellowish, iron-stained gravel and silty gravel & Saturated zone at $-6 \mathrm{I} 2-622$ \\
\hline $622-642$ & Bedrock & \\
\hline \multicolumn{3}{|c|}{ Core WL-BH-19 (Elevation at surface $=98.40 \mathrm{~m})$ : } \\
\hline $0-149$ & Dark brown, stony and silty clay with burned stones & Burned rock midden material? \\
\hline $149-218$ & Reddish brown silty clay with snails and burned rocks & \\
\hline $218-257$ & $\begin{array}{l}\text { Silty clay, less stony than above and with no burned rocks; some weak iron } \\
\text { staining }\end{array}$ & Possible base of Unit III \\
\hline
\end{tabular}


Table 6-7, continued

\begin{tabular}{l|l|l}
\hline Interval $(\mathrm{cm})$ & \multicolumn{1}{|c|}{ Field Description } & \multicolumn{1}{c}{ Comments } \\
\hline $257-344$ & Lighter, calcareous, chalky iron-stained silty clay & Unit II(?) \\
$344-474$ & Dark gray brown clay with iron staining & cienega (?) \\
$474-507$ & Interbedded gravel and silty clay with possible popcorn carbonates & \\
$507-637$ & Lenses of clean gravel and silty gravel & \\
$637-642$ & Bedrock & \\
\hline \hline
\end{tabular}

acteristics of the stratigraphy. Particle-size distribution of the sand fraction was determined by sieving and by pipetting of organic matter-free material of the fine fraction (Day 1965); this provided data on the sedimentology of the site and subtle pedological changes such as clay translocation. Organic carbon was measured by the Walkley-Black technique (Allison 1965) and $\mathrm{CaCO}_{3}$ content by acid-neutralization (U.S. Soil Salinity Laboratory Staff 1954). These latter techniques aided in characterizing pedogenic development. In addition, a few samples were taken for thin section analysis to further characterize pedogenesis.

Soil samples were also analyzed for phosphorous content, whereby total phosphorous (P) and $P p 5$ content can provide an indication of intensity of human occupation (e.g., Eidt 1984). The baseline for these studies are the samples from the cutbank profile (Holliday's Profile 11), where little evidence of human occupation was found. Horizons in Areas $\mathrm{A}$ and $\mathrm{B}$ with phosphorous content substantially higher than in Profile 11 are considered to have been the loci of human occupation.

\section{TARL Analyses}

Chemical and physical analyses were performed on selected sediment samples from the Column 200 series collected from the east wall of Square 20 (see Chapter 29). These analyses were run as a comparison to previous analyses performed by Holliday (1989b), to characterize the sediments, and to complement the micromorphological observations. The analyses consisted of grain-size analysis on raw and decalcified samples, organic matter content, calcium carbonate content, and available iron.

Chemical and particle-size analyses were carried out at the Geography Department, Univers ity of WisconsinMilwaukee using the following procedures. Grain-size analyses were performed on raw and decalcified samples, generally following the procedures in Folk (1974). Decalcification was carried out by soaking the sample in $6 \mathrm{~N}$ HCI for at least 4 hours, after which the samples were rinsed multiple times until the $\mathrm{pH}$ dropped to near 7. Hydrometer analysis followed the procedure presented by Gee and Bauder (1986). Organic matter and carbonate percent were determined by loss-on-ignition (Dean 1974). Oxalate-extractable iron was determined by atomic absorption, following Walker (1986).

\section{Results of Analyses \\ Grain-size Analysis}

\section{TxDOTRESULTS}

Results of grain-size analysis, performed on raw, nondecalcified samples from various profile localities are summarized in Table 6-1. In Profile I, situated at the north end of Block 4 (see Figure 6-1), sand appears to decrease slightly from bottom to top (Figure 6-15); the slight increase in Stratum I seems to reflect the gravel observed in this part of the profile (roughly TARL Unit lg!). Silt is variable, but tends to be highest in Stratum 6 (roughly TARL Unit Ill) and in Stratum 2A (roughlyTARL Unit lsi/lgl). Clay content tends to increase upward.

Profile 2 was at the south end of Block 4 (see Figure 61). The general trends outlined in Profile I are clearer here (Figure 6-16). From bottom to top, sand decreases and clay increases noticeably, whereas silt content increases gradually and slightly. Absolute values are roughly comparable in both profiles.

Profile 8 (Block I; see Figure 6-1) includes sediments only from Stratum 6 (comprised mostly ofTARL Unit Ille). Although there is some variability in the results, an overall increase in sand content can be seen in comparison to Stratum 6 samples situated downslope $\mathrm{f}^{\mathrm{r}}$ om here (e.g., Profiles I and 2). This increase could reflect anthropogenic inputs, although the phosphate data (see Table 6-1) do not seem to support this. Alternatively, this lateral downslope change could be due to differentiation along the slope, with removal of the fines from the upslope position and their deposition by runoff farther downslope.

Profile 9, situated in Area B not far from Brushy Creek (see Figure 6-1 ), has relatively low amounts of sand, with a spike in Stratum 4 (roughly TARL Unit 11) (see Table 6-1). This increase in sand matches the overall coarse nature of this unit in the field; otherwise, values are generally uniform from top to bottom.

Profile 10, from Square E40/S70 (see Figure 6-1 ), shows an increase in clay with depth in what appears to be Stratum 5 (base ofTARL Unit III). The sediment becomes coarser at the base although the stratigraphic assignments of the lowest layers are not clear; it was labeled "Stratum 3" in the field, but this is not entirely clear. It is possibly part ofTARL Unit lsi and, if so, would suggest that Stratum 4 (Unit Il) is missing in this profile for some reason. 


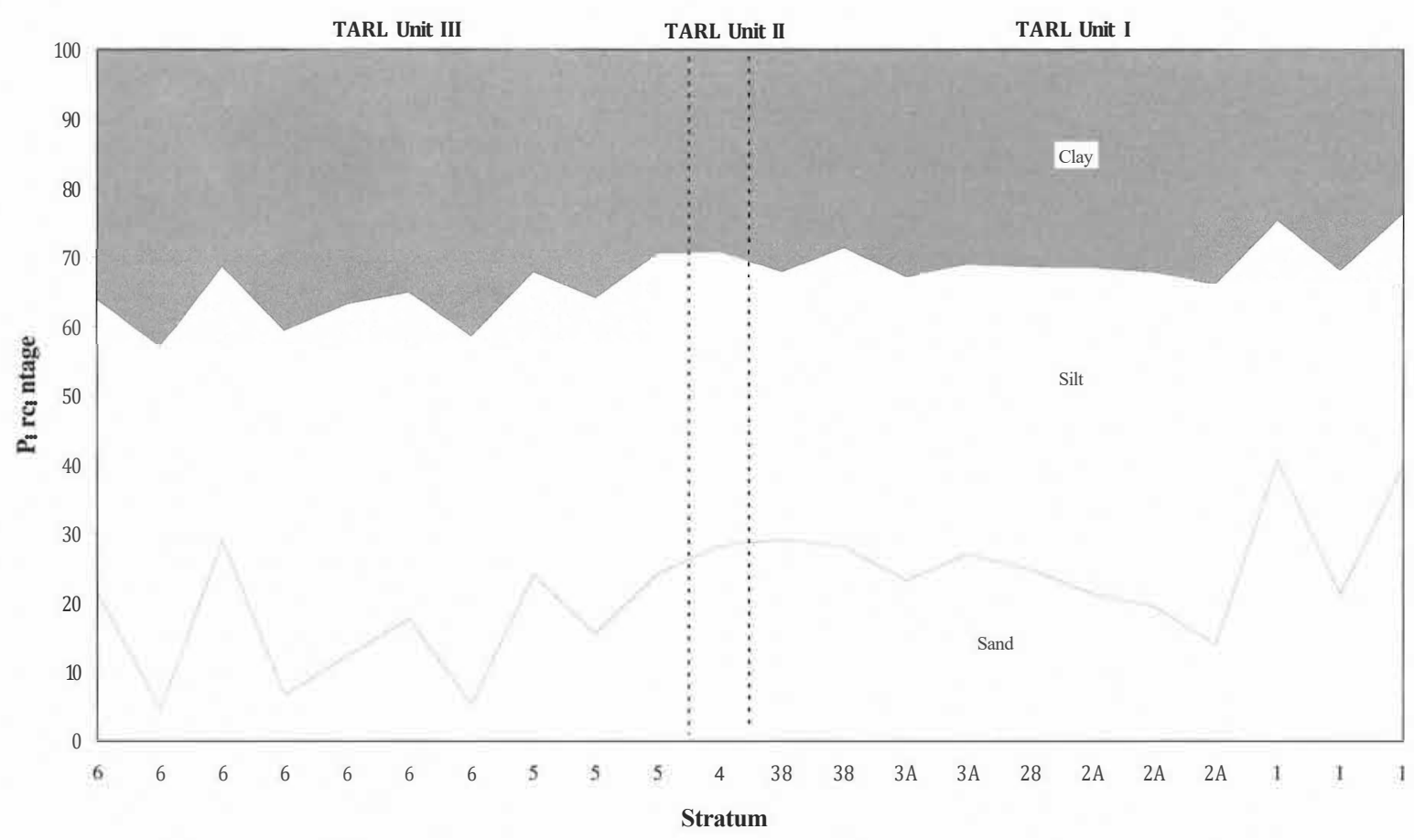

FIGURE 6-15. Holliday 1989 Profile 1, sand/silt/clay.

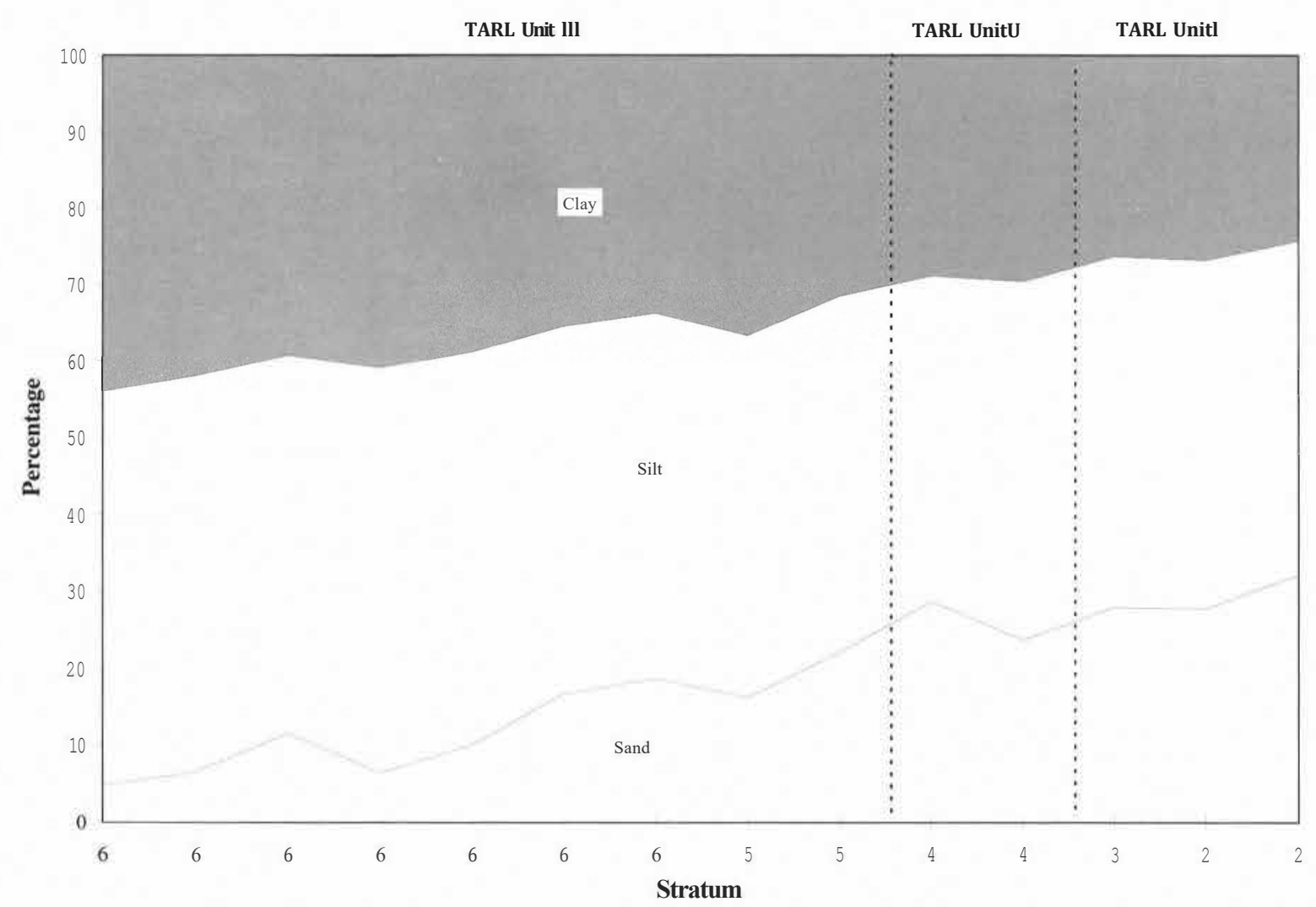

FIGURE 6-16. Holliday 1989 Profile 2, sand/silt/clay. 
Profile 11 is situated along Brushy Creek (see Figure 61). The sediments in this section were attributed by Holliday (1989b) to Strata 5 or 6, 2, and I. During the TARL excavations, this assessment seemed less clear, and at present it is not certain that these stratigraphic attributions are correct; this is particularly true for the lowermost designations, Strata I and 2. Strata 5 and 6 are probably more or less correct and would correlate roughly to TARL Unit Ill. In this profile, sand and clay appear inversely correlated, with sand values being somewhat higher at the very bottom and top; silt values are relatively constant.

In sum, there is not much overall variability among the profiles. Variations in sand, silt, or clay content appear to be local phenomena, and there do not seem to be any systematic changes up or downslope. For example, the increase in sand content in Stratum 6 at Profile 8 is probably associated with a burned rock feature exposed there. One should be reminded that this grain-size analysis utilized only the $<2$-mm fraction, a common practice in soil science.

\section{TARLRESULTS}

The grain-size analysis for the recent TARL excavations was performed on loose samples collected from Column 200 in Square 20 together with the sampling of blocks for micromorphological analysis (see Chapter 29, Table 292). Of the 36 samples collected for micromorphological analysis, 21 were submitted for grain-size and chemical analyses. These were spaced at regular vertical intervals, and in light of the previous TxDOT analyses, were thought to provide a comprehensive picture of vertical textural variations.

Two types of granulometric analyses were run (Table 68). The first involved raw, untreated samples. The second type constituted a subset of these, in which selected samples (92-203, 92-107, 92-211, 92-213, 92-215, 92-218, 92-222, 92224, 92-227, 92-232, and 92-235) were first treated with $1 \mathrm{~N}$ HCI to remove $\mathrm{CaCO}_{3}$.

The results from both calcareous and noncalcareous series are broadly comparable (see Table 6-8; Figures 6-17 and 6-18): sand is most abundant and clay least abundant in Unit II; silt content varies only slightly. Moreover, in the raw samples, clay content overall increases from bottom to top, with somewhat lower values in the top of Unit I and in Unit II. This trend is not seen in the decalcified samples, where clay is most abundant in the basal Unit I samples that correspond to the cienega (lei). A somewhat similar but more subdued trend also exists for the silt fraction.

Both these trends suggest that a considerable portion of the finer part of the raw fraction is comprised of calcareous silt- and clay-sized material. A possible explanation for this lies in the extensive bioturbation by earthworms of the upper, Unit III samples. The rnicromorphological evidence (see Chapter 29) implies that earthworm activity plays a significant role in the calcification of these upper samples.
In sum, the TARL analyses demonstrate the value of performing grain-size analysis on both raw and $\mathrm{HCl}$-treated samples. This is particularly true for calcareous environments such as that found in the site area where the accumulation of postdepositional calcite (e.g., earthworm activity) can drastically modify the distribution by grain size of the original material.

\section{Chemical Analyses}

\section{TxDOTRESULTS}

Chemical analyses-organic carbon, calcium carbonate, and phosphate-were performed on samples from Profiles 1, 2, 5, 8, 9, I0, and 11. The results are presented in Table 6-1. Since trends within each of the profiles are similar, it is most useful to discuss the results according to analytical technique, rather than on a profile-by-profile basis.

\section{Organic Carbon}

The organic carbon results are similar in most of the profiles (Figures 6-19 and 6-20). In general, the highest values occur in the upper part of each profile: generally around $2-3 \%$ near the modern surface. These amounts decrease to a constant value of about $0.1-0.2 \%$ in and below Stratum 4 (roughly TARL Units I and II). This trend reflects both the better preservation of the younger Wilson-Leonard soil and the increased inputs of organic matter in these upper, anthropogenic units (Strata 6 and 5; roughly TARL Unit III). The decrease with depth also mirrors the destruction of organic matter in the older and deeper units, a common phenomenon in deeply stratified deposits. The slightly higher values in Stratum 4 (roughly TARL Unit II) of Profile 1 could also point to the presence of burned rock features in the upper part of this unit.

\section{Calcium Carbonate}

Calcium carbonate analysis is somewhat variable from profile to profile (see Table 6-1). In Profiles I and 2 (main block) (see Figures 6-19 and 6-20) it varies between roughly $48 \%$ and $68 \%$ and is slightly higher in Strata 1-3 (roughly TARL Unit I). These slightly higher values correspond well with the marly/chalky nature of these lower units. Lower percentages are recorded for Strata 6 and 5 in Profiles 5 and 8 which are situated in the main trench upslope from Profiles 1 and 2 (see Figure 6-1); the reasons for the lower values in these profiles are not clear. In Profile 9, in Area B, a trend opposite to that of Profiles 1 and 2 is observed. Carbonate values are highest in Strata 5 and 4 (roughly TARL base of Unit III, Unit 11)-perhaps related to the input of gravelly material-and are lowest in Stratum 2 (Unit I).

In Profile 10, northeast of the main block, carbonate values are overall lower than those of the other profiles but 
TABLE6-8

W'I son-Leonard G ram-size and Chemlca1 Analyses forthe Column 200S enes (Square 20)

\begin{tabular}{|c|c|c|c|c|c|c|c|c|c|c|c|}
\hline \multirow[b]{2}{*}{$\begin{array}{c}\text { Sample } \\
\text { No. }\end{array}$} & \multirow[b]{2}{*}{ Unit } & \multirow[b]{2}{*}{$\begin{array}{c}\text { Elevation } \\
\text { (m) }\end{array}$} & \multirow[b]{2}{*}{$\begin{array}{c}\text { \% Organic } \\
\text { Carbon }\end{array}$} & \multirow[b]{2}{*}{$\begin{array}{c}\% \\
\text { Carbonate }\end{array}$} & \multirow[b]{2}{*}{$\mathrm{Fe}(\mathrm{ppm})$} & \multicolumn{3}{|c|}{ Non treated } & \multicolumn{3}{|c|}{ HO Treated } \\
\hline & & & & & & $\%$ Sand & $\%$ Silt & $\%$ Clay & $\%$ Sand & $\%$ Silt & $\%$ Clay \\
\hline 203 & Ille & 96.90 & 4.0 & 25.4 & 127. 1 & 10 & 48 & 42 & 46 & 28 & 26 \\
\hline 205 & Illb & 96.70 & 2.9 & 27.0 & 118.7 & 10 & 46 & 44 & & & \\
\hline 207 & $11 \mathrm{lb}$ & 96.50 & 2.2 & 26.5 & 191.9 & 8 & 50 & 42 & 48 & 26 & 26 \\
\hline 209 & IIIb & 96.33 & 2.2 & 27.3 & 127.1 & 14 & 44 & 42 & & & \\
\hline 211 & Illa & 96.00 & 1.6 & 25.4 & 126.3 & 13 & 46 & 41 & 48 & 25 & 27 \\
\hline 212 & Illa & 95.87 & 15 & 25.3 & 159.3 & 14 & 44 & 42 & & & \\
\hline 213 & Illa & 95.76 & 1.7 & 25.1 & 159.6 & 16 & 43 & 41 & 50 & 24 & 26 \\
\hline 214 & Ula & 95.63 & 2.0 & 25.7 & 130.2 & 18 & 42 & 40 & & & \\
\hline 215 & II & 95.53 & 1.8 & 27.1 & 73.5 & 18 & 42 & 40 & 54 & 23 & 23 \\
\hline 216 & II & 95.40 & 1.4 & 27.2 & 69.0 & 18 & 46 & 36 & & & \\
\hline 218 & II & 95.20 & 1.4 & 27.1 & 110.9 & 18 & 46 & 36 & 54 & 23 & 23 \\
\hline 220 & II & 95.00 & 1.4 & 30.1 & 91.8 & 20 & 48 & 32 & & & \\
\hline 222 & II & 94.78 & 1.6 & 29.8 & 91.8 & 25 & 39 & 36 & 60 & 22 & 18 \\
\hline 224 & Id/Isi-c & 94.57 & 19 & 26.0 & 92.0 & 20 & 46 & 34 & 46 & 30 & 24 \\
\hline 225 & lsi-c & 94.47 & 13 & 27.6 & 100.4 & 20 & 48 & 32 & & & \\
\hline 227 & Isi-c & 94.29 & 12 & 28.3 & 90.3 & 20 & 46 & 34 & 46 & 30 & 24 \\
\hline 228 & 1si-c/Id & 94.14 & 1.4 & 26.1 & 156.9 & 20 & 42 & 38 & & & \\
\hline 230 & lei & 93.95 & 15 & 25.2 & 86.1 & 12 & 50 & 38 & & & \\
\hline 232 & lei & 93.71 & 0.4 & 25.2 & 88.0 & 14 & 48 & 38 & 38 & 32 & 30 \\
\hline 233 & $\mathrm{kl}$ & 93.61 & 15 & 26.4 & 79.6 & 16 & 48 & 36 & & & \\
\hline 235 & lei & 93.37 & 13 & 25.9 & 81.6 & 14 & 50 & 36 & 40 & 30 & 30 \\
\hline Mean & & & 1.7 & 26.7 & 112.0 & & & & & & \\
\hline $\mathrm{I} \mathrm{CJ}$ & & & 0.7 & 1.4 & 33.4 & & & & & & \\
\hline
\end{tabular}

tend to increase at the very base in what appears to be Stratum 3 (see Table 6-1). In Profile 11 (the Brushy Creek Section), the trend is similar to that of Profiles 8 and I0, where the lowermost part contains the highest values which decrease upwards in the profile; the deposits at the very top exhibit relatively reduced values. The reasons for these trends are not clear. They do not appear to be associated with any leaching of the surface and near-surface deposits as no evidence of dissolution was observed in thin section (see below).

\section{Phosphates}

Phosphate analysis shows the greatest degree of variability of any of the analyses both within and between profiles (see Table 6-1 ). Not surprisingly, the highest phosphate values tend to occur within Stratum 6 (upper part ofTARL Unit Ill, likely Ille) sediments (see Figures 6-19 and 6-20). These correspond to the overall anthropogenic nature of the sediments as expressed by numerous burned rock features. A slight exception to this occurs in Profile 10 where phosphate concentrations at the base of Stratum 6 are apparently close to background level as shown by the low values in Stratum 5 and 3(?) below it. At present, the stratigraphic correlations in Profile $\mathrm{O}$ are not readily apparent.

Lower values are generally found in Stratum 4 (roughly TARL Unit II) and Stratum I (roughly TARL Unit Isi) (see Figures 6-19 and 6-20). Somewhat higher phosphate values can be found in Strata 2 and 3, and are possibly tied to the presence of Late Paleoindian features. On the other hand, the large spike in Stratum 2B (TARL Unit lei?) in Profile I would most likely be associated with the occurrence of cienega deposits there.

Lateral variations of phosphate content can also be observed within Stratum 6 (upper part ofTARL Unit III). For example, phosphate values in Profile I are on the whole considerably lower(mean $=232.14$ ppm; see Table 6-1) than those in Profile 2 (mean=495.71 ppm; see Table 6-1), situated about $\mathrm{O}$ m upslope from it. Profiles 5 and 8 exhibit the same trend, showing the greater concentration of human activities in this upper part of the site. In a similar way, the samples from Profile 11 along Brushy Creek (see Figure 6-1) show generally low phosphate values; the one spike shown near the top is generally lower than all the phosphate values in Profile I (see Table 6-1).

\section{TARLRESULTS}

Analyses carried out in conjunction with the TARL excavations were done on selected sediment samples from Column 200 in Square 20. These analyses overlapped with those done previously and consisted of both calcium carbonate and organic matter measurements. Phosphorous was not determined, however, although oxalate-extractable iron was measured. The results are summarized in Figure 621. 


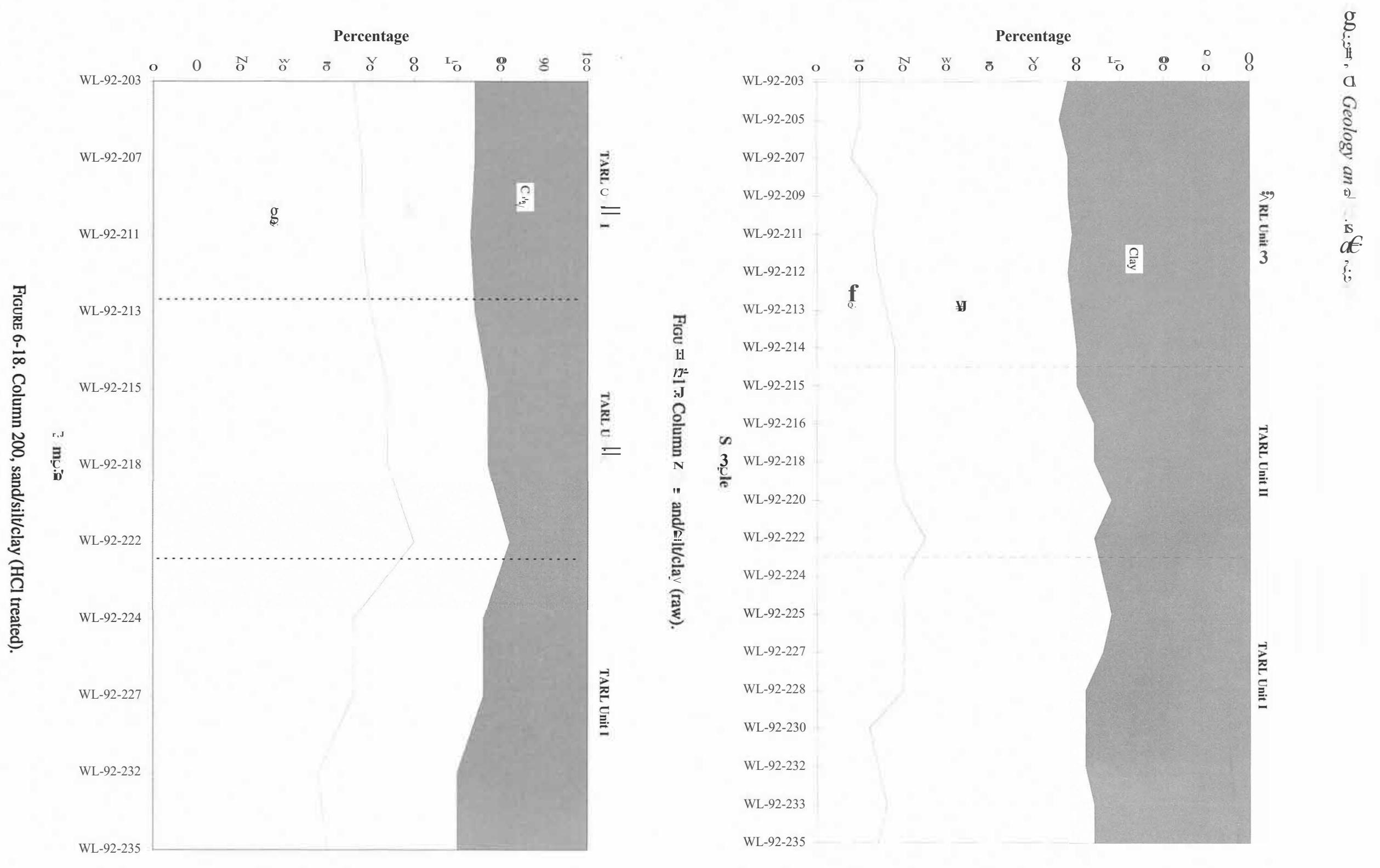




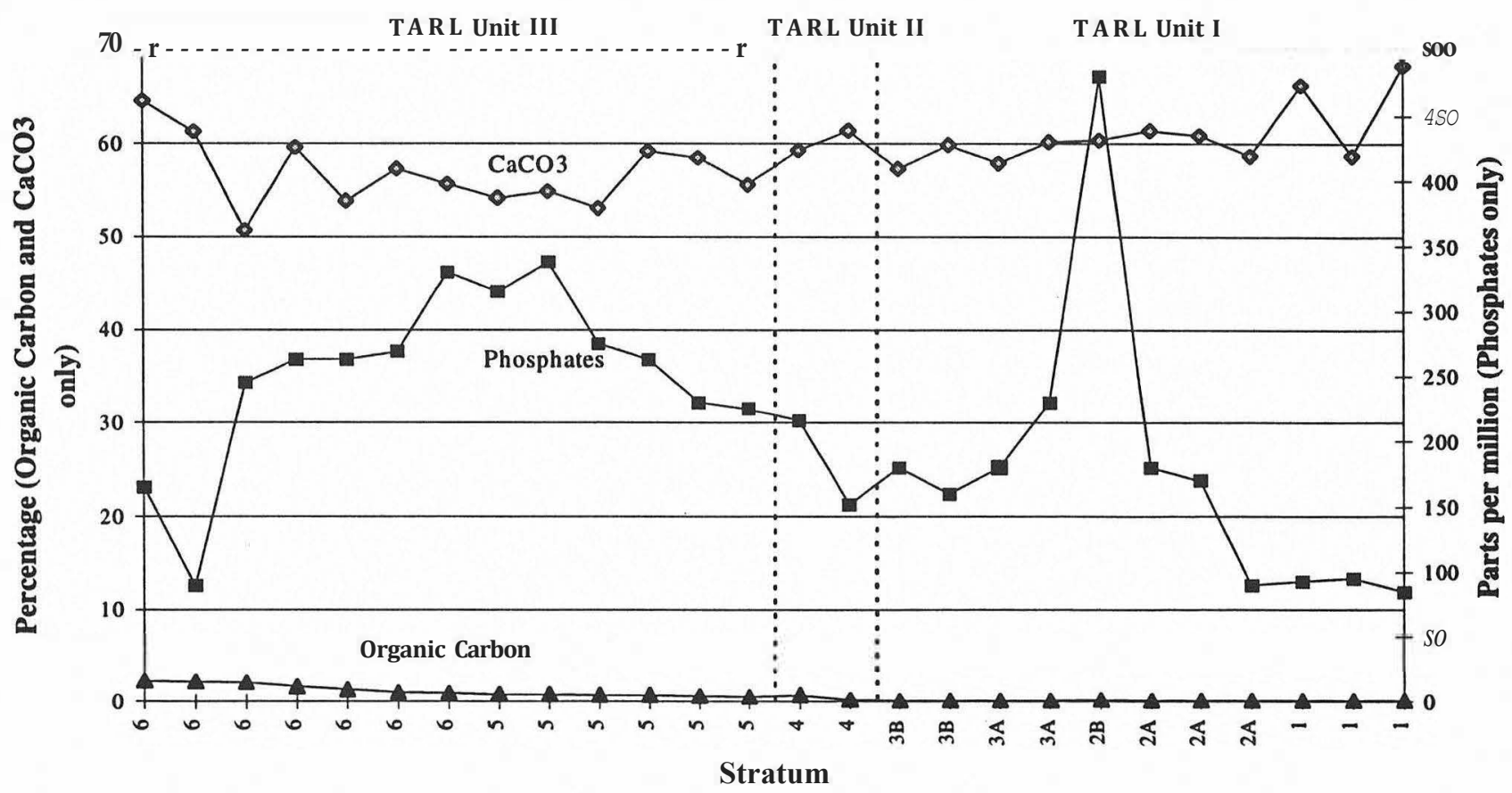

FmuRE 6-19. Chemical analyses of Holliday 1989 Profile 1.

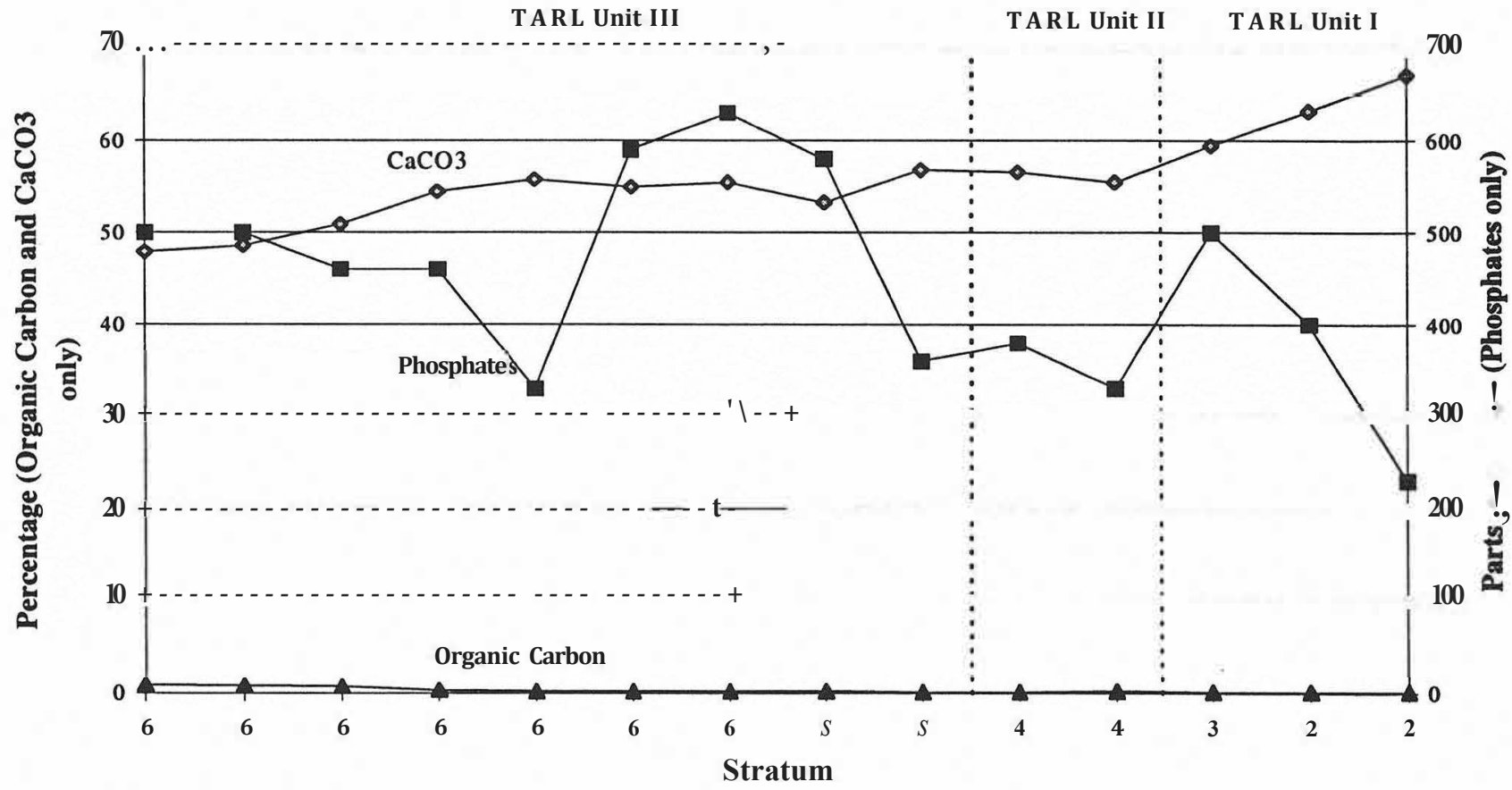

FGURE 6-20. Chemical analyses of Holliday 1989 Profile 2.

Organic Matter

The organic matter results (determined by the Loss-onIgnition method) overall follow the trend of organic carbon documented in the TxDOT analyses (measured by the Walkley-Black method), with generally high values (approximately 4\%) occurring in the uppermost samples in Unit III and decreasing with depth. Note, however, that the values are overall higher than the organic carbon results obtained by TxDOT. There are probably two reasons for these differences: (1) organic carbon is one component of organic matter, theoretically accounting for $50-60 \%$ of organic matter (Nelson and Sommers 1982); and (2) Loss-on-Ignition often provides inaccurate results for samples with relatively low 


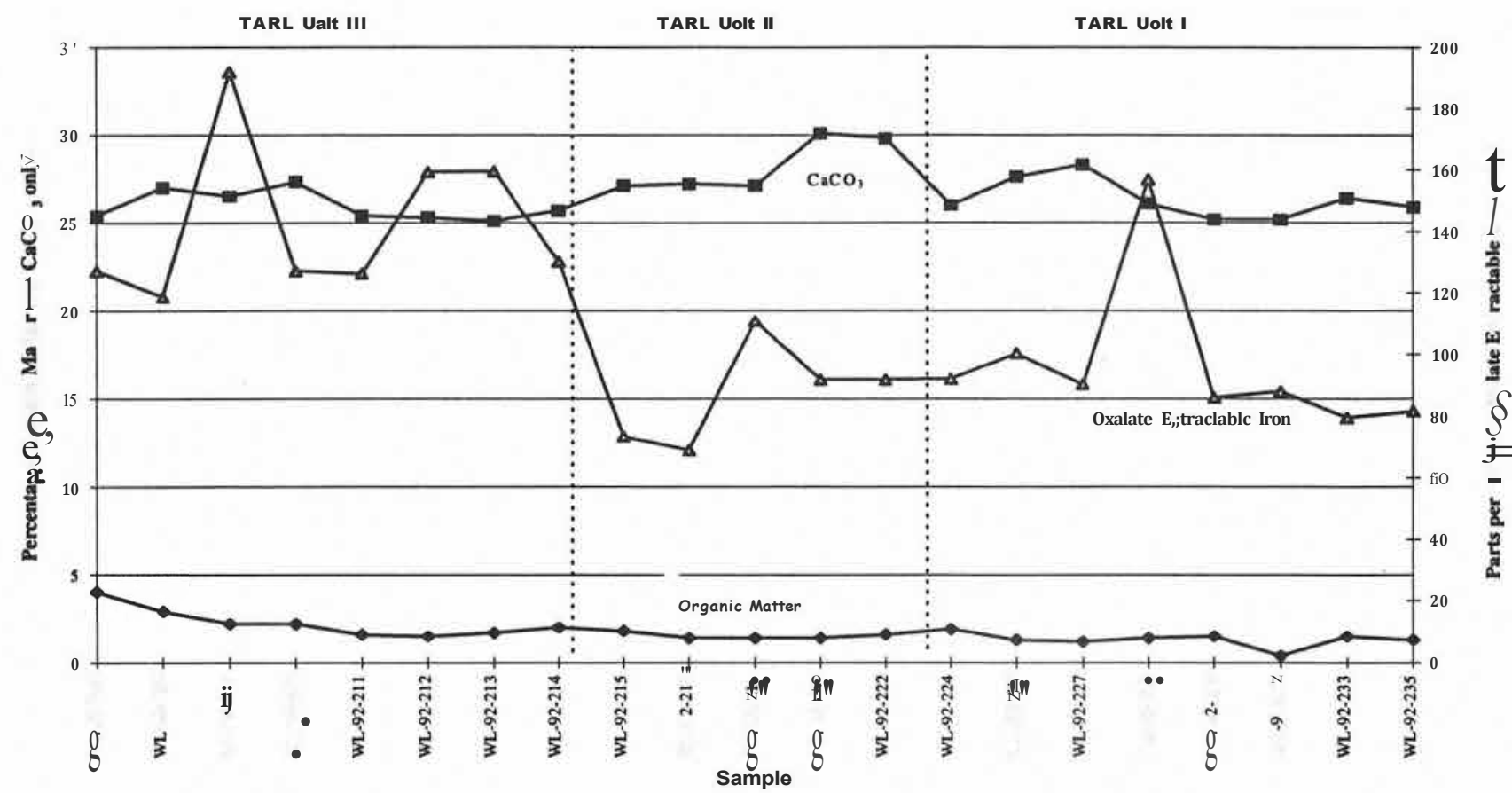

FlouRE 6-21. Column 200, $\mathrm{OM}, \mathrm{CaCO}_{3}$ and $\mathrm{Fe}$ analyses.

content or organic matter (Holliday and Stein 1989). Consequently, the variability of individual analyses below Unit III should not be overinterpreted, although the slightly higher value of sample $92-224(1.9 \%)$ at the top of Unit I is somewhat higher than any of the samples above or below it and could reflect the input of organic matter associated with the Leanne soil which occurs in this stratigraphic position.

\section{Calcium Carbonate}

The calcium carbonate values vary between $25-30 \%$, which is considerably Jess than those from the TxDOT analyses. Again, this could reflect the differences in analytical techniques employed by the different laboratories. In any case, trends within the TARL samples are not readily apparent and do not correspond with those observed in the most complete sections analyzed by TxOOT, Profiles I and 2, which include Strata 1 through 6 . The slight increase in carbon-ate within samples 92-220 and 92-222 in Unit II could be more imaginary than real, although there is a slight increase in sandiness in these samples, which would enrich the sample in carbonate, the principal component of the sand fraction.

Oxalate-extractable Iron

Oxalate-extractable iron was measured in an attempt to evaluate postdepositional (diagenetic) effects of iron mobilization. These effects are clearly evident, particularly in the lower part of the Wilson-Leonard profile (see Figure 6-21). Overall the samples from Unit III have higher values than those of Unit I or Unit II. These greater values are a com- bined result of higher amounts of clay in Unit III (see Figures 6-15 to 6-18), which enables greater adsorption of iron; this would also be slightly enhanced by the chelating effects of organic matter (Fanning and Fanning 1989). Furthermore, the presence of iron mottling in the field and in thin section (up to about $95.50 \mathrm{~m}$ elevation, corresponding to sample 92-214; see Chapter 29) suggests that iron has been immobilized in the lower units in an oxidized state. The reason for the large spike in sample 92-228 is not clear but is clearly aberrant in comparison to surrounding samples.

\section{SUMMARY OF CHEMICAL ANALYSES}

The chemical analyses from both the TxDOT and TARL sets of samples essentially support the field observations, although some of the down-profile variability remains to be explained. High phosphate amounts generally correspond to anthropogenically modified sediments in Unit III, which contains numerous burned rock features.

Calcium carbonate analyses are variable both between and within profiles. There is a general tendency for higher values to occur in the lower units (e.g., Unit I) and decrease upward; the uppermost, surface samples from Unit III (Stratum 6) tend to have slightly lower values than below the surface, suggesting some possible decalcification in these uppermost samples which would correspond to the A horizon of the Wilson-Leonard soil.

Total organic matter and organic carbon results do not appear to be of much use, and basically show the absence and destruction of organic matter with depth in the section. Some slightly higher values in subsurface samples can be 
observed, and these possibly represent pedogenic or anthropogenic influences. However, these slightly higher values are so close to background levels that their significance may be questionable.

Oxalate-extractable iron showed some clear trends with the samples from Units I and II having lower values than those in Unit Ill. This is reflected in the field where extensive iron staining of these sediments-particularly those in Unit I-were observed, indicating insolubilization of the iron in these levels.

\section{Selected Samples for ${ }^{18} 0$ and ${ }_{13}$ C Isotopes}

Carbon and oxygen isotopes of a few samples of popcorn carbonates were analyzed by Claudia Mora, Department ofGeological Sciences, University ofTennessee-Knoxville (Table 6-9).

The carbon isotope compositions of the nodules are quite light-certainly lighter than most marine values. But the (samples of) "limestone bedrock" are likewise light (although, in the case ofWL-IS01 , not as much so). The oxygen values are also consistent with carbonate precipitation or recrystallization in the presence of meteoric water [C. Mora, personal communication 1995].

These results indicate that the popcorn carbonate nodules are pedogenic in origin and not related to carbonate precipitation associated with a high groundwater table. Since popcorn nodules occur mostly in Unit lei and in Unit Isi only in the immediate vicinity of Unit lei (i.e., in interfingered, laterally equivalent levels), their formation seems to be tied to the presence of the cienega and not the overlying Leanne soil in which carbonate precipitation is expressed as chalky rhizoliths. Furthermore, since the cienega lasted at most about 900 years (ca. 10,600-11,500 B.P; see Chapter 25), they would have formed relatively quickly. The fonnation of the carbonates is discussed further below. The formation of such individualized, hard nodules can be envisioned by downward leaching of carbonate followed by intense rapid drying. Desiccation is supported by their noticeably cracked appearance in the field and in thin section. It seems clear that the conditions associated with their formation are not similar to present pedogenic ones, which are capable of producing only limey filamentous coatings and not concretions.

It is best to view the overall evolution of the site from the context of depositional and postdepositional processes. Each is considered separately.

\section{DEPOSITIONAL PROCESSES}

Depositional processes at Wilson-Leonard encompass alluviation associated with Brushy and Spanish Oak creeks, colluviation, and sheetwash tied to deposition from the slopes behind the site along with anthropogenic contributions, principally related to burned rock features. These processes are considered stratigraphically from bottom to top, Unit lgl up to Unit Ille.

The earliest depositional phase is represented by the accumulation of gravels,.Unit Igl, in the northern part of the site. As shown in the field, both in the excavations of Blocks 4 and 6 and in the bore hole data, these gravels have a lenticular, arcuate outline in plan and thin to the south. This lateral distribution, as well as the imbrication of the gravel clasts parallel to the strike of the gravel body indicate a channel bar origin for the gravels (McGowen and Garner 1970). Morphologically similar bars are found in Brushy Creek today underneath the bridge crossing ofRR 1431 and downstream from it. The accumulation of these channel gravels, therefore, indicates the position of the extant channel of the Brushy Creek/Spanish Oak Creek system.

An interesting aspect is the composition of the gravels. The gravels in the lower part of Unit Igl, particularly in the southern part of the excavation (e.g., Square 12, Test Unit A), contain numerous angular clasts and fossils from the Comanche Peak Limestone. These were furnished by actively eroding bedrock, which as described above, took the form of a bench between Square 12 and Test Unit I00 to the

TABLE 6-9

Carbon and Oxygen Isotopes $\mathrm{f}^{\mathrm{r}} \mathrm{om}$ Secondary "Popcorn" Carbonates*

\begin{tabular}{l|l|c|c|c}
\hline \multicolumn{1}{c|}{ Sample No. } & \multicolumn{1}{|c|}{ Description } & TARL Unit & o $^{13}$ C PDB $\%$ & $0^{18} 0$ PDB $\%$ \\
\hline WL-IS0-1 & limestone bedrock (Comanche Peak Fm) & - & -5.67 & -4.28 \\
WL-IS0-2 & limestone bedrock (Comanche Peak Fm) & - & -7.67 & -3.81 \\
WL-IS0-3 & WL-92-232(2); nodule \#2 & lei & -8.09 & -4.17 \\
$* *$ WL-IS0-4 & WL-92-232(2); nodule \#2, adjacent to IS0-3 & lei & -7.87 & -3.84 \\
WL-IS0-5 & WL-92-412( I); nodule \#3 & lei & -7.32 & -4.65 \\
WL-IS0-8 & WL-92-230; nodule \#2 lower & lei & -7.64 & -4.03 \\
WL-IS0-9 & WL-92-230; nodule \#2 upper, adjacent to IS0-8 & -7.72 & -4.00 \\
$* *$ lei & le] & -8.06 & -3.43 \\
WL-IS0-11 & WL-92-410( I) & lei & -8.13 & -4.31 \\
\hline
\end{tabular}

* Reported by Claudia Mora, Department of Geological Sciences, University of Tennessee-Knoxville.

${ }^{*}$ Sample reacted at $2{ }^{\circ} \mathrm{C}$. 
south ofit. In addition to these locally derived materials, within the gravels are clasts of "caliche" caprock that are remnants of weathering crusts formed as a B-k horizon of soils on calcareous bedrock in upland positions. Their occurrence in the gravel points to active Holocene erosion of the uplands, which had proceeded to the point that soil cover had been removed exposing the previously folmed caliche crust.

Intercalated with these gravels of Unit lgl are the massive silty deposits of Unit lsi. These sediments certainly represent overbank silts that accumulated during flooding of Brushy and Spanish Oak creeks. The transition from gravel deposition in Unit lgl to silt accumulation in Unit Isi testifies to the shift in the position of the former channel to the north in a direction toward the axis of the valley and away from the main excavated area of the site. It is presumed that this shift was caused by channel avulsion whereby the stream abandoned its previous channel in favor of a straighter course to the north.

Even though the channel had shifted northward away from the site, silty sediments of Unit Isi continued to accumulate for about 500 years (see Chapter 25). These accumulations were tied to repeated flooding of the Brushy Creek system.

Concomitant with the accretion of lighter-colored silts of Unit lsi was the accumulation of the slightly organic, darker clayey silts of Unit lei. As shown in Figure 2-9 in Chapter 2, the deposits of Unit lei accumulated in a arcuate depression that remained after the avulsion of Brushy Creek; pre-avulsion deposition in Brushy Creek is indicated by the accumulation of the channel deposits of Unit lgl. The lenticular shape of Unit lei is also demonstrated in cross-section in the East Block (see Figure 6-2). Both horizontal and vertical views demonstrate that some paleotopography existed at the end of the deposition of Unit lgl and the beginning ofaccumulation of Unit lsi, for Unit lei clearly is deposited within a depression. The occurrence of Unit lsi deposits overlying those of Unit lei, however, demonstrate that overbank accumulation of si Its continued after the swale of Unit lgl was filled.

Deposition of the silts of Unit Isi continued until ca. 9500 B.P. (see Chapter 25). Sedimentation must have slowed somewhat toward the end of this period, however, in order to allow for the development of the Leanne soil, which is characterized by calcareous rhizolith formation and the incorporation of finely divided organic matter into the clayey silty matrix (see below).

After development of the Leanne soil, a renewed phase of silt accumulation took place, as evidenced by the deposition of Unit Id, which is a localized stratigraphic unit. For the most part, Unit Id occurs as patchy lenses that are most distinctly visible in the East Block and that appear to truncate the Leanne soil and some of the rhizoliths contained therein. Its silty composition and texture is identical to that of Unit lsi, and it is reasonable to consider Unit Id as prima- rily a fluvial deposit associated with the Brushy Creek system. The occurrence ofrelatively fewer rhizoliths than in the underlying Unit Isi points to relatively less carbonate mobilization, which in tum suggests that environmental conditions were beginning to change (see below) at this time. The uneven distribution and thickness of Unit Id is linked to erosion that occurred prior to the deposition ofUnit II, which overlies Id with a sharp contact. Because of the erosional upper contact with Unit II, it is not possible to determine the original thickness of Unit Id.

The deposition of Unit 11 points to a shift in the style of deposition of the Wilson-Leonard sediments. This shift is exemplified by the lithology of the unit, particularly the lower fine gravelly silts, and the sharp erosional contact with Unit Id, which is truncated by Unit II. Moreover, the composition, caliber, and morphology of these gravels is very similar to those found on slopes immediately to the south and southwest of the site. This similarity suggests that Unit II, unlike Unit 1 below it, includes a notable contribution of slope-derived material, presumably associated with sheetwash and colluvium from "behind" the site. The presence of a small gully at the western edge of the site, shown in Figure 6-1 and visible on aerial photographs taken before the TxDOT excavations, would support this view of a colluvial, non-Brushy Creek source of the sediment. The overall increase in thickness ofUnit II to the northeast (see Table 6-6), as well as the general dip of the lower contact of this unit, suggest that Unit II was prograding from this gully or slope and terminating in the Brushy Creek Valley as a wedge-shaped fan. Although deposition of Brushy Creek/Spanish Oak Creek alluvium was still taking place during Unit II time, it is evident that the deposition of Unit II represents a relative decrease in the contribution of alluvium and an increase in slope-derived material. Whether this shift is due to an overall decrease in alluvial activity of the Brushy Creek/Spanish Oak Creek system or a shift in the channel to the north, away from the site, is not clear. Temporally, however, the deposition of Unit II dates from approximately 9500 to 700 B.P. (see Chapter 25).

The onset of deposition of Unit III again signals a shift in the style of deposition at the site. The overall nature of the deposits is not unlike that ofUnit 11, being a combination of predominantly colluvium and less alluvium, as shown by the stony silts. In contrast to Unit II, however, the sediments of Unit III exhibit a noticeable anthropogenic influence as revealed by the abundance of burned rock features and associated dark, relatively organic-rich stony silts. The features occur throughout Unit III (see Chapter 26), but are particularly prominent in Unit Illa, just above the contact with the lighter-colored, more geogenic sediments of Unit Il, and in Unit Ille.

Although Unit III is essentially a colluvial and alluvial unit with marked anthropogenic contributions, field observations point to distinct vertical lithological differentiation: 
Units 1lla and Ille are considerably darker than the intervening Unit IIlb. Two alternative explanations can be proposed. Either these darker units represent variation of intensity of human activity or they reflect changes in sedimentation rate during the accumulation of Unit III.

Evaluation of these hypotheses is difficult. The TARL chemical analyses from Square 20 (see Table 6-8) and those from TxDOT (see Table 6-1), for example, show relatively higher amounts of organic matter in Units IIIa and 11lic in comparison to those from Unit IIIlb. Although there is an overall systematic decrease in organic matter with depth below the present surface, this trend is related to poorer conservation of organic matter with age, a common occurrence in Quaternary soils (Gerrard 1992). Consequently, the slight relative increase in organic matter values in Unit IIIa must be due to elevated inputs, which can be ascribed either to greater anthropogenic activity or to pedogenesis involved with development of the Stiba soil as described by Holliday (1989b). In light of the numerous cultural features and associated debris (bone, burned rocks, lithics, etc.) the cultural explanation would seem to be more reasonable in terms of inputting organic matter into the surface sediments extant at the time.

On the other hand, the above changes in organic matter could be interpreted in terms of changes in rates of sedimentation, with the overall rate of cultural activity remaining the same: reduced sedimentation rates would be associated with greater amounts of cultural debris per volume of geogenic sediment, whereas increased rates of sedimentation would have the effect of diluting anthropogenic inputs. The radiocarbon dates are interesting but not definitive in this regard (see Chapter 25), for they provide some indication of the overall rates of accumulation of the different subunits. Unit Illa accumulated between ca. 84208870 and 6500-6000 s.r.; Unit IIlb accumulated between ca. 6500-6000 and 3780-4440 B.P.; and Unit Ille accumulated between ca. 3780-4440 B.P. and the middle twentieth century. These dates are too imprecise as a basis for estimating the depositional rates of Units Illa, Illb, and Ille. Thus, the explanation for the relatively lighter color of Unit IIIb remains elusive.

In summary then, deposition at Wilson-Leonard is essentially alluvial in Unit I (including channel gravels in Igl, overbank silts in lsi and Id, and stagnant water cienega fill in lei). Above this, however, starting with Unit II, the proportion of alluvial sediment decre.ases sharply, and we observe a greater input of slope-derived silts, clay, and soil material, and centimeter-sized lithoclasts originating from the slopes; much of this slope material seems to be associated with a broad gully originating southwest of the site area. This colluvial and slope sedimentation was enhanced in Unit III by anthropogenic activities, especially those associated with the construction of numerous burned rock features.

\section{POSTDEPOSITIONAL PROCESSES}

Postdepositional processes at Wilson-Leonard include both chemical and physical transformations that can be ascribed to diagenetic, pedogenic, and biogenic processes. Each of these types is considered as it occurs within the profile.

\section{Iron Staining and Mottling (Redoximorphic Features)}

Iron staining and mottling are widespread at the site, and were evident at the time of the initial excavations (see original descriptions by excavators and Holliday [1989b]). Iron mottles (iron accumulation features) associated with bleached areas (iron depletions) are most prominent in Unit lg! and the lower parts of Unit Isi, particularly in the South Block and Test Unit B. The degree of development of the iron staining, both in tenns of percentage of mottles and density of impregnation of the matrix, decreases in an upward direction where traces of iron staining disappear at elevations ranging from ca. 94.40 to $95.10 \mathrm{~m}$ (see Table 6-4). In the field, part of the variability in elevation of the staining is due to partial concealment by the presence of the Leanne soil. Interestingly, in Column I00, the uppermost level of detectable iron staining was observed in the field at ca. 94.87 $\mathrm{m}$; sample 92-126 [see Table 6-4]) while traces of iron can be seen in thin section at a slightly higher elevation $(95.10 \mathrm{~m}$; sample 92-123). A similar pattern was observed in Column 200 thin sections (see Chapter 29). Data presented in Table 6-4 also indicate that the mottling actually affects part of Unit II.

The decrease in mottling is mirrored in the lower values of oxalate-extractable iron in Unit III in Column 200 (see Figure $6-21$ ). It is not clear why there are generally low values of oxalate-extractable iron in Unit II (below sample 92-214), since for the most part they are not gleyed and appear quite oxidized.

It is likely that the mobilization of iron within these lower levels is due to water saturation mostly associated with groundwater (Driese et al. 1995; Fanning et al. 1992), whereby iron is solubilized as a result of oxidation of soil organic matter:

The combination of wetness and organic matter on ped faces or in channels causes anaerobic conditions to develop there with consequent reduction of the oxidized forms ofFe and $\mathrm{Mn}$ in oxides. This solubilizes the $\mathrm{Fe}$ and/or $\mathrm{Mn}$, and the soluble ions diffuse to the interiors ofpeds where higher partial pressures of $\mathrm{O}_{2}$ trigger the oxidation of the ions and the precipitation of $\mathrm{Fe}$ and $\mathrm{Mn}$ oxides. This can set off a diffusion gradient so that more reduced $\mathrm{Fe}$ and $\mathrm{Mn}$ can diffuse toward the ped interiors [Fanning et al. 1992: 109).

Furthermore, as discussed in Chapter 29, an additional source of water also originated from surface runoff and 
associated throughflow and is linked to the fact that the site rests upon bedrock and also abuts against it to the south. As was seen after heavy rains during the TARL excavations, sediment at the contact between bedrock and Unit Isi in Square 12 is commonly saturated, and standing water was found in both this square and Test Square A after rainfall events. Thus, during the deposition of Units I and II, redoximorphic features as well as carbonate hypocoatings would point to higher amounts of rainfall, runoff, throughflow, and higher water tables than exist during the time represented by Unit III.

It would appear that conditions of high sediment saturation by groundwater-augmented by surface runoff and throughflow-existed at the site either permanently or seasonally, and the level of the subsurface water probably kept up with the pace of alluvial accretion of sediments from the Brushy Creek system (see Slate et al. 1996 for similar conditions in Arizona). The period of iron mobilization spans the interval represented by UnitI in Square 12 and by Unit I and partofUnitII in Square 20, orca. 12,000 to ca. $9000-9500$ B.P. (see Chapter 25).

This presence of high groundwater implies overall wetter climatic conditions during this interval. This is particularly true if, after avulsion, Brushy Creek was situated at some distance from the site area whereby the effects of groundwater would have been reduced. This inferred wetter climate is also consistent with interpretations of pollen data from Weakly and Boriack bogs and fauna from Hall's Cave (see Collins 1995; Collins et al. 1993).

After the deposition of the middle part of Unit II, the degree of water saturation of the deposits declined, since above this the sediments do not show any traces of iron mobilization. This change took place some time after about 9000-9500 в.P. and would seem to be correlated with a relative decrease in alluviation from the Brushy Creek system described above and an increase in slope-derived deposits. Lower levels of water saturation due to lower amounts of runoff and throughflow would signal climatic drying that parallels the trend in the pollen and fauna data cited above. This inferred climatic shift also matches other paleoenvironmental data during this time interval from the Wilson-Leonard site, including phytoliths (see Chapter 41) and snails (see Chapter 37).

\section{Carbonates}

Postdepositional carbonate accumulation at the site is discussed in detail in Chapter 29, and here only the major points are mentioned. Carbonates occur in two macroscopic forms, either as hard, irregular spherical-shaped and cracked popcorn carbonates, or as softer, elongated rhizoliths.

A described above, popcorn carbonates are confined to the lower part of the profile, essentially Unit Igl and to some extent, in the laterally equivalent Unit Isi. As elaborated in Chapter 29, popcorn carbonates result from the coalescence of repeated hypocoating formation that took place under generally wet conditions, such as the ones associated with the redoximorphic features described above. Fluctuating soil moisture levels, however, must have occurred during their accumulation in Unit I for two reasons. First, periodic $d_{r y}$ ness is indicated by the desiccation cracks within most of the popcorn nodules. Secondly, both field and micromorphological observations show that there is no systematic stratigraphic relationship between the iron mottles and the carbonate nodules. Rather, an alternating precipitation of secondary carbonate and iron indicates periodic wetter conditions, perhaps seasonally, in which iron is associated with greater precipitation, runoff, and throughflow that is followed by drier climatic episodes in which previously formed carbonates $\mathrm{d}_{\mathrm{r} y}$ and crack and then become loci for newer episodes of carbonate precipitation.

Most of the carbonate precipitation in Units I and II is associated with roots as evidenced by rhizoliths observed in the field and under the microscope. The upward transition from popcorn nodular carbonate in Units lgl, lei, and lower Isi to individualized rhizoliths in upper Units Isi, Id, and II also indicates a decrease in iron/carbonate precipitation through time, reflecting a gradual climatic $\mathrm{d}_{\mathrm{r} y}$ ing. It also mirrors the overall shift in depositional regime from predominantly fluvial to predominantly slope-derived deposits.

Carbonate precipitation in Unit III takes on two forms. Hypocoatings are for the most part stratigraphically isolated and found associated with the Stiba soil in the upper part ofUnit llla. In the surface or Wilson-Leonard soil, which formed over a longer duration than the Stiba soil, secondary carbonates are poorly developed and expressed as needlelike crystals in voids and on ped surfaces. This indicates that Stiba soil pedogenesis was more intense, although briefer in duration, than that of the Wilson-Leonard soil, which in turn could suggest a short, moister interval at this time.

Another agent affecting carbonate precipitation is that of earthworms, and earthworm casts are very abundant in Unit III. As discussed further in Chapter 29, biogenic precipitation is indicated in noncalcareous domains that are interpreted as relicts of noncalcified soil that escaped seconda $_{\mathrm{ry}}$ precipitation by passage through the earthworm gut.

\section{CONCLUSION}

The geological histo $\mathrm{r}_{\mathrm{y}}$ of the deposits and soils of the Wilson-Leonard site discussed above is summarized in Table 6-10. As data in this and other chapters have shown, this history is complex and represents the mingled effects of both depositional and postdepositional processes of differing origins that include geogenic, pedogenic, and anthropogenic. This history can be concisely summed up by predominantly fluvial deposition in Unit I followed by a marked increase in proportion of slope-derived materials in Units II and III. The latter, in addition to contributions of slope material, received considerable amounts of anthropogenic inputs 
TABLE6-IO

Summary of F01matlon processes at W1 son-Leonard

\begin{tabular}{|c|c|c|c|c|c|}
\hline Unit & $\begin{array}{l}\text { Age of } \\
\text { Unit }^{*}\end{array}$ & Depositional Events & Postdepositional Events & $\begin{array}{c}\text { Cultural } \\
\text { Manifestation }\end{array}$ & $\begin{array}{l}\text { Interpretation and } \\
\text { Comments }\end{array}$ \\
\hline $\mathrm{me}$ & $\begin{array}{l}\text { ca. } 0-4,000 \\
\text { B.P. }\end{array}$ & $\begin{array}{l}\text { Predominately slope-derived } \\
\text { gravelly silts and some silty } \\
\text { alluvium, coevally modified by } \\
\text { anthropogenic activity and } \\
\text { occupation, continuing up through } \\
\text { Unit Ille }\end{array}$ & $\begin{array}{l}\text { Wilson-Leonard soil: } \\
\text { extensive bioturbation and } \\
\text { some carbonate precipitation } \\
\text { by earthworms }\end{array}$ & $\begin{array}{l}\text { Numerous } \\
\text { burned rock } \\
\text { features }\end{array}$ & $\begin{array}{l}\text { Cumulic soil, with coeval } \\
\text { geogenic sedimentation and } \\
\text { anthropogenic deposition and } \\
\text { modification, mainly in form } \\
\text { of burned rock features }\end{array}$ \\
\hline$[[\mathrm{b}$ & $\begin{array}{l}\text { ca. } 4,000- \\
7,000 \text { B.P. }\end{array}$ & $\begin{array}{l}\text { Predominately slope-derived } \\
\text { gravelly silts and some silty } \\
\text { alluvium, coevally modified by } \\
\text { anthropogenic activity and } \\
\text { occupation, continuing up through } \\
\text { Unit me }\end{array}$ & $\begin{array}{l}\text { Extensive earthworm } \\
\text { bioturbation coeval with } \\
\text { sedimentation }\end{array}$ & $\begin{array}{l}\text { Burned rock } \\
\text { features }\end{array}$ & $\begin{array}{l}\text { Lighter color than Illa or me } \\
\text { is related to less organic } \\
\text { matter }\end{array}$ \\
\hline (ma) & & & $\begin{array}{l}\text { Stiba soil: } \\
\text { precipitation of carbonate in } \\
\text { voids and vesicles }\end{array}$ & & $\begin{array}{l}\text { Brief pause in sedimentation } \\
\text { and relatively rapid } \\
\text { pedogenetic development of } \\
\text { carbonates }\end{array}$ \\
\hline $\mathrm{ma}$ & $\begin{array}{l}\text { ca. } 7,000- \\
8,700 \text { B.P. }\end{array}$ & $\begin{array}{l}\text { Predominately slope-derived } \\
\text { gravelly silts and some silty } \\
\text { alluvium, coevally modified by } \\
\text { anthropogenic activity and } \\
\text { occupation, and continuing up } \\
\text { through Unit me }\end{array}$ & $\begin{array}{l}\text { Extensive bioturbation by } \\
\text { earthworms in entire Unit } \mathrm{m} \text {, } \\
\text { coeval with sedimentation }\end{array}$ & $\begin{array}{l}\text { Burned rock } \\
\text { features }\end{array}$ & $\begin{array}{l}\text { Slope sediments and some } \\
\text { colluviation, with marked } \\
\text { anthropogenic contributions } \\
\text { and modifications }\end{array}$ \\
\hline (II) & & & $\begin{array}{l}\text { Erosion and truncation of } \\
\text { underlying soil }\end{array}$ & & \\
\hline I] & $\begin{array}{l}\text { ca. } 8,700- \\
9,500 \text { B.P. }\end{array}$ & & $\begin{array}{l}\text { Weak soil formation: } \\
\text { (calcification, fauna) } \\
\text { turbation) }\end{array}$ & & $\begin{array}{l}\text { Stabilization of surface with } \\
\text { increased biological activity } \\
\text { and slower sedimentation }\end{array}$ \\
\hline I] & & $\begin{array}{l}\text { Colluviation of gravelly silts } \\
\text { associated with fan, and alluviation } \\
\text { of silts from Brushy Creek }\end{array}$ & $\begin{array}{l}\text { rhizolith carbonate } \\
\text { precipitation }\end{array}$ & & $\begin{array}{l}\text { Greater proportion of } \\
\text { colluvial sediments derived } \\
\text { from small channel to SW; }_{\text {romer }} \text { slower rate of sedimentation; } \\
\text { environment becomjng } \\
\text { effectively drier }\end{array}$ \\
\hline (Id) & & & $\begin{array}{l}\text { - truncation and erosion of } \\
\text { Leanne soil and sediments of } \\
\text { Unit I, resulting in fan-like } \\
\text { geometry oriented to NE } \\
\text { - rhizolith carbonates likely } \\
\text { coeval with sedimentation }\end{array}$ & & $\begin{array}{l}\text { Transition from } \\
\text { predominately alluvial to } \\
\text { slope deposition }\end{array}$ \\
\hline Id & & $\begin{array}{l}\text { Deposition of silts of alluvial and } \\
\text { slope origin; the latter is in part } \\
\text { associated with fan originating } \\
\text { from gully to SW }\end{array}$ & $\begin{array}{l}\text { rhizolith carbonates likely } \\
\text { coeval with sedimentation }\end{array}$ & & $\begin{array}{l}\text { Transition from } \\
\text { predomjnately alluvial to } \\
\text { slope deposition }\end{array}$ \\
\hline (lsi) & & & $\begin{array}{l}\text { Leanne soil: } \\
\text { rhizolith carbonates }\end{array}$ & & $\begin{array}{l}\text { Stabilization of alluvial } \\
\text { sediments }\end{array}$ \\
\hline $\begin{array}{l}\text { lsi-c } \\
\text { (above } \\
\text { lei) }\end{array}$ & $\begin{array}{l}\text { ca. } 9,500- \\
10,000 \text { B.P. }\end{array}$ & $\begin{array}{l}\text { Deposition of overbank silts from } \\
\text { Brushy Creek/Spanish Oak Creek }\end{array}$ & & & \\
\hline (lei) & & & $\begin{array}{l}\text { - rhizolith carbonates coeval } \\
\text { with sedimentation [Units lsi, } \\
\text { Id] } \\
\text { - redoximorphic features } \\
\text { (iron staining) [Units lgl, lei, } \\
\text { Isi, Id] } \\
\text { - root burrows [Units lei, lsi] } \\
\text { - "popcorn" carbonates [Unit } \\
\text { lei; Isi] }\end{array}$ & & $\begin{array}{l}\text { Unit I generally wetter than } \\
\text { today }\end{array}$ \\
\hline $\mathrm{Td}$ & $\begin{array}{l}10,000- \\
11,200 \text { B.P. }\end{array}$ & $\begin{array}{l}\text { Deposition of black silty clays } \\
\text { (Units lei) interfingering with } \\
\text { brown silts (Units Isi) to the south }\end{array}$ & & & $\begin{array}{l}\text { Marshy conditions associated } \\
\text { with cienega in NE pail of } \\
\text { site }\end{array}$ \\
\hline
\end{tabular}

*Includes time encompassing depositional and postdepositional events (dates from Chapter 25). 


\begin{tabular}{|c|c|c|c|c|c|}
\hline Unit & $\begin{array}{l}\text { Age of } \\
\text { Unit }^{*}\end{array}$ & Depositional Events & Postdepositional Events & $\begin{array}{c}\text { Cultural } \\
\text { Manifestation }\end{array}$ & $\begin{array}{l}\text { Interpretation and } \\
\text { Comments }\end{array}$ \\
\hline $\begin{array}{l}\text { Isi } \\
\text { (below } \\
\text { lei) }\end{array}$ & $\begin{array}{l}11,200 \text { B.P. } \\
\text { (?) }\end{array}$ & $\begin{array}{l}\text { Alluviation of predominantly } \\
\text { overbank silts with local colluvial } \\
\text { additions; interfingers laterally } \\
\text { with gravels of Unit lgl }\end{array}$ & & & $\begin{array}{l}\text { Interfingering of gravels (Unit } \\
\text { lgl) in north with silts (Unit } \\
\text { lsi) to the south; best visible } \\
\text { alon2 E Profile }\end{array}$ \\
\hline lgl (ii) & $\begin{array}{l}11,500 \text { B.P. } \\
\text { (?) }\end{array}$ & Terminal deposition of gravel & & & $\begin{array}{l}\text { Final phase of gravel } \\
\text { deposition associated with } \\
\text { bar; finer and more rounded } \\
\text { gravel. }\end{array}$ \\
\hline $\operatorname{lgl}(\mathrm{i})$ & $\begin{array}{l}11,500 \text { B.P. } \\
\text { (?) }\end{array}$ & $\begin{array}{l}\text { Alluviation of gravels from Brushy } \\
\text { and Spanish Oak creeks with input } \\
\text { of angular gravel locally derived } \\
\text { from bedrock }\end{array}$ & & & $\begin{array}{l}\text { Cut and fill deposition } \\
\text { associated with gravel bar of } \\
\text { active stream channel; } \\
\text { laterally grades into stringers } \\
\text { of angular gravel derived } \\
\text { from underlying bedrock }\end{array}$ \\
\hline
\end{tabular}

in the form of burned rocks, bone, and ash in Unit II but mostly in Unit III.

The strategy employed here to infer this scheme is similar to that done in most geoarcheological investigations and involves careful field observations coupled with detailed laboratory analyses. For the Wilson-Leonard site, standard physical and chemical analyses were of restrained value in piecing together the site history. Rather, it is hoped that the discussions in this chapter and in Chapter 29 have demonstrated the effectiveness of micromorphology in unraveling the complex interplay of site formation processes occurring at Wilson-Leonard and no doubt at other sites in the region. 


\section{CHAPTER 7}

\section{EARLY PALEOINDIAN COMPONENTS}

by Michael B. Collins

\section{INTRODUCTION}

This chapter considers the evidence from WilsonLeonard relating to the early part of the Paleoindian period. "Early Paleoindian" is used here to denote cultural manifestations dating to the time when now-extinct Rancholabrean megafauna were still present, or prior to about 10,000 B.P. Fauna! and lithic specimens recovered from fluvial deposits up to $3 \mathrm{~m}$ thick in the deeply excavated part of the site constitute this evidence, and there is every indication of at least two distinctive cultural components among these materials. During this interval, natural rates of deposition were comparatively rapid which resulted in a moderate degree of separation of cultural materials. This is a synoptic presentation drawing upon more-detailed treatments of the site (found in Volume I), artifacts and features (Volumes II, III, and IV), biotic remains (Volume V), and other, more-specialized topics (Volumes III and IV).

Research into Paleoindian archeology throughout the Western Hemisphere at the time of this writing is as active and exciting as at any time in its history. New data and new perceptions of older data are expanding the temporal and geographic boundaries of early sites as well as the material cultural and inferred behavioral diversity of the early American populations. Even the biological characteristics of the earliest Americans are turning out to be different from what would be predicted from the prevailing theory on the peopling of the Americas. The comparatively well-stratified earliest components at Wilson-Leonard contribute in a small way to this by adding some previously unknown facts to Early Paleoindian archeology along the southern periphery of the Great Plains. Throughout all but the most recent months ofresearch on the Wilson-Leonard data, it was generally believed that there were only two cultural complexes, Clovis and Folsom, in the Early Paleoindian in Central Texas. This view is no longer viable, but its legacy is reflected in this chapter and throughout the rest of this report.
Among key issues addressed in this chapter are definition of the early components, their dating, and their environmental contexts at the site and regional levels. These lead to contemplation of the behavioral and adaptive significance of these components and their implications to archeology's growing awareness of cultural complexity in Early Paleoindian times. No single artifact from Early Paleoindian context at Wilson-Leonard would be accorded consensus agreement among typologists, but when considered in light of the dating and the technological attributes of various artifact classes, the earliest artifacts fit well in the Clovis rubric and those from slightly higher stratigraphic position have typological affinities with Plainview/Goshen and technological similarities to Folsom materials. Still higher in the Early Paleoindian sequence are flaking debris and nondiagnostic artifacts that, with the exception of one (intrusive?) Wilson dart point, remain unassigned to any defined culture. A few objects with Clovis affinities occur with those ofPlainview/Goshen/Folsom characteristics, and one Clovis as well as one Midland projectile point fragment was found displaced in even younger deposits at the site.

\section{PHYSICAL CONTEXT}

Excavations penetrating into or through the lowest deposits at Wilson-Leonard are restricted to eighteen 2-x-2-m excavation squares in TxDOT Blocks 3, 4, and 6 and to twentyone 1-x-1-m squares dug by the TARL team; one square in TxDOT Area B also reached Early Paleoindian deposits (Figure 7-1). Four of these (TARL Squares A, B, 12, and 20) reached bedrock. Remaining squares reached various depths and terminated in various geologic units, resulting in an uneven sampling of the early deposits, primarily because of logistical and cost limitations occasioned by the considerable depths of these excavations and the comparatively low return ofrecovered materials, especially from the basal gravel 


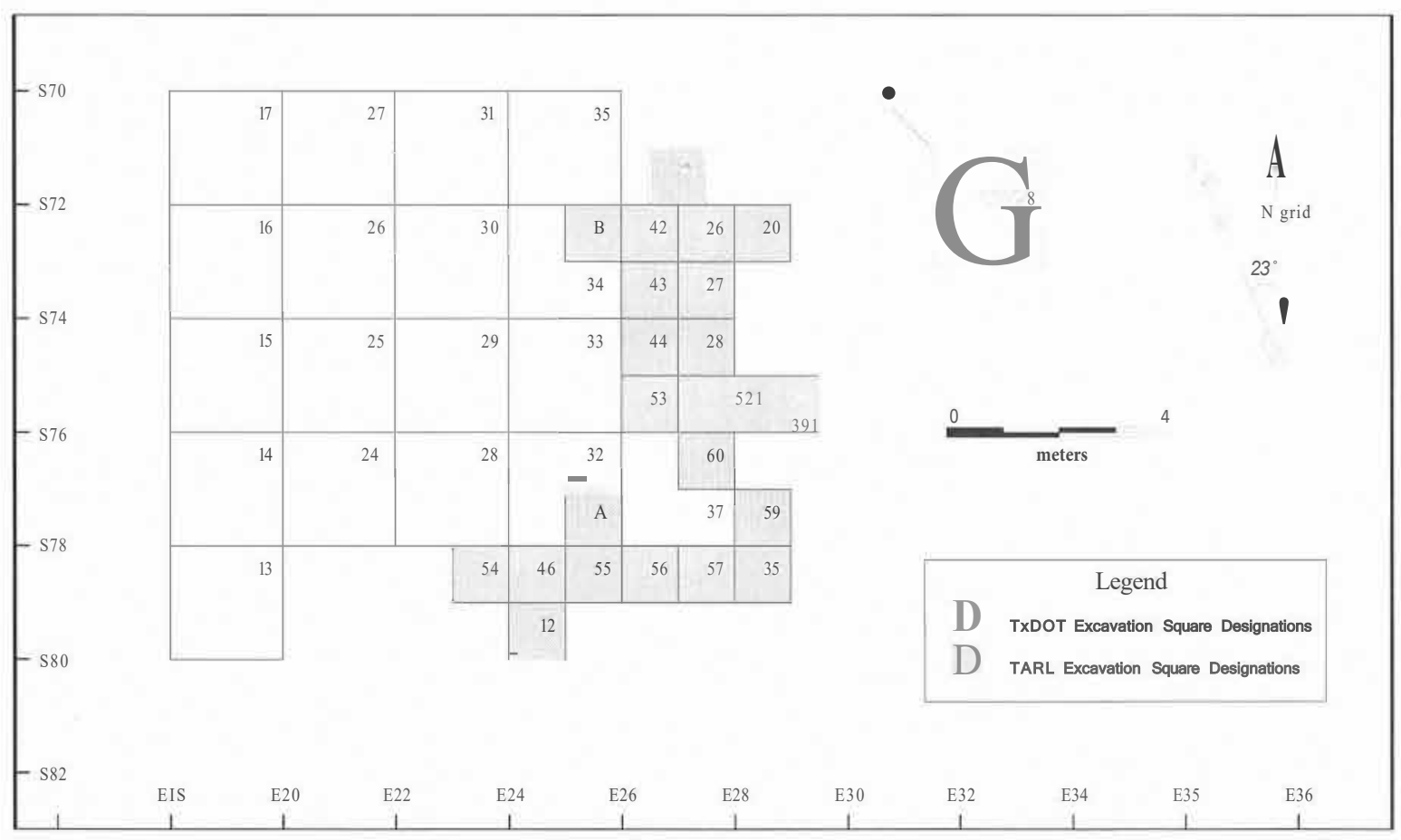

FIGURE 7-1. Plan of excavations showing the units in which Early Paleoindian-age deposits were encountered.

unit. In spite of these limitations, a sufficient sample was obtained to provide substantive information.

The geologic units identified in the main excavation block were not fully defined in Area B. Square 50 yielded Early Paleoindian diagnostics that are discussed below, but no attempt is made to treat the nondiagnostic materials from that part of the excavation nor to relate the stratigraphy to that in the main excavation block.

The vertical dimension of the Early Paleoindian archeological evidence is defined on the combined basis of natural stratigraphy, cultural stratigraphy, and radiocarbon dating. Cretaceous bedrock marks the lower boundary and the upper boundary is set as the basal contact of geologic Unit Isic, which is actually a soil with a distinctive Late Paleoindian archeological assemblage (the Wilson component [see Chapter 8]). Radiocarbon dating (see Chapter 25) brackets the Early Paleoindian manifestations within these boundaries between an extrapolated beginning age of slightly greater than 12,000 radiocarbon years and a well-constrained ending age of slightly more than 10,000 radiocarbon years. As detailed in earlier chapters (especially 2, 3, and 6), geologic context provides the organizing framework for the archeological and the environmental investigations at this site, and accordingly, the geologic units underlying Unit Isi-c are briefly reviewed here.

The early depositional regime at Wilson-Leonard was dominated by various kinds of stream action; the several stratigraphic expressions of this fluvial sequence are collectively designated as Unit I. Resting on bedrock is a thick gravel unit (Unit $\operatorname{lgl}$ ), overlain by a silty deposit (Unit Isi), overlain in tum by a clayey deposit (lei) that fills in a depres- sion on the surface of Unit lsi. Because none of the contacts between subunits of Unit I is sharp enough to be precisely detected or mapped in the field, several gradational subunits, such as Isi/Icl, have been recorded. All of these are covered in this discussion.

Brushy Creek valley floor and walls at the site are cut into Comanche Peak Limestone. Quaternary fill rests on this bedrock and contains the archeological materials ofWilsonLeonard and several other known sites in the vicinity. In the excavations, Unit Igl gravels were found resting directly on a clean, hard bedrock surface comparable to that found in the bed of many streams in the region today (notably the main branches of the San Gabriel River), suggesting that prior to deposition of the basal Quaternary gravels, Brushy Creek had been flowing on bedrock close to the right valley wall. At Wilson-Leonard, Quaternary valley fill began with gravel (Unit Igl) that accumulated in multiple lenses as channel and bar deposits along Brushy Creek channel at the confluence with Spanish Oak Creek. The lowest gravels include a significant proportion of well rounded clasts of caliche, intermediate lenses are dominated by well-rounded limestone clasts, and near the top, Unit Igl includes substantial numbers of more-angular limestone clasts. Clast sizes are mostly under $4 \mathrm{~cm}$, but a few larger stones are present, which is not much different from the gravel in modem Brushy Creek. Unit Igl becomes siltier toward the top. It is important to note that natural chert is virtually absent from the gravel of Unit Igl as well as from the nearby bed of modem Brushy Creek, which is a good indication that virtually all of the chert pieces found during excavation were introduced by humans. Unit Igl varies in thickness in the excavated area 
from $0.8 \mathrm{~m}$ to $2 \mathrm{~m}$, averaging close to $15 \mathrm{~m}$. Bedrock is fairly flat, and the top of the gravel rises to the northeast. Unit lgl was deposited in an environment of comparatively high energy. After deposition, this deposit was modified by root penetration and iron staining. Approximately $8.7 \mathrm{~m}^{3}$ of $\mathrm{lgl}$ were excavated by hand along with an additional $1 \mathrm{~m}^{3} \mathrm{oflgl} /$ Isi/lel.

Unit Igl gravels grade laterally into and interbed with the overlying Unit lsi, a massive, calcareous, iron-stained clayey silt with numerous thin gravel stringers. A prominent soil with burned tree stumps at the top of this unit is referred to as the Leanne soil (Unit Isi-c). Leanne soil development is associated with the Late Paleoindian Wilson archeological component. That portion of Unit lsi above the gravels and below the Leanne soil is relevant to the Early Paleoindian period. Unit lsi varies substantially in thickness, reflecting slopes and undulations of both its upper and lower contacts. In general, lsi thins from an undetermined thickness of greater than 0.9 min the southwestern part of the excavation to missing in places along the northern edge. Its lower contact rises from southwest to northeast in response to the increasing height of the top of the lgl gravels. The upper contact of lsi drops in elevation in the same southwest to northeast direction. The lower boundary of Isi is in places interbedded with lenses of gravel at the top of Igl, and in other places the boundary is gradational with Igl, probably from turbation. The lsi picture is one of overbank flooding and slopewash creating a drape or fan-like deposit of silty material against the valley wall, filling a low area between the valley wall and a large gravel bar, and thinly covering the top of the gravel bar. A pond or marsh (resulting in Unit Icl) later developed over the thinner parts of Isi in all but the southem and southwestern parts of the excavated area. Turbation by roots and probably by burrowing of small animals and trampling oflarge animals caused blurring of the upper contact oflsi, mapped as Isi/lcl over much of the excavated area. Outside of the ponded area, the upper surface of lsi is in places mapped as grading into the base of the Leanne soil (Isi-c) and designated lsi/lsi-c. In places where overlying lei is quite thin, there is another transitional unit mapped as Isi/ lel/Isi-c. The Leanne soil and its archeological content are discussed below in Chapter 8 . A scatter of poorly preserved bison bones (the "bone bed") occurs mostly in the upper part oflsi and lsi/lel in the eastern part of the excavated area and is associated with artifacts that occur with the bones as well as at the same stratigraphic position over a wider area of the excavations (the "Bone Bed component"). The bone bed and its associated artifacts are discussed below. A total of about $24.6 \mathrm{~m}^{3}$ of Unit Isi was band excavated; approximately another $7.7 \mathrm{~m}^{3}$ oflgl/Isi, $22.9 \mathrm{~m}^{3}$ oflsi/lcl, $53 \mathrm{~m}^{3}$ oflsi/ lel/lsi-c, and $7.5 \mathrm{~m}^{3}$ oflsi/lsi-c were excavated by band.

One of the more-distinctive parts of the stratigraphic record at Wilson-Leonard is Unit Icl which formed in a pond in the low area on the surface ofUnit Isi. Unit lei is a medium to dark brown clayey silt or mud with small limestone clasts dispersed throughout. The unit thins from north to south, completely pinching out along the south and southwest area of the excavation; on average it is less than $20 \mathrm{~cm}$ thick, but is up to $60 \mathrm{~cm}$ thick in the northeastern area oftbe excavation. Unit lei is heavily turbated with extensive filled root casts or burrows. Turbation has blurred the lower, upper, and lateral contacts of this unit, especially around its margin; the upper gradational boundary is mapped as lel/lsi-c. The depositonal environment is inferred to be a shallow, marshy pond (or cienega) with abundant aquatic plants and animals active throughout and moderately large trees growing around its margins. It seems that the excavations came down along the margin of the cienega and exposed evidence of human activity that occurred around it. Just over $1 \mathrm{O} \mathrm{m}^{3}$ of Icl were excavated by band as well as approximately $11.8 \mathrm{~m}^{3}$ oflcl/Isi-c.

\section{GEOCHRONOLOGY}

Intensive effort toward dating cultural components at Wilson-Leonard (see Chapter 25) resulted in a sequence of 29 dates for the early geologic units and cultural materials. These and the fossil bones in Unit Isi provide the geochronological evidence for the Early Paleoindian components. Little in the way of satisfactory material for radiocarbon dating was present in Unit lg!, and no dating was attempted for this deposit. Neither the matrix of Unit Isi nor the poorly preserved bone in the unit was found to be suitable for dating (see Chapter 25). However, the mud of Unit lei produced 20 dated samples, the gradational unit at the bottom of lei (Isi/Icl) yielded 3 dated samples, and the gradational unit at the top of Icl (Icl/Isi-c) was the source of 6 dated samples. Dates from the overlying Unit lsi-c are consistent in placing the beginning age of that unit, and constraining the age of the underlying deposits, at greater than 10,000 radiocarbon years ago.

Radiocarbon dates for the Early Paleoindian strata, Units Isi/lel, lei, and Icl/Isi-c at Wilson-Leonard are interpreted by Stafford (see Chapter 25) to indicate the following chronology for the main units (in radiocarbon years before present):

$$
\begin{aligned}
& 10,600 \\
& \text { lei, cienega } \\
& 11,000 \\
& \quad \text { lsi, silty alluvium } \\
& 11,500 \\
& \quad \text { lgl, gravel } \\
& \text { greater than } 12,000 \\
& \quad \text { Comanche Peak Limestone (Cretaceous) }
\end{aligned}
$$

Organic-rich mud in Unit lei is the source of most of the radiocarbon assays, and it is those 20 dates that provide the strongest evidence for this chronological interpretation, but some corroboration comes from the fossils. The poorly preserved bison bones in Unit lsi cannot be assigned to a species on the basis of morphological or metric criteria, bow- 
ever, it is likely that they are B. antiquus (see Chapter 33). There is a single tarsal bone of Equus found with the bison bones that, according to recent estimates (see Meltzer and Meade 1985), probably was extinct before 10,000 в.P., which is concordant with the radiocarbon dating.

\section{PALEOENVIRONMENT}

Physical stratigraphy and a small number of biotic remains are the primary paleoenvironmental indicators documented in the Wilson-Leonard excavations. These data are in general, but not perfect, accord with similar indicators from numerous archeological and geological localities in the central part of Texas recently summarized by Collins (1995:Table 2; Chapter 4, above). For the Early Paleoindian period, I infer a drought ending at about the beginning of the Wilson-Leonard sequence followed by an interval of increasingly mesic character during which most of the Early Paleoindian activities at the site transpired.

Regionally, bog pollen, microfaunal, and fluvial geologic sequences provide evidence that a strongly expressed drought was ending in Central Texas sometime near 11,500 years ago (Collins 1995), interpreted to be the local equivalent of a widespread interval referred to as the Clovis Drought by Haynes $(1991,1993)$. Pollen was not recovered from Wilson-Leonard, but the pollen records from two bogs (Boriack, I00 km east-southeast of Wilson-Leonard in Lee County and Weakly, located $200 \mathrm{~km}$ northeast of the site in Leon County) have been interpreted (Collins, Bousman, and Perttula 1993:59) as showing an early xeric interval (estimated to be ca. 13,000 to 12,000 B.P.) followed by a more mesic one beginning about 12,000 в.P. The ratio ofleast shrew (an indicator of mesic conditions) to desert shrew (proxy for xeric conditions) in the Hall's Cave faunal sequence $(175 \mathrm{~km}$ west-southwest of Wilson-Leonard in Kerr County) produced a better-dated and equally strong indication of dryer conditions from before I3,000 to about 11,800 B.P. (Collins 1995; Toomey 1993; Toomey et al. 1993). Most geologic sections in valley fill reveal evidence ofdowncutting that ended near 12,000 years ago with the onset of valley filling (see summary of these data in Collins 1995). Downcutting is interpreted as indicating droughty conditions whereas alluviation tends to correlate with more-mesic intervals.

In these terms, the Wilson-Leonard sequence is a close match with the regional pattern. Spanish Oak or Brushy creek, or both, were flowing directly on bedrock next to the right wall of the valley sometime not long before 12,000 в.P. The large gravel bar (Unit Igl) adjacent to that channel is typical of features that develop under a climatic regime where reduced vegetative cover contributes to the brief, high-energy runoff events that are characteristic of droughty intervals. The creek (or creeks) abandoned the channel next to the right valley wall sometime prior to about 11,500 years ago and the swale left behind began to fill with finer-grained sediments (1si). Unit Isi is not without its gravelly indicators of high-energy floods, but the prevalent texture of the deposits is in the silt range and is consistent with an aggradational, overbank flood regime with vegetation-retarding runoff in the catchment. A continued trend toward greater moisture is suggested by the vegetated cienega that developed near 11,000 years ago in the swale and prevailed, possibly without interruption, for some 400 years, or until about 10,600 в.P. Pluvial aggradation continued the buildup of silty deposits on which the Leanne soil later developed.

In addition to the physical stratigraphy, excavation at Wilson-Leonard recovered biotic indicators of environmental conditions in the form of soil isotopes, plant macrofossils, ostracodes, and microfauna. Phytolith (Chapter41), diatom (Chapter 38), and mollusk (Chapter 37) recovery was inadequate to contribute to this discussion. Soil isotopes (Chapter 42) from Unit Isi are indicative of a woodland (CJ floral community on the site. This is fully concordant with the several identifiable plant macrofossils (mostly wood and nuts [Chapter 40]) which consist of live oak, juniper, hackberry, and walnut. It is easy to visualize a sloping valley margin to valley floor habitat at the site, or generally up the valley, with hackberry and walnut lower and live oak and juniper higher on the slope.

Freshwater ostracodes (Chapter 39) from lower Unit I offer the most sensitive environmental data recovered. Anywhere from 4 to 11 species were identified from each of the Units Igl, lel/Isi, lower lei, and upper lei. All of these live in shallow, permanent, alkaline water with maximum depths of 2 or $3 \mathrm{~m}$. Maximum water temperature tolerances range from $19^{\circ} \mathrm{C}$ to $22^{\circ} \mathrm{C}$ for these species. The samples from upper lei are also indicative of eutrophic conditions. Minimally the presence of these species indicates that permanent water existed either at the site or somewhere upstream. If water was not standing permanently at the site, the presence of ostracodes could only be explained by introduction, either by tluvial transport or, less likely, by humans bringing in water. It is entirely possible that permanent water was present at the site during the deposition of both of the units yielding ostracodes, lgl and lei. Alternatively, the lg! specimens may have washed in whereas those from Unit lei could be part of the fauna living in the cienega. The alkaline water preferred by all of the ostracodes in these samples could be accounted for in either stream-channel pools or floodplain marshes by the limestone bedrock of Brushy Creek valley. Water temperature tolerances of these species are not very informative climatically since water temperature may vary more in response to highly localized conditions (such as a spring) than to air temperature. The eutropic water indicated by the upper lei sample is compatible with other indicators of a vegetated cienega.

Ostracodes were unexpected in the Unit lg! gravels, since this has been interpreted as having formed during the Clovis Drought when Brushy Creek may have been intermittent. Alternative resolutions to this contradiction include the possibility that the Igl ostracodes are reworked from an 
earlier deposit or that, even though the region was generally droughty, Brushy Creek valley had ground-water supported pools or springs.

Microfaunal data (see Chapter 35) are scarce for lower Unit I, but a bog lemming in mid Unit lg! and a yellow-faced pocket gopher from Isi/Icl are either the indicators of a disharmonious fauna, and therefore a seasonally moreequable climate, or their presence in the site is not as members of the same living fauna. If the bog lemming is redeposited from the reworking of an earlier deposit, its preference for a cooler and moister habitat would not contradict the inference that Unit Igl accrued near the end of the Clovis Drought. Alternatively, cool and moist microhabitats might have existed along the creek bottom even during a regional drought, and this lemming may have been part of a relict population. A yellow-faced pocket gopher in Unit Isi/Icl is also somewhat discordant with the inference that, by this time, the drought had ended. It is possible that this, too, is a survivor of an earlier population where the Clovis Drought was waning but conditions had not exceeded the temperature or moisture limitations of this pocket gopher. Much more troublesome is the implication of this gopher's need for deep, rock-free soils. Considerable evidence suggests extensive loss of soil from the uplands of Central Texas in the terminal Pleistocene which implies that soils throughout the Brushy Creek catchment should have been severely stripped. There is no indication, such as burning, that the pocket gopher specimen might represent a cultural introduction, but humans or another predator bringing a gopher carcass upstream from the deeper soil habitats of the black prairie could account for its presence in the site. Unfortunately, the vertebrate data from Wilson-Leonard Unit I are too scarce for resolving these issues.

On balance, the information on the paleoenvironment of the site is taken to indicate the following sequence. During the Clovis Drought, Brushy Creek was flowing in a fairly narrow channel on bedrock against the right valley wall. Soils were thin and vegetation was sparse on the uplands in and beyond the drainage resulting in flashy stream discharge and the construction of a large gravel bar along the left stream bank (Unit lg!), a short distance from the right valley wall. As the drought was waning sometime between 12,000 and 11,500 years ago, the stream evulsed to a channel somewhere in its valley away from the right wall and the swale that had been the former channel began to fill with silty overbank and slopewash sediments (Unit Isi). Occasionally, stronger floods deposited gravel in the swale. Continued increase in effective moisture led to the development of a marsh in the partially filled swale (Unit lei) that persisted from about 11,000 to 10,600 в.P. Slow fluvial aggradation and formation of a soil followed.

Woody vegetation persisted during the drought, at least in the valley, and permanent water bodies seem to have been present at the site or within a short distance upstream. The most plausible explanation is that Brushy Creek valley was not completely desiccated during the drought and that it provided a cool and moist microenvironment. After the drought, even more .water was present in the valley and runoff was reduced somewhat by increased vegetation throughout the catchment and beyond.

\section{FEATURES}

Excavators recorded seven archeological features in Early Paleoindian context (see Chapter 26). Two of these are unequivocally cultural, three are probably noncultural animal burrows, and two are not easily referable to either status (two other anomalies given feature designations 244 and 261 in the field were subsequently rejected and are not discussed here).

Feature 188 (Figure 7-2a) consisted of a chert core, a limestone hammerstone, a small limestone rock, and nearby bone splinters found near the southeastern edge of the excavated area in Unit lsi (specifically in Square E28/S78, Levels 43B and 44A). No flakes from the core were found associated with the feature, and the hammerstone is a nodule of Comanche Peak Limestone that is probably too soft to effectively detach flakes from the core which is a block of medium coarse chert. It seems probable that the core was flaked elsewhere with a harder percussor and that it was then used at this spot as an anvil upon which bison (?) bone was broken. One end of the hammerstone is battered into a slightly concave edge with a curvature that would roughly match the convexity of the larger bison limb bone shafts. Stratigraphically, the feature was beneath the bison bone bed and was probably not associated with it, but the bone splinters found around it have the structure and thickness of a large mammal. Two ofthese bone fragments exhibit spiral fractures.

Feature 170 (Figure 7-2b) was a cluster of at least 63 bone fragments found in Unit lsi at the same stratigraphic position as but about $2 \mathrm{~m}$ southwest of the edge of the bison bone bed in Level $31 \mathrm{~B}$ of Square E24/S78. In addition to the bone fragments specifically attributed to the feature, the same provenience unit yielded an additional 15 bone fragments, charcoal flecks, and debitage that might also have been associated with the feature. The 63 bone fragments lack burning and exhibit angular (dry bone) fractures; among the 15 nearby bone fragments, only angular fragments were found, but 8 show evidence of burning. In the field, the feature was noted as including humerus, tibia, and unidentified long bone fragments of bison(?) (see Figure 7-2b), but none of the 63 recovered fragments could be identified in the subsequent fauna! analysis. Among the 15 general-provenience bones is one identified as a distal fragment of a bison tibia. One interpretation of this feature is that it began as a grouping of several large long bones, most likely bison, that weathered into the cluster of fragments. An alternative is that it was a single bison tibia that splintered into the array of fragments. In either case, the 


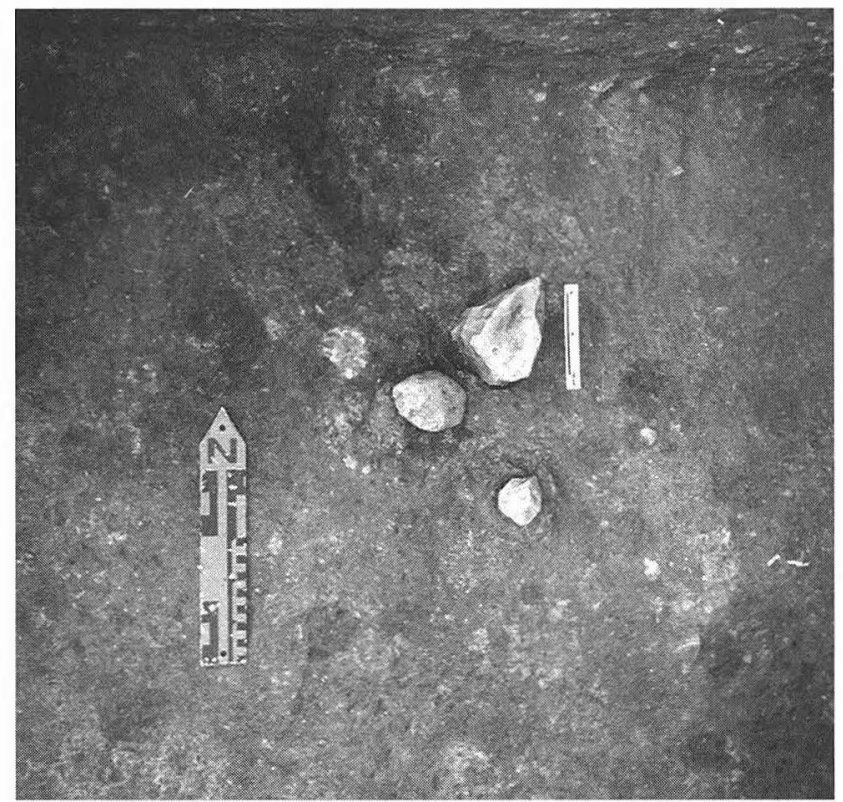

a

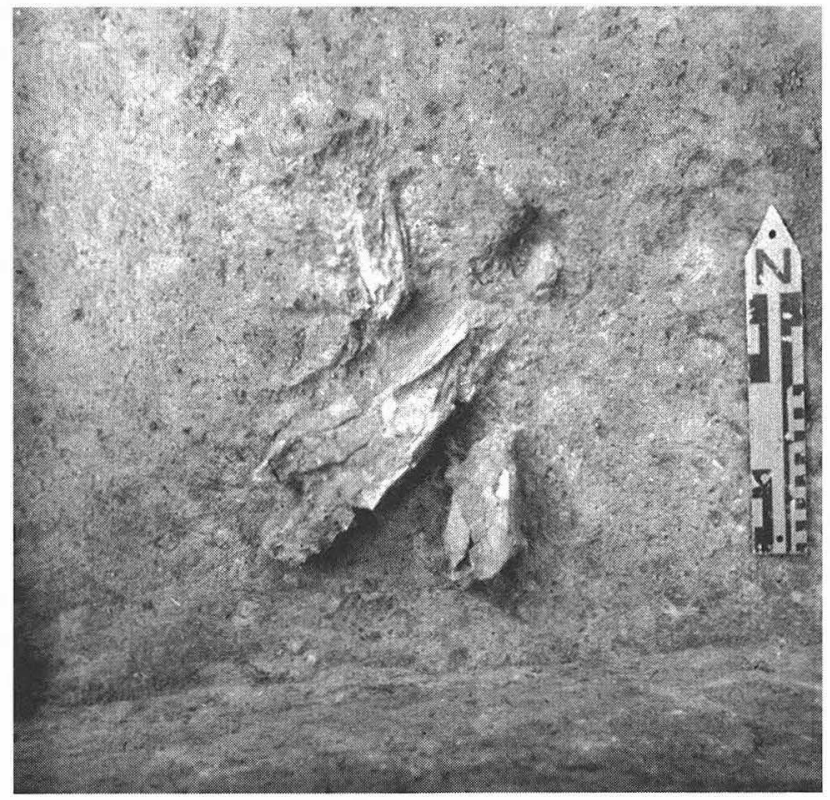

b

FlouRE 7-2. Cultural features of Early Paleoindian affiliation. (a) Feature 188; (b) Feature 170.

poor condition of the bone precludes the retrieval of very much information.

Feature 190 was a poorly documented stratigraphic anomaly in the turbated contact zone between lei and Isi in the northeastern part of the excavation (east wall of Square E26/N74). It cannot be determined whether this was a natural or a cultural anomaly given the limited information, and no manifestation of any recognizable feature was noted in the adjacent TARL excavation (Squares 42 and 43).

Features 175 and 178 were anomalies or disturbances inferred to be large animal burrows or similar products of turbation (perhaps windthrow [the uprooting of trees by wind]). Both of these occurred in Unit Isi/Icl but probably originated in Unit Isi-c, and they were similarly proportioned, Feature 175 being $80-x-70-x-35 \mathrm{~cm}$ and Feature 178 being $75-$ $\mathrm{x}-50-\mathrm{x}-22 \mathrm{~cm}$. Feature 175 was in TxDOT Squares E6/S76 and E26/S78, Levels 36A to 37B. Feature 178 was in TxDOT Square E24/S72, Levels 37 A-37B. Sixty-four bone fragments, 5 pieces of debitage, and a small amount of charcoal were recovered from Feature 175, and 1 flake was recovered from Feature 178 .

Features 259 and 262 were groups ofrocks. Feature 259 (Square 35, Levels 46-47) was a cluster of nine rocks that on field examination were considered possibly burned (but the two that were tested lacked archeomagnetic indications of burning). These rocks were associated with a thin uniface, a flake, and eight unburned bone fragments. Feature 259 was found in upper Unit le!, but it may have been intrusive from Isi-c. Feature 262 occurred in Isi/lel (Square 27, Levels 51 and 52). It consisted of a scatter of 6 limestone rocks, 9 piece-plotted bone fragments, 50 small bone fragments recovered on the 1/8-inch screen, and 455 bones recovered from the fine-screen with a small amount of charcoal flecks; since some of the rocks are angular, the possibility exists that they were burned, but they do not exhibit the usual constellation of attributes. The feature may have been a disturbed hearth or an anomalous concentration of general habitation debris. Its stratigraphic position corresponds to that of the bone bed.

Of the seven archeological features documented in the Early Paleoindian components,

- three seem to have been natural disturbances (two [175 and 178] intruding downward from Unit Isi-c into Unitlsi/ lei and one [190] intruding down from Unit lei into Unit Isi),

- two were ofuncertain origin (259 seems to have been an anomalous rock cluster in Unit lel/1si-c and 262 was an indistinct cluster of cultural debris probably associated with the bone bed),

- one was a grouping of fragments of fone or more large bones (170) probably part of the bone bed,

- and one (188), which predates the bone bed, was a possible anvil and hammer used in breaking bones.

\section{MA1ERIAI.SRECOVERED}

Bone and lithic materials are the only classes of recovered material of certain or probable cultural derivation in the Early Paleoindian deposits. Lithics consist of8,699 total pieces, of which 8,438 are debitage. In addition, there are 4 projectile points, 51 bifaces and biface fragments, 1 Clear Fork tool, 76 unifaces and uniface fragments, 74 tools on flakes or blades, 1 blade, 2 gravers, 26 cores and core tools, 6 battered stones, 5 burin spalls, 1 harnmerstone, 4 chert cobbles, 1 mano, 2 pieces of worked hematite, 4 pieces of sandstone, and 3 unanalyzed chipped stone tools. These were distributed among the stratigraphic units as shown in Table 7-1. Also shown in the same 
TABLE 7-1

Early Paleoindian Cultural Materials by Natural Stratigraphic Provenience

\begin{tabular}{|c|c|c|c|c|c|c|c|c|c|c|c|c|c|c|c|c|c|c|c|c|}
\hline Unit & 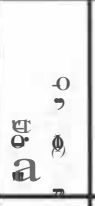 & 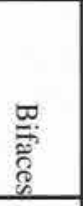 & $\begin{array}{r}\frac{8}{6} \\
>1 \\
0 \\
0 \\
0 \\
0\end{array}$ & 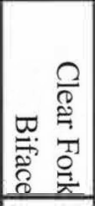 & 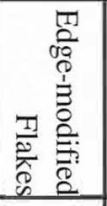 & $\stackrel{0}{0}$ & 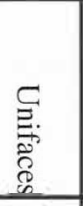 & $\begin{array}{l}8 \\
\mathbf{\alpha} \\
\underset{\alpha}{\alpha} \\
\stackrel{8}{8} \\
\end{array}$ & 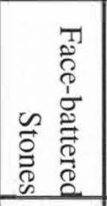 & 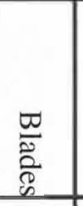 & $\begin{array}{l}\infty \\
\S \\
\S \\
= \\
0 \\
0 \\
0 \\
= \\
=\end{array}$ & క3 & 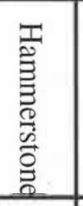 & 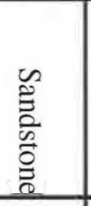 & $\begin{array}{l}\frac{T}{2} \\
3 \\
-2 \\
\end{array}$ & 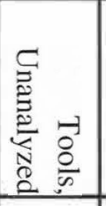 & 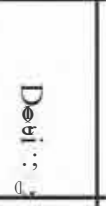 & $\frac{\overrightarrow{0}}{\frac{0}{n}}$ & 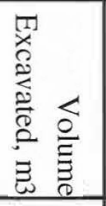 & 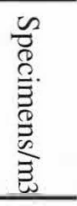 \\
\hline Isi/Isi-c & 1 & 8 & 1 & & 13 & & 8 & & & & & & & & & & 1,951 & 1,982 & 7.5 & 264 \\
\hline Icl/Isi-c & & 3 & 4 & & 4 & & 5 & & & & 1 & & & & & 1 & 810 & 828 & 11.8 & 70 \\
\hline Isi/Icl/Isi-c & 1 & 2 & 5 & & 7 & & 6 & 1 & & & & & & & & & 876 & 898 & 5.3 & 169 \\
\hline lei & & 3 & 1 & & 8 & & 11 & & & 1 & & & & & 1 & & 844 & 869 & 10.0 & 87 \\
\hline Isi/Icl & 1 & 24 & 7 & 1 & 17 & 2 & 32 & 1 & 6 & & 2 & 1 & & 2 & & 1 & 2,528 & 2,625 & 22.9 & 115 \\
\hline Igl/Isi/Icl & 1 & 1 & & & 1 & & & & & & & & & & & & 39 & 42 & 1.0 & 42 \\
\hline Isi & & 4 & 6 & & 13 & & 7 & & & & 2 & & 1 & 1 & & & 953 & 987 & 24.6 & 40 \\
\hline lgl/Isi & & 2 & 1 & & 8 & & 6 & 1 & & & & & & 1 & 1 & 1 & 385 & 406 & 7.7 & 53 \\
\hline Igl & & 4 & & & 3 & & 1 & & & & & & & & & & 52 & 60 & 8.7 & 7 \\
\hline Undifferentiated & & & 1 & & & & & 1 & & & & & & & & & & 2 & & \\
\hline Totals: & 4 & 51 & 26 & 1 & 74 & 2 & 76 & 4 & 6 & 1 & 5 & 1 & 1 & 4 & 2 & 3 & 8,438 & 8,699 & 99.5 & 87 \\
\hline
\end{tabular}


table are the densities of stone artifacts per cubic meter for each of the stratigraphic units. Artifact numbers and densities generally increased upward through the deposits with one noticeable exception, Unit Isi/lcl, which had a larger number and greater density of materials comprising the Bone Bed component. These same data are arrayed in Table 7-2 according to the components to which they are assigned.

Bone provenienced to Early Paleoindian context is mostly fragmentary (see Chapters 33 and 35, Appendixes 8, 9, and 10). Large bone and bone fragments were piece-plotted and smaller specimens were recovered by screening. Much of the TxDOT sample was collected using 1/4-inch screens whereas the TARL sample from general excavation was collected on 1/8-inch screens. In addition, finer-screen samples were processed as a column from TARL Square 20. The analyzed Early Paleoindian fauna! sample sizes are summarized in Table 7-3. These faunal data are the basis for both subsistence and paleoenvironmental interpretations, but by their nature, they do not accurately reflect the three-dimensional distribution of bone in the excavation.

\section{COMPONENT DEFINITION}

No unambiguously diagnostic Early Paleoindian artifacts were recovered from Wilson-Leonard, yet in aggregate, the context, dating, lithic technological, and very limited typological evidence suggest an earlier Clovis component, an intermediate "Bone Bed" component, and a later grouping of artifacts that may constitute another component, but no component designation has been assigned to this youngest manifestation in the present effort. The criteria for recognizing these three groupings (hereafter referred to as the Clovis, Bone Bed, and unassigned components) are presented next, followed by a discussion of each.

It is clear from chronostratigraphic evidence that all of the Early Paleoindian materials at Wilson-Leonard fall within the interval between ca. 12,000 and 10,600 radiocarbon years ago. It is central to the interpretations below that this dating brackets the time intervals established for Clovis, Folsom, Goshen, and possibly Plainview assemblages at various other sites in the United States (Frison et al. 1996; Haynes 1993). More specifically, after careful review of the reliability of available dates, Haynes (1993:220, Table 1, Figure 1) suggests the following age ranges for the Clovis and Folsom complexes:
Folsom
ca. 10,260-10,930radiocarbon years B.P.
Clovis ca. 10,690 - 11,650 radiocarbon years B.P.

Haynes (1993) and Frison et al. (1996) also discuss the dating of unfluted Early Paleoindian projectile points, namely Plainview, Midland, and Goshen, raising the issue of possible synonymy or, alternatively, greater cultural complexity within the 12,000 to 10,000 B.P. interval. The projectile point from the bone bed at Wilson-Leonard is dated to ca. 11,000 B.P., and since it was excavated in 1983 it has been provisionally classified by various individuals at various times as Plainview, Midland, and even Goshen. In light of these particular typological propositions and the recently established dating of similar points at the Mill Iron site at ca. 10,800 B.P., it is clear that the Bone Bed component at Wilson-Leonard is relevant to the issues raised by these early, unfluted points.

TABLE 7-2

Early Paleoindian Cultural Materials by Cultural Component

\begin{tabular}{|c|c|c|c|c|c|c|c|c|c|c|c|c|c|c|c|c|c|c|}
\hline Component & 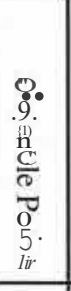 & $\begin{array}{l}\text { t1 } \\
\text { i) } \\
\text { i }\end{array}$ & 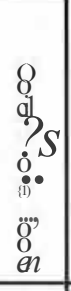 & 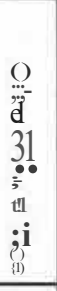 & 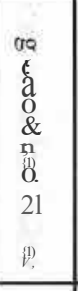 & 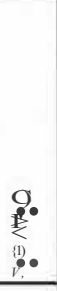 & 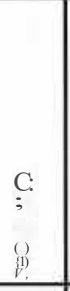 & $\begin{array}{r}8 \\
8 \\
0 \\
-5\end{array}$ & 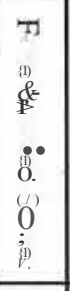 & $\begin{array}{l}\text { tII } \\
\text { i. } \\
\text { oil } \\
1\end{array}$ & 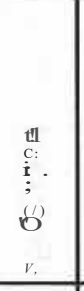 & $\begin{array}{l}p \\
\dot{b} \\
\end{array}$ & 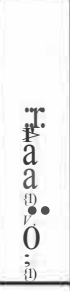 & $\begin{array}{l}(1) \\
\S \\
\delta . \\
0 \\
0 \\
(i) \\
\end{array}$ & $\begin{array}{l}\text { ir. } \\
\text { aid } \\
\text { a } \\
\dot{b}\end{array}$ & 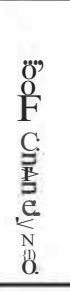 & $\begin{array}{l}\text { t:I } \\
\text { !y } \\
\text { ! } \\
\text { ii }\end{array}$ & $\begin{array}{l}\dddot{0} \\
\$ .\end{array}$ \\
\hline Clovis & 1 & 7 & 3 & & 16 & & 8 & 2 & & & 1 & & & & & & 658 & 698 \\
\hline Bone Bed & 1 & 26 & 14 & I & 23 & 2 & 33 & 1 & 5 & & 2 & 1 & & 4 & 1 & 1 & 3,258 & 3,373 \\
\hline Unassigned & 2 & 18 & 9 & & 35 & & 35 & 1 & 1 & 1 & 2 & & & & 1 & 1 & 4,522 & 4,628 \\
\hline Totals: & 4 & 51 & 26 & I & 74 & 2 & 76 & 4 & 6 & & 5 & & 1 & 4 & 2 & 3 & 8,438 & 8,699 \\
\hline
\end{tabular}

TABLE 7-3

Summary of Fauna! Data from Early Paleoindian Stratigraphic Units

\begin{tabular}{l|c|c|c|c|c|c|c|c|c|c}
\hline Sample & lgl & Igl/lsi & lsi & lgl/Isi/Icl & lei & Isi/lcl & Isi/lcl/lsi-c & Icl/lsi-c & Isi/lsi-c & Totals \\
\hline 1/4-inch screen & 12 & 1,115 & 566 & 9 & 257 & 1,860 & 203 & 373 & 153 & 4,548 \\
1/8-inch screen & 35 & 101 & 441 & 169 & 269 & 858 & 168 & 528 & 1,366 & 3,935 \\
Fine screen & 180 & & & 246 & 1,154 & 304 & & 168 & & 2,052 \\
\hline Totals: & 227 & 1,216 & 1,007 & 424 & 1,680 & 3,022 & 371 & 1,069 & 1,519 & 10,535 \\
\hline \hline
\end{tabular}


In addition to age, context, and typology, lithic technology is a sensitive indicator of cultural affiliation in the Early Paleoindian period (Bradley 1993; Collins 1996; Frison 1991; Stanford 1991). Early in the analysis of the Early Paleoindian materials from Wilson-Leonard, two technologically distinctive groups of chipped stone were recognized (Collins, Bousman, Goldberg et al. 1993; Collins et al. 1994). The first of these is the earliest cultural component at the site, was found primarily near the contact oflgl and lsi (Figures 7-3 and 7-4), and consists of a projectile point tip, bifaces, and indications of prismatic blade-core reduction. Technologically, these materials conform closely to Clovis $!<$ napping patterns (Bradley 1993; Collins 1990a, I996). The second group ofmaterials, found primarily in Unitlsi (see Figures 73 and 7-4), includes the Bone Bed point, fragments of extremely thin bifaces, other bifaces, and a preform. Technologically the bifaces closely resemble those found elsewhere in Folsom components, especially the "ultra-thin" bifaces as described for the Bobtail Wolf site (Root 1993, 1995; Root and Emerson 1994; Root et al. n.d.) and some of the smaller bi faces from the Hanson site (Frison and Bradley 1980). Also, a preform from the Bone Bed component resembles those from which Folsom points were made. In light of a biface technology strongly Folsom in character and the similarity of the Bone Bed point to some Midland points, the Bone Bed component was provisionally attributed in 1994 to the Folsom (Midland) complex (Collins et al. 1994; Collins n.d.). More recently, with publication of the Mill Iron site report (Frison 1996) and the opportunity for a number of Paleoindian specialists to see the Wilson-Leonard Bone Bed assemblage at the time of the Folsom Workshop in Austin (March 1997; see Acknowledgements for listing of individuals), it became apparent that the thin bifacial work characteristic ofFolsom knappers was also done by the knappers who made Goshen points, and the earlier attribution to Folsom was probably premature.

A quantity of nondiagnostic lithic artifacts from the upper part of the Early Paleoindian deposits have no particularly distinguishing technological characteristics (see Figures 7-3 and 7-4). Although this is the most numerous part of the Early Paleoindian collections from the site, it cannot be assigned even tentatively to any previously established complex nor does it seem to represent a distinctive but not previously recognized complex. In fact, the two projectile points are a Wilson point (supposedly intrusive) and a fragment of a small, thick lanceolate point that does not conform to any established type.

Clovis chipped stone artifacts from the southern periphery of the Great Plains share technological attributes with Clovis materials found widely in North America, but they also have some distinctive regional qualities (Collins 1990a, 1990b, 1996, n.d.; Collins et al. 1989). Clovis !<nappers made bifaces and prismatic blades, each with characteristic technological attributes. It is remarkable how similar the technology of these artifacts is over much of the North Ameri- can continent, but there is also a good deal of regional variation. For example, blades are much more prevalent in the southeastern area of the continent than in the southwestern, northwestern, and Plains areas, and extraordinarily large bifaces are more common in the northwestern area than elsewhere. Along the southern Plains periphery, blades and blade cores are moderately abundant, that is, less so than in the southeast but more so than in the northern Plains, southwest, and northwest; also, use of Edwards chert prevails. In spite of regional differences such as these, Clovis chipped stone artifacts have much in common technologically. The presentation ofClovis and ofFolsom technological patterns that follows is derived from Collins (1996, n.d.) and is based on review of data from 62 Clovis and Folsom components.

\section{Clovis Lithic Technology}

Clovis chipped stone artifacts from the southern periphery of the Great Plains seem exclusively to be utilitarian in nature with nothing comparable to the few extraordinarily large and possibly nonutilitarian pieces seen among the caches at such sites as Fenn, East Wenatchee, and Simon (Frison 1991 ). The utilitarian nature of southern Plains Clovis assemblages is clear from contexts, use wear, and refurbishing.

Prismatic blades were struck from large prepared cores, probably both by indirect percussion and by direct percussion. Indirect percussion is apparently indicated by the form of some of the blade cores. These cores are large and conical with the plane of the platform at a right angle to the proximal blade. facets. Multiple blade facets form a convex face extending partially or completely around the core. Although the overall platform plane is approximately perpendicular to the proximal core face, it is formed by multiple, short, deep flake scars extending in from its perimeter. The negative bulb scar of each of these flakes produces an acute angle of approximately $70^{\circ}$ with the core face. When positioned directly behind a ridge on the core face, a negative flake scar would serve as the platform, the punch could be placed in that concavity for blade removal, and the ca. $70^{\circ}$ angle would be retained on the platforms of the blades. These small platform maintenance flakes commonly terminated in hinges with the cumulative effect of producing large central knots or hinge stacks on the platforms. Part of the evidence for the use of indirect percussion on these conical cores is that these central knots would interfere with the approach path of any direct percussion blow. However, except when the knot or hinge stack is excessive, these conical cores could as easily have been reduced using direct percussion. Some blade cores exhibit paired platform flake scars positioned to isolate an eminence on the platform directly behind a ridge on the core face; this configuration is suited to direct percussion. All such platforms were rejuvenated by removal of core tablet flakes. 

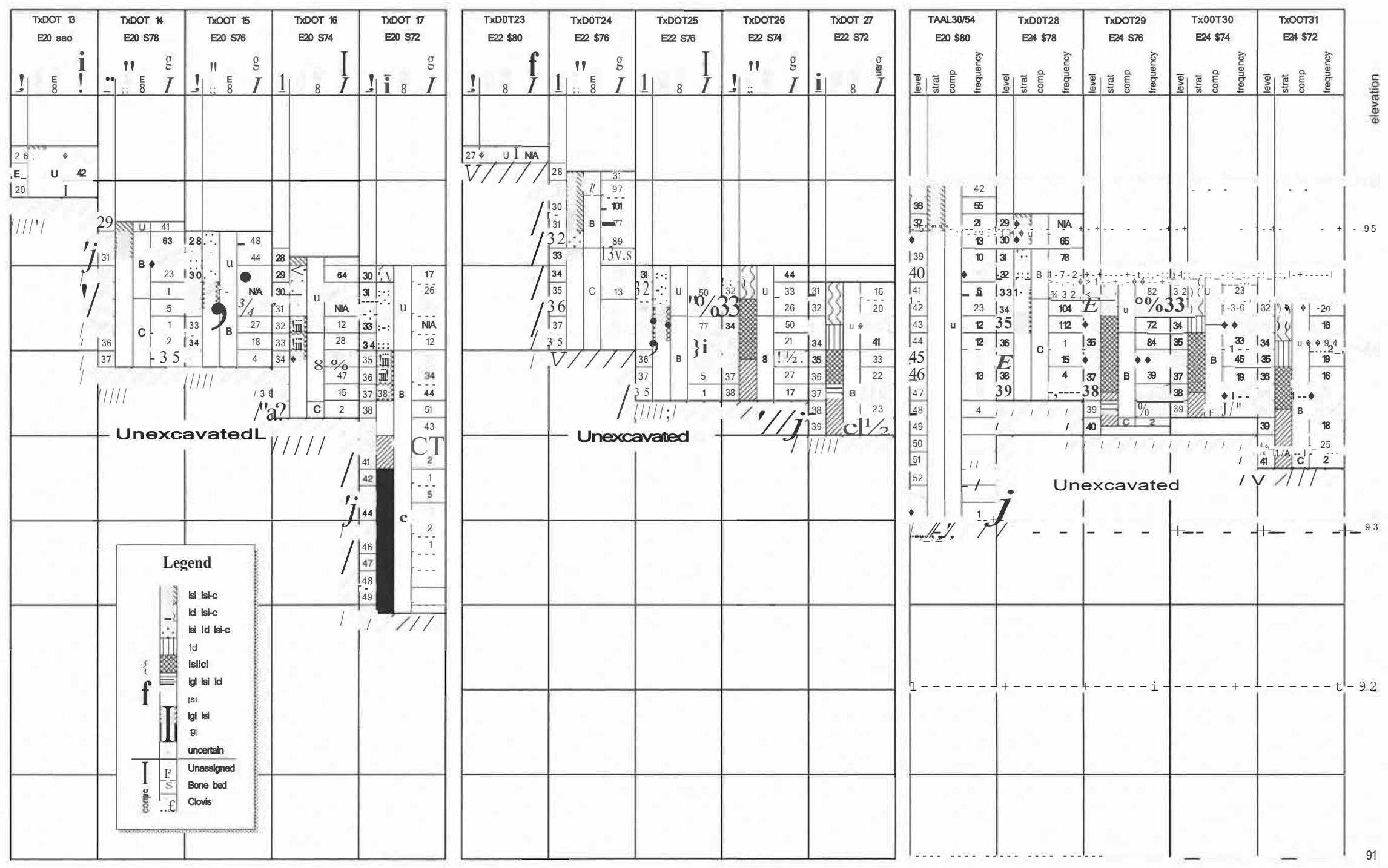

FIGURE 7-3. Early Paleoindian debitage frequencies by square, level, stratigraphic unit, and component.. 

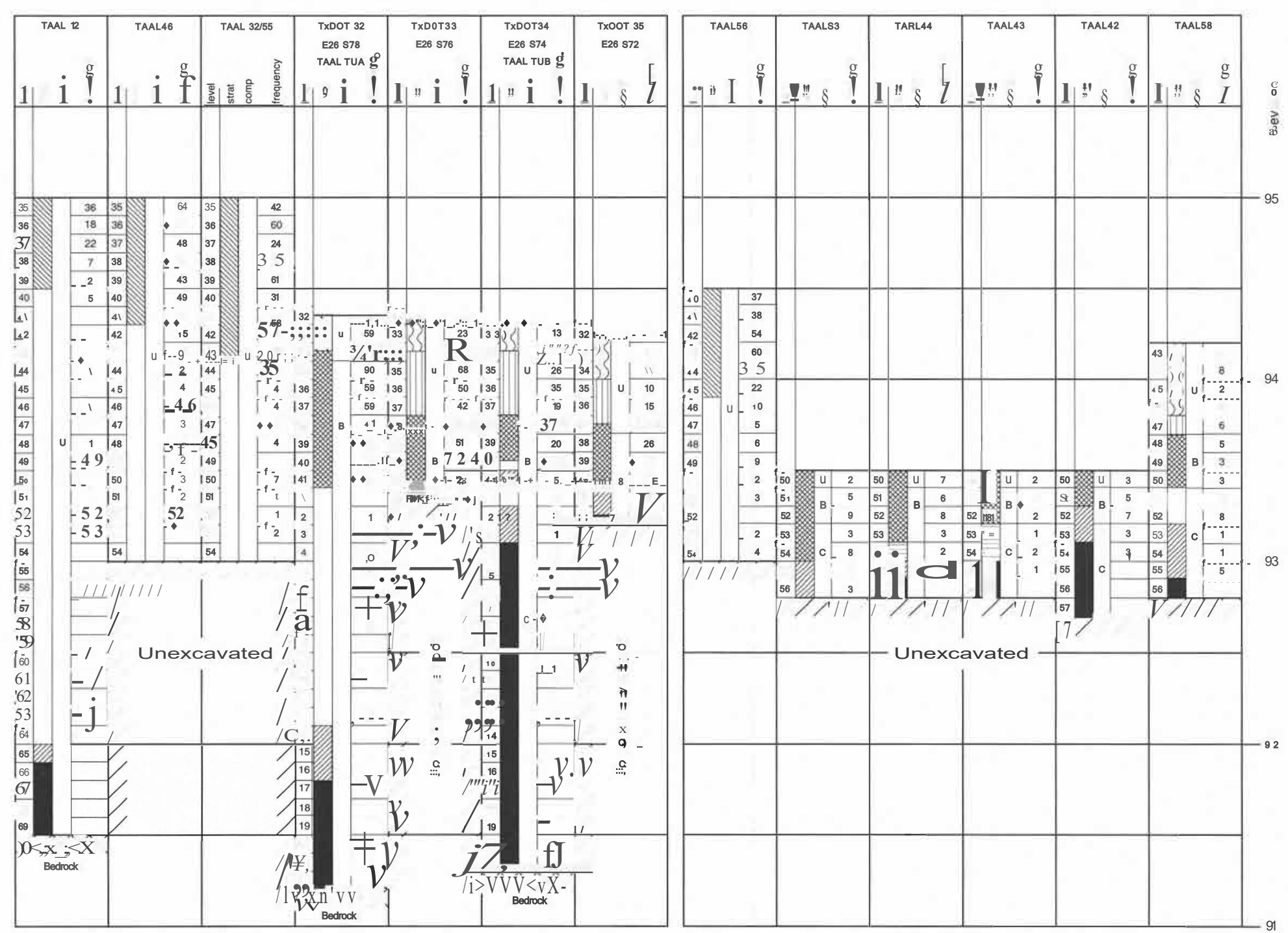

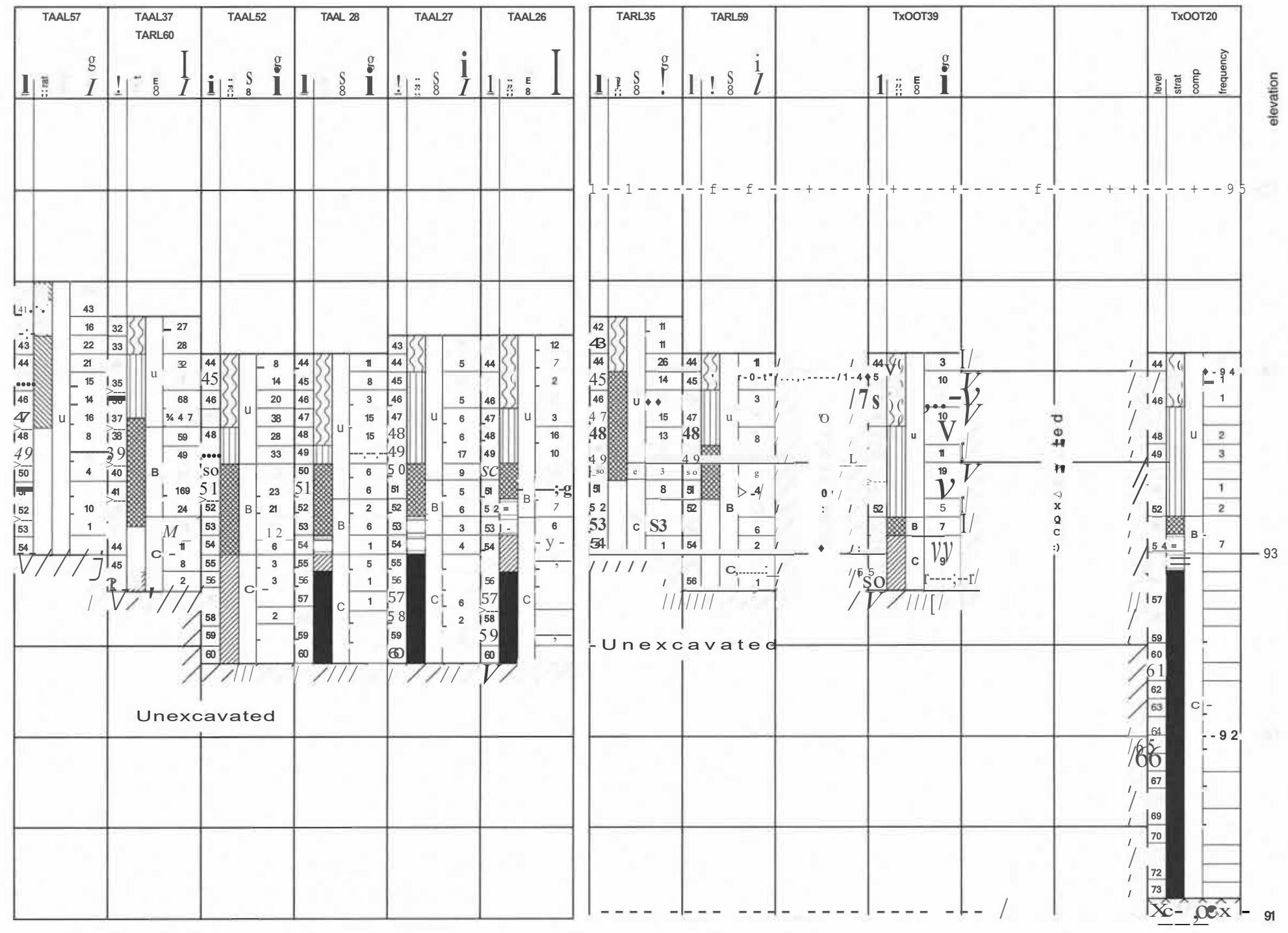

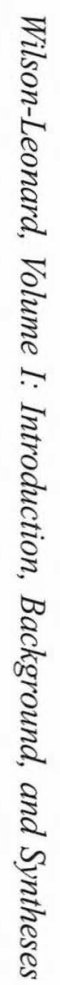



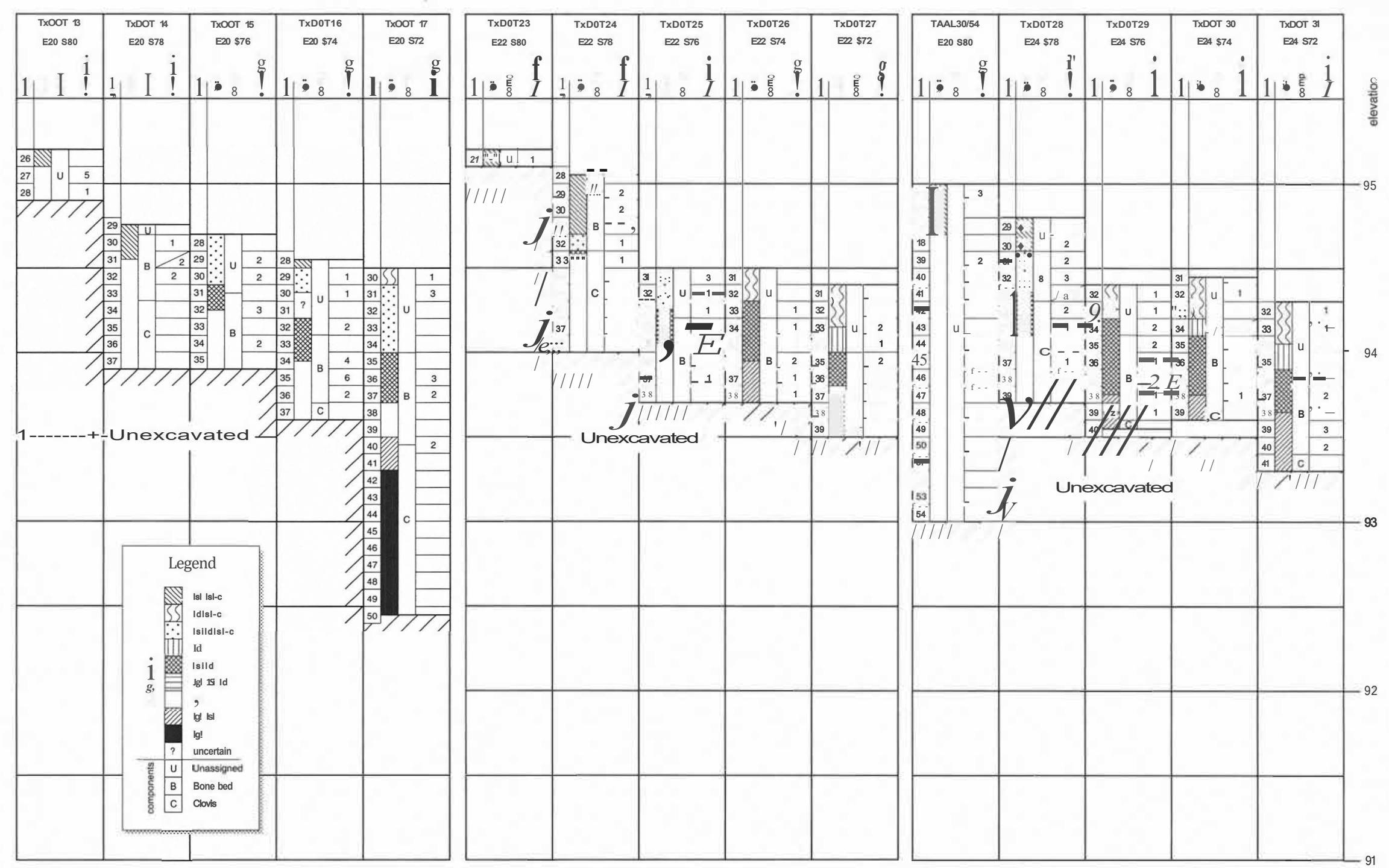


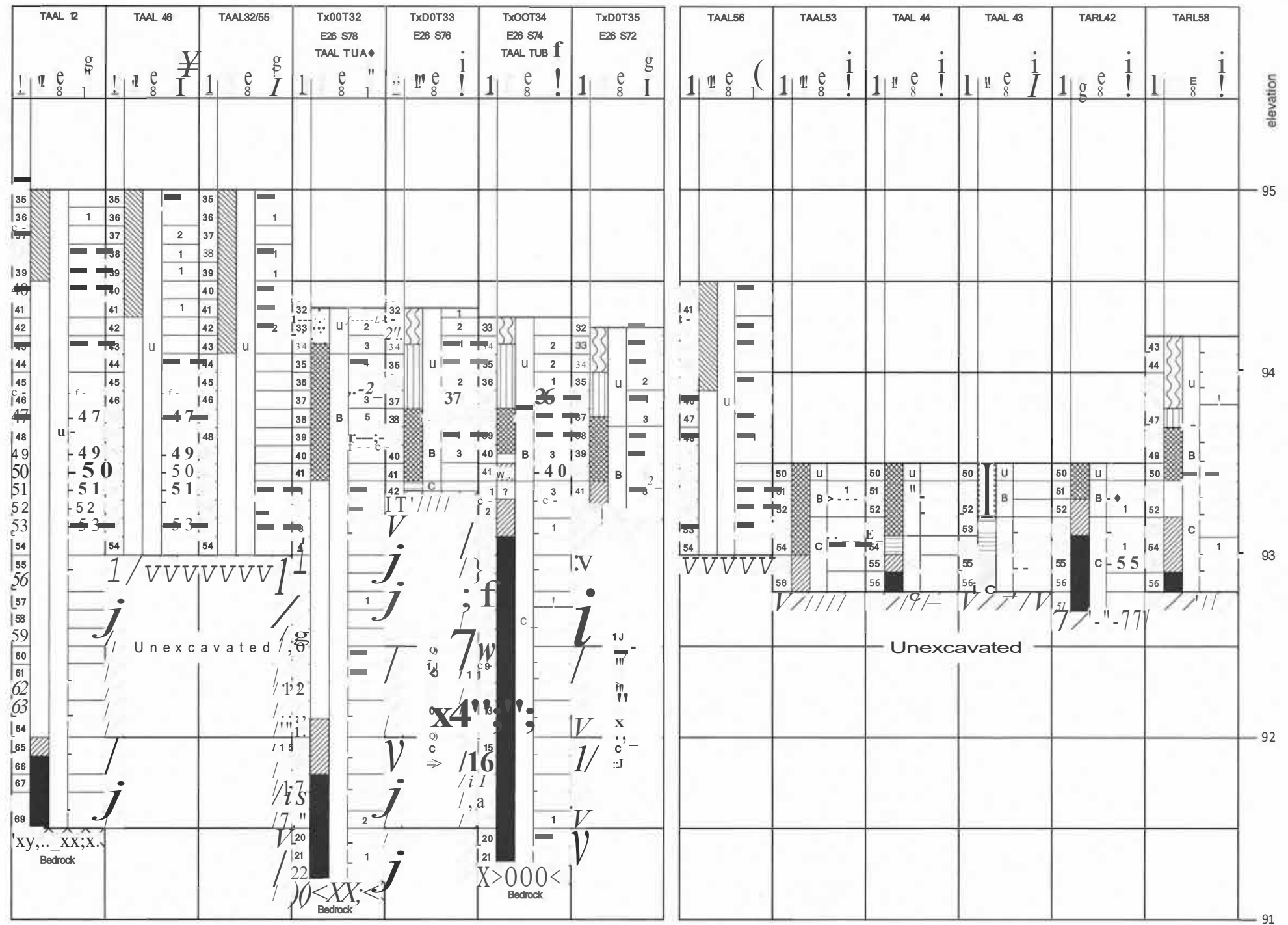




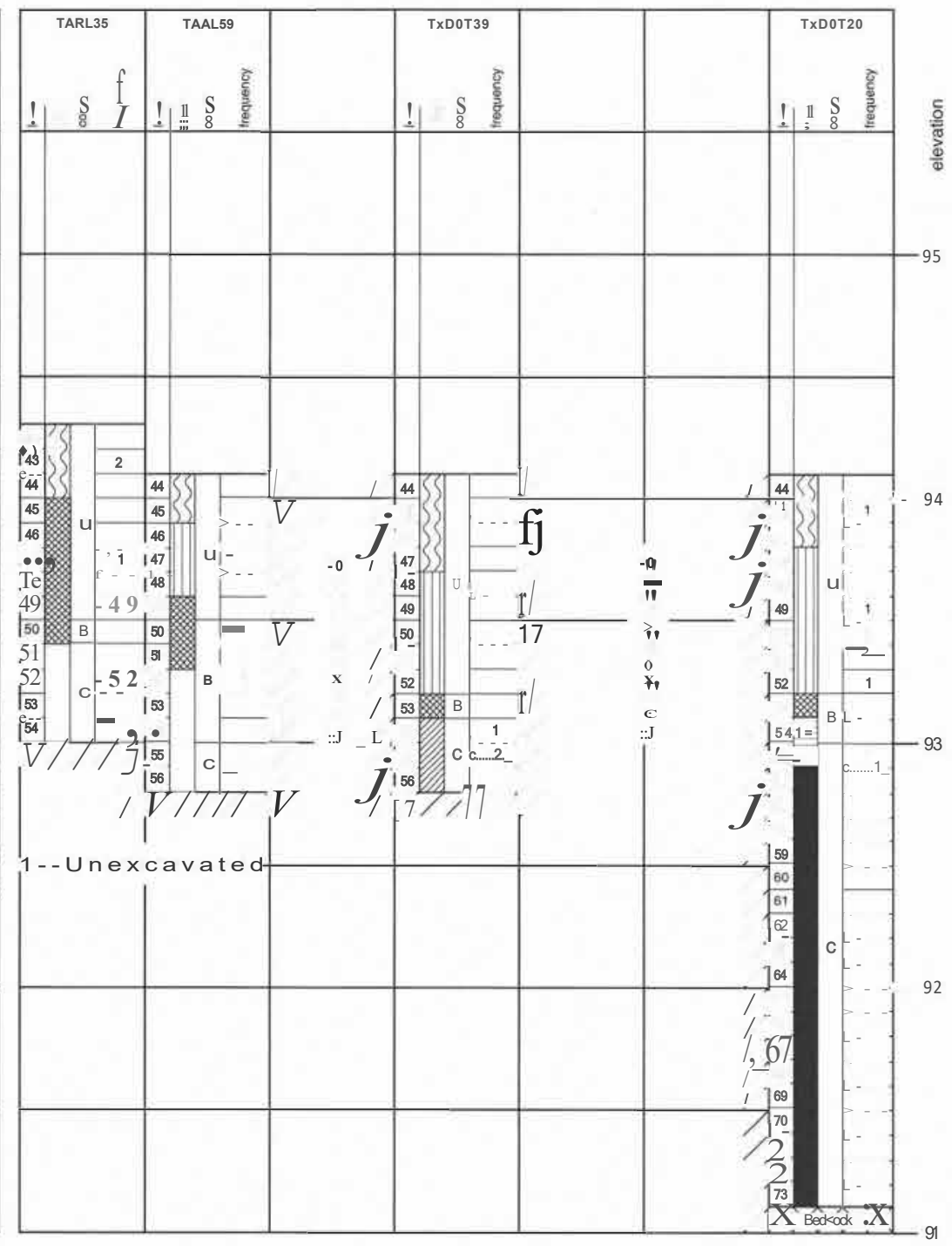


Less frequently encountered are blade cores that overall are wedge-shaped with blade scars restricted to a single face and with the platform set at an acute angle with that face. In these cases, direct percussion would be the likely means of blade detachment, and platform rejuvenation would consist of simple trimming of the platform without the need for core tablet removal.

Clovis blade cores were commonly initiated simply by preparing a platform on a piece of raw material with existing ridges rather than by flaking the first guiding ridge or crest. Even the initial platform was present or required minimal preparation in some forms ofraw materials.

Clovis blades are curved in longitudinal section, sometimes extremely so. In cross section, they range from prismatic to triangular, trapezoidal, and trapezium-like. Complete blades generally are longer than $100 \mathrm{~mm}$ but can be as short as $50 \mathrm{~mm}$, the apparent point at which blade cores were abandoned. They have smooth interior surfaces and minimal to nonexistent bulbs of percussion. Platforms are generally very small, and sometimes ground. Some ridges on blade exteriors as well as on core faces show minute crushing and oattering, apparently in part from curation or transport between episodes of blade removal. Although two kinds of blade cores are now known from Clovis sites, the blades detached cannot be reliably identified as having come from the conical or the wedge-shaped cores. This is because the core faces are similar and the detached parts of the platforms are similar on blades from both kinds of cores. Some blades have minute platforms whereas others have wider ones, making it tempting to suggest that the former were removed by indirect percussion from the conical cores, while the latter were detached with direct percussion from the wedgeshaped cores. This is speculative at present, and it can be demonstrated experimentally that there is no correlation between platform width and mode of detachment.

Some blades were used intact while others were snapped and the segments used without further modification. In some cases, blades or blade segments were retouched into end scrapers, burins, and other tool forms. There is no evidence that they were ever modified into points (in most cases for the obvious reasons that they are too narrow and too curved).

Clovis bifaces were made from large blade-like flakes or from cores. Virtually all bifaces seem to have been Clovis point preforms rather than finished bifacial implements on the southern Plains periphery (very large, thin bifaces and very large points seem to be known almost exclusively from sites in the northwestern part of the continent [e.g., Fenn, Anzick, East Wenatchee]). Direct, soft-hammer (including soft stone) percussion is indicated by all but final edge trimming. Early stage bifaces were fashioned with minimal platform preparation and removal of relatively few flakes. Platforms were prepared by roughly chipping a bevel along the biface edge without grinding. Broad flakes extending completely or nearly the width of the biface were removed; overshot flakes were frequently detached. Early in the shaping ofbifacial preforms, the Clovis-point outline (straight base, convergent tip, straight to slightly convex edges) was approximated and then maintained through the reduction. Flutelike removals from the base often occurred early in the reduction of bifacial preforms, but these were obliterated as the preform approached its final thinness. Then, the base was beveled with a few flake removals to serve as the first fluting platform. Subsequently, the opposite face was beveled to accommodate the second fluting. Flutes appear generally to have been produced by direct percussion. Final trimming, employing direct percussion as well as pressure flaking resulted in even edges and symmetrical outlines centered on the flutes. Some final flaking intrudes on the flute scars. Proximal and basal edges were ground as the final step.

Full-sized Clovis points, designed as weapon tips but also used as knives (Kay 1996), were resharpened, often repeatedly. Initial lengths were near or above $100 \mathrm{~mm}$. Unbroken but resharpened points near $50 \mathrm{~mm}$ in length were discarded at knapping localities close to raw material sources, evidently indicating what was considered the optimal uselife of such points. On the southern Llano Estacado, where suitable raw material was not available, heavily resharpened but unbroken Clovis points have been found as short as 40 $\mathrm{mm}$, apparently having been rejuvenated to their ultimate use-life. These short but full-width points are not to be confused with miniature Clovis points which are also known from several sites (Stanford 1991). The purpose of these miniatures is not known, and they are not considered further in this discussion.

Unfluted lanceolate points with ground lateral and basal edges are common at sites on the southern plains periphery. Many of these come from surface contexts and are commonly identified as belonging to the "Plainview" type, but most do not compare closely with those from the Plainview site in thinness and details of flaking. A significant minority of these unfluted lanceolate points lacking good context have all of the attributes of Clovis points, except the fluting. In this regard, they resemble certain unfluted or minimally fluted points from Clovis contexts, including the smaller point from Domebo (Leonhardy 1966) and the obsidian fragment from the Clovis component at Kincaid Shelter (Collins et al. 1989:Figure 1e; Hester et al. 1985:Figures 2 and 3). Perhaps there is an unfluted counterpart to the Clovis type somewhat like that seen in the Folsom and Midland points, although there is no apparent causal explanation in the presently limited data. This reference to comparatively thick unfluted lanceolate points does not include thin varieties discussed below in the discussion of the Bone Bed assemblage.

Large thin flakes, many of which were detached in the production ofbifaces, were utilized in an unmodified state or retouched for use, generally unifacially.

Clovis blades, bifaces, and flake tools were almost always made of high quality raw materials. Multiple sources 
are often represented at a single site. At Clovis workshops, the flaking debris is nearly always oflocal material, but discarded points of exotic stone may be present, suggestive of retooling. The Gault (Collins et al. 1991; Collins et al. 1992) and Kincaid (Collins 1990a, 1990b) sites are good examples, both with evidence that Clovis knapping transpired at abundant sources of high-quality Edwards chert. At Gault, a heavily resharpened and damaged Clovis point of Alibates chert, but no Alibates flaking debris, was found. At Kincaid, a basal fragment of an obsidian point, but no obsidian debitage, was found. The Alibates source area is $520 \mathrm{~km}$ from Gault, and the identified source of the obsidian (Queretaro, Mexico [Hester et al. 1985]) is $1,000 \mathrm{~km}$ from Kincaid.

These generalized Clovis technological traits are recognizable at Wilson Leonard in two provenience categories, those comprising the Clovis component, and a few additional specimens found higher up in the site (see below).

\section{Folsom Lithic Technology}

Folsom lithic technology is distinguished from that of Clovis in four significant ways: (1) blades were not being produced in Folsom; (2) many Folsom bifaces were made to be very thin with almost biplanar, rather than biconvex, cross sections; (3) fluting of Folsom points was a more involved process than was that of Clovis points; and (4) formal end scrapers are far more common in Folsom than in Clovis assemblages. Along with these four main differences, several other traits are noteworthy.

Folsom bifaces are of at least two forms. One form is small and thin, but not extremely thin. These are reported from Blackwater Draw, Hanson, and Agate Basin. Some of these are probably point preforms that were not thinned sufficiently, but some are evidently knives. Large and very thin ("ultrathin") bifaces constitute a second form that is characteristic of Folsom lithic technology. The larger of these are not commonly found because, like points and end scrapers (see below), their use resulted in continued reduction. Width-to-thickness ratios of between 7: 1 and 11: 1 are typical, reaching >13: 1 in some cases (Root and Emerson 1994:Table 41; Root et al. n.d.). This degree of thinning can only be achieved by removal of very straight thinning flakes that produce nearly flat faces on the biface. Thin bifaces were used as cutting tools (Root et al. n.d.), and the flakes from their manufacture and refurbishing were used as the blanks for scrapers (e.g., at Shifting Sands, Hanson, Agate Basin, and Blackwater Draw) and possibly for points (Hofman 1989). Large flake unifaces from the Shifting Sands site (Amick et al. 1989; Hofman et al. 1990) provide a graphic example of this practice. It is of particular interest that the Shifting Sands collection contains no large bifaces, only the flakes from such pieces; the four large retouched bifacial thinning flakes illustrated by Amick and Rose (1990:Figure 7; Hofman eta!. 1990:Figure 3a, d, t) closely match in size and proportions the scars on the extremely large thin biface ("Frank's Biface") inferred by Stanford and Broilo (1981) to be of Folsom affinity. Fragments of large ultrathin bifaces are not uncommon in Folsom knapping contexts at chert source areas (for example, sites such as Pavo Real [Collins n.d.]). The evidence seems to support the proposal (Boldurian et al. 1987; Hofman 1989; Stanford and Broilo 1981) that very large thin bifaces were carried by Folsom groups to be used as knives as well as cores. Flakes from these bifaces were suitable pieces of raw material for virtually the entire repertory of Folsom tools. These bifaces were sometimes steeply retouched unifacially, often broken intentionally to produce radial break tools, and occasionally otherwise broken pieces were used in the same manner.

Folsom points, like their Clovis counterparts, show significant variation and much attrition from use-damage and from refurbishing. A great deal has been written on the manufacture of Folsom points-especially their fluting-as inferred from experimental analogy and as reconstructed from prehistoric knapping debris (e.g., Akerman and Fagan 1986; Boldurian 1990; Bradley 1993; Crabtree 1966; Flenniken 1978; Frison and Bradley 1982; Gryba 1988; Root 1993, 1995; Root et al. 1995; Root and Emerson 1994; Sollberger 1977; Tunnell 1975, 1977; Wilmsen and Roberts 1978).

For whatever its purpose, the fluting of Folsom points was evidently an important objective that knappers considered worth the costs of tedious preform preparation, specialized procedures, and possibly equipment for channel flake removal, frequent failure, and increased fragility of the resulting points. It also seems likely that not every would-be knapper could master the techniques. The literature is replete with examples of fluting failures and with examples of the lengths knappers would go to get two flutes off of their preforms (fluting the obverse and reverse sides from opposite directions, for example). Replication experiments as well as the evidence from close examination of archeological knapping debris has been inferred (but not universally [Gryba 1988]) to indicate that preforms were supported in some form of holding device and possibly that either indirect percussion or some kind of mechanical advantage (leverage or crutch, perhaps) was employed to detach channel flakes, although the particulars of any such devices remain unknown (e.g., Akerman and Fagan 1986; Crabtree I966; Flenniken 1978; Frison and Bradley 1980, 1982; Sollberger 1977). Considerable skill, versatility, and adaptability are apparent in the fluting ofFolsom points. I suspect that, as in skinning a catfish, there was more than one way to flute a Folsom (c.f. Crabtree 1966). Besides, as Titmus and Woods (1991:125) note, since "it has now been demonstrated that channel flakes of all configurations can be removed using percussion, indirect percussion, or pressure flaking ... we feel that it is no longer as important to focus on the technique of fluting, as it is the rationale."

Folsom preforms were produced in at least two ways, from small bifaces and from flakes, but were all readied for 
fluting by pressure flaking. The particulars of Folsom point preforms from numerous sites have been thoroughly discussed in the literature.

Archeologists have probably overemphasized fluting failures to some degree. Virtually every irretrievable failure is likely to remain at the site where it occurred, whereas it is likely that virtually every successfully completed point was taken afield and used. Experimental data are more complete, but these are not produced by knappers enculturated from childhood in the art of making Folsom points.

Finished Folsom points and Midland points are both present on and near the southern plains, and the relationship(s) between them is no more clear here than elsewhere (Agogino 1969; Hofman 1989; Judge 1970). Midland points occur in Central Texas near abundant outcrops of Edwards chert, including a large (unresharpened?) Midland point recovered from the Crockett Gardens site (McCormick 1982).

Like Clovis points, Folsom points were frequently retipped; they were also rebased, a technique that I have not yet observed unequivocally on the Wilson-Leonard sample of Clovis points, although it has been reported elsewhere (e.g., Ready/Lincoln Hills site). An obvious factor here may be that on most Clovis points, loss of the base would mean loss of most if not all of the flute whereas with Folsoms, the distal portion of the relatively longer flute would still be present. Rebasing of a Clovis point fragment distal to the flute would require refluting, which has been noted among the specimens from the Ready/Lincoln Hills site in Illinois (Morrow 1995:171,Figure3).

The typical length of complete, pristine Folsom points must have been in the vicinity of 75 to $80 \mathrm{~mm}$ to judge from preforms (some in excess of $90 \mathrm{~mm}$ [e.g., Frison and Bradley 1980:Figure 35; Wilmsen and Roberts 1978:Figure IOOdD and the longer finished specimens (Johnson 1987 :Table 9. I; Suhm et al. 1954:Plate 92M). Resharpened points as short as ca. 25 $\mathrm{mm}$ are not uncommon, indicating that the useful sizes of Folsom points fell between approximately 75 and $25 \mathrm{~mm}$ (compared to a range of ca. 100 to $45 \mathrm{~mm}$ for Clovis).

End scrapers with a fairly consistent set of attributes are relatively common in Folsom assemblages. Typically, recovered end scrapers are small, have convex bits, convergent stem-like bases, and flat ventral faces. These are made on flakes rather than blades, although trimming the lateral edges symmetrically and subparallel to dorsal ridges on the flake blanks produces scrapers that may superficially appear to have been made on blade segments.

Enough similarity exists between these generalized Folsom lithic traits and the stone artifacts comprising the bone bed asemblage at Wilson-Leonard to almost sustain attribution of that assemblage to the Folsom complex. However, as discussed below, there is also some conflicting evidence, and in the absence of more diagnostic specimens, the present interpretation is to not assign this assemblage to any given complex but to discuss its affinities to Folsom and to Plainview/Goshen.

\section{CLOVIS COMPONENT}

Thirty-seven chipped stone artifacts, a hammerstone, 2 cobbles, and 658 pieces of debitage (see Table 7-2) are here inferred to have been in, or very nearly in, primary context and to represent a Clovis component at the base of the Wilson-Leonard stratigraphic sequence (see Figures 7-3 and 74). In addition, there were 5 specimens found in the overlying Bone Bed component that manifest Clovis technological attributes and likely represent pieces displaced from this Clovis component. Finally, from much higher in the site, there were 2 out of place pieces possibly from upslope in this site or introduced by humans into this site from elsewhere, a patinated base of a Clovis point (mixed Late Paleoindian/ Early Archaic context) and a Clovis blade (from Late Paleoindian context). All of these are discussed in this section.

Materials here considered to be ofClovis affiliation were concentrated primarily in the upper part of Unit Igl and in Unit Igl/Isi, with lesser numbers recovered from Unit lsi and Unit lgl/lsi/Icl (see Figures 7-3 and 7-4). It is unclear whether this sparse assemblage was in primary context or redeposited from upslope either on the valley wall or on the crest of the large gravel bar to the north. The greatest density of flakes per cubic meter per excavation unit occurred along the northern edge ofTxDOT Block 6, perhaps an indication that activity was concentrated higher on the gravel ridge north of the excavated area. If this material was transported there by moving water, the distance was very short, because the edges of almost all of the chipped stone pieces are close to pristine. The small amount of debitage and the mostly small sizes of that debitage are not indicative of this as a significant knapping area. The debitage that is present likely derived more from tool maintenance activities, although there is one early stage bi facial preform (Figure 7-5b) that shows no evidence of having been completed or used. The tool assemblage is dominated by flake tools $(n=24)$ and fragmentary bifaces $(n=7)$.

The more distinctive items in this assemblage are a large flake taken from a blade core and a distal projectile point fragment. The distal projectile point fragment (Figure 7-5a) is typical of Clovis points in this region in its size, outline, cross section, and flake scar pattern; however, it lacks the distinguishing basal portion, being too distal to retain either flutes or edge grinding. This point was found in the top $2 \mathrm{~cm}$ of Unit Igl gravel. Given the age of this deposit (slightly greater than 11,500 B.P.) and the form of the point, there is little in the present paradigm to suggest that it can be other than a fragment of a Clovis point.

The large flake was detached from the face of a blade core and has a disproportionately large, multifaceted platform (part of the core platform). This flake evidently ruined the core face when the knapper inadvertently removed too much platform while trying to flake past multiple hinge scars at the juncture of the core face and platform (Figure 7-5f). 


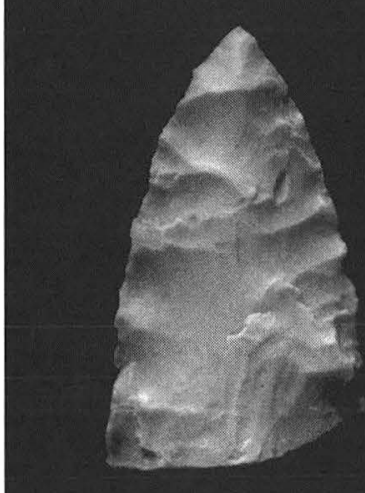

a
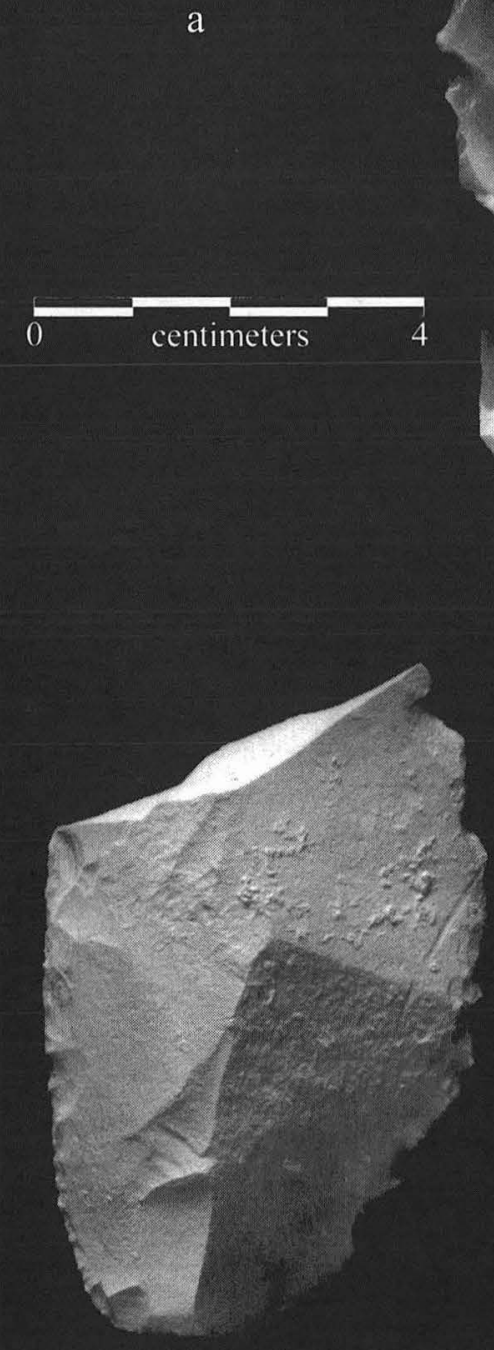

d
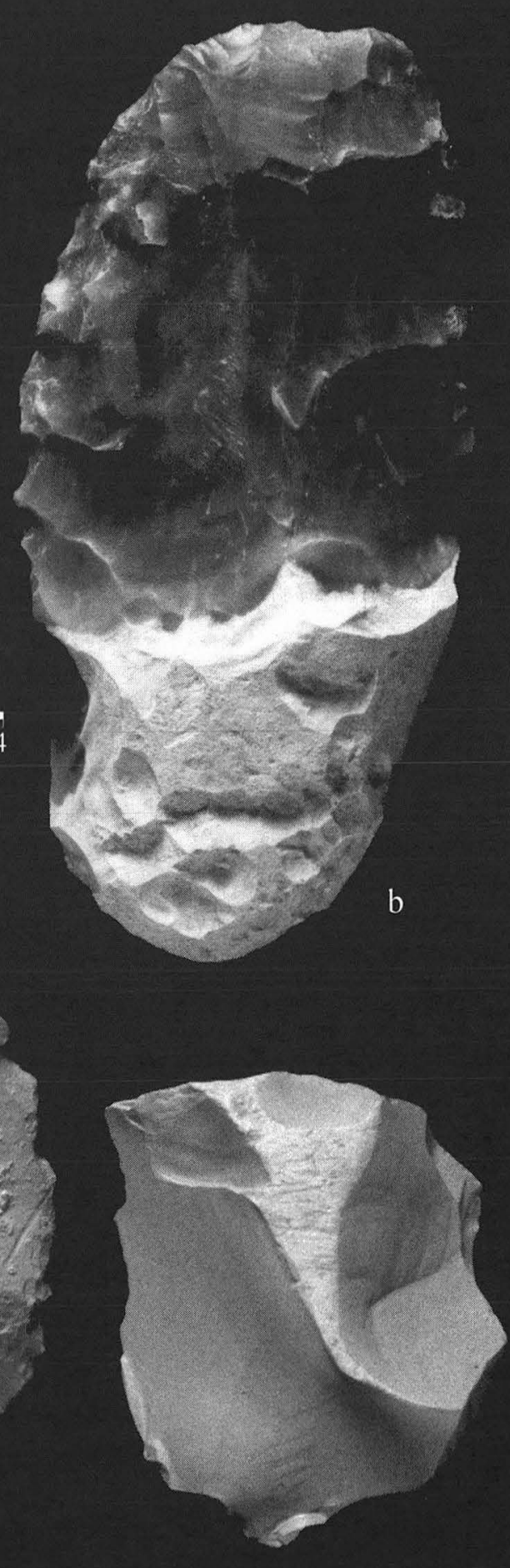

e
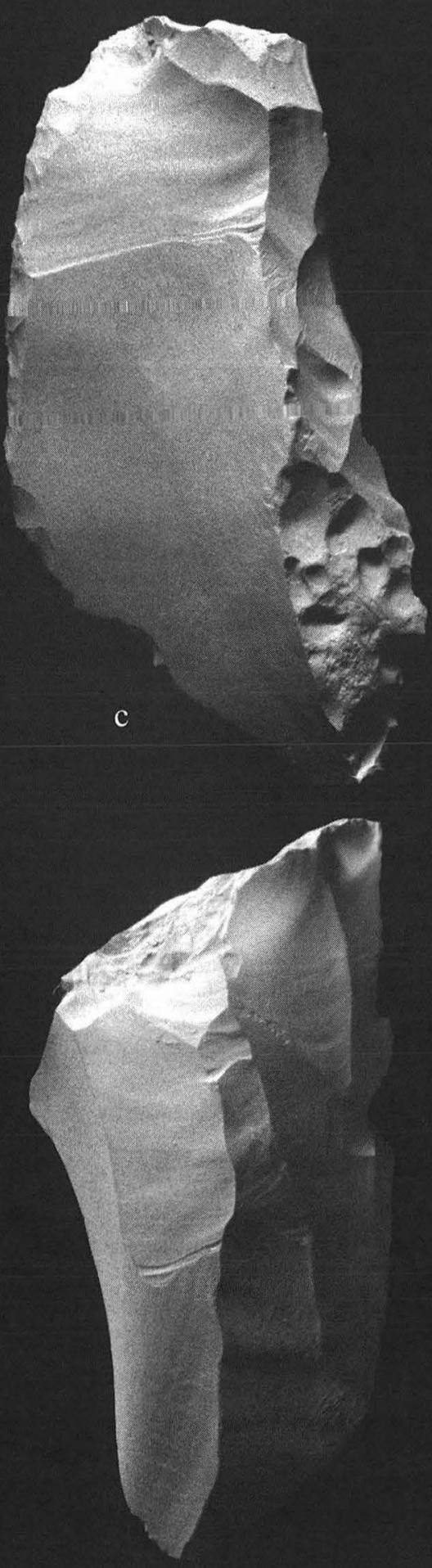

f

FIGURE 7-5. Clovis component artifacts. (a) projectile point tip (OR734) with Clovis attributes; (b) early stage biface (OR750); (c) thin uniface (37QQ1A-1); (d) thin uniface of nonlocal chert (28IllB-1); (e) core fragment (28LLJA-1); (f) flake removed from blade core (50KK.1/2A-1). 
One of the thin unifaces (Figure 7-Sd) is made of an unidentified, gray-and-black banded, coarse, non-Edwards chert. Otherwise, all of the specimens are made on locally available Edwards chert, mostly of the finer-grained varieties. Several specimens manifest a yellowish staining probably related to the iron in the ground water (see Chapter 6). In general the unifacial tools and edge-modified flakes are thin and would qualify as cutting tools. One of these, 31 MM2B-4, was examined by Driskell (see Chapter 22) and found only to have X-polish present.

Feature 188, a chert core and a limestone hammer (Figure 7-6) with nearby bison(?) bone splinters but no refitting flakes, is attributed to this component. It is interpreted to have been a place where bones were broken open.

Overall, there is not a strong signal of any one activity or set of activities among the materials making up this component, there being hints of knapping, chipped stone tool maintenance, and the breaking open of bones. The single projectile point tip is not sufficient as a basis for inferring component function. Only two specimens from this component were examined for use-wear, a thin uniface (Figure 7-Sc) and the blade-core flake (Figure 7-St). Both of these exhibited the dull polish thought to result from soil movement (X-polish; see Chapter 22). The blade-core flake also has a minor area of systematic microflaking next to slightly rounded edges, but there is no unambiguous evidence of use-wear.

There are also the base of a Clovis point (Figure 7-7b), two prismatic blades (Figures 7-7c and 7-8b), a broken preform (Figure 7-9a), and three other possible blade-core pieces (Figure 7-9b-d) from other contexts that increase the sample of Clovis materials from this locality. Most of these additional specimens also suggest that knapping was conducted by Clovis occupants of the site. The preform consists of the base and midsection and terminates in a perverse fracture. In outline, it is nearly parallel sided and has a slightly concave base. It is strongly biconvex in cross section. The faces show broad flake scars that carry past the midline which is characteristic ofClovis knapping (Bradley 1993; Collins 1996; Frison 1991). Blade production is indicated by an endscraper on a blade (see Figure 7-8b) and a blade (see Figure 7-7c) as well as a chert cobble with a single blade scar and two flakes detached from blade cores (Figure 7-9c-d). The chert cobble has a blade scar that failed to carry to the end of the core, possibly discouraging the knapper from any further attempts on this piece. One of the flakes (see Figure 7-9d) appears to be a failed attempt to remove a core tablet. It retains a portion of the perimeter of the core face, and its exterior is a large negative scar that was the core platform, but the present piece is wedge-shaped in section and would have left the core from which it was detached with an unusable obtuse angle between the core face and the scar left by this detachment (the intended core platform). The other flake (Figure 7-9b) is large and consists of a portion of the face of a blade core with remnants of three blade scars. The distal end and one edge of this flake retain cortex and the opposite edge and the proximal end have been steeply retouched to produce a side scraper. There is another uniface from Wilson-Leonard (Figure 7-8a) that appears to have been made on a blade, but this piece is unlike anything seen in Clovis components along the southern Plains periphery, and it is discussed below as part of the Bone Bed assemblage.

Recovered from a stratigraphic context dating to the transition from latest Paleoindian to earliest Archaic is the deeply patinated basal portion of a fluted Clovis point (see Figure 7-7b). This piece has slightly recurvate edges and a concave base, all heavily ground. It has a single, broad flute on one face and a flute composed of two narrower scars on the opposite face.

This aggregate evidence makes Wilson-Leonard fairly typical of Clovis sites as presently known along the southern Plains periphery (Collins 1995;Ferring 1989, 1990, 1994). It is situated adjacent to a stream near the base of the late Quaternary fluvial section, manifests a generalized set of activities, and consists of tools and debitage of both bifacial and prismatic blade technology.

The age of the intact Clovis component is inferred by Stafford (see Chapter 25) to be greater than 11,400 radiocarbon years B.P. for those materials in lower Unit Isi and greater than 11,500 radiocarbon years B.P. for those pieces in upper Unit lg!. These age estimates are at the extreme early end of the range of most dates for Clovis and are earlier by 200 to 300 years than the early end of the range proposed by Haynes $(1992,1993)$ in his critical review of all available Clovis radiocarbon dates.

All of the foregoing rests on assumptions that very little time is represented by the natural deposits and their cultural content between bedrock and the lowest well-dated deposit, Unit lei. In other words, the context is interpreted as having been one of rapid deposition, the archeological materials are assumed to have been found in primary context or very nearly so, and the age of all of this lowest cultural manifestation is, therefore, likely to date within a century or so of 11,500 radiocarbon years B.P. Since even the terminal date for this earliest component is pushing the early end of the Clovis interval, failure of either or both of these assumptions implies an earlier date for all or some of these artifacts, and possibly one that could be unacceptably old for Clovis. For all of the archeological materials currently assigned to the Clovis component to have been deposited less than 11,600 radiocarbon years ago, including those specimens from the upper gravels of TARL Squares 42, 26, 27, 28, Test Unit A, Test Unit B, and TxDOT Squares E20/S72, E22/S72, E24/S72, E20/S74, E20/S78, E22/ S78, E24/S78, and E26/S78, the average rate of deposition would have to exceed $1 \mathrm{~cm} /$ year, which is rapid but not unreasonable. And, since this is a fluvial setting, it is possible that all or some artifacts were washed in from somewhere upstream or upslope (although their condition indi- 


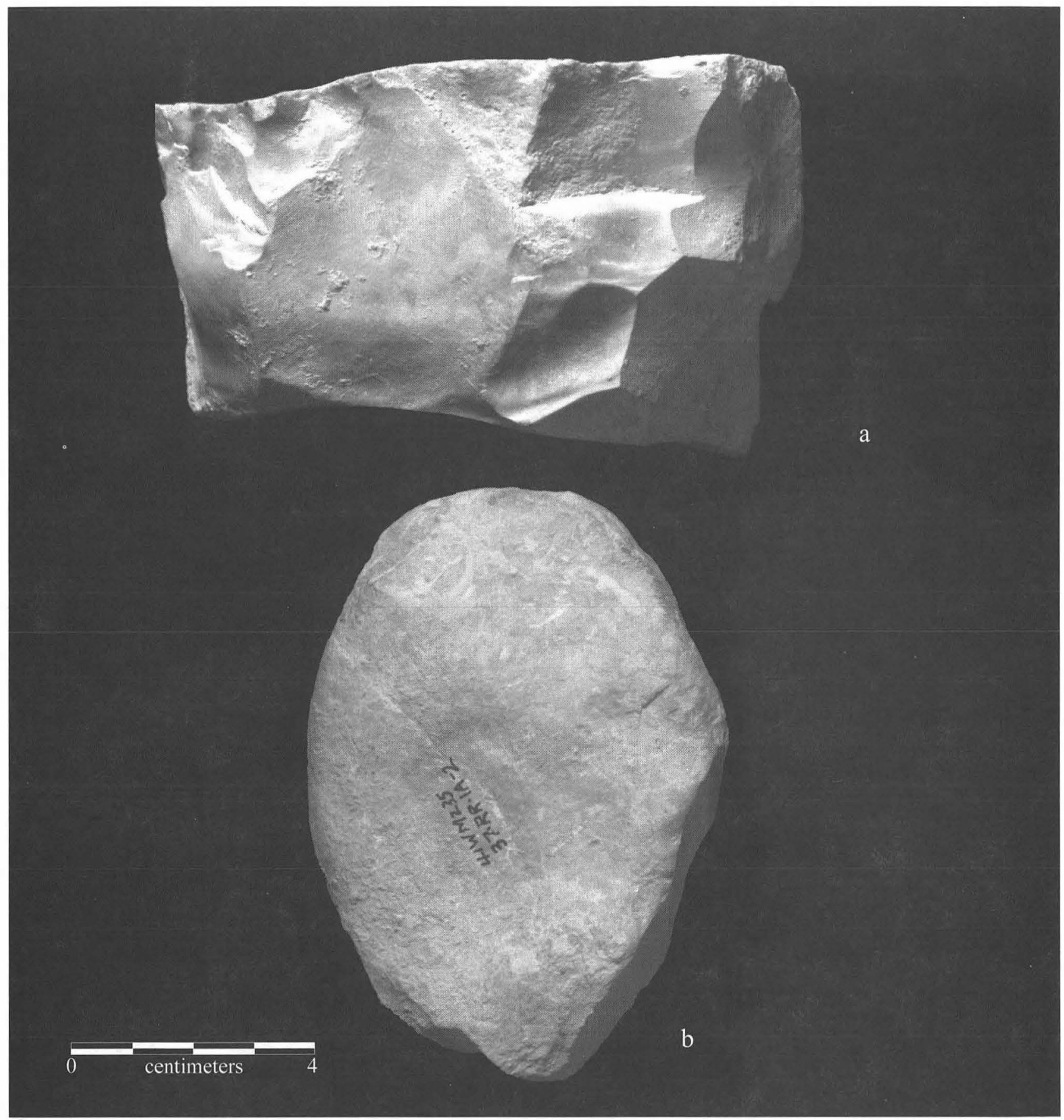

F1GURE 7-6. Chert core (a) and limestone hammerstone (b) from Feature 188.

cates that this was minimal if it occurred at all). It has to be assumed that if these specimens were redeposited, they could not have existed for very long before being buried in the deposits where they were found, or their true age(s) would be significantly greater than their apparent age. Since neither one of these assumptions can be independently verified, and both have to be met, the alternative possibility exists that some of the earliest Wilson-Leonard artifacts are, in fact, pre-Clovis in age. In this regard, the vertical distributions ofUnit lg! flakes in TARL Test Unit A, Levels
2-8, TARLSquare 27, Levels 57-59, and in TxDOT Square E20/S72, Levels 41-46 (see Figures 7-3 and 7-4), could be suggestive of an early and separate episode of activity at the site, either early Clovis or pre-Clovis. However, at this time, interpreting all of the early component as being of Clovis authorship, with notice made that the pre-Clovis alternative exists, is considered the more parsimonious conclusion. The place of this component in the Early Paleoindian record of the southern periphery of the Great Plains is considered further in Chapter 11. 


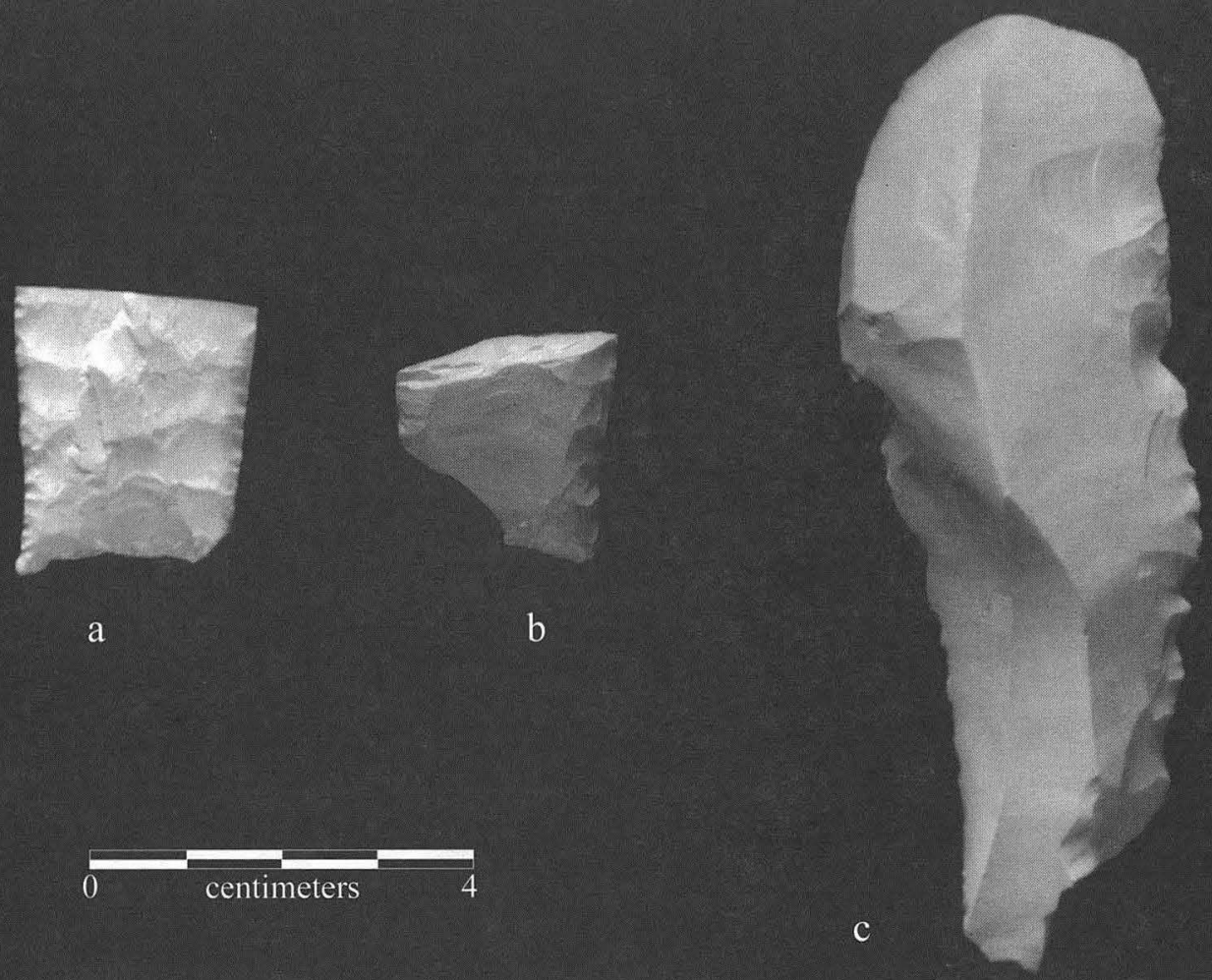

FlGURE 7-7. Early Paleoindian diagnostic artifacts from later contexts. (a) Midland point (26Y2C-3); (b) Clovis point (29S2D-10); (c) Clovis blade (15V2-2).

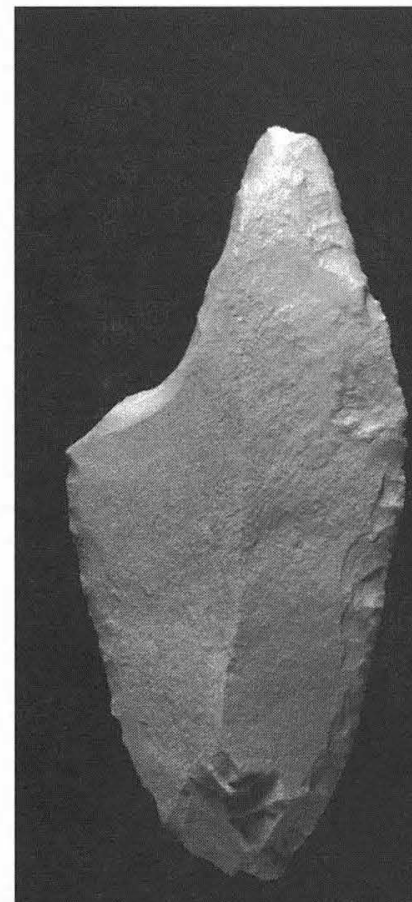

a

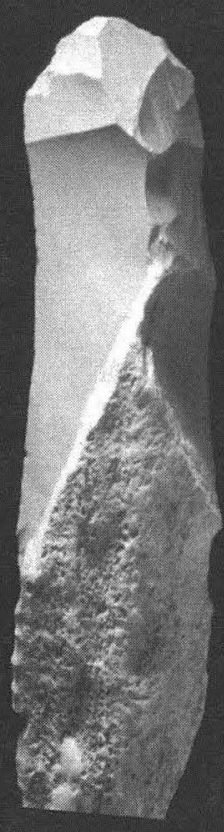

b

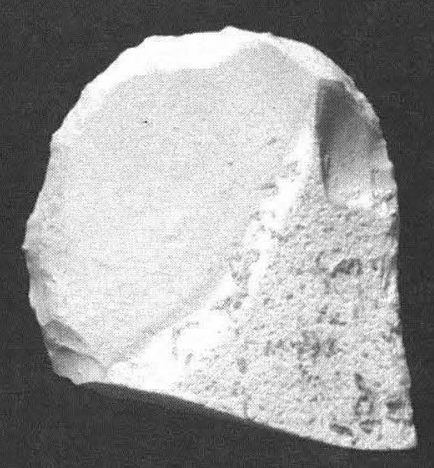

c

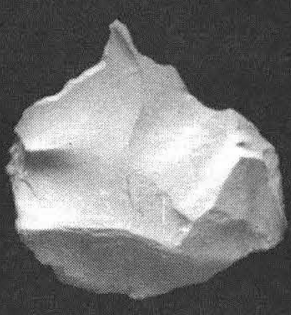

d
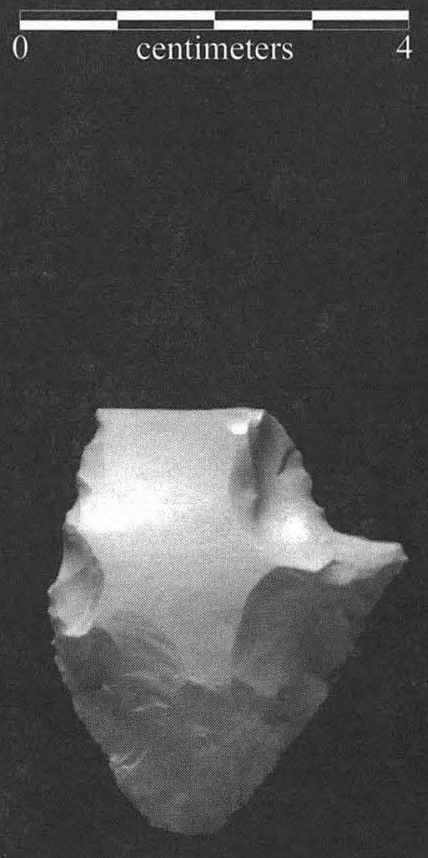

e

FGURE 7-8. Unifaces from the Bone Bed. (a) retouched blade (14EE2B-2); (b) end scraper on Clovis blade (16II1C-2); (c) thin uniface or end scraper on flake (14(fflB-1); (d) spur or graver on a thin flake (17JJ2/K.K1-2); (e) spur on a thick flake (26KK214). 

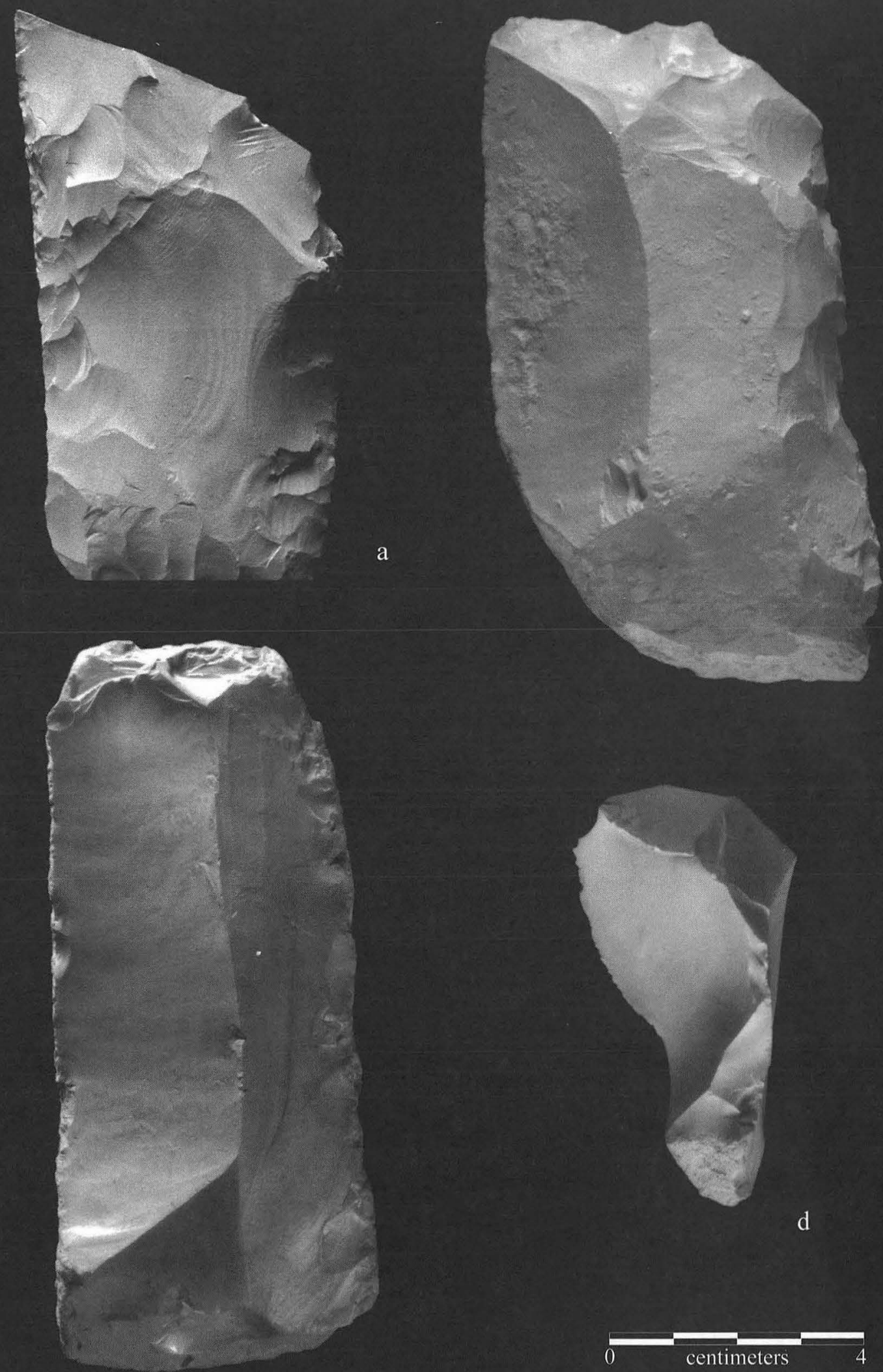

c

FGURE 7-9. Artifacts with Clovis technological attributes recovered from Bone Bed. (a) preform (32KK2B-2); (b) retouched flake from blade core (16HH2D-3); (c) failed blade core (17JJ21KK.1-1); (d) possible failed core tablet, flake from blade core (35002C). 


\section{BONE BED COMPONENT}

Among the more-distinctive cultural manifestations at Wilson-Leonard is the Bone Bed component which consists of a modest concentration of bison bones and artifacts found in and around a swale at the margin of Brushy Creek valley. This component is defined primarily on the basis of the distribution of bone but also of lithic artifacts. The bone includes pieces identifiable as bison, but the majority are splinters and fragments of large mammal bones considered most likely to be of bison. The evidence for this component was deposited prior to the swale becoming a more or less permanent cienega and dates to an approximate interval of 11,400 to 11,000 radiocarbon years ago (see Chapter 25).

Basically, the bone bed consisted of a recognizable lens or zone of bones and associated artifacts that cross cuts the stratigraphic facies of an alluvial fan draping into a swale at the edge of the valley. Slopewash, overbank flooding, bioturbation, weathering at the surface, bone damage at the hands of humans, and alteration after burial under the influence of ground water and soil chemistry are the recognizable processes that operated on the bone bed. It can also be postulated that humans may have scavenged usable stone off the surface of this feature at times in its development.

Topographically in the excavated area, the bone bed and its associated artifacts occuppied the lowest part of the swale along the eastern part of the excavation and extended upslope to the south, west, and, to a lesser degree, the east (see Figures 7-3 and 7-4). There was a fairly steep slope in the paleotopography down toward the swale from the valley wall on the west and southwest. Natural deposition in the lowest part of the swale was significantly different from that on the slopes, resulting in a complex stratigraphic context for the Bone Bed component (see Figures 7-3 and 7-4). In the swale, the bone bed was found primarily in Units lsi and Isi/Icl with its lowest portion being in Unit Igl/Isi in a few areas (see Figures 7-3 and 7-4). On the slopes above the swale, the bone bed occurred in Units Isi, Isi/Isi-c, and Isi/Icl/lsi-c. From its highest point in TxDOT Square E22/S78 to its lowest point in TARL Squares 20, 59, 52 and 28, there was a difference in elevation of the base of the bone bed of $1.6 \mathrm{~m}$.

Much of the evidence for this component was excavated in the 1982-1984 season and piece-plotted as individual bones, bone fragments (individual as well as clusters), and individual stone artifacts (Figures 7-10 and 7-11). The great majority of these piece-plotted specimens occurred within a vertical span of $20 \mathrm{~cm}$, but the present analysis considered all of the bone and accompanying materials, including highest and lowest items, in defining the bone bed. As a result, its thickness as an analytical unit averages about $35 \mathrm{~cm}$ and ranges from about $10 \mathrm{~cm}$ to almost $70 \mathrm{~cm}$. The bone bed was thickest next to the valley margin at the toe of the colluvial slope where turbation was also strongly in evidence (e.g., TxDOT Square E26/S78). Turbation is thought

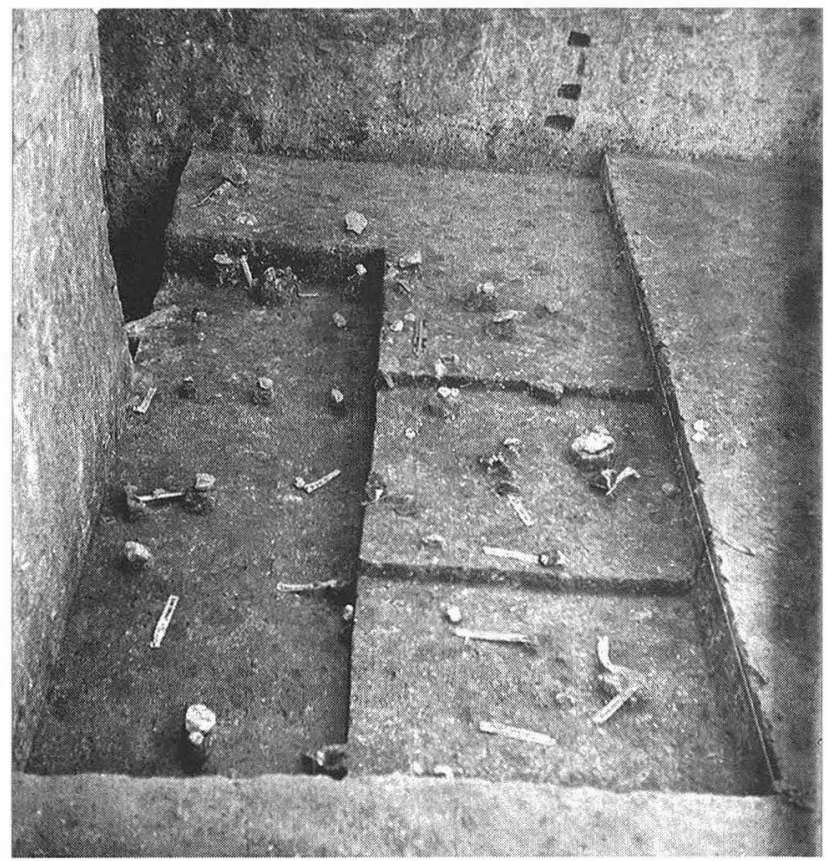

FIGURE 7-10. General view ofthe Bone Bed, looking south in TxDOT Squares E26/S76 (foreground) and E26/S78 (background); exposed are bones, bone fragments, chert objects, and limestone rocks. This is a moderately dense area of the bone bed.

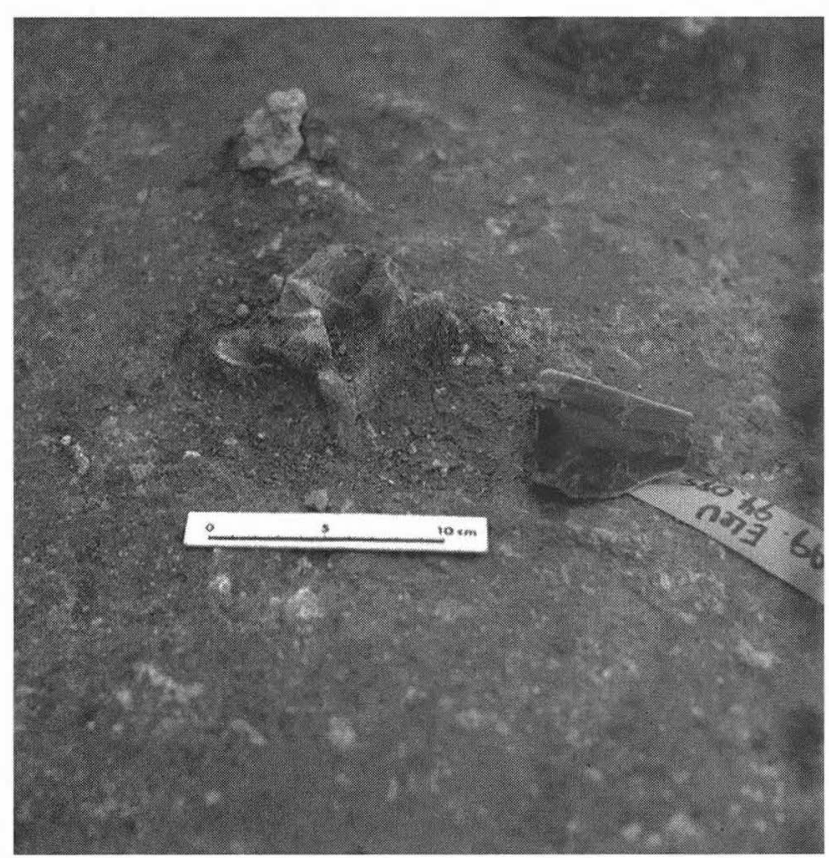

FIGURE 7-11. Eroded bone and nearby core fragment in Bone Bed, TxDOT Square E26/S76.

to be a significant factor in the configuration of this component throughout its extent, and it is probably safe to assume that some vertical movement, both upward and downward, of bones and associated artifacts occurred, giving an apparent thickness to the bone bed that is greater than it would have been had no disturbance taken place. 
In the field (e.g., see Figure 7-2b; Figure 7-12) and in the laboratory (see Chapter 33) it was clear that many of the larger bones were badly splintered while dry, indicating that they had laid exposed for a time prior to burial (e.g., see Figure 7-12). Upon analysis, however, the deposit is revealed as a rather diverse faunule. Two or more individual bison are represented by these bones along with a few bones identifiable as Canis sp., Carnivora, Odocoileus, Sternotherus, Leporidae, Antilocapra/Odocoileus, Testudinata, Serpentes, Equus, Rodentia, Sylvilagus, Phasianidae, Colubridae, Neotoma, Lepus, Geomys, Ondatra zibethicus, small mammal, small/medium mammal, and small/medium vertebrata (see Chapter 33). It is not known which elements are present in this assemblage as a result of human agency and which ones were introduced naturally; in all likelihood, there are some of both. In any case, none of these is numerous (see Chapter 33 and Appendix 10).

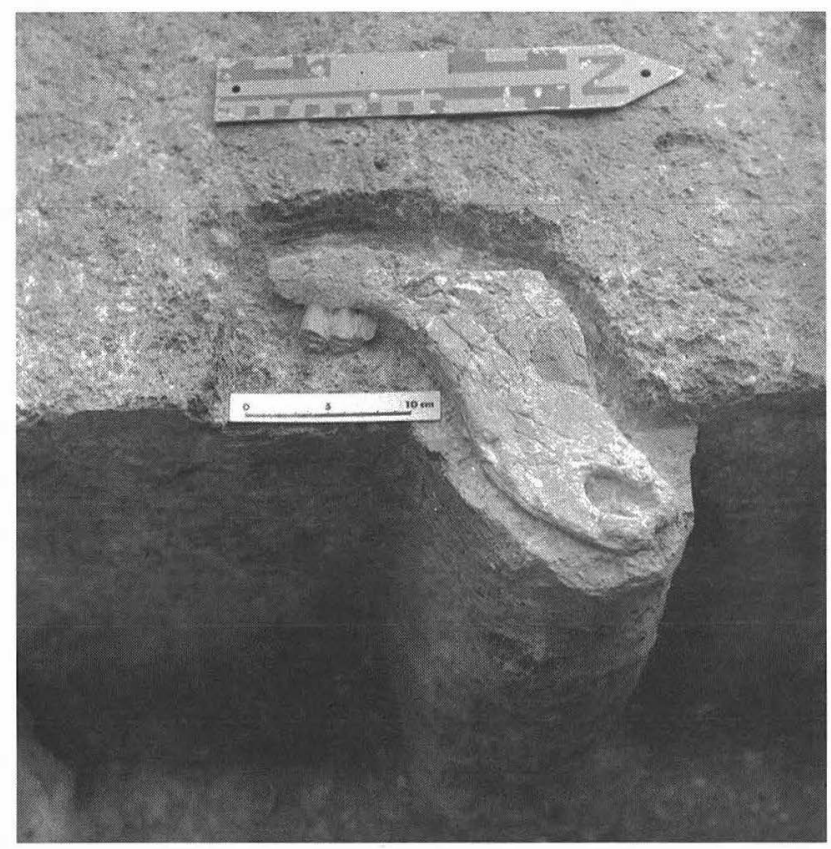

FIGURE 7- I2 Characteristic cracking and breakage of bones in the Bone Bed showing the mandible in TxDOT Squares E26/S78 (background) and E28S.78 (foreground).

Artifacts found with the bones include a projectile point, 26 biface fragments (representing 22 bifaces after 7 fragments are conjoined into 3 specimens), 14 cores and core tools, 23 edge-modified flake tools, 2 gravers, 33 unifaces, a chert cobble, 5 face-battered stones, 2 burin spalls, a mano, a piece of hematite, 4 pieces of sandstone, and 3,258 pieces of debitage. The projectile point (Figure $7-13 \mathrm{a}$ ) is a thinly biconvex lanceolate with slightly recurvate edges and concave base (see Chapters 13 and 14). The lateral edges are well ground and the basal edge is lightly ground. Collateral pressure flake scars converge toward the mid line on both faces. In size and thinness it resembles the type, Midland; however, the recurved edges and the biconvex cross section are not characteristic of Midland points. Recurved edges do occur on Folsom poi-nts (e.g., two Folsorns and one "pseudo Folsom" from the Shifting Sands site; Hofman et al. 1990:Figure 4h, j, k). This "bone bed point" shares its outline and collateral flaking pattern attributes with some specimens from the Bonfire (Dibble and Lorrain 1968:Figure 14c and d), Plainview, and Mill Iron sites as well (Frison et al. 1996:Figure 11.2). Driskell found Xpolish on this point, and Kay found striations indicative of a sequence ofuses from projectile point to knife to burin-like or projectile point (see Chapter 22).

Among bifaces are five fragmentary, early stage pieces (Figures 7- I4a-c and 7-15b), most of which retain traces of cortex and possibly represent beginning stages of projectile point or thin biface production. At least one of these was used after breakage as a hammerstone (see Figure 7- I5b).

There is a group of $\mathrm{IO}$ fragments of small, moderately thin bifaces of which 7 can be rejoined into 3 bifaces (e.g., Figures 7-13c-h and 7-16c). These all seem to be pieces of similar, broad lanceolate forms best represented by two of the conjoined sets (see Figure 7-1 3f-h and 7-13d-e). Percussion flake scars and lack of edge trimming suggests that these may be projectile-point preforms. The fragment 29112B1 (see Figure 7-13e) was examined by Driskell (see Chapter 22), and no use-wear was observed. Small Folsom bifaces from the Hanson site (Frison and Bradley 1980) are similar to these Wilson-Leonard specimens. All of the refits seem to be bend fractures but nonetheless may be the result ofmanufacturing failures. These are discussed again below as part of a broader look at refits in the bone bed.

Another biface (preform) from the bone bed (see Figure 7-9a) has already been discussed as probably being part of the Clovis assemblage from this site. Three other fragments are pieces of ultrathin bi faces (Figure 7-16a, b, and d). One of the fragments (OR722) is too small to determine the full size of the biface, but the other two are from large bifaces, probably knives. These closely resemble ultrathin bifaces from Folsom sites (Root and Emerson 1994).

Another specimen (Figure 7-13b) has affinities to Folsom artifacts. It is a fragment ofa thin biface made on a flake. The distal end is dull and terminates in the cortical band of the parent raw material piece and, unfortunately, the proximal end is missing. The workmanship, thinness, and outline of the fragment is highly reminiscent of some Folsom preforms (e.g., Frison and Bradley 1982). However, without the base and without conclusive evidence that Folsom knappers had any role in creating the Bone Bed component, it cannot be inferred that this is, in fact, such a preform. Whether intended for fluting or not, it does seem likely that this is a projectile point preform. Driskell found no evidence for use on this specimen (see Chapter 22). Six bi face fragments cannot be further categorized.

An aberrant artifact in many respects is part of a bi face ruined by an overshot flake from the proximal to the distal end, with a distal configuration similar to that ofClear Fork 


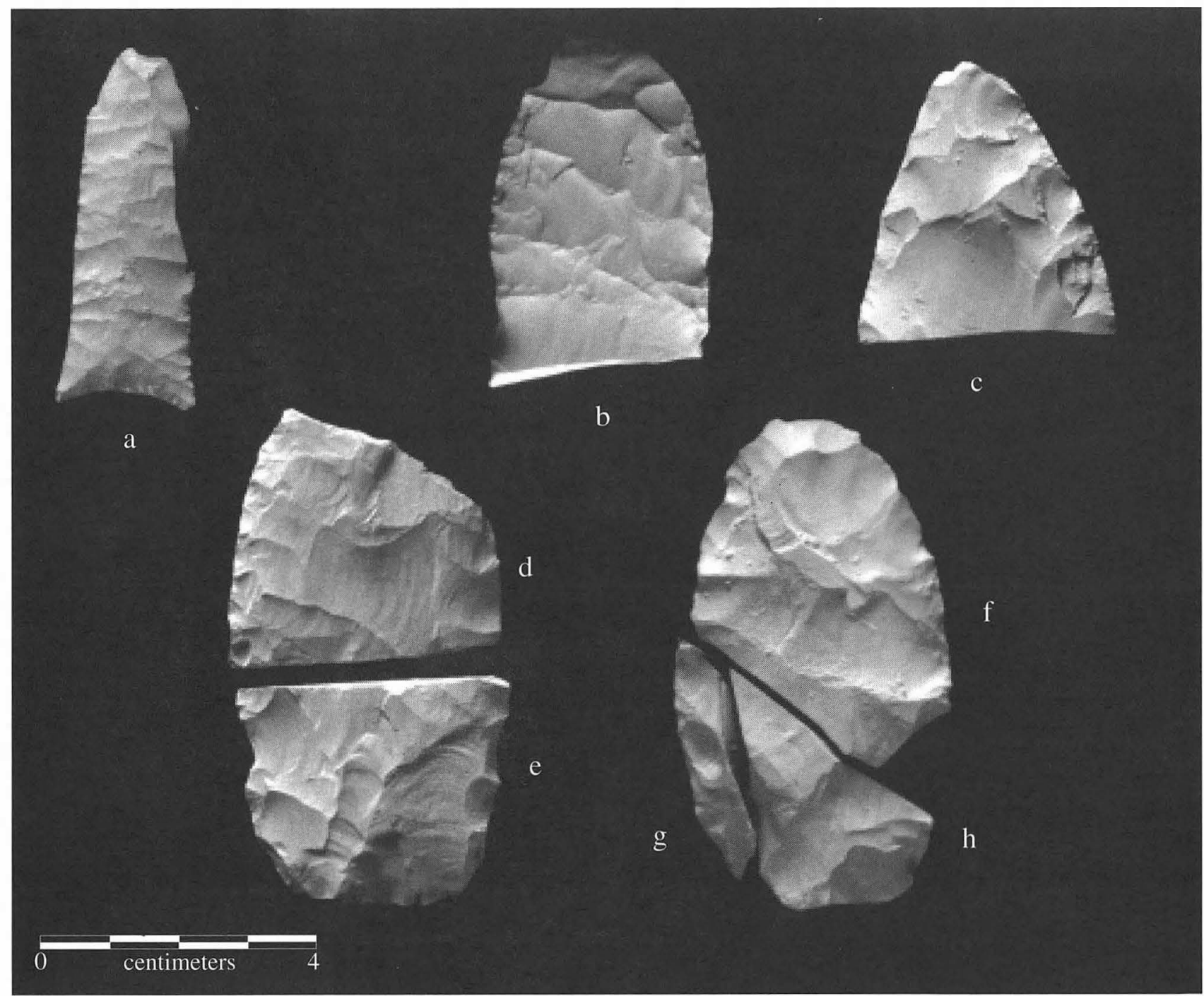

F10URE 7-13. Projectile point and thin bifaces (preforms) from the Bone Bed. (a) Bone Bed projectile point (1 7JJ2/KK.1-3); (b) preform fragment (30HH2C-I); (c) preform fragment (24EE IB-1 ); (d, e) conjoined preform fragments (29JJ1 D- I, distal, and 29**2B- I, proximal); (f-h) conjoined preform fragments (28GG2C-2, distal, 29112C-2, lateral, and 37MMJ C-1, proximal).

bifaces (Figure 7-14d). Wear patterns on the bit edge of this biface resemble those on Clear Fork bifaces (see Chapter 15). The form and apparent use-history and possibly even the Jong-axis fracture of this piece suggest woodworking activities.

Another unique specimen is a uni face on a blade (or, less likely, a blade-like flake) retouched around almost its entire perimeter (Figure 7-8a). There is very little longitudinal curvature to the blade, and it has a prominent ridge on the exterior face. One edge is convex for the entire length of the piece. The other edge has a similarly convex edge for about half of its length, but the other half has been more deeply flaked to form a narrow perforator or stem-like point centered on the ridge. Driskell found wear on the edges at the tapered end that he interprets as perhaps resulting from hafting in a bone or antler handle (see Chapter 22). A light to moderate patination covers most of this artifact.
There are five pieces of chert from the bone bed that have small areas of heavy battering on comparatively flat faces (Figure 7-17d-h). These are different from most hammerstones where the battering is on edges or promontories. An apparently related specimen is a core with battering in an arc on its platform (Figure 7-1 7a).

Thirteen specimens from the bone bed are categorized as cores or core tools. Most of these have edges with crushing or battering suggestive of use as chopping or crushing tools of some kind (Figures 7-15a, c; 7-1 7b, c; 7-18a-c). Found as these were with bones of bison may indicate their use in butchering or in breaking open large bones.

Two small, delicate gravers on flakes are another artifact category in common between this component and Folsom assemblages. These two specimens (Figure 7-8d) are made on small biface thinning flakes. A larger, stronger spur appears on the edge of a broken uniface (Figure 7-8e). 


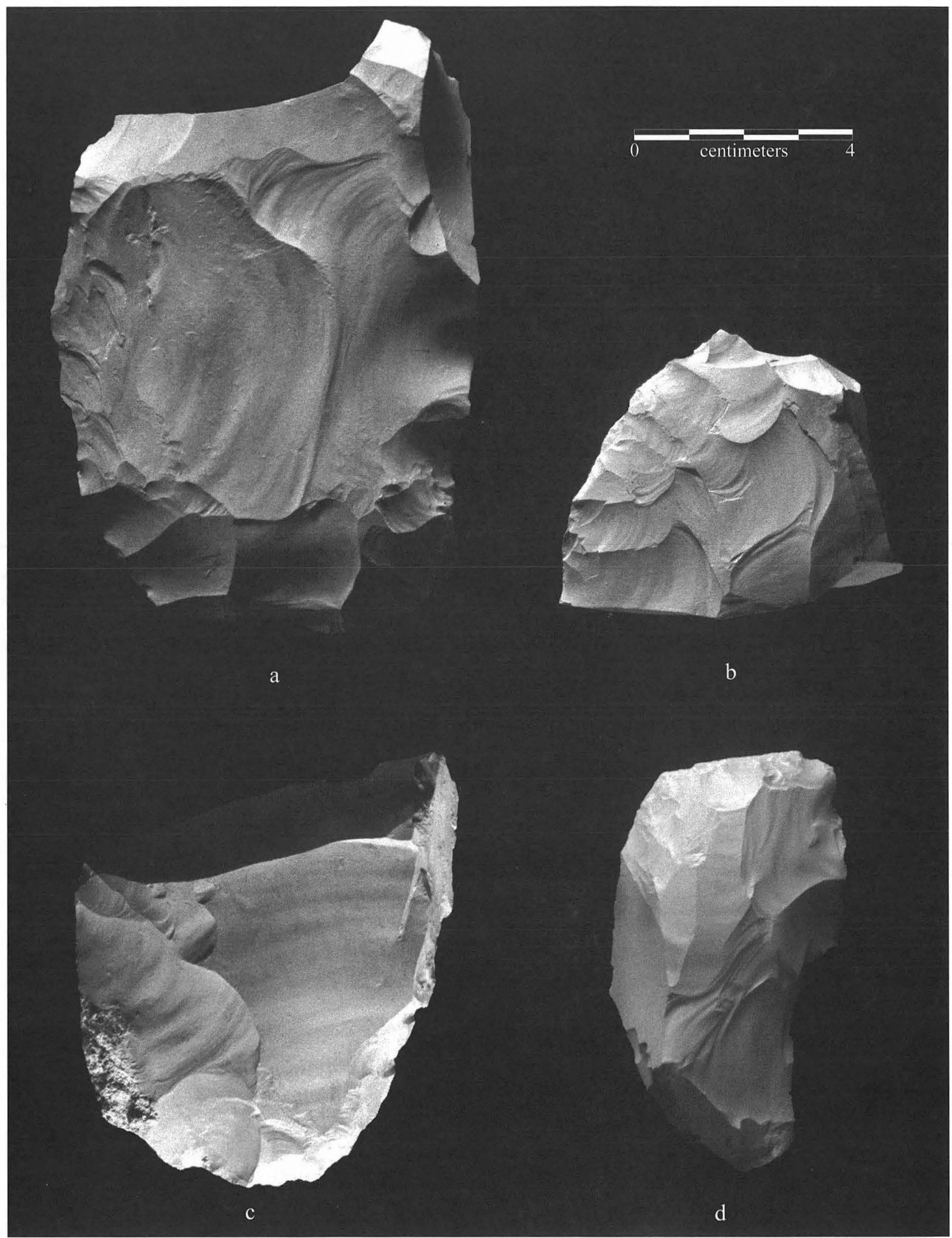

FIGURE 7-14. Bifaces from the Bone Bed. (a) large fragmentary early stage biface (35NN1\&2B-3); (b) fragment of early stage biface (37LL2C-2); (c) fragment of early stage biface (39FF-1); (d) Clear Fork-like biface (39FF-2). 


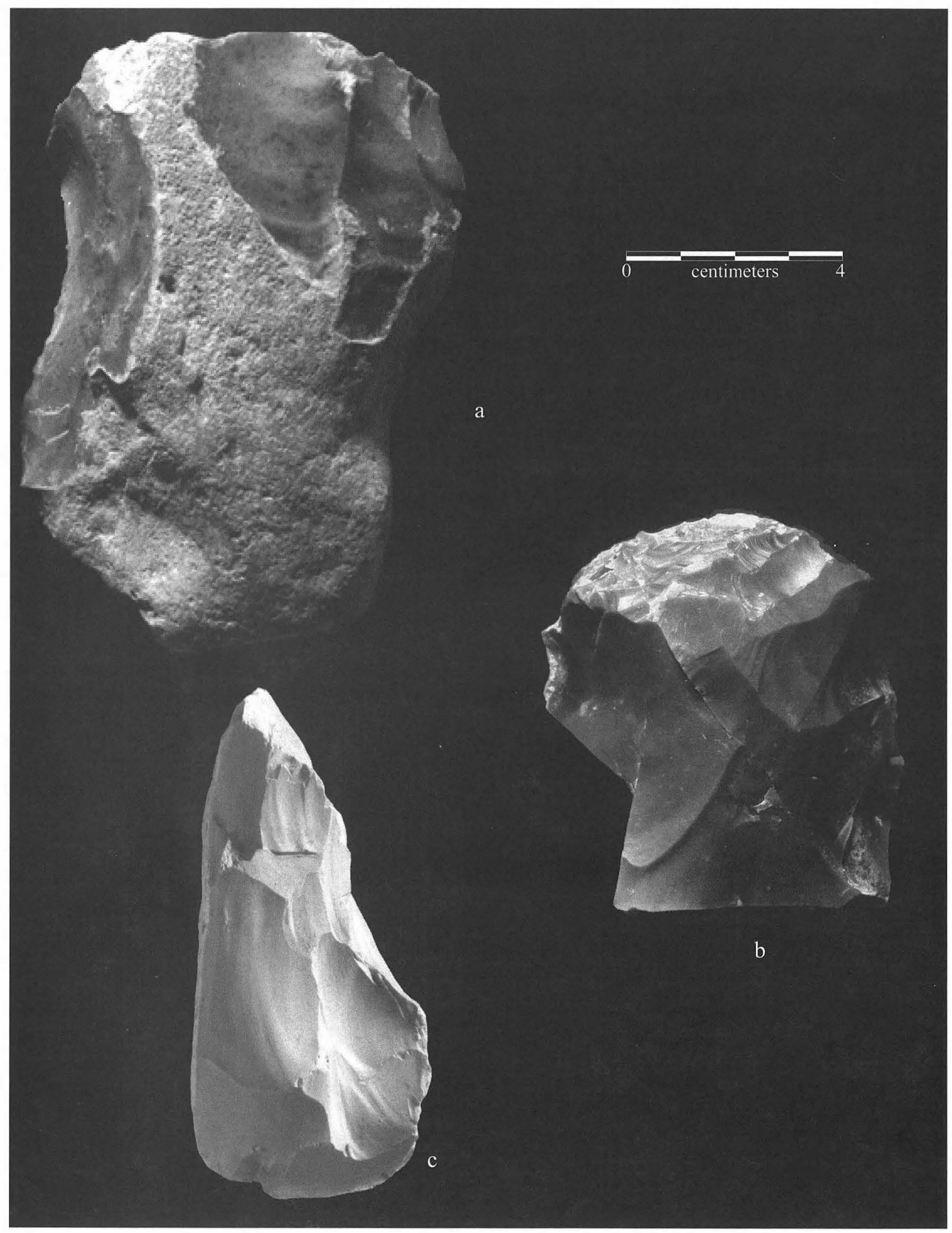

FIGRE 7-15. Bifacial tools and cores with evidence of heavy use as chopping or hammering tools. (a) core chopper (35NN 1-2D4); (b) core/ hammerstone (16111 B- I); (c) core/hammerstone (3 1NN 1A- I). 


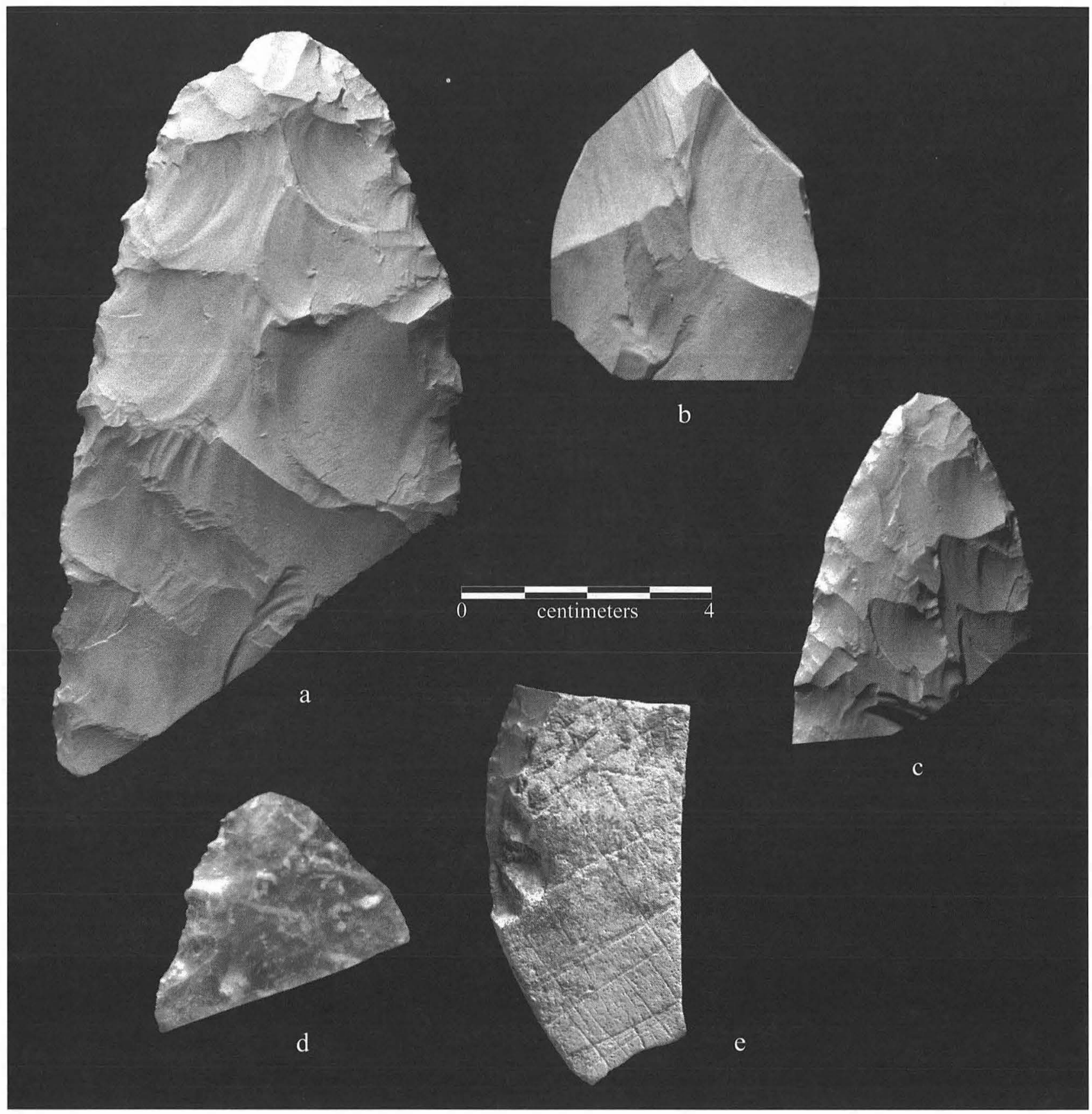

Figure 7-16. Thin bifaces and engraved stone from the Bone Bed. (a) ultrathin biface (31MM2A-2); (b) fragment from the center ofa probable ultrathin biface with thermal fractures on the perimeter (32MMIA-1); (c) preform (26HH2C-1); (d) thin biface fragment (OR722); (e) engraved stone (30LLIC-1).

Unifaces number 33. These are informal and made on a variety offlakes (e.g., Figure 7-8c) without any matching the formal end scrapers often found in Paleoindian contexts. The illustrated specimen does not show evidence of use on the retouched edge, however, the opposite, fractured edge has evidence of use like that seen on burins or radial break tools (see Chapter 22).

One uniface (Figure 7-16e) is worthy of special notice because of a pattern of cross-hatched lines engraved in the cortex on its exterior. This is similar to engraved stones reported from Early Paleoindian contexts at the nearby Gault site (Collins et al. 1991; Collins et al. 1992) and Blackwater Draw (Hester 1972:Figure 93g). In addition to the presence of the engraving, there is evidence of hide polish on the unifacial edge of this specimen (see Chapter 22).

One limestone mano was recovered from the bone bed (Figure 7-19). It is roughly oval with both ends slightly squared off from use in hammering. One face is moderately 


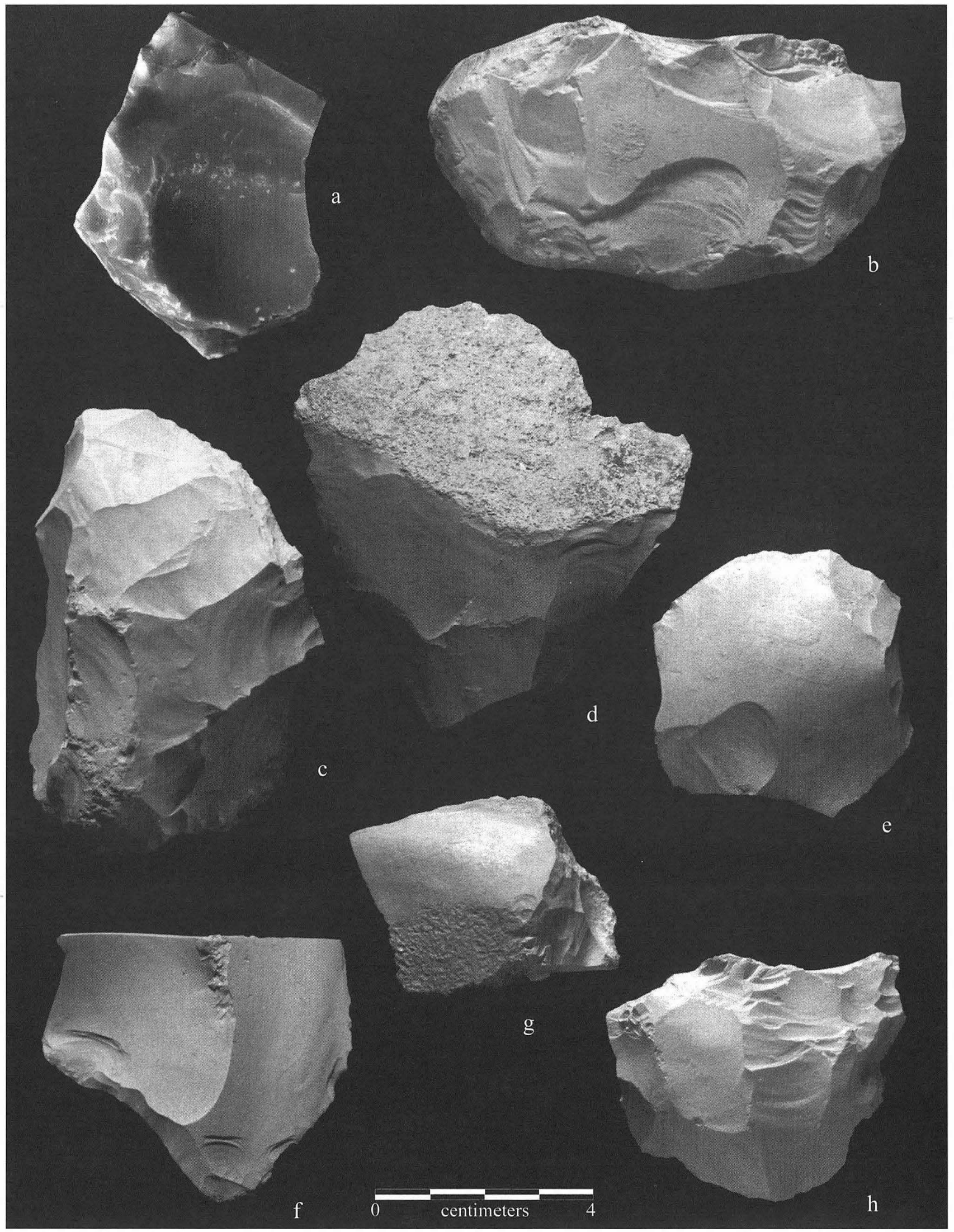

FIGURE 7-17. Bone Bed core and flake pieces with evidence of battering. (a) core with face battering (OR737); (b) core/hammerstone (24FF2B-1); (c) core/hammerstone (32KK2A-1); (d) large thin secondary flake with battering scars (34NN1B2); (e) thick flake with battering (3 IKKIA-1); (f-g) thick flake with heavy battering (29LL1C-1, 22LLID-1); (h) core fragment with face batteri ${ }_{\mathrm{n}}$ (37001A-4). 


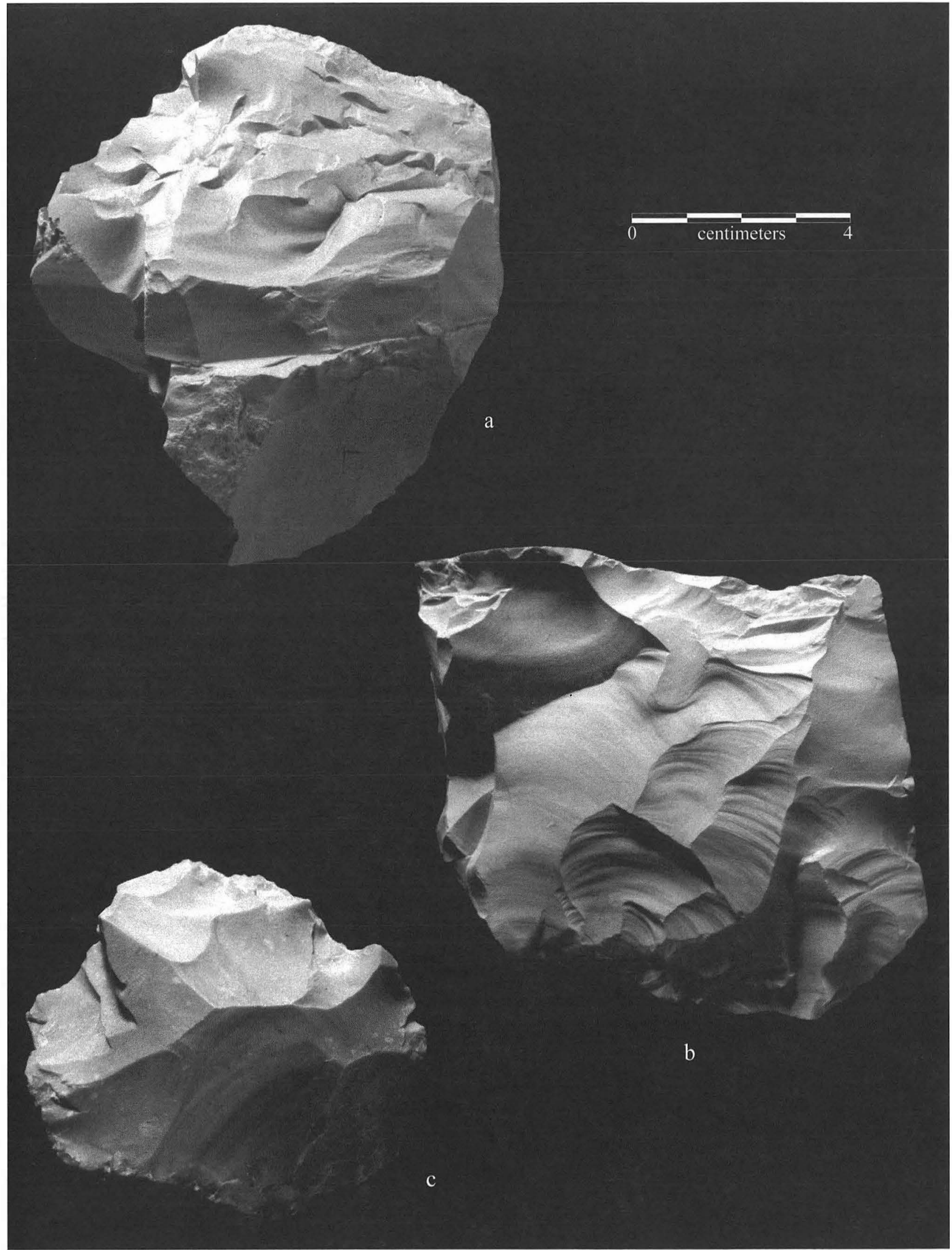

FIGURE 7-18. Bone Bed core tools with evidence of use as chopping or hammering tools. (a) core/hamrnerstone (33MM2D-1); (b) core/ harnrnerstone (17KK.2/LL1-1); (c) core/chopper (34NN12A). 


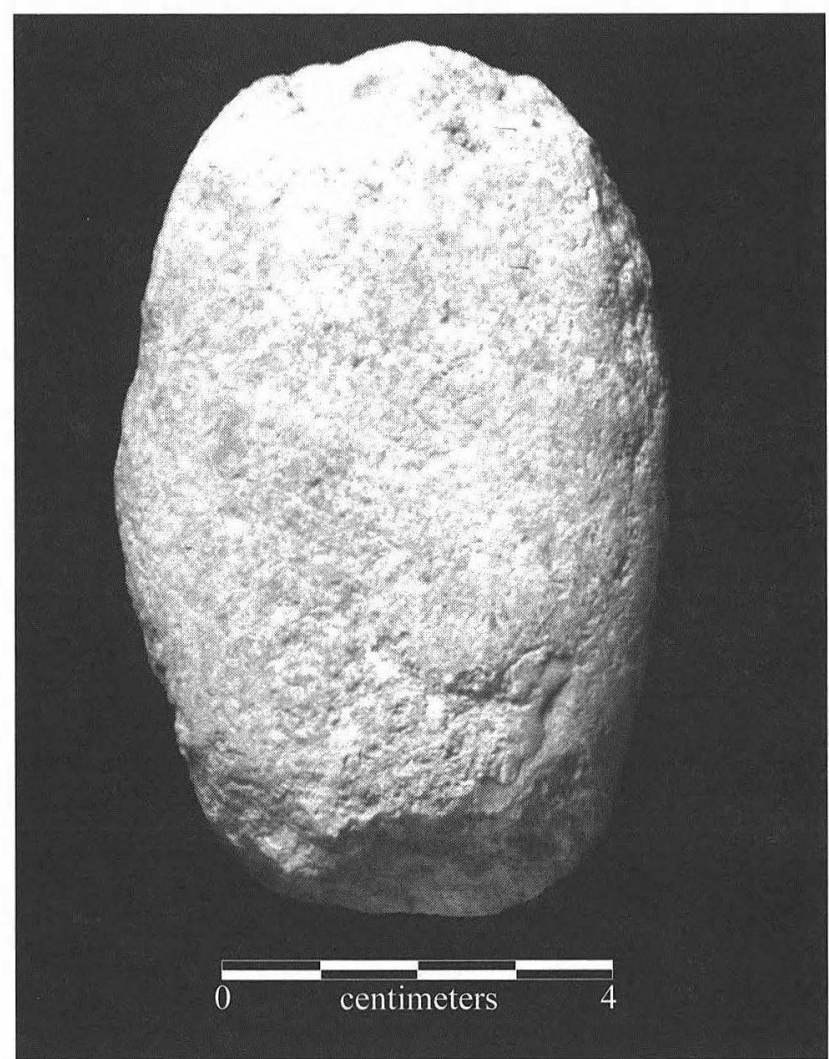

HGURE 7-I9. Mano/hammerstone from the Bone Bed component (34NNI-D-1).

convex and moderately smooth. The opposite f;;e is less convex and is quite smooth with many scratches and striations oriented in multiple directions. This face has obviously been used in the manner of manos, although it is far from clear that stone metates were in use in Early Paleoindian times.

One small piece of hematite and three small, irregular pieces of coarse, soft sandstone are present in this assemblage. Hematite is common in Early Paleoindian s ites and similar pieces of sandstone have also been reported (as at Stewart's Cattle Guard site [Jodry 1987]).

A small number (23) of edge-modified flakes and flake tools are also provenienced to this component as are two burin spalls. One edge-modified flake (32LL1B-3) examined by Driskell (see Chapter 22) shows both X-polish and usewear inferred to be from hide-working. Another (1 5HH1A-1) examined by Kay (see Chapter 22) appears to be the result of trampling rather than use or intentional retouch.

A flake (OR741) from TARL Square 53, Level 52 was tested for organic residues by Beck (see Chapter 23). It was found to have traces of six fatty acids present.

A number of the chipped stone pieces from the bone bed conjoin with others. These include the two pieces of a bi facial preform (321IlA-1 and 32II IB-1 ), two pieces of another bifacial preform (29JJ1D-1 and 29II2B-1), and three fragments ofa similar piece (28GG2C-2, 29H2C-2, and 37MM1 C1). The first two of these consist of bend breaks and could have broken during manufacture, during use, or from being trampled while on the ground (since the refitting pieces were found in proximity). The third case consists of perverse fractures, and the three pieces were found more widely dispersed; this one almost certainly was broken by the knapper. There are also four sets of refitting flakes. The first consists of a sequence oftwo small, noncortex flakes ofblack, fine-grained chert removed from the same platform of a core (these were found in TxDOT Square 16, Level 35). The second set of two secondary cortex flakes of coarse chert were found in TxDOT Square 26, Level 37. Two more sets ofrefitting flakes almost certainly were removed from the same parent piece, but the two sets cannot be connected to each other; one consists of two flakes, the other of three. These are all of a coarse chert, and all five flakes retain traces of soft, gray cortex. The five flakes were found in TxDOT Square E22/S74, Levels 37 and 38.

It is not known how horizontally extensive the bone bed and its associated artifacts might be. The area exposed reveals some interesting horizontal patterning (Figure 7-20 [map packet] and Figure 7-21), including the greatest concentration of bone in the northeastern part of the excavation. In fact, it may be that only the southwestern edge of a large bone bed was encountered in the excavation. Because of its depth, the excavation could not be expanded. Debitage, mostly tool maintenance and final production trimming, reaches its greatest concentration across the southern, more sparse distribuJion of bone and just southwest of the main bone bed (compare Figures 7-20 and 7-21). In Square E26/ S72, among the greatest concentration of bones, TxDOT excavators noted a large limestone slab surrounded by a large number of bone fragments (see Figure 7-20; Figure 722). Their field notes speculate that the slab may have been an anvil for bone cracking, which seems reasonable, especially in light of a core tool being recovered about a meter southwest of the slab. This grouping of objects was not given a feature designation, but it would qualify as a probable set of tools and bone pieces resulting from a specific activity.

Stone objects (see Figure 7-20) were unevenly distributed. Preforms, including three that are represented by two or more refitting pieces, were found primarily in the southeastern part of the excavation along with the concentration ofdebitage. Cores were also common in that same area. Core tools were found in both the areas of greater and lesser concentrations ofbone. All three of the fragmentary ultrathin bifaces were found within the area of bones. Retouched flakes and unifacial tools were found with the bones as well as in areas where bone was sparse. The single projectile point was situated at th(:; northwestern edge of the excavation, outside of the main bone bed, along with one of the two gravers. The other graver was found in the southeastern corner of the excavation. The single limestone mano, which also has evidence ofuse as a hammer, was among the concentration of bones in the northeastern part of the excavation. 


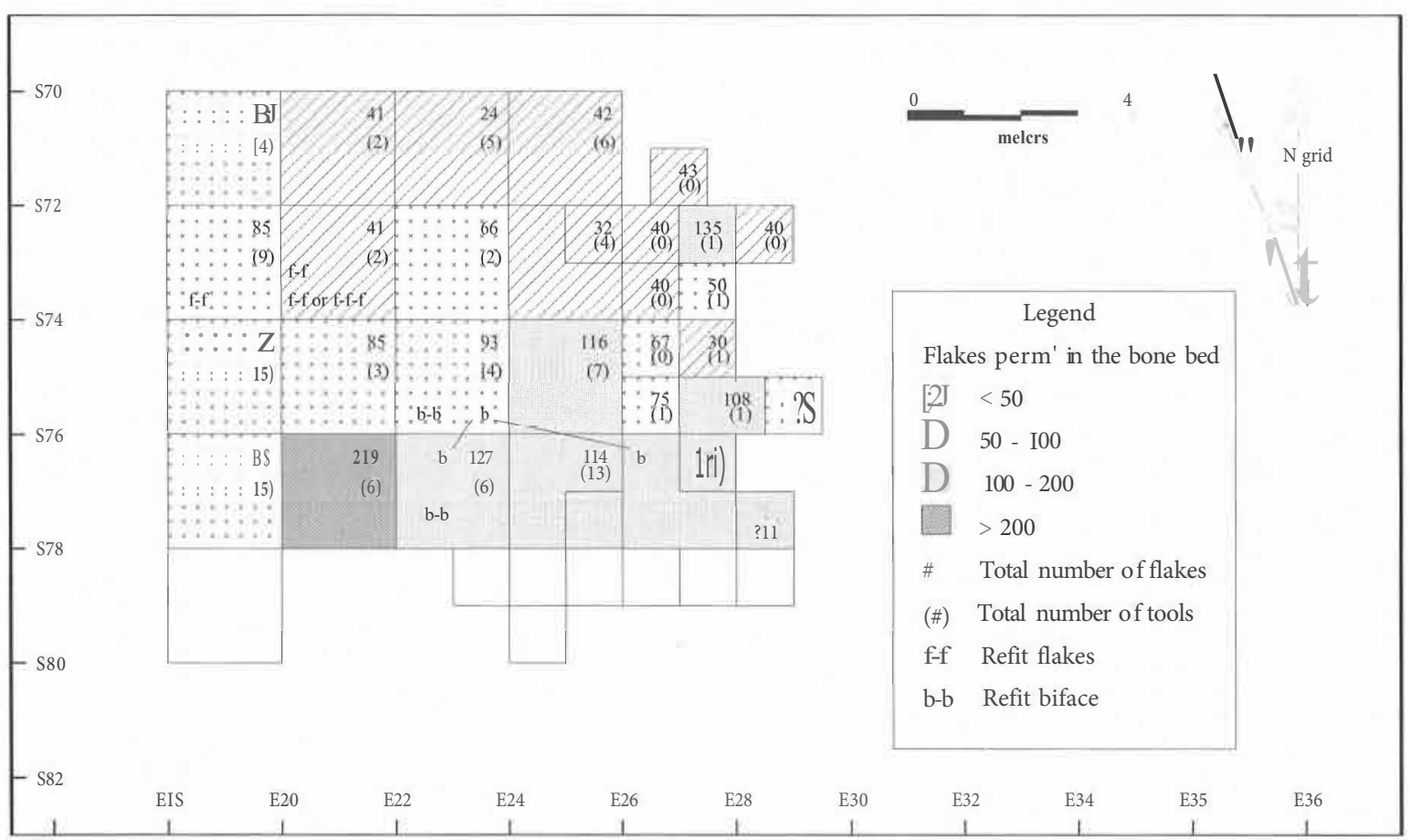

FIGURE 7-21. Map of the Bone Bed component showing distributions of debitage, tools, and refitted objects as well as debitage densities.

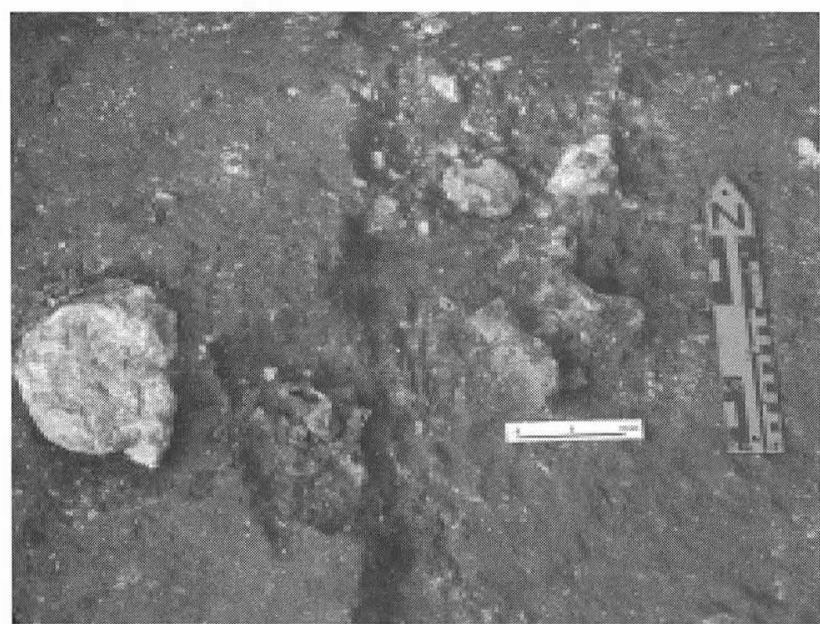

F1GURE 7-22. Limestone slab and large bone splinters in TxDOT Square E26/S72, bone bed, thought by the excavators to be a bonebreaking activity area.

Three of the four pieces of sandstone were in the southern part of the bone concentration and the fourth was located outside of the bone bed on the western edge of the excavation. All four of the enigmatic face-battered stones were located among the bones.

There was an apparently heat-hardened mud dauber nest in Tx.DOT Square E22/S72. It is not known if this is a cultural or a natural occurrence, but it could have been introduced and burned intentionally as a food item or inadvettently with firewood. It is even possible that some sort of temporary shelter that burned could account for the presence of this item. Alternatively, a natural event could have brought about the burning and deposition of this nest among the bone bed remains.

Throughout the bone bed were a few very small (less than $1 \mathrm{~cm}$ ) jasper and granite pebbles. Although it is possible that some of the jasper pieces are natural occurrences, the small pieces of granite (some of which are angular) as well as some of the jasper pebbles were probably present as a result of some aspect of human activities at the site.

Field notes from both excavations identify a few pieces of burned limestone in and near the bone bed. None of these is absolutely recognizable as burned. For the most part, they show minor color change and little else in the way of heat alteration. One piece of "burned" limestone from TARL excavation Square 53 was tested for an archeomagnetic signal indicative ofburning and determined to have been minimally heated, if at all. The alternative interpretation that these are lightly heated or that they are unheated rocks exhibiting discoloration from another cause cannot be resolved, but because their distribution is nonrandom, they are shown on the map (see Figure 7-20). The greatest number was found in the southeastern area of the excavation, and the small cluster in the south part ofTxDOT Square E26/S78 was found with the thermally damaged fragment of an ultrathin bi face and not far from a heat-damaged preform fragment. These observations raise the possibility that a hearth was in or near the southeastern part of the excavation.

In aggregate, these distributional data suggest, but not definitively so, a bone bed centered near the northeastern corner of the area excavated with a domestic area centered along its southern edge. This domestic area may 
have included a hearth. Activities included final trimming of small bifaces (preforms?) as well as tasks that made use of sandstone, ochre, a graver, and diverse unifacial tools. Another area of knapping and perhaps other activities is indicated west of the main part of the bone bed. Within the bone bed were found a number of tools that would serve in skinning and meat cutting (the thin bifaces) as well as heavy butchering and bone breaking (the core tools and the mano).

I am inclined to view the small number of bison individuals and the relatively few tools in this component to represent a very brief interval of site use, probably a single event. Of course, persuasive evidence to the contrary could easily lie just outside of the area excavated, but the remainder of this discussion rests on my assumption that a brief and limited use of the site is represented.

Baker was unable to specify a season of death for the bison, leaving the artifact assemblage as the only avenue for investigating this question. Jodry (1997) has made a strong case for the use of ultrathin bifaces in the cutting of meat for drying, which is typically a fall activity. This and the apparent cracking of bones (the anvil, core-chopper, and bone fragments in TxDOT Square E26/S72) are perhaps indicators of a fall kill and processing event. The identifiable skeletal elements include those of low meat yield that are generally not carried far from the kill site. This would mean that bison were either in Brushy Creek valley of their own volition or were driven there by hunters. Open grasslands were probably present within $10 \mathrm{~km}$ to the east on the Black Prairie, and even closer to the west and northwest on the Lampasas Cut Plain. Before having a few of its members dispatched, a small bison herd could have been driven up Brushy Creek valley and pressed against the west valley wall, they could have been driven from the more level upland immediately to the southwest down the point of land between Brushy and Spanish Oak creeks, or they could have been ambushed while watering at the creek confluence.

Any of these possible hunting scenarios followed by a brief encampment when butchering and processing of meat and bone is inferred. The lack of formal end scrapers in the assemblage may indicate that hide processing either did not occur or occurred outside of the area sampled in these excavations.

Having made these interpretations of the bone bed component, it remains to consider its cultural affinities. This task has been left for Chapter 11, below, where regional comparisons are made for all of the Wilson-Leonard components. Suffice it to say here that the brief hunting and processing behavior indicated for this component are comparable to evidence from most Early Paleoindian cultural complexes. The challenge is to evaluate the technological and meager typological evidence from Wilson-Leonard against the reported patterns seen among Folsom, Plainview, and Goshen assemblages.

\section{UNASSIGNED EARLYPALEOINDIANMATERIALS}

In the upper levels of the Early Paleoindian deposits, stratigraphically beneath Unit Isi-c, were found a considerable number $(4,522)$ of flakes as well as I04 tools (see Table $7-2$ ) and 2 projectile points. Neither the minimal typological evidence nor the indistinct technological pattern offers any indication that these materials constitute a coherent archeological component.

One of the projectile points was found at the very top of this array and fits into the Wilson type (Figure 7-23b). The other point was recovered from just above the Bone Bed component and is the basal poltion of a lanceolate piece made on a flake with minimal edge retouch. $\ln$ size and outline, it resembles a Midland point, but it is thicker and far less well flaked than Midland points (Figure 7-23a). These are the only items with potentially diagnostic typological attributes, and they provide primary clues for understanding the unassigned materials. Counts of tools and debitage increased upward in this array toward the base of the overlying Wilson component in Unit 1si-c (see Figures 7-3 and 74). This pattern and the presence of the Wilson point probably reflect downward intrusion from Unit lsi-c for at least the upper portion of the unassigned Early Paleoindian array.

Deeper in the sequence it is unlikely that any intrusion from the overlying Wilson component occurred. Here the lanceolate point fragment (see Figure 7-23a) is the only potentially diagnostic item, and other than being a generalized lanceolate form common in Paleoindian times, it is of little help in identifying the affiliation of the unassigned materials except that it seems not to have derived from the Wilson component above.

Among the other artifacts in this array are I8 small- to medium-sized bifaces and biface fragments (e.g., Figure 723c, e-g). Another fragment (Figure 7-23d) is probably an ultrathin biface (its weight:thickness ratio is greater than 6.15: 1), and in workmanship and outline it resembles the ultrathin bifaces of Folsom affiliation. There are also flake tools, unifaces, cores, and debitage along with a face-battered stone and a piece of hematite (see Table 7-2). The blade itemized in Table 7-2 is small and thin and does not resemble blades of Clovis affiliation.

Unifaces include end scrapers (Figure 7-23h, i) as well as side scrapers (Figure 7-24a, b) and denticulates (Figure 724c). There are burins and burin spalls (Figure 7-24d) and core choppers (Figure 7-25a, b). One face-battered stone is placed in this group (Figure 7-24e), but its stratigraphic proximity to the bone bed and its similarity to such stones in that component may indicate that it was originally part of the bone bed assemblage.

One flake (OR696) from TARL Square 59, Level 49, was tested for organic residues by Beck (see Chapter 23) and found not to have any volatile organic compounds present. A bi face (OR689) from TARL Square 20, Level 50, was found by Hurst (see Chapter 23) to retain traces of two amino acids 


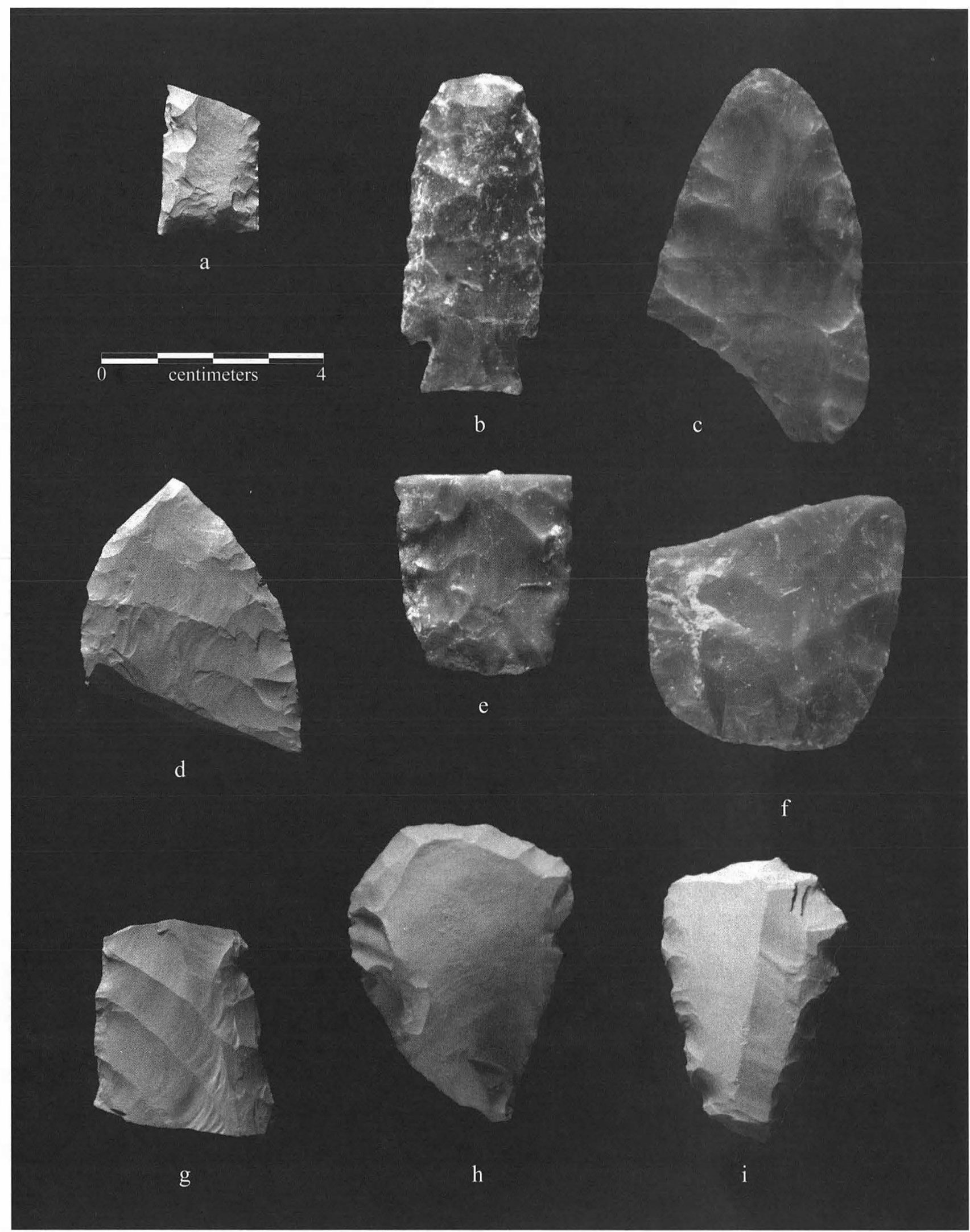

Figure 7-23. Representative artifacts of Early Paleoindian age but unassigned to any cultural affiliation. (a) untyped lanceolate point (25EE2B-1 ); (b) Wilson point (OR519); (c) biface (OR 689); (d) thin biface (2585-1 ); (e) bi face (OR649); (f) bi face (OR592); (g) bi face (28DD2D-2); (h) end scraper (33FF2B-1); (i) end scraper (32FF2B-1). 


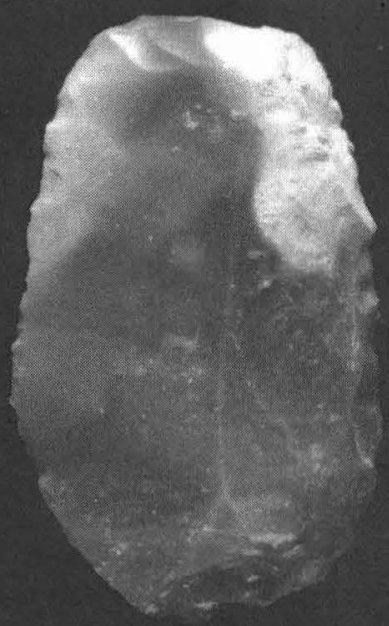

a
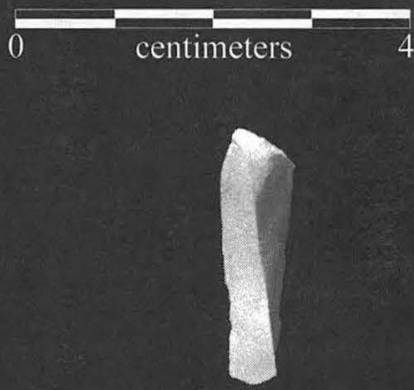

d
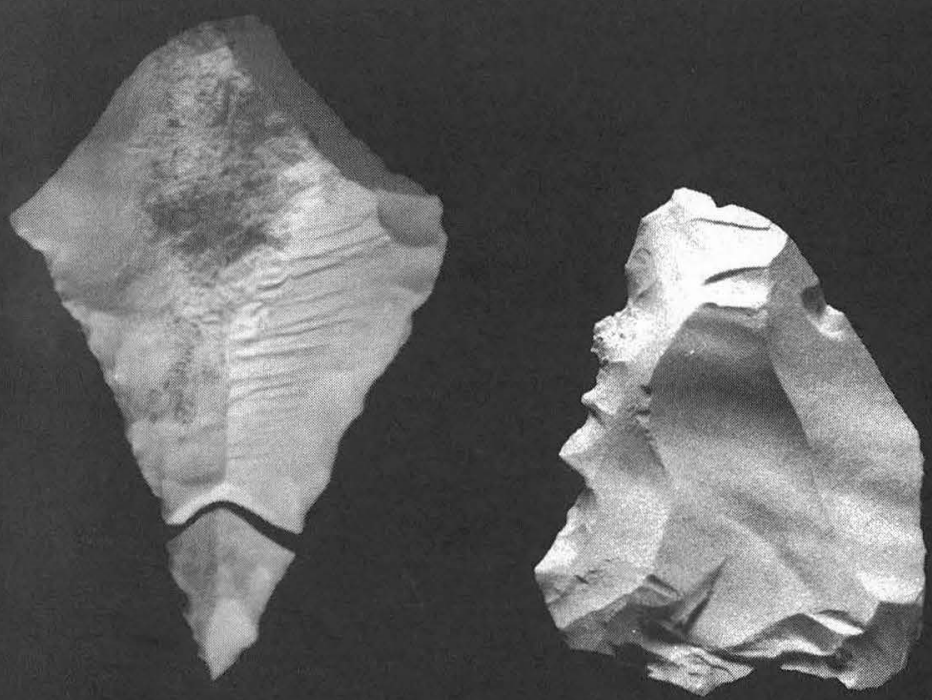

C

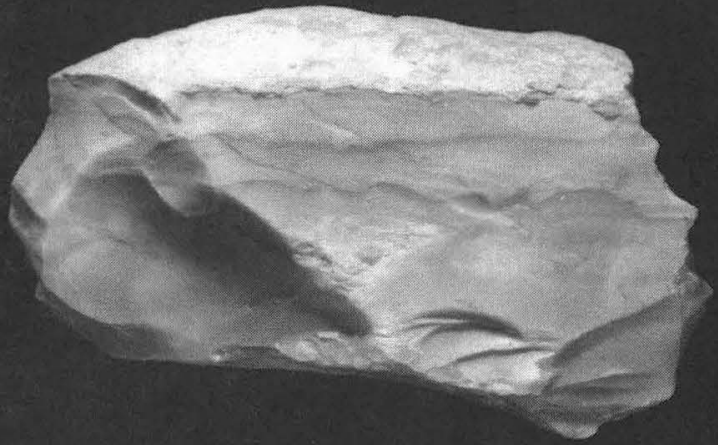

e

HGURE 24. Representative artifacts of Early Paleoindian age unassigned to any cultural complex. (a) uniface (OR693); (b) uniface (27GG2A-1); (c) denticulated uniface (27GGJC-J); (d) burin spall (1601-4); (e) face-battered stone (35KK2A-2).

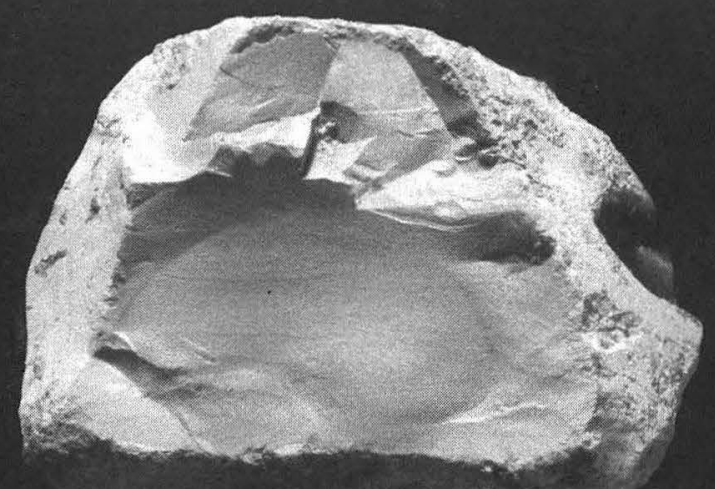

a

b

FGURE 25. Unassigned Early Paleoindian core tools. (a) core/chopper (30FF1D-1); (b) fragmentary core/hammerstone (16CC2-1). 
as well as inorganic compounds of chloride, sulfate, and carbonate.

It is apparent that human activity transpired at WilsonLeonard between the time of the Bone Bed component and that of the Wilson component and that it included knapping and perhaps other tasks. However, with the present sample it is not possible to suggest any cultural affiliation nor to offer any detailed interpretation of this material. Its significance to the regional prehistoric record is discussed briefly in Chapter 11.

\section{CONCLUSIONS}

Early Paleoindian cultural remains are buried in fluvial deposits dating between ca. 12,000 and 10,600 BP. at the site of Wilson-Leonard. Three components are discernible among these materials, an early one with affinities to the Clovis complex, an intermediate one referred to as the Bone Bed component which compares favorably with aspects of
Folsom, Plainview, and Goshen complexes from elsewhere on the Plains, and a late one lacking sufficient diagnostic material to be assigned to any known complex. Other than their presence and some limited indications of knapping and breaking of bones, very little can be said about early human activities on the basis of the Clovis materials. The Bone Bed component is inferred to be the result of slaughtering a small number of bison and processing at least the meat and some of the bones at or very near the spot of the kill. Other than some knapping of chert, it is unclear what transpired at the site during the latest of the Early Paleoindian components.

Wilson-Leonard is one of a number of sites investigated in recent years to yield evidence that traditional views ofEarly Paleoindian cultural complexes and the lifeways they reflect are in need ofrevision. The archeological assemblages indicate greater diversity in material culture and in subsistence behavior during Early Paleoindian times. These are among the issues addressed below in Chapter 11 . 


\section{CHAPTERS}

\section{LATE PALEOINDIAN ARCHEOLOGY}

by C. Britt Bousman

\section{INTRODUCTION}

The earliest Holocene occupations at Wilson-Leonard are represented by a number of components in the upper portion of Unit I and throughout Unit II. Accumulation of these sediments occurred between approximately 10,000 BP. and 8400 B.P. As the title of this chapter suggests these components are usually considered to be Late Paleoindian, but some believe that at least some ofthis material should be placed in the Early Archaic stage instead. No extinct megafauna was recovered from these sediments, and the shift to the exploitation of Holocene faunas was fully complete by 10,000 B.P. as indicated by the evidence at the Wilson-Leonard site. Also the presence of stemmed Wilson projectile points dating between approximately 10,0009500 B.P. places these assemblages in a less-secure Paleoindian category. Nevertheless, the occurrence of numerous lanceolate projectile points in a stratum that overlies the stemmed Wilson component leads us to include all these materials in the Late, i.e., Holocene, Paleoindian category.

The upper portion of Unit I contains at least two occupations, perhaps more, by Wilson peoples. The Wilson component, spanning the period between 10,000 B.P. and 9500 B.P. at this site, is characterized by a distinctive form of stemmed projectile point, the exploitation of modern fauna, and the presence of an inhumation of a single adult female. In the southern Plains and Texas, evidence of scattered Wilson components in the southern halfofTexas is known (Collins and Kerr 1993), but these are mostly clearly placed in terms of cultural stratigraphy and absolute chronology here at the Wilson-Leonard site. Similar stemmed projectile points found at other sites are rarely documented in a stratified context, even more rarely associated with secure absolute age estimates, and never before found in a context where the component could be firmly defined and conclusively identified as representing the remains of a single society. The WilsonLeonard site provides this context.
Unfortunately, in Unit II the stratigraphic separation of the various distinctive projectile point forms and the distribution of other artifacts were not clear enough to isolate individual assemblages or cultural components. It is clear that a number of components are present, and some in Unit II can be grossly seriated through time. Nevertheless, the stratigraphic separation of the materials is not secure enough and clear enough to reliably isolate individual components in terms of the complete archeological assemblages. The most common projectile point forms in Unit II include Golondrina-Barber, St. Mary's Hall, and Angostura, and it seems obvious that through time these occur in this same sequence (see Chapters 13 and 14 for detailed descriptions and analysis). Also in Unit II are a number ofrare forms such as Scottsbluff, San Patrice, Big Sandy, Midland, and Clovis as well as parallel-sided lanceolate forms and miscellaneous lanceolate forms that do not fall easily into known categories. The Wilson-Leonard site does not provide the cultural stratigraphic resolution that is necessary to define individual components in Unit II that can be confidently identified as a representative record of these various social groups. Nevertheless, intact and representative archeological materials are present in Unit II that span the period between 9500 B.P. and 8400 B.P., and these can be compared to the materials that occur before and after.

First, this chapter presents the stratigraphic context of these Late Paleoindian components, and then discusses the radiocarbon chronology. The discussion then focuses on the materials recovered from the excavations starting with the artifacts then the fauna and the features. The final section discusses the Wilson component and provides a spatial analysis of the materials from this component.

\section{GEOLOGYANDSTRATIGRAPIDCCONTEXT}

Archeological materials discussed in this chapter were found in the upper portion of Unit I and throughout the 
overlying Unit II (see Chapters 1, 2, and 6 for more detailed discussions of site setting and geological sequence). These sediments are found in a 6.5 -m-thick terrace near the south valley wall. The south valley wall consists of steeply sloping limestone bedrock, perhaps a bluff, that is buried by Late Quaternary sediments. The lowermost terrace deposits show the existence of an abandoned channel whose stream flowed against the south valley wall and deposited coarse-grained sediments during the Late Pleistocene. These coarse-grained sediments form the base of this terrace. Early in the Unit I sequence this stream avulsed to a new channel, and finergrained deposits, including cienega sediments and silts, began to accumulate in the abandoned channel along the south valley wall.

Upper Unit I sediments, more specifically the Leanne soil (Isi-c) and Unit Id, were deposited in this abandoned stream channel overlying the cienega deposits, Unit lei. The southern edge of the cienega deposits extend from the northwest comer of Block 4 to the southeast comer of Block 6 . Thus, the cienega deposits are restricted to the very northern portion of Block 4, northeast and east portions of Block 6 , the fine-screen unit (FSU), and TARL excavations that flank the east side of Block 6 . The Leanne soil overlies silty overbank alluvium, Unit Isi, in the remainder of the deeper excavations in Blocks 3, 4, 5, and 6. The upper and lower boundaries of the Leanne soil slope down toward the northeast suggesting that it inherited a sloping topography created by both the abandoned channel with its cienega fill, the Unit Isi sediments, and the bedrock topography.

Unit Isi-c, the Leanne soil, is a brown to yellowish brown stoney clayey silt with moderate to coarse crumbly structure. Gravels are much less common compared to the Unit Isi sediments below. Numerous rhizoliths, snail shells, and tubes or pores with carbonate coatings are present in the soil. The upper surface of the Leanne soil is unconformable with Unit Id and perhaps indicative of a brief depositional hiatus. It appears that the soil formed as sediment accumulated, thus it is cumulic, but pedogenic alteration of underlying cienega deposits also occurred.

Unit Id sits unconformably over the Leanne soil, and it marks the final stage of Unit I sedimentation. The distribution of Unit Id is irregular, but generally it thins upslope to the south where it occurs as thin discontinuous lenses. It consists of a pale brown to dark yellowish brown compact, slightly sticky and plastic clayey silt with subangular blocky structure and a spongy fabric. A few rhizoliths are found in Unit Id, some extend down into the Leanne soil, and a few of these terminate at the top of Unit Id at its Unit II boundary.

Unit II sediments unconformably cover all Unit I sediments. This contact represents the truncation by erosion of both the Leanne soil and Unit Id sediments. Unit II is described as a massive deposit consisting of nonsticky and nonplastic brown coarse crumbly sandy, clayey silt with angular pebbles. Pebbles are more common in the lower portion of Unit II, and sediments in the upper portion of Unit II often are redder. Different interpretations of the redding include alteration by pedogenic processes (Holliday 1992) or increased oxidation of rocks and sediment (see Chapter 6). In any case, the sediments of Unit II represent a subtle, but nevertheless distinct shift from alluvial to colluvial modes of deposition. Unit II sediments completely filled the abandoned channel and began to accumulate on the bedrock surface upslope of the channel. The lower and upper boundaries of Unit II slope down from the southwest to the northeast and the unit thickens toward the northeast comer of Block 6 and the TARL excavations. Unit II is mostly colluvial in nature, although some alluvial sediments continued to be deposited, and the bedrock upslope is a primary source of much of the colluvial sediments.

For the most part, sediments on the slope above and south of the channel, the Valley Margin, cannot be subdivided into the same units recognized in the Valley Floor portion of the site, but a subdivision is possible in terms of lower slope deposits (UnitX) and upper slope deposits (Unit Y). Unit II interfingers with Unit X sediments. Unit Xis described as a massive very pale brown compact silt with subangular blocky structure with diffuse gravel stringers. Clearly this deposit is colluvial in nature and perhaps the primary difference between Unit II sediments found in the Valley Floor and Unit X sediments found in the Valley Margin is a lack of alluvial sediment contribution to Unit X. Unit $\mathrm{Y}$ contains Archaic materials and is not discussed in this chapter.

The stratigraphic context of Burial 2 in the Leanne soil merits special mention. Unfortunately, no profile recorded the stratigraphic position of Burial 2, but photographs, sediment analysis, and elevation records indicate that Burial 2 was first recognized in the lower portion of Unit Isi-c, the Leanne soil. Photographs clearly indicate that the burial pit extended down into Isi and lei (cienega) deposits. Micromorphological analysis of sediment samples collected from the burial pit fill indicate that Isi-c, Isi, and lei sediments comprise the sediments in the burial pit and support the other lines of evidence for a lower Leanne soil position.

\section{RADIOCARBON CHRONOLOGY}

A major portion of the radiocarbon dating effort was expended on the Late Paleoindian deposits and 43 radiocarbon assays were made on organic materials from upper Unit I and Unit II sediments. These determinations indicate that the sediments span a 1,600-year interval between approximately 10,000 and 8400 B.P, and provide unique and critical chronological control for this poorly understood Early Holocene period. A variety of materials were analyzed, but usually the most reliable age estimates come from charred botanical remains such as wood charcoal or nut shells. Stafford provides a detailed analysis of these radiocarbon determinations in Chapter 25 and the discussion below extracts the most significant findings from that chapter. 


\section{Unitl Age Estimates}

Thirty-one determinations were obtained on upper Unit I materials. All of these were collected from Unit Isi-c, and none is from Unit Id. In this discussion, I present only the most reliable or significant assays. The reader is referred to Chapter 25 for a full listing of all radiocarbon determinations and a complete analysis of these determinations. The non-Burial 2 age estimates are presented in Table 8-1, and the reliable radiocarbon assays associated with Burial 2 are listed in Table 8-2. In Table 8-1, all 12 of the Leanne soil determinations made on sediments have been excluded, because these demonstrate contamination by younger carbon through pedogenic processes. Also, a single determination made on gastropod shell was eliminated as the $10,520 \pm 80$ B.P. determination (CAMS-6377) is directly associated with the Feature 253 tree stump and these determinations indicated a contamination of older carbon in the gastropod shell. termination is too inexact to offer any useful information. However, two burned roots stratigraphically above the burial within Unit Isi-c but originating from trees growing in Unit IJ help to constrain the possible age range ofBurial 2

The determinations presented in Table 8-2 suggest that the probable age ofBurial 2 is the middle of the tenth millennium as well. However, these determinations are slightly younger than the actual age of the burial event and provide only a minimum age for Burial 2. First, Feature 72 and Feature 167 are burned tree root systems that are stratigraphically above Burial 2. Based on the ages, it is possible that these root systems were on trees that were growing during Unit II times and totally postdate Unit I. Second, the sediment samples from the burial pit fill have probably been biased by younger carbon as have all Leanne soil sediments due to the pedogenic processes of leaching $<$ ind translocation. Unfortunately, the only materials that would definitely provide an accurate age estimate are the human bone or associated

TABLE 8-1

Reliable Radiocarbon Determinations from Nonburial Contexts in Unit Isi-c*

\begin{tabular}{l|l|l|l|l}
\hline Lab Number & Context & Feature No. & Material & Radiocarbon A2e B.P. \\
\hline none, average of 6 & upper Isi-c & 253 & Tree Stump & $9550 \pm 30$ \\
CAMS-13842 & mid Isi-c & none & Walnut Shell & $9750 \pm 60$ \\
CAMS-10195 & lower Isi-c & 255 & Hearth Charcoal & $9990 \pm 70$ \\
\hline
\end{tabular}

*See Table 25-8 for six upper Isi-c tree stump determinations.

TABLE 8-2

Reliable Radiocarbon Determinations Associated with Burial 2

\begin{tabular}{l|l|l|l|l}
\hline Lab Number & Context & Feature No. & Material & Radiocarbon Aire B.P. \\
\hline CAMS-14807 & mid Isi-c & 72 & Tree Root & $9430 \pm 60$ \\
CAMS-14805 & mid Isi-c & 167 & Tree Root & $9410 \pm 60$ \\
Tx-4787 & lower Isi-c & Burial 2 Pit & Sediment & $9470 \pm 170$ \\
Tx-4793 & lower Isi-c & Burial 2 Pit & Sediment & $9650 \pm 124$ \\
\hline \hline
\end{tabular}

The determinations in Table 8-1 show that the age range for Unit Isi-c is between $9990 \pm 70$ B.P. and $9550 \pm 30$ B.P. The ending age is an av.erage of six assays made on a single in situ tree stump (Feature 253) that had grown in and was covered by Unit Isi-c sediments. The beginning date for Unit lsi-c is wood charcoal from an in situ burned stone hearth very near the bottom on Unit Isi-c. These assays indicate that Unit lsi-c spans only a 440-year interval starting 10 millennia ago.

Eight assays were made on human bone and charcoal from Burial 2 (the Leanne Burial), but the two assays made on sediments collected from the burial pit appear to fix best the burial to the radiocarbon time scale. The radiocarbon assays made on human bone from Burial 2 were all contaminated by younger carbon, and the charcoal AMS de- organic artifacts. The bone is too poorly preserved to obtain accurate radiocarbon age estimates, and organic artifacts were not recovered. The most reliable age estimate of the burial pit actually comes from the stratigraphic information and rnicromorphological analysis. The micromorphological analysis of sediments indicates that portions of Unit Isi, Unit lcl, and Unit Isi-c were all present in the burial pit fill. This shows that the excavation of the shallow burial pit started in the Leanne soil (Unit lsi-c) and extended down into Unit lsi and Unit lcl (cienega) sediments. However, the top of the burial pit was not recognized until fairly deep in Unit lsi-c sediments. Thus, based on the preponderance of the radiocarbon and stratigraphic evidence, it appears that Burial 2 is close to 10,000 years old although its exact age is unknown. 


\section{Unit II Age Estimates}

Eleven radiocarbon determinations are from Unit II contexts (Table 8-3). The age range suggested by these determinations spans at least 800 years between approximately 9500 BP. and 8800 BP. Unit II may actually span a longer interval as the oldest radiocarbon determination within overlying Unit III is approximately 8400 BP. (see Chapters 9 and 25). Thus, Unit II may span an interval of 800 to 1,100 years. The termination ofUnit I sediments is extraordinarily well dated at $9550 \pm 30 \mathrm{BP}$. by the tree stump (Feature 253) in the upper portion of Unit Isi-c. The five assays from the lower portion of Unit II provide a average age of $9508 \pm$ ? BP. This is barely 40 years younger than the average of six determinations from Feature 253 in the upper portion of Unit Isi-c. Thus, little time is allowed for the termination ofUnit 1sedimentation, independent pedogenic development of the Leanne soil, the erosion of Unit I, and the beginning ofdeposition of Unit 11 sediments.
The extractable weight percentages hint at two brief grassy periods within the Leanne soil; one at the bottom and another in the upper half, and the upper grassy interval is supported by the woodland/grassland ratio. However, it appears from both sources of data that the environment during the accumulation of Unit II was more grassy than during the Leanne soil. Also, the transition from Unit I to Unit II is marked by a small decline in $\mathrm{C}_{3}$ versus $\mathrm{C}_{4}$ grass phytoliths. Other $\mathrm{C}_{3}$ and $\mathrm{C}_{4}$ grass phytolith shifts are more dramatic, but the Unit I/Unit II boundary shift is correlated with a significant increase in the extractable weight percent as well as a drop in the woodland ratio. All these lines of evidence suggest that the transition from Unit 1 to Unit II is marked by a shift to more grassy conditions and that changed to higher frequencies of $\mathrm{C}_{4}$ grass species. This shift to grassy conditions at the Unit I/Unit II boundary may correlate with a drop in arboreal pollen in the nearby Boriack Bog sequence that occurs at approximately $9500 \mathrm{BP}$. (Bousman 1998).

TABLE 8-3

Reliable Radiocarbon Determinations from Unit II

\begin{tabular}{l|l|l|l|l}
\hline Lab Number & Context* & Feature No. & Material & Radiocarbon Age B.P. \\
\hline average of Tx-4784a-c & upper II & - & Wood Charcoal & $8870 \pm 70$ \\
CAMS-10207 & upper I-mid II & 238 & Tree Root & $8830 \pm 90$ \\
CAMS-18640 & mid II & 157 & Hearth Charcoal & $9340 \pm 60$ \\
CAMS-7560 & lower II & 236 & Hearth Charcoal & $9650 \pm 80$ \\
Tx-4828 & lower II & 165 & Tree Stump & $9530 \pm 88$ \\
CAMS-14806 & lower II & 164 & Tree Stump & $9520 \pm 60$ \\
CAMS-14805 & lower II & 167 & Tree Stump & $9410 \pm 60$ \\
CAMS-14807 & lower II & 72 & Tree Stump & $9430 \pm 60$ \\
CAMS-19080 & II-Area B & 198 & Wood Charcoal & $9240 \pm 70$ \\
\hline
\end{tabular}

*Unless indicated. all assays are from Blocks 4 or 6 or TARL excavations.

\section{PAST ENVIRONMENTS}

Various evidence can be used to infer the nature ofpast environments and climates. The best on-site data are the phytoliths, even though preservation is a problem in Unit I and Unit II sediments. The percent of extracted weight and the woodland/grassland ratio is used by Fredlund (Chapter 41) along with the diagnostic grass phytolith forms to suggest that conditions were more wooded in the middle of the Leanne soil, Unit Isi-c (Figure 8-1). Fredlund collected 14 samples in vertical sequence from the Leanne soil and 5 samples from Unit II. If the duration of the accumulation of Leanne soil sediments is restricted to 440 years and Unit II limited to 1,100 years, this would make the average duration of a single phytolith sample approximately 30 years within the upper Unit I sediments and 220 years within Unit II sediments. These are only gross estimates and actual temporal durations of individual samples could, and probably do, vary greatly.
Only one diatom sample from the Late Paleoindian deposits produced diatoms in enough abundance for counting (see Chapter 38). This sample was from the bottom of the Leanne soil (Unit Isi-c), Square 20, Level 42-43. Apparently diatoms were only preserved within calcium carbonate nodules. These likely formed in place, either by pedogenesis or from a ground water source, but, in either case, any diatoms not encased in calcium carbonate were destroyed. The diatoms were characteristic of perennial but shallow, marshy, vegetated ponds or streams with standing or perhaps slow flowing water. One species, Cymbellagaeumannii, is founded in cooler habitats, and its presence may indicate slightly cooler conditions at approximately 10,000 BP. Freshwater ostracodes, also from Level 42 and 43 in Square 20, suggest a permanent shallow alkaline water source (see Chapter 39).

Even though charcoal is not abundant in the Early Holocene strata (see Chapter 40), the numerical distribution is revealing when compared to other forms of paleoenvironmental data such as the phytoliths (Table 8-4). The 


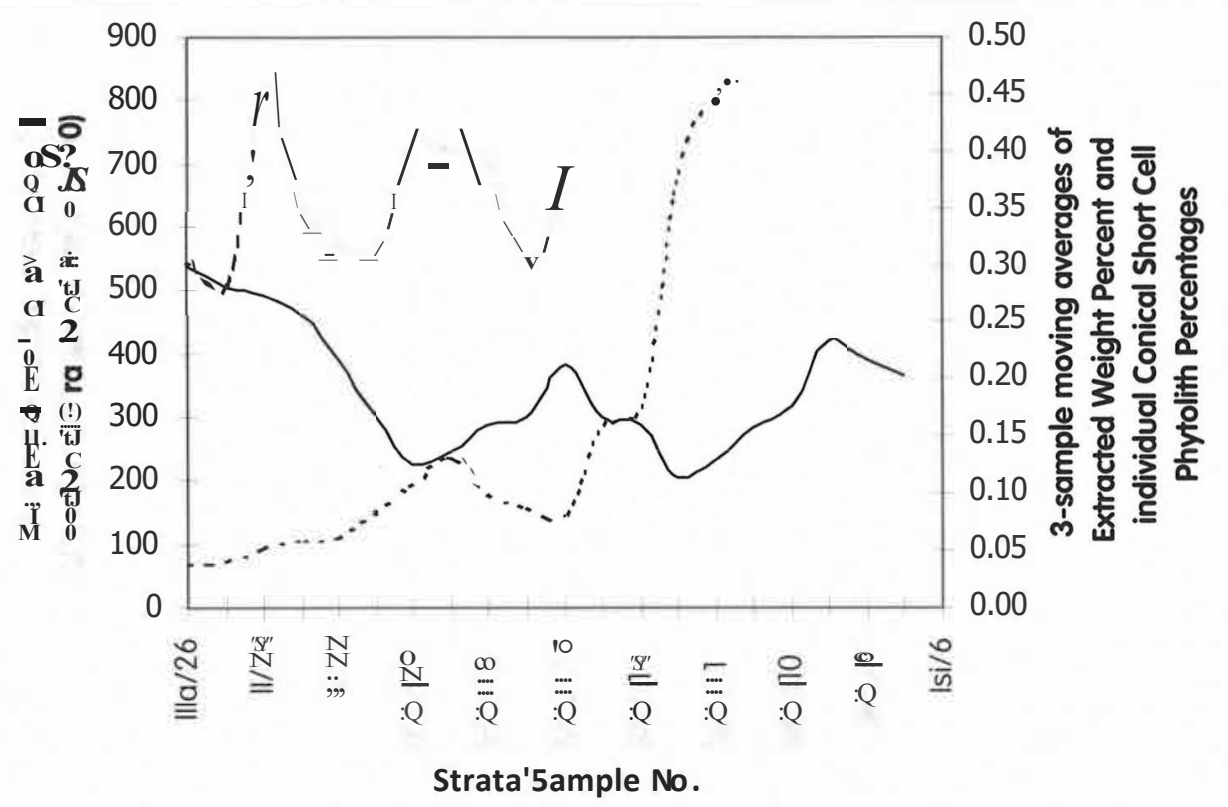

.......Woodland Ratio - - Extracted Wt. - - - - Conical-C3

FIGURE 8-1. Percent of extracted weight as measured in phytolith samples in Units I and II.

TABLE 8-4

Stratigraphic Distribution of Charcoal

\begin{tabular}{l|c|c|c|c}
\hline TARL Charcoal & Upper I & I/II & II & Totals \\
\hline Oak & 6 & $\mathbf{I}$ & 3 & 10 \\
Juniper & 1 & 2 & 4 & 7 \\
Elm & 0 & 0 & 1 & 1 \\
Totals: & 7 & 3 & 8 & 18 \\
\hline \hline
\end{tabular}

important point is that in Unit I oak is dominant, but by Unit II oak and juniper are roughly equal. The charcoal data, when linked with the phytolith evidence, implies that conditions may have been drier in Unit II times. As indicated above, this hypothesis is supported by the Boriack Bog pollen record (Bousman 1998).

The combination of on-site and off-site paleoenvironmental data suggests that conditions varied during the Late Paleoindian period. During the accumulation ofupper Unit I sediments the environment was probably relatively moister. With the termination of Unit I sediments a brief erosional event and the deposition of colluvial Unit II sediments may have been stimulated by drier conditions, reduced arboreal cover, and increased grass cover. However, too little data are available to propose attendant temperature changes.

\section{ARTIFACT ASSEMBLAGES}

The artifacts recovered in the various stratigraphic units provide a measure of the human activities that occurred dur- ing the Early Holocene and of the cultural affiliations of the groups that occupied the site. The data from this section draws from numerous chapters in the following volumes and the reader is referred to these as appropriate.

\section{Cultural Affiliations}

The first issue addressed with the artifactual data is the definition of cultural affiliation and identification of components. Wilson-Leonard offers a large sample of Paleoindian projectile points for analysis and classification. Ninety projectile points and projectile point fragments were recovered from the Early Holocene strata, and it is the physical characteristics as well as the stratigraphic distribution that provides the basis for assessing the cultural affiliations for the Late Paleoindian period. These can be grouped into two basic groups: lanceolate and stemmed (see Chapters 13 and 14). Some of these forms, such as the stemmed Wilson points, are very distinctive, but the unfluted lanceolate projectile points present a bewildering array of forms that defied easy classification in preliminary sorting. Many previous attempts to assess typological issues were hampered by small projectile point assemblages (e.g., Thoms 1993), and often no effort was made to conduct a systematic typological analysis. Clearly this was an early roadblock for a cultural historical analysis of the Wilson-Leonard materials, but such a large projectile point sample allowed a statistical analysis that is rarely possible at Paleoindian sites.

The typological classification of unfluted lanceolate projectile points by North American archeologists has a long 
history of problems and misapplications. Early efforts in classifying unfluted lanceolate projectile points resulted in the establishment of Yuma as a type and its varieties in the 1930s (Renaud 1931, 1932). However, the inconsistencies and complications were recognized and Yuma was abandoned as a type (Howard 1943). With the abandonment of Yuma as an acceptable type, Plainview as a type slowly and gradually seems to have taken over the role as typological catch-all (Irwin-Williams et al. 1973; Johnson and Holliday 1980; Knudson 1983; Wheat 1972). Since Krieger (1947) first described these projectile points from the Plainview site, Plainview, as a type, has become known as any unfluted concave-based parallel-sided lanceolate projectile point. As discussed in more detail in Chapter 14, archeologists have stretched and strained the definition to the point of making it useless. At least in the Southern Plains and surrounding areas fewer forms have been rescued from this typological blackhole (e.g., Golondrina) than sucked inside by its growing gravitation pull.

To address this general problem and the more specific problem of the site's culture history, the Wilson-Leonard sample was combined with unfluted lanceolate projectile points from a number of other Paleoindian sites in the Southern Plains and surrounding areas, i.e., Plainview, St. Mary's Hall, Ryan's site, Beidleman Ranch, Bonfire Rockshelter, Lubbock Lake, Levi Rockshelter, Milnesand, Winkler-I, Sloan site, Devil's Mouth, Baker Cave, Tombstone Bluff, and Wiley Williams. This is one ofthe largest and most diverse samples ever used for a systematic quantitative analysis of projectile point typology in the Southern Plains. The importance of this analysis has greater significance than just for WilsonLeonard, but the results also have very specific site implications that are discussed here. Following the approach of Kelly (1982), a detailed analysis ofunfluted lanceolate projectile points and Early Archaic bifurcated-stem forms was developed. The attributes chosen for typological analysis were both metric and qualitative. The metric attributes focused on the basal portion of the lanceolate form, and attributes were selected so that they were not readily altered by common forms of tool maintenance, damage, or retooling. Also, by limiting the primary analysis to basal attributes, a number of basal fragments could be included.

In the Early Holocene strata this analysis defined 11 forms ofunfluted lanceolate projectile points. Two of these are defined for the first time in Chapter 14 (Thrall and St. Mary's Hall) and two others have been merged to form a combined type (Golondrina-Barber). This analysis indicates that Golondrina and Barber projectile points represent two extremes along a continuum of a single variable form. Five others are previously known and named forms (Angostura, Big Sandy, San Patrice, Scottsbluff, and Midland). Another four forms (concave lanceolate preform, lanceolate base fragments, parallel side base, ground square stem base) remain unnamed, even though the lanceolate base fragments and the parallel side forms are fairly numerous. In addition to the unfluted lanceolate projectile points, one projectile point in the Late Paleoindian-aged deposits was fluted and is probably a Clovis projectile point base. The remaining forms are stemmed. A number of these can be put in Early Archaic groups (Hoxie and expanding concave base). However, the final stemmed form is a distinctive projectile point formally named Wilson for the first time in this report (see Chapter 13). At least at this site, Wilson projectile points are clearly much older than any local Early Archaic forms and indeed many Paleoindian lanceolate points found at the site as well. The implications of this temporal pattern are discussed in Chapter 11.

A brief description of Wilson projectile points and the Paleoindian lanceolate forms is included here for ease of reference, but the reader is referred to Chapter 13 for moredetailed descriptions and Chapter 14 for the analysis of these artifacts. Even though Early Archaic stemmed projectile points occur in association with the Late Paleoindian forms, the descriptions are not repeated here (see Chapter 9).

Wilson projectile points are characterized by very thick, wide, and straight expanding stems with straight to slightly concave bases (Figures 8-2 and 8-3). The stems have grinding on lateral and bottom edges, and the bases are thinned bifacially or unifacially. Shoulders are prominent to slightly barbed. One specimen is atypical with broad side notches, and a slightly concave base. Another Wilson projectile point was recycled to form a scraper (Figure 8-4). Wilson projectile points are morphologically very similar to the Early Stemmed projectile points from the Devil's Mouth site (Johnson 1964; Sorrow 1968). However, the Wilson-Leonard specimens are thicker and have shorter stems than the Devil's Mouth projectile points. Other examples come from a number of sites primarily in the southern halfofTexas (Collins and Kerr 1993). There is also a striking similarity between Early Archaic projectile points known from the southeastern United States, especially Kirk Comer-Notched, but these appear to date no earlier than 9000 B.P. in the southeast (Anderson and Sassaman 1996).

Golondrina (Spanish for swallow) projectile points were first defined at the Devil's Mouth site as a variety of Plainview points characterized by flaring basal ears and deep basal concavity (Johnson 1964). Johnson listed them as Plainview golondrina clearly evoking a genus-species relationship between Plainview and Golondrina. However, by 1977 Golondrina projectile points were considered a distinctive type and separate from Plainview (Hester 1977). Kelly (1982) argued for the clear distinction between Golondrina and Plainview projectile points. Later, Kelly (1983a, 1983b) suggested that Barber projectile points were distinctive from Golon-drina projectile points on the lack of flared basal ears, but those forms had deep basal concavities. It is suggested in Chapter 14 that these two forms are the extremes along a morphological continuum that do not display significant stratigraphic differences and thus should be combined at least until better evidence can be 


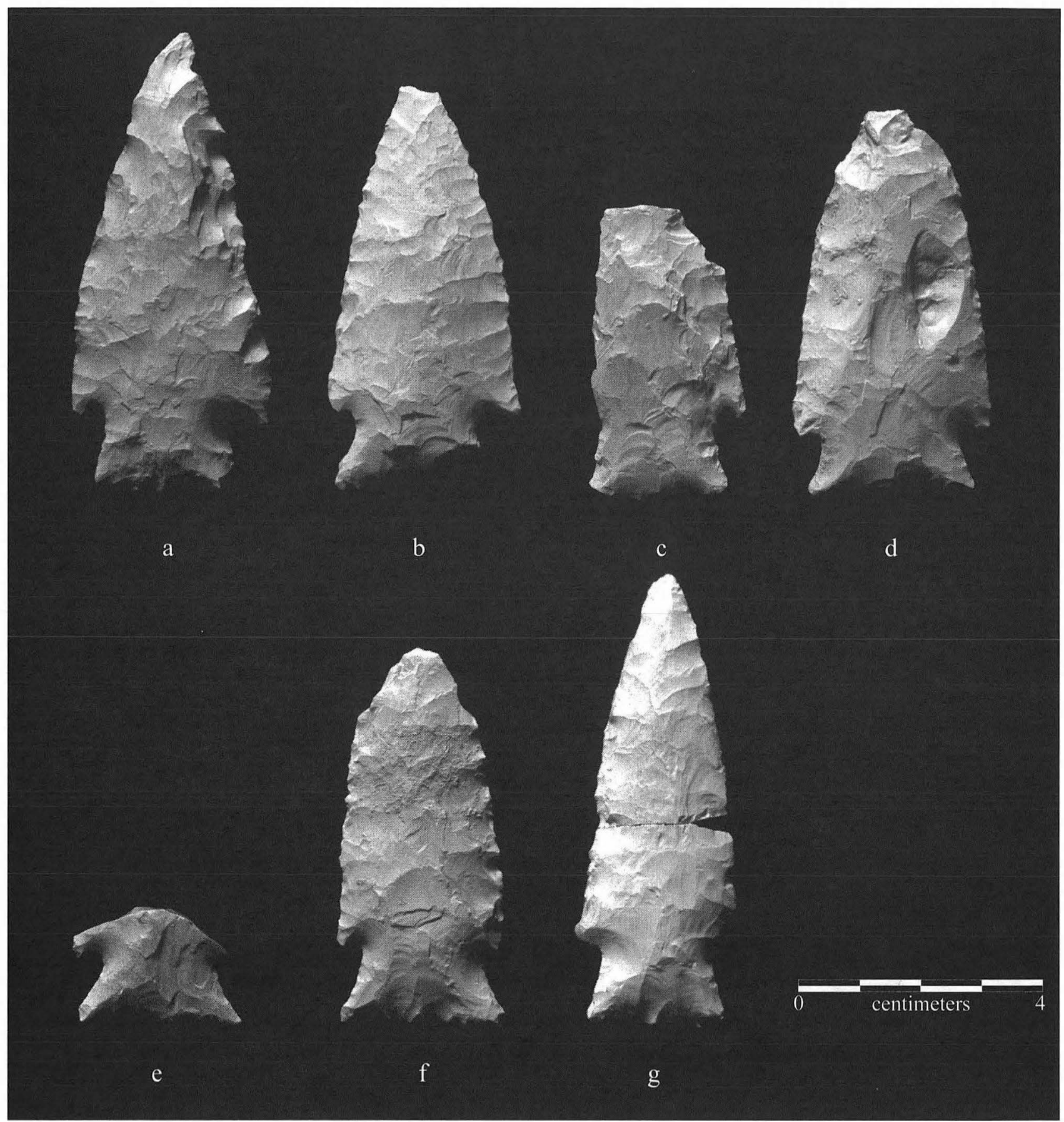

FIGURE 8-2. Wilson points from Late Paleoindian contexts (Unit Isi-c). Specimens numbers (a) 30CC2A-1; (b) 32CC2B-1; (c) 32CC2C1, (d) 32DD1B-1; (e) 32DD2C-1; (f) 33EE1C-1; (g) 35EEIA-1 conjoined with 34EE1B-I.

marshaled for their separation as individual types (Figure 8-5a-f). These projectile points have moderately thick, parallel-sided stems with very deep basal concavities. Bases often have bifacial or unifacial thinning. Light basal grinding is sometimes present, but lateral stem edges are always ground. Blades are fairly wide. Flaking patterns include subparallel, oblique subparallel, random, and collateral patterns.

St. Mary's Hall is also a newly defined type that has been confused with Plainview projectile points (Hester 1991).
In Chapter 14 it is suggested that these forms are morphologically distinct from Plainview projectile points, and that there is a distinctive temporal disjunction between Holoceneaged St. Mary's Hall and Pleistocene-aged Plainview projectile points. St. Mary's Hall projectile points are characterized by moderately thick, parallel-sided stems with moderate basal concavities (Figure 8-6). Lateral basal edges and the base edges are often ground. Flake patterns include subparallel, oblique subparallel, and random patterns. A subgroup of St. 


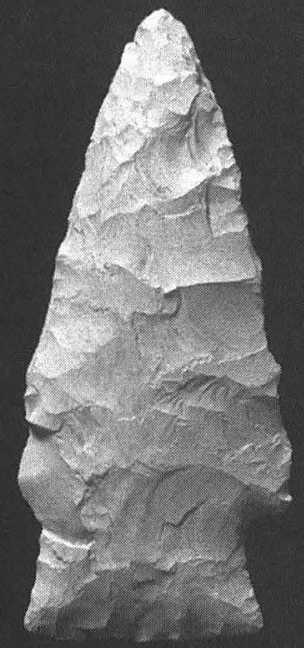

a

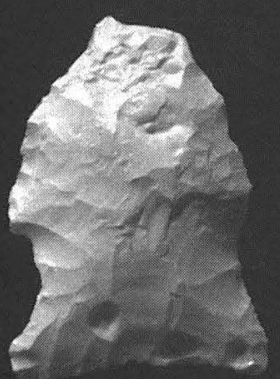

e

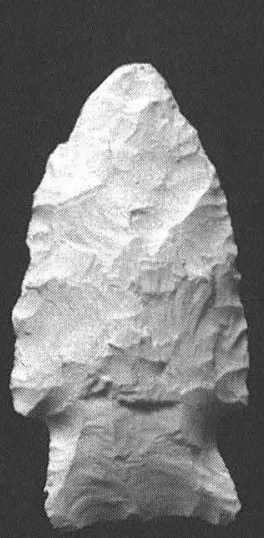

b

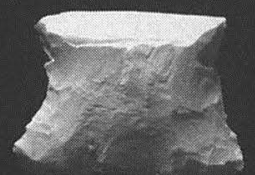

f

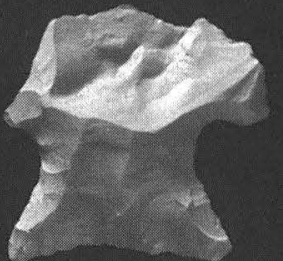

C

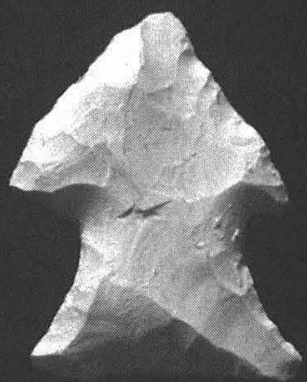

g
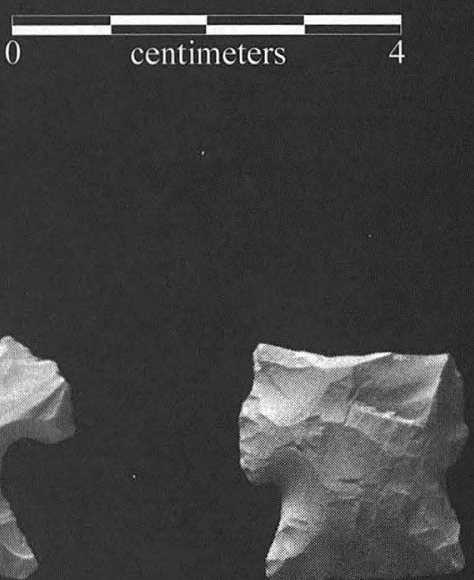

d

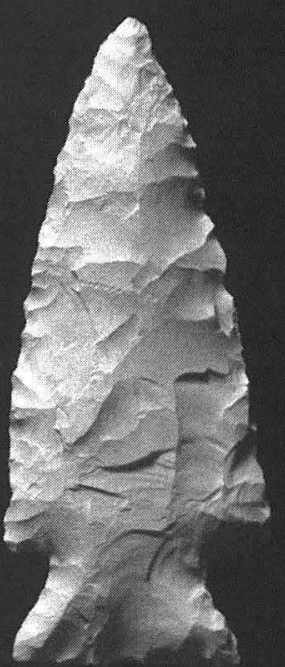

h

FIGURE 8-3 . Wilson points from Late Paleoindian contexts (a-c: Unit Id/II), (d-f: Unit II), (g, h: Valley Margin Unit X). Specimens numbers (a) 28Y2C-J; (b) 28Y2D-2; (c) 32Y2C-1, (d) 13U-1; (e) 15V1-1; (f) 29X1-1; (g) 20X-1; (h) 9V-1.

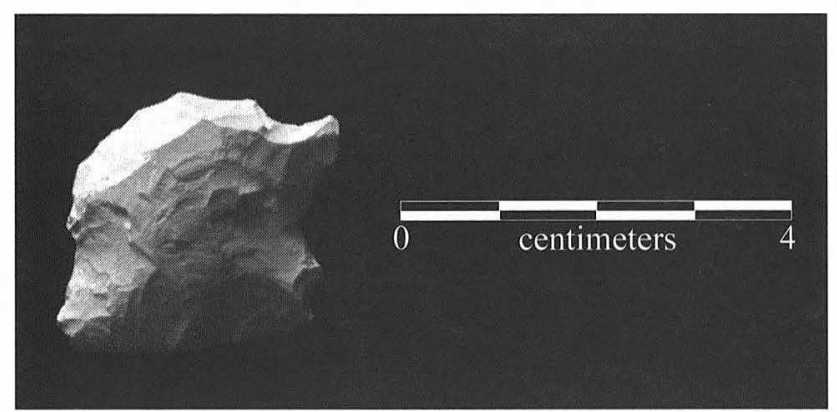

FIGURE 8-4 . Wilson point 17AA2-2 recycled as a possible hafted scraper.
Mary's Hall projectile points have deep basal concavities, and these have been named St. Mary's Hall-atypic. In this chapter both forms of St. Mary's Hall have been combined as both forms of projectile points occur in stratigraphically similar contexts. St. Mary's Hall projectile points are usually thicker, narrower, have more variable flake patterns and different cross-sections than Plainview projectile points.

Parallel-sided Stem lanceolate projectile points are fairly wide with moderately thick parallel-sided stems with flat to slightly concave bases (see Figure 8-51). A moderate degree of basal thinning is present, but basal grinding is generally absent. Lateral edges are ground. The specimens bear a 


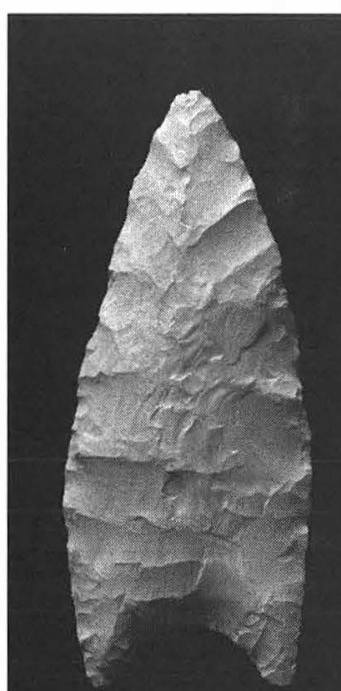

a

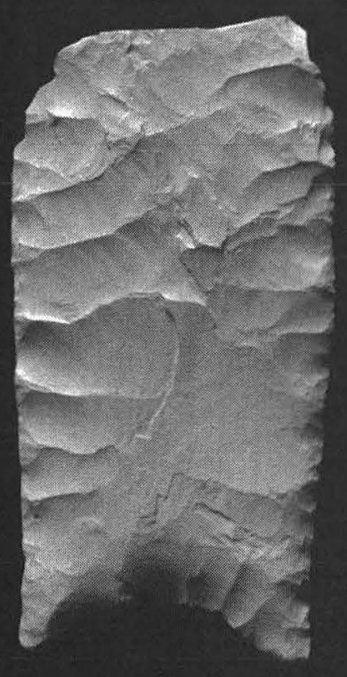

f

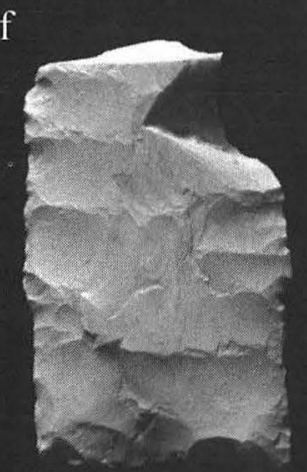

j

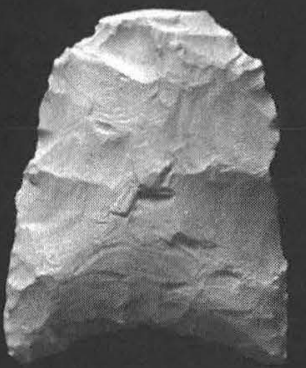

b

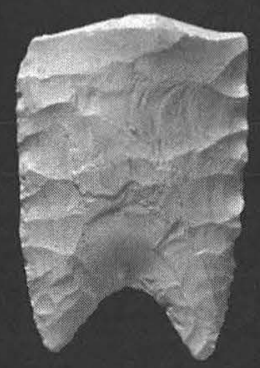

c

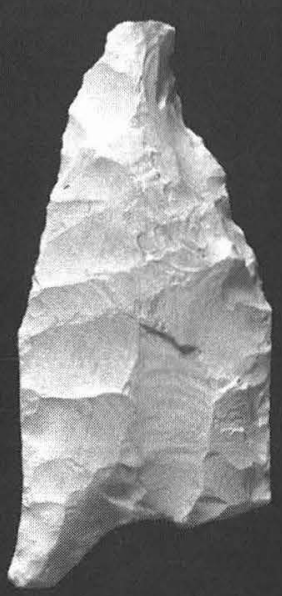

d

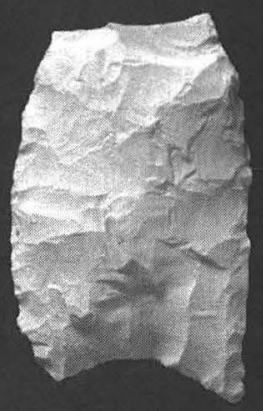

e
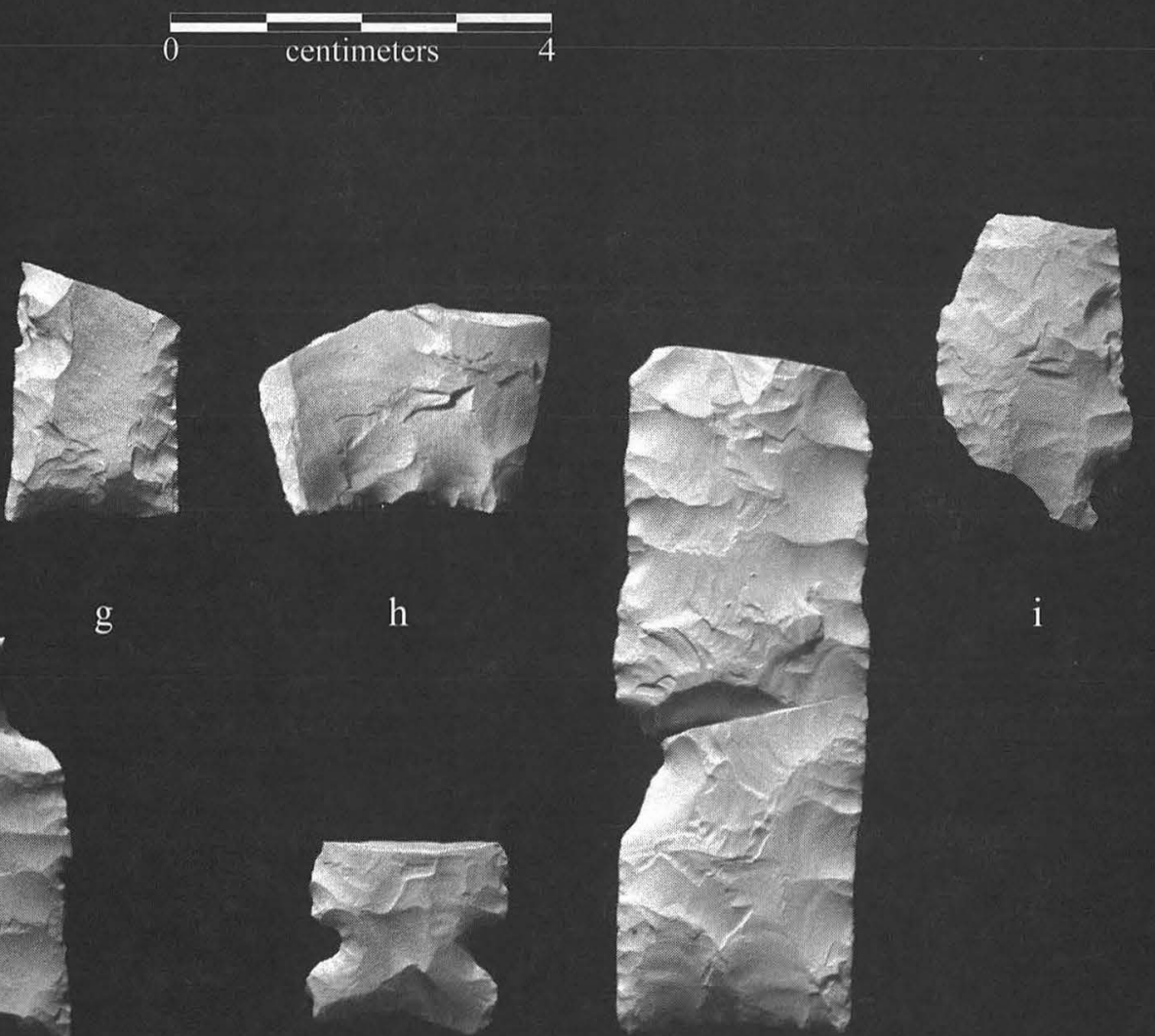

$\mathrm{k}$

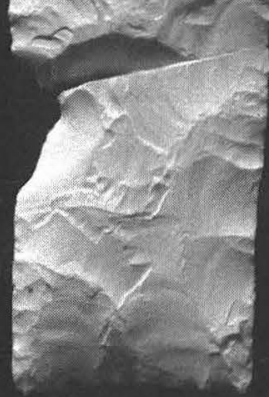

1

FIGURE 8-5. Representative Golondrina-Barber and other Late Paleoindian projectile points. (a-f) Golondrina-Barber; (g-h) miscellaneous lanceolate; (I) San Patrice; (j) Scottsbluff; (k) Big Sandy; (1) parallel-sided. Specimens numbers (a) I5X1-1; (b) 1473-1; (c) 33X2C-1, (d) 37T2B-3; (e) 1313; (f) 51 Y1B-1; (g) 25EE2B-1; (h) 25AA2C-4; (I) 340-9; (j) 26V2B-2; (k) 24U 1-1; (I) $22 \mathrm{~T}-1$. 


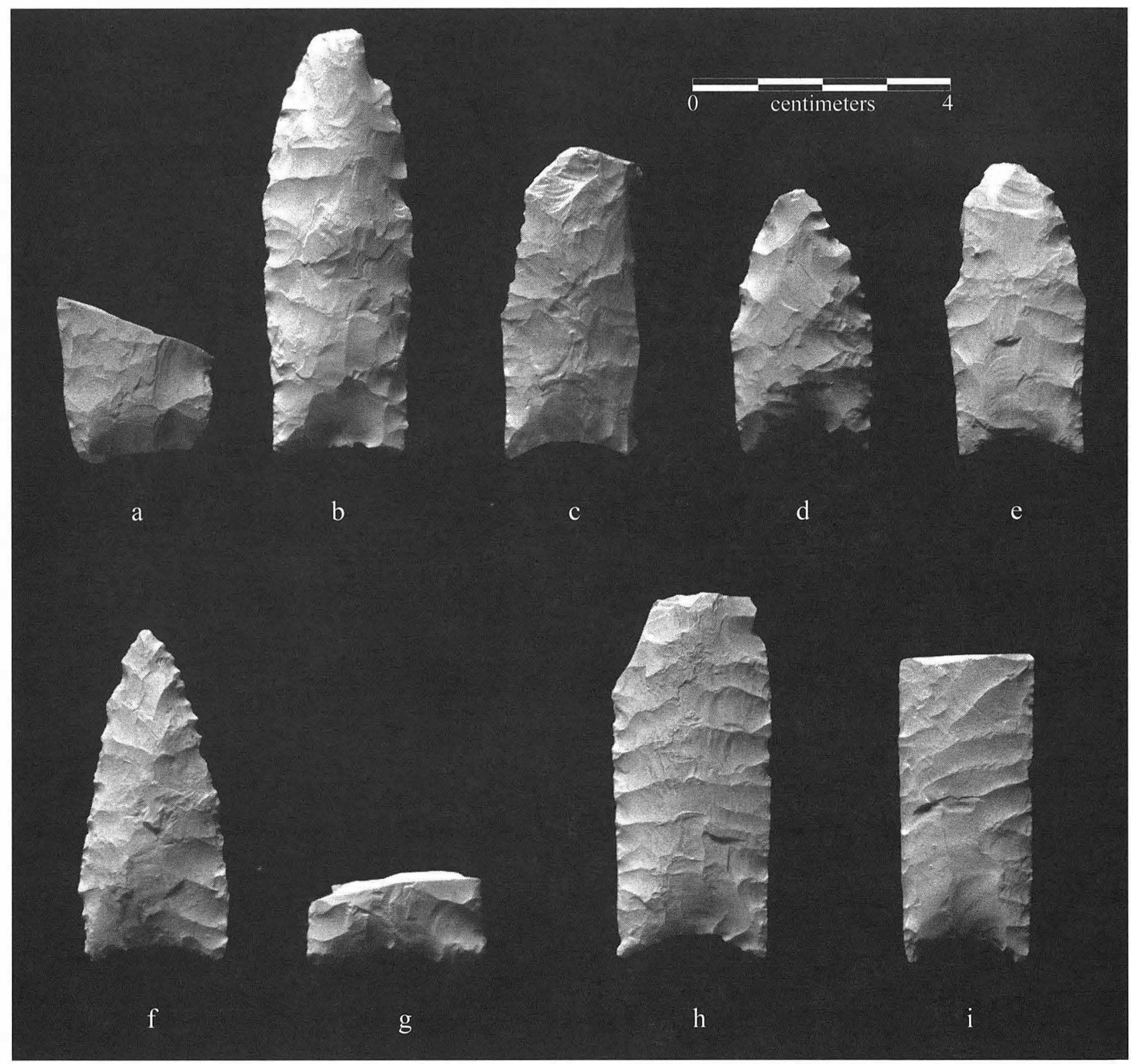

FIGURE 8-6. Representative Saint Mary's Hall projectile points. Specimens numbers: (a) 21Q-1; (b) 34UIBI; (c) 36R-1, (d) 7Q-1; (e) 25U2-l; (f) 28W2C-l; (g) 50XD-1; (h) 17Vl-4; (i) 20W-l.

superficial resemblance to Firstview (Wheat 1972), but the Wilson-Leonard specimens are significantly larger. These points also have metric and qualitative similarities to Golondrina-Barber projectile points but lack the distinctive deep basal notches. Ground Square Stem point is a moderately thick basal fragment with parallel sides and a straight base. This basal fragment is similar to the Parallel-sided Stem specimens above and is combined with this larger sample in the following analysis. A single lanceolate specimen is classified as indeterminate with coarse flaking and is distinguished by a thick parallel-sided stem with a moderate basal concavity. The base is bifacially thinned and grinding occurs on the lateral edges and the base.
Angostura points occur at the very top of Unit II and continue into Unit III. They have moderately thick but narrow blades with contracting ground stems and usually a slightly concave base that may be ground. Many specimens are represented by $1.5-3-\mathrm{cm}$-long snapped bases. The contracting stems often lead to a broader distal blade unless it was narrowed by resharpening. Most resharpening is beveled or alternately beveled. Flake pattern ranges from extremely well executed oblique parallel to subparallel, collateral, chevron, and random. Angostura projectile points are not well defined in the literature. Angostura points, initially called Long points by Hughes in 1949, were first identified in South Dakota at the Angostura Reservoir, but 
the descriptions were never published. Wheeler (1954) renamed these specimens Angostura. Alexander (1963) called similar lanceolate projectile points Plainview-Angostura in his report on Levi Rockshelter, and Kelly (1983a, 1983 b) attempted to clarify the concept by defining the Levi Rockshelter and other specimens as Texas Angostura (see Thoms [1993] for a more-complete history of the type definition).

A number of forms occur in very low numbers in Unit II. These include San Patrice, Big Sandy, and Scottsbluff. The San Patrice point is fairly short and wide with a broad stem with shallow side notches and prominent bifacial basal thinning (see Figure 8-5i). This specimen is similar to those found by Webb (1946) at San Patrice Creek, Louisiana. Employing variations in basal concavity and side notching, Duffield (1963) described three varieties of San Patrice projectile points: St. Johns, Hope, and Goodwin from the Wolfshead site in East Texas. Similar projectile points have been found at Homs Shelter north of Waco and called Brazos Fishtailed (Watt 1978). Hughes and Willey (1978) recovered comparable projectile points, called Rodgers side-hollowed, at the Rex Rodgers site in the Texas Panhandle. A single specimen classified as Big Sandy has a moderately thick stem with moderate basal concavity and fairly narrow side notch (see Figure 8-5k). Grinding is absent, and the blade has been snapped on a transverse fracture. The Scottsbluff point is characterized by thick parallel-sided stems with a fairly straight flat base (see Figure 8-5j). Grinding occurs on lateral stem edges and st'em base. The stems are defined by slight to moderate shoulders. Scottsbluff projectile points were first named and described by Barbour and Schultz (1932) from the ScottsbluffBison Quarry in Nebraska.

A single Midland point was recovered in Unit II. This point is a very thin base with a moderately contracting ground stem. Lateral edge retouch is very fine, and the lateral edges are ground although basal grind in absent. The flake pattern is subparallel. Midland projectile points were originally identified but not considered a formal type by Wendorf et al. (1955) from specimens they recovered at the Midland site. Later Wendorfand Krieger (1959) argued that these "unfluted Folsom" projectile points should be considered a formal type.

Also found in the Valley Margin Unit X were three Thrall points. Thrall is a newly defined type that is characterized by very thick, heavily ground, contracting stems with slight basal concavities, and wide, sometimes flaring, blades. The bases are usually ground. Flake patterns range from subparallel, collateral, and random. Initially some of these forms were identified as Hell Gap, others informally called "Fat Angostura" projectile points, and others were considered possible candidates for Victoria (Kelly 1983a, 1983 b), but their unique morphology, primary occurrence in Unit Illa in the Valley Floor, and strong association with Archaic forms justified a separate and local type definition. These are discussed more fully in Chapter 9.

The stratigraphic distribution of the projectile points in the TxDOT units is shown in Table 8-5 and graphically in
Figure 8-7. A number of distinctive patterns are present and this discussion proceeds from older to younger. Only two forms were found in Upper Unit I (Unit Isi-c and Unit Id) deposits (see Table 8-5). These are Golondrina-Barber projectile points and Wilson projectile points. Wilson points are most numerous in these strata, and most of the Wilson points occur in upper Unit I as well. In Unit I GolondrinaBarber projectile points are primarily restricted to the uppermost portions. Also as Table 8-5 indicates most (58.8\%) of the Golondrina-Barber projectile points occur in I/II or II sediments and as Figure 8-7 shows these are often restricted to the upper portions of Unit I and the lower portions ofUnitll, although Golondrina-Barber projectile points are the most widely distributed point type in the Early Holocene strata. Ofall the Early Holocene strata, upper Unit I has the least diversity of projectile point forms, and even though Golondrina-Barber projectile points are found in Unit I sediments, it is proposed that the archeological materials in these strata can be assigned to a Wilson component.

Levels that are mixtures of Unit I and Unit II are dominated by the same two forms (Golondrina-Barber and Wilson), but three other forms are found in these levels. These are Midland, Ground Square Stem, and Parallel-sided. No component assignments are attempted for these archeological materials besides a Late Paleoindian affiliation as these materials represent at least a mixture ofGolondrina-Barber and Wilson artifacts.

Unit II has the greatest diversity of projectile point forms in the deposits under review here. Present are Wilson, Golondrina-Barber, Scottsbluff, San Patrice, Big Sandy, St. Mary's Hall, Clovis, Angostura, and Parallel-sided Lanceolate, plus a few Early Archaic stemmed forms (Hoxie and expanding concave base). An inspection ofFigure 8-7 suggests that with better stratigraphic segregation the forms in Unit II would reflect a sequence starting with Golondrina-Barber (lower), St. Mary's Hall (middle), and Angostura (upper) forms. At least in Blocks 4 and 6 and the FSU no Early Archaic projectile point forms occur. However, so many other forms are scattered throughout the stratum that associations between these tools and other artifacts is too dubious to allow for the creation of these components. Plus the creation of components in this manner makes too many assumptions concerning the timing, duration, and exclusiveness of these forms. Clearly these assumptions cannot be made nor even assessed with the data from Wilson-Leonard.

The distribution of projectile points in levels assigned to XIII show a wide range of forms with Early Archaic stemmed projectile points clearly dominant and equal numbers ofThrall, Angostura, St. Mary's Hall, Golondrina-Barber, and Wilson projectile points. Except for a single Golondrina-Barber projectile point, Stratum X contains forms that are clearly found mostly commonly in the lower portion ofUnitIII. 
TABLE 8-5

Distribution of Projectile Points in Stratigraphic Units

\begin{tabular}{|c|c|c|c|c|c|c|}
\hline \multirow[b]{2}{*}{ Type } & \multicolumn{5}{|c|}{ Unit } & \multirow[b]{2}{*}{ Totals } \\
\hline & Upper I & $\mathrm{I} / \mathrm{II}$ & II & $\mathrm{X} / 11$ & $\mathrm{X}$ & \\
\hline Early Archaic & 0 & 0 & $\begin{array}{c}4 \\
14.8 \% \\
10.8 \%\end{array}$ & $\begin{array}{c}20 \\
66.7 \% \\
54.1 \% \\
\end{array}$ & $\begin{array}{c}5 \\
55.6 \% \\
13.5 \%\end{array}$ & 29 \\
\hline Thrall & 0 & 0 & 0 & $\begin{array}{c}2 \\
6.7 \% \\
50.0 \%\end{array}$ & $\begin{array}{c}\text { I } \\
11.1 \% \\
25.0 \%\end{array}$ & 3 \\
\hline Angostura & 0 & 0 & $\begin{array}{c}2 \\
7.4 \% \\
20.0 \% \\
\end{array}$ & $\begin{array}{c}2 \\
6.7 \% \\
20.0 \% \\
\end{array}$ & $\begin{array}{c}2 \\
22.2 \% \\
20.0 \% \\
\end{array}$ & 6 \\
\hline St. Mary's Hall & 0 & 0 & $\begin{array}{c}4 \\
14.8 \% \\
44.4 \% \\
\end{array}$ & $\begin{array}{c}2 \\
6.7 \% \\
22.2 \% \\
\end{array}$ & 0 & 6 \\
\hline Big Sandy & 0 & 0 & $\begin{array}{c}\mathrm{I} \\
3.7 \% \\
100.0 \%\end{array}$ & 0 & 0 & I \\
\hline San Patrice & 0 & 0 & $\begin{array}{c}1 \\
3.7 \% \\
100.0 \%\end{array}$ & 0 & 0 & 1 \\
\hline Scottsbluff & 0 & 0 & $\begin{array}{c}\mathrm{I} \\
3.7 \% \\
100.0 \% \\
\end{array}$ & 0 & 0 & 1 \\
\hline Indeterminate & 0 & 0 & $\begin{array}{c}1 \\
3.7 \% \\
100.0 \%\end{array}$ & 0 & 0 & I \\
\hline $\begin{array}{l}\text { Parallel-sided Lanceolate and } \\
\text { Ground Square Stem }\end{array}$ & 0 & $\begin{array}{c}3 \\
23.1 \% \\
50.0 \%\end{array}$ & $\begin{array}{c}3 \\
11.1 \% \\
50.0 \%\end{array}$ & 0 & 0 & 6 \\
\hline Golondrina-Barber & $\begin{array}{c}2 \\
18.2 \% \\
11.8 \%\end{array}$ & $\begin{array}{c}5 \\
38.5 \% \\
29.4 \% \\
\end{array}$ & $\begin{array}{c}5 \\
18.5 \% \\
29.4 \% \\
\end{array}$ & $\begin{array}{c}2 \\
6.7 \% \\
11.8 \% \\
\end{array}$ & $\begin{array}{c}1 \\
11.1 \% \\
5.9 \%\end{array}$ & 15 \\
\hline Midland & 0 & $\begin{array}{c}\mathrm{I} \\
5.9 \% \\
100.0 \% \\
\end{array}$ & 0 & 0 & 0 & 1 \\
\hline Wilson & $\begin{array}{c}9 \\
81.8 \% \\
45.0 \%\end{array}$ & $\begin{array}{c}4 \\
30.8 \% \\
20.0 \%\end{array}$ & $\begin{array}{c}5 \\
18.5 \% \\
25.0 \%\end{array}$ & $\begin{array}{c}2 \\
6.7 \% \\
10.0 \%\end{array}$ & 0 & 20 \\
\hline $\begin{array}{l}\text { Totals: } \\
\text { Percents: }\end{array}$ & $\begin{array}{c}11 \\
7.8 \%\end{array}$ & $\begin{array}{c}13 \\
9.2 \%\end{array}$ & $\begin{array}{c}27 \\
19.1 \%\end{array}$ & $\begin{array}{c}30 \\
21.3 \%\end{array}$ & $\begin{array}{c}9 \\
6.4 \%\end{array}$ & 90 \\
\hline
\end{tabular}

\section{Artifact Assemblages}

The distribution of all worked material through these units provides a indication of the types of tools that were manufactured and used, and the materials that were discarded. The presentation is hierarchical and by stratigraphic unit. Detailed descriptions and analysis ofall artifact classes can be found in Volume II and Volume III.

Table 8-6 presents the distribution of all artifacts. This table shows that debitage increases proportionately from upper Unit I through Unit II/Ill. The percentage of chipped stone tools, cores, ground/battered stone tools including core tools, chert cobbles, and worked bone are the greatest in upper Unit I and they generally decline up profile. Little difference is discernible among cores and core tools through time in the Late Paleoindian units (Figures 8-8 and 8-9). This pattern of low, in a relative sense, debitage frequencies in upper Unit I may be a reflection of on-site discard behavior and the differential transportation ofmaterials off-site rather than a relative measure of activities that occurred on the 


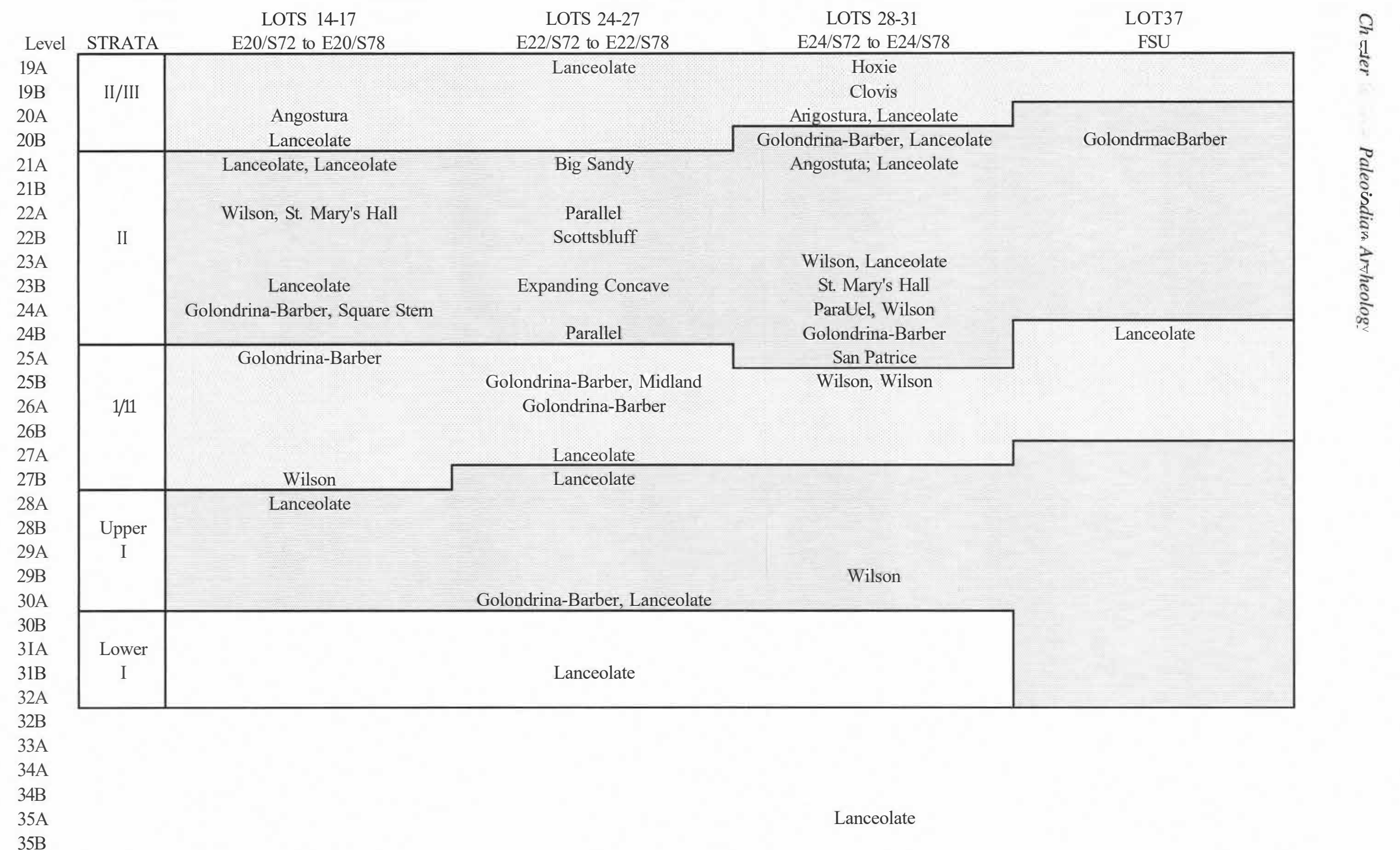

Plainview 
TABLE 8-6

Stratigraphic Distribution of All Artifact Classes

\begin{tabular}{|c|c|c|c|c|c|}
\hline \multirow[b]{2}{*}{ Artifact Classes } & \multicolumn{4}{|c|}{ Unit } & \multirow[b]{2}{*}{ Totals } \\
\hline & Upper I & I/II & II & $\mathrm{X} / 11$ & \\
\hline Debitage & $\begin{array}{r}10,916 \\
97.92 \% \\
\end{array}$ & $\begin{array}{c}9,632 \\
98.42 \% \\
\end{array}$ & $\begin{array}{r}42,675 \\
98.80 \% \\
\end{array}$ & $\begin{array}{c}3,817 \\
98.20 \% \\
\end{array}$ & 67,040 \\
\hline Cores & $\begin{array}{c}23 \\
0.21 \% \\
\end{array}$ & $\begin{array}{c}8 \\
0.08 \% \\
\end{array}$ & $\begin{array}{c}20 \\
0.05 \% \\
\end{array}$ & $\begin{array}{c}4 \\
0 . ! 0 \% \\
\end{array}$ & 55 \\
\hline Chipped Stone Tools & $\begin{array}{c}195 \\
1.75 \% \\
\end{array}$ & $\begin{array}{c}142 \\
1.45 \% \\
\end{array}$ & $\begin{array}{c}483 \\
1.12 \% \\
\end{array}$ & $\begin{array}{c}66 \\
1.70 \% \\
\end{array}$ & 886 \\
\hline Ground/Battered Stone Tools & $\begin{array}{c}8 \\
0.07 \% \\
\end{array}$ & $\begin{array}{c}3 \\
0.03 \% \\
\end{array}$ & $\begin{array}{c}13 \\
0.03 \% \\
\end{array}$ & 0 & 24 \\
\hline Chert Cobble & $\begin{array}{c}2 \\
0.02 \% \\
\end{array}$ & $\begin{array}{c}1 \\
0.01 \% \\
\end{array}$ & 0 & 0 & 3 \\
\hline Worked Bone & $\begin{array}{c}4 \\
0.04 \%\end{array}$ & $\begin{array}{c}1 \\
0.01 \%\end{array}$ & $\begin{array}{c}3 \\
0.01 \%\end{array}$ & 0 & 8 \\
\hline Totals: & 11,148 & 9,787 & 43,194 & 3,887 & 68,016 \\
\hline
\end{tabular}

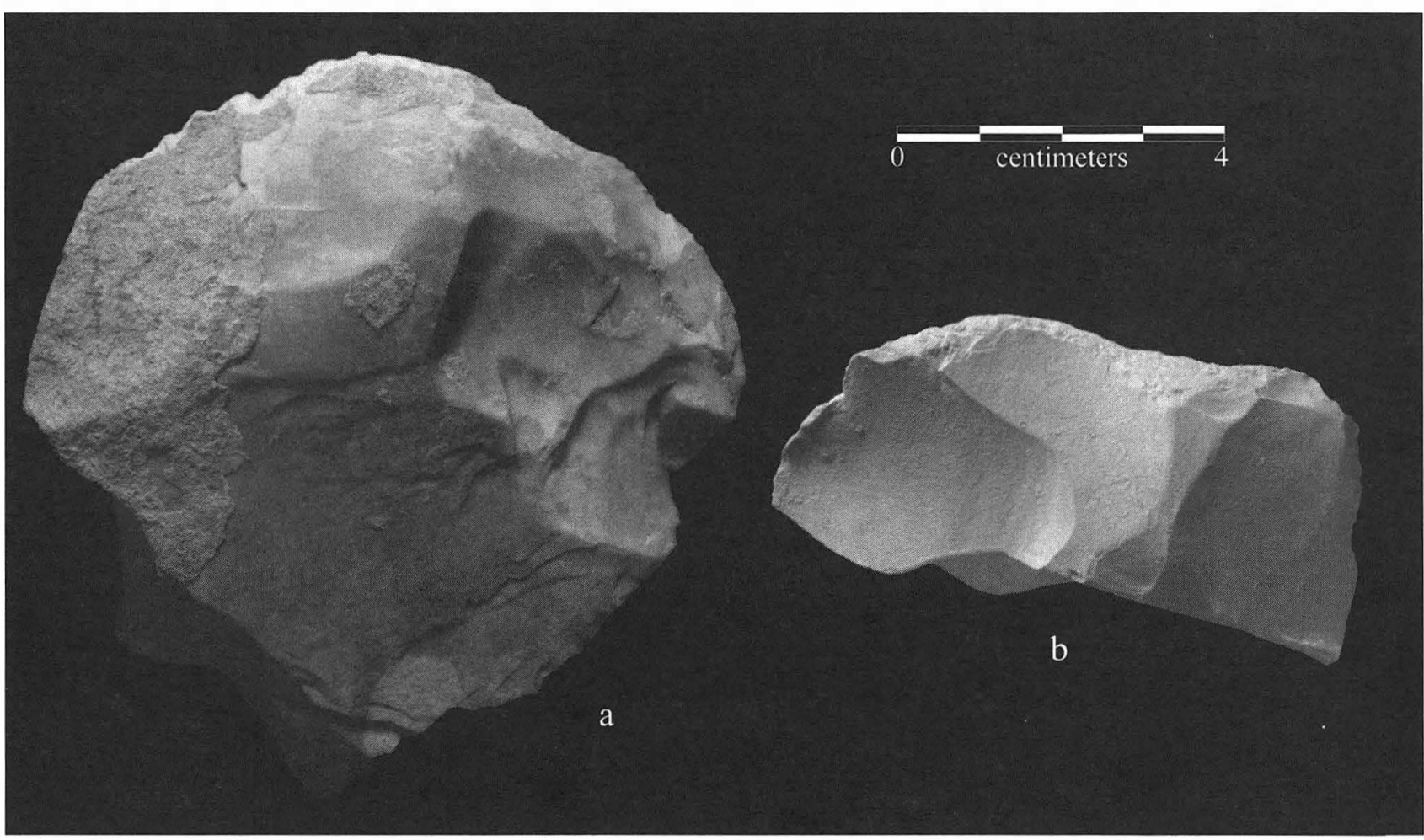

HGURE 8-8. Cores and core tools from the Wilson component (upper Unit I). (a) core tool (type 2); (b) large core harnmerstone. Specimen numbers: (a) 28TlA-1; (b) 22Q-15.

site. In other words, it appears that more material was transported off the site by the various inhabitants during Unit II times than by Wilson folks. This has an implication toward different curation strategies with Wilson occupants utilizing a more expendable strategy. Table 8-7 presents the distribution of all chipped stone tools, and it demonstrates that the percentages ofunifaces are the greatest in upper Unit I while projectile points are most common, at least in terms ofrelative abundance, in Unit I/II. Interestingly, upper Unit I has one of the least frequent occurrences of projectile points and the lowest percentage ofbifaces. Burins are chisel-like tools characterized by the removal of a unique flake known as a burin spall, and burin spalls are wedge cross-sectionshaped flakes that remove the edge of a flake, uniface, or biface (Figure 8-10). Burins and burin spalls are never common, and they are least frequent in upper Unit I (see Table 87).

The frequencies ofprojectile points and projectile point fragments show that complete projectile points are fairly common in upper Unit I and considerably less common in Unit II (Table 8-8). Unit II has roughly equal frequencies of basal, proximal, and medial fragments. These patterns are 


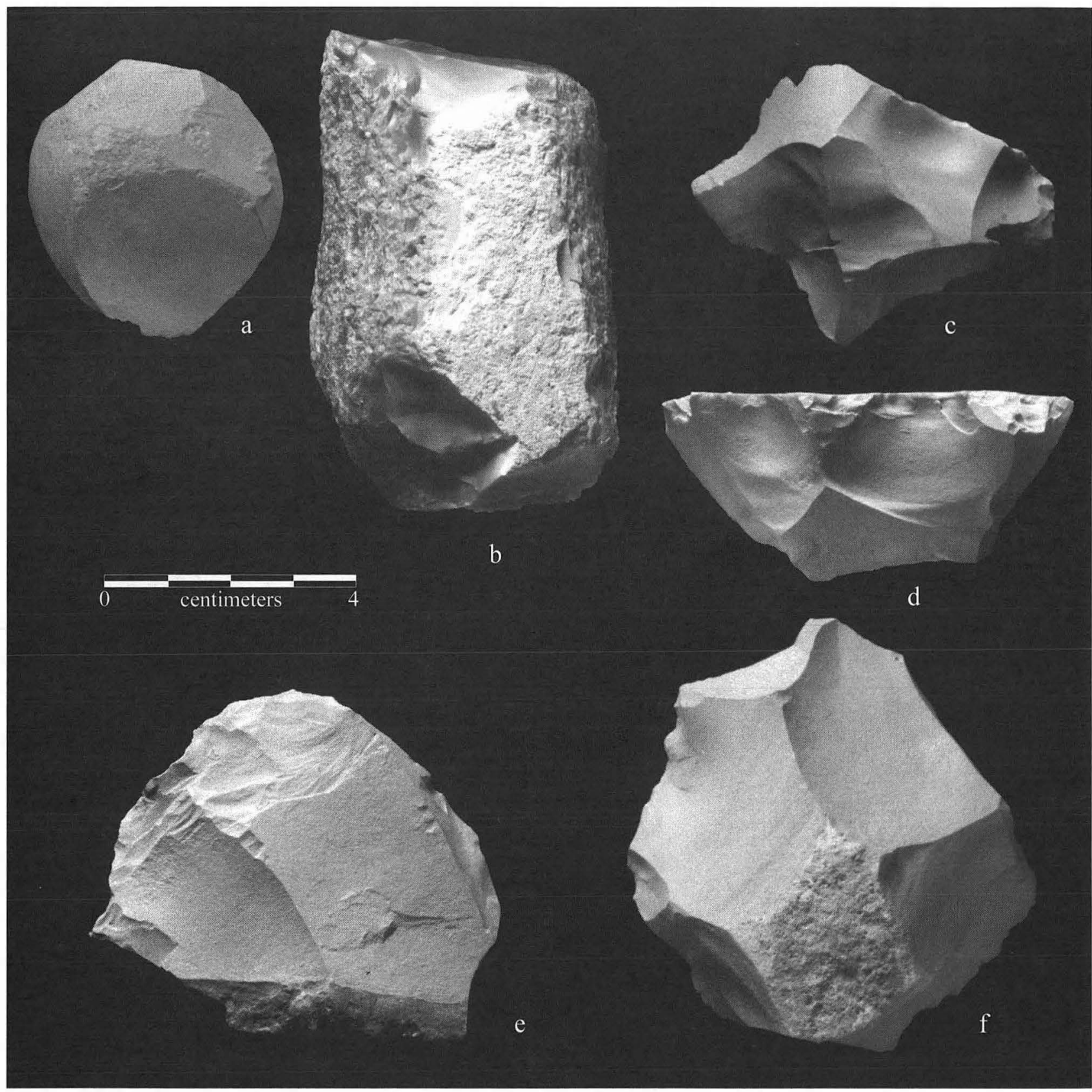

FIGURE 8-9. Core tools from Unit II. (a, b) core hammerstones; (c, d) large-flake microcores; (e) core tool (type 2); (f) multidirectional core. Specimen numbers: (a) 1428-2; (b) 28BB2A-1; (c) 1SZI-1; (d) 30DDIA-2; (e) 30BB2A-2; (f) 1SAAl-1.

probably related to the relative frequency of lanceolate versus stemmed projectile points in the various strata. These data can be used to suggest that lanceolate projectile points have a significantly higher breakage rate than stemmed projectile points. The diversity ofuses (see Chapter 22) as well as the long and narrow shape of lanceolate projectile points makes them easier to snap and more likely to be snapped.

Unfinished bifaces or bifaces that do not appear to be tools were assigned to three reduction stages that reflect increasingly more-finished specimens along a continuum represented by Stage 1 through Stage 3 classes (see Chap- ter 16). The distribution of the bifaces indicates that Stage 2 bifaces dominate the unfinished bifaces throughout the site (Table 8-9). A comparison of individual cell percentages shows that certain fluctuations do occur. To summarize these changes, Unit I has an unusually high percentage of Stage 1 bifaces and very low percentage of Stage 3 bifaces; Unit II/ III has the highest percentage of Stage 2 and Stage 3 bifaces; and Unit II has the most even spread between the three biface classes (Figures 8-11 and 8-12). Since access to lithic sources does not change during this interval, these changes are certainly a reflection of changes in either settlement, 
TABLE 8-7

Stratigraphic Distribution of Chipped Stone Artifacts

\begin{tabular}{|c|c|c|c|c|c|}
\hline \multirow[b]{2}{*}{ Chinned Stone Artifacts } & \multicolumn{4}{|c|}{ Unit } & \multirow[b]{2}{*}{ Totals } \\
\hline & Upper I & VII & II & XIII & \\
\hline Projectile Points & $\begin{array}{c}18 \\
9.4 \% \\
\end{array}$ & $\begin{array}{c}27 \\
19.4 \% \\
\end{array}$ & $\begin{array}{c}63 \\
13.2 \% \\
\end{array}$ & $\begin{array}{c}6 \\
9.2 \% \\
\end{array}$ & 114 \\
\hline Bifaces & $\begin{array}{c}44 \\
22.9 \% \\
\end{array}$ & $\begin{array}{c}34 \\
24.5 \% \\
\end{array}$ & $\begin{array}{c}129 \\
27.0 \% \\
\end{array}$ & $\begin{array}{c}20 \\
30.8 \% \\
\end{array}$ & 227 \\
\hline Burin and Burin Spalls & $\begin{array}{c}1 \\
0.5 \%\end{array}$ & $\begin{array}{c}9 \\
6.5 \%\end{array}$ & $\begin{array}{c}31 \\
6.5 \%\end{array}$ & $\begin{array}{c}4 \\
6.2 \%\end{array}$ & 45 \\
\hline Unifaces & $\begin{array}{c}129 \\
67.2 \%\end{array}$ & $\begin{array}{c}69 \\
49.6 \% \\
\end{array}$ & $\begin{array}{c}255 \\
53.3 \%\end{array}$ & $\begin{array}{c}35 \\
53.8 \%\end{array}$ & 488 \\
\hline Totals: & 192 & 139 & 478 & 65 & 874 \\
\hline
\end{tabular}

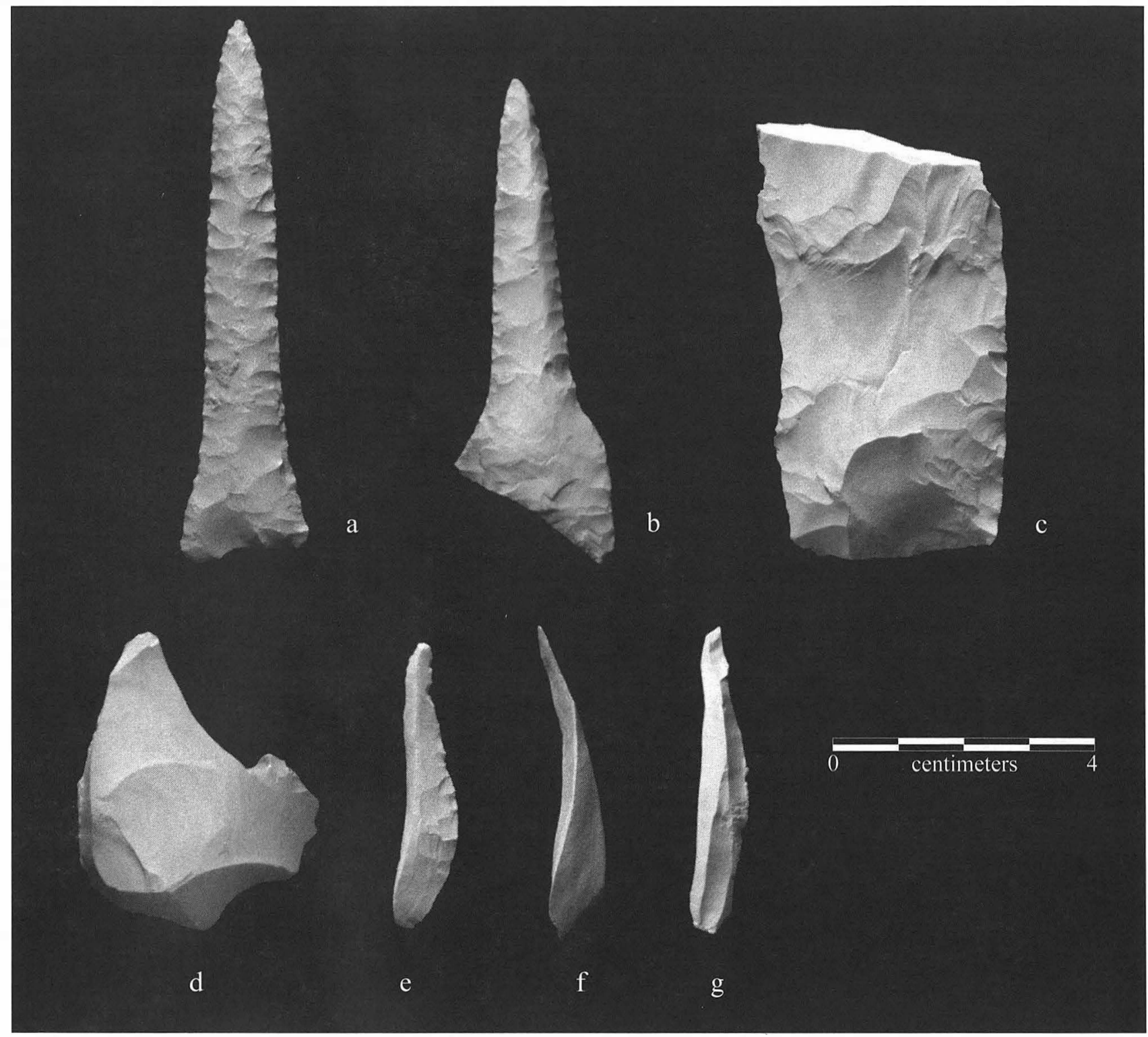

HGURE 8-10. Chipped stone tools from Unit II. (a, b) perforators; (c, d) burins; (e-g) burin spalls. Specimen numbers: (a) 32W1B-1; (b) 26UIB-3; (c) $11 \mathrm{~S}-2$; (d) 24VID-2; (e) 1685-1; (f) 29VI A-1; (g) 29X2A-1. 
TABLE 8-8

Stratigraphic Distribution of Complete and Broken Projectile Points

\begin{tabular}{|c|c|c|c|c|c|c|}
\hline & \multicolumn{5}{|c|}{ Unit } & \multirow[b]{2}{*}{ Totals } \\
\hline & Upper I & I/II & II & $\mathbf{X}$ & $\mathrm{X} / \mathrm{II}$ & \\
\hline Complete & $\begin{array}{c}5 \\
33.3 \% \\
\end{array}$ & $\begin{array}{c}5 \\
23.8 \% \\
\end{array}$ & $\begin{array}{c}7 \\
13.5 \% \\
\end{array}$ & $\begin{array}{c}23 \\
65.7 \% \\
\end{array}$ & $\begin{array}{c}5 \\
31.3 \% \\
\end{array}$ & 45 \\
\hline Basal & $\begin{array}{c}3 \\
20.0 \% \\
\end{array}$ & $\begin{array}{c}6 \\
28.6 \% \\
\end{array}$ & $\begin{array}{c}\text { O } \\
19.2 \% \\
\end{array}$ & $\begin{array}{c}5 \\
14.3 \% \\
\end{array}$ & $\begin{array}{c}5 \\
31.3 \% \\
\end{array}$ & 29 \\
\hline Proximal & $\begin{array}{c}2 \\
13.3 \% \\
\end{array}$ & $\begin{array}{c}4 \\
19.0 \% \\
\end{array}$ & $\begin{array}{c}12 \\
23.1 \% \\
\end{array}$ & $\begin{array}{c}3 \\
8.6 \% \\
\end{array}$ & 0 & 21 \\
\hline Medial & $\begin{array}{c}\mathrm{I} \\
6.7 \% \\
\end{array}$ & $\begin{array}{c}\text { I } \\
4.8 \% \\
\end{array}$ & $\begin{array}{c}10 \\
19.2 \% \\
\end{array}$ & $\begin{array}{c}1 \\
2.9 \% \\
\end{array}$ & $\begin{array}{c}2 \\
12.5 \% \\
\end{array}$ & 15 \\
\hline Lateral & 0 & $\begin{array}{c}1 \\
4.8 \%\end{array}$ & $\begin{array}{c}\text { I } \\
1.9 \% \\
\end{array}$ & 0 & 0 & 2 \\
\hline Distal & $\begin{array}{c}\text { I } \\
6.7 \% \\
\end{array}$ & $\begin{array}{c}3 \\
14.3 \% \\
\end{array}$ & $\begin{array}{c}6 \\
11.5 \% \\
\end{array}$ & $\begin{array}{c}\mathrm{I} \\
2.9 \% \\
\end{array}$ & $\begin{array}{c}3 \\
18.8 \% \\
\end{array}$ & 14 \\
\hline Barb & $\begin{array}{c}\mathbf{I} \\
6.7 \% \\
\end{array}$ & 0 & $\begin{array}{c}3 \\
5.8 \% \\
\end{array}$ & $\begin{array}{c}2 \\
5.7 \% \\
\end{array}$ & 0 & 6 \\
\hline Stem & 0 & $\begin{array}{c}1 \\
4.8 \% \\
\end{array}$ & 0 & 0 & 0 & 1 \\
\hline Indeterminate & $\begin{array}{c}2 \\
13.3 \% \\
\end{array}$ & 0 & $\begin{array}{c}3 \\
5.8 \% \\
\end{array}$ & 0 & $\begin{array}{c}1 \\
6.3 \% \\
\end{array}$ & 6 \\
\hline Totals: & 15 & 21 & 52 & 35 & 16 & 139 \\
\hline
\end{tabular}

TABLE 8-9

Stratigraphic Distribution of Bifaces Assignable to Reduction Stage

\begin{tabular}{|c|c|c|c|c|c|c|}
\hline \multirow[b]{2}{*}{ Bifaces } & \multicolumn{5}{|c|}{ Unit } & \multirow[b]{2}{*}{ Totals } \\
\hline & I-upper & I/II & II & $\mathrm{X} / \mathrm{I} / \mathrm{II}$ & XIII & \\
\hline Stage 1 & $\begin{array}{c}4 \\
23.5 \% \\
\end{array}$ & $\begin{array}{c}1 \\
4.3 \% \\
\end{array}$ & $\begin{array}{c}9 \\
17.0 \%\end{array}$ & 0 & $\begin{array}{c}4 \\
50.0 \%\end{array}$ & 18 \\
\hline Stage 2 & $\begin{array}{c}12 \\
70.6 \%\end{array}$ & $\begin{array}{c}18 \\
78.3 \% \\
\end{array}$ & $\begin{array}{c}36 \\
67.9 \% \\
\end{array}$ & $\begin{array}{c}\text { I } \\
100.0 \%\end{array}$ & $\begin{array}{c}4 \\
50.0 \%\end{array}$ & 71 \\
\hline Stage 3 & $\begin{array}{c}\text { I } \\
5.9 \% \\
\end{array}$ & $\begin{array}{c}4 \\
17.4 \% \\
\end{array}$ & $\begin{array}{c}8 \\
15.1 \% \\
\end{array}$ & 0 & 0 & 13 \\
\hline Totals: & 17 & 23 & 53 & 1 & 8 & 102 \\
\hline
\end{tabular}

perhaps seasonal patterns, or discard patterns. Virtually nothing is known ofWilson settlement patterns or seasonal use of the landscape, and the same can be said for the other components that comprise the record of Unit II. The low frequency of Stage 3 bifaces may indicate that these were consistently removed to other sites during Wilson component times.

Finished bifaces and related tools are classified into five categories: miscellaneous bifacial tools, Brushy Creek bifaces, Clear Fork bifaces and unifaces, bifacial perforators, pieces esquillees, and bi facial scrapers. Admittedly, samples sizes are low, nevertheless a few patterns should be highlighted. Clear Fork bifaces (Figure 8-13) occur throughout the Late Paleoindian strata, and this includes upper Unit I
(Table 8-10). The Wilson component is one of the oldest contexts for Clear Fork bifaces known in the Southern Plains. Brushy Creek bifaces (Figure 8-14) are first found in Unit II sediments, and they are most common in Unit II. Brushy Creek bifaces are long, narrow and thin, triangular, bifacially worked gouges. Brushy Creek bi faces differ from Clear Fork bifaces, which are broader and thicker and have gouge-like bits. It is unclear if these tools were functionally distinct. Bi facial perforators are bi faces worked to form long tapering to cylindrical tips (see Figure 8-13). Pieces esquillees usually are small bifaces with evidence of bipolar flaking and sometimes battering at one or both opposite ends (see Figure 8-12). Miscellaneous bifacial tools are variable, but usually consist of reused broken or discarded bifaces. None 


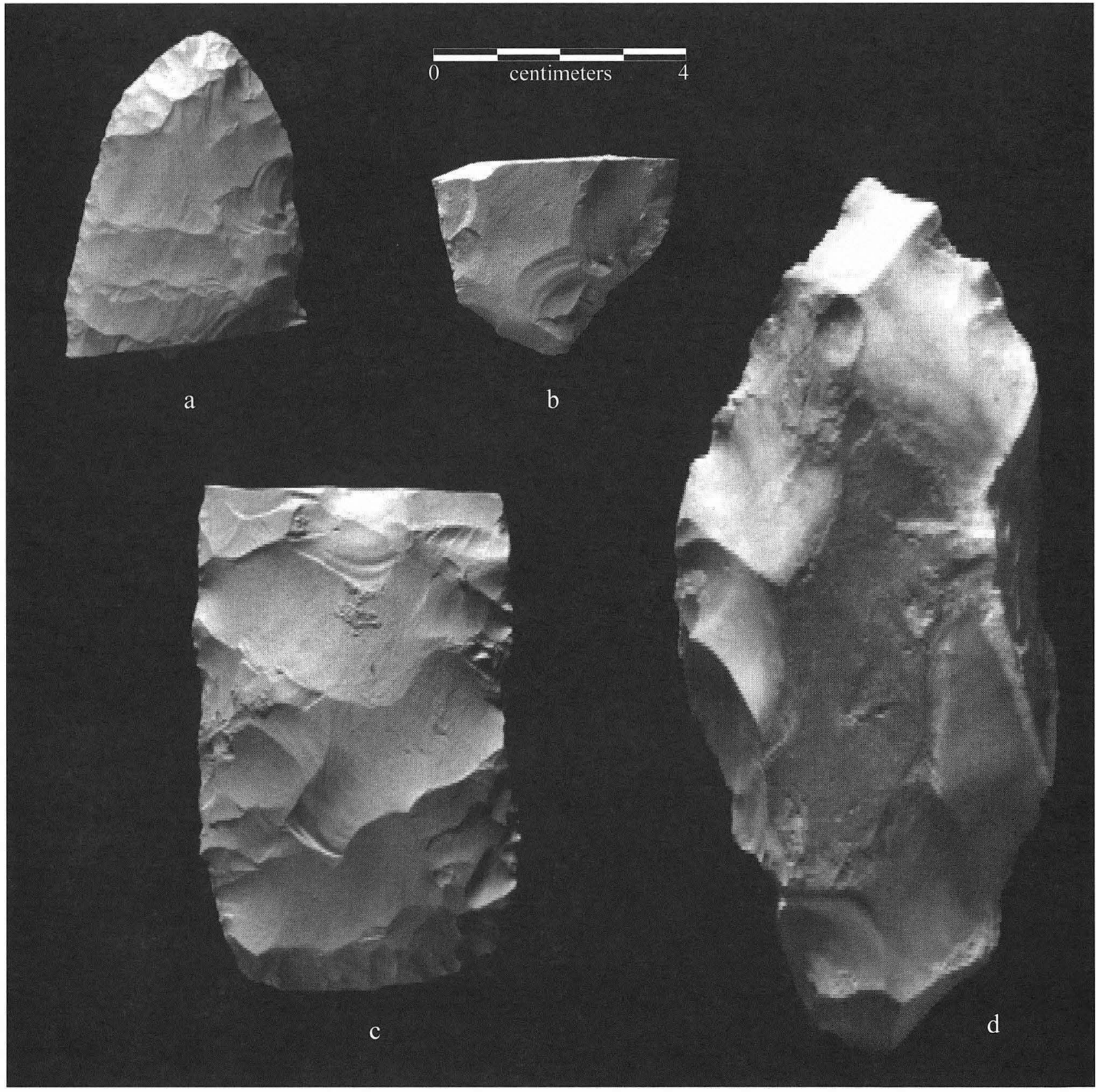

FlouRE 8-11. Bifaces from the Wilson component (Unitlsi-c). (a, c) Stage 2 Bifaces; (b, d) Stage 1 Bifaces. Specimen numbers: (a) 15AA21; (b) 15Z2-1; (c) 35CC2D-1; (d) 29DDIC-3.

was found in the Wilson component. A single Wilson point recycled as a scraper (see Figure 8-4) was recovered from a context that can be securely assigned to the Wilson component.

The unifacial tools are dominated by edge-modified flakes in all stratigraphic units (see Chapter 17). Edge-modified flakes (Figures 8-15 and 8-16) are flakes with minimal alteration of the edges, and the shape of the original flake is retained. Many of these tools are probably altered through use rather than intentional retouch. Other unifacial tools suggest more intentional edge alteration. Denticulates have serrated or multiple notched edges, while microdenticulates have a similar morphology but on a significantly smaller scale. Notches are chipped narrow circular to v-shaped indentations along an edge of a flake. Spurs are created by removing small flakes in two adjacent notches so that the portion of the flake between the two notches forms a prominent bee or tip that was presumably used as a graver. Microspurs produce a similar although much smaller and delicate morphology. Multiple notches are flake tools with more than one notch but placed so that they are not adjacent. Multiple spurs are flake tools with 


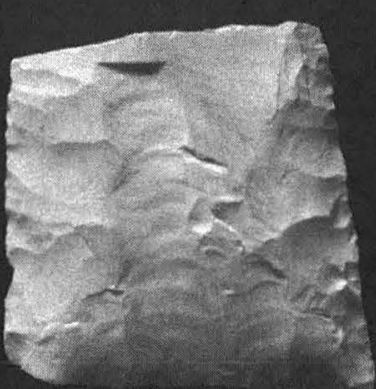

a

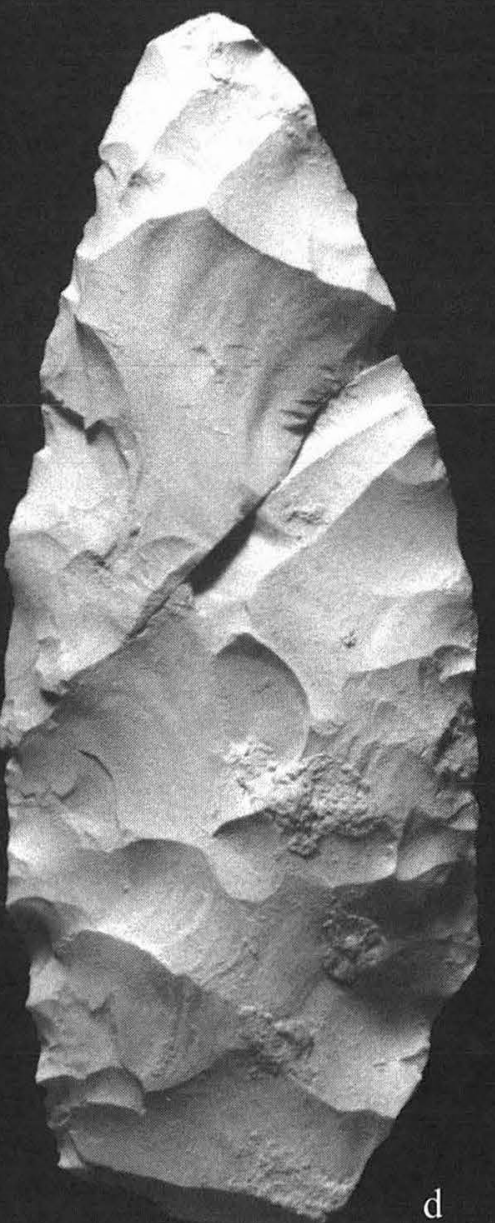

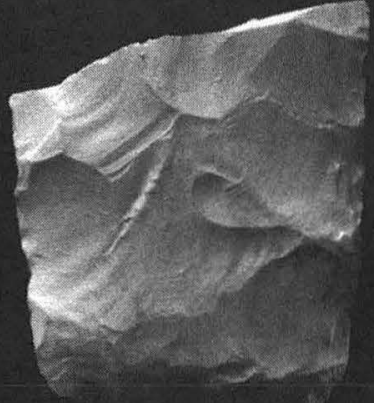

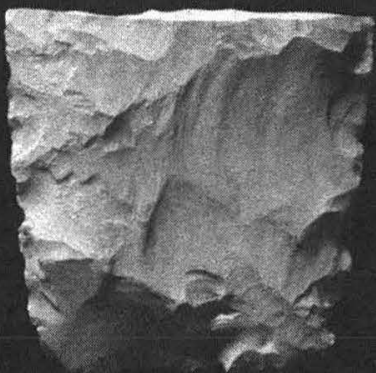

b

c
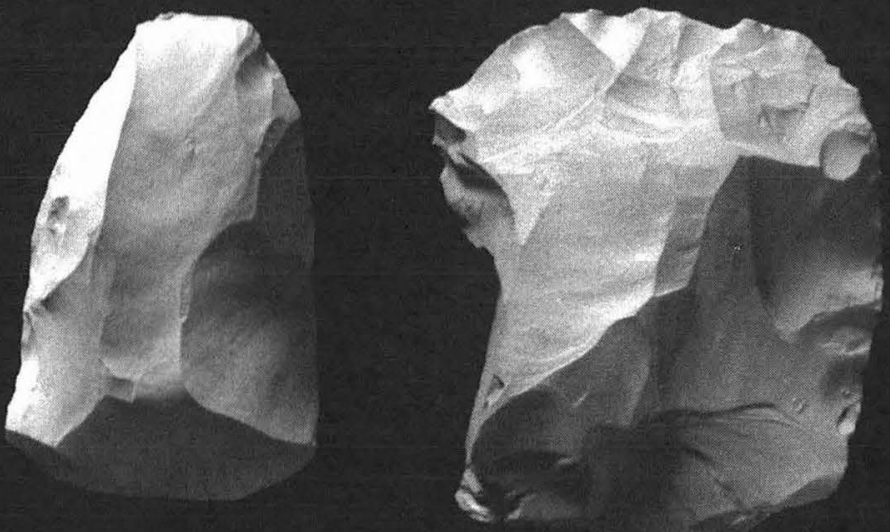

e

f

FlouRE 8-12. Bifaces and piece esquillee from Unit II deposits. (a-c) Stage 3 bifaces; (d, e) Stage 2 bifaces; (f) piece esquillee. Specimen numbers: (a) 26U2-1; (b) 22T-2; (c) 26V2C-4; (d) 31Y1B-2 \& 27YIA-3 conjoined specimens; (e) 22Q-27; (t) 21R-6.

more than one spur. Multiple tools are those with more than one type of retouch pattern, and this class represents a highly variable group ofunifacial tools. Retouched blades are simply blades with some form ofuse-altered or retouchaltered edge. Formal unifacial tools that display evidence of more-systematic edge alteration and indicate those tools with shaped edges are classified as thick and thin unifaces. In upper Unit I, edge-modified flakes occur in their lowest percentage (Table 8-11). This is due to very high numbers of thin unifaces and thin uniface fragments. Over $77 \%$ of the unifacial tools in upper Unit I are edge-modified flakes and thin unifaces or their fragments. The percentages of 


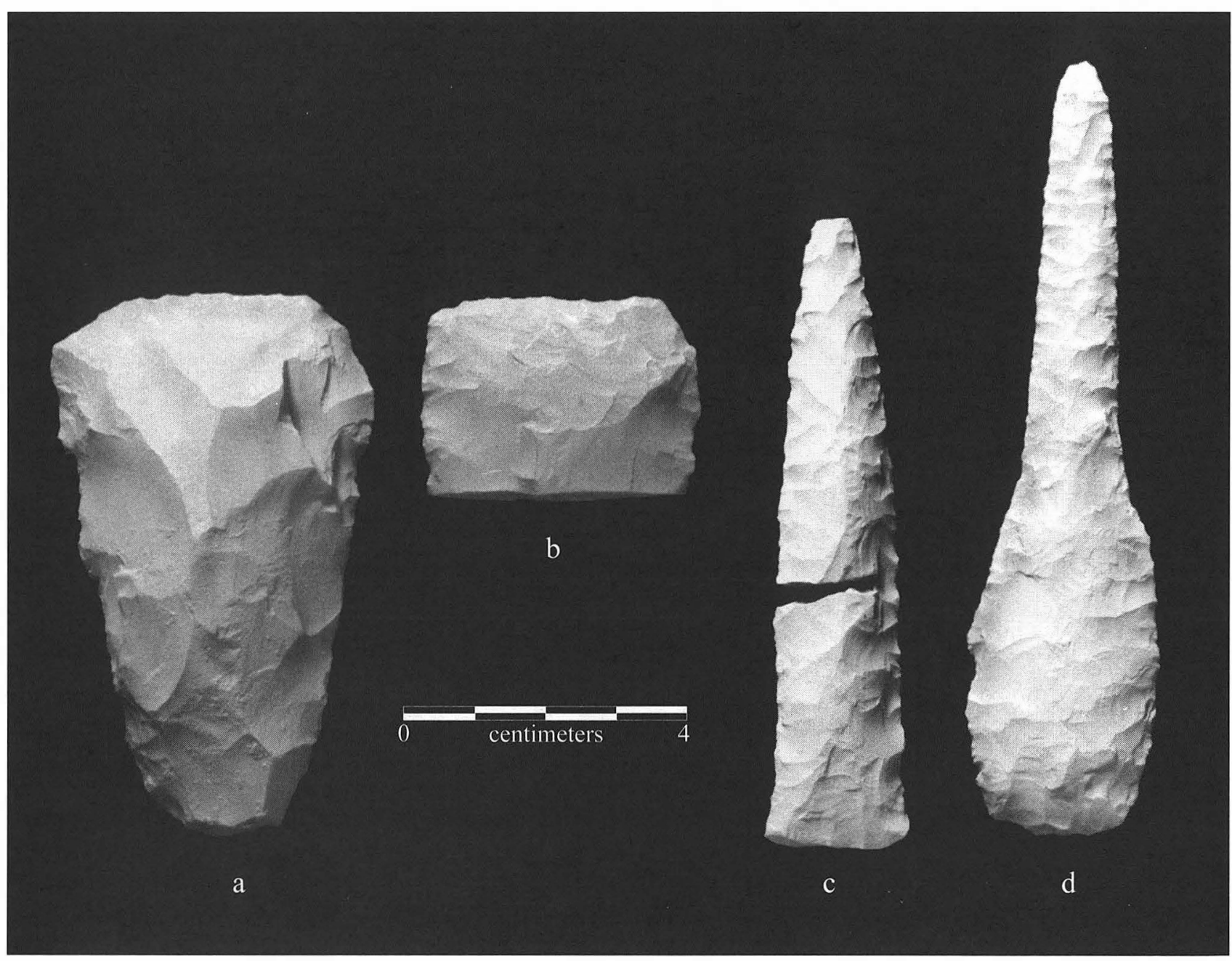

FIGUR 8-13. Bifacial tools from the Wilson component. (a) Clear Fork biface; (b) distal fragment of Clear Fork biface; (c) perforator (Group 4); (d) perforator (Group 1). Specimen numbers: (a) 25BB2D-2; (b) 15AA2-2; (c) 31EEID-1 \& 16AA2-1 conjoined specimens; (d) 25CCIA-1 \& 26YIC-2 conjoined specimens.

TABLE 8-10

Stratigraphic Distribution of Formal Bifacial Tools

\begin{tabular}{|c|c|c|c|c|c|}
\hline \multirow[b]{2}{*}{ Bifacial Tools } & \multicolumn{4}{|c|}{ Unit } & \multirow[b]{2}{*}{ Totals } \\
\hline & I-upper & $1 / 11$ & II & XIII & \\
\hline Miscellaneous Bifacial tools & 0 & $\begin{array}{c}3 \\
42.9 \% \\
\end{array}$ & $\begin{array}{c}9 \\
37.5 \%\end{array}$ & $\begin{array}{c}1 \\
16.7 \%\end{array}$ & 13 \\
\hline Brushy Creek bifaces & 0 & 0 & $\begin{array}{c}3 \\
12.5 \% \\
\end{array}$ & 0 & 3 \\
\hline Clear Fork bifaces & $\begin{array}{c}4 \\
44.4 \% \\
\end{array}$ & $\begin{array}{c}2 \\
28.6 \%\end{array}$ & $\begin{array}{c}5 \\
20.8 \% \\
\end{array}$ & $\begin{array}{c}3 \\
50.0 \% \\
\end{array}$ & 14 \\
\hline Bifacial perforators & $\begin{array}{c}4 \\
44.4 \%\end{array}$ & $\begin{array}{c}2 \\
28.6 \%\end{array}$ & $\begin{array}{c}6 \\
25.0 \%\end{array}$ & $\begin{array}{c}2 \\
33.3 \%\end{array}$ & 14 \\
\hline Pieces esquillees & 0 & 0 & $\begin{array}{c}1 \\
4.2 \% \\
\end{array}$ & 0 & 1 \\
\hline Bifacial scraper (Wilson point) & $\begin{array}{c}1 \\
11.1 \%\end{array}$ & 0 & 0 & 0 & 1 \\
\hline Totals: & 9 & 7 & 24 & 6 & 46 \\
\hline
\end{tabular}




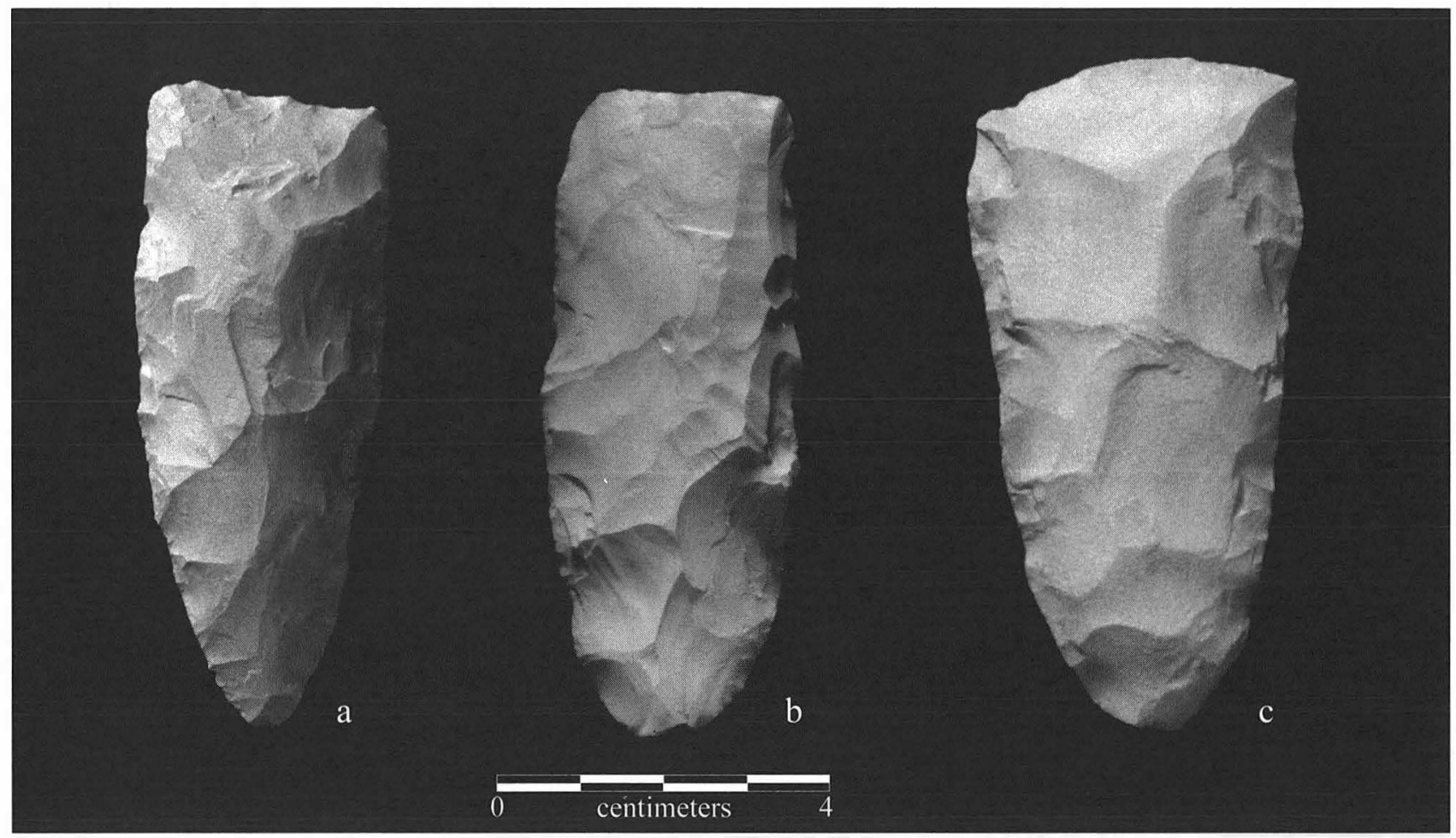

FIGURE 8-14. Brushy Creek and Clear Fork bifaces from Unit IL (a, b) Brushy Creek bifaces; (c) Clear Fork biface. Specimen numbers: (a) 29UIC-12; (b) 34X2A-1; (c) 22Q-3.

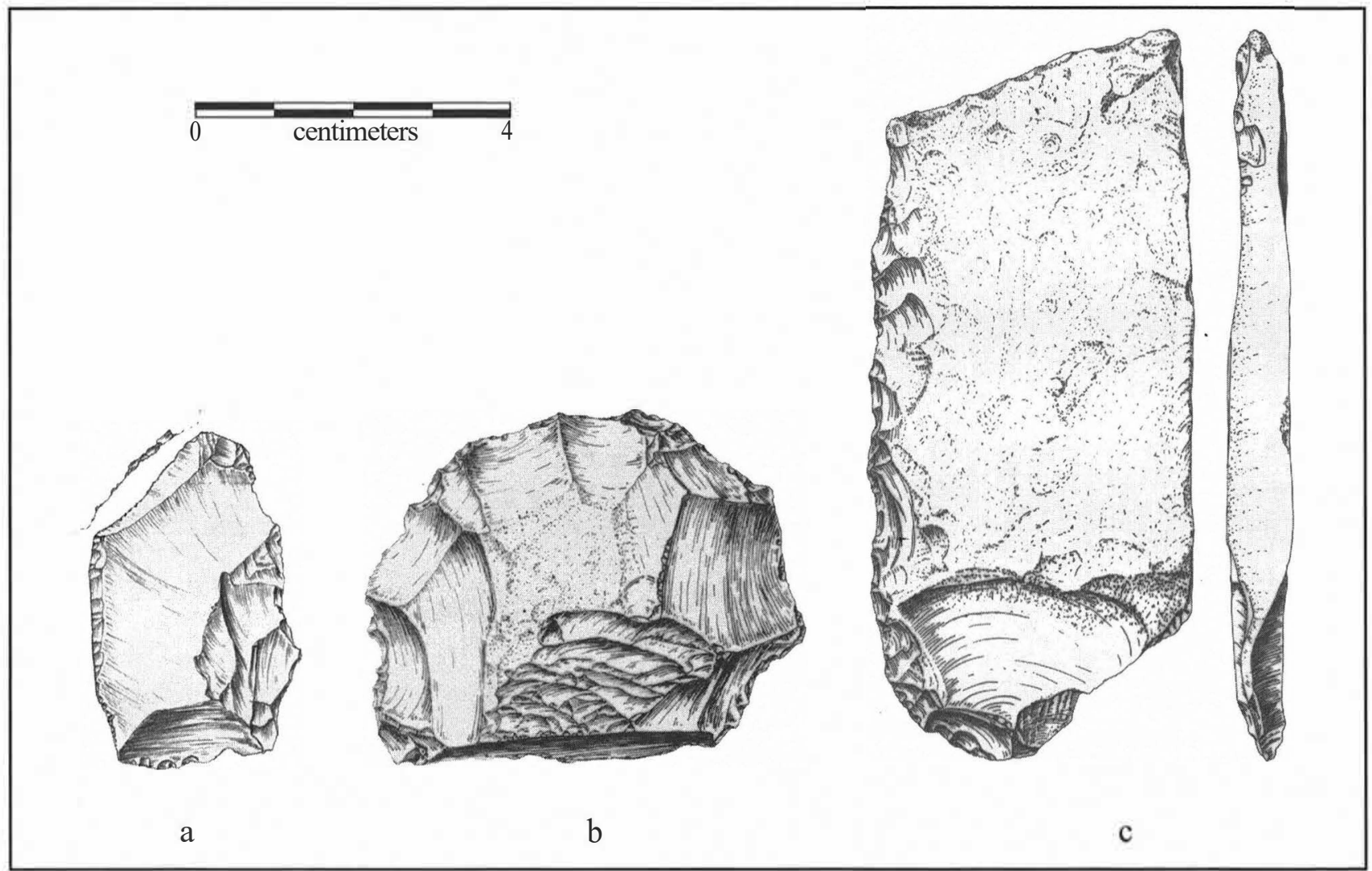

FGURE 8-15. Unifacial tools from the Wilson component. (a) edge-modified flake; (b) multiple tool; (c) thin uni face. Specimen numbers: (a) 17CC2-1; (b) 17CC2-2; (c) 25AAIA-2. 


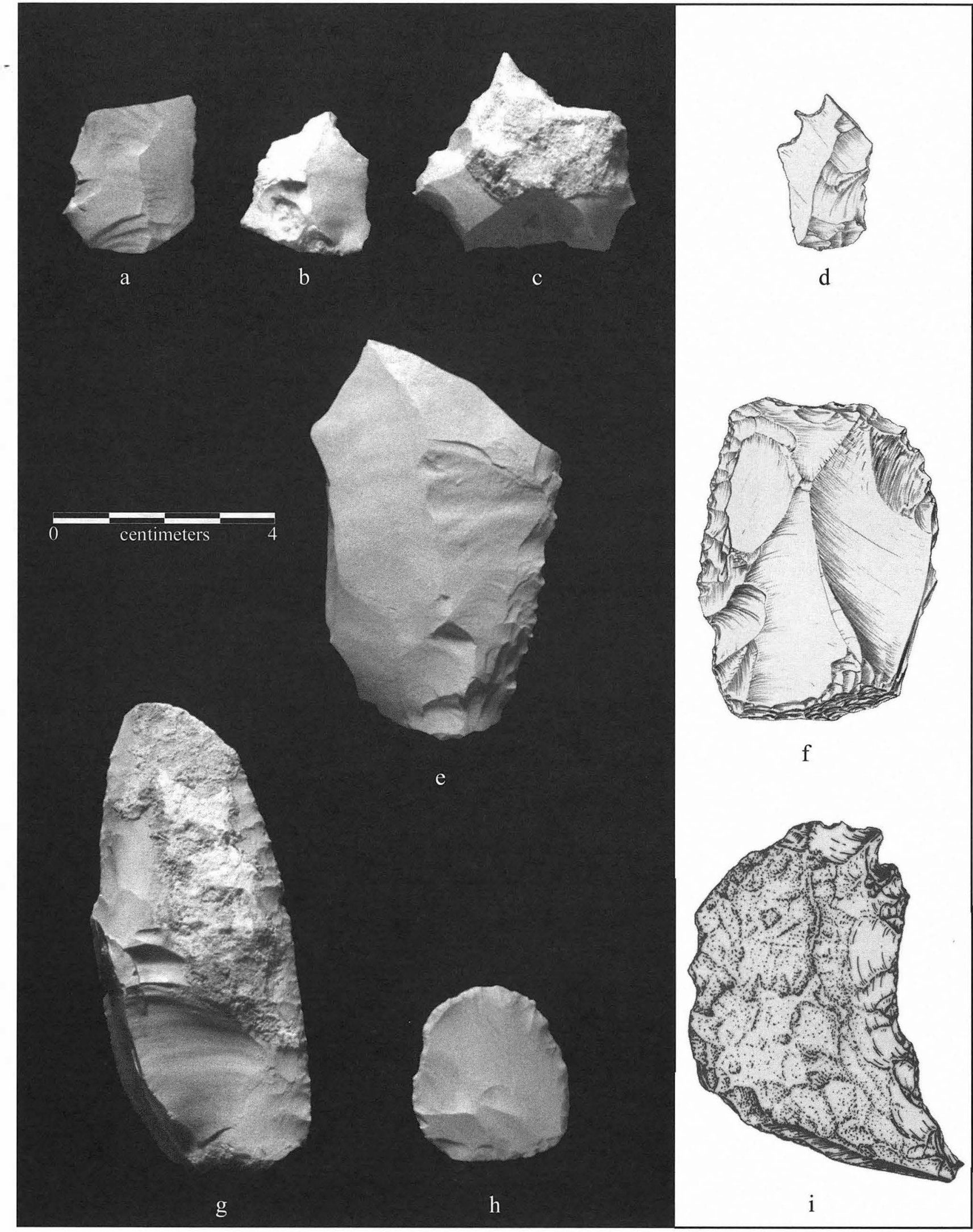

HGURE 8-16. Unifacial tools from Unit II. (a) edge-modified flake; (b, c) spurs; (d) microspur; (e) multiple tool; (t) thick uniface; (g-i) thin unifaces. Specimen numbers: (a) 1949-1; (b) 1685-2; (c) 1832-1; (d) 28T2D-7; (e) 22Q-28, 26T2B-2; (t) 21 R-11; (g) 30Y2A-1; (h) 19U1C11; (i)17Vl-3. 
TABLE 8-11

Stratigraphic Distribution ofUnifacial Tool Types

\begin{tabular}{|c|c|c|c|c|c|c|c|}
\hline \multirow[b]{2}{*}{ Uniface Tool Type } & \multicolumn{6}{|c|}{ Unit } & \multirow[b]{2}{*}{ Total } \\
\hline & I-upper & I/II & II & $\mathrm{X}$ & $\mathrm{X} / 1 / 11$ & $\mathrm{X} / \mathrm{II}$ & \\
\hline Edge Modified Flake & $\begin{array}{c}35 \\
37.6 \% \\
\end{array}$ & $\begin{array}{c}31 \\
48.4 \% \\
\end{array}$ & $\begin{array}{c}105 \\
45.3 \% \\
\end{array}$ & $\begin{array}{c}62 \\
50.8 \% \\
\end{array}$ & $\begin{array}{c}3 \\
75.0 \% \\
\end{array}$ & $\begin{array}{c}17 \\
48.6 \% \\
\end{array}$ & 253 \\
\hline Denticulate & $\begin{array}{c}\mathrm{I} \\
1.1 \% \\
\end{array}$ & $\begin{array}{c}2 \\
3.1 \% \\
\end{array}$ & $\begin{array}{c}1 \\
0.4 \% \\
\end{array}$ & $\begin{array}{c}3 \\
2.5 \% \\
\end{array}$ & 0 & $\begin{array}{c}1 \\
2.9 \% \\
\end{array}$ & 8 \\
\hline Notch & $\begin{array}{c}4 \\
4.3 \% \\
\end{array}$ & 0 & $\begin{array}{c}10 \\
4.3 \% \\
\end{array}$ & $\begin{array}{c}3 \\
2.5 \% \\
\end{array}$ & 0 & 0 & 17 \\
\hline Spur & $\begin{array}{c}1 \\
1.1 \% \\
\end{array}$ & 0 & $\begin{array}{c}5 \\
2.2 \% \\
\end{array}$ & $\begin{array}{c}1 \\
0.8 \% \\
\end{array}$ & 0 & 0 & 7 \\
\hline Multiple Notch & 0 & $\begin{array}{c}1 \\
1.6 \% \\
\end{array}$ & 0 & $\begin{array}{c}2 \\
1.6 \% \\
\end{array}$ & 0 & 0 & 3 \\
\hline Multiple Spur & 0 & 0 & $\begin{array}{c}1 \\
0.4 \% \\
\end{array}$ & 0 & 0 & 0 & I \\
\hline Multiple Tool & $\begin{array}{c}7 \\
7.5 \% \\
\end{array}$ & $\begin{array}{c}4 \\
6.3 \% \\
\end{array}$ & $\begin{array}{c}25 \\
10.8 \% \\
\end{array}$ & $\begin{array}{c}12 \\
9.8 \% \\
\end{array}$ & $\begin{array}{c}1 \\
25.0 \% \\
\end{array}$ & $\begin{array}{c}\mathrm{I} \\
2.9 \% \\
\end{array}$ & 50 \\
\hline Retouched Blade & 0 & $\begin{array}{c}1 \\
1.6 \% \\
\end{array}$ & 0 & $\begin{array}{c}1 \\
0.8 \% \\
\end{array}$ & 0 & 0 & 2 \\
\hline Microdenticulate & 0 & $\begin{array}{c}\text { I } \\
1.6 \% \\
\end{array}$ & $\begin{array}{r}10 \\
4.3 \% \\
\end{array}$ & $\begin{array}{c}9 \\
7.4 \% \\
\end{array}$ & 0 & $\begin{array}{c}2 \\
5.7 \% \\
\end{array}$ & 22 \\
\hline Microspur & 0 & 0 & $\begin{array}{c}2 \\
0.9 \% \\
\end{array}$ & $\begin{array}{c}\text { I } \\
0.8 \% \\
\end{array}$ & 0 & $\begin{array}{c}1 \\
2.9 \% \\
\end{array}$ & 4 \\
\hline Thick Uniface & $\begin{array}{c}6 \\
6.5 \% \\
\end{array}$ & $\begin{array}{c}4 \\
6.3 \% \\
\end{array}$ & $\begin{array}{c}16 \\
6.9 \% \\
\end{array}$ & $\begin{array}{c}3 \\
2.5 \% \\
\end{array}$ & 0 & $\begin{array}{c}3 \\
8.6 \% \\
\end{array}$ & 32 \\
\hline Thick Uniface Fragment & $\begin{array}{c}2 \\
2.2 \% \\
\end{array}$ & 0 & $\begin{array}{c}2 \\
0.9 \%\end{array}$ & 0 & 0 & 0 & 4 \\
\hline Thin Uniface & $\begin{array}{c}22 \\
23.7 \% \\
\end{array}$ & $\begin{array}{c}12 \\
18.8 \% \\
\end{array}$ & $\begin{array}{c}34 \\
14.7 \% \\
\end{array}$ & $\begin{array}{c}16 \\
13.1 \% \\
\end{array}$ & 0 & $\begin{array}{c}5 \\
14.3 \% \\
\end{array}$ & 89 \\
\hline Thin Uniface Fragment & $\begin{array}{c}15 \\
16.1 \% \\
\end{array}$ & $\begin{array}{c}8 \\
12.5 \% \\
\end{array}$ & $\begin{array}{c}21 \\
9.1 \% \\
\end{array}$ & $\begin{array}{c}9 \\
7.4 \% \\
\end{array}$ & 0 & $\begin{array}{c}5 \\
143 \% \\
\end{array}$ & 58 \\
\hline Totals: & 93 & 64 & 232 & 122 & 4 & 35 & 550 \\
\hline
\end{tabular}

edge-modified flakes increase up profile within the Valley Floor sequence, and at the same time the amount of utilized edge decreases, suggesting an increased reliance on expedient tools (see Chapter 17). It seems that whatever is reflected by the differences between edge-modified flakes, and thick and thin unifaces, it is not a significant amount of work required to produce one over the other. Nevertheless, the edge-modified flakes probably do represent an extremely expedient approach to the manufacture and use of stone tools. Except for the presence of high percentages of thin unifaces in upper Unit I, any strong evidence of reliance on specialized tools during upper Unit I or Unit II times is lacking.

Ground and battered stone tools occur in extremely low numbers in these units (see Chapter 20). The general assumption that manos and metates (Figure 8-17) were used to grind plant foods cannot actually be assessed with these data, but, if true, then these data indicate that plant foods were always a dietary component. This should come as no surprise. The most significant information in Table 8-12 is the occurrence of notched stones, also known as Waco sinkers, in Unit II (Figure 8-18). In addition to other similarities to the Early Archaic, the presence of Waco sinkers suggests a continuity between what has traditionally been considered Late Paleoindian and Early Archaic. The general assumption of Waco sinkers being used as fishing net sinkers may have some merit, although the proposal that Waco sinkers were used on hunting nets (Harry Shaver, personal communication 1994) suggests a variety of food collection methods may have been used by Early Holocene hunter-gatherers. The presence of a single grooved stone, perhaps used as a bola stone but certainly as some form of weight in Unit II furthers this suggestion. The presence of worked hematite (Figure 8-19) suggests the 


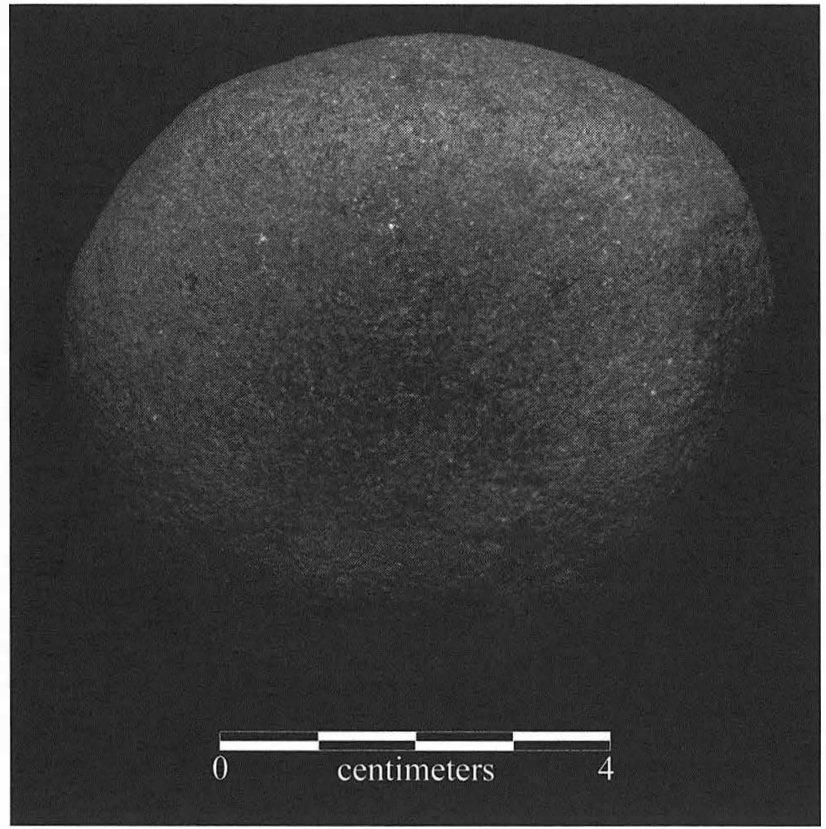

FlouRE 8-17. Limonite sandstone mano from the Wilson component, Specimen 34CC2D-2. sis and for most assemblages, and especially large assemblages like Wilson-Leonard, this would be very expensive and time consuming. Nevertheless, an important amount of information concerning the use of expedient tools is going unrecorded.

\section{SUBSISTENCE}

The most informative evidence on subsistence is the fauna! evidence (see Chapters 33, 35, 36, and 37) and the results presented below are derived from these chapters. However, the fauna! data are less than ideal. The fauna has been greatly altered by differential processing and preservation (see Chapter 33 for a detailed discussion of the taphonomy of the fauna! materials), thus individual pieces of bone can be identified to a variety of taxonomic levels. The discussion below presents the fauna) data in a hierarchical fashion from the most general to the most specific. Also since the TxDOT excavations collected material through 1/4-inch-mesh screen and the TARL excavations used a finer mesh (1/8 inch), these two data sets are somewhat incomparable. For the following discussion, each data set is pre-

TABLE 8-12

Stratigraphic Distribution of Ground and Battered Stone Tools

\begin{tabular}{|c|c|c|c|c|c|}
\hline \multirow[b]{2}{*}{ Ground/Battered Stone Tools } & \multicolumn{4}{|c|}{ Unit } & \multirow[b]{2}{*}{ Totals } \\
\hline & I-upper & I/II & II & $X I I I$ & \\
\hline Battered cobble & 0 & 0 & I & 0 & 1 \\
\hline Core hammerstone & 3 & 1 & 6 & 0 & 10 \\
\hline Grooved stone & 0 & 0 & I & 0 & I \\
\hline Ground stone & I & 0 & 0 & 0 & I \\
\hline Mano & I & 1 & 0 & 0 & 2 \\
\hline Waco sinkers and grooved stones & 0 & I & 3 & 0 & 4 \\
\hline Worked hematite & 3 & 0 & 2 & 0 & 5 \\
\hline Totals: & 8 & 3 & 13 & 0 & 24 \\
\hline
\end{tabular}

use of pigments throughout the entire Late Paleoindian record and the presence of a modified shell bead (Figure 820) from Unit II also suggests the use ofpersonal adornment during this interval.

\section{Wear Analysis}

The analysis of microscopic wear on stone tools provides an additional and intriguing insight to the use of stone tools (see Chapter 22). A great amount of recycling occurs especially among the projectile points (Table 8-13). In fact all projectile points are recycled and all are used as both projectile points and knives (Table 8-14). No temporal patterns are apparent, although the number of specimens is too low to accurately assess this. One significant result from the microwear analysis is the use of unmodified flakes as tools. This apparently can only be monitored by microwear analy- sented and discussed separately. Also the stratigraphic assignments are lumped into four fairly simple units, and these are upper Unit I(Unit lsi-c and Unit Id), Unit I/II (Unit lsi-c/ II, Unit Id/II or Unit Isi-c/Id/11), Unit II, and Unit X (Unit 11/X, Unit lsi-c/X, Unit $X N$ ). The first four units provide a temporal stratigraphy in the Valley Floor, and the fifth represents those units from the Valley Margin of the site. The numbers represent identified specimens only. No attempt has been made to calculate minimum numbers of individuals.

At the most gross level of identification many bone fragments could only be identified as within the subphylum ofVertebrata. These are highly fragmented, and usually small fragments and splinters; however, they compose the largest single group ofrecovered fauna) remains from both the excavations. A smaller subset of this group could be further classified in terms of gross size categories, and these data are presented along with the unclassifiable fragments in Table 


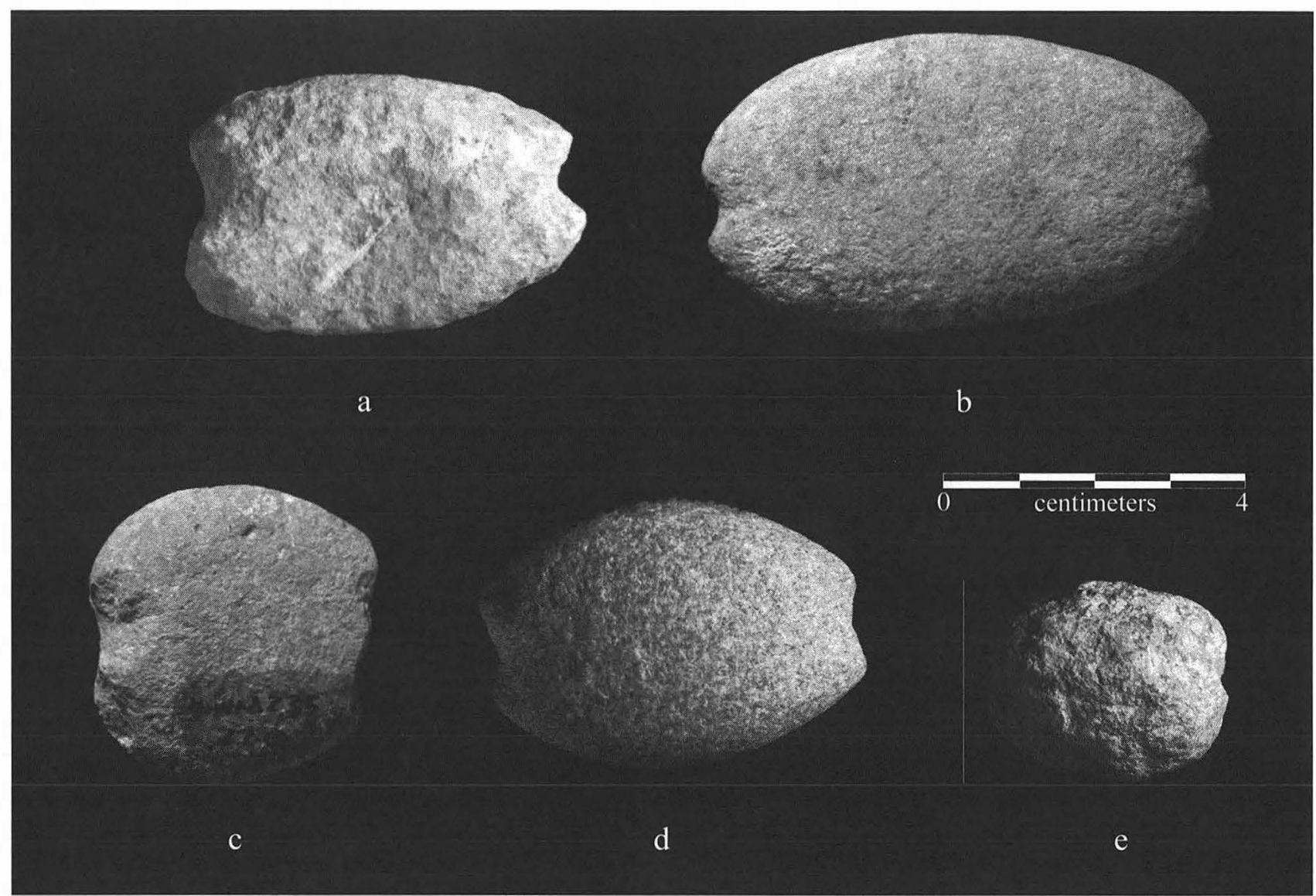

FIGURE 8-18. Notched stone Waco sinkers (a-d) and grooved stone (e) from Unit IL Specimen numbers: (a) 37T2A-1; (b) 22Q-4; (c) 22Q5; (d) 17Y2-1; (e) 34VlB-1.

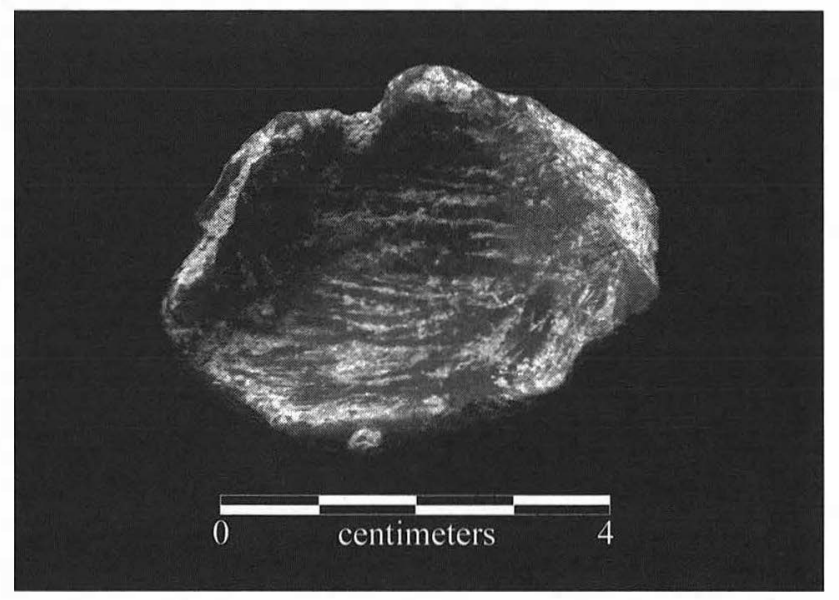

FIGURE 8-19. Worked hematite, Specimen $13 \mathrm{~W}-3$ in Unit Isi-c/Id.

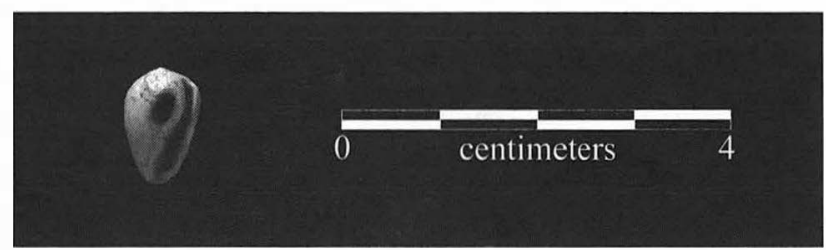

F1GURE 8-20. Modified shell bead, Specimen 2071 in Unit II.
8-15. The percentages in this table have been calculated two separate ways. The percentages of the indeterminate category considers all fragments, but the percentages in the various size groupings only use the "size diagnostic total" which consists of only those fragments that could be classified according to size.

A number of observations can be made on these data. First, even though the TARL excavations removed a great deal less sediment, the total number of recovered specimens is almost twice as great. Second, in all Late Paleoindian stratigraphic contexts the general class of Indeterminate Vertebrata is the most common category, although the relative frequencies of this group within the TARL excavations is smaller. Third, in terms of size groupings, it is important to note that no materials within the micro or small groupings were recovered from the Tx.DOT excavations. Also for each stratigraphic division the raw number and the relative frequency of fragments within the Small/Medium class are greater in the TARL data. The Tx.DOT results suggest a greater representation of Medium/Large fragments, while the TARL evidence indicates that Small/Medium fragments are represented in greater numbers. All of these differences between the TxDOT and TARL samples are probably a reflection, to a great degree, of the difference between excavation 
TABLE 8-13

Stratigraphic Distribution of Artifact Use History as Determined by Microwear Analysis

\begin{tabular}{|c|c|c|c|c|c|}
\hline \multirow[b]{2}{*}{ Use History } & \multicolumn{4}{|c|}{ Unit } & \multirow[b]{2}{*}{ Totals } \\
\hline & Upper I & $\mathrm{I} / \mathrm{II}$ & II & $\mathrm{X}$ & \\
\hline Awl & 0 & 0 & 1 & 0 & 1 \\
\hline Burin/distal snap tool & 1 & 0 & 3 & 0 & 4 \\
\hline Burin/radial break tool & 2 & 0 & 2 & 0 & 4 \\
\hline Graver & 0 & 0 & 1 & 0 & 1 \\
\hline Indeterminate & 1 & 0 & 4 & 0 & 5 \\
\hline Knife only & 1 & 0 & 1 & 0 & 2 \\
\hline Knife>projectile & 2 & 1 & 0 & 0 & 3 \\
\hline Knife $>$ projectile $>$ burin & 0 & 0 & 1 & 0 & 1 \\
\hline Knife $>$ projectile $>$ knife & 1 & 1 & 0 & 0 & 2 \\
\hline None & 3 & 0 & 4 & 0 & 7 \\
\hline Projectile $<->$ knife & 0 & 1 & 1 & 2 & 4 \\
\hline Projectile $<->$ knife $>$ radial break tool & 0 & 1 & 0 & 0 & 1 \\
\hline Projectile $<->$ knife $>$ repointed & 0 & 0 & 0 & 1 & 1 \\
\hline Projectile $>$ knife & 1 & 2 & 1 & 1 & 5 \\
\hline Projectile $>$ knife $>$ burin & 1 & 0 & 0 & 0 & 1 \\
\hline Unifacial butchering tool & 0 & 0 & 1 & 0 & 1 \\
\hline Unifacial soft cutting tool & 1 & 0 & 0 & 0 & 1 \\
\hline Totals: & 14 & 6 & 20 & 4 & 44 \\
\hline
\end{tabular}

methods and screen size. Thus it appears that the TARL data are probably more reliable, although the TxDOT data must still be considered if for no other reason than they represent a much greater volume of sampled sediment.

The TARL data in Table 8-15 suggest that the highly fragmented remains show an abundance of Small/Medium (rabbit-sized) that increases through time while the percentages of Medium/Large fragments decrease in tandem. In both the TARL and TxDOT samples the number of specimens in Unit Xis too low for reliable interpretation.

Table 8-16 lists the fauna) remains by class and again the TxDOT and TARL data are shown independently. The representation of nonmammal forms is greater in the TARL data set with mammals comprising a total of $89.3 \%$ versus a total of $96.4 \%$ in the TxDOT sample. Again this discussion focuses on the TARL sample. In upper Unit I, the Wilson Component, reptiles are surprisingly common ( $12.1 \%)$, but they are present in all strata. Although not numerous, fish are most common in Unit II (2.1\%), and they are also present in all strata. The higher frequency offish in Unit II is interesting considering the occurrence of Waco sinkers in the same stratum. Birds are more rare, but they were found in upper Unit I and Unit II. Given the likelihood of preservation bias against the more-fragile fauna! remains such as fish, amphibians, reptiles, and birds, it seems reasonable that these classes probably were exploited in greater proportions than these numerical representations indicate.

The next step in the presentation of fauna! remains is the documentation of fragments that are reliably identified as mammal. These cannot be further identified in terms of taxon except for segregating them into gross size classes. These data are presented in terms of TxDOT and TARL samples in Table 8-17. Again the smaller size groups (Small/ Medium and smaller) are absent or underrepresented in the TxDOT sample so the TARL sample is used primarily. Mediurn/Large :fragments are most common and the second most common size class is Small. The Medium/Large group probably includes fragments from animals that range in size from deer to raccoons. Small (rodent to raccoon-sized) fragments occur in their lowest percentages in upper Unit I. TARL and TxDOT samples indicate that Very large specimens occur in upper Unit I and Unit II contexts. It is very likely that these are bison remains, but no definite bison bones were present in Unit II. However, bison are present in the upper Unit I and Unit I/II TxDOT samples. In the TARL data set, an increased :frequency ofrodent-sized remains are present in Unit II and Unit II/III. This may represent actual use. However, mediumsized faunal remains are most numerous in Unit I. These data hint at the possibility that diet breadth increased from Unit I to Unit II.

Table 8-18 presents the distribution offauna! remains in Order groupings. Here, most clearly, a bias in favor of Artiodactyla is present in the TxDOT sample. The TARL sample clearly shows that rabbits and hares and then rodents occur in greater :frequencies. Unlike the general mammal size group data, rodents appear to decrease through time. These two data sets could be used to suggest that there is a shift in rodent processing through time rather than an increase or 
TABLE 8-14

Artifact Use History as Determined by Microwear Analysis by Artifact Type

\begin{tabular}{|c|c|c|c|c|c|c|c|c|c|c|c|c|c|c|}
\hline Use History & Angostura & $\begin{array}{l}\text { Bifacial } \\
\text { Perforator }\end{array}$ & Burin & $\begin{array}{l}\text { Golondrina- } \\
\text { Barber }\end{array}$ & $\begin{array}{l}\text { Ground } \\
\text { Square } \\
\text { Stem } \\
\end{array}$ & $\begin{array}{l}\text { Micro- } \\
\text { sour }\end{array}$ & \begin{tabular}{|l|} 
Parallet- \\
Sided \\
Lanceolate \\
\end{tabular} & Scottsbluff & \begin{tabular}{|l|} 
St \\
Mary's \\
Hall \\
\end{tabular} & $\begin{array}{l}\text { Stemmed } \\
\text { Biface }\end{array}$ & $\begin{array}{l}\text { Thin } \\
\text { Uniface }\end{array}$ & $\begin{array}{l}\text { Unifacial } \\
\text { Perforator }\end{array}$ & $\begin{array}{l}\text { Unmodi- } \\
\text { tied Flake }\end{array}$ & Wilson \\
\hline Awl & 0 & $\mathrm{I}$ & 0 & 0 & 0 & 0 & 0 & 0 & 0 & 0 & 0 & 0 & 0 & 0 \\
\hline Burin/distal snap tool & 0 & 0 & 0 & 0 & 0 & 0 & 0 & 0 & 0 & 0 & 0 & 0 & 4 & 0 \\
\hline Burin/radial break tool & 0 & 0 & 0 & 0 & 0 & 0 & 0 & 0 & 0 & 0 & 0 & 0 & 4 & 0 \\
\hline Drill & 0 & 0 & 0 & 0 & 0 & 0 & 0 & 0 & 0 & 0 & 0 & I & 0 & 0 \\
\hline Graver & 0 & 0 & 0 & 0 & 0 & 1 & 0 & 0 & 0 & 0 & 0 & 0 & 0 & 0 \\
\hline Indeterminate & 0 & 0 & 1 & 0 & 0 & 0 & 1 & 0 & 0 & 0 & 1 & 0 & 3 & 0 \\
\hline Knife only & 0 & 1 & 0 & 0 & 0 & 0 & 0 & 0 & 0 & 1 & 0 & 0 & 0 & 0 \\
\hline Knife>projectile & 0 & 0 & 0 & 2 & 0 & 0 & 0 & 0 & 0 & 0 & 0 & 0 & 0 & 1 \\
\hline Knife>projectile>burin & 0 & 0 & 0 & 1 & 0 & 0 & 0 & 1 & 0 & 0 & 0 & 0 & 0 & 0 \\
\hline Knife>projectile>knife & 0 & 0 & 0 & 0 & 0 & 0 & 1 & 0 & 0 & 0 & 0 & 0 & 0 & 1 \\
\hline None & 0 & 0 & 2 & 0 & 0 & 0 & 0 & 0 & 0 & 0 & 1 & 0 & 5 & 0 \\
\hline Projectile<->knife & 1 & 0 & 0 & 1 & 0 & 0 & 0 & 0 & 2 & 0 & 0 & 0 & 0 & 1 \\
\hline Projectile<->knife >radial break tool & 0 & 0 & 0 & 0 & 1 & 0 & 0 & 0 & 0 & 0 & 0 & 0 & 0 & 0 \\
\hline Projectile<->knife>repointed & 0 & 0 & 0 & 0 & 0 & 0 & 0 & 0 & 0 & 0 & 0 & 0 & 0 & 1 \\
\hline Projectile>knife & 0 & 0 & 0 & 0 & 0 & 0 & 0 & 0 & 2 & 0 & 0 & 0 & 0 & 3 \\
\hline Projectile>knife>burin & 0 & 0 & 0 & 0 & 0 & 0 & 0 & 0 & 0 & 0 & 0 & 0 & 0 & 1 \\
\hline Unifacial butchering tool & 0 & 0 & 0 & 0 & 0 & 0 & 0 & 0 & 0 & 0 & 1 & 0 & 0 & 0 \\
\hline Unifacial soft cutting tool & 0 & 0 & 0 & 0 & 0 & 0 & 0 & 0 & 0 & 0 & 0 & 0 & 1 & 0 \\
\hline
\end{tabular}


TABLE 8-15

Fauna! Remains from TxDOT and TARL Excavations Diagnostic only to Vertebrata Categories

\begin{tabular}{|c|c|c|c|c|c|}
\hline \multirow[b]{2}{*}{ TxDOT-1/4 inch } & \multicolumn{4}{|c|}{ Unit } & \multirow[b]{2}{*}{ Totals } \\
\hline & Upper I & $\mathrm{I} / \mathrm{II}$ & II & $\bar{X}$ & \\
\hline Indeterminate Vertebrata & $\begin{array}{c}1,731 \\
85.5 \%\end{array}$ & $\begin{array}{c}670 \\
82.6 \%\end{array}$ & $\begin{array}{c}846 \\
71.9 \%\end{array}$ & $\begin{array}{c}140 \\
78.7 \%\end{array}$ & 3,387 \\
\hline Micro & 0 & 0 & 0 & 0 & 0 \\
\hline Small (smaller than cottontail rabbits) & 0 & 0 & 0 & 0 & 0 \\
\hline Small/medium & $\begin{array}{c}107 \\
36.5 \%\end{array}$ & $\begin{array}{c}33 \\
23.4 \%\end{array}$ & $\begin{array}{c}110 \\
33.2 \%\end{array}$ & $\begin{array}{c}11 \\
28.9 \%\end{array}$ & 261 \\
\hline Medium (jackrabbit to fox-sized) & $\begin{array}{c}0 \\
0.0 \%\end{array}$ & $\begin{array}{c}\mathrm{I} \\
0.7 \%\end{array}$ & 0 & 0 & 1 \\
\hline Medium/large & $\begin{array}{c}185 \\
63.1 \%\end{array}$ & $\begin{array}{c}107 \\
75.9 \%\end{array}$ & $\begin{array}{c}221 \\
66.8 \%\end{array}$ & $\begin{array}{c}27 \\
71.1 \%\end{array}$ & 540 \\
\hline Large (larger than fox- sized) & $\begin{array}{c}1 \\
0.3 \%\end{array}$ & 0 & 0 & 0 & 1 \\
\hline $\begin{array}{l}\text { Totals: } \\
\text { Size-diagnostic totals: }\end{array}$ & $\begin{array}{l}2,024 \\
293\end{array}$ & $\begin{array}{l}811 \\
141\end{array}$ & $\begin{array}{l}1,177 \\
331\end{array}$ & $\begin{array}{l}178 \\
38\end{array}$ & 4,190 \\
\hline TARL-1/8 inch & Upper I & $1 / 11$ & II & $\bar{X}$ & Total \\
\hline Indeterminate Vertebrata & $\begin{array}{c}1,921 \\
77.7 \%\end{array}$ & $\begin{array}{c}876 \\
76.9 \%\end{array}$ & $\begin{array}{l}3,006 \\
72.8 \%\end{array}$ & $\begin{array}{c}26 \\
89.7 \%\end{array}$ & $\overline{5,829}$ \\
\hline Micro & 0 & 0 & 0 & 0 & 0 \\
\hline Small (smaller than cottontail rabbits) & $\begin{array}{c}5 \\
0.9 \%\end{array}$ & $\begin{array}{c}5 \\
19 \%\end{array}$ & $\begin{array}{c}19 \\
1.7 \%\end{array}$ & 0 & 29 \\
\hline Small/medium & $\begin{array}{c}450 \\
81.5 \%\end{array}$ & $\begin{array}{c}227 \\
86.3 \%\end{array}$ & $\begin{array}{c}1,023 \\
91.3 \%\end{array}$ & $\begin{array}{c}3 \\
100.0 \%\end{array}$ & 1,703 \\
\hline Medium (jackrabbit to fox-sized) & $\begin{array}{c}9 \\
1.6 \%\end{array}$ & $\begin{array}{c}3 \\
1.1 \%\end{array}$ & $\begin{array}{c}4 \\
0.4 \%\end{array}$ & 0 & 16 \\
\hline Medium/large & $\begin{array}{c}88 \\
15.9 \%\end{array}$ & $\begin{array}{c}28 \\
10.6 \%\end{array}$ & $\begin{array}{c}75 \\
6.7 \%\end{array}$ & 0 & 191 \\
\hline Large (larger than fox-sized) & 0 & 0 & 0 & 0 & 0 \\
\hline $\begin{array}{l}\text { Totals: } \\
\text { Size-diagnostic totals: }\end{array}$ & $\begin{array}{c}2,473 \\
552\end{array}$ & $\begin{array}{l}1,139 \\
263\end{array}$ & $\begin{array}{l}4,127 \\
1,121\end{array}$ & $\begin{array}{r}29 \\
3\end{array}$ & 7,768 \\
\hline
\end{tabular}

decrease in overall use. Both samples suggest a slight increase in rabbits or hares between upper Unit I and Unit II and a slight decrease in Artiodactyles in the same interval. At this level of analysis the TxDOT data set is probably more revealing because of the small size ofthe TARL sample.

Table 8-19 presents the most detailed taxonomic classifications achieved, and a number of important patterns are present although percentages were not calculated because the counts are so low. First, both the reptiles and rodents show a reduction in species diversity from upper Unit I to the later units in the TARL data set. This may represent a response to climate change at the end of the Pleistocene, or it may be a reflection of reduced diet breadth through time. Importantly, these data demonstrate the existence of Bison sp. in Unit I and Unit I/II. Previously reported data (see Table 8-17) suggest that bison were also present during Unit II times as well. However, as the TxDOT sample indicates, deer were certainly a significant source of protein for these early Holocene hunter-gatherers.

The distribution of body elements can often provide revealing information on processing patterns, unfortunately counts are low when looking at specific species or genera. Nevertheless, certain patterns are present and suggestive, if not informative. Table 8-20 shows that the TARL number of identified specimens for major body portions ofall mammals shifts from Unit I to Unit II and these changes are significant $\left(\mathrm{G}^{2}=19.2, \mathrm{df}=8, \mathrm{p}\right.$ value $\left.=0.0138\right)$. All mammals were included in this table because counts were so low for most species, and one of the most significant shifts is among the indeterminate mammal bone. In Table 8-20 the frequency of bones from the torso (pelvis, scapula, ribs, and vertebra) increase in relative frequency through time although this shift is not statistically significant. This change is primarily in the rabbits and hares. Lower leg (tibia, fibula, ulna, and radius) and foot bones also increase, and the adjusted residuals indicate that this is an important change. At the same time the relative frequency of indeterminate bones declines, and this is also statistically significant. Heads and upper leg (humerus and femur) bones do not seem to change very much.

The decrease of indeterminate bones in Unit II might be a reflection of improved preservation, and Baker (see Chapter 33) documents physical decomposition of bones. 
TABLE 8-16

Fauna! Remains from TxDOT and TARL Excavations Diagnostic only to Class Categories

\begin{tabular}{|c|c|c|c|c|c|}
\hline \multirow[b]{2}{*}{ TxDOT-1/4 inch } & \multicolumn{4}{|c|}{ Unit } & \multirow[b]{2}{*}{ Totals } \\
\hline & Upper I & $\mathrm{I} / \mathrm{II}$ & II & $\mathbf{X}$ & \\
\hline $\begin{array}{l}\text { Chondrichthyes } \\
\text { (Cartilaginous Fish) }\end{array}$ & $\begin{array}{c}1 \\
0.3 \%\end{array}$ & 0 & 0 & 0 & 1 \\
\hline $\begin{array}{l}\text { Repilia } \\
\text { (Reptiles) }\end{array}$ & $\begin{array}{c}19 \\
5.4 \%\end{array}$ & $\begin{array}{c}5 \\
2.5 \%\end{array}$ & $\begin{array}{c}3 \\
0.8 \%\end{array}$ & $\begin{array}{c}2 \\
1.7 \%\end{array}$ & 29 \\
\hline $\begin{array}{l}\text { Aves } \\
\text { (Birds) }\end{array}$ & $\begin{array}{c}1 \\
0.3 \%\end{array}$ & 0 & $\begin{array}{c}\mathrm{I} \\
0.3 \%\end{array}$ & 0 & 2 \\
\hline $\begin{array}{l}\text { Mammalia } \\
\text { (Mammals) }\end{array}$ & $\begin{array}{c}331 \\
94.0 \%\end{array}$ & $\begin{array}{c}192 \\
97.5 \%\end{array}$ & $\begin{array}{c}361 \\
98.9 \%\end{array}$ & $\begin{array}{c}113 \\
98.3 \%\end{array}$ & 997 \\
\hline Totals: & 352 & 197 & 365 & 115 & 1,029 \\
\hline TARL-1/8 inch & Upper I & $1 / 11$ & II & $\mathbf{X}$ & Totals \\
\hline $\begin{array}{l}\text { Osteichthyes } \\
\text { (Bony Fish) }\end{array}$ & 0 & $\begin{array}{c}\mathrm{I} \\
0.9 \%\end{array}$ & $\begin{array}{c}\mathrm{I} 0 \\
2.1 \%\end{array}$ & 0 & 11 \\
\hline $\begin{array}{l}\text { Ampibilia } \\
\text { (Amphibians) }\end{array}$ & 0 & 0 & 0 & 0 & 0 \\
\hline $\begin{array}{l}\text { Repitilia } \\
\text { (Reptiles) }\end{array}$ & $\begin{array}{c}46 \\
12.1 \%\end{array}$ & $\begin{array}{c}5 \\
4.3 \%\end{array}$ & $\begin{array}{c}31 \\
6.7 \%\end{array}$ & 0 & 82 \\
\hline $\begin{array}{l}\text { Aves } \\
\text { (Birds) }\end{array}$ & $\begin{array}{c}\mathrm{I} \\
0.3 \%\end{array}$ & 0 & 0 & 0 & I \\
\hline $\begin{array}{l}\text { Mammalia } \\
\text { (Mammals) }\end{array}$ & $\begin{array}{c}333 \\
87.6 \%\end{array}$ & $\begin{array}{c}\text { Ill } \\
94.9 \%\end{array}$ & $\begin{array}{c}425 \\
91.2 \%\end{array}$ & $\begin{array}{c}3 \\
100.0 \%\end{array}$ & 872 \\
\hline Totals: & 380 & 117 & 466 & 3 & 966 \\
\hline
\end{tabular}

However, if this was the only factor then bones from other portions of mammals such as the upper legs should increase along with lower leg and foot bones. Perhaps a more likely explanation for this pattern is that it represents a shift in bone processing from the Wilson component to Unit II. This implies less-intensive bone processing by the various groups that occupied Wilson-Leonard during the accumulation of Unit II sediments, although destruction by carnivores cannot be ruled out. The Unit II decline in small fauna (see above) supports the hypothesis that these changes are related to changes in human diet breadth.

The microfauna data from Square 20 (Table 8-21) presents a slightly different picture (see Chapter 35). When these data are grouped by class, clear patterns emerge. In Figure 8-21 clear shifts can be identified. In the Leanne soil levels (39-44) rodents dominate the sample, followed numerically by rabbits and hares. This pattern continues into Unit II (Levels 26-38) through Level 30 except for Levels 33 and 34 where rabbits and hares are extremely common. In Level 29 the number of turtles and especially fish begin to compose a greater percentage of the fauna. In Levels 26 and 27 fish are the most common taxa, and turtles almost equal rodents. Thus the fine-screen data suggest a shift to aquatic taxa in the upper portion of Unit II. Rather than a reduction in diet breadth as indicated by the mammalian data, human diets appear to expand by the exploitation of aquatic species. This preempts or perhaps sets the stage for the fauna! exploitation patterns that help define the Early Archaic period.

Analysis of eggshell also demonstrates that a variety of species were exploited (see Chapter 36). Although positive species identification could not be made, the data in Table 8-21 show that eggs from numerous species were utilized. Judging from the thickness of the eggshell the types of birds were generally small and range from Killdeer-sized to Prairie Chicken or American Coot-sized. Two-thirds of the recovered eggshell is between $0.21-0.27-\mathrm{mm}$ thick, and these represent size ranges from the black-crown night-heron to American coot. A brief inspection of the number of eggshells recovered per liter of sediment clearly indicates that eggshell density is much higher in Unit II than in the Leanne soil (Unit lsi-c). Still, these data show that eggshell can be obtained from sediments that are 10,000 years old and do not represent good conditions for preservation as long as careful recovery methods are employed.

To summarize, the fauna! samples suggest that subtle economic changes occurred among the Late Paleoindian hunter-gatherers that occupied the Wilson-Leonard site between 10,000 and 8400 B.r. The most important differences between the Wi Ison component in upper Unit I and the other 
TABLE 8-17

Fauna! Remains from TxDOT and TARL Excavations Diagnostic only to Mammal-size Categories

\begin{tabular}{|c|c|c|c|c|c|}
\hline & & & & & \\
\hline TxDOT $1 / 4$ inch & Upper I & $\mathrm{I} / \mathrm{II}$ & II & $\mathbf{X}$ & Totals \\
\hline Micro (rodent-sized) & 0 & 0 & 0 & 0 & 0 \\
\hline Micro/small & 0 & 0 & 0 & 0 & 0 \\
\hline Small (up to cottontail rabbit sized) & 2 & 0 & 2 & 0 & 4 \\
\hline & $0.7 \%$ & & $0.6 \%$ & & \\
\hline Small/medium & I & 0 & I & 0 & 2 \\
\hline & $0.4 \%$ & & $0.3 \%$ & & \\
\hline Medium (raccoon, canid sized) & 28 & 12 & 14 & 4 & 58 \\
\hline & $10.1 \%$ & $6.6 \%$ & $4.2 \%$ & $3.7 \%$ & \\
\hline Medium/large & 231 & 154 & 288 & 93 & 766 \\
\hline & $83.1 \%$ & $85.1 \%$ & $86.2 \%$ & $85.3 \%$ & \\
\hline Large (deer, pronghorn sized) & 16 & 14 & 24 & 12 & 66 \\
\hline & $5.8 \%$ & $7.7 \%$ & $7.2 \%$ & $11.0 \%$ & \\
\hline Very large (bison-sized) & 0 & 1 & 5 & 0 & 6 \\
\hline & & $0.6 \%$ & $1.5 \%$ & & \\
\hline Totals: & 278 & 181 & 334 & 109 & 902 \\
\hline TARL-1/8 inch & Upper I & $\mathrm{I} / \mathrm{II}$ & II & $\mathrm{X}$ & Totals \\
\hline$\overline{\text { Micro (rodent-sized) }}$ & $\mathrm{I}$ & I & 16 & 0 & 18 \\
\hline & $0.4 \%$ & $1.4 \%$ & $6.0 \%$ & & \\
\hline Micro/small & 0 & 0 & 0 & 0 & 0 \\
\hline Small (up to cottontail rabbit sized) & 37 & 17 & 53 & 0 & 107 \\
\hline & $15.6 \%$ & $23.6 \%$ & $19.8 \%$ & & \\
\hline Small/medium & 3 & 1 & 4 & 0 & 8 \\
\hline & $1.3 \%$ & $1.4 \%$ & $1.5 \%$ & & \\
\hline Medium (raccoon, canid sized) & 17 & 4 & 21 & 0 & 42 \\
\hline & $7.2 \%$ & $5.6 \%$ & $7.8 \%$ & & \\
\hline Medium/large & 172 & 40 & 168 & 2 & 382 \\
\hline & $72.6 \%$ & $55.6 \%$ & $62.7 \%$ & $100.0 \%$ & \\
\hline Large (deer, pronghorn sized) & 5 & 8 & 6 & 0 & 19 \\
\hline & $2.1 \%$ & $11.1 \%$ & $2.2 \%$ & & \\
\hline Large/very large & 0 & I & 0 & 0 & I \\
\hline & & $1.4 \%$ & & & \\
\hline Very large (bison-sized) & 2 & 0 & 0 & 0 & 2 \\
\hline & $0.8 \%$ & & & & \\
\hline Totals: & 237 & 72 & 268 & 2 & 579 \\
\hline
\end{tabular}

Late Paleoindian components in Unit II are a greater use of artiodactyles, rodents, and reptiles, especially turtles, in upper Unit I, and Unit II marks a shift to slightly more fish, rabbits, and hares. Bison appear to have been present and utilized in small numbers throughout most of this time period, but deer were probably the most common larger mammal utilized for food. Small numbers of bird eggshells were found throughout the Unit I and Unit II deposits, and it seems highly likely that bird eggs were used for food. No period has evidence for economic specialization. A decline in rodent and reptile diversity from upper Unit I into Unit II probably reflects fluctuations in the availability of certain species as the animal populations respond to changing climates at the end of the Pleistocene and early Holocene eras. The only direct botanical evidence for subsistence in the Late Paleoindianaged deposits is the presence ofa walnut shell in the Wilson component in upper Unit I. Clearly the absence of evidence does not reflect the lack of a botanical component in the diets of Late Paleoindian hunter-gatherers at the WilsonLeonard site or in Central Texas, but the details are missing.

\section{FEATURES}

Fifty-seven features were recorded in the deposits identified as containing Late Paleoindian-aged archeological remains (Table 8-22). Nine of these features are not made by humans but appear to be natural features such as burned tree stumps or a gravel pocket or lens. Another five form a 
TABLE 8-18

Fauna! Remains from TxDOT and TARL Excavations Diagnostic only to Mammal Order Categories

\begin{tabular}{|c|c|c|c|c|c|}
\hline \multirow[b]{2}{*}{ TxDOT-1/4 inch } & \multicolumn{4}{|c|}{ Unit } & \multirow[b]{2}{*}{ Totals } \\
\hline & Upper I & UIT & 11 & $\mathbf{X}$ & \\
\hline Rodentia (rodents) & $\begin{array}{c}1 \\
1.9 \%\end{array}$ & 0 & 0 & 0 & $\mathrm{I}$ \\
\hline Artiodactyla (even-toed ungulates) & $\begin{array}{c}29 \\
54.7 \%\end{array}$ & $\begin{array}{c}7 \\
63.6 \%\end{array}$ & $\begin{array}{c}\text { II } \\
40.7 \%\end{array}$ & $\begin{array}{c}3 \\
75.0 \%\end{array}$ & 50 \\
\hline Camivora (carnivores) & $\begin{array}{c}7 \\
13.2 \%\end{array}$ & $\begin{array}{c}2 \\
18.2 \%\end{array}$ & $\begin{array}{c}4 \\
14.8 \%\end{array}$ & 0 & 13 \\
\hline Leporidae (rabbits and hares) & $\begin{array}{c}16 \\
30.2 \%\end{array}$ & $\begin{array}{c}2 \\
18.2 \%\end{array}$ & $\begin{array}{c}12 \\
44.4 \%\end{array}$ & $\begin{array}{c}\text { I } \\
25.0 \%\end{array}$ & 31 \\
\hline Totals: & 53 & 11 & 27 & 4 & 95 \\
\hline TARL-1/8 inch & Upper I & $1 / 11$ & II & $\mathbf{X}$ & Totals \\
\hline Rodentia (rodents) & $\begin{array}{c}21 \\
21.9 \%\end{array}$ & $\begin{array}{c}8 \\
20.5 \%\end{array}$ & $\begin{array}{c}29 \\
18.5 \%\end{array}$ & 0 & 58 \\
\hline Artiodactyla (even-toed ungulates) & $\begin{array}{c}4 \\
4.2 \%\end{array}$ & 0 & $\begin{array}{c}2 \\
1.3 \%\end{array}$ & 0 & 6 \\
\hline Carnivora (carnivores) & $\begin{array}{c}1 \\
1.0 \%\end{array}$ & 0 & $\begin{array}{c}3 \\
1.9 \%\end{array}$ & 0 & 4 \\
\hline Leporidae (rabbits and hares) & $\begin{array}{c}70 \\
72.9 \%\end{array}$ & $\begin{array}{c}31 \\
79.5 \%\end{array}$ & $\begin{array}{c}123 \\
78.3 \%\end{array}$ & $\begin{array}{c}\text { I } \\
100.0 \%\end{array}$ & 225 \\
\hline Totals: & 96 & 39 & 157 & I & 293 \\
\hline
\end{tabular}

group consisting of burned sediment and charcoal with an occasional burned rock, and these could be either of human or natural origins. In the remaining 43 human-made features, 3 different types of features were discovered in the Late Paleoindian strata at Wilson-Leonard. These are burned rock features, pits, and a human burial. A great deal of effort and time was expended on documenting and analyzing these features, and they provide a critical source of evidence for Late Paleoindian adaptations.

The features in the upper portion of Unit I (Units 1si-c and Id) provide some of the most spectacular finds from the excavations. In the lower portion of the Leanne soil was Burial 2. Burial 2 was a flexed fairly complete skeleton of a young (ca. 25 years old) female with no known agent of death (see Chapter 31 for more details and analysis of the burial remains). Even though the remains had been altered by postdepositional processes, her stature can still be reasonably estimated at approximately $158 \mathrm{~cm}$ (5 feet 2 inches). When the pit fill was removed she was lying on her right side, with legs flexed halfway to her chest, her right and left arms bent with elbows toward her knees and hands toward her head, and her cranium resting on the palm of her right hand (Figure 8-22).

The top of the burial pit $(52-\mathrm{x}-104 \mathrm{~cm})$ was within the Leanne soil (Unit Isi-c) and extended down at least $22 \mathrm{~cm}$ into Unit Isi and Unit lei, the cienega (see Chapters 26 and 29). The age of the burial is not known exactly. It most certainly falls within the range of 10,000-9500 B.P., and most probably in the older portion of that range. Three sets of information are used to assess the age of the burial. First are two radiocarbon assays averaging 9560 B.P. on sediment from the burial pit fill (see Table 8-2 and Chapter 25). Second are two radiocarbon assays averaging 9420 B.P., which were run on charcoal from Feature 167 and Feature 72 (see Table $8-2$ ). These features are burned root systems that extend stratigraphically over Burial 2 and thus as minimum ages constrain the age of Burial 2. Third is the general stratigraphic sequence and associated radiocarbon chronology for stratum Unit I (see Table 8-1) which strongly demonstrates that the Leanne soil formed between 9990-9550 s.r. All three sources of chronometric evidence indicate an age for Burial 2 as greater than 9420 B.P., at the least, and as indicated above the true age of Burial 2 is probably closer to 10,000 BP. than 9500 BP.

Much can be deduced from the physical remains in the burial pit. Microscopic wear on the teeth in the form of frequent pits and occasional moderate-to-large striations suggests a varied diet that included hard materials such as hulls or hard seeds (see Chapter 31). Stable carbon and nitrogen isotope values (see Chapter 32 ) were influenced by diagenetic chemical changes, but $\mathrm{d}^{13} \mathrm{C}$ measurements on bone apatite of $-11.2 \%$ oo indicate that while her diet favored $\mathrm{C}_{3}$ plants, the woman probably also ingested $\mathrm{C}_{4}$ plants or herbivores that consumed $\mathrm{C}_{4}$ plants. The $\mathrm{C}_{4}$ plants in this region could consist of prickly pear (actually a CAM plant that produces a $\mathrm{C}_{4}$ isotopic signal) or perhaps $\mathrm{C}_{4}$ grass seeds. 
TABLE 8-19

Fauna! Remains from TxDOT and TARL Excavations Diagnostic to Family, Genera or Species Catagories

\begin{tabular}{|c|c|c|c|c|c|}
\hline \multirow{2}{*}{$\begin{array}{l}\text { Taxon } \\
\text { TxDOT-1/4 inch }\end{array}$} & \multicolumn{4}{|c|}{ Unit } & \multirow[b]{2}{*}{ Totals } \\
\hline & Upper I & VII & II & $\mathrm{X}$ & \\
\hline \multicolumn{6}{|l|}{ Repilia (Reptiles) } \\
\hline Kinosternidae (Mud and Musk Turtles) & 1 & 0 & 0 & 0 & 1 \\
\hline Emydidae (Water and Box Turtles) & $\mathrm{I}$ & 0 & 0 & 0 & 1 \\
\hline \multicolumn{6}{|l|}{ Artiodactyla (Even-toed Ungulates) } \\
\hline Antilocapra/Odocoileus (Pronghorn or Deer) & 13 & 5 & 10 & 2 & 30 \\
\hline Odocoileus sp. (Deer) & 9 & 1 & 0 & 0 & 10 \\
\hline Bison sp. (bison) & 1 & 1 & 0 & 0 & 2 \\
\hline \multicolumn{6}{|l|}{ Carnivora (Carnivores) } \\
\hline Canis sp. (Coyote/Wolf/Dog) & 0 & 0 & 1 & 0 & 1 \\
\hline cf. Canis sp. & I & 1 & 0 & 0 & 2 \\
\hline \multicolumn{6}{|l|}{ Leporidae (Rabbits and Hares) } \\
\hline Lepus californicus (Blacktailed Jackrabbit) & I & $a$ & I & 0 & 2 \\
\hline Sylvilagus sp. (Cottontail Rabbit) & 9 & 2 & 7 & 0 & 18 \\
\hline cf. Sylvilagus sp. & 0 & 0 & 1 & 0 & 1 \\
\hline Totals: & 36 & 10 & 20 & 2 & 68 \\
\hline TARL-1/8 inch & Upper I & $1 / 11$ & II & $\mathrm{X}$ & Totals \\
\hline \multicolumn{6}{|l|}{ Repitilia (Reptiles) } \\
\hline Kinosternidae (Mud and Musk Turtles) & 1 & 0 & 0 & 0 & 1 \\
\hline Emydidae (Water and Box Turtles) & 1 & 0 & 0 & 0 & 1 \\
\hline Colubridae (Colubrid Snakes-nonpoisonous) & 1 & 2 & 2 & 0 & 5 \\
\hline Viperidae (Pitviper Snakes-poisonous) & 1 & 0 & 3 & 0 & 4 \\
\hline \multicolumn{6}{|l|}{ Rodentia (Rodents) } \\
\hline Blarina sp. (Shrews) & 2 & 0 & 0 & 0 & 2 \\
\hline cf. Spermophilus mexicanus (Mexican Ground Squirrel) & 1 & 0 & 0 & 0 & 1 \\
\hline Geomys sp. (Pocket Gophers) & 7 & 4 & 16 & 0 & 27 \\
\hline cf. Geomys sp. & 1 & 0 & 0 & 0 & 1 \\
\hline Neotoma sp. (Wood Rats) & 7 & 0 & 1 & 0 & 8 \\
\hline \multicolumn{6}{|l|}{ Artiodactyla (Even-toed Ungulates) } \\
\hline Antilocapra/Odocoileus (Pronghorn or Deer) & 1 & 0 & 0 & 0 & 1 \\
\hline Odocoileus sp. (Deer) & 1 & 0 & 1 & 0 & 2 \\
\hline \multicolumn{6}{|l|}{ Carnivora (Carnivores) } \\
\hline Canis sp. (Coyote/Wolf/Dog) & 0 & 0 & 0 & 0 & 0 \\
\hline \multicolumn{6}{|l|}{ Leporidae (Rabbits and Hares) } \\
\hline Lepus californicus (California Jackrabbit) & 4 & 0 & 9 & 0 & 13 \\
\hline cf. Lepus californicus & 0 & 0 & I & 0 & 1 \\
\hline Sylvilagus sp. (Cottontail Rabbit) & 40 & 19 & 76 & 0 & 135 \\
\hline cf. Sylvilagus sp. & 1 & 0 & 3 & 0 & 4 \\
\hline Totals: & 69 & 25 & 112 & 0 & 206 \\
\hline
\end{tabular}

Three items were found in the burial pit fill. A ground stone tool, a fossil shark tooth, and a moderate-sized subangular limestone cobble. The ground stone tool (FBU2-1) is made of sandstone with pink feldspar grains (Figure 8-23).
This material does not occur locally, but most certainly originated in the Central Mineral Region in Central Texas and might be available from gravel deposits in the Colorado River valley some $15-20 \mathrm{~km}$ to the southwest. It is pecked, ground 
TABLES-20

Fine-screen Fauna from Square 20

\begin{tabular}{|c|c|c|c|c|c|c|c|c|c|c|c|c|c|c|c|c|c|c|c|c|}
\hline \multirow[b]{2}{*}{ Taxon } & \multicolumn{19}{|c|}{ Levels } & \multirow[b]{2}{*}{ Totals } \\
\hline & 26 & 27 & 28 & 29 & 30 & 31 & 32 & 33 & 34 & 35 & 36 & 37 & 38 & 39 & 40 & 41 & 42 & 43 & 44 & \\
\hline $\begin{array}{l}\text { Unidentified Teleost } \\
\text { Ictalurid }\end{array}$ & $\begin{array}{c}42 \\
6\end{array}$ & $\begin{array}{c}28 \\
0\end{array}$ & $\begin{array}{c}25 \\
0\end{array}$ & $\begin{array}{l}8 \\
0\end{array}$ & $\begin{array}{l}5 \\
0\end{array}$ & $\begin{array}{l}2 \\
2\end{array}$ & $\begin{array}{l}2 \\
\mathrm{I}\end{array}$ & $\begin{array}{l}3 \\
0\end{array}$ & $\begin{array}{l}2 \\
0\end{array}$ & $\begin{array}{l}\text { I } \\
2\end{array}$ & $\begin{array}{l}\text { I } \\
0\end{array}$ & $\begin{array}{l}0 \\
0\end{array}$ & $\begin{array}{l}3 \\
0\end{array}$ & $\begin{array}{l}0 \\
0\end{array}$ & $\begin{array}{l}0 \\
0\end{array}$ & $\begin{array}{l}0 \\
0\end{array}$ & $\begin{array}{l}0 \\
0\end{array}$ & $\begin{array}{l}0 \\
0\end{array}$ & $\begin{array}{l}0 \\
0\end{array}$ & $\begin{array}{r}122 \\
\text { II }\end{array}$ \\
\hline Centrarchid & 3 & 5 & 0 & I & 3 & 2 & 0 & 0 & 0 & 0 & I & I & 0 & 0 & I & 0 & I & 0 & 0 & 18 \\
\hline Unidentified Anuran & I & 0 & 0 & 2 & 0 & 0 & 0 & 0 & I & 0 & 2 & 0 & 0 & 0 & 0 & 0 & 0 & 0 & 0 & 6 \\
\hline Unidentified Chelonia & 27 & 16 & 18 & 3 & I & 2 & 0 & 7 & I & 8 & 2 & 5 & 0 & 0 & I & 0 & 0 & 0 & 0 & 91 \\
\hline Trionyxsp. & 0 & 0 & 0 & 0 & 0 & 0 & 0 & 0 & 0 & I & 0 & 0 & 0 & 0 & 0 & 0 & 0 & 0 & 0 & I \\
\hline Unidentified Serpentes & II & 5 & 8 & 3 & 0 & 2 & 2 & I & 0 & 2 & 3 & 3 & 4 & 2 & 3 & I & 0 & 2 & 0 & 52 \\
\hline Elaphe sp. & 0 & 0 & 0 & 0 & 0 & 0 & 0 & 0 & 0 & 0 & 0 & 0 & 1 & 0 & 0 & 0 & 0 & 0 & 0 & 1 \\
\hline Sonora sp. & 0 & 0 & 0 & 0 & 0 & 0 & 0 & 0 & 0 & 0 & 0 & 0 & 0 & 0 & 0 & 1 & 0 & 0 & 0 & 1 \\
\hline Unidentified lizard & 0 & 1 & 0 & 0 & 0 & 0 & 0 & 0 & 0 & 0 & 0 & 0 & 0 & I & 0 & 0 & 0 & 0 & 0 & 2 \\
\hline Ophisaurus attenuatus & 0 & 0 & 0 & 0 & 0 & 0 & 0 & 0 & 0 & 0 & I & 0 & 0 & 0 & 0 & 0 & 0 & 0 & 0 & 1 \\
\hline Phrynosoma sp. & 1 & 0 & 0 & 0 & 0 & 0 & 0 & 0 & 0 & 0 & 0 & 0 & 0 & 0 & 0 & 0 & 0 & 0 & 0 & 1 \\
\hline Unidentified Aves & 0 & 0 & 1 & 2 & 0 & 3 & 1 & 0 & I & 0 & 0 & 0 & I & 0 & 0 & 0 & 0 & 0 & 0 & 9 \\
\hline Eggshell & 0 & 0 & 0 & 3 & 2 & 5 & 5 & 0 & 6 & 3 & 2 & 0 & 12 & 2 & 0 & 1 & 0 & 0 & 0 & 41 \\
\hline Lepus $\mathbf{s p .}$ & 2 & I & 0 & 0 & 0 & 0 & 0 & 0 & 0 & 0 & 0 & 0 & 0 & 0 & 0 & 0 & 0 & 0 & 0 & 3 \\
\hline Sylvilagus sp. & 10 & 9 & 19 & 6 & 6 & 11 & 7 & 18 & 19 & 12 & 5 & 2 & 7 & 2 & 2 & 4 & 2 & I & I & 143 \\
\hline Spermophilus sp. & 0 & 0 & 0 & 0 & 0 & 0 & 1 & 0 & 0 & 0 & 0 & 0 & 0 & 0 & 0 & 0 & 0 & 0 & 0 & I \\
\hline Sciurus sp. & 0 & 0 & 0 & 0 & 0 & 0 & 0 & 0 & 0 & 0 & 0 & 0 & 1 & 0 & 0 & 0 & 0 & 0 & 0 & I \\
\hline Geomys sp. & 2 & 0 & 6 & 3 & 2 & 3 & II & 2 & I & 4 & 7 & 3 & 3 & 1 & 0 & 0 & 3 & I & 1 & 53 \\
\hline Perognathus sp. & 0 & 0 & 0 & 0 & 0 & 0 & 0 & 0 & 0 & 0 & 1 & 0 & 0 & 0 & 0 & 0 & 0 & 0 & 0 & I \\
\hline Perognathus/Reithrodontomys & 0 & 0 & 1 & 0 & 0 & 0 & 0 & 1 & 0 & 0 & 0 & 0 & 0 & 0 & 0 & 0 & 0 & 0 & 0 & 2 \\
\hline Peromyscus sp. & 1 & 0 & 0 & 1 & 0 & 0 & 0 & I & 0 & 0 & 0 & 0 & 0 & 0 & 0 & 0 & 0 & 0 & 0 & 3 \\
\hline Sigmodon hispidus & 4 & 10 & 3 & 2 & 4 & 8 & 7 & 4 & 2 & 9 & 1 & 0 & 0 & 0 & I & 1 & 0 & 0 & 0 & 56 \\
\hline Neotoma sp. & 1 & 1 & 0 & 0 & 2 & 0 & 2 & 2 & 0 & 1 & 0 & 1 & 0 & 0 & 0 & 2 & 0 & 0 & 0 & 12 \\
\hline Ondatra zibethicus & 0 & 0 & 0 & 0 & 0 & 0 & 0 & 0 & 0 & 0 & I & 0 & 0 & 0 & 0 & 0 & 0 & 0 & 0 & I \\
\hline Microtus sp. & 1 & 0 & 2 & 1 & I & 2 & 2 & 7 & 3 & 5 & 2 & 0 & 2 & 0 & 1 & 0 & 0 & 0 & 0 & 29 \\
\hline Oryzomys palustris & 0 & 0 & 0 & 0 & 0 & 0 & 0 & 0 & 0 & 0 & 0 & 0 & 0 & 0 & 1 & 0 & 0 & 0 & 0 & I \\
\hline Unidentified Rodent & 21 & 18 & 24 & 14 & 14 & 23 & 16 & 15 & 15 & 24 & 33 & 6 & 8 & 7 & 2 & 8 & 6 & 6 & 1 & 261 \\
\hline Unidentified Carnivore & 0 & 0 & 0 & 0 & 0 & 0 & 0 & 0 & 0 & I & 0 & 0 & 0 & 0 & 0 & 0 & 0 & 0 & 0 & I \\
\hline Canis sp. & 0 & 0 & 0 & 0 & 0 & 0 & 0 & 0 & 0 & 0 & 0 & 0 & I & 0 & 0 & 0 & 0 & 0 & 0 & I \\
\hline Procyon lotor & 0 & 0 & 0 & 0 & 0 & 0 & 0 & 0 & 0 & 0 & 0 & 0 & 0 & 0 & 0 & 0 & 0 & 0 & I & 1 \\
\hline Unidentifi,ed Artiodactyl & 0 & 0 & 0 & 0 & 0 & 0 & 1 & 0 & 0 & 0 & 0 & 0 & 0 & 0 & 0 & 0 & 0 & 0 & 0 & 1 \\
\hline Small mammal & II & 10 & 0 & 0 & I & 0 & 9 & 12 & I & 3 & 13 & 1 & 2 & I & 5 & 0 & 4 & 0 & 4 & 77 \\
\hline Medium mammal & 2 & 1 & 4 & 1, & 0 & 0 & II & 1 & 5 & 2 & 0 & 0 & 5 & 0 & 0 & 0 & 0 & 0 & 0 & 32 \\
\hline Large mammal & 0 & 0 & 0 & 2 & 0 & 1 & 0 & 2 & 1 & 0 & 0 & 0 & 1 & 0 & 0 & 0 & 0 & 0 & 0 & 7 \\
\hline Unidentified venebrate & 686 & 686 & 649 & 312 & 543 & 536 & 558 & 316 & 369 & 462 & 616 & 260 & 470 & 188 & 171 & 161 & 203 & 67 & 68 & 7,321 \\
\hline Totals: & 832 & 791 & 760 & 364 & 584 & 602 & 636 & 392 & 427 & 540 & 691 & 282 & 521 & 204 & 188 & 179 & 219 & 77 & 76 & 8,365 \\
\hline
\end{tabular}


TABLE 8-21

Frequency of Eggshell by Feature and Thickness of Eggshell

\begin{tabular}{c|c|c|c|c}
\hline \multirow{2}{*}{ Thickness } & \multicolumn{3}{|c|}{ Unit } & \multirow{2}{*}{ Totals } \\
\cline { 2 - 4 } 0.15 & Isi-c & I/II & II & 1 \\
0.16 & & 1 & 1 & 1 \\
0.17 & & & & \\
0.18 & 1 & & & 1 \\
0.19 & & & & \\
0.20 & 1 & & & 1 \\
0.21 & 1 & 1 & & 2 \\
0.22 & & & & 2 \\
0.23 & 1 & & 1 & 2 \\
0.24 & & & 2 & 1 \\
0.25 & 1 & & & 1 \\
0.26 & & 1 & & 2 \\
0.27 & 1 & 1 & I & \\
0.28 & 6 & 4 & 5 & 15 \\
\hline Totals: & 176.6 & 46.5 & 2.2 & \\
Matrix Volume & & & \\
(liters) & & & & \\
eggshell/liter & 0.03 & 0.09 & 2.27 & \\
\hline \hline
\end{tabular}

was a portion of a necklace or some other type of ornament (Figure 8-24). The purpose of the limestone cobble (Figure $8-25$ ) is completely unknown, but it is possible that it may have been used to cover something or hold something down in the burial pit.

Other features in Unit I include two, perhaps three, excavated pits (Features 168,169, and 252). Feature 169, in the lower portion of the Leanne soil, is a roughly circular (60-x$65 \mathrm{~cm}$ ) and U-shaped pit excavated to a depth of at least 55 $\mathrm{cm}$ (Figure 8-26). Two unburned tabular limestone rocks were clearly placed at the base of the pit and micromorphological analysis of the sediments indicates a limited amount oflightly burned sediment. Unfortunately the rocks were not collected, but it is possible that this pit functioned as some form of stone boiling pit. Other uses such as storage cannot be ruled out. Another pit (Feature 168) was discovered by TxDOT archeologists nearby and slightly higher in the Leanne soil (see Figure 8-26). Feature 168 is also circular (70$\mathrm{x}-87 \mathrm{~cm}$ ) but with a flat base $40 \mathrm{~cm}$ below the top of the feature. Little direct evidence can be used to infer function.

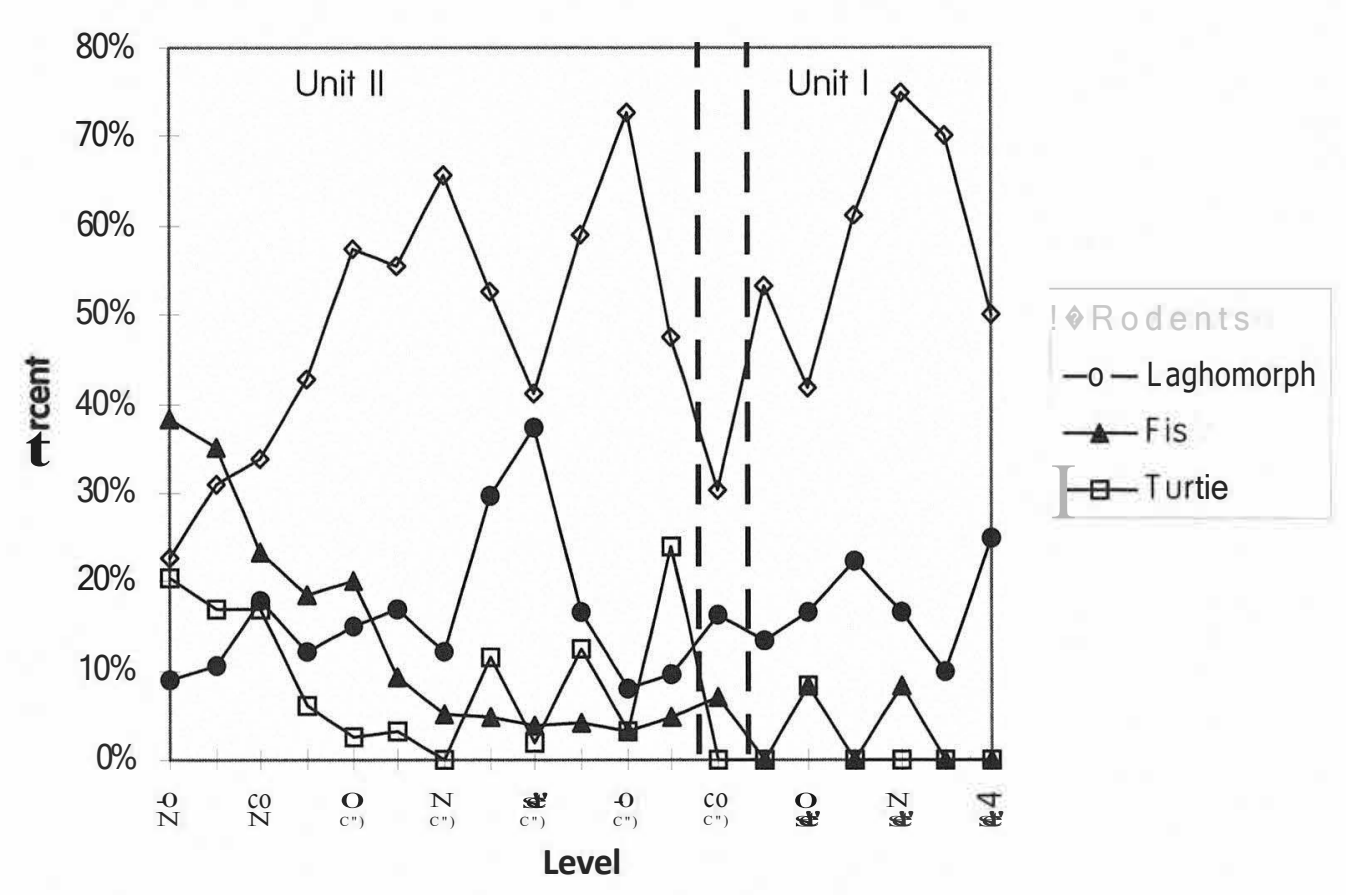

FIGURE 8-21. Relative abundance of small animals in fine-screen sample.

bifacially, and has striations on both slightly convex faces. It also has a bifacially flaked edge with evidence of crushing, battering, and microflaking. The flake scars are fresher in appearance than the rest of the stone's surfaces. This evidence suggest the ground stone was used as a mano and then later as a chopper. The fossil shark tooth was below the cranium in the area of the neck and it is possible that this
No evidence of burning was present, but the feature could be either a stone boiling pit or a storage pit. The third possible pit feature is Feature 252. This is a roughly oval discoloration discovered in the lower portion of the Leanne soil and extends below into Unit Isi. It is approximately $45-\mathrm{x}-50$ $\mathrm{cm}$ in horizontal plan and at least $19 \mathrm{~cm}$ deep and consists of two rough oval depressions (Figure 8-27). The pit fill is very 
TABLE 8-22

Attn'butes of Features Recorded $m$ the Late Pałomd'lan DeposIts at WIlson-Leonard

\begin{tabular}{|c|c|c|c|c|c|}
\hline $\begin{array}{l}\text { Feature } \\
\text { Number }\end{array}$ & $\begin{array}{l}\text { Stratigraphic } \\
\text { Unit } \\
\end{array}$ & $\begin{array}{l}\text { Feature } \\
\text { Type } \\
\end{array}$ & $\begin{array}{l}\text { Number } \\
\text { of Rocks }\end{array}$ & $\begin{array}{l}\text { Size } \\
(\mathrm{cm})\end{array}$ & $\begin{array}{l}\text { Associated } \\
\text { Radiocarbon Assays }\end{array}$ \\
\hline 71 & Isi-c/upper & burned rock ring & 6 & $70 \times 35$ & \\
\hline 72 & Isi-c/upper & burned root (F167) & & & $9430 \pm 60$ \\
\hline 73 & Isi-c/upper & burned root (F167) & & & \\
\hline 74 & lsi-c/lower & gravel pocket & & & \\
\hline 109 & II & burned rock cluster & 15 & $50 \times 40$ & \\
\hline 111 & II & burned rock cluster & 25 & $90 \times 65$ & \\
\hline 112 & $\mathbf{X}$ & burned rock cluster & 6 & $45 \times 10$ & \\
\hline 113 & $\mathrm{X} / \mathrm{II}$ & burned rock cluster & 8 & $15 \times 18+$ & \\
\hline 114 & XIII & burned rock cluster & 6 & $40 \times 15$ & \\
\hline 115 & $\mathbf{X}$ & burned rock cluster & 15 & $95 \times 30$ & \\
\hline 116 & $\mathbf{X}$ & burned rock cluster & 6 & $40 \times 40$ & \\
\hline 117 & $\mathrm{Id} / \mathrm{II}$ & burned rock cluster & 11 & $120 \times 53$ & \\
\hline 118 & $\mathbf{X}$ & burned rock cluster & 10 & $110 \times 50$ & \\
\hline 119 & Isi-c/Id & burned rock cluster/ring & 12 & $65 \times 60$ & \\
\hline 153 & II & burned rock ring & 18 & $90 \times 90$ & \\
\hline 154 & I & burned tree Uuniper?) & & & \\
\hline 155 & II & burned rock cluster (basin?) & 60 & $90 \times 70$ & \\
\hline 156 & II & burned rock ring & 16 & $70 \times 50$ & \\
\hline 157 & II & burned rock cluster & 17 & $160 \times 140$ & $9340 \pm 60$ \\
\hline 158 & II & burned rock ring & 7 & $50 \times 40$ & \\
\hline 159 & II & mineralized root & & & \\
\hline 160 & II & burned sediment (burned root?) & & & \\
\hline 161 & $\mathrm{Id} / \mathrm{II}$ & debitage cluster & & $30 \times 30$ & \\
\hline 162 & II & burned rock cluster & 5 & $40 \times 30$ & \\
\hline 163 & 1si-c/Id & burned rock cluster & 17 & $60 \times 30$ & \\
\hline 164 & Isi-c/Id/II & burned tree & & & $9520 \pm 60$ \\
\hline 165 & Isi-c/II & burned tree & & & \\
\hline 166 & Area B-I/II & burned rock basin & 75 & $160 \times 120+$ & \\
\hline 167 & Isi/Icl/Isi-c & burned live oak tree & & & $9410 \pm 60$ \\
\hline 168 & Isi-c/upper & pit & & $87 \times 70$ X40 & \\
\hline 169 & Isi-c/lower & pit & & $65 \times 60 \times 55$ & \\
\hline 171 & Isi-c/lower & burned rock cluster & 9 & $135 \times 80$ & \\
\hline 184 & II & burned rock basin & 60 & $135 \times 75+$ & \\
\hline 185 & II & burned rock cluster & 21 & $70 \times 35$ & \\
\hline 187 & Jsi-c/lower & burned rock cluster (basin?) & 45 & $70 \times 55$ & \\
\hline 193 & Isi-c/mid & burned rock cluster & 14 & $35 \times 30$ & \\
\hline 198 & Area B-I/II & burned live oak tree below F166 & & & $9240 \pm 70$ \\
\hline 232 & II & burned sediment and rock & 3 & $75 \times 100+$ & \\
\hline 234 & Isi-c/II & burned sediment and charcoal & & & \\
\hline 235 & Isi-c/II & burned rock cluster & 26 & $65 \times 60$ & \\
\hline 236 & Id/II & small burned rock basin & 20 & $60 \times 60$ & $9650 \pm 80$ \\
\hline 238 & Isi-c/II & burned sediment and charcoal & & $60 \times 40$ & $8830 \pm 90$ \\
\hline 239 & II & burned rock cluster & 15 & $65 \times 60$ & \\
\hline 241 & II & burned rock cluster & 13 & $55 \times 45$ & \\
\hline 243 & II & burned rock cluster & 5 & $50 \times 25$ & \\
\hline 246 & $\mathrm{Id} / \mathrm{II}$ & burned rock cluster & 20 & $60 \times 55$ & \\
\hline 247 & II & burned rock cluster & 4 & $25 \times 20$ & $8090 \pm 70$ \\
\hline 248 & II & burned rock cluster & 37 & $55 \times 40$ & \\
\hline 250 & II & burned rock cluster (basin?) & 20 & $55 \times 50$ & \\
\hline 251 & Isi-c/upper & burned sediment (burned root?) & & & \\
\hline 252 & 1si-c/lower & pit or burrow & & $50 \times 40 \times 19$ & \\
\hline 253 & Isi-c/upper & burned live oak tree & & & $9550 \pm 30$ \\
\hline 255 & Jsi-c/lower & burned rock cluster & 20 & $55 \times 50$ & $9990 \pm 70$ \\
\hline 256 & Isi-c/mid & burned rock cluster & 6 & $50 \times 50$ & \\
\hline 257 & Isi-c/upper & burned rock cluster & 4 & $20 \times 10$ & \\
\hline 260 & Isi-c/lower & burned rock cluster or ring & 22 & $100 \times 100$ & \\
\hline Burial 2 & 1si-c/lower & human burial & & $104 \times 52$ & $9470 \pm 170,9650 \pm 124$ \\
\hline
\end{tabular}




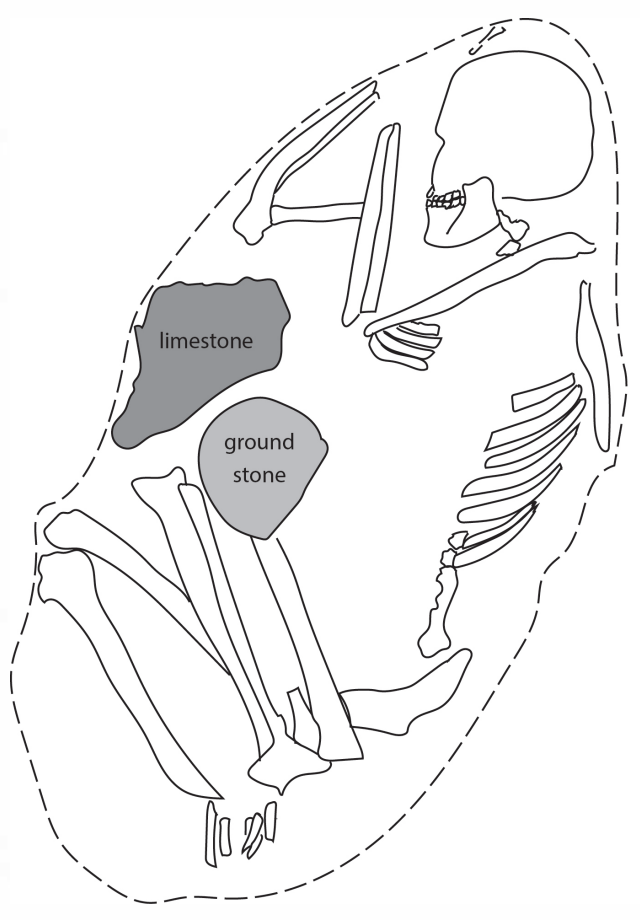

FGURE 8-22. Burial 2 in context. similar to the sediments found in the Leanne Soil thus the top was very difficult to discern. Again no clear evidence for use was discovered, but Feature 252 bears a resemblance to the other two pit features and may have played a similar, although unknown, role.

Thirty-nine burned rock features were recording Unit I, Unit II, and Unit X. The Wilson component features range from dense clusters (Figure 8-28) to concentrated but small clusters (Figure 8-29) to dispersed clusters (Figures 8-30 and 8-31) to burned rock rings (see Figure 8-31).

The distribution of burned rock feature types does not demonstrate any significant patterns through time at Wilson-Leonard (Table 8-23). If the burned sediment and rocks represent unprepared hearths, then this is not a common feature type in the Late Paleoindian sediments at the site. However, patterned changes are present through time in the average number of rocks and the average feature size (Table 8-24). Both the average number of rocks per feature and the average size offeatures increase from Unit I to Unit II. These data suggest that the burned rock features are not static and that their size is increasing during the Late Paleoindian period, however it does not appear that there is a shift in the type of feature.

The next critical link in the feature evidence is the results from the archeomagnetic analysis (see Chapter 27). Burned rocks from 11 Late Paleoindian features were subjected to

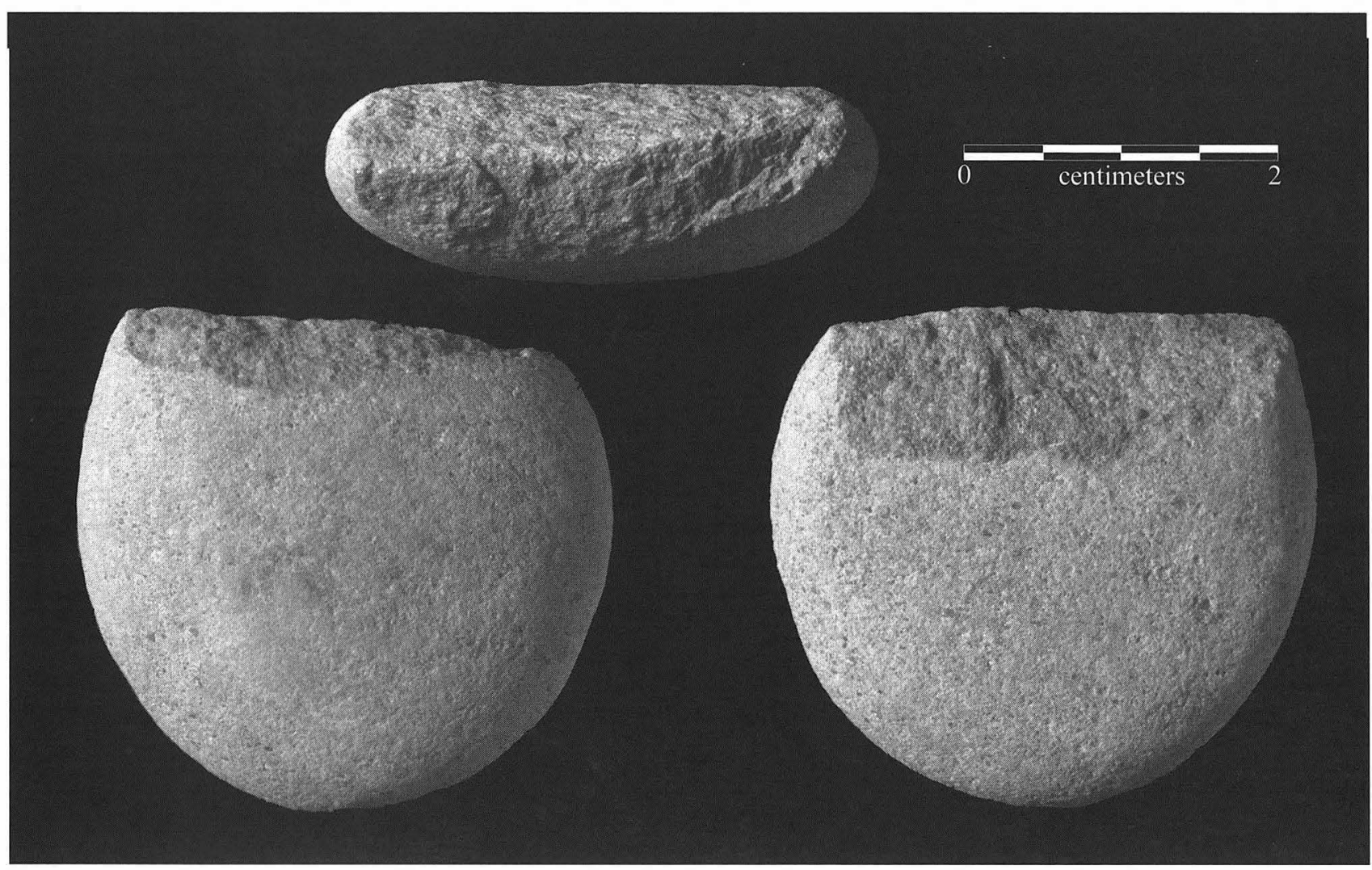

FGURE 8-23. Ground stone tool (two faces and edge-on) from Wilson component Burial 2 shown at 50\% size, Specimen FBU2-1. 


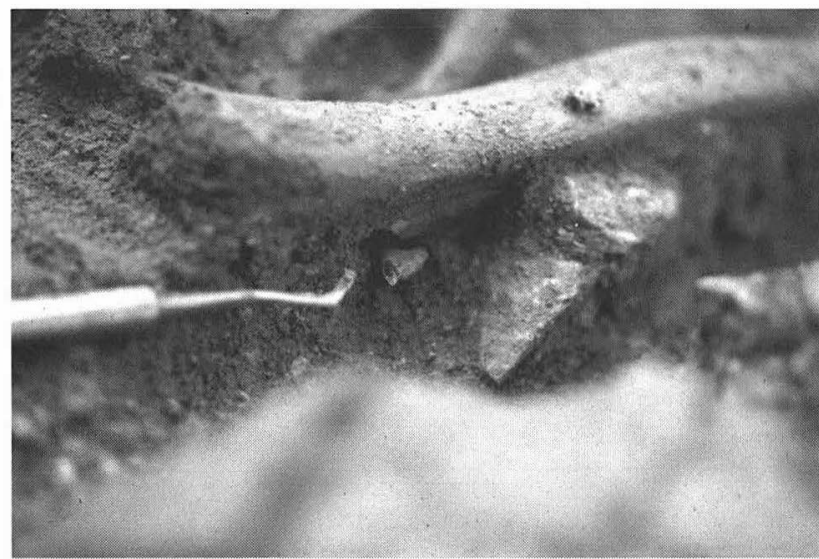

a

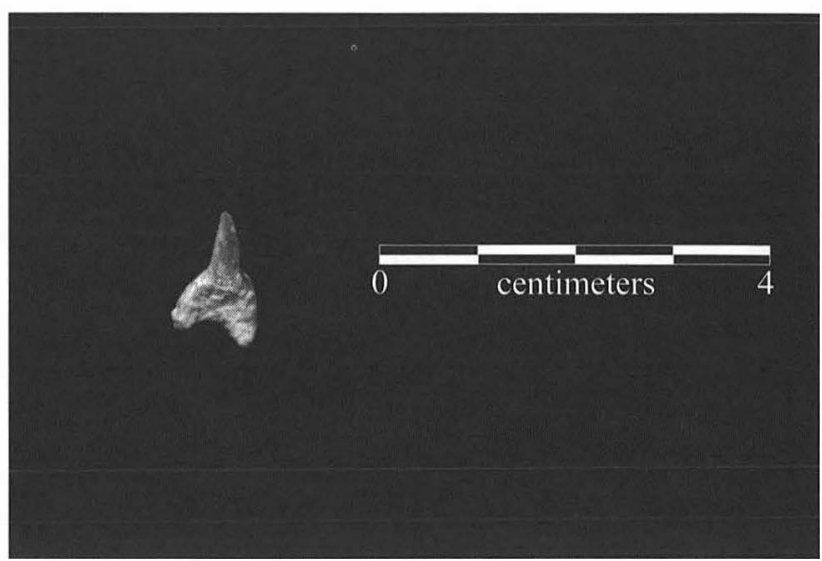

b

FlaURE 8-24. Fossil shark tooth from Wilson component Burial 2, Specimen FBU2-3; (a) removing specimen from under left humerus with dental pick, (b) close-up of shark tooth.

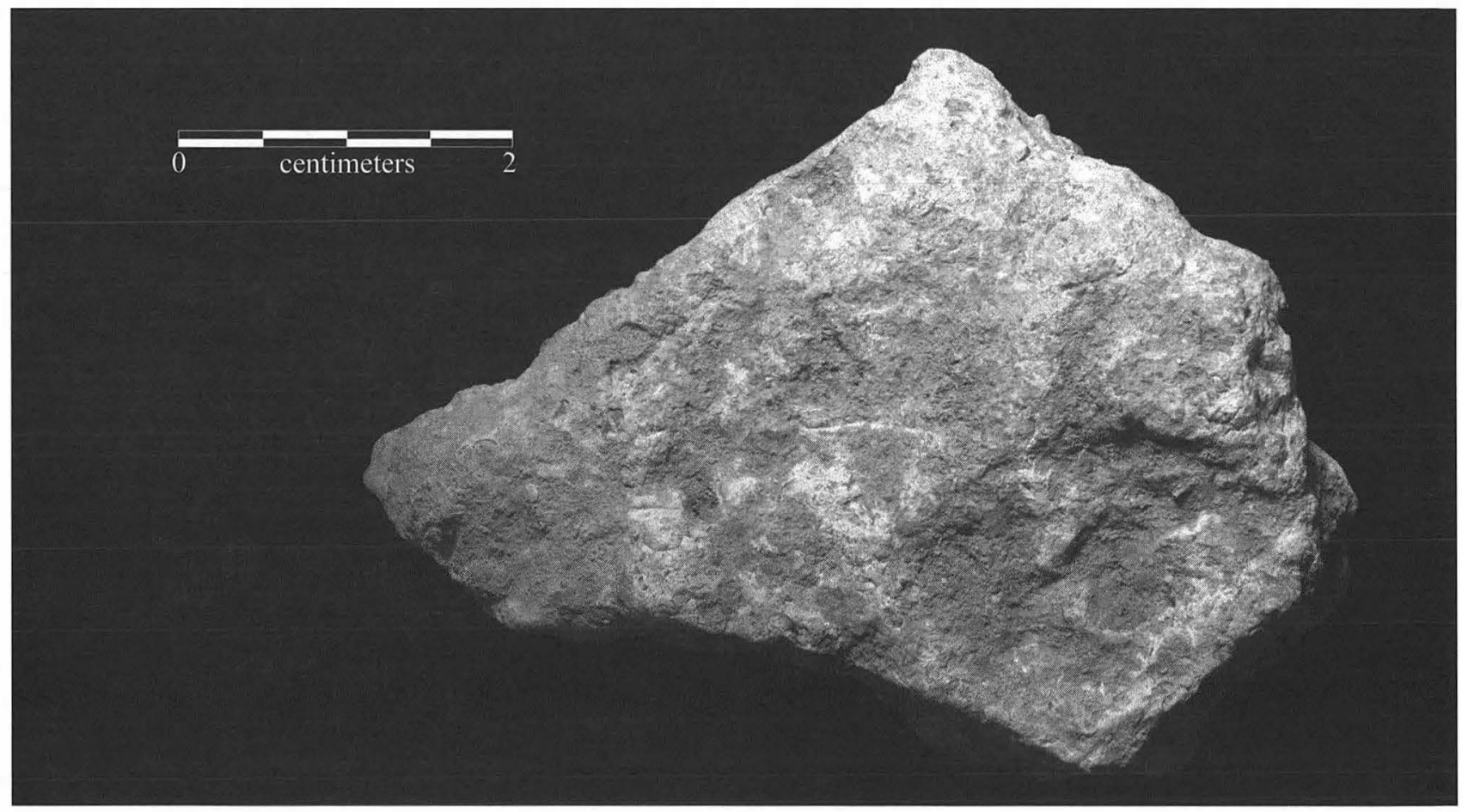

FlouRE 8-25. Limestone slab from Wilson component Burial 2 shown at 50\% size, Specimen FBU2-2.

magnetic analysis (Table 8-25). This analysis demonstrates that 9 of the 11 features where heated to considerable temperatures, cooled in place, and have mostly remained in place since that time. This conclusively demonstrates that the site's stratigraphy has maintained high integrity for these Late Paleoindian deposits. At one point in the investigations, it was suggested that the stratigraphic placement of the stemmed projectile point Wilson component below other Late Paleoindian lanceolate components was due to erosion and thus the site had a reversed stratigraphy. However, this hypothesis is highly unlikely considering the presence of intact heated-and-cooled-in-place burned rock features throughout upper Unit I and Unit II.

Feature use is very difficult to decipher. Even when the physical characteristics vary so greatly as between the Unit I pit and the other burned rock features. It is possible that cooking could be the primary function of both types. Nevertheless, the associated fauna! remains can provide some indication of feature use (see Chapter 36 and Appendix 10). Only 15 of the 38 burned rock features had associated fauna! remains and these are presented below in Table 8-26 and Table 8-27. Some interesting patterns are present in these data. First, in the fine-screen data the highest number and greatest diversity of fauna occurs in the two Unit I pits 


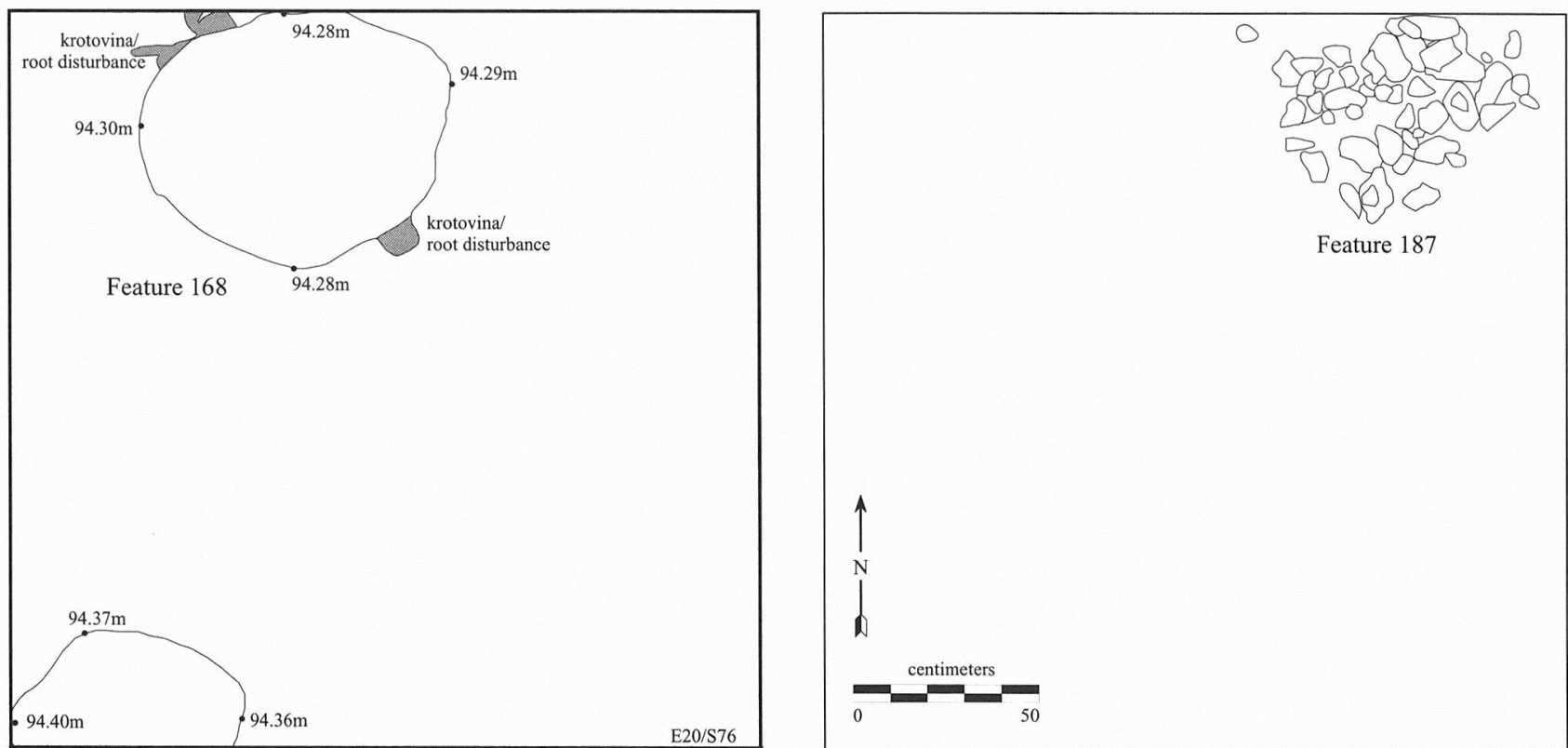

FIGURE 8-28. Plan of Feature 187, a possible burned rock basin.

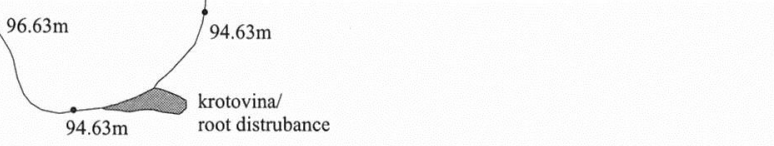

Feature 169

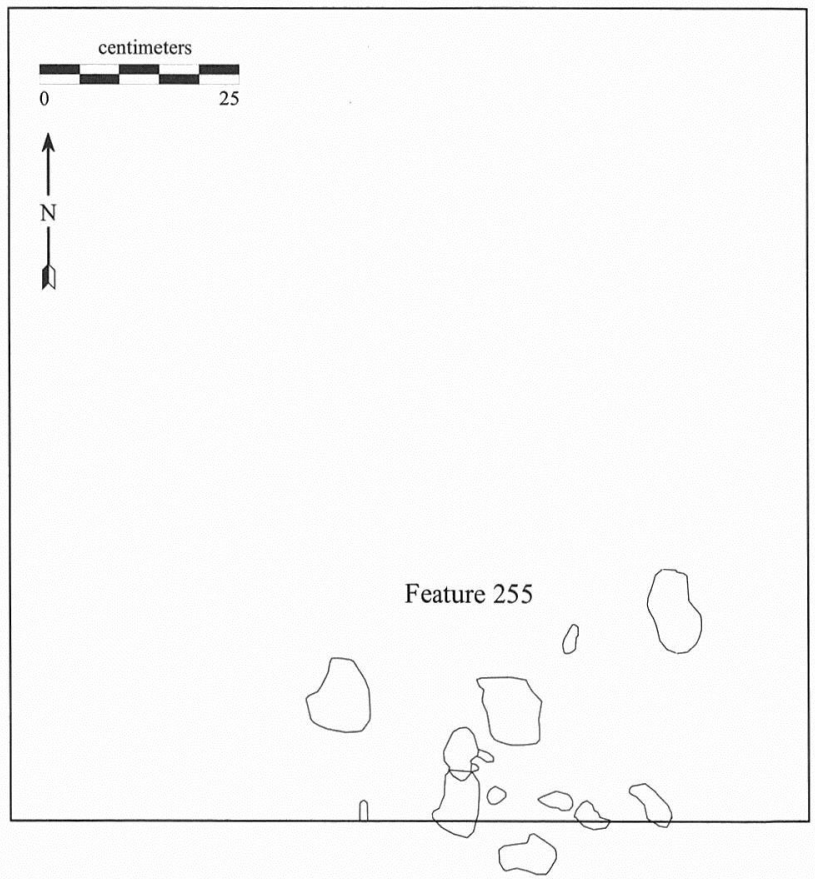

FigURE 8-29. Plan of Feature 255, a concentrated burned rock cluster

(Feature 168 and Feature 169). Only Feature 236 has similar counts and diversity. No doubt this is due to the amount of material that was processed, although the available data only hint at this. One way to overcome this problem is to lump the features by stratigraphic unit but segregate the Unit I pits. Table 8-28 shows that the greatest relative frequencies of mammals, rodents, and turtles occur in the burned rock features in Unit I. Still, the Unit I pits have the

FIGURE 8-27. South wall of Square 55 showing Feature 252. highest counts and the greatest diversity. 


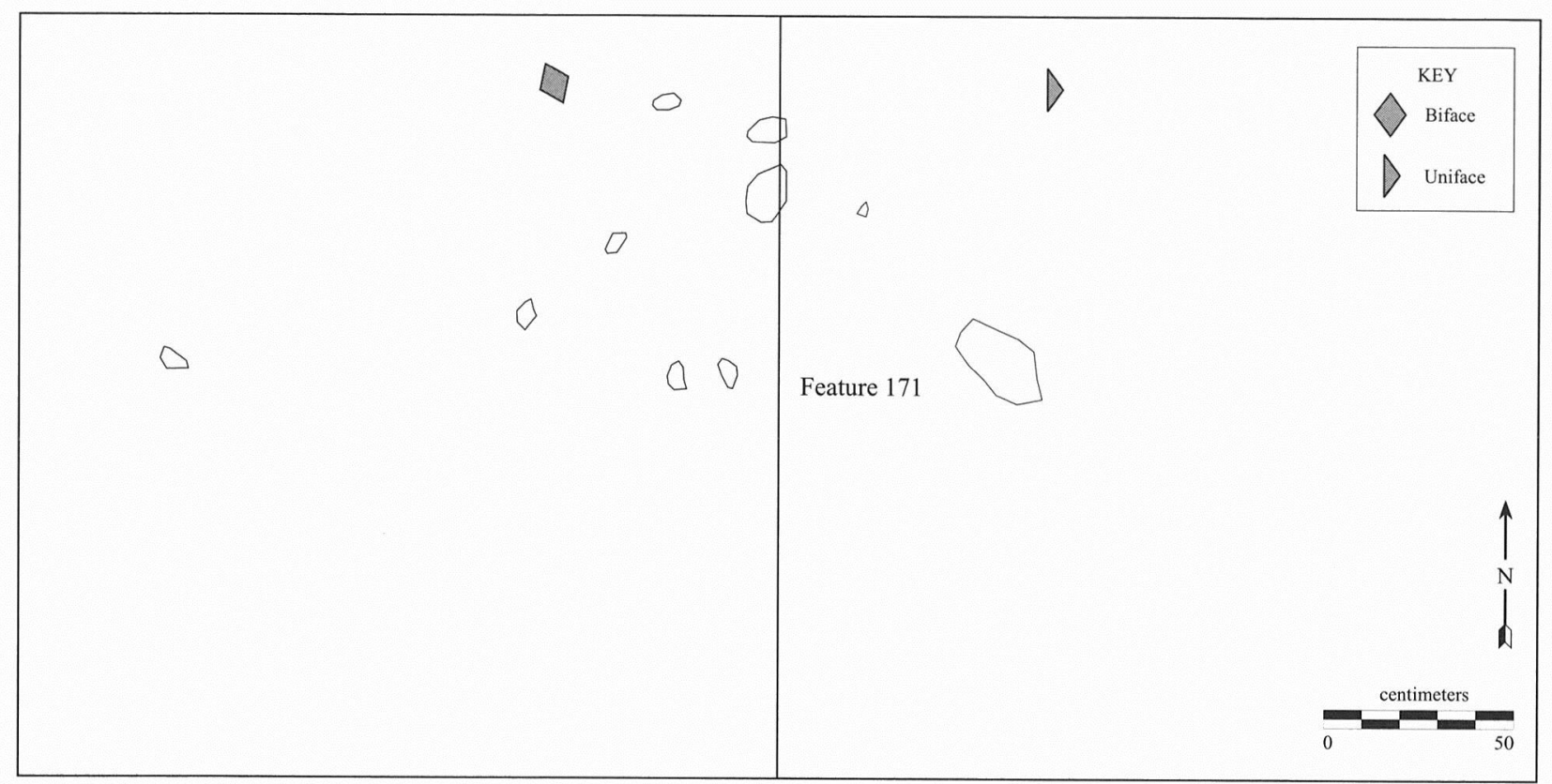

FIGURE 8-30. Plan of Feature 171, a dispersed burned rock cluster.

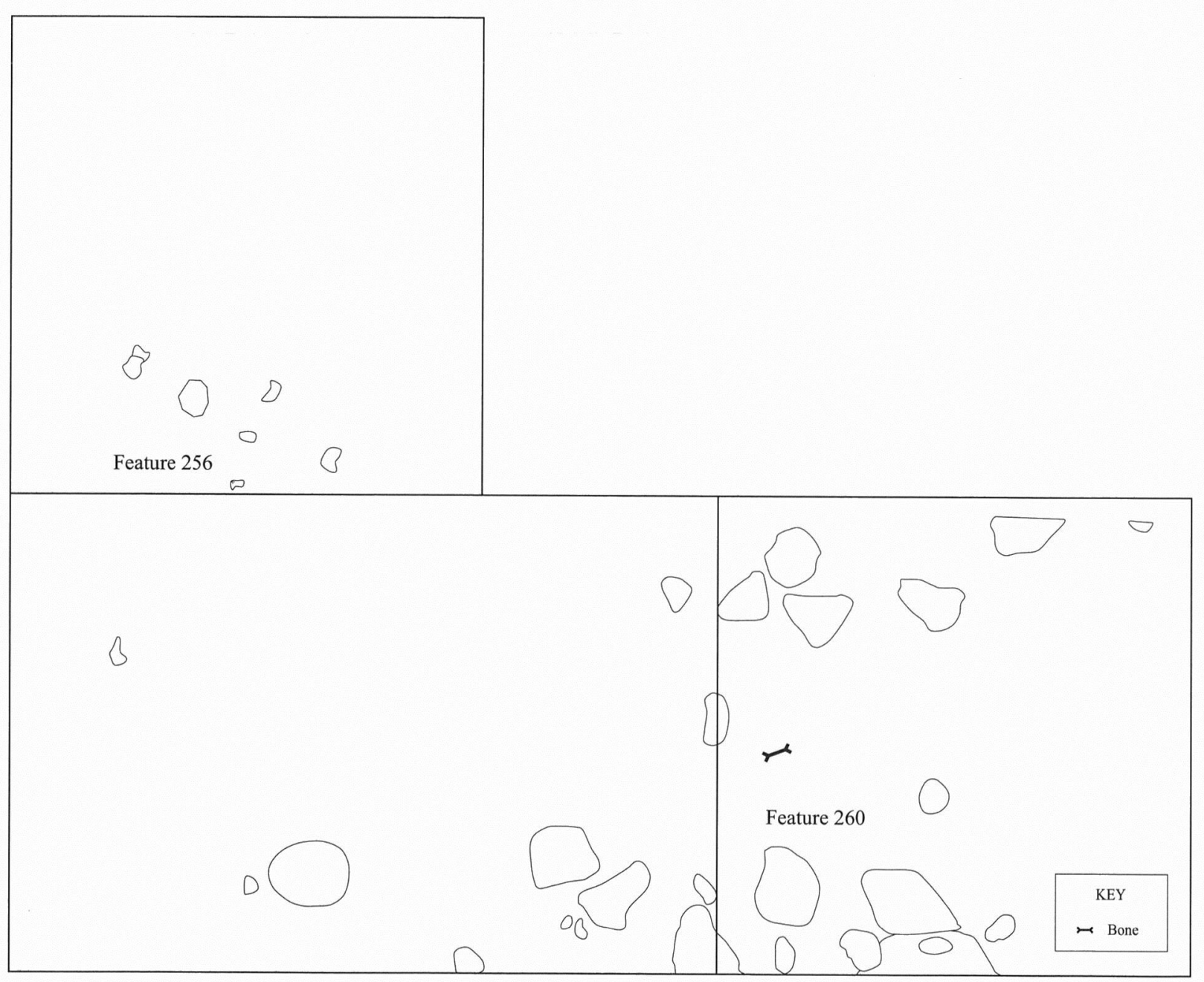

FIGURE 8-31. Plan of Feature 256 a dispersed burned rock cluster; and Feature 260 a burned rock ring. 
TABLE 8-23

D'strn'butlon of B urned Rock Feature Types im the Late Paleomctian Strata

\begin{tabular}{|c|c|c|c|c|c|c|}
\hline Unit & Basin & Cluster & Ring & Cluster or Ring & Burned Sediment and Rocks & Totals \\
\hline Upper I & 0 & $\begin{array}{c}7 \\
70.0 \% \\
\end{array}$ & $\begin{array}{c}\mathrm{I} \\
10.0 \%\end{array}$ & $\begin{array}{c}2 \\
20.0 \% \\
\end{array}$ & \begin{tabular}{|l|}
0 \\
\end{tabular} & 10 \\
\hline $\mathrm{I} / \mathrm{II}$ & $\begin{array}{c}1 \\
25.0 \% \\
\end{array}$ & $\begin{array}{c}3 \\
75.0 \% \\
\end{array}$ & 0 & 0 & 0 & 4 \\
\hline II & $\begin{array}{c}\mathrm{I} \\
5.9 \% \\
\end{array}$ & $\begin{array}{c}12 \\
70.6 \% \\
\end{array}$ & $\begin{array}{c}3 \\
17.6 \% \\
\end{array}$ & 0 & $\begin{array}{c}1 \\
5.9 \% \\
\end{array}$ & 17 \\
\hline $\bar{X}$ & 0 & $\begin{array}{c}6 \\
100.0 \% \\
\end{array}$ & 0 & 0 & 0 & 6 \\
\hline Area B-1/II & $\begin{array}{c}1 \\
100 \%\end{array}$ & 0 & 0 & 0 & 0 & 1 \\
\hline Totals: & 3 & 28 & 4 & 2 & 1 & 38 \\
\hline
\end{tabular}

TABLE 8-24

Average Num erof R decPF er eature and Average S·lze of F eatures $m$ Stratlgraplh'lc $U$ nits

\begin{tabular}{|c|c|c|c|c|c|c|}
\hline & \multicolumn{4}{|c|}{ Unit } & \multirow[b]{2}{*}{ Area B-1/ll } & \multirow[b]{2}{*}{ Totals } \\
\hline & Uooer I & $1 / 11$ & II & $\mathrm{X}$ & & \\
\hline $\begin{array}{l}\text { Average of No.Rocks } \\
\text { Average of } \mathrm{m}^{2}\end{array}$ & $\begin{array}{l}15.5 \\
0.39\end{array}$ & $\begin{array}{l}19.3 \\
0.43\end{array}$ & $\begin{array}{l}20.1 \\
0.50\end{array}$ & $\begin{array}{c}8.5 \\
0.19\end{array}$ & $\begin{array}{r}75.0 \\
1.92 \\
\end{array}$ & $\begin{array}{l}18.4 \\
0.45\end{array}$ \\
\hline Sample Totals: & 10 & 4 & 17 & 6 & 1 & 38 \\
\hline
\end{tabular}

TABLE 8-25

Results of Archeomagnet1c Analysls (from Chapter 27)

\begin{tabular}{c|c|l|l}
\hline Feature & Stratigraphic Unit & \multicolumn{1}{|c}{ Context } & \multicolumn{1}{|c}{ Heating Level } \\
\hline 255 & Isi-c/lower & intact cooled in place & high temperature \\
260 & lsi-c/lower & probably intact & medium/low temperature \\
234 & I/II & intact cooled in place & Curie point \\
235 & m & partially intact & high temperature \\
246 & I/II & partially intact & medium/low temperature \\
239 & II & disturbed & medium temperture \\
241 & II & disturbed & medium/low temperature \\
248 & II & intact cooled in place & low/mod temperature \\
250 & II & intact cooled in place & Curie point \\
236 & II-lower & mostly intact with some movement & Curie point \\
184 & II-upper & intact cooled in place & \\
\hline \hline
\end{tabular}

\section{SPATIALANALYSIS OF THE WILSON COMPONENT}

The distribution of materials securely in upper Unit I (Isi-c and Id) is presented here to provide a picture of the spatial organization of these occupations. Unfortunately no division could be made in terms of multiple occupations even though the vertical distribution of features suggests their occurrence. Also, only the materials in Block 4, Block 6, and the FSU were included. Data from Blocks 3 and 5 were excluded because it was evident that recovery rates were lower, especially for bone, and this would bias the distribution results. The TARL excavation data were excluded because the use of 1/8-inch screens and water screening dramatically increased the recovery rate ofall materials including bone, thus the TARL and TxDOT samples are incomparable at least for spatial analysis. Also, the excavations were not able to sample all sediment in the TARL squares due to erosion loss and gaps were present. The TxDOT sample was selected because it represents a larger contiguous distribution of artifacts and bone.

The methodology used for the spatial analysis began by isolating the artifacts and bone for each level assigned with a Unit Isi-c or Unit Id context in Blocks 4 and 6 and the FSU. Then the numbers of artifacts and fauna were converted into volumetric measurements, and these values used to construct isopleth maps on SURFACE III+ for MacIntosh. Volume measurements were used because they provide an independence of individual artifact classes and the ability to inspect changes in density. The next step involved conducting cluster analyses using the assemblages from the individual units based on volume. This follows the unconstrainted cluster analysis technique divised by Whallon (1984) except he used percentages. Then the clusters were plotted on a map and the distribution assessed.

The distribution of artifacts, fauna, and burned rock features are illustrated in Figures 8-32 through 8-42. The 
TABLE 8-26

Fauna! Remains Associated with Late Paleoindian Burned Rock Features

\begin{tabular}{|c|c|c|c|c|c|c|c|c|c|c|c|}
\hline & & & & & Feature & d Stratic & aphic $U_{1}$ & & & & \\
\hline & F169 & F187 & F252 & F260 & F168 & F257 & F235 & $\mathrm{B} 5 / 166$ & F155 & F157 & F236 \\
\hline Class & $\begin{array}{c}\text { Isi-c } \\
\text { lower }\end{array}$ & $\begin{array}{c}\text { Isi-c } \\
\text { lower }\end{array}$ & $\begin{array}{c}\text { Isi-c } \\
\text { lower }\end{array}$ & $\begin{array}{c}\text { Isi-c } \\
\text { lower }\end{array}$ & $\begin{array}{c}\text { Isi-c } \\
\text { upper }\end{array}$ & $\begin{array}{c}\text { Isi-c } \\
\text { upper }\end{array}$ & $\begin{array}{c}\text { Isi-c } \\
m\end{array}$ & $\begin{array}{c}\text { II } \\
\text { lower }\end{array}$ & $\begin{array}{c}\text { II } \\
\text { upper }\end{array}$ & $\begin{array}{l}\text { II } \\
\text { mid }\end{array}$ & $\begin{array}{c}\text { II } \\
\text { lower }\end{array}$ \\
\hline Aves & $\begin{array}{c}\mathrm{I} \\
0.1 \%\end{array}$ & & $\begin{array}{c}1 \\
3.0 \%\end{array}$ & & & & & & & & \\
\hline Lagomorph & $\begin{array}{c}2 \\
0.3 \%\end{array}$ & & & $\begin{array}{c}1 \\
7.1 \%\end{array}$ & & & & & & $\begin{array}{c}\mathrm{l} \\
1.6 \%\end{array}$ & $\begin{array}{c}5 \\
0.9 \%\end{array}$ \\
\hline Amphibia & & & & & $\begin{array}{c}2 \\
0.6 \%\end{array}$ & & & & & & $\begin{array}{c}\mathrm{I} \\
0.2 \%\end{array}$ \\
\hline Mammalia & $\begin{array}{c}58 \\
8.0 \%\end{array}$ & $\begin{array}{c}6 \\
40.0 \%\end{array}$ & $\begin{array}{c}2 \\
6.1 \%\end{array}$ & $\begin{array}{c}3 \\
21.4 \%\end{array}$ & $\begin{array}{c}51 \\
14.3 \%\end{array}$ & $\begin{array}{c}11 \\
16.9 \%\end{array}$ & $\begin{array}{c}1 \\
3.7 \%\end{array}$ & $\begin{array}{c}9 \\
37.5 \%\end{array}$ & $\begin{array}{c}7 \\
16.7 \%\end{array}$ & $\begin{array}{c}2 \\
3.2 \%\end{array}$ & $\begin{array}{c}61 \\
11.3 \%\end{array}$ \\
\hline Osteichthyes & $\begin{array}{c}12 \\
1.7 \%\end{array}$ & & & $\begin{array}{c}1 \\
7.1 \%\end{array}$ & 3 & $\begin{array}{c}\mathrm{l} \\
1.5 \%\end{array}$ & & & & & $\begin{array}{c}3 \\
0.6 \%\end{array}$ \\
\hline Reptilia & $\begin{array}{c}2 \\
0.3 \%\end{array}$ & & & & $\begin{array}{c}\mathrm{I} \\
0.3 \%\end{array}$ & $\begin{array}{c}\mathrm{I} \\
1.5 \%\end{array}$ & & & $\begin{array}{c}\text { I } \\
2.4 \%\end{array}$ & & $\begin{array}{c}2 \\
0.4 \%\end{array}$ \\
\hline Rodentia & $\begin{array}{c}48 \\
6.6 \%\end{array}$ & & $\begin{array}{c}3 \\
9.1 \%\end{array}$ & & $\begin{array}{c}27 \\
7.6 \%\end{array}$ & $\begin{array}{c}10 \\
15.4 \%\end{array}$ & $\begin{array}{c}1 \\
3.7 \%\end{array}$ & & $\begin{array}{c}8 \\
19.0 \%\end{array}$ & $\begin{array}{c}7 \\
11.1 \%\end{array}$ & $\begin{array}{c}46 \\
8.5 \%\end{array}$ \\
\hline Serpentine & $\begin{array}{c}2 \\
0.3 \%\end{array}$ & & & & $\begin{array}{c} \\
0.3 \%\end{array}$ & & & & & & \\
\hline Testudines & $\begin{array}{c}4 \\
0.6 \% \\
\end{array}$ & $\begin{array}{c}2 \\
13.3 \%\end{array}$ & $\begin{array}{c}2 \\
6.1 \% \\
\end{array}$ & & $\begin{array}{c}3 \\
0.8 \%\end{array}$ & & & & & $\begin{array}{c}1 \\
1.6 \%\end{array}$ & $\begin{array}{c}1 \\
0.2 \%\end{array}$ \\
\hline Vertebrata & $\begin{array}{c}593 \\
82.1 \%\end{array}$ & $\begin{array}{c}7 \\
46.7 \%\end{array}$ & $\begin{array}{c}25 \\
75.8 \%\end{array}$ & $\begin{array}{c}9 \\
64.3 \%\end{array}$ & $\begin{array}{c}268 \\
75.3 \%\end{array}$ & $\begin{array}{c}42 \\
64.6 \%\end{array}$ & $\begin{array}{c}25 \\
92.6 \%\end{array}$ & $\begin{array}{c}15 \\
62.5 \%\end{array}$ & $\begin{array}{c}26 \\
61.9 \%\end{array}$ & $\begin{array}{c}52 \\
82.5 \%\end{array}$ & $\begin{array}{c}423 \\
78.0 \%\end{array}$ \\
\hline $\begin{array}{l}\text { Totals: } \\
\text { Volumes: } \\
\text { No. Classes: }\end{array}$ & $\begin{array}{c}722 \\
61.4 \\
9\end{array}$ & 3 & $\begin{array}{c}33 \\
3.35 \\
5\end{array}$ & 4 & 356 & $\begin{array}{c}65 \\
12.4 \\
5\end{array}$ & $\begin{array}{c}27 \\
0.5 \\
3\end{array}$ & $\begin{array}{c}24 \\
1.25 \\
2\end{array}$ & $\begin{array}{c}42 \\
5.5 \\
4\end{array}$ & $\begin{array}{c}63 \\
0.85 \\
5\end{array}$ & 542 \\
\hline
\end{tabular}

TABLE 8-27

Thicknesses of Eggshell in Features

\begin{tabular}{|c|c|c|c|c|c|c|c|c|c|c|}
\hline \multirow[b]{2}{*}{ Thickness } & \multicolumn{9}{|c|}{ Feature and Stratigraphic Unit } & \multirow[b]{2}{*}{ Totals } \\
\hline & $\begin{array}{c}\text { F157 } \\
\text { II }\end{array}$ & $\begin{array}{c}\text { F184 } \\
\text { II }\end{array}$ & $\begin{array}{c}\text { F185 } \\
\text { II }\end{array}$ & $\begin{array}{c}\text { F236 } \\
\text { VII }\end{array}$ & $\begin{array}{c}\text { F246 } \\
\text { VII }\end{array}$ & $\begin{array}{l}\text { F169 } \\
\text { Isi-c }\end{array}$ & $\begin{array}{l}\text { F255 } \\
\text { Isi-c }\end{array}$ & $\begin{array}{l}\text { F257 } \\
\text { Isi-c }\end{array}$ & $\begin{array}{c}\text { Burial } 2 \\
\text { Isi-c }\end{array}$ & \\
\hline 0.15 & 1 & & & & & & & & & 1 \\
\hline 0.16 & & & & 1 & & & & & & 1 \\
\hline 0.17 & & & & & & & & & & \\
\hline 0.18 & & & & & & & & I & & I \\
\hline 0.19 & & & & & & & & & & \\
\hline 0.20 & & & & & & & & & I & I \\
\hline 0.21 & & & & 1 & & & & 1 & & 2 \\
\hline 0.22 & & & & & & & & & & \\
\hline 0.23 & I & & & & & & & I & & 2 \\
\hline 0.24 & & 1 & 1 & & & & & & & 2 \\
\hline 0.25 & & & & & & 1 & & & & 1 \\
\hline 0.26 & & & & & I & & & & & I \\
\hline 0.27 & & 1 & & 1 & & & & & & 2 \\
\hline 0.28 & & & & & & & I & & & 1 \\
\hline Totals: & 2 & 2 & 1 & 3 & 1 & 1 & 1 & 3 & 1 & 15 \\
\hline
\end{tabular}


TABLE 8-28

Total Identified Specimens and Percents of Fauna! Remains from Features m Ulpper Unt

\begin{tabular}{|c|c|c|c|}
\hline Class & \begin{tabular}{|l|} 
Total Unit I \\
Pits
\end{tabular} & \begin{tabular}{|l|} 
Total Unit I \\
Burned Rock \\
Featuress \\
\end{tabular} & \begin{tabular}{|l|} 
Total Unit II \\
Burned Rock \\
Features \\
\end{tabular} \\
\hline \multirow[t]{2}{*}{ Aves } & & & \\
\hline & $0.1 \%$ & $0.8 \%$ & \\
\hline \multirow[t]{2}{*}{ Lagomorph } & 2 & & 6 \\
\hline & $0.2 \%$ & $0.8 \%$ & $0.9 \%$ \\
\hline \multirow[t]{2}{*}{ Amphibia } & 2 & & 1 \\
\hline & $0.2 \%$ & & $0.1 \%$ \\
\hline \multirow[t]{2}{*}{ Mammalia } & 109 & 22 & 79 \\
\hline & $10.1 \%$ & $173 \%$ & $11.8 \%$ \\
\hline \multirow[t]{2}{*}{ Osteichthyes } & 15 & 2 & 3 \\
\hline & $1.4 \%$ & $1.6 \%$ & $0.4 \%$ \\
\hline \multirow[t]{2}{*}{ Reptilia } & 3 & & 3 \\
\hline & $0.3 \%$ & $0.8 \%$ & $0.4 \%$ \\
\hline \multirow[t]{2}{*}{ Rodentia } & 75 & 13 & 61 \\
\hline & $7.0 \%$ & $10.2 \%$ & $9.1 \%$ \\
\hline \multirow[t]{2}{*}{ Serpentine } & 3 & & \\
\hline & $0.3 \%$ & & \\
\hline \multirow[t]{2}{*}{ Testudines } & & 4 & 2 \\
\hline & $0.6 \%$ & $3.1 \%$ & $0.3 \%$ \\
\hline \multirow[t]{2}{*}{ Vertebrata } & 861 & 83 & 516 \\
\hline & $79.9 \%$ & $65.4 \%$ & $76.9 \%$ \\
\hline Totals: & 1,078 & 127 & 671 \\
\hline $\begin{array}{l}\text { Number of } \\
\text { Features: }\end{array}$ & 2 & 4 & 4 \\
\hline
\end{tabular}

distribution ofdebitage is highest in Block 4 and especially Squares E20/S74, E20/S76, and E20/S78. In general, the density of debitage declines to the northeast and is lowest in Square E26/S72. Square E26/S72 was lower topographically, and it was directly over the underlying cienega deposits. Perhaps this portion of the site was more soggy and less suitable for human activities. However, there are smallerscale patterns as well. Three squares have locally high concentrations that are adjacent to low density squares (E20/ S76-E22/S76, E24/S76-E26/S74, and E26/S78-E28/S78). These concentrations linked with low density squares suggest that these are loci where knapping occurred. Fauna) remains have a distinctly different distribution and are found in greatest concentrations in the middle of the big block made up of Blocks 4 and 6 and the fine-screened unit (E22/S72, E22/S74, E24/S76, E26/S76, and E22/S78. The distribution ofprojectile points is concentrated in three squares (E20/S74, E22/S76, and E26/78), and no simple association can be established between debitage and projectile point densities. Bifaces are concentrated in four squares (E20/S74, E22/S74, E22/S76, and especially E20/S76). Two of the squares with high concentrations of bifaces also have high concentrations of debitage. Unifaces are concentrated in the western portion of the big block in Squares E20/S72, E20/S76, E22/S76, and E20/S78. Cores are clustered in the southwest corner of the big block in Squares E22/S78 and E20/S76, while core tools occur in Squares E22/S78 and E24/S74. Manos are limited to Square E26/S74 and hammerstones are restricted to Square E24/S78. Worked hematite pieces are found in Square E24/ S76. These distributions clearly show that the density of artifacts and bone vary greatly across the TxDOT excavations. These maps also show that the east and southeast portion of the site, i.e., the area excavated by TARL, was the area with the lowest density of materials. The greatest density ofWilson component materials is now below RR 1431 . As shown in Figure 8-42 burned rock features occur in the southern portion of the excavation areas and generally away from the extremely low density occurrences over the cienega deposits. The possible pit features occur in areas with high debitage densities as does the burial pit.

The cluster analysis identified four clusters and the distribution of clusters is presented in Figure 8-43. The density data for each artifact class as well as bone are presented in Table 8-29. The first cluster consists of only one square (E22/S72). Very high bone density along with low debitage density and an absence of other artifacts characterizes this square. Cluster 2 (Squares E20/S74, E20/S76 and E20/S78) is defined by very high debitage densities, low bone densities, and relatively high uniface and biface densities. Cluster 3 (Squares E24/S72, E24/S74, E26/S72, E26/S74, and E28/S78) is distinguished by the lowest debitage densities in the sample, low bone densities, a consistent presence of unifaces, and the most consistent presence of projectile points in any of the clusters. Cluster 4 is characterized by high densities of debitage and fairly high densities of bone as well a consistent occurrence of unifaces and a moderate density of bifaces. This distributional study shows that the highest densities of bone and debitage do not occur near the burned rock features. The general interpretation of these features is that they served as domestic hearths. The presence of the possible pits in the area with the highest debitage densities does not provide contextual information that assists in the interpretation of these features beyond the likelihood that they were located on the periphery of the residential concentration and perhaps played a role in an activity that was too messy, too dangerous, or too offensive to be in close proximity to the domestic hearths. The high bone concentration nearby in Square E22/S72 may represent another messy activity on the edge of a residential site. The location of the burial in a similar context supports the peripheral interpretation of these high density clusters.

\section{SUMMARY AND CONCLUSIONS}

The Late Paleoindian archeology at the Wilson-Leonard site is both exciting and disappointing. The Wilson component in upper Unit I demonstrates the existence of a heretofore 


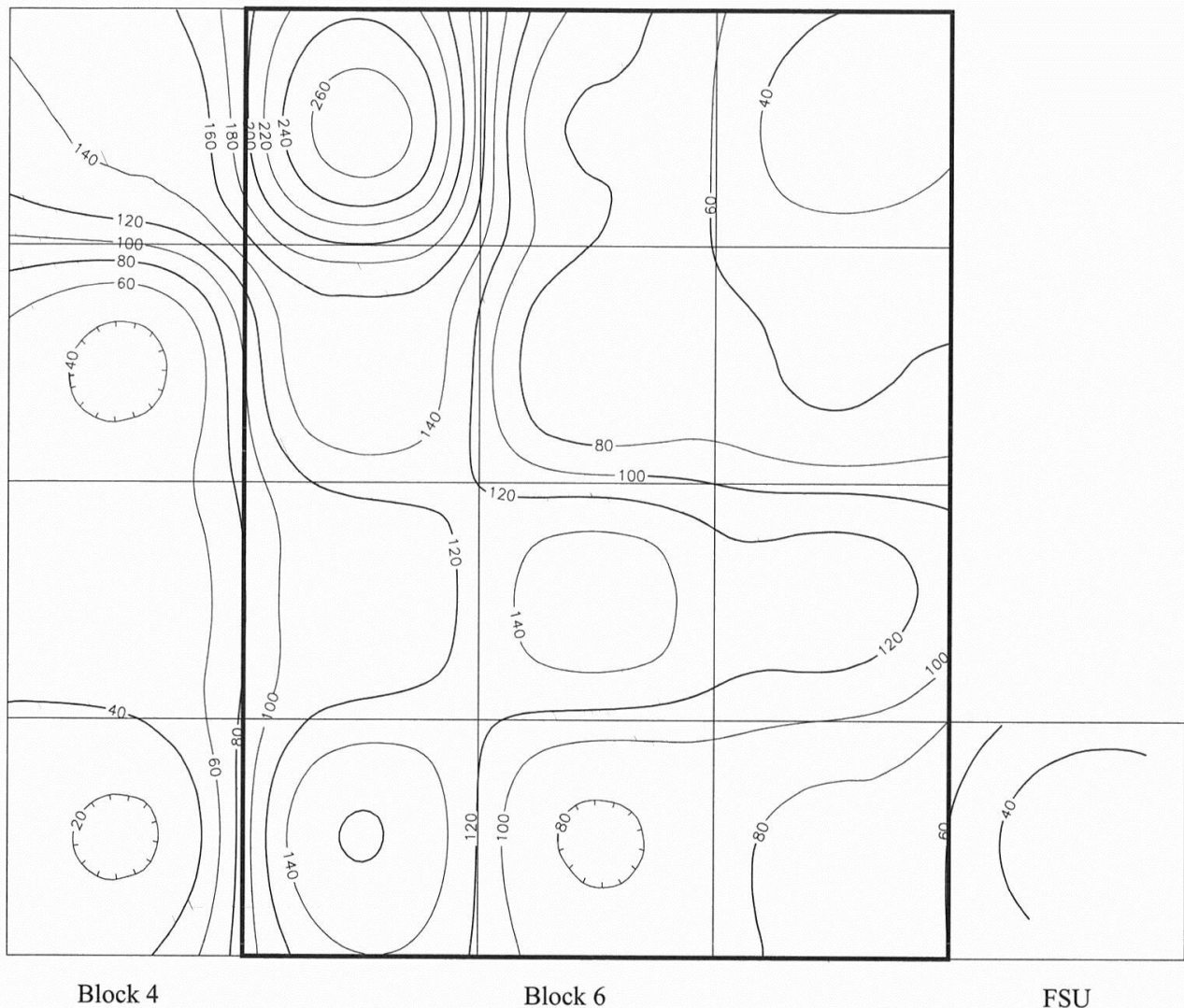

FIGURE 8-32. Bone density distributions in the Wilson component in Blocks 4 and 6 and the FSU.

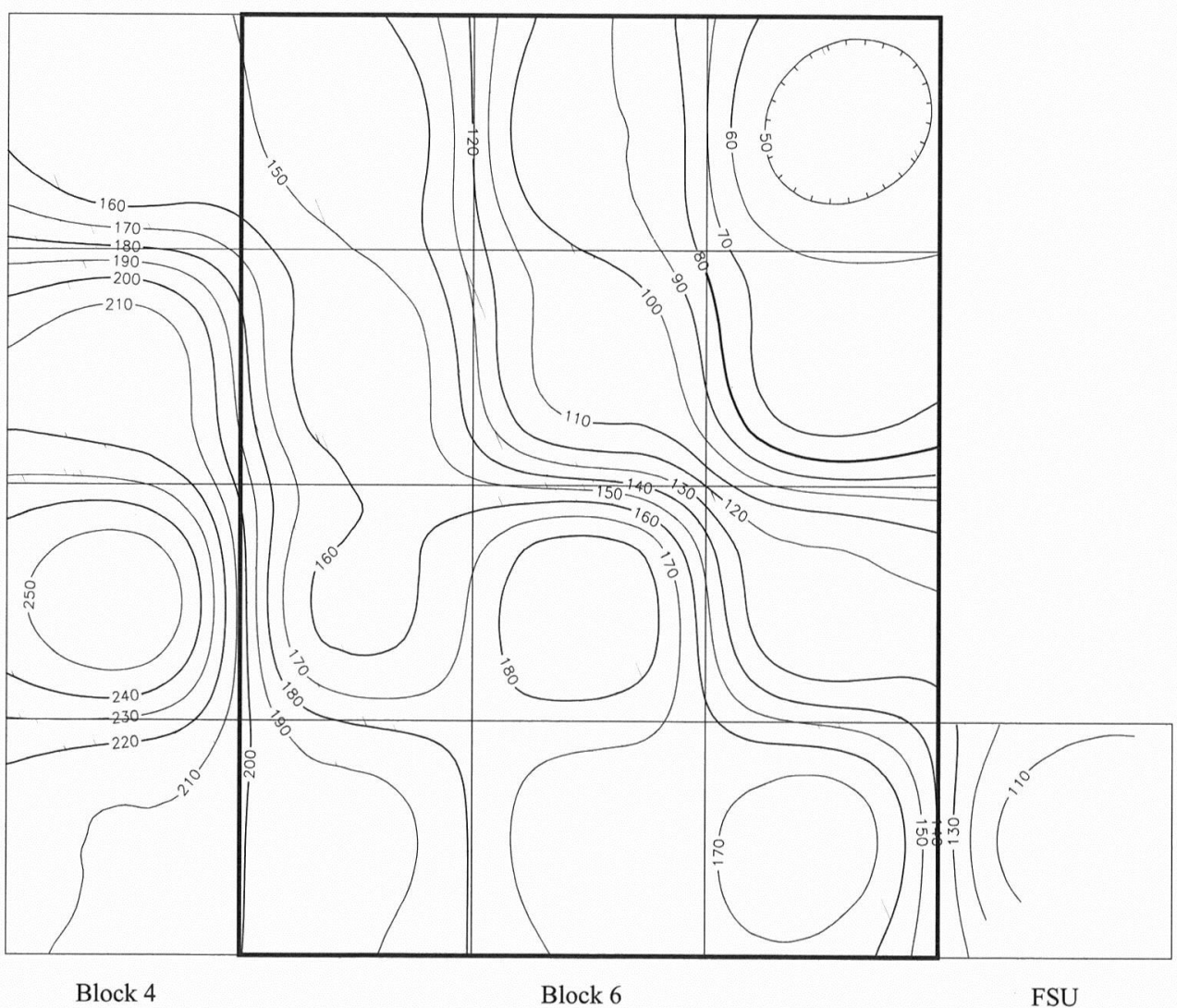

FIGURE 8-33. Debitage density distributions in the Wilson component in Blocks 4 and 6 and the FSU. 


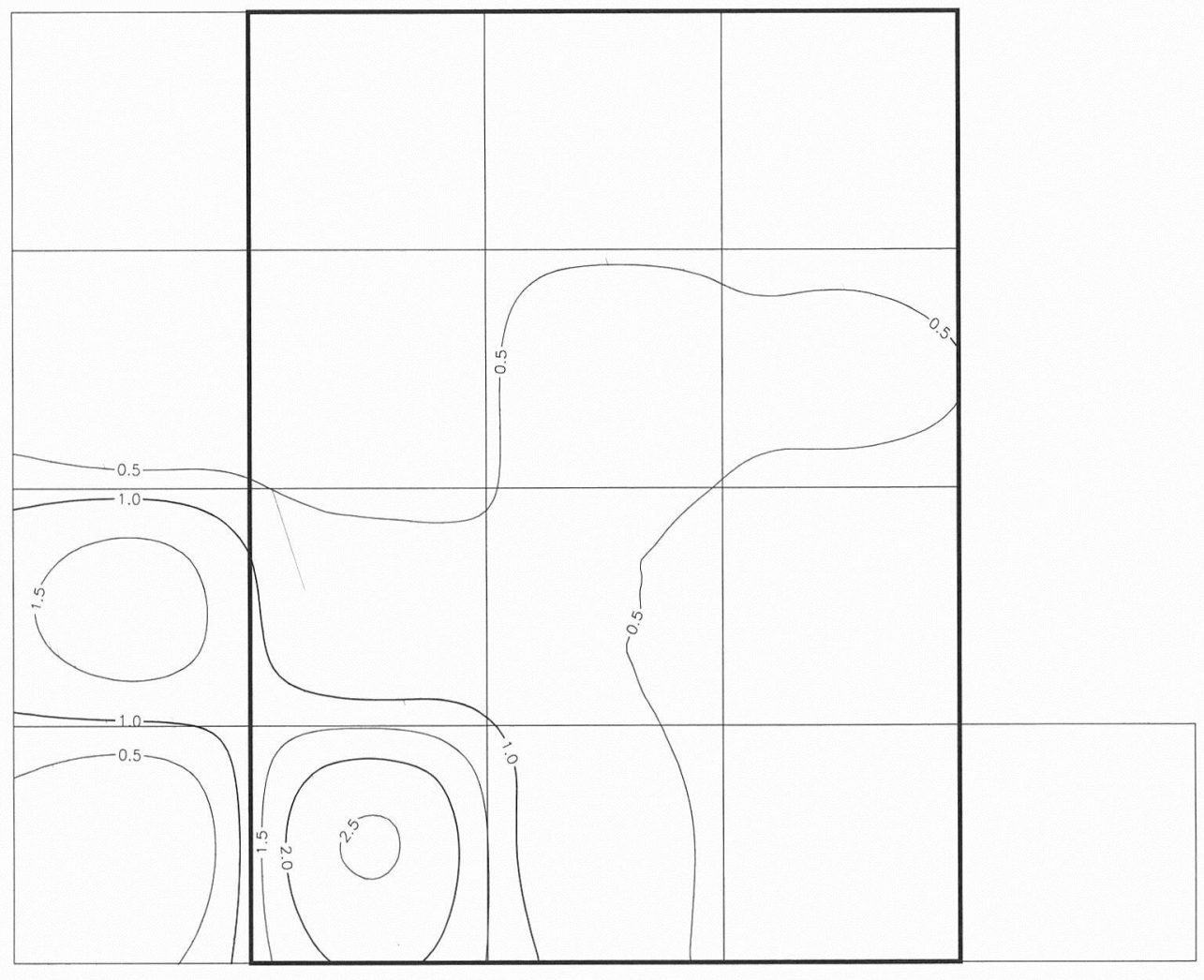

Block 4

Block 6

FSU

FIGURE 8-34. Core density distributions in the Wilson component in Blocks 4 and 6 and the FSU.

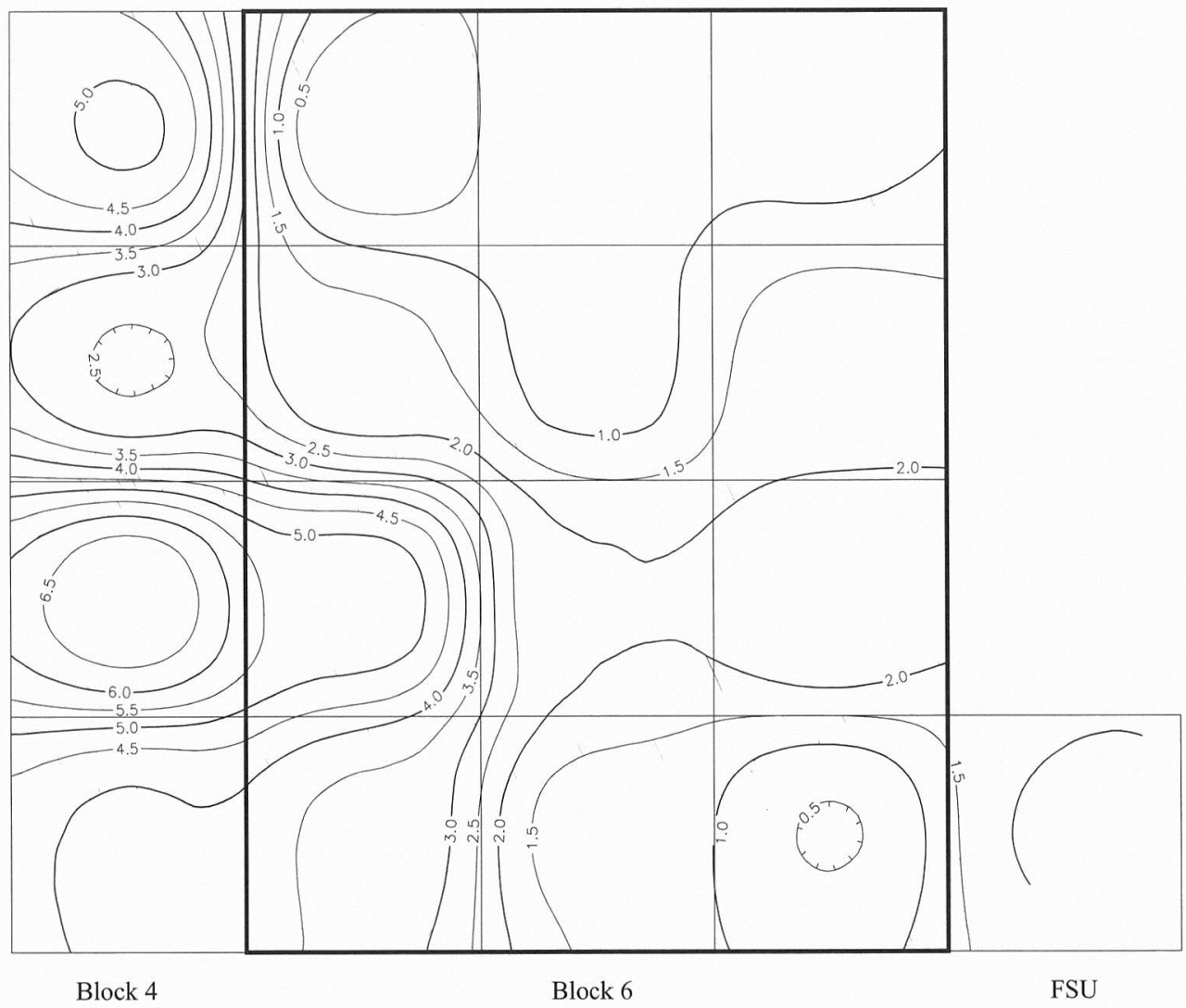

FIGURE 8-35. Uniface density distributions in the Wilson component in Blocks 4 and 6 and the FSU. 


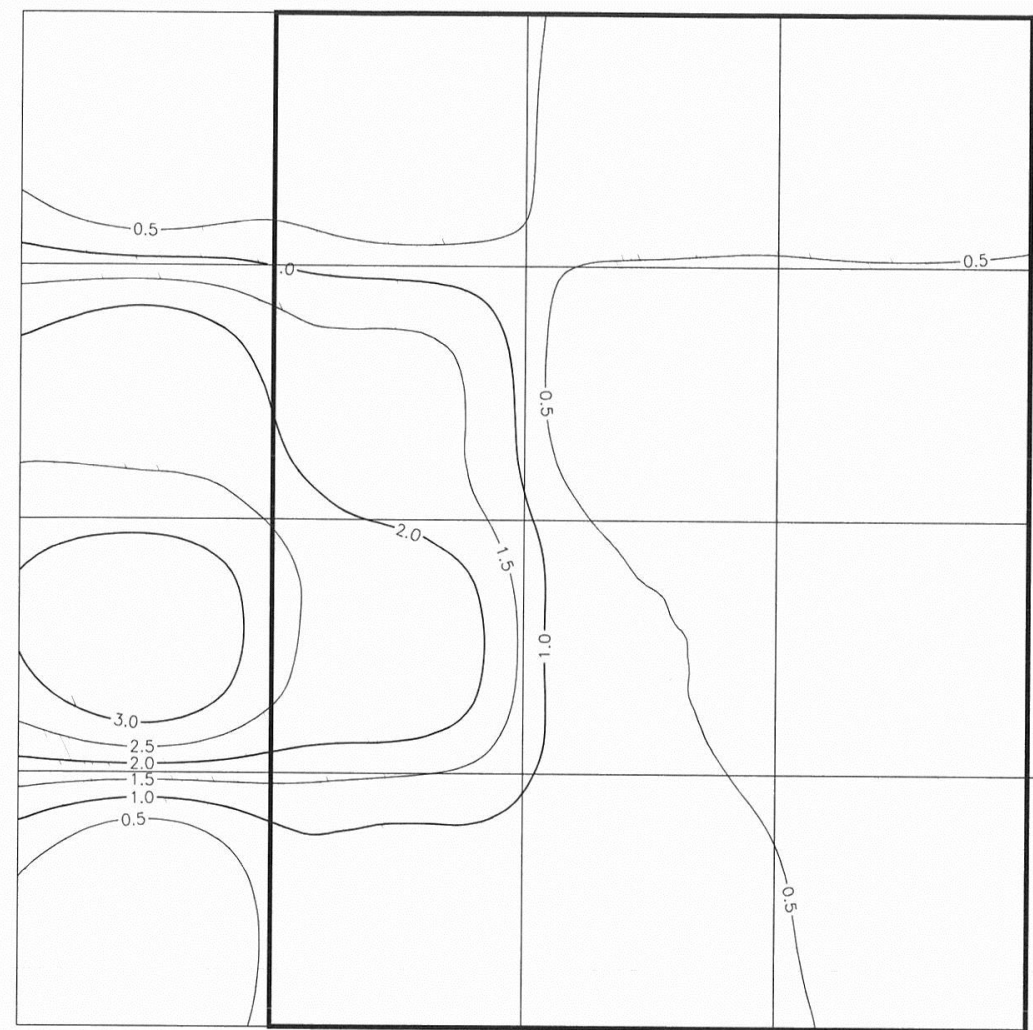

Block 4

Block 6

FSU

FIGURE 8-36. Biface density distributions in the Wilson component in Blocks 4 and 6 and the FSU.

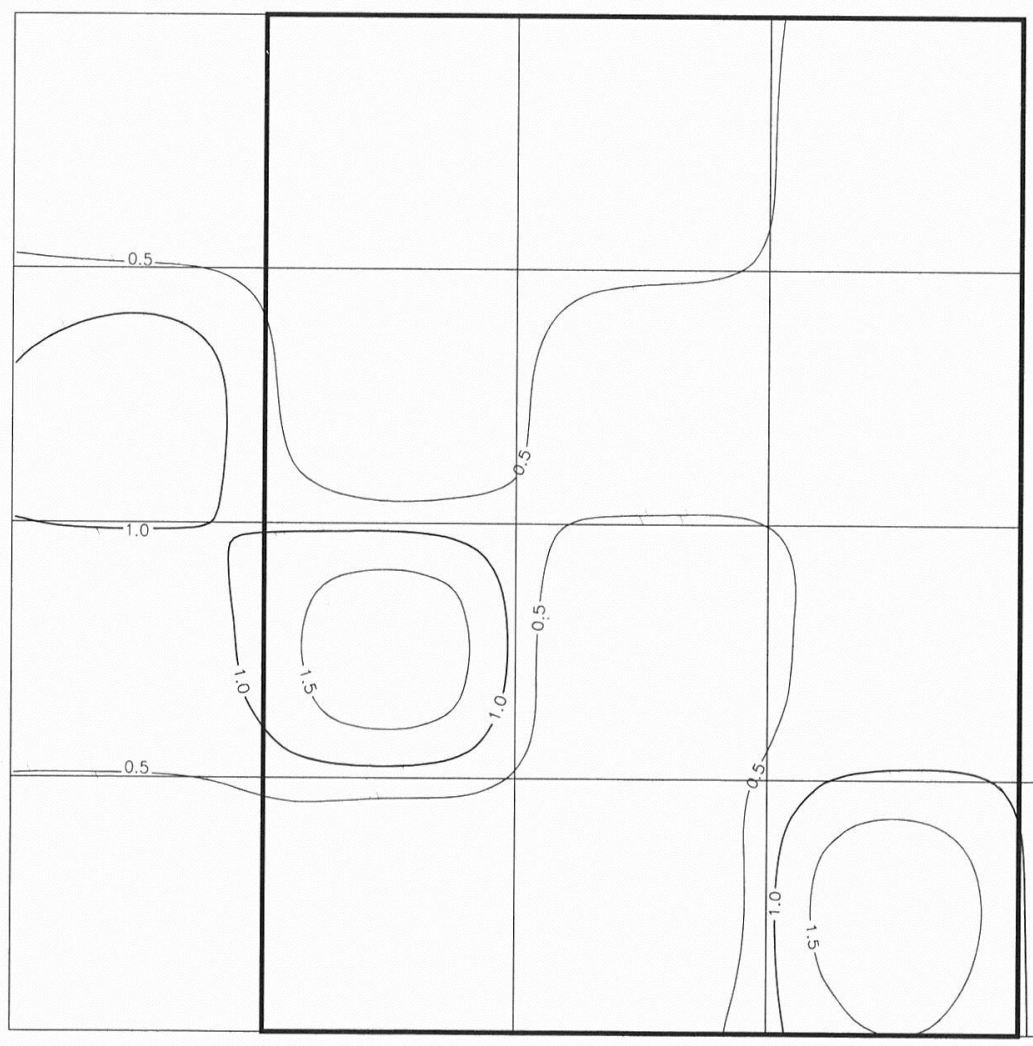

Block 4

FIGURE 8-37. Projectile point density distributions in the Wilson component in Blocks 4 and 6 and the FSU. 


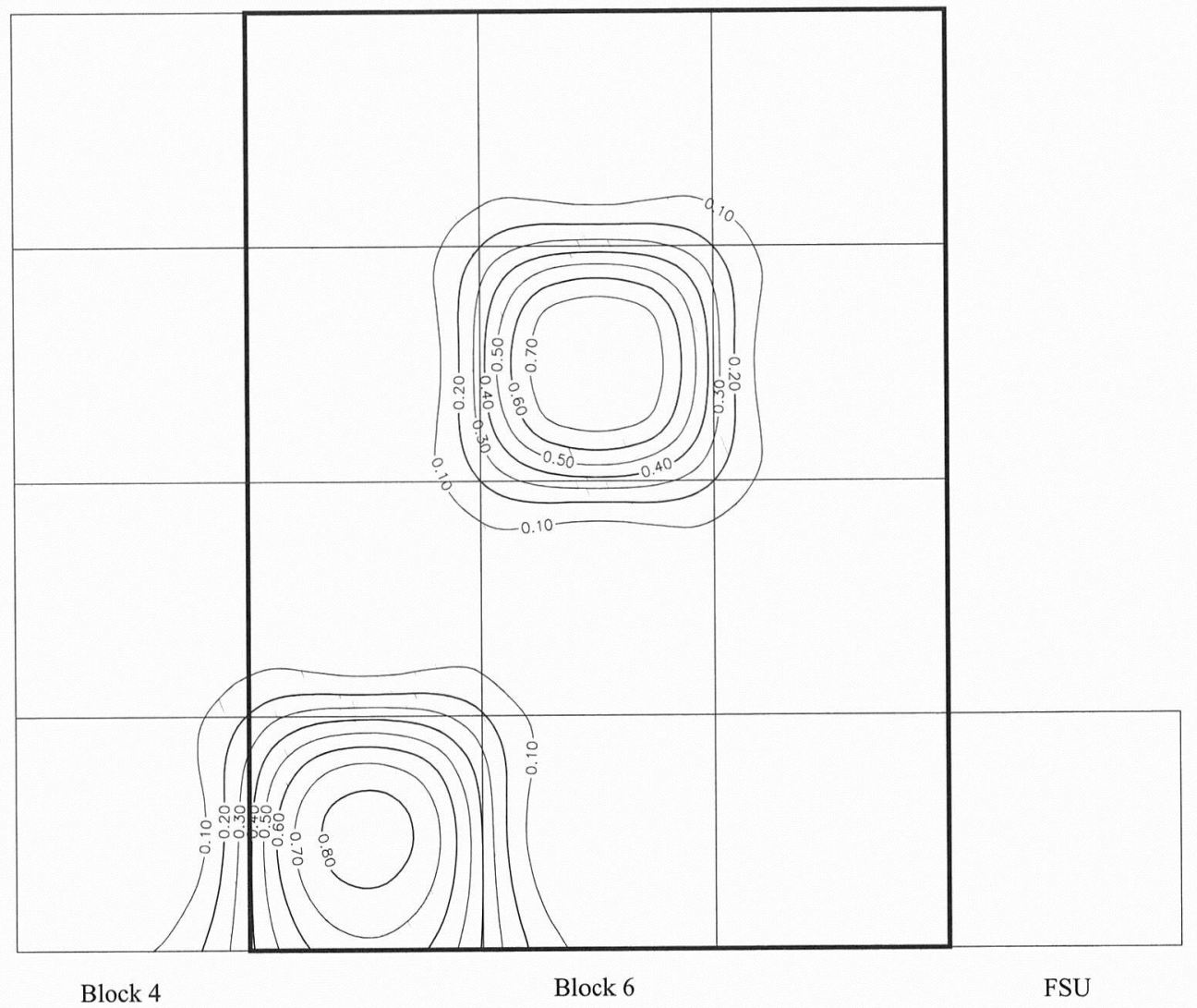

Figure 8-38. Core tool density distributions in the Wilson component in Blocks 4 and 6 and the FSU.

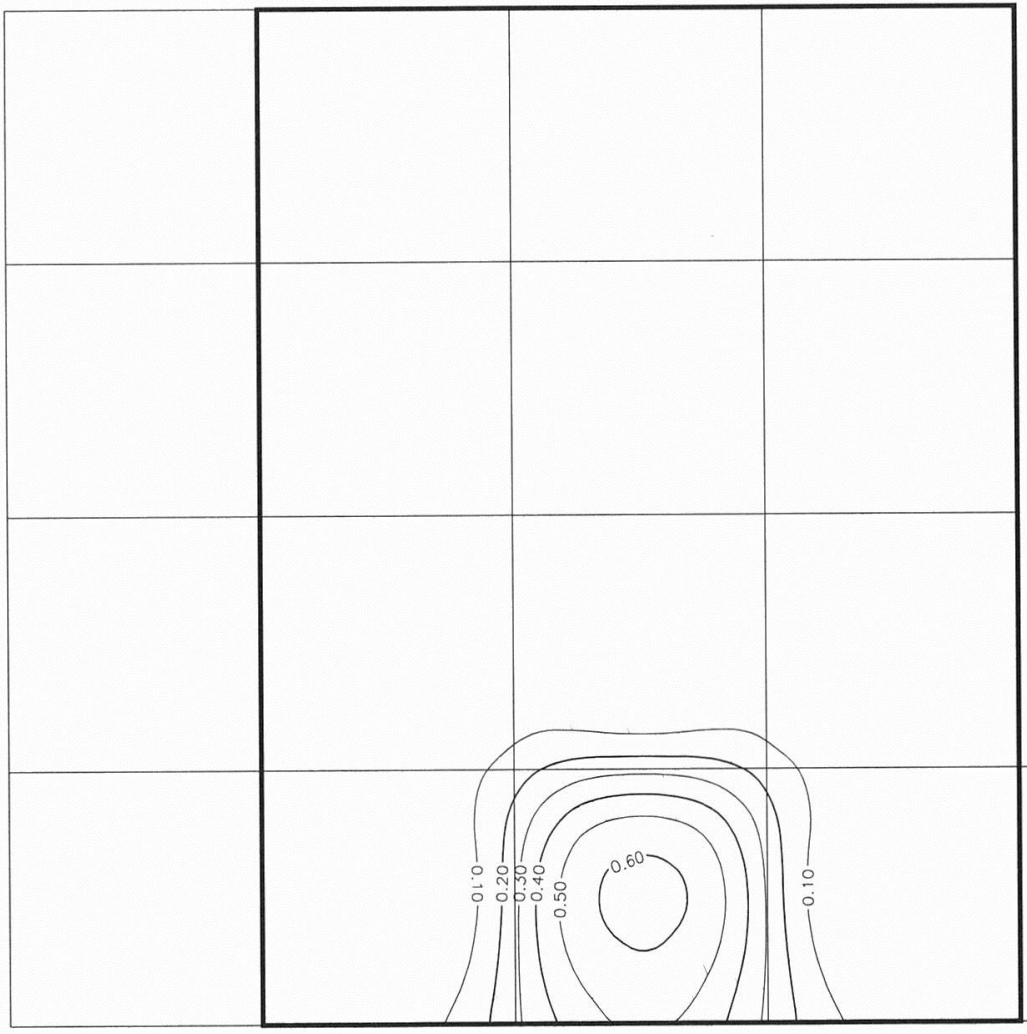

Block 4

FIGURE 8-39. Hammerstone density distributions in the Wilson component in Blocks 4 and 6 and the FSU. 


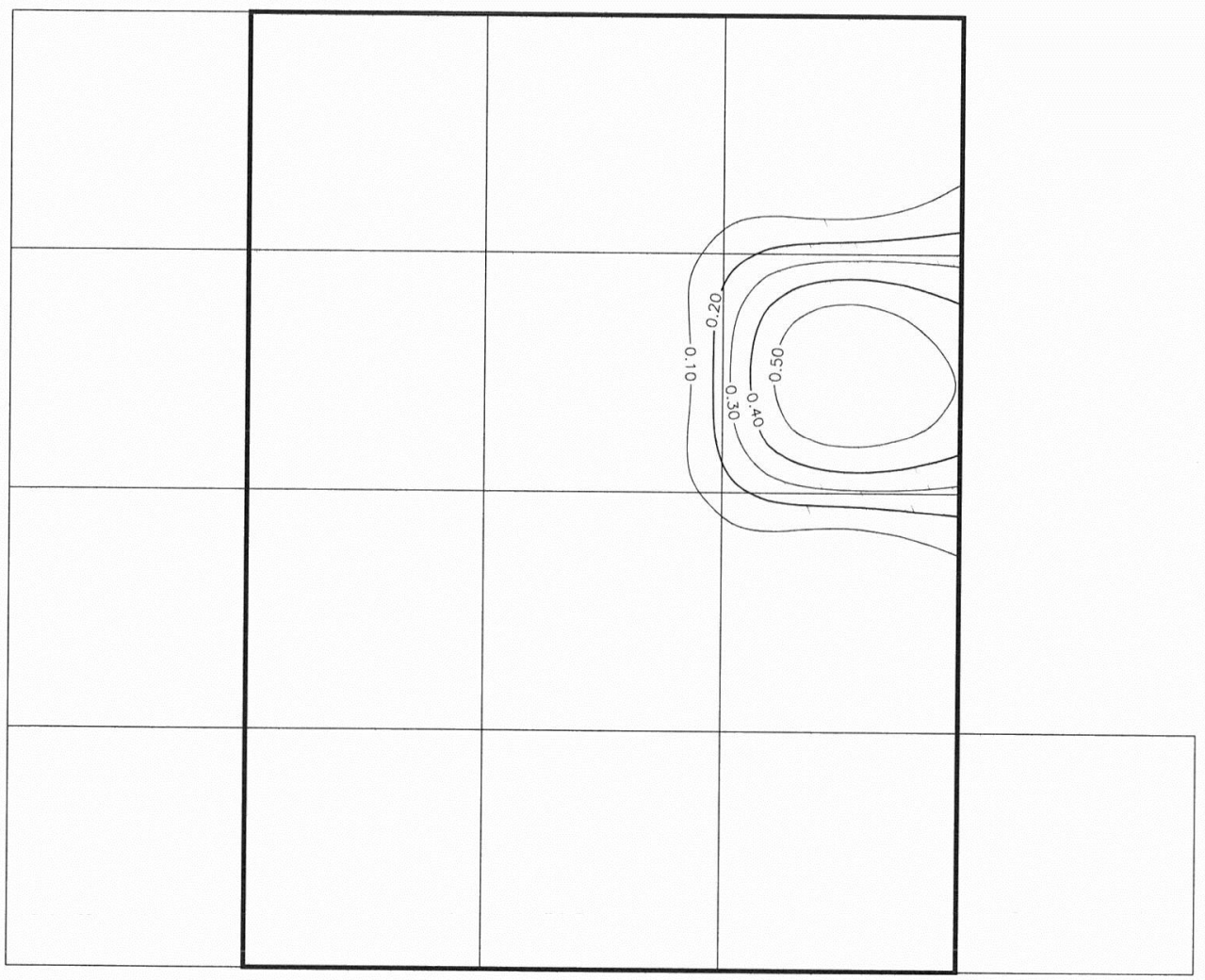

Block 4

Block 6

FSU

FIGURE 8-40. Mano density distributions in the Wilson component in Blocks 4 and 6 and the FSU.

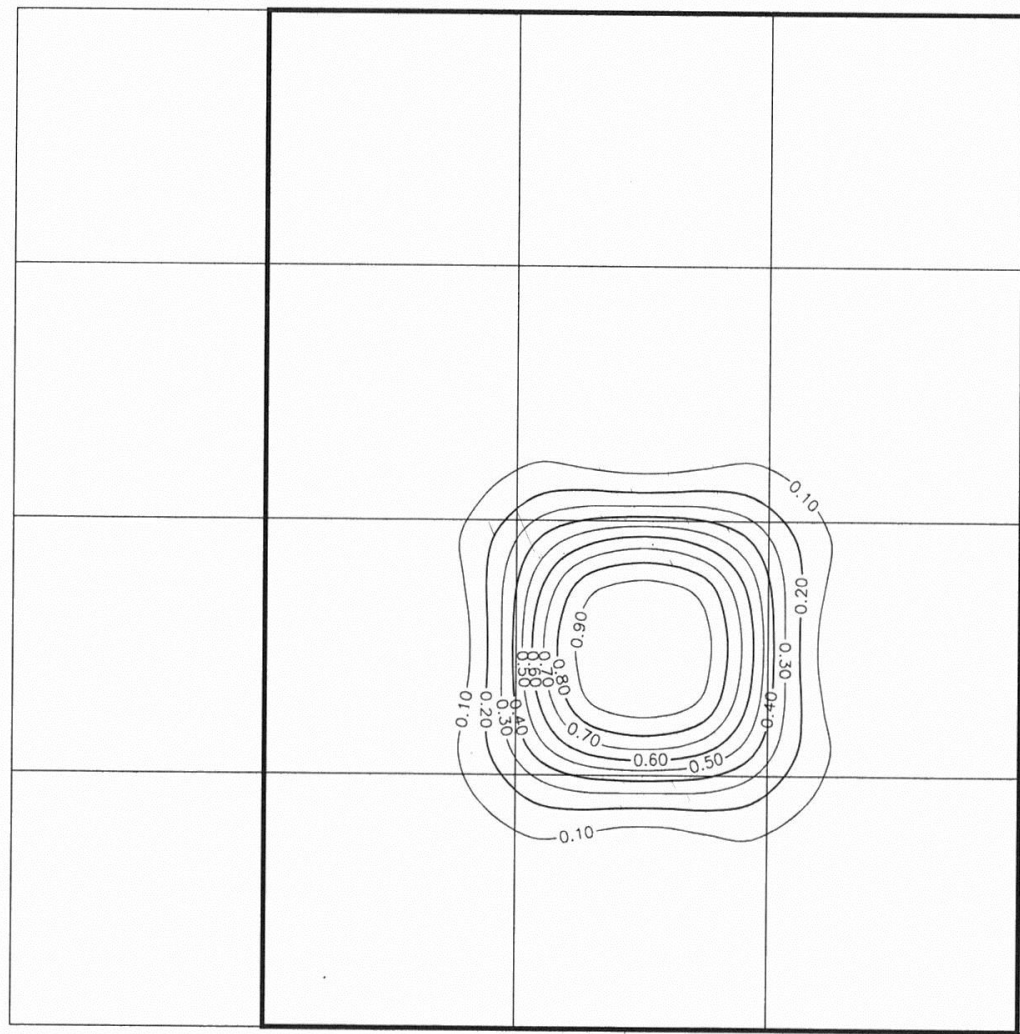

Block 4

Block 6

FSU

FIGURE 8-41. Worked hematite density distributions in the Wilson component in Blocks 4 and 6 and the FSU. 
Block 6

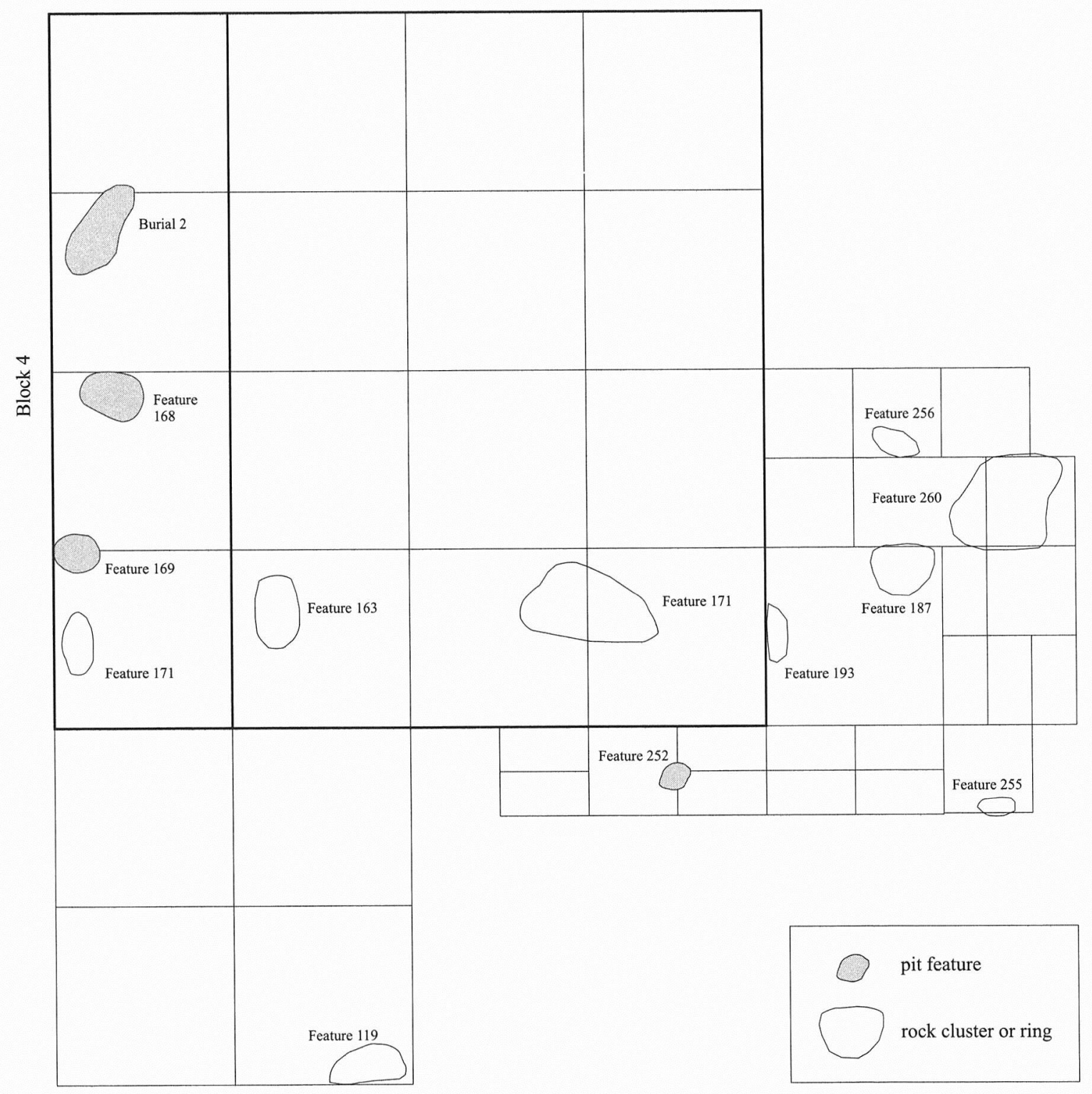

FIGURE 8-42. Plan of the distribution of burned rock features, possible pits, and human burial in upper Unit I, the Wilson component.

poorly known group in the very Early Holocene. The Wilson component at Wilson-Leonard is securely dated by radiocarbon to between 9990 B.P. and 9530 B.P. This 450-500-yearlong component represents one of the earliest stemmed projectile point occurrences in North America, and it appears that these peoples had adopted a foraging life-style. They exploited a range of fauna including bison, deer, rabbits and hares, turtles, fish, and even snakes. Evidence for plant exploitation is extremely meager with only walnut recovered. Tool manufacturing and use-patterns demonstrates that most lithic materials were obtained locally from abundant Central Texas lithic sources and that tools, especially projectile points, were used intensively. Feature, artifact, and faunal distributions indicate that the site probably functioned as a residential camp with the highest density artifact and bone concentrations occuring on the margins of the camping area. Included in this peripheral area was a burial of a single adult female and two pit features of unknown function.

Statewide distributional data suggest that EarlyStemmed Projectile occurrences including sites with Wilson projectile points are not common $(\mathrm{N}=19)$ and are restricted to the southern half of the state (Figure 8-44). Paleoenvironmental information is meager, but the data from WilsonLeonard itself, and Boriack Bog, $40 \mathrm{~km}$ to the east, suggest that it was a mesic interval and not particularly harsh, nevertheless all Pleistocene megafauna were extinct by that time.

The remaining Late Paleoindian remains at WilsonLeonard occur in abundance in Unit II between 9500 B.P. and 


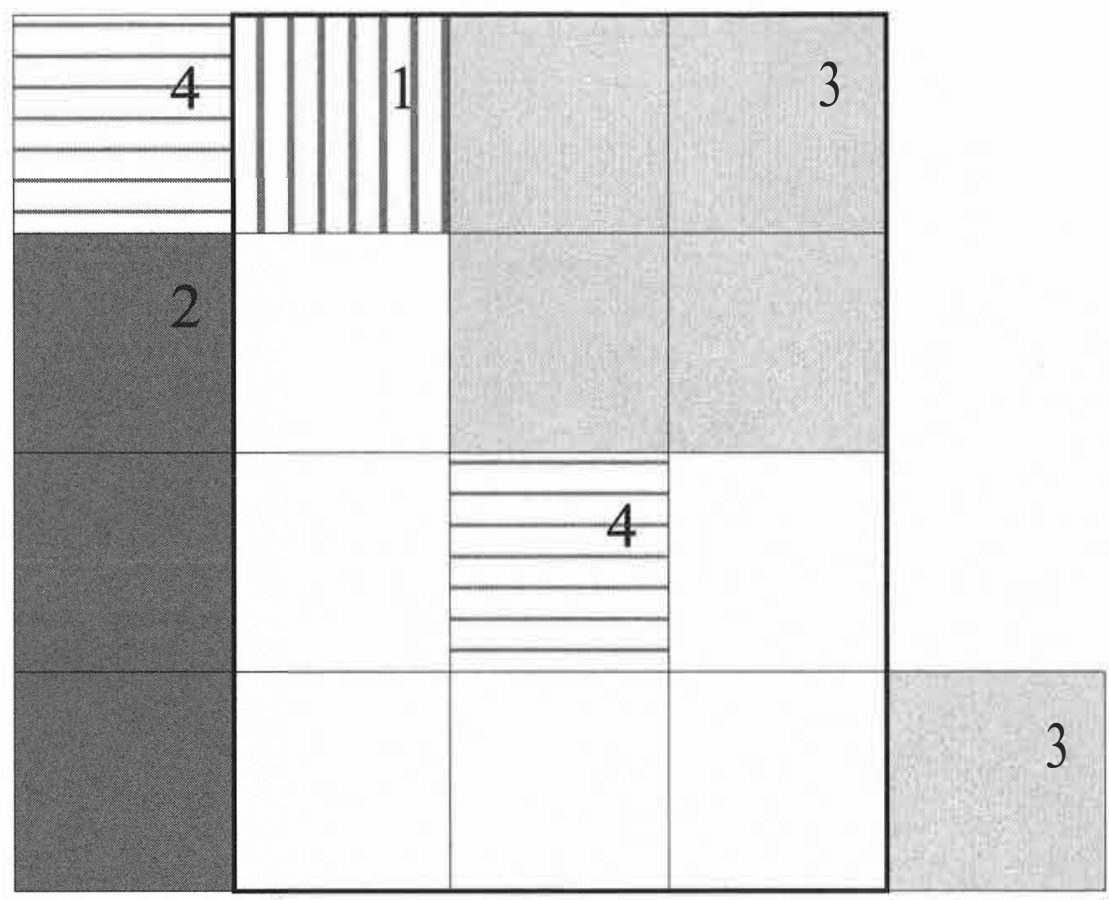

Block4

Block 6

FSU

FiGURE 8-43. Plan of spatial clusters in Blocks 4 and 6 and the FSU.

TABLE8-29

Artifact and Fauna! Counts for Each Square along with Volume of Excavation by Square

\begin{tabular}{|c|c|c|c|c|c|c|c|c|c|c|c|c|}
\hline Square & Points & Bifaces & Unifaces & \begin{tabular}{|l|} 
Core \\
Tools
\end{tabular} & Mano & $\begin{array}{l}\text { Worked } \\
\text { Hematite }\end{array}$ & Cores & $\begin{array}{l}\begin{array}{l}\text { Hammer- } \\
\text { stones }\end{array} \\
\end{array}$ & Debitage & Bone & Totals & Volume \\
\hline E20/S72 & \begin{tabular}{|l|}
0 \\
\end{tabular} & 0 & 5 & 0 & 0 & 0 & 0 & 0 & 148 & 138 & 291 & 0.98 \\
\hline E20/S74 & 1 & 2 & 2 & 0 & 0 & 0 & 0 & 0 & 178 & 29 & 212 & 0.82 \\
\hline E20/S76 & 1 & 4 & 8 & 0 & 0 & 0 & 2 & 0 & 298 & 51 & 364 & 1.15 \\
\hline E20/S78 & 0 & 0 & 6 & 0 & 0 & 0 & 0 & 0 & 323 & 27 & 356 & 1.54 \\
\hline E22/S72 & 0 & 0 & 0 & 0 & 0 & 0 & 0 & 0 & 176 & 325 & 501 & 1.2 \\
\hline E22/S74 & 0 & 2 & 2 & 0 & 0 & 0 & 0 & 0 & 194 & 194 & 392 & 1.25 \\
\hline E22/S76 & 3 & 4 & 9 & 0 & 0 & 0 & 1 & 0 & 268 & 185 & 470 & 1.7 \\
\hline E22/S78 & 0 & 1 & 4 & I & 0 & 0 & 3 & 0 & 227 & 190 & 426 & 1.18 \\
\hline E24/S72 & 0 & 1 & 1 & 0 & 0 & 0 & 0 & 0 & 111 & 96 & 209 & 1.23 \\
\hline E24/S74 & 1 & 0 & 1 & 1 & 0 & 0 & 1 & 0 & 134 & 82 & 220 & 1.25 \\
\hline E24/S76 & 0 & 1 & 4 & 0 & 0 & 2 & 1 & 0 & 376 & 296 & 680 & 1.99 \\
\hline E24/S78 & 0 & 1 & 2 & 0 & 0 & 0 & I & I & 265 & 125 & 395 & 1.6 \\
\hline E26/S72 & 1 & 1 & 1 & 0 & 0 & 0 & 0 & 0 & 52 & 37 & 92 & 1.13 \\
\hline E26/S74 & 1 & 0 & 3 & 0 & 1 & 0 & 1 & 0 & 106 & 98 & 210 & 1.69 \\
\hline E26/S76 & I & 0 & 4 & 0 & 0 & 0 & 0 & 0 & 196 & 205 & 406 & 1.61 \\
\hline E26/S78 & 4 & 1 & 1 & 0 & 0 & 0 & 0 & 0 & 381 & 169 & 556 & 2.17 \\
\hline E28/S78 & 1 & 1 & 5 & 0 & 0 & 0 & I & 0 & 251 & 80 & 339 & 2.4 \\
\hline
\end{tabular}

8400 B.P., but they do not occur in a context that allows the separation of what must be distinct components. Detailed analysis of projectile point forms suggest that at least three distinct components, possibly more, were present: Golondrina-Barber, St. Mary's Hall, andAngostura. The tern- porally diagnostic tools in Unit II can be roughly divided sequentially, but the remainder of the artifacts cannot. Even with this limitation, Wilson-Leonard provides one of the best preserved records of Early Holocene archeology in Texas. One of the most signficant aspects of this analysis is the 


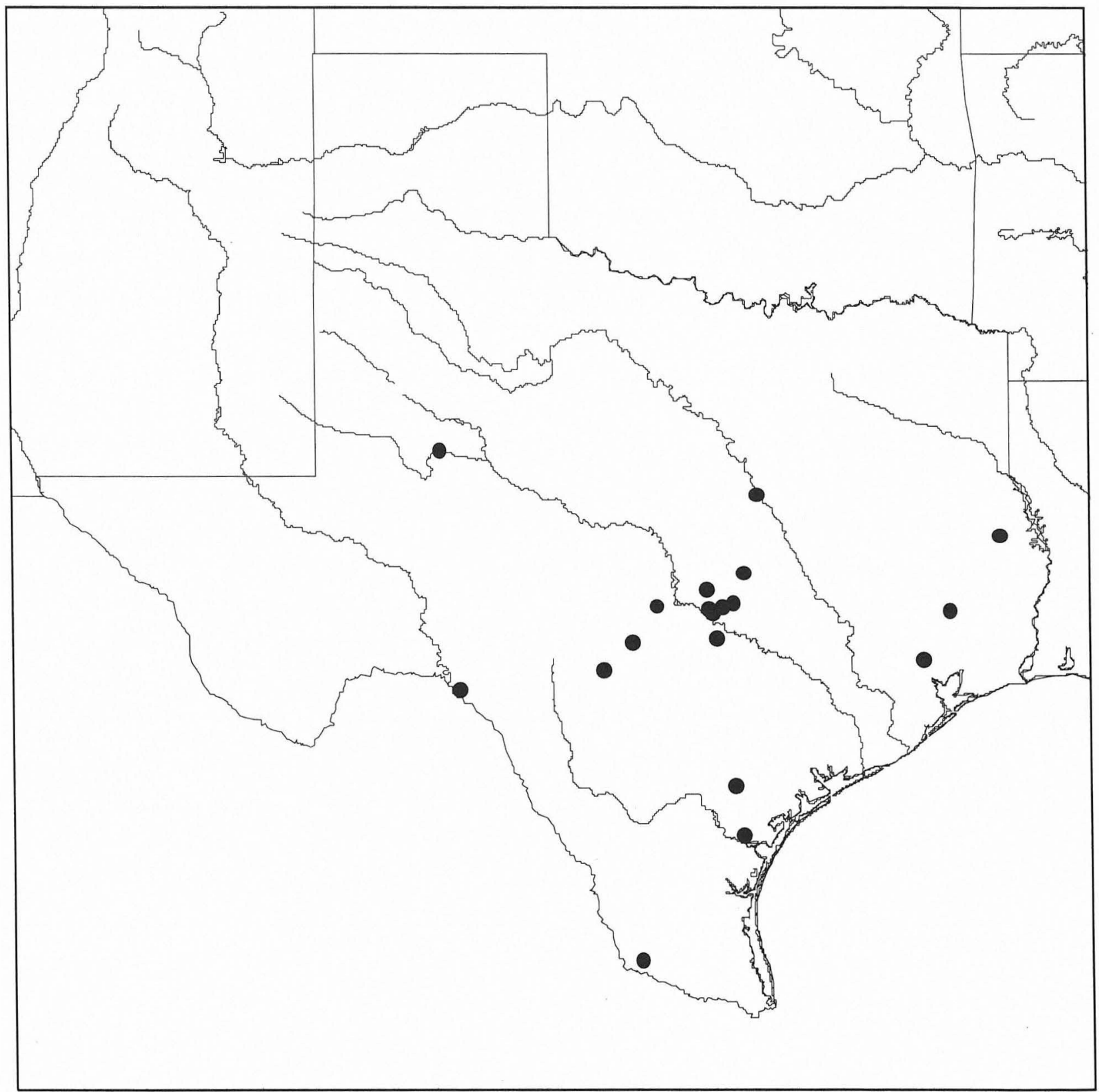

FIGURE 8-44. Distribution of sites with Wilson projectile points or similar early stemmed projectile points. Sites are 41BE2, 41BL85, 41BQ46, 41GL54, 41HR571, 41HW5, 41KR29, 41LL5, 41PK36, 41SA108, 41SP99, 41SR25, 41TV102, 41TV25, 41TV34, 41TV36, 41TV753, 41 VV188, and 41WM235.

documentation of Late Paleoindian lanceolate projectile points stratigraphically above the Wilson component. In situ burned rock features in both stratigraphic units demonstrate the reliability of the sequence. Fauna\} remains from Unit II indicate that exploitation during this interval began to focus more intensively on a wider range of taxa, espe- cially aquatic species in the later portion of the interval. This shift in subsistence may be explained by an environmental shift toward drier conditions at approximately 9500 B.P. Subtle shifts in tool manufacture and use suggests minor adjustments in technological organization occurred during this interval as well. 


\section{THE ARCHAIC PERIOD, 8800 TO 1300 в.P.}

by Michael B. Collins, Jan Guy, and Susan W. Dial

\section{INTRODUCTION}

Both in terms of the amount of evidence present and the length of time represented, the major portion of the Wilson-Leonard record is attributable to the Archaic period, a circumstance that is common at sites in the region. Burned rocks, chipped stone, ground stone, and bone make up the bulk of the archeological evidence along with minor amounts of shell (other than snails) and a few specimens of charred plant material. With a combination of radiocarbon dating and diagnostic kinds of artifacts, the Archaic temporal span at Wilson-Leonard can be fairly accurately pegged to the 7,500-year interval between 8800 and $1300 \mathrm{BP}$.

An array of features from artifact clusters to burned rock middens was documented and affords some of the most significant information on the site's prehistory. The Early Archaic subperiod is better isolated stratigraphically and is represented by more features and cultural materials than are the Middle and Late Archaic subperiods. Finer divisions, such as components consisting of individual style intervals (see Chapter 4; Collins 1995), are discernible only as trends among diagnostic projectile points, but not isolable to the degree that complete assemblages can be identified.

Considerable debate has centered on exactly what distinguishes "Archaic" from "Late Prehistoric" or "Paleoindian." Wilson-Leonard can contribute toward refining the distinction between Archaic and Paleoindian regionally but not toward that between Archaic and Late Prehistoric. In part, this debate has been a case of archeologists inconsistently using three aspects of archeological systematics, these being technological, temporal, and adaptational. Obviously these are highly interrelated and in an ideal system ofterms, all three variables would be considered, but as a practical matter, technological variables are far more tangible and consistently accessible. Thus, if, as some have done (e.g., Hester 1980:94-108), early lanceolate projectile points with ground edges are used as a technological (or typological) marker for the Paleoindian, most such specimens are readily identifiable even out of context; however, neither the age nor the prehistoric lifeway represented by such points is directly knowable. The alternative to using age as the primary criterion (e.g., the periods employed by Collins 1995; Chapter 4, above) fosters an objective assessment of technology and lifeway for the defined periods, but rigid time lines are arbitrary and many archeological data are recovered from contexts of unknown age. What emerges at Wilson-Leonard is continuation of projectile point forms of Paleoindian technology and typology into what is here treated as Early Archaic based on other lines of evidence for a significant shift in subsistence technology.

The most satisfying outcome of cultural-historical research is to know how people lived at any given time in the past, and ultimately, major cultural-historical terms such as "Archaic" should refer to past lifeways that are truly and significantly distinct from others in the succession. This has been the objective of many prehistorians at the continental (e.g., Jennings [1968]; Willey [1966]; Willey and Phillips [1954]; Wormington [1957]), as well as the regional (Johnson and Goode [1994]; Prewitt [1981]; Suhm et al. [1954]) scales. The main difficulty with this approach is one ofpracticality. Basically, it takes a great deal of research to gain an understanding of prehistoric adaptations, and the conduct of that research requires a fundamental structure that includes systematics. The result of this paradox is that systems of cultural-historical terminology are developed on the best available evidence, but new findings constantly challenge each system. These challenges can be met either by keeping the system intact and forcing newly recognized evidence into the structure or by revamping the structure. The latter option is probably the more academically honest, but it results in almost constant change in what is supposed to be a basic framework for organizing and describing the prehistoric record. Used in this way, all such systematics become inherently impermanent. The Wilson-Leonard investigations 
brought to light a great deal of solid technological, temporal, and adaptational evidence pertaining to the distinction between Paleoindian and Archaic as they are perceived in Central Texas. Therefore, we engage this fundamental aspect of systematics and argue that the three lines of evidence, taken together, provide a compelling case for a significant change in subsistence technology in Central Texas that can be dated to ca. 8,800 years ago. Some other aspects of technology change at that time and some do not. These findings are not unique to Wilson-Leonard, but it has yielded more pertinent data than any other single site. A result of this is a break between Paleoindian and Early Archaic that places certain lanceolate dart point forms (Angostura, Thrall) in the Archaic rather than with morphologically similar Paleoindian forms.

In addition to briefly summarizing the Archaic record for Wilson-Leonard, this chapter focuses on the following topics:

- dating of the Early Archaic subperiod,

- typology and technology of Early Archaic diagnostic artifacts,

- subsistence commodities and technologies in the Early Archaic, including evidence that the activities leading to the formation of burned rock middens began early in the Early Archaic (the numerous, large burned rock features at the site are central to this discussion), and

- site formational evidence relating to large burned rock features and the growth of burned rock middens.

It is fortunate that a large sample of relatively well-dated and stratigraphically bounded features and artifacts ofEarly Archaic affiliation were documented at this site, and it is extremely fortunate that a sample of rarely recovered bulbs was found in good Early Archaic context. Offsetting these bonuses to some extent are a lack of component definitions more precise than gross style intervals within the Early Archaic, only moderately well-preserved fauna! remains, and minimally preserved macrofloral materials from general proveniences. In spite of these limitations, information gleaned on and from features and burned rock middens constitute the major contribution Wilson-Leonard makes toward our understanding of the Archaic period in Central Texas.

None of the artifact assemblages from the subperiods of the Archaic at this site is very informative when viewed singularly. However, when viewed comparatively with the other components at this site and with other sites, two very significant observations emerge. First, the Archaic artifact assemblages are remarkably consistent at this site for 7,500 years, and, second, the assemblages at Wilson-Leonard are quite distinct from those at certain other Archaic sites. These observations and clues from the features at this site raise the possibility that during the Archaic in Central Texas, there were localities that were the focus of specific subsistence activities for very long periods of time and that these activities varied between localities.

\section{PHYSICALCONTEXTAND DATING}

Every single square excavated in this site penetrated Archaic deposits, and there is every indication that most of the Valley Floor and Valley Margin at this locality was used by people at times during the Archaic. This observation leads to the caveat that this discussion of the stratigraphy and dating refers only to the comparatively small areas excavated. There is at least one other burned rock midden at the site and undoubtedly there are extensive buried deposits containing features and artifacts of Archaic age (see Chapter 2). It is unknown how representative of the whole site the investigated areas may be.

The partial transect excavated from Valley Margin to Valley Floor (Figures 9-1 and 9-2) exposed part of an alluvial fan that, through its complex history, has consisted of two distinct areas. The Valley Margin has always been dominated by colluvial natural deposition affected variously by deposits of cultural origin. The Valley Floor evolved from primarily a fluvial to predominantly a colluvial and anthropogenic depositional feature. The Archaic segment of the site's history as found in the Valley Floor began after fluvial dominance had given way to colluvial and rates of deposition had slowed significantly; basically, this is geologic Unit III (see Chapter 6). There is some mixing of Archaic and Paleoindian diagnostic artifacts in the lowest, transitional part (Unit II/Illa) of the sequence discussed here as well as an indistinct boundary between Late Archaic and Late Prehistoric materials near the top of Unit III (in Unit Ille). Between these indistinct upper and lower limits, Archaic features and artifacts reside in the three main subdivisions ofUnit III, designated as IIIa, Illb, and Ille. Unit III averages about $1.8 \mathrm{~m}$ thick in the Valley Floor and represents roughly 7,500 years. This modest rate of aggradation-on the order of $0.024 \mathrm{~cm} /$ year-implies that there was at least slight pedogenesis at work throughout the time represented by Unit III. Pedogenesis progressed sufficiently to produce two recognizable soils, one extending down from the present surface and another buried in roughly the lower third of Unit III. Sediments exposed in excavation Area Bon the Valley Floor north of the main excavation block (see Figure 2-12) are generally similar to those in Area A, however, efforts to correlate between the two areas were not entirely successful. Much of Unit III was mechanically stripped and disposed of without screening during the TxDOT excavations (Blocks 5 and 6; see Chapter 3).

On the Valley Margin, excavation exposed a thinner and less-easily deciphered stratigraphy. Fluvial contribution on the Valley Margin may never have occurred, or if it did, it was during extremely high (and therefore very brief) flood events for which no record is discernible. Otherwise, aggradation on the slope can be inferred to consist of some combination of all or some of the following processes: 


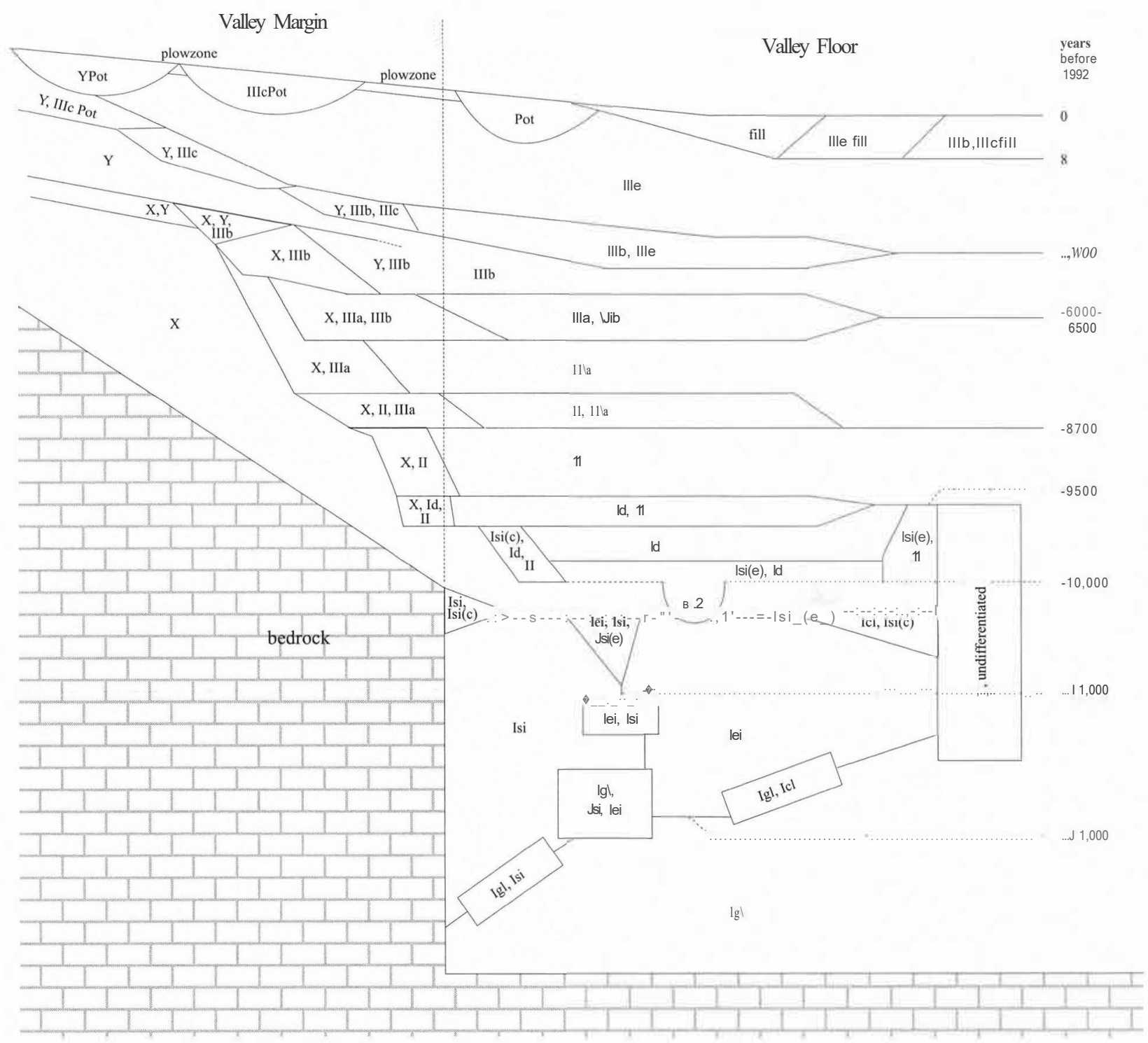

FIGURE 9-1. Diagrammatic depiction of the stratigraphic units and their relationships.

weathering of bedrock, downslope movement, decay of organic material, settling of atmospheric dust, aeolian deposition, and introduction of organic and inorganic materials by humans. Because of the contrasting depositional environments between the Valley Floor and the Valley Margin, slightly different designations were attached to the lower units on the Valley Margin. The characteristics ofthe stratigraphy are detailed in Chapter 6 .

\section{Valley Floor, Area A}

Archaic materials at Wilson-Leonard are found almost exclusively in the major stratigraphic suite designated as Unit III. A trace of mixing of Unit III as well as of Archaic and Paleoindian cultural materials is found along the indistinct boundary between Units II and III, designated as II/
Illa. In the general categorization of the site stratigraphy, Unit II represents colluvial deposition with minor contributions from fluvial and from human processes, and Unit III is similar with even less fluvial and considerably more anthropogenic deposition indicated. Overall, Unit III averages about $1.5 \mathrm{~m}$ thick in the Valley Floor area of the site, and is basically stoney, clayey silt. Unit III is divided into three subunits, IIIa, IIIb, and Ille, and there are transitional designations for the contact zones of each (Illa/Illb, Illb/ IIIc). Units Illa and Ille are darker and contain somewhat more organic material than Unit Illb. Unit IIIa corresponds in part to a soil, designated the Stiba soil, that seems to be at least partially anthropogenic in origin. Unit IIlb is slightly less stony than are the other two subunits of III. Unit Ille, the uppermost unit in the site, is the cumulic WilsonLeonard soil with abundant cultural material present. 


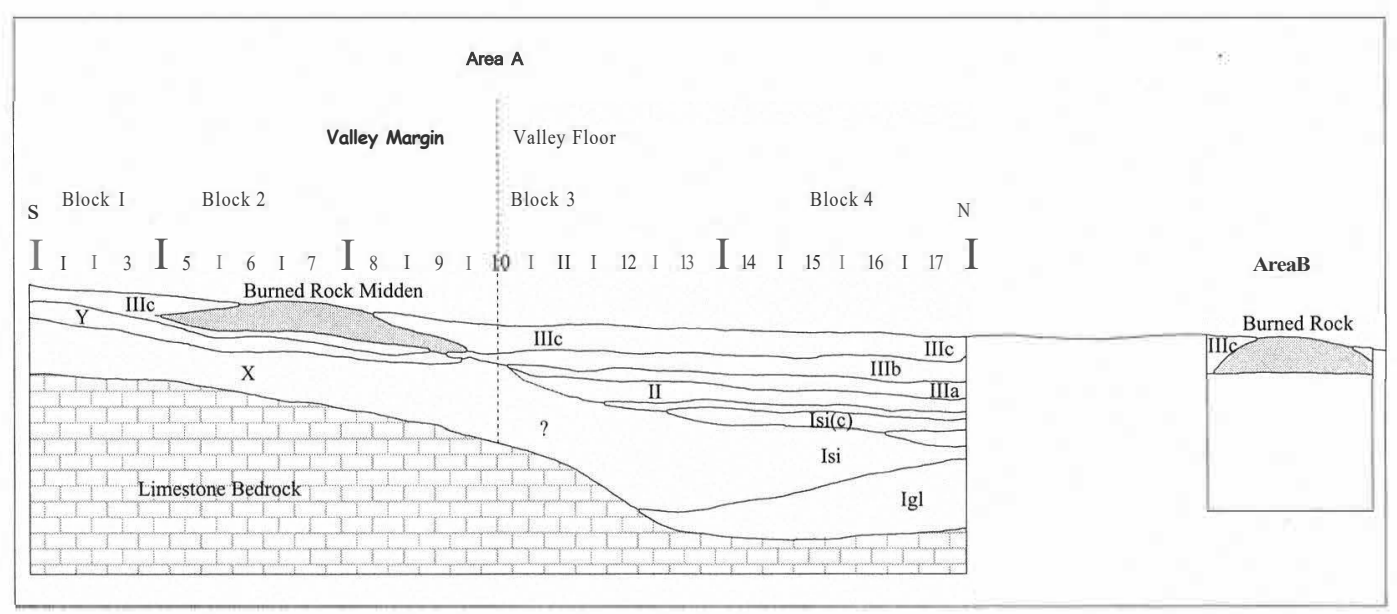

FGURE 9-2. North-south section showing the major stratigraphic units and major burned rock features.

\section{Paleoclimate}

Paleoclimatic data from localities in and near Central Texas have recently been reviewed and interpreted for a span of slightly greater than the last 12,000 radiocarbon years (see Chapter 4; Collins 1995:375-380). The Archaic period, some 7,500 years within that span from ca. 8800 to 1300 B.P., witnessed a protracted dry interval of 6,000 or 6,500 years duration (the Altithermal), preceded and followed by more-mesic conditions and somewhat ameliorated for 500 years or so near its midpoint (see Chapter 4, Figure 4-1). Thus it seems to be apparent that through most of its existence, the Archaic lifeway was an adaptation to comparatively xeric conditions. This is not to say that it represents specialized adaptations to such conditions, because it is equally apparent that the Central Texas Archaic period was one during which the populace had versatile capabilities for Jiving under varying climatic regimes (see Chapter 4; Collins 1995).

Taking a closer look at the regional data (see Chapter 4, Figure 4-1; Collins 1995), the two most complete proxy climatic sequences are one of bog pollen and one of cave fauna. These independent sets of data are very similar in their succession of mesic and xeric climatic regimes, but there are considerable differences in the radiocarbon ages of what seem to be the same events (differences ranging from ca. 500 to 1,500 years). The more securely dated of the two is the fauna! column from Hall's Cave, which portrays a climatic sequence for the Archaic beginning as conditions were becoming significantly drier. This dry interval lasted for the entire Early Archaic, peaking some 6,800 years ago and becoming less extreme near 6000 B.P. It was less severe but drier than at present at the end of the Early and beginning of the Middle Archaic, but it became and remained significantly drier for most of the Middle Archaic, or until about 3500 в.P. The Late Archaic existed during a comparatively mesic climatic regime. As noted in the regional summaries, bison are generally more prevalent during moister times, and soil for- mation or erosion is more characteristic of the drier times (Chapter 4; Collins 1995).

At Wilson-Leonard, more specifically, paleoenvironmental data covering the Archaic are oftwo scales, site specific and regional. Phytoliths and most of the vertebrate terrestrial fauna indicate a regional drying through most of the Archaic interval. Soil isotopes, snails, and macrofloral remains all indicate fairly continuous arboreal cover. The two combined can best be interpreted as resulting from a predominantly xeric regional climate with the site itself situated in a better-watered, forested stream valley.

\section{MATERIALEVIDENCEFORTIIEARCHAIC}

There are 178 cultural features at Wilson-Leonard that are inferred to be of Archaic affiliation (Table 9-1). The nature offeatures is discussed below for each of the subperiods of the Archaic, but some general observations are worth mentioning here. Activities related to the use of fire are represented by almost all of these features, and it is further inferred from their forms, contents, and contexts that domestic activities prevailed, which is not to say that ritual or other behavior was not also involved in some use of these features. It is possible that some of these features were even exclusively ritualistic, as for example, heating elements in ritual sweat lodges, but no evidence for this was discerned. Features not directly or indirectly related to the use of fire are only three in number, a cluster of bifaces and two partial human burials. It is probable that poor conditions for preservation are responsible for the lack of more features not related to the use of fire. Ten of the 13 categories of features tabulated here are defined at least in part by the presence of burned rocks, and an eleventh contains burned sediment. Pits, postholes, caches of perishables, or other imprints destructable by the elements and soil processes were probably left in considerable numbers at times in the site's history but have not survived. Thus, as valuable as this sample of features is in its yield of information on 
TABLE9-I

Frequencies of Feature Types in the Archaic Period

\begin{tabular}{|c|c|c|c|c|c|c|c|c|c|c|c|c|c|c|}
\hline & 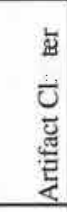 & 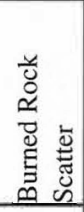 & 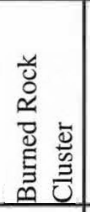 & 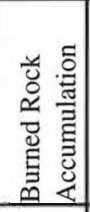 & 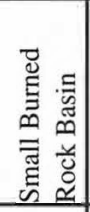 & 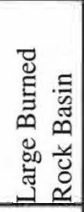 & 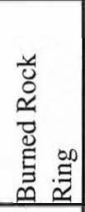 & 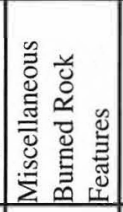 & 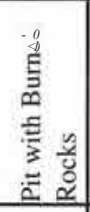 & 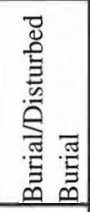 & 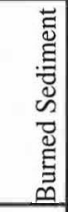 & 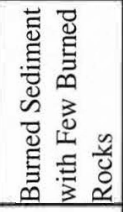 & 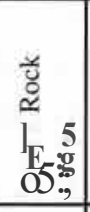 & Totals \\
\hline $\begin{array}{l}\text { Late Archaic/Late } \\
\text { Prehistoric }\end{array}$ & & 1 & 1 & & & & & & & & & & & 2 \\
\hline Late Archaic & & 5 & 9 & 1 & & & 1 & & & & & & & 16 \\
\hline Late Archaic? & 1 & & 3 & & 1 & & & & & 1 & & & & 6 \\
\hline $\begin{array}{l}\text { Middle Archaic/ } \\
\text { Late Archaic }\end{array}$ & & 1 & 8 & & & & & & 1 & & & 1 & & $\mathrm{Ii}$ \\
\hline Middle Archaic? & & & $\mathrm{JO}$ & 1 & & & & & & & & & & II \\
\hline $\begin{array}{l}\text { Middle-Late } \\
\text { Archaic }\end{array}$ & & & & & & & & & & & & & 1 & 1 \\
\hline Middle Archaic & & 1 & 3 & & & & & 1 & & & 1 & 1 & & 7 \\
\hline $\begin{array}{l}\text { Early Archaic/ } \\
\text { Middle Archaic }\end{array}$ & & 2 & 4 & & & & 1 & & & & 1 & & & 8 \\
\hline Early-Late Archaic & & & & & & & & & & & & & 1 & 1 \\
\hline Early Archaic & & II & 68 & 3 & 5 & 9 & 2 & & & & 1 & 1 & & 100 \\
\hline $\begin{array}{l}\text { Late Paleoindian/ } \\
\text { Early Archaic }\end{array}$ & & 2 & 10 & & 1 & & 1 & & & & & & & 14 \\
\hline Archaic & & & & & & & & & & 1 & & & & 1 \\
\hline Totals: & 1 & 23 & 116 & 5 & 7 & 9 & 5 & 1 & 1 & 2 & 3 & 3 & 2 & 178 \\
\hline
\end{tabular}

domestic activities in the Archaic, it is almost certain that with better preservation, features resulting from diverse other activities also would have been present.

It is immediately apparent from inspection of the data that, numerically, burned rock clusters are the dominant form (at $65 \%$ of the total) and that the majority (56\%) of the 178 features are attributable to the Early Archaic (see Table 9-1). Two factors in the archeological excavation and analysis must be kept in mind when considering these data. First, in TxDOT excavations, the upper halfmeter ofBlock 5 and the upper 1.5 m ofBlock 6 were mechanically stripped, reducing the potential sample of Late Prehistoric, Late Archaic, and, to a lesser extent, Middle Archaic features. Constructionrelated disturbance prior to TARL excavations similarly reduced slightly the sample of Late Prehistoric and possibly Late Archaic features. Also, the category, burned rock cluster, is just that, a cluster of burned rocks (see Chapter 26). As such, it encompasses considerable variability and undoubtedly includes features that came about in a number ofdifferent ways. In some cases, field documentation was reliable only in indicating the presence of a cluster of burned rocks, although it suggested that with better recording, the feature might have been recognizable as belonging to another category, as for example, a small burned rock basin. In other cases, it is likely that evidence permitting more-definitive classification was simply not preserved. Among burned rock clusters are a majority that likely represent simple hearths. Finally, number of features is far from being an adequate descriptor. Large burned rock basins, burned rock accumulations, and burned rock middens are each counted as one feature in Chapter 26 and in the accompanying table, although it is obvious that the amount of human activity represented by a burned rock accumulation or midden is greater by orders of magnitude over that represented by a burned rock cluster.

Features do not change dramatically through time within the Archaic period at this site. Large and small burned rock basins, as isolated features, are characteristic of the Early Archaic and virtually absent from the rest of the Archaic record (see Table 9-1). However, it is our interpretation that the activities producing these kinds of features continued, but that their repetitiveness began in the Early Archaic to result in the formation ofburned rock middens, seen here as burned rock accumulations. The evidence for this interpretation is complex; it is given extended treatment in this chapter and is considered again in Chapter 11 as it relates to other sites.

Basically, several large burned rock features of Early Archaic age at Wilson-Leonard constitute small- to mediumsized burned rock middens that were sufficiently isolated 
stratigraphically to escape being directly capped with younger midden deposits. By virtue of this stratigraphic isolation, structural details were preserved that provide important clues to the human activities responsible for midden development. The presence of large burned rock features and middens in contrasting natural stratigraphic contexts on the Valley Margin and in two areas of the Valley Floor afford valuable comparative formational data as well.

Almost a half million stone, bone, and shell artifacts $(\mathrm{N}=470,538)$ were provenienced to the Archaic (Table 9-2). The majority, of course, are pieces of debitage $(n=463,696)$, and about half of the total derives from Early Archaic contexts (see Table 9-2). There are 6,842 specimens other than debitage, of which all but 22 are of stone (17 artifacts of bone and 5 of shell). Chipped stone dominates the assemblage at 6,692 items. This number is actually a little low in that it does not include hammerstones, most of which are recycled cores that, technically, are chipped stone. This dominance, viewed another way, is a reflection of the unexpectedly low numbers ofground stone artifacts $(n=57)$ and ofharnmerstones $(n=29)$. Cores and core fragments at only 199 specimens, are also surprisingly infrequent at this site given its proximity to outcrops of excellent Edwards chert.

Overall, the relative frequencies of major artifact classes within the Archaic reveal small but interesting changes over time (Table 9-3). The data are expressed as simple ratios between selected, major artifact classes. No more sophisticated approach to this analysis is warranted given the nature of the sample and the only generalized subdivisions of the Archaic that could be made at the site. Of the nine temporal subdivisions in Table 9-2, two (Archaic/Late Prehistoric and Archaic), do not appear in Table 9-3 because they are considered to have little analytical value.

The ratio of projectile points to bi faces increases gradually through the Archaic from 0.29: 1 to $1.16: 1$ with a modest reversal between the Middle Archaic and the Middle/Late Archaic. A quite similar pattern exists in the ratio of projectile points to unifaces, the figure increasing from $0.26: 1$ to 1.95: 1 with a slight reversal at the same place in the sequence. In aggregate, these patterns reflect the fact that projectile points make up a greater proportion of the Archaic assemblages over time (note row percentages in Table 9-2). Projectile point and projectile point fragment percentages combined increase from $12 \%$ in the Early Archaic to $30 \%$ by the Late Archaic/Late Prehistoric (see Table 9-2). In contrast, the sum of percentages ofbifaces and biface fragments (see Table 9-2) varies only between about $22 \%$ and $28 \%$ for the entire data set.

Bi faces and biface fragments show a modest increase in their ratio to unifaces over time from 0.97: 1 to 1.68 : 1 (see Table 9-3). A functional linkage between projectile points and bifaces may be reflected in this trend. Unifaces remain fairly consistent in their ratio to edge-modified flakes throughout the Archaic sequence (see Table 9-3).
The ratios involving ground stone (unifaces:ground stone, manos:metates, chipped stone:ground stone, and projectile points:ground stone) all show considerable variation over time, but the low numbers of ground stone pieces are driving this variation, and these small sample sizes are probably not reliable.

The ratio ofburin spalls to burins was calculated to see if there were any indications of changes in the pattern of manufacture and use of these tools. If burins were being used (and discarded) but not being manufactured or refurbished, the ratio of spalls to burins should be low. In the present data, the spall to burin ratio is quite low in the Early/ Middle and in the Late Archaic (more burins than spalls), suggesting discard but neither manufacture nor refurbishment. In the remainder of the time segments, ratios of 1.5 to 3.3 spalls per burin are more consistent with active manufacture and refurbishment ofburins (see Table 9-3).

Finally, the ratio of flakes to all chipped stone objects varies from a low of 55: 1 in the Early/Middle Archaic to a high of 82: 1 in the Early Archaic/Late Paleoindian (see Table 9-3). All of the classes of chipped stone objects are larger than the 1/4-inch mesh used in most TxDOT screening, so there is no systematic difference in artifact sizes between TXDOT and TARL assemblages. However, debitage densities are much larger for those TxDOT proveniences screened with fine mesh wire and for all TARL proveniences because of the recovery of small flakes. Because about $36 \%$ of the Archaic sample of flakes was recovered on fine screens, the ratio of flakes to chipped stone objects reflects this higher recovery rate. With this in mind, the ratios are not particularly high, indicating comparatively little knapping. This is consistent with the scarcity of cores and hammerstones at the site.

For the entire Archaic, fauna! remains are numerous but in very fragmented condition. To a certain degree, this fragmentation is probably due to such cultural practices as butchering, cooking, bone greasing, and marrow extraction (see Chapter 33). For the Archaic, recovery and identification of small bones and small pieces of larger bones provided the majority of the information, especially from features.

\section{TIIEEARLYARCHAIC}

Considered here are the 2,878 artifacts, over 220,000 pieces of debitage, 100 features, and associated floral and fauna! data attributable to the Early Archaic. There is also reference to those data in the less secure contexts, Late Paleoindian/Early Archaic and Early Archaic/Middle Archaic.

Significant intermixing of Early Archaic with Late Paleoindian materials occurred in Valley Floor Unit II/Illa and its equivalents in the Valley Margin (Figure 9-3). Most Early Archaic evidence resided in stratigraphic Unit Illa in the Valley Floor and from the upper part of Unit X to the lower part of Unit Y in the Valley Margin (Figure 9-4). The Early Archaic assemblage is tabulated by artifact categories in Tables 9-4 through 9-13. 
TABI.E9-2

Freouencies of Artifact Tune,. in the Archaic Period

\begin{tabular}{|c|c|c|c|c|c|c|c|c|c|c|c|c|c|c|c|c|c|c|c|c|c|c|c|c|c|c|c|c|c|}
\hline & $\begin{array}{l}1 \\
1 ! \\
0 !\end{array}$ & 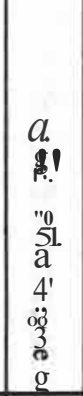 & $\begin{array}{l}0: \\
8 \\
8\end{array}$ & $\begin{array}{l}\text { 0: } \\
\boldsymbol{0} \\
\mathrm{og} \\
\mathrm{O} \\
\mathrm{i} ;\end{array}$ & $\begin{array}{l}f^{\prime} \\
\mathrm{e}^{\circ} \\
0 \\
0\end{array}$ & 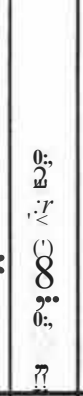 & $\begin{array}{c}11 \\
\text { e. } \\
\text { er } \\
\text { c. } \\
8 \\
8\end{array}$ & $\underset{;}{\stackrel{\mathrm{C}}{\mathrm{E}}}$ & $\begin{array}{l}(') \\
{[} \\
{[}\end{array}$ & & $\begin{array}{l}0: \\
: i \\
\cdots i \\
i \\
1\end{array}$ & 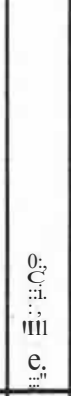 & $\begin{array}{l}d \\
\text { rii } \\
:=\end{array}$ & $\begin{array}{l}\ldots . \\
\ldots \\
\mathrm{g}, \\
2 . \\
\mathbb{1} \\
4 !\end{array}$ & (') & 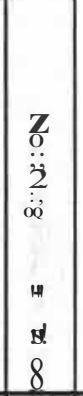 & $\underset{S^{\prime}}{S r}$ & 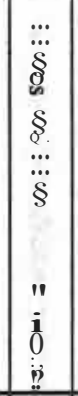 & $"$ & $\begin{array}{l}\mathscr{C} \\
\$ \\
\$ \\
\vdots\end{array}$ & 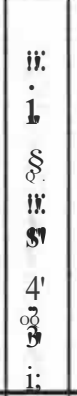 & 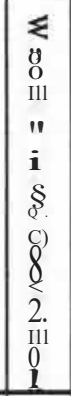 & $\begin{array}{l}\text { Ill } \\
\text { ?! } \\
?\end{array}$ & 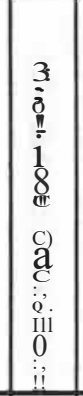 & $\begin{array}{l}* \\
2 . \\
! c \\
3 \\
\end{array}$ & 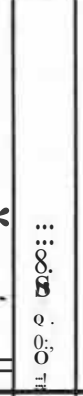 & 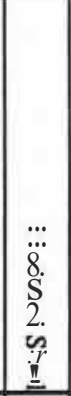 & 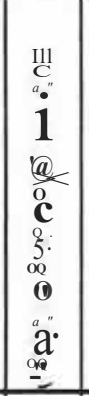 & 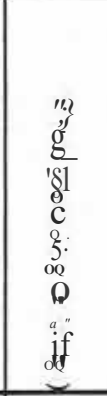 \\
\hline $\begin{array}{l}\text { Late Archaic/ } \\
\text { Late } \\
\text { Prehistoric }\end{array}$ & \begin{tabular}{|l|}
76 \\
$(17.7)$ \\
\end{tabular} & \begin{tabular}{|l|}
53 \\
$(12.4)$ \\
\end{tabular} & \begin{tabular}{|l|}
74 \\
$(17.2)$ \\
\end{tabular} & \begin{tabular}{|l}
37 \\
$(8.6)$
\end{tabular} & \begin{tabular}{|l}
0 \\
$(0.0)$ \\
\end{tabular} & $\begin{array}{l}0 \\
(0.0) \\
\end{array}$ & $\begin{array}{l}0 \\
(0 . Q)\end{array}$ & $\begin{array}{l}66 \\
(15.4) \\
\end{array}$ & $\mid \begin{array}{l}2 \\
(0.5)\end{array}$ & $\begin{array}{l}3 \\
(0.7)\end{array}$ & \begin{tabular}{|l}
4 \\
$(0.9)$
\end{tabular} & $\begin{array}{l}9 \\
(2.1)\end{array}$ & \begin{tabular}{|l|}
3 \\
$(0.7)$
\end{tabular} & \begin{tabular}{|l}
79 \\
$(18.4)$ \\
\end{tabular} & \begin{tabular}{|l|}
16 \\
$(3.7)$
\end{tabular} & $\begin{array}{l}0 \\
(0 . Q) \\
\end{array}$ & 25,323 & \begin{tabular}{|l|}
3 \\
$(0.7)$ \\
\end{tabular} & \begin{tabular}{|l|}
0 \\
$(0.0)$ \\
\end{tabular} & \begin{tabular}{|l|}
0 \\
$(0 . Q)$
\end{tabular} & \begin{tabular}{|l|}
0 \\
$(0.0)$
\end{tabular} & $\begin{array}{l}0 \\
(0.0)\end{array}$ & \begin{tabular}{|l|}
0 \\
$(\mathbf{0 . 0})$ \\
\end{tabular} & $\begin{array}{l}2 \\
(0.5)\end{array}$ & $\begin{array}{l}0 \\
(0.0) \\
\end{array}$ & \begin{tabular}{|l|}
2 \\
$(0.5)$ \\
\end{tabular} & \begin{tabular}{|l|}
0 \\
$(0.0)$ \\
\end{tabular} & 429 & 25,75 \\
\hline $\begin{array}{l}\text { Archaic/Late } \\
\text { Prehistoric }\end{array}$ & \begin{tabular}{|l|}
30 \\
$(22.1)$ \\
\end{tabular} & \begin{tabular}{|l}
8 \\
$(5.9)$
\end{tabular} & \begin{tabular}{|l|}
33 \\
$(24.3)$ \\
\end{tabular} & \begin{tabular}{|l|}
4 \\
$(2.9)$ \\
\end{tabular} & $\begin{array}{l}0 \\
(0.0) \\
\end{array}$ & \begin{tabular}{|l|}
0 \\
$(0 . Q)$
\end{tabular} & \begin{tabular}{|l|}
$\mathrm{I}$ \\
$(0.7)$
\end{tabular} & \begin{tabular}{|l|}
21 \\
$(15.4)$ \\
\end{tabular} & $\begin{array}{l}0 \\
(0.0)\end{array}$ & $\begin{array}{l}2 \\
(1.5) \\
\end{array}$ & $\begin{array}{l}\mathrm{I} \\
(0.7)\end{array}$ & $\begin{array}{c}\mathrm{I} \\
\mathbf{( 0 . 7 )} \\
\end{array}$ & \begin{tabular}{|l|}
0 \\
$(0.0)$
\end{tabular} & \begin{tabular}{|l}
33 \\
$(24.3)$ \\
\end{tabular} & $\begin{array}{c}\mathrm{I} \\
(0.7)\end{array}$ & \begin{tabular}{|l}
0 \\
$(0 . Q)$
\end{tabular} & 5,108 & \begin{tabular}{|l|}
0 \\
$(0.0)$
\end{tabular} & \begin{tabular}{|l|}
0 \\
$(0 . Q)$
\end{tabular} & \begin{tabular}{|l|} 
I \\
$(0.7)$
\end{tabular} & $\begin{array}{l}0 \\
(0.0)\end{array}$ & $\begin{array}{l}0 \\
(0.0)\end{array}$ & \begin{tabular}{|l|}
0 \\
$(0.0)$ \\
\end{tabular} & \begin{tabular}{|l}
0 \\
$(0.0)$
\end{tabular} & $\begin{array}{l}0 \\
(0.0) \\
\end{array}$ & $\mid \begin{array}{l}0 \\
(0.0)\end{array}$ & \begin{tabular}{|l|}
0 \\
$(0.0)$ \\
\end{tabular} & 136 & 5,24 \\
\hline Late Archaic & \begin{tabular}{|l|}
124 \\
$(14.1)$ \\
\end{tabular} & \begin{tabular}{|l}
42 \\
$(4.8)$ \\
\end{tabular} & \begin{tabular}{|l|}
140 \\
$(15.9)$ \\
\end{tabular} & \begin{tabular}{|l|}
60 \\
$(6.8)$ \\
\end{tabular} & $\begin{array}{l}1 \\
(0.1)\end{array}$ & \begin{tabular}{|l|}
0 \\
$(0.0)$
\end{tabular} & \begin{tabular}{|l|} 
I \\
$(0.1)$ \\
\end{tabular} & $\begin{array}{l}144 \\
(16.4)\end{array}$ & \begin{tabular}{|l|}
6 \\
$(0.7)$ \\
\end{tabular} & $\begin{array}{l}\text { JO } \\
\text { (I.I) }\end{array}$ & \begin{tabular}{|l|}
20 \\
$(2.3)$
\end{tabular} & \begin{tabular}{|l|}
17 \\
$(1.9)$ \\
\end{tabular} & \begin{tabular}{|l|}
0 \\
$(0.0)$
\end{tabular} & \begin{tabular}{|l|}
268 \\
$(30.5)$ \\
\end{tabular} & \begin{tabular}{|l|}
21 \\
$(2.4)$ \\
\end{tabular} & \begin{tabular}{|l}
0 \\
$(0.0)$ \\
\end{tabular} & 56,527 & \begin{tabular}{|l}
9 \\
$(1.0)$
\end{tabular} & \begin{tabular}{|l|}
0 \\
$(0.0)$
\end{tabular} & \begin{tabular}{|l|}
3 \\
$(0.3)$
\end{tabular} & \begin{tabular}{|l|}
5 \\
$(0.6)$
\end{tabular} & $\begin{array}{l}0 \\
(0 . Q)\end{array}$ & \begin{tabular}{|l|} 
\\
$(0.1)$ \\
\end{tabular} & \begin{tabular}{|l}
0 \\
$(0 . Q)$
\end{tabular} & $\begin{array}{l}1 \\
(0.1) \\
\end{array}$ & \begin{tabular}{|l}
5 \\
$(\mathbf{0 . 6})$
\end{tabular} \mid & \begin{tabular}{|l|}
0 \\
$(0 . Q)$ \\
\end{tabular} & 878 & 57,405 \\
\hline $\begin{array}{l}\text { Middle/Late } \\
\text { Archaic }\end{array}$ & \begin{tabular}{|l|}
32 \\
$(7.4)$ \\
\end{tabular} & $\begin{array}{l}27 \\
(6.3) \\
\end{array}$ & \begin{tabular}{|l|}
70 \\
$(16.3)$ \\
\end{tabular} & \begin{tabular}{|l|}
31 \\
$(7.2)$
\end{tabular} & $\begin{array}{l}\mathrm{I} \\
(0.2) \\
\end{array}$ & \begin{tabular}{|l|}
$\mathrm{I}$ \\
$(0.2)$ \\
\end{tabular} & \begin{tabular}{|l|}
2 \\
$(0.5)$
\end{tabular} & \begin{tabular}{|l|}
84 \\
$(19.6)$ \\
\end{tabular} & \begin{tabular}{|l}
5 \\
$(1.2)$
\end{tabular} & \begin{tabular}{|l}
4 \\
$(0.9)$ \\
\end{tabular} & \begin{tabular}{|l|}
4 \\
$(0.9)$ \\
\end{tabular} & \begin{tabular}{|c|}
6 \\
$(1.4)$ \\
\end{tabular} & \begin{tabular}{|l|}
0 \\
$(0 . Q)$
\end{tabular} & \begin{tabular}{|l}
144 \\
$(33.8)$
\end{tabular} & \begin{tabular}{|l|}
$\mathrm{JO}$ \\
$(2.3)$ \\
\end{tabular} & $\begin{array}{l}0 \\
(0.0) \\
\end{array}$ & 28,682 & \begin{tabular}{|l|}
4 \\
$(0.9)$ \\
\end{tabular} & \begin{tabular}{|l|}
0 \\
$(0.0)$ \\
\end{tabular} & \begin{tabular}{|l|}
$\mathrm{I}$ \\
$(0.2)$ \\
\end{tabular} & \begin{tabular}{|l|}
$\mathrm{I}$ \\
$(0.2)$ \\
\end{tabular} & \begin{tabular}{|l}
0 \\
$(0.0)$ \\
\end{tabular} & \begin{tabular}{|l|}
0 \\
$(0.0)$ \\
\end{tabular} & \begin{tabular}{|l}
2 \\
$(0.5)$
\end{tabular} & $\begin{array}{l}0 \\
(0 . Q) \\
\end{array}$ & \begin{tabular}{|l|}
0 \\
$(0.0)$
\end{tabular} & \begin{tabular}{|l|}
0 \\
$(0.0)$ \\
\end{tabular} & 429 & 29,111 \\
\hline $\begin{array}{l}\text { Middle } \\
\text { Archaic }\end{array}$ & \begin{tabular}{|l|}
68 \\
$(13.3)$ \\
\end{tabular} & $\begin{array}{l}27 \\
(5.3) \\
\end{array}$ & \begin{tabular}{|l|}
99 \\
$(19.4)$ \\
\end{tabular} & \begin{tabular}{|l|}
41 \\
$(8.1)$ \\
\end{tabular} & \begin{tabular}{|l}
2 \\
$(0.4)$ \\
\end{tabular} & \begin{tabular}{|l|}
0 \\
$(0.0)$ \\
\end{tabular} & \begin{tabular}{|l|}
0 \\
$(0.0)$ \\
\end{tabular} & \begin{tabular}{|l|}
89 \\
$(17.5)$ \\
\end{tabular} & \begin{tabular}{|l|}
3 \\
$(0.6)$ \\
\end{tabular} & \begin{tabular}{|l|}
4 \\
$(0.8)$ \\
\end{tabular} & \begin{tabular}{|l|}
2 \\
$(0.4)$ \\
\end{tabular} & \begin{tabular}{|l|}
8 \\
$(1.6)$ \\
\end{tabular} & \begin{tabular}{|l|}
0 \\
$(0.0)$
\end{tabular} & \begin{tabular}{|l}
137 \\
$(27.0)$ \\
\end{tabular} & \begin{tabular}{|l|}
11 \\
$(2.2)$ \\
\end{tabular} & $\begin{array}{l}\mathrm{I} \\
(0.2) \\
\end{array}$ & 33,404 & \begin{tabular}{|l|}
5 \\
$(1.0)$
\end{tabular} & \begin{tabular}{|l|}
0 \\
$(0 . Q)$ \\
\end{tabular} & \begin{tabular}{|l|}
0 \\
$(0.0)$
\end{tabular} & \begin{tabular}{|l|}
4 \\
$(0.8)$ \\
\end{tabular} & \begin{tabular}{|l}
0 \\
$(0.0)$ \\
\end{tabular} & \begin{tabular}{|l|}
0 \\
$(0.0)$ \\
\end{tabular} & \begin{tabular}{|l|}
3 \\
$(0.6)$ \\
\end{tabular} & \begin{tabular}{|l|}
3 \\
$(0.6)$ \\
\end{tabular} & \begin{tabular}{|l|}
2 \\
$(0.4)$
\end{tabular} & \begin{tabular}{|l}
0 \\
$(0.0)$ \\
\end{tabular} & 509 & 33,913 \\
\hline $\begin{array}{l}\text { Early/Middle } \\
\text { Archaic }\end{array}$ & $\begin{array}{l}58 \\
(9.0) \\
\end{array}$ & \begin{tabular}{|l}
21 \\
$(3.3)$ \\
\end{tabular} & \begin{tabular}{|l|}
109 \\
$(17.1)$ \\
\end{tabular} & \begin{tabular}{|l|}
38 \\
$(6.0)$ \\
\end{tabular} & $\begin{array}{l}\mathrm{I} \\
(0.2) \\
\end{array}$ & \begin{tabular}{|l|}
0 \\
$(0.0)$ \\
\end{tabular} & \begin{tabular}{|l|}
3 \\
$(0.5)$ \\
\end{tabular} & \begin{tabular}{|l|}
144 \\
$(22.6)$ \\
\end{tabular} & \begin{tabular}{|l|} 
\\
$(0.5)$ \\
\end{tabular} & \begin{tabular}{|l|}
8 \\
$(1.3)$ \\
\end{tabular} & \begin{tabular}{|l|}
15 \\
$(2.4)$ \\
\end{tabular} & \begin{tabular}{|l|}
8 \\
$(1.3)$ \\
\end{tabular} & \begin{tabular}{|l|}
6 \\
$(0.9)$ \\
\end{tabular} & \begin{tabular}{|l|}
204 \\
$(32.0)$ \\
\end{tabular} & \begin{tabular}{|l|}
16 \\
$(2.5)$ \\
\end{tabular} & \begin{tabular}{|l}
0 \\
$(0.0)$ \\
\end{tabular} & 33,654 & \begin{tabular}{|l|}
2 \\
$(0.3)$ \\
\end{tabular} & \begin{tabular}{|l|}
0 \\
$(0.0)$
\end{tabular} & \begin{tabular}{|l|}
0 \\
$(0.0)$
\end{tabular} & \begin{tabular}{|l|}
$\mathrm{I}$ \\
$(0.2)$ \\
\end{tabular} & \begin{tabular}{|l}
0 \\
$(0.0)$ \\
\end{tabular} & \begin{tabular}{|l|}
0 \\
$(0.0)$
\end{tabular} & \begin{tabular}{|l}
0 \\
$(0 . Q)$
\end{tabular} & $\begin{array}{l}\mathrm{I} \\
(0.2) \\
\end{array}$ & \begin{tabular}{|l|}
0 \\
$(0.0)$
\end{tabular} & \begin{tabular}{|l|}
0 \\
$(0 . Q)$ \\
\end{tabular} & 638 & 34,292 \\
\hline Early Archaic & $\begin{array}{l}266 \\
(9.2) \\
\end{array}$ & $\begin{array}{l}90 \\
(3.1) \\
\end{array}$ & \begin{tabular}{|l|}
437 \\
$(15.7)$ \\
\end{tabular} & $\begin{array}{l}219 \\
(7.6) \\
\end{array}$ & \begin{tabular}{|l}
29 \\
$(1.0)$ \\
\end{tabular} & \begin{tabular}{|l|}
0 \\
$(0.0)$
\end{tabular} & \begin{tabular}{|l|}
4 \\
$(0.1)$
\end{tabular} & \begin{tabular}{|l|}
60 \\
$(20.1)$ \\
\end{tabular} & \begin{tabular}{|l|}
23 \\
$(0.8)$
\end{tabular} & \begin{tabular}{|l|}
70 \\
$(2.4)$ \\
\end{tabular} & \begin{tabular}{|l|}
46 \\
$(1.6)$
\end{tabular} & $\begin{array}{l}150 \\
(5.2) \\
\end{array}$ & \begin{tabular}{|l|} 
II \\
$(0.4)$
\end{tabular} & \begin{tabular}{|l}
784 \\
$(27.2)$ \\
\end{tabular} & \begin{tabular}{|l|}
87 \\
$(3.0)$ \\
\end{tabular} & \begin{tabular}{|l|}
0 \\
$(0.0)$
\end{tabular} & 220,449 & \begin{tabular}{|l|}
9 \\
$(0.3)$ \\
\end{tabular} & \begin{tabular}{|l|}
1 \\
$(0.0)$
\end{tabular} & \begin{tabular}{|l|}
15 \\
$(0.5)$
\end{tabular} & \begin{tabular}{|l|}
5 \\
$(0.2)$ \\
\end{tabular} & \begin{tabular}{|l|}
3 \\
$(0.1)$ \\
\end{tabular} & \begin{tabular}{|l|}
0 \\
$(0.0)$ \\
\end{tabular} & \begin{tabular}{|l|}
7 \\
$(0.2)$ \\
\end{tabular} & \begin{tabular}{|l}
12 \\
$(0.4)$ \\
\end{tabular} & \begin{tabular}{|l|}
5 \\
$(0.2)$
\end{tabular} & \begin{tabular}{|l|}
5 \\
$(0.2)$ \\
\end{tabular} & 2,878 & 223,327 \\
\hline $\begin{array}{l}\text { Early Archaic/ } \\
\text { Late } \\
\text { Paleoindian }\end{array}$ & $\begin{array}{l}27 \\
(4.4)\end{array}$ & \begin{tabular}{|l}
10 \\
$(1.6)$
\end{tabular} & \begin{tabular}{|l|}
88 \\
$(14.4)$ \\
\end{tabular} & \begin{tabular}{|l|}
41 \\
$(6.7)$ \\
\end{tabular} & $\begin{array}{l}9 \\
(1.5) \\
\end{array}$ & $\begin{array}{c}1 \\
(0.2) \\
\end{array}$ & \begin{tabular}{|l|}
0 \\
$(0.0)$
\end{tabular} & \begin{tabular}{|l|}
142 \\
$(23.3)$ \\
\end{tabular} & \begin{tabular}{|l|}
4 \\
$(0.7)$ \\
\end{tabular} & \begin{tabular}{|l|}
15 \\
$(2.5)$ \\
\end{tabular} & \begin{tabular}{|l|}
11 \\
$(1.8)$ \\
\end{tabular} & \begin{tabular}{|l|}
29 \\
$(4.8)$
\end{tabular} & \begin{tabular}{|l|}
1 \\
$(0.2)$ \\
\end{tabular} & \begin{tabular}{|l}
184 \\
$(30.2)$ \\
\end{tabular} & \begin{tabular}{|l|}
32 \\
$(5.2)$ \\
\end{tabular} & \begin{tabular}{|l|} 
\\
$(0 . Q)$ \\
\end{tabular} & 49,298 & \begin{tabular}{|l|}
3 \\
$(0.5)$ \\
\end{tabular} & \begin{tabular}{|l|}
0 \\
$(0.0)$
\end{tabular} & \begin{tabular}{|l|}
6 \\
$(1.0)$
\end{tabular} & \begin{tabular}{|c|}
1 \\
$(0.2)$
\end{tabular} & \begin{tabular}{|l}
0 \\
$(0 . Q)$
\end{tabular} & \begin{tabular}{|l|}
0 \\
$(0.0)$
\end{tabular} & $\begin{array}{l}0 \\
(0.0)\end{array}$ & \begin{tabular}{|l|}
4 \\
$(0.7)$ \\
\end{tabular} & \begin{tabular}{|l|}
2 \\
$(0.3)$
\end{tabular} & \begin{tabular}{|l}
0 \\
$(0.0)$ \\
\end{tabular} & $610^{\prime}$ & 49,908 \\
\hline Archaic & \begin{tabular}{|l|}
48 \\
$(14.9)$ \\
\end{tabular} & \begin{tabular}{|l}
7 \\
$(2.2)$ \\
\end{tabular} & \begin{tabular}{|l|}
69 \\
$(21.5)$ \\
\end{tabular} & \begin{tabular}{|l|}
14 \\
$i 4.4$ \\
\end{tabular} & $\begin{array}{c}2 \\
0.6 \\
\end{array}$ & \begin{tabular}{|l|}
0 \\
$(0.0)$ \\
\end{tabular} & \begin{tabular}{|c|}
2 \\
$0.6)$ \\
\end{tabular} & \begin{tabular}{|l|}
51 \\
115.91 \\
\end{tabular} & $\begin{array}{c}0 \\
0.0) \\
\end{array}$ & \begin{tabular}{|l|}
6 \\
$11.9)$ \\
\end{tabular} & \begin{tabular}{|l|}
7 \\
$: 2.2$ \\
\end{tabular} & \begin{tabular}{|c|}
6 \\
$11.9)$ \\
\end{tabular} & \begin{tabular}{|l|}
0 \\
$<0.0)$ \\
\end{tabular} & $\begin{array}{r}93 \\
229.0) \\
\end{array}$ & \begin{tabular}{|l|}
5 \\
$11.6)$ \\
\end{tabular} & $\begin{array}{l}\mathbf{0} \\
(0.0) \\
\end{array}$ & 11,251 & \begin{tabular}{|l|}
2 \\
$<0.61$ \\
\end{tabular} & \begin{tabular}{|l|}
0 \\
$(0.0)$ \\
\end{tabular} & \begin{tabular}{|l|}
3 \\
$(0.9)$ \\
\end{tabular} & \begin{tabular}{|l|}
4 \\
$(1.2)$ \\
\end{tabular} & $\begin{array}{l}0 \\
(0.0) \\
\end{array}$ & \begin{tabular}{|l|}
0 \\
0.0 \\
\end{tabular} & \begin{tabular}{|l|}
$\mathrm{I}$ \\
$(0.3)$ \\
\end{tabular} & \begin{tabular}{|c}
0 \\
$0.0)$ \\
\end{tabular} & \begin{tabular}{|l|} 
\\
$(0.3 \mathrm{~J}$ \\
\end{tabular} & \begin{tabular}{|l|}
0 \\
$(0.0)$ \\
\end{tabular} & 321 & 11,572 \\
\hline Totals: & 743 & 285 & 1,119 & 485 & 45 & 2 & 13 & 1,341 & 46 & 122 & 110 & 234 & 21 & 1,926 & 199 & I & 463,696 & 37 & I & 29 & 21 & 3 & 1 & 15 & 21 & 17 & 5 & 6,842 & 470,538 \\
\hline
\end{tabular}


TABLE 9-3

Ratios of Selected Artifact Types by Archaic Subperiods

\begin{tabular}{|c|c|c|c|c|c|c|c|c|c|c|}
\hline & 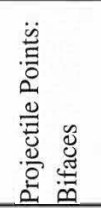 & 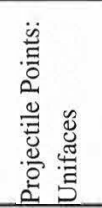 & 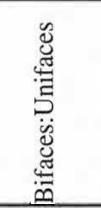 & 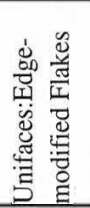 & 壱 & 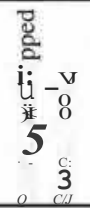 & 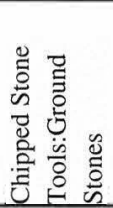 & 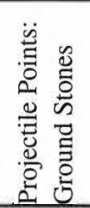 & 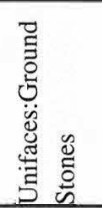 & 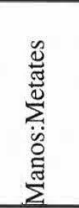 \\
\hline $\begin{array}{l}\text { Late Archaic/Late } \\
\text { Prehistoric }\end{array}$ & $1.16: 1$ & 1.95: I & $1.68: 1$ & 0.8: I & $2.3: 1$ & $60.0: 1$ & $84.0: 1$ & 26.0:1 & 13.0: I & $\mathrm{n} / \mathrm{a}$ \\
\hline $\begin{array}{l}\text { Late Archaic } \\
\text { Middle/Late }\end{array}$ & $0.83: I$ & $1.14: 1$ & 1.39: I & 0.5: 1 & $0.9: 1$ & $66.0: 1$ & $57.0: 1$ & 11.0:1 & $10.0: 1$ & $1.8: 1$ \\
\hline Archaic & $0.58: 1$ & $0.68: 1$ & $1.20: 1$ & 0.6: I & 1.5: I & $69.0: 1$ & $60.0: 1$ & $8.0: 1$ & $12.0: 1$ & 4.0:1 \\
\hline $\begin{array}{l}\text { Middle Archaic } \\
\text { Early/Middle }\end{array}$ & $0.67: 1$ & $1.07: 1$ & 1.60: I & $0.6: 1$ & $4.0: 1$ & $68.0: 1$ & $41.0: 1$ & 8.0: 1 & $7.0: 1$ & $1.3: 1$ \\
\hline Archaic & $0.53: 1$ & $0.53: 1$ & 1.01:J & $0.7: 1$ & $0.5: 1$ & $55.0: 1$ & 211.0:1 & $26.0: 1$ & $49.0: 1$ & $2.0: 1$ \\
\hline $\begin{array}{l}\text { Early Archaic } \\
\text { Early Archaic/ }\end{array}$ & $0.54: 1$ & $0.52: 1$ & 1.13:1 & $0.8: 1$ & 3.3:1 & $78.0: 1$ & $115.0: 1$ & 14.0:1 & $24.0: 1$ & 1.8: I \\
\hline Late Paleoindian & $0.29: 1$ & $0.26: 1$ & 0.97:1 & $0.8: 1$ & $2.6: 1$ & $82.0: 1$ & 145.0:1 & $9.0: 1$ & $36.0: 1$ & $3.0: 1$ \\
\hline
\end{tabular}

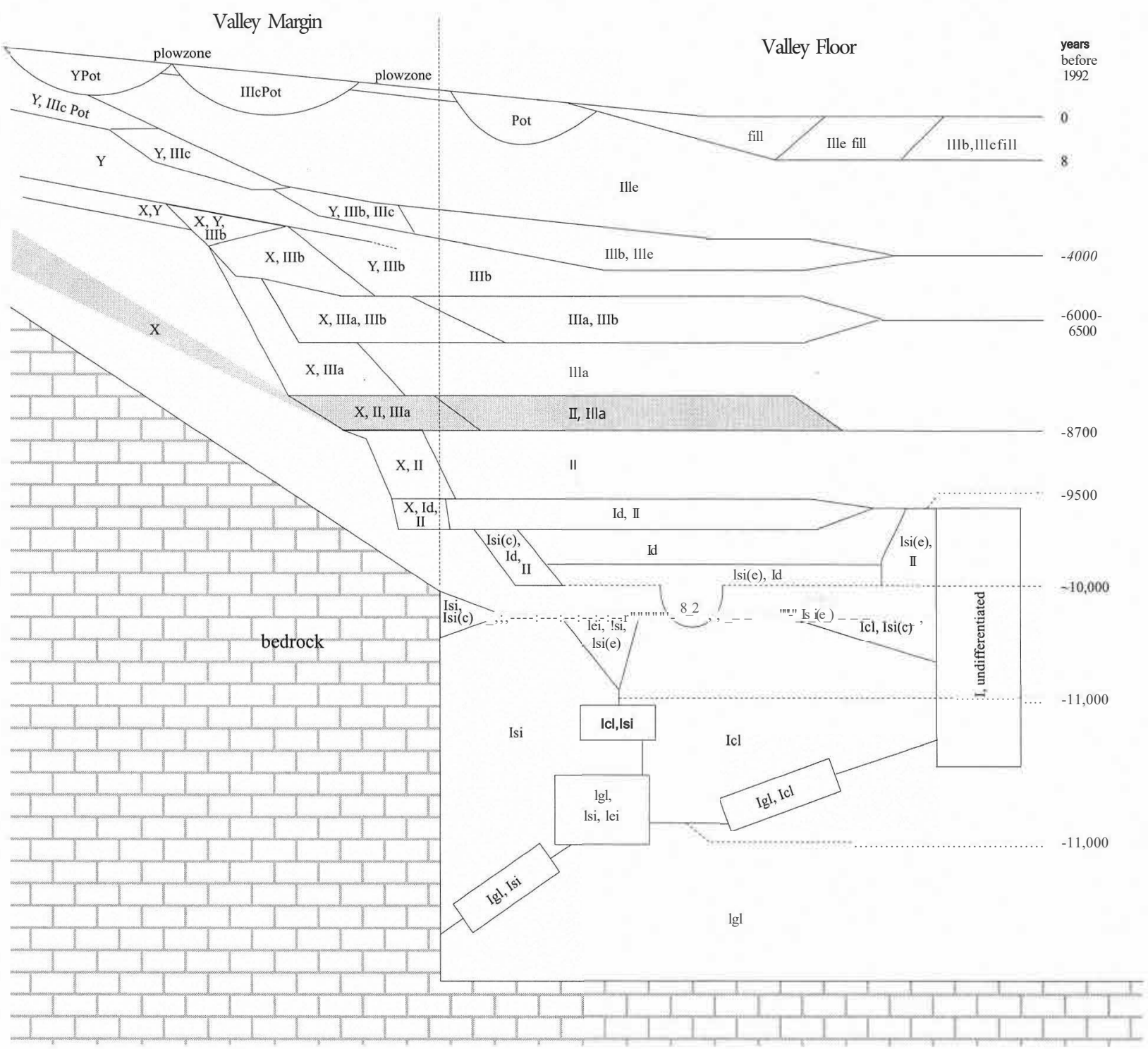

FlouRE 9-3. Stratigraphic profile of the Valley Margin/Valley Floor showing Late Paleoindian/Early Archaic units. 


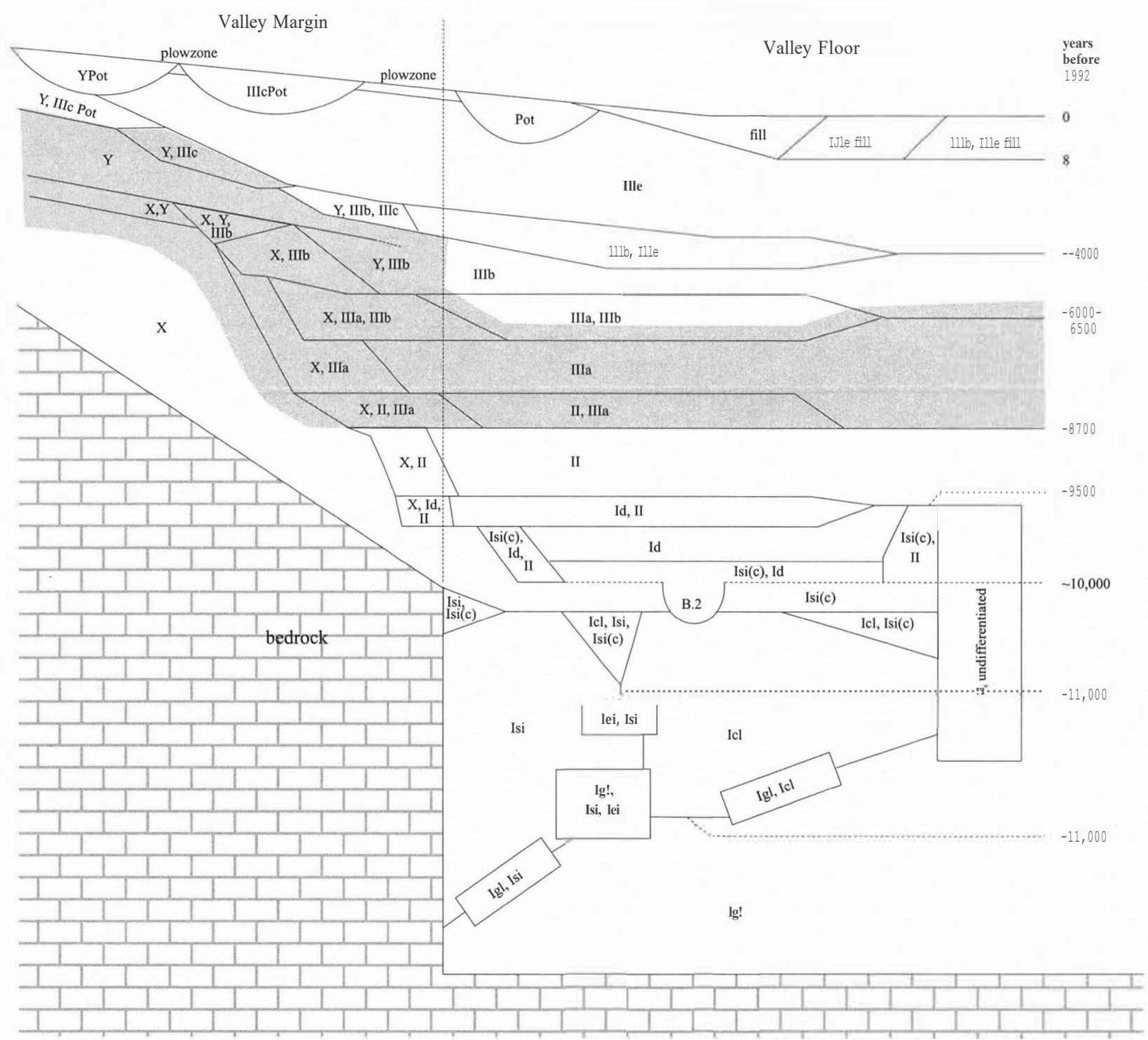

FlouRE 9-4. Stratigraphic profile of the Valley MarginNalley Floor showing Early Archaic units.

TABLE 9-4

Fn quencies of Projectile Points by Types from Early Archaic/Late Paleoindian Contexts Period

Early Archaic/Late Paleoindian Early Archaic/Late Paleoindian Early Archaic/Late Paleoindian Early Archaic/Late Paleoindian Early Archaic/Late Paleoindian Early Archaic/Late Paleoindian Early Archaic/Late Paleoindian Early Archaic/Late Paleoindian Early Archaic/Late Paleoindian Early Archaic/Late Paleoindian Early Archaic/Late Paleoindian Early Archaic/Late Paleoindian Early Archaic/Late Paleoindian Early Archaic/Late Paleoindian Early Archaic/Late Paleoindian Early Archaic/Late Paleoindian Analysis Identification

Projectile point, Angostura

Projectile point, Clovis

Projectile point, bifurcate stem fragment

Projectile point, concave lanceolate preform

Projectile point, early bifurcate stem preform

Projectile point, Golondrina/Barber

Projectile point, Hoxie

Projectile point, Hoxie A

Projectile point, Hoxie B

Projectile point, Hoxie/Gower

Projectile point. Hoxie?

Projectile point, Jetta

Projectile point fragment

Projectile point, miscellaneous lanceolate

Projectile point, St. Mary's Hall

Projectile point, Thrall
Count of Item 6 1 1 1 1 4 3 3 1

1

1

1

11

11

4 1 
TABLE 9-5

Frequencies of Projectile Points by Types from Early Archaic Contexts

\begin{tabular}{|c|c|c|}
\hline Period & Analysis Identification & Count of Item \\
\hline Early Archaic & Projectile point, Angostura & 20 \\
\hline Early Archaic & Projectile point, Baker & 6 \\
\hline Early Archaic & Projectile point, Bandy & 7 \\
\hline Early Archaic & Projectile point, Bell/Andice & 1 \\
\hline Early Archaic & Projectile point, bifurcate stem fragment & 30 \\
\hline Early Archaic & Projectile point, concave lanceolate preform & 2 \\
\hline Early Archaic & Projectile point, contracting stem, concave & 4 \\
\hline Early Archaic & Projectile point, early bifurcate stem preform & 1 \\
\hline Early Archaic & Projectile point, expanding concave A & 2 \\
\hline Early Archaic & Projectile point, expanding concave B & 14 \\
\hline Early Archaic & Projectile point, expanding concave $\mathrm{C}$ & 3 \\
\hline Early Archaic & Projectile point, expanding concave D & 1 \\
\hline Early Archaic & Projectile point, expanding stem A & 1 \\
\hline Early Archaic & Projectile point, expanding stem B & 1 \\
\hline Early Archaic & Projectile point, expanding stem $\mathrm{C}$ & 3 \\
\hline Early Archaic & Projectile point, expanding stem D & 1 \\
\hline Early Archaic & Projectile point, Golondriua/Barber & 3 \\
\hline Early Archaic & Projectile point, Gower & 11 \\
\hline Early Archaic & Projectile point, Gower/Jetta & 5 \\
\hline Early Archaic & Projectile point, Gower/Uvalde & 4 \\
\hline Early Archaic & Projectile point, Hoxie & 17 \\
\hline Early Archaic & Projectile point, Hoxie A & 6 \\
\hline Early Archaic & Projectile point, Hoxie B & 4 \\
\hline Early Archaic & Projectile point, Hoxie C & 5 \\
\hline Early Archaic & Projectile point, Hoxie/Gower & 6 \\
\hline Early Archaic & Projectile point, indeterminate & 3 \\
\hline Early Archaic & Projectile point, Jetta & 8 \\
\hline Early Archaic & Projectile point, long stemmed & 2 \\
\hline Early Archaic & Projectile point, Marcos & 1 \\
\hline Early Archaic & Projectile point, Martindale A & 6 \\
\hline Early Archaic & Projectile point, Martindale B & 4 \\
\hline Early Archaic & Projectile point, miscellaneous bifurcate & 4 \\
\hline Early Archaic & Projectile point, miscellaneous expanding stem & 3 \\
\hline Early Archaic & Projectile point, miscellaneous lanceolate & 30 \\
\hline Early Archaic & Projectile point, miscellaneous side-notched & 1 \\
\hline Early Archaic & Projectile point, rectangular stem A & 1 \\
\hline Early Archaic & Projectile point, rectangular stem $\mathrm{C}$ & 1 \\
\hline Early Archaic & Projectile point, square stem & 4 \\
\hline Early Archaic & Projectile point, San Partice & 1 \\
\hline Early Archaic & Projectile point, Scotts Bluff & 1 \\
\hline Early Archaic & Projectile point, St. Mary's Hall & 5 \\
\hline Early Archaic & Projectile point, Thrall & 16 \\
\hline Early Archaic & Projectile point, Uvalde & 7 \\
\hline Early Archaic & Projectile point, Uvalde-like & 3 \\
\hline Early Archaic & Projectile point, Wells & 2 \\
\hline Early Archaic & Projectile point, Wilson? & 1 \\
\hline Early Archaic & Proiectile point fragment & 90 \\
\hline
\end{tabular}

The earlier part of the Early Archaic is characterized by two general groups of projectile points, lanceolate and stemmed (see Tables 9-4 and 9-5). The lanceolate forms are principally types Angostura and Thrall, a type defined in this study (Figure 9-5), along with some miscellaneous Janceolate forms. The small numbers ofGolondrina-Barber (7) and St. Mary's Hall (9) points could represent either specimens intrusive from earlier origins or forms that began in the Late Paleoindian and continued in vogue into the Early Ar- chaic. The other Paleoindian types (Clovis, San Patrice, Scottsbluff, and Wilson?) are fairly securely dated as earlier than the Early Archaic and are considered intrusive. The stemmed points include the types Hoxie, Gower, Jetta, and similar bifurcate stemmed forms (see Tables 9-4 and 9-5; Figure 9-6). There is heavy lateral grinding on all of the lanceolate and most of the stemmed point hafts. Later in the Early Archaic, types Uvalde, Baker, Bandy, and Martindale are more prevalent (see Tables 9-4 and 9-5; Figure 9-7). Both 
TABLE 9-6

Frequencies of Bifaces, Clear Fork Tools, Core Tools, and Cores from Early Archaic/Late Paleoindian Contexts

\begin{tabular}{|c|c|c|}
\hline Period & Analysis Identification & Count of Item \\
\hline Early Archaic/Late Paleoindian & Biface Stage 1 & 19 \\
\hline Early Archaic/Late Paleoindian & Biface Stage 2 & 48 \\
\hline Early Archaic/Late Paleoindian & Biface Stage 3 & 9 \\
\hline Early Archaic/Late Paleoindian & Bifacial tool & 6 \\
\hline Early Archaic/Late Paleoindian & Bifacial tool Form A & 4 \\
\hline Early Archaic/Late Paleoindian & Bifacial tool Form B & 1 \\
\hline Early Archaic/Late Paleoindian & Bifacial tool Form E & 1 \\
\hline Early Archaic/Late Paleoindian & Piece esquillee & 1 \\
\hline Early Archaic/Late Paleoindian & Brushy Creek biface & 1 \\
\hline Early Archaic/Late Paleoindian & Clear Fork biface & 6 \\
\hline Early Archaic/Late Paleoindian & Clear Fork biface, proximal & 3 \\
\hline Early Archa.ic/Late Paleoindian & Biface fragment & 39 \\
\hline Early Archaic/Late Paleoindian & Biface fragment & 2 \\
\hline Early Archaic/Late Paleoindian & Core tool & I \\
\hline Early Archaic/Late Paleoindian & Core tool, Type 2 & 3 \\
\hline Early Archaic/Late Paleoindian & Core tool, Type 4 & I \\
\hline Early Archaic/Late Paleoindian & Chert cobble, chunk & 2 \\
\hline Early Archaic/Late Paleoindian & Chert cobble, unmodified/tested & 6 \\
\hline Early Archaic/Late Paleoindian & Core fragment & 6 \\
\hline Early Archaic/Late Paleoindian & Core, multidirectional & 2 \\
\hline Early Archaic/Late Paleoindian & Core, thermal & 10 \\
\hline Early Archaic/Late Paleoindian & Core, unidirectional & I \\
\hline Early Archaic/Late Paleoindian & Micro-core, intermediate & 2 \\
\hline Early Archaic/Late Paleoindian & Micro-core, large & 1 \\
\hline Early Archaic/Late Paleoindian & Micro-core, small & 2 \\
\hline
\end{tabular}

TABLE 9-7

Frequencies of Bifaces, Clear Fork Tools, Cores, and Core Tools from Early Archaic Contexts

\begin{tabular}{|c|c|c|}
\hline Period & Analysis Identification & Count of Item \\
\hline Early Archaic & Biface Stage 1 & 80 \\
\hline Early Archaic & Biface Stage 2 & 236 \\
\hline Early Archaic & Biface Stage 3 & 52 \\
\hline Early Archaic & Bifacial tool & 13 \\
\hline Early Archaic & Bifacial tool Form A & 16 \\
\hline Early Archaic & Bifacial tool Form B & 9 \\
\hline Early Archaic & Bifacial tool Form C & 5 \\
\hline Early Archaic & Bifacial tool Form D & 2 \\
\hline Early Archaic & Bifacial tool Form E & 15 \\
\hline Early Archaic & Bifacial tool Form F & 2 \\
\hline Early Archaic & Bifacial tool Form $\mathrm{H}$ & 3 \\
\hline Early Archaic & Bifacial tool Form J & 4 \\
\hline Early Archaic & Piece esquillee & 11 \\
\hline Early Archaic & Clear Fork bi face & 19 \\
\hline Early Archaic & Clear Fork biface, proximal & 9 \\
\hline Early Archaic & Clear Fork biface, proximal (refit) & I \\
\hline Early Archaic & Clear Fork uniface & 4 \\
\hline Early Archaic & Biface fragment & 211 \\
\hline Early Archaic & Biface fragment & 8 \\
\hline Early Archaic & Core tool, type I & 5 \\
\hline Early Archaic & Core tool, type 2 & 6 \\
\hline Early Archaic & Core tool, type 3 & 3 \\
\hline Early Archaic & Core tool, type 5 & 9 \\
\hline Early Archaic & Chert cobble, chunk & 7 \\
\hline Early Archaic & Chert cobble, unmodified/tested & 6 \\
\hline Early Archaic & Core fragment & 25 \\
\hline Early Archaic & Core, multidirectional & 7 \\
\hline Early Archaic & Core, thermal & 21 \\
\hline Early Archaic & Micro-core, intermediate & 13 \\
\hline Early Archaic & Micro-core, large & 3 \\
\hline Early Archaic & Micro-core, small & 5 \\
\hline
\end{tabular}


TABLE 9-8

Frequencies of Perforators and Burins from Early Archaic/Late Paleoindian Contexts

\begin{tabular}{l|l|c}
\hline \multicolumn{1}{c|}{ Period } & \multicolumn{1}{c}{ Analysis Identification } & Count of Item \\
\hline Early Archaic/Late Paleoindian & Perforator Group I & 1 \\
Early Archaic/Late Paleoindian & Perforator Group 2 & 2 \\
Early Archaic/Late Paleoindian & Perforator Group 4 & 1 \\
Early Archaic/Late Paleoindian & Perforator Group 5 & 1 \\
Early Archaic/Late Paleoindian & Perforator Group 6 & 1 \\
Early Archaic/Late Paleoindian & Perforator Group 7 & 4 \\
Early Archaic/Late Paleoindian & Perforator Unifacial & 5 \\
Early Archaic/Late Paleoindian & Burin & \\
Early Archaic/Late Paleoindian & Burin spall & \\
\hline \hline
\end{tabular}

TABLE 9-9

Frequencies of Perforators and Burins from Early Archaic Contexts

\begin{tabular}{l|l|c}
\hline \multicolumn{1}{c|}{ Period } & \multicolumn{1}{c}{ Analysis Identification } & Count of Item \\
\hline Early Archaic & Perforator Group 1 & 8 \\
Early Archaic & Perforator Group 2 & 3 \\
Early Archaic & Perforator Group 3 & 4 \\
Early Archaic & Perforator Group 4 & 6 \\
Early Archaic & Perforator Group 5 & \\
Early Archaic & Perforator Group 6 & \\
Early Archaic & Perforator Group 7 & 1 \\
Early Archaic & Perforator Unifacial & 38 \\
Early Archaic & Burin & 8 \\
Early Archaic & Burin spall & \\
Early Archaic & Burin spall, unanalyzed & 148 \\
\hline \hline
\end{tabular}

TABLE 9-10

Frequencies of Unifaces and Edge-modified Flake Tools from Early Archaic/Late Paleoindian Contexts

\begin{tabular}{l|l|c}
\hline \multicolumn{1}{c}{ Period } & \multicolumn{1}{c}{ Analysis Identification } & Count of Item \\
\hline Early Archaic/Late Paleoindian & Denticulated flake & 8 \\
Early Archaic/Late Paleoindian & Edge-modified flake & 78 \\
Early Archaic/Late Paleoindian & Microspur/microdenticulate & 11 \\
Early Archaic/Late Paleoindian & Notched flake & 14 \\
Early Archaic/Late Paleoindian & Retouched blade & 1 \\
Early Archaic/Late Paleoindian & Spurred flake & 2 \\
Early Archaic/Late Paleoindian & Thick uniface & 8 \\
Early Archaic/Late Paleoindian & Thin uniface & 28 \\
Early Archaic/Late Paleoindian & Thin uniface fragment & 11 \\
Early Archaic/Late Paleoindian & Uniface, unanalyzed & 67 \\
Early Archaic/Late Paleoindian & Unifacial multiple tool & 14 \\
Early Archaic/Late Paleoindian & Blade & 1 \\
Early Archaic/Late Paleoindian & Denticulated flake & \\
Early Archaic/Late Paleoindian & Edge-modified flake & \\
Early Archaic/Late Paleoindian & Edge-modified flake, unanalyzed & \\
Early Archaic/Late Paleoindian & Microspur/microdenticulate & \\
Early Archaic/Late Paleoindian & Notched flake & 4 \\
Early Archaic/Late Paleoindian & Spurred flake & \\
Early Archaic/Late Paleoindian & Thick uniface & \\
Early Archaic/Late Paleoindian & Thin uniface & \\
Early Archaic/Late Paleoindian & Thin uniface fragment & \\
Early Archaic/Late Paleoindian & Unifacial multiple tool & \\
\hline \hline
\end{tabular}

the lanceolate and the stemmed forms almost universally exhibit evidence for resharpening that commonly is in the form of alternate beveling of the blades, although this mode ofresharpening wanes in the later part of the Early Archaic (see Chapter 13).

Among the early bifurcate stem points, a stratigraphic trend was observed: points with more parallel-sided, heavilyground stems (e.g., Hoxie) occurred in greatest frequency in 
TABLE 9-11

Frequencies of Uni faces and Edge-modified Flake Tools from Early Archaic Contexts

\begin{tabular}{l|l|c}
\hline \multicolumn{1}{c|}{ Period } & \multicolumn{1}{c}{ Analysis Identification } & Count of Item \\
\hline Early Archaic & Denticulated flake & 32 \\
Early Archaic & Edge-modified flake & 424 \\
Early Archaic & Microspur/microdenticulate & 102 \\
Early Archaic & Notched flake & 39 \\
Early Archaic & Retouched blade & 8 \\
Early Archaic & Spurred flake & 16 \\
Early Archaic & Thick uniface & 13 \\
Early Archaic & Thick uniface fragment & 2 \\
Early Archaic & Thin uniface & 114 \\
Early Archaic & Thin uniface fragment & 52 \\
Early Archaic & Uniface, unanalyzed & \\
Early Archaic & Unifacial multiple tool & 252 \\
Early Archaic & Denticulated flake & 101 \\
Early Archaic & Edge-modified flake & I \\
Early Archaic & Edge-modified flake, unanalyzed & 124 \\
Early Archaic & Microspur/microdenticulate & 1 \\
Early Archaic & Notched flake & 19 \\
Early Archaic & Retouched blade & 9 \\
Early Archaic & Spurred flake & I \\
Early Archaic & Thick uniface & 8 \\
Early Archaic & Thin uniface & 2 \\
Early Archaic & Thin uniface fragment & \\
Early Archaic & Uniface, unanalyzed & \\
Early Archaic & Unifacial multiple tool & \\
\hline \hline
\end{tabular}

TABLE 9-12

Frequencies of Ground Stone Tools from Early Archaic/Late Paleoindian Contexts

\begin{tabular}{l|l|c}
\hline \multicolumn{1}{c|}{ Period } & \multicolumn{1}{c}{ Analysis Identification } & Count of Item \\
\hline Early Archaic/Late Paleoindian & Grinding basin & 1 \\
Early Archaic/Late Paleoindian & Mano fragment & 3 \\
Early Archaic/Late Paleoindian & Battered cobble & I \\
Early Archaic/Late Paleoindian & Small core hammerstone & 5 \\
Early Archaic/Late Paleoindian & Worked hematite & 4 \\
\hline \hline
\end{tabular}

TABLE9-I3

Frequencies of Ground Stone Tools from Early Archaic Contexts

\begin{tabular}{l|l|c}
\hline \multicolumn{1}{c|}{ Period } & \multicolumn{1}{c}{ Analysis Identification } & Count of Item \\
\hline Early Archaic & Grooved stone & 1 \\
Early Archaic & Mano & 4 \\
Early Archaic & Mano fragment & 5 \\
Early Archaic & Metate fragment & 5 \\
Early Archaic & Pestle & 1 \\
Early Archaic & Possible ground stone & 7 \\
Early Archaic & Waco sinker & 2 \\
Early Archaic & Battered cobble & 3 \\
Early Archaic & Large core hammerstone & 1 \\
Early Archaic & Small core hammerstone & 11 \\
Early Archaic & Worked hematite & 12 \\
\hline \hline
\end{tabular}

lower Early Archaic and mixed Late Paleoindian/Early Archaic levels, followed by Gower and Jetta in slightly higher deposits. Early bifurcate points with more expanding stems and little to no lateral stem edge grinding (e.g., Martindale, Bandy, and Uvalde) also occurred higher in the Early Ar- chaic deposits (predominantly Unit IIIb and above; see Chapter 13).

These later Early Archaic points seem to coincide with the onset of a technological change in Clear Fork tools. As discussed in Chapter 15, Clear Fork bifaces continue through- 


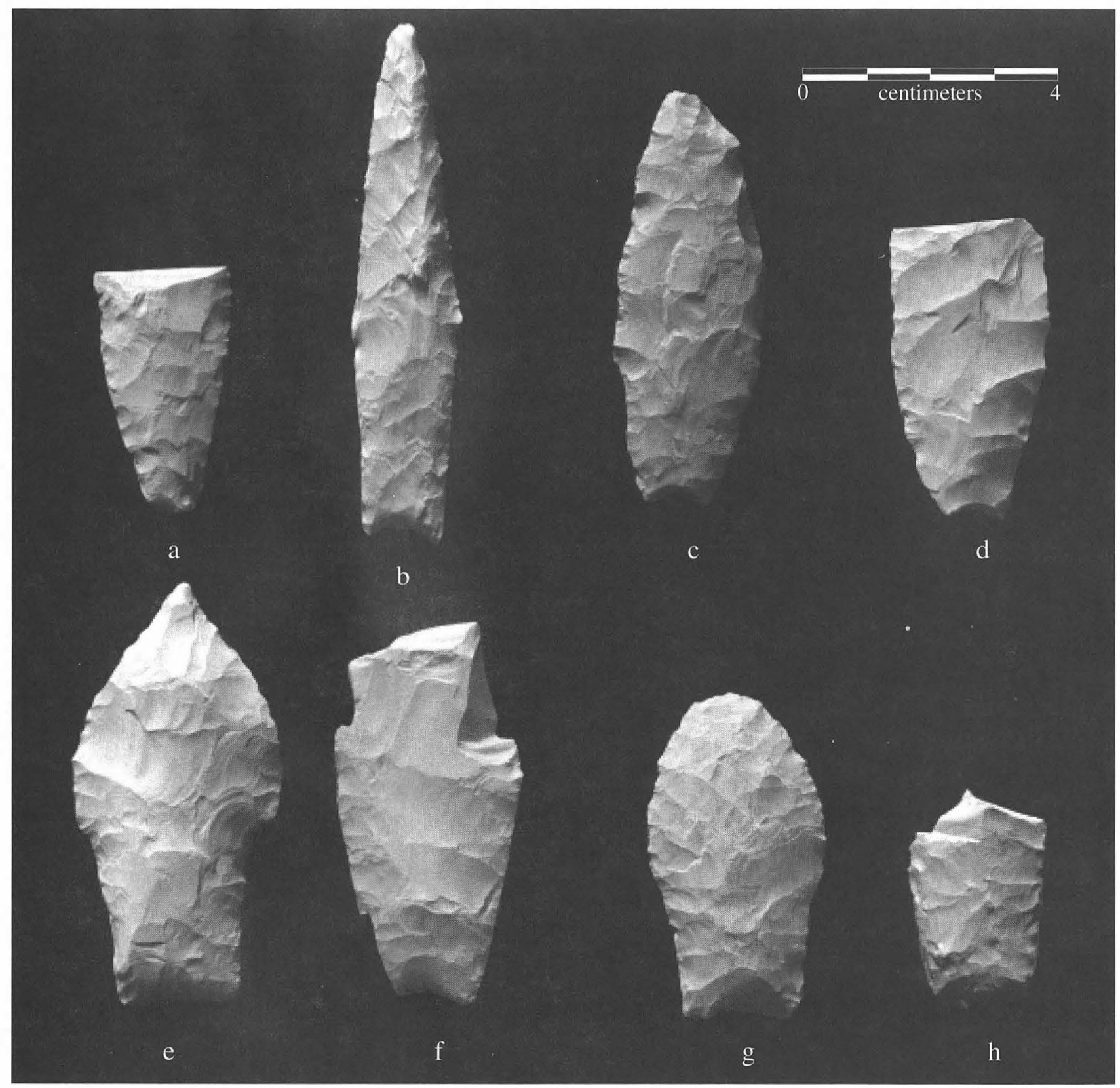

FIGURE 9-5. Early Archaic lanceolate projectile points. (a-d) Angostura; (e-h) Thrall. Specimen numbers: (a) 17QJ-1; (b) 11Q-1; (c) 29TIC-J; (d) 3 IUIC-2; (e) 31Rl-3; (f) 25R1-2; (g) 31P1-1; (h) 22P-I.

out much of the site's history, whereas the unifacial form first appears in deposits related to the later part of the Early Archaic (e.g., Unit Illa/band related Valley Floor deposits). Diagnostic points from the same or nearby proveniences include Gower, Martindale, and Golondrina. An Angostura was found in the level immediately underlying, while Baker, Bandy, and an untyped expanding stem form in the level above.

There is some evidence to suggest early antecedants for the Early Archaic stemmed dart points, as two such dart points (termed expanding stem, concave base A) were recovered in Late Paleoindian context in Unit II (Figure 9-8).
Among other tool forms, bifacial as well as unifacial Clear Fork tools are well represented in the Early Archaic (Figure 9-9). A Clear Fork preform evidently broken during manufacture (Figure 9-9a) is a good indicator that at least some production of these tools transpired at this site. Other bifaces include tools and preforms (Figure 9-10), and there is a wide array of perforators, burins, and unifacial tools (Figures 9-11 and 9-12). Grinding stones are not numerous but include manos and metates that generally are not pitted (Figures 913 and 9-15). Waco sinkers and a grooved stone are among the distinctive Early Archaic artifact forms (Figure 9-14), and the only pestle from the site was found in an Early Archaic 


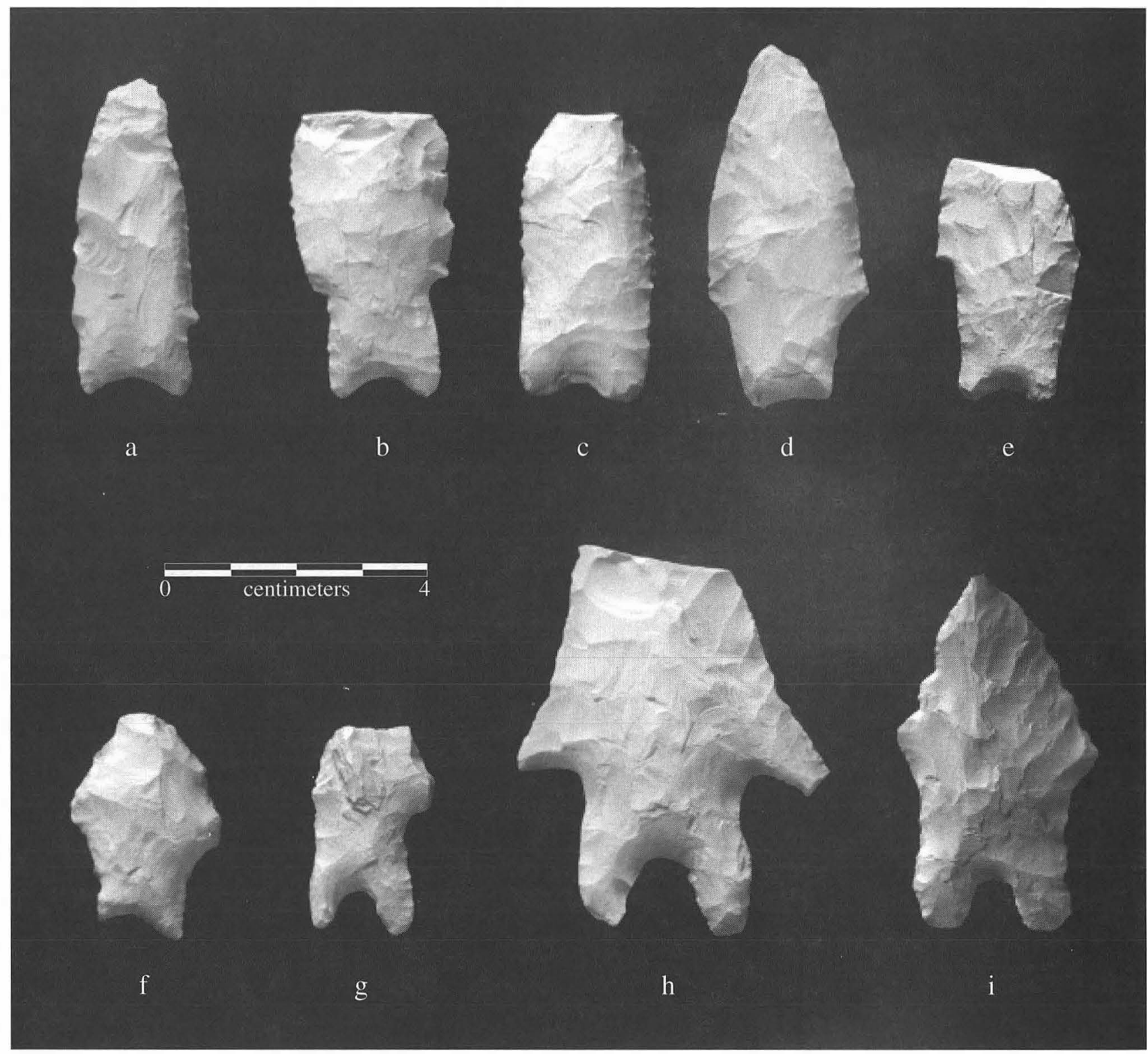

FlouRE 9-6. Representative early split stem points from lower Early Archaic deposits. (a, b) Hoxie; (c) Hoxie A; (d) Hoxie B; (e) Hoxie C; (f, g) Gower; (h, i) Jetta. Specimen numbers: (a) 3702B-7; (b) 21 P-1; (c) IOR-10; (d) 29S1-5; (e) 32P-1 2; (f) 3 IR2-1; (g) 280-3; (h) 15N21; (i) 370 !D-1.

feature (Figure 9-14). Cores, which are not numerous, were commonly recycled as hammerstones or heavy chopping tools (Figure 9-16).

Small marine shell beads (one olive nerite and four marginella) are almost unique to the Early Archaic in the present sample, and a few bone artifacts were also recovered (Figure 9-17). Among the most informative materials recovered from the Early Archaic were bones of small animals (Figure 9-18) and charred plant parts (Figure 919).

Minor cultural or probable cultural features of Early Archaic affiliation include two areas of burned sediment, one (Feature 237) being part of a large burned rock accumulation (see Feature 231, below) and the other (Feature 221) that could not definitely be attributed to either cultural or natural origins. Two burned rock rings (Features 137 and 180; Figure 9-20) were found in Early Archaic context and may represent small fireplaces surrounded by reflectors, prop stones, or containment rings, or they may be remnants of more-complex features. These features were each about 60 $\mathrm{cm}$ in diameter and rested on flat surfaces; almost no data were collected from which function could be inferred. Neither the areas of burned sediment nor the burned rock rings provide very much information on the Early Archaic at the site. The remaining features, all consisting of burned rocks, are more informative.

Sixty-eight burned rock clusters were the most numerous kind of feature in the Early Archaic as well as all other 


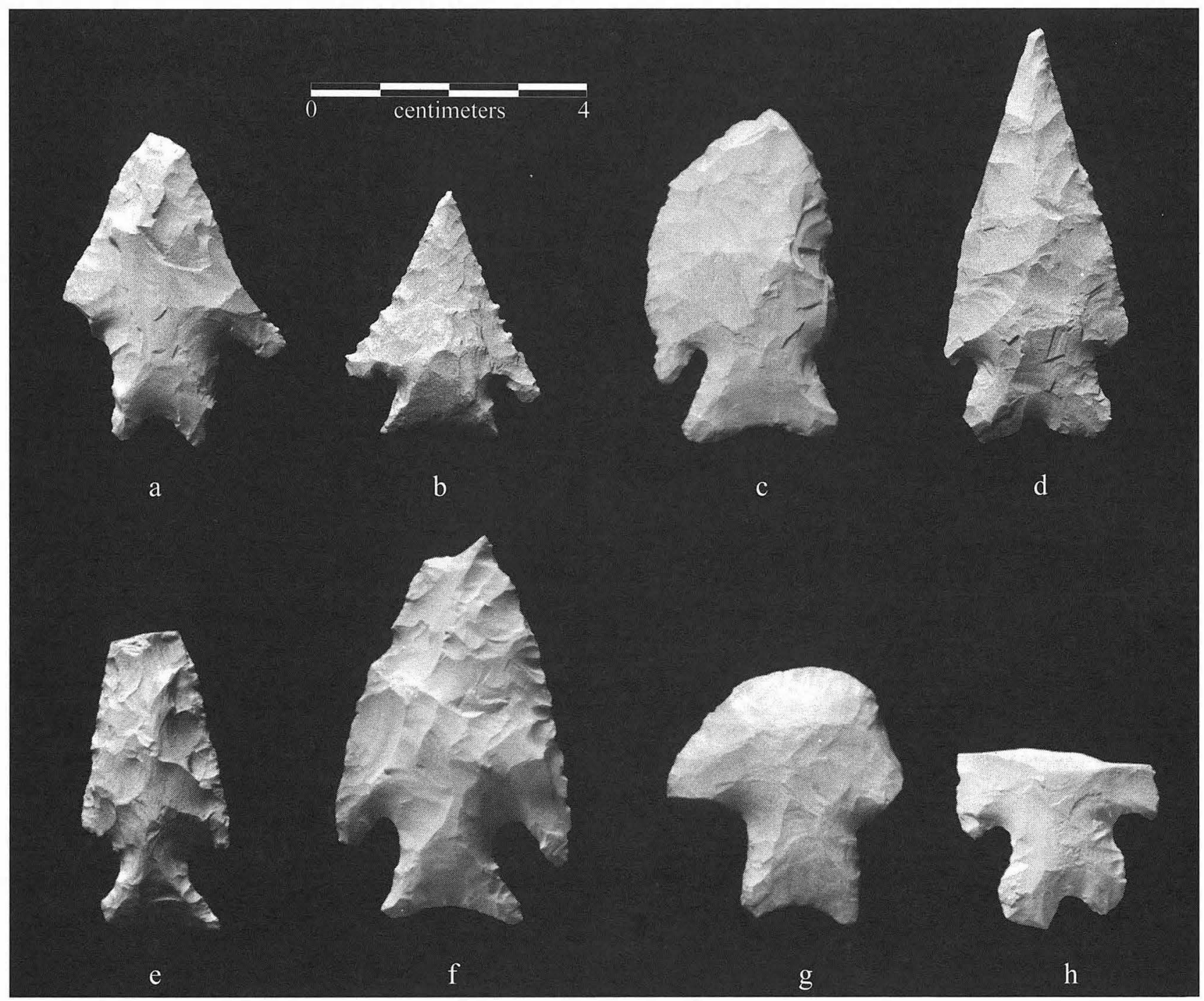

FIGURE 9- 7. Early comer-notched projectile points from later Early Archaic contexts. (a) contracting stem; (b) Bandy; (c, d) Martindale; (e, f) expanding concave base B; (g) expanding concave base D, (h) Uvalde. Specimen numbers: (a) 21M-2; (b) 14K1-1; (c) !OK-I; (d) 361-1; (e) 12M-10; (f) 17L-l; (g) 37NB-7; (h) $51-2$.

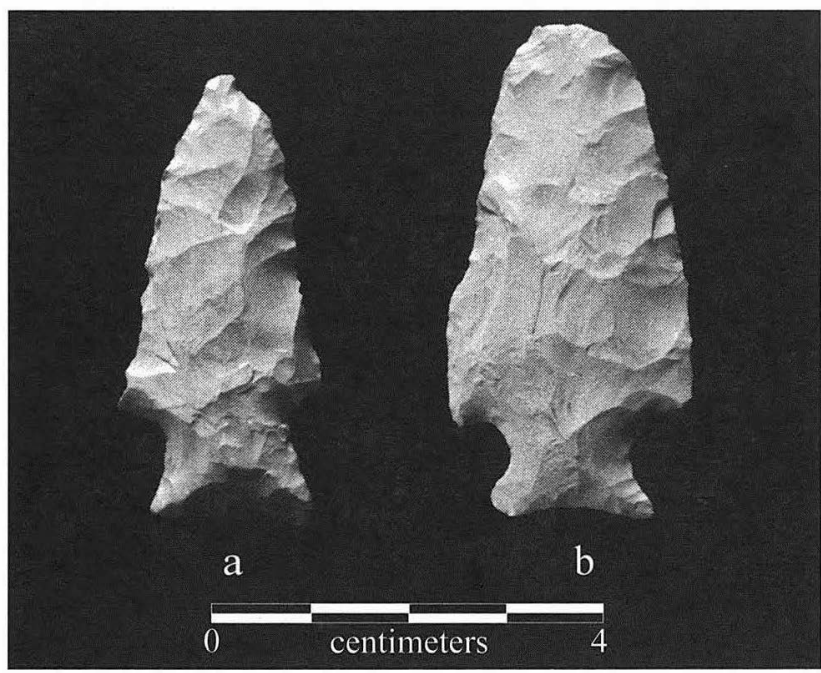

FIGURE 9-8. Expanding stem points from Unit II, Late Paleoindian contexts. (a) 21R-8; (b) 26W2A-1. time periods at the site. Those assigned Early Archaic affiliation were found from the lowest to the highest position in the Early Archaic stratigraphic context. Probably most of these were small hearths, remnants ofhearths, or clusters of discarded hearth stones (see Figure 9-20). Several retained evidence of in situ burning and are inferred to represent small, discrete, and probably entirely domestic hearths. This is not to say that they were used uniformly as they exhibit considerable variation in size, shape, number of rocks, and sizes of rocks. Burned rock clusters ranged from ca. 45 to 140 $\mathrm{cm}$ in diameter, and all seemed to have formed on flat surfaces. Archeomagnetic and micromorphological data indicate that Features 220,222, and 226 represent in-place hearths whereas one, Feature 242, may represent something other than a hearth-perhaps a disposal pile for burned rocks. One (Feature 220) contained wood charcoal identifiable as juniper and as willow. Rabbit bone was found in two ofthese features (220 and 226). An Angostura point base was found 


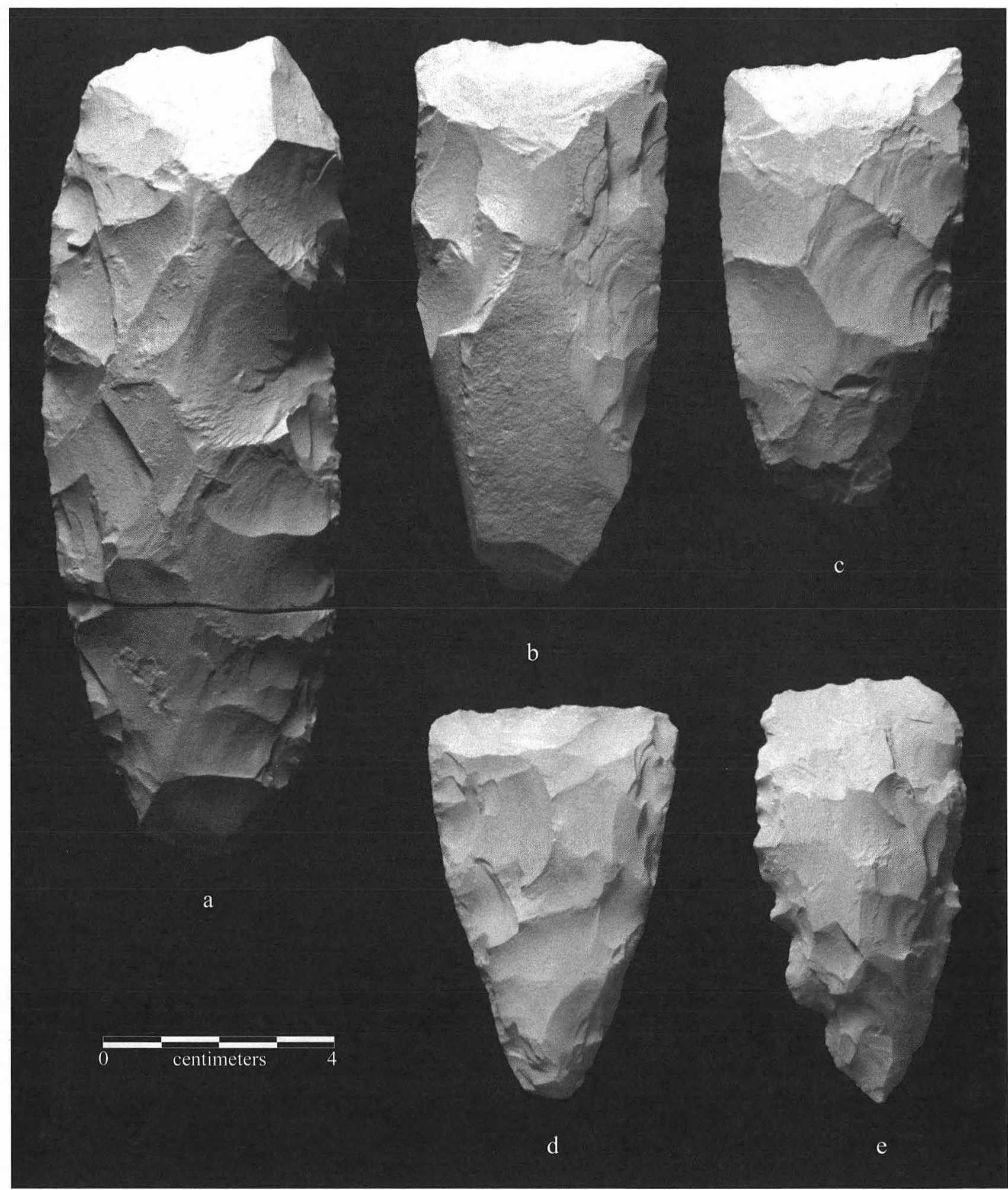

FIGURE 9-9. Representative Clear Fork tools from Early Archaic contexts. (a-d) Clear Fork bifaces; (e) Clear Fork uniface. Specimen numbers: (a) 743-11 conjoined with I7L2-1; (b) 33Q2-5; (c) 30Q2-1; (d) 22P-4; (e) 2IL-38.

associated with Feature 29, and the only stone pestle from the site was found in burned rock cluster, Feature 107.

In Early Archaic contexts were found five (or six, counting one that may be of Late Paleoindian origin) small burned rock basins (basin-shaped features generally less than $1 \mathrm{~m}$ in diameter). These were small basins, $10-20 \mathrm{~cm}$ deep lined with burned rocks and often showing evidence of in situ burning (see Figure 9-20). Some of these (Features 123, 139, 


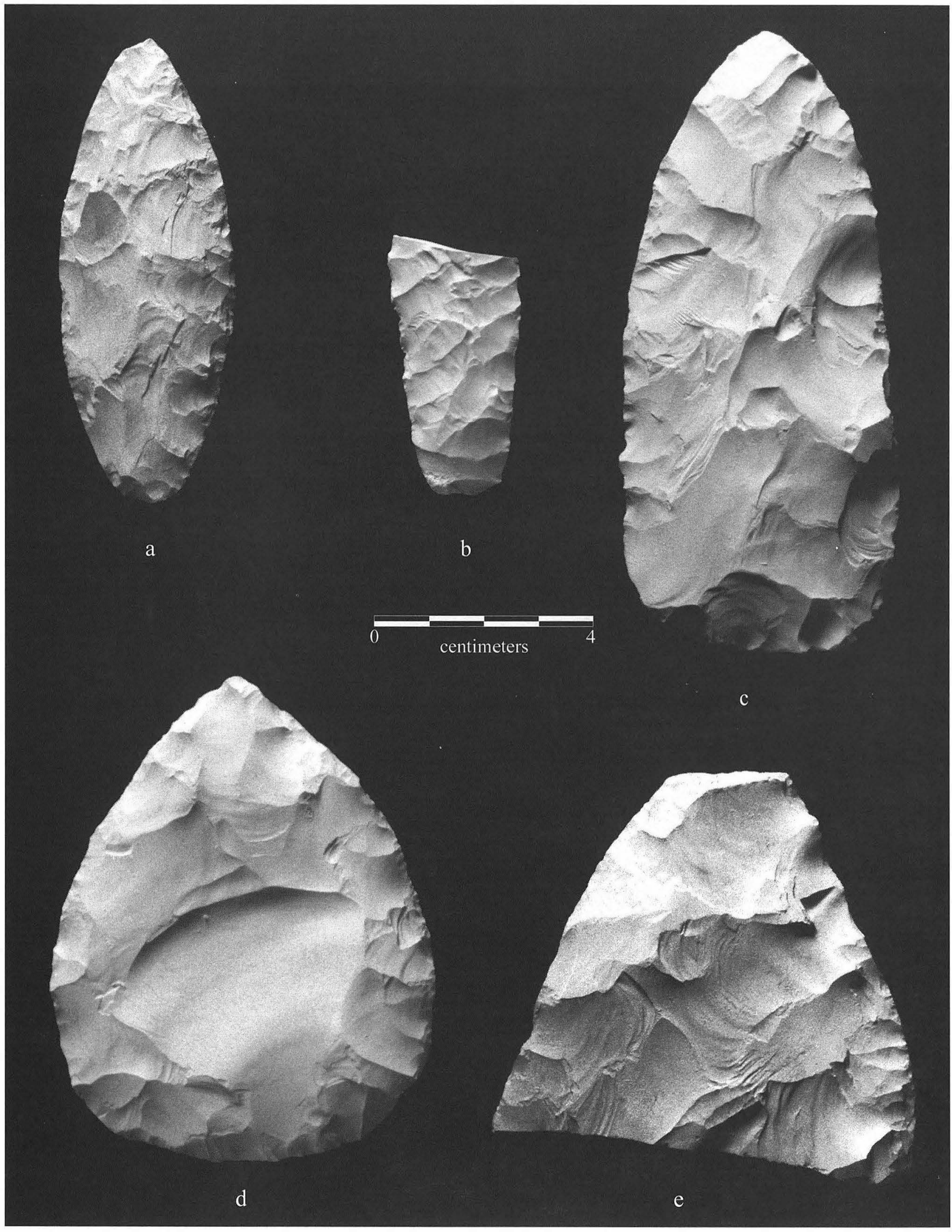

FIGURE 9-10. Representative bifacial preforms from Early Archaic and mixed contexts. (a, c, e) Early Archaic; (b) Late Paleoindian/Early Archaic; (d) Early/Middle Archaic. Specimens b-e are Stage 2, Specimen a is Stage 3. Specimen numbers: (a) 28R2-1; (b) 31 TIA-2; (c) 6401 conjoined with 679-1; (d) 13K-5; (e) 29QJ-6. 


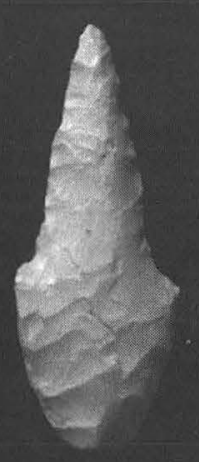

a

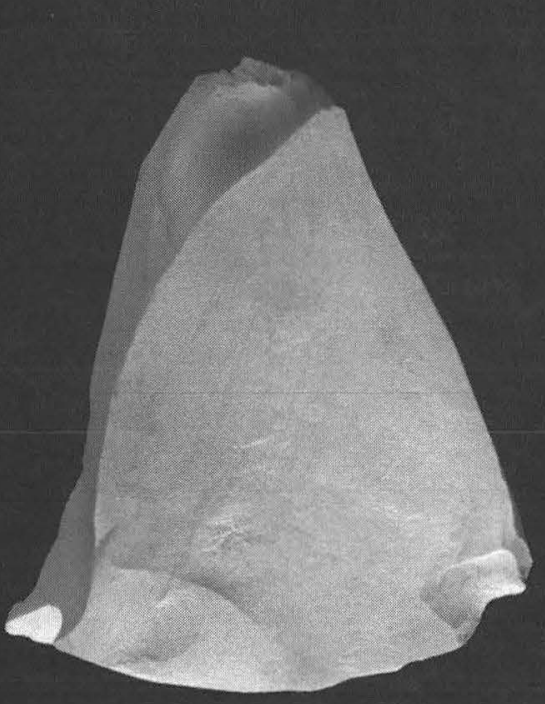

e

b
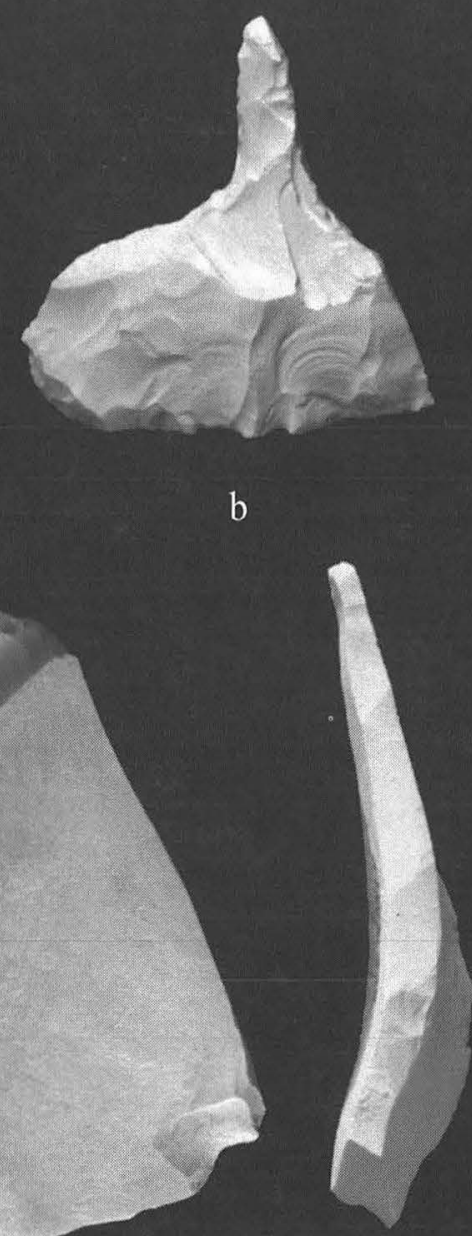

f

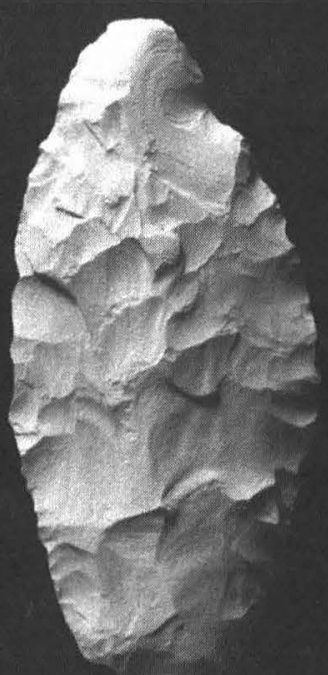

j

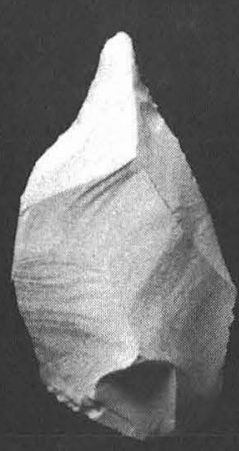

c
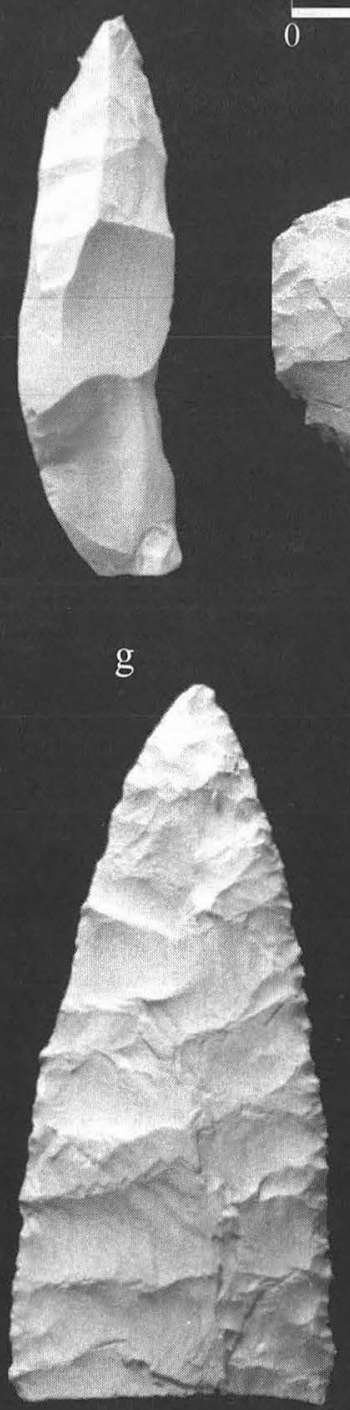

$\mathrm{k}$

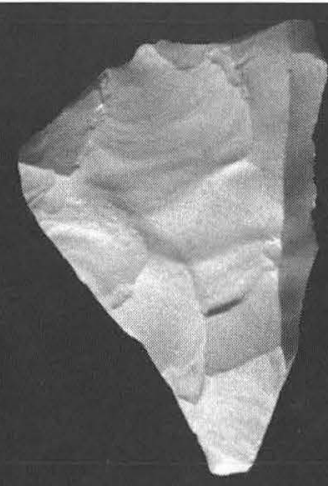

d
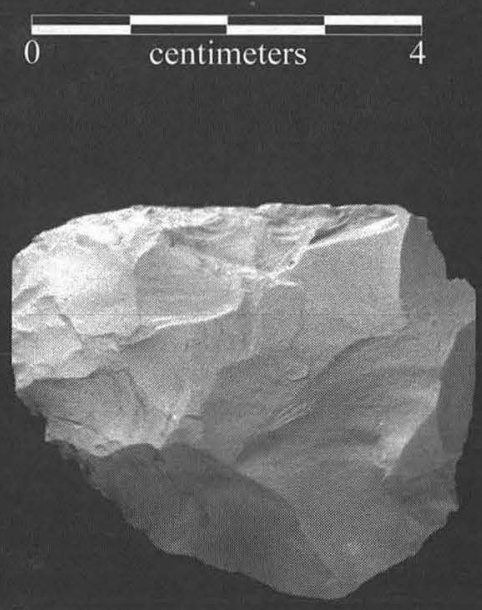

h

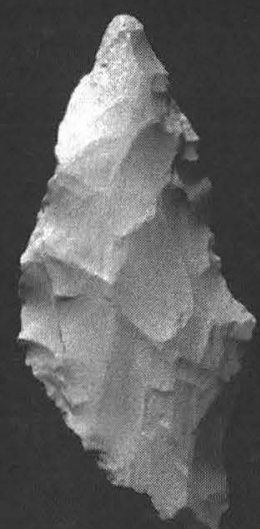

1

FIGURE 9-1 1. Representative bifacial and unifacial tools from Early Archaic contexts. (a) perforator Group 3; (b) perforator Group 5; (c) unifacial perforator; (d, e) burin; (f, g) burin spails; (h, i)pieces esquillees; (j, k) knife-like bafacial tools, Form A; (l) bifacial tool Form E. Specimen numbers: (a) 14Pl-1; (b) 51 VA-I; (c) 22P-33; (d) 11P-3; (e) 31 Rl-4; (t) 27Rl-6; (g) 31Q2-1 1; (h) 15P2-1; (i) 14K2-10; (j) 37Q1A-1; (k) 28R2-2; (I) 31S 1-3. 


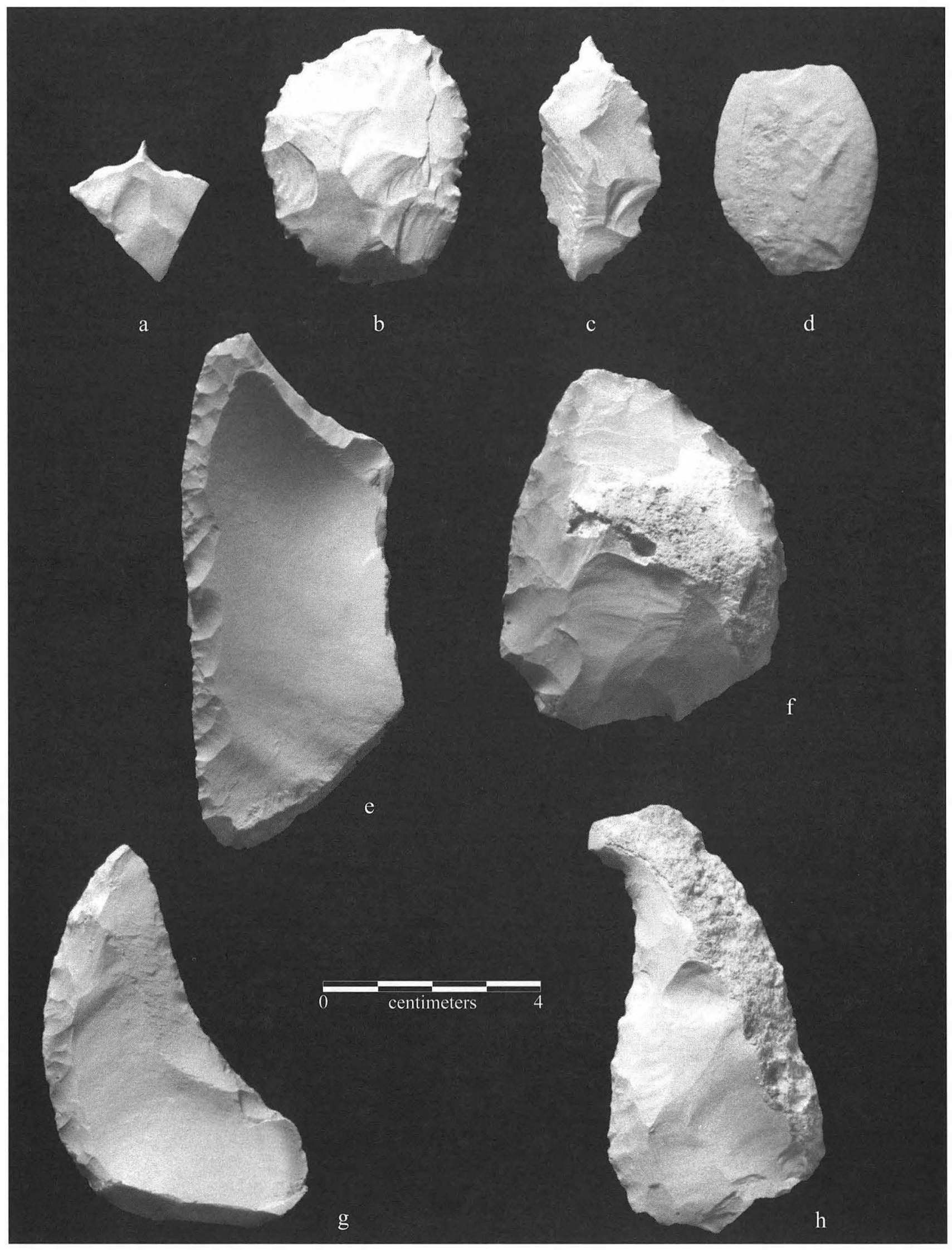

FIGURE 9-12. Representative flake tools from Early Archaic contexts. (a-c) microspur/rrucrodenticulate; (d) edge-modified flake; (e-g) thin unifaces; (h) unifacial multiple tool. Specimen nwnbers: (a) J7N2-13; (b) 31RJ-12; (c)29R1-2; (d) 33R2-JO; (e) 22L-17; (f) 34R2-2; (g) 31 S1-7; (h) 33Q2-14. 


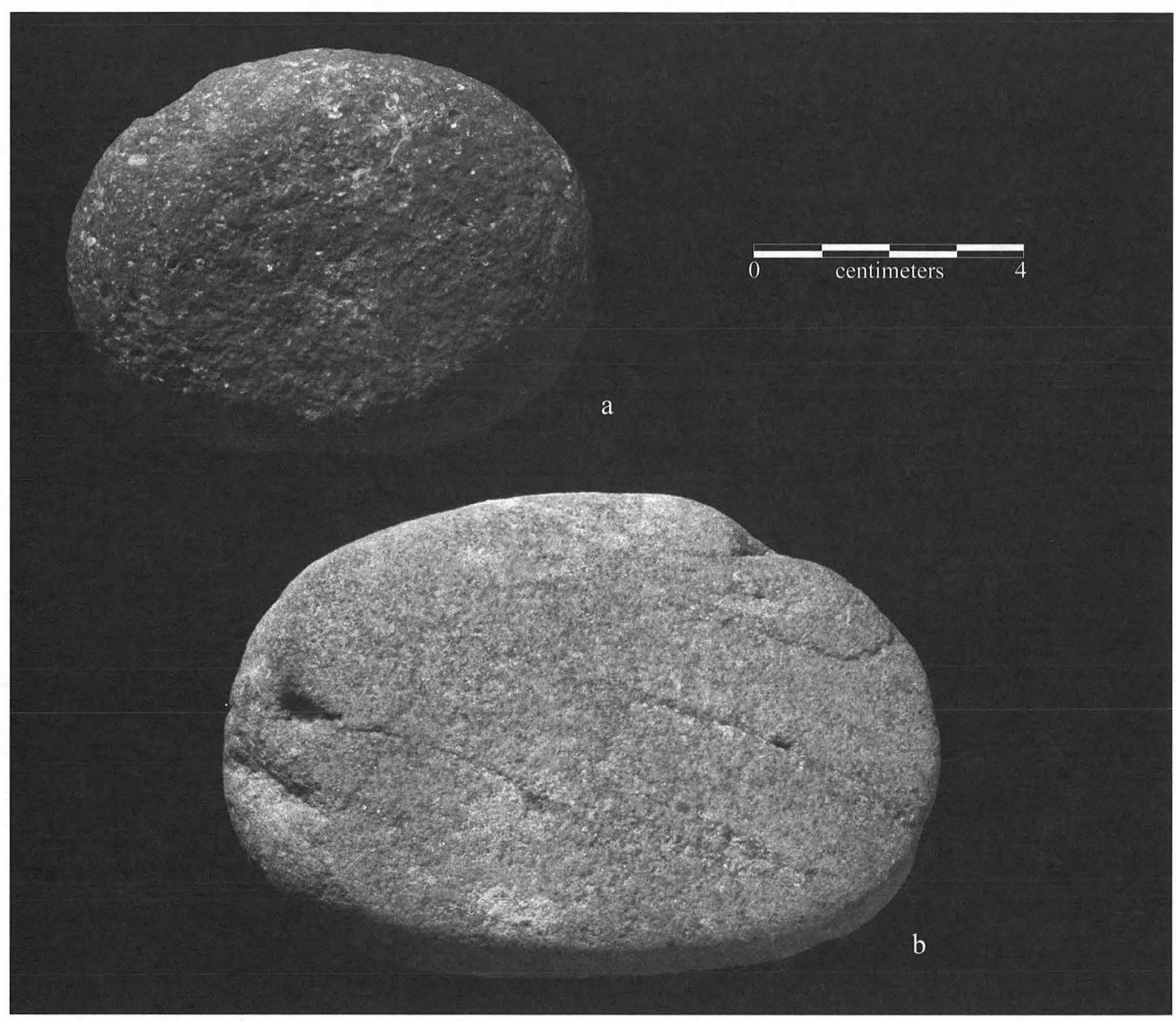

FIGURE 9-13. Representative ground stone manos from Early Archaic contexts. (a) 23P-2; (b) 29Rl-7.

224, and 227 [which may be of Late Paleoindian age]) are inferred to have been small, discrete, domestic, basin-shaped hearths; others (Features 13 and 230) were part of larger, more-complex features. The four discrete examples ranged from ca. 50 to ca. $100 \mathrm{~cm}$ in diameter and 10 to $17 \mathrm{~cm}$ in depth. Charcoal as well as some archeomagnetic or micromorphological evidence for burning was found in Features 139,224, and 227. Fauna! recovery from Features 224 and 227 shows a diverse array, including turtle, fish, rodent, amphibian, bird eggshell, snake, jackrabbit, and cottontail rabbit. The bone in Feature 224 showed little evidence of burning and aquatic snails were also present, possibly indicating cooking by boiling. Such snails might also have been introduced along with aquatic plants or animals (including fish, turtles, or mussels). Some of the archeomagnetic samples from the features indicate that rocks were occasionally moved while cooling but that final cooling occurred in the position in which the rocks were found. This suggests intentional or uninten- tional disturbance of these small hearths as they cooled. The small basins may be small "pit hearths," typically used for roasting or baking starchy plant foods or fatty meats (Wandsnider 1997).

The burned rock rings, clusters, and some of the small basins either by design or by happenstance seem not to have been used intensively, repeatedly, or for extended periods. Perhaps each relates to only one or a very few of the intermittent occupations that almost certainly characterize the history of this site. This interpretation contr sts sharply with inferred repetitiveness, intensity, and protracted life of the next four categories of burned rock features to be discussed. These are the large burned rock basins, burned rock scatters, burned rock accumulations, and the earliest part of one large burned rock midden.

For descriptive purposes (in Chapter 26), it was necessary to discuss features individually, and the morphological groupings of large burned rock basins, burned rock scatters, 


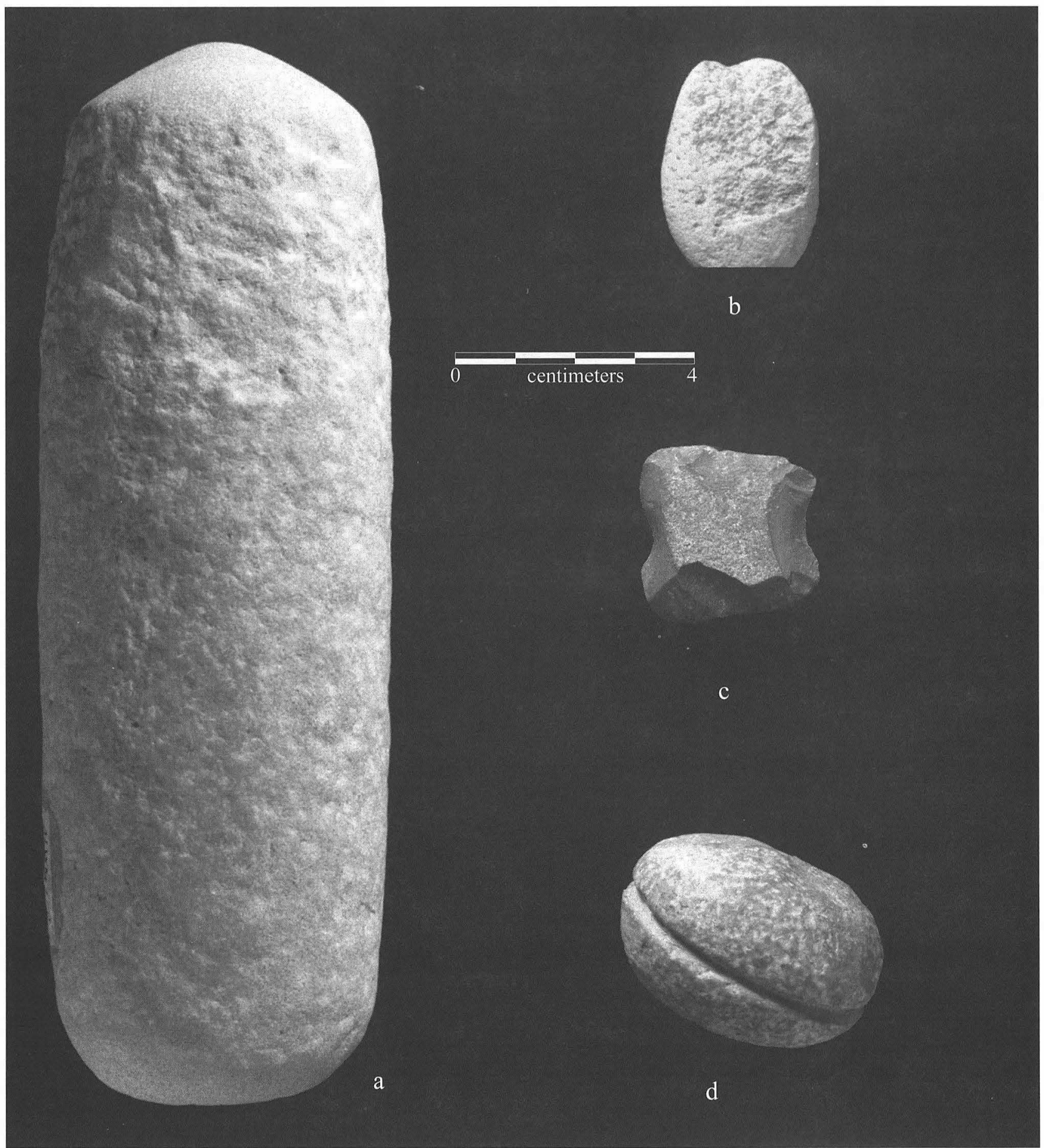

FIGURE 9-14. Ground stone tools from Early Archaic contexts. (a) pestle; (b, c) notched stone; (d) grooved stone. Specimen numbers: (a) 22P-5; (b) 26R1-19; (c) 36P-2; (d) 30Q1-1.

burned rock accumulations, and burned rock middens were employed in organizing those descriptions. However, there is persuasive evidence that these were simply distinctive parts oflarge, complex cooking appliances and, furthermore, that they represent isolable elements that over time accreted and became indistinguishable in ever-increasingly complex masses. These masses are the burned rock middens so char- acteristic of most of the Archaic record in Central Texas.

In their seminal and essentially accurate account of this process, Kelley and Campbell (1942) observed that in contexts of rapid natural deposition, individual hearths became buried and were preserved as small, discrete features. In contrast, they noted, hearths built on more-stable surfaces were not quickly buried so they intersected, overlapped, 


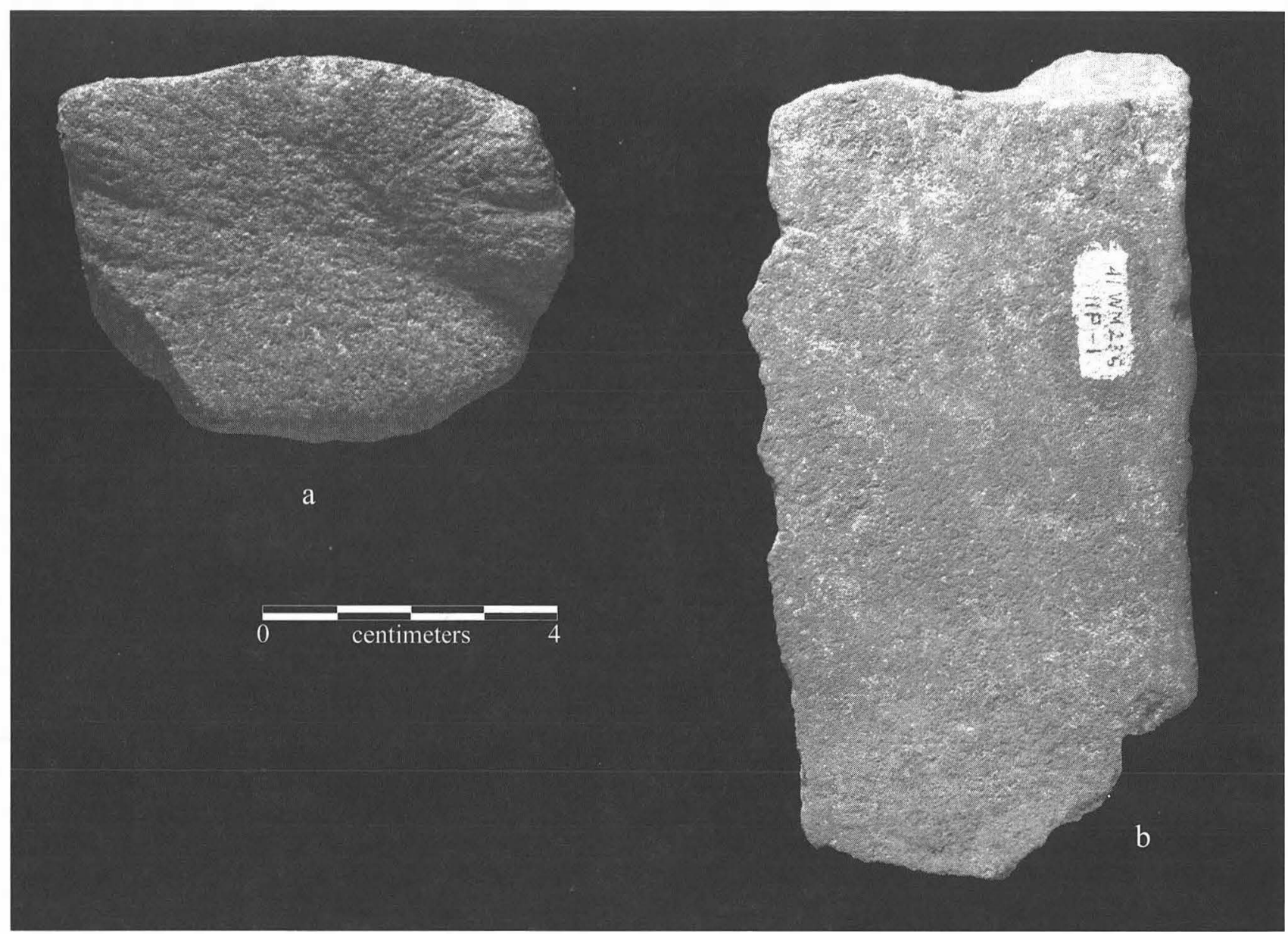

FIGURE 9-15. Ground stone tools from Early Archaic and mixed deposits. (a) grinding basin 9T-2 from Valley Margin Unit X (Late Paleoindian/Early Archaic); (b) metate fragment! IP-I from Unit Illa (Early Archaic).

and eventually coalesced into the great masses we call burned rock middens. Burned rock features at WilsonLeonard tend to confirm Kelley's and Campbell's central concept but clarify several important details and may even contribute a partial answer to the perplexing question of why people continued to build "hearths" at excactly the same place for centuries or millennia (Collins 1991 b:3). First, the "hearths" that coalesced into middens were not ordinary, simple fireplaces but large earth ovens. Second, small discrete fireplaces continued to be built and used but not in a manner that resulted in coalescence into middens. Third, the subsistence activities maintained through the use of earth ovens seem not to be the same as those supported by the small, discrete hearths.

During the Early Archaic at Wilson-Leonard, much activity transpired on the Valley Margin and on the Valley Floor near the toe of the Valley Margin slope (exposed in TxDOT excavation Area A and TARL excavations); less activity is indicated farther out on the Valley Floor (TxDOT Area B). One or more Early Archaic feature was found in every 2-x-2-m square dug in TxDOT Area A and in all but four of the $1-x-1-m$ squares dug in the TARL excavations (see Tables 26-1 and 26-2). No Early Archaic feature was found in the eight square meters dug in TxDOT Area B, and Early Archaic diagnostic artifacts are less frequent than in comparable excavation volumes in TxDOT Area A. On the Valley Margin, where rates of deposition were modest throughout the Archaic, a complex of Early Archaic features (here referred to as the "proto midden A") predated the formation of Midden I, a large, domed burned rock midden with Early Archaic materials in its lowest levels and abundant evidence for continued use through the Middle and Late Archaic and possibly even into the Late Prehistoric. A thin, relatively rock-free deposit separated the proto midden from the overlying Midden I. At the toe of the Valley Margin slope was found "proto midden B," composed of another several Early Archaic burned rock features, but completely buried without an overlying domed midden. Natural deposition at the toe of this slope was somewhat more rapid in Archaic times than it was on the Valley Margin. In Area B, the other domed burned rock midden, Midden 2, also had an underlying burned rock complex ("proto midden C"), but it was of Middle, rather than Early, Archaic age. Here rates of deposition during 


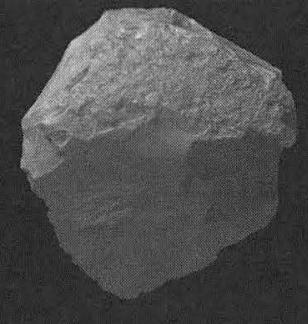

a

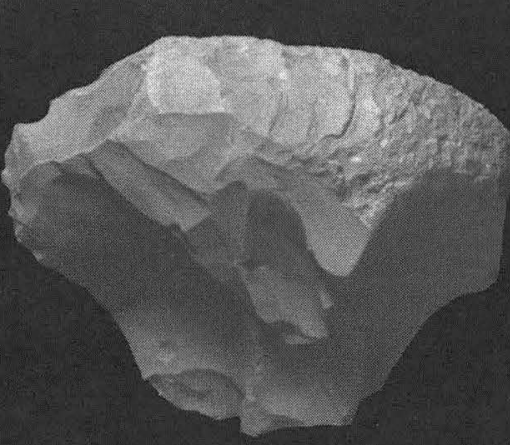

b
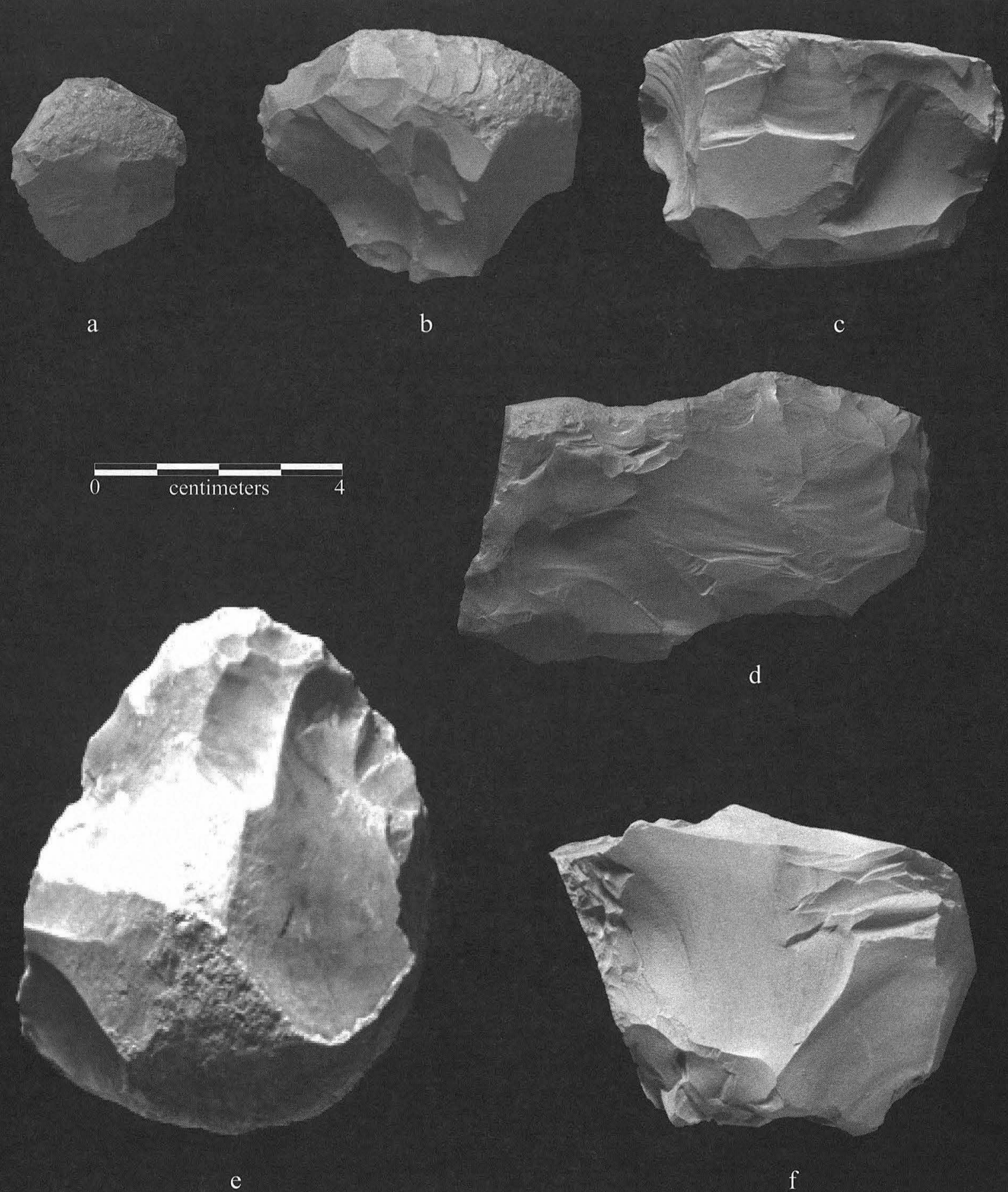

d

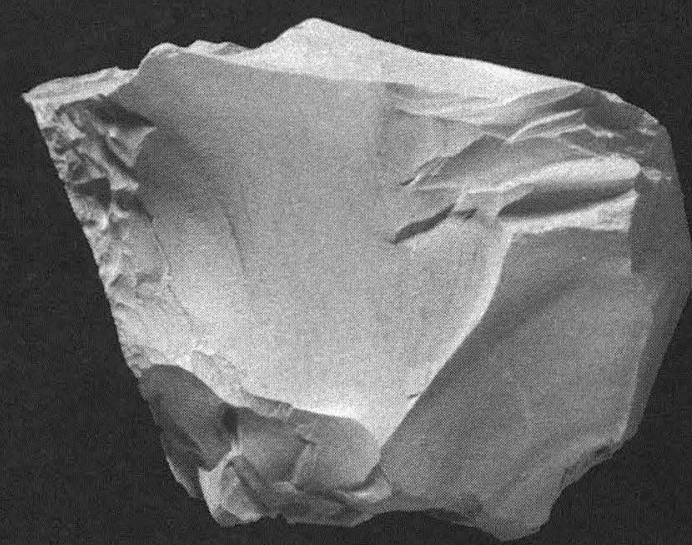

f

FIGURE 9-16. Representative batte.red stone, cores, and core tools from Early Archaic contexts. (a, b) small core hammerstone; (c) intermediate microcore; (d) large core hammerstone; (e) core tool type 2; (f) multidirectional core. Specimen numbers: (a) 33Rl-3; (b) 15L1-3; (c) 220-9; (d) 32R2-20; (e) $1 \mathrm{IN}-2$; (f) 15Q2-7.

the Archaic seem to have been more comparable to those on the Valley Margin. The contrasting geoarcheological histories in these three settings are the basis for a comparative look at midden formational processes.
It is to be kept in mind that the term, "proto midden," as used here is a literary device to emphasize the developmental thrust of this discussion. In fact, all three of these burned rock masses qualify as burned rock middens in the usual 


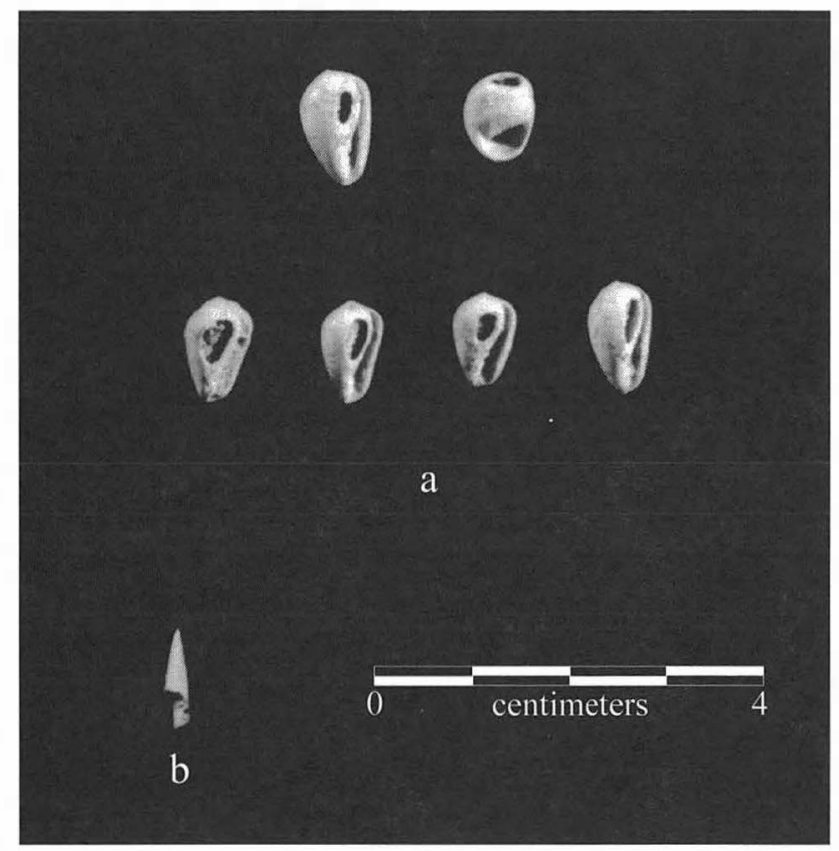

FGURE 9-17. Modified shell and bone from Early Archaic contexts. (a-e) shell beads; (f) pointed bone tool fragment.

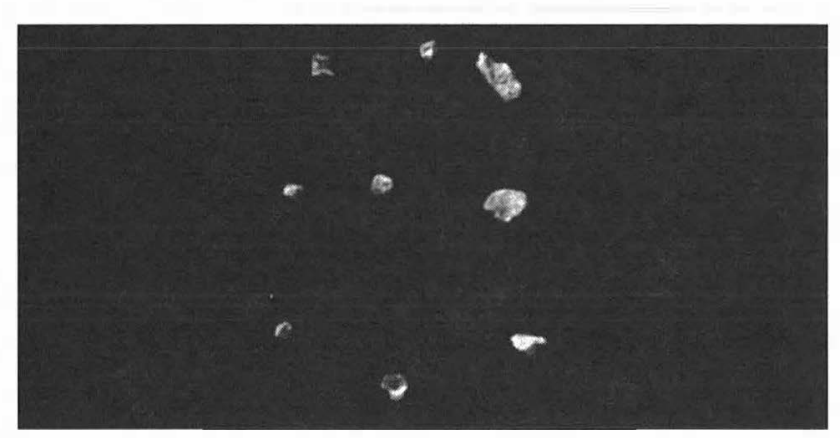

FGURE 9-18. Examples of small fish bones from Early Archaic contexts.

sense (Howard 1991; Weir 1976), but they are distinctive in two ways--each had well-preserved internal features, and none was lost in the jumbled mass at the base of a large, domed midden. Proto midden $\mathrm{C}$ and its developmental relationship to Burned Rock Midden 2 are discussed in a later section on the Middle Archaic subperiod.

Proto midden A was centered beneath Burned Rock Midden 1 (see Figure 9-2) and in the excavated exposure, consisted of an isolated, large burned rock basin (Feature 19/104) overlain by, and slightly stratigraphically isolated from, an integrated complex consisting of one large burned rock basin (Feature 12), one small burned rock basin (Feature 13), and an extensive burned rock accumulation (Feature 8). The top of Feature 8 was separated from the base of Midden I by about 10-30 cm ofless rocky fill. Feature 19/104 was a large basin, ca. $2 \mathrm{~m}$ in diameter and $40 \mathrm{~cm}$ deep, containing over 500 burned rocks. Larger rocks lined the base and perimeter of the basin. Burned sediment and charcoal

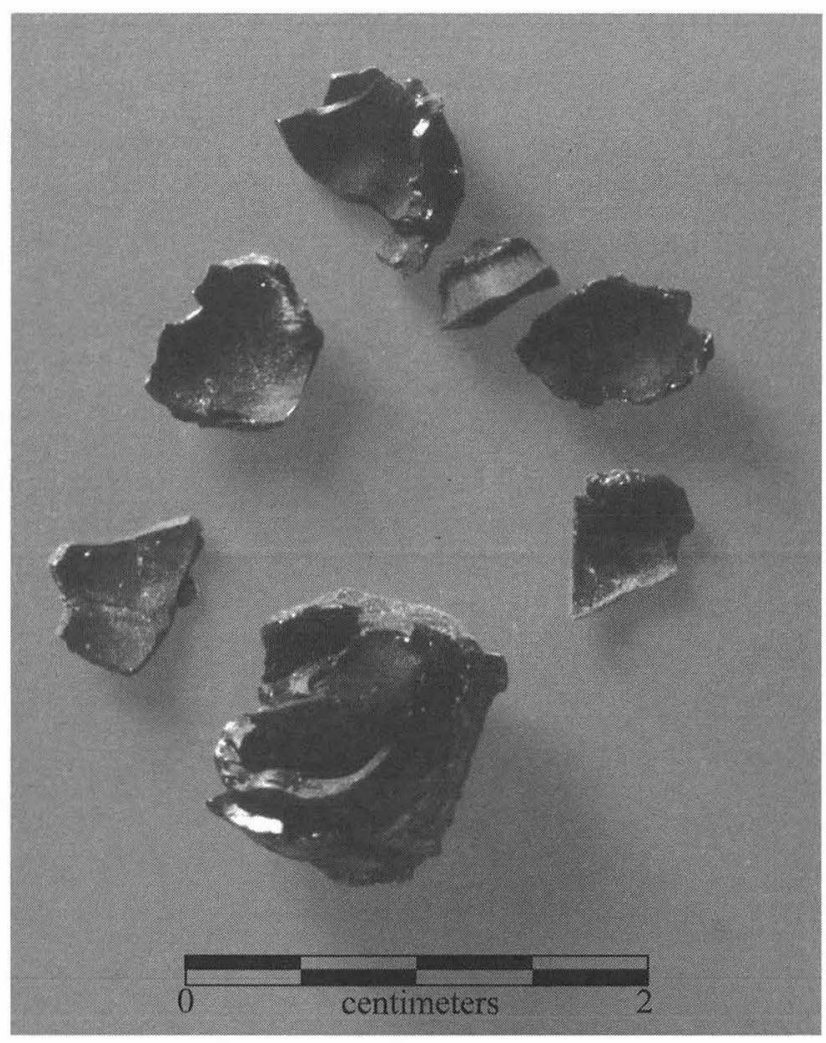

FGURE 9-19. Sample of charred bulbs recovered from Early Archaic Feature 181.

indicate that the rocks in this feature were heated in place. A Baker point, a Thrall point, mussel shell fragments, turtle shell, and a deer/antelope phalanx were among the contents of this feature. This deepest feature in the proto midden complex may have become buried before additional activity transpired at this spot, but similar activity was repeated here and eventually Burned Rock Midden 1 developed. Proto midden A may have been larger and more complex if it extended south of Square E22/S90 and east ofE20/S92.

Two smaller burned rock basins (Features 12 and 13) just northwest and west of 19/104 were next in the succession. Feature 12 was oval, $1.05-x-1.50$ min diameter and ca. $30 \mathrm{~cm}$ in depth. It contained over 200 burned rocks, charcoal, bone, and a mano fragment. Feature 13 was about $90 \mathrm{~cm}$ in diameter and $20 \mathrm{~cm}$ in depth with more than 100 burned rocks. Charcoal and bone were also recovered from Feature 13. The documentation of the overlying Feature 8 suggests that there was probably another, similar burned rock basin feature that went unrecorded close to Feature 13. The upper reaches of these basins merged into the large, overlying burned rock accumulation, Feature 8 . This accumulation was at least 2-x-4 min horizontal extent and 30 to $40 \mathrm{~cm}$ thick. It consisted of several layers of rocks, over 500 of which were mapped. Burned sediment and charcoal were intermixed with the rocks as were a bifurcate stem dart point, a Clear Fork uni face, and fauna! remains of river mussels, turtle, snake, rabbit, and deer/antelope. It is inferred that the basins served 


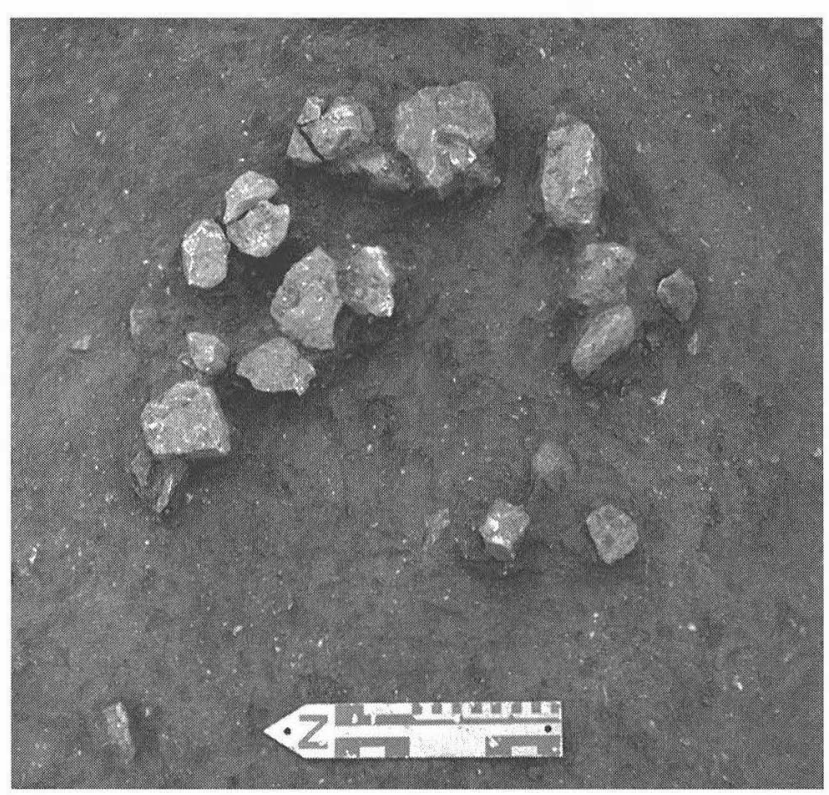

a

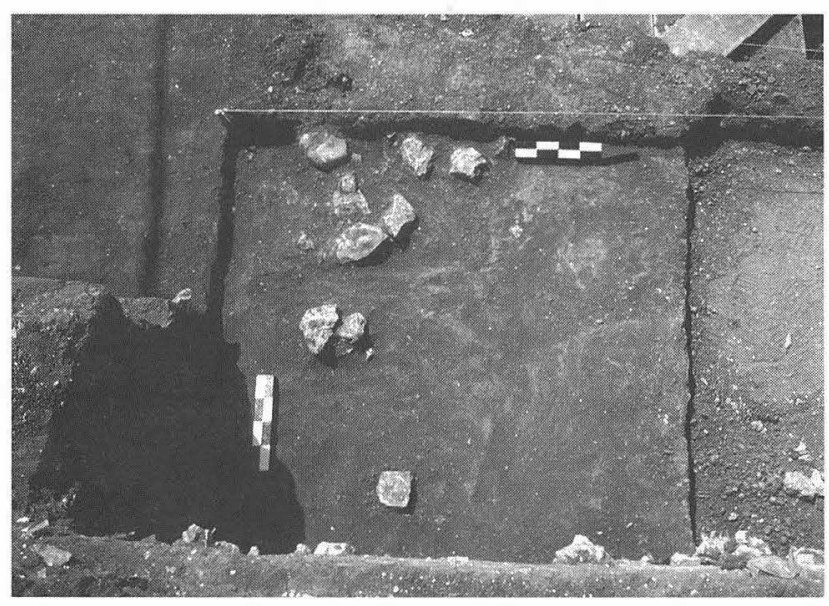

C

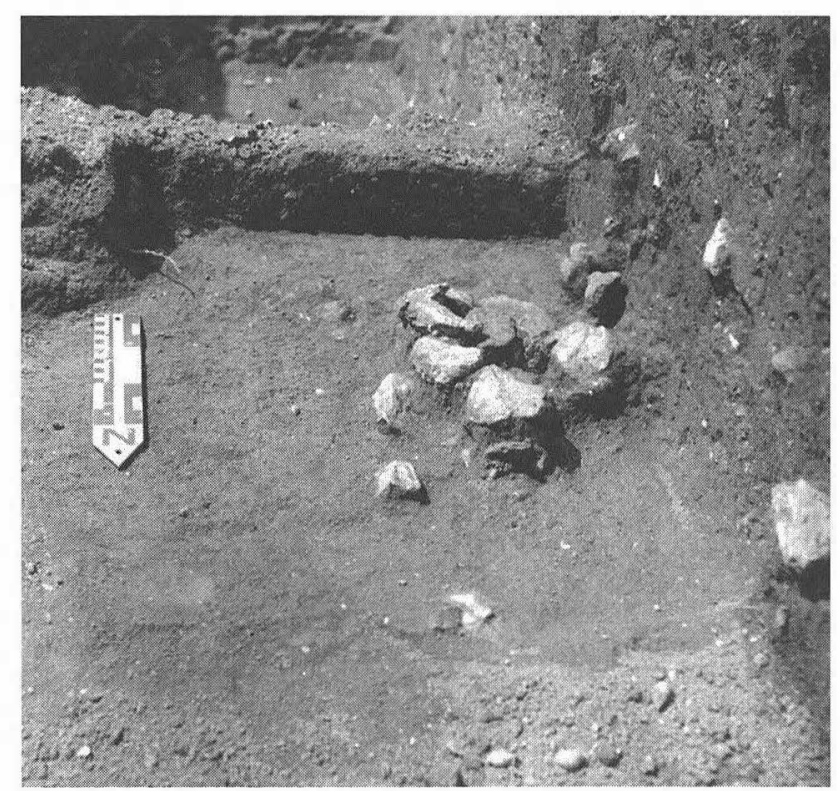

$\mathrm{b}$

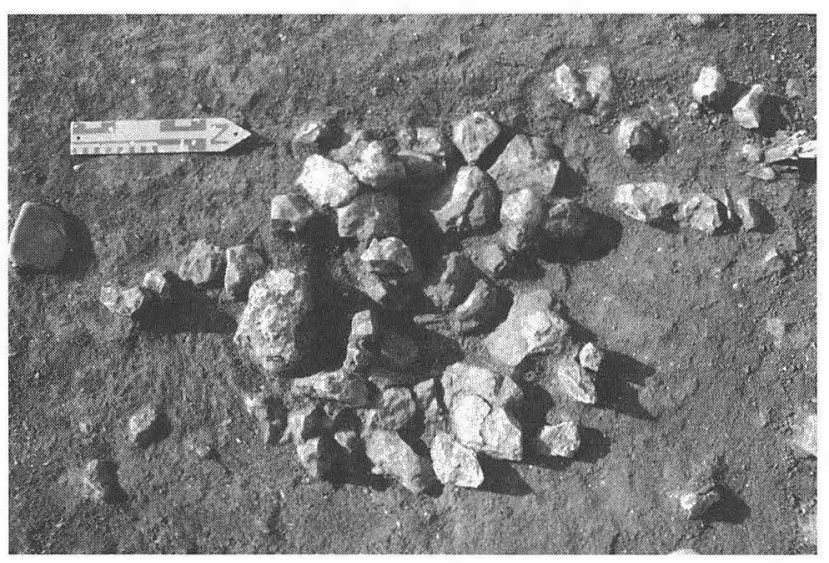

d

FlorRE 9-20. Early Archaic burned rock features. (a) burned rock ring (Feature 137); (b, c) burned rock clusters (Features 22 and 222); (d) burned rock basin (Feature 139).

as earth ovens and that the burned rock accumulation represents discarded stones from repeated episodes of use of the ovens. Just above the top of Feature 8 was recovered a charred wild hyacinth bulb that yielded an AMS radiocarbon age estimate of ca. 8,250 years. It is not clear if this bulb was among the refuse cleaned out of an oven after use or if it was actually associated with the base of the overlying Burned Rock Midden 1. Whichever it was, it gives an indication either of the age or a minumum age of the ovens.

Burned Rock Midden 1 is discussed along with Burned Rock Midden 2 in a separate section below, but aspects of this feature related to the Early Archaic are mentioned here. Stratigraphically, the oldest part of Midden I was near its center, overlying proto midden $\mathrm{A}$, and its content (including such diagnostic forms as Uvalde, Martindale, Baker, and Gower/Uvalde dart points as well as Clear Fork bifaces and unifaces) suggests a later Early Archaic age for this initial phase in its growth. Early materials were distributed primarily in the central and southern (upslope) parts of the midden, indicating that its early trajectory of growth was to the south. Archeomagnetic data on burned rocks from the Unit Y (oldest) levels of Midden 1 in Square 100 showed that a fairly high proportion (ca. 67\%) were displaced since last cooling. No intact ovens or other features were found at the base of Midden 1, but these cannot be easily discerned within a burned rock mass such as this midden.

Proto midden B consisted of a burned rock cluster (Feature 132), a small burned rock basin (Feature 230), and six largeburnedrockbasins(Features 130,131,146,150,181, and 245) (Figure 9-21) integrally associated with a mass of burned rocks recorded in the field as three burned rock scatters (Features 217,223, and 225) and two burned rock accu- 


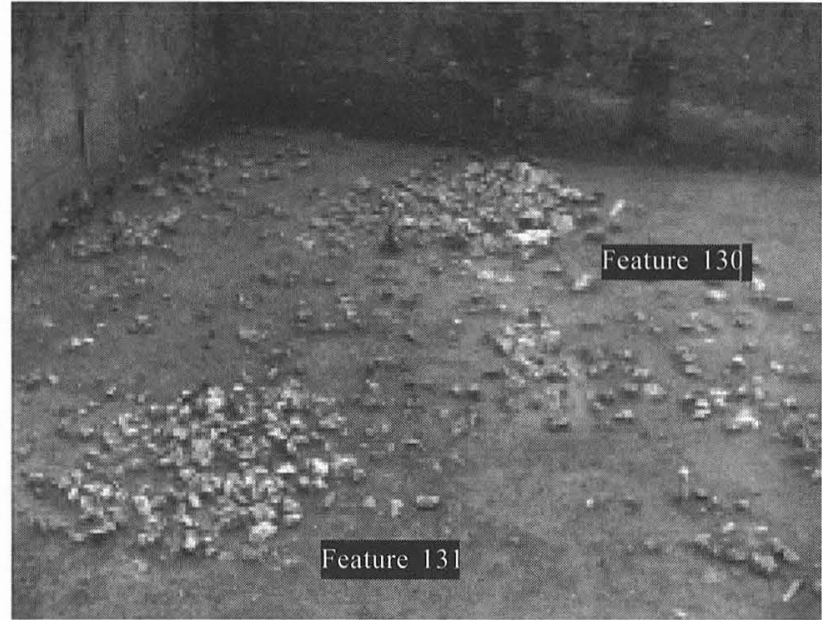

a

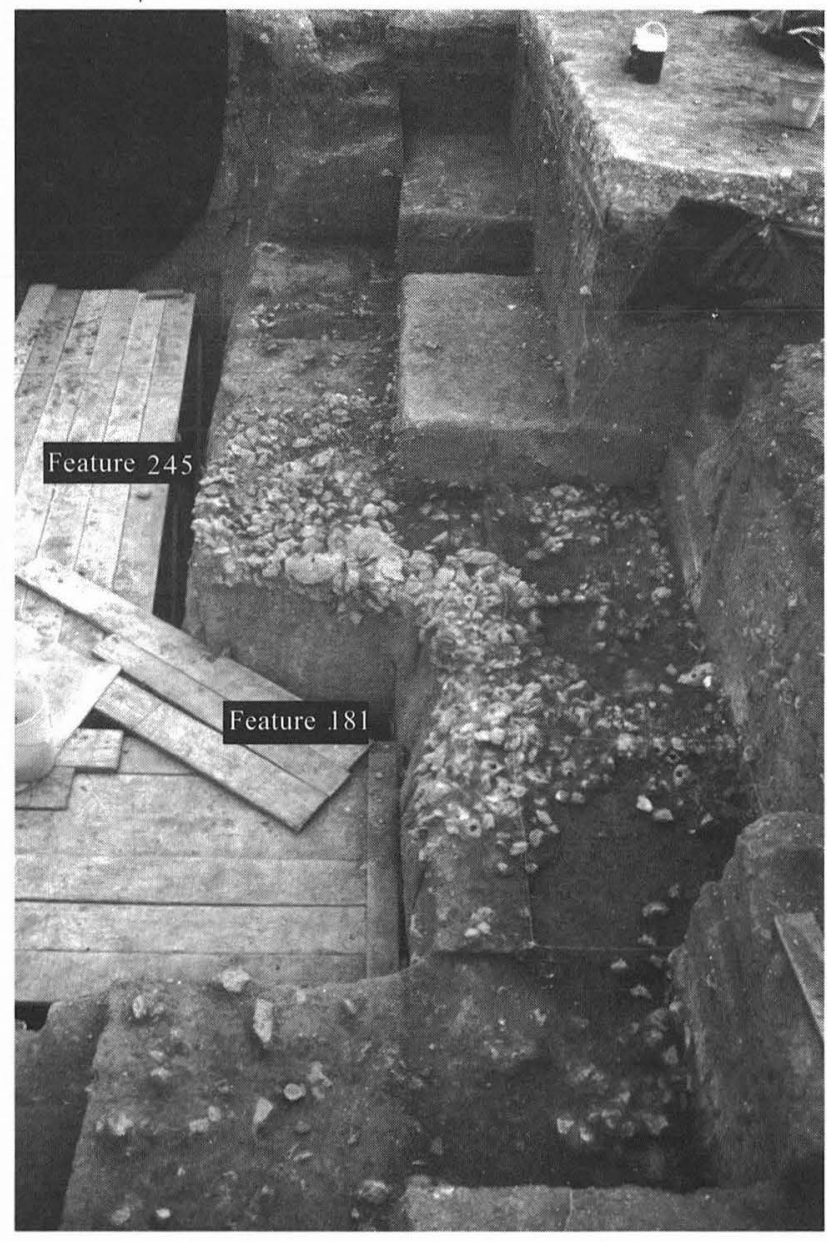

c

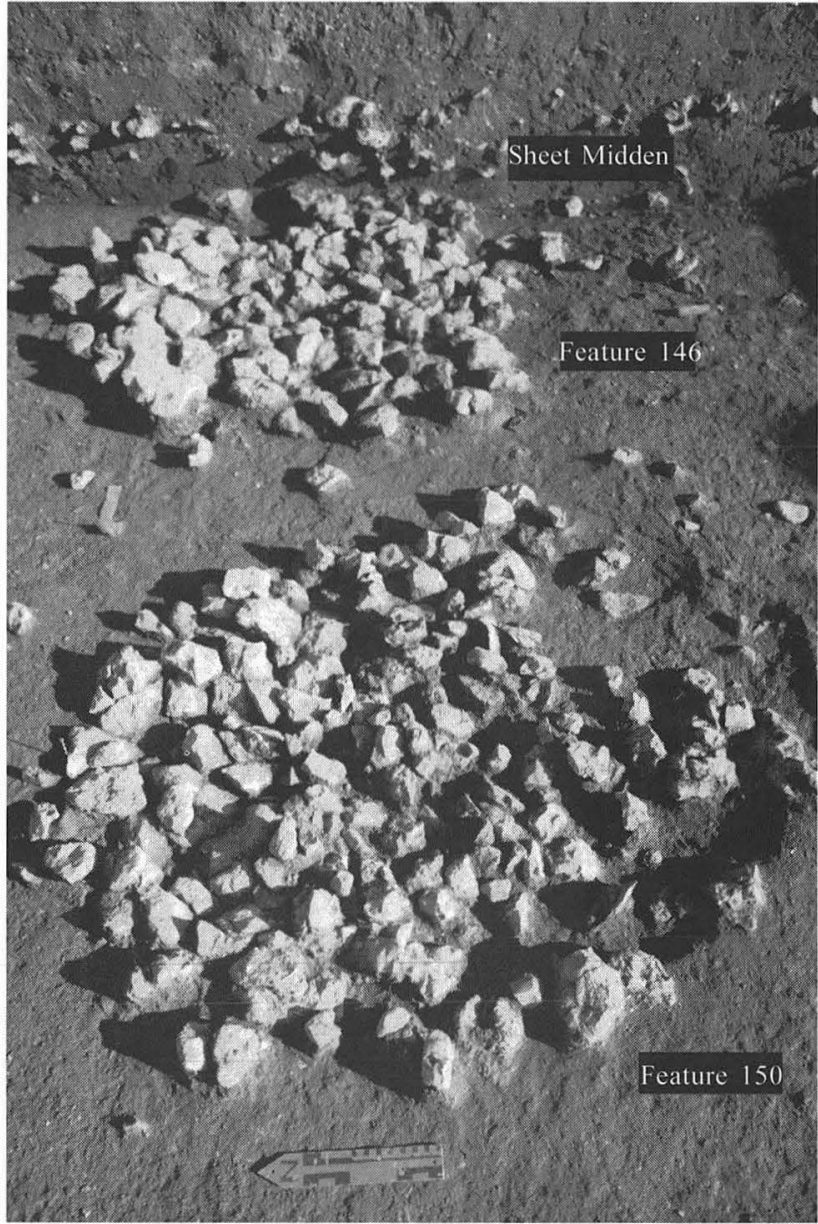

b

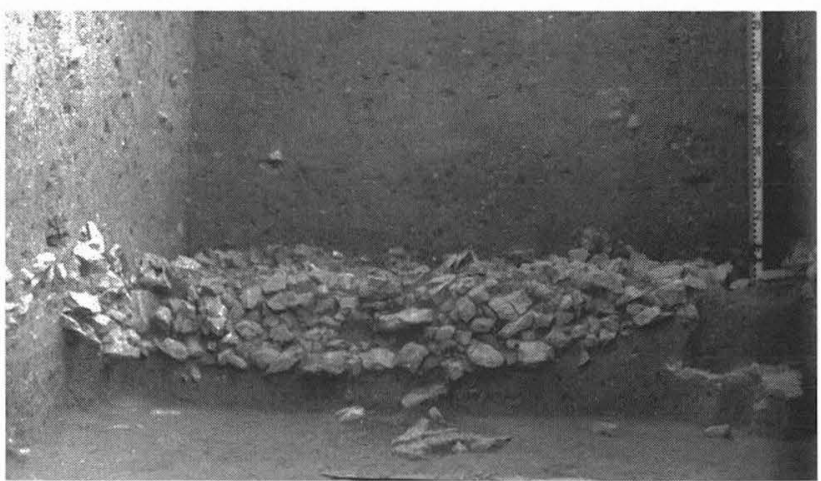

d

FigURE 9-21. Discrete large burned rock basins comprising Early Archaic proto midden B. The overlying sheet midden had been removed at the times of these photographs, but it can be seen clearly in the background profile above Feature 146 (frame b). (a) Features 130 and 131; (b) Features 146 and 150; (c) Features 181 and 245; (d) Feature 181 in section.

mulations (designated as Features 124 and 231). Proto midden $B$ was investigated at the south and east edges of the excavated area and was probably larger than the area exposed. There may have been more contributing features to the east or south of the exposed area. If that were the case, the largest burned rock basin (Feature 181) may have been near the center of the complex, although as the situation is presently known, it is near the southeastern edge (Figure 9-22). 
TxDOT Block 6

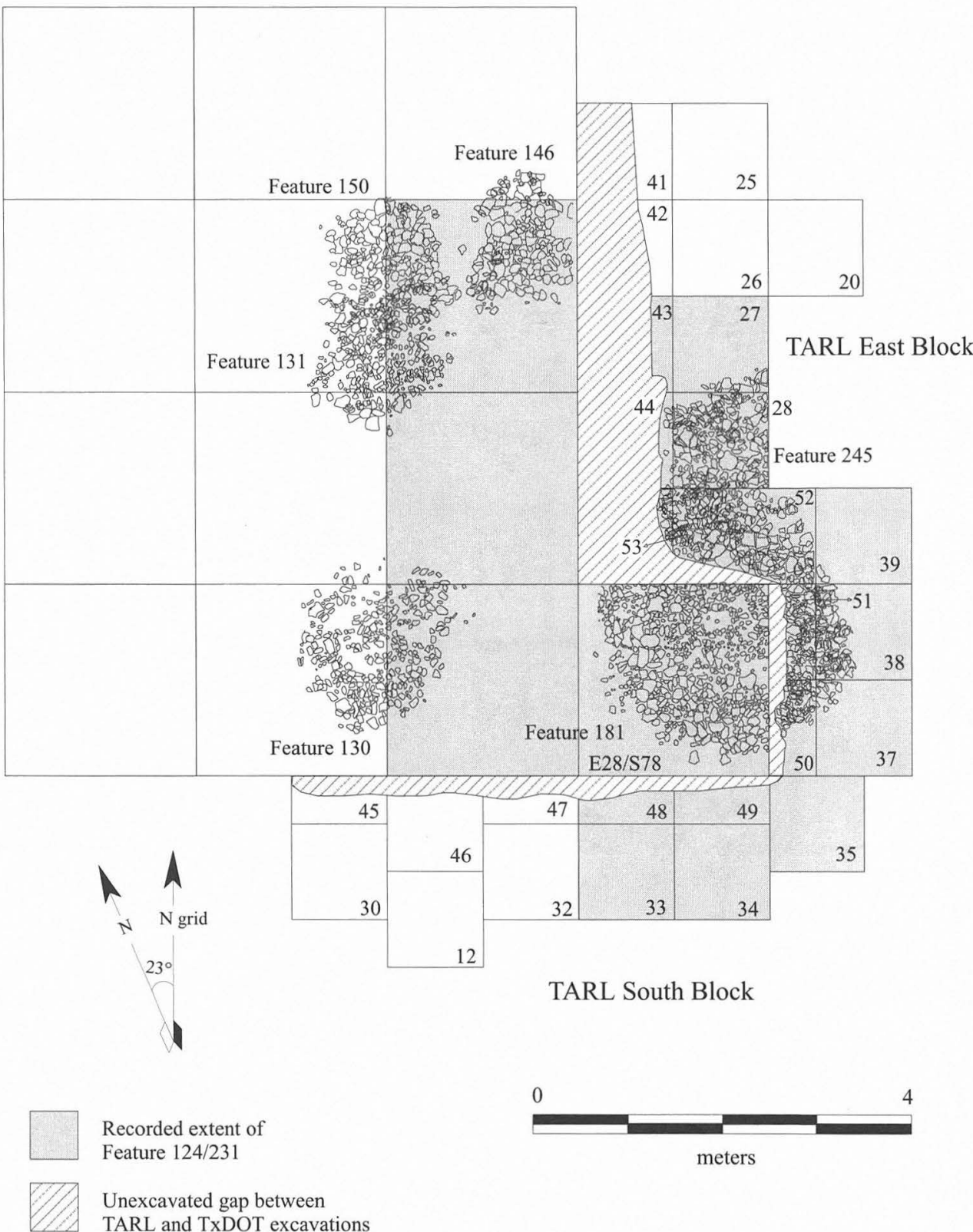

Figure 9-22. Composite plan drawing of Features 130, 131, 146, 150, 181, and 245.

In the area investigated, this complex consisted of one very large burned rock basin (Feature 181) with five large (but not as large) burned rock basins to the west, northwest, and north and a small burned rock basin to the north, all overlain by an extensive burned rock accumulation (see Figure 9-22). The accumulation was documented over an area at least $7.5 \mathrm{~m}$ north to south and $5.5 \mathrm{~m}$ east to west. In most places, it was several stones thick, and in all likelihood, thinner edges of the accumulation around its perimeter were not documented. As with proto midden A, the upper surface of this complex was relatively flat and the total thickness from this flat surface to the base of Feature 181 was about $50 \mathrm{~cm}$. Features 131, 146, and 150 were three closely spaced, large burned rock basins near the northwestern margin of proto midden $\mathrm{B}$. They were from 1.25 to $1.5 \mathrm{~m}$ in diameter and 10 to $20 \mathrm{~cm}$ in depth and each contained from 400 to 700 or more burned rocks. Larger slabs formed the linings of these features with smaller rocks in the interior fill. All three contained charcoal. Feature 130 was another large burned rock basin at the southwestern edge of proto midden $\mathrm{B}$. It is $1.5 \mathrm{~m}$ across and $15 \mathrm{~cm}$ deep and is composed of more than 500 rocks. Larger rocks formed the lining and charcoal was present. These four "satellite" appliances lay between 2 and $3.5 \mathrm{~m}$ from the edge of the larger basin (Feature 181). The fifth, Feature 245 , was immediately north of Feature 181 . It measured $1.5 \mathrm{~m}$ 
across and $.25 \mathrm{~m}$ deep, contained more than 500 rocks, and its lining consisted of larger rocks while smaller rocks made up the central fill. Burned sediment and charcoal were documented in Feature 245 and most of the rocks analyzed for magnetic properties cooled in place with little movement. Among the fuel woods used in this basin, juniper and an unidentified hardwood were recognized. Wood charcoal yielded three consistent radiocarbon dates averaging $\mathrm{ca}$. 8220 B.P. River mussels, turtle, fish, various sized mammals, rodent, squirrel, jackrabbit, cottontail rabbit, and deer/antelope were among the faunal remains in the basin.

Just northeast of Feature 181 was a small burned rock basin, Feature 230. It consisted of ca. 100 burned rocks in a small basin about $0.75 \mathrm{~m}$ across and $14 \mathrm{~cm}$ deep. The magnetic properties of the burned rocks indicate that most cooled in place, some with very little movement while cooling. Neither charcoal nor burned sediment was found with this feature and faunal recovery was limited to a few mussel shell fragments and bones that could not be identified.

The very large burned rock basin, Feature 181, was $2.6 \mathrm{~m}$ across and $50 \mathrm{~cm}$ deep. It was lined with large rocks and filled with smaller ones. It is estimated that more than a metric ton of rock was present in this feature at the time it was investigated. Most of the tested rocks cooled in place and some were moved while cooling. Burned sediment was documented, including one sample from beneath a lining stone. Bits of poorly preserved charcoal were dispersed throughout the fill but were in greater concentrations near the base of the pit. A most significant find in this feature was 10 charred bulbs of the wild hyacinth, delicate geophytes that are recoverable from archeological contexts only under extraordinary circumstances. These bulbs yielded radiocarbon dates averaging ca. 8000 B.P. Also recovered were mussel shell and bones of rabbit, small mammal, fish, turtle, snake, amphibian, and reptile. Two Hoxie and a Jetta dart points were found in association with Feature 181.

The combined burned rock scatters and accumulations comprised a "sheet midden" that covered these more-discrete features, the areas between them, and the areas around them. Generally, this burned rock accumulation consisted of multiple layers of rocks in places up to $30 \mathrm{~cm}$ thick. Although only documented to be close to $6-\mathrm{x}-8 \mathrm{~m}$ in extent, it was probably slightly larger, accounting for underdocumentation of the thinner edges. In the TxDOT excavation of this expanse of rocks (Feature 124) were found a Hoxie point, two manos, mussel shell, and turtle shell. In that portion (Feature 231) investigated by TARL were found sparse charcoal (including oak and juniper wood) and very minor patches of burned sediment. A comparatively high proportion of the rocks tested had magnetic properties indicating that they had been displaced since last cooling. One obviously erroneous radiocarbon date from this feature has been disregarded. Among diagnostic artifacts are dart points (two Hoxie/Gower, one Hoxie, one Angostura, and one Golondrina/Barber) and a Clear Fork biface. Faunal remains include rabbit, turtle, fish, snake, carnivore, deer, deer/antelope, frog/toad, and mussel shell.

In summary, proto midden B was a complex of burned rock basins surrounding a very large burned rock basin. These were capped with a sheet midden roughly $6-\mathrm{x}-8 \mathrm{~m}$ in extent and $30 \mathrm{~cm}$ thick. Functionally, this seems to be a grouping of earth ovens and an associated scree of material resulting from multiple episodes of using, clearing, and rebuilding the ovens. Wild hyacinth bulbs, which require long cooking times in moist conditions, were among the commodities cooked here, along with diverse aquatic and terrestrial animals. The radiocarbon age of this proto midden is between 8000 and 8200 B.P. and the associated diagnostic artifacts are characterized by the very early Archaic types, Hoxie, Hoxie/ Gower, and Angostura dart points; a single Clear Fork biface is consistent with this group of points. Some of the earth ovens were dug into underlying Late Paleoindian deposits, which may account for the presence of a Golondrina/Barber dart point. A comparatively rock-free deposit overlay proto midden $\mathrm{B}$, and no burned rock midden grew over the top of it.

To summarize, the Early Archaic at Wilson-Leonard exhibits continuities and contrasts with the Late Paleoindian intervals that preceded it. Among continuities are continued use of lanceolate projectile points along with a variety of stemmed dart point forms. Stemmed dart points, themselves, are also present in the Late Paleoindian Wilson component that predated the Early Archaic by some 800 years. Another continuity is the use of small- to medium-sized hearths and subsistence based on diverse floral and faunal resources. There was increasing consumption of fish that began in the Late Paleoindian and continued in the Early Archaic. The major discontinuity beginning in the Early Archaic was the use of earth ovens to cook geophytes. This is inferred to represent an important addition to the subsistence base as well as the technology. Dating for the beginning of the Early Archaic is fairly secure at 8700 to 8800 в.P.

\section{THEMIDDLEARCHAIC}

In contrast to an abundant and highly visible Early Archaic record at Wilson-Leonard, the Middle Archaic is comparatively sparse, not well isolated stratigraphically, and characterized by a smaller artifact assemblage and only a few securely dated features (see Tables 9-1, 9-2, Tables 9-14 through 9-23). Much of the present evidence was recovered from the two burned rock middens with their notoriously unclear stratigraphy. In addition, mechanical stripping in TxDOT excavation Block 6 probably removed the portion of the site with the best potential for stratigraphically isolating Middle Archaic features and artifacts.

Stratigraphically the most important units for the Middle Archaic are Valley Floor IIIb and IIIb/c, but Middle Archaic materials extend into lower Unit IIIC as well (Figure 9-23 and 9-24). Units IIIb/c, Y/IIIb/IIIc, Y/IIIIc, and IIIc on the Valley 
TABLE 9-14

Frequencies of Projectile Points by Type from Middle/Early Archaic Contexts

\begin{tabular}{|c|c|c|}
\hline Period & $\begin{array}{l}\text { Analysis Identification } \\
\end{array}$ & Count of Item \\
\hline Middle/Early Archaic & Projectile point, Baker & 1 \\
\hline Middle/Early Archaic & Projectile point, Bandy & 1 \\
\hline Middle/Early Archaic & Projectile point, Bandy-like & 1 \\
\hline Middle/Early Archaic & Projectile point, Bell/Andice & 6 \\
\hline Middle/Early Archaic & Projectile point, bifurcate stem fragment & 4 \\
\hline Middle/Early Archaic & Projectile point, Bulverde-like & 2 \\
\hline Middle/Early Archaic & Projectile point, Early Triangular & 1 \\
\hline Middle/Early Archaic & Projectile point, expanding concave A & 1 \\
\hline Middle/Early Archaic & Projectile point, expanding concave B & 2 \\
\hline Middle/Early Archaic & Projectile point, expanding concave $\mathrm{C}$ & 2 \\
\hline Middle/Early Archaic & Projectile point, expanding concave D & 3 \\
\hline Middle/Early Archaic & Projectile point, expanding stem A & 2 \\
\hline Middle/Early Archaic & Projectile point, expanding stem C & 1 \\
\hline Middle/Early Archaic & Projectile point, expanding stem D & 1 \\
\hline Middle/Early Archaic & Projectile point, Gary & 1 \\
\hline Middle/Early Archaic & Projectile point, Gower & 1 \\
\hline Middle/Early Archaic & Projectile point, Gower/Uvalde & 2 \\
\hline Middle/Early Archaic & Projectile point, Hoxie & 1 \\
\hline Middle/Early Archaic & Projectile point, indeterminate & 2 \\
\hline Middle/Early Archaic & Projectile point, Jetta & 1 \\
\hline Middle/Early Archaic & Projectile point, Marcos & 1 \\
\hline Middle/Early Archaic & Projectile point, Martindale A & 3 \\
\hline Middle/Early Archaic & Projectile point, Martindale B & 1 \\
\hline Middle/Early Archaic & Projectile point, miscellaneous bifurcate & 2 \\
\hline Middle/Early Archaic & Projectile point, miscellaneous expanding stem & 1 \\
\hline Middle/Early Archaic & Projectile point, miscellaneous lanceolate & 1 \\
\hline Middle/Early Archaic & Projectile point, miscellaneous side-notched & 1 \\
\hline Middle/Early Archaic & Projectile point, Nolan & 2 \\
\hline Middle/Early Archaic & Projectile point, rectangular stem A & 1 \\
\hline Middle/Early Archaic & Projectile point, rectangular stem $\mathrm{B}$ & 1 \\
\hline Middle/Early Archaic & Projectile point, rectangular stem C & 1 \\
\hline Middle/Early Archaic & Projectile point, Travis & 2 \\
\hline Middle/Early Archaic & Projectile point, Uvalde & 3 \\
\hline Middle/Early Archaic & Projectile point, Uvalde-like & 1 \\
\hline Middle/Early Archaic & Projectile point, Wilson? & 1 \\
\hline Middle/Early Archaic & Projectile point fragment & 21 \\
\hline
\end{tabular}

Margin yielded most of the Middle Archaic material (Figures 9-23 and 9-24).

Diagnostic projectile point types of the Middle Archaic include a small number of Bell-Andice and Early Triangular forms along with more numerous Nolan and Travis (Figure 9-25; see Tables 9-14 and 9-15). Nolan points stand out in this collection for the comparatively high occurrence of the very dark colored varieties of Edwards chert. Other chipped stone artifact categories that can be attributed to the Middle Archaic (see Tables 9-16 through 9-21) are not particularly distinctive (Figures 9-26 and 9-27). It is of interest to note that although no preforms or manufacturing failures of Andice dart points were recognized in the collection, one notching practice piece (Figure 9-28) of the kind generally attributed to the knappers of Andice points was recovered. Ground stone tools include both manos and metates, and some of the manos have roughening of the kind required for the grinding of hard seeds (Figure 9-29).
Features interpreted as Middle, Early/Middle, Middle?, and Middle/Late Archaic in age and definitely or possibly cultural in origin number 39 , counting the 2 burned rock middens (Burned Rock Middens 1 and 2). In addition, there are five burned plants of probable Middle Archaic age (Features 20,50, 196, 199, and 213). Feature 50 was a burned live oak tree that yielded a radiocarbon age of $5520 \pm 80$ years and Feature 199 was a red mulberry tree that burned $5560 \pm$ 60 radiocarbon years ago. These are two of the better indicators of absolute age for the Middle Archaic features at the site. Of comparatively minor importance-because of either low yield of information or uncertain origin - are a miscellaneous burned rock feature (Feature 216), two patches of burned sediment (Features 49 and 79), and two areas of burned sediments with minor amounts of burned rocks (Features 176 and 209).

A single burned rock ring (Feaure 89) in Early/Middle Archaic context consisted of ca. 25 stones found in a circu- 
TABLE 9-15

Frequencies of Projectile Points by Type from Middle Archaic Contexts

\begin{tabular}{l|l|c}
\hline \multicolumn{1}{c|}{ Period } & \multicolumn{1}{c}{ Analysis Identification } & Count of Item \\
\hline Middle Archaic & Projectile point, Travis & 5 \\
Middle Archaic & Projectile point, Travis-like & 1 \\
Middle Archaic & Flake, Bell/Andice practice? & 1 \\
Middle Archaic & Projectile point, Bell/Andice & 6 \\
Middle Archaic & Projectile point, Bulverde & 3 \\
Middle Archaic & Projectile point, Bulverde-like & 2 \\
Middle Archaic & Projectile point, Early Triangular & 4 \\
Middle Archaic & Projectile point, expanding concave A & 1 \\
Middle Archaic & Projectile point, expanding concave C \\
Middle Archaic & Projectile point, expanding concave D & 1 \\
Middle Archaic & Projectile point, expanding stem A & 3 \\
Middle Archaic & Projectile point, expanding stem C & 2 \\
Middle Archaic & Projectile point, expanding stem D & 1 \\
Middle Archaic & Projectile point, indeterminate & 2 \\
Middle Archaic & Projectile point, Lange-like & 2 \\
Middle Archaic & Projectile point, long stemmed & 1 \\
Middle Archaic & Projectile point, miscellaneous expanding stem & 1 \\
Middle Archaic & Projectile point, miscellaneous lanceolate & 1 \\
Middle Archaic & Projectile point, Nolan & 2 \\
Middle Archaic & Projectile point, Nolan-like & 21 \\
Middle Archaic & Projectile point, Pedernales & 3 \\
Middle Archaic & Projectile point, regular stem A & 1 \\
Middle Archaic & Projectile point, regular stem B & 2 \\
Middle Archaic & Projectile point, square stem & 1 \\
Middle Archaic & Projectile point fragment & 1 \\
\hline \hline
\end{tabular}

TABLE 9-16

Frequencies of Bifaces, Clear Fork Tools, Cores, and Core Tools from Middle/Early Archaic Contexts

\begin{tabular}{l|l|c}
\hline \multicolumn{1}{c|}{ Period } & \multicolumn{1}{|c}{ Analysis Identification } & $\begin{array}{c}\text { Count of } \\
\text { Item }\end{array}$ \\
\hline Middle/Early Archaic & Biface Stage 1 & 19 \\
Middle/Early Archaic & Biface Stage 2 & 55 \\
Middle/Early Archaic & Biface Stage 3 & 15 \\
Middle/Early Archaic & Bifacial tool Form A & 6 \\
Middle/Early Archaic & Bifacial tool Form B & 1 \\
Middle/Early Archaic & Bifacial tool Form E & 2 \\
Middle/Early Archaic & Bifacial tool Form J & 1 \\
Middle/Early Archaic & Clear Fork biface & 1 \\
Middle/Early Archaic & Clear Fork biface, proximal & 1 \\
Middle/Early Archaic & Biface fragment & 40 \\
Middle/Early Archaic & Biface fragment & 1 \\
Middle/Early Archaic & Core tool, type 2 & 1 \\
Middle/Early Archaic & Chert cobble, chunk & 2 \\
Middle/Early Archaic & Core fragment & 4 \\
Middle/Early Archaic & Core. multidirectional & 3 \\
Middle/Early Archaic & Core, thermal & 4 \\
Middle/Early Archaic & Micro-core, intermediate & 1 \\
Middle/Early Archaic & Micro-core, small & 2 \\
\hline \hline
\end{tabular}

lar arrangement, $70 \mathrm{~cm}$ in diameter and $5-10 \mathrm{~cm}$ in thickness. This was similar to the two Early Archaic burned rock rings mentioned above.

Twenty-five burned rock clusters account for twothirds of the features affiliated or possibly affiliated with the Middle Archaic (Figure 9-30). Most of these $(n=22)$
TABLE 9-17

Frequencies of Bifaces, Clear Fork Tools, Cores, and Core Tools from Middle Archaic Contexts

\begin{tabular}{c|l|c}
\hline Period & \multicolumn{1}{|c}{ Analysis Identification } & $\begin{array}{c}\text { Count of } \\
\text { Item }\end{array}$ \\
\hline Middle Archaic & Biface Stage 1 & 19 \\
Middle Archaic & Biface Stage 2 & 55 \\
Middle Archaic & Biface Stage 3 & 15 \\
Middle Archaic & Bifacial tool Form A & 6 \\
Middle Archaic & Bifacial tool Form B & 1 \\
Middle Archaic & Bifacial tool Form E & 2 \\
Middle Archaic & Bifacial tool Form J & 1 \\
Middle Archaic & Clear Fork biface & 1 \\
Middle Archaic & Clear Fork biface, proximal & 1 \\
Middle Archaic & Biface fragment & 40 \\
Middle Archaic & Biface fragment & 1 \\
Middle Archaic & Core tool, type 2 & 1 \\
Middle Archaic & Core tool, type 4 & 1 \\
Middle Archaic & Core tool, type 5 & 1 \\
Middle Archaic & Chert cobble, chunk & 1 \\
Middle Archaic & Core fragment & 2 \\
Middle Archaic & Core, thermal & 7 \\
Middle Archaic & Micro-core, large & 1 \\
\hline \hline
\end{tabular}

were small- to medium-sized groupings of burned rocks on fairly flat surfaces, ranging in diameter from about 33 to 80 $\mathrm{cm}$ and in thickness from 5 to $24 \mathrm{~cm}$ (but averaging about 8 $\mathrm{cm})$. There were from 4 to more than 70 stones in these features, with the average being about 25 . Three were larger, ranging from 90 to $130 \mathrm{~cm}$ in diameter with between 40 and 
TABLE 9-18

Frequencies of Perforators and Burins from Middle/Early Archaic Contexts

\begin{tabular}{c|l|c}
\hline \multicolumn{1}{c|}{ Period } & \multicolumn{1}{|c}{$\begin{array}{c}\text { Analysis } \\
\text { Identification }\end{array}$} & $\begin{array}{c}\text { Count } \\
\text { of Item }\end{array}$ \\
\hline Middle/Early Archaic & Perforator Group 2 & 1 \\
Middle/Early Archaic & Perforator Group 3 & 1 \\
Middle/Early Archaic & Perforator Group 5 & 1 \\
Middle/Early Archaic & Perforator Group 7 & 2 \\
Middle/Early Archaic & Perforator Unifacial & 3 \\
Middle/Early Archaic & Burin & 15 \\
Middle/Early Archaic & Burin spall & 8 \\
\hline \hline
\end{tabular}

TABLE 9-19

Frequencies of Perforators and Burins from Middle Archaic Contexts

\begin{tabular}{c|l|c}
\hline Period & Analysis Identification & Count of Item \\
\hline Middle Archaic & Perforator Group 2 & 1 \\
Middle Archaic & Perforator Group 5 & 1 \\
Middle Archaic & Perforator Group 7 & 2 \\
Middle Archaic & Burin & 2 \\
Middle Archaic & Burin spall & 8 \\
\hline \hline
\end{tabular}

TABLE 9-21

Frequencies of Unifaces and Edge-modified Flake Tools from Middle Archaic Contexts

\begin{tabular}{c|l|c}
\hline Period & \multicolumn{1}{|c|}{ Analysis Identification } & $\begin{array}{c}\text { Count of } \\
\text { Item }\end{array}$ \\
\hline Middle Archaic & Denticulated flake & 7 \\
Middle Archaic & Edge-modified flake & 47 \\
Middle Archaic & Microspur/microdenticulate & 1 \\
Middle Archaic & Notched flake & 3 \\
Middle Archaic & Retouched blade & 1 \\
Middle Archaic & Thick uniface & 5 \\
Middle Archaic & Thin uniface & 4 \\
Middle Archaic & Thin uniface fragment & 5 \\
Middle Archaic & Uniface, unanalyzed & 46 \\
Middle Archaic & Unifacial multiple tool & 10 \\
Middle Archaic & Blade & 1 \\
Middle Archaic & Denticulated flake & 3 \\
Middle Archaic & Edge-modified flake & 68 \\
Middle Archaic & Edge-modified flake, unanalyzed & 1 \\
Middle Archaic & Microspur/microdenticulate & 2 \\
Middle Archaic & Notched flake & 2 \\
Middle Archaic & Spurred flake & 1 \\
Middle Archaic & Thick uniface & 3 \\
Middle Archaic & Thick uniface fragment & 1 \\
Middle Archaic & Thin uniface & 7 \\
Middle Archaic & Thin uniface fragment & 2 \\
Middle Archaic & Unifacial multiple tool & 6 \\
\hline \hline
\end{tabular}

TABLE 9-20

Frequencies of Unifaces and Edge-modified Flake Tools from Middle/Early Archaic Contexts

\begin{tabular}{l|l|c}
\hline \multicolumn{1}{c|}{ Period } & \multicolumn{1}{c}{ Analysis Identification } & Count of Item \\
\hline Middle/Early Archaic & Denticulated flake & 4 \\
Middle/Early Archaic & Edge-modified flake & 112 \\
Middle/Early Archaic & Microspur/microdenticulate & 11 \\
Middle/Early Archaic & Notched flake & 15 \\
Middle/Early Archaic & Retouched blade & 3 \\
Middle/Early Archaic & Spurred flake & 1 \\
Middle/Early Archaic & Thick uniface & 4 \\
Middle/Early Archaic & Thick uniface fragment & 1 \\
Middle/Early Archaic & Thin uniface & 23 \\
Middle/Early Archaic & Thin uniface fragment & 14 \\
Middle/Early Archaic & Uniface, unanalyzed & 57 \\
Middle/Early Archaic & Unifacial multiple tool & \\
Middle/Early Archaic & Blade & 25 \\
Middle/Early Archaic & Denticulated flake & 1 \\
Middle/Early Archaic & Edge-modified flake & 2 \\
Middle/Early Archaic & Flake, unanalyzed & \\
Middle/Early Archaic & Microspur/ microdenticulate & 1 \\
Middle/Early Archaic & Notched flake & 1 \\
Middle/Early Archaic & Retouched blade & 1 \\
Middle/Early Archaic & Spurred flake & 1 \\
Middle/Early Archaic & Thin uniface & 6 \\
Middle/Early Archaic & Thin uniface fragment & \\
Middle/Early Archaic & Unifacial multiple tool & 12 \\
\hline \hline
\end{tabular}

100 stones; these were all very flat, being between 5 and 10 $\mathrm{cm}$ in thickness. For the entire sample of 25 , outlines varied from round to strongly elliptical, and most were generally a single stone thick, but layering of up to 2 or 3 rocks did occur in a few cases. Burned sediment was documented and ash or charcoal found in only a few of these features. For those few, wood charcoal could be identified as juniper in one hearth and was the source of radiocarbon dates in two features, both of which could be securely attributed stratigraphically to the Middle Archaic (Feature 204, at 4440 
TABLE 9-22

Frequencies of Ground Stone Tools from Middle/Early Archaic Contexts

\begin{tabular}{c|l|c}
\hline \multicolumn{1}{c|}{ Period } & \multicolumn{1}{|c}{$\begin{array}{c}\text { Analysis } \\
\text { Identification }\end{array}$} & $\begin{array}{c}\text { Count of } \\
\text { Item }\end{array}$ \\
\hline Middle/Early Archaic & Mano & 1 \\
Middle/Early Archaic & Mano fragment & 1 \\
Middle/Early Archaic & Metate fragment & 1 \\
Middle/Early Archaic & Worked hematite & 1 \\
\hline \hline
\end{tabular}

TABLE 9-23

Frequencies of Ground Stone Tools from Middle Archaic Contexts

\begin{tabular}{c|l|c}
\hline \multicolumn{1}{c|}{ Period } & Analysis Identification & $\begin{array}{c}\text { Count of } \\
\text { Item }\end{array}$ \\
\hline Middle Archaic & Mano & 1 \\
Middle Archaic & Mano fragment & 4 \\
Middle Archaic & Metate fragment & 4 \\
Middle Archaic & Possible ground stone & 3 \\
Middle Archaic & Worked hematite & 3 \\
\hline
\end{tabular}

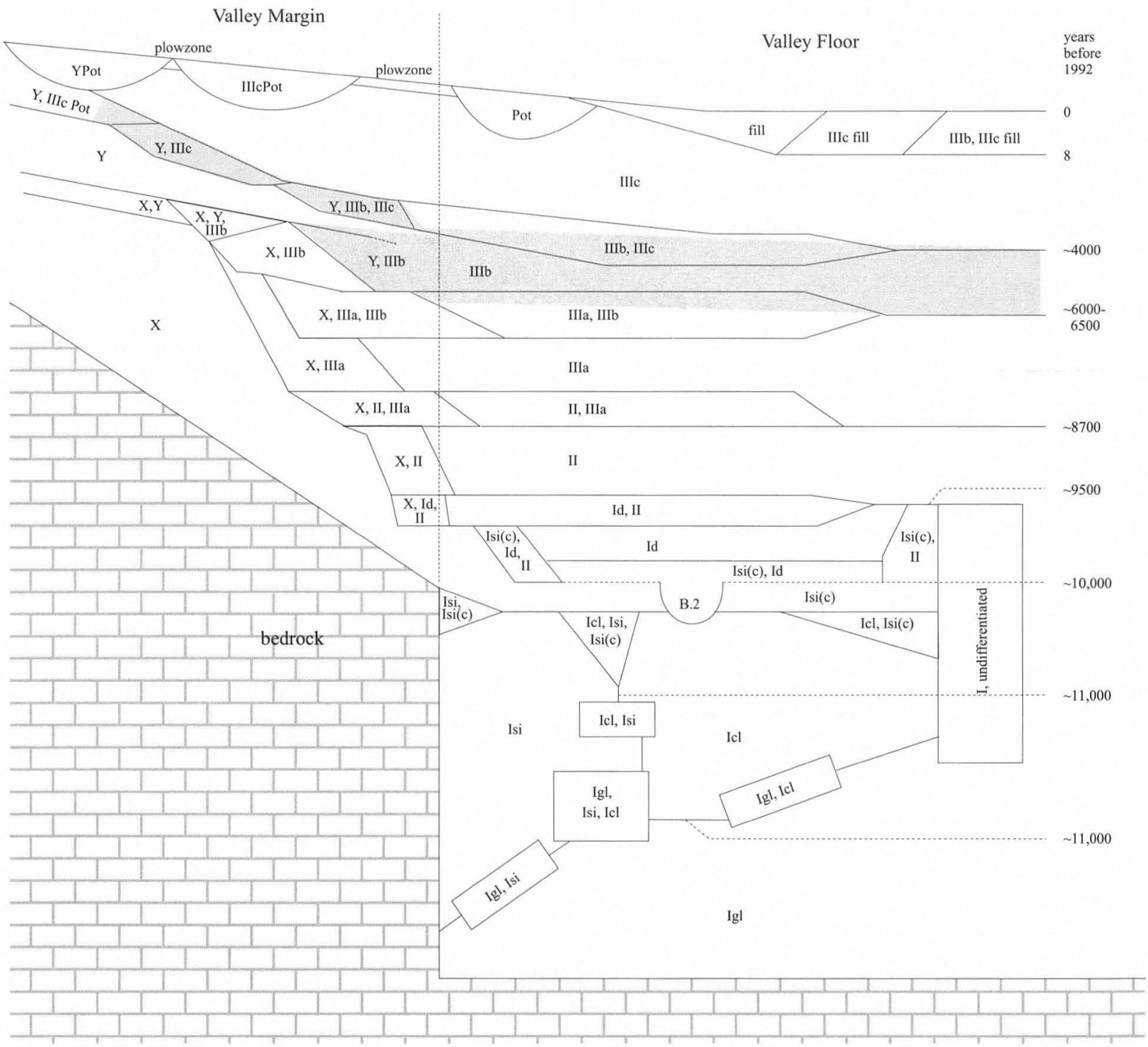

FIGURE 9-23. Stratigraphic profile of the Valley Margin/Valley Floor showing Middle/Early Archaic units.

\pm 60 and Feature 214 at $4880 \pm 70$ B.P.). The faunal remains from three burned rock clusters include rabbit, turtle, rodent, deer/antelope, turtle, snake, fish, bird eggshell, cottontail rabbit, jackrabbit, and various sized mammals. Phytolith and snail taxa from Feature 204 are indicative of xeric conditions as are the snails and grass seeds from
Feature 209. The evidence supports an inference that a majority of these features were hearths. Archeomagnetic data on rocks from two features seems to corroborate this interpretation.

Four burned rock scatters (Features 81, 179, 210, and 218) of Early/Middle or Middle Archaic age were documented. 


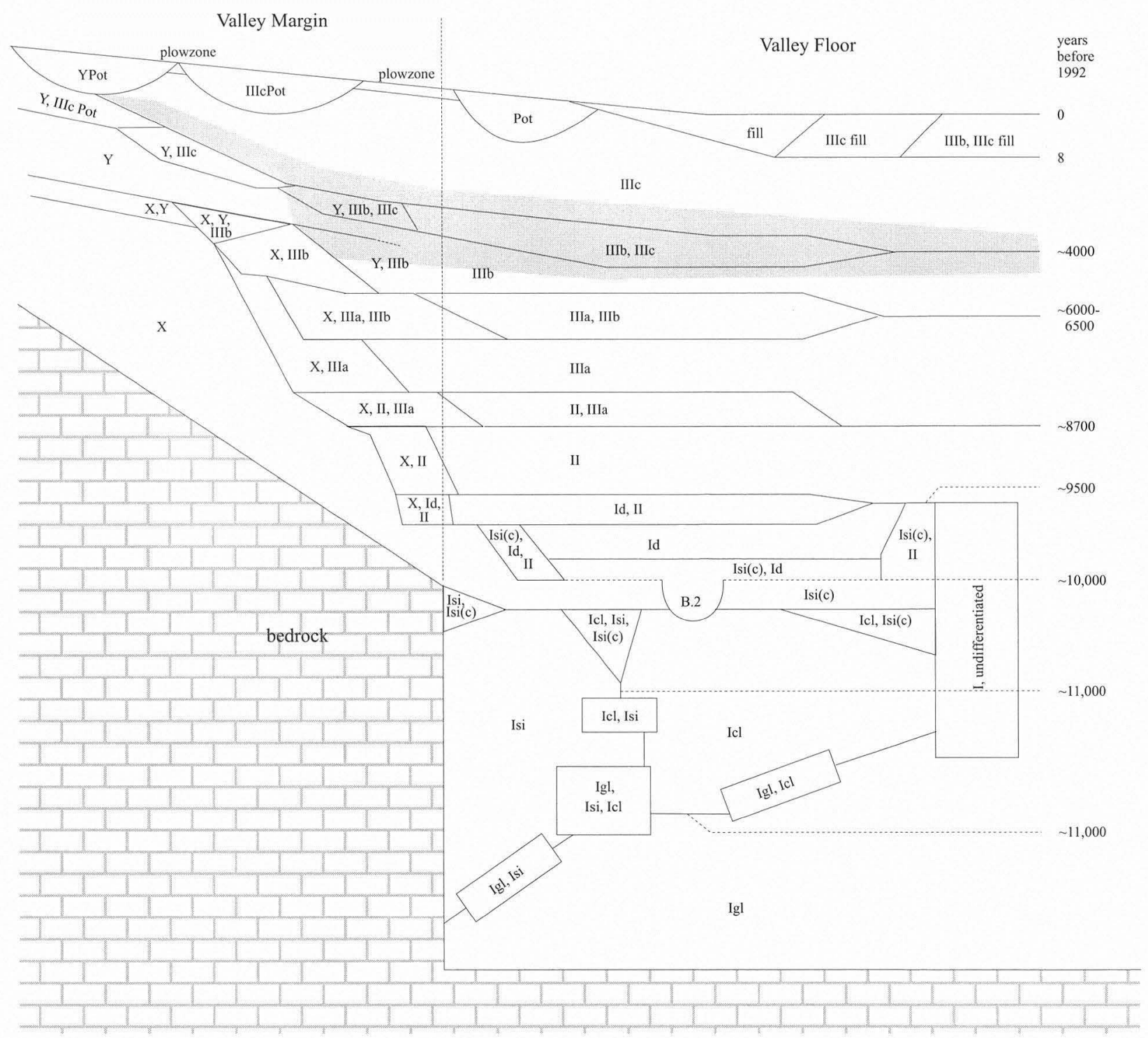

FIGURE 9-24. Stratigraphic profile of the Valley Margin/Valley Floor showing Middle Archaic units.

Each consisted of a loose scatter of burned rocks, generally one stone thick. Two were about $2 \mathrm{~m}$ across, one was about $1.5 \mathrm{~m}$, and one was less than a meter. One of the larger scatters (Feature 81) directly underlay Burned Rock Midden 1 and the other (Feature 179) rested directly above Feature 181, the very large, Early Archaic earth oven. The two smaller ones (Features 210 and 218) were in the Valley Floor. It is believed that these represent burned rocks dispersed from hearths or similar features.

Proto midden $\mathrm{C}$ was a single burned rock accumulation (Feature 195) beneath Burned Rock Midden 2, from which it was separated by about 5 or $10 \mathrm{~cm}$ of comparatively rock free fill (Figure 9-31). The proto midden was not fully exposed, but an area 1.4-x-2.7 m was documented. In this area, the feature was relatively flat and consisted of a dense layer of rocks some $10 \mathrm{~cm}$ thick. The rocks were slightly larger than those found in the overlying midden.
Burned sediment and wood charcoal (live oak with some walnut and elm) was present. Faunal remains include mussel, turtle, deer, deer/antelope, and rabbit. A mano and a metate fragment were found along with dart point types Nolan ( $\mathrm{N}=3)$, Travis $(\mathrm{N}=2)$, Bulverde $(\mathrm{N}=1)$, and Early Triangular $(\mathrm{N}=1)$ as well as untyped dart points $(\mathrm{N}=2)$. This assemblage is strongly Middle Archaic. The apparent size, thickness, and composition of this feature were similar to the more fully exposed proto middens of Early Archaic age, and it is inferred to be analogous. Furthermore, it is is inferred to represent an early phase in the development of Burned Rock Midden 2.

Within the burned rock mass of Burned Rock Middens 1 and 2 were found Nolan and Travis dart points of Middle Archaic derivation. No intramidden features or distinguishing characteristics of the middens can be attributed unequivocally to activities during the Middle Archaic. 


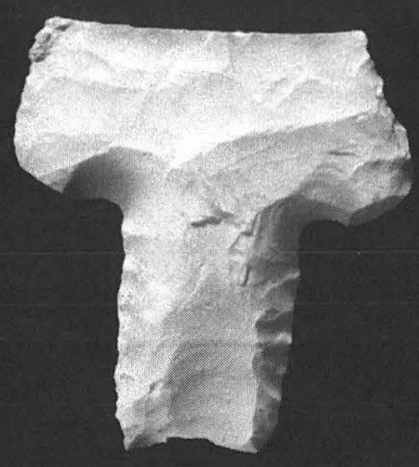

a

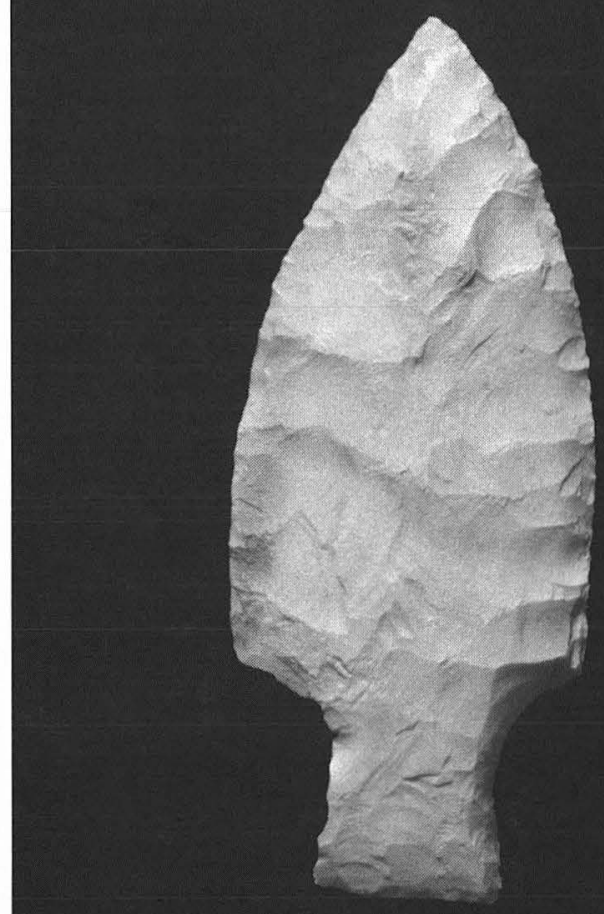

e

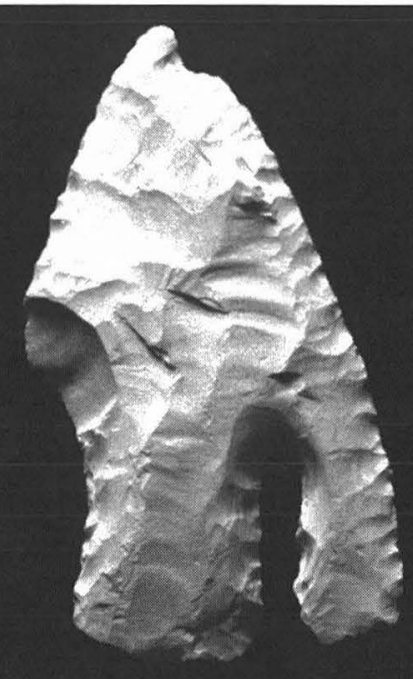

b

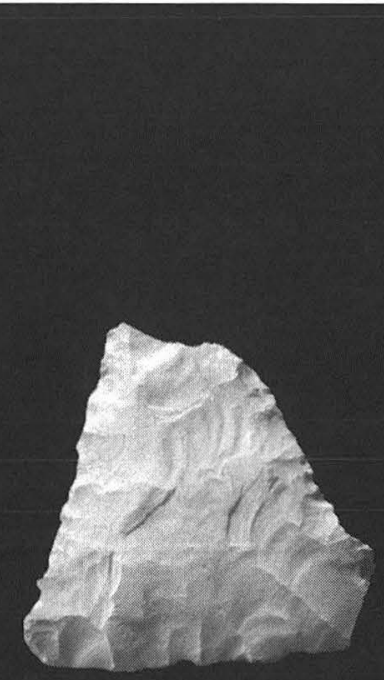

C

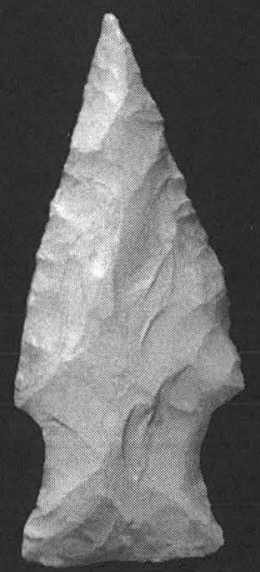

d

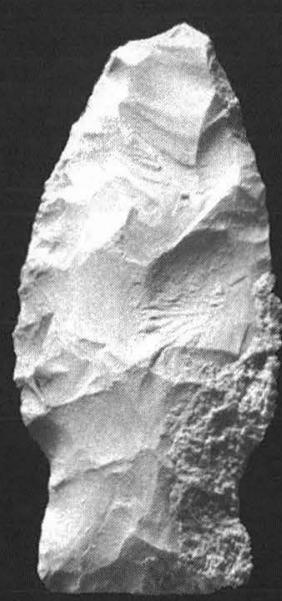

f
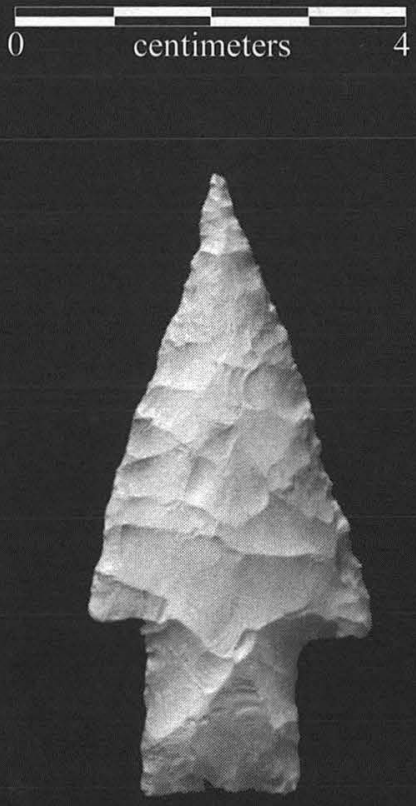

g

FIGURE 9-25. Projectile points from Middle Archaic and mixed Early/Middle Archaic contexts. (a, b) Bell/Andice; (c) Early Triangular; (d, e) Nolan; (f) Travis; (g) Bulverde-like. Specimen numbers: (a) 51MA-1; (b) 12J-1; (c) 11K-3; (d) 12F-1; (e) 22H-2; (f) 51JB-8; (g) $20 \mathrm{H}-1$.

\section{THELATEARCHAIC}

A substantial amount of Late Archaic material was recovered and a number of features documented, indicating considerable use of the site during this subperiod (see Tables 9-1 and 9-2). This is especially apparent considering the stripping of the upper $.5 \mathrm{~m}$ from TxDOT Block 5 and the upper $1.5 \mathrm{~m}$ from TxDOT Block 6 . In spite of the quan- tity of data recovered, there is not a great deal of new information on the Late Archaic to be derived from this site, in large part because of the compressed stratigraphy and extensive intermixing of Middle Archaic and Late Prehistoric material with that of the Late Archaic (Figures 9-32 through 9-34).

Artifacts of Late Archaic affiliation are notable for the comparatively greater frequencies of projectile points, the 


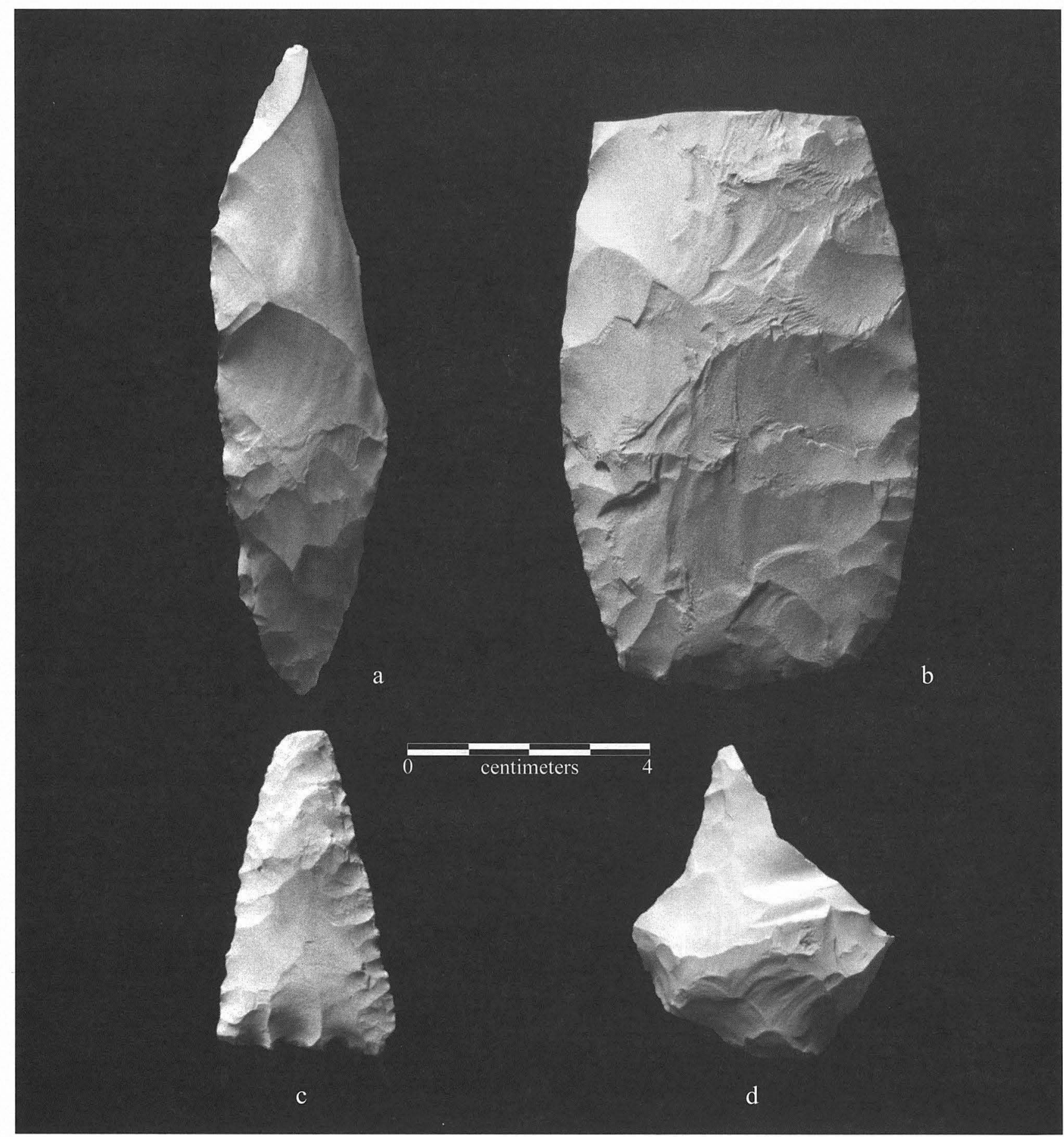

FIGURE 9-26. Representative bifaces and bifacial tools from Middle Archaic and mixed contexts. Specimen a is from deposits assigned to Middle/Late Archaic; the remainder, Middle Archaic. (a) Biface Stage 2; (b) Biface Stage 3; (c) knife-like bifacial tool Form A; (d) perforator Group 5. Specimen numbers: (a) 50FD-8; (b) 16H-3; (c) 16I1-2; (d) 15H-6.

only stone pipe at the site, and the composition of the dart point assemblage (see Table 9-2; Tables 9-24 through 9-38). Darl, Ensor, Fairland, Frio, Marcos, Marshall, and Castroville dart point types (Figures 9-35 and 9-36) appear in comparable frequencies to those in many Late Archaic sites in Central Texas, but there is a notably low number of Pedernales dart points. Bifaces (Figures 9-37 and 9-38) include both preforms and tools with considerable variation represented in both. A cache of bifaces (see below) contains preforms typical of those found in Late Archaic sites. One uncommon biface form is a single corner tang (Figure 9-38h) which was found oriented vertically in the ground. The remainder of the chipped stone (Figures 9-39 and 9-40) includes common Late Archaic forms. Ground stone is notable for a stone pipe 


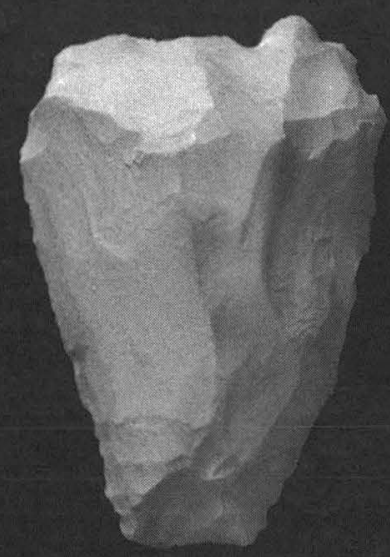

a

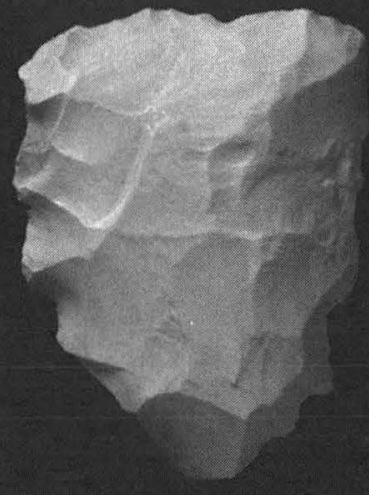

b
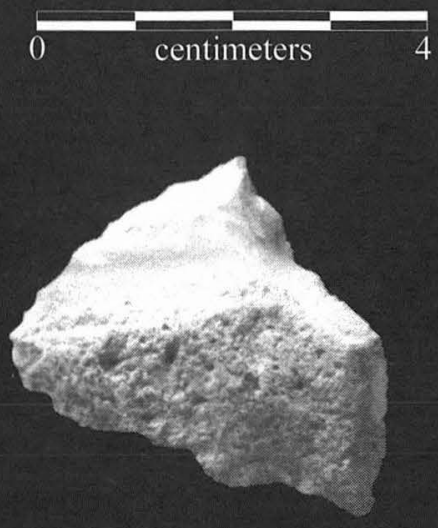

c

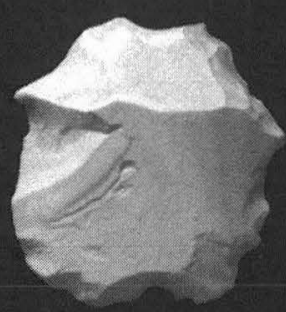

d

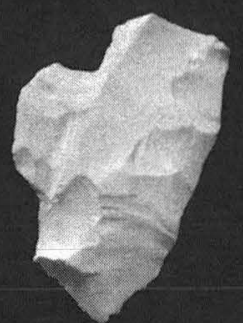

e

FIGURE 9-27. Representative tools from Middle and mixed Middle Archaic contexts. Specimen a is from deposits assigned to Early/Middle Archaic; b, Middle/Late Archaic; the remainder, Middle Archaic. (a, b) Clear Fork unifaces; (c) spurred flake; (d) denticulate flake; (e) notched flake. Specimen numbers: (a) 593-3; (b) 18F-7; (c) 556-2; (d) 16I1-7; (e) 518-4.

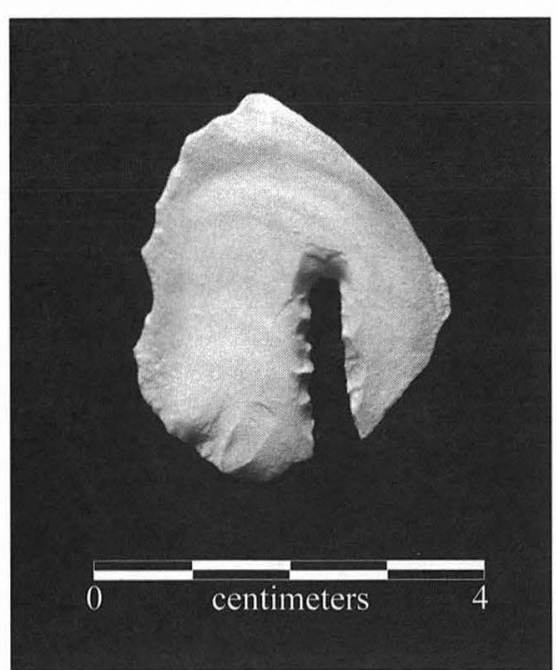

FIGURE 9-28. Notched "practice" flake Specimen 556-4 from Middle Archaic deposits (Unit IIIb).

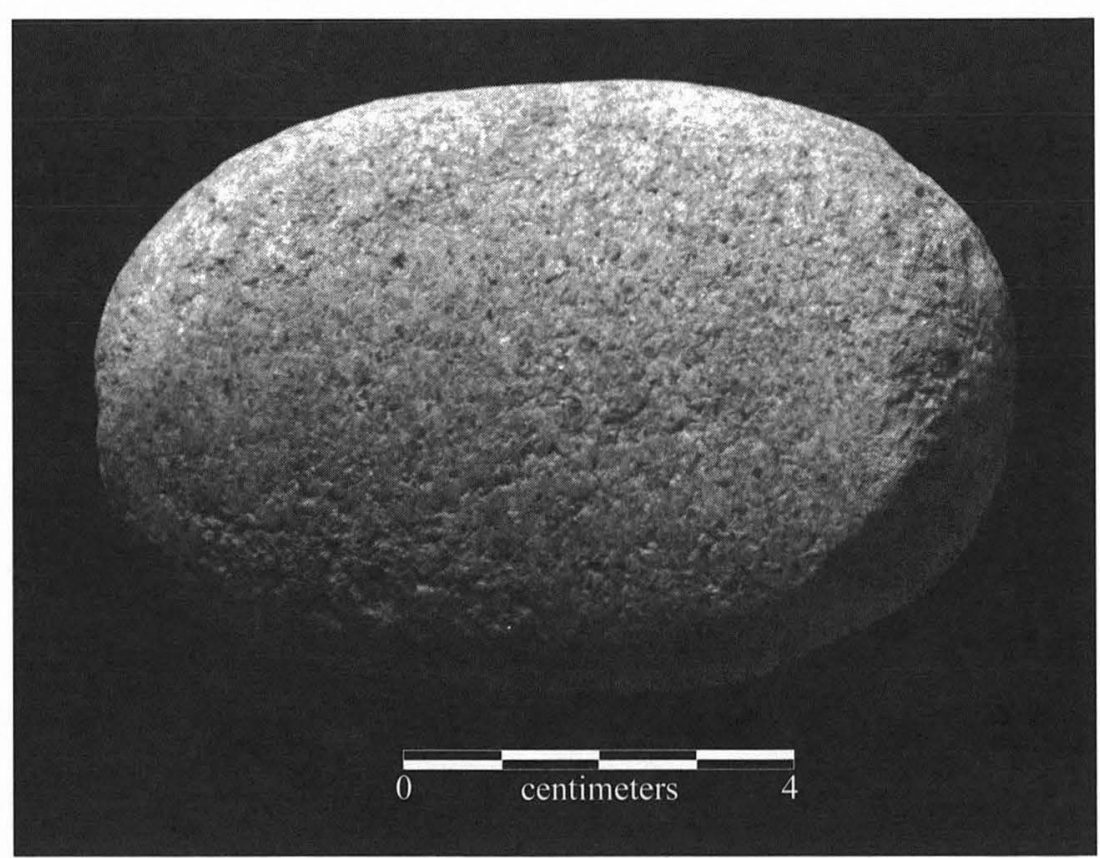

FIGURE 9-29. Representative mano (Specimen 51KB-3) from Middle Archaic context. 


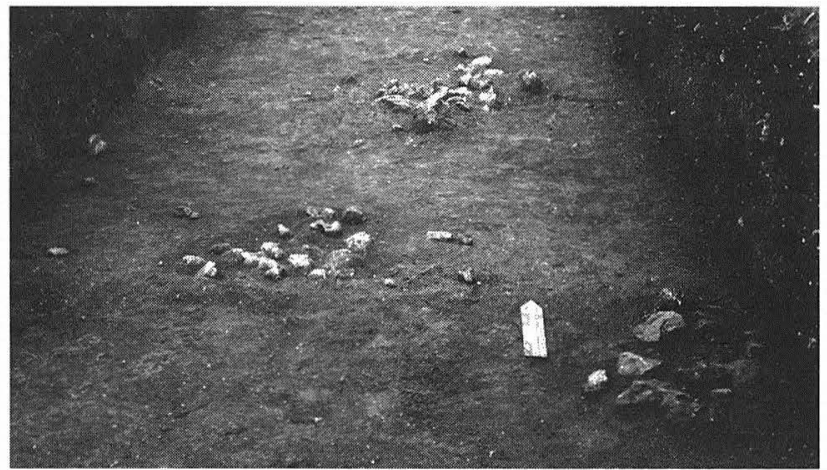

Figure 9-30. Middle Archaic burned rock clusters, Features 42 (foreground), 41 (midground), and 40 (background).

W0/N8

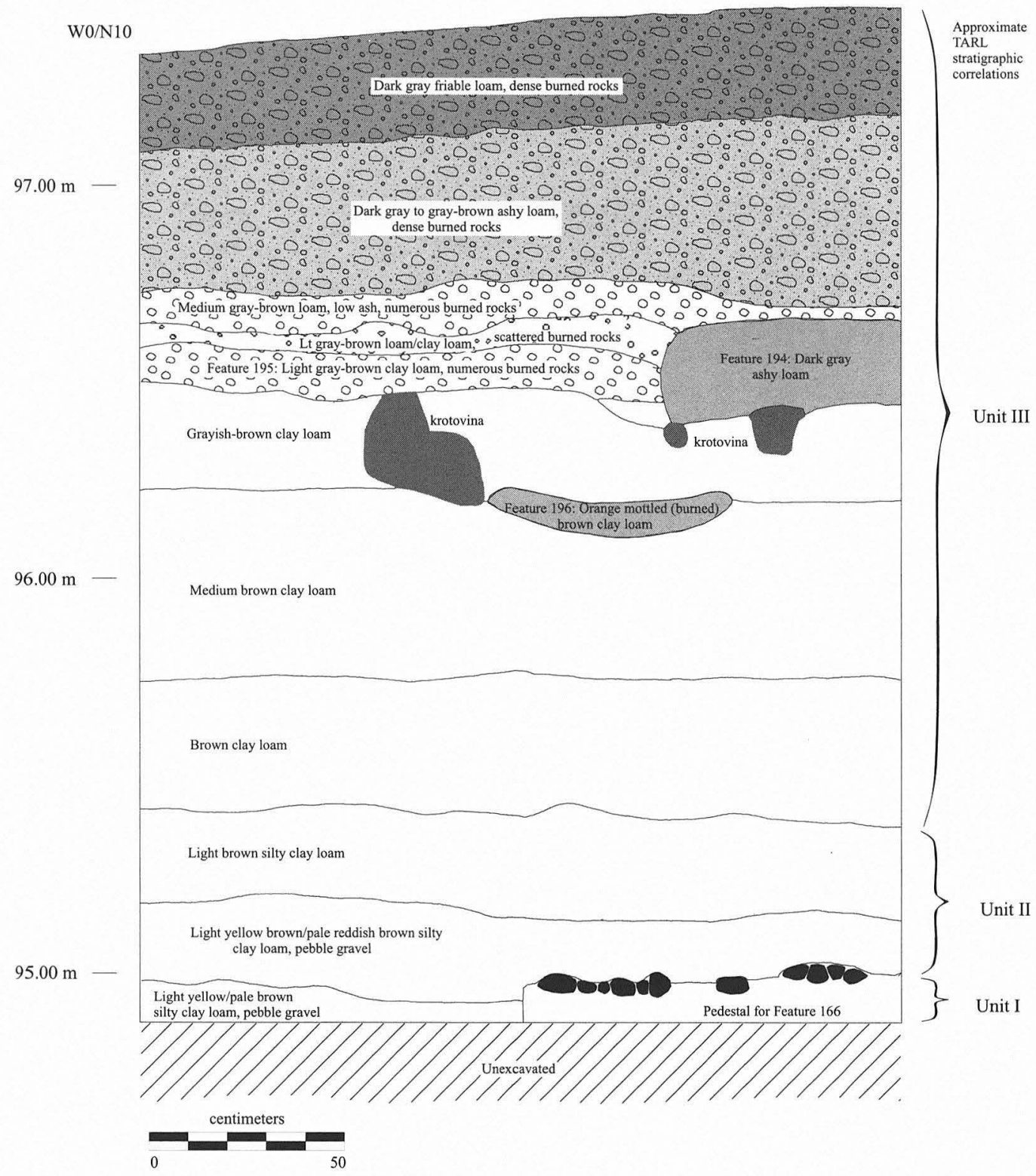

Figure 9-31. Section through Burned Rock Midden 2 and proto midden C. 


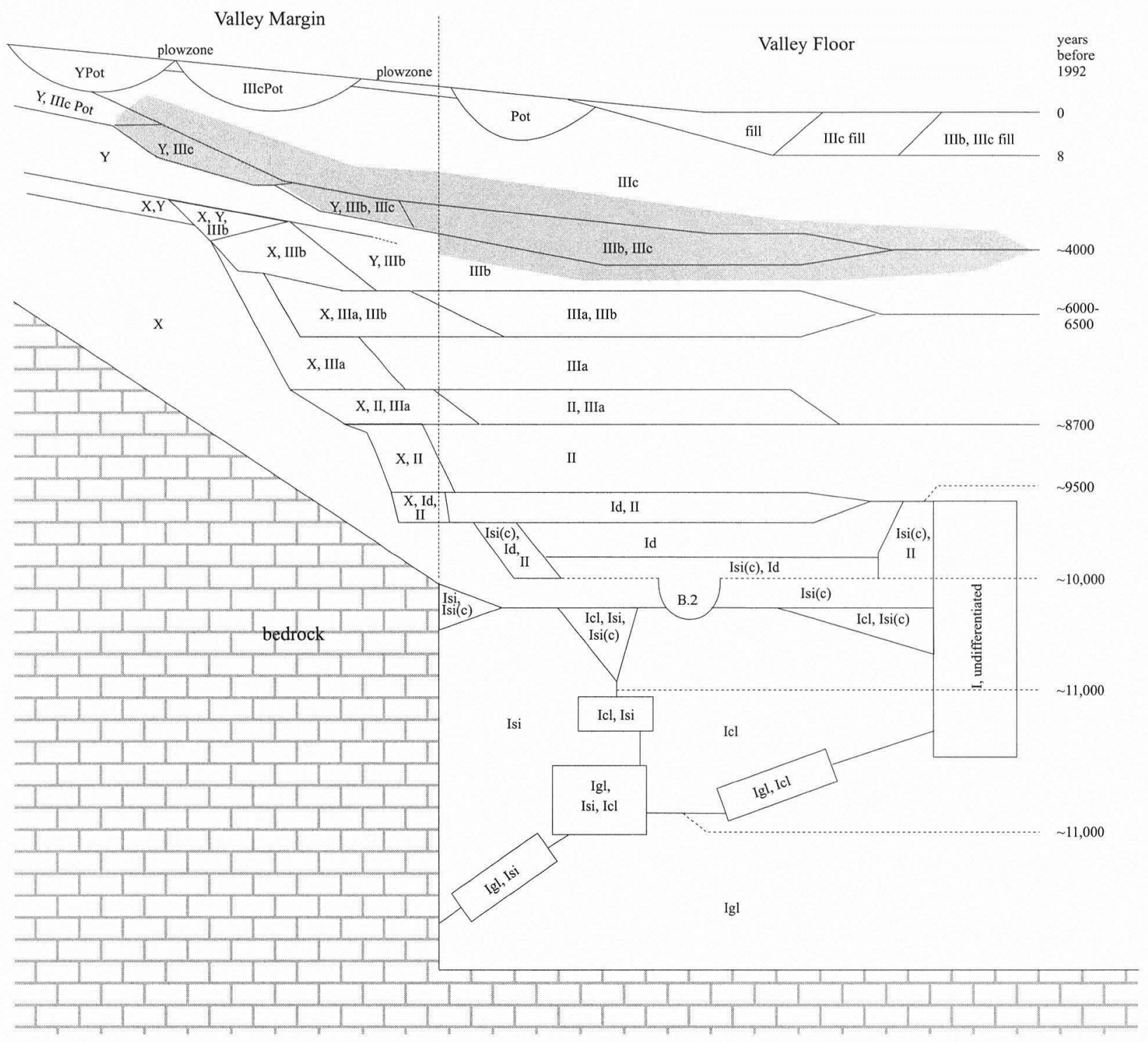

FIGURE 9-32. Stratigraphic profile of the Valley Margin/Valley Floor showing Late/Middle Archaic units.

(Figure 9-41) and pitted manos and metates (Figures 9-42 and 9-43). At least one decorated bone object is represented by numerous fragments (Figure 9-44).

Twenty-four features are attributable to Late Archaic, Late Archaic/Late Prehistoric, or Late Archaic? contexts (see Table 9-1). One of these was a cache of three bifacial preforms (see Figure 9-37a) and a core (Feature 11). The grouping of bifaces is typical of many Late Archaic caches in Central Texas, but the presence of a core is less common and this core, being of quartz and having a blade-like scar on its face, is especially noteworthy.

Four burned rock scatters (Features 7, 120, 121, and 173) consisting of randomly dispersed burned rocks were encountered in the Late Archaic levels of three 2-x-2-m squares in TxDOT excavations. The scatters covered all or most of the four square meters of the squares in which they were found (E20/S82, E40/S70, and E28/S78). Very little data exists for these occurrences, however, Feature 7 (E20/S82) was documented to be at least $1.8-\mathrm{x}-2.0 \mathrm{~m}$ across and $11 \mathrm{~cm}$ thick with charcoal pieces (including elm wood) present. In all likelihood, these were debris from hearths.

The single Late Archaic burned rock feature classified as a burned rock ring (Feature 35) was actually a crescentic arrangement of 20 rocks with several nearby rocks that may have been dislodged from a more-complete ring. The feature was about $50-x-100 \mathrm{~cm}$ across and $10-15 \mathrm{~cm}$ thick. It may have been the disturbed remnant of a hearth.

One small burned rock basin (Feature 75) consisted of four fairly large burned rocks lining a small (40-cm diameter) basin. This is inferred to have been a small hearth.

Nine burned rock clusters (Features 10, 32, 34, 36, 38, 76, 77,78 , and 202) of Late or probable Late Archaic affiliation were documented. These consisted of groupings of anywhere from 7 to 80 rocks and ranged in size from ca. 20 to 90 


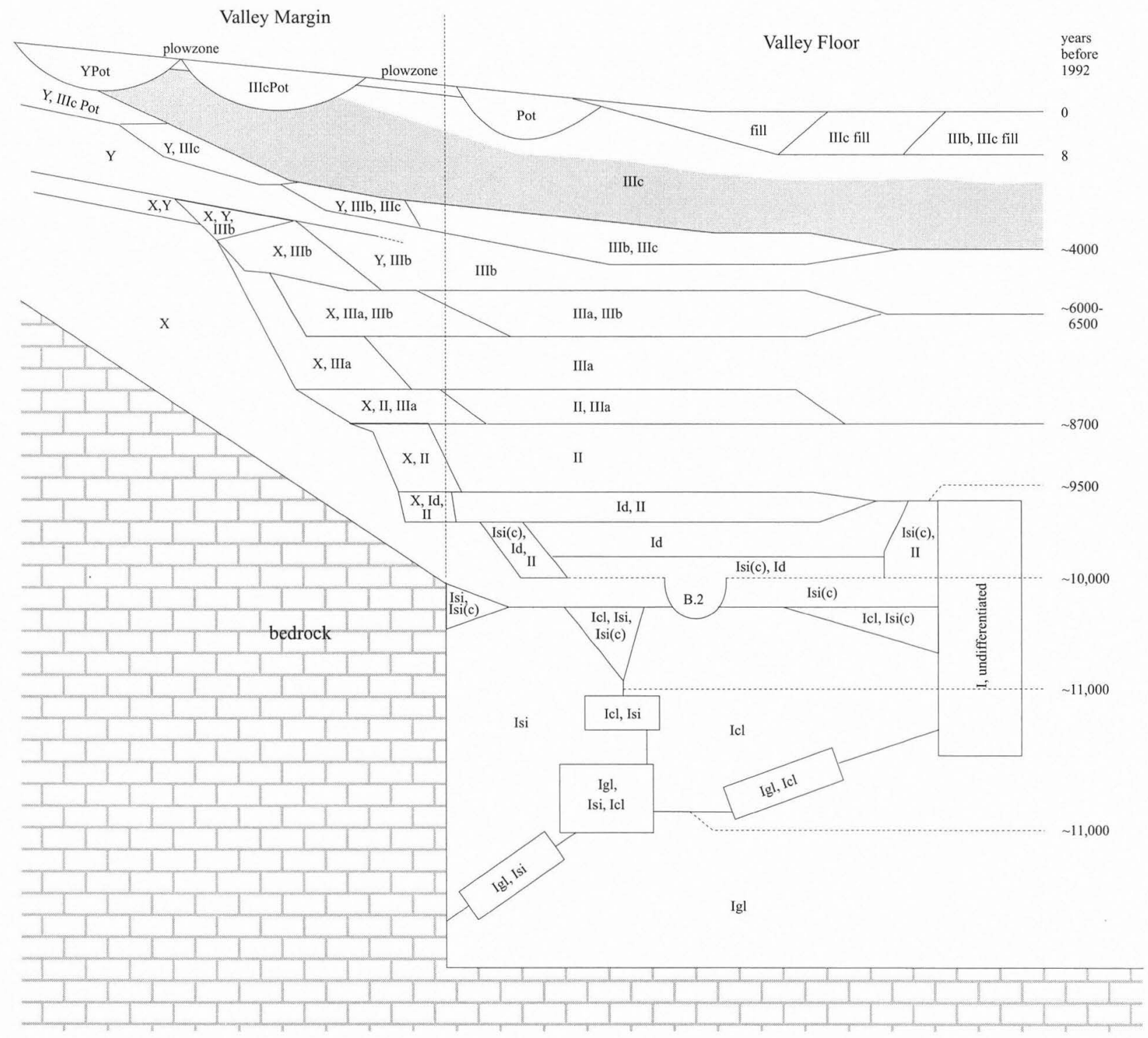

FIGURE 9-33. Stratigraphic profile of the Valley Margin/Valley Floor showing Late Archaic units.

$\mathrm{cm}$ across. Most were around $10 \mathrm{~cm}$ thick and fairly flat. There are hints that some of these may have rested in shallow basins, but the evidence is not clear; others almost certainly rested on a flat ground surface. In all but the case of Feature 78 with its two layers of stones, the data suggest single layers of rocks. Hackberry wood from Feature 10 yielded a radiocarbon age of $1990 \pm 60$ B.P. Feature 10 as defined contained about 80 rocks, but an additional 50 or so rocks nearby may have been intentionally cleared from the feature. Associated artifacts include an Ensor point and a fragmented sandstone metate with Feature 36 and a Montell point with Feature 76. Although confirming evidence of in situ burning was generally lacking in this series of features, it is still probable that a majority represent simple stonelined fireplaces.

A large burned rock accumulation (Feature 201) incorporating six additional burned rock features (two scatters
[Features 203 and 205] and four clusters [Feaures 206, 207, 208, and 211]) was documented across all of the TARL east bock and the eastern half of the TARL south block, an area roughly $4-x-10 \mathrm{~m}$. Burned rock densities and the thickness of the accumulation varied considerably across this feature. Densities increased to resemble clusters in at least four areas and scatters in two others. The thickness of the accumulation ranged from 20 to $40 \mathrm{~cm}$. There were sparse portions of the feature where it was a single stone thick, but in most places it was several stones thick. A minor amount of charcoal was dispersed among the stones and archeomagnetic evidence shows that a majority of the individual rocks moved while cooling but cooled in place. Associated diagnostic artifacts are predominantly of Late Archaic types (Ensor, Marcos, Marshall, Castroville, Montell, Williams, and Pedernales) but also include one Early Archaic Uvalde and two Late Prehistoric Scallorn points. The 


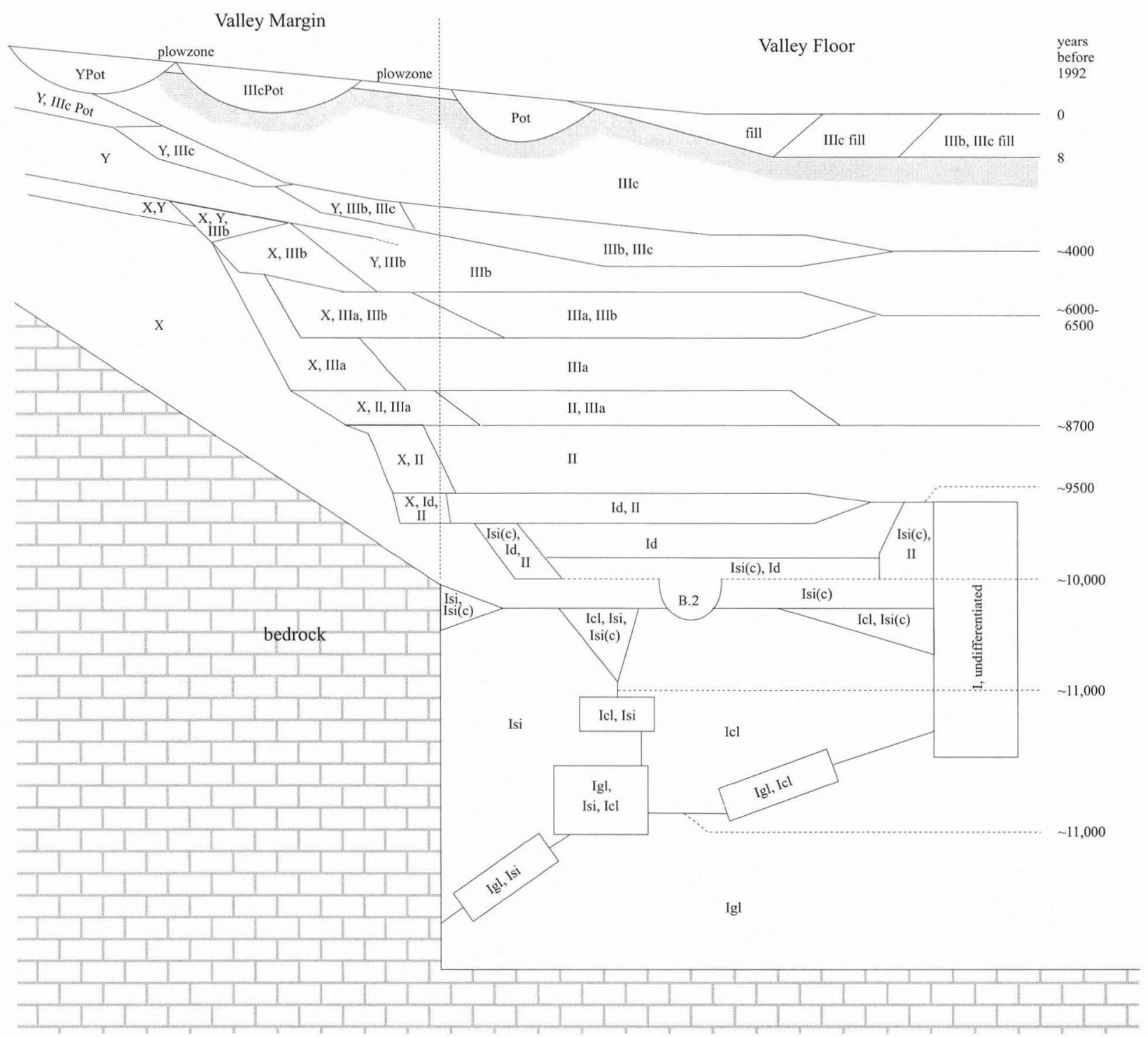

FIGURE 9-34. Stratigraphic profile of the Valley Margin/Valley Floor showing Late Archaic/Late Prehistoric units.

Uvalde almost certainly and the Scallorns possibly represent intrusions. This accumulation was quite similar to those above referred to as proto middens, and the term might apply here as well. However, it is possible that further excavation to the east or south would show this burned rock accumulation to be the periphery of another buried burned rock midden. The accumulation was clearly midden-like in every respect and could have been either an initial phase in midden development or the edge of a midden that actually developed. Faunal remains from Feature 201 include more identifiable large and medium mammals than from the other accumulations (i.e., large mammal, medium/large mammal, medium mammal, deer, canis, and carnivore). Also identified are rabbit, turtle, rodent, snake, fish, bird, and river mussel.

Human bones were found in several Late Archaic proveniences, mostly near a disturbed interment referred to as
Burial 1. The remains consist of several incomplete pelvic and lower limb bones, apparently the surviving portion of a disturbed grave. In nearby proveniences were a human skull and several other human bones, but it was not possible to ascertain if any of these may have once been part of Burial 1.

\section{MISCELLANEOUSARCHAIC MATERIALS}

In the Valley Margin, stratigraphic separation of cultural materials, especially in Unit Y and in pothole-disturbed areas, was insufficient for even gross temporal separation (Figures 9-45 and 9-46). There are two groupings of artifacts resulting from this condition, those assigned to undifferentiated Archaic and those to mixed Late Prehistoric and undifferentiated Archaic. These are tabulated here (Tables 9-39 through 9-47). 
TABLE 9-24

Frequencies of Projectile Points by Type from Late/Middle Archaic Contexts

\begin{tabular}{|c|c|c|}
\hline Period & Analysis Identification & Count of Item \\
\hline Late/Middle Archaic & Projectile point, Angostura & 2 \\
\hline Late/Middle Archaic & Projectile point, bifurcate stem fragment & 2 \\
\hline Late/Middle Archaic & Projectile point, Bulverde & 7 \\
\hline Late/Middle Archaic & Projectile point, Bulverde-like & 7 \\
\hline Late/Middle Archaic & Projectile point, Castroville & 2 \\
\hline Late/Middle Archaic & Projectile point, Darl & 2 \\
\hline Late/Middle Archaic & Projectile point, Edgewood & 1 \\
\hline Late/Middle Archaic & Projectile point, expanding concave B & 1 \\
\hline Late/Middle Archaic & Projectile point, expanding concave D & 2 \\
\hline Late/Middle Archaic & Projectile point, expanding stem B & 1 \\
\hline Late/Middle Archaic & Projectile point, Gary & 1 \\
\hline Late/Middle Archaic & Projectile point, indeterminate & 2 \\
\hline Late/Middle Archaic & Projectile point, Lange & 1 \\
\hline Late/Middle Archaic & Projectile point, Marcos & 3 \\
\hline Late/Middle Archaic & Projectile point, Marcos/Marshall & 1 \\
\hline Late/Middle Archaic & Projectile point, Martindale B & 1 \\
\hline Late/Middle Archaic & Projectile point, miscellaneous expanding stem & 1 \\
\hline Late/Middle Archaic & Projectile point, miscellaneous side-notched & 1 \\
\hline Late/Middle Archaic & Projectile point, Montell & 5 \\
\hline Late/Middle Archaic & Projectile point, Nolan & 10 \\
\hline Late/Middle Archaic & Projectile point, Nolan eccentric & 1 \\
\hline Late/Middle Archaic & Projectile point, Pedernales & 2 \\
\hline Late/Middle Archaic & Projectile point, rectangular stem A & 2 \\
\hline Late/Middle Archaic & Projectile point, rectangular stem B & 2 \\
\hline Late/Middle Archaic & Projectile point, square stem & 2 \\
\hline Late/Middle Archaic & Projectile point, Thrall & 2 \\
\hline Late/Middle Archaic & Projectile point, Travis & 2 \\
\hline Late/Middle Archaic & Projectile point, Uvalde-like & 2 \\
\hline Late/Middle Archaic & Projectile point, Wells & 1 \\
\hline Late/Middle Archaic & Projectile point, Bell/Andice & 3 \\
\hline Late/Middle Archaic & Projectile point fragment & 27 \\
\hline
\end{tabular}

\section{BURNED ROCKMIIDDENS}

As was commonplace at the times of the 1973 survey and 1981 testing of the Wilson-Leonard site, its array of multiple burned rock middens was the primary criterion upon which an assessment of significance was based. The initial excavation plan of 1982 targeted two of these middens as well as the area between them. These came to be designated Burned Rock Midden 1 (Figure 9-47) and Burned Rock Midden 2 (Figure 9-48). Both were near a gully that joined Spanish Oak Creek just up from its confluence with Brushy Creek. Midden 1 was adjacent to the head of the gully low on the slope of the valley wall, and Midden 2 was on the Valley Floor next to the mouth and the gully and close to the edge of Spanish Oak Creek. Evidently, there were at least two other middens at the site. Although the 1982-1984 excavations did not explicitly target midden formational history for investigation, the data gathered proved to be important in that regard.

The other finding, of utmost importance, is evidence that the processing of wild hyacinth bulbs occurred in these middens at least during both the Early Archaic (a hyacinth bulb from the base of Midden 1 or from the proto midden underlying it radiocarbon dated to $8250 \pm 80$ B.P.) and the Late Archaic (a hyacinth bulb from the middle of Midden 2 radiocarbon dated to $3789 \pm 70$ в.P.). On the surface of it, it might not seem prudent to place much importance on only two charred bulbs, but a consideration of the probabilities inherent in this sample argues otherwise. Hyacinth bulbs are soft and highly perishable with no part either macroscopic or microscopic that would endure in recognizable form in the ground for more than a few months at most. For these to have had any chance of surviving in the archeological record, they first had to escape being consumed by the people who gathered and cooked them and, that having happened, to last beyond almost immediate rotting, they had to be thoroughly charred. Even thorough charring was insufficient for the survival of most wood charcoal under the onslaught of earthworms at this site. Therefore, it is surprising that these and 10 bulbs in proto midden $\mathrm{B}$ charred to a consistency beyond the destructive powers of worms, roots, soil movement, and other factors. Beyond just durability of the charred matter, these delicate bulbs with their onion-like layering also had to remain intact in order to be 
TABLE 9-25

Frequencies of Projectile Points by Type from Late Archaic Contexts

\begin{tabular}{|c|c|c|}
\hline Period & Analysis Identification & Count of Item \\
\hline Late Archaic & Arrow point, preform & 1 \\
\hline Late Archaic & Arrow point, Scallorn & 1 \\
\hline Late Archaic & Projectile point, Bell/Andice & 1 \\
\hline Late Archaic & Projectile point, beveled narrow stemmed & 3 \\
\hline Late Archaic & Projectile point, Bulverde & 9 \\
\hline Late Archaic & Projectile point, Bulverde-like & 4 \\
\hline Late Archaic & Projectile point, Castroville & 9 \\
\hline Late Archaic & Projectile point, Darl & 4 \\
\hline Late Archaic & Projectile point, Edgewood & 2 \\
\hline Late Archaic & Projectile point, Ensor & 17 \\
\hline Late Archaic & Projectile point, Ensor/Fairland & 1 \\
\hline Late Archaic & Projectile point, expanding concave B & 1 \\
\hline Late Archaic & Projectile point, expanding stem D & 1 \\
\hline Late Archaic & Projectile point, Fairland & 4 \\
\hline Late Archaic & Projectile point, Frio & 2 \\
\hline Late Archaic & Projectile point, Hoxie & 1 \\
\hline Late Archaic & Projectile point, indeterminate & 1 \\
\hline Late Archaic & Projectile point, Jetta & 1 \\
\hline Late Archaic & Projectile point, Marcos & 9 \\
\hline Late Archaic & Projectile point, Marshall & 5 \\
\hline Late Archaic & Projectile point, miscellaneous bifurcate & 3 \\
\hline Late Archaic & Projectile point, miscellaneous expanding stem & 2 \\
\hline Late Archaic & Projectile point, miscellaneous lanceolate & 1 \\
\hline Late Archaic & Projectile point, miscellaneous side-notched & 2 \\
\hline Late Archaic & Projectile point, Montell & 15 \\
\hline Late Archaic & Projectile point, Nolan & 1 \\
\hline Late Archaic & Projectile point, Pedernales & 9 \\
\hline Late Archaic & Projectile point, rectangular stem B & 1 \\
\hline Late Archaic & Projectile point, rectangular stem $\mathrm{C}$ & 4 \\
\hline Late Archaic & Projectile point, square stem & 3 \\
\hline Late Archaic & Projectile point, Travis-like & 1 \\
\hline Late Archaic & Projectile point, Uvalde & 1 \\
\hline Late Archaic & Projectile point, Wells & 1 \\
\hline Late Archaic & Projectile point, Williams & 3 \\
\hline Late Archaic & Projectile point fragment & 42 \\
\hline
\end{tabular}

TABLE 9-26

Frequencies of Projectile Points by Type from Late Prehistoric/Late Archaic Contexts

\begin{tabular}{l|l|c}
\hline \multicolumn{1}{c|}{ Period } & \multicolumn{1}{c}{ Analysis Identification } & Count of Item \\
\hline Late Prehistoric/Late Archaic & Arrow point, medial & 1 \\
Late Prehistoric/Late Archaic & Arrow point, Perdiz & 1 \\
Late Prehistoric/Late Archaic & Arrow point, preform & 2 \\
Late Prehistoric/Late Archaic & Arrow point, Scallorn & 19 \\
Late Prehistoric/Late Archaic & Arrow point, Scallorn/Edwards & 1 \\
Late Prehistoric/Late Archaic & Arrow point, stemmed & 8 \\
Late Prehistoric/Late Archaic & Arrow point, tip & 3 \\
Late Prehistoric/Late Archaic & Projectile point, bifurcate stem fragment & 2 \\
Late Prehistoric/Late Archaic & Projectile point, Castroville & 1 \\
Late Prehistoric/Late Archaic & Projectile point, Darl & 10 \\
Late Prehistoric/Late Archaic & Projectile point, Ensor & 10 \\
Late Prehistoric/Late Archaic & Projectile point, Gower & \\
Late Prehistoric/Late Archaic & Projectile point, indeterminate & \\
Late Prehistoric/Late Archaic & Projectile point, Marcos & \\
Late Prehistoric/Late Archaic & Projectile point, miscellaneous bifurcate & \\
Late Prehistoric/Late Archaic & Projectile point, miscellaneous side-notched & 1 \\
Late Prehistoric/Late Archaic & Projectile point, Montell & 3 \\
Late Prehistoric/Late Archaic & Projectile point, Nolan & \\
Late Prehistoric/Late Archaic & Projectile point, rectangular stem (eccentric) & \\
Late Prehistoric/Late Archaic & Projectile point, rectangular stem A & \\
Late Prehistoric/Late Archaic & Projectile point, Uvalde-like & 1 \\
Late Prehistoric/Late Archaic & Projectile point fragment & 1 \\
\hline \hline
\end{tabular}


TABLE 9-27

Frequencies of Bifaces, Clear Fork Tools, Cores, and Core Tools from Late/Middle Archaic Contexts

\begin{tabular}{l|l|c}
\hline \multicolumn{1}{c|}{ Period } & \multicolumn{1}{c}{ Analysis Identification } & Count of Item \\
\hline Late/Middle Archaic & Biface Stage 1 & 12 \\
Late/Middle Archaic & Biface Stage 2 & 40 \\
Late/Middle Archaic & Biface Stage 3 & 11 \\
Late/Middle Archaic & Bifacial tool & 2 \\
Late/Middle Archaic & Bifacial tool Form A & 3 \\
Late/Middle Archaic & Bifacial tool Form D & 1 \\
Late/Middle Archaic & Bifacial tool Form H & 1 \\
Late/Middle Archaic & Brushy Creek biface & 1 \\
Late/Middle Archaic & Clear Fork biface & 1 \\
Late/Middle Archaic & Clear Fork uniface & \\
Late/Middle Archaic & Biface fragment & \\
Late/Middle Archaic & Biface fragment & \\
Late/Middle Archaic & Core tool, type 2 & 1 \\
Late/Middle Archaic & Core tool, type 3 & 1 \\
Late/Middle Archaic & Core tool, type 4 & \\
Late/Middle Archaic & Core tool, type 5 & \\
Late/Middle Archaic & Chert cobble, chunk & \\
Late/Middle Archaic & Chert cobble, unmodified & \\
Late/Middle Archaic & Core fragment & 3 \\
Late/Middle Archaic & Micro-core, intermediate & 2 \\
\hline \hline
\end{tabular}

TABLE 9-28

Frequencies of Bifaces, Clear Fork Tools, Cores, and Core Tools from Late Archaic Contexts

\begin{tabular}{|c|c|c|}
\hline Period & Analysis Identification & Count of Item \\
\hline Late Archaic & Biface Stage 1 & 26 \\
\hline Late Archaic & Biface Stage 2 & 69 \\
\hline Late Archaic & Biface Stage 3 & 29 \\
\hline Late Archaic & Bifacial tool & 1 \\
\hline Late Archaic & Bifacial tool Form A & 6 \\
\hline Late Archaic & Bifacial tool Form B & 5 \\
\hline Late Archaic & Bifacial tool Form F & 1 \\
\hline Late Archaic & Bifacial tool Form $\mathrm{H}$ & 1 \\
\hline Late Archaic & Bifacial tool Form $\mathbf{J}$ & 2 \\
\hline Late Archaic & Clear Fork biface, proximal & 1 \\
\hline Late Archaic & Clear Fork uniface & 1 \\
\hline Late Archaic & Biface fragment & 59 \\
\hline Late Archaic & Biface fragment & 1 \\
\hline Late Archaic & Core tool, type 1 & 1 \\
\hline Late Archaic & Core tool, type 2 & 1 \\
\hline Late Archaic & Core tool, type 4 & 3 \\
\hline Late Archaic & Core tool, type 5 & 1 \\
\hline Late Archaic & Chert cobble, chunk & 1 \\
\hline Late Archaic & Chert cobble, unmodified & 1 \\
\hline Late Archaic & Core fragment & 6 \\
\hline Late Archaic & Core, multidirectional & 2 \\
\hline Late Archaic & Core, thermal & 5 \\
\hline Late Archaic & Micro-core, intermediate & 1 \\
\hline Late Archaic & Micro-core, large & 2 \\
\hline Late Archaic & Micro-core, small & 3 \\
\hline
\end{tabular}


TABLE 9-29

Frequencies of Bifaces, Core Tools, and Cores from Late Prehistoric/Late Archaic Contexts

\begin{tabular}{l|l|c}
\hline \multicolumn{1}{c|}{ Period } & \multicolumn{1}{c}{ Analysis Identification } & Count of Item \\
\hline Late Prehistoric/Late Archaic & Biface & 2 \\
Late Prehistoric/Late Archaic & Biface Stage 1 & 7 \\
Late Prehistoric/Late Archaic & Biface Stage 2 & 49 \\
Late Prehistoric/Late Archaic & Biface Stage 3 & 8 \\
Late Prehistoric/Late Archaic & Bifacial tool & 1 \\
Late Prehistoric/Late Archaic & Bifacial tool Form A & 3 \\
Late Prehistoric/Late Archaic & Bifacial tool Form B & 1 \\
Late Prehistoric/Late Archaic & Bifacial tool Form E & 1 \\
Late Prehistoric/Late Archaic & Bifacial tool Form F & 1 \\
Late Prehistoric/Late Archaic & Bifacial tool Form J & \\
Late Prehistoric/Late Archaic & Pièce esquillée & \\
Late Prehistoric/Late Archaic & Biface fragment & 3 \\
Late Prehistoric/Late Archaic & Biface fragment & 35 \\
Late Prehistoric/Late Archaic & Biface fragment & 1 \\
Late Prehistoric/Late Archaic & Core tool, type 1 & \\
Late Prehistoric/Late Archaic & Chert cobble, chunk & \\
Late Prehistoric/Late Archaic & Chert cobble, unmodified/tested & \\
Late Prehistoric/Late Archaic & Core fragment & 1 \\
Late Prehistoric/Late Archaic & Core, multidirectional & \\
Late Prehistoric/Late Archaic & Core, thermal & \\
Late Prehistoric/Late Archaic & Micro-core, intermediate & 1 \\
\hline \hline
\end{tabular}

TABLE 9-30

Frequencies of Perforators and Burins from Late/Middle Archaic Contexts

\begin{tabular}{l|l|c}
\hline \multicolumn{1}{c|}{ Period } & \multicolumn{1}{c}{ Analysis Identification } & Count of Item \\
\hline Late/Middle Archaic & Perforator Group 1 & 1 \\
Late/Middle Archaic & Perforator Group 2 & 1 \\
Late/Middle Archaic & Perforator Group 7 & 2 \\
Late/Middle Archaic & Burin & 4 \\
Late/Middle Archaic & Burin spall & 6 \\
\hline \hline
\end{tabular}

TABLE 9-31

Frequencies of Perforators and Burins from Late Archaic Contexts

\begin{tabular}{l|l|c}
\hline \multicolumn{1}{c|}{ Period } & \multicolumn{1}{c}{ Analysis Identification } & Count of Item \\
\hline Late Archaic & Perforator Group 1 & 2 \\
Late Archaic & Perforator Group 3 & 2 \\
Late Archaic & Perforator Group 7 & 5 \\
Late Archaic & Perforator Unifacial & 1 \\
Late Archaic & Burin & 20 \\
Late Archaic & Burin spall & 17 \\
\hline \hline
\end{tabular}

TABLE 9-32

Frequencies of Perforators, Burins, and Burin Spalls from Late Prehistoric/Late Archaic Contexts

\begin{tabular}{l|l|c}
\hline \multicolumn{1}{c|}{ Period } & \multicolumn{1}{c}{ Analysis Identification } & Count of Item \\
\hline Late Prehistoric/Late Archaic & Perforator Group 1 & 1 \\
Late Prehistoric/Late Archaic & Perforator Group 3 & 1 \\
Late Prehistoric/Late Archaic & Perforator Unifacial & 1 \\
Late Prehistoric/Late Archaic & Burin & 4 \\
Late Prehistoric/Late Archaic & Burin spall & 9 \\
\hline \hline
\end{tabular}


TABLE 9-33

Frequencies of Unifaces and Edge-modified Flake Tools from Late/Middle Archaic Contexts

\begin{tabular}{l|l|c}
\hline \multicolumn{1}{c|}{ Period } & \multicolumn{1}{c}{ Analysis Identification } & Count of Item \\
\hline Late/Middle Archaic & Notched flake & 9 \\
Late/Middle Archaic & Thick uniface & 4 \\
Late/Middle Archaic & Thin uniface & 7 \\
Late/Middle Archaic & Thin uniface fragment & 3 \\
Late/Middle Archaic & Uniface, unanalyzed & 47 \\
Late/Middle Archaic & Unifacial multiple tool & 12 \\
Late/Middle Archaic & Denticulated flake & 4 \\
Late/Middle Archaic & Edge-modified flake & 78 \\
Late/Middle Archaic & Microspur/microdenticulate & 2 \\
Late/Middle Archaic & Blade & \\
Late/Middle Archaic & Denticulated flake & \\
Late/Middle Archaic & Edge-modified flake & \\
Late/Middle Archaic & Retouched blade & \\
Late/Middle Archaic & Spurred flake & \\
Late/Middle Archaic & Thick uniface & 1 \\
Late/Middle Archaic & Thin uniface & \\
Late/Middle Archaic & Thin uniface fragment & \\
Late/Middle Archaic & Unifacial multiple tool & \\
\hline \hline
\end{tabular}

TABLE 9-34

Frequencies of Unifaces and Edge-modified Flake Tools from Late Archaic Contexts

\begin{tabular}{l|l|c}
\hline \multicolumn{1}{c|}{ Period } & \multicolumn{1}{|c}{ Analysis Identification } & Count of Item \\
\hline Late Archaic & Denticulated flake & 6 \\
Late Archaic & Edge-modified flake & 125 \\
Late Archaic & Microspur/microdenticulate & 1 \\
Late Archaic & Notched flake & 7 \\
Late Archaic & Retouched blade & 1 \\
Late Archaic & Spurred flake & 2 \\
Late Archaic & Thick uniface & 1 \\
Late Archaic & Thin uniface & 16 \\
Late Archaic & Thin uniface fragment & 10 \\
Late Archaic & Uniface, unanalyzed & 72 \\
Late Archaic & Unifacial multiple tool & 22 \\
Late Archaic & Denticulated flake & 7 \\
Late Archaic & Edge-modified flake & 101 \\
Late Archaic & Edge-modified flake, unanalyzed & 1 \\
Late Archaic & Microspur/microdenticulate & 1 \\
Late Archaic & Notched flake & 12 \\
Late Archaic & Retouched blade & 1 \\
Late Archaic & Spurred flake & 3 \\
Late Archaic & Thick uniface & 2 \\
Late Archaic & Thin uniface & 6 \\
Late Archaic & Thin uniface fragment & 3 \\
Late Archaic & Unifacial multiple tool & 12 \\
\hline \hline
\end{tabular}

TABLE 9-35

Frequencies of Unifaces and Edge-modified Flake Tools from Late Prehistoric/Late Archaic Contexts

\begin{tabular}{l|l|c}
\hline \multicolumn{1}{c|}{ Period } & \multicolumn{1}{|c}{$\begin{array}{c}\text { Analysis } \\
\text { Identification }\end{array}$} & $\begin{array}{c}\text { Count of } \\
\text { Item }\end{array}$ \\
\hline $\begin{array}{l}\text { Late Prehistoric/Late Archaic } \\
\text { Late Prehistoric/Late Archaic }\end{array}$ & $\begin{array}{l}\text { Edge-modified flake } \\
\text { Notched flake }\end{array}$ & 21 \\
Late Prehistoric/Late Archaic & Retouched blade & 10 \\
Late Prehistoric/Late Archaic & Thin uniface & 9 \\
Late Prehistoric/Late Archaic & Thin uniface & 7 \\
fragment & \\
Late Prehistoric/Late Archaic & Uniface, unanalyzed & 27 \\
Late Prehistoric/Late Archaic & Unifacial multiple & 11 \\
& tool & 1 \\
Late Prehistoric/Late Archaic & Denticulated flake & 1 \\
Late Prehistoric/Late Archaic & Edge-modified flake & 40 \\
Late Prehistoric/Late Archaic & Microspur/ & 1 \\
microdenticulate & 1 \\
Late Prehistoric/Late Archaic & Notched flake & 1 \\
Late Prehistoric/Late Archaic & Retouched blade & 2 \\
Late Prehistoric/Late Archaic & Spurred flake & 2 \\
Late Prehistoric/Late Archaic & Thick uniface & 1 \\
Late Prehistoric/Late Archaic & Thin uniface & 2 \\
fragment & 1 \\
Late Prehistoric/Late Archaic & Uniface & 8 \\
Late Prehistoric/Late Archaic & Unifacial multiple \\
& tool & \\
\hline \hline
\end{tabular}

TABLE 9-36

Frequencies of Ground Stone Tools from Late/Middle Archaic Contexts

\begin{tabular}{l|l|c}
\hline \multicolumn{1}{c|}{ Period } & \multicolumn{1}{c}{ Analysis Identification } & Count of Item \\
\hline Late/Middle Archaic & Indeterminate ground stone & 2 \\
Late/Middle Archaic & Mano & 1 \\
Late/Middle Archaic & Mano fragment & 3 \\
Late/Middle Archaic & Metate fragment & 1 \\
Late/Middle Archaic & Battered cobble & 1 \\
\hline \hline
\end{tabular}


TABLE 9-37

Frequencies of Ground Stone Tools from Late Archaic Contexts

\begin{tabular}{l|l|c}
\hline \multicolumn{1}{c|}{ Period } & Analysis Identification & Count of Item \\
\hline Late Archaic & Mano & 4 \\
Late Archaic & Mano fragment & 4 \\
Late Archaic & Mano/hammerstone & 1 \\
Late Archaic & Metate fragment & 5 \\
Late Archaic & Stone pipe & 1 \\
Late Archaic & Battered cobble & 1 \\
Late Archaic & Large core hammerstone & 1 \\
Late Archaic & Small core hammerstone & 1 \\
Late Archaic & Worked hematite & 1 \\
\hline \hline
\end{tabular}

TABLE 9-38

Frequencies of Ground Stone Tools from Late Prehistoric/ Late Archaic Contexts

\begin{tabular}{l|l|c}
\hline \multicolumn{1}{c|}{ Period } & Analysis Identification & Count of Item \\
\hline Late Prehistoric/ & Mano fragment & 3 \\
$\begin{array}{l}\text { Late Archaic } \\
\text { Late Prehistoric/ } \\
\text { Late Archaic }\end{array}$ & Possible ground stone & 2 \\
\hline \hline
\end{tabular}
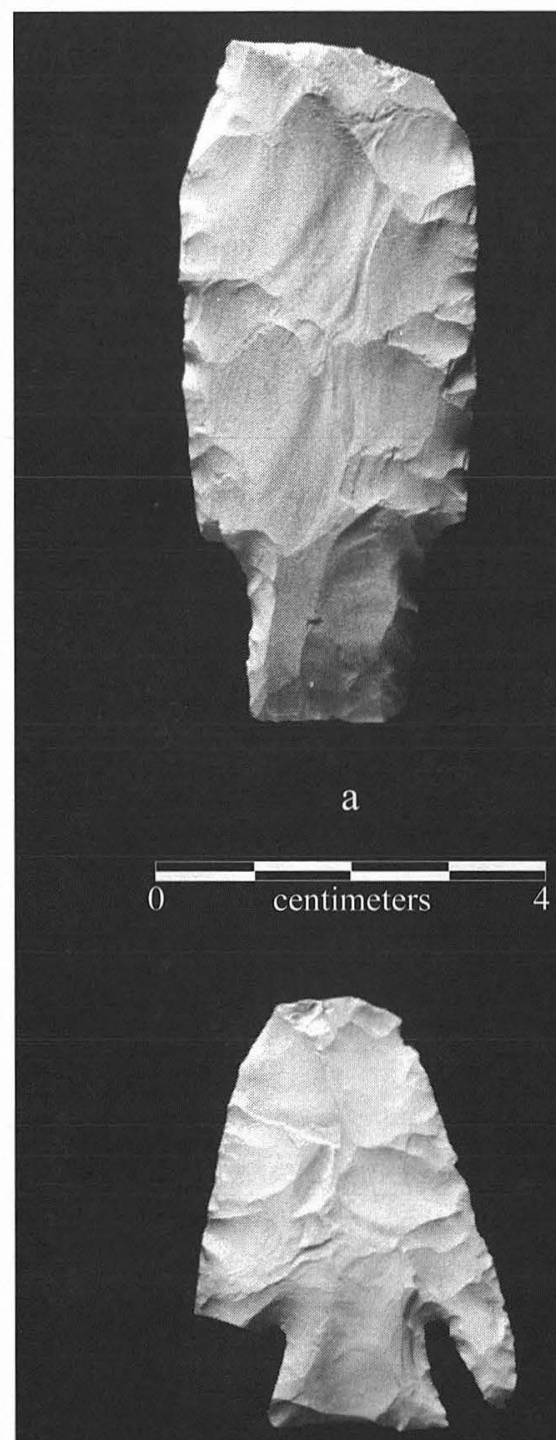

d

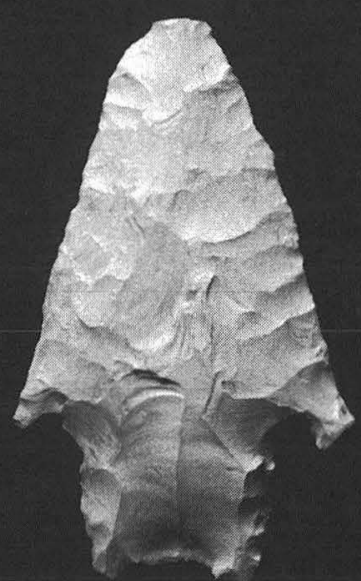

b

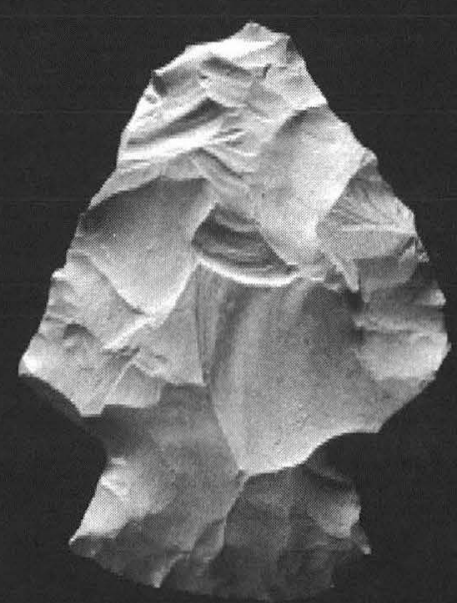

e

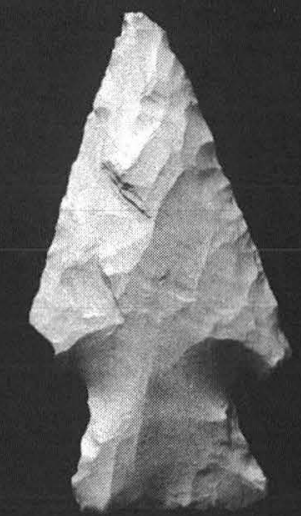

c

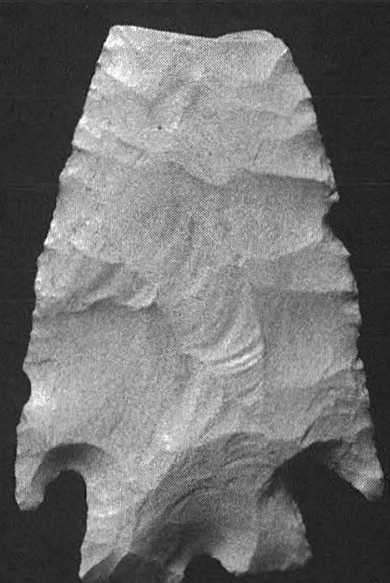

f

FIGURE 9-35. Projectile points from Late Archaic and mixed contexts. Specimen a is from deposits assigned to Late/Middle Archaic; the remainder are Late Archaic. (a) Bulverde; (b) Pedernales; (c) Marcos; (d) Marshall; (e) Castroville; (f) Montell. Specimen numbers: (a) 10G-1; (b) 37EC-39; (c) 1315-1; (d) 463-1; (e) 37ED-56; (f) 10D-2. 


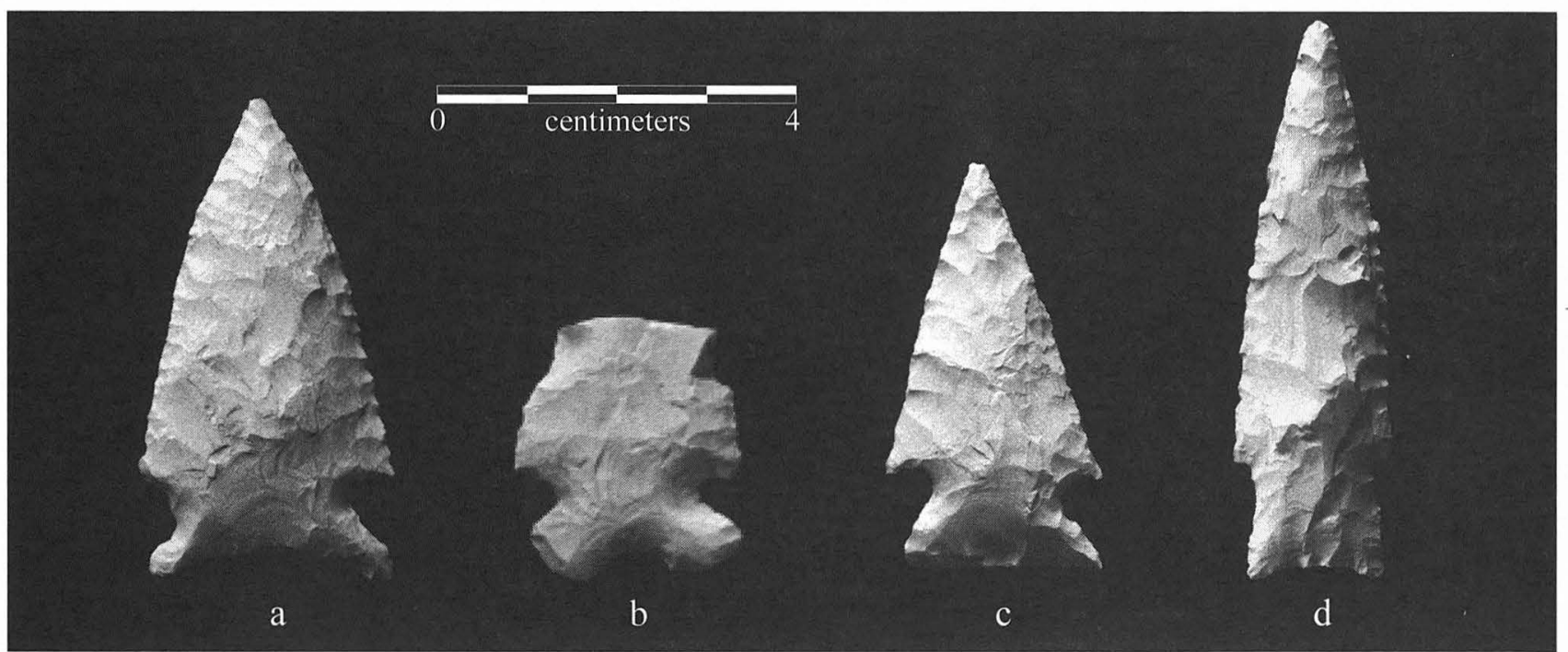

FIGURE 9-36. Representative projectile points from the later part of the Late Archaic. (a) Fairland; (b) Frio; (c) Ensor; (d) Darl. Specimen numbers: (a) 2E-2; (b) 11D-2; (c) 260-1; (d) 9C-1.

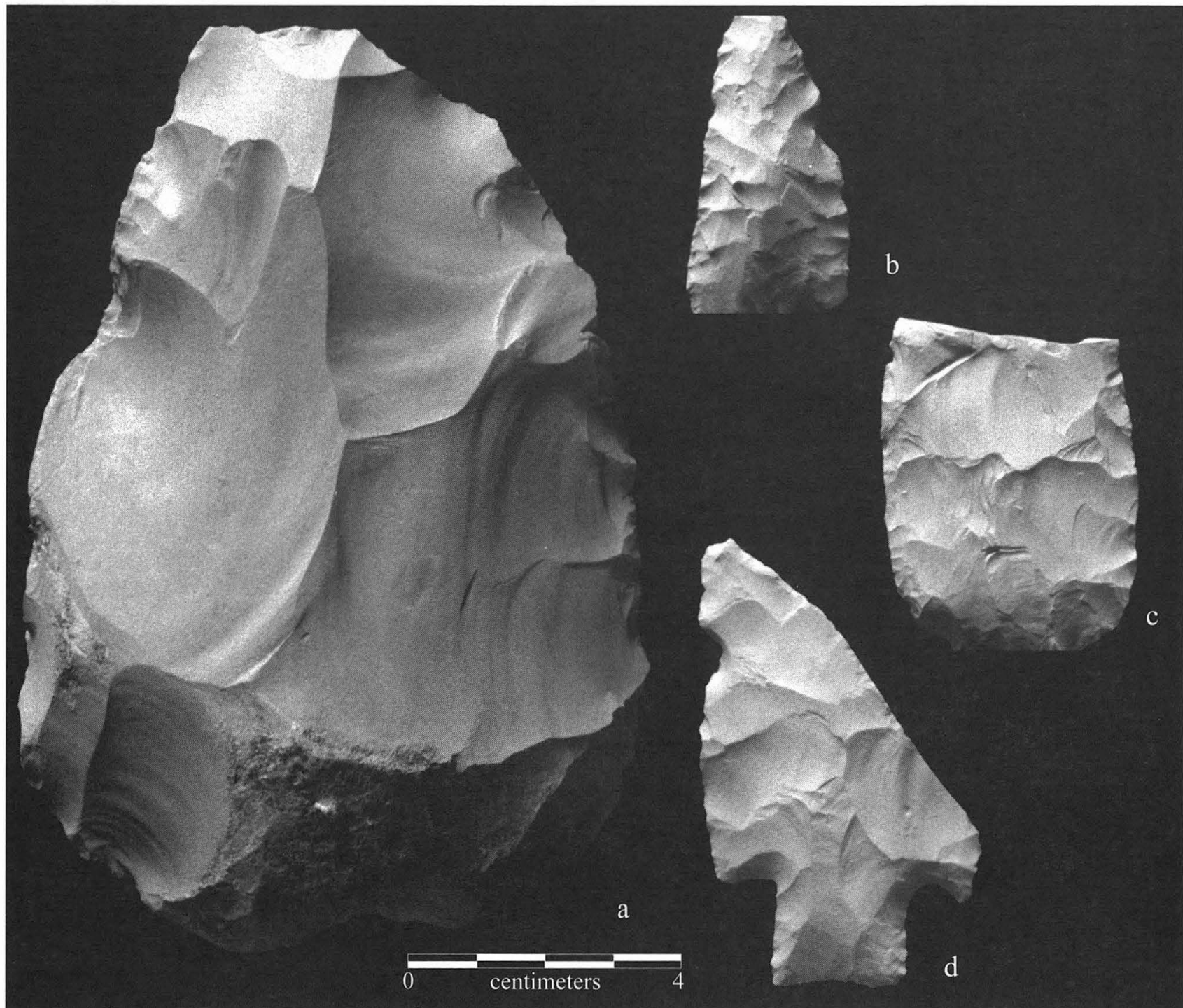

FIGURE 9-37. Representative bifaces and preforms from Late Archaic contexts. (a) Stage 1 biface from "cache" Feature 11; (b-d) Stage 3 bifaces. Specimen numbers: (a) 10E-1; (b) 8C-1; (c) 13E-5; (d) 15D-1. 


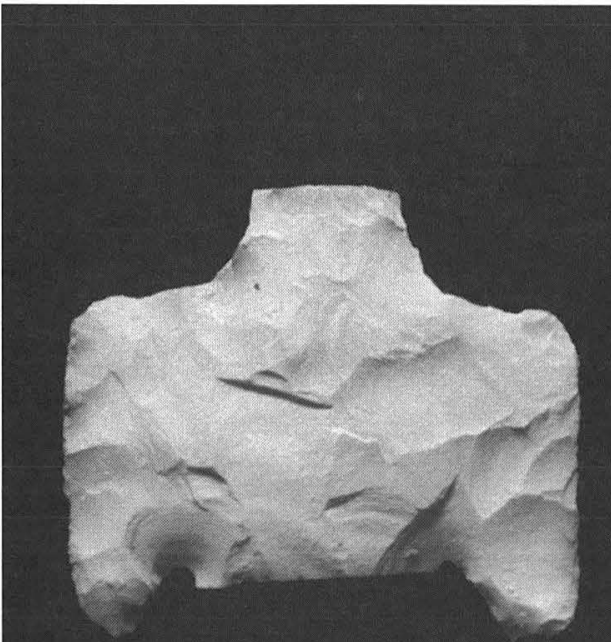

a

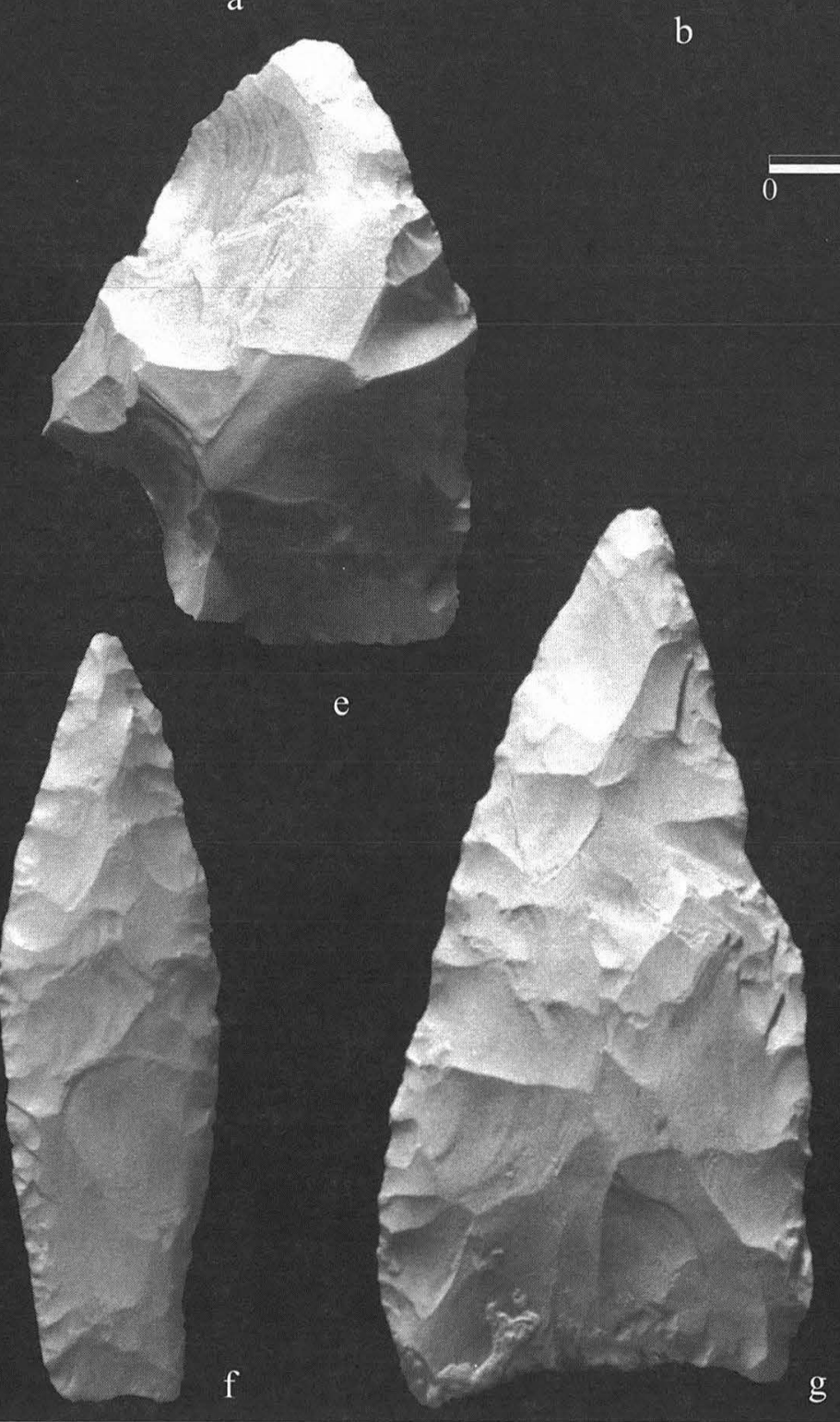

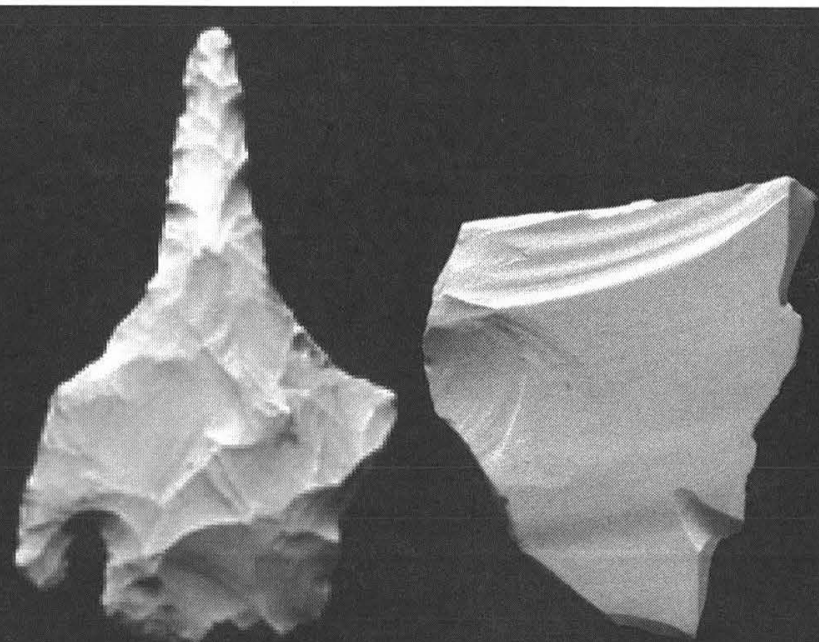

c
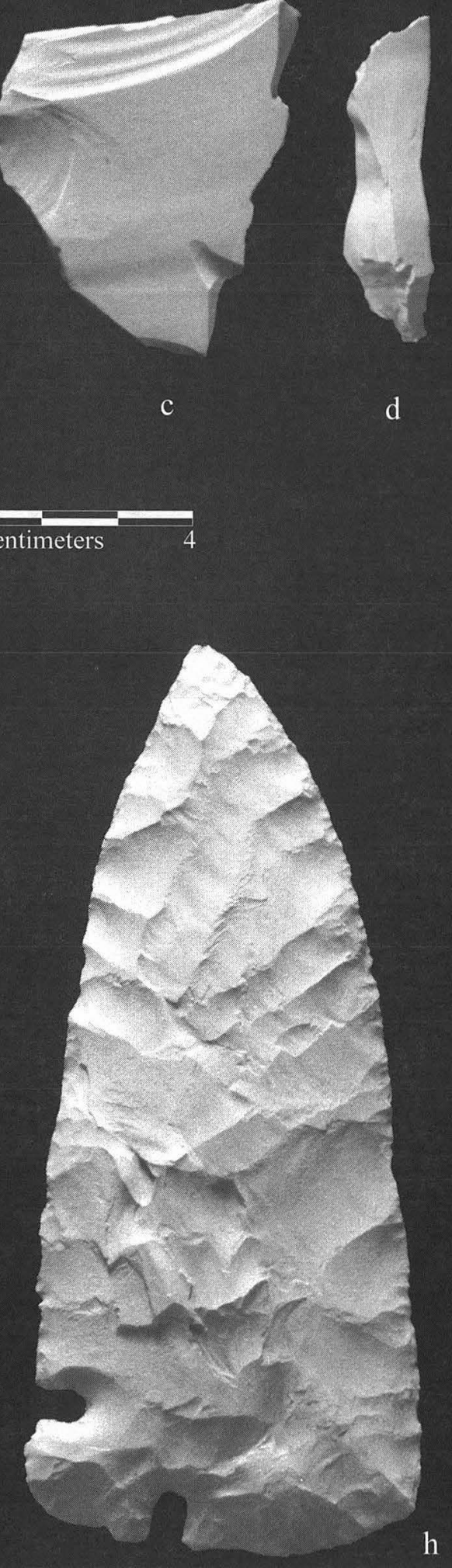

FigURE 9-38. Bifacial tools from Late Archaic contexts. (a, b) Group 3 perforators; (c) burin; (d) burin spall; (e) bifacial tool Form 11; (f, g) Form 1 knife-like bifacial tools; (h) corner tang biface. Specimen numbers: (a) 36D-8; (b) 14D-2; (c) 8D-4; (d) 16C-6; (e) 14D-8; (f) 10D1; (g) 51ED-10; (h) 37DA-11. 


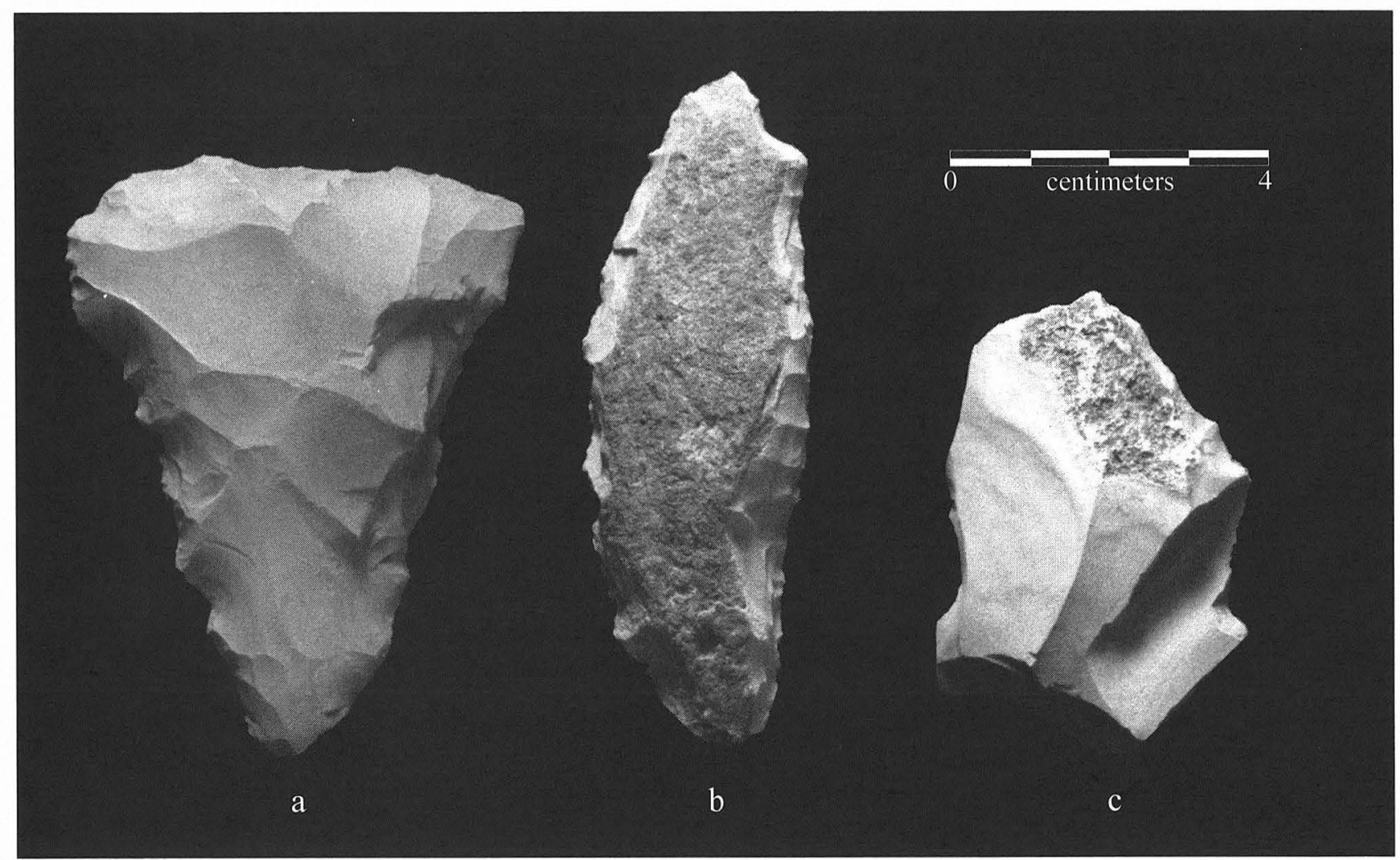

FIGURE 9-39. Representative unifacial tools from Late Archaic contexts. (a) Clear Fork uniface; (b) unifacial multiple tool; (c) notched flake. Specimen numbers: (a) 3D-7; (b) 36D-30; (c) 37ED-46.

recovered and recognized archeologically. So survival of a small number of charred hyacinth bulbs for 3,700 or 8,200 years under overwhelmingly adverse odds is best explained by the inference that they represent a sample from a very large population and that, therefore, the cooking and consumption of this geophyte was an important subsistence activity at this site. The chance preservation of these delicate bulbs is probably similar to that seen elsewhere in the archeological record where archeologists accept the fact that even commonplace aspects of past cultures are known from extremely rare cases of preservation. Plant foods, textile impressions, and human foot prints are very rarely found in open archeological sites, but we assume that people always consumed plants, that textiles have long been widely in use, and that humans always had feet that left tracks in the mud or dust of their habitation areas.

Although Burned Rock Midden 1 (see Figure 9-47) began to grow during the Early Archaic and the beginnings of Burned Rock Midden 2 can be dated to the Middle Archaic, both of these features increased greatly in volume and achieved their final, domed shape during the Late Archaic. Intensive use of Burned Rock Midden 1 seems to have continued later in the Late Archaic than was the case in Burned Rock Midden 2, and it is possible that some use of Burned Rock Midden 1 occurred during the Austin interval of the Late Prehistoric. Two features, Feature 11 (biface cache) and Burial 1, were found within Burned Rock Midden 1, but both are considered intrusive, Late Archaic features that are probably functionally unrelated to the midden.

Burned Rock Midden 1 was approximately $16 \mathrm{~m}$ in diameter, $1 \mathrm{~m}$ in thickness, and completely buried. It was crosssectioned in the excavation and showed an even, domed upper surface. Its structure consisted of an undifferentiated mass of fragmentary burned limestone rocks, little ash, and sparse, fine-grained charcoal. Some charcoal pieces could be identified and included wood of juniper, live oak, dogwood, elm, mulberry, and arboreal legume as well as black walnut nutshell. Although no clear-cut burned rock features were discerned within the midden, there are indications in the profile drawings and photographs of stone-lined pits. Diverse taxa are represented by the faunal remains, including deer, antelope, carnivore, jackrabbit, cottontail rabbit, rodents, snake, turtle, toad/frog, and mussel. Also present are fish, bird eggshell, and aquatic snails.

From an underlying, Early Archaic proto midden, Midden 1 grew upslope to the south in Early Archaic times and then grew up and eventually north, downslope in the Middle and Late Archaic. These trajectories of growth are recorded both in the distribution of diagnostic projectile points and the stratigraphic contexts of the base, upslope margin, downslope margin, and upper surface of the midden. In the main mass of the midden, Darl and Ensor points predominate in the upper $40 \mathrm{~cm}$ of the main part of the midden while Marcos, Marshall, Bulverde, Nolan, and Travis characterize the lower $40 \mathrm{~cm}$. 


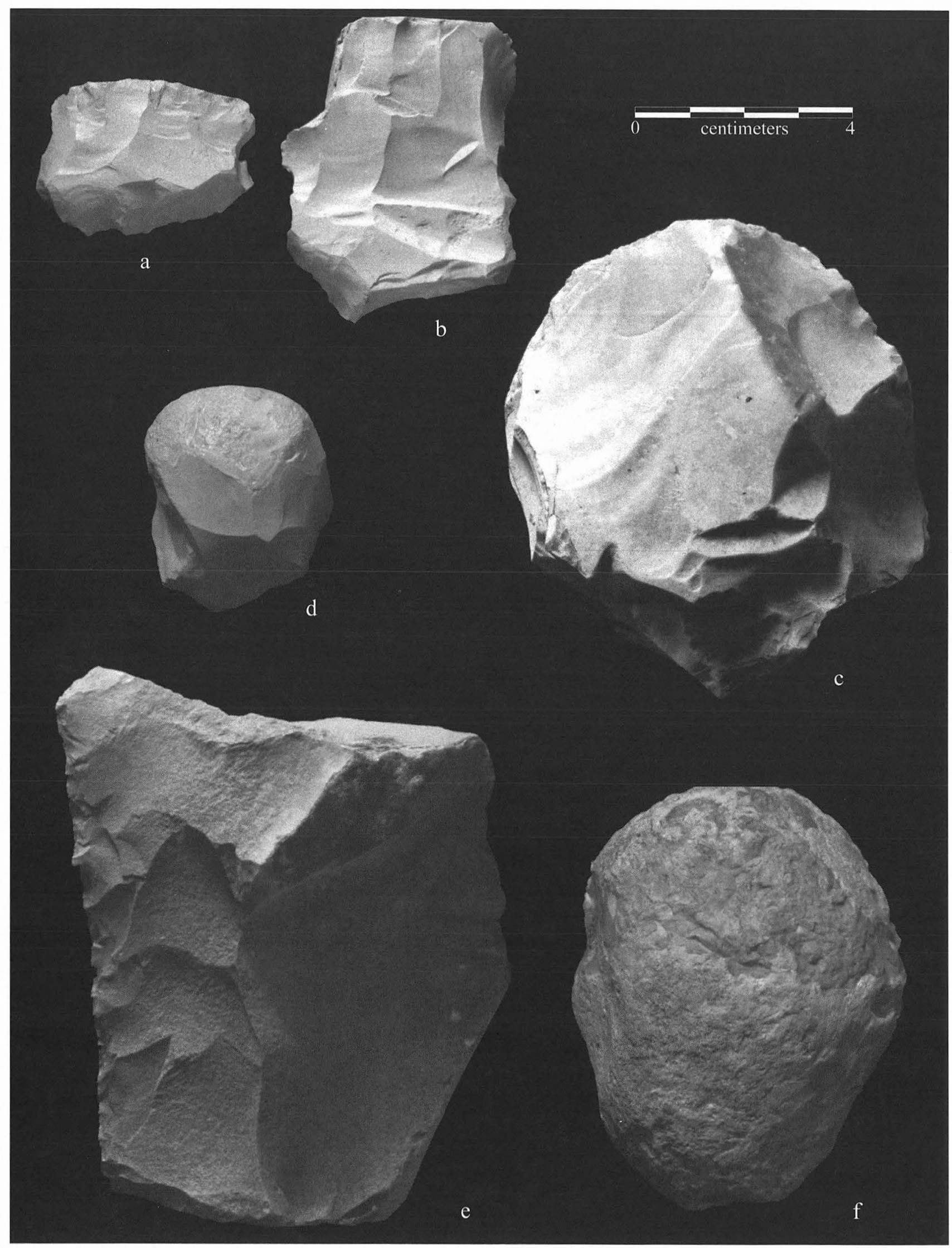

FIGURE 9-40. Representative cores and core tools from Late Archaic contexts. (a) small microcore; (b) intermediate microcore; (c) small core hammerstone; (d) core tool Type 2; (e) core tool Type 4; (f) battered cobble. Specimen numbers: (a) 9C-25; (b) 17C-11; (c) 11C-9; (d) 36D28 ; (e) 24D; (f) 1D-3. 


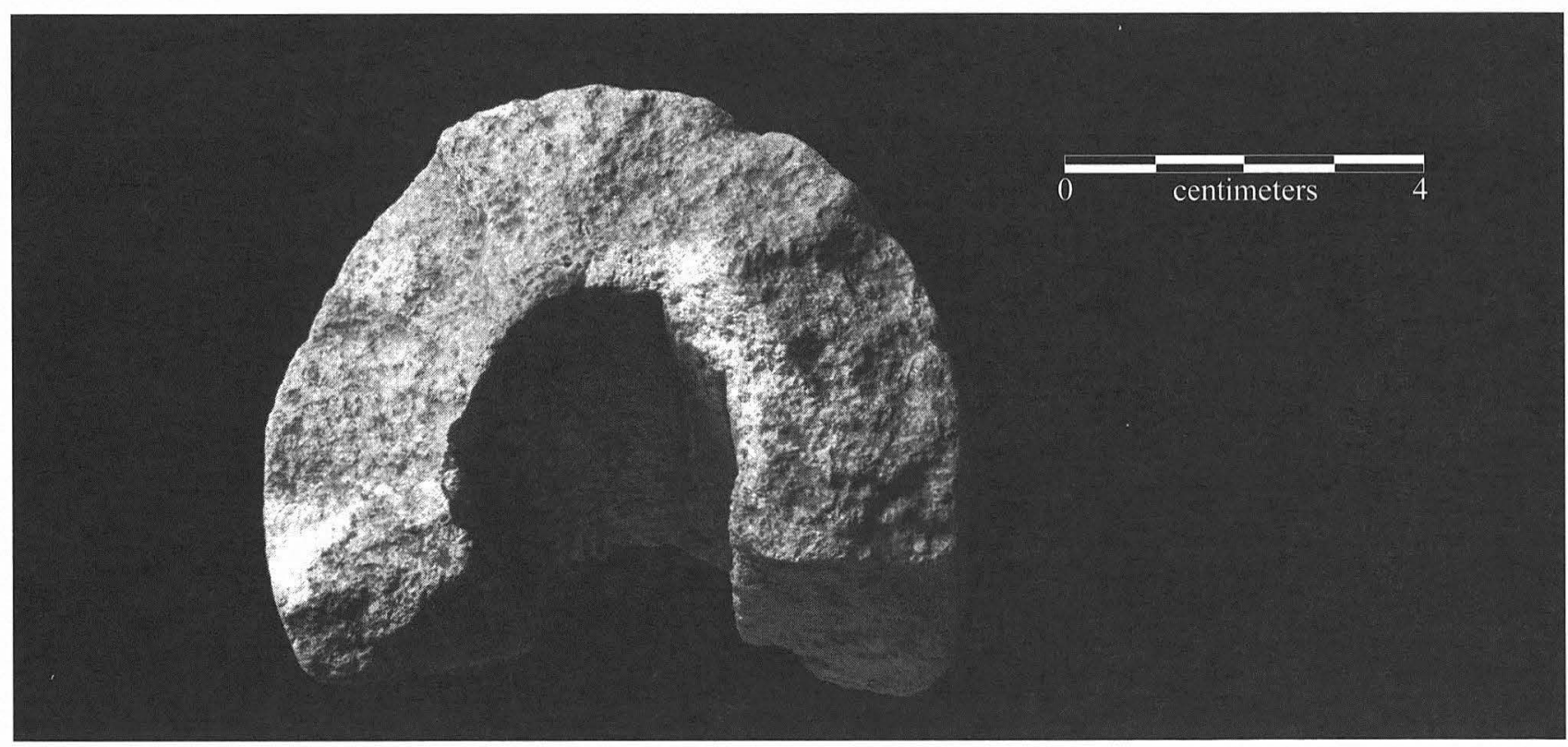

FIGURE 9-41. Ground stone cylindrical pipe fragment (Specimen 16C-2) from Late Archaic context.

Earlier Uvalde, Martindale, Baker, and Gower/Uvalde are noteworthy dart point types in the proto midden. Ground stone artifacts were almost absent from the entire midden.

Burned Rock Midden 2 (see Figure 9-48) was visible at the surface at the time of the TxDOT investigations, and it was determined that the midden was about $18-\mathrm{x}-20 \mathrm{~m}$ in extent. A small area (2-x-4 m) was excavated near the center of this midden where the burned rock deposits were found to be about $1 \mathrm{~m}$ thick. The upper $60 \mathrm{~cm}$ were dense, rocky, and ashy with comparatively low amounts of chert debris or other artifacts. Diagnostic artifacts are primarily Bulverde, Nolan, Travis, and Lange. From 70 to $90 \mathrm{~cm}$ below surface, the structure of the deposit was less densely packed with rocks and contained less ash. The artifact content was greater, and diagnostic artifacts include Nolan and Bulverde. It was from this lower section that the 3,700-year-old hyacinth bulb was recovered. A pit (Feature 194) with ashy fill extended from the lower portion of this midden into the midden subsoil, possibly representing the remains of an earth oven.

Underneath the main part of Midden 2 was found proto midden C (Feature 195). The only ground stone artifacts from the Midden 2 area were recovered from the proto midden levels and consist of one fragmentary mano and one fragmentary metate. Diagnostic artifacts include Nolan, Travis, and Early Triangular dart points. There was more faunal material in proto midden $\mathrm{C}$ than in overlying Burned Rock Midden 2, including mussel, turtle, deer, and rabbit. On the other hand, the midden yielded more charcoal, including that of walnut, elm, and live oak wood.

\section{CONCLUSIONS}

Human use of the Wilson-Leonard site for 7,500 years during the Archaic produced an artifact record notable more for its consistency than for its changes. Though varying in detail, representation of each of the major artifact classes remains comparatively similar throughout the period. It is not known if brief interval fluctuations have been lost in the coarse-grained temporal separations that could be discerned in the site stratigraphy, and it is possible that with better stratigraphic resolution, more variation over time would be revealed. However, the fairly static artifact record seems to be corroborated by the history of burned rock features at the site.

Although the archeological expression of domestic burned rock features shows substantial change over time, the activities producing that record seem not to have changed greatly. Small stone-lined hearths were in use throughout the Archaic period at the site and from the earliest Archaic through to the end of the Late Archaic, earth ovens were also used. Because with centuries or millennia of repeated use on slowly aggrading surfaces, earth oven use gradually resulted in the accumulation of middens of burned rocks, the material consequencies of one kind of behavior are dramatically different from early to late in the continuum.

Hunter-gatherers confronted with patchy resource distributions commonly maximize their exploitation of two or more resources by coordinating extractive activities according to the spacing, timing, or both, of those resources (Jochim 1981; Kelly 1995; Winterhalder and Smith 1981). But it is sometimes the case that one resource is the principal one in determining where and when it and nearby resources are exploited (Kelly 1995:90-97; Winterhalder 1981:68-98). The evidence from Wilson-Leonard raises the possibility that one principal resource, inulin-rich hyacinth, may largely account for the site's Archaic pattern. As Wandsnider (1997:34) notes, "ethnographic accounts indicate that inulin- and lipid-rich 

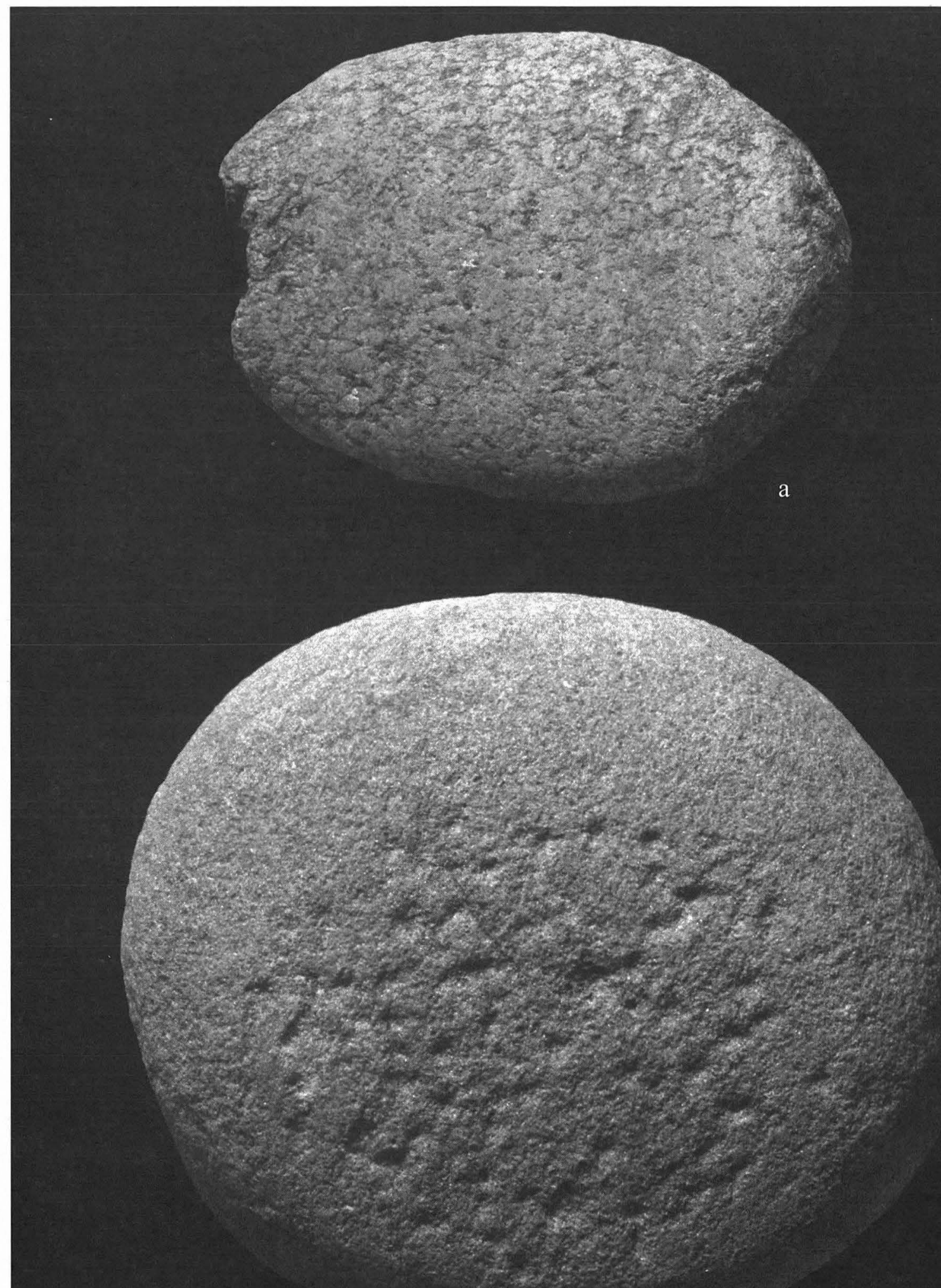

FIGURE 9-42. Ground stone manos from Late Archaic contexts. (a) 9C-4; (b) 36D-20. 


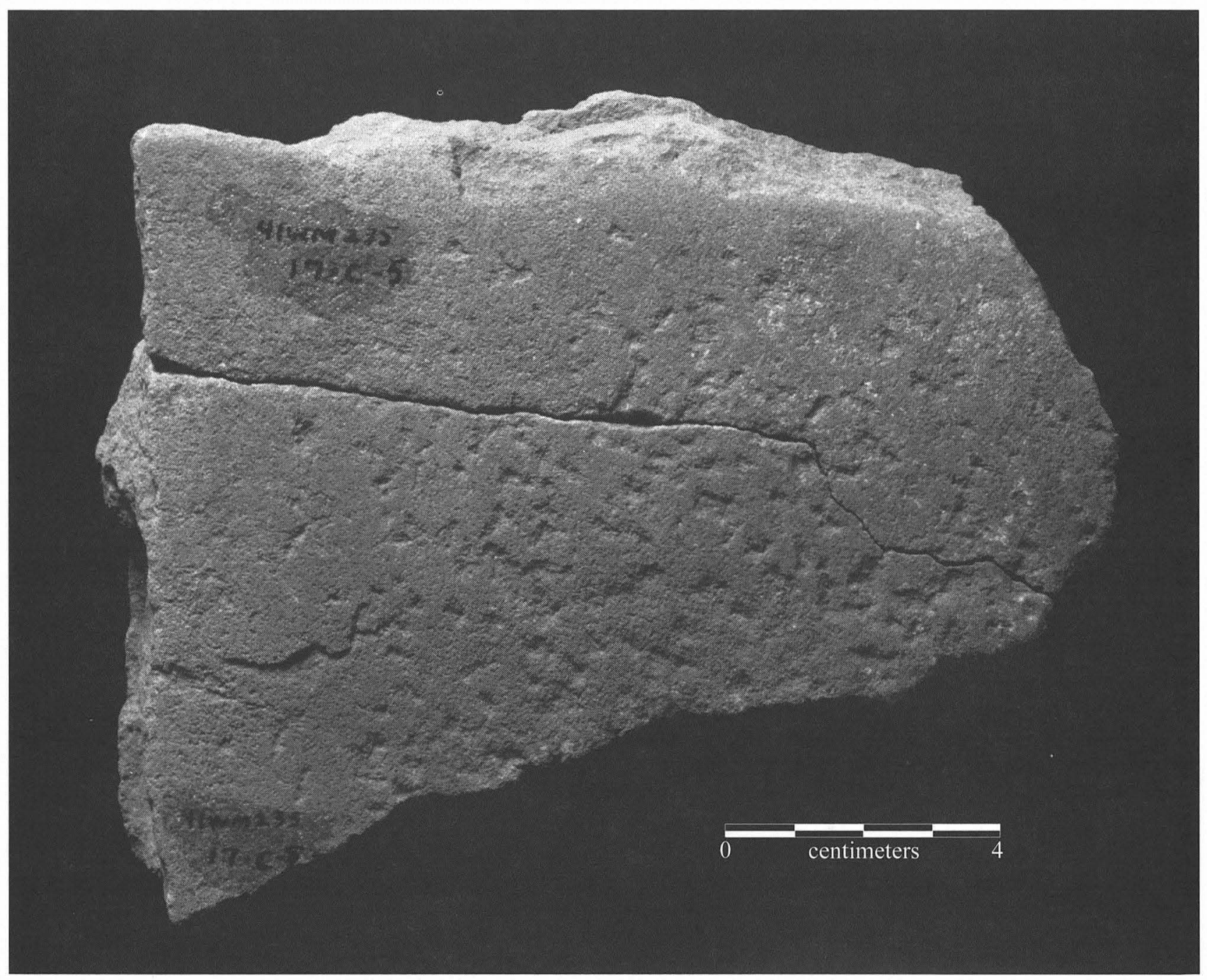

FIGURE 9-43. Metate fragment 17C-5 from Late Archaic context.

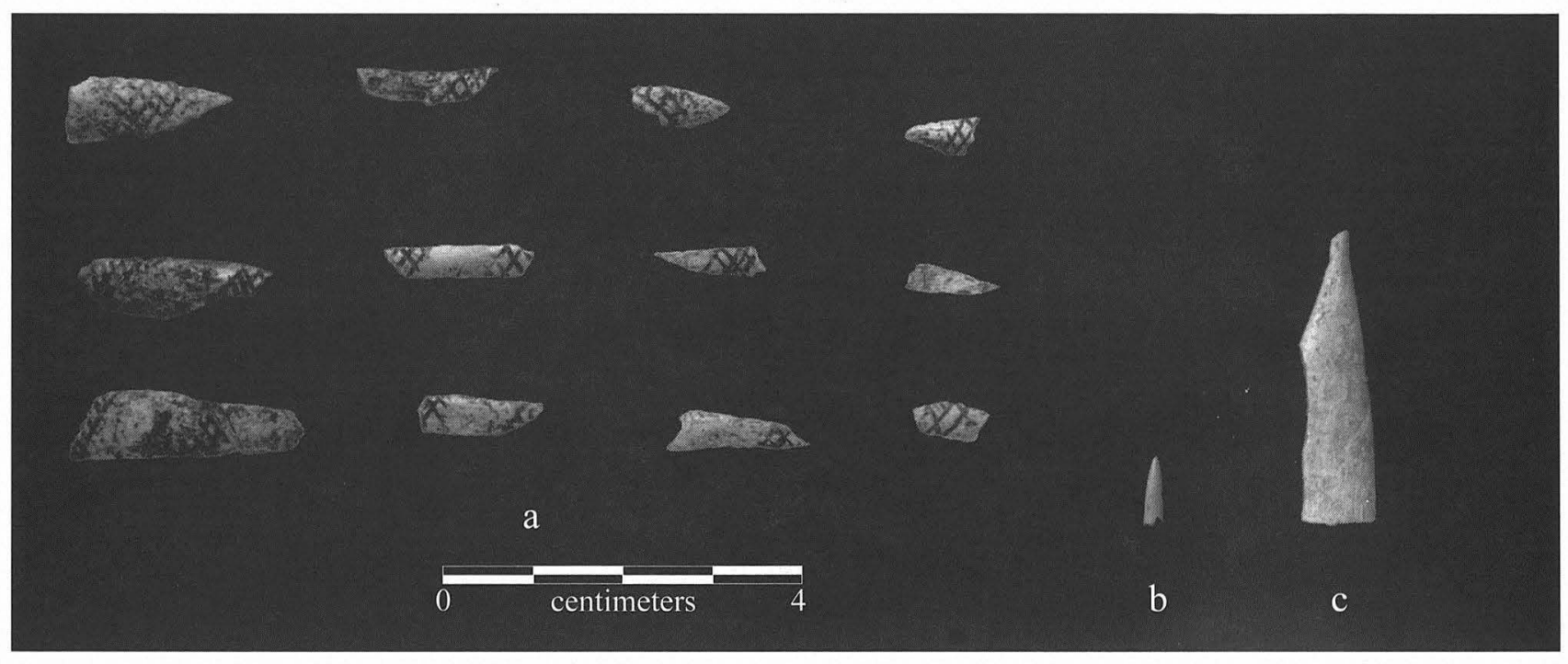

FIGURE 9-44. Incised tubular bone and pointed bone tool fragments from possible Late Archaic contexts. Specimen numbers: (a) 258-13; (b) 203-9; (c) 506-6. 


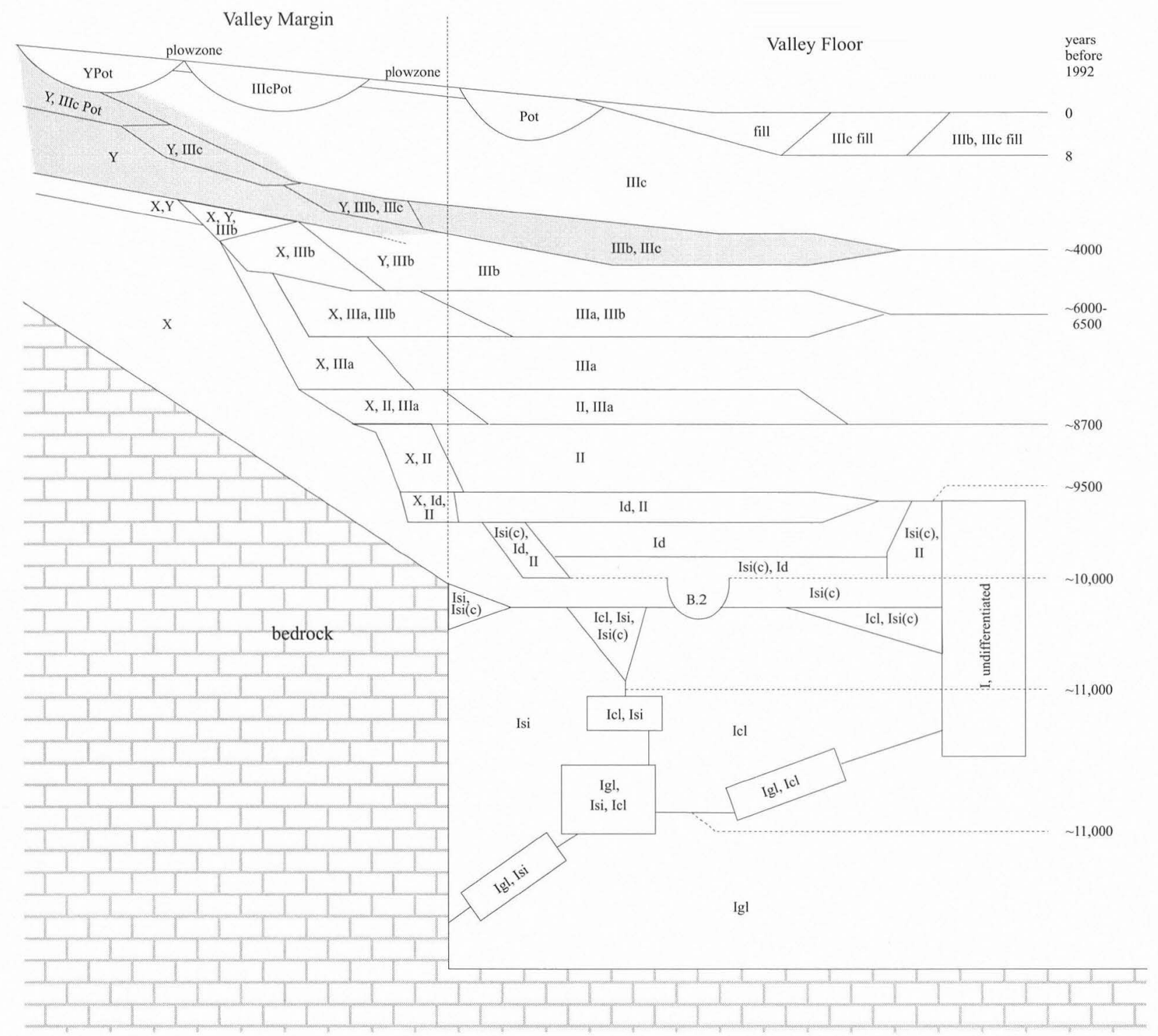

FIGURE 9-45. Stratigraphic profile of the Valley Margin/Valley Floor showing Archaic units.

foods of moderate and large quantities were pit-processed." This possibility is explored here and in Chapter 11 along with its implications for interpreting variability in the archeological record of the Central Texas Archaic.

If hunter-gatherers during the Archaic in Central Texas were moving from site to site based on the availability of one or more commodities occurring as localized patches and if those commodities required a specialized technology for either extraction or for processing, then the archeological evidence for that technology would be distributed unevenly in an approximation of the distribution of the resource patches. Each site would have the archeological signature of the technology appropriate to the exploitation of the resource patch or patches that attracted people to the site. This leads to the prediction that the more distinctive the different technologies, the greater the differences between sites. Two corollaries would be a prediction of little variation between sites created by any group who moved from patch to patch of the same resource or from patch to patch of different resources that were exploitable using the same technology. Another corollary might be that ethnically different groups could leave nearly indistinguishable archeological records if the consumption of a particular resource dictated a specialized technology.

For that early part of the Early Archaic when splitstemmed dart points were in vogue, we see differences between contemporary sites in the artifact assemblages and in the kinds of cooking appliances that were used. Consider, for example, two broadly contemporary but very different assemblages. At the Sleeper site, small, flat hearths ("baking heaps") are associated with numerous grinding stones, interpretable as evidence of the grinding of seeds and the baking of food (bread?) (Johnson 1991). In contrast, at Wilson-Leonard, larger earth ovens are associated 


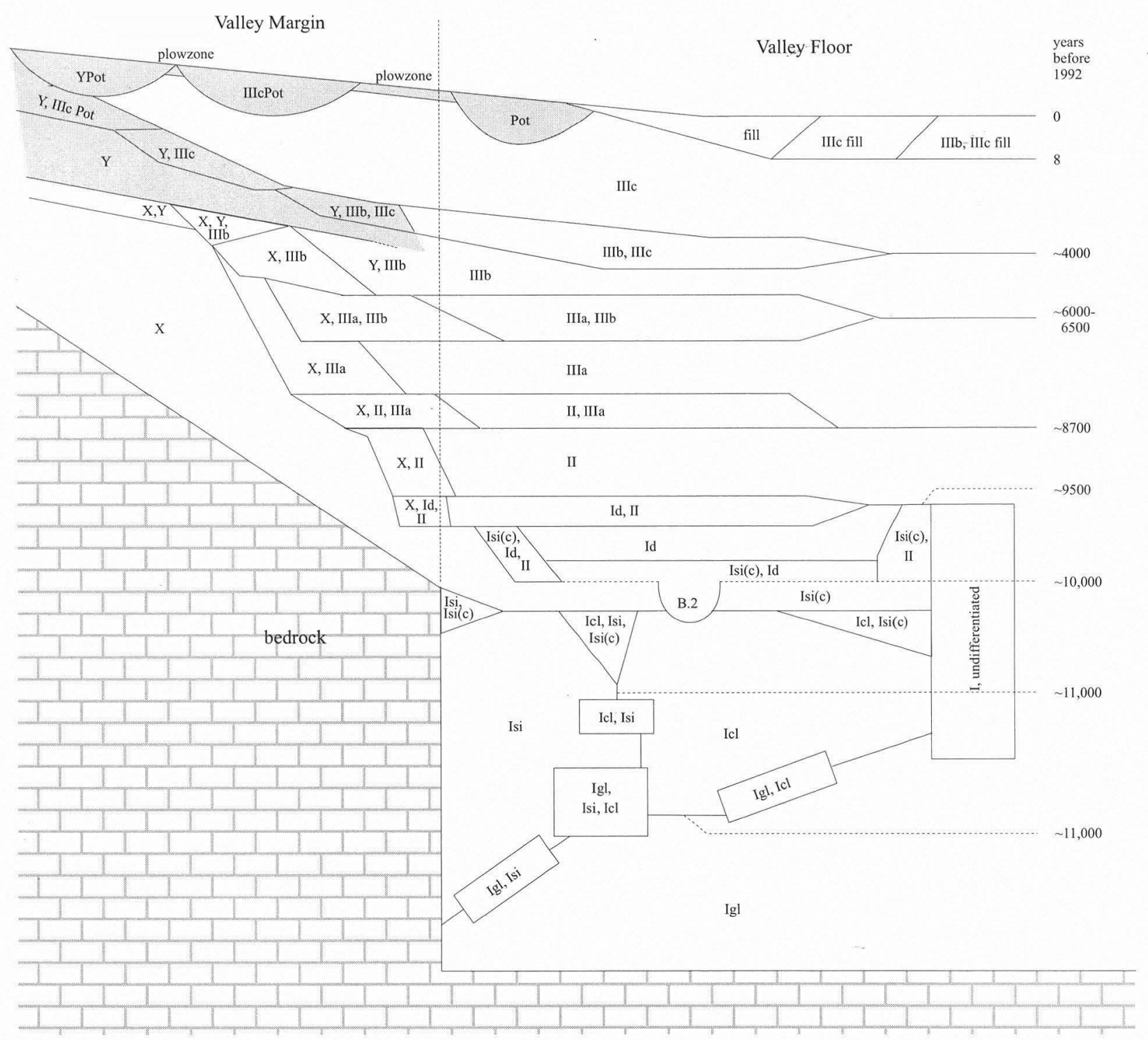

FIGURE 9-46. Stratigraphic profile of the Valley Margin/Valley Floor showing Archaic/Late Prehistoric units.

with a negligible number of grinding stones; these ovens were used, at least in part, to cook hyacinth bulbs. It seems reasonable to hypothesize that Sleeper was near a seed patch (grass, amaranth?), that Wilson-Leonard was near a patch of hyacinth, and that their very different archeological signatures largely reflect the contrasting technologies for processing these two commodities. It would even be plausible to speculate further that the very same group of people could have used these two sites at different times. This is not an argument that either site was the scene of a single activity, but that a single commodity, when plentiful, brought people to the locality and they devoted their efforts primarily toward the harvesting and processing that commodity while at the same time also tapping other nearby resources. Hunting, trapping, fishing, gathering of other plant foods, aquiring good chippable stone, as well as making and maintaining gear can be inferred from the Early Archaic tools, features, and floral and faunal remains at Wilson-Leonard and probably at Sleeper, but none of these emits a deafening signal at either site.

Because the artifact assemblage and the activities inferred for most domestic features at Wilson-Leonard remain little changed for the entire Archaic, a hypothesis of this being a site for hyacinth processing in Early Archaic times becomes a hypothesis that Wilson-Leonard was primarily a hyacinth processing locality throughout the Archaic and into the early part of the Late Prehistoric.

If the prevailing adaptation during the late part of the Late Prehistoric (Toyah interval) was, as we infer, based primarily on the hunting of bison, the apparent absence of a Toyah component at the Wilson-Leonard camas patch may be explainable in those terms.

Faunal remains for the Archaic at Wilson-Leonard are diverse. There is an increase in fish and later turtle during 
TABLE 9-39

Frequencies of Projectile Points by Types from Archaic Contexts

\begin{tabular}{|c|c|c|}
\hline Period & Analysis Identification & Count of Item \\
\hline Archaic & Projectile point, Bandy & 1 \\
\hline Archaic & Projectile point, bifurcate stem fragment & 5 \\
\hline Archaic & Projectile point, Bulverde-like & 1 \\
\hline Archaic & Projectile point, Ensor & 2 \\
\hline Archaic & Projectile point, expanding concave B & 2 \\
\hline Archaic & Projectile point, expanding concave $\mathrm{C}$ & 3 \\
\hline Archaic & Projectile point, expanding concave D & 1 \\
\hline Archaic & Projectile point, expanding stem B & 2 \\
\hline Archaic & Projectile point, expanding stem C & 1 \\
\hline Archaic & Projectile point, Gower/Jetta & 1 \\
\hline Archaic & Projectile point, Gower/Uvalde & 1 \\
\hline Archaic & Projectile point, Hoxie/Gower & 1 \\
\hline Archaic & Projectile point, indeterminate & 1 \\
\hline Archaic & Projectile point, Jetta & 1 \\
\hline Archaic & Projectile point, Lange & 1 \\
\hline Archaic & Projectile point, Marcos & 3 \\
\hline Archaic & Projectile point, Marshall & 2 \\
\hline Archaic & Projectile point, Martindale A & 3 \\
\hline Archaic & Projectile point, miscellaneous bifurcate & 3 \\
\hline Archaic & Projectile point, miscellaneous expanding stem & 3 \\
\hline Archaic & Projectile point, Nolan & 1 \\
\hline Archaic & Projectile point, Pedernales & 1 \\
\hline Archaic & Projectile point, square stem & 1 \\
\hline Archaic & Projectile point, Travis & 1 \\
\hline Archaic & Projectile point, Uvalde & 2 \\
\hline Archaic & Projectile point, Uvalde-like & 2 \\
\hline Archaic & Projectile point, Wells & 1 \\
\hline Archaic & Projectile point, Williams & 1 \\
\hline Archaic & Projectile point fragment & 7 \\
\hline
\end{tabular}

TABLE 9-40

Frequencies of Projectile Points by Types from Late Prehistoric/Archaic Contexts

\begin{tabular}{l|l|c}
\hline \multicolumn{1}{c|}{ Period } & \multicolumn{1}{c}{ Analysis Identification } & Count of Item \\
\hline Late Prehistoric/Archaic & Arrow point, preform & 2 \\
Late Prehistoric/Archaic & Arrow point, Scallorn & 9 \\
Late Prehistoric/Archaic & Arrow point, stemmed & 5 \\
Late Prehistoric/Archaic & Arrow point, tip & 2 \\
Late Prehistoric/Archaic & Projectile point, Darl & 3 \\
Late Prehistoric/Archaic & Projectile point, Ensor & 2 \\
Late Prehistoric/Archaic & Projectile point, Ensor/Fairland & 1 \\
Late Prehistoric/Archaic & Projectile point, Fairland & 1 \\
Late Prehistoric/Archaic & Projectile point, Frio & 1 \\
Late Prehistoric/Archaic & Projectile point, Marshall & 1 \\
Late Prehistoric/Archaic & Projectile point, miscellaneous bifurcate & \\
Late Prehistoric/Archaic & Projectile point, Nolan & \\
Late Prehistoric/Archaic & Projectile point fragment & \\
\hline \hline
\end{tabular}

the Early Archaic as the region was becoming drier, suggesting greater reliance on riparian habitats as upland environments deteriorated. Deer and rabbits prevail throughout the sequence and their skeletal remains are most often parts of the extremities, a pattern that would result from intensive processing of those parts of the body with the greatest amount of food value both as soft tissue and as bone.

The small hearths and the small burned rock basins (or "pit hearths") are well suited to the cooking of most animal foods, but ethnographic accounts also show a preference 
TABLE 9-41

Frequencies of Bifaces, Clear Fork Tools, and Cores from Archaic Contexts

\begin{tabular}{|c|c|c|}
\hline Period & Analysis Identification & Count of Item \\
\hline Archaic & Biface Stage 1 & 6 \\
\hline Archaic & Biface Stage 2 & 43 \\
\hline Archaic & Biface Stage 3 & 9 \\
\hline Archaic & Bifacial tool Form A & 6 \\
\hline Archaic & Bifacial tool Form B & 2 \\
\hline Archaic & Bifacial tool Form E & 1 \\
\hline Archaic & Bifacial tool Form $\mathrm{H}$ & 1 \\
\hline Archaic & Bifacial tool Form J & 1 \\
\hline Archaic & Clear Fork biface & 2 \\
\hline Archaic & Clear Fork uniface & 2 \\
\hline Archaic & Biface fragment & 14 \\
\hline Archaic & Core fragment & 1 \\
\hline Archaic & Core, thermal & 4 \\
\hline
\end{tabular}

TABLE 9-42

Frequencies of Bifaces, Core Tools, Core Fragments, and

Hammerstone Tool from Late Prehistoric/Archaic Contexts

\begin{tabular}{l|l|c}
\hline \multicolumn{1}{c|}{ Period } & Analysis Identification & $\begin{array}{c}\text { Count of } \\
\text { Item }\end{array}$ \\
\hline Late Prehistoric/Archaic & Biface Stage 1 & 1 \\
Late Prehistoric/Archaic & Biface Stage 2 & 21 \\
Late Prehistoric/Archaic & Biface Stage 3 & 8 \\
Late Prehistoric/Archaic & Bifacial tool Form A & 1 \\
Late Prehistoric/Archaic & Bifacial tool Form B & 2 \\
Late Prehistoric/Archaic & Clear Fork uniface & 1 \\
Late Prehistoric/Archaic & Biface fragment & 4 \\
Late Prehistoric/Archaic & Core fragment & 1 \\
Late Prehistoric/Archaic & Large core & 1 \\
& hammerstone & \\
\hline \hline
\end{tabular}

TABLE 9-43

Frequencies of Perforators and Burins from Archaic Contexts

\begin{tabular}{l|l|c}
\hline Period & Analysis Identification & Count of Item \\
\hline Archaic & Perforator Group 2 & 1 \\
Archaic & Perforator Group 6 & 1 \\
Archaic & Perforator Group 7 & 4 \\
Archaic & Burin & 7 \\
Archaic & Burin spall & 6 \\
\hline \hline
\end{tabular}

TABLE 9-44

Frequencies of Perforators and Burins from Late Prehistoric/Archaic Contexts

\begin{tabular}{c|l|c}
\hline \multicolumn{1}{c|}{ Period } & \multicolumn{1}{|c}{$\begin{array}{c}\text { Analysis } \\
\text { Identification }\end{array}$} & $\begin{array}{c}\text { Count of } \\
\text { Item }\end{array}$ \\
\hline Late Prehistoric/Archaic & Perforator Group 7 & 2 \\
Late Prehistoric/Archaic & Burin & 1 \\
Late Prehistoric/Archaic & Burin spall & 1 \\
\hline \hline
\end{tabular}

for oven cooking of fatty meats with moisture present (Wandsnider 1997). Thus, versatile use of the large burned rock basins at Wilson-Leonard seems likely, and we can hypothesize use of these large ovens for the cooking of hyacinths as well as other plants along with some meats (espe-
TABLE 9-45

Frequencies of Unifaces and Edge-modified Flake Tools from Archaic Contexts

\begin{tabular}{c|l|c}
\hline Period & \multicolumn{1}{|c|}{ Analysis Identification } & Count of Item \\
\hline Archaic & Denticulated flake & 4 \\
Archaic & Edge-modified flake & 73 \\
Archaic & Microspur/microdenticulate & 7 \\
Archaic & Notched flake & 1 \\
Archaic & Spurred flake & 1 \\
Archaic & Thin uniface & 22 \\
Archaic & Thin uniface fragment & 3 \\
Archaic & Uniface, unanalyzed & 14 \\
Archaic & Unifacial multiple tool & 8 \\
Archaic & Edge-modified flake & 5 \\
Archaic & Retouched blade & 2 \\
Archaic & Thin uniface & 1 \\
Archaic & Thin uniface fragment & 3 \\
\hline \hline
\end{tabular}

TABLE 9-46

Frequencies of Unifaces and Edge-modified Flake Tools from Late Prehistoric/Archaic Contexts

\begin{tabular}{c|l|c}
\hline \multicolumn{1}{c|}{ Period } & \multicolumn{1}{|c}{ Analysis Identification } & $\begin{array}{c}\text { Count of } \\
\text { Item }\end{array}$ \\
\hline Late Prehistoric/Archaic & Denticulated flake & 1 \\
Late Prehistoric/Archaic & Edge-modified flake & 27 \\
Late Prehistoric/Archaic & Microspur/microdenticulate & 2 \\
Late Prehistoric/Archaic & Notched flake & 1 \\
Late Prehistoric/Archaic & Spurred flake & 1 \\
Late Prehistoric/Archaic & Thin uniface & 14 \\
Late Prehistoric/Archaic & Thin uniface fragment & 7 \\
Late Prehistoric/Archaic & Retouched blade & 1 \\
\hline \hline
\end{tabular}

TABLE 9-47

Frequencies of Ground Stone Tools from Archaic Contexts

\begin{tabular}{l|l|c}
\hline \multicolumn{1}{c|}{ Period } & \multicolumn{1}{|c|}{ Analysis Identification } & Count of Item \\
\hline Archaic & Mano & 1 \\
Archaic & Mano fragment & 1 \\
Archaic & Metate fragment & 4 \\
Archaic & Possible ground stone & 1 \\
Archaic & Battered cobble & 2 \\
Archaic & Small core hammerstone & 1 \\
\hline
\end{tabular}

cially those with considerable fat). The other cooking appliances at the site were probably also used for cooking various plants and animals.

Among other possible plant foods indicated from charred remains at Wilson-Leonard are walnuts, hackberry nutlets, and seeds of several grasses (see Chapter 40). Because these samples represent chance survivals in an environment unfavorable for the preservation of plant remains, it is virtually certain that numerous other edible plants were consumed, but before speculating on what those may have been, the issue of seasonality must be considered.

The inulin-rich camas (of which hyacinth is but one variety) are of greatest food value just after flowering (Wandsnider 1997:23). Hyacinths in this part of Texas flower in the spring from March to May, which may imply spring as 


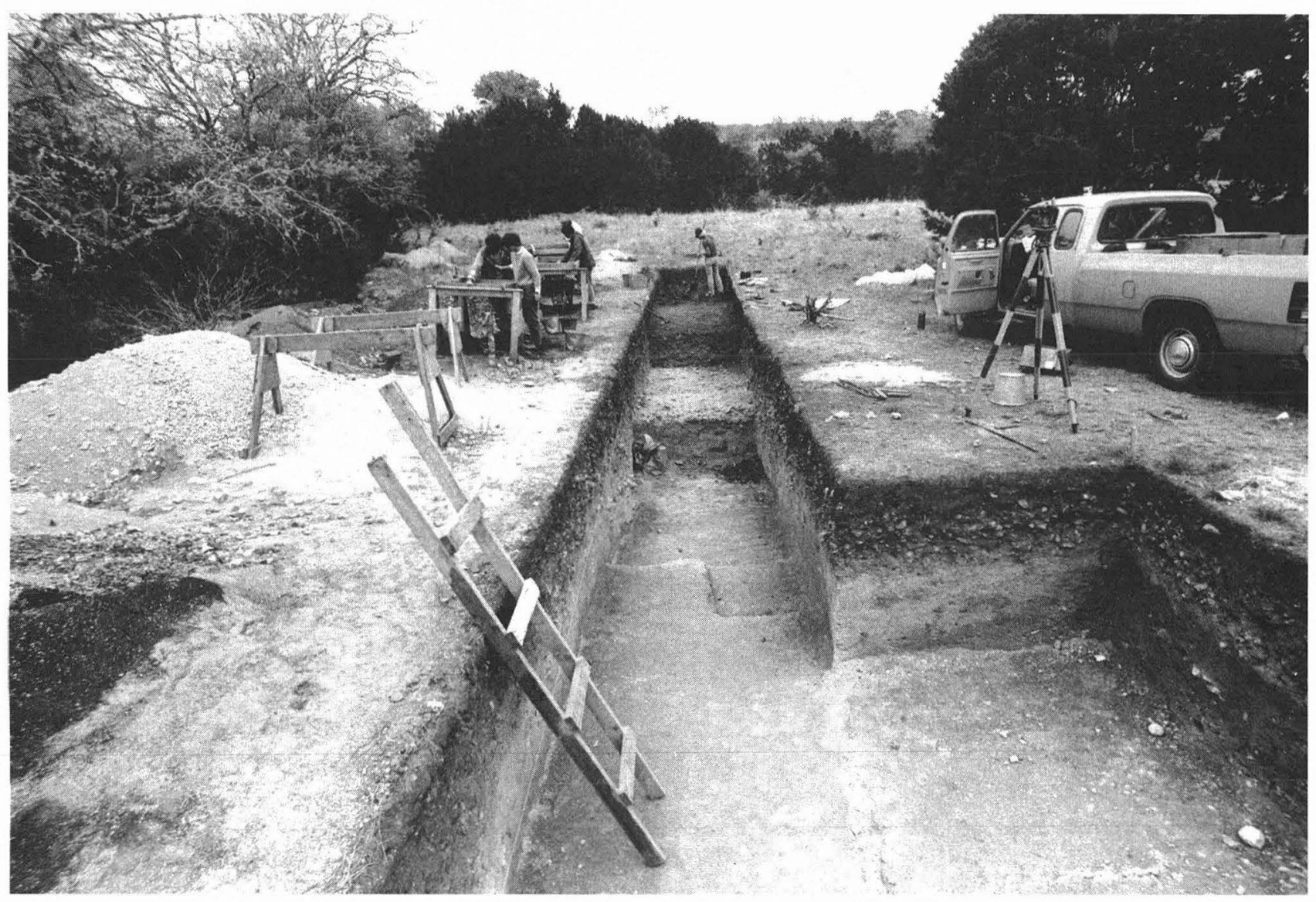

a

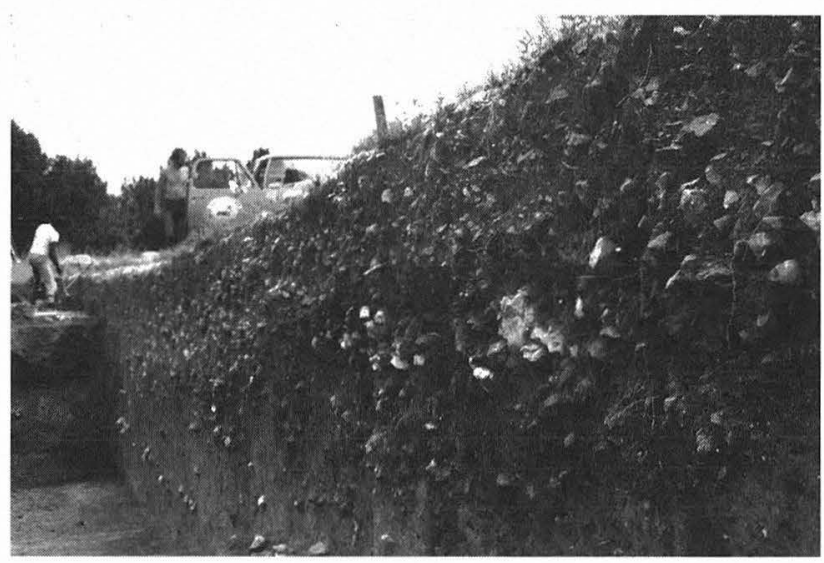

b

FIGURE 9-47. Burned Rock Midden 1. (a) general view during excavation; (b) close-up of midden structure.

the season of greatest use of the Wilson-Leonard locality. There is nothing in the faunal and very little in the noncamas floral remains to bring to bear on this question. Presuming that the few walnut nuts and hackberry nutlets were, in fact, food items, the probable seasons for collecting these items would be fall and late summer, respectively. The array of grasses (bristlegrass, panic grass, paspalum) in the Middle Archaic burned rock cluster (Feature 209) might indicate a late summer or early fall occurrence. In aggregate, then, the best represented food item in the sample is hyacinth for which the optimal season of exploitation is spring, and the few other surviving taxa might be interpreted to indicate late summer to fall as the likely seasons of exploitation. If milling stones are primarily for use on (grass?) seeds, their scarcity, too, may be a seasonal indicator (summer to early fall, depending on which seeds were being processed).

Thus, it could be hypothesized that during the Archaic, Wilson-Leonard was predominantly used in the spring as a 


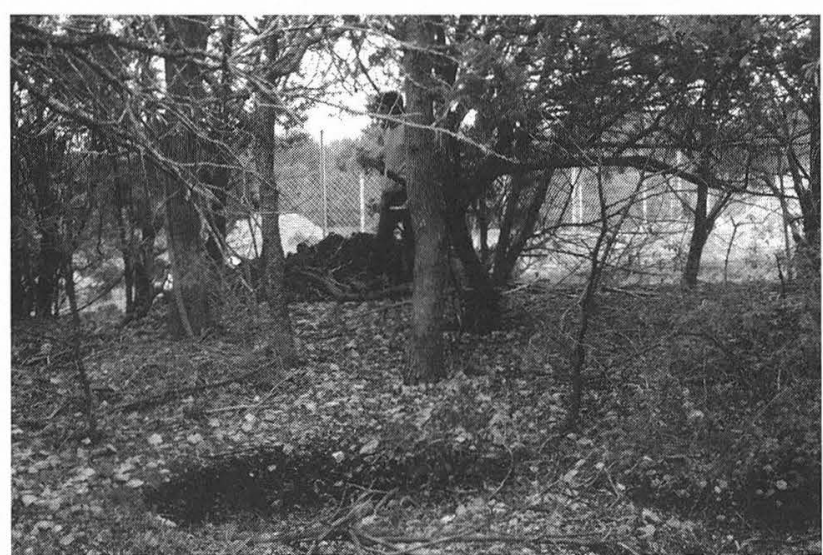

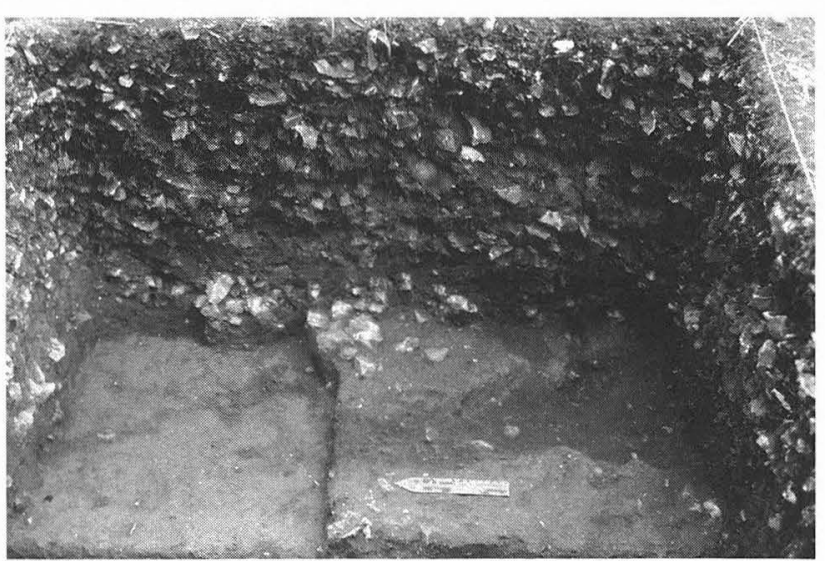

$b$

FIGURE 9-48. Burned Rock Midden 2. (a) general view of midden surface as damaged by pothunting; (b) detail of midden structure.

locality for the cooking of hyacinth bulbs in moderate bulk, that various other foods were acquired and processed concurrently, and that secondary use of the site may have occurred in summer or fall when grasses or nuts were exploited. If people were at Wilson-Leonard during the season that walnuts were available, it seems likely that live oak acorns would also be gathered, processed, eaten, or stored, even though no record of this has survived.

The very generalized nature of most of the stone tool assemblage during the Archaic is consistent with this hypothesis. When at this locality for the hyacinth harvest, people undoubtedly engaged in a mix of other activities, including hunting, fishing, trapping, and gathering other plant foods as well as manufacturing and maintaining various tools and other gear. The co-occurrence of Waco sinkers and an increase in fish remains during the Early Archaic may be more than coincidence. It is also possible that the Clear Fork tools were used, among other things, for making and maintaining wooden digging tools for extraction of hyacinth bulbs.
A fair number of preserved mud dauber nests were also found in the Archaic levels at Wilson-Leonard (see Appendix 2). These may have been brought to the site intentionally as a food item, or they may have become burned inadvertently as firewood or as victims of house fires (see Appendix 2). None of these were found in patterned occurrences to suggest that a once-present structure had burned, and no other hints of architecture were found in the site. It seems probable that at least some domestic structures would have been built and used during the Archaic occupations of this site, but evidence is lacking. This lack of evidence is more likely the result of impermanent construction rather than of nonuse of shelter.

When considered in the broader temporal and spatial contexts of the prehistoric record for the southern periphery of the Great Plains, the foregoing interpretations of the Archaic at Wilson-Leonard find additional support and take on added significance (see Chapter 11). The implications for these interpretations for future work in the Archaic record of Central Texas also become clearer. 


\section{Chapter 10}

\section{LATE PREHISTORIC COMPONENTS}

by Michael B. Collins

\section{INTRODUCTION}

Traditionally, the long culture history of Central Texas has been divided into the three major periods, Paleoindian ("Paleo-American"), Archaic, and Late Prehistoric ("NeoAmerican"). Early in its conceptualization (Suhm et al. 1954:20), the Late Prehistoric (then referred to as the "NeoAmerican") denoted a time when people were cultivating domesticated plants, making pottery, and using the bow and arrow, but small arrow points became the diagnostic culture trait by which many Late Prehistoric components were recognized by archeologists. Pottery was found at some, but by no means all, of the sites where arrow points occurred. Lack of preservation was presumed to account for the virtual absence of perishable cultigens. In spite of the intent stated by Suhm et al. (1954:20) to only refer components to the Late Prehistoric when at least two of the three cultural elements were present, the habit of using the single trait of arrow points has prevailed.

In Central Texas, an earlier Austin and a later Toyah interval of arrow point-bearing archeological assemblages seem well established (Jelks 1962; Prewitt 1981, 1985). The earlier of these, the Austin, lacks pottery or any indication of plant food production. It has also become evident in recent years that a few burned rock middens, once considered a hallmark of the Archaic period, continued in use into the Late Prehistoric, at least during the Austin interval (Goode 1991; Johnson and Goode 1994).

It might be argued that the Austin interval is the archeological manifestation of an Archaic way of life and that it is no longer productive to refer to it as being of Late Prehistoric affiliation simply because the bow and arrow was in use. This has been suggested (e.g., Prewitt 1981), but no consensus has emerged. On the other hand, contemporary groups in southeastern and northeastern areas of Texas were producing pottery, settling into villages, and growing some domesticated plants (Story 1990:243-319). Scallorn arrow points are found over most of Texas (Prewitt 1995; Turner and Hester 1993) and are often recovered in contexts suggesting fatal arrow wounds (Prewitt 1974). This far-flung distribution, including areas where villages and food production were emerging, and the possible implications of widespread political hostilities tend to link the Central Texas Austin components to broader, Late Prehistoric developments, in spite of an apparent continuation of "Archaic" lifeways in the area. These possible links argue strongly for retaining the Late Prehistoric status of Austin manifestations, at least until this interval is better understood and the linkages rejected or confirmed and diagnosed. Unfortunately, Wilson-Leonard does not afford well-defined assemblages in the late Holocene of the kind needed for addressing such issues.

The later Toyah interval, which in Central Texas reflects a bison-hunting adaptation that also had pottery and some cultigens, is essentially nonexistent in the excavated sample from Wilson-Leonard. If the site were used beyond a minimal degree in Toyah times, that use occurred in areas not sampled by the investigations reported here. In light of the notion that Austin interval adaptations were Archaic in nature at least in Central Texas, it is perhaps telling that the long Archaic sequence at Wilson-Leonard is capped by a modest Austin component and not by a Toyah component.

This chapter considers the Austin component at Wilson-Leonard, defined primarily on the basis of Scallorn arrow points. Most investigators date the Austin interval as lasting from ca. A.D. 700 to ca. A.D. 1200.

\section{ARTIFACTS DIAGNOSTIC OFTHE LATE PREHISTORIC}

Ninety-four chipped stone artifacts (arrow points, arrow point fragments, and arrow point preforms; see Chapter 13) were recovered that can be considered indicators of the Late Prehistoric period. These include 54 arrow points of 
named types (2 Alba, 1 Perdiz, 1 Sabinal, 48 Scallorn, and 2 Scallorn/Edwards), 20 miscellaneous stemmed arrow points (probably a majority of which are Scallorns damaged to an extent that defining attributes are lost), 11 arrow point fragments, and 9 arrow point preforms. Also recovered was 1 small ceramic sherd. No other clearly diagnostic kinds of artifacts were recovered.

\section{Physical Context}

Artifacts diagnostic of the Late Prehistoric are confined primarily to the upper portion of Unit IIIc in Valley Floor, Area A and in the Valley Margin. No Late Prehistoric artifacts were identified in Valley Floor, Area B, and artifacts diagnostic of the Late Prehistoric are decidedly concentrated upslope from the crest of Burned Rock Midden 1 (Figure 10$1)$.

Two factors constrain contextual evidence for the Late Prehistoric at Wilson-Leonard. First, by the time of the Late Prehistoric, natural deposition at the locality had all but ceased, relegating these late materials to a thin deposit where mixing with earlier materials was pervasive, a condition exacerbated somewhat by an apparent preference during Late Prehistoric times to use the upslope edge of the site where fluvial deposition was completely lacking and where materials were probably subject to some degree of movement downslope. Second, as part of the archeological investigations, the upper deposits were mechanically stripped off of TxDOT excavation Blocks 5 and 6, removing whatever Late Prehistoric materials existed in those areas; subsequent disturbances related to highway construction had largely removed the upper part of Unit IIIc east and south of TxDOT Block 6 prior to excavation in those two areas by TARL. No such twentieth-century factors, including plowing, account for the lack of Late Prehistoric materials in Valley Floor, Area B (see Chapter 2).

By far the majority of excavated Late Prehistoric diagnostic artifacts occur in the upper three excavation levels (ca. $30 \mathrm{~cm}$ ). This translates to approximately the upper third to half of Unit IIIc (which typically varies from 50 to $80 \mathrm{~cm}$ thick). Both plowing and pothunting have disrupted upper Unit IIIc deposits in parts of the site, plowing to depths of ca. $20 \mathrm{~cm}$ and pothunting in places to depths of about $1 \mathrm{~m}$. Plowing may not have reached as far upslope as TxDOT excavation Block 1, but this is not entirely certain (see Chapter 2).

\section{Distributions of Late Prehistoric Diagnostic Artifacts}

As already noted, all arrow points as well as Scallorn type arrow points tend to be more numerous on the Valley Margin than on the Valley Floor (see Figure 10-1). Vertically, the clearest picture of the distribution of Late Prehistoric diagnostics is seen in TxDOT Blocks 1, 2, 3, and 4, all of which can be compressed onto a single tabulation depicting a north-south transect along the west side of the TxDOT excavation (Tables 10-1 through 10-4). The distribution of all 52 arrow points (including fragments and preforms) with secure context is shown in Table 10-1 (there are another 18 specimens from pothole-disturbed levels in the same area of the site). Those 28 typed as Scallorn among these 52 are shown by provenience in Table 10-2 (not including 9 specimens from pothole-disturbed levels). Were these the only kinds of diagnostic artifacts in these proveniences, it would be reasonable to assume that the associated nondiagnostic artifacts were part of the same cultural assemblage. However, in the same proveniences (squares and levels) where the 94 Late Prehistoric diagnostic specimens were found were also found 28 Late Archaic style dart points (16 Darl and 12 Ensor), 28 dart points diagnostic of earlier intervals in the Late Archaic, Middle Archaic, and Early Archaic, as well as 72 dart point fragments.

Proveniences of the diagnostic dart points found in squares along the western edge of the TxDOT excavation are shown in Tables 10-3 and 10-4. This commingling precludes any attempt to isolate a Late Prehistoric assemblage among the debitage, flake tools, bifaces, unifaces, and ground stone objects from these proveniences. There is a significant number of nondiagnostic artifacts tabulated in the accompanying analytical chapters and appendixes as deriving from Late Prehistoric contexts, meaning, in this case, that they were found in the uppermost $10-\mathrm{cm}$ level of the excavation units in the Valley Margin and Valley Floor A areas. Included are 43 bifaces, 28 biface fragments, a retouched blade, 7 burin spalls, 123 modified flake tools, 5 pieces of ground stone, and a large sample of debitage. Probably a substantial proportion of these are, in fact, of Late Prehistoric derivation, but without better stratigraphic control, little confidence could be placed in assigning any given artifact to that period.

Faunal remains (see Chapter 33), like the nondiagnostic stone artifacts, undoubtedly include many specimens left at the site during the Late Prehistoric, but these are surely mixed with others from earlier occupations. Close to 4,000 faunal specimens were recovered from "Late Prehistoric" and from "Late Archaic/Late Prehistoric" contexts combined (see Tables 33-2 and 33-3). It is of interest to note, however, that of the 827 specimens with the highest probability of being introduced into the site during the Late Prehistoric, bison are not represented (see Table 33-9) nor are they present in the sample attributed to the Late Archaic/Late Prehistoric (see Table 33-10). Nothing in the condition of the bone (breakage, burning) from probable Late Prehistoric contexts distinguishes it from assemblages assigned to the various Archaic subperiods (see Tables 33-4 and 33-6).

An important question in regard to the Late Prehistoric component is whether or not its authors contributed to the growth of burned rock middens at the site. In the case of the midden in Area B (Midden 2), the complete lack of Late Prehistoric diagnostics in, on, or around the midden strongly 


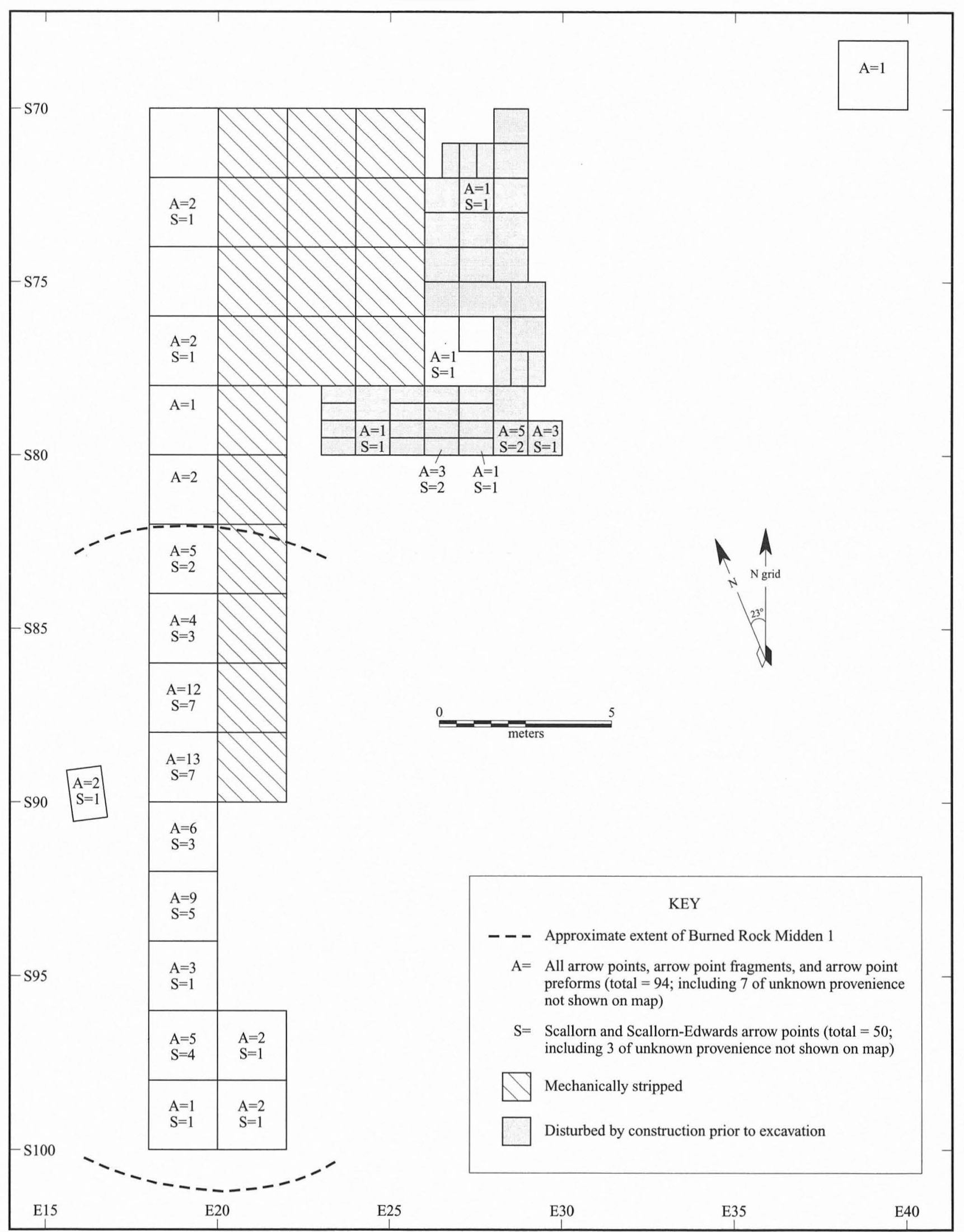

FIGURE 10-1. Plan of the excavations showing recovery of Late Prehistoric artifacts. 
TABLE 10-1

Distribution of All Arrow Points in TxDOT Blocks 1, 2, 3, and 4 (Burned Rock Midden 1 is shown by shading)

\begin{tabular}{|c|c|c|c|c|c|c|c|c|c|c|c|c|c|c|c|}
\hline Level & $\mathrm{S} 100$ & S98 & S96 & S94 & S92 & S90 & S88 & S86 & S84 & S82 & S80 & S78 & S76 & S74 & S72 \\
\hline 1 & 2 & 4 & 1 & & & 6 & 6 & & 3 & 1 & 1 & 2 & & 2 & \\
\hline 2 & 1 & 3 & & & & 6 & 6 & 2 & 2 & 1 & & 1 & & & \\
\hline 3 & & & & & & 1 & & 1 & & & & & & & \\
\hline 4 & & & & & & & & & & & & & & & \\
\hline 5 & & & & & & & & & & & & & & & \\
\hline 6 & & & & & & & & & & & & & & & \\
\hline 7 & & & & & & & & & e & & & & & & \\
\hline 8 & & & & & & & & & & & & & & & \\
\hline 9 & & & & & & & & & & & & & & & \\
\hline 10 & & & & & & & & & & & & & & & \\
\hline
\end{tabular}

TABLE 10-2

Distribution of Scallorn Arrow Points in TxDOT Blocks 1, 2, 3, and 4 (Burned Rock Midden 1 is shaded)

\begin{tabular}{|c|c|c|c|c|c|c|c|c|c|c|c|c|c|c|c|}
\hline Level & S100 & S98 & S96 & S94 & S92 & S90 & S88 & S86 & S84 & S82 & S80 & S78 & S76 & S74 & S72 \\
\hline 1 & & 3 & & & & 5 & 3 & & 1 & & & 1 & & 1 & \\
\hline 2 & 1 & 2 & & & & 2 & 4 & 2 & 1 & & & 1 & & & \\
\hline 3 & & & & & & & & 1 & & & & & & & \\
\hline 4 & & & & & & & & & & & & & & & \\
\hline 5 & & & & & & & & & & & & & & & \\
\hline 6 & & & & & & & & & & & & & & & \\
\hline 7 & & & & & & & & & 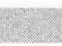 & & & & & & \\
\hline 8 & & & & & & & & & & & & & & & \\
\hline 9 & & & & & & & & & & & & & & & \\
\hline 10 & & & & & & & & & & & & & & & \\
\hline
\end{tabular}

TABLE 10-3

Distribution of Ensor and Darl Dart Points (Burned Rock Midden 1 is shaded; does not include 3 specimens from pothole contexts)

\begin{tabular}{|c|c|c|c|c|c|c|c|c|c|c|c|c|c|c|c|}
\hline Level & S100 & S98 & S96 & S94 & S92 & S90 & S88 & S86 & S84 & S82 & $\mathrm{S} 80$ & S78 & S76 & S74 & $\mathrm{S} 72$ \\
\hline 1 & 2 & & & & & & 1 & 1 & 1 & & 1 & 2 & & 1 & \\
\hline 2 & 1 & & & & & 2 & 3 & 5 & 2 & & & & & & \\
\hline 3 & & & & & & & & 1 & & & & & & & \\
\hline 4 & & & & & & & & & & & & & & & \\
\hline 5 & & & & & & & & & & & & & & & \\
\hline 6 & & & & & & & & & & & & & & & \\
\hline 7 & & & & & & & & & & & & & & & \\
\hline 8 & & & & & & & & & & & & & & & \\
\hline 9 & & & & & & & & & & & & & & & \\
\hline 10 & & & & & & & & & & & & & & & \\
\hline
\end{tabular}

TABLE10-4

Distribution of Bulverde, Castroville, Edgewood, Fairland, Frio, Marcos, Marshall, Nolan, and Other Dart Points (Burned Rock Midden 1 is shaded; does not include 5 points from pothole contexts)

\begin{tabular}{|c|c|c|c|c|c|c|c|c|c|c|c|c|c|c|c|}
\hline Level & S100 & S98 & S96 & S94 & S92 & S90 & S88 & S86 & S84 & S82 & S80 & S78 & S76 & S74 & S72 \\
\hline 1 & & 1 & & & & & 2 & & & 1 & 1 & & & & \\
\hline 2 & 1 & 2 & & & & & & 1 & 1 & 1 & & & & & \\
\hline 3 & & & & & & & & 2 & & & & & & & \\
\hline 4 & & & & & & & & & & & & & & & \\
\hline 5 & & & & & & & & & & & & & & & \\
\hline 6 & & & & & & & & & & & & & & & \\
\hline 7 & & & & & & & & & & & & & & & \\
\hline 8 & & & & & & & & & & & & & & & \\
\hline 9 & & & & & & & & & & & & & & & \\
\hline 10 & & & & & & & & & & & & & & & \\
\hline
\end{tabular}


indicates that they did not. For the large midden in Area A (Midden 1), where arrow points are found clustered near the midden and 13 even occur in the top of the midden (see Table 10-1), the evidence is inconclusive (see below).

\section{FEATURES}

Two features are here interpreted as being affiliated with the Late Prehistoric component. Feature 1 is a small burned rock cluster in the upper $10 \mathrm{~cm}$ of Unit IIIc near the south end of the TxDOT excavations, in Square E22/S98. This is within the part of the site with the greatest concentration of arrow points, and diagnostics in the same square and level consist of a Scallorn arrow point and an arrow point preform but no dart points. There is considerable bone around the feature, mostly mammalian, including a few elements of deer or antelope. Other artifacts from this general provenience include 1 mano fragment, 3 Stage 2 bifaces, an arrow point preform, 1 bifacial tool, 1 edge-modified flake, and 675 pieces of debitage. There are also 3 unidentifiable projectile point fragments that could be pieces of dart points.

Feature 7 is a scatter of approximately 100 burned rocks of small to medium sizes among which are some vague clusters that could be remnants of former hearths. A minor amount of charcoal, including burned elm wood, was present in this feature. This scatter is 20 to $30 \mathrm{~cm}$ above the northern edge of the burned rock midden, in upper Unit IIIc, and less than $20 \mathrm{~cm}$ below the surface. Generally, this stratigraphic position is consistent with a Late Prehistoric age estimate, but the diagnostic artifacts within the scatter consist of a single stemmed arrow point and a side-notched dart point. Other materials in the scatter are debitage, mussel shell fragments, and bone. The bone is mostly fragmentary and unidentifiable, but deer or antelope is indicated by several elements.

The prominent cultural feature, Burned Rock Midden 1, is also a minor topographic feature at Wilson-Leonard. Prior to becoming almost completely buried, its topographic expression was probably relatively greater and enough to locally interrupt the downward slope of the Valley Margin. The cultural content of the deposits that lap onto the upslope margin of the midden indicate that sedimentation onto the Valley Margin side of the midden was active in Late Archaic and in Late Prehistoric times. Some proportion of that deposition was anthropogenic, but at least a minor proportion was also colluvial. The distinct concentration of Late Prehistoric diagnostic artifacts in the thin wedge of sediments overlying the upslope side of the midden could result in part from these pieces having washed from higher up the valley margin to come to rest in a minor sediment trap against the midden. Simple provenience distributions show that horizontally, artifacts diagnostic of the Austin interval are concentrated in the Midden 1 area (see Figure 10-1). Vertically, those from comparatively secure contexts (see Table 10-2) are found stratigraphically above the midden ( 22 specimens) as well as in the top of the midden in two squares (6 speci- mens). This pattern could be interpreted in either of two ways. It is arguable that use of the midden had ceased prior to Austin times and that a small proportion (less than 30\%) of the Austin diagnostics became mixed into the uppermost level of the midden in the area of excavation Squares E20/ S90 and E20/S88. It could also be argued that Austin interval peoples used the summit of the midden to a limited extent.

Frequencies of heat-damaged artifacts were tabulated by Collins (1994b) in an effort to determine association with midden growth at the Mustang Branch site. Among the 1,461 chipped stone tools recovered from the Mustang Branch midden, 525 (36\%) showed evidence of heat alteration, but different classes exhibited individual percentages significantly different from that average. Late Prehistoric arrow points and knives for the most part were recovered from soil formed on top of the midden and had only a $1 \%$ incident of heat alteration. Higher percentages included flaking debris $(69 \%)$, biface fragments $(66 \%)$, dart point fragments $(60 \%)$, and Late Archaic dart points (43\%). The number of diagnostic artifacts at Wilson-Leonard with suitable proveniences is small, but in an effort to possibly shed more light on the question of their relationship to midden formation, the frequency of burning among Late Prehistoric diagnostics in the vicinity of Midden 1 was compared to that among Late Archaic diagnostics from the same units. Of 23 Late Archaic diagnostics, 3 of 12 Darl points (25\%) and 1 of 11 Ensor points (9\%) show heat alteration (combined, these numbers are 4 of 23, or $17 \%$ ). Among 31 Scallorn arrow points, $5(16 \%)$ exhibit alteration by heat. None of these percentages compares to the higher ranges seen at the Mustang Branch midden. For Wilson-Leonard as a whole, 7 of 27 Darls (26\%), 6 of 37 Ensors (16\%), and 6 of 48 Scallorns $(13 \%)$ are heat altered. When the much smaller samples from within the Wilson-Leonard midden are considered, 0 of 7 Scallorns ( $0 \%$ ), 1 of 2 Ensors (50\%), and 1 of 3 Darls (33\%) show heat alteration. These very small numbers suggest that the dart points might be more intimately associated with the heat of a burned rock midden than is the case with the arrow points, but the inference is not very compelling on the basis of so few specimens.

No Late Prehistoric burials were discovered at WilsonLeonard. Of the several pieces of human bone from Unit IIIc discussed in Chapter 31 under the heading, "Archaic/Late Prehistoric Human Remains," Archaic affiliations seem more probable except possibly for two femur fragments from Level 2 of Square E40/S70. Even if these are of Late Prehistoric derivation, they yield neither mortuary nor very useful human biological information.

\section{INDICATORS OF OTHER COMPONENTS}

Two Alba arrow points and two possible Gahagan bifaces in the upper levels of Wilson-Leonard could be indicative of excursions into Central Texas by early Caddoans, the acquisition of Caddoan objects by a Central Texas group, 
or the borrowing of Caddoan styles by Central Texas makers of chipped stone artifacts. Whatever the case, it resulted in a very minor presence of such objects; too few for any meaningful interpretations.

The Toyah interval is indicated by a single very small potsherd (14 $\mathrm{mm}$ by $12 \mathrm{~mm}$ and $5 \mathrm{~mm}$ thick, buff-colored paste, sand and crushed rock temper) and a single Perdiz arrow point. These are also insufficient to support much interpretation.

\section{CONCLUSIONS}

Most of the Late Prehistoric materials found at WilsonLeonard have affinities to those of the Austin interval of Central Texas. Very minor amounts of material relate to early Caddoan and to Toyah interval cultural configurations. Overall, these findings indicate that in the early part of the Late Prehistoric the site was used almost exclusively by possessors of Austin material culture trappings and that the site saw very little use of any kind in the late part of the Late Prehistoric.
Wilson-Leonard adds little to our understanding of the late prehistory of the region. There was clearly use of the locality during the Late Prehistoric, but the evidence for that use resides in poor context, and there is no reliable way to isolate distinct assemblages or components. What evidence does exist is consistent with that from other sites in the region where subsistence during the early part of the Late Prehistoric seems little changed over that seen in the Archaic.

A comprehensive and thoughtful review of the Austin interval of Central Texas is overdue, but it is imperative that when such a study is undertaken that it not be restricted to Central Texas. It appears from the evidence that people were using the Austin-interval diagnostic Scallorn arrow point over much of what is now Texas and that some of that usage was hostile. We do not understand the cultural dynamics that account for that archeological pattern, but events significant to a broad region seem to be indicated. An integration of the considerable but disjuncted data that already exist would be a significant contribution. 


\section{Chapter 11}

\section{THE PLACE OF WILSON-LEONARD IN SOUTHERN PLAINS PREHISTORY}

by Michael B. Collins

\section{INTRODUCTION}

Wilson-Leonard consists of cultural materials buried in an alluvial fan on the margin of Brushy Creek valley. Fan deposits are predominantly fluvial at the base and become more dominated by colluvial and anthropogenic deposition higher in the section. In places the culture-bearing deposits reach thicknesses of greater than $6 \mathrm{~m}$. An estimated 12,000 years of sedimentation and pedogenesis are represented by these deposits, and the cultural materials they contain are datable to about the first 11,000 years of that span (all dates in this chapter are uncalibrated radiocarbon years before present unless noted otherwise). Natural deposition, pedogenesis, erosion, and cultural activity have all been varied and complex contributors to the formation of the site with the result that the very long cultural sequence is not as crisply stratified as it might have been, but it is, nonetheless, the most complete single-site record of its kind for the southern periphery of the Great Plains. Very few deeply stratified sites of this kind have been investigated in or near Central Texas, although they may not be as scarse as archeologists once thought (Collins 1995).

Among the more significant aspects of that record to emerge from the investigation of Wilson-Leonard are the following:

(1) new data toward a regional paleoenvironmental sequence;

(2) improved chronostratigraphy for the Paleoindian period;

(3) a probable pre-Clovis component;

(4) improved definition and stratigraphic separation of Paleoindian and earliest Archaic diagnostic artifacts, St. Mary's Hall, Golondrina-Barber, Angostura, and Thrall;

(5) information toward clarification of the status of Plainview and other unfluted lanceolate point forms in Central Texas;
(6) documentation of a newly identified Paleoindian cultural component, referred to as Wilson;

(7) an early human skeleton;

(8) new data on early Paleoindian adaptations and cultural complexity;

(9) evidence of Early Archaic subsistence and cooking behavior;

(10) an assessment of stylistic variation in Early Archaic, bifurcate-stemmed projectile points;

(11) documentation of a 9,000-year-long sequence of burned rock features;

(12) a geologic setting that brings into clearer focus some factors in the formation of burned rock middens;

(13) evidence that Wilson-Leonard may have been a specialized site for the preparation of tuberous plants (specifically, inulin-rich geophytes) through much of its history; and

(14) evidence that the Balcones Canyonland ecotone sustained an almost exclusively hunting and gathering way of life throughout the entire local prehistory of nearly 12,000 years.

These topics are briefly reviewed below followed by a cultural-historical synopsis of the site and its place in the local prehistory. Some intervals in this sequence are better represented, and afforded fuller discussion, than others in this presentation. This chapter concludes with comparisons between the local prehistory and some of the major developments seen elsewhere in North America.

\section{SIGNIFICANT FINDINGS OF THE WILSON-LEONARD INVESTIGATIONS}

Several kinds of evidence useful in paleoenvironmental reconstruction were recovered from Wilson-Leonard, including physical stratigraphy, macrofauna, micro-vertebrate fauna, molluscs, bird eggshells, diatoms, ostracodes, 
macroflora, phytoliths, and carbon isotopes. None of these alone nor the entire aggregate from this one site provides an adequate basis for reconstructing a comprehensive paleoenvironmental sequence. However, most of the paleoenvironmental evidence from the site is consistent with that from other data sets in the region. When all of these are considered together along with the cultural data from Wilson-Leonard as well as other sites, a regional paleoenvironmental sequence can be outlined for about the last 12,000 years and considered in light of the major cultural developments in Central Texas.

In brief, this sequence began ca. 12,000 B.P. under comparatively xeric climatic conditions. Stream valleys were deeply incised, and erosion prevailed over alluviation along most streams. At Wilson-Leonard, Brushy Creek at its confluence with Spanish Oak Creek was flowing on bedrock adjacent to its right valley wall where neither natural nor cultural deposition was occurring. Alluviation resumed in the valleys of Central Texas at different times in different localities over the next millennium. This was in the form of multiple gravel lenses at Wilson-Leonard where nearly $2 \mathrm{~m}$ of this coarse fill had accumulated by 11,500 years ago. A small number of chipped stone artifacts are present in these gravels. Initially only well-rounded gravels were deposited by Brushy Creek, but over time, more-angular clasts transported by Spanish Oak Creek appear in the section. This marks the beginning of gradually increasing dominance of valley margin sediments over main stream fluvial sediments in the development of the site. Just prior to 11,500 B.P., when regionally, a shift toward a more mesic climate is indicated, Brushy Creek abruptly shifted to another channel, leaving a swale that began to fill with finer-grained deposits. The swale continued to accumulate sediment for the next 900 years, first from mixed fluvial and colluvial siltation and then as a muddy pond or marsh. Prior to formation of the pond, an earlier Clovis (ca. 11,500 B.P.) and a later "Bone Bed" (ca. 11,400-11,000 B.P.) archeological components accumulated along with silty sediment in and around the swale. Soon afterward, the pond began filling with a deposit of organicrich mud. Mixed colluvial and fluvial deposits of loamy texture later buried the muddy pond fill during the interval of 10,600 to 9500 B.P. under conditions that regionally continued to be relatively mesic. A soil ("Leanne") formed in this loam and fairly intensive human use of the locality resulted in formation of the Wilson archeological component. After a brief time of erosion that affected the surface of the Leanne soil, mostly colluvial deposition resumed under continued relatively mesic climatic conditions, and a variety of Late Paleoindian cultural materials accumulated. The fluvial stratigraphy of the interval from ca. 10,000 to 8000 B.P. is poorly known in Central Texas, and it is possible that future work will determine that the Leanne soil and the erosion which followed are indicators of a brief period of more xeric conditions (perhaps between 10,000 and 9500 в.P.).

Rates of deposition at Wilson-Leonard dropped abruptly at about 8000 B.P. to remain low for the remainder of the site's history, and paleoenvironmental data have much lower resolution. Regionally, though, a significant shift to more xeric conditions is well evidenced stratigraphically and biotically between 8000 and 8800 в.P. Xeric conditions prevailed until about 5500 B.P., ameliorated slightly for about 500 years, and returned to last until sometime between 3300 and 2300 B.P. This is interpreted as the regional expression of the Altithermal, and significant cultural adjustments are evidenced in response to its onset at Wilson-Leonard as well as at other sites.

Another xeric interval is seen in the regional stratigraphy beginning about 1000 B.P., but the biotic signal is not consistent nor is it detected at Wilson-Leonard. By some indicators, the region remains today under much the same dry conditions that set widespread erosion of valley alluvium in motion. Other findings, including an increase in bison population numbers about 800 B.P., indicate that the dry interval was brief and was followed by a time of slightly greater moisture with a very recent return to the drier regime of today.

Throughout the last 12,000 years, deposition has generally prevailed over erosion at Wilson-Leonard, bringing about what Brown (1997) refers to a positive archeological outcome. The paleoenvironmental indicators over that time, compared to modern conditions, depict a dominance of relatively xeric climate, with a total of approximately 8,000 years compared to a total of approximately 4,000 years of relatively mesic conditions. At the site, stable carbon isotopes, macroplant fossils, snails, and ostracodes suggest that Brushy Creek valley may have sustained relatively mesic microhabitats during some of the xeric times. There was apparently standing water in the creek during the "Clovis Drought" and several lines of evidence suggest that the soils, vegetation, and snails at the site were responding to less-xeric conditions than prevailed regionally. Well-watered, verdant canyons and valleys surrounded by hot, dry uplands create the distinctive character of the Balcones Canyonlands today, and clearly did so in the past.

There was a concerted effort devoted to determining a radiocarbon-based chronostratigraphy for the WilsonLeonard site, particularly for the better-stratified Paleoindian and earliest Archaic components. A total of 96 dates was obtained, 70 of which pertain to the Paleoindian period and 13 of which relate to the Early Archaic. These constrain an Early Archaic construction of multiple earth ovens at ca. 6,500 to 8,000 years ago and a sequence of at least five Paleoindian components between about 11,500 and 8,400 years ago. These are designated as follows: Clovis (ca. 11,500 to 11,400 B.P.), Bone Bed (ca. 11,400 to 11,000 B.P.), unassigned (ca. 11,000 to 10,600 в.P.), Wilson (10,000 to 9500 B.P.), and Unit II with St. Mary's Hall, Golondrina-Barber, and Angostura projectile point styles (ca. 9500 to 8400 в.P.).

Haynes (1993) offered a critical assessment of the radiocarbon dates for Clovis and for Folsom sites. His results 
suggest a range of about 11,200 to 10,700 B.P. for Clovis and a range of about 10,900 to 10,200 B.P. for Folsom. He notes that three dates on charcoal from the "Pre-Folsom" level at the Agate Basin site (Wyoming) average about 11,650 \pm 60 . In the absence of any diagnostic artifacts from that level, Haynes (1993:224) observes that the component could either be very early Clovis or pre-Clovis. Precisely the same situation exists for the earliest artifacts at Wilson-Leonard. A coherent assemblage technologically similar to Clovis was recovered from the lowest silty unit and dated to about 11,400 to 11,500 B.P. This assemblage included the tip of a projectile point highly similar to tips of Clovis points, but lacking the diagnostic proximal portion. These dates are early for Clovis, yet stratigraphically deeper in the underlying gravels at Wilson-Leonard were a large biface, 3 other bifacial pieces, 3 edge-modified flakes, a uniface, and 52 flakes. The krotovina and other signs of turbation in the silty deposits where the Clovis and Bone Bed components occur end abruptly at the top of the compact gravel deposits, absolutely precluding any downward movement of these artifacts from above. There is no basis for determining the age of these objects other than to note that they are greater than 11,500 years old. As an additional possible indication of these earlier objects being pre-Clovis, the biface (see Figure 7-5b) lacks the characteristic Clovis flake scar pattern.

Unfluted lanceolate dart points in Central Texas are often classified as belonging to the Plainview type. WilsonLeonard data afforded the opportunity to test the validity of some of these classifications using detailed morphological and metrical comparisons with the original Plainview site specimens. The results strongly suggest the presence of a previously undefined type and the possibility that two former types should be combined. The name "St. Mary's Hall" is proposed for one of the types previously classified as Plainview. Also, points previously classified as two distinct types (Golondrina and Barber) were found not to form distinct morphometric types, and it is proposed that these be lumped into a single group, Golondrina-Barber. St. Mary's Hall and Golondrina-Barber are dated to the interval of approximately 9500 to 8400 B.P. at Wilson-Leonard.

From that same analysis, it emerged that projectile points of the Plainview type in the strict sense are extremely rare to absent in Central Texas and that most of the lanceolate forms commonly classified as Plainview are actually St. Mary's Hall and are as much as a millennium younger than true Plainview points. Plainview points that morphometrically closely match those from the Plainview site are dated elsewhere to the interval 11,200 to 10,100 B.P.

A previously undefined archeological style interval, Wilson (Weir 1985), was documented at Wilson-Leonard. This interval, dated between 10,000 and 9500 B.P., falls well within what is generally considered to be the Paleoindian period, yet the artifact assemblage, features, and subsistence data present a very Archaic-like constellation of traits. The diagnostic artifacts for this interval are corner-notched dart points and hafted end scrapers. Points of this general form had been previously recognized as being quite early at such sites as Merrell (Campbell 1948), Landslide (Sorrow et al. 1967), Berclair Terrace (Sellards et al. 1940), Devil's Mouth (Johnson 1964; Sorrow 1968), and others in the central, south, and Lower Pecos areas of Texas. It was Wilson-Leonard, however, that produced the first sizable, dated sample of these points associated with other artifact forms and with features. Grinding stones from this component include true manos with striations from use. A burial ("Burial II"), at least two pits, and several hearths built with limestone rocks were found in the Wilson component. The faunal remains reflect a generalized subsistence dependent upon a variety of animals.

Burial II, recovered in 1983, was a shallow pit containing the flexed skeletal remains of a young adult female, a chopper made from a worn mano, a large limestone rock, and a fossil shark's tooth. This interment was made during the Wilson occupation of the site sometime between 10,000 and 9500 B.P. Morphologically, this individual is similar to other early skeletal remains in the Americas in having a narrower skull as well as a shorter and narrower face than later American Indian and northeast Asian populations. Dental wear and bone isotopic data indicate a varied diet of local plants and animals.

Early Paleoindian components at Wilson-Leonard contribute to the growing body of evidence that the traditional, simple sequence of Clovis, Folsom, Plainview style intervals for the Southern Plains is no longer viable. There now appears to be greater variation within each of these intervals and Folsom and Plainview may be more nearly contemporary than sequential. The Bone Bed component at WilsonLeonard is quite similar to Folsom in terms of its association with bison and in terms of its lithic technology, however, typologically, its single point is unfluted and does not fit well into any established type. Dates for the Bone Bed component range approximately from 11,400 to 11,000 B.P., somewhat earlier than is generally accepted for Folsom components.

Beginning ca. 8800 B.P. occupants of the Wilson-Leonard site began to construct and use diverse and mostly large domestic cooking appliances that employed hot rocks as heating elements. Previously, smaller cooking features each with fewer stones were in use. This shift from smaller and simpler to larger and more complex hot rock appliances marks the beginning of the Early Archaic which by 8200 B.P. saw large, fully-developed, rock-lined earth ovens. Evidence suggests that various foods, both plant and animal, were cooked in the earth ovens, but that inulin-rich camas (wild hyacinth) bulbs may have become an important staple. Inulin is a nondigestible polysaccharide that occurs in place of starch in certain tuberous plants; it can be converted by hydrolysis into a highly nutrituous food. The wild hyacinth is a perennial geophyte that stores inulin in an onion-like bulb beneath the surface of the ground. These bulbs require moist 
baking or steaming for extended periods of time, conditions that can only be met in a sealed oven. This technology, once perfected for the cooking of hyacinth bulbs, may have been used in the preparation of almost every other kind of food, and remains of fish, large and small mammals, turtles, and molluscs, along with acorns, walnuts, and other plant foods are found closely associated with ovens. Or, as Black (1997:255-268) suggests, perhaps the ovens remained specialized facilities for those commodities requiring long cooking times. In his view, other kinds of plant or animal remains found in or near ovens were not prepared in the ovens.

Morphometric cluster analysis of the sizable sample of Early Archaic bifurcate forms of projectile points from Wilson-Leonard demonstrated that the considerable variation seen in this assemblage is actually a continuum of attributes and that the several defined "types" appear to grade from one to another. Bandy, Jetta, Martindale, and Hoxie were the only traditionally recognized types to find support from the attribute study, and even these were far from absolute.

Burned rocks are virtually ubiquitous at prehistoric archeological sites in Central Texas and the Wilson-Leonard excavation provided a sample of 212 burned rock features beginning with the Wilson component, ca. 10,000 years ago, and continuing throughout the site's history. Small hearthlike concentrations of burned rocks and a few larger burned rock features that may have been earth ovens date to the Late Paleoindian period. For the Archaic, a diverse array of burned rock features was documented. These include small hearths, large hearths, small to medium-sized ovens, large ovens, and very large burned rock middens. Smaller burned rock features continued into the Late Prehistoric at the site, although use of the burned rock middens likely continued as well. The fundamental significance of a majority of these features is the use of rocks to control, store, and emanate heat. It becomes apparent that this was central to a subsistence technology that lasted for at least 9,000 years in Central Texas.

More than 50 years has passed since Kelley and Campbell (1942) insightfully postulated that burned rock middens were basically multiple intersecting hearths that formed on stable landsurfaces. With better data and far better control on the chronology of burned rock features in the archeological record, it is now possible to confirm their basic concept. However, it is primarily large, rock-lined earth ovens, rather than hearths, that generate the coalescent quantities of burned rocks (Black and Creel 1997). Also, because large rock-lined earth ovens such as those seen in the Early Archaic levels at Wilson-Leonard can generate a great deal of burned and fire-cracked rock in a fairly short period of time, it is possible for moderately large middens to form on aggrading landforms. The very large, "typical" burned rock middens of the region, however, form only on stable surfaces. Finally, even on those stable or slowly aggrading surfaces where burned rock middens form, isolated burned rock features also occur. Many of these would seem to be hearths, or possibly smaller ovens.

A number of charred bulbs of the wild hyacinth (Camassia scilloides) were recovered from Wilson-Leonard. These plants are entirely of soft, pulpy tissue with no chance of preservation in the archeological record except under extraordinary circumstances - totally caramelized and charred, in the case of this open site. Most of these came from a single earth oven dating to about 8,000 years ago, but another example was recovered from a burned rock midden and dated to about 3800 B.P. The odds of one of these delicate floral specimens being preserved are so low that the number recovered from this site suggests that enormous numbers must have been processed here.

From earliest times until European contact, the peoples of Central Texas remained hunters and gatherers. Even the latest Late Prehistoric Toyah interval with its few corn cobs and modest numbers of ceramics was a time of primarily hunting and gathering. Neighboring culture areas in almost all directions witnessed beginnings of the development of food production long before the arrival of Europeans-conservatively, four millennia in the Southeastern United States, three millennia in the Southwestern United States, four millennia on the central and southern High Plains, and more than five millennia in Mesoamerica. It is inconceivable that inhabitants of Central Texas would remain unaware of these food-producing economies for thousands of years, and it is clear from the centuries of successful farming by Euroamericans that the region is capable of supporting horticulture. The conclusion to be drawn from these observations is that Central Texas groups were neither attracted to nor driven toward food production, which suggests that ample resources could be gotten by hunting and gathering. It could well be that the diversity of edible plants and animals and the technology for bulk processing geophytes was a combination unbeatable by food production. Being centered on the Balcones Canyonlands in the great ecotone along the edges of the oak savannas of the Edwards Plateau and the prairies of the Coastal Plain evidently afforded the requisite abundance and diversity of resources.

\section{A BRIEF SYNOPSIS OF THE WILSON-LEONARD ARCHEOLOGICALSEQUENCE}

Stratified remains attributable to seven principal segments of the local archeological record were documented at this one site. These are, from earliest to latest, pre-Clovis, Early Paleoindian, Late Paleoindian, Early Archaic, Middle Archaic, Late Archaic, and Late Prehistoric.

\section{Pre-Clovis}

With growing acceptance of an archeological component dated to 12,500 B.P. at Monte Verde in southern Chile, the primary implication is that peoples must have passed 
through North America at an earlier time (Meltzer 1997). The record for that passing may be very sparse and of very low archeological visibility. Of the several long-established criteria for verifying a pre-Clovis component, the most straightforward is unambiguous cultural material stratified beneath a Clovis component (Haynes 1969). In the lowest gravels at the base of the site were found a small number of chipped stone artifacts greater than ca. 12,000 years old. These include flakes, modified flakes, and a biface lacking the distinctive flaking pattern seen on Clovis bifaces. Although these are not obviously stream-rolled, it is possible that they are in secondary context. Even so, they clearly predate the next oldest, Clovis component.

\section{Early Paleoindian}

\section{Clovis}

A projectile point tip, 7 bifaces, 31 other chipped stone tools, a hammerstone, and 658 flakes comprise a component with strong technological similarities to Clovis. The projectile point tip closely resembles tips of Clovis points. Dating places this component in the 11,500 to 11,400 B.P. range at Wilson-Leonard. Without a larger sample and examples of more complete projectile points, it is impossible to be absolutely certain that this component belongs to the Clovis complex, however, the affinities of the small assemblage are sufficiently close to warrant that tentative assignment. The data are also too meager to indicate whether this assemblage is more closely similar to Clovis manifestations on the Plains, the Southwestern United States, or the Southeastern United States.

\section{Bone Bed}

Overlying the Clovis materials is another assemblage that has strong technological affinities-in this case with Folsom - but is not easily diagnosed on stylistic grounds. A single projectile point, 26 bifaces, numerous other chipped stone tools, a mano, pieces of sandstone and hematite, and more than 3,000 pieces of debitage are associated with skeletal remains of bison and a single horse bone. Radiocarbon dating places this assemblage in the interval, ca. 11,400 to 11,000 B.P. The unfluted, lanceolate projectile point is thin with slightly recurvate edges. The workmanship is excellent, but more reminiscent of that on Plainview than on Folsom (or Midland) points. An engraved stone in this assemblage is similar to those apparently from Clovis context at the nearby Gault site (Collins et al. 1992) and to one from the Folsom component at Blackwater Draw, New Mexico (Hester 1972:Figure 93g). Ultrathin bifaces and other characteristics of this assemblage compare closely with Foslom assemblages throughout their geographic range. This component exhibits the strongest affinity to the Plains and to the Southwest seen in the Wilson-Leonard sequence.

\section{Unassigned}

A modest number of chipped stone artifacts $(4,500+$ flakes and 104 tools) were found in deposits above the Bone Bed and dating between 11,000 and 10,000 years old at Wilson-Leonard, but these completely lacked diagnostic technological or typological characteristics, except for one of two dart points. A Wilson dart point was among the uppermost items in this group, stratigraphically, which may indicate that at least some of these are artifacts intruded downward from the overlying Wilson component. The other point is a crudely made lanceolate specimen with no clear typological affinities. The interval of time represented by this assemblage is that in which Folsom or Plainview materials might be expected, but it is also a poorly known segment of the cultural record in Central Texas, and as-yet undefined cultural manifestations may have existed.

\section{Late Paleoindian}

\section{Wilson}

An assemblage with strong resemblances to certain Early Archaic materials in the eastern United States is the earliest Holocene component at Wilson-Leonard. Named Wilson, and first defined at this site by Weir (1985), this component dates to the interval ca. 10,000 to 9500 B.P. Corner-notched Wilson dart points are generally similar to some Hardin Barbed and Kirk Corner Notched forms found over wide areas in the Midwest, Northeast, and Southeast (Justice 1987:51-53, 71-75). Temporally, Wilson may be slightly older than Kirk Corner Notched (ca 9500-8900 B.P. [Justice 1987:71]) and contemporary with the early part of the Hardin Barbed range (ca. 10,000-7500 B.P. [Justice 1987:51-53]). Also characteristic of the Wilson component are a few manos, stemmed end scrapers, pit features, rock-lined hearths, and the burial of a young adult female. Faunal remains reflect exploitation of diverse early Holocene forms.

\section{St. Mary's Hall/Golondrina-Barber/Angostura}

Following the Wilson component with its cornernotched points is a later, apparently mixed assemblage characterized by at least three kinds of unfluted lanceolate dart point forms. These are types St. Mary's Hall, GolondrinaBarber, and Angostura. Dates for these Late Paleoindian materials at Wilson-Leonard range from ca. 9500-8800 B.P. The former two are often mistakenly typed either as Plainview or Plainview variants. A few notched stones, possibly net sinkers or bolas, occur with these forms as do a variety of bifacial and unifacial chipped stone tools and a few manos. Woodworking is indicated by Clear Fork tools by their overall morphology as well as by use wear. Burned rock features include large clusters of rocks that functioned as hearths or perhaps shallow ovens. Faunal remains are diverse. These 
Late Paleoindian materials have no recognized close affinities outside of Central Texas and nearby areas.

It is important to note that this discussion views the point style, Angostura, as occurring in both the Late Paleoindian and the Early Archaic time periods. This implies a continuity in weapon technology even though aspects of subsistence technology were changing.

\section{Early Archaic}

A substantial change in subsistence technology marks the beginning of the Early Archaic at Wilson-Leonard and other sites in Central Texas. This is the advent of large rocklined earth ovens. It is not known if the smaller and shallower rock-lined features of earlier times are developmental antecedents to these ovens or if an abrupt shift to ovenbaking occurred. Whatever their developmental history, ovens seem to herald the beginning of burned rock middens. At several better-stratified sites in the region, it is possible to sort out at least three style intervals in the Early Archaic (Angostura, Early Split Stem [types Hoxie, Gower, Jetta], and Martindale/Uvalde [sometimes with Baker and Bandy]), but these are somewhat intermingled at this site and are discussed together. The Early Archaic at Wilson-Leonard is dated using both chronometric and cross-dating evidence to ca. 8700 to 6000 B.P., all within the early part of the Altithermal. Two significant aspects of subsistence are well represented in the Early Archaic biotic remains, namely charred bulbs of the geophyte, Camassia scilloides, and a variety of faunal remains with fish, turtles, and other riparian taxa well represented. Grooved or notched stones that may have served as net sinkers are present.

\section{Middle Archaic}

The Middle Archaic is dated approximately to the interval, 6000 to 4000 B.P. by a small number of radiocarbon dates at this site as well as by cross-dating from other sites in the region. There are infrequent Bell-Andice and Early Triangular projectile point forms along with frequent and somewhat later Nolan and Travis forms. Two burned rock middens were actively forming at the site during this subperiod and a variety of smaller burned rock features were in use as well. Ground stone is relatively more frequent in the Middle Archaic than at any other time in the site's history. Some of the grinding tools have pitted surfaces suited to the grinding of hard seeds, possibly grasses. The entire Middle Archaic interval is inferred as existing under drier conditions than at present, although it began during somewhat ameliorated conditions.

\section{Late Archaic}

Dated from ca. 4000 to 1200 B.P., the Late Archaic at Wilson-Leonard is characterized by dart point types Darl,
Ensor, Frio, Fairland, Marcos, Marshall, and Castroville; Pedernales points are unusually scarce (only 9 of 124 typed specimens). Deposition was slow and mixing of components was considerable by this time in the site's history. Two burned rock middens were in active use along with a variety of smaller burned rock features, climatic conditions were comparatively mesic, and at least some consumption of wild hyacinth is indicated by a single charred specimen.

\section{Late Prehistoric}

Early Late Prehistoric diagnostic artifacts, primarily Scallorn arrow points, are present in modest numbers whereas later Late Prehistoric types (including Perdiz arrow points and Harahay bifaces) are virtually absent. Evidence is inconclusive as to whether or not Late Prehistoric peoples contributed to the growth of Burned Rock Midden 1, but to judge from findings at other sites, it is probable that they did (Black and Creel 1997).

\section{SELECTED THEMES INNORTH AMERICANPREHISTORY}

In spite of numerous and diverse theoretical and methodological constructs used in contemporary archeology, the venerable comparative approach is still fundamental to characterizing and investigating the human record. As presently understood, the Wilson-Leonard site and the regional archeological record of which it is a part reveal a long sequence of hunter-gatherer adaptations decidedly different in overall configuration from contemporary and proximate sequences in Mexico, the Southeastern United States, the Southwestern United States, and the Great Plains. In contrast to each of these areas where sooner or later all, most, or a few of the major trappings of formative culture developed, available evidence reveals that Central Texas remained an area occupied by hunter-gatherers whose pursuit of formative lifeways was negligible. Formative cultural traits discussed here include the domestication of indigenous plants, adoption of introduced tropical cultigens, use of ceramics, sedentism, and construction of nondomestic earthworks. Use of cemeteries is also discussed, not as a formative trait, but as an indicator of one of the more distinctive aspects of the regional prehistory. Of particular concern here is the evidence for the beginnings, that is the time depth, of each of these cultural traits.

Archeological systematics in much of North America were once based on a simplistic premise that "Archaic" manifestations were the leavings of hunter-gatherers, that "Woodland" sites had been occupied by horticulturalists, and that the authors of the "Mississippian" were agriculturalists. As more has been learned, these distinctions have become increasingly blurred, although some popular writings and introductory texts still present this traditional view. In this discussion, "hunter-gatherer" is used in the ethnographic 
sense to refer to subsistence dependent entirely or very largely on wild resources, "Archaic" follows the usage common to whatever geographic region is being discussed, and no rigid correlation is implied between hunting-and-gathering subsistence and Archaic archeological manifestations.

Several factors conspire to lessen the comparability of the various regional chronologies as well as the confidence that can be placed in them. Archeological chronologies in Central Texas, the Southeastern United States, and the Great Plains are built almost exclusively on radiocarbon dating. In the Southwest, dating has been primarily based on, or corrected to, tree-ring chronologies, but uncorrected radiocarbon dating is also reported for the earlier, "Archaic," manifestations. In some cases, radiocarbon dates are reported with no information on whether or not corrections have been applied. Mesoamerican dating is variously based on decipherment of calendrical inscriptions as well as the techniques of radiocarbon and obsidian hydration; ceramic typology is the most widely used basis for cross-dating. In keeping with the standard adopted for this project, the Plains, Southeastern, and Texas chronologies are discussed in uncalibrated radiocarbon years before present; this also applies to most of the earlier Archaic dates from the Southwest. The few- to several-hundred-year discrepancies introduced between this standard and the chronologies based on other dating techniques in the Southwest and Mesoamerica are probably minor for present purposes by comparison to the other major sources of inaccuracy. Foremost among these is the inescapable fact that finding and dating the origin or "oldest" of anything is virtually impossible.

Another significant factor is terminology. Regional differences in the use of terms such as "village," "agriculture," or "cemeteries" are substantial. Other problems are regionally differing standards of evidence, techniques of data recovery, and concepts of significance that determine how data are discovered and reported; what is a major village to Plains archeologists could go virtually unnoticed in Mesoamerica. Also, I have not attempted to cover the vast primary literature for these topics and, therefore, have undoubtedly missed important information that has not yet found its way into the synoptic literature. In spite of these limitations, the broad and general outlines of cultural history in the major culture areas surrounding Central Texas contrast so clearly and for such long periods of time that more precise and complete details would change the general picture very little.

Remains of tropical cultigens (maize) have been recovered from a few Late Prehistoric sites in Central Texas (e.g., Kyle [Jelks 1962] and Timmeron [Harris 1985] rockshelters), but whether these were grown locally or acquired from farmers outside of the region, they and the modest number of ceramics (for example, 49 sherds at Kyle and none at Timmeron) that also occur were minor formative elements in what was basically a hunter-gatherer economy. With the possible exception of a brief interval of specialized bison hunting in the Early Paleoindian period, even the peoples living in Central Texas during the Late Pleistocene were evidently relatively unspecialized hunter-gatherers. Viewed in this way, Central Texas is a virtual archeological laboratory for the study of hunter-gatherers. In traditional terms, this is a classic and purely Archaic archeological sequence unfettered by any but the briefest and most minor existence of formative archeological traits unlike nearby regions where archeologists have modified the Archaic concept to embrace varying degrees, manifestations, and combinations of sedentism, cultivation, use of ceramics, and construction of ceremonial architecture.

Paramount among the questions posed by the Central Texas record is why an Archaic lifeway persisted with only minor local development of formative traits or experimentation in the cultural changes taking place in nearby culture areas. If there is merit to notions that formative archeological traits reflect cultural responses to risks or stresses, it does not seem plausible to suggest that Central Texas was lacking in either. Even if there were no internal causes, why would the area be immune to external stimuli? Isolation brought about by external factors does not seem to be a satisfactory explanation, nor does millennia of conscious isolationism on the part of Central Texas peoples; in other words, there was probably never a time when the local peoples were not well aware of the people and their lifeways in surrounding regions. Exotic materials are never abundant in the prehistoric sites of Central Texas, but they are present in sites of all periods and attest to contacts with other regions. Obsidian that often can be identified with very specific sources has been documented in Paleoindian, Early, Middle, and Late Archaic, and especially Late Prehistoric sites in and near Central Texas (Hester et al. 1991; Hughes 1989). Other exotic stone includes Alibates agatized dolomite (e.g., Gault site [Collins et al. 1991]), granite, andesite, and an unidentified igneous rock (e.g., Wilson-Leonard [Chapter 20]), quartz crystal (e.g., Gault site [Collins et al. 1992]), quartzite (e.g., Mustang Branch [Ricklis and Collins 1994]), and soapstone (Kincaid Shelter [TARL collections]). Marine shells occur in Central Texas in Early Archaic context at Wilson-Leonard (Chapter 21) and in numerous Late Archaic and Late Prehistoric sites (Prewitt 1981:80-83). Caddoan ceramics are found in Late Prehistoric sites in Central Texas (Ricklis 1995:197).

Further, given the wide range of environments where early trends toward formative lifeways are found, it seems improbable that anything in the local natural ecology precludes such developments. Even the fact that climatic conditions during 8,000 of the last 12,000 years in Central Texas were evidently drier than those at present would not seem to explain the pattern given the early establishment of horticulture in semiarid portions of the American Southwest.

Besides a lack of horticulture, the minor amounts of pottery and few examples of domestic architecture that have been documented in Central Texas prehistory are neither as 
common nor as prominent as their contemporaries in surrounding culture areas, seemingly an indication of comparatively little development toward formative lifeways. An alternative to be considered is whether the local archeological record has been misread in regard to any possible formative traits. A closer look at these issues follows.

Although the formative archeological traits are here discussed individually, they are generally found in intimate archeological associations (ceramics with houses and cultigens, cemeteries in mounds, etc.) and were undoubtedly functionally interrelated in the living cultures who left them behind. It is important to remember, however, that there is no a priori set of interrelationships between the various aspects of formative culture. For example, it was long thought that food production was an absolute prerequisite to the development of all other kinds of formative cultural endeavors, but this theoretical notion has not been born out by the evidence (Smith 1997). It is therefore critical that the patterns of cultural integration be thoroughly and independently investigated for every region where formative traits make an appearance.

\section{Food Production}

Two categories of plant foods were cultivated in the American culture areas north of Mexico, indigenous plants and introduced tropical cultigens. Archeological evidence for the initial cultivation of plants in either of these categories is elusive and inferred histories of, and explanations for, early plant cultivation are often controversial in the broad culture areas surrounding Central Texas. However, there is compelling evidence that peoples living an "Archaic" lifeway over much of North America were experimenting with the cultivation of plants beginning in the Middle Holocene (Smith 1998).

Maize and squash were introduced into the American Southwest by 3500 B.P. or perhaps earlier and beans appeared somewhat later (perhaps by 2500 B.P.), evidently with little or no antecedent cultivation of native plants (Figure 11-1)(Ford 1981; Hogan 1994:162-163; Huckle 1995:12; Minnis 1985; Simmons et al. 1989a:59; Tagg 1996; Wills 1988). These plants were being grown under comparatively arid conditions in some parts of the Southwest, necessitating selection of well-watered microhabitats in the more extremely dry areas (Huckle 1995). Cultivation of domesticated tropical plants in the Southwest predated the use of ceramics and the establishment of villages. By ca. 1600 or 1500 B.P., horticultural villages of pit houses and the use of ceramics were well and widely established in the American Southwest; by 1300 or 1200 B.P. aggregated residential complexes ("pueblos") began to appear across the region with attendant advances in ceramics, far-flung trading links, and even irrigated farming in some localities (Cordell 1984). Along its southeastern margin in that part of the Southwest closest to Central Texas - the eastern extension of the Jornada
Mogollon-formative traits were less-fully developed. Dispersed, small horticultural villages of pit houses and partial reliance on hunting and gathering continued until protohistoric times in westernmost Texas and adjacent parts of southeastern New Mexico (Simmons et al. 1989b:112-113).

A different history is seen in the Southeastern United States where in the fourth millennium B.P. at least four native seed plants were brought under cultivation (Smith 1992). These are Iva annua (marshelder), Helianthus annuos (sunflower), Chenopodium berlandieri (chenopod), and Cucurbitapepo ssp. ovifera (squash) (Smith 1992:267-279). This roster of native plants is based on an interpretation that the gourd Cucubita pepo was a native to the Southeast (Smith et al. 1992:67-100) and was the stock from which early squashes were domesticated in the region. Additional species of native plants were brought under cultivation over the next centuries (O'Brien and Wood 1995:54-55; Smith 1992:290-293). Tropical corn and beans followed later, with corn dated as early as ca. 1700 B.P. in Tennessee and Ohio (Smith 1992:291) and beans no earlier than 600-1000 B.P. (Smith 1992:293). A few grains of corn (Zea mays) pollen have been reported from several localities in the eastern United States from older contexts (from 2200 to 3500 B.P. [Fearn and Liu 1995:110]), raising the possibility that corn was introduced earlier than generally believed, but this interpretation has been convincingly challenged (e.g., Crawford et al. 1997; Eubanks 1997). Gourds and squashes were clearly in use long before any indication that they were domesticated (Gremillion 1996); bottle gourds are dated as early as ca. 7000 B.P. in Florida and squash and bottle gourd are both dated to ca. 4200 B.P. at Phillips Springs in the Missouri Ozarks (Sabo and Early 1988:61).

Along the western fringe of the Southeastern Culture Area in northeastern Texas, southeastern Oklahoma, southwestern Arkansas, and northwestern Louisiana are seen the fullest developments of formative culture traits in geographic proximity to Central Texas, culminating in the protohistoric Caddoan village farming complex (Perttula 1992; Story 1990). Anywhere from 2200 to 1300 B.P., depending on the subregion, Caddoan people began variously to make use of ceramics, bows and arrows, permanent houses, burial mounds, and several species of domesticated plants (Story 1990:243-255).

Horticulture in the Central and Southern Great Plains began during the "Late Archaic" with cultivation of native species and later saw the adoption of tropical cultivars (Adair 1988, 1996:106-108; Hofman 1996:83-100; Story 1990:253; Wyckoff and Brooks 1983:13-15). Dates for domesticates in the Central Plains Late Archaic are thought to be as early as 4500-3000 B.P. (Hofman 1996:97) with more fully developed Woodland horticulture seen as early as 2500 B.P. (Adair 1996).

Comparatively little work has been devoted to cultural history along the northern periphery of Mesoamerica, but as part of one of the world's main nuclear areas, it is an area potentially of considerable significance to the broad regional context of cultural history in Central Texas. MacNeish (1958, 


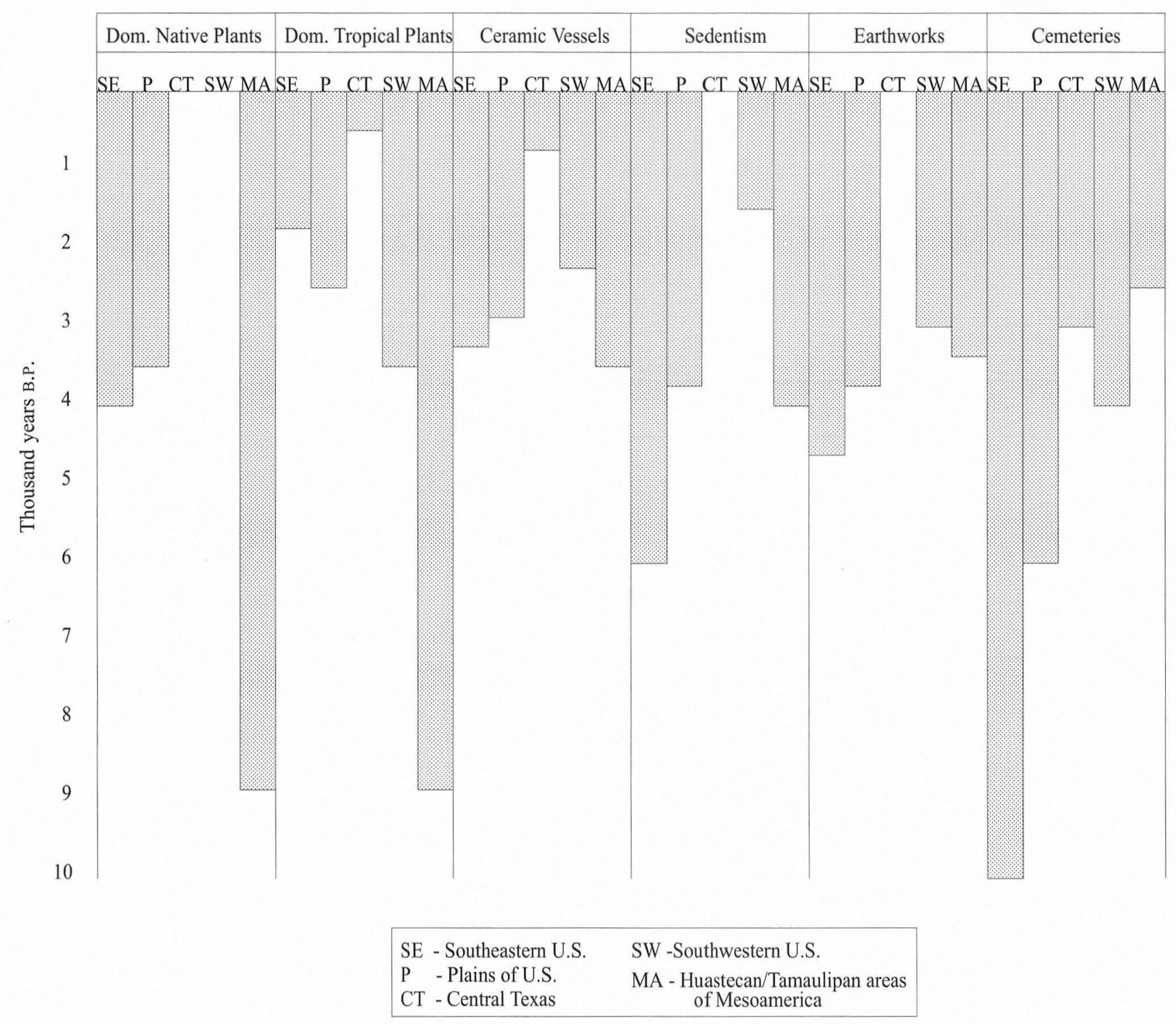

FIGURE 11-1. Approximate time depth of selected formative cultural traits and cemeteries in Central Texas compared with the Southwest, Southeast, Plains, and Huastecan/Tamaulipan culture areas.

1964) proposed early "incipient agriculture" of pumpkins, beans, corn, and squash as a long-lasting developmental phase in southern Tamaulipas with radiocarbon beginning and ending dates of ca. 7000 and 3000 B.P., respectively. These interpretations have been widely repeated in the synoptic literature (e.g., Coe and Flannery 1971; Culbert 1978:409412; Meggers 1979:29-34; Willey 1966:79-81), but neither rigorously verified nor refined with greater detail until recently (Smith 1997). Smith (1997; see also Roush 1997) among others recognized a need to verify the MacNeish hypothesis, and found squash to have been domesticated even earlier (ca. 9000 B.P. [Flannery 1986; Smith 1997). However, the other major Mesoamerican domesticates (gourds, corn, and beans) seem to date no earlier than ca. 3000 B.P. (Fritz 1994; Smith 1995, 1997).
Although charred macrobotanical remains of corn, beans, and squash have been recovered from Late Prehistoric sites in and near Central Texas (Fields 1995:312-313, 318-310; Harris 1985; Jelks 1962; Story 1990:249-255), the evidence does not support an interpretation of any significant dependence upon tropical cultigens by prehistoric peoples in Central Texas. Likewise, there is no indication that any native species (such as chenopod, sunflower, or sumpweed) was an important cultigen, and only meager evidence that there was any cultivation of such plants (Story 1990:253-255).

\section{Use of Ceramics}

In contrast to plant remains that are perishable and not always easily placed on the native-to-cultigen continuum, 
pottery is near the opposite extremes of durability, archeological survivability and recoverability, and unequivocal status as a human product. Like plant cultivation, ceramic production has its beginnings in "Archaic" times in the Plains and American Southeast, but generally, its presence defines the Puebloan cultural tradition in the Southwest and the "Early Preclassic" cultural status in Mesoamerica. This discussion is confined to ceramic vessels.

Ceramics in the Southwestern United States debut in the Mogollon area by ca. 2300 B.P. (see Figure 11-1), well after the appearance of domesticated plants and the establishment of pit house villages (Cordell 1984; Willey 1966; Simmons et al. 1989b). Toward the eastern periphery, Southwestern pottery appears in southeastern New Mexico and western Texas later, around 1200 to 1000 в.P. (Simmons et al. 1989b:112-113).

Fiber-tempered pottery makes a comparatively early appearance in the Southeastern United States (see Figure 11-1) but initially may have been a minor innovation (Sassaman 1996). Earliest dates for pottery in the lower Mississippi Valley approach 3200 в.P. where fiber-tempered sherds occur in small numbers at Poverty Point sites, but intensive use does not appear until is ca. 2800 to 2600 B.P. at Tchefuncte sites (Jetter and Williams 1989:111). In eastern Texas, Tchefunctelike ceramics datable between ca. 2500 and 2100 B.P. are known from a very few sites (Story 1990:246).

A few, simple fiber-tempered vessels are represented by sherds in Nebo Hill sites at the eastern edge of the Central Plains, datable to 3000 B.P. or before (Hofman 1996:97). Significant use of pottery, however, is not evidenced until about 2500 B.P. (Adair 1996:101). Early Woodland pottery in Oklahoma goes back at least to ca. 1500 B.P. (Hofman and Brooks 1989:67) followed by relatively abundant pottery dated to ca. 1200 B.P. in early village farming sites (Brooks 1989:71). Story (1990:217) suggests dates perhaps as early as 1800 to 1300 B.P. for shell-tempered ceramics in northcentral Texas.

Huastecan pottery first appeared ca. 3500 в.P. (Willey 1966:96), somewhat later than the earliest Mesoamerican ceramics of ca. 4300 в.P. (Clark 1997). MacNeish (1958:105, 157-160,193-199) places the earliest pottery in Tamaulipas as appearing ca. 2500 B.P.

Ceramics in Central Texas are absent at most sites, infrequent at a few, numerous ( 100 or more sherds) at very few, and abundant at none (Collins 1995; Johnson 1994; Prewitt 1981, 1985; Ricklis 1995; Suhm 1960). With rare exception (e.g., Black and McGraw 1985:237), they are also confined to the latest part of the prehistoric sequence, the Toyah interval, ca. 800 to 300 B.P. (Collins 1995; Prewitt 1981, 1985). Indigenous pottery of Central Texas is of a single type (Leon Plain [Suhm and Jelks 1962]), a plain, bone-tempered ware that infrequently is brushed (Boothe Brushed [Suhm 1955]) or has a red slip (once referred to as Doss Redware [Kelley 1947]). Caddoan sherds as well as pieces of apparently locally made vessels decorated to resemble Caddoan wares have been reported (Ricklis 1995). A preponderance of the evidence indicates a hunting-and-gathering, relatively mobile subsistence and settlement system for the bearers of Toyah culture (Johnson 1994; Ricklis 1994). The observed minor numbers of ceramic vessels are consistent with this inferred lifeway. Wilson-Leonard is entirely typical of many Late Prehistoric sites in Central Texas, having yielded only one small, plain potsherd. Given this pattern, it is not clear how we should interpret the exceptions - the occasional site (such as the Collins site [Suhm 1955]) where ceramics are numerous.

\section{Sedentism}

On the continuum from highly mobile to fully sedentary lifeways, there are, theoretically, almost infinite degrees of sedentism, but empirical demonstration of a sedentary occupation using archeological evidence is often problematic. Substantial domestic architecture is the primary indicator considered here; when evidence for houses is found in conjunction with some combination of extensive refuse, remains of cultivated plants, pottery, storage facilities, and biotic indicators of year-round activities, the case is more convincing than when based upon architecture alone.

Pit houses appeared in the Jornada Archaic toward the eastern edge of the American Southwest as early as ca. 4700 or 4500 B.P., but supporting evidence for sedentism is lacking until ca. 1500 в.P. when Mesilla villages of a few pit houses also exhibit storage pits, considerable refuse, and other indicators of relatively long occupations (see Figure 11-1) (Whalen 1994:626-627).

Houses are sometimes evident in Middle and Late Archaic sites of the Southeastern United States; early examples include structures dated to ca. $6300-5000$ B.P. along the Tombigbee River in Mississippi (Sassaman and Ledbetter 1996:75-80). Accompanying these and most other early structures in the Southeast is material evidence of long but seasonal use (Sassaman and Ledbetter 1996:83). Beginning near the middle of the third millenium B.P., Woodland sites in much of the Southeast almost always included evidence for substantial structures. Nonresidential structures are documented at a few Early Ceramic sites in eastern Texas and western Louisiana (Story 1990:290-291), raising at least the possibility that domiciles also existed. In the Caddoan area, possible Early Ceramic structures have been noted (e.g., at the Hurricane Hill site [Story 1990:308]), but later domestic structures are well documented for - in fact characteristic of - Caddoan sites (postdating 1200 в.P.) in northeastern Texas (Story 1990:334-338).

Very early architecture is inferred for Paleoindian components at the Hell Gap (Irwin-Williams et al. 1973), Paleo Crossing (Brose and Barish 1992), and Hanson (Frison and Bradley 1980) sites. These and most other early domestic structures are not considered to be evidence of sedentism (Lintz et al. 1995:179). 
Pit houses on the High Plains are indicated by $4300-$ 2800 B.P. in the Archaic McKean complex of Nebraska and Wyoming (Hofman 1996:87-89). Architecture in the eastern Central Great Plains may be evidenced as early as 4000 to 3200 в.P. (Hofman 1996:96-97) in the Late Archaic. Large villages with some evidence for houses occur in Middle Woodland, Kansas City Hopewell sites (after ca. 2000 B.P.) (Adair 1996:108-111). An Early Archaic (ca. 5500 в.P.) structure is inferred near the southern edge of the Rolling Plains of westcentral Texas at the Turkey Bend Ranch site (Treece et al. 1993:204-211). Late Prehistoric residential structures (Antelope Creek) are common on the High Plains of Texas and adjacent Oklahoma and in Henrietta sites of north-central Texas (Brooks 1989:80-82, 85-86).

By ca. 4000 B.P. farming villages were common to most of Mesoamerica. These were each composed of numerous, substantial houses (Weaver 1993). Less-substantial housing and possibly even less-aggregated villages likely preceded these small villages (Marcus and Flannery 1996:5759).

Traces of domestic architecture have been found at a few sites in Central Texas dating from the Early Archaic to the Late Prehistoric (Lintz et al. 1995). One interesting kind of structure consists of a large hearth central to a ring of what appear to be piles of stones used to stabilize posts, examples of which include one that is Late and another that is Early Archaic (Johnson 1997; Lintz et al. 1995). These are fairly large features (up to ca. 5-x-6 m) and may have been windbreaks rather than roofed structures. At other sites, such evidence as wattle-impressed daub or sharply demarcated patterns in refuse and artifact distributions may indirectly represent former structures; most of these being of Late Archaic or Late Prehistoric age (Lintz et al. 1995). In the western part of Central Texas and farther west are several sites, again mostly of either unknown or of Late Prehistoric age, with distinct stone rings interpretable as former sites of tipis or wickiups (Lintz et al. 1995). All of this evidence is for relatively impermanent structures, entirely compatible with short-term residency as part of relatively mobile hunter-gatherer subsistence behavior. In fact, with improved field strategies and careful attention to elusive evidence, archeologists working in Central Texas may greatly increase the number of temporary domestic structures in the local record.

\section{Nondomestic Earthworks}

As well stated by Russo (1996), concepts vary considerably among archeologists regarding the nature and significance of earthworks and mounds. Because the distinction between mounded domestic refuse ("middens") and intentional earthworks ("mounds") is not always easily made and the implied levels of cultural and social complexity thought to be prerequisite for mound construction exceed what some archeologists are willing to attribute to the
“Archaic" (Russo 1996:259-262), early earthworks are probably underrepresented in the archeological record.

Although their purposes have been variously interpreted as anything from ceremonial to defensive to agricultural, the earliest "earthworks" in the Southwest are hillside terraces known as cerros trincheras (Fish et al. 1986; Hard and Roney 1998; Smith 1998), dating as far back as ca. 3000 B.P. in northern Chihuahua (see Figure 11-1) (Hard and Roney 1998). The preponderance of evidence indicates that these terraces were probably built for agricultural purposes, but there is every indication that more than enough suitably level land was available in the basin floors near the terraced hills, suggesting that additional considerations motivated the construction of these features. Much later, ball courts and small platform mounds occurred in minor numbers at a few Hohokam sites in the Southwest. Ball courts date as early as 1500 B.P. and platform mounds by ca. 1100 в.P. (Fagan 1995; Willey 1966:225-226).

It is in the Southeastern United States where very early, Middle Archaic, earthworks are found, the earliest being in Louisiana and in Florida. These date to an interval of ca. 4700 to 4300 B.P. (Saunders et al. 1997). Late Archaic, Poverty Point, earthworks are somewhat later, dating mostly to the interval of ca. 3800 to 2500 B.P. (Russo 1996). Clearly, mounds were being built over a wide area of the Southeast during the Middle and Late Archaic and more generally in the eastern United States in Woodland times. Mounds in eastern Texas are widespread and numerous, especially in Caddoan times, however, earlier, Early Ceramic, mounds are also known to date as early as 1900-2000 B.P. (Story 1990:288).

Minor mound construction is reported in the Central Plains to be as early as 4100 to 3300 B.P. (Hofman 1996:95-96). These are small, low mounds evidently used primarily for human interments. In the interval of 2500 to 2000 B.P. moreformalized burial mounds characterize the Kansas City Hopewell along the eastern margins of the Plains (Adair 1996:111). Along the East Fork of the Trinity River in northcentral Texas, the characteristic earthwork consists of large, Late Archaic or Late Prehistoric pits (greater than $16 \mathrm{~m}$ in diameter and $2 \mathrm{~m}$ in depth), known as "Wylie pits." At least one of these features dates between 2200 and 2000 B.P., but others may be later. Burials are typically found in the fill of Wylie pits (Story 1990:228-236). Earthen mounds are among the principal Caddoan archeological features of northeastern Texas. Both platform and conical mounds are known.

It is, of course, in Mesoamerica where the greatest development of monumental architecture is found in North America. Large mounds, pyramids, platforms, courts, ramps, and monumental stone sculpture all had early expressions in the Olmec region along the Gulf coast by at least as early as 3500 в.P. (Grove 1981; Weaver 1993).

Nothing interpretable as an earthwork has been found in the archeological record of Central Texas. The descriptor, "mound," is sometimes applied to the large burned rock middens of the area (e.g., Kelley and Campbell 1942). This 
term combined with the occasional occurrence of burials (e.g., Weir 1979) within these features has the potential of being misconstrued as implying intentional burial mounds (cf. Russo 1996), but every indication is that the interments are incidental to what is almost exclusively a build-up of refuse from the domestic activities of cooking in earth ovens (Black and Creel 1997).

\section{Development of Cemeteries}

Archeological evidence for the development and maintenance of cemeteries, an important but not necessarily formative aspect of behavior, shows considerable variation across the regions discussed. Especially notable is that in the literature, as few as three graves at a single site may be reported as a cemetery even when it is not clear that they are affiliated with the same social group. What does emerge clearly is that cemeteries, like the other traits discussed, have considerable time depth and complexity in some areas.

It is generally inferred that a cemetery is an expression of a strong sense of place and either limited mobility or very regular territorial rounds on the part of any mobile society whose dead are buried in such concentrations. Because cemeteries interpreted in this perspective are prominent in the archeological record of the Gulf Coastal Plain of Texas, these are treated separately below (e.g., Hall 1995a, 1995b).

In the American Southwest, cemeteries are not common in the Archaic, but have been reported (see Figure 11-1) (Simmons et al. 1989a:60). For example, some Early Agricultural villages (4000-3000 B.P.) of southern Arizona included numerous burials that would seem to represent cemeteries (Huckle 1995). Large cemeteries are common aspects of the later, aggregated communities in all of the major Southwestern subareas, Mogollon, Hohokam, and Anasazi (Cordell 1984).

Cemeteries in the Southeastern United States are documented from Paleoindian (Morse 1997; Morse and Morse 1983:89-92), Early Archaic (Mocas 1977), Middle Archaic, Late Archaic, Woodland, and Mississippian times (Charles and Buikstra 1983; Griffin 1978; Muller 1978; Rose and Harmon 1989:316-317; Willey 1966). These are often large, even in the Archaic (as at Indian Knoll, Kentucky [Webb 1946]). Beginning in the early Woodland, burial ritual became elaborate for at least the social elite over vast areas of the eastern United States; this is well expressed in the burial mounds of eastern Texas (Hamilton 1997; Story 1990, 1997). Further discussion of Archaic burials in southern and eastern Texas is presented below.

In the Central and Southern Plains, Archaic cemeteries beginning as early as 6000 B.P. are inferred from multiple burials at single sites, burial mounds, and possibly even ossuaries (Hofman 1989:51, 1996:83-99). Woodland period cemeteries are considerably more common in the Central and Southern Plains (Hofman and Brooks 1989; Adair 1996). Wylie pits in north-central Texas are of Late Archaic age and most seem to have been the locus of multiple burials (Story 1990:228-236).

Cemeteries in the Huastecan and southern Tamaulipan areas are documented beginning by ca. 2500 B.P. (MacNeish 1958:133-134). These are relatively complex, and probably indicate considerable time depth not discerned by MacNeish.

Cemeteries of Archaic and Late Prehistoric age and occurring as multiple interments in open sites, multiple graves in small mounds, or as accumulations of remains in vertical shaft caves are prominent aspects of the archeological record on and near the Gulf Coastal Plain of southern and eastern Texas (Aten et al. 1976; Bement 1994; Boyd et al. 1997; Hall 1995a, 1995b; Hester 1980:73-82; Prewitt 1974; Story 1990; Taylor and Highley 1995). Archaic cemeteries in eastern and southeastern Texas are open sites usually situated in or near areas of habitation (Hall 1995a, 1995b; Story 1990:237-243). Some of the data from these sites are indicative of complex funerary behavior as well as access to material goods from widely in the southeastern United States (Hall 1995a, 1955b). Archeologically, the number, size, and complexity of Late Archaic cemeteries across the Gulf Coastal Plain of Texas contrast dramatically with the prosaic daily lives seemingly indicated for the people who used them (Hall 1995a, 1995b). These large Late Archaic cemeteries include many graves containing lavish offerings of artifacts fashioned from local as well as exotic materials.

In Central Texas, per se, cemeteries are not common until Late Archaic and Late Prehistoric times. Examples include graves in open sites (e.g., Loeve-Fox, Frisch Auf!, Olmos Dam, Locke Farm [Hester and Collins 1969; Lukowski 1988; Prewitt 1974; Woolsey 1936]), interments in rockshelters (as reported by Watt 1936), as well as human remains in vertical shafts (e.g., Bering Sinkhole, Hitzfelder, Mason Creek Burial Cave) (Bement 1994; Collins 1995; Hall 1995a; Prewitt 1981). Vertical shaft cemeteries are surely significantly underrepresented in the regional archeological record for want of systematic survey by archeologists (speleologists occasionally note human bones in such caves, but this information does not systematically find its way to archeologists).

\section{CONCLUSIONS}

Adaptive trends at Wilson-Leonard and in Central Texas consisted of minor adjustments in a lifeway that remained essentially Archaic in the sense that hunting and gathering subsistence and impermanent settlement prevailed throughout almost 12,000 years of prehistory. Variations in technology and artifact styles are factors prehistorians have used to subdivide this long record into periods and style intervals, but compared to developments seen in each of the major culture areas surrounding Central Texas, these subdivisions represent cultural changes that are distinctive but, in terms of adaptive significance, are really quite minor. This is in spite of the fact that of the past 12 millennia, 
close to 8 witnessed drier conditions than exist in Central Texas today and the other 4 were somewhat more mesic. Artifact materials, preserved animal, and, less commonly, plant remains attest to exploitation of diverse terrestrial and aquatic habitats and support the inference that local resources were sufficiently available and reliable to maintain a hunting and gathering lifeway from the Late Pleistocene through the Holocene.

A rich, diverse, and decidedly Archaic-like archeological record of the Paleoindian period is emerging for Central Texas. Evidence from Wilson-Leonard and a number of other sites for the interval ca. 11,500 to 8800 B.P. reflects several style intervals (Clovis, Folsom/Midland, Dalton, San Patrice, Wilson, Golondrina-Barber, St. Mary's Hall, and possibly Plainview) without any specialized big game hunting, except perhaps for the Folsom/Midland interval. Extensive, intensive, and widespread use of heated-rock cooking technology began by 8800 to 8500 B.P. in Central Texas and reflects important changes in food processing. This change marks the beginning of the Archaic and, basically, centers on the use of large earth ovens. It seems clear that bulk processing of starchy foods was made possible by this technology. What is less clear is how significant were the changes in the inventory of food items being processed. Preserved plant remains are far more abundant from Archaic than from Paleoindian components, which thwarts direct comparisons. Many of the same animals, and presumably the same plants, were consumed, but plants such as the camas bulbs that require specialized oven cooking may have been important additions to the menu at this juncture.

Exploitation of fish and other riverine resources during the Archaic seems to have been more important to subsistence in the drier intervals in a pattern mildly reminiscent of Desert Archaic adaptations where subsistence often was focused on rich aquatic habitats found in Great Basin lakes (Janetski and Madsen 1990). Bison remains are more often found in archeological components dating to the mesic intervals, probably reflecting increased numbers of bison during such times. The Wilson-Leonard data are consistent with those from the region in general in these regards.

There are contrasting kinds of Archaic sites in Central Texas. At some, including Wilson-Leonard, food grinding tools are few in number whereas at others (such as the Sleeper site) grinding gear is prolific. Earth ovens occur at many but not all sites and the same is true of burned rock middens. Such differences may reflect the exploitation of localized resource patches - possibly camas at WilsonLeonard and grass seeds at Sleeper. This is the expectable archeological pattern to result from a subsistence response to the mosaic of natural habitats in and near the Balcones Canyonlands.

In the Balcones Canyonlands, the availability of important resources ranges from almost ubiquitous to very restricted. Deer, turkeys, squirrels, acorns, wild grapes, and limestone are among resources that could be found almost everywhere. Adequate water, certain riparian plants and animals, grasses, chert, and a number of other commodities are widely but unevenly available. Such items as pecans, walnuts, mussels, and sandstone are available in comparatively limited areas. In addition to varying patterns of spatial occurrences, many biotic resources are available only during limited seasons of each year (e.g., most fruits and nuts), some vary greatly in abundance from year to year (e.g., turkeys and acorns), while others (e.g., rabbits and deer) can be found in all seasons and do not vary as greatly in abundance over the years as do some species. Longer-term fluctuations in climate add another source of variation in resource availability (e.g., relative abundance of xeric- to mesicadapted plants). Humans relying on hunting and gathering in such an environment must remain sufficiently mobile to tap resources when and where they become available, but in and near the Balcones Canyonlands, this could well include fairly extended stays at some favored localities. Hence the presence of some domestic structures in conjunction with the archeological signature of mobile hunting and gathering is expectable.

Cultivars at most contributed in a minor way to subsistence in Central Texas, and then only in the 300 or 400 years immediately prior to the arrival of Europeans. Ceramics, too, were in use only in the last half of the Late Prehistoric and their numbers remained small. The groups responsible for these minor amounts of cultigens and pottery - the Toyah archeological interval of the Late Prehistoric period-were also engaged in the most active pursuit of bison since the end of the Pleistocene in addition to exploiting basically the same wide array of plants and animals that had supported Archaic hunters and gatherers for the previous 8,000 or so years. Earth ovens continued in use even though Toyahinterval pottery afforded an alternative means for cooking some kinds of foods.

Millennia earlier in the surrounding culture areas, people made significant shifts toward cultivation, built mounds or other communal earthworks, began to live more permanently in certain preferred locations, and buried their dead in cemeteries. Were the hunter-gatherers of Central Texas unaware of these developments? The record suggests not. In fact, as Nassaney and Sassaman (1995:xix-xxxviii) have observed, archeologists probably have grossly underestimated the extent to which prehistoric peoples in North America interacted over great distances. This view is supported by the several broad technological changes shared between regions in spite of the otherwise conspicuous contrasts. Importantly, the record shows that peoples in Central Texas adopted a number of technological changes at roughly the same times as did peoples over much of North America, especially eastern North America and the Plains. These roughly synchronous developments are unlikely to be coincidental. Examples include the replacement of Paleoindian-style, lanceolate points having ground edges with points having stems formed by deep corner-notches ca. 9,000 years ago; popularity of 
bifurcated-stem followed by Calf-Creek style projectile points in the Early Archaic and Middle Archaic; development of bifacial chipped stone adzes ca. 10,000 B.P.; and adoption of the bow and arrow ca. 1200 B.P.

By now, archeologists have probably established reasonably complete answers to the when, what, and where of most formative kinds of archeological traits in North America, but the why questions remain barely answered. This is especially apparent when the record for Central Texas is considered in light of those in the surrounding culture areas - the unanswered question for Central Texas becomes, "why not?" The long Central Texas Archaic sequence with only very late and very minor amounts of pottery and tropical cultigens focuses inquiry on how hunting and gathering was sufficient in maintaining the local population. If enough native plant and animal foods were reliably accessible in the Balcones Canyonland ecotone, there remains the problem of uneven availability, especially seasonally. Seasonal adjustments, including transhumance, to locally available foods would be one strategy, perhaps resulting in large seasonal aggregations of people. Combined food preservation and storage is an alternative, but not mutually exclusive, response. Once bulk processing began at ca. 8500 B.P., preservation and storage are strongly implied. Earth ovens and food grinding stones were minimally present late in the Paleoindian period, but became characteristic aspects of the Archaic period. No unambiguous evidence for food storage facilities has been found in the Central Texas Archaic, but it is hard to envision a successful hunting and gathering economy without preserved foods that could be either stored or transported as circumstances demanded.

Meat preservation techniques suitable for the local climate include smoking and drying. Dried meat packed in fat ("pemmican") may account for the growing evidence of bonegrease extraction in the local Archaic sites. Plant foods suitable for cooking, drying, grinding into flour, and preserving either as flour or as baked bread include acorns, native grass seeds, and camas bulbs. Rarely would breads and pemmicans stored above ground in skin pouches or baskets leave a recognizable archeological record.

In the broadest terms, then, the local archeological record begins in the Late Pleistocene with mostly generalized huntergatherers who were probably few enough in numbers and sufficiently mobile to survive by foraging. The exception to this mode of subsistence may have been during a time of bison abundance when people employing Folsom technology stuck close to the grasslands of Central Texas and seem to have specialized in hunting bison. What remains unclear is what besides bison contributed to the subsistence of these people and what the relative importance of the various commodities were. Early in the Holocene, as conditions became more xeric, large earth ovens began to be used in bulk processing starchy plant foods. Bone greasing and plant food grinding also become important parts of the subsistence technology. It is postulated here that the making of flour or bread and pemmican served to preserve food for leaner seasons during which the taking of game and smaller animals continued. More aquatic resources were exploited during the drier paleoclimatic intervals. Evidently population numbers increased but never to the point that native plant and animal resources failed to be adequate. It is further postulated that even though regional peoples were well aware of formative developments in surrounding regions they were never inclined by necessity or emulation to pursue those activities. Some degree of mobility was needed to adequately exploit the patchiness of key resources, but occupancy of some localities was long enough to warrant the construction of shelters. Perhaps territories were well enough defined that the practice of disposing of the dead in vertical shaft caves or in burial plots led to the development of cemeteries. There is no conclusive evidence for cultivation of native plants, minimal evidence for the adoption of tropical cultigens, and no evidence for construction of earthworks.

Two other conspicuous aspects of neighboring archeological traditions are minimal or absent locally. Whereas native peoples in all of the surrounding culture areas consumed quantities of exotic items of material culture obtained through long distance exchange networks, there is comparatively less evidence for the acquisition of obsidian, marine shell, or other foreign items in the Central Texas Archaic. The small numbers of such items do, however, reinforce the observation made earlier that the people of this region were not totally isolated from the surrounding regions. Also, the local peoples did not produce highly polished stone implements such as celts or grooved axe heads, but they did make atlatl weights (boat stones).

Exactly why this particular mix of cultural traits emerged is not yet known. It is unknown in part because archeologists working in the region have only recently begun to probe some of the key elements in this distinctive, local Archaic tradition. It is a tradition worthy of closer scrutiny precisely because of the contrasts it bears to other regional traditions.

Unless archeologists have failed to discover earthworks (very unlikely), domesticated native plants (certainly possible), or earlier use of tropical cultivars (also possible), Central Texas bears witness to a very long and successful tradition of hunting and gathering in a diverse and rich environment with a finely honed subsistence technology centered on the use of earth ovens. Even if a few examples of formative traits are found, the basic character of the region as the long-time home to hunting and gathering peoples would not be changed.

If this postulated, unusually conservative, and successful tradition of hunter and gatherers is to be verified, considerably more-detailed information is needed on what foods were consumed in what relative proportions, what the seasonal patterns of exploitation were, and what role - if anyfood preservation played in the subsistence strategies. These 
needs will be met only with improved archeological strategies and methods, especially in the recovery and study of plant remains. We need to better understand this regional variant of the American Archaic and, ultimately, contribute toward better understanding of the archeological record of hunting-gatering peoples in general.

Several lessons were learned from work at WilsonLeonard that are important at this juncture in our investigation of the region's long hunter-gatherer record. These include aspects of the formation of the archeological record, archeological data recovery, and the need to seek out and investigate sites with optimal conditions for yielding new or better information.

The setting of Wilson-Leonard is at once optimal at a regional scale and somewhat paradoxical at the local scale. Regionally it afforded about equal access to resources in the Balcones Canyonlands, Black Prairie, and Lampasas Cut Plain environments as well as the ecotone along the Balcones Escarpment. It was strategically located in terms of access to the Brazos and Colorado River drainages, and it was close to the Central Mineral Region. Yet in those majority of millennia when conditions were relatively dry compared to modern times, much of the uplands immediately surrounding the site were evidently almost arid. Brushy Creek valley seems to have remained moderately well watered during the drier intervals, but many localities along the escarpment as well as in and near the Balcones Canyonlands were better watered. It is postulated that a local patch of camas plants with their abundant and nutritious bulbs could have contributed to the attractiveness of this locality. Overall, favorable aspects of the setting clearly outweighed unfavorable ones throughout the known prehistory of the region.

Although no known single site better represents the archeological sequence of Central Texas, another paradox is that Wilson-Leonard is not very representative of the content of many of the other sites in the area. For any interval in the regional sequence, there is significant variation among contemporary sites - often more differences exist between sites of the same age than there are between components of different ages at Wilson-Leonard. Consistently through time, the Wilson-Leonard assemblages are overwhelmingly of chipped stone; local chert acounts for all but miniscule amounts of the chippable raw material; chert cores are informal, commonly depleted and often recycled as hammerstones or other tools; there are relatively few formalized tool forms among bifaces as well as unifaces; ground stone tools are relatively infrequent and of very ordinary forms; and there are no polished stone tools. Woodworking tools are found through much of the sequence, but it is not clear what needs were met by the working of wood.

Generalized hunter-gatherers intermittently occupied the site for some 11,000 years and employed an earth-oven cooking technology for at least the last 8,500 years of that interval. In this sense, the site epitomizes the regional archeological record and underscores the need to better understand this long and conservative tradition. WilsonLeonard also provides the most complete temporal framework for organizing future inquiry into the regional prehistory, and it is unlikely that any comparable site will be investigated in the near future.

It is curious that, in spite of its regional distinctiveness and conservativism, the regional record has parallels with broader trends in North America. As mentioned earlier, subcontinent-wide shifts in projectile point forms are found in Central Texas and at Wilson-Leonard. These include the transition from lanceolate Paleoindian to corner-notched Early Archaic forms followed by bifurcate-stemmed types. The widespread popularity of the Calf Creek form has a local expression in the Andice points of the early Middle Archaic. The bow and arrow debuts in Central Texas at about the same time as it does in much of North America. This last event certainly, and the earlier ones probably, are the surviving expression of significant technological advances in weapon design and construction (especially hafting).

Wilson-Leonard grudgingly yielded floral and faunal clues to subsistence practices and paleoenvironmental conditions, but better-preserved evidence is urgently needed. Sites where conditions exist for the preservation of plant and animal remains are of the highest premium in Central Texas. Investigators must seek out sites that contain wellpreserved plant and animal artifacts as well as ecofacts. Sheltered localities, inundated deposits, or favorable soil conditions need to become top priorities for researchers and cultural resource managers. With Wilson-Leonard and the hundreds of other already-investigated sites providing the regional framework, even minor assemblages of preserved organic specimens that can be directly dated are potentially informative, culturally and environmentally.

More-detailed data on archeological assemblages and features from brief intervals of time across the mosaic of microenvironments in Central Texas are also needed. These should confirm, expand, modify, or challenge the general cultural history outlined here. Some of these data will come from newly investigated sites, but a closer look at the reported as well as the unreported but curated record from previously excavated sites will be fruitful. One of these previously excavated sites is Wilson-Leonard. Although an effort was made to thoroughly analyze and report the data from this site, there are many curated samples of rocks, soil, bones, shells, and plant parts that were not analyzed, and, of course, everything that was analyzed could be profitably restudied with newer and better perspectives or techniques. There were many analytical paths untaken. Wilson-Leonard still has great untapped potential for contributing to the study of Central Texas prehistory. 


\section{REFERENCES CITED IN VOLUME I}

Abbott, J. T.

1994 Geomorphic Context of the Barton Site (41HY202) and the Mustang Branch Site (41HY209). In Archaic and Late Prehistoric Human Ecology in the Middle Onion Creek Valley, Hays County, Texas, by R. A. Ricklis and M. B. Collins, pp. 353-379. Studies in Archeology 19. Texas Archeological Research Laboratory, The University of Texas at Austin.

Abbott, J. T., and W. N. Trierweiler (editors)

1995 NRHP Significance Testing of 57 Prehistoric Archeological Sites on Fort Hood, Texas. Archeological Resource Management Series Research Report 34. United States Army Fort Hood. TRC Mariah, Austin.

Adair, M. J.

1988 Prehistoric Agriculture in the Central Plains. Publications in Anthropology 16. University of Kansas, Lawrence.

1996 Woodland Complexes in the Central Great Plains. In Archeology and Paleoecology of the Central Great Plains, edited by J. L. Hofman, pp. 101-122. Research Series 48. Arkansas Archeological Survey, Fayetteville.

Adovasio, J. M.

1993 The Ones that Will Not Go Away: A Biased View of PreClovis Populations in the New World. In From Kostenki to Clovis, edited by O. Soffer and N. D. Praslov, pp. 199218. Plenum, New York.

Alexander, H. L., Jr.

1963 The Levi Site: A Paleo-Indian Campsite in Central Texas. American Antiquity 28:510-528.

1983 The Pre-Clovis and Clovis Occupations at the Levi Site. In Peopling of the New World, edited by J. E. Ericson, R. E. Taylor, and R. Berger, pp. 133-145. Ballena Press, Los Altos.

Ammerman, A. J., and M. W. Feldman

1974 On the "Making" of an Assemblage of Stone Tools. American Antiquity 39:610-616.

Anderson, D. G., and K. E. Sassaman (editors)

1996 The Paleoindian and Early Archaic Southeast. University of Alabama Press, Tuscaloosa.

Anonymous

1978 Preserving Texas' Natural Heritage. Project Report 31. Natural Heritage Policy Research Project, Lyndon B. Johnson School of Public Affairs, The University of Texas at Austin.

Antevs, E.

1955 Geologic-Climatic Dating in the West. American Antiquity 20:317-335.

Atchison, D. E.

1954 Geology of Brushy Creek Quadrangle, Williamson County, Texas. Master's thesis, Department of Geology, The University of Texas at Austin.
Aten, L. E., C. K. Chandler, A. B. Wesolowsky, and R. M. Malina 1976 Excavations at the Harris County Boys School Cemetery. Special Publication 3. Texas Archeological Society.

Baker, B.W.

1994 Vertebrate Remains from the Wilson-Leonard Site (41WM235), Williamson County, Texas: Holocene Animal Exploitation in Central Texas Prehistory. Unpublished Master's thesis, Department of Anthropology, Texas A\&M University, College Station.

Baker, V. R.

1975 Flood Hazards along the Balcones Escarpment in Central Texas-Alternative Approaches to the Recognition, Mapping, and Management. Geological Circular 75-5. Bureau of Economic Geology, The University of Texas at Austin.

Bamforth, D. B.

1986 Technological Efficiency and Tool Curation. American Antiquity 51:38-50.

Barbour, E. H., and C. B. Schultz

1932 The Scottsbluff Bison Quarry and Its Artifacts. Nebraska State Museum Bulletin 34, Volume 1. Nebraska State Museum, Lincoln.

Barnes, V. E.

1981 Geologic Atlas of Texas, Austin Sheet. Bureau of Economic Geology, The University of Texas at Austin.

Bartram, L. E., E. M. Kroll, and H. T. Bunn

1991 Variability in Camp Structure and Bone Food Refuse Patterning at Kua San Hunter-Gatherer Camps. In The Interpretation of Archaeological Spatial Patterning, edited by E. M. Kroll and T. D. Price, pp. 77-148. Plenum Press, New York.

Beasley, T. S.

1978 A Site with Edwards Points in Bandera County, Texas. La Tierra 5(4):23-31.

Bement, L. C.

1991 The Thunder Valley Burial Cache: Group Investment in a Central Texas Sinkhole Cemetery. Plains Anthropologist 36(135):97-109.

1994 Hunter-Gatherer Mortuary Practices During the Central Texas Archaic. University of Texas Press, Austin.

Bettinger, R. L.

1991 Hunter-Gatherers: Archaeological and Evolutionary Theory. Plenum Press, New York.

Binford, L. R.

1977 Forty-Seven Trips: A Case Study in the Character of Archaeological Formation Processes. In Stone Tools as Cultural Markers: Change, Evolution, and Complexity, edited by R. V. S. Wright, pp. 24-36. Australian Institute of Aboriginal Studies, Canberra. 
1979 Organization and Formation Processes: Looking at Curated Technologies. Journal of Anthropological Research 35:255-273.

1980 Willow Smoke and Dogs' Tails: Hunter-Gatherer Settlement Systems and Archaeological Site Formation. American Antiquity 45:4-20.

1981 Bones: Ancient Men and Modern Myths. Academic Press, New York.

Black, S. L.

1989 Central Texas Plateau Prairie. In From the Gulf to the Rio Grande: Human Adaptation in Central, South, and Lower Pecos Texas, by T. R. Hester, S. L. Black, D. G. Steele, B. W. Olive, A. A. Fox, K. J. Reinhard, and L. C. Bement, pp. 17-38. Research Series 33. Arkansas Archeological Survey, Fayetteville.

1997 Oven Cookery at the Honey Creek Site. In Hot Rock Cooking on the Greater Edwards Plateau: Four Burned Rock Midden Sites in West Central Texas, by S. L. Black, L. W. Ellis, D. G. Creel, and G. T. Good, pp. 255-268. Studies in Archeology 22. Texas Archeological Research Laboratory, The University of Texas at Austin. Archeology Studies Program Report 2. Environmental Affairs Department, Texas Department of Transportation, Austin.

Black, S. L., and D. G. Creel

1997 The Central Texas Burned Rock Midden Reconsidered. In Hot Rock Cooking on the Greater Edwards Plateau: Four Burned Rock Midden Sites in West Central Texas, by S. L. Black, L. W. Ellis D. G. Creel, and G. T. Goode, pp. 269-305. Studies in Archeology 22. Texas Archeological Research Laboratory, The University of Texas at Austin. Archeology Studies Program Report 2. Environmental Affairs Department, Texas Department of Transportation, Austin.

Black, S. L., and A. J. McGraw

1985 The Panther Springs Creek Site: Cultural Change and Continuity in the Upper Salado Creek Watershed, South Central Texas. Archaeological Survey Report No. 100. Center for Archaeological Research, The University of Texas at San Antonio.

Blair, W. F.

1950 The Biotic Provinces of Texas. Texas Journal of Science 2(1):93-117.

Bleed, P.

1986 The Optimal Design of Hunting Weapons: Maintainability or Reliability. American Antiquity 51:737-747.

Blum, M. D.

1992 Modern Depositional Environments and Recent Alluvial History of the Lower Colorado River, Gulf Coastal Plain of Texas. Unpublished Ph.D. dissertation, Department of Geography, The University of Texas at Austin.
Blum, M. D., and S. V. Valastro, Jr.

1989 Response of the Pedernales River of Central Texas to Late Holocene Climatic Change. Annals of the Association of American Geographers 79:435-456.

Blumenschine, R. J.

1991 Hominid Carnivory and Foraging Strategies, and SocioEconomic Function of Early Archaeological Sites. Philosophical Transactions of the Royal Society 334:211-221.

Bomar, G. W.

1983 Texas Weather. University of Texas Press, Austin.

Boule, W. W., F. D. Hole, and R. J. McCracken

1989 Soil Genesis and Classification. Iowa State University Press, Ames.

Bousman, C. B.

1993 Hunter-Gatherer Adaptations, Economic Risk and Tool Design. Lithic Technology 18(1, 2):59-86.

1994 The Central Texas Pollen Record: A Reinterpretation. Current Research in the Pleistocene 11:79-81.

1998 Paleoenvironmental Change in Central Texas: The Palynological Evidence. Plains Anthropologist 43:40-59.

Bousman, C. B., M. B. Collins, and T. K. Perttula

1988 Quaternary Geomorphology at Cooper Basin, A Framework for Archeological Inquiry, Delta and Hopkins Counties, Texas. Reports of Investigations 55. Prewitt and Associates, Inc., Austin.

Boyd, J. B., D. E. Wilson, T. R. Hester, and T. K. Perttula

1997 Southern Island, a Prehistoric Cemetery Site in the Falcon Reservoir, Tamaulipas, Mexico. Bulletin of the Texas Archeological Society 68:387-425.

Brain, C. K.

1981 The Hunters or the Hunted?: An Introduction to African Cave Taphonomy. University of Chicago Press, Chicago.

Briuer, F. L.

1976 New Clues to Stone Tool Function: Plant and Animal Residues. American Antiquity 41(4):478-484.

Brooks, R. L.

1989 Village Farming Societies. In From Clovis to Comanchero: Archeological Overview of the Southern Great Plains, by J. L. Hofman, R. L. Brooks, J. S. Hays, D. W. Owsley, R. L. Jantz, M. K. Marks, and M. H. Manhein, pp. 71-90. Research Series 35. Arkansas Archeological Survey, Fayetteville.

Brose, D., and B. Barrish

1992 Investigations at Ohio Site Push Back Dates for Clovis. Mammoth Trumpet 7(4):1, 3.

Brown, A. G.

1997 Alluvial Geoarchaeology. Cambridge University Press, Cambridge. 
Brown, J. A.

1975 Deep-Site Excavation Strategy as a Sampling Problem. In Sampling in Archaeology, edited by J. W. Mueller, pp. 155-169. University of Arizona Press, Tucson.

Brown, K. M.

1985 Three Caches of Guadalupe Tools from South Texas. Bulletin of the Texas Archeological Society 56:75-126.

Bryant, V. M., Jr.

1977 A 16,000 Year Pollen Record of Vegetational Change in Central Texas. Palynology 1:143-156.

Butzer, K. W.

1982 Archaeology as Human Ecology: Method and Theory for a Contextual Approach. Cambridge University Press, New York.

Cahen, D., L. Keeley, and F. Van Noten

1979 Stone Tools, Tool-Kits and Human Behavior in Prehistory. Current Anthropology 20:661-683.

Campbell, T. N.

1948 The Merrell Site: Archaeological Remains Associated with Alluvial Terrace Deposits in Central Texas. Bulletin of the Texas Archeological and Paleontological Society 19:7-35.

Camper, H. A.

1991 Pollen Analysis of Patschke Bog. Unpublished Master's thesis, Department of Botany, Texas A\&M University, College Station.

Caran, S. C., and V. R. Baker

1986 Flooding along the Balcones Escarpment, Central Texas. In The Balcones Escarpment: Geology, Hydrology, Ecology, and Social Development in Central Texas, edited by P. L. Abbott and C. M. Woodruff, p. 1014. Comet Reproduction Services, Santa Fe Springs, California.

Carr, J. T.

1967 Climate and Physiography of Texos. Report 53. Texas Water Development Board, Austin.

Charles, D. K., and J. E. Buikstra

1983 Archaic Mortuary Sites in the Central Mississippi Drainage: Distribution, Structure, and Behavioral Implications. In Archaic Hunters and Gatherers in the American Midwest, edited by J. L. Phillips and J. A. Brown, pp. 117 145. Academic Press, New York.

Cheek, C. S., S. Bearden, W. Young, and C. B. Bousman

1980 Archeological Investigations at the Graham Site, 34AT90: 1975, 1977, and 1978. Research Report 23. Archeological Research Associates, Tulsa.

Chlachula, J.

1994 A Paleo-American (Pre-Clovis) Settlement in Alberta. Current Research in the Pleistocene 11:21-23.

Clark, J. E.

1997 The Arts of Government in Early Mesoamerica. Annual Review of Anthropology 26:211-234.
Coe, M. D., and K. V. Flannery

1971 Microenvironments and Mesoamerican Prehistory. In Prehistoric Agriculture, edited by S. Struever, pp. 131-142. Natural History Press, Garden City, New York.

Cofman, R. J., M. C. Trachte, and M. B. Collins

1986 Cultural Ecology of the Kenyon Rockshelter and the Cunningham Site, Canyon Creek Development, Travis County, Texas. Reports of Investigations 53. Prewitt and Associates, Inc., Austin.

Collins, M. B.

1975 Lithic Technology as a Means of Processual Inference. In Lithic Technology: Making and Using Stone Tools, edited by E. Swanson, pp. 15-34. Mouton Publishers, The Hague.

1988 Thoughts on Future Investigations of Burned Rock Middens. Paper Presented at the Council of Texas Archeologists, Austin, Texas.

1990a Observations on Clovis Lithic Technology. Current Research in the Pleistocene 7:73-74.

1990b The Archaeological Sequence at Kincaid Rockshelter, Uvalde County, Texas. Transactions of the 25th Regional Archeological Symposium for Southeastern New Mexico and Western Texas, pp. 25-33. Midland Archeological Society, Midland, Texas.

1991a Rockshelters and the Early Archaeological Record in the Americas. In The First Americans: Search and Research, edited by T. D. Dillehay and D. J. Meltzer, pp. 157-182. CRC Press, Boca Raton.

1991b Thoughts on Future Investigations of Burned Rock Middens. In The Burned Rock Middens of Texas: An Archeological Symposium, edited by T. R. Hester, pp. 1-24. Studies in Archeology 13. Texas Archeological Research Laboratory, The University of Texas at Austin.

1993 Comprehensive Lithic Studies: Context, Technology, Style, Attrition, Breakage, Use-Wear and Organic Residue. Lithic Technology 18(1\&2):87-94.

1994a Evidence of Early Archaic Occupation. In Archaic and Late Prehistoric Human Ecology in the Middle Onion Creek Valley, Hays County, Texas, by R. A. Ricklis and M. B. Collins, pp. 67-100. Studies in Archeology 19. Texas Archeological Research Laboratory, The University of Texas at Austin.

1994b Late Archaic Evidence in the Project Area. In Archaic and Late Prehistoric Human Ecology in the Middle Onion Creek Valley, Hays County, Texas, by R. A. Ricklis and M. B. Collins, pp. 67-100. Studies in Archeology 19. Texas Archeological Research Laboratory, The University of Texas at Austin. 
1995 Forty Years of Archeology in Central Texas. Bulletin of the Texas Archeological Society 66:361-400.

1996 The Keven Davis Cache (41NV659) and Clovis Blade Technology in the South Central United States. Report to Texas Historical Commission, Austin, Texas.

Collins, M. B., and C. B. Bousman

1990 Cultural Implications of Late Quaternary Environmental Change in Northeastern Texas. Manuscript on file at the Texas Historical Commission, Austin.

1993 Quaternary Environments and Archaeology in Northeastern Texas. In Archeology in the Eastern Planning Region, Texas: A Planning Document, edited by N. A. Kenmotsu, and T. K. Perttula, pp. 49-68. Cultural Resource Management Report 3. Department of Antiquities Protection, Texas Historical Commission, Austin.

Collins, M. B., C. B. Bousman, P. Goldberg, P. R. Takac, J. C. Guy, J. L. Lanata, T. W. Stafford, and V. T. Holliday

1993 The Paleoindian Sequence at the Wilson-Leonard Site, Texas. Current Research in the Pleistocene 10:10-12.

Collins, M. B., C. B. Bousman, and T. K. Perttula

1993 Historic Context: Quaternary Environments and Archeology in Northeastern Texas. In Archeology in the Eastern Planning Region, Texas: A Planning Document, edited by N. A. Kenmotsu and T. K. Perttula, pp. 49-67. Cultural Resource Management Report 3. Department of Antiquities Protection, Texas Historical Commission, Austin.

Collins, M. B., B. Ellis, and C. Dodt-Ellis

1990 Excavations at the Camp Pearl Wheat Site (41KR243): An Early Archaic Campsite on Town Creek, Kerr County, Texas. Studies in Archeology 6. Texas Archeological research Laboratory, The University of Texas at Austin.

Collins, M. B., G. L. Evans, T. N. Campbell, M. C. Winans, and C. E. Mear

1989 Clovis Occupation at Kincaid Shelter, Texas. Current Research in the Pleistocene 6:3-4.

Collins, M. B., J. Guy, and S. Carpenter

1991 An Evaluation of Documentation from 1981-1984 Investigations at the Wilson-Leonard Site (41WM235) Williamson County, Texas. Technical Series 21, Texas Archeological Research Laboratory, The University of Texas at Austin.

Collins, M. B., T. R. Hester, and P. J. Headrick

1992 Engraved Cobbles from the Gault Site, Central Texas. Current Research in the Pleistocene 9:3-4.

Collins, M. B., T. R. Hester, D. Olmstead, and P. J. Headrick

1991 Engraved Cobbles from Early Archaeological Contexts in Central Texas. Current Research in the Pleistocene 8:13-15.
Collins, M. B. and A. C.Kerr

1993 Archeology of the Earliest Texans. Paper presented at the Texas Archeological Society Meeting, Laredo.

Collins, M. B., and J. L. Lanata

1993 About Lithics, Technologies and Other Topics: Introduction. Lithic Technology 18(1\&2):5-9.

Cordell, L. S.

1984 Prehistory of the Southwest. Academic Press, Orlando.

Council of Texas Archeologists

1992 Council of Texas Archeologists Guidelines. On file at the Texas Archeological Research Laboratory, The University of Texas at Austin.

Courty, M. A., P. Goldberg, and R. Macphail

1989 Soils and Micromorphology in Archaeology. Cambridge University Press, Cambridge.

Crawford, G. W., D. G. Smith, and V. E. Bowyer

1997 Dating the Entry of Corn (Zea mays) Into the Lower Great Lakes Region. American Antiquity 62:112-119.

Creel, D. G.

1990 Excavations at 41TG91, Tom Green County, Texas, 1978. Publications in Archaeology Report No. 38. Texas State De-partment of Highways and Public Transportation, Austin.

1991 Assessing the Relationship Between Burned Rock Midden Distribution and Archaic Subsistence in West Central Texas. In The Burned Rock Middens of Texas: An Archeological Symposium, edited by T. R. Hester, pp. 33-43. Studies in Archeology 13. Texas Archeological Research Laboratory, The University of Texas at Austin.

Culbert, T. P.

1978 Mesoamerica. In Ancient Native Americans, edited by J. D. Jennings, pp. 403-453. W.D. Freeman and Co., San Francisco.

Dalquest, W. W., E. Roth, and F. Judd

1969 The Mammal Fauna from Schulze Cave, Edwards County, Texas. Bulletin of the Florida State Museum 13:206-276.

Davis, W. B.

1974 The Mammals of Texas. Bulletin 41. Texas Parks and Wildlife Department, Austin.

Dering, J. P.

1992 Macrobotanical Analysis of Three Flotation Samples from Justiceburg Reservoir. In Phase III Cultural Resource Investigations at Justiceburg Reservoir, Garza \& Kent Counties, Texas: Data Recovery, Season 1, by D. K. Boyd, C. B. Bousman, S. A. Tomka, K. M. Gardner, and M. D. Freeman. Reports of Investigations 84. Prewitt and Associates, Inc., Austin. 
Diamond, D. D., D. H. Riskind, and S. L. Orzell

1987 A Framework for Plant Community Classification and Conservation in Texas. The Texas Journal of Science 39:202-221.

Dibble, D. S.

1970 On the Significance of Additional Radiocarbon Dates from Bonfire Shelter, Texas. Plains Anthropologist $15: 251-254$.

Dibble, D. S., and D. Lorrain

1968 Bonfire Shelter: a Stratified Bison Kill Site, Val Verde County, Texas. Miscellaneous Papers 1. Texas Memorial Museum, Austin.

Dillehay, T. D.

1974 Late Quaternary Bison Population Changes on the Southern Plains. Plains Anthropologist 19(65):180-196.

1996 Monte Verde, A Late Pleistocene Settlement in Chile. Volume 2. Smithsonian Institution Press, Washington, D.C.

Duffield, L. F.

1963 The Wolfshead Site: An Archaic-Neo-American Site in San Augustine County, Texas. Bulletin of the Texas Archeological Society 34:83-141.

Elliot, W. R. and G. Veni (editors)

1994 The Caves and Karst of Texas. National Speological Society, Huntsville, Alabama.

Ellis, G. L.

1994 Archeological Overview and Theoretical Perspectives. In Significance Standards for Prehistoric Cultural Resources: A Case Study from Fort Hood, Texas, by G. L. Ellis, C. Lintz, W. N. Trierweiler, and J. M. Jackson, pp. 41-99. Technical Report CRC-94/04. U. S. Army Corps of Engineers, Construction Engineering Research Laboratories, Champaign, Illinois.

Ellis, L. W., G. L. Ellis, and C. D. Frederick

1995 Implications of Environmental Diversity in the Central Texas Archeological Region. Bulletin of the Texas Archeological Society 66:401-426.

Ensor, H. B., and C. S. Mueller-Wille

1988 Excavations at the Bull Pen Site 41BP280, Colorado River Drainage, Bastrop County, Texas. Contract Reports in Archaeology, Report Number 3. Texas State Department of Highways and Public Transportation, Austin.

Eubanks, M.

1997 Reevaluation of the Identification of Ancient Maize Pollen from Alabama. American Antiquity 62:139-145.

Evans, G. L.

1961 The Friesenhahn Cave. Bulletin of the Texas Memorial Museum 2. Texas Memorial Museum, The University of Texas at Austin.

Fagan, B.M.

1995 Ancient North America. Thames and Hudson. New York.
1997 The First American. Archaeology, March/April 1997:6063.

Fearn, M. L., and K. Liu

1995 Maize Pollen of 3500 B.P. from Southern Alabama. American Antiquity 60:109-117.

Fehrenbach, T. R.

1968 Lone Star, a History of Texas and the Texans. Collier, New York.

Fiedel, S. J.

1987 Prehistory of the Americas. Cambridge University Press, Cambridge.

Fields, R. C.

1995 The Archeology of the Post Oak Savannah of East Central Texas. Bulletin of the Texas Archeological Society 55:301-330.

Fish, P. R., S. K. Fish, A. Long, and C. Miksicek

1986 Early Corn Remains from Tumamoc Hill, Southern Arizona. American Antiquity 51:563-572.

Flannery, K. V. (editor)

1986 Guila Naquitz, Archaic Foraging and Early Agriculture in Oaxaca, Mexico. Academic Press, Orlando.

Ford, R. I.

1981 Gardening and Farming Before A.D. 1000: Pattern of Prehistoric Cultivation North of Mexico. Journal of Ethnobotany 1(1):6-27.

Freeman, L. G., Jr.

1968 A Theoretical Framework for Interpreting Archeological Materials. In Man the Hunter, edited by R. B. Lee, and I. Devore, pp. 262-267. Aldine-Atherton, Chicago.

Frison, G. C.

1991 The Clovis Cultural Complex: New Data from Caches of Flaked Stone and Worked Bone Artifacts. In Raw Material Economies Among Prehistoric Hunter-Gatherers, edited by A. Montet-White and S. Holen, pp. 321-333. Publications in Anthropology 19. University of Kansas, Lawrence.

Frison, G. C. (editor)

1996 The Mill Iron Site. University of New Mexico Press, Albuquerque.

Frison, G., and B. Bradley

1980 Folsom Tool Technology at the Hanson Site, Wyoming. University of New Mexico Press, Albuquerque.

Frison, G. C., C. V. Haynes, Jr., and M. L. Larson

1996 Discussion and Conclusions. In The Mill Iron Site, edited by G. C. Frison, pp. 205-216. University of New Mexico Press, Albuquerque.

Fritz, G. A.

1994 Are the First American Farmers Getting Younger? Current Anthropology 35:305-309. 
Gehlbach, F. R.

1988 Forests and Woodlands of the Northeastern Balcones Escarpment. In Edwards Plateau Vegetation, Plant Ecological Studies in Central Texas, by B. B. Amos and F. R. Gehlbach, pp. 57-77. Baylor University Press, Waco.

1991 The East-West Transition Zone of Terrestrial Vertebrates in Central Texas: A Biogeographical Analysis. Texas Journal of Science 43(4):415-427.

Godfrey, C. L., G. S. McKee, and H. Oakes

1973 General Soil Map of Texas. Texas Agricultural Experiment Station, Texas A\&M University in cooperation with Soil Conservation Service, U.S. Department of Agriculture, College Station.

Goldberg, P.

1974 Sediment Peels from Prehistoric Sites. Journal of Field Archaeology 1:323-328.

Goode, G. T.

1991 Late Prehistoric Burned Rock Middens in Central Texas. In The Burned Rock Middens of Texas: An Archeological Symposium, edited by T. R. Hester, pp. 71-93. Studies in Archeology 13. Texas Archeological Research Laboratory, The University of Texas at Austin.

n.d. Report on Excavations at the Anthon Site, Uvalde County, Texas. Manuscript on file. Texas Department of Transportation, Austin.

Gould, R. A.

1980 Living Archaeology. Cambridge University Press, Cambridge.

Graham, R. W.

1976 Pleistocene and Holocene Mammals, Taphonomy, and Paleoecology of the Friesenhahn Cave Local Fauna, Bexar County, Texas. Unpublished Ph.D. dissertation, The University of Texas at Austin.

Green, L. M., and T. R. Hester

1973 The Finis Frost Site: A Toyah Phase Occupation in San Saba County, Texas. Bulletin of the Texas Archeological Society 44:319-333.

Gremillion, K. J.

1996 The Paleoethnobotanical Record for the Mid-Holocene Southeast. In Archaeology of the Mid-Holocene Southeast, edited by K. E. Sassaman and D. G. Anderson, pp. 99114. University Press of Florida, Gainesville.

Griffen, J. B.

1978 The Midlands and Northeastern United States. In Ancient Native Americans, edited by J. D. Jennings, pp. 221-279. W. D. Freeman and Co., San Francisco.

Grove, D.

1981 The Formative Period and the Evolution of Complex Culture. In Handbook of Middle American Indians, Supplement 1, Archaeology, edited by J. A. Sabloff, pp. 373-391. University of Texas Press, Austin.
Hall, D. A.

1995 Bones of Nebraska Mammoths Imply Early Human Presence. Mammoth Trumpet 10(1):1, 4-7.

Hall, G. D.

1995a Description and Chronology of Some Prehistoric Cemeteries in Texas. In Archeological Investigations at the Loma Sandia Site (41LK28), A Prehistoric Cemetery and Campsite in Live Oak County, Texas, by A. J. Taylor and C. L. Highley, pp. 47-57. Studies in Archeology 20. Texas Archeological Research Laboratory, The University of Texas at Austin.

1995b Prehistoric Cemeteries on the Texas Central Coastal Plain: Interpretations and Hypotheses. In Archeological Investigations at the Loma Sandia Site (4ILK28), A Prehistoric Cemetery and Campsite in Live Oak County, Texas, by A. J. Taylor and C. L. Highley, pp. 633-647. Studies in Archeology 20. Texas Archeological Research Laboratory, The University of Texas at Austin.

Hall, S. A.

1982 Late Holocene Paleoecology of the Southern Plains. Quaternary Research 17:391-407.

1990 Channel Trenching and Climatic Change in the Southern U.S. Great Plains. Geology 18:342-345.

Hamilton, D. L.

1997 Observations on Caddoan Burial Practices at the Sanders Site (41LR2). Bulletin of the Texas Archeological Society $68: 115-134$

Hard, R. J., and J. R. Roney

1998 AMassive Terraced Village Complex in Chihuahua, Mexico, 3000 Years Before Present. Science 279:1661-1664.

Harris, E. S.

1985 An Archaeological Study of the Timmeron Rockshelter (41HY95) Hays County, South Central Texas. STAA Special Publication No. 4. Southern Texas Archaeological Association, San Antonio.

Hayden, B.

1986 Resource Models of Inter-Assemblage Variability. Lithic Technology 15(3):82-89.

Haynes, C. V., Jr.

1969 The Earliest Americans. Science 166:709-715.

1991 Geoarchaeological and Paleohydrological Evidence for a Clovis-age Drought in North America and Its Bearing on extinction. Quaternary Research 35:438-450.

1992 Contributions of Radiocarbon Dating to the Geochronology of the Peopling of the New World. In Radiocarbon after Four Decades, edited by R. E. Taylor, A. Long, and R. S. Kra, pp. 355-374. Springer-Verlag, New York.

1993 Clovis-Folsom Geochronology and Climatic Change. In From Kostenki to Clovis, edited by O. Soffer and N. D. Praslov, pp. 219-236. Plenum Press, New York. 
Henderson J., and G. T. Goode

1991 Pavo Real: An Early Paleoindian Site in South-Central Texas. Current Research in the Pleistocene 8:26-28.

Hester, J. J.

1972 Blackwater Locality No. 1.: A Stratified Early Man Site in Eastern New Mexico. Fort Burgwin Research Center Publication No. 8. Rancho de Taos, New Mexico.

Hester, T. R.

1977 The Current Status of Paleoindian Studies in Southern Texas and Northeastern Mexico. In Paleoindian Lifeways, edited by E. Johnson, pp. 169-186. The Museum Journal, XVII, West Texas Museum Association, Texas Tech University, Lubbock.

1980 Digging into South Texas Prehistory. Corona Publishing, San Antonio.

1991 Notes on South Texas Archaeology: 1991-3. Further Notes on the Lithics from the Plainview Occupation at the St. Mary's Hall Site, South Central Texas. La Tierra $18(2): 1-6$.

Hester, T. R. (editor)

1991 The Burned Rock Middens of Texas: An Archeological Symposium. Studies in Archeology 13. Texas Archeological Research Laboratory, The University of Texas at Austin.

Hester, T. R., F. Asaro, F. Stross, H. Michel, A. C. Kerr, and P. Headrick

1991 An Overview of the Results of the Texas Obsidian Project. La Tierra 18(1):4-7.

Hester, T. R., and M. B. Collins

1969 Burials from the Frisch Auf! Site: 41FY42. Texas Journal of Science 20(3):261-272.

Hester, T. R., and T. C. Kelly

1976 Archaeological Investigations at Sites near Natalia, Medina County, Texas. Archaeological Survey Report 20. Center for Archaeological Research, The University of Texas at San Antonio.

Hietala, H. (editor)

1984 Intrasite Spatial Analysis in Archaeology. Cambridge University Press, Cambridge.

Hill, R. T.

1891 Notes on the Geology of the Southwest. The American Geologist 7:366-370.

1901 Geography and Geology of the Black and Grand Prairies, Texas. Twenty-First Annual Report of the United States Geological Survey 1899-1900. United States Geological Survey, Washington, D.C.

Hill, R. T., and T. W. Vaughn

1900 Physical Geography of the Texas Region. Topographic Atlas, Austin, Folio 76. United States Geological Survey, Washington D.C.
Hofman, J.

1989 Prehistoric Culture History-Hunters and Gatherers in the Southern Great Plains. In From Clovis to Comanchero: Archeological Overview of the Southern Great Plains, edited by J. L. Hofman, R. L. Brooks, J. S. Hays, D. W. Owsley, R. L. Jantz, M. K. Marks, and M. H. Manheim, pp. 25-60. Research Series 35. Arkansas Archeological Survey, Fayetteville.

1996 Early Hunter-Gatherers of the Central Great Plains: Paleoindian and Mesoindian (Archaic) Cultures. In $\mathrm{Ar}$ cheology and Paleoecology of the Central Great Plains, edited by J. L. Hofman, pp. 41-100. Research Series 48. Arkansas Archeological Survey, Fayetteville.

Hofman, J. L., and R. L. Brooks

1989 Prehistoric Culture History, Woodland Complexes in the Southern Great Plains. In From Clovis to Comanchero: Archeological Overview of the Southern Great Plains, by J. L. Hofman, R. L. Brooks, J. S. Hays, D. W. Owsley, R. L. Jantz, M. K. Marks, and M. H. Manhein, pp. 61-70. Research Series 35. Arkansas Archeological Survey, Fayetteville.

Hogan, P.

1994 Foragers to Farmers II; A Second Look at the Adoption of Agriculture in Northwestern New Mexico. In Archaic Hunter-Gatherer Archaeology in the American Southwest, edited by B. J. Vierra. Eastern New Mexico University Contributions in Anthropology 13(1):155-184.

Holliday, V. T

1985 Morphology of Late Holocene Soils at Lubbock Lake Archeological Site, Texas. Soil Science Society American Journal 49:938-946.

1987 Cultural Chronology. In Lubbock Lake, edited by E. Johnson, pp. 22-25. Texas A\&M University Press, College Station.

1992 Soil Formation, Time and Archeology. In Soils in Archaeology, Landscape and Human Evolution, edited by V. T. Holliday, pp. 101-118. Smithsonian Institution Press, Washington, D.C.

n.d. Geoarchaeological Investigations at the Wilson-Leonard Site. Manuscript on file at the Texas Archeological Research Laboratory, The University of Texas at Austin.

Holloway, R. G., and V. M. Bryant, Jr.

n.d. Pollen Analysis of Site 41WM235. Manuscript on file, Texas Archeological Research Laboratory, The University of Texas at Austin.

Holloway, R. G., and M. W. Pendleton

1986 Pollen and Macrobotanical Remains at the Kenyon Rockshelter (41TV742) and the Cunningham Site (41TV743). In Cultural Ecology of the Kenyon Rockshelter and the Cunningham Site, Canyon Creek Development, Travis County, Texas, edited by R. J. Coffman, M. C. Trachte, and M. B. Collins, pp. 403421. Report of Investigations 53. Prewitt and Associates, Inc., Austin. 
Howard, E. B.

1943 Folsom and Yuma Problems. Proceeding of the American Philosophical Society 86(2):255-259.

Howard, M. A.

1991 Burned Rock Midden Excavations, Hearths and Botancial Remains. In The Burned Rock Middens of Texas: An Archeological Symposium, edited by T. R. Hester, pp. 45-69. Studies in Archeology 13. Texas Archeological Research Laboratory, The University of Texas at Austin.

Huckle, B. B.

1995 Of Marshes and Maize, Preceramic Agricultural Settlements in the Cienega Valley, Southeastern Arizona. Anthropological Papers of the University of Arizona 59. The University of Arizona Press, Tucson.

Hughes, J. T.

1949 Investigations in Western South Dakota and Northwestern Wyoming. American Antiquity 4:266-277.

Hughes, J. T., and P. S. Willey

1978 Archeology at Mackenzie Reservoir. Archeological Survey Report 24. Office of the State Archeologist, Texas Historical Commission. Austin.

Hughes, R. E.

1989 Notes on Obsidian from the Fort Hood Area of Texas. Bulletin of the Texas Archeological Society 59:193200.

Irwin, H. T.

1971 Developments in Early Man Studies in Western North America, 1960-1970. Arctic Anthropology 8(2):42-67.

Irwin-Williams, C., H. Irwin, G. Agogino, and C. V. Haynes

1973 Hell Gap: Paleo-Indian Occupation on the High Plains. Plains Anthropologist 18(59):40-53.

Janetski, J. C., and D. B. Madsen

1990 Wetland Adaptations in the Great Basin. Occasional Papers No. 1. Museum of Peoples and Cultures, Brigham Young University, Provo.

Jelinek, A. J.

1967 A Prehistoric Sequence in the Middle Pecos Valley, New Mexico. Anthropological Papers 31. Museum of Anthropology, University of Michigan, Ann Arbor.

Jelks, E. B.

1962 The Kyle Site: A Stratified Central Texas Aspect Site in Hill County, Texas. Archeology Series 5. Department of Anthropology, The University of Texas at Austin.

Jennings, J. D.

1974 Prehistory of North America. McGraw-Hill, New York.

Jetter, M. D., and G. I. Williams, Jr.

1989 Ceramic-Using Cultures, 600 B.C.-A.D. 1000. In Archeology and Bioarcheology of the Lower Mississippi Valley and Trans-Mississippi South in Arkansas and Louisiana, by M. D. Jetter, J. C. Rose, G. I. Williams, Jr., and A. M. Harmon, pp. 111-170. Research Series 37. Arkansas Archeological Survey, Fayetteville.

Jochim, M. A.

1981 Strategies for Survival. Academic Press, New York.

Johnson, E., and V. T. Holliday

1980 A Plainview Kill/Butchering Locale on the Llano Estacado: The Lubbock Lake Site. Plains Anthropologist 25:89-111.

1987 Lubbock Lake Artifact Assemblages. In Lubbock Lake, edited by E. Johnson, pp. 120-158. Texas A\&M University Press, College Station.

Johnson, E., V. T. Holliday, and R. W. Neck

1982 Lake Theo: Late Quaternary Paleoenvironmental Data and New Plainview (Paleoindian) Date. North American Archaeologist 3(2):113-137.

Johnson, E. H.

1931 The Natural Regions of Texas. University of Texas Bulletin 3113. The Universisty of Texas at Austin.

Johnson, L., Jr.

1964 The Devil's Mouth Site: A Stratified Campsite at Amistad Reservoir, Val Verde County, Texas. Department of Anthropology, The Univesity of Texas at Austin.

1987 A Plague of Phases: Recent Sociocultural Taxonomy in Texas Archeology. Bulletin of the Texas Archeological Society 57:1-26.

1989 Great Plains Interlopers in the Eastern Woodlands during Late Paleo-Indian Times. Office of the State Archeologist Report 36. Texas Historical Commission, Austin.

1991 Early Archaic Life at the Sleeper Archaeological Site, 41BC65, of the Texas Hill Country, Blanco County, Texas. Publications in Archaeology, Report 39. Texas Department of Transportation, Austin.

1994 The Life and Times of Toyah-Culture Folk as Seen From the Buckhollow Encampment, Site 41KM16 of Kimble County, Texas. Office of the State Archeologist Report 38. Texas Department of Transportation and the Texas Historical Commission, Austin.

1997 The Lion Creek Site (41BT105): Aboriginal Houses and Other Remains at a Prehistoric Rancheria in the Texas Hill Country (Burnet County). Report 1, Environmental Affairs Division, Archeology Studies Program, Texas Department of Transportation and Report 41, Office of the State Archeologist, Texas Historical Commission, Austin.

Johnson, L., Jr., and G. T. Goode

1994 A New Try at Dating and Characterizing Holocene Climates, as well as Archeological Periods, on the Eastern Edwards Plateau. Bulletin of the Texas Archeological Society $65: 1-51$. 
Justice, N. D.

1987 Stone Age Spear and Arrow Points of the Midcontinental and Eastern United States. Indiana University Press, Bloomington.

Keeley, L. H.

1991 Tool Use and Spatial Patterning: Complications and Solution. In The Interpretation of Archeological Spatial Patterning, edited by E. M. Kroll, and T. D. Price, pp. 257268. Plenum Press, New York.

Kelley, J. C.

1947 The Lehmann Rock Shelter: A Stratified Site of the Toyah, Uvalde, and Round Rock Foci. Bulletin of the Texas Archeological and Paleontological Society 18:115-128.

Kelley, J. C., and T. N. Campbell

1942 What are the Burnt Rock Mounds of Texas? American Antiquity 7:319-322.

Kelly, R. L.

1983 Hunter-Gatherer Mobility Strategies. Journal of Anthropological Research 39(3):277-306.

1988 The Three Sides of a Biface. American Antiquity 53:717734.

1995 The Foraging Spectrum. The Smithsonian Institution Press, Washington, D.C.

Kelly, R. L., and L. C. Todd

1988 Coming into the Country: Early Paleoindian Hunting and Mobility. American Antiquity 53:231-244.

Kelly, T. C.

1982 Criteria for Classification of Plainview and Golondrina Projectile Points. La Tierra 9(3):2-25.

1983a The Brom Cooper Paleo-Indian Collection from McMullen County, Texas. La Tierra 10(3):17-40.

1983b The Barber Paleo-Indian Point. La Tierra 10(4):10-25.

1987 Archaeology of the Gamenthaler Valley, Gillespie County, Central Texas: A Preliminary Report. La Tierra 14(1):527.

Knudson, R. (was 1973)

1983 Organizational Variability in Late Paleoindian Assemblages. Report of Investigations 60. Laboratory of Anthropology, Washington State University, Pullman.

Krieger, A. D.

1947 Artifacts from the Plainview Bison Bed. In Fossil Bison and Associated Artifacts from Plainview, Texas, by E. H. Sellards, G. L. Evans, and G. E. Meade. Bulletin of the Geological Society of America 58(10):927954.

1964 Early Man in the New World. In Prehistoric Man in the New World, edited by J. D. Jennings and E. Norbeck, pp. 23-81. University of Chicago Press, Chicago.
Kroeber, A. L.

1939 Cultural and Natural Areas of Native North America. University of California Publications in American Archaeology and Ethnology 38.

Kuhn, S. L.

1989 Hunter-Gatherer Foraging Organization and Strategies of Artifact Replacement and Discard. In Experiements in Lithic Technology, edited by D. S. Amick, and R. P. Mauldin, pp. 33-47. BAR International Series 528. British Archaeological Reports, Oxford.

Largent, F. B., M. R. Waters, and D. L. Carlson

1991 The Spatiotemporal Distribution and Characteristics of Folsom Projectile Points in Texas. Plains Anthropologist 36:323-341.

Larkin, T. J., and G. W. Bomar

1983 Climatic Atlas of Texas. Publication LP-192. Texas Department of Water Resources, Austin.

Leonhardy, F. C.

1966 Domebo: A PaleoIndian Mammoth Kill in the PrairiePlains. Contributions of the Museum of the Great Plains 1. Lawton, Oklahoma.

Leroi-Gourhan, A., and M. Brézillion

1972 Fouilles de Pincevent:essai d'analyse ethnographique d'un habitat magdalénien. Gallia Préhistoire Supplement 7. Centre National de la Recherche Scientifique, Paris.

Lintz, C., A. Treece, and F. Oglesby

1995 The Early Archaic Structure at the Turkey Bend Ranch Site (41CC112), Concho County. In Advances in Texas Archeology, Volume I, edited by J. E. Bruseth and T. K. Perttula, pp. 155-186. Cultural Resource Management Report 5. Texas Historical Commission, Austin.

Luke, C. J.

1980 Continuing Archaeology on State Highway 16: The Shep Site (41KR109) and the Wounded Eye Site (41KR107). Publications in Archaeology 19. State Department of Highways and Public Transportation, Austin.

Lukowski, P. D.

1988 Archaeological Investigations at 41BX1, Bexar County, Texas. Archaeological Survey Report 135. Center For Archaeological Research, The University of Texas at San Antonio.

Lundelius, E. L., Jr.

1974 The Last Fifteen Thousand Years of Faunal Change in North America. In History and Prehistory of the Lubbock Lake Site, edited by C. C. Black, pp. 141-160. The Museum Journal 15. Texas Tech Museum, Lubbock.

MacNeish, R. S.

1958 Preliminary Archaeological Investigations in the Sierra de Tamaulipas, Mexico. Transactions of the American Philosophical Society 48, Part 6. Philadelphia. 
1964 The Food-gathering and Incipient Agriculture State of Prehistoric Middle America. In Handbook of Middle American Indians, Volume 1, edited by R. C. West, pp. 413-426. University of Texas Press, Austin.

Marchbanks, M. L.

1989 Lipid Analysis in Archaeology: An Initial Study of Ceramics and Subsistence at the George C. Davis Site. Unpublished Master's thesis, Department of Anthropology, The University of Texas at Austin.

Marchbanks, M. L., and M. Quigg

1989 Organic Residue and Phytolith Analyses. In Phase II Investigations at Prehistoric and Rock Art Sites, Justiceburg Reservoir, Garza and Kent Counties, Texas, by D. K. Boyd, J. T. Abbott, W. A. Bryan, C. M. Garvey, S. A. Tomka, and R. C. Fields, pp. 495-520. Reports of Investigations 71. Prewitt and Associates, Inc., Austin.

Marcus, J., and K. V. Flannery

1996 Zapotec Civilization. Thames and Hudson, London.

Masson, M. A., and M. B. Collins

1995 The Wilson-Leonard Site (41WM235). Cultural Resource Management News and Views 7(1):6-10. Texas Historical Commission, Austin.

McCormick, O.

1982 41WM419 (Crockett Gardens Site). In Archaeological Investigations at the San Gabriel Reservoir Districts, Central Texas, compiled and edited by T. R. Hays, pp. 12.135-12.166. Archaeology Program, Institute of Applied Sciences, North Texas State University, Denton.

McKinney, W. W.

1981 Early Holocene Adaptations in Central and Southwestern Texas: The Problem of the Paleoindian-Archaic Transition. Bulletin of the Texas Archeological Society 52:91-120.

McNeish, R. S.

1958 Preliminary Archaeological Investigations in the Sierra de Tamaulipas, Mexico. Transactions of the American Philosophical Society 48(Part 6). Philadelphia.

1964 The Food-gathering and Incipient Agriculture State of Prehistoric Middle America. In Handbook of Middle American Indians, Volume 1, edited by R. C. West, pp. 413-426. University of Texas Press, Austin.

Mear, C. E.

1995 Notes on Geologic Stations in Brushy Creek Valley, Williamson County, Texas. On file, Texas Archeological Research Laboratory, The University of Texas at Austin.

n.d. Geomorphology and Quaternary Geology of the WilsonLeonard Site Area. Manuscript on file, Texas Archeological Research Laboratory, The University of Texas at Austin.

Meggers, B. J.

1979 Prehistoric America. Aldine, New York.
Meltzer, D. J.

1991 Altithermal Archaeology and Paleoecology at Mustang Springs, on the Southern High Plains of Texas. American Antiquity 56(2):236-267.

1993 Is There a Clovis Adaptation? In From Kostenki to Clovis, edited by O. Soffer and N. D. Praslov, pp. 293-310. Plenum, New York.

1997 Monte Verde and the Pleistocene Peopling of the Americas. Science 276:754-755.

Meltzer, D. J., and M. R. Bever -

1995 Paleoindians of Texas: An Update on the Texas Clovis Fluted Point Survey. Bulletin of the Texas Archeological Society 66:47-81.

Meredith, J. R.

1980 The Management of Operations. John Wiley \& Sons, New York.

Minnis, P. E.

1985 Domesticated Peoples and Plants in the Greater Southwest. In Prehistoric Food Production in North America, edited by R. I. Ford, pp. 309-339. Anthropological Papers 75. Museum of Anthropology, University of Michigan, Ann Arbor.

Mocas, S. T.

1977 Excavations at the Lawrence Site, 13TR33, Trigg County, Kentucky. University of Lousiville Archaeological Survey, Louisville.

Morse, D. F.

1997 Sloan, A Paleoindian Dalton Cemetery in Arkansas. Smithsonian Series in Archaeological Inquiry. Smithsoanian Institution Press, Washington, D.C.

Morse, D. F., and P. A. Morse

1983 Archaeology of the Central Mississippi Valley. Academic Press, San Diego.

Muller, J. D.

1978 The Southeast. In Ancient Native Americans, edited by J. D. Jennings, pp. 281-325. W.H. Freeman and Co., San Francisco.

Nassaney, M. S., and K. E. Sassaman

1995 Understanding Native American Interactions. In Native American Interactions, Multiscalar Analysis and Interpretations in the Eastern Woodlands, edited by M. S. Nassaney and K. E. Sassaman, pp. xix-xxxviii. University of Tennessee Press, Knoxville.

Neck, R. W.

1986 The Balcones Fault Zone as a Major Zoogeographic Feature. In The Balcones Escarpment, Geology, Hydrology, Ecology and Social Development in Central Texas, edited by P. L. Abbott and C. M. Woodruff, Jr., pp. 3540. Comet Reproduction Service, Santa Fe Springs, California. 
n.d. Analysis of the Paleomolluscan Assemblages of the Wilson-Leonard Site (41WM235). Unpublished manuscript on file, Texas Archeological Research Laboratory, The University of Texas at Austin.

Nelson, M. C.

1991 The Study of Technological Organization. In Archaeological Method and Theory, edited by M. B. Schiffer, pp. 57-100. The University of Arizona Press, Tucson.

Newman, A. L.

1982 Vertisols in Texas: Some Comments. U.S.D.A., Soil Conservation Service, Temple, Texas.

Nordt, L. C.

1992 Archaeological Geology of the Fort Hood Military Reservation, Ft. Hood, Texas. Research Report Number 25. Fort Hood Archaeological Resource Management Series, United States Army, Fort Hood, Texas.

Nordt, L. C., T. W. Boulton, C. T. Hallmark, and M. R. Waters

1994 Late Quaternary Vegetation and Climate Changes in Central Texas Based on the Isotopic Composition of Organic Carbon. Quaternary Research 41:109-120.

O'Brien, M. J., and W. R. Wood

1995 The Prehistoric Archeological Record. In Holocene Human Adaptations in the Missouri Prairie-Timberlands, by W. R. Wood, M. J. O'Brien, K. A. Murray, and J. C. Rose, pp. 47-77. Research Series 45. Arkansas Archeological Survey, Fayetteville.

O'Connell, J. F.

1987 Alyawara Site Structure and its Archaeological Implications. American Antiquity 52:74-108.

O'Connell, J. F., and K. Hawkes

1981 Alyawara Plant Use and Optimal Foraging Theory. In Hunter-Gatherer Foraging Strategies: Ethnographic and Archaeological Analyses, edited by B. Winterhalder and E. A. Smith, pp. 99-125. Prehistoric Archeology and Ecology Series. University of Chicago Press, Chicago.

O'Connell, J. F., K. Hawkes, and N. B. Jones

1991 Distribution of Refuse-Producing Activities at Hazda Residential Base Camps: Implications for Analyses of Archaeological Spatial Patterning. In The Interpretation of Archeological Spatial Patterning, edited by E. M. Kroll and T. D. Price, pp. 61-76. Plenum Press, New York.

Perttula, T. K.

1992 "The Caddo Nation:" Archaeological and Ethnohistoric Perspectives. University of Texas Press, Austin.

Prewitt, E. R.

1974 Archeological Investigations at the Loeve-Fox Site, Williamson County, Texas. Research Report 49. Texas Archeological Survey, The University of Texas at Austin.

1981 Cultural Chronology in Central Texas. Bulletin of the Texas Archeological Society 52:65-89.
1982 Archaeological Investigations at the Loeve-Fox, Loeve, and Tombstone Bluff Sites in the Granger Lake District of Central Texas. Archaeological Investigations in the San Gabriel Reservoir Districts, Central Texas, Vol. 4. Institute of Applied Sciences, North Texas State University, Denton.

1985 From Circleville to Toyah: Comments on Central Texas Chronology. Bulletin of the Texas Archeological Society 54:201-238.

1995 Distributions of Typed Projectile Points in Texas. Bulletin of the Texas Archeological Society 66:83-173.

n.d. The Rogers Springs Site: 1974 Investigations. Research Report 54. Manuscript on file, Texas Archeological Research Laboratory, The University of Texas at Austin.

Quigg, J. M., and J. Peck

1995 The Rush Site (41TG346) A Stratified Late Prehistoric Locale in Tom Green County, Texas. Technical Report 816C. Mariah Associates, Inc., Austin.

Ray, C. N.

1940 The Deeply Buried Gibson Site. Bulletin of the Texas Archeological and Paleontological Society 12:223-237.

Redder, A. J.

1985 Horn Shelter Number 2: The South End, a Preliminary Report. Central Texas Archeologist 10:37-65.

Renaud, E. B.

1931 Archaeological Survey of Eastern Colorado, First Report. Archaeological Survey, Department of Anthropology, University of Denver, Denver.

1932 Yuma and Folosm Artifacts, New Material. Proceedings of the Colorado Museum of Natural History, 11(2).

Ricklis, R. A.

1994 Toyah Components: Evidence for Occupation in the Project Area During the Latter Part of the Late Prehistoric Period. In Archaic and Late Prehistoric Human Ecology in the Middle Onion Creek Valley, Hays County, Texas, by R. A. Ricklis and M. B. Collins, pp. 207-316. Studies in Archeology 19. Texas Archeological Research Laboratory, The University of Texas at Austin.

1995 The Ceramics of the Toyah Horizon and the Rockport Phase as Indicators of Some Basic Sociocultural Patterns. In Prehistoric and Historic Aboriginal Ceramics in Texas, by T. K. Perttula, M. R. Miller, R. A. Ricklis, D. J. Prikryl, and C. Lintz, pp. 195-202. Bulletin of the Texas Archeological Society 66:175-235.

Ricklis, R. A., M. D. Blum, and M. B. Collins

1991 Archeological Testing at the Vera Daniel Site (41TV364), Zilker Park, Austin, Texas. Studies in Archeology 12. Texas Archeological Research Laboratory, The University of Texas at Austin. 
Ricklis, R. A., and M. B. Collins

1994 Archaic and Late Prehistoric Human Ecology in the Middle Onion Creek Valley, Hays County, Texas. Studies in Archeology 19. Texas Archeological Research Laboratory, The University of Texas at Austin.

Rigaud, J. P., and J. F. Simek

1991 Interpreting Spatial Patterns at the Grotte XV: A Multiple-Method Approach. In The Interpretation of Archaeological Spatial Patternings, edited by E. M. Kroll and T. D. Price, pp. 199-220. Plenum Press, New York.

Rose, J. C., and A. M. Harmon

1989 History of Bioarcheology and Bioarcheological Resources. In Archeology and Bioarcheology of the Lower Mississippi Valley and Trans-Mississippi South in Arkansas and Louisiana, by M. D. Jetter, J. C. Rose, G. I. Williams, Jr., and A. M. Harmon, pp. 291-322. Research Series 37. Arkansas Archeological Survey, Fayetteville.

Roush, S.

1997 Squash Seeds Yield New View of Early American Farming. Science 276(5314):894-895.

Russo, M.

1996 Southeastern Archaic Mounds. In Archaeology of the MidHolocene Southeast, edited by K. E. Sassaman and D. G. Anderson, pp. 259-287. University Press of Florida, Gainesville.

Sabo, G., III, and A. M. Early

1988 Prehistoric Culture History. In Human Adaptation in the Ozark and Ouachita Mountains, by G. Sabo, III, A. M. Early, J. C. Rose, B. A. Burnett, L. Vogele, Jr., and J. P. Harcourt, pp. 34-120. Final Report Study Unit 1, OzarkArkansas-Ouachita Archeological Research, Synthesis, and Overview Report. U.S. Army Corps of Engineers, Southwestern Division, Dallas.

Sackett, J. R.

1982 Approaches to Style in Lithic Archaeology. Journal of Anthropological Archaeology 1:59-112.

1985 Style and Ethnicity in the Kalahari: A Reply to Wiessner. American Antiquity 50:154-159.

1989 Statistics, Attributes and the Dynamics of Burin Technology. In Alternative Approaches to Lithic Analysis, edited by D. O. Henry, and G. H. Odell, pp. 51-82. Archaeological Papers of the American Anthropological Association No. 1.

Sassaman, K. E.

1996 Technological Innovations in Economic and Social Contexts. In Archaeology of the Mid-Holocene Southeast, edited by K. E. Sassaman and D. G. Anderson, pp. 5774. University Press of Florida, Gainesville.

Sassaman, K. E., and R. J. Ledbetter

1996 Middle and Late Archaic Architecture. In Archaeology of the Mid-Holocene Southeast, edited by K. E. Sassaman and D. G. Anderson, pp. 75-96. University Press of Florida, Gainesville.

Saunders, J. W., R. D. Mandel, R. T. Saucier, E. T. Allen, C. T. Hallmark, J. K. Johnson, E. W. Jackson, C. M. Allen, G. L. Stringer, D. S. Frink, J. K. Feathers, S. Williams, K. J. Gremillion, M. F. Vidrine, and R. Jones

1997 A Mound Complex in Louisiana at 5400-5000 Years Before the Present. Science 277:1796-1799.

Schiffer, M. B.

1987 Formation Process of the Archaeological Record. University of New Mexico Press, Albuquerque.

Scott-Cummings, L.

1991 Pollen, Phytolith, Macrofloral, and Charcoal Analyses in the Jewett Mine Project Area. In Excavations at the Bottoms, Rena Branch, and Moccasin Springs Sites, Jewett Mine Project, Freestone and Leon Counties, Texas, by R. C. Fields, L. W. Klement, C. B. Bousman, S. A. Tomka, E. F. Gadus, and M. A. Howard, pp. 329-362. Reports of Investigations 82. Prewitt and Associates, Inc., Austin.

Sellards, E. H., T. N. Campbell, and G. L. Evans

1940 Pleistocene Artifacts and Associated Fossils from Bee County, Texas. Geological Society of America Bulletin 51:1627-1657.

Sellards, E. H., G. L. Evans, G.E. Meade, and A. O. Krieger

1947 Fossil Bison and Associated Artifacts from Plainview, Texas. Geological Society of America Bulletin 58:927-954.

Semken, H. A., Jr.

1961 Fossil Vertebrates from Longhorn Cavern, Burnet County, Texas. Texas Journal of Science 13:290-310.

Shafer, H. J.

1963 Test Excavations at the Youngsport Site: A Stratified Terrace Site in Bell County, Texas. Bulletin of the Texas Archeological Society 34:57-81.

Shafer, H. J., and R. G. Holloway

1979 Organic Residue Analysis in Determining Stone Tool Function. In Lithic Use-Wear Analysis, edited by B. Hayden. Academic Press, New York.

Shott, M. J.

1986 Technological Organization and Settlement Mobility: An Ethnographic Examination. Journal of Anthropological Research 42:15-51.

1989 On Tool-Class Use Lives and the Formation of Archaeological Assemblages. American Antiquity 54:9-30.

Silverman, S., and N. J. Parezo (editors)

1992 Preserving the Anthropological Record. Wenner-Gren Foundation for Anthropological Research, Inc., New York.

Simmons, A. H., D. D. Dykeman, and P. A. Hicks

1989a The Unknown Archeology of the Southwest: The Archaic. In Human Adaptations and Cultural Change in the 
Greater Southwest, by A. H. Simmons, A. L. W. Stodder, D. D. Dykeman, and P. A. Hicks, pp. 39-74. Research Series 32. Arkansas Archeological Survey, Fayetteville.

1989b The Formative Period-Neolithic Archeology in the Southwest. In Human Adaptations and Cultural Change in the Greater Southwest, by A. H. Simmons, A. L. W. Stodder, D. D. Dykeman, and P. A. Hicks, pp. 75-118. Research Series 32. Arkansas Archeological Survey, Fayetteville.

Slade, R. M., Jr.

1986 Large Rainstorms along the Balcones Escarpment in Central Texas. In The Balcones Escarpment, Geology, Hydrology, Ecology, and Social Development in Central Texas, edited by P. L. Abbott and C. M. Woodruff, Jr., pp. 15-19. Comet Reproduction Services, Santa Fe Springs, California.

Smith, B. D.

1992 Rivers of Change, Essays on Early Agriculture in Eastern North America. Smithsonian Institution Press, Washington, D.C.

1995 The Emergence of Agriculture. Scientific American Library, New York.

1997 The Initial Domestication of Cucurbita pepo in the Americas 10,000 Years Ago. Science 276(5314):932-934.

1998 Between Foraging and Farming. Science 279:1651-1652.

Smith, B. D., C. W. Cowan, and M. P. Hoffman

1992 Is it an Indigene or a Foreigner? In Rivers of Change, Essays on Early Agriculture in Eastern North America, by B. D. Smith, pp. 67-100. Smithsonian Institution Press, Washington, D.C.

Smith, E. A

1991 Inujjuamiut Foraging Strategies: Evolutionary Ecology of an Arctic Hunting Economy. Aldine de Gruyter, New York.

Smith, E. A., and B. Winterhalder

1992 Evolutionary Ecology and Human Behavior. Aldine de Gruyter, New York.

Smith, P. E. L.

1972 The Consequences of Food Production. Module 31. Addison-Wesley, Reading, Massachusetts.

Sorrow, W. M

1968 The Devil's Mouth Site: The Third Season-1967. Papers of the Texas Archeological Salvage Project 14. Texas Archeological Salvage Project, The University of Texas at Austin.

Sorrow, W. M., H. J. Shafer, and R. E. Ross

1967 Excavations at Stillhouse Reservoir. Papers of the Texas Archeological Salvage Project 11. Texas Archeological Salvage Project, The University of Texas at Austin.
Speth, J. D.

1983 Bison Kills and Bone Counts: Decision Making by Ancient Hunters. University of Chicago Press, Chicago.

Stafford, T. W., Jr., A. J. T. Jull, K. Brendel, R. C. Duhamel, and D. J. Donahue

1987 Study of Bone Radiocarbon Dating Accuracy at the University of Arizona NSF Accelerator Facility for Radio Isotope Analysis. Radiocarbon 29(24):44.

Stanford, D.

1991 Clovis Origins and Adaptations: An Introductory Perspective. In Clovis: Origins and Adaptations, edited by R. Bonnichsen, and K. L. Trunmire, pp. 1-13. Center for the Study of the First Americans, Oregon State University, Corvallis.

Steele, D. G., and J. F. Powell

1992 Peopling of the Americas: Paleobiological Evidence. $\mathrm{Hu}$ man Biology 64:303-336.

1993 Paleobiology of the First Americans. Evolutionary Anthropology 2:138-146.

1994 Paleobiological Evidence of the Peopling of the Americas: A Morphometric View. In Method and Theory for Investigating the Peopling of the Americas, edited by $\mathrm{R}$. Bonnichesen and D. G. Steele, pp. 141-163. Center for the Study of the First Americans, Oregon State University, Corvallis.

n.d. An Osteological Examination of Prehistoric Hunters and Gatherers of the Southern Desert and Semi-Desert Regions of North America. Manuscript on file, Department of Anthropology, Texas A\&M University, College Station.

Stein, J.

1984 Organic Matter and Carbonates in Archaeological Sites. Journal of Field Archaeology 11:239-242.

Stephenson, R. L.

1970 Archeological Investigations in the Whitney Reservoir Area, Central Texas. Bulletin of the Texas Archeological Society 41:37-286.

Stevenson, M. G.

1991 Beyond the Formation of Hearth-Associated Artifact Assemblages. In The Interpretation of Archeological Spatial Patterning, edited by E. M. Kroll, and T. D. Price, pp. 269-299. Plenum Press, New York.

Story, D. A.

1990 Culture History of the Native Americans. In The Archeology and Bioarcheology of the Gulf Coastal Plain, edited by D. A. Story, J. A. Guy, B. A. Burnett, M. D. Freeman, J. C. Rose, D. G. Steele, B. W. Olive, and K. J. Reinhard, pp. 163-366. Research Series 38. Arkansas Archeological Survey, Fayetteville.

1997 1968-1970 Archeological Investigations at the George C. Davis Site, Cherokee County, Texas. Bulletin of the Texas Archeological Society 68:1-113. 
Suhm, D. A.

1955 Excavations at the Collins Site, Travis County, Texas. Bulletin of the Texas Archeological Society 26:7-54.

1957 Excavations at the Smith Rockshelter, Travis County, Texas. The Texas Journal of Science 9:26-58.

1960 A Review of Central Texas Archeology. Bulletin of the Texas Archeological Society 29:63-107.

Suhm, D. A., and E. B. Jelks

1962 Handbook of Texas Archeology: Type Descriptions. The Texas Archeological Society and the Texas Memorial Museum, Austin.

Suhm, D. A., A. D. Krieger, and E. B. Jelks

1954 An Introductory Handbook of Texas Archeology. Bulletin of the Texas Archeological Society 25.

Tagg, M. D.

1996 Early Cultigens from Fresnal Shelter, Southeastern New Mexico. American Antiquity 61:311-324.

Taylor, A. J.

1995 An Overview of Mortuary Traits at Loma Sandia and Certain other Texas Sites. In Archeological Investigations at the Loma Sandia Site (41LK28), a Prehistoric Cemetery and Campsite in Live Oak County, Texas, by A. J. Taylor and C. L. Highley, pp. 663-699. Studies in Archeology 20. Texas Archeological Research Laboratory, The University of Texas at Austin.

Taylor, A. J., and C. L. Highley

1995 Archeological Investigations at Loma Sandia Site (41LK28), A Prehistoric Cemetery and Campsite in Live Oak County, Texas. Studies in Archeology 20. Texas Archeological Research Laboratory, The University of Texas at Austin.

Texas Archeological Research Laboratory

1995 Texas Archeological Research Laboratory Curation Procedures. On file at the Texas Archeological Research Laboratory, The University of Texas at Austin.

Thoms, A. V.

1989 The Northern Roots of Hunter-Gatherer Intensification: Camas and the Pacific Northwest. Unpublished Ph.D. dissertation, Department of Anthropology, Washington State University, Pullman.

1992 Late Pleistocene and Early Holocene Regional Land Use Patterns: A Perspective from the Preliminary Results of Archaeological Studies at the Richard Beene Site, 41BX831, Lower Medina River, South Texas. In Late Cenozoic Alluvial Stratigraphy and Prehistory of the Inner Gulf Coastal Plain, South Central Texas. Guidebook, 10th Annual Meeting, South Central Friends of the Pleistocene.

1993 Knocking Sense from Old Rocks: Typologies and the Narrow Perspective of the Angostura Point Type. Lithic Technology 18(1\&2).
Thoms, A. V., and R. D. Mandel

1992 The Richard Beene Site: A Deeply Stratified Paleoindian to Late Prehistoric Occupation in South-Central Texas. Current Research in the Pleistocene 9:42-44.

Toomey, R. S., III

1989 Hall's Cave. In Geomorphology, Quaternary Stratigraphy, and Paleoecology of Central Texas, by M. D. Blum, J. F. Petersen, and R. S. Toomey, III. Guidebook, 7th Annual Meeting, South Central Friends of the Pleistocene.

1993 Late Pleistocene and Holocene Faunal Changes at Hall's Cave, Kerr County, Texas. Unpublished Ph.D. dissertation, Department of Geology, The University of Texas at Austin.

Toomey, R. S., III., M. D. Blum, and S. Valastro, Jr.

1993 Late Quaternary Climates and Environments of the Edwards Plateau, Texas. Global and Planetary Change 7:299-320.

Torrence, R.

1983 Time Budgeting and Hunter-Gatherer Technology. In Hunter-Gatherer Economy in Prehistory: A European Perspective, edited by G. Bailey, pp. 11-22. Cambridge University Press, Cambridge.

1989 Time, Energy, and Stone Tools. Cambridge University Press, Cambridge.

Treece, A. C., J. M. Quigg, K. Miller, and C. Lintz

1993 Turkey Bend Ranch Site (41CC112). In Cultural Resource Investigations in the O. H. Ivie Reservoir, Concho, Coleman, and Runnels Counties, Texas, Volume III: Data Recovery Results from Non-Ceramic Sites, by A. C. Treece, C. Lintz, W. N. Trierweiler, J. M. Quigg, and K. A. Miller, pp. 67-242. Technical Report 346-III. Mariah Associates, Inc., Austin.

Turner, E. S., and T. R. Hester

1993 A Field Guide to the Stone Artifacts of Texas Indians. Gulf Publishing Co., Houston.

Van Auken, O. W.

1988 Woody Vegetation of the Southeastern Escarpment and Pleateau. In Edwards Plateau Vegetation, Plant Ecological Studies in Central Texas, by B. B. Amos and F. R. Gelbach, pp. 43-55. Baylor University Press, Waco.

Wandsnider, L.

1997 The Roasted and the Boiled: Food Composition and Heat Treatment with Special Emphasis on Pit-Hearth Cooking. Journal of Anthropological Archaeology 16:1-48.

Watt, F. H.

1936 A Prehistoric Rock-Shelter Burial in Bell County, Texas. Bulletin of the Central Texas Archeological Society 36:99110.

1938 The Waco Sinker. Central Texas Archaeologist 4:21-70. 
1965 Notes on the Clark Site, McLennan County, Texas. Bulletin of the Texas Archeological Society 36:99-110.

1978 Radiocarbon Chronology of Sites in the Central Brazos Valley. Bulletin of the Texas Archeological Society 49:111138.

Weaver, M. P.

1993 The Aztecs, Maya, and Their Predecessors: Archaeology of Mesoamerica. Academic Press, San Diego.

Webb, C. H.

1946 Two Unusual Types of Chipped Stone Artifacts from Northwest Louisiana. Bulletin of the Texas Archeological and Paleontological Society 17:9-17.

Webb, W. S.

1946 Indian Knoll Site, Oh2, Ohio County, Kentucky. Reports in Anthropology and Archaeology 4(3). University of Kentucky, Lexington.

Wedel, W. R.

1961 Prehistoric Man on the Great Plains. University of Oklahoma Press, Norman.

Weir, F. A.

1976 The Central Texas Archaic. Ph.D. dissertation, Washington State University, Pullman.

1979 Greenhaw: An Archaic Site in Central Texas. Bulletin of the Texas Archeological Society 50:5-67.

1985 An Early Holocene Burial at the Wilson-Leonard Site in Central Texas. Mammoth Trumpet 2(1):1, 3 .

Weissner, $\mathrm{P}$

1983 Style and Social Information in Kalahari San Projectile Points. American Antiquity 48:253-276.

1984 Reconsidering the Behavioral Basis of Style. Journal of Anthropological Archaeology 3:190-234.

1985 Style or Isochrestic Variation? A Reply to Sackett. American Antiquity 50:160-168.

Wendorf, F. D., and A. D. Krieger

1959 New Light on the Midland Discovery. American Antiquity 25:66-78.

Wendorf, F. D., A. D. Krieger, C. C.Albritton, and T. D. Stewart 1955 The Midland Discovery: a Report on the Pleistocene Human Remains from Midland, Texas. The University of Texas Press, Austin.

Weniger, D.

1984 The Explorers' Texas. Eakin Press, Austin.

Werchan, L. E. and J. L. Coker

1983 Soil Survey of Williamson, County, Texas. United States Department of Agriculture, Soil Conservation Service. Washington, D.C.
Wesolowsky, A. B., T. R. Hester, and D. R. Brown

1976 Archeological Investigations at the Jetta Court Site (41TV151), Travis County, Texas. Bulletin of the Texas Archeological Society 47:25-87.

Whalen, M. E.

1994 Moving out of the Archaic on the Edge of the Southwest. American Antiquity 59:622-638.

Whallon, R.

1984 Unconstrained Clustering for the Analysis of Spatial Distributions in Archaeology. In Intrasite Spatial Analysis in Archaeology, edited by H. Hietala, pp. 242-277. Cambridge University Press, Cambridge.

Wheat, J. B

1972 The Olsen-Chubbuck Site, a Paleo-Indian Bison Kill. Memoirs of the Society for American Archaeology, No. 26. American Antiquity 37(1)Part 2.

Wheeler, R. F.

1954 Selected Projectile Point Types of the United States. Bulletin of the Oklahoma Anthropological Society II:1-6.

Willey, G. R.

1966 An Introduction to American Archaeology, Volume 1: North America. Prentice-Hall, Englewood Cliffs, New Jersey.

Willey, G. R., and P. Phillips

1954 Method and Theory in American Archaeology. The University of Chicago Press, Chicago.

Willey, P. S., B. R. Harrison, and J. T. Hughes

1978 The Rex Rodgers Site. In Archaeology at MacKenzie Reservoir, edited by J. T. Hughes and P. S. Willey, pp. 51114. Archeological Survey Report 24. Office of the State Archeologist, Texas Historical Commission, Austin.

Wills, W. H.

1988 Early Prehistoric Agriculture in the American Southwest. School of American Research Press, Santa Fe.

Winkler, A. J.

1990 Small Mammals from a Holocene Sequence in Central Texas and their Paleoenvironmental Implications. The Southwestern Naturalist 35(3):199-205.

Winsborough, B.

1991 Diatom Paleoecology of Lacustrine Sediments from East Texas with Evidence of Local Ground-Water Chemistry Anomalies. In Excavations at the Bottoms, Rena Branch, and Moccasin Springs Sites, Jewett Mine Project, Freestone and Leon Counties, Texas, by R. C. Fields, L. W. Klement, C. B. Bousman, S. A. Tomka, E. F. Gadus, and M. A. Howard, pp. 369-382. Reports of Investigations 82. Prewitt and Associates, Inc., Austin.

Winterhalder, B.

1981 Foraging Strategies in the Boreal Forest: An Analysis of Cree Hunting and Gathering. In Hunter-Gatherer Foraging Strategies, edited by B. Winterhalder and E. A. Smith, pp. 66-98. The University of Chicago Press, Chicago. 
Winterhalder, B., and E. A. Smith (editors)

1981 Hunter-Gatherer Foraging Strategies. The University of Chicago Press, Chicago.

Wobst, H. M.

1978 The Archaeo-Ethnology of Hunter-Gatherers or the Tyranny of the Ethnographic Record in Archaeology. American Antiquity 43(2):303-309.

Woolsey, A. M.

1936 Notes on Field Work at H. C. Locke Farm 1 Mile West of New Braunfels, Comal County, Texas. Excavated April 21 to May 3, 1936. Unpublished manuscript on file. Texas Archeological Research Laboratory, The University of Texas at Austin.

Wormington, H. M.

1957 Ancient Man in North America. 4th ed. The Denver Museum of Natural History, Denver.
Wyckoff, D. G.

1995 A Summary of the Calf Creek Horizon in Oklahoma. Bulletin of the Oklahoma Anthropological Society 42:179-210.

Wyckoff, D. G., and R. L. Brooks

1983 Oklahoma Archeology: A 1981 Perspective. Archeological Resource Survey Report 16. Oklahoma Archeological Survey, Norman.

Yellen, J. E.

1977 Archaeological Approaches to the Present: Models for Reconstructing the Past. Academic Press, New York.

Young, K.

1986 The Pleistocene Terra Rossa of Central Texas. In The Balcones Escarpment, Geology, Hydrology, Ecology and Social Development in Central Texas, edited by P. L. Abbott and C. M. Woodruff, Jr., pp. 63-70. Comet Reproduction Services, Santa Fe Springs, California. 
ISBN 1-887072-25-X (Volume I)

ISBN 1-887072-24-1 (5 Volume Set) 